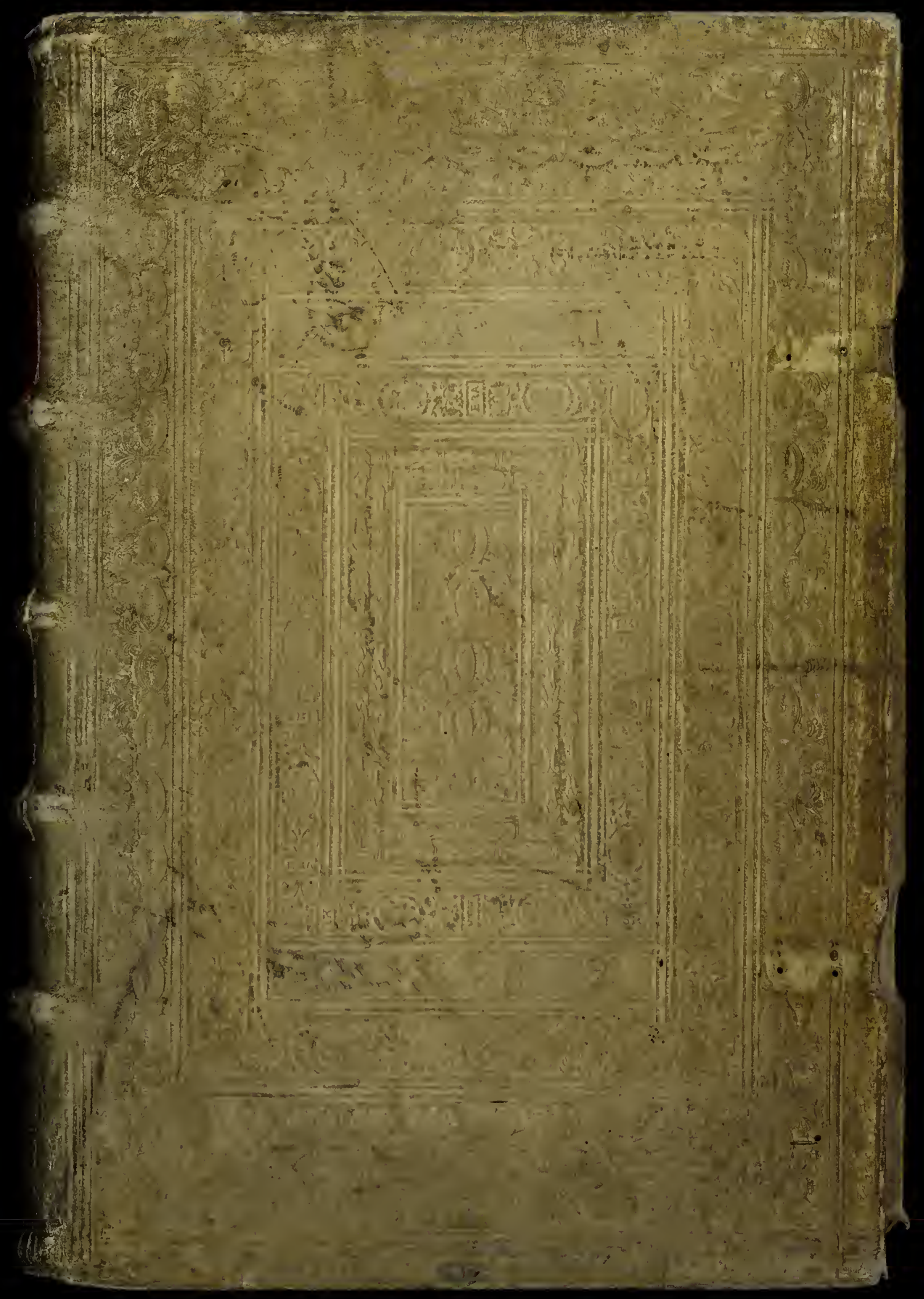




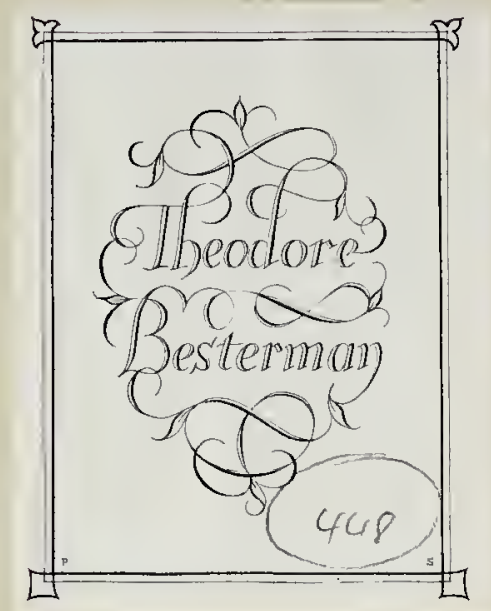




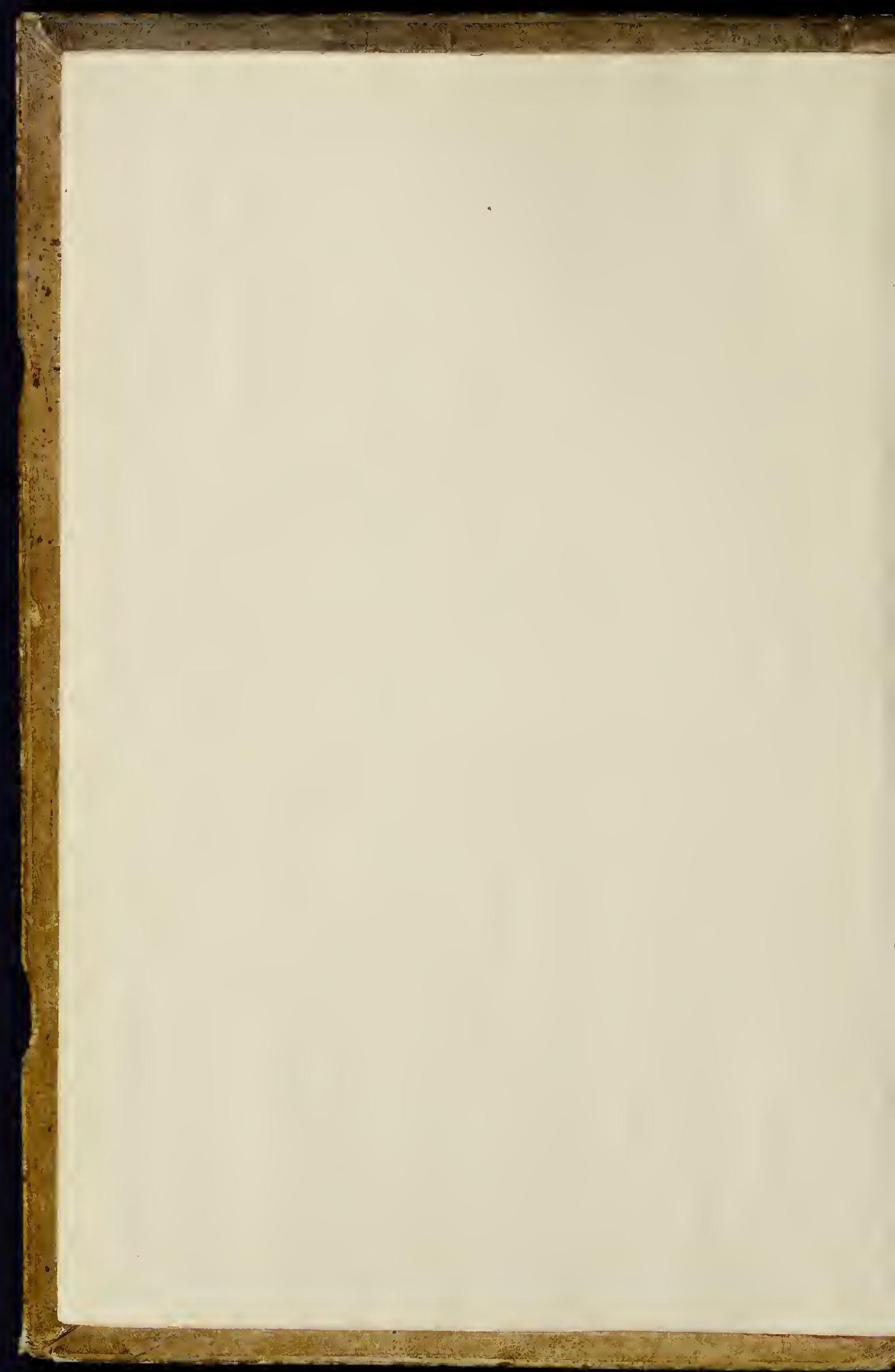




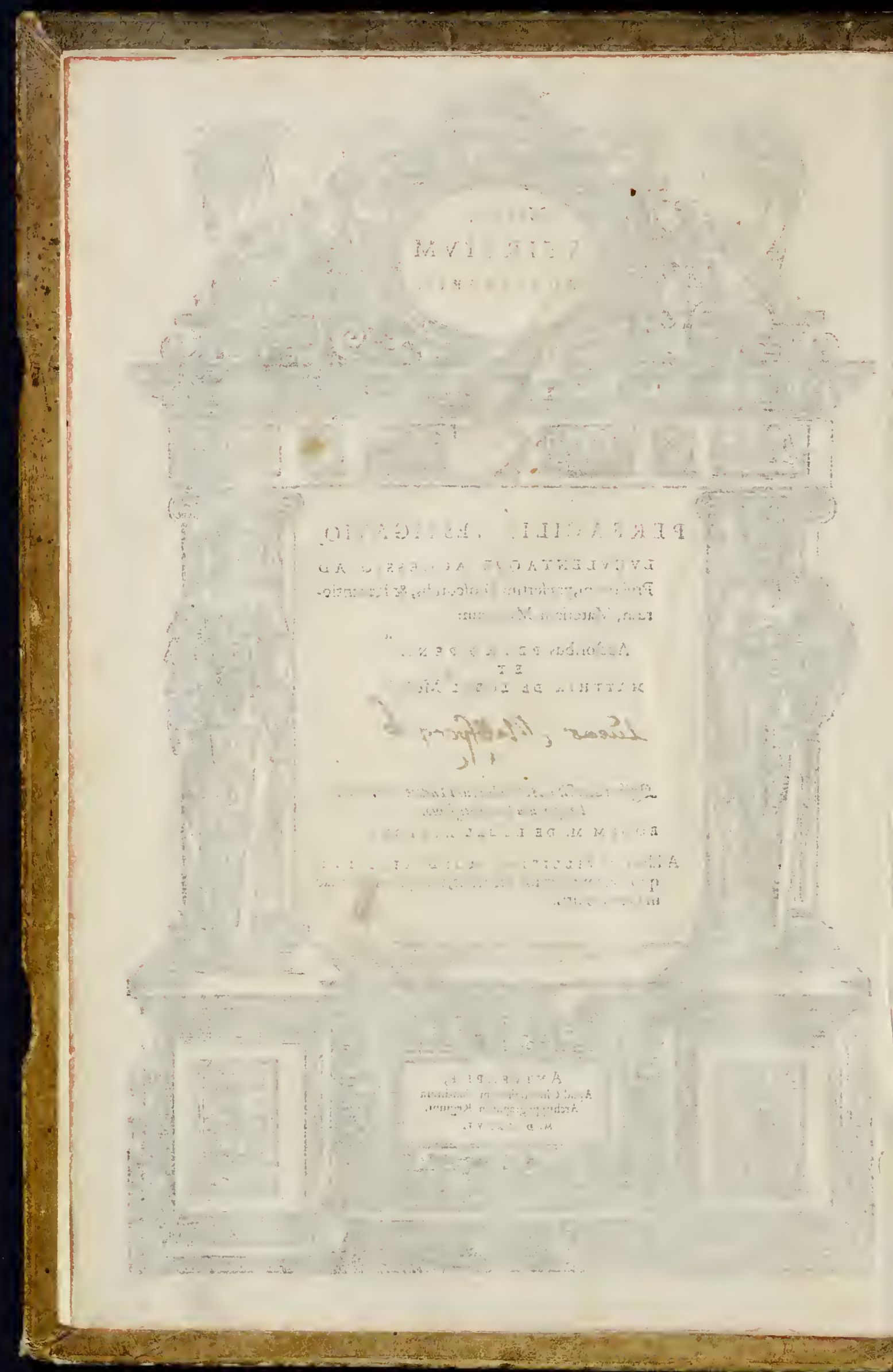




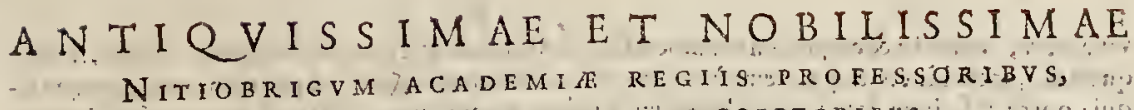

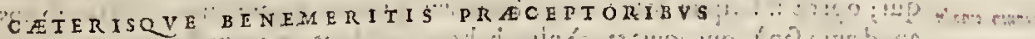
MONSPELLIACI

operis udfuerfariorum aygumcntum conolumentum.

T s. 1 atredan fatalis Orci filia feritas, diris extema deformitatis exemplisiam

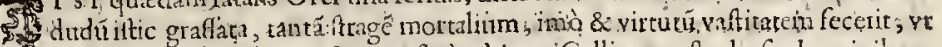

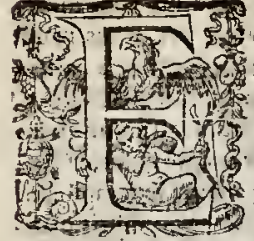
7. non rantim vibes \& Acrdemias ferè vbique Galliarum ftudıofs hominibus, feteciam fudiofos ipfos officiof gracáque humanitate exbauferit ramen iftus

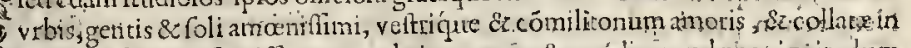

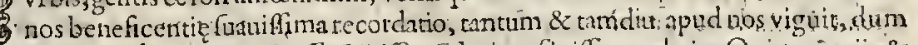

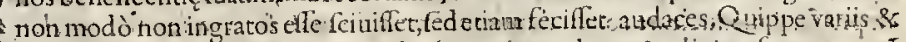

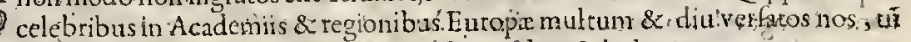

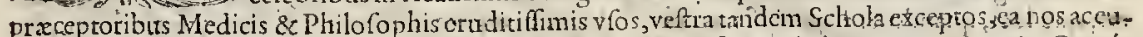

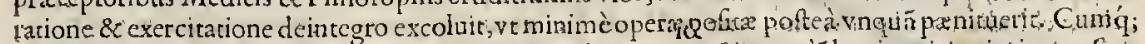

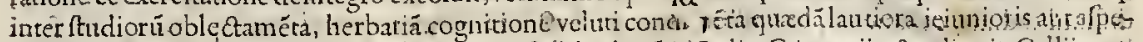

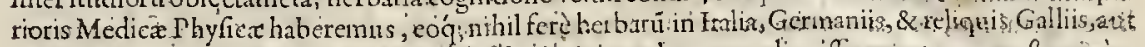

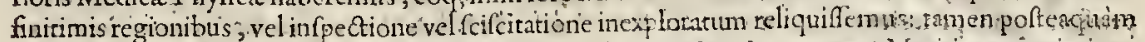

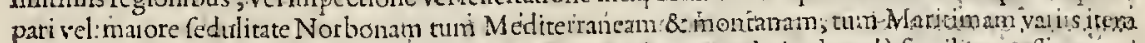

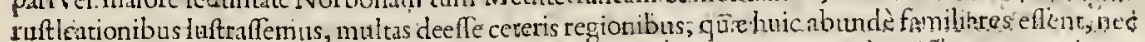

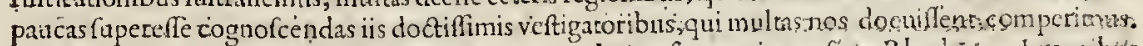

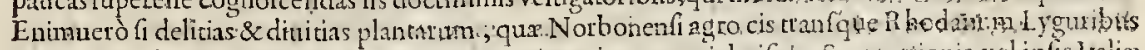
\& Pyrenęisalpinis verinque maritinis contermino vitent, cum pletifque S ptentiotis

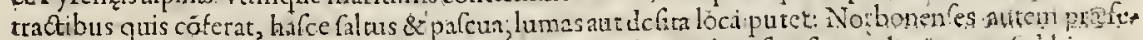

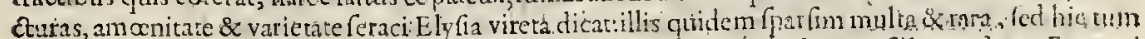
eadem, tum longè plurina \& laxiora etian in montis \& conullis ambiru puftlo quati yo Enropiri

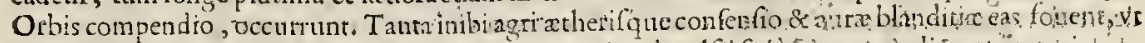

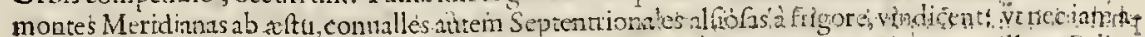

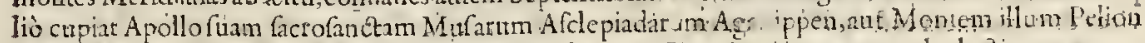

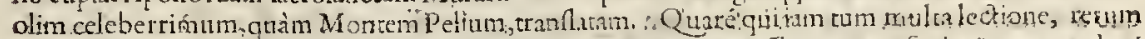

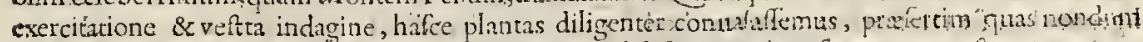
in literas miffás rebamur, veriti communem biènnio pòf fequntaminaufngan tenypefaren, arque

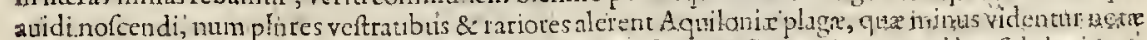

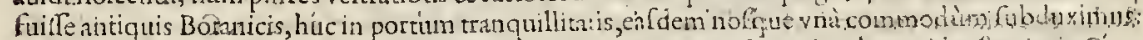

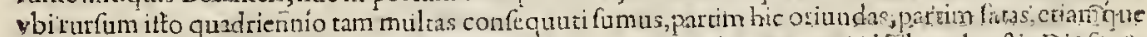

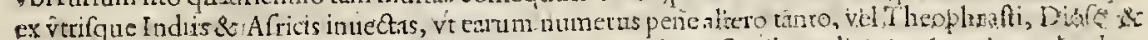

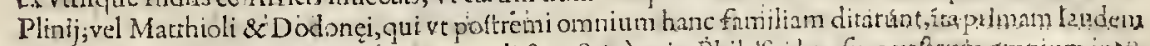

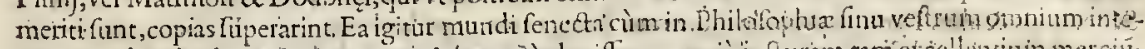

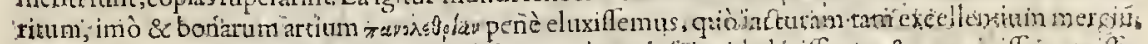

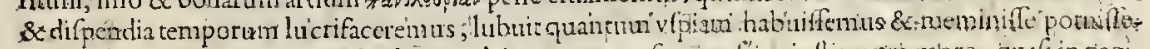

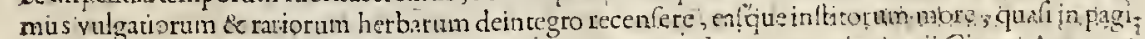

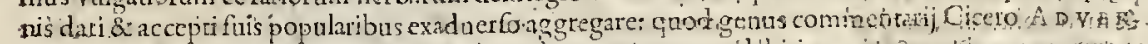

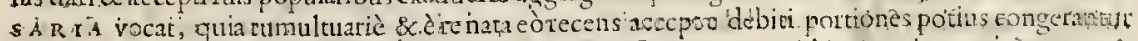

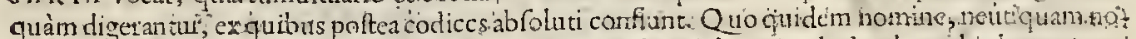

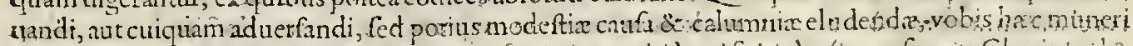

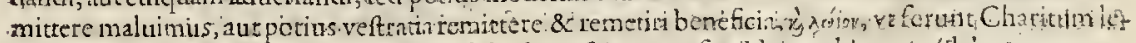

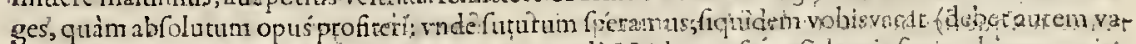

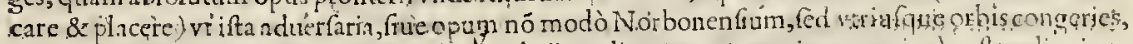

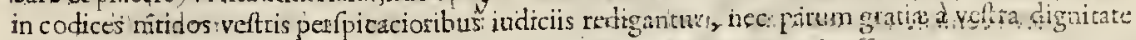

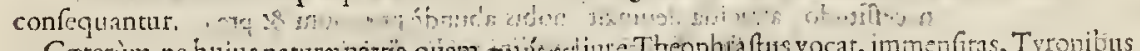

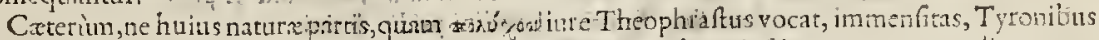
metum vel laborem niminm afferter, néve refcjo qüis Caprimulgus, intitutum, res, aut ordinem, potius quàm fores ant fru ctus in hoc opere carpar, monendus eft benignus ledter nos fummo ludio

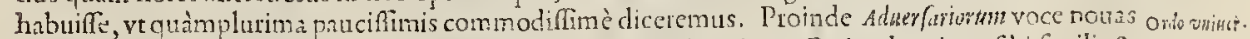
veteribus addicas plantas, \& noutm ordinem quadnmtemus inmuimus. Qui ordo vtiguc fibi finilis \& faik. vnus progreditur, ducitque à fenfui propinguioribus, \& magis familinubus ad ignotiora \& compofitiora, modumq́ue fue progreffum fimilitudinis fequitur \& fumiliaritatis, quo \& vininerfim \& particulatim, quantuin licuit per rerum vatietatem, \& valtitatem, fibi refponderet. Sic enim ordue, quo nihil pulchrius in calo aut in fapicntis animo, quæ longè lateq́; difparata funt, vnú quıfi fuunt, mạnoo 
verborum, memorix \& cognitionis compendio, vt A riftoteli \& Theoplirafto plucet. Verùm, fi iderm

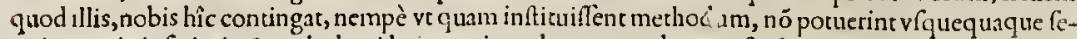
Iernam moilu. qui ; operis infcriptio \& turbulenti huius rui quo hxc apparabamus, fluctuatio nos excufatos habeat, lase proportia. apud cum fanc̀, qui nouit tantò plus habere perplexitatis tantum negotium, quantò venix minus, nto. Quaınuis dum reliquarum Itirpium, qux hîc non habentur, quaf'que plurimas per fiperiorem calamitatem huc ex Galliis accerfere non licuit, Icones cis tò rósł 0 - arguta manu \& emodulata ad plantarum ipfarum magnitudines \& effigiaturas proportione (quam alij picturx folcecifnis crebrò deformant, dum herbulas xquè magnas ac arbores \& frutices pingunt) delineantur \& exfculpuntur, datur opera in appendice, ne quenquam huius lectionis poniteat. Quin eum pudeat potius prenituiffe, nec vidiffe domi \& vno incuitu, fibi nuiquam vifa aut lecta, qux multis menfibus aut annis pauci Meshadus par. vix videre potuerunt. Et quia plantaruin duplex eft cognitio, altera nempede facie exterior, altera sicwlarss. virium, quafíque interior: illam huic anteuertere oportere monet Philofophi opera, imò ipfa Natura. Neque enim porett quis vllam certam cognitionem fibiarrogare eorum fimplicium qu $x$ nunquam afpexit. Proinde nos primùm cuiufque nomenclatutam, vt quæ non rarò ipfam rem aptè notat, c̀ $\mathrm{Gra}$ cis præfercim,enucleare conati fumus: obiter regionent, \& in ea feorfim natales; illam Geographiam, hanc Corographiam vocant; prefiitus quàm quifquam auctor antehac, defignamus : ve quafuis plan tas, quo loci, quando \& à quo ipfi nancif $c i$, vel amicos rogare mittendas, vbicunque tandem noftri orbis, vel Indiarum illæ orirentur, fcire pnffemus. Defcriptiones autem inter congeneres \& fimilimas, diffimilitudinis, collationis, \& fimiliti anis ope, breuiores femper, emendatiores plerumque \& faciliores aptauimus, non tam antiquorum hiftorix, quàm iterat $x$ infpectioni \& $\mathrm{ex}$ viuis ipfis plantis $\mathrm{ex}-$ penfioni, quam penesius eft \& norma rectè \& verè defcribendi. Sed vires parciùs \& confuliò eatenus atrigimus, quantum vel ad cognofendum, vel ad probandum quampiam vnam plantam fatis vide. baru r, Ariftotelen nempè in alio, \& Theophraft. in fimili inftituto, imitati. Nam recentiores quidam, qui Commentatoris nomine turgent, potius videntur fuum faftum, quàm plantas viámve eas nofcendi defcribere. Nec ex locis natali tífve feriem hiftoriarum inire, vt doetiflimus \& candidiffimus feriptor Dodonæus capit, finunt plant $x$ plurimx, qux tum aridis, tum humentibus \& riguis erumpunt, ve Cardamine in vinetis, viis, \& riguis: Lapatium vtrunque, vtrobique, aut vbique : quxdam in mon. tibus pariter \& conuallibus, vt Eryngia, Calamenthü, Polium, \& alia quàm plurima. Et quod in primis obferuatu dignum, quæ iugis montium regionum calidiorú proueniunt, eadem in planis, fyluofis vel depreffis regionum Septentrionalium exeunt. Grecorum verò auctorum extant porius Indices Alphabetici,quàm fmplicium Methodi, præterquàm opus Diofc. \& fragmenta Crateux, ex quibus illi vires \& verba mera exferipfife videntur:vtinam notas non neglexifent: aut eo pudore fuiffer Plinius; quo diuinus Senex, qui fe parum in Stirpium cognitione profecifle profeffus eft: aut Diofcoridem diligennus legiflet. Diofcoridea tamen methodus, optima quidem illa, illis qui iamdiu noueruntplantas: verùm ad cognitionem compendiofam, fiaurofiav infpectionéve, quam tantopere laudat Diofc. com parandam, minus eft accommoda. Diuerfis quippe libris eiufden fpeciei \& fimilicudinis plantas diftrahit, quas alioqui vno intuitu ferè difcas:veluti Cucumerem fylueflrem à fatiuo, Colocynthides, $\sqrt{1}$ ue Cucurbitulas, ab efculentis Cucurbitis, Thapfiam à ferulaceis, Crocum à Colchico, Scammonium \& Soldonellam, à volubilibus, Sify mbriü à Mentha, Hieracia à Chondrillis, \& quàmplurima paffim: tametfi alicubi volés à fefe defciuir, fequutus, quã nos hîc adumbramus, Methodú, vt in Portulacis, Séperuiuis \& aliis. Tyrones proinde monemus \& rogamus, vt rei herbarix totius Medicatricis certiffi-

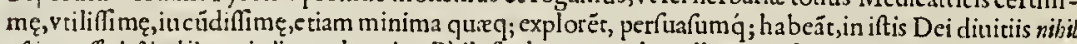
vppiam effe deppicabile aut indignum homine Philofopho, cti ini hrc ille condidit, voluitque, vt eft in facra pagina, nos fanari herbis, non verbis, ne fapientix fux opera irrita forent.Nec putent tritico, vino, lacte, \& melle,olufculo, aut herbulis etiam contemptifinis, non poffe corpora aquè fanariatque ali : Néve Ariftippos quofdam fericatos, vndulatos, a uri \& auræ popularis, quam penitioris eruditionis fiticulofiores, audıant, quos pudet hxc ferò doccri, \& difcere feriò, arduiquel aboris tædet. Volque pracepto. res clarifimi, impendiò oramus, ve multorum annorum, regionum \& virorum doctifimorum aduerfaria hæc, non fecus ac peregrini aut holtes expendatis, foucatis autem, concinnetis, \& augeatis vt parentes: nof'que ficubi nolentes lapfi fumus (imò quia fapè fumus) benignè moneatis. Nec enim laudem venamır, duntaxat culpam vel inuidiam deprecamur : vefter cæterò amor , benéque fibi animi noftri confciị, quos multi anni, mult a peregrinatio, ttudia, omniumq́ue rerum arêtifima neceflitudo, amiciria deuinxic, nobis abundè præmium \& precium funt futuri. Londini pridic diuini

Natalitij. I $\$ 70$. 
STIRPIVM ADVERSA.

R I A N O P A.

\section{Graininis omne Genus.}

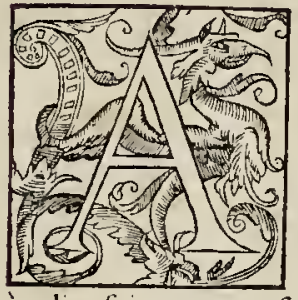

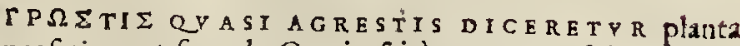
necfatiua aut ferenda Grecis feitc̀ nuncupata fuit : vtpote quæe ruri vbique fponte quouis anni cardine, coslo, folo \& $f_{-}-$ dere luxuriet : eius namque perennis prouentus feracitatis reAtibilis, nec minus immenf $x$ vtilitatis quantùm toto orbe extat terrarum, virore ornat amœno, \& veluti gradatim fefe propagando amicit décore, vnde Latinis Gramen defexum putatur. Triticeo generi, vt cognata, \& fimilis, fic perinde vaè radice, fpicata com , folio \& nobilitate proxima. Quin differentia magis confpicuz è radice, fpicata coma, folio \& flore funt ducend $x$ : quas etiam cunctas partes \& diffe, rentias (quia varias tritici fpecies æmulantur, déque mutua inter fe collatione faciliùs difcernuntur \& difcuntur) aptius fore duximus nominibus \& notis quamque fuis, vel minimas quafy; profequi, quas natura pecori quidem vefcendas, fed homini vni non modovtendas, adeóque priùs cognofcendas, peperiffet . Nullum enim vcl defpicatifsimum illius operum, noftra , id eft,mortalium Philofophantium indignum cognitione \& admiratione ducendum, fummus Philofophus in libro, De partibus animalium, luculen ter docuit, ciufque alumnus Theophraftus in Plantarum hiftorijs,

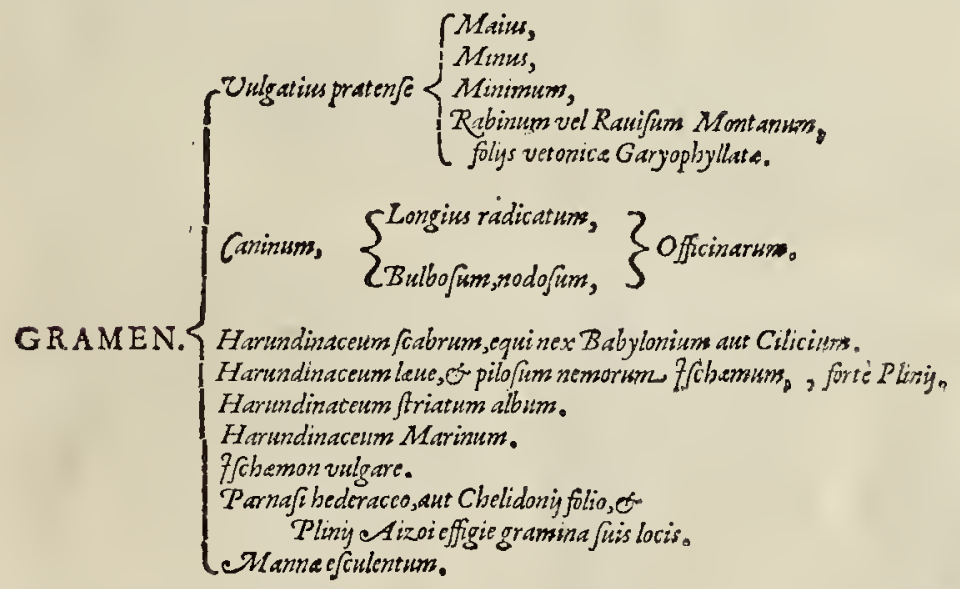

\section{GRAMEN PRATENSE MAIYS VVLGATIVS。}

FOENYX1.

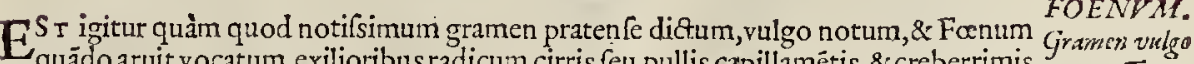

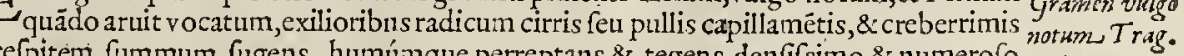
cefpitem fummum fugens, humínque perreptans \& tegens, denfifsimo \& numerofo Epitomes foliorum triticeorum ftipatu:culmos pedem \& cubitum aitos furrigens, tenues genicu- Eptone 207. latos, læues:lanofa, fparfa \& magis harundinem Vallatoriam imitante fpica faftigiatum. Eius femine in horreis è fpicis excurfo \& collecto vtimur complures Medici ad obftruEtiones vifcerum, calculum, potu, admotúque ad difcufsionem pertinacium tuinorum, \& flatuum, tamedfi officinis vfu ignoto. 
CII NVS.

Iftud idem quod fundit Montanus, vel decliuis incultus, exnctus \& aridior ager, vt pabulo gratius \& v rilius velleri, fic multò delicatitis, minus, \& fomine efficacius eft.

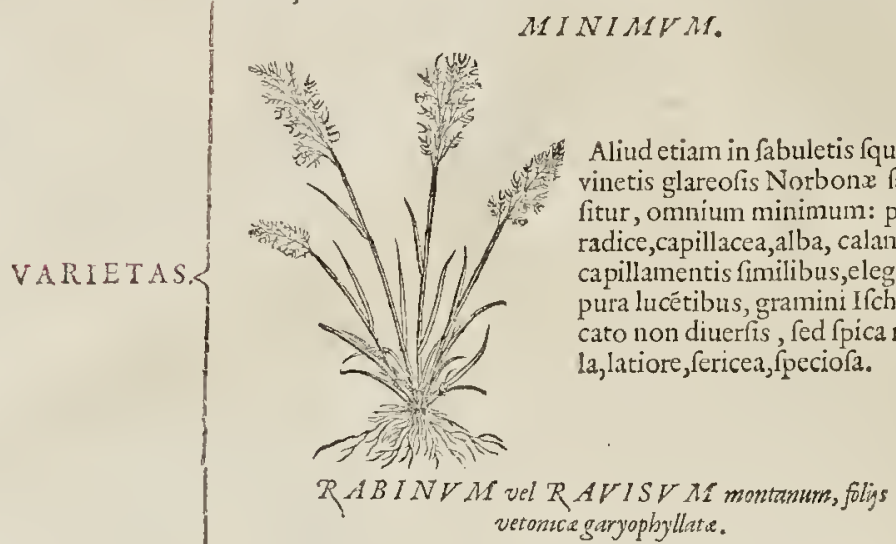

Sagina \& lactis vertati omnium laudatífimum: Montium accolx opiliones Sabaudi \& Heluetij Rabis vel Rabinú vocāt, quafi preltantius \& preciptium gramen dicas, (vt quafi Robus in Triticeo genere) Folijs eft crafsioribus, camolioribus, breuioribus ad Tunicé vetonicam propius accedétibus, Mótolis vdis Anglix \& Heluetie familiare.

$G R A M N$ CANARIVM, Medicatum Officinarum.

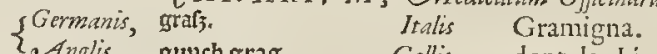

YeAnglis, qupchgras. Gallis, dent dechien.

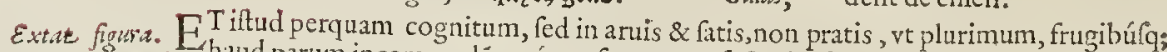
folo 345. "sput Vere, manibus runcandu : cóque fementem facturi raftris Septembri, etiamq; primo Dodonem apud Mathio- implexis, candidis, guftanti dulcioribus, geniculatis, longè latéque fubtus tellurem ferLum 999. pit:minus numcrofam fobolem promit foliorum triticeorum \& harandinaceis minorum, egeniculatis calamulis, rigidioribus, crafsioribus \& longioribus, vti \& folia, quàm pratenfis : flore item fpicato, minus tamen lanuginofo, afperiore femine, totáq; planta magis vefca dulcis \& frumentacea, vfibufq; Medicis receptifsima, prefertim radix, qux referat vifcerum farctus $\&$ renum, citra calefactionem, lumbricóf, huius fillatitia in-
terimit, nempe pabulo humorum putridorum fraudatos.

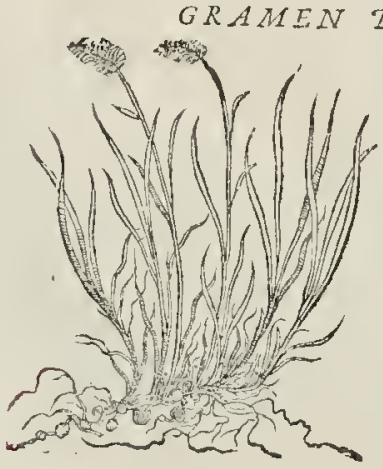

Rarius aliquantò iftud, minúfq; plerifq; Europæregionibus vfu cognitum:Lemmano autem Laufanx finitinis aruis \& fegetibus plurimum. Frequétifsimum etiam Sabaudix \& Anglix, vbi idem efficacifsimum experiuntur Medici eruditifsimi quidam, Londinenfes prafertim . Cuncta prorfum ei canino gramini fimilia funt, fi huic glandulas teretes, rotundas, guftu dulces, radicis anfractibus hrentes, demas, aut illi addas. 


\section{STIRPIVM aduerjaria noula. \\ CAL AMAGROST IS wel HARVNDINACEVM \\ forte B A B Y L O N I M.}

PR A I I vdis, fed ftrigofis, macilentis \& fabulofis neglectis familiare graminis genus iftud, quod apprimè Babylonio refpondet, ac quă Caninü gramen altero tanto maius eft,calamis \& folijs rigidioribus, fcabris, quibus ad harundiné valatoriam non parț accedit, nec pabulo cedit, nifi nultum efuriant \& penuria melioris admodum laborêt veterina, nec eo greges vefcutur, quippe, quibus non modo ingratifsimum (aigre of $\mathbf{g} a t$, feu acidum, Rura vernaculè dicunt) verum ctiam maciem, fitim \& tabem conciliare creditur, linguam \&cefophagum vulnerat \& arctat, fanguinem in ventriculum elicit, vnde tumefactio, inflammatio \& mors plerumq;. Q nod fi Babylone fuit enatum, vbi id maleficij pernicie adferre proditur, ficcius \& rigidius, grex verò imbecilior \& aluo duriore, minus mirum illius efu iumenta illic enectum iri. Sic enim videas interdum iumétorun labra \& fauces cruore manantia \& fauciata, qua cum reliquo framine per fenicecia, huius aut cófrmilia harundinacea folia efitarint: medixitaque inter harundinem \& gramen cft naturx, figuræ, Radice genicrilata,alba, promifsiore \& longo reptatu vagata, comprefsiore tame \& crafsiore, Canario gramini fimili, fed valatorium equante.Spicata, Panci aut Sorgi comofa lanugine.

\section{GRAMEN HIRSVTVM NEMOROSFM, 7F chamum videtur Plinianum.}

MO n t o s s 8 \& opacis fyluis Pedemontium \& Lugdunenfis Galliç lubens prouenit, Mduplo quàm Caninum nuaioribus folijs, mollioribus, \& deorfum refexis milij, pilis \&. fetacea lanugine multum hirtis, pallentibus. In fefquicubitali calamo geniculato, floribus canini graminis, frmilibus, naioribus, albidioribus, fed radice exilibus fibriser capillamentis barbata, pratenfis graminis. Iunio \& Augufto, nec nifi nemorofis floret.

H O L O S I V M quidam doeti amici, fed in becilla coniektura, augura bantur . Longè rerius coniecturi fi qqupou llinianum dixiffent : è terra quippe aut in terram ferpit milio fimilis, foliis afperis \& Ianuginofis, in nares farcitur. At recentiores aliud gramen fubdendum docuêre ígxino's, de quo mox.

Hozostivy. Ifchamum, Pli. L6r.25.cap.s,

GR AMEN SVLCATVM vel STRIATVM albram.

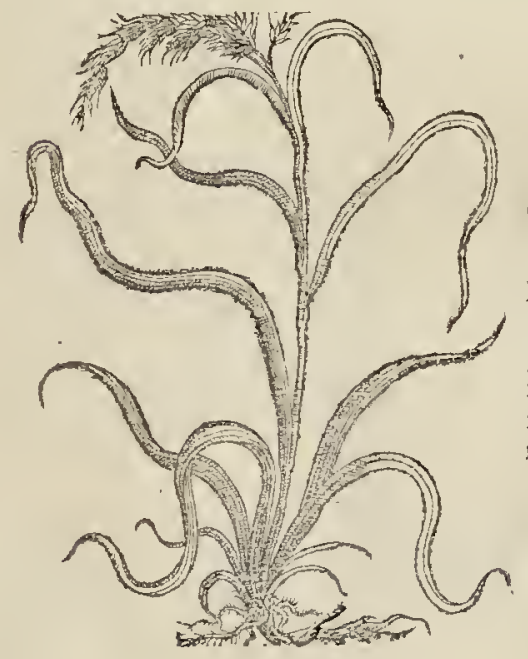

Con zTr R iftud in Belgio \& Anglia, Cyluofis autem, montoliff; Sabaudiz \&. Gallix Allobrogx fpontè nafcitur, milij potius folijs, fed vt canne Valatorięrigidıs, mucronatis: lögitudinem mediam glaucam, complures candid $x$ venæ vel linexargenter infigniunt : culmos \& $\mathrm{Pa}$ nici fylueftris vel canini erigit. Radix puGlla, fibrofa, albida, pratenfis graminis. 
GR. $\mathscr{C} A R I N V M \quad H A R V N D I N A C E V M$ maximun.

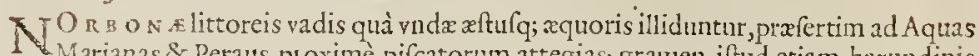
Marianas \& Peraus, proxime pifcatorum attegias; gramen iftud etiam harundinis amulum, \& vtritifque particeps naturx, plurimun reperitur: verum luculentioris magnitudinis, \& radicibus quidem ternas quaternafuè vlnas prolixis, digitum crafsis multis Pe:ilibus fubter fabuleta, vbi Eringiu,reptantibus: geniculatis, cädidis, guftu \& figura prorfum Canini graminis, fed paucioribus anexis fibrillis. Calami vero \&e ftipula geniculis \& folijs fuperiorifmilibus donantur; Sed procerioribus \& commofis lanofify; inter harundinem \& caninum gramen; floribus in auras, incunte hyeme, cuolantibus.

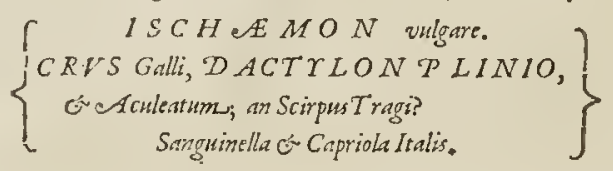

7nter fcones. VT V ET A Galloprouincix \& Norbonx ifto featent nonnullis aftatibus; exiguum eft Treg fol.209. gramen, for um tamen elegantia, \& viticulorum cognitu dignum. Sunt namq; purpureo nitido hianthino lucidi çalamuli, geniculati, furreeti, finguli, in quinas fenafvè exiles florum fpicatas candicellas, vel pannofas propagines, cyperidis modo, digitatim fparfi; aut potius graminis Manne vocati; Radice \& folijs graminis pratenfis minimi,
fapore fubdulci, fed aftringente, \& exficcante; vndè potuit conieEtura arripi Ifchrmi

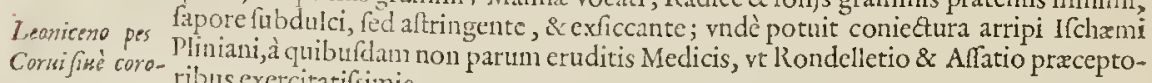
Corsifimè coro- ribus exercitatifsimis.
nopses

\section{T A R NASIVM bederaceum.}

PA R N A S I V M verò Diofcoridi memoratum gramen, \&r fie diEtum magis vti videtur,propter paftionem falubrem \& opimam, quam propter fimilitudinis comparationem, quia facie longè alia(folio nempè hederacco \& tlore al bo eft) proximè chelidoniam minorem \& Cochleaream, cognitionis facilioris, \& noftri inftituti caufa, relegamus. Alioqui pofsit quis ex vulgi vfu Burgundiacum fxnum diêm, Cytifum, aliaq; loti \& trifolij genera pabulo laudatifsima, gramina vocare; 3 h huc aduocare; cadem prorfus ratione, \& confuetudine plebeia : qux anfam dediffe etiam Plinio videtur enumerandi quxdan A I Z O I VRENTI seffigie gramina, quorum alterum medeatur ParonyGramin, P Plin. chiis vnguium, \& carnium excreffentiis in digitis, eoq; D A c r Y L o N vocetur.

efizoi effigie. Alterum verò in parietinis \& tegulis nafiens, cui etiam cauftica vis , \& fiftendo vleeDaitylon. ribus qux ferpunt apta. Qux vrramque Illecebram, fiuè Aizoi quartam fpeciem, ita reprafentant, vt nulli paulun verfato, non liquidò conftet, eandem plantam propter margines viarum aridiores, atque in parietinis fpontè nafcentem, defignatam a Plinio.

Qui an Diofcorideü Cilieium gramen non defcriptü,nifi quod bones infännat intellexerit, coniętari licct; afferere non item noftri eft infitititi: Id autem interfuit illius magni Senéfis apud Diofcoridem, in quem tamen, operâfui fimilis, \&̀ adeò ieiuna ad plantas nofcitancas \& difcernendas eft; ve nifi, quia veluti quifpiam putidus pedotriba, Pliniana loca inconditè \& infcitè aceruat; fatius duxiffemus de Graminis \& Tritici vaga \& varia hiftoria quempiam Auernum aratorem, quam iftum eommentatorem confuluiff. Ne nihil tamen egiffe videatur hoc capite, ad Leonicenum \& Ruellium à fe repræhenfos nos amandat; \& gramine Parnafio nouo (vt funt pleraque omnia Cortufiana) nos doApud CMan nai nec tantillum defriptionis dat : Et cum Ifchæmum, feu vulgatam fanguinariam,
thiol. fol.100\%. cum gramine Mannæeãdem affeucrat, non parum dubios animi relinquit iftos anxios herbarum exploratores amicos noftros, qui putarant potius effe congenerem quam
eandeminulli enim cibo cedit illa.

$$
\begin{aligned}
& G R A M E N M A N N \mathscr{A} \text { efculentum, } \\
& \text { Germanis }
\end{aligned}
$$

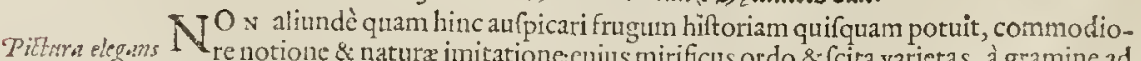
in Mathi 1000, Tritic notione \& naturx imitatione; cuius mirificus ordo \& 8 cita varietas, à gramine ad pro- 


\section{STIRTIVM aduerfarianoua.}

promifcur naturx; cuiufmodi eft graminis Cerealis huius, tommcls dran, ì Scptentrionalibus dicta planta, id oft, $C . \Sigma \mathrm{L}$ E $\mathrm{ST}$ E $\mathrm{MAN}_{\mathrm{A}} \mathrm{A}$, fcu Ros. Efthæc fanè adco fimilis Ifchxmo vulgari, vt cultu duntaxat difare videantur: habitior quippè tantum tota, radice fibrofiore, lationibus folijs, 2 calamis minus rubellis, plurcs fipicatos ftilos ocrenribus; femine in glumis magis conf́picuo, exigto tamen albido \& comprefo orizą gu1tu. In pultibus, iufculifque pinguibus incoetum, non difpari gratia clitant Cermani Alpini,qui femen iftud Manna cxlicum vocant, ferunt ix colunt.

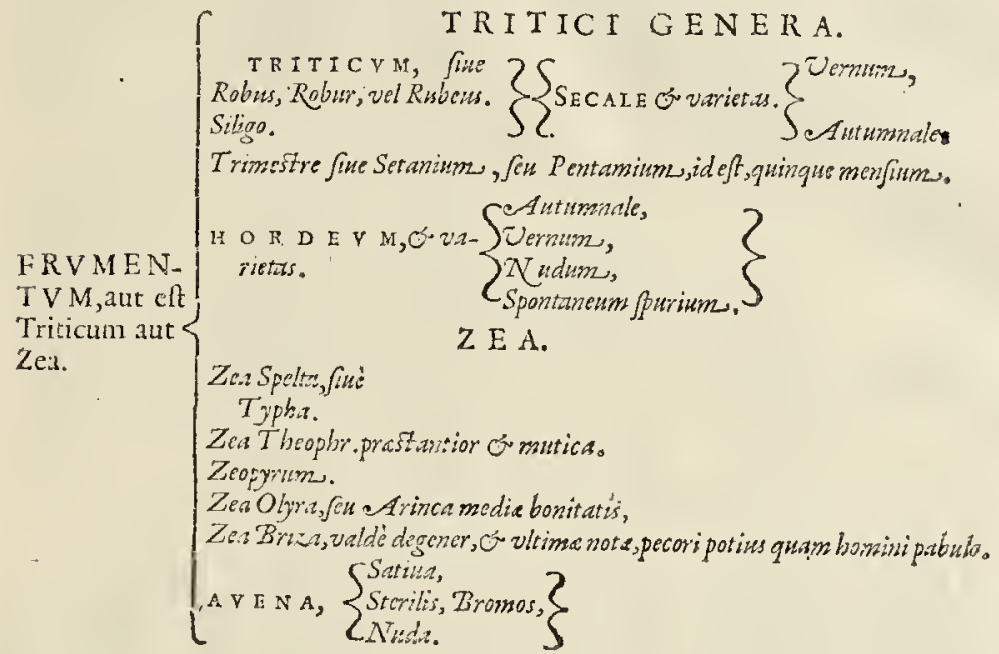

TRITICVM.

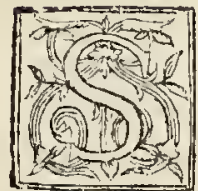

T I R P I v mobilifsima \& mortalium forti vtilifsima, vt qua animantium princeps homo, vitú trahit, T R I T I C V M eft: fic vti videtur latind dictum, quia molis teratur, Grecæautem zópos abacutic, aut fimilitudine cum fructum nonnullorum gygartis, nuclcis \& granis, qux

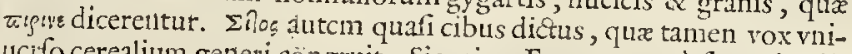
ucifo cerealium generi congruit. Sicetiam Frumentum à fruendo dixerc prala, qu Triticum in quamplurimas differentias diftraxcrunt ; cognomincs regionibus fuis \& exoticis, vndè illud aduectum fuifet, folo, cælo, fact , cultu \& induftria varium, cæterocuin pecie, \& natura re apfe vnum.

Eft namgue annua planta canini graminis folijs, fed pratenfis radice, multo notisima; fpicis feminum feracissimis; cuius etiannum coloui binas vcl ternas agnofcunt differcitias, à coloris, alijfque bonitatis notis quæfitas : quæ Varroni \& Columellx $R$ o вo

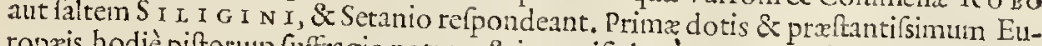
ropxis, hodiè piftorum fuffagio notam, \& in panificia receptum; videtur illud quod è quibufdam Ciliciæ atcue Corficx mercatis, Lucam \& Genuan venum afportatum meminimus: Non ita tumidum, fed folidum, flaum, grauè \& ficcius manfuque minimum mufcidum, fed friabile \& nitidum, c̀ folo letiore \& pingui minime vliginofo, fed flatibus \& folibus ficcioribus obuerfo, cuiufmodi etiam quibufdan Hyfpanix Beticx, \& Norbonx aruis enatum vidimus. Iftud mirum, ni Varronis \& Columellæx fit primę conlmendationis R o в y s. Nec enim prifcorum fedulitatem in colenda annona neglectui $R$ o s t s, habuife, tam excellentis frumenti fementem, \& propagationem fas eft crederc : tantò minus noftę xtatis auidam, ad gul $x$ cupedias comminifcendas fatagentiam hưus adeò parabili cibi vum, fructum non repetituram putandum, etiam $\int_{1}$ in vltimos orbis receffus(vndè multò minoris momenti, quamplurima accerfit grana \& aromara)antiquis abrepta fuiffet: Sed hxc mutatio cum eft frugibus \& fructibus qux vefcendo funt, valdẹ 


\section{STIRPIVM aduerfarianoud.}

confueta(vt pomis, pyris, peponibus \& melonibus)tum maximè triticeo generi : cuius femen \& iden frustus triticum iftud cum fit, fpeciem quidem feruat, fed qualitates faporis, odoris, coloris, aliáfque affectiones afcif cit, aut exuit:prout fuerit ager, imber, fuccus, flatus, cultus, fol.Itaque Rов v R; Roв v s, vel R v в E v s non fuo folo fatus abit in S I I G I N E M, id eft, TR IT $1 \mathrm{CV}$ M, deterius pondere, colore, etiantque polli-

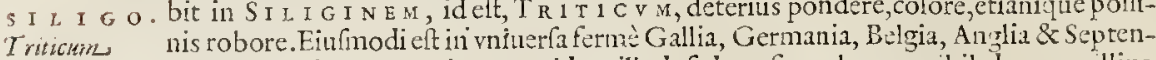
trione : cuodtamen optimum quidem illud, fed quafi proles nonnihil degener illius Effgies apud prattantifsimi habendum. Iftud tamen noftras feracius \& vberius, illud paciores culMub. 39\%. mos,minufque grauidas femine fpicas fegete fert : ac facilè videre eft, quan non omnis omnia tellus ferat funilia: Etenim Scotix agri nonulli glareofi triticum annum fpatium, vel menfes tredecim, propter hyemis fuitiam, fotum \& educatum edunt, ex quo panis longè excellentifsim!s pinfitur. At illud cuius Oftlandi, feu eorum vicini Septentrionales Orie!ntes, Antuerpiam, maximam quotannis vim \& comeatum, vetum nauibus important, minus lautum atque cädidum confat panens:tametfi penè fub iifdem cæli fegmentis vtrunque enatum fit: fed iftud vliginofo \& deprefto aruo. Illud auterh fubactiore, glarcofo, decliuiore, \& magis perflato : cuiufmodi quod ex folo Hyfpanico fquallido vidinus aduectum in Belgio pellucidum, Rubellum, rutilum, fed adeo durum, vt quia vix molis frangi pofter a Flandris mercatoribus fp=rneretur. Quapropter id dun

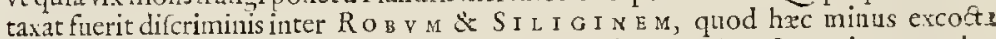

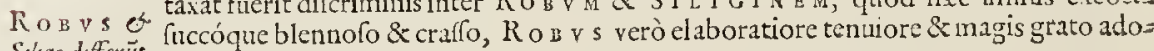
Stligo differür. leuit.

\section{$\varepsilon S T A N I V M G r . T R I M E S T R V M$. Flandris, Gomuner teruen. Gallis,Bled de Mars.}

TI 1 DE $M$ ab vtroque horum non fpecie, fed imbecilliore quadamtenus conftirutione, Tr I M S T R v M triticum, quod S E T A N I Y M Greci vocant, differt : Eius quippè folutior crafsis \& corporatura, celcrius germine \& culmo proficit, fubgute equino stium Vernum fatum, ante Autumnale cum dittifsimè cunctatur, fpicam maturat : Nec quis neutiquam perferre hyemis rigores potis fit, fatio in vernum teporem differtur, vt autumant :Sed quod amita tempeftua Autumni fementis occafione, propter vel imbres aliauè incommoda, huius ferotina fatio fubfidium venit agricolis. Huius in Gallix Nor-

TR E ME 3. bonenfis montofis fatio multa, vbi TREMES quafi TREMESTRF vocatur. Franci verò M A R T I V M dicunt, à menfe cognomine, quo feritur. Septentrionales somnince tetucu, hoc eft, xftium triticum, nuncupant. maturat enim $x$ ftate ineunte Meridionalibus, ideo Trimeftre vocatü.Septentrionalibus verò exeunte, idcircò P E N T A M I$\mathrm{N} v \mathrm{M}$ feu quinque menfium poteft dici : non perindè tamen aut delectat, aut reficit huius efus, minufque vberè pronenit. Folicius longè exiturun, \& vberius fi eodem quo reliqua duo genera tempore aruo mandaretur: Nam quodlibet triticum vbiuis gétium, \& quolibet anni vertentis momento fatum, germinabit \& proueniet, \& adolefcet modó fuperuentu frigoris, aut ardoris non enecetur.

\section{$S E C A L E$}

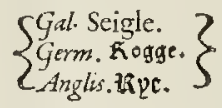

TO т I r \& vfitatius quam gratius plebeculx frumentum iftud, quo inuitx frum-

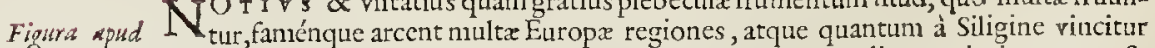
Math. fol. 402 , bonitate, tantum accedit grani fimilitudine, l1agnitudine, nuditate : nigrius tamen \& longius \& anguftus iftud. Inter glumas è fpicis, per maturitatem pendulis arifte horrcnt, cuiufmodi filiginis: non perindè vt hordei tigid $x$, fcabrx, pun gentes in culmis fenis feptenifque filigineis multo procerioribus, fed gracilioribus tenerioribus, \& internodia terna aut quina habentibus, Radice item triticex non difsimili: E fatione faciune differre coloni. 


\section{STIRP IV $M$ aduerfarianoud.}

Serunt quippe vtroq; cquinostio, \& A v T v M N A L E quidem iftud robultius, maius varic-S Vernis \& habitius dicunt; VER N v M vere feu Martio fatum, minore ftipula culmo, fica, tas. $\{$ Aut um grano, \& ad alendun eficatia. Vtriufq; alioquin pollen \& farina panificio \& Byeris, feu $Z_{\text {nale }}$ $Z$ this apud Belgas, Antuerpianos piltores, \& ciues Siliginis anonam \& commeatu fupplet, nullum eniin granum propter folum fabulofum \& macillentum (quale amat) ibi frequentius crefcit ailt panificio cedit . ex quo tamen multa \&r fedula fubactione, \& pe-

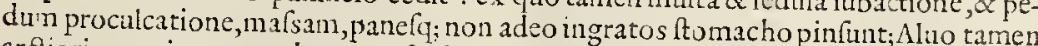
arctiori, non inconmodus acerofus hic panis, \& medicamentis etiam oportunus. Siquidem laxioribus cerebri meatibus \& continuis defuxionibus elt præfidio, panis vel pollen ex aceto \& oleo rofaceis, \& nuce mofchata vnà fub zetis. Huius palex \& corticum arantiorum decoftum muliercularum frequenti experimento faumm, \& nitidum efficit capillitium.

\section{$H O R D E V M$.}

$S^{V}$ M м A duo fuiffe videntur apud Antiquos Segetis faltigia $\{$ Siligo of 7 Efjg. Matho $S_{1 l l u d}$, de quo iam diet.xm fuit, quia ruffum rutilumuè effet $\{$ Hordeum. $\}$ quorum $39 \mathrm{~s}$.

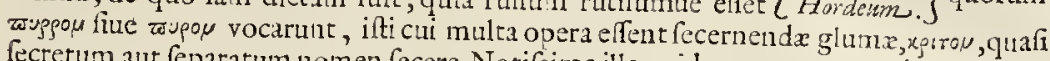
fecretum aut feparatum nomen fecere. Notifsima illa quidem ac prx cateris omnibus cerealibus vtilissim?, \& quarum cætera fint quafí abortus, aut illarū degeneres fæetus, natureq; mixtæex filigine \& hordeo: Quin hordeú ipfum nontullis vifum Siligo Spuria. Hxc enim maximas fubit mutationes, non fpecificas, fed accidétarias, fe u aduentitias, nempè magnitudinis, coloris, faporis, ariftis, glumis \& alijs affectionibus. Eapropter difcuifa illorum vaga, \& magnoperè confufa recenfione, mox hic non minus perplexan Zearum, Auenarum, afinumq; fegetum, qux vitia , \& prauaricationes illor um vocan. tur,excutiemus hiltoriam paucis \& perficuis.

Vniuerfx Europx, \& multo vfui notifsimum hordeum, x९llu dixcrunt Greci. Septentrionales \& Germani, Geerften: Angli, 13arly: Orge, Gall):cuius magna etiam varietas, magnitudine, colore, fpica, glum 3 , verfu, fatione, prouentu \& vfu. Nam culmis procerioribus è grano pleniore, maiore coloreq; rubello prouenit. Sed infignior differentia eft in glabritie, nuditateue grani.Siquidem oritur hordeum, aut folicello pertinaci adhæru granú fepiente, aut leuiore gluma \&exutu facili, cuiufmodi eft illud gen", quod nudū vocatur vulgo. Notifsimú noftras, quod à femétis occafione $\{$ A V T V N M NALE

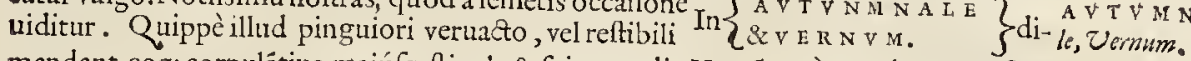
mandant, eoq; corpulêtius, maiúf́; ftipula \& fpica euadit.Vernü verò, vt minore perficitur fpatio, fic minus granum, minufq; alen s è graciliore tum ftipula, tum fpica oromit: proportione quadả cum filigine trimeltri. Alimentis \& medicatis cibis plurina commendatio: deglubitum maxima vi vænú fertur hodiè è Germania fuperiore in Belgicam, Angliāq; Septentrionales plagas, nudatí glumis \& acere, quod M V N D A T V M YOCant. H O R DE V M Reliqux $\mathrm{G}$ allix officinx, ligneo piltillo affufa feruida pauca mortarióq; inditü hordei ALixadatum. leniter tundendo tunicis palleaceis extit, mundunq; vocitat ad Ptyfanam, forbitiunculas,aliarq; pulticulas, xgris non parum accómodas faetitandas. Eft iftud manfu fuauius, albidum, pellucidum, \& tranfparens, minufq; vtrunq; quam triticum vifidum, minufq; vel calidü vel pingue. Eoq; pleureticis $\$$ :Hepaticis multo vtilius. Nâa potionbus diurnis diuturnifq; temetis, Cuiufmodj Gallix quxdam pars inferior aut Germania, Rufcia, Flandria Anglia, Hybernia, Mofcouia Nortuegia , \& Suetia potat, cxteræq; gentes ad Septentrionem, non exuitur : fed tridum integris granis maceratur ad

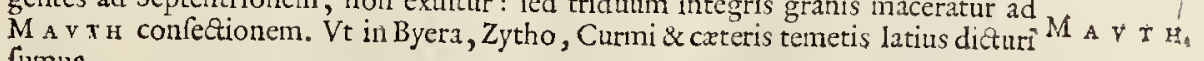
fumus.

\section{HORDEVM SPONT ANEVM SPVRIVM.}

Is Belgij, Anglix, \& Francix aggeribus,mæniis dirutis \& parietinis colligüt,ludibundi pueri in manipulos:fegetem hanc, qua vapulät mutuo, atq;verrüt quafí fcopis afferes, Mulierculx etiam hac non fecus atq; fecalis \& maioris Hordei. Vulgo S O v C R I o N S O y C R I O N quod fauius eft ftipula \& fpica,lixinio maceratis crinem flaum efficiutr; fibrofa, pufilla hordei radice, pluribus in imo folijs gramineis, cubitum altx plures ftipulx aflurgunt,

$$
\text { A.iiij. fpicis }
$$


fpica aritifque futigiatx hordei prorfum; fed mollinfulr, minores \& gano cafx, vti auena nothat aut Egylops; ad cuius cognominem morbum Kgylopem diatum valere fcimus: Sed longe magis ltraminis cineres ad $x$ demata poditgrica.

\section{$Z E A R V M H I S T O R I A$}

SPEITHA. V $V_{\text {L }}^{\text {D }}$ q quam vagum 3 Gorvel Zex nomen, \& perplexæ notionis fuit; latiufque mulSPELTHA. to olim patuit quam hodie, SP E L T A vel SPEA Y T R A huis xtatis, quaid iloapud Masl. 3 s minis duntaxat vni frumenti gencri largitur, acerofo multum glumofo, leuiorc, \& ariftis horrido pauci alimenti, non tamen praui fuccinec infueti: apud Italos Infubres, Genucules, Longobardos, Sabaudos, Galloprouinciales, \& vafcones; qui ferunt propicr varietatem grani \& agri : nec nifi potioris grani penuria vefcuntur. Hæc planè viderue

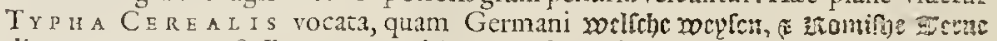
dicunt, Peregrinum \& Romanum Triticum vel far; cuia indiden allatum. Ef fiquidem tenui calsmo, \& vt plarimum fingularifpica, multis \& pralongis hordci non difsimilibus armata ariftis fabris \& rigidis, quibus $\mathbb{E}$ gyneta fcite procipit narium interna va punctim lacefcenda ad fanguinem in quartanariis eliciendü. Granum auté languidius, \& exilius multò, multiplicique fcabriore \& membraneo pertinacius hxrente folliculo

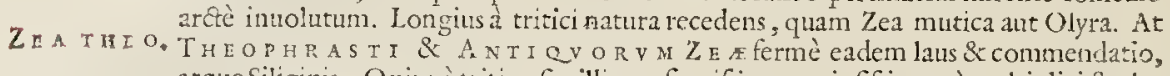
arque Siliginis. Quippè tritico fimillina, frmifsima, copiofifsima, c̀ multiplici \&asla radicc, culmo numcrofo \& al to fruticat; nec vllis valatur aritis fpica, grano multis folliculis inclufo, lauifsimo \& cunctis aninantibus iucundo, lati pingtif que foli alumna, \&olim Gracix folius vernacula; poften regionibus mulris expetita \& fata. Vndè facile difcas noftratem SPE A Y T R A M multum abhac Theoph. abcife, \& tamen congenerem, aut potias degeneren Zeam effe, Qmantüque Zea à prxftantiore filigine, tantịdem hanc à Zea melioris notze defeciffe: Sunz cnim, \& poflunt effe mutationes coplures \& familiares inter SI I I G I NEM, ZEAM \& HORDEVM, propter cómunia reminis \& eflentix principia interiora; atq; foris multiplicem euentum : vt confulti Rufticx rei norunt. Quapropter cum ex Diofcoride tres fint Zex differentiæ, (illi enim eft $O_{L}$ y $R$ A è $Z \mathrm{E} 1 \mathrm{~s}$ ) fatis liquet, xtatem Theophraftum fequmam, latiote huius nominis fignificatu vam; \& complexam non folum $Z_{E O P Y R V M}$, fed etiam O L YR A M TY PHAM, \& BR I S A M, præter illam primi meriti Zzam. Idcirco fi rem adeò difsipatam \& perplexam, quis prefla \& facili defignatione digerere \& perfringere queat, adhunc modum tentandum.

\section{ZEOPTRVA FUE TRITICOSPELTHVAT.}

HV n c proximèlocum vendicat Zeopyrum triticum; cui nomen conflatum extriHORDE Y M Hico \& Zea, quia cffigiej fit inter Zeam \& filiginem vel robum, media. Stioult li-
Nudum vilgo quidem culmo, fpica \& arifis Zex eft: granum autefimplici gluma \& folutu faciliami-

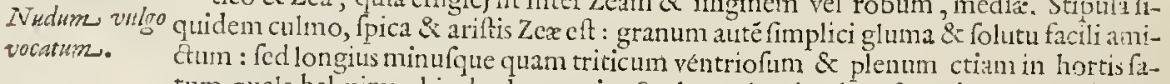
tum, quale habuimus his duobus annis; Spcltæ vulgari colore \& cuticula nonnihil ad fecale accedente, guftu minus quam cómunis hordei fuau, non tamen ingrato. Vtilitas, vt copia , rarior.

\section{ZEA THEOPH.}

2 E A Theophrafi omnium fecundum filiginem prifantifima; eft admodum afinis

Siligini, nec nifi perpufilla varietate diftans, non tamen eadem prorfus; nam veterina efu filiginis crepant, aut torminibus intereunt, quibus tamen Theophrafti Zea iucunda \& commoda. Huic mutica nec vallata ariftis fpica donata eft;glumis tamen tuniceis occlufia.

\section{$O L T R A$.
Siligo Tragi, feufur candidum,}

Trag.ico, ig4. D E I c e s Olyra fubdenda, qux Zea Herodoto vocatur; panificijfque apta habetur. Hanc Gcrmani,quia pollinis perquam boni \& candidi fit, in $A$ A $Y_{L}$ v y foluút, 


\section{$S T I R \mathcal{P} I V M$ adwerfaria noud.}

\& A M MEIKORN, id eft, Amyleum triticum vocant; putántque nonnulli,propter huius in panificio candorem \& fuacitatem Siliginem effe prifcorum, vel S E T A N I V M,
verum fecus eft.

\section{TrPHA, an SPELTHA?}

SE Q y I т y R Typha; cognata \& hxc Tritico; fed Theophrafto monente,crteris multò læuior quam Zea, nec pinguis fæcundique foli , fed foluti \& macillentioris feges. Hanc noftrates, vti fermè auenam alternis ferunt annis, non veruacto, fed etiam defeffo agro; S P E L T A M QV E vocitant : Admodùm acerofo, fcabro, fquallido \& arrido grano, minimi ponderis, \& eiufdem fermè cum auena indicaturx apud colonos, quare Olyra deterior, Briza autem melior \& lazuior videtur.

\section{$B R I Z A . \quad\{$ Ger. F. Pitters hozn.}

$\mathrm{Z}^{\mathrm{s}}$

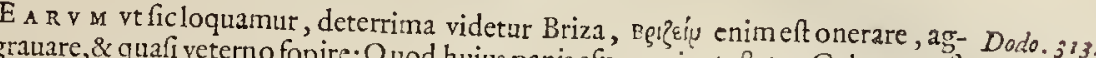
grauare, \& quafi veterno fopire: Quod huius panis efu euenire teftatur Galenus poit Muefiteum Medicum. Typhæ culmo \& fpica fimillima, grano folliculis inclufo ex fufco ruffefcente; panem acerofum, atrum, improbum, olidum, perquam ingratum dant.

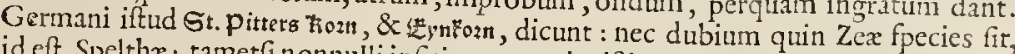
id eft, Spelthr; tametfinonnulli inficiantur, qui ariftis carere dicunt. Quod fuperius contigere vniuerfo triticeo generi, monuimus ; fic etian quandò de faltem Zex vitium efie, eoq; hifce accenfendum, per criticos herbarios nobis liceat.

$$
\begin{aligned}
& \text { AVENA VESCA C STEKILIS }
\end{aligned}
$$

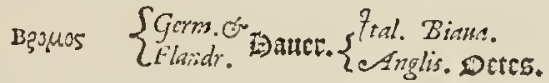

NI $\mathrm{s}$ in hordeum, quod rarius, aut Zeam, quod frequentius fit, defciuerit Siligo, $M a t b i .40 \%$ in vitium illud fegetum primum ac minus cæteris malü abit, qua auena latinis, Grxcis autem ß̧९ouos vocatur : non à fotore, fed potius quia veterina eâ multa vefantur, vel à fragore, fonituuè quem feges matura minimo tacta flatu, edit. Frugum generi fiquidem colatur accenfenda ; fin neglecta inculta, aut femine fuerit vidum geneti fi- $\mathrm{B}$ s 0 м $0 \mathrm{~s}$. crit, edendo inepta, \& quade Vircilius $S T$, OMIN ANT Y R A VENA, Dodo. 346 , \& figura non diuer $f_{\text {. }}$.rig a vtriq; enim vt nomen fic facies \& natales eadem. Sed minore, graciloreq; pedali ftipula, apiculifque ftamineis delicatioribus, minimè mordacibus, co-

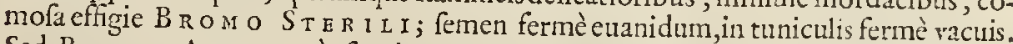
Sed BROMO A v E N Evè frugi procerioracrafsioraq; calamus \& fetacei apices tunicis prognati; femen plenum fecali fimile, fed aretus, longins \& acutius ; colore interdum pullo, alias nigro, frpifsimè albicante, 8admodum per meffes caduco. Vninerf Gallix, Germanix, Italiæ, equis eft laudatifsimum pabulum granum. At in Anglia huius locò panes fabaceos plerique omnes dant: Iumentaque auen $x$ efu minus bellè habere, aut labores ferre perfuafi funt: Tametfi bonä habeant auenam, qua in Wallia, quæ Cambria eft occidua Anglix pars, panes \& placentas ex hac exuta glebis nó prorfum refpuenda fxpits efitauimus. Pultes illic etiam ex farinx polline aut fore, cuiufmodi meminimus in Heluctia arque Cermanix Alfatia: potionibus etian acconmodant integram; vel farinam, dccoetis aluum ficcantibus 2 aftringentibus.

$$
\text { AVENA NVDA. }
$$

NOn proculab amxno Tamefi quà Londinum preterlapfus eft, atque in Cantia Anglix patent alicubi planities nudata auena cốfitæ; cuius omnia fimilia, fi granú quod colore ad Speltham, \& nudatum hordeum fiuè Zeopyrum accedit, exceperis. Mirum quantùm, cuniculis hæc feges placeat. Parant ifta fruge tabefacta aqua macerando, optimam ceruifiam; nam fuauior aliquantò \& vefcendo gratior hæc eft, nequedum valdè frequens. 
N $O$ M e obtinuit à motbo perquam difficilicuratu, cui medicationem pon!iceznr Egylops, affectio notans proximè oculi vtrinfuis magnum canthum, canernulam,

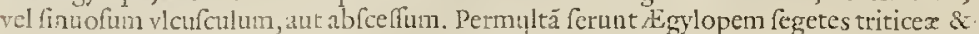
horiteacex agri Norbonenfis \& Galloprouincix, aftuofis \& glareofis marginibus, qualem Diofcorides docet : herbulan fefquipalmú, binofque palmos altam, foliis triticeis, Afir vore Ala exilibus, fpica exigua, breui, duo plurimum, interdum tria grana gerente, glumis athodo ef Enylops mida ftriatis, \& ariftis finguli grani evapice, nó foica emergentibus: hordeacea grana, a!tera figt: 1206 radice triticea puftila. Hac nulla propior genuine K gylopi, cui morbo potiù fieri cepto, ci proza axtera guamianlongius progretio, non fencl periclitati fumus profuiffe. Exiccat enim afalfo Bromes. ftringendo cieri calcfacionen multam. Potui cereali etiam addita femina, cerebrum temulentuin faciunt.

\section{$P H O E N I X$, Latini bordeums muinum.}

Fol.34.6. Hifro- D ICT A Phonix fuife videtur, quemadmodum Phonicopteros auis à colore Phocras Dods. Dnicco, puniccótıe, quafi flammeo, cóque vocant Flamment iftam aucm Norbonenfes maritimi, nancum radices, exiguaque folia \& viticulos Tritici vel Egylopis habeat, fpican obtinut rubello colore, purpurafcentéue ex fufco nitenten, al terno fitu

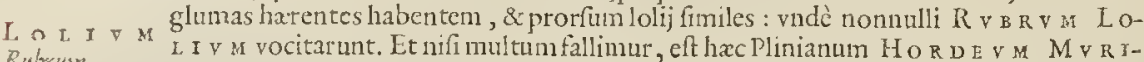
Rubruan. $\quad$ N V M, folio hotdeaceo breuiore, anguttiore : fpica lolio fimilis. Rami digitorum fenum radicem circundant: In aruis \& tcgulis, recens illitis, trita \& vino pota praclare menfes cict: quod nobis hadenus incompertum, non enim fuimus auli experiri, veriti nè capiti doloren moueret, a liaque incommoda temulentix faceret, cuiufnodi nouimus Lolium facere folitum: Præfertim apud Prouinciales, Delphinates. Repertu \& cognitu hac facilis, Germanix, Anglix, \& Gallix.

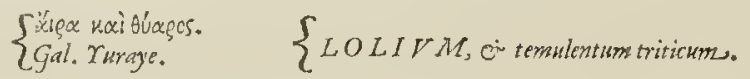

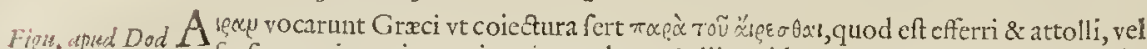
320. affinem tencbricofim vertiginem, temulentiámque efficit. Quo quidem maleficio vcl infinx ple beculx notum, \& inuifum plus fatis eft, prxfertim Galloprouincix, Norbo$n x$, \& pafsim in reliqua Gallia, vbi yuraye, quafi ebriofa vel inebrians vocatur. Quippe ctiam in Nortmania, Belgio, \& Anglia, non folum pani mixtafarina, fed multo magis Cercalibus potionibus, Ale \& Byere addita, \& feruefacta, torpore \& temulento veterno cerebrum opprimit, \& opacat, reliquáque membra torpida reddit. At foris admotum, ciufdcm ex axungia depfitum cataplafma, eadempellit incommoda, doloréfque diutumos artuum \& pericranei foluit. Spica fimilior liluli quam phœnici, vt fitè Diofcorides monet : eóquequi alterutram norit, ambas nouerit. Granum in dura tunica : ftipula, radix, \& reliqua tritici, vel fecalis funt : é́que ca in opinione, qui ex Theophrafto eft Senenfis, vt hac tritici peftis, rurfum in triticun redire folita fit : vt verun dicit, ita ineptum \& Phyfices imperitum fe prodit; quum de Hippocrate hiftoriam, è Plinio exemplum fexus humani mutati adducit. Quippe neque ad rem facit hic fexus mutatio, \& in plantis fexuum diftin ftio non vera, fed metaphorica \& figurata dotis meritò cenfetur: igitur res vera, ratio improba. Nullus cuim non nouit hic defecilfe Lolium à tritico, nec in fominam abilfe, fed in vitium quodpiam, aut alian fegetis fpeciem: calidius enim \& Gccius elt lolium, reliquo quolibet frumento, impto- 


\section{STIRPIV Maduerfarianous.}

bum alendo,prafertim homini, tritico auten planè contrariun natura. Hocenim homin falubre, veterinarix autem nex plerüque. At lolium hifce, vti neque alitibus galfoeminx, vt blaterabat Com plurimum : quare fpecificx difserentix funt, non maris ant tanicus minimè malus.

VSIILAGO.

\{ Germ. Banant, $\{$ Gal. Bruflure.

NON è deprauatis humi granis, fed ambuftis culmorum faftigiis, qux iam fpicari res dicunt: Brulture Galli, apud quos, quòd ideo Branor Germani, \& vftilaginem recétio- Hifroris. Dodo. Dum enim in foris atque aranorum, inter filiginem, fecale \& auenas, frequens oritur. $32 t$. imbre fucrit, ac repente granorum pe adhuc ett fpica tenera, fi compluta madidáque Medicina commodi comperti : comiore arefacta, iam vitium iftud fterile fit, nillius in filigineis, vcl anenaceis: Spica : cognitu tamen facile, quia culmis, foliis \& $\mathrm{r}_{\mathbf{q}} \mathrm{dice}$ eft lico, quafí defloref́ccret in puluercin ambuitánue teredinem cariofun, fatifcit.

\section{CRAT EEGONON.}

CRAtagos, vel Cratxgon arbor eft, qua de inter Mefpila dictum. Crategonum verò herba Ccrealis videtur, \& affinis melampyro, cuins vfus \& clus, femen viui-

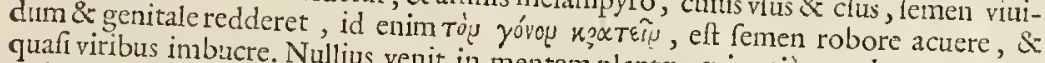
quàm ei, qux propter fimilitudinem recentiorib plantæ, cui aptius quadrarent notæ, tatur. In Syluofis collibus, \&deuexis, vinbrofis, Norbon M E L A M P Y R I genus pu- M E L A M P Y。 demontis pafsim multa æftate fruticat, cubitum, Norbonx, Anglix, Sabaudix, \& Pe- ram alterim niculatis germinibus, in alas multas dubitum, fefquicubitúmque plufculis, \& ge- Neotericorum . maioribus, quas ab imo totas folia meläpyri, eufrafix ritu : dè multò crafsioribus \& gallinace dictx, pfyllii aut linarix ambipyri, feu tritici vaccini vocati, vcl luteæ criftæ ticul is minoribus, quam Albredigimbiunt : Flores in fummis herbacei exluteo, calarix effigiatis. Semee in folliculo digitalis, fed fimiliter digeftis, \& vt melampyri aut lindnihil teftantur, vti \& foliculo exiguo milio non difpari, cuius odor \& fapor acre nonmen iftud femen in pollinem nnltómmone Action videatur hiclocus lacunofus \& hians, ta-

CXslimpyrum perpuf fllum luteums.

FVit \& hxefpcces, hic addenda, vt pote nö defcripta aut depicta familiaris Galloproui ncir fegetibus. Dodrantem aut fefquinnciam vixfu perat:tota facie fuperiorem prefert, fed fios illi luteus, \& folia altius diuifa, Ccronopo propiura.

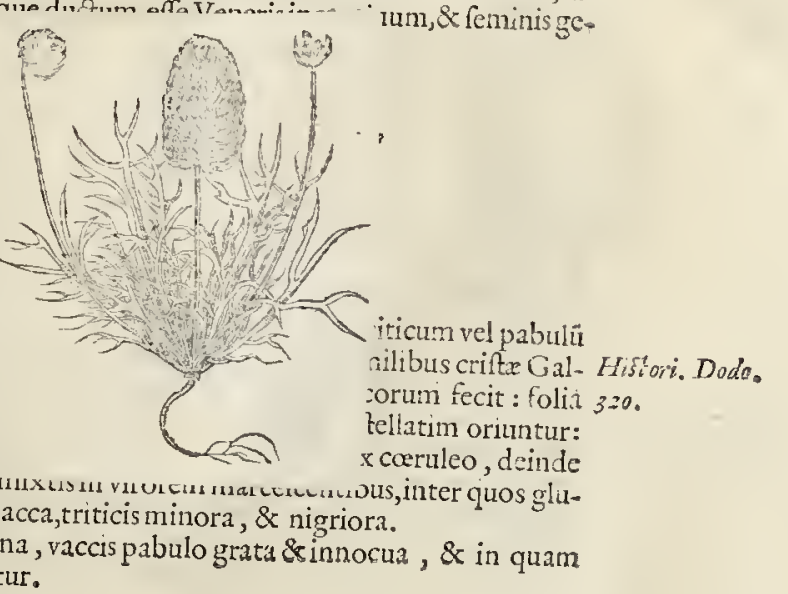

PSEY 
Germa. Karen \& fonnrof5.

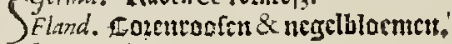

37talis. Gittone.

Gallis. Nielle des bledz.

POR R o fui generis eft Pfeudomelanthium vocatum, nam tritieo permixtum atque

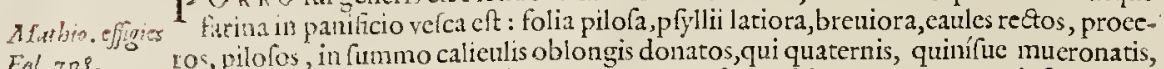
Fol.799. exithus manguculis, flores maluz eolore \& modo ambientes. Semen copiofum fufco pulóuc colore foris, intus albido.

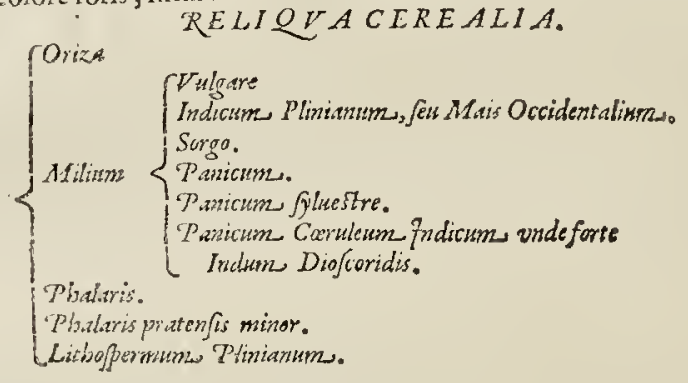

O R I Z A.

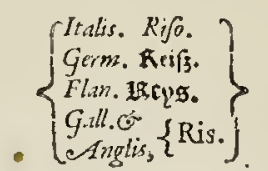

Mathiol. fo3. VT femen ex India primum fuit allatum, fic \& indidem nomen adfitum videtur, $O \mathrm{R}$ I $\mathrm{z}$ O N Theophraftus, Diofeorides verò $O \mathrm{R} I \mathrm{z} \mathrm{AM}$, Noftrates trunca voce $R i s$ vel $R$ ffo Italis vocarunt. Notifsimum illud Afix \& Europx, fed vnius duntaxat generis nobis vifum in Prouincia Norbonenfi \& Hyfpania, fed maximo prouentu in agri Mediolanenfis deprefsis, \& parenti planieie vdi agri, quem tamen euripis \& illieibus à funine c̀ lacu Maior vocato ductis, crebriùs, quoties opus vident, rigant : alioqui nullam alut caffam fegetem laturum, vt mirum fit tam fieeun \& exudum granŭ, tam palJufrem \& humentem optare fundum, bonum alimentum \& lautum fuggere, etiámque valetudini prodefie poffe. Huius mefsisferotina eft eirca æquinoctiü Autumnale, quippe maturefcitæatiuis folibus multis : eóque Septentrionales, tametfi humentes magis refpuit tractus, vtpote alfiofos. In arifta flexuofa, fed rigidula fpicatim alterno fitu infunt grana, fubflauo follieulo, aentis feu angulofis ftriis in longitudine donata : quo cum fibi fupernc̀ hxrentibus ariftis mordacibus, exuta grana, eandida, pellueida, dura \& multò pultibus gratiora, atque eandidior? quouis praftantísimo tritieo filigineo. Culmi hordeacei fefquieubitales \& cubitales, radix tritiei: at folia potiùs milii aut hordei quam porri nobis (ni multum labat memoria) vifa in Longobardicis \& Hetrufcis campis latifsimis \& vliginofis, atque in Prouincia Gaiia. Eapropter Mathiolus Senen-

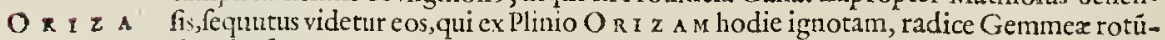
Plinir. ditatis, flore purpureo, foliis earnofis porri funilibus, \& latioribus, altitudine cubitali, cum noítrati vulgata Oriza infcitè eonfuderunt. Illud porrò radicis rotund $\mathrm{R}$ I $\mathrm{s}$ v $\mathrm{M}$, fortè fit illud, quod Romanis inuidebat iam tŭ Afra, \& Syria Barbara, iureiurando adigere folita mefores \& inftitores, ne prins quam excoxiffent, vlli venderent, veriti ne femin in alias regiones eommuicaretur, qua femina fis coctioue cranimata, munere 


\section{STIRTIVM aduerfarianoua.}

accepta, nos metipfos non rarò fefellerunt. Plurimún \& optimum alimentum fifficit probè laeti inco tus faccharo'ir amygdalo noltratis Oryzæ pollen, cóg; languinem \& femen auget, quod non dubius animi ille Sencusis efferet fi in Mauritaria vel Hifpania egiffet, vbi etiam cx Otyzx macerato lace frumento deftillant liquorem, limpidum primò, deindè oleofun habent, nec parü fuauĕ,ncc minus exhilaräté fóritus \& \&inebriantë, quàm ipfum ( quo illi abftinent, vel carent) vinum. Etian eius pabulo nirè delecantur $\$$ dociles fiunt Aphri Elephantes.

$$
\begin{aligned}
& \text { K'́y X } \\
& \left.\begin{array}{l}
\text { Flandris, Ming fen Milie. } \\
\text { Italis, Miglio. } \\
\text { Gallis, Millet. }
\end{array}\right\}
\end{aligned}
$$

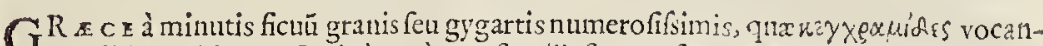
tur, dicum videtur. Iatinè verò quafi millefimum ferat granum : eft cnim tantre feracitatis, vt granum fingulum ternos reddere fextarios feratur. Nifi potiùs dictun pu- Mathiol. 40S. tet quis quia communi nomenclatura Græci $\mu \varepsilon \lambda$ ivk vocartunt, tum Panicum,tum Milium authorc Varrone. In Hetruria \& Norbonenfi Gallia, primo Vere ferunt, mctíntque tertio ferè menfe póft. Solum pingue, limofun \& glebam glutinofam, is ä̈rcin tepidiorent amat : ab radice fibrofa Panici ternos quaternófque culmos binum, triúmue cubitorú altos, hirfutos harundinaceos porrigit: toliis \& comofa foctura, faciéq; fumma quadantchus oryza, fed longc̀ maiore \& magis fparfa foerura iubata, comam harundinaceam imitante, \& grauida pufillis granis, leuiore tunica tedtis Phalaridis aur Lini, fed rotundioribus, nunoribus, magifquelubricis, qux tamen facilè friata, inque pollincm redaeta panes, lagana,placentáfque cófant, grauia concoctúque difficilia, \& mandendo glutinofit, atque ingrata, nifi mox quum cocta fuerint cdantur. 'Eóque Vcnetijs, calentia adhuc efitant \& vernúdat plcbecula in compitis, addito elogio recentis à clioano vel furno caliditatis. Sed feu recens, feu vetus elt, vtique compactz compendio \& ponderof molis, prauúquc fuccum \& multò filigine ac oryza deterius alimentun fuggerit, vcl quiburfuis Carbonarijs, opilionibúque Tiriolenfibus Iudicibus, nedum Galeno : quos illic cum percontaremur, num vera fcripfiffet Mathiolus, nimirum eos poffe victitare, nifi pane miliaceo, vel polenta lacte incocta, nos ridebant, \& Commentatori fimilem victum pcrpetuum \& lautitias optabant, \& ioco addebant, Ce non poffe quidem perdurare,vt quorum res, pccuniáue neutiquam potis elfet meliores cmere panes. Auicule ifto non fecus ac Phalaridis, Lini \& Canabini feminibus vietitant, vt Canarix Philome-

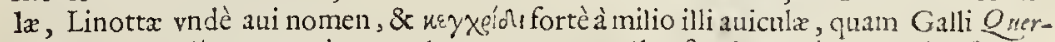
cereas vocant. Siccat tenuitate multa, pauco aut nullo eft calore, eóq!ı cerebriffuxionibus valdè accommodum. Itidem ad Aluxioncs artuum, flatúfque inteltinorum magno leuamento. Torrefactis falis manipulis duobus ferreo cochleari vel imbrice, addunt milij tantundem, fed fubducto ab igni cochleari, nè vratur milium, quod calorc \&: contactu falis vel furfuris, dum remifcentur vnà crepat, medullámque candidam tumidam, Anifi aut Carui conditi parem, fimilem, \& concolorem adeo excludit, vt pueris fpecie tragematis facchariti illudat. Ex faccis lineis excepta, calida admonentur, etiam partibus delicatioribus, torfionibus vexato abdomini, lateri, denique cuilibet ad humorem crafsiorem impactum digerendum.

$$
\begin{gathered}
\text { MILIVM INDICVM PLINIANVM fen MAIS } \\
\text { Occidentalium, Frumentum T urcickm, vulgo. } \\
\text { Elandris, Eutchetozen. }
\end{gathered}
$$

FR v c v M maxima \& perquan fpeciofahxc noftro orbi inquilina, indè à Neronis principatu in Italiam inuceta, iamque noftra ætate magis oblectationi quam Panificio fata \& culta, Turcicumque frumentum, tum vulgo tum doctifimo Fufchio nuncupata eft. Quem tamen perbonum doctorem, cum alias non fcmel, tun

$$
\text { B.i. hic }
$$


hic potifsimum immerentem lapfus incufat commentator Senenfis : quod ifud Milism perperim triticum appellarit, vt pote non ex Turcica allatum, fed ex Occidentatbus Indis primum afportatum. Atqui cum huius delis.ationem, proceritatem \& feecunditatem fcitè Plinius adumbret, cuilus æuo nulli Europxortm nota fuit aut peria Occidua India, perperàn illius primum allatum fuile commentatoris Chronographiaftatuit : quare reAtius naucleriqui ex Alia Turcica maiore, Indiis tinitima aduexifent, Turcicum vocarmnt. Radice, folijs, \& floribus eft planć Milij, fed multo maioribus atque culmis procerioribus, feptenûm, oftonûmue pedum, harundinaceis, rigidis, digitum \& pollicem crafsis, geniculatis \& medulla farctis denfa, candida, cuiufmodi faccharinæharundinis, è cuiusmedio, inter geniculorum \& foliorum finum fe prodit Cylindrea effigie Typhx claua crafsiore, fed bretiore, tunicea \& tenui vagina operta, in qua conduntur grana Pifi magnitudine, comprefia \& denis pluribúfue verfibus rectis fcitè \& arcè ftipata, colore purpurea, interdum fulua, nonunquan alba $\&$ fufca : quorum varietate flores vtique concolores miliaceis fimiles refpondent, in fummóque culmo nutant nullo indidem prodeunte grano, raro natura luxu, qux non vt pararet vmbram focturx, fed vt oftento fpefatorem obleftaret, eofdem caffos femine feciffe videtur, quod rarò alijs in frugibus animaduertas. Aprili \& Maio triduo maceratum femen (vti cotera duriora grana) compluto mandant aruo, fcrobibúfuqe deprefsis infodiunt \& operiunt, non lecus ac Pifa, \& Fabas rurales. Maturat Augufto \& Septembri in Anglia. Perunianum M A I s verò fertunt, qui illic fuerunt, ferme toto vertente anno polfe \& feri, \& meti. Eft quod, trimeftri, bimeftríque aut fex hebdomadarum fpatio maturat, prout terrx \& atheris fert temperis, nec difpar fementis facilitas in Afiaticis Oricntalibus Indiis. Eft huius M A I s panis, vt miliaceus, grauis \& gratus minimè ventriculo: præficcus enim \& terreus, alimentofi fucci expers longè noftrati filigineo bonitate inferior, quem Phronęa illi genti apparauit, vt fimiles haberent labra lactucas. Mouendo puri, faucibus, faliua \& manfu fubigunt quidam: dulcedinem quandam infulfam percipias \& gluten, quo, occlufis calori natiuo fpiraculis, facilius \& citius pus fit.

\section{SORGHIITALIS\&GALLIS.}

Fis r etiam Sorgha re \& nomine Indicum Milium huic afiñe, \& indidem aduetum, fed vt minus fpeciofum, ita frequentius mul tò in Italia, præfertim vbi fecus viam, \& mguriola ruftica : inter Patauium \& Ferrariam, videas hanc fegeten Septembri mefsibus aptam, quam Vergiliarm ortu feuerint. Similiter fuperiori harundincis quaterErratapud Do. nis, quinífue, medulla farctis afturgit culnis hominis proceritate, gracilioribus aliAe frug.pag. 17. quantò, fúcis, geniculis tuberofis, fuperioris folijs mucronatis, fed fummitatibus fpicata fattigia Panico maiora infunt, qux poft del ipfos flores luteos, geana oblongx rotundita tis, fubrubra, canabis, nilij maiora duplò, \& duplici tunica inuoluta promür. Mifelli illic coloni pertxfi operx \&longioris mor $x$, qua egent coter fruges, forgam ferunt ad pané ficiendum, aut columbis \& pullis alendis. Concinnant etian fcopas huius arefastis reEtioribus \& rigidioribus, exilibus fummis viticulis, aut virgis, ad veftes pannóf; quofLibet verrendos in Italix \& Gallix varijs locis.

\section{$P A N \perp C V M$.}

E Exuos \& uédivos: Italis, Panico.

$\{$ Germanis, Plenich a beyolfabenich.

Flandris, Wanichtrouen.

Gallis. Paniz on Panic.

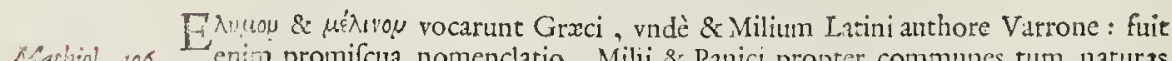
enin promícua nomenclatio, Milij \& Panici propter communes tum naturas tum vfus . Eft quippe fpecies milij, fed Panicum dictum à glomerofis tuberosífue quafi racemis, in paniculam, fue conicam fpicam hirfutam, nutantem, palmum \& fefquipalmum longam aggeftis : Miliaceis, fed exilioribus, numerolioribuffa; multo granis, 


\section{STIRPIVM aduerfarianona.}

multáque tunica obfitis concoloribus, interdum albis, fufcis, interdum ex pallido luteis: folia item Miliacea, mucronata in culnis firmis harundinaceis denfé geniculatis quinûm, fenúmue pedum. In Gallia \& Vafconia vltima, etiámque Belgicx Galliz hortis, fed foolicius in foluto \& fabulofo aruo, ficcioréque \& tepidiore Climate. Nullius ferècommodi hodie, nec Ofïcinis, nec Panificio : elt enim præficci, macillenti , \& leuioris, vt fic dicam, alimenti, eóque auiculis ad cibum erogatur, non fecus atque Phalatidis \& fylueftris iam defcribendi,fpicx.

\section{$P A N I C V M S I L V E S T R E$.}

I s T A T noftrate Sylueftre vocatum, inter Italix \& Norbonx rudera, \& vrbium

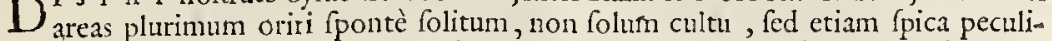
ari, nec in turbonem collecta, fed minore multò \& alterno fitu fummo cauli harente, Perficarix,aut Potamogetonis fimilitudine. C'otera verò facies multum præ fe fert Panicum, ftipula , folio, culmo, radice, \& internodiis : omnia non difsimilia, tametfi longè minora, eóque Panici reeepto nomine herbariorum donata, vfu hodie neglecta.

\section{PANICVM COERVLEVM INDICVM \\ vndeforté INDYM DIOSCORIDIS.}

QV I D pofsit in plantanem æther, aër, \& tellus, vel hęcluculenta,fi qux alia plan ta , luculento exemplo erit : cuius femen recens ex Indijs acceptum, \& fumm $x$ humanitatis, \& fummiadmiratoris ftirpium, generofi loannis Brancionis Mechlinienfis munere acceptum, à nobis Monfpellij hortis fazum Martio menfe, antè Auguftü harundinaceos culmos, quales cannx facchara$\mathbf{t} x$, hominis proceritate erexit:crafsiores digito, medulla fungofa pallente farctos, rectos,geniculatos, qui proximè radicem (quam pro fui magnitudine minorem, \& ferme Panici prioris magnitudine haber) coruleo, eleganti, nitido purpurafcunt, vti etiam in fummo cylindre fpicęvel coni fupernè retufo fattigio, ad effigiem Indici

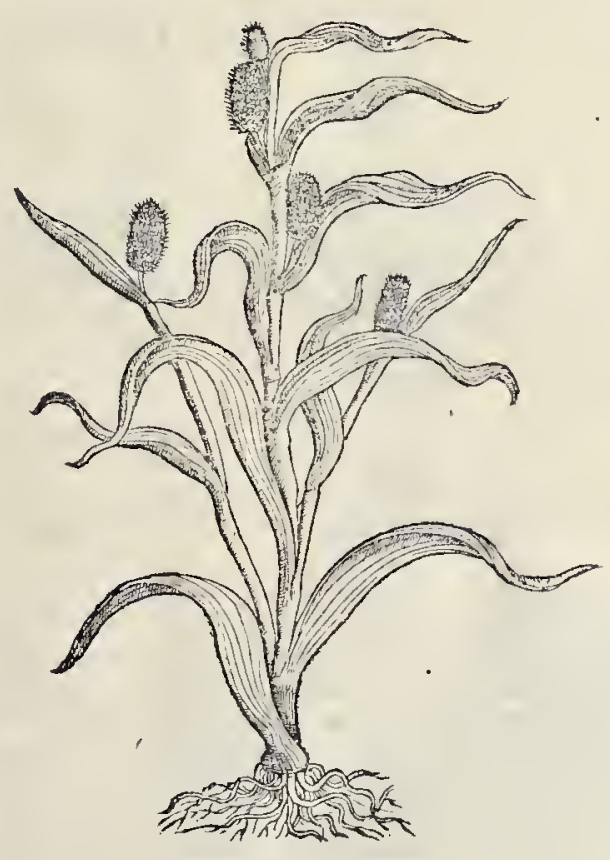
$\mathrm{M}_{\mathrm{A}}$ I $\mathrm{s}$, feu Milii Turcichi, nitent ftamineis apicu-

lis florum ex cœruleis dilutis \& gemmulis, grano denfe elegantérqueftipatis,oblongis, teretibus, cœrules, auenx nudatx fimilibus quadantenus, minoribus, copiofilsimis. Folia harundinacea, medius fecundum longitudinem neruus percurrit, lata medio tenus internodia inuoluentia : gultus miliaceus, vfus nullus, quia inter rarifsimas fruges rarahzc. 


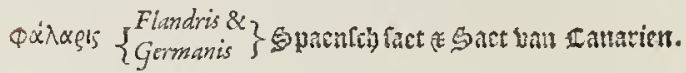

NO s modò è Canarijs Saccharinis \& Hifpanijs, fed etiam Norbonenfi agro, via ad Magalonem propè fcgetes ad pontem, Phalaridem veram, eiúfque enatum femen foeliciter in Belgio \& Anglia habuimus : quô inftitores Canarijs Philomelis plufquam faccharatas \& mellifuas cätilenas modulantibus alen dis vœnum afportant feninis magnam vim:Sefamo paulò maius \& concolor, aliquantò deprefsius, \& ninus quàm lini femen : in fpicatis culmis, \& glumis acerofis, æqualibus: cubitales funt culmi, geniculati, folijs \& radice hordei, aut potiùs, v ti tota facies, Zex. Alimento eft, \& nönulli panes pinfendos curant, cfitántque ad calculum farctúfque veficx.

$$
\begin{gathered}
P H A L A R I S P R A T E N S I S \text { MINOR. } \\
\text { Trago EAgylops Pli. }
\end{gathered}
$$

Inter Icones $\mathrm{V}$ o modo \& quantum diftat gramé pratenfe minimú à canino gramine, tantū hæc à Phalaride:quippe non in fegetibus, fed herbidis pratenfibúfque Getmanix, Gallię, Hero, Tra, 204 Anglix oritur, gracilioribus ac fufcis ex fanguineo lucidis ftipulis, fefquipalmaribus, inrerdum \& pedalibus, perfummam in fericeis capillamentis fparfim copiofas glumas geftantē, nitidas, ex atro fufcas, \& femina fuperioris phalaridis duplo minora:folia item \& radixminimi graminis vel Ifchxmi.

$$
\begin{gathered}
\text { LITHOSPERMVM PLINIANVM, fue Mains. } \\
\text { LACHRYM Iо в fen Chrifi. }
\end{gathered}
$$

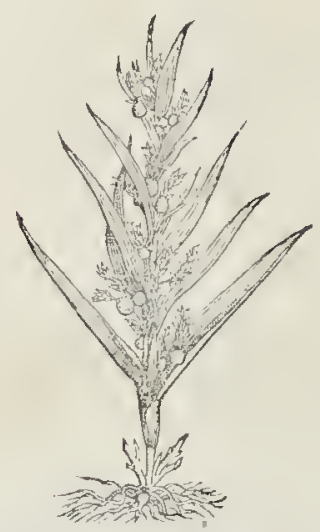

GAlloprouincir \& Norbonéfia vireta,pręer$\mathrm{G}_{\text {tim Cęnobiorü, nondūi inteftinis bellis effer }}$ uentibus euetía, hanc plantam fedulò colere folita erant, feminis lapidei caufa: quo traieCto filo preculas funditabant \& fupputabant. Etetianunum ad calculum Renum \& Veficę faburram,polline \& decocto prafidium vulgatum. Rotundum, leuiter altera parte turbinatum, altera nonnihil depreftum, Staphylodendri baccx haud difmile, magnitndine Ciccris:nitore, lęuore, candore, colore Lithofpermi maioris Diofcoridis : fed duritiefilicea, \& lithofpermo multò pertinacius : prafertim quod è Creta, Syria, atque Rhodo allatum , \& Cpontè natum erat : mcdulla intus pauca, guftn emplatico: nofratis autem foliz Orizæ, milij, vel pufillæ harundinis,palmum \& fefquipalmü longa, digitü lata, furreeta: Atatimab radice Tritici culfreos cauliculos, geniculatos, rotundos, cubitum altos complexa : quorum è fingulo fithu fingulæ barbulx (vt hic Plinius ait) Feu panniculæ miliacex prodeunt, feménque continent magnitudine ciceris, duritie lipidis, vt idem defcribere pergit Plinius. Cuitus fi quis exactius verba perpendat, \& cun vtroque comparet Lithoformo, facilè animadwertat vttumque $a b$ eodem defignatum, fed (qui illi penè fatalis lapfus, vt de Chryfanthemo monuimus) in vnam defcriptionem conflatum. Primú sióomveo, id eft Iouis triticum indicat triticcis aut harundineis fimilem, aut congenerem: herba quinquйcialis, folijs rutæ duplò maioribus, ramulis furculofis, crafsitudine Iunci, qux ex vtriufque deliniatione mixta funt. Sed poft addit lapillos magnitudine Ciceris, duritie lapidis,cädore \& rotunditate margaritarum, cauernulas habent qua pediculis har ent: quæ poftrema prorfum Lachrymz Iobex quadrant, neutiquam Diofcoridis Lith ofpermo. Quod licuit illi quãplurimis in agro Romano locis videre: haud fanc̀ tam ftupéda mirabilitate, fi vulgo cognitü Miliü folis intellexiffet : cóque dicir, fibi non hæienté, fed vulfam vifam plantam n Italia crefcere, puta hortis. In Creta optima, nimirü natiuo folo : quin tantus decor veluti cãdicantibus margaritis: cxteráq; inibi verb э, neutiqua à deformi \&- triti Lithofpermo congrtant, fcd Lachrymx Iobx longè hilariore \&riucundiore afpectu: 


\section{STIRPIVM aduerfarianona.}

quibus intus ineft femen (vt idem dicit) \&e fubtus canernulx, neutiquam cómuni. Muttit hic Rapfodus Senenfis, \& fuperius in Fufchium ineptit, \& fuperiore volumine nobis phalaridem vormat.

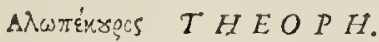

Cauda vulpis Monpellienfinm.

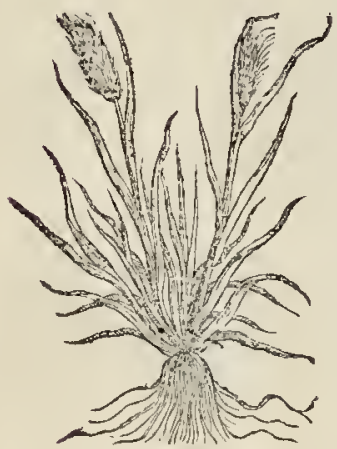

FE R A M quam caudis Vulpinis fmilem \& cognomi-Lib.7.crpi. 10. nem factam dicit Theophrafus, cun de fuperiorum collatione, tum verò de ifta Plilofophi deliniatione, notísima eft, frequénfque maritimis ad Magalonam Aquas Marianas, \& Monfpellio propinquioribus. Pedé alta tota planta,albicans tenui canicic \& triticeis culmis, folijs, gcniculis \& radicibus exilibus. Speciofiorem tamen ex fiauo pallentem, paleo colore molliorem, \& denfia lanugine obductã, pilis delicatioribus \& longioribus in Vulpinam caudam, etiam vulgi illic fuffragio \& nomenciatura, eleganter eftormatam habet, quale \& vndè Theophraltus nomen mutuo habuife dixit : fapore fruntentaceo infipido. Huius autem non wfquequad; accuratus Belgarvm.

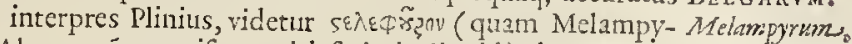

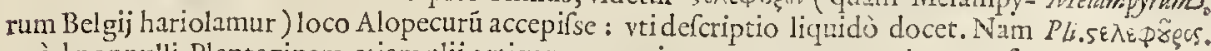
quòd nonnulli Plantaginem,etiam alij ortigen acceperint, non propterea plantago fit ftatim cenfenda, vt monuimus, varijs adducti cxemplis in Stcobe : funt enim nomenclationes vulgi incertx, nifi certioribus ftabiliantur coniefturis.

\section{HOLOSTEV $M$ DIOS. foribus albis vel oxósqu eAgineta.}

HE r в v r a fit oportet toa tenella \& graminea holoftum, fic contratia notione di- Perperam Fufc, Aa tota offea, quafi nihil duriofféue haberet : fic etiam Graculi tù yruxéx id eft Gramen. dulcia fella contrario lignificatu, vt quæ fint amarisima, yocant: fic etiamnum vulgus fco: 74 . Iuam mofchatam, \& Vngucm odoratum dictitat. Dux vero funt plantx graminex, quarum altera perperam à Dostis:altera non malè forfan à nobis, proponuntur. Quâplurimis Gallix , Belgix, \& Anglix locis incultis, \& viarum nuarginibus, exiles, tenellos videas \& humi caducos, per interualla geniculorum, bina folia gramineis breuiora, acuriora, habentes cauliculos : Horibus lafteolis Ornithogali, \& Morfu gallinz minoribus: vtriculos, Lini feminis, aut Anagallidis fimiles relinquentibus : Radicibus Ramineis, albidis geniculatis prolixè per terram vagantibus, gramineis nultò exilioribus, quibus taméctian hodie abutuntut quamplurimi Angli Pharmacopci, graminis loco \& ignoratione. Hanc Lutetiani Parifienfes pręceptores iandiu holofium opinati funt.

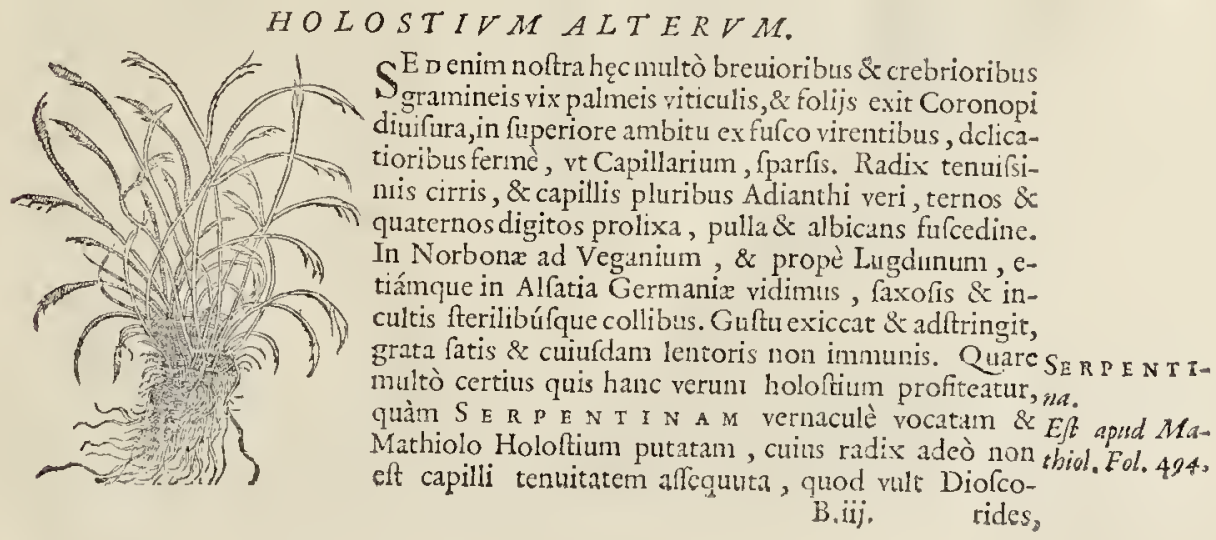


rides, vt crafsicie lignofa \& fufca minimun digitum fermè crafla manifeftò confpiciatur. Reliquíque plata capitulis \& femine plantaginis : non molicella aut tenera, fed durior, rigiciórque, quian ve hololtio datum fit. Folia illi inncea, angufta, crebra, in terram proscimoentia.

\section{HOLOSTIVM MONSPELLIENSE}

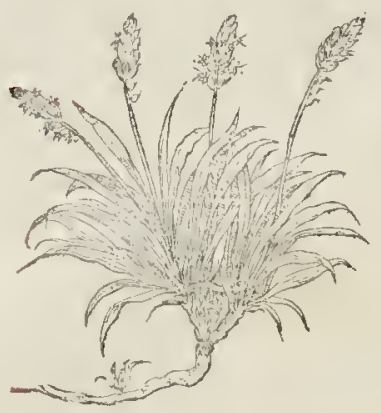

T E c quam Monfpellienfes Holoftium fufpicabantur probädx, propter eandé planè radicis cótrariand nota. Eft enim(tametfi alba) lignofa, cratla, lux aut Cotulx, aut Cichorii æqualis, furculor, ftatim foliz Pfyllii aut Coronopi non incifa tamen, albicătia, complura, \& nónhil lanuginc pilora emittens. Viticulis etiam \& Aoribus Coronopi vel Plantaginis, fed albidis. In Monfpellienfibus aridis olinetis, \& non procul ab artis viáque Bontoneti proxima frequens oritur. Exiccat \&hæc nonnihil adftringit, terreo fapore, fubfalfo, faliuan ciente.

$P H A L A N G I V M$ an $M O L Y$ PLI.

фx́x $x y=1$.

Non reste 1)od. W $\mathrm{O}$ fine difpendio noftr cosnitionis, \& txdio conquiftionis omiffa funt folia Moby. Fol. 348 Phalangii,in Diofcoridis Pliníque deliniatione. Cui tamen multùn ditique, vt nonnihil quod bellè quadraret, nancifceremur, a nobis elaboratum eft. Lugduni in collium accliuibus ad Rhodanu, non procul ab arce noua Lucerne portæ, \& Pedemontis Tau rino, Eridinóque fumini collibus vicinis planta eft gramineis folijs latioribus, pallidioribus, caulem inum cubitalem \& fefquicubitalem amplex is, ab vno ortu exeuntibus \& reflexis, radice exili, fibrofa:plures pufillo: ramos in fummo promens, quibus ex pediculis flores aptantur candore \& diuifura Lilij, fed crebriore Afphodeli pares, nec abfimiles. Semen angulofum pencarpio Lini, aut Afphodeli occlufum, fed multò minus. Varijs Londini \& in Belgio hortis colitur, nominéque Phalangij donatur. Multò fanè aptius quàm $\mathrm{M} \mathrm{o} \mathrm{z.} \mathrm{Y} \mathrm{,} \mathrm{feu} \mathrm{Diofcoridis,} \mathrm{feu} \mathrm{Plinij,} \mathrm{ve} \mathrm{nonnulli} \mathrm{volnerunt} \mathrm{non}$ indocti: nullo enim bulbo, ne quidem atra radice præditum eft, vt cotera taceamus.

$$
\text { PHALANGIVM CReATEA Salonenis. }
$$

D V M Monfpellio Gallopronincix Marsilęam lufum iremus, cumplures commilitones per Crętain, glarcofífue, \& fufas planicies Salonæ, qux vocantur Craux de Salon, alter am non difsimilë huic copiofan collegimus, nifi magnitudine differentem, qua pedemvir aquabat : \& folio minore quidem, fed crafsiore, rigidiore multó, ad Garyophyliatä accedente.Iunio flos, \& femen Augufto fundebat fumilia, fed nunora.

\section{PHALANGIVM. H. TR AGI.}

PHA L A N T V M verò fingularisiudicij Tragi, non Lilij fore, fed potiùs pappofo

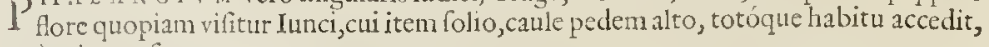
quò etiam referemus.

PHALANGIVA $M A T H I O L I$.

COmment a t or is Senenfis verò Phalangium piçum, vti pleraque alis, nec dcfcriptum nobis, nec multis doctioribus nufuam vifum, (forte nec Mathiolo) qui quafi mutus foret, fculptori munus commentandi relinquit. Multus alioqui hic \& alibi, in ex Ruellio \& Plinio iandin pertritis locis vel interpretationibus conferruminandis.

A RVN- 


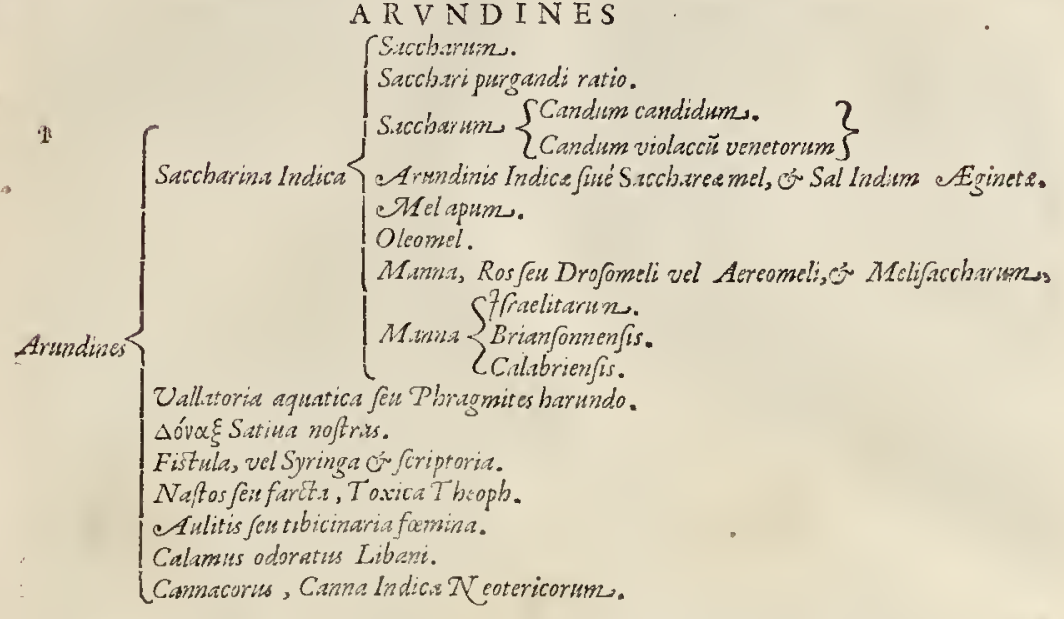

HARVNDO SACCHARINA INDICA.

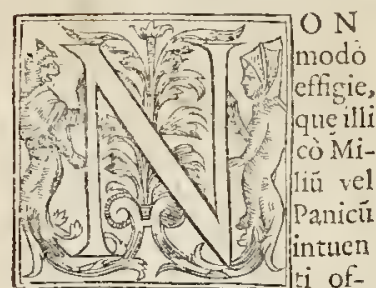

fert, fed etiam natura \& vfu hunc proximè locú fibi vendicant Harundines : vt quarum radicibus tufis arefactis \& in farinam molitis, etiamnum hodie nonnulla gentes panem nó infuanem conticiunt. Quinetiā gramineo eft fapore, etiam noItratis arundinis radix. Et ea qux Saccharum fundit delicias lautitiáfque, tum culinæ, tum Pharmacarix vtiliorné an finilior Miliaceis fir incertum eft, idcirco hancillis proximè fubdere confilim eft, Medius fiquidem inter Miliaceas atque Arundinaceas videtur hic Saccharatus Calamus, nobilifsimus hodie \& orbi Europeco iä multis ad Mediterraneü Oce,

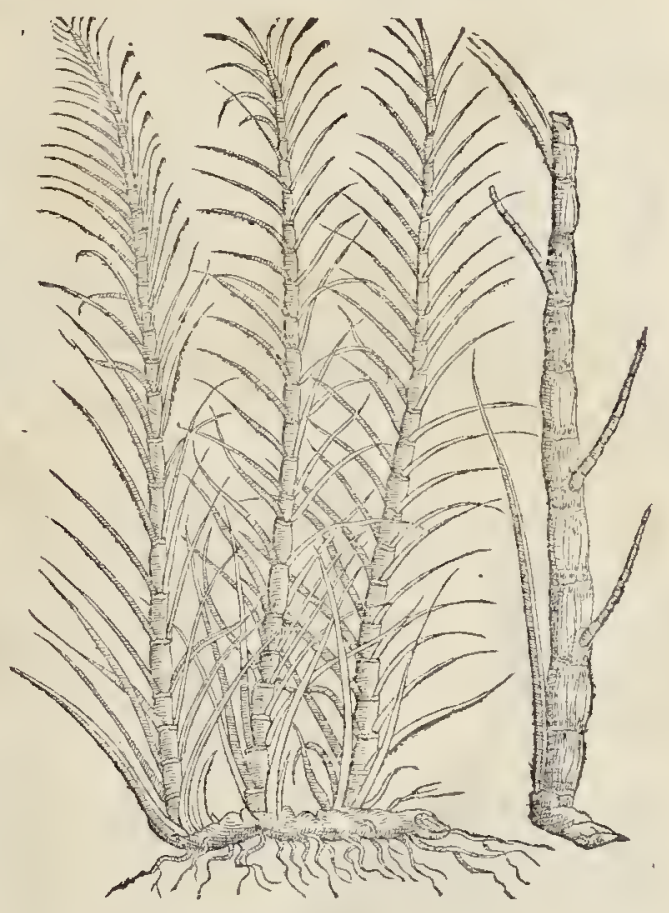
anumque tractibusinquilina:vt Hyfpanicis, I.ufitanię atq; amænifsimis Oibię in Galaloprouincia viretis, non procul, \& exaduerfo Stochadibus infulis, quem virentem ini bi \& alibi habuimus, \& in Belgio meminimus. Septenum oftonúnue pedum calanos - pollice crafsiores, denfis geniculis, fungofa, perquam dulci, fucculentáque medulla ob- Earcta albida promit. Folia binos cubitos equant, anguftiora tansen Donacis, fcabra \& B.iiij. fecundum 
fecundum longitudiné ftriata, numcrof: Stolones harundinibus ceteris concolores, complures amplefetia, angultio quàm ea funt, quibus Saccharate Metæinuolute puí fim apudinftitores cernútur. Comofo Hore, \& quadatenus Sorgi, Radix ad Canna radicem accedit, fed dulciore, fucculentiore, minufque lignofa: vndè germintila erumpunt fationi oportuna, refeqta. Panguntur etiam talex inx radiciabfiffe, atqua bete primò proficiunt in Gallia \& Belgio, fed byemis fencia enecantur, humentis foli, fed tepidioris aëris \& auræalumnx atque amafix. Laticem hxc dat prorfum inconparabilis vtilitatis efui potuíque, fecundxatque aduerfę valetudinis cuituis at ati, forti, \& regioni plufquan mel merum, \& meras cupedias. Nec tanen Indico hodie prima laus, tamedi ex India primùn in citeriorem Afram, Rhodum, Cyprum, aliáque non pauca loca träfmifffent. Nam hodie Canatium \& Maderenfe longe omnibus fuatritate \& candore excellit: quippe taneti quod Genuam, Mafsilaam ex India, Alexandria, \&alijs Aphric emporijs, Liburnicis Venetias afportant, fepius exco:tum, candore marmoreo Canariü pronocat : multò tamen fuauitate \& dulcedine gratifsima fuperatur. Dum enim lixitio illo acriore, quafi fapone ex calce parato, feculentioris, nigriorífque pinguedinis fordes eluuntur \& abfterguntur, vber dulcedinis gtatioris perit, atque nefcio quid rancidx acrimonix inuritur: vndè bilis gignitur, \& fanguis vritur, caput grauatur. Quod quilibet noffe poteft ex efu vfúque Thomxi rubri vocati Sacchari, ex cognomine infula, fub ip o fermè Equatore fitæ. Antuerpiam enim \& Londinum Anglix, vbi defęcare folent quidam induftrij artifices', fi guftes adhuc impurum \& rubrum, multò fuauius \& dulciam repcrias, quàm excofum, lixiuiáque \& cortinas expertum. Et quia, qua purius reddant ind iftria, colant Pharmacopoorum plebem : Iubitum eft hic monere. In Cortina feu ahenum, facchari Thomæi, vel alterius quantum volunt, immittunt. Lixiuij fortis fola ex calce viua parati, iuftum modum, \& quod ebullitioni, defpumationíque fuffe. cturum fit, affundunt : tum agitatione, fcopulifque fpumas tumidas muitorum albuminum ouorum fenfim affundunt, vicifsim defpumando, \& rurfun infillando, donec fitulam plenam mellca \& fordidiore pingıe dine, defpum ádo exemerint. Tunc probè lympidum \& fuluum factum fyrupum, lixiuio nondum abfimpto, tranfinittunt per cilicium, colum, vel ftamen, quo inibifefucas, quifquiliáfque relinginant. Tum feruet denuo, donec expirarit in vaporem lixiuium. Quod fi ( ve ferè fir) feruens faccharum impetu,artifice inuito, labrum effurione, \& ebullitionefuperet, non aquam:nam fic(vt illi loquătur)decoqueretur, recrudefcerétue : fed butyri momentum illicò addunt, atque acturú refident vindantes fpumx. Iam è fyrupo ad duritiem excoctum, faccharum in nolas, infudibuláue figlina vafa, (Veneti ęnea) quibus fubtus in anguftiore loco ineft foraminulú, priùs fontana imbutas, Saccharo adhic calente, opplent, eodem obturato foramiaulo: recuudúntq; promo, cella, aut Hypocaufto ficciore, tepidiore cumque induruerit. Mete ordine difpofitr latiorem bafum inducunt, luto ex figlina fufca anc pulla terra \& aqua calida fubacto dilutiore, loricam latam duorum triumnè digitorum. Qux crufta vti partim loci, partim facchari tepore ficco \& bibaci,aructit, démitur, noua apponitur : bis térue repetnt : fed fingula in mutatione fufi mucronem in foraminulum immittut, ve facilius effluat crafamentum pinguius, \& fordidius, quod Syrupum vulgo vocant, Gallis $\lambda 1 e$ hafe : qua quidam improbiores pharmacarij, fuos fercorcos fytupos códunt. Poftreno bis aut tertio ex Metis erutum fontana licuefaciunt: rnfúmque in Mecas infufo, referant fubtus foramen, fupernéquelutum addunt, cuiufinodidiximus.

\section{$S A C C H A R V M \quad C A N D V M E$.}

Nos r I etiam eft candoris impertiri difcendi cupidis modum, quo Veneti Can1. dum faccharum efficiunt. Primæ notæ, fu fnifsimi vocati Sacchari accipiunt vicenas tricenáfuc libras, pauca aquula fontana, vt liquécat, ficiunt : \& nè multum in multa aq'ia bulliat (nam flutefceret) \& quia parum aqux ineft illicò in crafum fyrupum abit. Tuuc arundinaceos bacillos, aut ridicas pufillas, quas prius cancellatim, deculiatimque ad oll imum, \& latera aptarint, merfa faccharo fyrupóue calente, \& vas paulò fuperius, quàm medio tenus opplente, mulum inuolutum bombace denfa, vas cella, aut officina calefacta reponunt fuper afere, femimenfe ant viginti poft diebus aperiunt os, \& nódum concretum fyrupum prius effundunt repente affufa calida, ad fyrupi eluendam pinguedinem. 


\section{STIRP IV $M$ aduerfarianoma.}

guedinem. Qua denuo \& illicò affura, reponunt quouis calidiore, aut quonis alio !oco: efractóq; eodem die aut biduo vafe,pellucidi candoris cryftallinas bacillis aggeftas habent glebas, multò durifsimas, quas citius vres, quàm liquefacies i jni, nifi liquore ad-
ưlito.

\section{$C A N D V M U I O L A C E V M$.}

PVR P V R E V M Violaceun æquè pellucidum, fed pulcherrimum, nec minus vtile, folis

Venetis, dum illic ageremus, notun, fic paratur. Sumito, exempli gratia, facchari finifimi $\mathcal{L}$. vi. liquefcant $\&$ bulliant quàm fieri potelt pucifsima aqua, donec ad tabellarum clectuarium crafsitiem deducatur. Tunc affufis y ncijs 24 .exprefsionis coatex, cōpendiof $x$, \& recens eduat $x$ ex frigida \& violis contufis : aut potius violacca fallaticia (ne vires colórue deleatur) recrudefcat, feu(vt illi loquuntur) decoquatur, vt recedat ad fyrupi fuperioris fimplicis Candi craf́sitié. Feftucis olla, \& codéloco \& modo paretur elegantifsimum Violaceum. Dum faccharo percokto mifcetur Violarum dilutum, vel exprefsio purpurea, qualem diximus, addendo aliquot guttas lucci Lintonum, viuidiore colore \& limpidiore diaphano placebit.

Denique vtilifsimum fimul atque fragrantius, curauimus parandun, additis drachmis duabus iridis candidifsim $x$ laciniainuolutx, qux amica focictate, folita eft Violr fragrantiam \& gratiam, tum addere, tum cxcitare, nec parum fic Arteriacis commodiadferre. Sic decet nitidum Pharmacopoum parare, nec perpetuò , quaí mifellus foret feruitor, Seraphico Vercellëfi radiato Apollini aufcultarc, qui imperat vas códendum \& obruendü fterquilinio, vt fermentando \& putrefaciendo fortè \& ipfe perfuafus à Theophraftinis ftcrcorcis Philofophis) fuaues imbibat penitus fragrantias \& vapores, ftercoreólque adfcifcat fpiritus.

Multa fcitx elegantix etian è faccharo conflantur, loricantur, condiuntur, \&c cócinnantur dulciaria \& tragemata \& gulx blaudimenta: quibus quia prolixiora, fuperfede. mus, confultò prolixitatis holtes perennes: nedum vt Triuiales, prolixáfq; lites huc adducamus ex Ruellio, Manardo, Fuf́chio \& alijs, Senenfis exemplo. Vt quid cnim quxrunt tandiu \& blatiunt tain multa, notum ne fuerit Antiquis faccharam? Sanè fuit, ctiä Diofcoride \& Galeno antiquiori Theophrafto, huiúfque præceptori Philofopho. Ait enim Theophraltus mel arundinibus Indicis excipi : cadem ferme etiam Ariftoteles. Quod porrò vlteriùs tumultuantur \& fcifcitantur num illi vfi fuerint faccharo hodierno? ex hiftoria in promptu refponfum: Galenus $\phi \alpha s i$, id ent, inquiunt dicit,oriri fcilicet in Indicis harundinetis Mel faccharum vocatum : igitur auditione magis, quàm ex-Sal Indumas plorationc norat. Et Paulus facetc̀ cenfet inter fales S A C C HAR, SA L E I I DVM fapore dulci, faccharum innuens, dentibus vt fal fragile. Quinetiam Plinius, quafi valdè rarum, nec adco alimentofum vel familiare foret noltro corpori, inquit fumi quantitate nucis caftancæ aut auellanæ. Eóque primò è Græcis Acturiọs, Medicatos fuccos faccharo excepiffe', no:nénque Iofacchari, Rhodofacchari commentus fuife putatur.

AtDiofcorides paucis litem dirimet : Salis in modum concretum, \&edentibas fragile faccharum, in India, \& frlicis Arabix arundinibus, quod aqua folutum, posui , fomacho vtile. Sed addit voגễT<!, id eft, vocatur : vtpote cuius nó valdè certus crat: quia vfum tantum nondum ars locupletarat. Vocarant quippe rem minus notam propter dulcedinem Mel: quemadmodum fal Egineta, propter concretionem duram lucidam, fragilem, \& candorem. Rimas namque anule harundines, præ fenio, aut turgid a agut, excludúntque fuccum faccharatum pauciorem, fed folidum, \&- falis afpecu, quale vulgatum arte excoftum faccharum, etiánıque rt Candum. Quia verò admodum paucum \& exoticum, minus crat notum, vfuque receptum : quod neutiquam mirandum, cum Manna roridum, Lariceúmque, Europæ multis locis familiare, illis penè fuerit prætermiffum : quia nondum commodum experimento auditionéue compererant.

Norbonenfis Varro \& Strabo, etiamtum ex radicibus fuccum premi fuauifsimum,ex. arundine arborea non nimis magna.

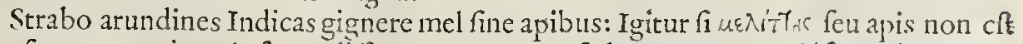
penfum, non crit mel, feu meliff excrementum, fed plantæ: quam eiufue laticem, Sacchar Indi vocarunt.

Et Seneca à nobis facit : Inucniri in India Cannas, quarum liumor pinguis, dulcifue, 
in mel abeat. Et fapor cannarum fermè omnis dulcis, radicis prefertim. Fluxiones fittit fufitu Saccharum. Et noftrate Candum, ctiámque vnl gatum abftergit, oculífque !:"Qdett, vti tempore Diofcoridis faciebat Spontaneum : quare idem efle nulli contrwiern. fum. Nechodie foret ignotum illud Antiquorum: cum vniuerfa pateat per Mciverr.:neum \&Oceanum Erhiopicum Arabia \& India.

$$
M E L A P V M C O M M V N E \text {. }
$$

A с с м а r o nobilitate, vtilitate \& originc proximum mellis nectareus liquor: quem

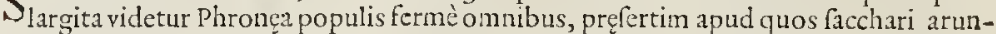
do nullo nequidem mangonio, cultu viuere quit. Eadem vtriufque natura,ortus \& fcrme modus videtur. Verü mel calidius, acrius, aèreum, magíque igneum \& fpirituofum: vnde tantopere prodefe fenio confectis \& calori languido, Democratis exemplo fertur. Nec abs re fanè , quippc vini ficclarique vigorem, vitam \& efficacitatem mel meri-

M v I S A. tò complexum effe quis dicat: $M$ L S A enim, vbi aqux plurimum, mellis non multum, diuturna inteftináque mellis ebullitione, in vinum vicinúmue faporen mul tò vtilifsinû́

ME D A. abit. Et Pannonica fen Polonica Mofcouitarúmque potionum M D A rocata, atque Cambricorum Anglorum M E T E G I I N, fuatiora funt, \& falubriora non paucis optimis vinis. Quarum quidem vfum, quàm fcimus certò profuturum Meridionalibus, tam lubenti animo illis hic impertimur:qux fic habet.

\section{Rec. Mellis boni Lib. 20. Aque plunia, funtiatilis vel fontane Lib. 120. Bulliant defpumando ad Ltbr. 80.}

Quibus femifrigefactis, inditis in vas vinariü, addantur fermëti panis, vel Alæ, vel Byerz acidioris vncix.vi.vel quod fatis fit excitandę ebullitioni \& defocationi. Et vnà de licinia vel nodulo hxe fufpendantur mergantúrque, nec fundum tamen tangant arromata.

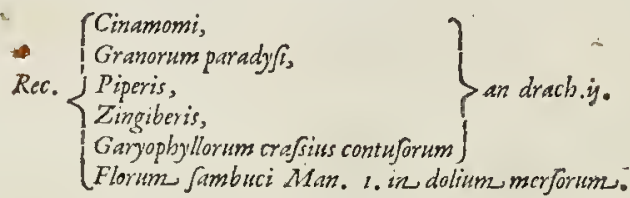

Sinantur in cella vina ria tepente per hyemem: eftate verò in fole maneant 40 . dies, vf quedum adfcifcat vineum faporem \& exuat dulcorem ingratiorem nellis. Qui vinum colore ementiri cupiunt, panni Tornefolis (nomen fonat heliotropium purpureun verrucarium ) Lib. S. addunt. Nonnulli efficacius \& gratius, addita vini tertia parte, reddunt. Hxc fi quis, non vt quotidiano potu, fed quafi medicato vtatur, mul tuin conmodi percipiet, tum ad febres quartanas, tum ad cachexias, \& ad morbos cerebri, quibus potus vini perniciofus, vt Epilepfix \& Analepfiz: adq; noxas aquarum corrigendas, vbi hę multas putridas febres cxcitare folitæ funt: eóq; Troglodytx, propter multos fruEtus aqueos, \& putres aquits plurimo, tametfi feruida in regione fint, vefcuntur pipere.

\section{$M E T E G L I N$.}

A M I R I C v ctiamille potus Metegla, non patrio'vti putant illi) fed Graco nomine dictus, vt multò falubrior parari poteft, ita multò dignior qui Tranfinarinis innotefcat : eft namque altera liquida \& limpida Septentrionis TH E R 1 A C A. Eadem proportione fermè mifcetur mel \& aqua, addunturque defpumatis herbx ficcata quamplurimę, fermè numero fexagenę, bulliúntque diutifsimè ad dimidias, intcrdum ad tertiam partem. Quò fit (vt cótra quàm ferunt vulgata Pharmacix documenta) diurna co ftione herbacei viroris \& faporis exuat faftidium, adipifatúrque vegetiorem, \& quafi tertiam quandam peculiarem alendi vim, \& gratiam faporis Maluatici vini xm!lam, nec minus duratione perennem. Triennij enim \& quadriennij colore, craft, \& $\sqrt{2}-$ pore maluatici vcl Mufcati Meteglam non rarò illic bibinus. Quotidiano hxc fenibus 


\section{STIRP IV $M$ aduerfarianoua.}

potui placet, \& plurimùm prodeft : nec adeò temulentian vertiginofan, fed amœniore facit. Multò aptior forct \& vtilior, fi Medici Do ti Inltituto, quilibet fibi accommodan pis.ridam curaret.

:Qui'k ". fd am naturis, etiam hepate calidioribus, mel iciuno fumptum ventricnlo, mul tùm conferre fcimus, \& compertunn ( fecus quam vulgò videatur) maiore copia \& fatictate ingeftun crudum purum Anglicum plus prodeffe, quàm moderatè fumptum Hifpanicum, optimum putatum. Quippe acrius Atticum, Norboncnfe, vel Hifpanicum crudum, facilius in bilem abit, magis fanguinem adurit, \& minus vcntrem fubducit, nec perindè recens hîc habetur. Minus fpeciofum ac delicatum Anglum: fed quibufda , prefertim faltibus \& pafcuis, vbi lana commendatior, lectum, vernum aut xtiuum, biliofa excrementa inferius extergendo pellit, \& aciei oculorum prodeffe putatur. Venetias \& Veronam ad Theriacx confectionem delata frpius Greca famigeratifsima, Attica \& Hyblea mella guftauimus, fuluiora \& puriora, fed minus candida Norbonenfi aut Hifpanico: qux duo tamen celebriora apud Francos, Germanos, Belgas \& Anglos, adé́que multò cariora.

$$
\begin{gathered}
\text { TVRONES NORBONENSIBVS. } \\
\text { ftalis, cAmigdalato. }
\end{gathered}
$$

I S T O Norbonenfes Pharmacopoci parant placentulas nitci candoris Turescs illic

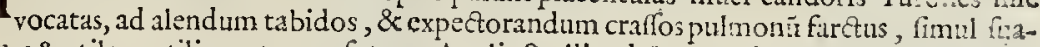
thes \& vtiles : vtiliores tamen futuras Anglis \& alijs ad Septentrionem populis, etiámq; PI G N O I A $\mathrm{T}$ O dicto medicatiores. Nam Italis valdè quàm elegans \& marmoreum niueum PI G N OL AT Y M (hodie ex puluerato finifsimo faccharo, \& poftea albuminibus \& modica rofacea , \& fucco Limonum fubacto, \& donec fummum contrahat candorem, atque pelluciditatem, agitato : pineis lotis, \& ficcatis furfuribus \& abRerfis, additis, \& remixtis omnibus, viuido fed pufillo, puróque in igne exiccatis, \& in duritiem coctis, in morcellos digitum longos, conflatur) tameti prodeft \& alit, tamerominis intrò fubit aut incidit \& abftèrgit arterix vel vifcerum muccofos farctus, quàm ex melle $\&$ amygdalis parati $T$ urones, qui fic fiunt.

$$
\left\{\begin{array}{l}
\text { Mollis prima ste of purisimi Librafex: } \\
\text { eAlburnina ossorum fox. }
\end{array}\right.
$$

In pelui tamdiu frigida piftillò ligneo agitantur, donec lacteum candorem aftequantur. Tunc prunis cinere obrutis, ne vrantur aut nigrefant, fer.lò verfando piftillo ad fuppofitoriorum crafsitiem ian fragilem coqumntur. Tum aćäütur dulcium amygdalarum integrarü deglubitarum furfuribus torridis toftarum vnciz, quantas excipere moles iam Pignolati (pecie poteft. Calentes fuper Ncbulis(qque cruftula funt)extenfæ ducuntur in placentulam, vnciam crafsam, latiore fuperficie, quan acie adhuc calentes in rhombos difpefcunt, Medico vol ente, interdum adduntur puiuifculi gemmei, coralli, cryftalli aut aliorum.

$$
\begin{aligned}
& M A N N A \text { ARABVM TERENIABIN } \\
& \text { Drofomeli. Aereomeli o Melifaccharum: Manhu. } \\
& \triangle \text { ¿ого́ } \mu \in \lambda \text {. }
\end{aligned}
$$

POSTR I I I quam Toua largitus effet vi\&um Plebi Ifraeliticx, complutáque fuifet humus, \& confperfa rotundo femine Coriandri fimili, minuto, albo, guftu mellite placente, aut fpecie Bdellij : ex quo diftricto mola, panes factitabant fapore libi ex olco: Gens Ifraelitica mirabunda, cum primum hrc coeleftia, \& nufquam antea vifa munera fuiffet confpicata, cœpit dicere : $M$ A $\mathrm{N}-\mathrm{H}$ v, id eft quidnam iftud? Cuius nominis veftigia remanfiffe apud pofteros Indicat Mannæ Thuris Libani Paleftin $x$ montis nomen: cuius funilitudo cum illo Bdellio fimili Mannæ nonnulla effet: vndè etian verifimile La- 
21

tinis deductum no. men Manum, quod bonum interpretatul perbonus Latinitatis autor Marcus Varro. Et indiden putandú Medicatun iftud Manna, quo de hic iam agemus, dictü fuife recentioribus Grxcis \& Latinis. Eximium fanè Naturx opus, ac mirabilitatis plenum : nec valdè antiquis notum: indicio eft quòd patı cis \& vacillantibus verbis illius memi= nerint, nee quante effetad purgandum fulubritatis monueLib.s. Hiftori. rint. Theophraftus \& Ariftotele fuecum mellitum ex $x$ there quercub ${ }^{9}$ fue Robori illaplü putat, quak Galesus provétu portentofo é Libani arboribus excursis memorat: \& Celfus S Y R I A C V M MEL M E I. CE- vocat : qui omnes draum. Hippo. perfuafi fuifevidenSuccus Mellitus tur ( prxterquam experientifsimus fenex Hippocrates, qui non aëreum fed C E D R 1- . Theoph. Syria- o v M M E L vocat)nihil aliud effe Manna ifud, quim roridú ex humo in xthera fubuecurn $\mathrm{Mel}$ Celfi. Etum interdiu, vi \& calore Siderum, vapidú fpiritum, qui reduce uocte oceurfans frigori liquor refuus \& quafi ftillatitius factus, arbores, telluremque rurfum, horis antelucanis præfertim irroret. Quam opinionem, vt improbare nolumus : ita ctiam fequi, nefcio quo modo, renuit animus. Qux nam tenutatis tantæ. partim aquex, partim aërex, euinfinodi ros effe videtur, deftillatitia, illico vel imbecillis Aurorx radijs diffiri in auras folita, pofsit in grumos mafticheos, gummofos, farinaceos, emplafticos, folidos \& denfos abire? Quin Manna etiam ealidiufcula eft, grauis ac pinģis, \& folutu non adeò facilis. Imò foluta, liquori calido non vtimel, aut faecharum, mixta,perftat, fed plurimı quafi aqueú refpuens liquorē relinę gummi, \& Caphuræ factitię modo rurfum coit, \& colleta vafis lateribus hxret. At imbrium eceleftum proles nix,grädo, pruina, gelu, ros, omnia frigida, neutiquam pinguia, fed facillimè vel calore, vel humore foluuntur, nec quicquam pinguis veftigij relinquunt. Quare fufpieio magna eft Manna non aëreum roreu, quirefrigerando, temperandóque diurnum æitum natura comparatus fuit : fed fuccum vaporémque viuificum cuilibet tum arbori,tum herbæinfitum iam per foles tëpeftiuos \& genitabiles maturitatem affequutum, qui extillans expiránfque interdiu trans latentes eorticis fuperficié́q; meatus, in auras à fole feruido dísipatur: noctu verò ros confuetus illabens fefe cum ifto permifeet, atque ne difsipetur, partim obftat, partim feipfun vna fermentat, inque amicam naturam vnà cö̈unt, ac demum quippiam con- 


\section{STIR P IV $M$ aduerfarianona.}

flant medir inter mel \& Saccharum natura. Quod quifiam $M$ E I I S A C C HAR V M vocare pofit. Iftud noftrum paradoxum confirmat eorum diligentia Pharmacoporum, qui ramos magnos præfciffos Laricis \& Fraxini, inquc vinarian cellam, quo aftatis tempore Manna colligi folitum eft, a fportatos, Manna poftero die, tametri non perinde nitidum, confpectum fibi affirmabant. Quod etiam uninus mirum videatur iilis, qui fciunt $\mathrm{R}$ o R I COM $\mathrm{C}$ V I deciduo purgatoriam vim inefe, non a $\mathrm{fe}$, fed foliis herbarum, qua abluuntur \& abfterguntur ab illo. Sic Brafsicx foliis \& Ró- Ros coelefis. farum rorem exceptum detergente, nitrofo \& laxante fucco magis lubricare certú.Eapropter confuito huic infundunt Rofas nonnulli ad fyrupum Rofarum ex infufionibus. Quare cum quilibet obfernare pofsit poft ramos \& truncos aumlfofue frurculos, vel etiam radices Laticis, Pinex, Iuniperi, \& aliarum gummofarum aut tediferarum atborum gummi, Lacrymas \& micas etiannum in fuperficie congeri atque concrcfcce, quas idcò propter fimilitudinem Manna Thuris Grxci, Ruftici autem Norboncufes Metaphorice in Iunipero \& Teda glaciem, Galli Vemicem vocant, poterit fecum perpendere idem Larici, Ornoglofso, Anyggdale, Prunis ac aliiis quamplurimis vfu vonire poffe. Quin quod de cleomelite Norbonenfi diximus in

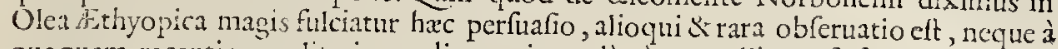
quoquam recenticrum literis prodita, quin potiùs à nomnullis quafi fabula forct cxcepta,nec ipfinet affentiri recenfioni aufsi effemus, nifi oculis manibúfque id comperiffimus in Prouincia. Norbenenfi maritima, non procul Monfpellio vrbe tam lauta quàm
nobili.

\section{$O E L E O M E L I$.}

$\mathrm{EX}$ olca arbore vilgari perquàm amara tota \& ingrata, cortice, caudice , fructu

nondum fale condito, emanare $M$ A N N a verć melleum, non folum colore, faporc, fed etiam durarione incorruprü experti fumus. Habemus namq; partim iam duodecim ab hinc aimis collectun i Rondelletio prxceptore aliquot vncias, partim à nobis quinque ab hinc annis, cum co nos duxiffet Stephanus Barrallius Monfpellienfis Diofcorides vocatus, atque in tenellis ramis \& ftipitibus Olearum arborum tam infolitas diuitias affatin nos latere monuifet. Tunc enim rimofis è corticibus, partim fealpello faueiatis, fatis excepimus non modò ad explorandun,fed etiam amicis impartiendum. Verùm non tifi propemodum pene matura olina ac nigricantc vel purpurafecnte, quam Nouembri \& ingrucnre Hycmis fouitia decerpunt, quifquam reperict mel iftud:vt nos plcbecula moncbat, qux intcrdum tantan copiam ranis aggeftan fe vidife vna aut altera die ante vel poft D. Catherinz feftum aiebat, vt auiditatı explédẹ pueri \& mendici eô certatim confuerent. In proximis vinetis pone fanum func-cinctorum Francifcanorum, via adLatreníen portam, etian nonnihil cmanabat, \& plurimum ferebatur Lunellæ extillarc, præfertim feceis maioribus ttuncis, c̀ quibus initio nelle liquidior latex glutinofus effucbat, poftea inibi refidens aliquamdiu frigore denfior euadebat, atque non tam mel quàm Manna verum præ fe ferebat fpecie, guftu, fapore, concretione onnitm comilitonum iudicio qui deguftarant, inter quos Iacobus Vtenhouius Gandanenfis generofus, \& nultarum literarum Medicus doctifsimus. Quin iam dum hæc proderemus, cum multi alij deguftarunt \& mirati funt, tum Medici fingulari cruditionis, vniuerfaque inaterix medicx confultifsimi D.Parifienfis Drouetus, \&D.Penius Anglus.

An cum Arabcs exfcribunt fortè de Galenico Manna rorido, quo cōpluerat arbores Libani atq; lapides Tuppiter, hallucinantur nominis \& naturę affinitate, interpretati nempe qụı̨ Graci antịqui de latice illo mellito fuauique rore antelıcano, qui inftar fudoris expirantis, parrim è puro fudóque aëris ambientis madore, parimque ex potiore genitabiliq; cuiufq; arboris \& herbx faliua gutticellas lynupidas $\&$ prædulccs in arborí folijs \& herbarum conftituit : vnde mellis apum ortum \& naturam facilè quis affequetur? Sanè fic videtur, nec enim manna illud fordidü, gümofum, granatum, quifquilijs 
arborum mixtü, in ranis lapidibúfq; diu delitefcens, non Sole Caniculx feruido, ant imbribus ica facilè liquefecre folitü cuiufmodi mãna intelligunt Arabes, idé cú rore çthereo. Eaproptet Grecorum Stillatitiā aereúmue roren mellitum illum tenuern, neutiquam Maına Iudxum Arabicúmue putamus, fed grana ifta Maftichina pellucida, folita è ramis folijfque arborum elabi pre copia, totunditate \& lubricitate gtanorum, ficcuffatione \& veitorum impetu, qui montes crebriùs petflant, sicque colligi in montofis fyluofis humi, \& ideo putaffe quofdam inftat grandinis è Coelo manaffe. Iftud noftrate porrò nos quafi vtrifq; naturæ cinnum \& particeps plutima arborum genitabili faliua fuaui \& madore, qui cuilibet ineft pro fua natura plantæ varius, conflatum putanus. Cui dú occutrit noctis periodus anteculana frigidiufcula, quemadmodum tunc coacto in sithere vel aëre vapore aqueum facit $R$ o R E M vocatum, fic in arboris fuperficie cogendo \& ad Ros. denfandoexpirantem per latentes poros mellitam exhalationen, fiftit iuibi manna. M A N A Quẹ eadem caufa efficit, vt ficus fuos fructus noftu maturare verè dicatıi, non propter

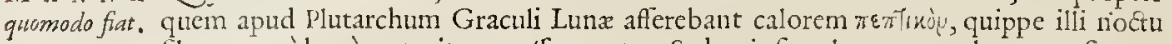
filente æquè benè maturitatem affequuntur. Sed quia ficunleus cortex, laxa cum fit tex-

Ficum math- turæ, vti tota arbos, facilè Solis radios adnittit, qui fpiritum calorćmque infitum laratio. Eteo liquori disipant interdiu, vnde concoctioni officitur : at noctu hic non difflatur, cóque naturitati impenditur totus, quam celeriùs \& perfectiùs abfoluit, nifi propter laxitatem arboris \& lactei fucci vbertatem nimiā obruacur, vt in ficu Ngyptia euent, qux idco non nifi vulnetibus fäucia matutat quia plus iufto obruebat lac alinentúnue quod per vulnus effuxit.

Nec difpar modus opúfque mellificij : vt enim efficit ex rore aut cum rore \& fucco benigno atboris, natiua infíáque vis Manna, fic ex vtroque è floribus decerpto, $M \wedge N$ N A fuo calore \& fpiritu conficit apicula fedula, etianque alix volucellx infectx, carpto in Fraelitarum tuncis arborum humore, quem percoquant in nel album faccharo fnnilc, fue Sterqualis. cus fuanifsimum, quod etiam Hifpanus à Vega magni nominis Medicus fibi vifum narrat. Non enim rore folo caduco, fed fuaui, odotatóque vapote, \& plantæ tenuifsimo fucco, quem fuis fibi inteftinis fonet apis, confit mel. Nam quî pofsit tos Stillatitiúfue imbet aut vapor in Ceram, Propolidem, freéfque quot continent faui abire? Quin mel grauius multò oleo, vino, aqua, lacte, fanguine, quorum xmulatut aut fuperat dulcedinem. Quin anatum mel, improbum, venenatum, ex Abfinthio, Erica, Oleandro \& aliis. Cur 11011 potius è foliis Iuglandis aut quetcus hauriat apicula, vbi plus neEtatei \& dulcis roris, quàm è florun aridis calyculis? Nif́ quia vbi optimus eft aër, inibi optimum mel,nodó Stirpes fint natura aptx mellificio, fugántque ć folo probum alimentum. Sed hac latiù in Larice \& Fraximo.

Hebręum Germanicŭ notü, \& Rabbinam admodum callenten Philofophię habuimus, qui Manna iftud purun \& Maltichinú vocatum affrmabat efie iden cum fuo Ifraclitico, bidellii frecie, Coriandri granis fimile, melleo fapore, quale etiammum eft in Paleftina, Syria \& Arabia. Porro, nobis obiectantibus illius fupercoleftes vires, portenta, \& putredinem: Refpondebat Iouam cunctipotentem pro eo ac ferebat fua voluntas, vfum \& fruitionem Mannx illis latgitum fuiffe, qualem, cuantum \& quamdiu illi vifum fuit : réque $\mathrm{ab}$ fe conditavti folitum ad fuam oftendendan fue gloriam, fue munificientiam, prxter \& fuper natur $x$ leges ratas. Sic quoque $M$ A $R$ A $C$ н perquam anıarum

M A R A C H \& falfum edulcuit iniceto ligno: \& Arabicus finus quafi medius fectus, vadum fecit ptoli Ioux, hoftes vero obruit: Solis otbita curfum inhibuit \& $x$ quor montibus innatauit.

Maftichina igitut vel Granata vocata, quę hodie ex orientis Emporijs Venetiis \& GeBrianfonnenfis nux proftat,optima. Nec tamen fpernenda Brianfonéfis ad Galloprouincix \& Allobrogum alpes prouenire folita, qua yniuerfa fermè vtitur Gallia, modò delectus nitidioris, purioris, candidioris, \& recentioris grani habeatur, qualen illic nos effractis è larice furculis copiofaın habuimus, qux nec dofi, gultu \& effectu purgandi nihil planè cedere illi exoticx videtur, \& multo minoris enitut, minoréque mangonij fufpicione: 


\section{STIRT IVM aduerfarianona:}

blandè namque educit biliofa è primis venis \& Iecore, éque pulmonibus pituitofa, veluti Lariceus liquor, Terebinthina Veneta vocata. Hac igitur, fiillius Syriace pure copia defit, aut C A L A B R I EN S I s, vtendŭ ab vnciar. S. ad vncias 3 . Cälabrienferm tamé hodie perpaucam, aut nullam inueniri,quidam inftitores qui illinc veniebant, planéque defiiffe conquerebantur.

$$
\text { ARVNDO VALLATORIA. }
$$

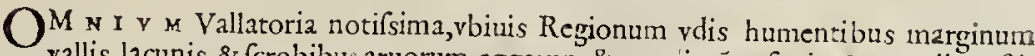
vallis lacunis \& fcrobibus aruorum, aggerum \& moniorū tefquis, \& attegriis, rufticanifque tectis multum accommoda: fic \&e fepiendis tutandifque fatis. Multi c̀ radice gramminea, geniculata, prolixius reptante, marini graminis graciliores exeunt culmi recti , ex pallore pulli, concaui: alterno pullulatu folia cmittēte graminea, militaceislongiora, fcabriora, firmiora: fpicas fert Milii modo fparfas, lanofa, mollique cefarie nutantes \& purpurafcentes, maiores \& elegantiores, cafsidum plumas imitantes, qux ventis hybernis abripiuntur, nullo comparente feninum veftigio , radice namque etian combufta \& eruta, feipram denuò inftaurat. Equidem quam nota depacta, albida, dulcis prolixa, \& vti diximus graninea: quare fcita confequutione grammeis 3 ' tririccis fubduntur híc arundinzcea.

$$
\text { DOंX } D O N A X \text { SATIVA NOSTRAS. }
$$

NO s parum frequens hxc hortis $\&$ Satis Galloprouinciz \& Norbonx, vbi colos ad nendum \& clatras feneftris Ruftici mulierculis factitant, flećtíntque ad fornices topiarias, aliaque viretorum ornamenta, adque fulciendas vitcs humi depangunt. Similes iftius funt tubiillins Vallatorix, fed proceritas \& crafsitics naagnam æquat haftam: denfifsimis geniculis, è quorú acetabulis vel cauernulis bafis latioris prodit neruus medio tenus ambiens calami ferme fpatium,intergenicula. Acori vel Schenx radix prolixa, tuberofa geniculis multis, late huc \& illuc fubtus humum porreta, albida foris intúfque dulcis guftanti. Ex qua vfta A rabum Spodium paratur Pharmacopeis quamplurimis, tametfi vt non necef́ariò, ita non magno commodo: quando melius nec difficilius ex Myrtho aut Cithonio arbore, oleaue (vti monuerat in Antifpodio Diof-Spodium atmcorides ) conficerent. Longè tamen grauius delinqunt qui loco Palma foliorum tene- ripodikm. riorum harundinis huiufce fubdunt radices : namque harum facultas ex alto cum vel fpicula euellerc prodatur, calida etiam authore Diofcoride fit,planè Palma contraria fit huic oportet, cuius ad frenandă cohibèndámque Chalcytidis vehementiam addita folia videntur. Verum iti audaculi,quid interfit foliane harundinis, qux fortè quadrarent, anradices addas, qux prorfum aduerfantur fcopo, fupino faftu malunt nefcire quàm
difcere.

$$
\text { FISTVLA vel STRINGA, \& SCRIPTORIA. }
$$

$\mathrm{EA}$ D x M cum Donace harundine hac eft, vt cernere eft in Galloprouincix \& Corfica vdis \& pinguibus prope vrbes locis, compzetiore eft carne, ninore \& pollicem vel indicem digitum æquante crafsitie, octonunn denúmque pedmu, radices \& folia non difparia, Pueris etiam quxfiti calami ad maiufcula characterum crura delinianda : \& hæc vtifuperiores dua, caua.

$$
\text { NASTOS for FARCT A, TOXICA Theophr. }
$$

$\mathrm{R} A$ R I o R hęc Europxis, nota tamen iam diu harundo mediterranei \& Tyrrheni maris mercatibus : vbi interdum à naucleris emunt fenes, robutiores \& aduitiores Stolones, quibus fipionibus fiue labantis veftigii fulcris vtuntur : Jeues namg; funt elegantes \& robuftr. Exiliores Stolones verò Scythx Afratici \& Syrij aptant ad iacula : quos emptos à quodá Pictàio circulatore Alexãdro vocato habemus exiles, leues, politus cnodes prorfum, rectos, folidos, nec graues, colore cærio pullo \& purpurafcéte nitentes. Ioubcrtus Monfpellienfis habuit, ni fallit memoria, perquan folidam \& elegantem, puto ex
Aphrica Argyera, non Alcpo.

$$
\text { C.ij. AVLI }
$$


TAYM E I I fominam hanc nuncuparit Diofcorides, tamen putamus nos à noftratibus vulgatis, non nifi textura delicatiore carnéue folidiore diftare, proindéque tubulam inagis effe fonorum lxuiorem \& nitidiorem, cuius delectus penes aulçdos \& tibicines efto.

\section{INDICA FLORIDA.}

FX o I I c elegantix pulcherrima planta hac,ambigux inter Cannas \& Acorum naturæ \& figuræ. Ea ex femine Indiæ Occiduæamicis in Beigio, deinde nobis Mon* fpellij in horto latos forcs, Augufto ineunte,dcdit:colos purpurç miniatę nitidus \& vegetus:figura \& magnitudo, numerus \& habitus florum Gladioli, in ferulaceo vel harundinaceo bicubitali \& tricubitali caule, lruore herbaceo, crafsitie digiti minimi, quem circa geniculos ambiunt folia alternò \& A cori vel Cannæ, fitu \& ritu,magnitudine \& effige hellebori albi adultioris. Radices Canne noftratis fiue Donacis vel acori paluftris xquant, èquibus prima foliorū eruptio pereleganti volumine Helicborialbi crúpentis firulacrum oftentat. Rarifsima in Italia \& Gallia \& Anglia etiámgue Eelgio vbi tametfi quotannis nouoex India aut Lufitania femine ab elegantiz amafiis fata, tamen nec feniper floret, nec frigus ferre potis cft. Idcirco commodi medici adhuc ignoti : fed cui locus hîc merito relictus, quo ad Acorum, plantafque confimilis vultus viam inftitutam pergeremus.

\section{$A C \cap R \vee S$.}

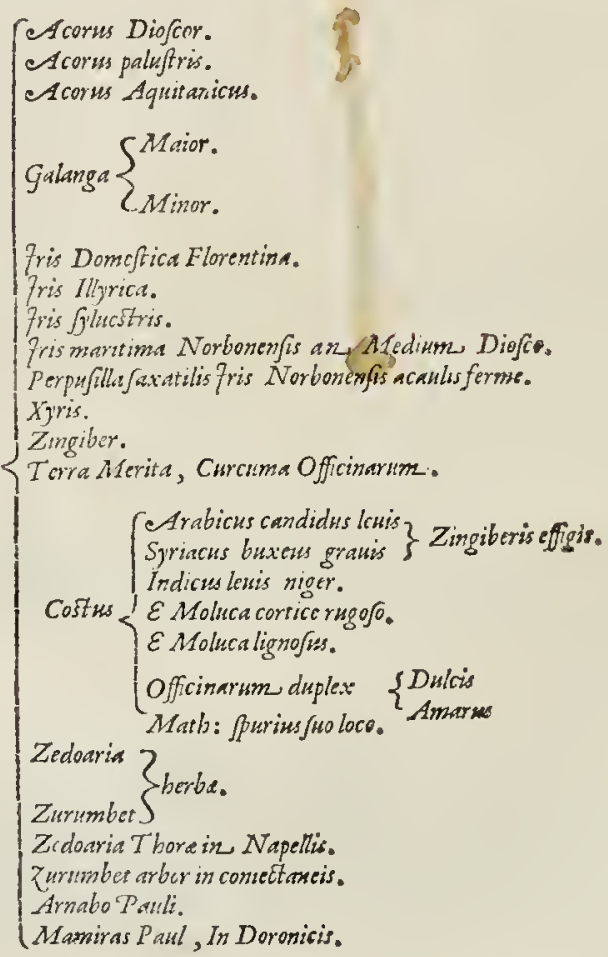




\section{$S T I R P I V \cdot M$ aduerjarianoua. CACORVS DIOS: \& AMogos THEO PH. Offiris foifo Calamis.}

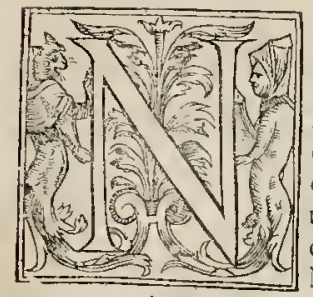

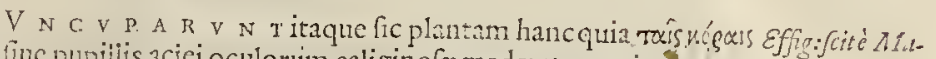
fiuc pupililis acici oculorum caliginofe mederetur, vti cognatx thiol, $2 \pi$. Zingiberis radiccs faciunt. Nani Amo silla Theoph:Verieris mirifice incentiua longè aliı cf?. Acorun verò veruñ cffe iftan ra- Acori veri, Gadicem odoram \& geniculatä, \& longè sb vtraque Galanga difsi- lange vtrinfoue, dere, etian cacula officinarum fciunt, nedun viri cruditi, quo- of Calumi arorum fuctur opera, vt non folum innotuerit, fed etia adeo vfut te- maticidifurm. cepta fit, vt pudor fit denuò illos rationum acéruos euoluerc. Nec hodie Itali, Galli, Germani confultifsini rei herbarix, alio vtuntur quam ifto è Tranfyluania Mofcouiticifq; trątibus Venctias, Antuerpiam, aliaq; celebriora Emporia asportato:vbi nó rarô ctiamnum folijs integris vifitur Iridis emulis, cuiufmodi à Diofcoride defcriptus fuit. Eapropter minimè multis opus fuit verbis ad difcernendú à Calamo aronatico has cafdcm radices, quas etiam pcrperä Calamem officinx ftatuêre: non enim modò odore cẹterifque facultatibus, fed etiam natura \& effigie tota difsident. Nec enim Acoro Arundinis, fed Iridis caulis ineft, gracilior \&r longior ranaen: at Calamus non modò caui tubi harundinaceo caule donatur, fed affilatim frangitur.Porro cum hanc radicem ignotam tum Calamo fuffeciffent ( $v t$ fit melionun pentria \& ignoratione) demum proregem quafi Regcm agnoucrunt \& tutati funt. Qum pertinaciam etiamnun fouent plerique Salgamarij,potiùs quàm Plarmacopœi cæcitate Impudenti, fed non t:unta infolicitate. Quippe rque benc explet ifta radix interdum deferiptionis pollicitationes atque gcnuinus Calamus : intenfo namque eft odore; \& pra-
fentifsimis ad mulicbres norbos viribus.

$$
\begin{gathered}
\text { AGORIS NOSRAS PALVSRIS } \\
\text { Germa. Gelb waffer Lelien, ideft Lilium aquaticum } \\
\text { luteum. }
\end{gathered}
$$

VVI G A R I s hoftratis haud alpernendx aut vires vel vfus vt quidam minus vere tradunt, qui primore lingua, non intimo gutture hanc cxplorarnt, cui aliquid acrimonie guftando fempcr inurit, non quidem illico prima impreffione, fed aliquanta cunctatione. Idem experiaris in Phyllo Mófpellienfi alifif plantis, quarum vis calcfaciens multa terrea mole eft fopita. Nam tametfi illi odor fermc nullus, calor remiffis, tamen alijs dotibus multos ad morbos peregrino preferenda : plus namque roboris \& caloris addit ventriculo, partibufq; finitimis, quàm illa quiz fuo feruore difsipat potius innatum calorem atque vires infitas populatur. Qui igitur illi nonniỉil gratix co nciliät, Garyophyllis non fecus ac Iuglandes, traiiciunt, at neutiquam cótemnendum experiuntur.

$$
\text { ACORVSAQFITANICVS. }
$$

PL y 3Cv L I s abhinc annis cruta fuit quædam Acori fpecics in agro Tholofano, quam Pharmacopoi pro Schina \& vonditare \& vęnüdare aufi fucere: quia facie effet haud ita difsimili, fapore ferme nullo, eóque Apio affíni. Radise crafsiore, denforc quả Schin $x$ aut Galangæ, concolore, pradura, fragéti contumace, lignofiore quam Schine, prælonga, tuberofis geniculis cincta: Harundinacea effigie Antuerpiam, Londinúmque delata Chynann emétita; propter quandã finilitudinę, qux multos Médicus in ftultann lẹtitiam coniecit, ratos fe in Gallia Schinam inueniffe, ad luis.Vcnerexapparatum. Sed A cortu non Schinam guftus: \& cuentus patefecit: aftrictionis namque plurimum habet, totacft craffe, inertifque facultatis, nihil leuitatis cmplaftica, vti Schina. Morbo Neapolitáno ćrando ineptifsimam norunt, qui fruftra frpius experti funt: tametfi ad vlcera mala \& frumas,
non defint illi fux dotes. - Illas autcm radices pregrandes; turbinatas, Americi orbis Schinam fuperioribus annis
cmentitas, in caput de apio feruamus.

$$
\text { A.tbial.22. }
$$


J I I Gallatium Acorum, qui cxtelis authore Diofcoridc anteit, deprauarit in Galangx fine Galauga flexum Arabica fcola, vt qux fpeciem Acori Galangan forte putarit, ignotan hanc fuiffe antiquis Gracis neceffum fateamur. Cum autem è proximo fermone authorúmque defcriptione Acorum noftrum effe Antiguorum genunu liquet, tum diuerfum effe abvtrauis Galanga maiors \& minuta Officinis di\&a, vtriufque radices perpendéti perfpicuú illicò fit. Acorus namque albida, odora \& amaricans etiam monente Galeno, effraqúque facilis, eoque vt colore, fic concretione fimilicr Iridis, quam vtrauis Galanga: quia ex fufco intus forifque ruffefcir, nec tundendo facilè cedit, acriore quidem fapore \& aromatico fed minimè amaro, magis aftringente, minúfoue proinde vires vicarias Iridis ad muliebres affectus excrente, qualcm optant Diofcorides, Galenus \& cateri clafsici. Quibus an notx fuerint vtriufuis Galangx radices, vt incertum, ita nobis perfuafum elt iamdiu Acoro aut Iridi congenerem effe, nempe A cori paluf'ris vulgaris radices habere, folia autem Iridis aut Xyridis nigricantia anguftiora tamen. Alebant hanc, non multis ab hinc annis, horti Patauni \& Vencti, vbi plurimum nobis vifum virentem neminimus. Nec multo pónt à ficlifsimis s peritifsimis herbarijs accepinus hanc candem è Syrix montibus culifam, vivitgo Iris putatatur \& nominatur, propter arctam foliorum potius fimilitudinem, quàn radiciscolorem, odorem, aut efficadiam : aftringendo nangue roborat, vt Aco:us paluftris, nec tenuitate partium çuanta eft in Iride \& Zingibere elt, fine afticione pollet, prafertim maior Galanga, quam hîc intelligimus.

\section{$G A L A N G A$ MINOR.}

A I o Qr I minutam fiue minorem, quam rocant Officinx, an fit Cyperi fpecics potiùs quàm Galangæaut Acori difficile fit ftatuerc. Nam tamctf radices afpectu, duritie, odore, fapore \& nonnihil figura Cyperum longun præferant (quo guidom inftitorum fraude aduiteratur, \& permutatur) tamen folia fi fun Myrthi (vt quidam Indicorum fimplicium exploratores affirmant) non parum ab vtroque illorum etiámque maiore Galanga difsidebit, quam alioqui viribus, odore, fapore, colore \& nomine proximè rquabat, ac fortè fuperabat. Hanc tamen, vt \& Zedoariam, Chinarum Emporia in reliquan Afiæ Indiam, Europámque occiduam nizunt: maiorem verò Jaua trans Equatorem ditifsima Infula Liburnicis in Septentrionem redituris venundar: vndè verifimile fit, aur diucrfas putatas fuife Arabibus, aut nó admodŭ notas Atricennx \& Serapioni, vtpote Grxcos fcquutis, ac propterea eos(vt folent de rebus peregrinis,parüque notis) caput duplex de ea inftituife: interdum duo admodum diuerfa fimplicia in vnum caput mifcuilic, veluti vbi Cancamum hiftorix de Manna intexuit, geminato errore, \& quia Cancamum è colo defluere, \& quod in Sorbum cxcipidixit, qux de Manna, non Cancamo, ramis fraxini vel Omoglofsi , non forbi excepta intclligendavidentur.

\section{IRIS DOMESTICA, FLOREN= restina, Illyrica.}

PR I c A gens horum forum confpicata; amonam varictatem coloriam \& variegatam coleftis Iridis xmulam, qux opacx luridx nubis obice, Soli obuerfo luminis repercuffu occurfans athera pingit, plantam Iridem vocanit : fic \& Iatini,

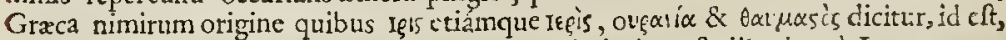
facra coeleftis atque admirabils, qualem arcum foderis poft diluuitm à I E I: o $\mathbf{v}$ A fancti narrat diuina pagina. Hodie hanc tametfi admodum frequentem, tanet cunfx ferme gentes deprauatè yocitant, Germani enim Bilgen, Sibluctril Flandri, Ita- 


\section{STIRTIVM aduerfarianona.}

li, Hifpani Lilium, Galli etiam Glazeul, propter aream florum ipfortum inter fe cum Lilio \& Gladiolo fimilitudincm. Quod idem vfu venifie Poëris \& impofuife Hiftoricis in Hyacinthis \& Liliis dicetur, de quorun tamen collatione facilè nofcitur Iris, \&: ab ijfdem difcernitur , folijs acntioribus, rigidioribus \& latioribus quàm Acori, ant Gladioli. Fiorum autem oræ diduetiores hiantéfque magis, magifquc reflexa foliola, fena ve plurimun, qux alternatim in anfule fpcciem curuantur, intróque ficxa ftaminum fibrillas condunt aliquot, quibus marcidis, $x$ ftate media ferè, filiqua Xytidis aut Acori paluftris non difpari, angulofo itcm femine erui, fcd minore, fe prodit. Radice viliada, plantx quippe fcmper vircntis, plcna, folida, albida, multas in propagincs per fummum cefpitem fufa : amaro, vchcmenti, acriori \& feruidiore, dum reccns eft, guftu, vt \& purģandi vi, quam arida faeta prorfum amittit , multúmquc foruoris ingratique faporis renittit, \& odoratior, eóquc commendatior euadit, prafcrtim T v s C A, fine FLORENTIN A, hodic primam laudan merita. Qux plurima in Mediterraneis, non procul Florentinis montibus eruitur, multum temperic agri \& $x$ thcris ad Illyricos traQus accedentibus, adeóquc prę̧tantior IL I YR ICA H A BETVR: nam hac nonnihil ruffécit, minúfquac nitida, cuiufmodi vtuntur Vcneti. Florentina vcrò candiIRIS FLOrentina.

ILIYRICA dior \& elegantiore afpectu, fuauioréque odore vifitur. Neutra tamen illic flaccida, tilgofa, rancida, fufcáue aut mufcida infolatu fit, vt noftras, præfertim Septétrionalis , cujus ficcum Hydropicis propinant Medicelli lectione practicorum freti quidam: incertum maiore ne cruciatu an incommodo ægros vexent. $\Lambda$ c tametfi Galenus Illyricx palmam ftatserit, tamen cum idem fanxcrit : vnde quodlibet fimplcx, in fuo genere quo eft fragrantius, eo prxftantius efie, de eius fententia Florentinx poftponet quis Illyricam , ̀̀ cuius bonitate tantum abeffe Aphricanum, quantum animal vegetum à fio cadauere idem dixit : eaproptcr videtur hac Natalitiis gaudere neque admodum fcruidis vt Aphricx, neque ita frigidis yt Septentrionum : fed montofis temperatis \& riguis, cuiufmodi $c x$ Hifpania hodie valdè odoratam laudatifsimam fcrunt, \& ad fummun crepidines canit Nicander Naronianam Illyticx non maritimx, fed Scptentrionalioris \& rigux à fumine Macedonix, fic vocato.

Múutiplicem igitur fortitur varictatem, non modò viribuss, vt dixinus, fed etiam magnitudine, odore \& potifsimım florum colore. Cuius multiplicis venufta miftura, non modò in diuerfis plantis, fed etiam in vnius dumtaxat floribus fpectanda vcnit. Elegantix fiquidem hortenfis amantes non modo purputeam (quxe vbilis formè Eutopx ruri oritut , omniúmque frequentifsima vifitur ) fed etiam quafdam foribus candidis, liliaceis alunt, non item luteam, vt quidam doctus putat, tatus vulgatem auteis floribus vbique in pratis A corum elfe Iridem, cuius radices, vt idem Doctus Belga ait, tätopcre altringlint, \& planè Iridis facultatibus aduerfantur, vt neutiquam futilis author literis mandarit, hafce ycl duntaxat appenfas appreffáfque corpori quemlibet fanguinis fuxum filtere : quare maluimus nos Acoto aut potiùs Galangis, quibus figura\& viribus coznatior, redécre.

\section{IRIS STLVESRIS.}

I N O D O R E dux irides, quas Sylueftres vocant recentiores, minùs obuix funt, minúfque nultò aromatica dote commcndabiles. Hortenfi ferme eadem, nifi quia tota gracilior, harum qua plurimum fquallidis faxorum marginibus fponte oritur, cultaque retinet fpeciem qua diftat à fatila,etiam fapore ingrato, odote nullo in fubalpinis Lygurum $\&$ Taurinenfium pafsim occurrit, nec vlla poteft efie earum, quas commendat Plinius feu Illytica, feualia.

\section{IRIS MARITIMA NORBONENSIS an Medism Diafcori.}

TE V I I e V A $\mathrm{M}$ triuialis venuftatis eft hxc altera quam verbis \& typis hỉc appictam damus, primùn in Nitiobrigum maritimis \& fabuletis hetbidis nobis leea, diúque D. Affatio Monfpellienfi medium putata, riguis herbidis cis lacú non procul C.iiij, 


\section{2 STIRPIVM aduerarianoua.}

ab oppido Frötignana cx aduerfo montis Ccti multa, nec vfquam alibi vniucere Galliz aut Italix facilis repertu, nifi marituis illic: quare num in Germania etian reperialo affentria, fides penes recétiores efto, quibus malo affentiri, quàn tantilla de re rixari, tametfi radicis crutz recenfque effracta nullum viquan olfecerimus Armeniaci mali odorem, qualem illi inefe ait Commen tator. Radix, caulis, folium, filiqua \& femen, Iridis illi, fed minora, minúfque aromatica, falten qubus locis matalitiis nobis obferuata eft, nempè vt plurinum humidis \& incultis. Flores tamen Calendis Iunijs aptiì Xyridem colore \& figura foliolifque minus repandis exprimunt. Sapor illi feruidus, amarus, tenuitas multa quan etian medicis experimentis compertam habc-
mus.

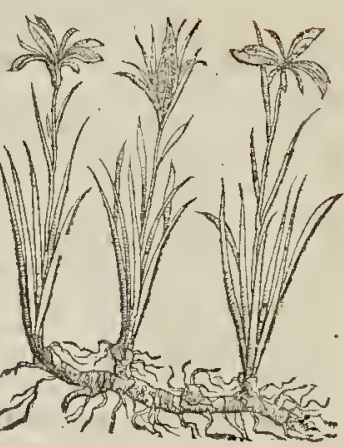

$$
\begin{gathered}
P E R P V S I L L A S A Y A T I L I S I R I S \\
\text { acanlis forms. }
\end{gathered}
$$

M I i m a \& rarifsima omniñ ctiam Norbonenfis hac : radicis plexu, fubftätia défa \& colore Illyrica non abfimilis, caule vero nullo, pręfertim natalitiis, folio latiufculo, rigido, mucronato,palmum alto, cuiufmodi Gladioli:fore, femine filiqua, Xyrid is fętidx. Hec mox quam è terra afurgit Chamelèntis albi modo pu filla humilifque remanet, proindéque nonnullis Clia meiris muncupanda videtur. Plurima ofitur in agro Norbonenfi, locis aridis \& faxofis, fccus fpecum illam fefquimiliare Monfpellio difsitam, via qua Frontign nam itur, in cuius cautibus \& rupiun comniffuris fre quens adolefcit prope Ferulam:

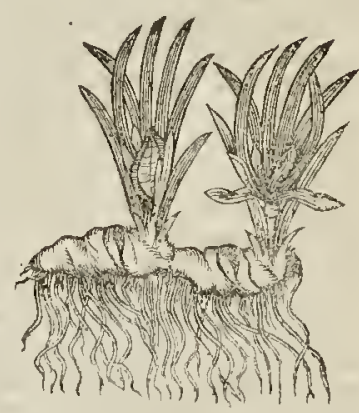

$X Y R I S$ grine IRIS aypia THEOPH.

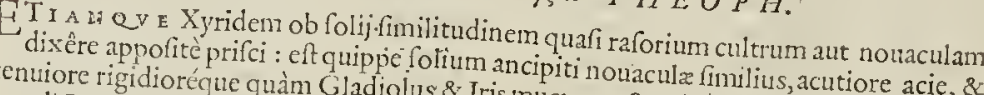

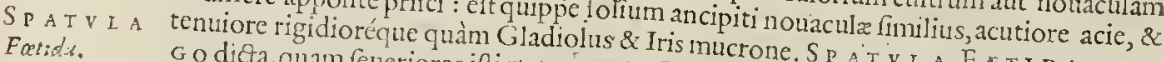
Go dicta, quam felieriores ifti grarum tas plant:ls vernaculis natalibus cruifle, neque virium improbant, indicant fe nec mulnim nefcio quid coloris \& magnitudinis defideran periculum multum feciffe. Dum cvträuis hartin, vt plerafque alias, facilè nonderant in radice \& fore, non meminerunt firidis mdices \&-flores colore, maonitudiul nou ita magna de caufa mutari, Etenim anr, vt cum Florentina fi nofram coniudine, denfitate, bonitate \& odore adeo varipofsit tantilla mutatio Xy ridi contingere, qux etiac aliam colore \& odorc putes, quid ni quemadmodum olim Theophrafto a $\alpha$, quæ etiamnunı omnibus vulgò vocitatur Iris: dix fubruffa, noftrati pulla \& cineritia: Hetruficta fuit? Quin Hlyricx \&. Sclauonic ra ltras vero ingrata ferme fater : s vbi : Hetrufcre auten candida, eximiafragrantia, no

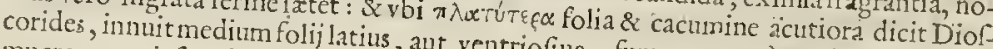
mucrone, cuinfmodi prorfum $S_{\text {parule }}$ rentriofius, fummum verò multo anguftiore uincix \& Auglix, vbi quàm vberrima: prope vda fontè quibufdam prafertim Galloprocere licet. Eamque fi conferas ruri cnatrope vda prata \& littoreos maris aggeres infpiobferuabis folio: \& caules etian cubito Iridi in parietinis \& ficcs glarcofis, anguftiore diocri per media folia recti affurgunt: maiores, plures, glabri, teretes, crafsitiemenis foliolis furrectis, nec reflexis, punt: foréfque in fummo promunt Iridis Syluefris, ternullis luteis, \& pheniceis apparentibus Iunio \& Viole Martix, \& in medio venis non- 


\section{STIRPIVM aduerfarianond.}

triquetris, trináque carina dehifcentibus: quando maturuit fenen, quod rubrum, nitidum, rotundum, gemina fecundum longitudinem feric, conditur in filiquarum membrancis loculis, aut pręfepiolis, vti in Paonia, Orobi, vt quidam ex Oribafio legunt, ant fabr, hon vulgaris noltratis, fed antiquz \& Diof coridex, qux multò minor, \& noftrate rotundior fuific probaturà doftis. Radix (facilis enim \& frequens mutatiuncula uanpìy, in uue i. ) parua, geniculata, fibris multis donata \& Iridi concolor, fimilis aut fufca. Ea vi \& acrimonia pradita, tametfi Cutulam aut cimices oleat, vt multorum noftratatis Mediconm monumétis \& experimentis conftet ea pręfare, qux Diofcorides Xyridi reddidt. Quin non modò Iridi limilis facic, fed \& viribus anteit, tu!n ad ylcera, olláque defquammanda, tum intro fumpta dcco\&to aut fucco, vehementius lotiun ciet, $\&$ fudores, fed pharingem adurit fermè. Si multa decoto bibatur, vomitum excitat, \& tormina ventris, vti Iris facit. Guftaumus acte, \& quod in Anglix maritimis ad Brumam ferme vfque in filiquis pendulis hiantibus vifitur.

$$
\begin{aligned}
& \text { zIyiespl ZINGIBER. } \\
& \left\{\begin{array}{ll}
G \text { all. } & \text { Zingembre. } \\
\text { Jnal. } & \text { Gengeuo. } \\
\text { Ger. } & \text { Jngher. } \\
\text { Flas. } & \text { Gengeluer. } \\
\text { Ang. } & \text { Gnger. } \\
\text { Hifp. } & \text { Gengiure. }
\end{array}\right\}
\end{aligned}
$$

L L A m radicem exoticam, Terratn Meritam vulgò vocatam, vel Curclima Scslafiariis 1 dicam, quàm Zingiberis effigre nafci in India auditione acceperat Dioforides, propiorem Zingiberi quam Cyperi putanus, etf idem author fpeciem Cyperi effe apud quempian legcrit, eóque forte minus aptè dixerit Zingiberis radices parus, cädicantes 


\section{STIRPIVM aducrarianoua.}

ab oppido Frótignana ex aduerfo montis Ccti mulıa, nee vfquam alibi vniuerfa Gallixe aut Italiz facilis repertu, tiif maritimis illic : quare num in Germania etiam reperiatur ant Heluetia, fides penes recétiores efto, quibus rnalo affentiri, quàm tantilla de re rixari, tametí radiciserutx recénfque effractx nullum vnquan olfecerimus Armeniaci mali odorem, qualem illi ineffe ait Commentator. Radix, caulis, folium, filiqua \& femen , Iridis locis fed minora , minufque aromatica, faltcin quibus locis natalitiis nobis obferuata eft, nempè vt plurinum hyridis \& incultis. Flores tamen Calendis Iunijs aptiì Xyridem colore \& figura foliolifque minus repandis exprimunt. Sapor illi feruidus, amarus, tenuitas multa, quan etian medicis experimentis compertam habc nus.

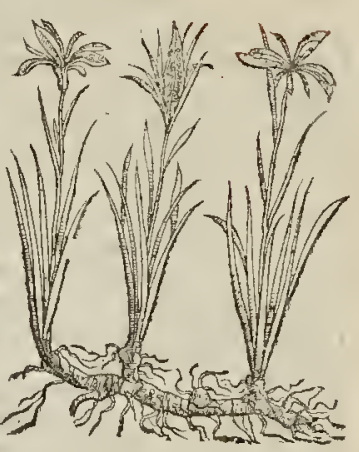

$$
\text { PERPVSILLA SAXATILIS IRIS }
$$

$M_{\text {I n м a \& rarifsima omniñ etiam Norbonenfis }}^{\text {I }}$ hæc : radicis plexu, fubłtãtia défá \& colore lllyricx non abfimilis, caule vero nullo, pręertim natalitiis, folio latiufculo, rigido, mucronato, palmum alto, cuinfmodi Gladioli:fiore, femine frlinna Xrrid:n fortid $1 r$

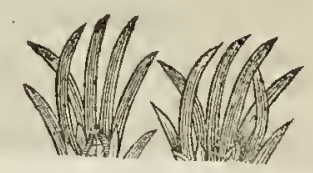

$$
\begin{aligned}
& \text { fill. } \\
& \text { me }
\end{aligned}
$$

No $\quad C$ Ondituretiam or proftat in Officinis alia radix Mechinum hofefr die dicta Zingibcricognata, à quo nec maturitate, aut improbitanar te differt, vt paldun verè feripeque $\quad$ runt, fed potius fpecie \& concre Matheffgiggl $\quad$ foliditate, \& acriore guftu, nec $\mathrm{E}$
P A T Techinirara vitrietas. Fatids. tione (caret quippe fibris \& flamétis) perfoicuitate, fufcedıe,

$G i$

tas

nit

vtr

fi I

an

$\mathrm{po}^{3}$

di

iti

$\mathrm{CC}$

in

ui

ce

of

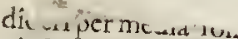

Necrnquam nobis vifa antea

Whęc quam icone exhibemus Mechinifpecies, nuper adferri cepta, cuivis Morganus nofter al quot emit libras, Vulgatú Zingiberemaut Mechinum refert,

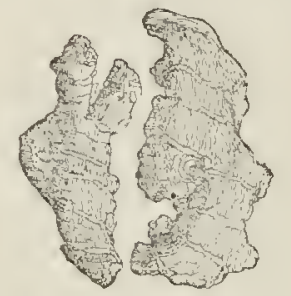

fed elegätore afpectu, colore Mechini,cortice Zingibers albi, fed fquä. matim geniculato,\& ferè articulato veluti Doronicum:afpectu pellucido: guftu quàm Zingiberis multò acriore,\& ficciore, carıe nó exefá.

nis foliolis furrectis, nec reflexis, purpura faturiore Violæ Martix, \& in medio venis nonnullis luteis, \& phœniceis apparentibus Iunio \& Augufto in Anglia. Siliquis, item Iridis trique- 


\section{STIRPIVM aduerfarianota.}

triquetris, trináque carina dehifccntibus: quando maturuit fenen, quod rubrum, nitidun, rotundum, gemina fecundum longitudinem ferie, conditur in filiquarum membraneis loculis, ant prefepiols, vti in Pronia, Orobi,vt quidan ex Oribalio legunt, ant fabx, non vulgaris noftratis, feci antiqux\& Diofcoridex, qux multò minor, \& noftrate

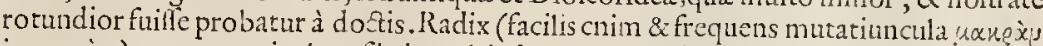
in une ix? ) partua, geniculata, fibris multis donata \& Iridi concolor, fimilis aut fufca. Ea vi \& acrimonia predita, tametfi Cutulam aut cimices oleat, vt multorim noftræxtatis Medicorum tnonumétis \& expcrimcntis conftet ea pręftare, qux Diof corides Xyridi reddidt. Quin non modò Iridi fimilis facie, fed \& viribus anteit, tum ad vlcera, ofláque def fuammanda, tum intro funpta decocto aut fucco, vehementius lotin! ciet, \& fudores, fed pharingem adurit fcrmè. Si multa decocto bibatur, vomitum excitat, \& tormina ventris, vti Iris facit. Guftauimus acre, \& quod in Anglix maritimis ad Drumam ferme vfque in filiquis pendulis hiantibus vifitur.

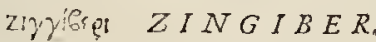

$$
\begin{aligned}
& \text { (Gall. Zingembre.? } \\
& \text { ftal. Gengero. } \\
& \text { KGer. Jatubr. } \\
& \{\text { Flan, Eengeycr. } \\
& \text { Ang. Benger. } \\
& \text { Hijp. Gengiure. }
\end{aligned}
$$

ES T ctian Zinģibet, aut Gingiber vt in

Plinii codice legitur, herba \& noinenclamētura Barbara, antiqüitati viribus quä facie notior: vt cuius Diof corides reliqua defcriptione fuperfedens, radicellas dintaxat paruas, vt Cyperimemorat, cui tamen nec firniles admodum, \& multò maiores funt, nec pendulx Cyperidis ritu, fed Iridis modo implexx. Iancue plebeculx $\mathrm{v}$ bique gentium notiöes \& vitatiores, qua vt fufiore egcaint Hiftoria. Verùn rcliquam effigiem, qux cft tota Iridis aut Xyridis,cx virore nioricancibus foliis furrcetis, hic damus nulli dum depiQam, qualen àlebat Antuerpianus cilis perbonus, perindutri us \& peritus Pharmaconcus Guilielmus Driefch, cuius muneze habuimis : tametif flores, vipote Septétrionali rigidóg; coolo nullos prompfit. Imbecillo ftomacho vircs inftaurat, calorem foret, aluúmque emollit Diofcoridi:nempe fi maturæ fed tenerx

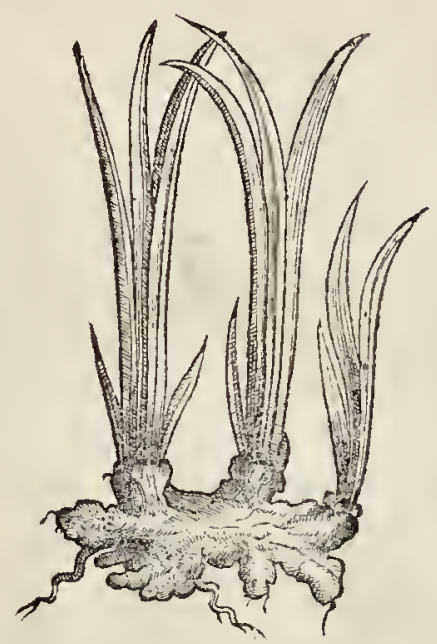
rccentéfque radices comedantur, nondum exhafto humido lubricante \& purgante, vti vidimus in Iride, qure vetuftiores ficcät potius $\&$ fiftunt aluum. Succulentr autem recens conditx, multa cómendatione ex Indix varijs locis, nec non $\Lambda$ phricx finitim $x$ in Furopan vltimă Septentrionalem \& Meridianã vœnum ferütur : tametí iam vi emolliente exoleta, maceratas lixiuio condiunt faccharo etiä noftrates Veneti , Antuerpiếes \& alii inftitores pafsim.

\section{TERRA MERITA, CVRCVMA Officinarum.}

I L a a radicem exotican, Terran Meritam vulgò vocatam, vel Curcuma Seplafiariis dictan, quàm Zingiberis effigie nafci in Indiz auditionc acceperat Diofcorides, propiorem Zingiberi quam Cyperi putamus, etfi idem autho: fpecicm Cyperi effe ap!n quempiam lczerit, é́que forte minus aptè dixerit Zingiberis radices partus, cädicantes 


\section{4 \\ STIR PIVM aduerfarianowa.}

Ddoratas Cyperi modo libro fecundo : alioqui enim nifi perquam exigua illi cum $\mathrm{Cy}$ peris intercedit fimilitudo. At vires perquam finiles quafdam habet (prætcr Croceú fuccum, que!n manfu remittit) cum Zingibere, tametf gufu ignauiore, ingratiore, dore autem refcrandi vifcera potiore :ideoque hodie curforcs \& mulierculx cum Zingibere mifent ad Yeterum. Vis ututem pfilothri illa feruida videtur elanguefcere, longa tcmporis \& locorum intercapedine atc; teredine, cui eadem obnoxia cit, fed minus quam Zingiber. PiCoribus \& Chymiltis, quàm medicamentis hodie frequentior.

\section{ZINGIBERIS EFFIGIE COSTHS \\ Arabicus ơ Syriacus.}

IN T R I C A T I O R multò Cofti dignotio, vtpote etiam plant $x$ peregrinę Indic $x$, nec yllis liniamétis fignat $x$, nobis tamen vfibus \& prefidio futturę. Spernendx tamē recentiorü contentiones 8 i a $\Gamma^{-}$ ponendre recenfiones, qux doctis poffunt effe $2 \mathrm{r}$ gumento \& emolumento ad vberiorẹn cognitıonem. Scxto abhinc ferme anno, ccepit vehi radix è Syria $\&$ Egypto Venetias Zedoarix aut Zingiberis effigie, quan prim us omnium fingularis modeftic anicus nolter Valerandus Donrez Hlander Infulanus, 8 Hiftoriz huius peritilsimus verum Coltú cenfuit effe, cui Gefuerus primùm fruftum inter magnam copiam Zingibcris fortè repertum fpecinen futurum donorat Venetias ituro, indéq; in Syriam Simpliciü pcrquirendorum caufa nauigaturo. Radix intus candida,

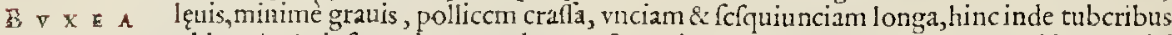
Coftus. oblongis altrinfecus donata, odora, guftu acri, odore intëfo \& iucúdo Cyprefsi aut Cedri Libani quadätenus, interdü \& B B X E A viftur, vti vulgata odore \& fapore fimilis, fubamata vtraque, catera fimiles. Qui Turca intitores perfupe venditabant amico noftro, rati effe Zingibercm Sylueftrem, haud ita magno pretio diftrahebät. Ea Venetorum Medicorú collegio oblata, adeo placuit, vt dignan cenfucrint, qux inter lectifsima Theriacx paranda fumplicia, anno $156_{3}$ infereretur, quod paulò póft factum fuit, iamque inde ma iore copia aduecta fui: Venetias. Et noftra opera factum fuit, vt amicis noftris 'Antuerpiæinnotwerit, gruibus unifimus. Qux quidem, vt non effet Coftus genuina, tamé quia \& radix eft, eximiáque odoris faporifque acris gratia aromatica pollet, merita videtur C o $5 \mathrm{~T}$ V s parem Coftolaudem \& gradum, prxferendáque non modo F V S \& G R A V I \& I NOfficinam. ODOR R R A I CI, Helenii compatit concretionc ignotx, qua Offinx hodie abutuntur, fed etiam Zedoarix, gux minus odora, aromatica \& guftu gratacf. Quin ne Coftzs niger. Angelica quidé preferenda eft, quam N I GR v $\cos T$ v $M$, fiuc Indicum, propterinfignes vires \& odorem fuauifsimum hodie faciunt : non enim of adeo peregrina planCostues Spurius ta, fed Europa familiarifsina, nec admota vrere folita, nihilque adftrictionis habet, quaArathifoli.53. lem Galenum in cofto optare author elt Sencnfis Commétator. Cuius plantam fuis poftrcmis commentariis infertam Cofti nomine, nobis fepiùs ab Herbariis Jllyricis oftenfam, quia nihil Cofto digum habet, fed porius facie Elaphobofci eft, illuc reicicnda.

$$
\text { COSTVS DVLCIS O CAMARVS. }
$$

Cos v dulcem nouimas nullum, nifi collatione quadam cum acriore \& amariore

Cofto fic vocetur : quo intellęu quis A\&uarium accepiffe puter, vel eandem plantę radicem, qua dum tccentior mitior multo, vetuftior vcro amarore \& feruore ingratior facta,amara ant inamona vocetur. At Galeno nulla Cofus non amara. Sedenim Arabes fequetis tecentioribus indulgendum illud vt quxdam fpecics Cofti fuanore quasique, vt veriaculè logutintur, dulciore odore, feruore nitiore, dulcis illis dicta fit, \& vfu recepta: quo modo yuis dicat Zingiber, Iridem, Helenium, Centaurcun \& piciáfque alias radices mitiores \& dulciores, dun tenella funt : vetuftiores vcro \& vieras acriores \& calidioats. Id euidencitis excmplo fuccornm excoctorü natura vel arte, in A Ice explicuimus. 


\section{STIRP IV $M$ aduerfarianoua. COSTVS MOLVCENSIS \\ Corticofus, rugofus.}

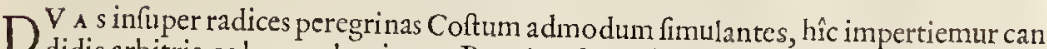
didis arbitris, ea beneuolentia qua Rupellenfis Medicus doctifsimus Lamnaius eafdẽ nobis, quadriennium iam eft, impertiuit. Ambas acceperat à Naucleris è Molucis Infulis reducibus, quarum altera maior arboris maiufcula cortex videtur, \& figura Sambuci adultioris \& cineracei, rugis \& plicis frequens, fapore \& odore æquè vehementi.

\section{$M O L V_{C} E N S$ IS LIGNO. Jiss feruidior.}

M I n o R quidem altera radices Solani Syluetris valdè quam fimilis, colore diluto pullo, guftu vrente vt vix ardorem lingua ferre aut fultinere queat. Illis iam perfuafum erat Cofti effe fpeciem, tametfi parum odorum effet: quod vti non inficiamur, ita priorem vt potiorem retinemus, \& hafce ambas Molu-

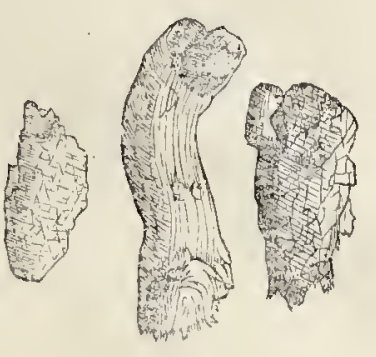
cenfes nempe, minus odoras indicio ftudioforum pi-
otas fubdidimus.

\section{$Z E D V A R I A$ fine $Z A \mathcal{D} V R A$ berba o}

$Z$ E R V M B ET.

PR os т A N T itidem peregrinx dureradices in Officinis non perinde not $x$ è totius plantx partibus, vt funt celebres facultatibus. Neutra quidem Græcis memorat?, fed dútaxat figura Zingiberis à recétioribus prodita. Earü quæ notifsima, Zedoaria vocatur: altera quæ rarior Z E R v A B E T : \& vtraque vt nominis, fic generis eiufdem merito putatur, nec fecus inuicem differre, quàm Cyperus rotundus \& lōgns, videntur. Eoque Serapio Zedoarium eandem Zarumbeto dixit, rotundáfque radices Arstolochiæ defcribir \& Zingiberis colore \& fapore, in Chinis vltimis nempe Indiis oriundas. Auicenna auté, nifi fint cius tenebriones interpretes, permutatis nominibus contrarias planè Zedoariæ \& Zerumbet affinxit comparationes: apud quem idcirco malim legere, Zedoariam Cypero fimilem, minus tamen odoratam, Zerumbet autem Ariftolochix rotundas radices ineffe. Quod tamen parum intereft rerum cognofcendarum cupidi veftigatoris. Satis enim difcernitur apud Serapionem, modo fic accipat, vtramuis harum radicum tuberofam effe, ac quemadmodum Doronicis fiue Ariftolochiis \& cenanthis contingit variare oblonga tereti, vel orbiculata \& nodofa mole radicis : fic euenife Zeduariæ høbæ, chius naturx, quemadmodum nominis eft particeps Zurumbet, quippe amaror, feruor, odor, color, ingratus rehementior guftus, modus, durities, duratio caden \& vfus ad Colicos cruciatus, prafertim aduerfum venenata, certifsimus, vnde nomen forte flixit. Indéque videntur Auicennas, Serapio ac Mauri nonnulli defignafse antidota pluria,aut prefidia ad vencna comparata, laxiore vt plurimum folent nominis ambitu, quemadmodum $B$ E Z E A R D I C A gencratim vocantur Arabicè, quæ vitam tuentur:eóque quã- DEZ ARDICA. piă celebré arborem codem nomine implicuiffe Zedoarix aut Zerumbet foliis fäligncis CA Arhor Zedow? Citri odore, qux item ad Ze particula multú alludit . Potiorẽ etiam eam Zedoariã, qưafi dicas antidotum, qux radicibus Napelli adnata foret, ciufdem venenati Napelli prxftantifsimam Theriacam merito dicit, quale nos experti fumus, Q eruimus copiofan variis in montibus, vt capite de Thora dictum. Ne dehinc porrò Principem Auicennam ve$\mathrm{r} 1$ feuerum vindicen \& ferium Philofophü fabulatorem vocet illeSabbatarius Indicarum $T_{\text {н }}$ о $\mathrm{R}$ A. mercium ex commentarijs triuialibus Nauigationum interpolator, qui valdè vereor ne

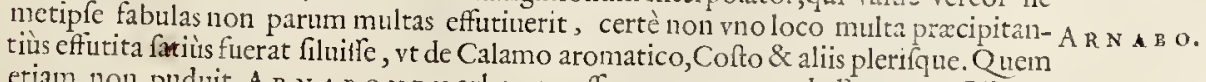
etiam non puduit, AR N A B O N E s arborem effe proceram apud Ligynetan Libr.7 
Cap 3.prodere, cum nullius pror fum arboris ac ne ftirpis quidem mentio fit inibi de A R A в O N $23^{l}$ pagina Graci codicis.Bonum Medicinn nimirum decepit Commetator Senenfis, qui affirmat Arnabonem Panli \& Zarumber Serapionis eadé êfe, quòd eafdem is Zarumbeto, quas ille Arnaboni reddiderit facultates. At id fccus eft, nec Paulus

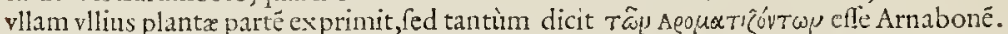
Et vt eadem fcripfifset Scrapio de Zurumbet qnxille de Arnabone, non tamen illico id effe dictum oportuit, cum Zurumbet cidem Serapioni fit ipfa Zeduaria, radice nempe rotunda,adeóque Auicenna plantam Cypero fmilem fed minis odoriferan dicat.Quin Ifacco v troque illorum antiqniori Zurumbet radices funt A riftolochix rotund $x$ colore \& fapore Zingiberis fimiles è Chinis petende, Sed enim illufte doctifsimis viris(vndè hane haufit labsm Conmentator) nominnm anceps allufio, vt dudum monuimus. Ergo Zeduarian triplicem innuere voluife Arabes putanus: Oblongam nimirum valgatiorem, Cyperopropì̀s accedentem, \& huius fpcciem Zurumbet officinis infrequentiorem, nobis rotundam diatam, tertiam autem luculentam arborem minis hodic cornitam.Illas itaque, quia recentiöcs foliis \& natura Zingiberis amulas deliniant, nec nif radicum fignra diftare affirmant, huc non incommodè attexuimus. Si cui auten propins Zeduariä videtur exprimerc nofter Coftus Syriacus Zingiberis radice fimili \& maiore, fua fane opinione fruatur : nam \& lianc dicunt ab vfijue vltimis () ceani Oriciatalis Chinarum plagis in Perfiam \& Syriam, ybictian, fed pauca, oriatur, tranfnitti. Probabilins tamen vulgatiozes veriores efte, cum fint fibi per omnia fimiliores, vt Cuitani- bulbi cum cetelis cenanthis, exemplifque aliis fuperius oftenfun fuit. Arnaboné verò Pauli \& M A M IMAMIRAs. R AM, nobis ionotan adhuc effe, fortè \& fore magis dolcndum, qnàm mirandum : cnm prifcorum pudor non aufus fit res peregrinas, nentiguan compcrtas temerc pofteritati

NARCAPH. figurare: vnde NARCAPHTH O N corticéaromatici, ac pleraq; alia thymiamata famigcratifima nullo ligno memorix mandata fuerunt. Mamiram tamen qui Doronicum vnum quodpiä arbitratur, neutiquam infrma coniectura nititur:at qui Arnabonem eiufdem Zurumbet Arabum hariolabitur, verum fi dicat, illum putato vaten optiumu.

I V NCI VArictates.

I V NCI \& I V N C E A

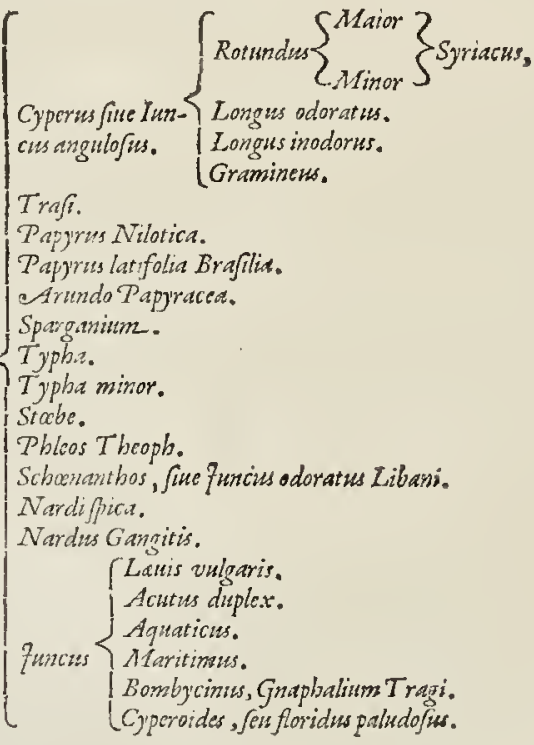




\section{STIRTIVM aduerfariarioun. \\ $C X P E R S$, fure funcus angulofies. \\ $\left\{\begin{array}{l}\text { Gal. Soucbet. } \\ \text { Ital. Cypero. } \\ \text { Ger. woilocr Galtan. }\end{array}\right\}$}

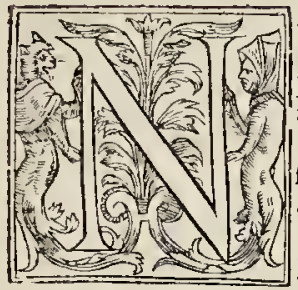

A т y R A natalitior úc; cognatione fuccedcnt Iuncea Cyperorä feriei,vetiă Theophraftus innuere vifus fuit,cum Cypeı ú, $\mathrm{Pa}-$

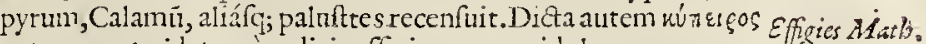
aut nutep!s videtur iradicis effigic,qux pyisidulam, aut pocu- 26 .

lum pufillum vafculúm ne imitatur:ficetia apud Theophraftum folliculum Vlmi xúnȩ̧s legitur. Huius certior multò Hiltoria quàm cognatæ Curcun $x$, fiuc Cyperi Babylonici putati, de quo fuperiore capite, propterea quia nö multi funt anni,cum quidä horti Itali rariorem, rotundum vocatú alebant, nófque copiam duorum generum Rotundi vocati ex Syrię Emporijs Venetias aduehi vidimus apud Albertum Martinellum Pharmacopceum peritun à quo etiamnum habemus. Quare plures funt fpecies, quàm quot Diofcoridi reccnfita fuerint. Nempe Diofcoridis maior \& minor rotundus: vterque peregrinus, Syriacus vocatus Noftratium autem Longus odoratus, \& Longus inodorus: poltremò etiam Veronenfun Trafi, que fanè Cyperi funt cógenetes. Oninium effigies fimilis \& eadem fermé, folijs porraceis Afphodeli ftriatis, angulofis, rigidis Sparganij vel Iunci foridi aquatici,caulc gracili, nitido, triquetro,iunceo, floribus item feminibus \& cacuminibus pannicularum Iunceis fpicatis. Vda, etiam frobcs \& ripas fluminum, vbi Iunci, amant: quare meritò Iuncum angulofum fine triangularem vocartunt antiqui \& nos hic collocaumus. Omnium tamen in radicibus difcrimē: Syriaci maioris etenim radices multis filametis implexæ numerof $x$, glandularum inftar aut filipendul $x$ annexæ rotundiores, oliuis pares, intus albid $x$, foris fubruff $x$, fapore minute Galangæ, odoréque aromatico, antidotis maiori gratia \& vi mifceri folito.

Minor verò radix duplò minor eft, cortice fufco villofiore, dutiore intus candore, alioqui \& fapore \& odore fimili, non modo è Syrıx montofis humentibus, fed etianı. Il'yriz \& Apulix confimilibus nitalibus, vbi fponte prouenit, in Italiam ferunt,emúntque magno vtramque harum, \& ad Theriacx compofitionć,ceraque oblinunt ne teredine exedantur. Aptifsimam enim Xylobalfami fuecedaneam iamdiu Patauina \& Veneta colicgia fanxerunt \& vfurparunt, tametf eommodiora hodie fuceedanea fuffici poffenţ vt fumus dicturi in Antibalomenis.

\section{$L O N G V S I I A B I T I O R$ :}

NOstr a t I s duplicis Europxi frequentior multò prouentus \& vfus Septentrionslibus regionibus, vt Germaniæ, Belgix, Anglix \& Gallix, quàm Meridionalibus tranfmarinis. Harum pariter altera maior habitior, carnofior odoratiórque eft. Radices illi longx fibi cohæfu mutuò implexæ Polypodij modo, etiam odore fuauifsimo mulieribus notæ, quæ exilla deftillationes \& pulueres inftituunt.

\section{LONGVSINODORVS.}

A L t e R A verò minor inodora fermè neglecta, quam Theophraftini in Heluetia mifeebant fuis quintis ineptijs.

\section{RECENTIORVM T RASI, fine efculenti Cyperi.}

$E S_{\text {T }} \&$ hxe prorfum è Cyperi genere, feu radices feu plantam reliquam totam fpectes, eiúfq; nat alia, nec differre videtur, nili radicum fapore, qui gratus vefeendo nec vtilis minuseft, vndé nomen in vulgus Italorum manauit, quod forfan Tragum effe illam fpe- T ragos c Coneiem frugis, quæHalicæ fpeciem gerere quadamtenus defcribitur, fecundo Diofcoridis drus Diofco, fatVolumine, tametfi vtraque illarum factitia elt :at Trafi planta eft equidem rara, nee vfpi- Ztitia. aın Chriftiane ditionis oriri fpontè folita, preterquam in amcnifsimo Veronenfum agro non procul ab vrbe, vbi ctiam colitur pingui riguóque aruo, quò nos, dum floreret Iulio menfe, duxit optimus ciuis, Pharmacopceus diligentifsimus, Andreas Bellicoquus, cuitus radices in Gallia, Belgio, Anglia fatæ non paucis amicis opinionem fecerant Cyperi rotundi minoris. Cui equidem par eft \& fimilis: agnitu tamen facilis, quia cant- 
didior, pellucidior, nec odora, nec medicata, fed alimentofo dulcioréq; quàm Caltanez fapore, vnde vulgo, Dole Trafi Veronx \& Veneciis per vrbes puerulos audiss, qui radicum harum circumferunt vœum plenos quafillos. Crudas coctáfque efitant in bellariis, adacres finxiones commendantur, necdubium quin ptifana ex iifdem parata multum profutura fit, addito Coriandri femine, \& pauca Iride quemadmodum quidam parant.Afri, quibus etiam fpontè oritur, Hab-allélim vocant.

CYPERVS GRAMINEA fue MILIACEA.

A CCEERSEN D A M etiam Cyperis hanc caulis natiuúfque locus fuadent : elf cnim inodori Cyperi quadătenus affinis, breuior tamen foliis, quæabimo orta medio fui tenus fermè caulem ambiüt pedalem,gracilem, ternis angulis afper $\overrightarrow{\text {, }}$ coma donatum fparfa eleganti, \& maiore quàm pro fui magnitudine, copiofo Milit aut Innci referta femine, circum quam imam aliquot foliola cnafcuntur, vt in Cypero ant Papyro, lectam induftria fummæ fedulitatis Medici Thomæ Penii habuimus, ad Neccarum fumen agro Hcidelbergenf.

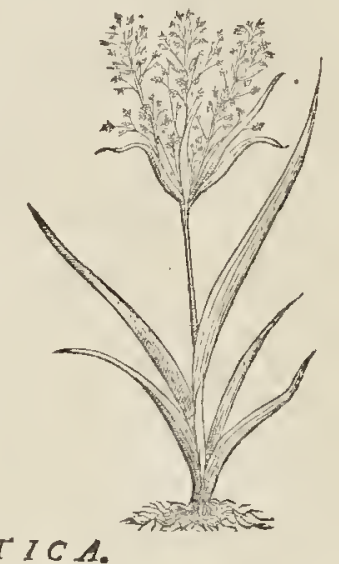

\section{PAPTRVS NILOTICA.}

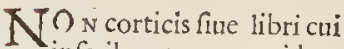
incriberetur, vt quidam putarút, eft Egyptia Papyrus, fed plant $x$ magnitudinis Cpeciofe adnodum, Cypero fimilis effigie, natalibuis, etiámg; nomenclatuia Egyptia, qua in regione fecus flucta in $\mathrm{Ni}$ li paiuftribus adolefcit, nec è profundo cmergit, fed tantum è vadofis frutefcit, non procul à ripis, vt etiam diuina pagina narrat Mofen diuinz fpei \& elegantix deliculum puellum à matre inuita eiectú prope Nili ripam inter Papy. ros, vade diuinitus iufu filiz Pharonis eduetus, indég; Mofes vocatus, quafi aquis ereptus, fuit. Niloticam Papyrum, vinde \& qualem defcribunt Theophraftus \& Plinius aduectan hortique Pifani totius oræ Thyrrhenæ lógè amcenif. fimi \& raris ftirpibus ditifsimi inquilinam factä vidimus, \& forenté icgimus bencuolentia eruditissimi lrofeffo-

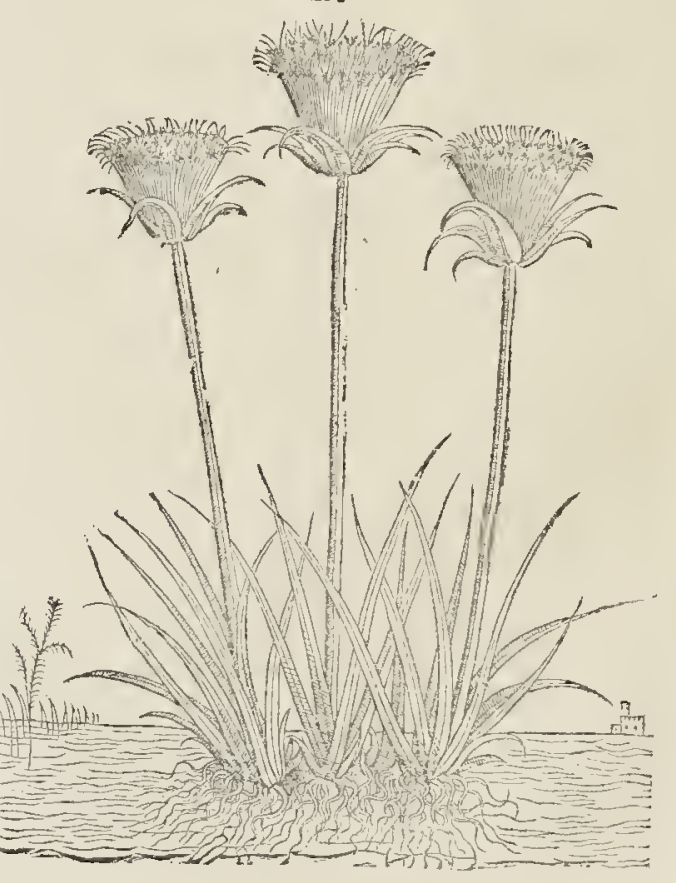




\section{STIRTIVM aduerfaria noua.}

ris in Academia Fîna Andrę Acroarix Cifaloini, quo etiam hortante nonnullos Stolones Papyri, \& aliarum rariorum plantarum Gefinero mignus : quarmm oblectatus peregrina clegantia, vt erat inco parabilis modeftix \& eruditionis , non ita multò pổ literis gratulabundis hre fignificulit. Rarum fpectaculü fui mihi præbucrunt ftirpes due munera tua rarifsima, quarim illam Papyrum Niloticam vocas, altera, mihi tecun ignota eft:fed necillam nouifsen, nifi tu monuisses efe Papyrum Nilocican è Pifano horto le\&am. Plinio videtur gemina Egytia \& Babylonia ex qua proparantur aci charta dinifę in prxtenues, fed çuàm tenufísimas philyras. Tua verò an fic pofsit parari nefcio:?'li-

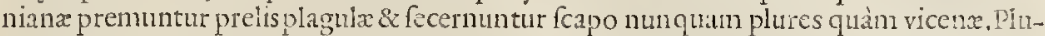
rima qux ibi haber Plinus uon afequor, nec nunc cum Theophraft. conferre vacat, fed peruelim fcire cuiufmodi tux fint folia, \& an nö Cyperus fit, vt cü noftrum opus in lıcem exibit curem depingendas, ac tibi acceptas feram.

Neutiquam mirum doctifsimo Gefnero vifam effe Cyperum, chm illi fit congeneris \& finillima : verun elégantior multò eft, Iunceo harundinaceolie triquetro cảıle, medull farfo tomentacea, qux tufa glutiníque in fpeciem fubacta duccbatur in bracteas Papyraceas, qua mutio fibi appreilix folia crafsiora confabunt feriberdo apta, quemadnodum etiannum fit ex lacinils linei panni contufi \& in candidum gluten redacii. Medullavero vtebantur ex precepto antiquorum, quemadmodurn hodie Chirurgi Itali linamentis, \& turundis ex medulla Sambucina aut Spon rix paratis, guò fuis poris melius faniem imbibant, fráque qualitate deficcando filutás latiores faciant, quod factitari folitum meminit Diofcorides. Stjpitum numcroforun proceratas, $\mathfrak{x}$ uis, nitida, furrecta fenum, feptenumue interdim cubitozum, quibus nufian, nifi ad imum folia infint Cyperi aut Sparganii repanda : radices autem arundinacce fibrofrequas in Egypto erutas afferebant non illic ortas, propterea çuia feminc caret, tametf floribus eft perquam fpeciofis \& luculentam in ambitu cęfariem effigiantibus: numerofis gracilibus thyrfulis, donfo \& rquabili comarum itipatu, \& apicibus prominentibus, Ferulx in modum colle:tis, non ve Cyperi fparfis, quos circa ottum ambiunt radiatin fcita folia multò minora illis, qua funt ad imum, rti in Cypero. Idcitco verifimile fit hanc veram Theophrafti effe, \& Papyri defcriptionen apud Plinium geminara effe, fed mutilam, eque duabus diuerfi generis l'apyrs confufam, nempe ex Ägyptia hac \& ex Babylonia, cuius etiam alii fcriptores meminerunt. Nam,vt nomen \& res indicat, Theophrafti papyrus non alia eft, quam Diofcoridis quæ notifsima omnibus, fuit cx cun praparabantur chartx, \& vtilifsima Medicis ad ora fiftularum diducenda, nempemedulla, vt fuperius oftendimeis, etiámque è Itncea medulla hodie fieri fcinus, nam ipfiun chartā non effe, fed medulilĭ, indicio eft guòd Diofcorides dicat cinerem crcinatx $P$ apyri praftantiorem effe quàn è Charta, \& ipfos ftipites neutiquan inferi finibus aut fintilis folitos, fed medullam, propter commoda qua recenfet Diofcorides. Ideóque aut rfum tumfunium, tum chartæ obfcuriùs Plinius tradit, cum dicit: texuntwir omnes tabula madente Nili aqua, quod de funibus quis fortè interpretetur. Et mox : turbiẹs liquor vim glutinis prabet, cum prino ftupina tabula fchøda illinitur longitudine $P$ apyri,qux potuit effe fegmentis vtrinque alnputatis : tralifuerfa poftea cratis peragitur, premuntur cieinde prelis \& ficcantur Sole plagulæ, atque inter fe itnguntur, qux medullæ gluten in Cliartas duci folitm inntuere videntur. At v bi in Euphrate circa Babylonium nafci fcribit, non eandem videtur defcribere, fed cundem vfum habere chartas, qua dinifa acu in prętenues, fed quälatisimas philyras praparantur. Quare \& fi ifta folia admodum lat:, quibus metx faccharatx adforuntur pafim Folium faccha. inuolute ex Auftrinis trans Equatorem Infulis vocari poffun $P$ apyracea, quemadmo- intuolucrum. dum olim etiam folia $P$ alma $\&$ aliarum arborun, quibus poterat quippiam commodè fcribi, tamen non effe genuinam certumeft, Quapropter confultius cft, vbi defuerit hac noftra Papyrus, cinerem parare ex Cyperivulgaris, ant lunci magni aquatici medulla, vtendum ad depafcentium vlcerurn rabiem feram compefcendam.

PAPTRVS LATIFOLIA BRASILIA. 


\section{STIRPIVM adwerfarianowa.}

NEc ctian Papyrum efe illud folium quod doctifsimus Generus defcribit, vel inde perfpicuum, quod Diofcoridi ren folia, fed quidpiam certo modo paratum \& pläca Papyrus vocatur. Tametr, vt monumus, Hihil obftet, quin folia hxc, vt quibus concinne admodum characteres ac quiduis alind exarantur, pof sit papyrus dici : prefertin etiam cum ijfdem vigeat locis, quibus Arundo Saccharata \& ccetcræ aquatica,

$$
A R V N D O P A P R A C E A \text {. }
$$

$A D x$ o $\mathrm{v}$ M fimilis Papyri deferiptioni, \& nulli non Gallix regioni familiaris, lacuf tris planta altera fpeciofæ proccritatis, quam nó femel in Lani torpentibus aquis non Frocul Monfpellio confpicati papyrum Diofcoridis vt pote notifsmam fufpicati fuifemus, nifi illi fcapi minus angulofi effent, fcnûm oftonumue cubitorum, crafsitie \& fim:litudine Typhx, fed harndinis in morem fore fiftigiato thyrf cacumine, folia item arundinaceis aut 〔parganij longiora, carinata, carnofa, triquetra, radice ampla, craffa, multas lateratim hinc \& illinc propagines fundente, vrendo apta cum ficca. Ex folijs verò texuntur tergeftia, quas Mattas vocant, non fecus atq; è Iunco maiore, Sparto, Alga
\& alijs non paucis.

$$
\begin{gathered}
\text { SPARGANIVM BVT O MOS, } \\
\text { Theophr. Lib.l. Cap.s. }
\end{gathered}
$$

A F I I I s valde Typhx Iunco florido Papyris \& Cyperis Sparganium, qui idem Bŕtous id eft admodura fcindens. Theophralti videtur, nominisargumento id doceute. Iifdem namg; paludofis \& riuis inter \& prope illa proucnit folijs cófmilibus, triquctris, dorfo prominulo \& carinofo, acieq; vtrínq; manū arripićtis cæfim fauciante, partim ab radice graminea, fibrofa, furrectis: partim è bicubitali caule alterno ortu fparfa \& reflexa:inq; alarum cauo globulos echinatos faturè vircntes, duros, firmos, Platani pares habente, guftu fubaftringente \& ficciore, infipido. Sunt qui refpumt vt Senenfis, nec tamen defcribunt, non magis quàm Iuncum floridum vocatum, pcr eius commentaria hactenus minus fane notum, iniquius paulò tamen interpretantur duas voculas

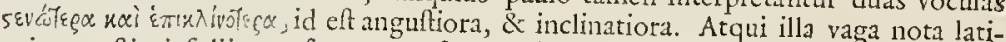
oris, anguftioris folij, non fxpe certa, fxpifsimè contratiofenfuaccepta in Diofcoridis lectione, oftenditur alibi: \& vbi dicit magis quàm Gladioli inclinata, apcrtè indicat effe magis difparata \& fparfa (vt fanè funt) quam fint Gladioli, qux vt plurimum reca , \& proximè caulem parallela aflurgunt. Sed Commentatori illufit triuialis intellectio liter $x$ qux fic habct; folia ad terram inclinata magis, vel procumbentia.

$$
\begin{aligned}
& \text { T } Y P H A \text {. } \\
& \text { fialis, Mazze Sorda. }
\end{aligned}
$$

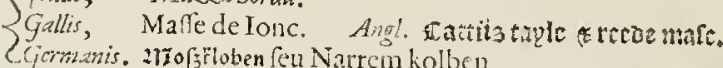

CYI I NDRE A turbinatíque florum efigies quafiTyplonis fefe gytantis turbinem aut gigantis ftaturã minacem figuaret nomen huic dediffe videtur. Earum cft \& hrc qux non nif certis natalibus nempe ammibus leniter fluentibus, \& vada, fangnantéfque a yuas \& paluftes eñicientibus emergit, c̀ radice iuncea caulis procerior interdì homine procero teres, refus lauore coloréq; \& parilitate illius funci funiatilis maioris, qué propè haud raro nafcitur folijs ab imo excunribus alterno fitu carinatis triquetris mucronatis Cyperidis: faftigium tereti, pappofáque claua claufum, fefquipalmü, pedémue longtm, quadam Tritici Turcici fimilitıdine. Ventis abrepta lanugo pulla intus foris nigricans, cogitur à Tomaclarijs mulieribus, \& renibus aftuantibúfque lumbis haud parum commodi adfernnt puluilli thorinè eadem farcti:etian intufa pinguedini prafertim axungix, aut larido illiquato, arcet ambult is partibus tumorem \& inflammationem ferigue vrentis collectiones. Quod prodiderunt ad Enterocelas tantopere facere, non huius reor, fed admotorum \& aliorum mixtorum merito accetum ferendun, nempe Hippoglofi, Gladioli, Bethonicr: vnde malim hanc abefie lanuginé, quret fuffocationis periculum ninatur, nures enim fic cnectos yel plebs nouit, \& ineptiora crteramedicanenta cficit. 


\section{STIRPIVM aduerfarianowa.}

An verò fit huic congener Theophrafto Cerealis Typha, tum fitne Zea Spautra Ga!lis, inter fruges diximus.

TYPHA MINOR,

IN agro Genuenfi, qua confuunt Rhodanus \& Arua Typha purilla,fiue Typhula exit planè iunceis culmis, enodibus, rigidulis, cubitum \& fcfquicubitum vix excedentibus, binóque faftigiolo floris Tométacei donatis : nempe in cxtremo vno cxiguo \& femine erofo, cui adnafcitur foliolum triticem , \& intorquetur: altero autem inferius relicto fpatio,crafsiore \& corpulentiore inncum ambiente Typha non difsimilë, fed multò minorę vti \& folia qux ad imuin funt aliquantum rigida: radix prolixius reptat, monente peritifsimo \&adinodum accurato plantarum expenfore Thona Penio Anglo, qui hane vulfit fuperioribus annis \& nobisimpertiuit.

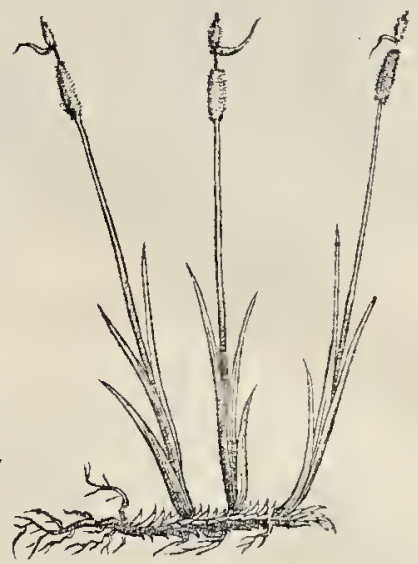

\section{$S T O E B E$}

PLVS quindecin amnos fpes ferebat noftra Stoben verā alicubi fefe nobis obuiam daturam, at iam ferme dcípondimus đnimum: cum nufpiam lacuú, paludú, ftagnorun, lacunar ú, aliorúmuc vdorum fedulis ftirpiü venatoribus cóparuerit. Qui faltem fi Phleon $\Phi \lambda$ ǵos. Theo. Theophrafti inueniffent, $S$ T Е в E N ] Diofcoridis fe nactos putafsét, propterea quia candem eife vtramque Perfuafi effent, Cómentatoris ex docto Ruellio furtiuis verfuris acceptis. Vcrùm haud neceffaria nominis folius communis protrita arguméta, qua Stcoben eandem $P$ H $L$ e o plantam effe illicò afferunt, imbecilla vna dumtaxat conjectura, quia à quibufdam $P$ н $L$ E о $\mathrm{N}$ vocari Stoben lib.6. Cap. primo feripférit. Nam cadé nomenclatura in quamlibet tomentitiam vel fungofam alius generis ftirpem quadrare poteft, vt Typhr, Centunculis, Gnaphaliff́; veris, Cynaris \&Spinis albis. Quin Galenus cum Stceben acris valdè \& calidx facult atis dicit libro de antidotis, fatis indicio eft idem nomen etiam contrarix naturx plantis indi potuiffe: quippc octauo Simplicium aliam Stoben mordacitatis expertem, qualë planè Diofcorides \& \& gyneta, recenfet. Diofcoridea cùm defcriptione careat quòd notitix plebeix extitifie videatur, quafi vfu frequenti vulgatior, alia à $₫ \lambda \varepsilon_{\varepsilon}^{\prime}($ Theophrafti Indica lacus Oromeni frutice fuiffe videtur, quę de fpinofarum claffe eft. Nec ex llinio probatio vllius nométi eft, vt qui dumtaxat vertit \& per-

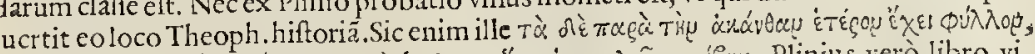

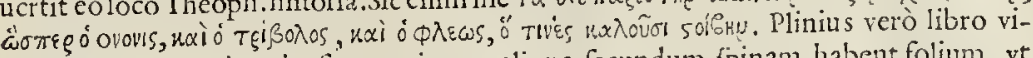
gefimo primo Capite vigefino quinto, aliqua fecundum fpinan habent folium, vt Tribulus \& Anonis: qurdam in folio habent $\&$ in caule, vt Phleos : quod aliqui Stoben appellauêre : cuin tamen Theophraftus neget Folium Phlei Spinofim effe Cap. quinto \& fexto. Qure labeculx illi frequentiores. Scd \& iftud Theophrafti P H L E O Nà feminis vbertate, vt rentur, vocatum, non magis ex defcriptione, qua fatis plena \& perfpicua colligitur, notum eft, quàm Folium Indicum Cinamomium, \& alia que iifdem natalibus quăplurima à noftro coelo difsitis oriunda funt. Frutex enim eft aculeatus in caule (Falfo acuti-folium aut aculeato folio verterunt) femine molli, rubido, pecori radix gratifsima, non alibi qualm in aquaticis nafcens, feeminam in eo accipi qux fterilis fit, \& ad nexus vtilis. Item Phleon tradunt folio nafci carnofo multipliciter laciniato, ftirpe numerofa germinare Virgiliarum exortu, primóque aratro, vnà nec id folia dimittere, vitam annuam longiorem effe, ad bimatum aut trinatum prorogari, caullem non folum fed folium aculeis armari : Item fecundum fpinam folium habere D.iij.

Phleon 
Phleon, quam nonnulli Stcben appellant; lanugine nulieres ad lixitium vti, pabu$1_{0}$ effe folia ouibus, germina fuibus, partem inam radici proximan pueris teneram cfitari, non in profundum actan radicem inque Orchomeno copiofim haberi, atque in Arabia exaduerfo Ethiopico tractui, fumine prefertim quod Cinamoferam difterminat Strabone narrante. Qux tot notæ fatis docendo erant, jpfam Plantam ficubi ea in Europa cerneretur. Diofcoridea tamen vix vnquam certacrit, cum nullis fit deferipta notis, nifi vulgato vagóque nomine, \& facultatibus quas nec diuerfas nec ignaniores quis in Burfa Paftoria, Gnaplaliis marinis, Iaceis, Scabiofis, Bellidibus \& Globularia experietur : quarum maxima pars tamet fí antiquis indicta merito putetur, fieri tamen poteft, vt vna quxpian Diofcoridis fit Stæebe, aut faltem non magno vel defiderio vel difpendio illus vfum expleat : eafdem namque vires fermè Graphalio, Typhx \& Iuncis reddiderunt antiqui.

\section{IVNCVS ODORATVS FE SCHOENANTHOS.}

I N N O Y v præfantifsimus odoratus Schœnanthos olim vocatus a multis tempore 1 Galeni, florum prærogatiua roféque fragantia, tametfi Galenus dixerat fuo tempore ninus aptè fic dici, atque precepiffe quofdam Schonanthum nufendum efle compofionibus, cuits forum non admodum fuppetet copia, fxpe depafcentibus nimirúlummitates Camelis Aphricanis, qui Schonantho vefcuntur \& maximè oblctantur. Quam Galeni rationen, vt prauam \& veluti mendacii ream ricetanilite Conmentator, quafi nufpiam vllum eius florum veftigium Europxis compareret, fed onnes ligurile $\mathrm{Ca}$ melos diceret. At ille dumtaxat fxpe truncam adferri reliquam herbam dicit, nempe radicem, folium, caulem, cóque foris minorem fuppetere copiam, quemadinodum hodie videas in Emporiis, Venetiis, Ge nux \& alibi longè copiam plantx maximam, florum. verò non admodum mercem frequentem. Quippe cum fint çuadătenus flores pappofi, tenues, faciléque delabantur, ctiámque cum cæteris gramineis vef́cendo refecentur, calore odor cortum exoluatur, facturn fuit partim cortum paucitatc, partimetiam inftitorum negligentia vt perpauci adferrerentur. Ian lucri fpes luculentior adeo fedulos colligendo adferendóque fecit mercatores, vt nulli dubium, quin vericalami foribus integris quamplutimum habeatur Nabathęi, Arabici \& Aphrici : quorum etiamnum ex odore dotes nofitare quiuis facilè pofsit(proftant enim interdü in Officinis) veri quiAL $A$ I I ys fem fed adeo foluti viribus, vt nonnulli putarint non alian cffe plantam, quam qux pafgranances Jm- im in Adriaticis frequens \& nonuunquam in Mediterraneis littoreis \& fabuletis occurcus folus Sekc- rit,planérpecie, magnitudine, culmóque concolori Schœnanthi odorati : meninimúfnext he. que hanc nobis obtrufam à Pharmacopeis Venetiis \& Monfpellii, qui affirmarent effe verę congenerem. Verum ab illius præftantia longiùs abeft quàm Canna vulgaris ì Calamo aromatico : deinde foliis gramineis eft, \& longe difparem florem profert: qualem aromaticum in Campania oriundum ex Plinit memoratione, fed minus viribus pollentcm quifpiam coiectet. Siccatus hodie conundari folitus in faf iculos vinetus, radice of exigua, durinfcula, arida, fbris exilibus multis fummo cefpute fparfis, foliácue promentibus vnà conuoltita \& fquämatim interferta crafsiora, rigida, fefquipalmü alta, mucronata pallida propits amplexa calamulum gcniculatum rotundum, plenum, non caum, nitidum, pedé altum, Cyperi Junceane concretione $\&$ lauore, $\&$ in fummo graciliorem, quem ornat gemind feries fofculorum ex pallido rubentium, acerofis glum is aut calyculis rubellis foris intúfue pappofis, leubus, qux Cyperum tota olent, fed tritæ in mortario aut digitis tantoperc flagrant, prefertin interiora folia \& calannli, vt legitimum hunc efe qui inficietur, planè muccofæ naris dici nereatur. Ne nunc blatercat de Cypepericaule, quem non odorati Iunci, fed vulgaris, nulla expreffa adiectione innuere videtur Diofcorides. Cxter a porrò defcriptio adeo cum fit lucida, pudeat iftos maleferiatos exactores putidulx feucritatis in notis exquirendis.

$$
\begin{gathered}
N A R D V S \text { DIOSCORI. Jims } \\
\text { Nardostachis Egineta. }
\end{gathered}
$$

I T V dicta fuerit à Naardo vrbe Syriacz Euphrati contermina, vbi etiam Nardum slians 


\section{STIRPIVM aduerjarianona.}

aliam meminit Plinius incertum,certú tamen legittimá plerífque locis \$gypti \& Syrix in Europam adferri, no modo radicem qualem Galenus vult, fed etiam quatuor diftinctas partes, nimirum radicem, fpicas comáfue, feftucas \& folia ipfa. Ima radix Schcenanthi, exili $\&$ arido ftanine à radicula fiue torulo exit, cui innafcuntur fpicatr com $x$ confcrtxque glomerationes quafi per cirros torulos nucleófue diftinetx \& cỏflatx capillamentis, vt in Męo : è quarü fpatiis mediis emergunt nonnulla iuncea folia marinæ Algx modo, tametfi minora multo. Hafce ficcas inter ingentes fafciculorum ftrues con picati fuimus in adibus amici noftri \& periti Pharmacopoei Alberti Martinelli Veneti ad Angeli fymbolum , \& fcimus nonnullis aliis ftudiofis Lugduni fuiffe animaduerfas.

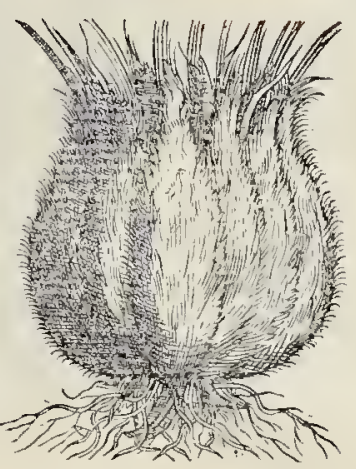

\section{NARDVS GANGITIS SPVRIA NORBONEE.}

Q V INT Y s iam agitur annus, cum aliä huic fimillinã - \& copiolam nacti fuimus. Eft in Gallia Norbonenfi à Gangc vrbecula feptem plis minus niliaria difsitus mons pcrquam amœnus \& celfus, herbarum lectiorum feracilsimus, cui idcirco vulgò nomen L'hort de Diou, id eft Dei Paradifus, inditum : in huius cliuo qua ad mcridiem maréue Mediterraneum vergit, hæc vberi prouentu erumpit, mufcidis \& vdis tracibus, infima radix pufilla, exilibus fibris clurss \& raris, quæ fubfunt ipicatis comofif que torulis minimum digitum crafsis, colore pallefcentibus ex fufco,ferè palmum altis, non valdè mucronatis, fed quadătenus per extrema recifis, folio eft viridi, rigido, iunceo, vix pedéalto, numerofo quod ab ima radice ortü trans f́piceam comam imum caulë ambicntem fćce exerit : multrque plantra quafi vno cefpitis ambitu implex $x$,

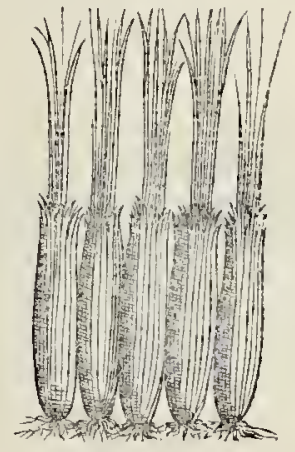
vaius effigiem præx fe ferunt. Tota inodora eft,præterquam capillaméta fpicea, quæ multò crafsiora quam Indič funt', odore Mufchi Querni, vcl terreftris, cui femimerfa humo inferuntur comofa capillamenta: è quibus gracilis acnitidns iunceus culmus Elphæ vocatr non difsimilis, cubitŭ altus exit, à medio cuius ad fummú al ternacim funt admo, dum exiles herbacex filiqux apiculis è calyculis aliquantum Schœnanthi fori aut deforclcenti Gcranio \& Cotyledoni fimilibus. Hæc'tum vifa fuit Rondelletio præceptori \& Iacobo Vtenhouio generofo Gandauenfi cómilitoni cruditifsimo, \& in hac parte nô fccus ac in cæteris rci medicx apprimęexercitato, qui cam fuis ipfius manibus collcgit, \& etiamntun nobis videtur G A N G I T I D I Diofcoridi prorfum quadrare. Nec cuiquä mirum fit Gangis vrbeculæà nobisfactam mentionem, nam nullum occurebat oppidulum nullúfue infignior \& propior locusilto, quem alluunt duo amnes fuanifsimi, quorum alter eft fabulo, micis baluribúfque aureis mixtus, vnde etiam Aurü colligunt. Quo verò fato factum fit vt id nomen ad fiuerie, equidem nefcitur, non effe Indicam fcitur.

$$
\text { IVNCVS L EEVIS VVLGATVS. }
$$

N V N C ad reliquam Inncorum Hiforiam pergamus ficuti à loris \& funibus Schxnum, fic à iungendo Iuncum dixerunt. Pratis vdis deterioribus nihil viuidius fumiliariffuc iunco laui vulgato, qui duplex elt, aut mucrone tenus diftans.Vtrique tamen rectx, laues, herbaceo colorc virentes, nitentéfque virgx aut culmi mucronatis cufpidibus \& femine nigro confpicuis, medulla alba elychnum referente \& vfu fupplente rigidis, cubitū \& féfquicubitum altis, minúfq; duris mucronibus armatis culmis:

$$
\text { D.iiij. }
$$

femine 
44

STIRPIVM aduerfarianoua.

femine nigricante mufcofo in pufillis accrofis glumis. Nullius neque pecori, neque homini vfus, nifi in fernendis anlis 2 dcambulacris, in Anglia potissimum.

Complures afperitate \& fquallore tantum \& copia medulla varietates iftus vbique, quas recentiores minus fcitè in quaternas aut quinas fpecies diffundunt.

$$
M A R I T I M D S D V P I E X \text {. }
$$

$A^{T}$ huius acuti dnz apud rura Norbonenfia maritima differentix, multò proceriores, nec ternis cubitis inferiores. Vtraque ftagnolis maritimíf que lacuftribus inter Latera \& Peraus eodem cefpite virefcunt, multò acutic maiores \& infeftiores puncim occurrendo. Vni feminis nigticantis fecunditas in glumofis afperis \& nigricantibus glomis: alteri niuea, tomentofäue inftar barbulx lanugo mollior propender. Etiam horum medulla elychuis atque circulatorum neuroq; Plaftorum iocofis ingenijs \& ludibrijs apta materia :è qua columbulas commentitias volitätes, atque aëre fefe librantes memininus conflatas.

$$
\text { AQVATICVS MAXIMVS. }
$$

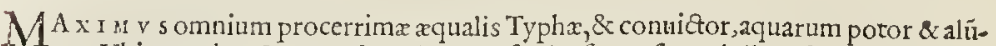
nus. Vbique etiam Septentrionalium prafertim fungofa medulla, ftoreis texendis ad triclinia infernenda, perquam notus,

$$
\begin{gathered}
\text { IVNCVS CTPEROIDES FLORIDVS } \\
\text { Poludefus. }
\end{gathered}
$$

IL I s ommibus vt diuerfus, ita excellit Floridus vocatus Iuncus, quippe nonnihil ad Cyperü accedere folio \& vmbella cernitur, alioqui nó difsimili illis radice. Iunceus rotundus \& virore herbaceo, caulis Typho non abfimilis, fed gracilior, tres cubitos eqquans mufario decorus Cyperi, fed floribus ex purpura candore diluta Ampelopraflum referentibus. Folia item Cyperi aut Afphodeli longiora à radice Iunci, fed crafsiore, nó nihil carinati. In lacunijs \& torpidis aut lentè fluentibus riuulis Belgix, Anglia \& Londini ad arcem Regiam caferiúmque nauium Liburnicarum nafcitur.

$$
\text { CAIARTIMVS. }
$$

TIV I c non ita difsimilis, fed tantum littoribus \& Harenofis Norbonx \& Galloprouincix frequens, vix peden \& fefquipalmum xquans. Folis conplura, tenuia, albida, angufts, ir caule fefquipalmeo duplò longiora, lenta, fparfa, infexa, crafia \& porreacea è tadice nigra fimplicioze Cyperi modo lógi geniculora \& prolixius ferpente, \& multis villofis pilofifquc cirris \& crinibus fufcis depasta, fapore grato. In fúmo caule foliola plurimin terna, tres pollices longa, florem globofum Iunceis feminbus glumofis ftipatum, afperiufculum, exfufco \& purpurco pallidulum Ampeloprafsi nagnitudine \& effigie emittit.

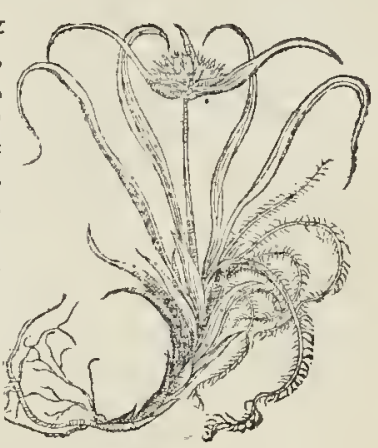

IVNCELIVS.

$\checkmark E_{\text {r }}$ v $M$ aridis glareis \& fterilibus Erycetis Septentrionalibus omnium minimus paffim vifitur, qui vix fefquipalmum xquat, pufilla breuíq; radice, fpicis tenellis, difper-
ifs flofculis mucrone carentibus.

$$
I V N C V S B O M B Y C \perp Y S \text {. }
$$




\section{STIRP IV $M$ aduerfarianoua.}

ES I ctian Maio \& Yunio in vdis pratis \& riguis, exilibus \& quafi gramineis foliolis

donatum Iuncum videre, pannicula aut cęfarie niueo candore lucente infignem, qux etiam perquam procul oculos nitore pulchro allicit: radice fibrillis tenuibus, \& mucronc minus rigido donatur. Germani ob tométum lineúmue flore \& vfum. 27atten. Slactys, quafi culcitrx fupam, aus tomentum dicunt.

\section{A S P H O D ELI.}

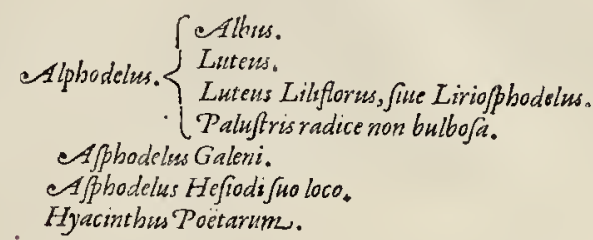

ASPHODELVS ALBVS, fme HASTVLA REGIAi

SGerm. Boid Dourts.

ZGallis. Afrodiles.

Citalis. eAphodelo.

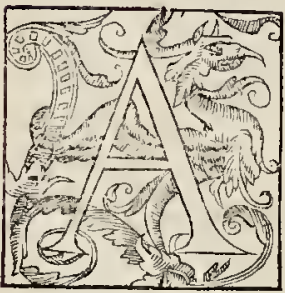

R I D A Narbonx littora Afphodeli comunis feracifsima fune, nec minùs mōtes à mari difsiti, vbi bulbis illius, adultioribus roftro efforsis, quaatumuis acribus fues lubenter vefcuntur : homini iam in cibum non cẹdit, vt Galeni A prohodelus, cuitus vis etiā non clixi ignauior multo, \& feruor mitior. Folia illi Cyperi, $\infty_{-}$ n anthes, aut Porri fimilia, triquetra, carin ata : Caulis rotundus, læuis, cubitalis \& fcfquicubitalis : fores ftellati candidi Onnithogali maiores:femcn fufcum triquetrum Sefami Theophraft, in orbiculatis capitulis obfcurè virentibus occlufü. Radices teretes numerofx ab vno capite, Pxonix minores, concolores fermè, acres, glandibus fimiies fubfunt, acrioréfque multò \& ingratiores quàm ve vefcendo fint noltrx gulofitati vt fuerunt holus prifc $x$ fiugalitati, cuius teftis Hefiodi verfus etiamnum extant : nifi huius cum Galeni eadem Afphodclus fuit, ant mitioris foli alumnus, vel coctus, vt de Aro Egyptio,de Copis \& bulbaceis acribus legimus \& feimus.

$$
\text { ASPHODELVS LVTTEVS MINOR. }
$$

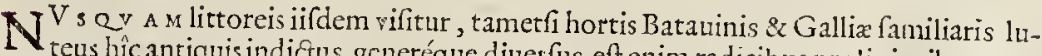
teus hic antiquis indictus, generéque diuerfus, eft enim radicibus prolixioribus, nec ica bulbofis, fed Corrudx modo minus tubcrofis, leniúfque turbinatis, è quibus Cyperi folia complura exeunt exilia, -faturo virore. Caulis restus, floribus crebribus, luteis alterius fimilibus faftigio tenus itipatus : femen triangulum pericardiis continetur primi
modo.

\section{LVTEVS LILIFLORVS.}

L I I O S P H O D E L v s inter naturæluxuriantis Iufus, quia non minus elegans quàm noua, hîc fubdenda \& defcribenda, qualem Venetijs fuperioribus annis vidimus, ac dein Antuerpię cum Afphodcloluteo in officinis Guillielmi Driefch \& 2 Petri Coldenbergii amicis peritifsimis, deníque Monfpellifeuimus. Radices illi œnanthes aut Afphodeli albi exiliores, caulis fefquicubitalis, folia ftatim à radice furrecta, exilia porracea. Extrcmus caulis in turiones fifsus qui fores ternos quatcrnófue Liliaccos referunt, colore Lilinm lut sum flauo, vel aureo, quibus fuccedunt filiquæ angulof femine lucido, atro, oblongo, Pconix forminæ minorc. Hunc Lilium luteum vel Afphodelum nuncupabant iam tum quidam Pharmacopœi Veneti.

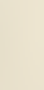


ANGL 1. Flandriag; humentibus paludosifor; pronenit è radice fibrofafparfa ron admodum protuberantibus per interualla graninea appendiculis, folia cxecunt Gledioli aut Acorianguftiora, atro virentia \& Itriata, caulíque fe fquipalmaris, ortt nagnitudine \& modo feminćcue in lagæaú culis Hyacinthi.

$$
\text { ASPHODELVS HYACINTHINVS fortè Galcni. }
$$

eAphodelus IJV I cradix Ornithogali aut Hyacinthi, bulbus cft vnicus albus, folia porreacez, exiformana Dodo. liora, breuiora, caulis vnicus, rectus, pedalís, cauliculi triquetri altrinfecus harent 452. Spicxin morem, è quibus flores itellati ladei fe explicant, è nédio faminibus quibufdan productis Ornithogalum referentes, quare Ornthogalum fpicatnu quidan vocaSpiratkm Or- runt, Monfpellienfium nonnulli Pancratiun,alii Afphodelï Galen, propterea quia annithogalum. cipitis videtur figurx \& promifui generis ex $\Delta$ phodelo cuius flores habet, éxque hyacintho, propter non chifsimilem radicen.

Nos itaq; copinus à ferie gladioli \& fimilibus, hine è cognatis principiis Hyacinthorum Hiforià bulbofis annectemus aे Poërico primùm orf Hyacintho vt qui Irides inter I.lia \& Hyacinthos gladiolos \& Afphodelos quadamtenus ambigat : quen roluifsemus Iridum clafsi proximè fubdere, \& poterat fane, nifi potior collatio Acori \& alionm fefe obtulifet, quibus hac tantopere fimilis foribus, ve Iridem multi putarint. Verim bulbis \& foliis cognatior natura hyacinthis fimiliorem facit, eóque nos huc digclsinus:varis enim de partibus \& collationibus, varias ad ftirpium gentilitates allufife videtur De dala \& munifica parens Natura.

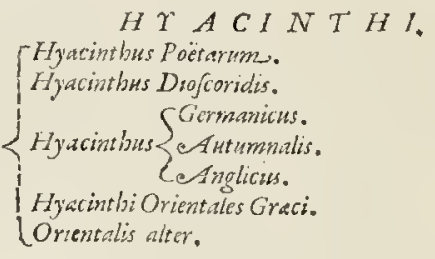

HTACINTHVS POETARVM.

A D e o affinia funtı, \& v eleméta, vt facilè fit augurari tà i' $\alpha$, idef violas cognométo dictos fuifle antiquis flores fpeciofilsimos quofque, prafertim remos \& coronamentis inneai folitos, vnde tot forum generibus diuerfis violx vox quaf hyolx communis facta fit, \& proinde accomm odata hyacinthis, quorum purpurewin Flinius ab antiquis nigras Violas vocatas memmit,propter concolorem hyanthinum fue violaceú forem, vt liquet de Theocr ito, pariq; ratione putandü Diofcotideum d: ctum fuiffe piopter hyanthinam incusuámq; \& pronan deorfum con:a, forbus plenani purpureis, cuiumodideliniatur $\&$ hodie confpicitur.

THEOCRITI \& POET ARVA Hyacinthus fore Iridis.

NV r y s dum feriptor neotericus videtur feitè diftinxife aut agnouiffe hafce fpecies hyacinthi:ea propter nonuuli Iridcm, alii Gladiolum ferututi Palladium coniefarunt, quidam rati lughbrem illim cruorem, gui fufus bura fignancrat borbas, ac defierat cfle cruor Tyrógue nitentior oftro, foris Lilii forman excepcrat, eadem prorfun: fi non purpureus color his nempe lyyacinthis, argentetis effct in illis, nimirum lilis candidis, vt Ondius canit, rati inquan crucntos debere effc à cruore flores, Lilium rubrum Diofcoridis, Martagon Chymiftarum, Hyacinthum Ouidianum fecerunt. Atqui ifum Hyacinthi $P$ oëtici coloren cife purpurcum vjolacem, non phoniceum fure puniceum, cuiufnodi in Minio, Anagallide «̌ Martagone fpeetatur, oftrei Tyrii colorviolaceus fius hyanthinus abundè explicant, \& oftcntant buccina purpura, clius 〔a- 


\section{STIRPIVM aduerfarianous.}

cuius fanies ex violaceo tantillum rubet, vnde apud fuauifsimum Maronen fuauc rubens hyacinthus dicitur, at Martagoni non fuauter rubent folia, fed Aämeo flauente exuberãti rutilát. Et porro, lberaferrugine tinctum, cum canit Poëta, iunuit coloré, quem politx calsides igni calfaet $x$ aut candefactx fimul ac frigefcunt, violacen rubidum, nitidum contrahunt, vocant Bruriffure Galli, de quo etiam ferrugineas Violas dixit Claudianus, neutiquam vt putarunt, funclas, aut lugubres intelligens, nam Vergilij verfus contrarium indicat: Pittus acu Chlamydé, co ferrusine clarus lbera. Quare vndequaque aptifsimè uofras Pocticus Hyacinthus fudiof huius ætat is cxpeEationi fatisfaciet, cui nullus hactenus poterat placere, cum iftum nondum norat : quique non modo è Hyacinthorunı gencre eft, fed etiam tantùm habet cum Lilio, Iride \& Gladiolo fimi-

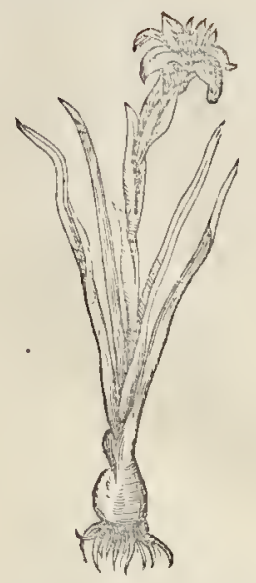
litudinis, vt hinc facilè fit coniectari Poëtis, Hiftoricis, Ruftice rei fcriptoribus \& aliis collatum fuife penitus cum illis ijfdem dc plantis; \& interdum ijfden acceptum, quod à plcbccula etiamnum ficri in Iride diximus. Si enim huius fotem, femen, vniuerfúnque caulcm, \& filiquam oculis Pocticis intuaris, Hyacinthum neges, Iriden dicas : fin bulbü, foliáque perpendas porracea, colorēque hyantinum, Hyacinthum affeucres.Sed harum rerum peritus arbiter (tametf videat Paufaniam, Palladium aliófque fcriptores ambiguis fententijs fuctuare) rei ipfus explorationc nifus, neque hyacinthum prorfum dicet, quia nonnulla reclamant, \& Iridem negabit, quòd incque radix foliáue congruĩt: neque tamê illi defpondendum erit, quin ea potius, quam nos fæpiùs híc inculcamus, noderatione \& methodo exfedienda Poetarum: Hiforicorúmque contronerfia. Ne miferam nuperorum quorumdam fattagentiam imitcris, qui adco fe torquent in delectu ex antiquis plantarum habendo, vt fruftrà putent ortan plantam, \& ferme in Naturacenfu perditam, nifi cuipiam gencri abillis dc.cripto, quafi fub vexillo fuo pofsit aggrcgari. Atqui nos, quod Ariftotcles \& Theophraftus in Lapidum, Pifciü, Quadrupedúmque hiftoria prodidêre, híc poffumus multò verifmilius diccrc, nô parın multas effe plantas ancipitis mixtrque naturx, non fecus atque linnuli ex contrarijs aut diuerfs fpeciebus confati ₹wóøuta, hybridas \& amphibia non panca. Proindé cum if thęc planta Iris non fit , \& tamen illi atque Lilij forum elegantix abfimilis non fit, quorum amula venuftate Poëtz afsimilarunt, \&Palladius dixerat Iriden vel Gladiolun à foliorum fimilitudine vocari" : fanè nobisPoëticus Hyacinthus efto, qualem in Anglix, Flandrixque amcenioribus viretis videre pafsimef corollis expetitam. Difparis igitur generis duflex hyacinthus erit , Poëticus nofter fcilicet purpurcus, cocrulcus hyanthinus violaceufue ferrugineus vocatus Iridis Hiftoricis, \& Palladio, Gladioli Poëtis, \& vulgo Lilij fimilis, qualem exaftè nofter exprimit : effigie nimirtum Iridis aut Gladioli propior, quàm Diofcoridei hyacinthi:quarc priùs hîc de Gladiolo hyacinthifquc fpurijs germanico, Anglico, Græco bino, \& Autumnali, quia fint floribus ftellatis \& Iiliaceis, móx que de altera Diofc. comofa fpecic hyacinthi dicetur.

$$
\begin{aligned}
& \text { Iipsop; } G L A D I O L V S \text {. } \\
& \text { \{Germa. Bct)uuettel. } \\
& \text { \{Gal. Glais. }\}
\end{aligned}
$$

X I н г о feu Gladiolo aut cnficulo nomen factum à folij figura, qux tametfi eadem propemodum fit multis plantis, vt Iridi, Xiridi, Acoro \& bulbofis quibufdam, atque nonnullis ctiam pifcibus, tamen huic pra catcris remanfit, proptcrea quia propius mu-
cronatum effigiat, friatumquc liris \& neruis fcabris, rigidifouc frmiufcul frequentifsinum, ea propter dioum fegetalé Romąnis, Caulis fungularis, rectus, rotun- 


\section{A8 STIRPIVM aluerfarianona.}

dus, ftriatus, nitidus, è folijs quafi fefe exerens $\&$ forcs conditos deinceps habene per interualla, interdum vnico tantum \& ad vnam partem verfus (fic noltras Norbonenfis) interdum binis ordinibus vtrinq; vno, vt in Italo. Flores rutilant hilari faturáq; purpura, fenis \& feptenis foliolis conftantes Liliaceis funilibus vel Ornithoguli, fed nininus repädis aut diuullis. Semcn in folliculo rubrum Erucx magnitudine : gemini bulbi radici funt, quorum habitior \& corpulentior interdum fuperior inferiori incumbit, interdúmque hæc inferior maior \& languidior Vere exacto iam cffota, plufcul is pufillis bulbis propagatur Ornithogali modo coma fibrofa, fubtìs radicāturglutin of bulbi \&:villofo inuolucro teguntur füco, fapore non ingrato, acri, ad tumores frumofos \& fcrophulas tante opis, vt nulla huic comparanda videatur, Recentiorum certifsimis periculis factis. Arua \& fata Norbonenfia vero Gladiolo fcatent, éque cun Draba vulfam furculatores in proximan viam aut tramitem proijciunt.

\section{$H \Upsilon A C I N T H V S G E R M A N I C V S$, Liliforus. \\ \{Germa. Elo Dertzenbiumen.? \\ \{eAngli. Dut ladics flour. $\}$}

E Gr A D I o r o \& P'oëtarum Hyacintho nofcenda eft fpeciofa illa planta bulbacea

Hyancinth.

Germanix notifsima, quam propter florum pufillorum colorem purpureum, \& diuifellatus. Futer furam Lilij aut potiùs Arphodeli doctifsimi quidam cum Fufchio Poëticun Hyacinthü fones Fufch. diuinabant:elegantia, magnitudine plaufibilior fpectanti, Iridis floribus gratia is no484.483 . ftrum longè fuperat, Et reliçua illius effigiatura congruentior multò Diofcoridis $\mathrm{Hya-}$ cintho quàm Poëtico foret, magnitudine etiam par, fed buibi candidi, flores cxrulei purpurei A fohodeli vel Ornithogali ftellulis vifuntur. Norbonę mótolis arduis, Geneuę, aut Heluetr \& Germanix in campeftribus \&iuxta fepes nafcitur.

$$
\text { II } Y \text { A INTHYS ANGLICVS. }
$$

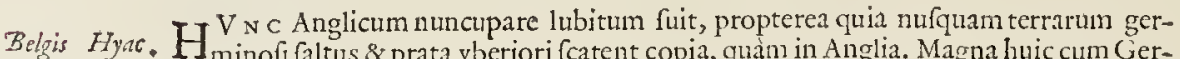
Bruxellenfis

friptus.

Dod. 167. manico fue Fufchiano affinitas bulbi \& foliorum, fed confpicua forum difcrepantia: funt enim his oblongi calyces Iefamini vel Filij ante patrem, cęrulei,cæfíue, \& interdũ albidi extrema ora fimbris ftellatim reflexis dehifcëtes plures è cauliculo nudo pedali nitentes, \& inæquali fitu penduli. Semen in folliculo her baceo atrum Nigellx vel Cxpe, vt cxterorum Hyacinthorum.

$$
\text { HYACINTHVS AUTVMNALIS. }
$$

Dod. effig. de HVI v s effigiaturæ minimus, fed pulchellus, quem primi omnium Antumnalis donaflorib.leb.pug.

tum nomine Antuerpiam è Veronenfi agro mifunus Guillielmo Driefch. Plurimus poftea etiam Lutetix Parifiorum,Norbonæ ad Açuas Marianas, \& ad Ccllam nouam Monfpellij vifus nobis glareofis afperis, Autumno ineunte, llon Vere, vt fuperjores, non flofulos lagenofos edit, fed radiatos quinis ferifue foliolis ceruleis Ornithogali nunoribus, cxtera prorfum cadem, fed minora.

$$
\text { HI } A C I N T H I O R I E N T A L E S G R A E C I .
$$

Effigies. Math.

A N o I 5 2.Patanii primum vidimus,donóque accepimus hafce duas bulbofas, rnà

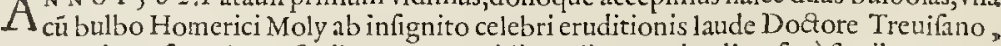
quę tum inter fe multum fimiles erant, tum illi Anglico non ita diuerfę: è floribus tamen difcernuntur, alter enimeft crafsiore, breuiore bulbo \& flore, qui funt veluti vtriculi violacei cortei vel albi Anglici Hyacinthi, vel Iacex medix vel albx fimiles, tariores \& à medio caule ad fummum vfque hærent. Bulbusaliquanto crafsior quàm Anglici, \& Moly Homerico paŕ.

ORIENTALIS AAT TER 


\section{STIRTIVM aducrarianous.}

A L t e r verò bulbus non difsimilis feptú caulem pedalem attollit, à medio totum floribus fiue calicuhs in fpeciem comæelegantis digefts, purpureis alias albis Afpho deli Galcnici, fue Ornithogalli fpicati fimilitudine \& fitu. Ambx quadrienum, quinquenniúmue durarunt Antuerpix, quas in Belgio inforsis bulbis feuifemus: in delitiis Adonidíqque penfilibus hortialunt veneti.

$$
\text { HY ACINTHWS COMOSVS Diogico. }
$$

Q VA v Is fit difficilis notionis verus Hyacinthus, tamen propterea quia coma Neotericor. 39 .

incurua floribúfque plena purpureis defcripfic hunc Diofcorides, Hyacintho- Dod.l 72 ,

rum claffem à fuperiore fecreuinus, vt quem putanus magis ad Diofc. Hyacinthum accedcre, huícq; proximè fubdidimus, quia fimillimus etiam eft, nifi quòd ílli fponte frequentiùs Septentrionalibus regionibus, hi Meridionalibus lubentius florent. isiquidem Italix, Norbonx, reliquę etian Gallix tepidiori abundè in fatis \& viarum marginibus proucnit maior Hyacinthus, folijs porraceis, bulbi Vomitorij latioribus, in terram reHexis, caule laxui abicantè ex herbacco tenero, quem ì medio fummo tcius amiciunt numerofi flofculi fpicatim confertímque digelti, purpurei oblongi in tantillis pedicellis vuæ gygarta aut Lauendulæ fofculos imitantibus, fupernéque comofam vmbellam Bulkws latiufculā, circinnatam deorfum vergentem, nutantem \& incuruam efficientibus, ex cfchlentrh. purpura violacea fuaui rubore permixtā. Radix Cxpacea fermè quanta Narcifsi, fed extimus color nitidus illi rofeus dilutiore purpura, propter qué B V L B I N A M P I I N I I

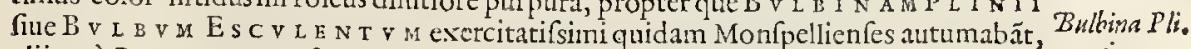
alij verò $P_{A}$ N $C$ R A T I I fpeciem:quia minorem ian defcribendaun veriorem putabant.

$$
\text { HTACINTHVSCOMOSFS MINOR. } \quad \text { Palterï Monfpel, }
$$

FS r fiquidem hic toti Meridiano tractui multò frequentifsimus, \&s Scptentrionalibus in hortis tantum. Vere (quim fuperior floret) ornat hæc planta editiota, agrorúm- Ncoter 19.Dod que nargines herbidos, flofculis item venuftis inque comam perficuam per verfus 170 . fpicatam digeftis lagenulas numerofas \& admodá exiles confertinaggeftas, \& patulas oftentantibus, vnde vulgus Prouincialium Rarreletz vocat, quafi lagenulas : cauliculis eft fefquipalmum altis, folijs Imnceis tenerioribus, fparfis, ftriatis.

\section{N A R CISSI.}

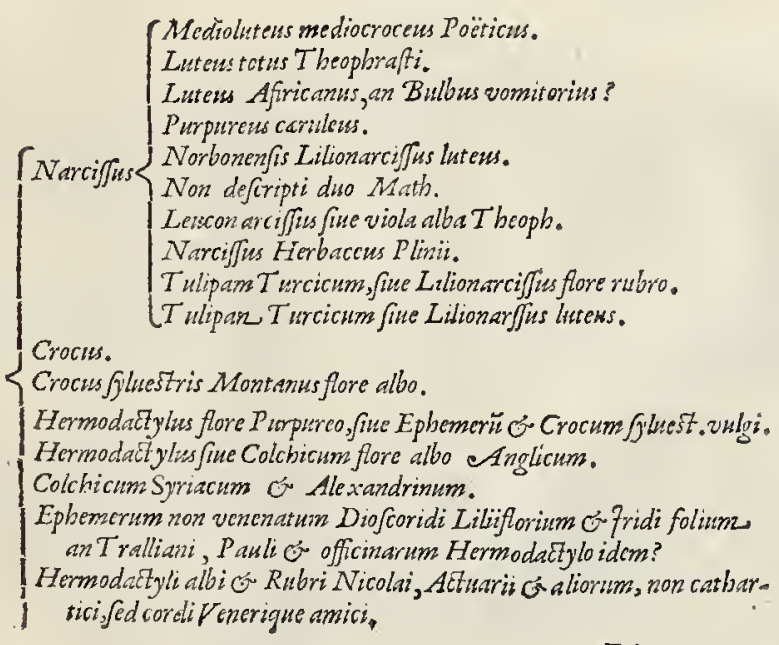

$$
\text { E.i, Ornis }
$$



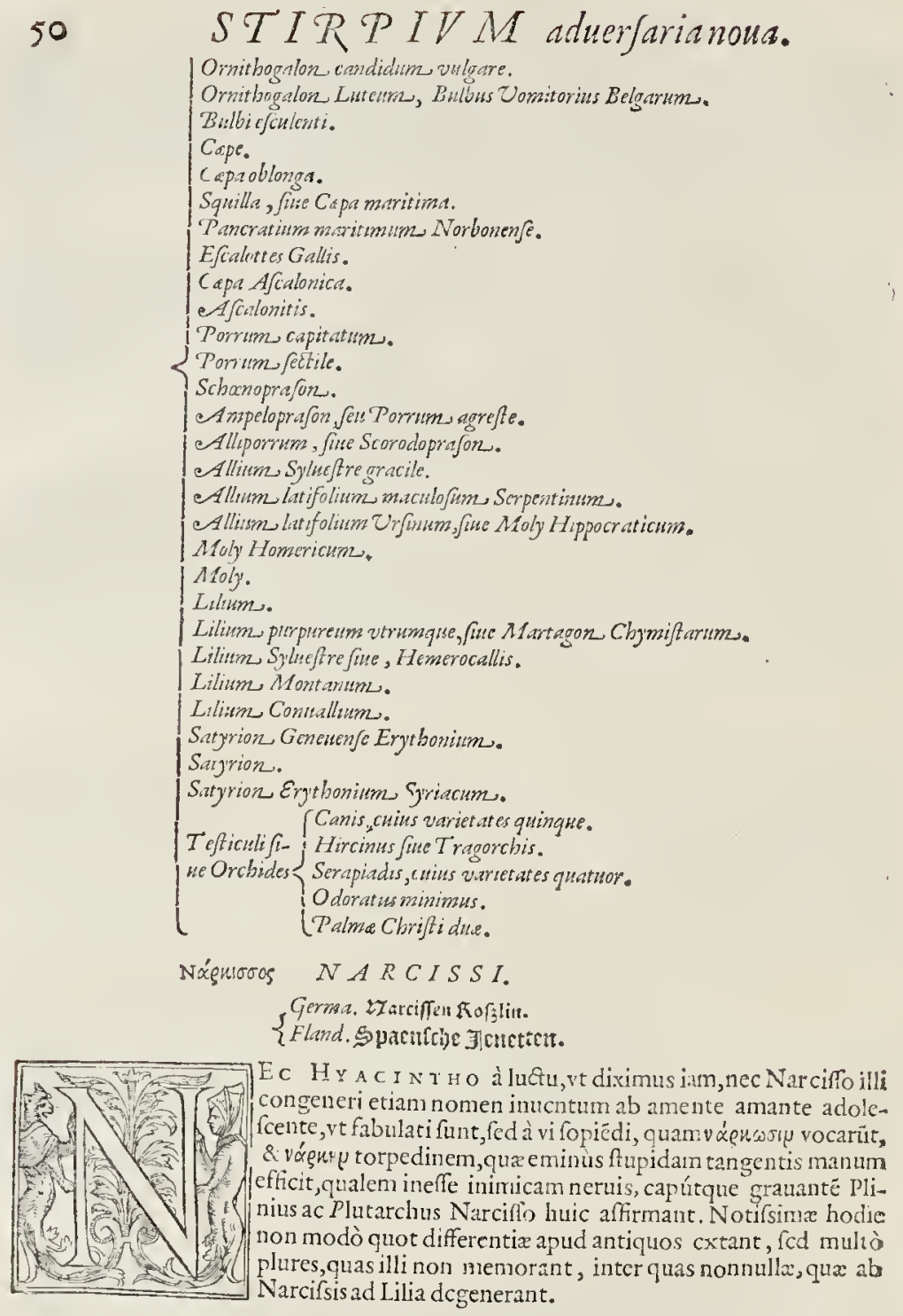

\section{POETICUS MEDIOCROCEUS purpurens.}

VVL G A I I S I M $\mathrm{V} S$ omnium Poëticus, cuius croceum florem videre eft, folis mediMediopurpu- ciffus, Narbonéfia Gallóque Prouincix prata Liliaceo Stcllarú candore ornans, Februa-
reus Dod. 18 . reus Dod. 181. rio \& Martio. Flores cnim habet cádore micantes lacteo, fents foliolis radiatos, corolla mediü occupäte fimbriata, ex croceo purpurafcente, odote fuanifsimo \& verè foporifero, quafi quiddă Nymphęz florü redoléte, folliculo mëbraneo ex nodulo exorto primú occli:- 


\section{$S T I R \mathcal{T} I V M$ aduerjaria nowa.}

occlufi in caule glabro rotundo, fed vtrínq; com preffo vel ftriato. Semé nigrum in vtriculis mëbraneis Nigellæ, multiplıci tunica bulb us cöuolutus, \& cute denfa obfitus Pancratij narini vel Squillæ admodú fimili,fed minore. Folia funt Porracea, mucore albido plena, vti Hyacinthi, Cxpe, \&\& Squilla.Hortis Belgicis, Germanicis \& Anglicis inquilinus.

$$
\text { NARCISSVS MEDIOLVTEVS. }
$$

$E_{\text {I I }}^{\text {I }}$ pratis iifdem fed frequentiùs vberioréque ornamento floret hic Narciffus, qui

floribus eft vno ex pediculo fenis, denis, duodenífue fparfis minùs candidis, \& circin- Dod. 183 . nato vertıcis calyculo in luteum languefcente, nigro foris \& habitiorc bulbo, crafsioribúfque folijs. Galloprouincia, vbi etiam funt Grámini detrimento, Donas fores quos corollis inneciunt, vocitat.

TOTVS LVT EVS NARCISSVS Montanus Theoph.

Germanis, Deltblunen, boanungeblumen, is jeitloren.

$\left\{\begin{array}{l}\text { Belgis. GedT Jdeloofen. } \\ \text { Gallis. Coquelourde. }\end{array}\right.$

NEc difsidet hic à Diofcorideis facie vel viribus, fed tantùm floribus, quos admodum fpeciofos, luteos promit, itq; quafi duplicati forent non corona exili,fed nolx effigic Dod.de flo 190 Prinula Veris duplo maiore, luteo atq; infigniore criftatur vtriculus, non tame difpar, vit nec folia aut bulbus, nifi quod graciliora, minora. Februario \& Martio featet ifto forum Londini holitoriī, \& nemorofa relique Anglix Belgí́g; prata.Ad Meridié regiones propiores, vt Norbona,Vafconia, \& Hifpania, nó nifi editis montibus, \& Maio, Iunióq̨; forêt, vtin Veganiiis, Mindenis Pyrenęis iugis non procul Tholofa, inodorus, inefficacior, nec perinde narcofin inuehit.

NARCISSVS LVT EVS AAPHRICANVS, an Bulbu Vomitorim?

HV N c quidam chyrurgus barbitonfor triremium Genuenfiun oftendebat allatum

ex Bona, \& Argiera, Chartaginíque finitimis locis Aphricæ, planè foribus luteis languidis odoris , fed effigie Mediocrocei Narcifsi Norbonenfis, minoribus tamen, exilioribúfque foliis \& durioribus, minùs mucagineis, fed magis viticeis \& fequacibus, \& fructu contumacibus, nihil alioqui vlla fui pai te à Luteo difsidentibus. Non procul Agathenfi finu affirmantinueniri, etiámque ex Hifpanicis nuper in Belgiun \& Franciam delatos audimus.

$$
\text { NARCISSVSPVRPUROCOERULEUS. }
$$

O VINET I A M afferebant non poltrem $x$ fidei amici, fe nactos totis foribus purpu- reis Narciffos prope Lanum fluuium, non procul Monfpellio, quos tamen nos diu fxpéq; inibi \& aliis adiectis pratenfibus fruftrà venati fumus, aut ftudiofos Simplicium, \& pręceptores noftros, vt indicarent, rogauimus.

\section{NORBONENSIS LILION arcissus Luteus Montanus Tulipe pecies.}

E R v r v m huncè Dei Paradifij Ingis vocatis Seuenæ Norbonenfis, iam plures funt anni, in Belgium deferendum curauimus amicis Antuerpianis, qui primum Tulipam illum vocarunt, nos verò Narcifiolilium luteum andaciùs fortè(vti folemus quò rerum cognitioni diftinctiori confulamus)indigitauimus. Flos itidem fingulo bulbo \& caule Dod. Tulips minor de florb. Narcifsi minore, teneriore, delicatiore, vnicus luteus, fenis foliis conftans ad Lifium aut potius ad Lilij lutei Afphodeli florem, filamentis luteis è medio enatis. Bulbus exilior inul tò, nucleum oblongum Allij zqquat, fibígue frepius adnatum allium exili filo adnexum habet: foliacrafsiora pauca è caule medio porracea.

\section{IEUCONARCISSO LIRIO N Pratenfe Vernum,num, UIOLA ALB A T HEOP H. vel Moly Rondelletio?}

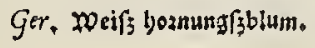

$$
\text { E.ij. }
$$




\section{2 $S T I R P I V M$ adwerfarianowa. \\ HV \& y s coronarixbulbofx triplcx è foribus \& magnitudine vatietas, nam Norbo- Narcis. Math: namque lacteo Ornithogali candore, fed Lilii parui effigie, è finguli caulis fuperioris mul- tiplicis nodulo vno feni vel fepteni procumbentes, feménque rotundum Poconix nigrum in folliculo membraneo cohioétes: folia \& radices Narcifsi mediolutei in pratis, vel ger- minofis deptefsis atque lacunofis fcrobibus, non procul Monfpellio \& Magalona ad La- teranum dirutum caftrum plurimus foret, eenénque foenifeciis maturat. \\ In Germania, Gallia \& Belgia vifitur idem nifi paucioribus floribus diftans, Gitos non difsiniles, led fingulos in fingulis cauliculis ninoribus habct, luteíq; filamenta è medio exerentibus, femine fufco. \\ Omnium minimus palmari cauliculo,etiam Septentrionalibus plagis, vt Ant- varietas uerpix \& in Nortmänia frequentifimus, paucirate foliorum, qua terna vi pluni- \\ mum, vel quaterna, habet, \& flore, exiliore, qui vnicus illi inet herbace vi: lateo- \\ An Narcif. \\ Herbaceus Plär

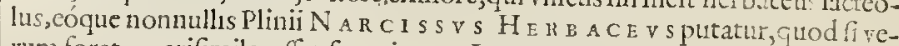
rum foret, verifimile effet fuperiorem $L_{1}$ L I O N A R C ISS v M ciufdem album nuncupatum , Narcifum futurum : quibus cun tis nonnulla fubtus lineo lx exaratx herbidi viridantifue coloris confpiciuntur, inde fortè Plinio caufa nominandi.
\end{abstract}

$$
\begin{gathered}
\text { TVLIPAN TVRCICVM, fue LILIONAR- } \\
\text { ciffus Sanguinens. }
\end{gathered}
$$

M ${ }^{\text {z } ~ т ~ I ~ f u n t ~ e x a c t i ~ a n n i c u m ~ p r i m i m ~ M a c c-~}$ donium fue Grxcum Lilium ifud Tulipan à Turcico vernaculo dictum propter amiculum capitis abillis geftari folitum, cui floces fimiles funt effigic, fanc quàmluculenta purpura Venetiis primú \& Patauii vidimus, deinde $L V$ T E V M \& Phaniceü Hore Florentix, \& Genuz Lygurie. Bulbus eft Narcisi, folia promens Liliacco læuore virore, crassitie, aliquätum concaua carinata $\&$ vndulatis quis, caulem verò fingularem pedalem \& flor: Liliacea venuftate [pedtãdü, purpura fanguinea nitente Pconiz foribus concolori, Lilio rubro fere pari, qunis \& fenis foliolis crafsis, obtufo calathifundo in latius fefe pädëte, veluti viols Mariane, porrectis èmedio Liliaceis ftaminibus. Semen Ariftolochix clematitidis foliofum angulofum, compreftum nëbraneo folliculo oblógo clauditur. Medio Vere iã floret nó modò Italis, fed etiä Belgicis \& Gallicis hortis.

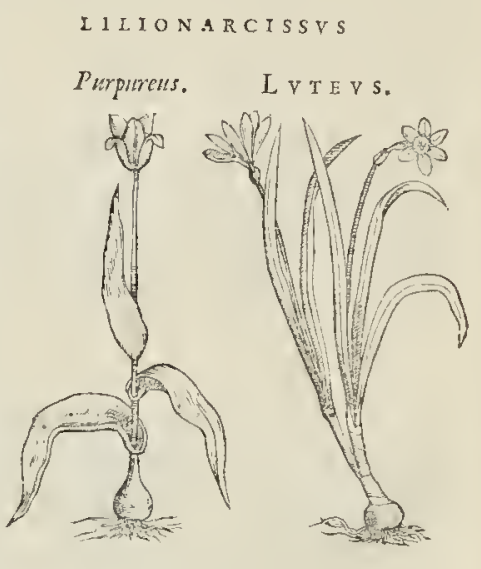

$$
\text { NARCISSI DVO A MATH: nondefripti. }
$$

CV L T y R A lenociniis hanc amatoriam plantã variatis foliis, floribus \& bulbis poffe admodum à priftina effigie defcifcere, \& rumor eft iamdiu apud Venctos quoldä ftirpium mangones, qui inditis bulbo feminibus quibufdam, vcl infertis pullulationibus, nouas \&wifendas excitari figuras affrmant, cuiufmodi Taraconi è Cepa enata, aliifque, colorem, \& florem, \& figuram mutantibus. Eapropter confultò alias Narcifsi varietates reticuimus, tru quod ne vifas quidem planè in memoria habemus, tum etiam quia nullí operx pretium ducimus artis oftenta \& lufus profequi: fed dütaxat naturæ opes in iftud albumfedulò digerere \& perfpicué,neutiquã Senenlem imitaturi, cui fatis pi\&uras, quafi puer pueris pingerct \& illuderet, in numerofos fed mutos clenchos fabulare. Non folim enim nullum defcribit è tam multis Narcif́f, fed neq; dif́cernit eos inter fe, quos bis inculcat, \& an illi duo quorú alterum radice fouammof \& nucleis ftipata, floribus multiplicibus \& foliofis:alterum veri Narcifsi Bulbo, fed florú foliis prolixioribus, anguftioribus, 


\section{STIRP IV $M$ aduer farianona.}

guftioribus,porrectioribus ftaminibus, nó explicat. Vbi \& quando \& quomodo nafcátur arténe an fpointe: vt neq; Narbonenfes híc alios flores, quos etiam vt non paucos alibi, fecir Cóftantinopolitanos, iactare potuifet:etenim eius Conftätinopolitanus Narciflus, nihil aliud effe videtur, quàn Maritimú Pancratium à nobis memoratum fuo loco.

CROCYS SATIVVS.

ngókos $\left\{\begin{array}{l}\text { ftalis, Zaffranz. } \\ \text { Ger. Gaffran. }\end{array} \quad\left\{\begin{array}{l}\text { Gallis. \& Mauris, Saffran. } \\ \text { Angl. Saftron. }\end{array}\right.\right.$

GE r m A n I r a r I s eiufdem cum Narcilsis effe Crocum docent, non modò figura $\&$ natales, fed etiam facultates peculiares, qux vtrique epifpafticx, deinde quadamtenus odoris foporiferi infunt. Nec in Crocum verfi adolefcentis Croci fabella alliud Otidius Inter Icones innuit, quàn iftam abditä dotem Veneris myfteriis celebrem, cuiufmodi Poëticæ Philo- $F u / c h .24 \rho$. fophia funt inuolucra, Hyacinthi, Narcifsi, Daphnes \& quäplurimorum tranformationes. Nam alioqui кৎókn filum, villúmue, \& tramam fignat, cuiufmodi funt Croci flau flammeáue ftamina, \& villi \& focci quæ ugoxiภes vocantur. Porrò notifsimum \& optimú crocú nó folùm regiones ad Meridiē Aphrica,Syrena, Sycilia, \& Gallia, fed etiä ad Septëtriones fitz Anglia \& Hibernia laudatifsimum abüdè dant carnofis, latis, quafiq; oleo delibutıs cruoréque aurco nitētibus filamentis intenfi odloris cum quadam acutie, fed foporiferi, quo Belgia, Germania, aliique vicini cibos condiunt,ac medicamétis mifcent. Ruftici radices pangunt admodum viuaces cultúmclue humanum fpretas, vnico hyacin thi Narcifsi aut Gladioli bulbo carnofo, fiquidem negligantur aut pedibus proterantur florem ftamináque elegantiora prodere confuetas purpureas calycis in modum, prorfum Hermodactyli pratenfis. Bruma, Ianuario, \& Vere virent folia interdí perenna, Au. tumno leguntur dü nitent nutántq; purpurei phœnici ftamina, quæ trita carpis aut fub māmis admota, illitáue vires fuas cordi cerebróq; illico tranfmittunt, quafiq; vertiginem tenebricofam inuehunt, aciem oculorí preftringunt, aut hebetant. Germinofa herbidáq; loca vult, nec apud Italos aut Gallos fóte prouenit, nifi Silueftris, qui diuerfus natura eft.

\section{CROCVS STLVESTRIS Montanusforealbo.}

I Q I DE M Sylueftri Autumno nifi mriùs, fed plurimún primo vere venit flos miSnor,candidus, interdum purpureus, locis pręertim alfiofis, vbi perpetua perennat nix, $v t$ in Oftenfis vallis arduis funt planities albicantes niue Hyberna \& iftius floribus purpurafcentes \& albicátes, non procul à Bernardi monte : radix \& caulis futiuo fimilis, folio anguftiore \& breuiore. Ifto foris dumtaxat ytendum, intus non perinde: illitum pubi vrinas elicit crebras atq; craffas, tumores Hydropico rú difcutit, fpicula euellit. Ifto agreAt faciliùs abigeret c̀ fuis interulis pediculos gens Hibernica, nan virofior eft, \& penetrãtior. Verùm vulgatior præterquam quod Hibernis miferis tam importunos hofpites, quietis \& famis hoftes abigit, etiam colorem floridum, vegetímque calorem vigorem \& animorü ferocitatem artubus \&alit \& auget, illuuićq; fordid as veftes colore commendat, militix idcirco non parum conducibilis.

\section{COLCHICVM Jue STR ANGVLATORIVM Ephemerum Crociflorum o Bulbifolium, Hermodabyli vulgares.}

V а м minimùm videtur plebis iudicio Pratenfis vulgaris Hermodactylus Ephemerü dictus, à Croco fylueftri aberie: vocant enim \& putant vbiq; vulgò Sylueftrem Crocum propter flores, natales, tempúfque florendi non difimilia.Actametfi tum ipf res, tum Diofcorides diuerfas effe abundè monét, tamen iuxta hî́c ponend $x$ fuerunt Crocus \&Hermodactylus, deindéq; huius vel fpecies vel varietas Colchicum Ephemerum, quo vtrauis ambas oftendat quxrenti. Etenim duas non ita difsumiles eft complexus Diofcorides, vt Paulus \& Galenus, ex Prifcortm defcriptione, \& fua obferuatione: quarum primam pòf \& proximè fungos collocandam duxit ille, cum quòd efculenta gratáque cibo videretur, tum quia non fecus ac fungi, vt idem author exprimit, difertè fuffocatu enecaret, ftrangulat namque illa itidem vna diecula:vnde Theoph. huius nominis occafio profecta vifa, longè ante Diofcoridis ætatë, fuit. Hæc auté non alia eft quã vulgatiffimü plebIPRATENSE CROCVA \& SYLVESRE vbiq; vocitatum. Floret namg; 


\section{STIRTIVM aduerdarianona.}

vti Crocus Autumno flore perquam finvili, cöcolote, nec difpari ritu, iamdiu antea vrimo Vere orta, \& Eftate amittit folia qux Porreis latiora Pancratii funt æqualia, vel bulbi pinguora, terna aut quaterna, vircntia, nitentia ab radice, caule fefquipalmari, bulbofa, femirotunda radice, altera parte comprefia Caftanex figura, aut Anacardi : foris tunica ruféfcente ex fufco, ab ima latioréque baff ad a picem canaliculum imprimit prima calllis germinatio, intus tota al ba, fungofa, muccida, virofa, guftu non ingrata, quam quouis anni cardine crutam à quibufdā Pharmacopoeis pro Hermodactylo habitam vidimus, \& ficcatam, flacidam, victam, rugofámque, tangcnti partim euanidam, partion fungofam meminimus, vti \& Syriacum \& Alexädrinum mox defcribendum venetijs nobis fapius vifum, denique nigram \& longè diferctu facillimam ab Officinarum Hermodactylis.Sunt enim peregrini hi, neutiquam exitiof, vt multis foculis plurinus vfus doctos docuit: inque farinam vel pollinem candidum facillimè abeunt. Nec verifimile fit, quod Colchide vberrimè fcatebat(vt ait Diofcorides) aliud à nofrate fuiffe, fed pernecabili interimendi facultate cæteris omnibus excelluife, tum quia fucco magis excoeto illic, tum etiam quia foli,aërífque prerogatiuam quandam nactus fuit . Sic fungi non paucis locis exitiofi proueniunt, \& nifi lacte ijfdem quibus Colchicum remedijs, euincantur, interimunt: alibi innocui pafsim efitantur. Sic Taxus Norbonica \&Hifpanica deleteria fola vmbra prodit antiquitas: in Anglia \& alibi neutiquam malefica. Cicutx \& alijs idem vfu venit, vt nouimus alibi. Quapropter quot qualéfque varictates in radicibus, floribus, ortu \& colore, alia atque alia peperit regio, tules differëtias facultatum inter Syriacum ruffefentem, \&- Anglicum fore candidum intercedere certum nobis periculo facto ftar.

$$
\text { COLCHICVM STRIACVM CALEXANDRINVM. }
$$

R A prc s \& bulbos aliquot huins adhuc habemus munere Dominici Chirurgi Veneti, qui quamplurimas claffe triremium rediens illinc, vbi fungebatur vulnerarij offcio, à fe auulfas Venetias aduexit, quibus vtebaturidem, cafdēq; fxpe nifcebat decoetis Guaiaci,ad Luem Vcneream, alifífue fudorificis magno remedionum cópendio \& $x g r o-$ rum commodo, edoctus illic à plebecula. Huic bulbofa tadix non parum à noftrati differt, tametfi Diofcorides deliniationem non minùs benè refert : non enim canaliculus lateratim depreffus mittit ad caulem, fed caulis erumpens medium findit bulbum, quasíque geminum Colchici bulbum ab imo coagmentatım, caulémque vtrinque amplexatum oftendit, nigriórque noftrati euadit intus forífque, aliogui è Capacea nec difsimili fungofa concretione, vti nec totius figura.

\section{COLCHICVM A NGLICVM candidoflore.}

IS T v D nufpiam herbarijs memoratum, quia Anglia copiofifsimum fpontè fundit, nee alibi facilc reperias, Anglicum nuncupauimus. Perpulchra planta, lacteis foribus Ornithogali vel Afphodeli maioribus, Croci montani Sylueftris paribus, caulem ornant fefqui palmare radix \& folia, alioqui pratenfis vulgaris funt, foris fufca, intus candida. Londini hor tis merfar radices Hyemé ferunt, Vere emergunt, non fecus ac in collibus \& montofis prope Briftoliā \& agro Somerfeti, Syluofis ornatifsimi armis \& literis Generofi nec parú ftirpium periti,D. Eduardi Samtloo, cuius humanitati, vt pleraque alia, hane fcrimus acceptam.

$\varepsilon P H E M E R V M$ non venenatum Diofc. Lithforium, of Pridifolium an, HE RMO D ACT Y LO Officinarum, T ralliani C P Palli idem.

VE $\_$v r I Syriacum innocurm medicamétis, aliáfque non paucas plantas varijs locis diuerfas aut contrarias adipifci facultates dudum in Colchico monuimus : fic ex nomenclatione deliniationéque vtriufque Ephemeri apud Diofcoridem, \& perpenfione harum radicum, quas vfus diurnus dinturnúfque probauit, Hermodactylun fue Ephemerum falubre, dote dumtaxat \& leuiore aliqua nota, non item fpecie ab Officinarum hermodactylo difsidere certú. Tria tamen quæ obijci poffunt, partim diluenda, partim diftingenda funt, vt faltem doceamur, fi son illa quidem eadé funt, certè admodü affinia 


\section{STIRPIVM aduerfarianowa.}

effe: Acptimùm obijciet quis factam feorfim Hermodactyli \& Ephemeri vtriúfque mentionem apud Trallianum \& Paulü: fatemut, \& arbitramut eos vel quòd vires purgatrices primùm in Ephemeri aliqua fpecie cópererint, aliam arbitratos pręiertim Trallianú qué Paulus citat, non Galenü, qui Hermodactyli non meminit.Vel quia Trallianus Ephemerum non venenatum fub nomenclatura Hiermodactyli in remedia arthritica adduxerit, quia in defcribenda radice Diofcorides digiti fiue Dactyli voce vfus fit, qux admota vel fotu dentium mulceret dolores, deptimeret:tumores, quod Officinarum Hermodactyli arthriticis adeo plenè præftant, vt.nullum præftantius fuppetat, ex lacte prçertim fubactü remedium. Quippe digerit moderatè nullo aut pufillo calore, aliquanta adfrictione, fed miti emplaftica \& natiuum calorem parti reddente. Nec fi non meminit Diofcorides vis Cathatticæ, non ideo neceflum inficiandum Ephemernm effe:non pauca fiquidem repepetias apud antiquos clafsicos Simplicia, quotum vires purgatrices illi filuerunt, ne dicä fortè nec notas habuerunt, vt $\&$ allia compluriu: quare fi non eft Ephemetum Diofcoridis nofter Hermodactylus, certè non alio putarim differre modo,quàm quo Colchicum Anglicum \& Syriacum. Quare ridiculè xeftuant cum Comentatore Senenfi plerique, atque doctis Barbaris infultant, qui Officinarum Hermodactylos purgationibus mifceant, enimucrò arrodere interiora, veneno petere, ac nihil aliud quàm Colchic um nimirum deletetium effe. Verùm bis falluntur: \& quod Colchicum hermodactylon noft tate effe dicunt, quum tamé folia non norint, qua longè minora funt \& humi fưfa, q tuàm vulgaris Colchici: \& quia ftatunnt necatorium, quum Diofcotides id maleficij non cuilibet Ephemero, fed Colchico dumtasat, id eft, in Colchide enato, adferipferit. Tum Solidx huius candidxque radicis \& plenæ concretio, quantum à rugora, vieta, languida, noftrati \& nigra abfit fatis indicio eft. Nullam videas etiam Venetijs, vel Genure millibus è multis quantumuis recens allatam, quæ non leuiufcula tufione illicò in puluerë farinaceum fluat, colore \& Capore planè Tutbith, Iridis, vel Agarici, quo ctiam modo nec incommodo maiore purgare norunt, qui fapius vfi funt noftri practici, quibus vfquedum experimento certo certa ratione nixo, aliud vfurpandum, aut frufta Conftantinopolitanum viribus ignotŭ obtruferit \& perf̊aferit Commentator : \& falfò accufaric Serapione11, qui non lauli, fed Diofcoridis, vt liquidè conftat merus verfor, qux in codi. ce antiquo reperit, fida barbaric retulit, vt alibi fẹper fermè Hermodactylon explorädo guftu neutiquam feruidum, fed ignaui acrimonia puffilla, \& vi obruta emplantica potius facultatis purgatricis moderatrice, quàn vlceratrice, qua non parum commodum effe arthriticis purgationibus facilè petcipiant, qui medicamentorum mifcendorum methodú callent. Nec enim lacte eget vt Turbith, quo ninùs adhuc noxium, quare \& $\mathrm{Ca}$ tharticum non refpuendum, vt vocifetantur declamarores fed commendandum.

HEMODACT Y LI albi, Rubri Nicolai, ACtuarii o aliormm non Cathartici, fed Cord, Venerig, amici:an fint Behen albrom of Rubrum endem?

$\checkmark$ O С в M Hermodactyli æquiuocam fuiffe, \& Ephemero Diofcotidis cópatari potuiffe, nó modo Caput Pentaphylli indicat (vt cuilis radix Hermodactylus fit vocata, nó tam fimilitudine, quam fuperftitione \& incantatoria expiatione) fed etian qux extant apud Actuarium \& Nicolaum celebres admodum compofitiones arguunt. Quippe Auream Alexandrinam reginam illam \& Diamofcu Hermodactylo rubro \& albo non carent, mifcetúrque alijs apud Arabcs compofitionibus cordialibus, quibus funt vifi defignaffe Behen albi \& Rubri nomine, quod etiam defluxiffe à Dactylite palmæ ftuctibus, quibus confert Diofcorides Balanü nucem myrifticam apud Arabes Ben vocatã . Igitur Arabiftatŭ Hermodactilus fiue fit Behen, vt verifimile fit, fiue fit A uicenn $\mathfrak{x}$ Digiti Citrini Palma Chrifti(cuius mentio inter Orchides facta, nullum enim Hermodactylon rubrum habenus, vt cum Rubro \& albo Ben confundi pofsit)eorum compofitionibus cardiacis præfertim mifcendus: Officinarunı vero Cathärticis \& Topicis vti di\&tum, capite de ben \& nuce Myrepfica.

O RNITHOG ALON candidsm vulgare.

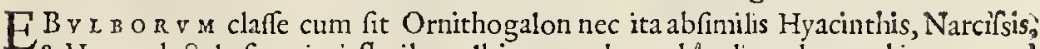
\& Hermodactylo fuperiori foribus albis, non abs re hic dicendus, vt hinc mox ad E.iiij. bulbos 


\section{STIRPIVM aduerfarianona.}

Bulbos veniamus, cuius fpeciem faciunt quidam Ornithogalon lutcum vocatum, propter inter hunc \& illum ambiguam effigiem. Et tametfi Ornithogalo nomé dedit lafteus florü candor, cuiufmodi in Gallinarü alis rcnidet aut ouis, non earum lacte(quo carent volucrum genus) tamen propter totius figurx affinitatem nobis erit etiam vocandus 2liıs, qui flore lutco elegãtifsimus, nec ita frequés Italix, Norbonę calidioribúfq̨; vifitur.

\section{ORNITHOGALON LVTEVA. an Bulbus Fomitorisu?}

Belgis Bulbus Vomitoriss.

IN Auernis \& ad Lugduni pomaria pone \& prope fuburbium trans Rhodanum vulgo Aiguilleticre in campis latis \& glareofis, etiámque in Borbonio agro, quà ducit regia via Lutetiam, plurimífque Belgix, Anglix nemorofis Sommerfeti Ornithogalon luteum collegimus. Tota planta minor multo, fed fimillima candido Ornithogalo. Martio floret, bulbus vnicus, vt plurimum Allij Scorodoprafi oblongior, inodorus, pauciora fed latiora quàm Ornithogali folia : flores prorfum Ornithogalifparfi, \& quidem foris herbidi, vt Ornithogali, fed luteoli non candidi, intus verò eleganti luteo nitent.

\section{$B V L B V S E S C V L E N T V S$.}

T. ON fecus atque Afphodeli bulbi plerique omnes edi mortalium luxu \& mollitie defiĉre, prę̧ertim Europxis regionibus, feu fuerint guftu minus cómendabiles aut vtiles, quàm bulbacea multa, Porri,cepx, Allia, \& fimilia. Vifcidi námq; funt mucco Pancratij omnes fermè quos nouimus, \& plerifque infulli \& magis excipiendo condimëta, vt hyacinthi multi, Galenicus Afphodelus, quàm ad condiendum apti. Quando igitur ex Diofcoride conictari magis, quam alleuerare quicquam licet, videntur bulbi efculenti fuiffe cxpís aut Pancratis fimillimi, \& prętantiores ruffi, acres, locis calidis oriundi, vt funt Lybica littora vel Norbonica. Afcalonicum tamen vix eft Cape, nam nec ruffum vt plurimum, nec acre, faltem vbi nos fxpius efitaumus Lutetix \& in Flandria, fieri tapoteft, vt Afcalone fucrit acrius, ruffius \& maius.

Bulbus ille rubida foris tunica, quem Hyacinthum fecimus, alins putauimus perfuafi à doetifsimus Monfpellienfibus effe efculentum bulbum : quemadmodum hodie nonnull Iuteum Ornithogalon noftrum Vomitorium Bulbum credunt.

$C A E P E$.

$$
\begin{aligned}
& \text { \{7ta. Cipole. S Angl. onvon, Belg. ayenyn. } \\
& \text { \{Ger. zwibel. }\{\text { Gal. oignon. }
\end{aligned}
$$

$F_{4} 6 h .1 c 0: 242 . \mathrm{B}$ V I B O R ₹ M,quantum vfpiam eft in naturz ditione, fpeciofifsima \& notifsima Capa, vel de Graca appellation e uófussoj dicente, quia oculorum tunicam pupillamque \& folliculos mordaci vapore lancinando, conniuere, contrahíq; cogat, lachrymas eliciédo, vnde Latinis lachrymo[a Cxpa. Etiamnum hodie varietas è locis, colorc, magnitudine, żcrimonia, tenerıtudine, varióque mangonio petenda, fermè cuiufmodi Theophrafti \& Diofcoridis æuo. Verùm non neceffe habemus perfequi plures, quàm quot hodie nouimus infigniores \& digniores vel efu vel fama, quibus cuius olitori quafibet alias addere integrum per nos erit.

Suautate \& molc omnibus Italicis vel Gallicis', quas nouimus, excellunt Aphricæ ac Hifpanicx, \& Hifpanicis maiores atque fpcciofiores Ditui Altomari in Gallobelgia fati$u x$, quibus prima commendatio, \& magnitudo capitis exuberantis, compreffe vtrinque rotunditatis rapam non mediocrem æquantis. Squámofa cuticula, extimíque tunicis fanguineo faturo colore rubentibus nitent bus, \& uihilo feciùs efui Flandrix, \& Anglix cunaţ, aliíque Sepentrionalibus expetitx:ad quas tamen gentes afportätur quotannis Hifpanicę nô mınore copia, aut cómédatione qux partin albx,partim purpurafcêtes, guftúq, aliquãtò acriores, pares teneretudine \& mole, cibis \& códimentis qua mcdicamétis aptiores. Cxterarum omniúmq; nufpiam non gentium in Italix Hetruria, Germania, Anglia, Gallia vafconia prouentus plurimus hortis olitoribus venit , \& vt quxque ad harum bonitatem proximè accedit, ita optima habenda . Omnibus eadem facultas incidendi, \& lachrymas ciendi, non odor infuauis, fed vapor \& fapor intentior, 


\section{STIRPIVM aduerfarianowa.}

aut mitior nonnullis, quemadnodü $\mathrm{M}_{\text {A I OR }}$ \& $\mathrm{M}$ I NOR BVL B V OBI. ONG teres,orbiculatus, \& turbinatus quibufdā plurimus verò \& cómunioribus cxpis à caulis ceruice fenfim in cóprefsam latiorem, fed à lateribus reductan vtrínq; circumferentiam bulbaceam abeuntibus, quorū Bulbi vinboni fibrarum numerofa coma aptata fubeft, Hellebori albi modo, quod Cxpis omnibus có mune, vti folia Porreacea cócaua glabra, niténfque caulis vacuus, \& flos in cumulo villofo purpurafcente, femine copiofo nigro Nigellæ.

$$
\Sigma \sim \hat{\lambda} \lambda \alpha
$$

$$
\left\{\begin{array}{l}
S C I L L A, \text { fine } \\
C A E P A M a r n a . \\
P A N C R \perp T / V A
\end{array}\right.
$$$$
\left\{\begin{array}{l}
\text { Ang. Sca onyong, } \\
\text { Germa. mzer zwobel. } \\
\text { Hifp. Cebolla albatrana. } \\
\text { Gall. ()ignon marin. }
\end{array}\right.
$$

$\{C A E P A$ Marina.

Gall. ()ignon marin.

EP A C E o generi tantopere eft cópar Scilla, vt multi eam M A R I N A C × P A M

vocét. Quia autem inter hanc \& marinú teftaceú pif́cem à tunicea fquanımarun cópactili ferie Squillam vocarum, tanta fimilitudo intercefsit, hac putaturfic didta. Po. Fufcisco: 453 tuir etiam à fabuletis maritimis Sole torridis, cuiufnodi funt in Hifpania \& plope aridze Luftanix tefqua maritima. Huius duas differentias colore dumtaxat inter Hifnanicus is multas animaduertere eft, quarum extimæ tunicx vni rubent, vt Cxpis oblongi; alceri albét, magnitudine pares. Vtrauis maxima Pomü Affrium nô fuperat:è tam multis âtü millibus, qux quotannis tum Venetias, tum Antuerpiam deuehuntur, nullam meninimus maiorem, ea qua fata \& perbellè adulta fuit Monfpellii in horto Iacob Farges Pharmacopoi. Vniuerfa namque folii carina vel dorfum palmum fermè lata, pedem al ta, crafsitudo minor quam Aloes, crebra c̀ bulbo pullulant fuammatim compacta, caulis fefquicubitalis, gracilis, fofculos Fragrarix gerit fimiles fed minores, in fpicam poftremò deficiens.

Neutiquam mirum Mathiolum,poft alios neotericos nuperos, fententiam de Scilla mutafle, cum nunquam fibi genuinam vifam, fed tantùm verbis depictå fateatur. Quinetiam fi verum Pancratium vidiffet, nunquam pro illo fpeciem Scillæ, aut potiùs vietam plantulam aut adolefcentem, cuiufmodi Venetiis vęneunt, fubdidiffet. Et foliorü gracilitas, à qua fe deceptum conqueritur, fanè non aliam fpeciem conftituit Scillx: fed tantú cótingit habitiora \& maiora adolefcere folia, mutatione coli, foli \& cultu. Sic Cap is euenit angufto interiecto tractu, fic in foliis Aloes \& aliis multis obferuatur. His verò bulbis flores, folia, om nia prorfum fimilia, aliquanto dumtaxat graciliora, vt bulbaceis mul tis prxproperè enatis \& aliô tranfplantatis euenit. In cótignatione fufpenfä, dum fabulo inerguntur, aut feruantur languidiora promunt folia, \& fucco feu pabulo cólueto defraudantur, exilioráq; fiunt. Ratio par in Scillis tuis pufillis, quas Pancratium aftruebas.

$$
P A N C R A T I V M M A R I N V M \text {. }
$$

VT Panaces doloribus placandis, fic ad cunetos morbidos affectus profligandos promittit auxiliü benè ominata noméclatura Pancratii, qux tamen Scillæfpecies maritimúfq; bulbuseft. Siquidem plurimú toto littore illo, $a b$ Aquis Marianis ad vfque Norbon $x$ vrbis maritima, (xpius vidimus \& eruimus. Radix Scill $x$ cú maxima, quanta maximi Lilii aut Arancii vel Limonij, corcice Cxpx obtecta pullo, intu s candida Scillæ modo. Sabulo arido vndis alluto merfa fefquipalmum altè, folia feptena vel oftona indidé erumpunt, rigidula furrecta, latitudine \& crafsitie Iridis ferè, nigriora, fummis retura non acuta. Caulis cubitalis crafsitie Afphodeli,fed tencrior, qui extremo flores ternos quarernófue cãdidos Liliaceos narcifsilutei modo promit, qui defluentes relinquút filiquam

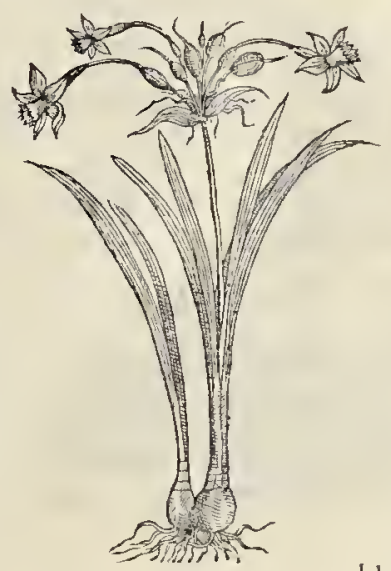

oblon- 


\section{STIRPIVM aduerjarianoua.}

oblongă, Ariflolochix Clcmatidis finilidudine, \& feminc comprefio, fed nigro. Radices his omnibus albx, non rubre, quod accidit regionis fitu \& Superum afpeetu, vt in floribus Rhododcudri, foliis Cyclaminis, vitis, Caulibus, Atriplicibus, Betis, bulbis, Crpis, \& Scillis iftis Hifpanicis, vt Pharmacopoxi Antuerpienfes fatis norunt. Littoris incola pifcatores \& prædones raptu interdum victitantes, rati hanc effe Cæpe,voratam ex fale \& pane, quanuis famelici, hanc naufeabant.

$$
\text { A SC ALO NIT IDES, antiquorum Efcalottes Gallici. }
$$

ES C A L O T T A Gallicas, quas antiquorum Afcalonitides fiue Paleftinas capas arbitramur, peculiarem quandam naturam vcl figuram habent, vt etiam Theophraftus monet, fiquidem ancipitis \& dubix naturx inter capam, Allium \& Porrum, fumiliores tamen cxpis, fed multò minorcs funt, \& crudi in Ientaculis lautiores frequentioréqque: SEI A N I V S eapropter francigenę Appetis, vocitant, quia edendi cupiditatem renocent. B v I I v s
Buté S E T A I Y S, quem Theoph.\& Pli. Cape genus quoddam teftantur.

$$
S C H O E N O P R A S O N \text {. }
$$

$\{$ Belgis, bieflooch.'

$\{$ Ger. Bintzenlaúch, non B:ifzlauch, quod elt featie.

I V N C E A illa, quam perperam Commentator Theophrafti Afcalonitidcm fue Paleftinam dicit, minima fefquipalmü alta eft, pufillis Porrace is bulbis obloggis fectilibus finul cohęrentibus \& implexis pullulat, \& fata fafciatim magno femper ftipatu capitulorum Allijvrfini modo prouenit in hortis vbique,adeóque porrum effigiat, vt quibufdam veri Porri non folum vicem expleat, fed opinionem faciat, fore perpufillo Iunci vel cape. Crudæ huius folia ace tariis guftum gratísimum addüt. Bulbuli, qui exutis tunicis, vniones imitantur, videntur apud Gallos nomen feciffe cxteris capis, quas illi $O$ tgrons vocant Germani Biefauch, quafi Iunceum Allium vel Porrum.

$$
\text { PORRVMCAPITATVM\&SECTILE. }
$$

$$
\left\{\begin{array}{l}
\text { Angl. Inke. } \\
\text { Ger. Iarch. } \\
\text { Gal. Porreau. } \\
\text { Belg. Paraye. }
\end{array}\right\}
$$

PR A s I v M à colore dictum Gracè, \& Latinè porrum à callofa Porri capitis fimillima in ofsibus ferruminatis concretione coniectamur. Non modò eft hic bulbus Crpacea affinitate, fed etiam cæpe, tunicarú inuolucris demptis, interius capitulum cor vocatum refert: ncc foliis, floribus, caule, aut femine, quod tamen elt pullum, differunt. Sapor idem \& facultas, fed mitior calor, efus in olere frequens vbiuis.

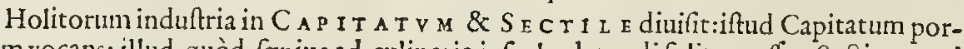
rum vocans: illud quòd fxpius ad culinaria iufcula detundi folitum eflet, Sectuum vel tunfile dixit.

$$
\text { SCORODOPRASON, fHe A LLIPORRVM. }
$$

VT vocabulo fic effigie Porri atque Allij mixtam plätam fignat Scorodoprafon, quod fanè non admodum abludit ab Ampeloprafo vel natalibus, vel facultatibus \& $\&$ lineamentis, magis tamen fpirat allium : fed exprimit propuis Porrum, ni memoria labat, quod in cliu ofis vinetis \& incultis ericetis Lygurum, Niczque Sabaudiz fpontè na-
tum memininus.

ALLIVM 


\section{STIRTIVM aduerjarianous. \\ A $L L I \cup M$ Satiuum vel domesticum. \\ SeAnglicé, Barlpke. \\ ZGerma. Gartentinoblauch.}

K ORO OD O N adeò nobilitarunt odor, fapor, cfus, virćfque medicatx, vt nulli non Fufch effig. Stuerit femper notifsimum. Vibtat namque halitum quendä $æ$ ftuofum, atq; tædiofam 428 . acrimonia faucibus inurit, edendo:vaporéfque excrementitios ad cutenı pellendo 1 'an-

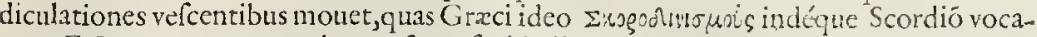
runt. E Crpaceo genere, cui accenfetur, facilis dignotio:ctenin gramine ü cxpaceñue fo lium, flos \& femen in caule inani, tereti, bubo exiliore emittit ur, for is dilutè purpurätibus membraneis cuticulis, nucleos multos vnà coactos fpicatimque coagmêtatos inuoluentibus, è quorum medio vertice fibr $x$ tortiles \& graciles porriguntur terra runtur.

ALLIVM SYLVESTRE tentifolium.

$\left\{\begin{array}{l}\text { Germa. Woilder Fnoblauch. } \\ \text { Angl. 2ollde Gatlos. }\end{array}\right.$

FR r g r is calidifue pratis, macilentis \& aruis Sylueftre pafsim oritur inuifum alicu-

bi, vt in Brabantia \& Francia colonis, quiz fegeti innatum tritico pratum odorem \& faporem cómunicat, quo deinceps tum frina, tum panes unbuuntur. Pufillus, oblon- Fufcb.l 29 . gus bulbus, non ex nucleis conftuls, fed vnico lauque capitulo, nonnullis interdum adnatis minoribus fefe propagante: Iuncea panca foliola in gracili, tenui, pedali cau: le:fore \& femine cateris non difpari.

$$
\begin{aligned}
& \text { A L LIV A V RSI NVM Latifolinm, fiute } \\
& \text { Moly Hippocraticum. } \\
& \left\{\begin{array}{l}
\text { German. Waldinob!surb. } \\
\text { eAnoli. 12aultits. }
\end{array}\right.
\end{aligned}
$$

NOR в ON in editisfyluofis, Trancix verò \& Anglix vmbrofis vel vdis pratenfibus Inter Icones

frequentifsimum, magis tamen odore quàm habitu præferens Vrfinun Allium Fuch.43l. vocatum, quare Moly Hippocratico fuffecinus, Lilii cóualliu vocati eft fermè foliis, minoribus, viridantibus, flaccidis, politis in tenellis caulibus, Hyacinthi minotibus. Hores lactei, ftellati complures Ornithogali vel Afphodeli, bulbus aliquot nucleolis oblongis fparfis candicans odorem Allii tadiofum fpirat, guftantíque faporem acren, non in: gratum prabet. Vires Theriacales \& imminentiun norborun loofes inibi diximus.

$$
\begin{gathered}
\text { ALLIVM LATIFOLIUM MACULOSUM } \\
\text { fine Serpentinum. OPHIOSCORODON. }
\end{gathered}
$$

O R r \& habitu non ita huic abfimile, Ophiofcorodon dictum à caule, foliiff; Serpentarix modo maculofis, qux tamen proximè Vrfinum deliniant \& redolent : rádicis ceruice longiore, rimofa cute obfita,montofis oriunda.

\section{MOLY DIOSCORIDEVM PVTATVM.}

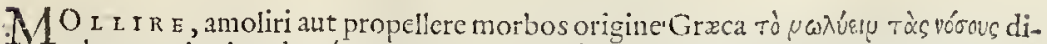
cebant antiqui,vnde $\mu \omega ́ \lambda v$ vocabulü Superûm nutu \& ritu Deorum inditum plantx Poëtx canunt: Moly vocant fuperi, radice nigra tenctur. Verum ill ud non vni, fed pluribus poftea accommodarunt plantis, vt infigni quopiam odore, vigore, \& figura, non ita difsimili, donatis, vt Rut $x$ Harmalan, fiue fylueftri, cui radix nigra, flos cardidus autore Diofcoride. Peculiare tamen fuife certum eft planta buibofx, Alliiq; fimiliori, indicio eft $\mu \omega \dot{\lambda} \nu\{\alpha$, qua Hippocra. Galeno explicante, aliifque, Grarcis $\lambda$ llii caput, eft is antiquitùs celebris ad venenata, adeoque fafcinationes, non fecus ac Moly, cui for tè nomé mutuatî eft : nam Diofcorides inquit habere quippiam in cacumine Allii figura,prater re- 
6o STIRT IV $M$ aduer farianous:

Jiquam fimilitudinem, qualis videtur ea quä Itali patanini \& Bononienfes iamdin,nunc ctiam Belge geminä Moly fpeciem alune, cui bulbus exigums, oblongus forme Porrialbicans, Triticess aut Gramineis folis, flos in cauliculis cubitum altis lacteus Ornithogali aut allij vrfini xmulus, femen in filicua, iftud Diofcoridis faciunt.

N $O L Y$ Liliftorum Homericum forté.

T O Ia E R I C v M verò putant alterú qu od bulbo donatur, Narciffú, Cxpéue Afcalo-

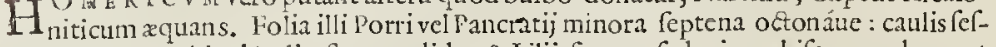
quicubitalis aut bicubitalis: flos candidus \& Lilij figura, fed minor:hifce nos donarat Trenifanus Patauius Doctor.

\section{HIP POCR ATIS Molyin Allio Vrjmo.}

Angl. atamfong.

A N Sitallium Vrfinum Hippocratis Moly, cuiufmodi Galenus interpretatus videtur,

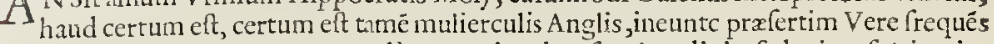
cfitari i $x$ quafi amuletum non modò corporis aduerfę valetudinis, fed etiam falcinationis auerruncandx auertendæque caufa prafumi, tametfi intinctibus non vulgarem init cum plebccula gratiam.

\section{$L I L I V A T C A N D I D V M$.}

nģinos

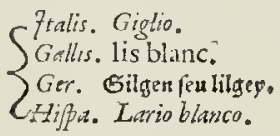

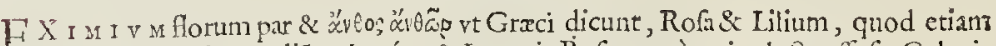
cecinêre Veneris gaudiü volupéne \& Iunonis Rofam:vt è cuius ladte effufo Galaxia via fiue lactea in $x$ there, Lilij aut fios fidereo candorc uifendus in tellure diuinam duxerintoriginem, cuias indicium effe perennem illam gove efiluuiumuc, diuini, quem halint, odoris, vnde Rof rox \& $\lambda$ éş́ $^{\prime}$ oy fuaue, blandum aut concupitum fonar, compluréfque flores \& bulbaceas herbas notat, vt Narciffos, hoc tamen nomine fignatur perquam nobilis flos Francigenis fceptris aufpicatifsium Symbolum, intaminati candoris fulgens honoribus, fapientis Solomonis folı infidentis gloria magis confpicuus. Recto námquc caule \& eręto Haftulx Regix, bulbo nucleolis fquämatim compasto,foribus concolore. Folia pallido virore nitentia, carnofa, fecundum longitudincm ftriolas habentia, rotundus caulis cubitalis in cuius fummitate $A$ fphodeli flores aut Croci, fed ma* iores, candidi, odorati, fenis vt plurimum foliolis difpofiti tepandis, effigiem quafilli vel nolx exprinétibus, fibræ è medio Croceáne ftanima educütur, vt in Colchico:vniuerfa planta mucagineo turget fucco, immenfi tota commodi modica, eftque vna è bulbaceis rotasima.

$$
\begin{aligned}
& \text { L I L IV AI Purpureum vitrumgue, fue Chymifarum Mitrtagon. } \\
& \text { S7tal. Giglio Roffo. } \\
& \{\text { Gal. Lis orengè. }
\end{aligned}
$$

Cor or e s lilio candido quafitos mangonio fuific \& fi ex Rei Ruftica fcriptoribus Plinius affeneret, tamen purpurei lilij duo gencra fpontè non arte oriri cum Diofcoride quàm plurimi monies hodie teftantur. Verum nihil ab illo prorfum difsidere videntur nifianguftioribus, longis, obfenriúfque rucntibus, \& numerofioribus, quibus donantur foliis. Nec flores difpares à candidis, fed hilari in flaum corufcant purpura, nonnullis rubiginofis maculis afperfi \& lineolis intus nonunllis infcripti, yt in iride : bulbi etiam fimiles, fcd luteoli aut pallentes.

$$
L I L I V M T \text { Purpureum mizus, }
$$




\section{TIRPIVM aduerfarianona.}

E A D E M fermè, fed minor, minorique elcgantia hæc purpurea planta, paucioribus floribus, Lilij diuifura, \& bulbis iifdem, infrà, fupraque quos appenduntur fibræ plufculs.

\section{LILIVMMONTANVM。}

$\mathrm{R}$ A D I CE ac buibo haud abfimili Lilium frequens montibus oriundum, fed caulis procerior, quàm Purpurei lilij minoris : è geniculis folia exerens ftellatim Gentianelix magnitudine \& figura Lilij, purpurei item flores vel afphodeli, fed ad extrema pediculi apiculis reflexi, vt in Cyclanine. Color ferrugineus, pufillis variits notulis, purpus reis ftaminibus concoloribus foras prodeuntibus, 3 reflexis deorium:

$$
\begin{aligned}
& \text { HE MER O C A L L I S, fue Sylueftre Lilinm. } \\
& \left\{\begin{array}{l}
\text { ftal. Giglio fatuatico. } \\
\text { Goll. Lis faunage. }
\end{array}\right.
\end{aligned}
$$

S I cui libet accuratiùs expendere Lilium \& Hemerocaliidem, certò conftabit nihil

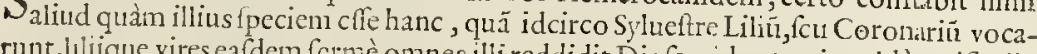
runt, hlilique vires eafdem fcrmè omnes illi reddidit Diofcorides : qutin valdè verifinile fit,quod Lili um Purpureum in Syria orirs auditione acceperat, vnum faltem ex hifce tribus hic defcriptis fuiffe. Nulla igitur magis accedit Lilio aut Hemerocallidi Sylueftri, quàm primum illud Puniceum, feu Phœniçeum, purpureńmue, cuus etiam bulbos eadé pofé, quę Diofcorides vult, fcimus:iụ̣́; vocitarüt meritò $B$ Y L B V M C R V E N T V M, foren Liliaceo \& Purpurco Hippocratis, eóq; vertendum non palliảum valdè, fed ochreŭ, cuiufntodi videmus in Ochra faturaci lutei, que putpurex aut phoniceę Anagallidis colore vifitur. Hinc fedulitas \& candor Commentators Senentis, quantus fuerit, meminifie inuabit, qui vocis huius ignarus, planfrii magis, quàm cognitioni verę fudĕs, phceniceum Lilium valdè ahoquin norü, dicic effe colore perquam pallido, Diofcoride falfò tefe addueto. Ecquis color eft perquã pallid us, nifi fit albus, ctu proximus palleus aur pallidus? Lcuiufcul momenti cftargutatio illia de appendiculis \& f forú numero, quę nonnulli defiderare videntur. Sed $f_{1}$ quis animaduertat Lilium candidum interdum cxortus iftos facere, in quibus cóplures tores congefti interdum finguli funt, non magnopere refragabitur. Cxterum folia quod longe plura purpureo ifti ineffe dicunt, id accedere cultu verifimile fit : quippe purpureo vtrius \& montano mulio panciora funt. Eoq; fi cui horŭ vtrumuis magis pro Hemetocallide allubefcit, per nos liceat fane. Iftud tamé poftremū montan̄i nolim Liliú coronariū , aut Hemerocallidê fancire, quia nefcio quid tetri aut virofi halat. Quod huius vero floré Athenęi conuiz tabefcere Sole cadéte 8 rurfum oriente pullulare dixcrint, fic accipiendü: non quidēe prorfum marcefcere aut defluere, fed occurfu humentis noctis \& frigidıufculę contrahi collabique in fefe forcs, qui proxima luce \& rad is Solis collufteati, explicantur, \& quafi reuiuifcunt,
veluti Tragopogo, Solifequiis \& Heliotropiis cxteris accidit.

$$
\begin{aligned}
& \text { LILIVM CONI ALLIVM, velvernum Theopls. } \\
& \text { SGermanis. a17eybluombim. } \\
& \{\text { Gollis. Grand mugnet. }
\end{aligned}
$$

I T I D E M hanc pcramonama afpectu \& odore pufillam herbă antiquís Gracis indictä, Lilium Conuailium vocauit recentior $x$ tas, putaruntque quidam Lilium inter fpinds memoratum in Salomone,propter folia, fuaursimum odoré, etiamq; florem Lilij, qui niucus,pulchellus, Lilij fimilis quadātenus, \& odore fuanifsimus, Maio prafertim inter fenticofa nemorum, vmbrofáq; conualliŭ emicat, eóq; Germana plebs vocat nzeienrisłf Prodeût è caule palmú al to exiles medio fúmo tenus in pcdicellis nolæ Cytiníue pufilli, penduli, niuei, in fumma ora crenati, reinquétes bacculas rubellas minores 110 ó difsimiles Afparagi, duriufculas, amaras. Folia lilij, Allij vrfini, autSatyrij lauore viridätia, bina aut terna: radices reptant exiles, geniculatx. Hortifque nota \& expctita planta $\mathrm{Fi}$. 
pari nonine \& commendatione, eóque nos inter Lilia inferuimus, quando alicubi conuenientiùs non potuimus.

\author{
$T E S T I C V Z I$, fue $O R C H I D E S$. \\ Ital. Teficolo dicane. \\ Cynosorchis. $\quad$ Hip. Coyon de perro. \\ SGer. Knaben frant. \\ Gall. Couillon de chien.
}

E A D E min generis tribn cum bulbis, Cxpaceis, Hyacinthis \& aliis plerifque reponen$\mathrm{d} \boldsymbol{x}$ Tefticuli differentix atque Satyrii, que longè plures funt, quàm quot prifcis memoratx : omnéfque ab effigie radicis Orchis, ab effęqu nonnullx Satyrix vocatx, quòd Veneris incentiui effent prx catcris bulbis, vti poltea apud Latinos Plinium \& Apuleium Venerei dicerentur : è radicis tamen bulbo inita eft diftinctio.Vnicus namq; bulbus Satyriis eft, geminus vel didymi fpecie orchidi, quorü Caninus, vulpinus, \& Hircinus funt \& infigniores indidépetitz varietates. Opacis, filuofis, \& fabulofis, vdifque pratis pafsim peruix. Cynoforchis varietas multiplex: omnium notifsimus magnitudine, in pratis frequentifsimus riguis primo pullulatu fpeciem Ellebori erumpentis, vel Colchici, deinde Lilii couallii, aut vulgaris folia exciit tema \& quaterna, lenta, craffa, \& mucore turgentia. Caulem vero fefquipedem longum, glabrum, nitidum cauum in fummo, fpicato flore conficuum, odoratum, purpureum, maculis albicantibus, atque pullis variegatum, Radix geminis conftat bulbis effigie tefticulorum, quos quafi pubes fupernè multz ambiunt fibrx, quibus, non fecus atq;ipfa planta fuperior, bulbi alinoniam adipifcuntur, $\&$ alternis perennem: alteri nempe iam flaccido $\&$ vacuo, al tero fuccedente turgido \& fucci vifcidi limpidi pleno albuminis oui, quafi foret femen genitale, magnitudo quanta maior dactylus, interdum nucis inglandis adulto: vieto veró, $\&$ rugoro multò mino: \& fitus inferior. Dulcis fapor, mucagineus, emplafticus, infulfus, color candidus, pellucidus.

Difcrimen huins \& varietas obferuatur in magnitudine \& folionum numero, quod non magni eft momêti ad obferuandủ \& cognofcendũ: aliquãto maioris iftud, \& cuidétioris: aliud eft foliis maculatis \& paucioribuslongioribus neruulis: vnde maculatü vocis licet cxtere diftin tiones obfcurę nifi exercitatis, nec ita v tiq; côftantes funt, vt certū quid genericæ differentix it atui queat. Colore népe rcmifsiore, dilutiore, vegetiore, mixto variegato, nitente, languido, paulum quid diftantibus item tefticulis \&- folis, primùn Cynoforchin intuenti offerentibus, iifdem natalibus Sole Gcminos ingrefsuro florét omnes.

T E S T I CV L V S Hircinus, fen T rezorchts o leporistefticulus,

$A$ commodiorem notionem vnam è fummis differentiis conftituit tefticulus Hircum olcns \& f fyrrillis aruncis barbā caprillä cmentiens. Iifdem locis crit foliis pluribus, \& itidem liliaceis amplexatis imü pedalem caulem, leuẽ à medio fummo tenus, perpulchra feric forum fpicatum vtriculis vel galeatis floribus, qui dehifcentes caudicellam finguli fingulä purpureis diftinfam punctis, cuneti Hyrcinx barbx aruncos cirrórue effigiantes, obtincnt: odore graui \& virofo: femine pufillo in capfulis, hæc huius vnica differentia.

\title{
VVLPINI TESTICVLI.
}

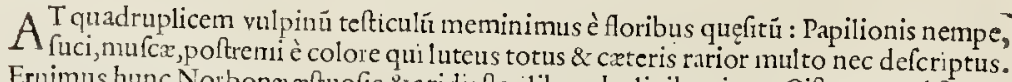
Eruimus hunc Norbon $x$ xtuofis 2 aridis fterilibus, decliuibus inter Ciftum marẽ \& xllicem Cocciferä,prope fpecū vaftam, qux redeunti Frontignana Monfpclliă lxua eft:etiāque in herbidis aridis Gränuntię fylux vicinis. Iftis verò minor, qui foliis paucioribus binis népe aut ternis caulē fpithameü imú ambientibus, fummü foribus luteo fuluis paucis Afilonem aut potius Fucí colore $\mathcal{Q}$ effigie pre fe ferentibus:exigui fubfunt bini tefticuli.

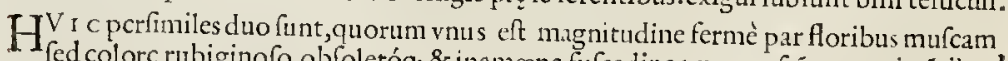
fed colorc rubiginofo,obfoletóg; \& inamoena fufcedine purpurafcéte, exprimëtibus'. 


\section{STIRPIVM aduerfarianoud.}

A L T E R maioribus, latioribus folins Phalangineis, venofis, rcpandis, reflexis:caule in tetdum palmari, mecedum fefquipalmum alto, nonnihil purpureo:lloribus colore ita afpectu fodo non difsinilıbus.

Dıfcernitur facillımè poftremus foliis latiufculis, \& toto caule apprefsis, floribusịpapiliones volantes, alifue pafsis fe librantes amuiantibus.

\section{TESTICVLVS ODORA广்S.}

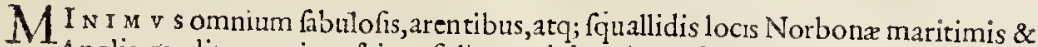
Anglia mediterraneis nafcitur:folia exerit breuia, pufilla \& fubpallida, venofa vaa collecta mirtoris Plantaginis : cauliculum palmarem, gracilem \& forculis odore Lilij conualliú \& involutx modú claniculatim caulé ambrientes:Bulbı pufilli, vt fuperioris.

$$
\begin{aligned}
& P A L M A E \text { dux Chrifiades. } \\
& S E R A P I A D E S .
\end{aligned}
$$

$H^{I} s \mathrm{c}$ accenfet Triorchim Serapiada Egineta (addere enim tertiam quandam videtur) tcrno donatum didymo, quem alias Palmam Chrifti opinabamur: tum qua fucculenta minùs, ficciorq; eft, \& vehementer deterget intro, forifíp; vlceribus adnota: tum etiam quòd Melancholicis, Quartanariis, Epilepticis, neruorum offaretu \& pituitofa faburra opprefsis mixam proilet opem, fluxum dyfentericum fiftat, quot qualéfq; Pahmx Chrifti recentiores vindicant (ne cuiquã imponat Palmx Chrifti veheméteí purgạ̃tis homonynia) diguandas fanè Ægyptiis Venerädx Serapiadis dcæ Augufto cognomine : alio quin nihil attinuit à cæeteris fecrauife, \& Serapiadas nutcupalfe. Rationibus hifce fauebat ex lectione coniectura, nam vbi morixpнsop multi vfus, Icgendum

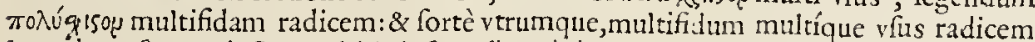

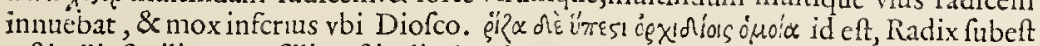
tefticellis fimilis aut pufillis tefticulis, legeban multifida,leuiore methathefi multò, quá in fuperiore capite, vbi pró olea fuffecerunt meritò quidā Squillam tencram pancratiū. Verum tamen fi cui hx minus allubefcant Serapiades, exploret fuperiorum Orchium facultates, qux multò tamen ignauiores \& mucorc elumbes magis videntur, aut alias ap. tiores adducat, \& lubenter vltrò indįtas iftas palmatas antiquis profitebimur.

Herbidos pratenféfq; colles frigidiores annant tum minor tü maior, legimus etiam in alpinis Rauffburgi \& Nozoreti Germanię. Maio flore \& folîs exit : maior foliss fimilibus, fed latioribus porri mucronatis, ad terrā reflexis, crafsis, interdü maculatis, fufcis, \& nigricantibus notulis: flores purpurafentis cynoforchis adcò fimiles funt, vt nifi propiùs fpectes eafdem putcs. Radici itẽ geminus eft bulbus, al tero cuanido, al tero pregnãte \& fucculento, vtroque tamen oblongiore, nonnihil compreffo, \& ima fui parte in fibras inæquales ternas aut quaternas veluti digitatas abeunte. Hunc marem apellant.

F œ I N A verò floribus candidis, vel è purpura rubentibus, dilutéue cxrulcis cuculatis crebriores maculas purpureas, \& rieum oftentantes habentibus: foliis minoribus \& infperfis punctulis:radice confimili.

$$
\text { MINOR ORCHIS ODORATUS. }
$$

HV r v s fuauem efllant odoréfores mucrone fpicati, purpurei amuranthi, qui foliis augutioribus, porraceis, vel croceis, caule palmari \& leui, radicibus minoribus dumtaxat differt, vtraque radix orchin odorem \& faporem dat guftanti, \& Diofcoridiad eadem facit, minùs tamen modeftè facit Senenfis, qui hærentibus ant inficiantibus citrinos Digitos Auicennx effe hafce Monachis conuiciatur, nullamá; allatam rationenı cōqueritur: cum ipfe nè vmbram quidcm adferat vllius. Et vires Digiti citrini huic afferit, magno in commodo oorū, qui fidem forent fequuturi: Citrini veró fuêre Hermodacty. li, vt nomen \& color docent.

$$
\text { F.ii. ERITHRO }
$$


ERTTHRONIVM.

T. O nultis ab hinc annis innotuit bulbus perelegans, cui amici noltri Satyrion nomen fecerunt, is confultis Medicx materix Lugdunenfibus, qui condicudum curafient, \& exploratum habuiffent, vifus eit Diofcor . genuinus: multo quidé periculo factò códitæ multan copiã Lutetiam, aliáfque Gallia vrbesafportatã Ccimus, nulla interim defiderata nota preterouá coloris, qui valdè variat loci varietate, vt in Squilla, Cxpis \& aliis bulbaceis videre eft. Allij vrfini, aut Lilij fimilia folia bina, plurimum terna in humum denexa, minora:caulem tenellum palmum altum, nudum humi foliis tenus merfun \& Cyclaminis modo pediculum porrigentë exilem,flexilem:florē Croci vel Lilij, radiatum ex albo purpurafenté: radix dactylü xquat \& affinilat, Orchidis concolor, cui nönull $x$ fibrillx appenfx funt, \& pufillus femirotundus compreflus bulbus exiguus lateri imo hæret, aut fubeft, vti in gladioli radice videre eft. Lugduni florcbat Aprilı in horto Valerandi Donre z è Iura, monte cuius fedulitate primum nobis innotuit, eruta Alpibus Lemano fuitimis : \& poltea in collibus Taurinenfi Padoféquileucam difsitis, candem eruimus,

\section{$S A T X R I O N E R Y T H R O N I V M$.}

DV, m effemus venetiis, fuperioribus annis, vidimus nófemel in Angeli Symbolo Alberti Martinelli officina, radices fubrotundas, magnas rugofo tuberofóq; cortice ex fúćco rubello, effigié \& magnitudimé Cyclaninis vel potius Ariftolochiæ rotōida \& pragrändis a/fequutas, carne intus albida cduli, dulci \& Bulbocaftano bunio dicto adeo actedente, vt eadem, nimirum folo lætiorè \& peregrino enutritam, fufpicaremur. Sed illiłò Martinellus aliquot milfas Alepo Syrix à fratre Cequino, qui vt erat explorator nó minus auidus, quàm peritus exoticarü firpin̈,Erythronium Satyrion iudicabat.Harum vaã celebris ille Leo Scamnidicus magnus. Marci fori Vencti tympanum, popularis philofophix, cuius nec impericus, nec parü ftudiofus fuit, amatns aluit aliquãdiu, cuius folio Ia minùs prodere audemus, quia parŭ meminimus. Earundé Iaco bo Cortufio alteram dedit idế Phamacopocus, quã multò pòft, quấ uunquã vidiffemus, munificus ille Patauinus oftentabat nobis, \& penè inuitis rifum excuticbat, qui diceret fe manibus dumtaxar attrekando totum turgere Venereis libidinibus. Hancipfam Mathiolo poftea mifit, nou Cequinus, vt audiuinus. Is folitus namque fuit etiam minus peritis quantum poterat, plenè defcriptiones addere rebus peregrinis, qux in Mathiolo nullę nifi ra. dicisfunt.

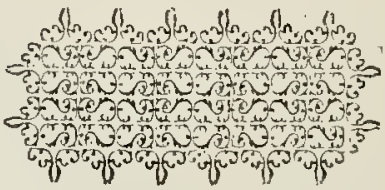


STIR PIVM aduerfarianoua.

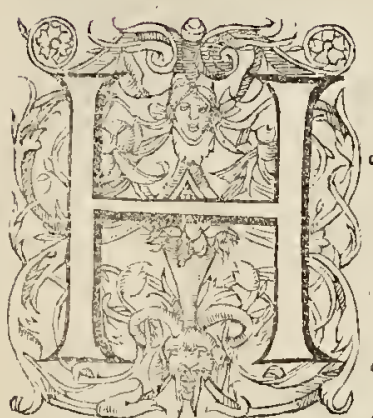

ACTEX VS comparando quot potuimis plantarum genera, guarum effigieses nature ordinis confequntione ita fibi mutuo bererët, vt \& facillimè nofcerentur, \&o memorice mandarêtur, a'Gramineis, Segetibus, Harundinibus ad Acoros, Irides, Cyperos, bincq, Aipbodelos bulborum tuniceorü Cepaceorumwe naturam preterueeli Jumus. Ac eorü quidem maxime parti folia confimilia, uniumodimucronata, angufta, rigida, nec uppiam intercifa erant, iam verò fuperfunt alia Tä fine latinis capitatorumillifque confimilium genera, vt plurimum Imuata é laciniofa, que ipfa \& quia bolera maxima cxparte funt, er cuilibet ad cognofcend ï inoculis, ad vefcendum in cibis quotidie’unt, non incommodè illa expediemus, nufquamalioqui aptiorem locum nacturi in uniwerfa plantarum familio.

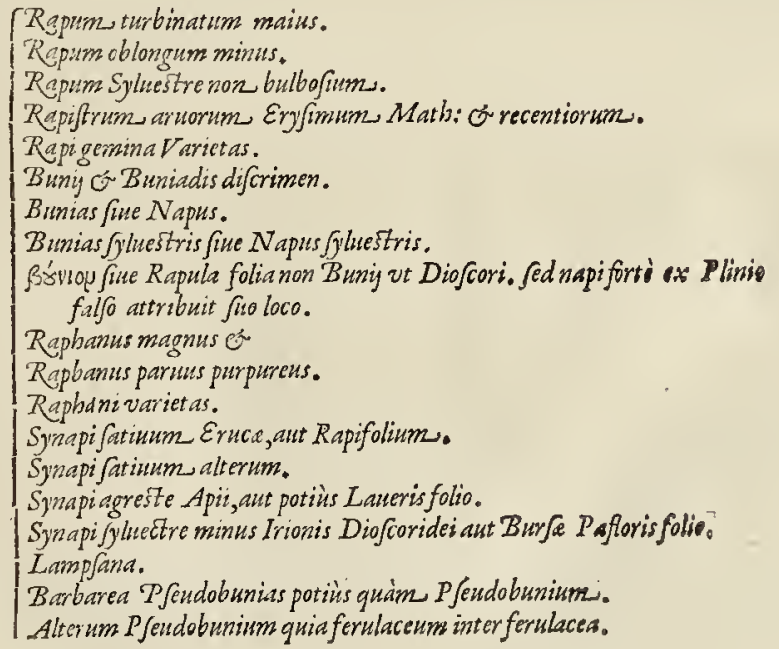

F.iij。 


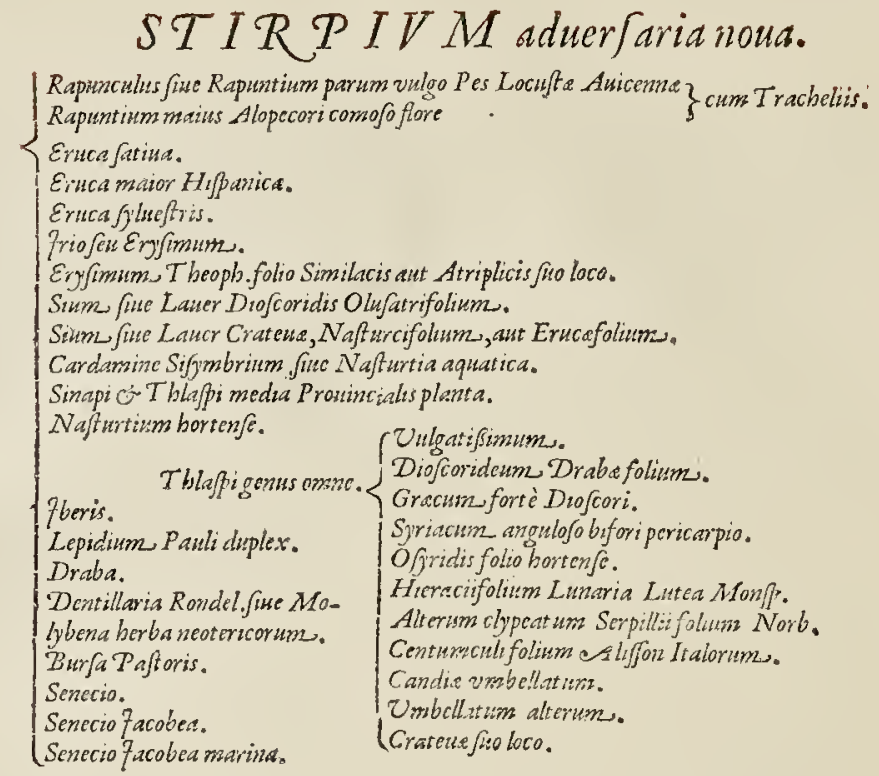

MAIVS ORBICVLATYM, fenturbinatum Rapism.

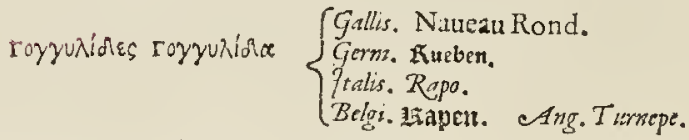

CV r r i в e tregioni abundè crefcit Raporum omne genus, quod Graci vna voce defignarunt roy yudiólos, qux rotunditatem orbiculatámue globof radicis figuram docet, vnde notitix eft plebeix, inque cibosegeftati amicos per Hyemem multum accommodum, crudum, \& coctú. Fronde perampla, laciniofa Erucx, aut potiùs Rhaphani,etia filiquis adcò fimile, vt radice globofa, Horibúfque lateis, \& minore femine, vt Sinapi nigricante cxceptis, eadem putcs. Radice dumtaxat à fuperiori diftare videtur, qux tcres atç; rotüda oblongior
eft, \& Napo finuilior cffigie, fed maior triplò, etiam vbiuis notifsima.

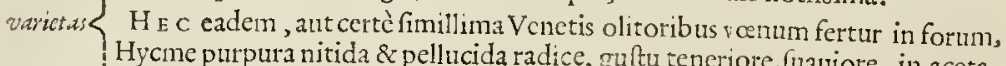
Hycme purpura nitida \& pellucida radice, guftu teneriore, fuauiore, in acctarris cruda cum Eruca, Laeuca, \& aliis illic elitari folita.

RAPVM STLFESTRE non bulbolum.

ES r ctiam frequentifsimu Syluefre Rapum, prafertim apud Flandros, Germanos,qui ferunt hoc, quò folia bobus pabulo cedant. Luxuriat enim tanto foliorü numcro, vt radix iam non tuberofa aut Rapofa, fed exilis, nec ventriofa vfuiam fit,alioqui fatiux rot idx turbinatx non abfimilis, fed difcretu facilis, crifpiore, rugofioréq; \& vberiore folio.

$$
R A P I S T R V M A R V O R V M .
$$

$E$ R p o R $\mathrm{M}$ fylueftrium confuetiam eft $R$ apiltrum vulgo vocatum, pafim viarum margines \& fegetes ornans, vbique prafertim Septëtrionaliü: flöibus luteis numerofis Brafsica aut Rape, in caulibus felquibitalibus folia infunt Läpfana, aut Rapi Sylueftris, 


\section{TIRTIVM adverfarianowa.}

Brafficx virore \& lxuore, non Erucx, vt debentur Irioni Diofcoridis. Radice, tenui neutiquam fibrofa, guftu item Rapi Sylleftris, cuius facultates propc̀ fortita eft, fed vehementiores, tametfi vius neglecti aut igno:i. Neutiquam oft Eryfimum Diofcoridis:certè admodum affinis eft Napis \& Sinapi : tufum namque femen Sinapi ementitur, \& vfis ex-
plet ruflicis.

$$
\begin{aligned}
& \text { Buv: ¿́s fine } N A P Y S \text {. } \\
& \text { CGerma. Etectruben. } \\
& \{\text { Belyis. Stcrkrapen, a karijfbe Lapen. } \\
& \text { Ital. Napo. } \\
& \text { Gallis. Nauet. Ang.Nape. }
\end{aligned}
$$

Q VE M A D M O D V M Antucrpianum folum, vtpote fabulofum, tuberof $x$ t turbinat Rapx feracifsimü, fic Lutetianum Iutofum Napi fertilisimum.Vtrique plantæ congencr, imò $\&$. fimilis adeò Rapx oblóongæe eft Bunias, vt eadem pror um dicas, nifi Napo folia minus fcabra forent, radixq; media fui parte minùs ventriofa, imoq; exiliore multò efet, fapore funuiore, cibífuc dclicatiore, prafertim Francigena, qux plenis dolis vonú in Belgium eit ferri folita.

$$
B V N I A S \text { STLVESTRIS NAPVS. }
$$

$S$ E c v s agrorum amniúmq; ripas hæc lubens oritur,prafertim regionú frigidionum cu-

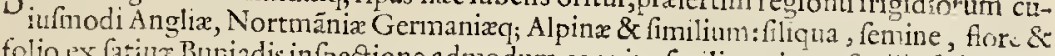
folio ex fatiux Buniadis infpectione admodum cognitu facilis, quia forfinilis, fed minor to ia, foliorumq; profundiore lacinia \& radice rotundiore, breulore, ficum aut Sorbü $\approx-$ quante. Huins napi, aut Satiui femen antidotis \& eximis antiquorú compofitionibus ad- B y N I Y Mă, dendum, vt Theriacx Andromachi \& aliis, non $B$ v ss i f f mé, quod nominis propter radicem rapofam fiue turbinatä Bunij \& Buniadis affinitate multis impofuit, vt Plinio qui vtrăque Rapum appellat, \& Senenfi cométatori admodum ieiuno \& frpius decepto, nee melius in Diofcoridea quàm Pliniana lectione verfato. At Buniü neq; bunias eft, neque eadem figura, viribus, aut clafe cum Buniade defcripta eft, vt paulò inferiùs dicemus.

$$
\begin{aligned}
& \text { RHAPHANVS MAGNVS \& parun Purpureus. }
\end{aligned}
$$

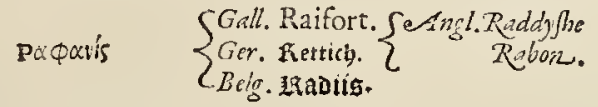

VE I nomêclatura Rhaphani vnde Rapum latinis deductum fuit,indicat Rapi fpeciem cffe Rhaphanú, quippe omnia Rapi habet,fi longiorem,graciliorem excipias radicê, flores fimiles, fed purpura obfoleta, filiquam ctafsiotem pyxidatim effigiatá feminis ruffimaiores Rapi : efficaciormedicamentis, quàm vtilior alimentis, expetita tamen fermè vbique \& notifsima radix.

P I v x I в y s hortis Italix 'prxicrtim rubello colore colunt \& efitant Rhaphanos: vt minores (quod de Rapo Rubro monuimus)fic efu fuauiores, minus acres, lautioréfque ex áqua falita excitand $x$ appetentix, quam cocta prorfim euertit : foetet namioue admodum fiue per fe, fiue carnibus incoeta, tum hæc, tum alba, eóque fale \& de prima V A I I E T $A$ s menfa confultius eft vt edantur.

$$
\begin{aligned}
& \text { SINAPI SATIUUM Eruce, ant Repifolitan. } \\
& \text { SGall. Sencue domeRique. }\{\text { Bels. }
\end{aligned}
$$

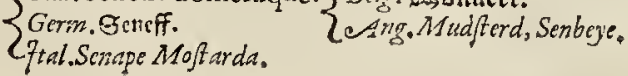

$$
\text { F.iiije Mls. }
$$




\section{STIRPIV M adverfaria nowa.}

$M^{A}$ G I s abeft Sinapi à mapo virium acrimonia, quan fpecie, facie, vel nomine, quod quidem tum liniamenta plante, tum effrenis acrimonia infinuant. Napi enim immite aut vehemens interpretantur, cuiufmodi eft Sinapi femen vrendo, fternutamenta lachrymáfque ciendo:vnde notifsimum fue diuitum, frue pauperum menfis, præfertim fatiuum, caule, fronde, flore, filiquáq; Rapacea,femine minore acerrimo, oleolo, copiofo, aruis mandari folito, non fecus atque rapx. Folia etiam tenera in acetaria veniunt.

\section{SIN A P I ALT E R V M Satinum. \\ SGalls, Seneue blanc. \\ $\{$ Belgis, popt moftaet. \\ ZGerm. Deiffer Geuff.}

FR v c a albo femine eft fatiuum Sinapi al terum, chius vfus Officinis ad comp ofitiones vt Diafatyrione, Elect: de Ouo. Prorfus figura \& femine Napi vulgaris, fed albo maiore duplò.

$$
\begin{aligned}
& \text { SI N API AGRESTEApi, aut potius Lasterisfolia. } \\
& \text { Ggall. Senene faumage. } \\
& \{\text { Ger. Doiloer Eenff. } \\
& \text { ¿Belg. wilden mothart. }
\end{aligned}
$$

HV r v s haud admodum difpar figura aut feminis acrimonia, tametfi folia incifura fitúque \& natalibus,magis Lauerem vel Apium exprimant, nec non ruxibus femen nigrum penuriam fatiui refarciat, quod oftendit forc \& filiquas ad fatorum viarúmque riuulos \& depletas fofius luxuriare folitum.

\section{SINAPI SYLVES. minus Irionis veri follo, allt $\mathcal{B}$ utrfe pazforis}

R I $D$ r s tamen locis iuxta margines, \& rudera, propè vrbes nafcitur, foliis lacinio$A_{\text {fis admodum burfe paftorix fimilibus, fed acutioribus minutioribúfque laciniis. Vun- }}$ bellofi fiores \& filiqux fecundum fummitates Irionis Diofcoridis, caulis pedalis, minorc mul to, fed to ta planta guftu Synapi feruidifsima.

\section{$E R V C \mathscr{A}$, O I RIONES fen Eryfirmi.}

$D^{V M}$ poftremò in Iriones commentabatur Senenfis dichator, augurabatur non defuturos canes ( fic enim modefè omnes etiam fe doctiores folitus nunctipare) qui fe ita ambiguun \& confeum fux hic imoeritix allatrarent. Vtinam habuifset ille canes fimiles non ad laträdum fed vefigandum Eryfimum, quod vel pharmacopocorum Monfpellienfun lixx poffen tilli hodic in trituij \& ruderibus pafsim indicare : eft enim ibi doctis \& indoctis vt vfu frequentifimum, ita multiplici \& foelici fucceffu notifsinsŭ. Ac vt perfí_ cuü fiat vniuerfum hoc Erscarum of Irionis genus, vno nos capte omnia complectemur.

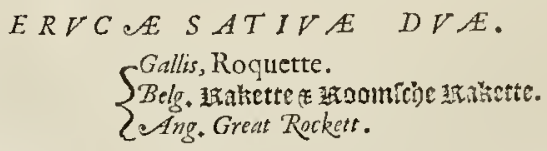

E R V C A SA T I V x dur cibis gratiores \& nobiliores: Maior Hifpanica vocata, à noftrati maiomaior fune $H_{i-}$ ribus foliis Sifymbrii \& femine nigro, foribus luteis, corniculo Sinapi maiore, dittat. panica of $G e n-H x c$ vel quia in condimentis lautior, vel ad Venerem vegetior erat Gentrlis vulgò vocasilis. $\quad$ ta fuit : quo vocabulo Hifpanica \& Itala gens defignat quamlibet rem aptam reddere hominem latum \& experrectum ad munia vulgò paufibilia, vt ioca, ludicra \& Venerem. Qux commoda vt ex ea perciperet Monachorú Saginata „caterua in perquam amoena Magalonx infula maris Norbonenfs, huiws Gentilis Erucx femine a fratre quodam Hi- 


\section{STIRP IVM aduerfaria nowa.}

fpano ambulone donata, quotănis hocce ferebat $\&$ in menfis cuilibet vel maximo gule irritanento vel blandimento preferebat:nimirum vfu gnara quantü frequens efus conferret ad calorem Venereum in ills otio \& frequenti crapula obrutum, ad vigorem an!mi excitandun, \& prafertim corpus obefum extenuandum, fomnumqué excutiendum, quo illi veluti vrfi glyréfue tota hyeme faginati, fermè adipe fuffocabantur. Verum ifto Hifpanico remedio adeò hilarefcebant \& gentiles fiebant, vt plerumq; recinetis lumbis caftitate, coacti effent vota \& cęnobii mcenia tranfilire, \& alıquid folatii Venerei ab vicinis plebanis efflagitare: nobis hæc vifa \& rifa. Eruca verò inibi fuperftes eft copiofifsima, monumentum futura Monafticx caftitatis \& rei veritatis, nec eget vtrauis fufioris defcriptionis, cum vulgaris fit notif sima $\&$ ex illa facillimè percipiatur hifpanica.

\section{$\varepsilon R V C A S T L V E S T R I S$}

\section{Belgis, Doild Hakette.}

SY L v E S I R I serratica fquallido folo vel parietinis passim oriens, Dentis leonis diui $\varepsilon_{\text {r zua fy luefris }}$ priores \& notifsimx Erucx.

$$
I R I O \text {, fue } E R Y S I M V M \text {. Diofc。 }
$$

Anglis. Cadoke, Kedloke.

H I s proxime accedunt Iriones. Diofcoridis Irio, quem medici docti notis \& experimentis commendant, eft radice lignofa, foliis Erucx fylueftris, qux prinu ü erumpentia non nifi ab oculis exercitatis . poftüt à Burfę paftoris foliis difcerni, qux huic non ita viridia, \& in extremo magis acuta funt:illi eryfimo verò lacinia gräd!or \& in fummo rotundú retufiúfue foliü fubpingue, quod multiplex in imo folum opetit. Caulis fefquicubitalis, interdum maior : femen in filliquis Erucæ fylueftris multò minoribus, acre, feruidum: fofculi in fummo lutei. In compitis, fepulchretis, \& ruinofis locis frequens, multis Gallia regionibus notifsimä, fed in Anglia nó i. tem, quamuis nó minùs obuia. Nã ne Medicis quidem aut pharmacopæis peritioribus certü ftat, quană fit Irio: hoc factú, ¥ut quia in vfum Medicū nondü fuit hỉ deductus, aut quia à Mathiolo, cuius có. mentariaplerifq; funt veluti Sybillz folia,

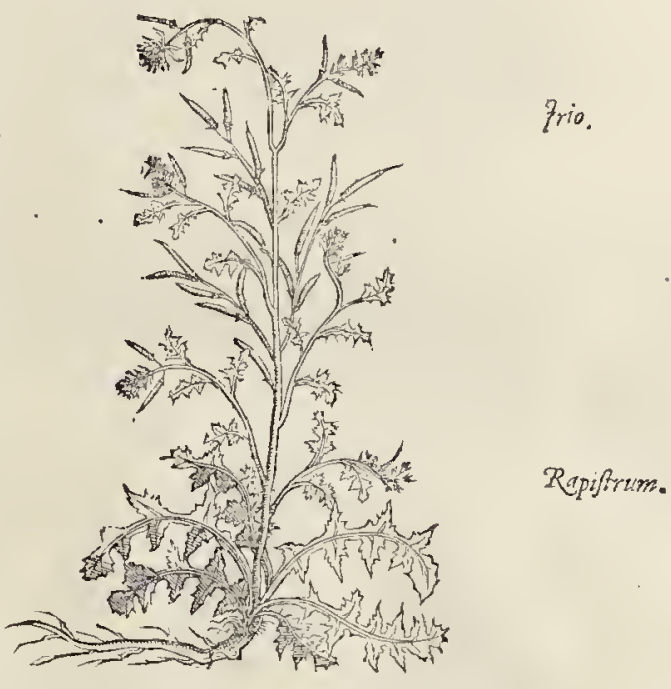
Rapiftrum vulgi à fapore Rapæ, \& nonnulla foliorum fimilitudine, loco Irionis acceperunt. Quod neque Diofcoridi refpódet, neque cum Mathioli erucæ fylueftris foliis $\sqrt{1}-$ militudine init, tum fapor, odor rapæ, nec adeo vt Irionis acris, nec proinde ab hac fpectandx eximi genuin Eryfimi dotes qux afthmaticis \& farctui PuInonum vocícue rauze ctiā diuturnx \& prope imuizx füt adeò præfenti præfidio, vt fidé fermè fuperét. Eft enim moderata quxdä tenuis fubftantix \& incidentis, cum humidis abftergentibus partibus permixtio, cuius beneficio craffx blennoféque pituitx citra exficcationem niniam inciduntur, \& incif $x$ propter flatum nonnihil commixtum non magno conatu expectorātur, \& abfterguntur. Arteriacum igitur eft laudatifsimum, nempe idem vinum prxparäs \& educens. Exempla fuccurrunt quamplurima, qux fecundifsimè tum prxceptoribus, tum nobis poftea fuccefferunt. Phonafcos memini tum inuenes, tum xtatis prouectx, quibus fermè iam amiffa voce \& firitu, limpida fonoráque yos pauculis diebus reftituta 
fuit, vnius Eryfimi \& opera eximii pręceptoris Rondelietij qui primus vfum monuit. Mathioli æquanimitas, quaG fux imbecillitatis cófcia primo fuo lrioni fubdidit aliu in poftreno aıttario, quem pot orem prino putat,quia folia mino:a, \& cornicula paulò vegetiora fint, vt ex iconibus, inquit comentator, patet. Sic nos auidos difcendi huius mutatx fententix cuufam alıquan, vt folitus eft, in ficco deferit. Quid hic folia minora, \& cornicula vegetiora agant, nefcimus:vt vt fit, nos benignè omnia interpretamur, népe tantum virum (vt conftantis \& grauis animi opinionem, quam de fe doctis viris iftis cómétariis excitauit, retincret $\&$ foueret) noluife quicquan demere, aut demendum eile fufpitionen dare, fed humano more \& prudentiu tacitè meliora, qux à meliore tum ft:o tum aliorum iudicio profecta effent, deterioribus prioribus fobdere, ausáque vniuerfum opus deintegro recoquere, Magni Cicer onis exemplo, qui fe dedit recoquendum Molonio Rhodio oratori:id videre hic eft, capite de Męo, Sefeli, Cumino Sylueltri, ac paffim hoc nono opere magno fculptorum \& bibliopolatum applaufu.

$$
\begin{aligned}
& \lambda x \mu f \alpha y \alpha \quad L A M P S A N A \text {. } \\
& \text { jftaitis. Diluendri, of di Lafana. } \\
& \{\text { Gallis, Sanues blanches quafi finapiftrum album. }
\end{aligned}
$$

Erifinz Theop. Dod. Fed fallitur fol. 431 .

F i a $a$ Napis \& rynapi reddenda Lamplana, vt quam olim Romani Napum fylueftem vocarunt, vulgus etiamnum in Gallia Sanues blanches, quari Sinapiftrum album dicit, a foliorum mollitie caduca, decubitúue in humun, quan quia lambere viderentur Lampfana diEta putatur: nifi potiùs fuerit a Lafana matella nempe, fiue'ventris oneri excipiendo vafe contemptus caufa fic vocitata. Etcnim olus olim fuife Lamplanam admodum contemptibile, fed non parum vtile, prafertim plebeculx, pauperum, \& efuritioni militum annona deficiète, vel diui Iulij Cæfaris milites carminibus teftatum fecêre, qui exprobauerunt ea fe vixifle apud Dirthachium præmiorum parcimoniam cauillätes, vt narrat Plinius, qui olus Sylueftre pedalis altitudinis trium foliorum Napi fimilli-

T amorun candidiore flore \& in cibo coqui eam defcribit:vnde fatis liquet effe iftud olus

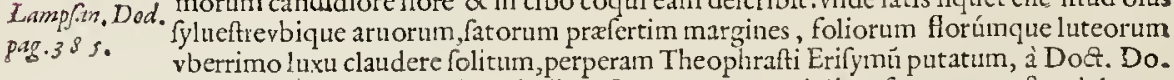
qui aliam plantã parietinis, ruderibus, \& aruorum marginibus frequentem ftatuit lampfanum. Sed neutiquam eft hæc Synapi Napis aut Brafficis congener : potiùs Hieractis, floribus nimirum luteis ftellatis, non braflicx. Folia item Cichorij fylueftris Hicracii laciniis fefquipedem \& binos pedes altos, grandes canles è fibrofa radice exigua emittic, femine pufillo, ncc vlla fui parte planta in olere mandi putamus. Eapiopter vera exiftimanda lampfana rapiftrum poft Rapas fuperius defcriptum, vt quod per egefatem in vus venerat, \& è cuius floribus apes mellificant \& oblectantur, qualem intellexit Columella Lampfanam. Senenfis verò comentator interfertis alienis plumis, ac multis Plinij verbis ambiguos ipie ambiguus, quod ft atuerit nos deferens, enolat. Cum f.ltem fuit nudi recitatoris plantam quam intel'exit verbis exprinere, \& boni commétatorisexplicare, non truncare verba Plinii trium foliorum fimillmorum Napi, quibus videtur Plinius innuere cum Iriones \& Napi huic congeneres mult is foliis infternant operiantque humum, Lampfanam vt plurimú tribus folits extremis cefpitem tangere ant tegere, eaque nota yocatam fic effe, \& ab illis difsidere.

$$
\begin{aligned}
& \text { PSEVDOBVNIAS potilis quam. } \\
& \text { PSEVDOBVNIV } A, B A R B A R E A
\end{aligned}
$$

fue Herbas, Barbare vulgi.

Liyfo.dod.43s. P O s e a quam docuimus plurimùm abefte Buniumà Buniade in promptu cuilibec eft, Barbaream vulgo diçä neutiquả Pfeudobuninm effe, fed potiùs Pfeudobuniadēfi cui libuerit, dici poffe. Eft quippe incifura, nagnitudine, floribus, \& filiqua Napi fiue 


\section{STIRP IV M aduerfarianona.}

Buniadis, qualen defcripfimus, in aruis humidis \& veruactis deprefsioribus, tota nitet virore atro:fapore aliquantü acri rapaceo, fed in terpres hallucinatus nominum affinitate, foliz non bunii, vt Diofcorides, fed Napi, fiue Buniadis fortè ex Plinio falfò at-
tribuit.

Nifi itaque verũ fit Bunium, ea quam cenfuimus bulbocaftanon dicta planta, nulla pror fum fuccurrit, qux Buni adumbret vel nomenclaturam,tantò minùs oftédat aliam plan- Bulbocaftanon tam, nifi fit folius Crate , qux Pfeudobunii Diofcoridis folia, ramulófque ferat:fin autem aut caftanon. fit, vti non paucis vifum, non nos fallit coniectura de illa noua planta ferulacea, quam Pfeudobuniun Diofcoridis fecimus, \& fuo loco pictam defc:iptánque dedimus.

\section{SIVM SIVE LAVER DIOSCORIDIS Olufatrifolio, fine aquatica paftinaca.}

BVN I A D M M,Napi,Sinapi, Erucarumq; generi, quia ortus, vultus, vfúfq; oleraceus Sionis, Syfumbrii \& nafturtii non multum funt diuerfa, hic fuccedent demum annectenda Thlafpis, Ibiridi, Drabis, \& fimilibus, qux pauciou ibus \& facilius poctea addifcentur. Doolo. de florib.

Duabus diuerfa figuræ plătis aquaticis indidêre nomé Sionis, àmò Toũ ofíę quia quati- lbello. 240. untur, vacillandóque in aquis iugiter fuccutiuntur prxterlabentibus vndis, dtque iugiter alluentibus : vnde etiam Laucris Latinis nomenclatio, nifi quis malit fufpicari ab vrinis calculíf yue ciendis, \& excutiendis dictam Earum alteram, quam Diofcorides lato olufatri folio minore, odorato, erectă fruticulă efculentam depingit, herbarii, pharmacopœi Paftinacam aquaticam ab odore \& foliorum effigie, propterquam etiam Germania iteffich woater id eft, a pium aquaticum, quod dimerfum fimile tamen palud:pio eft, vocitat. Quo fit vt quin hre fit verum Diofcoridis Sion nulli dubitandum fit, \& fi perbonus \& doctus medicus Dodon. hallucinans Crateuæ Sion fecerit, quod neque notas è Diofcoride,
neque Germanican appellationem perpenderit.

$$
\text { CRATEVAS SION ERVCAEFOLIVM. }
$$

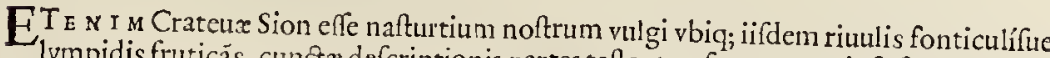
lympidis fruticăs, cunctx defcriptionis partes teftantur:funt namq; ipfa folia fingula, Matheol. 287 . rotundiora \& latiora quàm Minthæ nigricätia, \& extremisoris incifuris profundioribus Erucæe fylueftris fimilibus, guftu non perinde odorato, vt Diofcoridis Sioul, minúfq; medicato \& acri fapore, idcirco plebecula in quadrageno Veris ieiunio mul tü huius in acetariis vorat, vocátq; Nafturtiū aquatıcū. Videtur etiam cadé de caufa Crateuas hanc vocaffe ỏ $\lambda$ iyge id eft, vile $n$, aut paruif ciendam, vt quidam interpretantur, fi cum priore viribus efficatiori \& medicatiori cóferatur, tametii vires non inftrentuas exerat ad quofdam morbos, prefertim ad eos qui Stomacace morbo difficili, fiue Scorbuto vexantur:

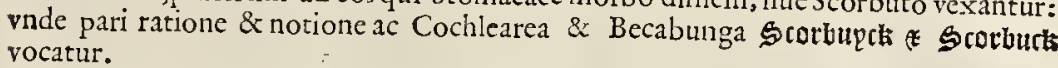

Huius varietas duplex è magnitu dine, fiquidē riuulis altioribus enata fruticat, foliis fermè Terebinthi magnitudine : aliis verò exiguis \& penè arentibus riuulis, triplò minor, xquali ferme Diofc. Sioni fue Laueri, cui conuictor, \& fimilis eatenus, vt non rarò ruftici vtramuis pro vtralibet accipiant in acetariis, \& potionibus ad calculum, nec malè cedit imperitia illis, nam veriufuis vires paris funt commodi.

$$
\begin{gathered}
C A R D A M I N E \text { fine } N A S T V R T I A \text { AQVATI- } \\
\text { ca, fue alterum Sifymbrium, Diofico. }
\end{gathered}
$$

A C A r d a m o,cuius acrimoniam vefcentibus refert, dicta Cardaminc fuit, veluti Hel-

leborine ab Helleboro, tametfi propiùs accedit Crateux Laueri, fiue Nafturtio vulga- Matheol. 488 . ri aut vero, quàm Diofcoridis Sio, aut etiam quàm Sifymbrio : etfi Diofcorides Sifymbrii fecerit fpecië tribuerítque idem nominis plantę menthę hortenfi fimillimę, atq; huic aguaticx, anfamq; Plinio confundendi vires laueris atq; huius Sifymbrii,quod Sion etiã 


\section{STIRPIVM aduer Jarianoua.}

vocarint. Eft enim fontium lympidorúmque riuulorum fectatrix hac vb1 Sion, fed tota tenclla, gracilífy;: folia promés ima ftrata latiùs, in nerucis cauliculis rotüdæ Erucæ, aut aquarici Nafturcij vul garis:qux anté in caule fefquipalmari vel pedali anguftiora multò funt, ctianq; lortéfis Nafturtij diuifura:floribus fumis albidis, acri guftu, acin acetaris tamen minoris commendarionis. Sed enim primum illud Sifymbrium apud Diofc. in familiā potius Menthę \& Menthaftri relegandü, cum quibus tantopere illi conuenit, vt quafi naturę fymbolo inutuo, al tera in altera abeat, nempe mentha in Sifymbriü, hoc in illam, propter confufa naturæ principia in fernine.

\section{SINAPIO THLAS P I media Pronincialis planta.}

GT hanc nouä vifum fuit hifce inferere, propter comunü inter Sinapi, Buniadé, \& Thlarpi figuran \& vires, Pronenit ea nó procul Magdalene fano, \& cautibus illis colfifsumis funigeratifsimis Galloprouincix, floréqque Augulto promit luteos Eryfumi, nec filiquas difpares: in gracilibus ramis ad fummú \& imú vnà è radice digitü cralsıs, fibro ofsis, pedé lögis, Rapiltri folia, Thliffi, aut Drabx, leuiter laciniata, albida $\&$ hirfuta, fapore eryfimi , aut Buniadis Barbarcæ.

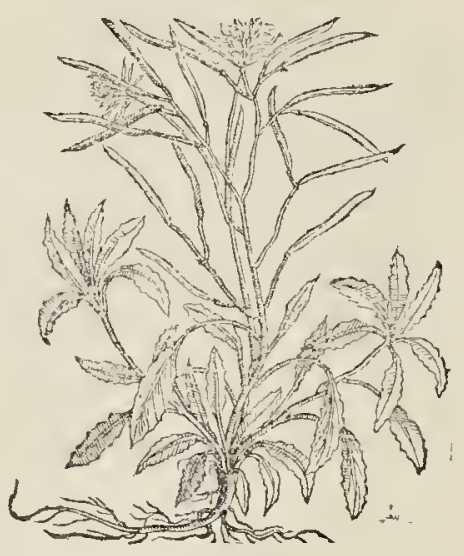
Kógoxuog ILASTVRCIVM. HORTENSE.

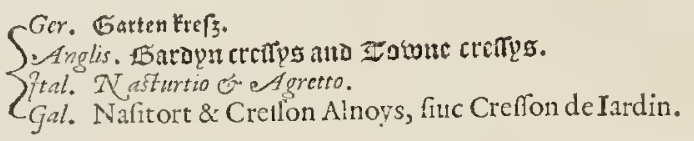

Math.s 65. A C RI M O N I vehementia os naréfq; vellicando Sinapi imitatum nafturciü, è Gra-

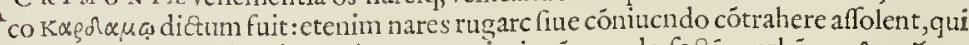

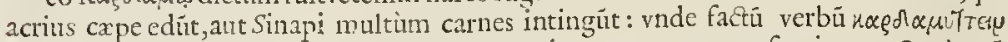
id eft conniucre, tametfi quia cordi vitam vigorénque tueretur prxentiorem, Cardamú dictum putant, Perfis præertin \& Lacedxnonibus, apud quós olim olus iftud multò celeberrimum fuit obfonium: nihil enim addere ad pancm prxterquam nafturcium folita fuit Spartana iumenta, vt apudXenophontem, \& Plutarchum, \& in Tufculanis legitur. Hodie autem in acetariïs \& medicamentis vfus plurimus, \& notifsima planta plebi nomine Crefjon, fortè quia perenni fobole, fummis fcruoribus, vel ctiam Brumæ rigoribus fprctis, crefcit. Francigenx etiam (re/son d'Alenois ab alendo fortè vocant. Notifsima planta, laciniofis, anguftis Erucre foliis \& Coriandri adultis non ita difsimilibus, acri fapore Thlafpi, feminéque fecundum thyrfulos Iberidis multiplici.

Dod. Histo.

T H L AS P I, fue Narsturcium tectorum, NaSturcium Syl. Scandulaceum, Cappella.

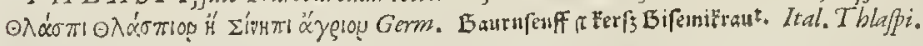

Gallis. Seneuc fautuge, Belgis. Boeten herte, 


\section{STIRPIVM aduerfarianoua.}

Q Vemanod r Phyteumati, Echio, Pfyllio aliifo; nó paucis herbis ob quampiã noúmue incufo aut diffracto fuminis inuolucto folliaceo apperlatio tranfuetfim per medituit Thlafpidium quafi frafun clypeolü. qualem adumbrollatio data: tametfi dici pofemen cohibentes Nalturtij, cui fuccedit ordinis confecun foliofe circinnata pelta

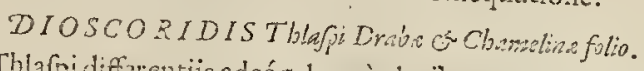

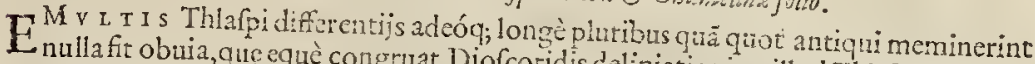
non in aruis copiofum què congruat Diofcoridis deliniationi ac illud Thlafpi nufquam mollionbus, leuiter laciniofis circa imum diuifo lentis, fequacibus, gracilib", Chameline fue Myagri, cauléq; maltis alis deinde cópreftá copiofa folliacen inuolucra eva fores albidos Tunio ferentibus pufillos, partun depreffa \& fiffa funt, emeno continen pu circinnatz pizterquam fupernè, quà

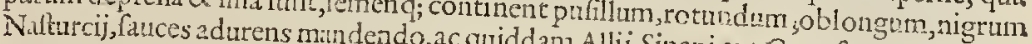
do:vinde vulgus Sinapi agrefe vocat ac quiddan Alli, Sinapi aut Cape fapore exhibenrijs vetuftioribus vifitur. Quare quin fit Thturtum Tcétorum, quia no1? rarò in macelijs ḋhos Xúver non prorfun videtur: funt enim pecies nulli regandü, an autem fit fo-

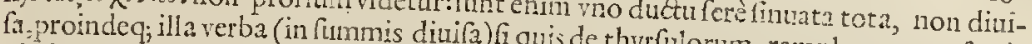
nis diuilura accipiar, necNaturz a duerfatur fuis de thyrfulorm, rammlorum auc femifacturus:verüm fic forcnt aliefpecies Thlatui videtur, nec Grecx defcriptioni vim vilï monia propiùs vero accedent.

$$
\begin{gathered}
\text { T H L ASP I Gracuma propinguinus forté Divfcor. Poligonati folio, } \\
\text { aut Olece, Lentis femine. }
\end{gathered}
$$

ETenta ifud ciumtaxat calidarñ rcgionum Syrie, Candie, ctianq; Prouncię Norbo nenfis indigena ef, ramulis multis un fummo diuifs, \& fenine fecundú longitudiné bina ferie digcito, planę lentis effigie compreffe, red nonnihil deprefsi inftar vitubilicelli medio oftentante, \& quafi iicufum cótufúmue fcutulum aut Thiápidiố exactius fequiofos, cöpaetos, albidos, in carle fre, venemens, fecundü totos ramulos lentos, ob. habente Leucoij lutei fed nultò minora, a dice exil i folia pufilla, glauca albidáue cis.

\section{THLASPI SYRI ACVM vel Grecum alterum angulofo . biforipericarpio lentifolio.}

FErrnt \& alterũ effe Sriacum aut Græcum illud, quod nos habrimus Venetijs \& in hortis vidimus mino:ibus ranulis, minúfq; compactis, albidis geminaq; donatis ferie, feminis angulofi, acerofi, rozũ $f_{i}$, compreffi, mediog; fui fifsilis in duas glumas minores acriora femina terna ant quatema amplexas, folijs non ita difsinilibus fuperiori. li, quòd ille nulla apta defcrintione gener nafci, nec fcimus fitne illud tertium Marhioter picturas congefferic.

\section{THL ASP'I Vulgatifsimum Vaccaria folio aut Myagri pinnato.}

Miro vberrimè prouenit cultis \& incultis aruis Iralię, Germianir, Gallix \& Anglize iftud ommbus Thlafpi vocatü \& receptī, cuius folia ima lógiora, nalioraq; quä primi noftratis, parum crenita, fuperiora autem ingultiona in acutum fenfum definentia, ta, fed continuaci, multos a cule figula porrectiorem non quafi appendice addi-

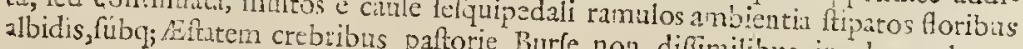

$$
\begin{aligned}
& \text { difimilibus in dnas glumas } \\
& \text { Gij. hiantibus }
\end{aligned}
$$


hiantibus inuolucris, acri femine \& fapore Sinapi aut Nafurcij, officinis in vfu ad antidota pro vero accipitur.

\author{
Ofyridis folio THL AS P L. minus Hortenfe vulgare, \\ acerrimum Luteum ou album.
}

PA v L o diligentiores Pharmacopcci \& Herbarij Anglix \& Germanix iftam minore fpeciê Thlafpi vacăt, \& alunt in hortis ad medicú vfum, quia fut fertuidioris guft ${ }^{\circ}$. Eius cateroquin tota facies, ramulis multis floribus \& foliolis Thlafpi fatetur, catenufq; differle videtur, quia tota minor \& tantopere farmentofa, vt fcoparü vice fit ad verrendü, non fecus ac Iberis, cuius etiam \& floribus, albidis, crebribus, paruis. Eadem in horto Morgani noftri, etiam luteis floribus vifebatur hoc m enfe Iunio.

\title{
TH L A S P I parum Hieracifolium, fue Lunaria luted Morspel. or Leucoinm Luteums marinum.
}

IN prata Monfpellienfia fecus Lauum amnem \& 1 Gramuntium lucum ftudiof ludibundi prodeuntes, nos comilitonéfque noftri fxpifsimé hoc collegimus, \& minorem alteram Lunariam, propter lunatos folliculos elegantes, vocitabamus. Sed attentiùs perpendentes, huic nullus locus certior, ant aptior, quàm inter Thlafpi omnium indicio, putabatur. Radix qualis Burf $x$ Paftoris aut Malux, folia mox a radice crebra fibi mutuo incumbunt, albent colore Hieracij aut Leucoij fed minora, vndulata, laciniofáuc in terram delifeunt. Caulis folijs exutus, cxilis, cubitalis \& pedalis, qui in cauliculos exit onuftos multis clypeolis foliaceis pallef-

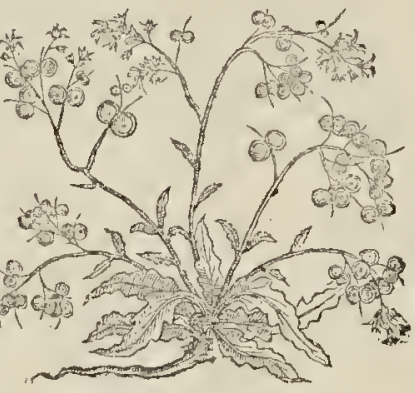
centibus Lentis cópreffx effigie qui prxtenues funt \& fermè pellucidi,quibus incft femé fingulum fingulo foliolo, Leucoij purpurei \& albi fapore \& effigie, potiùs quàm $\mathrm{Naftur-}$ tij.Flos in fummo paruus, luteus aut pallidus. Hac primum culta in hortis Italicis \& peregrina credita, vocabatur ab illis nomenclatoribus Leucoium luteum marinum, nó ita magna fimilitudine: maioré fanè multò fortita eft cum Thlafpis. Sed etiam cŭ Thlafpis nonnihil folijs \& viribus cognationis habent Le ucoij, prafertim purpurei \& albi.

T H L A P I altcrum minus clypeatum Serpilli folio etiam Norbonenfe.

TE e vipiá nobis iftud vifú, nifi in agro Norbonenfi Monfpelliêfí;; locis fquallidis, fabulo fis propè pufillas Anchufas: folia,flores, femináq; ex luteo pallent, \& peltz fuperioris aut Tordyllij funt fed pené pargamenç inftar pellucida funttenuia,fimilitudine, fapore, Leucoij, vnde quidam Leucoium luteŭ marinú autumabant: ramuli funt exiles, palmates, nitidi, foliolis albicantibis Thymi non ita numerofis.

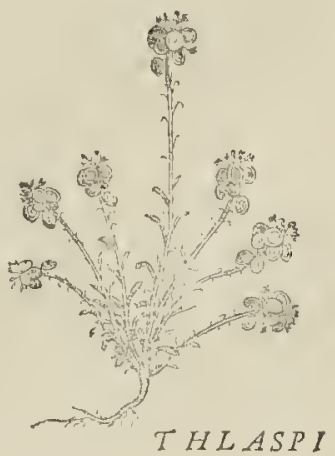




\section{STIRTIVM adwerfarianoua. THLASPI NORBONENSE CENTVMCVLI anguffit folio, Alyfjon Itelorum.}

FE C в R A N т iamditu hanc Itali Alyrson quodpiā, eof que Comentator fequatus, lubenter, inquit, pofurfé, Ir habuifemsigitur factum benè quod nó habucrit, quippe doctiorum onmium Monfipellienfium, apud quos frequës oritur,fuffragio, Thlafpis hæc annumeräda eft, nó $\mathrm{A}$ lyffo: cui aliā multò aptırem landiu compararüt feduli veftigatores Belgx \& Franci, quã un hortis alunt:in Italia non nifi aridam vidmus. IRud vero pufillǐ Thlarpi prope MonSpel. Nouú Caitr. cis Lanum amné, andiff; viarú crepidinibus, in ramulis multis fparfis rectus vimineis, palmaribus \&e fefquipalmaribus albidis, Thlafpi: foliola Poly gonati minora aut Centúculi, aut lauédulæ: \& flofculos albidos Iberidis, Thlafpi Creticl, aut Syriaci, Clypcolis nó difsimiles, fed duplò nuinores fert:totá planta albicat, no

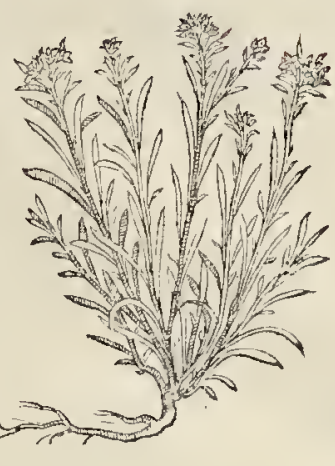
Itúque Thlarpi aut Nafturcium indicat.

\section{THLASPI CANDI A vmbellatum Iberidisfolio.}

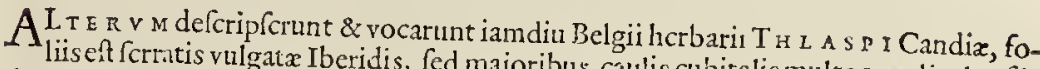
dils ent frrntis vulgatx Iberidis, fed maioribus, caulis cubitalis multos cauliculos fü- Hifor. Dodo. purafcentcs, Iulio vel noris finilibus, acre guftút : tuncque femen affatim cernitur in folliculis Thlafpi minęo hac naturx parte exercitatifsimo videtrof pe vmbellæ Sambucinx \& feminis videtur perfuafifse, vt Drabam hanc cenfuerit:nem gnita quibus eft Lepidii foliis, vmbellis albenta qux non magni momenti funt notx. Codemonftrandum, tum crtorem, tum difcrimcin vera Draba, non opus eft pluribus ad

$$
\begin{gathered}
T H L A S P I A L T E R V M \text { MINVS VMBEL. } \\
\text { latum Nafturciibortenfis folio, Norbonenfe. }
\end{gathered}
$$

MOn to s x satis Norbonx ad Lupi montis radices Maio \& lunio hęc copiofa flores mufcofos va bcllifq; cófertos, fuperioris nó abfimiles edit , fed albidos, feménq; minus multò, fed admodü acre, folia exilio ra, diuifura Nafturcii hortếfis per totos cauliculos numcrofos, grandes è radice non profunda, nce multum fibrofa, fapore acerrimo Thlafpi:verùm non magis hac quam fuperior vfu recepta.

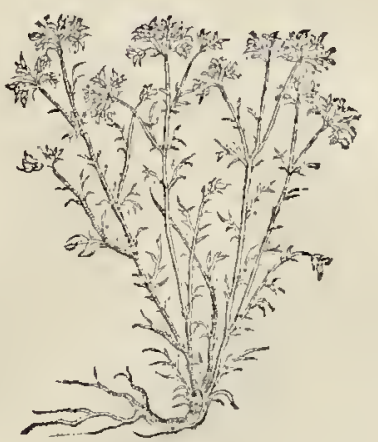

$A N$ THLASPICRATEVAE, SINAPI

Perficum vocatum latisfolis, radicibus magnis, ffchiadicis vtile, fit nofter Rhaphenus agreftis, quica Lepidium Peuli in Lepidio dictum?

G.ij, 


\begin{abstract}
76
$S T I R T I V M$ aduerfarianoua.

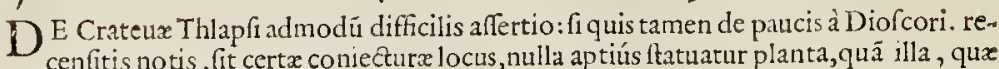
cenfitis notis, fit cert $x$ coniectur $x$ locus, nullia aptiús ftatuatur planta, quã illa, qux nonnullis Sinapi,propter radicis in condimentis v $(u m$, nonnullis $R$ haphanus Sylueftris propter nonnullam fimilitudinem, nuncupatur. Foliis eft amplis Lepidii aut Piperitidis naioris, plerumque latioribus :radicibus etiā prægrandibus, glomeratis, albicalutibus. Semen illi in filiquis Sinapi modo: fores Thlafpi conferti \& elegantes magis quadrare Luneria Kapha vidétur, quàn Lunarix vulgò nuncupatx Rhaphanitis, qux à nonnullis iftud Crateuxe nutis. Thlafpi credebatur, cuitus acrimonia ad Ifchiaticos multò inefficacior, tadix \& vfus dipar.
\end{abstract}

\title{
BVRSA PASTORIS.
}

Germa. Torchel Fraut.

Gall. Bourfe de Pafteur, on berger.

ZBel. Lotelekctis.

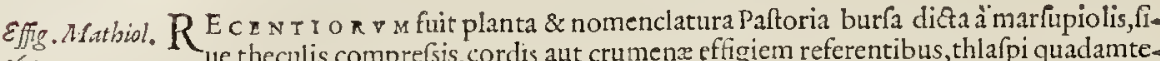
569. nus, cuictiam congener eft, vbiuis copiofifsima \& notifsima, fecus vrbium areas, \& mo: niorí ambulacra toliis \& facic Irionis aut Erucæ: Aloribus albicautibus thlafpi non difsimilibus, tametfi guftu nó perinde acri, fed exiccante potiùs quā refrigerante. Nam qui quia fanguinem fiftat (fiftit autem ftrenuè)frigidam faciunt, infolici argumento niruntur, etenim vmbellx, Horefá; guftanti al iquid acrimonix inurunt, indicióque funt ficcando colligendóque fiftere, vt porri fuccus, Vitriolum, vrtica, non refrigerando.

\section{RHESEDA PLINII NEOTERICORVM Bel yis vulgo Eruca peregrina, Italica vel Cantabrica.}

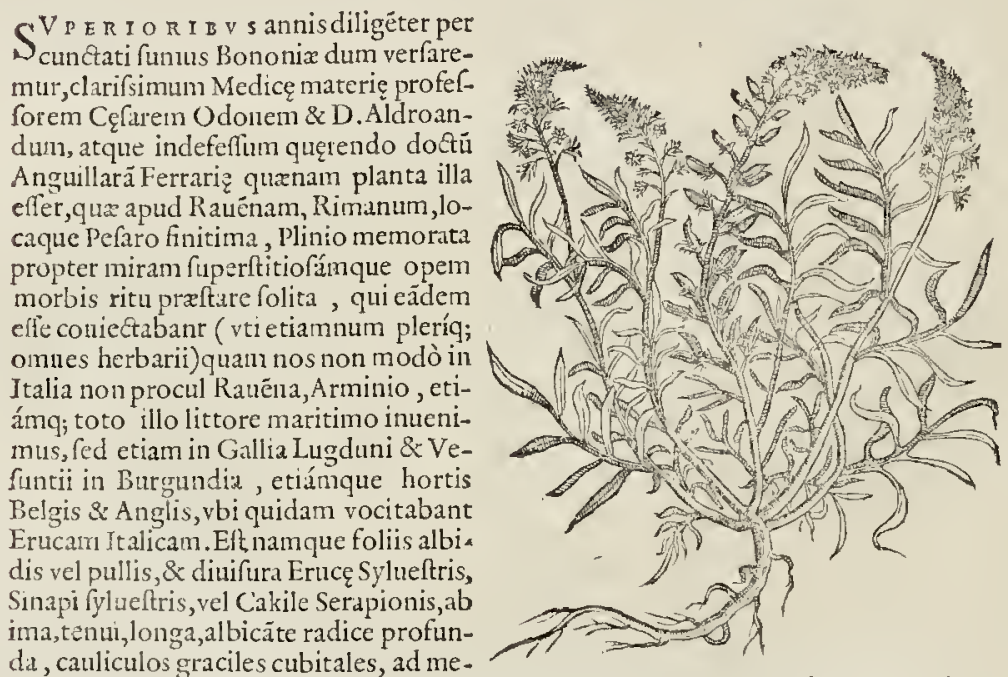
di, cauliculos graciles cubitales, ad medum vfque ambientibus, vbi flores thyrfuliuc denféfpicati Olex fummos ambiunt cauliculos, elegantéfque relinquunt per Auguftum \& Septembrem theculas membra neas, inftar calicis fupernè hiulcas, femen nigricans, pullum,pufillum Hyofchiami continentes, tota guftu \&x nonnulla tenui acrimonia Luteola adftringente: vnde non abs re 


\section{STIRT IV $M$ aduerjarianona.}

doctifsimi illi putarunt ex Plinio hanc Refedam effe,pofè; collectiones \& inflämatiodementiæ cômentis ad eftarim op us effe additis illis verbulis, aut murmurillis anilis morbos refeda, fifné, fcifné, quis bic pullos everit radices,

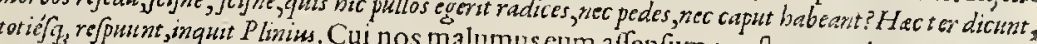
balbutiones earminum iactur nos malumus cum affenfum præftare, qualem merentur vel afferendo fidem temerare noftram \&

$$
\begin{gathered}
\text { CAKILE SERAPIONIS, Erucafolio,N Tapifore, } \\
\text { Vulgo Eruca Marina. }
\end{gathered}
$$

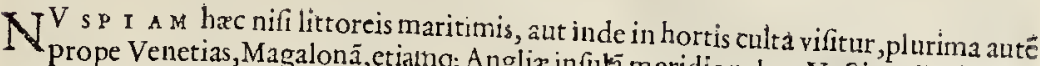
finuatis, diuifura crebra Senecioné vel Anglix infukä meridionalem Vectim. Folijs hxc Flores autem purpureos iuxta cauliü ramulos nifi crafsiora albidiorag; effcnt, prafert. habet, femine eft oblongo mucronato fun f parfos magnitudine \& fimilitudine Napi fibiq; mutuo apicum duntaxat cohæfu iungofo ex fingulo fore fecundum caulem, ;bino Radice lignofa $\mu x \lambda$ Hे, propter quam plurima vocauit.

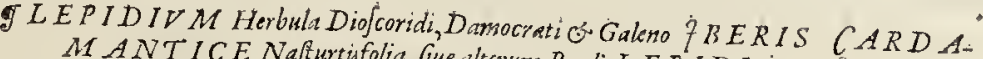 $M A N T$ ICE Nafurtifolia, fue alterum Pcali L E P IDIV $M$ I $B E$ -}

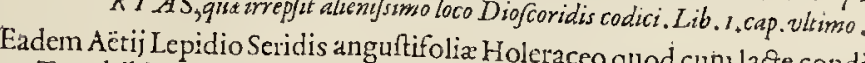
dum Tetrabibl.4. Sermone. 2. Cap. I 33. Holcraceo quod cun lacte conditum feruanSed Lepidiun primum Paulifuperiore aptum cibo, Rhaphanus Sylueftr is Francis \& Belgis Pharmacopois. Fer

FE c I t vis vrida cutiq; deglubendx \& fquammis excitandis (quod contingit fieri pleuidis plantis fecerint antiqui $: \lambda_{\varepsilon} \pi$ idecenim vnde ctiam lepra diata. Ne porrò toediolectori fquanımas è cute deciduas fignificant, qux diu nos fefellerūt, \& animaduerfionis \& caftigat ad recentiorü conniuem pleraq;

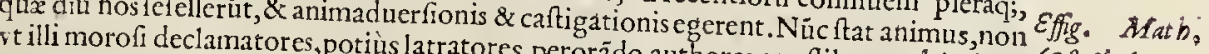
fed quantum plurimùm pofsinus amicoles, perorādo authores quoflibet proícindere, 608,600 ;

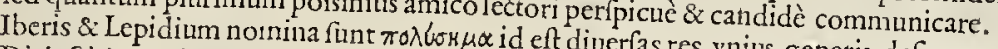
Dialecticis $\alpha$ quiuoca, \& im ponere folita, nifi priits finibus res vnius generis defignantia, dum. Iberis vel Diofcoridi Hore folita, nif priiss finibus fecernantur, quod hîc faciendice nafturcij, hxc notifsima Lepidio Diofcoridis Nafturcij cubitalem, flore lacteo, racolligitur, qui Lib. tertio, Cap.de Coxendioridis cadem, quantü ex Galcno \& Egineta eium nuncupari fribit: multò maioribus, cuius antiqui inedici fiticanteriz quandam plantam fol jis Laurinis, fed riculum fecerint: oruin fi defit copia, inquit idem multò vegetior, frequens in Eginetæ patria, cuilus folitaplafna effingito. Itidem in Simplicium corticem deglubito, \& ex adipe fubatum in caquarto calfacientium ordine vimplicium elencho, Iberiadem fen Lepidium recenfet ex nuis ficcando pollere. Hic iritur pau, alterum verò Lepidium nafturcio viribus fimile, miliginem. Vides Ibcridem \& Iberiadem alteram, qua de Jib pidium: idmultis vfuvenit plantis ve re de Coxendico, Paul agit eiufdé Pauli efie Legltetur Gingidio afsimulatum Diof reridis fint, nomenclaturis varix. Ac nequis aralfefu finile Nafturcio effe Iam haud coridis Lepidium, fciédum Gingidium vel authoris cum \& Iberis feu Lepidiü Diof coridis notifsimü fit \& Pyperitis procerü faftidiofas lites, plufquam rabida à feruido oultu Pauli etiám fit , \& Pyperitis Galliz plcbi Pafjarggs: at. Futiliter igitur 2 impie tenebrico etiámq; Plinij Iberidis fine Lepidij notas explecllio infultat, quum lapfos dicit, vt putarint Raphano Italis dietum Lepidium effe :

$$
\text { G. iij. perfíicue }
$$




\section{8 $S T I R T I V M$ adwerjaria noma.}

perfoicué Rucilius hunc elrorem detexit. Sed hunc fortè tunc Mathiolus Italus not intellexit, terfior cnim \& nitidior fcriptor erat, quàm ab Herbario latinè vix balbutiente percipi probè pofset. Id res ipfa docet multis locis. Sed hic probü quemlibet offenfione vexat: illi primum pofteris fecuerunt glaciem, \& fcipionem ad vadum tranfmittendum porrexerunt ingrate ambitioni,cuius poftea proditoris ictibus pofternerentur. Cumq; Authorü fparfas pafsim fentêtias nobis fuis immenfis vigiliis collegifsent, Cömentator neque illis intellectis, \& iftis fpretis, nefciuit ex Pauli perfpicuis locis diftinguere duo Lepidia, totidemque Iberides, fed vt confueuit, re infecta ad calumniam deflexit, quam tandem, cum futilem \& fcutica dignam effe confcientia moneret, iltis fomentis leniuit: nimirum fortaftè illos Piperitim Plinianum Pauli Lepidium intellexiffe, quod illi illic monuerant herbarios Lutetianos pharmacopoes \& Antuerpianos, te nondum nato herbario. Hodierna cnim die vocatur Rhaphanus agreltis officinis \& mulierculis Belgis. Hac Piperitis I.cpidium fecus ripas aquarü fruticat, radice oblonga indicé æquãte, vel maiore, caule cubitali \& bicubitali, durioribus foliis Cofti hortenfis vel Lauri, fed multò naioribus, molluf culis, ambitu lenitcr crenatis, colore ex viridi pallefcéte, flote exiguo mufcofo candido lberidis. Dolendú tantum virum deceptum à Plebecula fua, nam illa pro Rhaphano maxinăillam plantā, quam Verbafco comparabas intelligit: Gallica verò nonine Rhaphani Sylucfris Piperitin feu Lepidiü vocitat, yt monet Ruellius te decipiens, t1eutiquam deceptus.

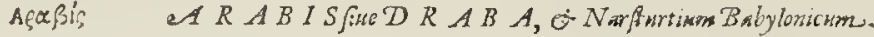

$$
\begin{aligned}
& \text { ägंbr Gallis. Draue. }
\end{aligned}
$$

Effg. Math. O V Is Q y s ille fuerit dotus, qui Iberidem Cardamanticen adiectam primilibri Diofcoridis calci defcriphit, videtur vfus fuife verbis comptioribus, \& oratione 57 .

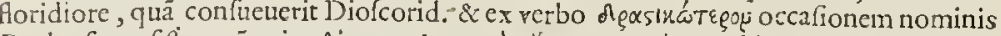

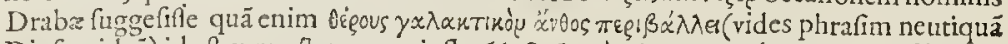

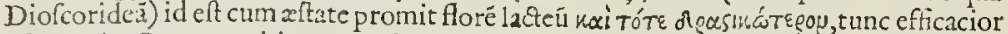
eft, inquit. Quo exepitheto potuit nominare alius quifpiä Drabam: \& comparare partim cum cardamine, fiue Iberide Lepidio vocato, vtpote qua etiam holeracea eflet \& cubitalis:partim cum Lepidij Eginetæ \& Plinij foliis, apud quos, quamuis multò plura quàm Diofcorides collegerint, nulla mentio fit Drabæ. Qux fi minus placeat conicetura, certè valdè confentaneum rationi videtur quempiam fuiffe non imperitum, fed atate pofteriorem, qui hanc Drabä fibi de facie \& viribus notam defcripferit, Iepidióq; Egineta vel Plinii follis fimilem fecerit:neutra enim à Diofcoride defcripta, nefcitur an cognita: ant denũ hucinferta fuerit, nullo alterius alicuius sudicio. Nã alióqui ifta Drabeplene fatis exprefẹ, \& $x$ in vum iamdiu deductx folia, Lepidij forma \& aliquantù incifura, mollicella colore albefcentè hirfuta radice $a b$ ima rmbellis tcnus veftientia caulem cubitalem fermè exilé, qux albicant lacteolis floribus Sambuco minoribus:femen acre fubrotundum, albidura Milij magnitudinc̀, acriore \& feruentiore guftu,quàm planta. Radice albida \& nonnihıl tuberculis interdum extantibus. Optandum hic, vt Senenfis cómentator nos docuiffet, pofteaquam reiecit hancè Diofcoridis familia, quibus rationibus indubitatum fit illi ( $v$ t loquitur) hane vnam effe legitimam Drabam: tam multis fruftra inculcatis, quid non addit pauca neceffaria? An non poftet Piperitis, an non Dentillaria Rondel. Lepidium Pauli hic recens, innuere? quid fi idem Lepidio Diofcoridis fimilem fecit, logge magis vt aberres, fecit enim Gingidio aut Nafturtio. Varix funt planta adhuc Recentiorum, qux Lepidium dici pofunt vaga illa nomenclatura, \& facultate cutem vlcerandi, fquammáfuc excitandi, quas ne nofto infituto officiăt, fuis quamq; popularibus \& fimilioribus fubdemus, vt Dentillariž Rondelletij, Coftum Hortenfe, Rhaphanum magnum.

$$
\begin{gathered}
\text { Múayou } \operatorname{Nr} A G R V M 1 . \\
\text { Germ. ó } \\
\text { Gall. }\} \text { Cameline. }
\end{gathered}
$$




\section{STIRPIV $M$ aduerjarianova.}

$4^{P} \nabla$ D E Einetam in elencho M duz leguntur plantx, nomine \& oleofo fucco vel fe-

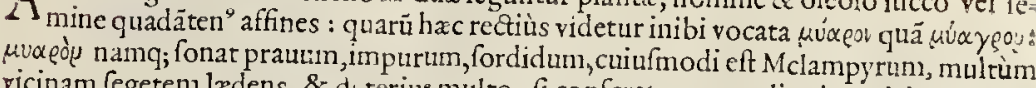
vicinam fegetem, lædens, \& di terius multo, fi conferatur cum reliquis triticis exiftens,

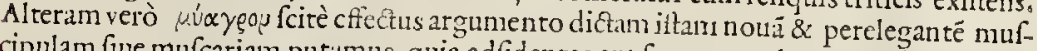
cipulam fue mufcariam putamus, quia adfidentes aut fe prateruolantes mulcas ramulis \& glutine fuo implicet, vt alibi dixinus.

Neglectis etiam aruis, nec Segetum mediocri difpendio nafcens vitium Myagros, ea Dod. fig. 339 eft quam minus Sefamum putarunt, vt cuius è femine Sefami perfimili oleum multũ multis in locis prematur, lucernis \& cibis idem xquè aptü. Exit hæc fefquicubirum alta \& multis anguftis folijs Rubix vel potius Lithofpermi fepta latioribus, perpaucis vt Thlafpi in ambitu denticellis cminëtibus, mollibus \& albicantibus folijs, Secundum extrema flofculi lutei Alyfsi, aut Eryfimi, quibus propagantur capfula compreffx Drabx aut Lini, femen Sefamo aut fonogræco fuluum, fed duplò minus $\&$ oblongum. Emendauir feduli-

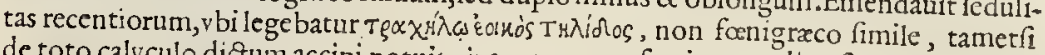
de toto calyculo dictum accipi potuit, intus namque femina coudita fitu, \& appreffi in ter fe verticillatım quid \& oblongum vidérur efformare: fed ifta leniora funt. Leuifsimè vcrò ineptit hic \& balbutit Senenfis dum doctis nulla rationis vmbra, aut rei cognitione, aut melioris hiftorix commutatione aduerfatur. Nempe fi in Anglix, Gallix, Bataviæ, Lotharingix \& Leodij aruis prouentum \& compédium mercatoriü, huius nouiffer, eam potius agnouiffer quàm Pfeudo nefcio quid fomper, vt folitus eft, qua vaccaria videsur perperam intrufiffet.

$$
\text { Helyipes SEN ECIO, fuse Erigeren. }
$$

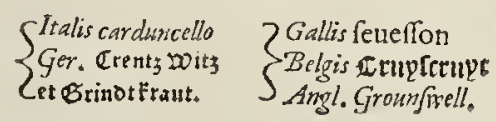

CV I v Is regioni \& foli conditioni inna ccitur Senecio, aftus æquè ac frigoris patiens, Effig; Math, qualibet fermè Luna flores luteos inftaurans nouos, qui in pappos breui abeunt $\mathrm{De}-1 / 32$. tis Leonis modo. Calyculi teneri virides, Cicerbitx minores, non nihil rubentes, quos folia infernè amplcctuntur oblonga laciniofa Er11cx, Cichoríue diuifura. Phlegmonum initijs atc; Eryfipelatibus optimè facit: peptica namg; eft, paucula adfrictione, moderatiore calore, aut digerit aut fuppurationem promouet.Sapor infulfus \& oleraceus.

\section{ACOBA A SENECIO \\ $\{$ Herba Santi Iacobi \\ Relgis \& Ger. S.37acobs bluum.}

NV I I I quàm Senecioni propior videtur Tacobęa vocata recétioribus inueftigatori- Matb. "13s,

bus.Locis lætatur amœnis, vt pratis \& collibus riguis: quam Senecio maior multò, radice fibrofa emergentes emiatas, \& interdum fubrubentes, fe fquicubitales \& cubitales rentia. Flores ftellati lutei, marus adfringens, non tamen ita calidus fuccus eft.

\footnotetext{
W $A R I N A$ I ACOB $A$ A, vel Coryjantb:mum ar Artemifla marina neo. tericorkm.
}

$$
\text { G. iiij. Rarior }
$$




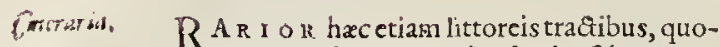
Rum eftindigena : maior fruticofiórq; Senecione, plumbus virgis duris, \& folijs maioribus profundiufq; incifis \& finuatis, vt Artemifis, rigidioribus, crafsioribus, cinereo tomento obdu Qis,vti reliqux partes: vnde nomen illi Cinerara inditum. Flores item melini Iacobęz Senecionis pappis diffluentes. Exiccat valde, digerit, \& inodora eft. Cxtera nondum comperta. Colunt Belgici Horti de Mediterraneo littore lc-

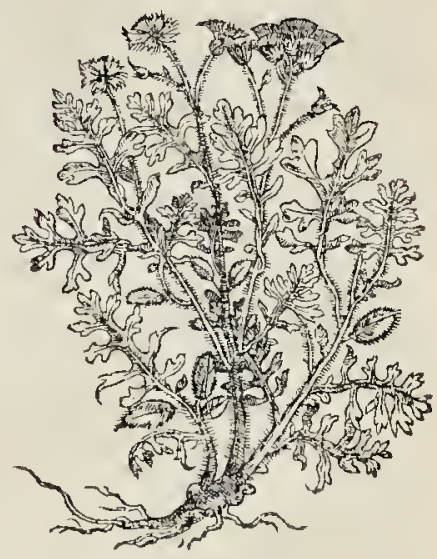
f.tam.

Exch 100 [N Oliuetis Namaufij cxtcrifq; tepidioribus \& apricis aruis agri Norbonéfis, vel Nitiobrigi fuapte fponte fruticat Botrys: Flandris, Germanis \& Anglis in Hortis. Radice eft fparfa ing; diuerfum acta mutuo fibrarú implexu, ramulos complures ab vno fcapo emittit holeraceos ftriatos,éq; intcrnodijs folia tres vncias longa, vnciamq; lata, per ambitum angulofis lacinijs profundè finuatis Cichorij,potius Hieracij, vel Erucx haud difparibus, flofculorum innumera fotura onufti ramuli, fecus, pone, fupráq; folia fpeciem primulùm florentis vux exhibentes (vnde nomen illi)fed languidè lutei, vti tota pláta ex luteo viret. Pertinacis odoris gratia fragrat, odoremg; haud ita difsimilem Ambro fix, fed multò regetiorem vibrat. Condiunt recentiores halac Saccharo, vtuntúrq; ad Cordis aftectus.

\title{
SERID ES Jue F XTYBA.
}

\begin{abstract}
A Dducenda \& huc intubacea, quorum cunctas famili . as aptè \& fingillatin Hercifcere, etfi maioris ett molctix, quàm laudis, non contemnéd $x$ tamé erit vtilitatis, quando videmus plerofq; Pharmacopoos, vtinã non \& celebcrrimos Medicos fenio confectos, etiamnum valdè anxios, quid in fuis, quídue in Nicolai compofitionibus quotidiano vfu tritis, pro Intybis, vtroq; Sonch o, Cicer bita, Taraxacone, LaÊnca agrefti \& fimilibus, fint accepturi. Quare nobis, tametfi hanc opellam fuccefiuis Horis \& furtiuis cudentibus, non licet effe tam ociofis : tamen amicx quorundam petitioni,\& memorix noftrx fubfidio paucis \& perfpicuis hxc difcernere, ato; in feriem cöcinniorem digerere lubitum fuit,ad ditis infuper, quas noueramus raris huius cognationis plantis.
\end{abstract}




\section{$S T I R P I V M$ aduerjarianowa.}

SSylueftrem Picrin fune Cichoriü Sonchi asperi vel Dët is Lconis folio Cultam altilem eandem, qua latioribus, babitioribugac folits Intybi Scariole fit, or aliguanto gratior.

Plinianam Hedipnoim fune Prorim lutean pratenfem dentis Leonis flore Hieracii folio, anueadem Verrucaria Cichoraces luteo flore $\circlearrowleft$ fulcatis capitulis fylueftris Coc horii folio.

Pufilum bulbofum Hieracium marinum Diofcoridis alterum, an Theoph:Perdion?

Condrillä Belgicam flore carnleo Cichori, Folio multim laciniofo Cichorii agreftis aut Eruca fylueftris, T araxacon Officinari.

Condrillam vulgare Luteam maiorem?

cominorem $\}$ folio dentis Leonis,

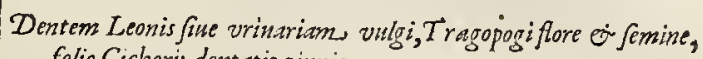
folio Cichoriy dentatis pinnis.

Dentem Leonis Norbonenfium Aphodeliaut Leucacanthe bul. billis.

Condrilla viminofam vifcidam vineartm, Norbonenfum.

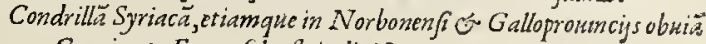
Cyaniaut Erucafylueftris dinifura.

Intybolacana, que Galenus ex antiquis vocat, fine Serides, funt multiplicis diffierentic, quar $\breve{u}$ fumme tres, nobis do. ctrinc catya erumt: Sylueftris Picris, horten/s, atque Soncbus: illa vt natura prior fic plures babet fpecies nempe

\section{Anguftifliam vocatam Endiuiam Sylueftrem Officinis, fore Ladtuca. \\ Altera varietatem Cripam, folio Ci. \\ Tertiä varietatem fatiuam Serios lam: paruam Seridem vocatam Cit chorii bortenfis folio of flore.}

S E R. D O. $\left\{\begin{array}{l}\text { Seridem, Endiuiwm horten- } \\ \text { fem communem flore Cicho- }\end{array}\right.$

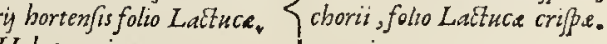

Habet varietatem.

eAperam viarum folio laciniato Cichoriy aut Hieracii.

Lauem maiorem altioribus folorum lacsniis, flore luteo Papaueris corniculati Cicerbitä. Officinarum fue Roftrum porcinum.

Alterü lenem minorë Kheadis papancivis folio, florelutco Senecionis.

fifcéque congener, fimiléque Hieraciür mains vnicaule, non, $d i p p$. rifolio Coflore, pinulis apperum.

S о к $\mathrm{CH}$. Hieracium minus premorfa radice Diaboli vulgò Hibernia, acutis

lacinis folits, paruis, paucis è radice, flore luteo minore.

Hieracium alterum puffllum non laciniofum foliis, Pilofelle.

Hieracium longius radicatum, caule numerofo nudo folis bumi in. orber acculant ibus, obtufe laciniatis, fiore Dent is Leonis.

Hieracium montanü Sabaudum grandius folits ci laciniis Condrille Carulec, flore luteo.

Hieracium montanum folio Lycop/is, Cirfit Sequanorim flore.

\section{SERIDIBVS INTYBACEOVE GFNERI}

cognate $T$ ridaces, fue Lactuca merito accenfentur: quippe quaruns

agreftisfit mixta è Seridum \& Papauersm natura. 
SERIS STLLESTRIS PICRIS, CICHORIFM.

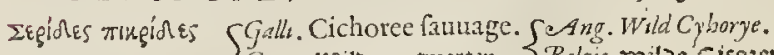
$\left\{\begin{array}{l}\text { Germ. woilde wagtwatin. } \\ \text { Ital. Cicoreafalieatica. }\end{array}\right.$

SE R I s fiue Intybum eft, aut poteft effe, fummum genus, ad omria q̣u $x$ Gaienus nomine con$\checkmark$ flato Latinogræco Intybolachana, id elt intybo-olera appellat conicctétq; quifpiam fefquiVarro nomen inde duetum, quia Seridı natura agreftis cumeffer, mitioris in hortis oleris caufa

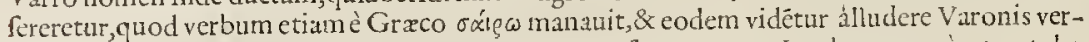
ba,Lib.3. de re ruftica:vbi ferunt, inquit, herban qux feris vocatur. Intyba autem à cauo tube fpecie caule videntur dixiffe:nam Cichoriun \& Anbubeia Egyptia funt vocabula,picris amaAmbubeia ráue infignen connotat amaroré pręertim Seridis, quę coeteriseft amarore prior, nufquả non frequentirsima, faluberrima, celeberrimáq; apud omnes gentes cónendatione, quan it fatiua Scride Scariola dienofes facilè de laciniofis magis, minúfue obfcuic̀ vrridantibus, anguftioribus foliis, \& anniore ingratiore, totíufq; plantx habieu, \& radice fcabriore, duriore, cxuEtiore.

\section{CICHORIVA fatium, caruicum, picris eadem,} fed cultu variatum.

Germ. Jam Blauroegwart:

SGal. Cichoree des Iardius.

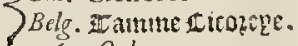

CAn. Cyclorye.

NO nifi cultu \& folo iftud diftare inde manifeftum, quia in Taurinenfi agro, Sabaudo, inque vinetis Burgundiacis lxtior is foli nec liniamentis, nec fupore, aliáue nota diftet à fuperiore. Brugis ac Antuerpix in Flandria depangunt tenellas plantas in patentibus aruis,quas feuerint poit Solftitium, aut feftum S. Ioannis, ne in florem luxurient : vt pert hyemen maiores tenerioréfque radices foucant ad vefcendum:minus tamen laciniofa \& fimilis illi eft, vbi multú coliur, illíque abundè fuggeritur alinenti in hortis: aliogui flore $\&$ femine non difpari.

\section{EDYPNO IS Plinit, Cichorium, luteum pratenfe, Dentis Leonis Flore, Huracijfolio : o an eadem fit Verrucarium Crchorium luteo flore, crfulcatis capitulis?}

S P, vti peritioribus vifum eft, hac fit Plinii Hedypnois, quam fuauiter halantem vel fomnum conciliantem interpretantur, quin fit Cichorii fpecies, haud dubium:quippe domeftici Cichoriiradix, foliorum ortus pofitus\& numerus, caulis \& fores, vninerfúf, habitus, planè Cichoriun Syluefte initantur. Hoc tamen dignofcuntur, quòd huic omnia maiora funt, folia albidiora, latiora leniúf, laciniofa, \& roti ramofo canli adnata, luteique flores, pappofi globilongè maiores, \& fucco amaro pedalis radix turget : in pratorum, vrbiúmque aggeribus pal'sim occuräit, vocata Germanis Beel ward, Gallis luteun Cichorium.

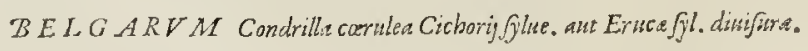

CON D R I I I e differentias effe Seridi fubaltcrnas, atque fimillimas, vel hac indicin eft que dumtaxat à Cichorıo fylueftri videtur differre evilitate foliorum, canliumg; nitidiorum eJegantia:pauciores etiä alas habet, fed Hores non difpates, vti nec radices, qux friniles fimiliter Cichorio eduntur, tametir non nifi hortis Gallicis \& Belgicıs nobis vifa, quia rara. 


\section{STIRP IV M aduerjarianoua. \\ CONDRI L L A pufilla Marina lutea Bulbofa, an Diofco. radice rotundas orbiculata s zoy yúds co an Theoph. Cichorium Perdiónue?}

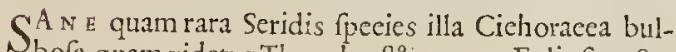
Sofa, quam videtur Theophraft' innuere. Foliafunt Scrydis fylueftris diuifura,aliquanto minora, Caule fermè nudo tenero, in cuius funmo vnicus flos luteus Détis Leonis, minor tamen, \& itidem in pappos euanefeens : ino cauli fubfunt filamenta terna vel quaterna, quibus totidem plurélue interdum bulbi appenfi funt perlucidi $\mathrm{ex}$ albo purpurafeentes, folidi \& fucei pleni,qui earnê Rhaphani fermè praferunt colore \& pelluciditate. In locis p.ucis, fed tancen magno prouentu oritur. In Italia doctiorum nullus fe vidiffe nos monuit, neq; vidinus ipfi alio loco, quàm fecus infulam \& lacuftres traqus Montis Cceti Narbonz ad pifeato:um atregias. Hac merita eft argutam pictoris manum, rt fit Diuini philofophi Theophra-

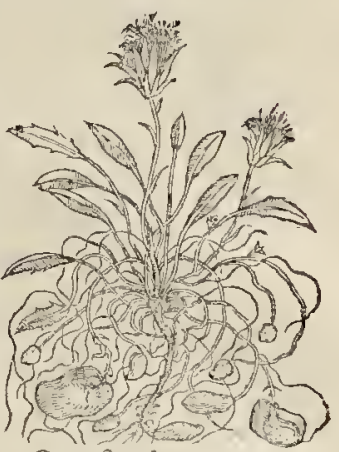
fti monumeatum, qui nos illius monnit, reccntiorum nullus, Qux fi Athenis nobis do. no mift: fuifiet, haud tamen con timuò magis A theniếfum, quàn Monfpelliêfium, Nar* bonenfiumue eichorium nuncupanda fuifict,

\section{Monpellienfum Dens Lcanis Afphodeli vel Leucacanthe bulbillis oblongis an Condrilla altera Diofcoridis?}

N Is r illud Bulbofum Cichorium nofrrx etati innotuiffer, meritò quis putaffet hanc ente Condrillam Diofcoridis oblongis \& eireum rofis folijs, humi fparfis:radiec rotunda, quatn etiam Plinins radice fabx finili aliquando numerofa deferibit. Verum vo trouis modo aceipias, è Pliniana defígnatione, aut Diofcoridis codice certum eft,ilii Códrillx melius congruere vel bulbofim Cichorium noftrun, rel Dentem Leonis vulgaren :etenion fi Pliniü fequaris, noftrum Bulbofum dicas illum exferipftfe ex Theophrafto, euits quidam Perdion Herbam efie augurantur, aut alio quopiam Botanieo.

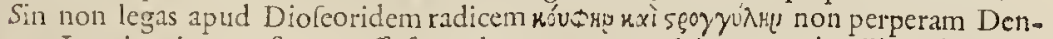
tem Leonis vulgarem ftatues effe fecundam veram Condrillam, atg; intelliges depraua-

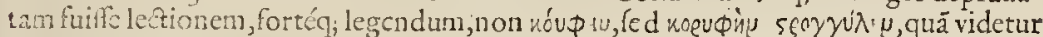
doetifimus Ruellius interpretatus. Quippe minùs aptè quadraret, radicem Sonchi huius benè adul tam efie \& fucco plenā dicere, candémq; leuem aut minùs ponderofam. $B V L B A S$. At ficctian aptiol foret hac, quam vtratis illarum ex hac \& Pliniana interpretatione, $P$ HOD E L: Radices namque huins plant $x$ tenues funt, carno: $x$, fucco refert $x$, rotund $x$ in mucro- Condrilla. nem ad verticem, oblongx fabx quadamtenus fimiles, vt Plinius notat, qucm hallueinatum, ve alıas putafsemus in collatione primi Sonchi Diofcoridis( cui adnafcuntur grumi, nodíne gummei eireum eaulem fabx tuberculo finiles) nifi plinius non primam, fed fecundam Condrillam deferiberet hîc verbum de verbo fermè è Diofcoride, aut eonfimili clafsico autore. Huius facilis prouentus in Hetrurix, Gallopronineix, \& Norbonx narginibus futorum \& pratorum Iunio \& Iulio flores luteos, pappofq; geftat nultò maiores, pallidiores quàm Dentis Leonis : nec tubi caulium abfimiles multum, folia etiam huni firata, fed minus altè incifa, aliquantum glauca \&. hirfuta propiùs Cichorium Syluefter referentia, fed multò lation. Guftu amaro aeri \& Dentis Leonis: vi- 504. Math; res, quas dieemus alibı oportuniùs, latuêre nofturum Conmentatorem, qqui hune Détem Ieonis nouitatis \& peregtinitatis titulo iactat Confantinopolitanum Cichorium, cum tamen Sienx illius patria , inque Hetrurix, Liguria, Galloprouineix \& Norbona puratis non parum copiofum iftud proueniat. Neq; crim fi flores funt huie duplò fermè naiores magıfg; pallentes, quìn communis, propterea putādum fit foeliciùs prouenire aut frequentius Confantinopoli, quàin Mafsilex, aut Monfpellij, vnde fomus tum Commentatori, tum alijs non paucis feriptoribus hodernis millas \& obtrufas plerafciplantas pro Aphricis, Syriacis \& Conftantinopoltanis. Sic res eadit pigris \& ambitiofis ingen:js, quos res nondum vifz oblectant, vt pueros piqura capiunt \& ciecipiüt. 
An putaratostros illicò iftud Cichoriun admiraturos, quia Confantinopolitanum erat 3 i Cafatco oratore miftum? An non pudet tantum rei Herbarix fcrutatorem non dun noffe Cichorium patrium, \& plus credere oratori occupato muneribus aulicıs, quả cxercitato ad difcendas varias fpecies Seridis.

\section{VVLGI D ENS Lemis, Gue Vrinaria, T ragopogiflore or Jewine, folio pimis dent ato.}

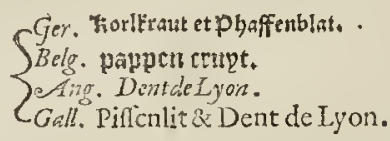

TEcye hxc fit Chódrilla, vt cui prorfú abfint tuberculi, tum radicis, qualcs Plinius to

Diofcorides innuere videntur, tum cauli imo grumi defunt quos nomen defignat:

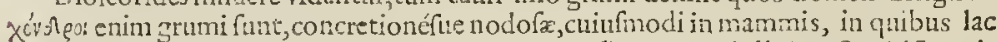

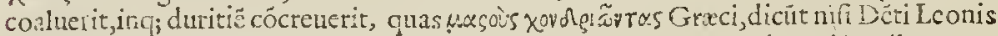
contigeritiden quod Draba, cuius radici interdü ineft tuberculus, interdu nullus, atq; nofrati : dé cued foniculo, Tragacanthz, Rut \& maftichæ, qux qubuf lä in regionib micas G ummi, laeteaue concretionis tuberculos habent: in noftris tractibus vt plurimü cale nihil. Etenim fecundurailam plantam corulcam \& Cichorescean,quam priorem Condrillam pofilimus, nó parum refert Cichorium \& Condrilam Dens Leonis vocata, fue Vrinaria Herbs Piferht Gallis pueris dietı, quali Lectimingz:alum namq; fupprimendo, pófrueionéf, referando Meferaicarm: plus lotij deriuat in veficam, quàn quanrum pueruli retiando fint, prefertin inter domicndum, coq; tuncimprudentes \& nuiti fraguia permingunt.Siquidem muliercula médica \& puctuli rutici in pratis, prope tumtlos aggevulófie Talparum terra femiobruta cón; (vcluti Endiuix cótingit) germina í:auora minúf; amari, candidiota effoffa in acetarijs vorant, aut iufculis indunt. Alt-,yrinas cict $\&$ fomncm conciliat, quapropter Hedypnoin quidam maluerunt dicere, c:1am fuperius Luteum Cichorium : tamatfi appellitio phutibus Intybaceis $\&$ Condrillis congrsuere pete?. Cuilıst genti hac muitò notifsima, folijs Cichorij fylueftris, lationib Q lacinis alticrib" teninc; dentatim, ferratis, linniq; fermè fratis. E radice Cichorij dioitum aral, aliquancum lutea, \& iscun fuccum, dum vulneratur, fundente, eddiculorum tubuli pctits quan crules teneili nitentes, laciéq; turgentes florem fpeciolum, luteú, nulciolum Tragopogi val Sco-fonera promut, vere \& ceftate parti culatim, cefarie pappofo cil.wlit, capitule infar Monachi capiris glabri aut calui vifutur.

\section{CONDRILLA Coromogiant Cyaziterusfolit, Lutea vineatum.}

PVt A R V N cciam nonnullidoetifsimi hanceffe alteran Condrillam Diofcoridis, vt qui fuperiores nódum noflent, nec hxc funè ita abimilis, turget enim amariore \& pluri lacec quàm Cicho :iur Sponte tota xfate calidiorum region:m vinetis \& oliuetis glareo is obuia parsim eft, folijs palmum \& fefquipalmum longis anguftis acutiff; laciniarü ligulis vtring; détatis, ctaf́siorib, pallidis Refede magnitudine, fimilitudine \& fitu,caulem ftipantib!s friatum Cichorij agreftis, luteun diufun alis forc Hieracij aut Lactuca gerentibus, inq; pappos difHuentibus, amariore 8 acriore fapore.

CONDRILLA viminea vifcofa

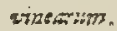




\section{STIRP IV $M$ aduer farianona.}

I I D E M fermè natalibus agri Linguagot tici eft quxdam Condrilla vifu pulcheirima. Plurima Iunio \& Iulio floret cis ponte Caftrinou à Monfpellio vix fefquimuliare. Radix vniuerfàq; planta lacte turget, \& vifcida cft tactui, crcberrinis vimineis viticulis. f̈exu mollibus, candidis, rećtis, cófertis, affurgit, duorum altitudine cubitorum, folia in imò Cichorij sut Cyani incifura, fed valde exilia \& tenera, reliqua foliola fecun. dum viticulorum longitudinem certis $\&$ xquis diftincta interuallis ad faftigium vfq; porrigmntur,fpeciemq; virgarum viridi albòq; variegatarum prabent, fummis viticulis prodeunt, fofculi lutei in pappos dehifcentes. Hic pictura adett.

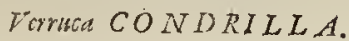

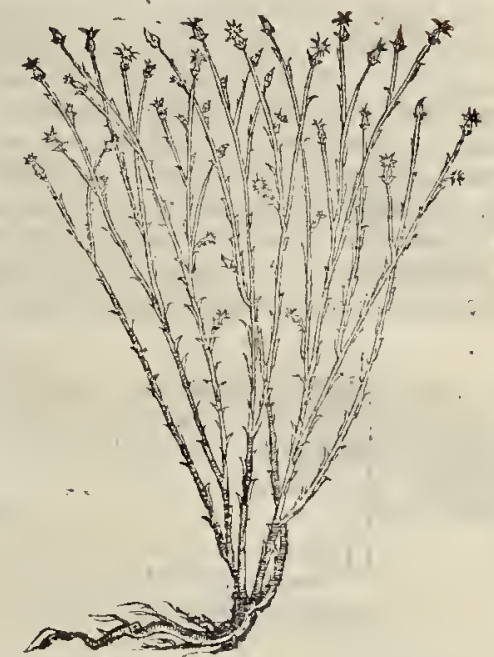

Catcrum Condriliana Cichoziumué illud Sylueftre quod Zacyntham viq; peregtinitatem affecustns rocat Conmentator:tam certum eft oriri in Italia, (ne è Zacyntho infula Graca eam cuocet) quan parum certum femcl voratam,quod att idem, ve multi de alijs quam plurimis fabulantur, delcre verrucas : Illita verò poffe, certum \& commune illi eft cum quamplurimis, quarum fucco exurantur aut exficcãtur verrucarum radices \& appendices tum calidis vt Tithymalo, tum frigidis vt Plantagine equifeto, intermea dijs vt Heliotropijs de quo nonen verrucariz teftatur idem.

\section{SERIS, fime INTY $B \cup M$ Satitum, Latifolium, ENDIVI C. SCARIOLA afficinis.}

Ger. Eratiolratubiuisn.

SGall. Endiui.

Belg. Doirte 1znoitté.

CAng. White Endine.

$Q^{2}$ V A.M I s Intubi nomen Latinis cunctas complexum effet Seridis differentias, ta- $M v t b_{\star} 49 g_{i}$ mé poftea Graca prolatio ex Intubo Endibion, quafi Intubion detorfit,atq; dütaxat uni fpeciei domeftice Seridis adfrinxic, quã Endiuiam \& Scariolam (pariter c̀ Se ride deprauatami) dicimus vulgo . Ea gratioris amaroris, prafertim fi mitefcat Holitorum induftria, fcd frigidions facultatis eft quam Cichorium, à quó non tantú cultu gra du, agriuć bonitite, fed etiam generica differentia dittat:nullo enim neglectu, tranfmotione alioué incommodo vifa fuit vnquam in Sylueftrem aut picrim Cichorium degene raffe, aut hęc ad fpeciem huius Seridis promouffe. Et manifefta radicun differétia, eft enim Cichorij benc habita carnofa admodum grata : Endiuix verò fibrofa penè nulla nulliufq; vfus in cibis, alicubi tamen in quibufdam compofitionibus, Et tametfi non ne garim omnia fumna genera in naturæ ditione fuife Sylueftria, antequam feri, aut coli copta fuiffent: tamen cerrum eft tum placitis, tum obferuationibus rei Rufticæ multis, quamplurimas plantas effe qux nunquam noftro faltcm orbi Europco fuerunt,aut fieri potuerunt Sylucftres: tametfi aliquantim varient vt hæc, anguftio:ibus iam, iamg; latioribus folijs, \& 1xtiore habitu : yerum femper ideam fuâfibi aut retinct, aut inteit. 
Lxtior multò exit è feminę Italico, aut cuiufpiam regionis meridionalis, vnde folent ferere quidam Brabanti, Angli, \& Germani holitores : fimul ac terna, quaternauè foliola eruperunt, in folum pinguius latamine multo tranfmouetur, lateritioq; fruftro media onerätur folia, quo latius fe porrigant luxurientq; qua induftria amarorem exuit, gratiamq; mitcum Hybernis menfis ad acetarna, feruatur obruta terra, fime to, ftraminéq; :infi mæ plebeculx notisima, nomine Alba Endisic, quando folia funt candorem aficquuta, per Autumn $\bar{u}, \&$ Hyemen virens, folj, ${ }^{\prime} \mathrm{l}$ tis oblongis, ex candore viridantibus initio eft, Lactucaceis proximis, proximumcaulem amplexis, in quo fores crulei Seridis, Cichorii femina, (\& interdum flos) alba, non fecus atq; Cichorinm interdum meninimus:radice albida,prolixa,marcefcente,dum femen maturuit.

$$
\text { Cripa. }
$$

(HA N c (quod idem Lactucis \& B̈raffica contigit)apud cultiores Romanos holitores videre meminimus: folijs amplioribus, rugofis, inq; plicas côtractis,crifpantibus, Brafsicæ in norem, caulem, tlores, \& femen non difpaIrarictas. ria alentibus.

FA N DEM hanc acutis, non altis lacinijs, folijs anguftioribus, nec diuerfam caule,flore, femine, \& radice alunt, quidan Horti Ligurum, Tufchorum, \& Gallorum, vocantq; Endiuiolam, \& Seriolam, quia minor tota fit.

\section{SERIS DOAIEST IC A, altera Laducina Diofo. amara, angustifolia, Officinis iamolim, fols $E N D / V I$, agnita of recepta, perperany recentioribues La- Etuca Syluestris putata.}

S E C I E M hanc incultam Seridis fatiux, non varietatem facimns. Eft enim folijs dum Sprimulum pullulant, \& cmergunţaltius, Scariol $æ$ hortenfis : poftea adultiora in effigien Dentis Leonis finuantur dentatisoris, \& nonnullis quafi in orfi fpina aculeis vti in noftra vera Sylueftri Lactuca: Caulis quaternum cubitorum, hifpidus,vnicus, rectus, lacte turgid us, floribus luteis, pallidis Laetucx donatus: amaro guftu, \& pręfertim vetuftioris, acri radice, pufilla, fibrofa, Seridis horten fis, Syrupo de radicibus mifcenda confuctudune Practicantium, quos doetifsimos barbaros, tam proteruè quam infcitè, quidã declamatores putidi rident, \& fpurcis connicijs lacerant, quod hanc plantam Endiuiam veram putarint, \& etiamnư vfurpent nó modo ad Syrupos de radicibus, de fucco Endinia \& alios Nicolai, fed etiam ftillatitias ex ea eliciant, quibus fuas Rhabarbari macerationes parent. Eile quippe nimis calidam, amaran, ingratam, quidam illorum rcprahenforum, alij autem cffe Sylueftrem Latucam, ncc aliam fe nofe dictitant. Sed enim qui inftitutum perpenderit veteris Barbarorum noftrorum fcholæ, animaduertet illos magna ratione \& cxperimento neutiquam contemnendo fultos. Quippe uon folum hanc Endiuiam, aptiorem effe decosto fucco, \& fillatitia ad intemperies, obturationes Hepatis, \& primarum venarum, fed etian macerationes Rhabarbari, Myrobalanorum, \& fimiliú medicamentorun : cum enim fit páulo tenuiore \& minus excrcmentofo humido, melius referat, \& abftergit: tum etiam intima rerum macerandarum peruadit,nec calore exuperat, aut amarore nocet, cum eius amaror non fit à calido, aut faltem non calidus, vt norunt cultioris Philofophix periti, \& ftudiof conciliare apud Galenum, \& Auerroen, quętionem de Opio, Meconio, Papauere,Lactuca, Mã. dragora, \& non parum inultis alijs amaris, multum tamen frigidıs, qua accuratè in remedijs dicétur. Quin Diofcori. docēte, Sylneftria Intuba, fiue Scrides Sylueftres, ftoma cho meliores fatiuis, quia ipfum ęfuantem \& tenore refolutum refocillet: in cibis vor2$t \mathfrak{x}, \&$ foris admotx. Et notę huius melius congruunt Endiuic fue Seridi amarę anguftifolix, quam Lactucæ Sylueftri, cui noftra pauló inferius defcribenda, paucis adhuc cognita \& nulli depieta plenè quadrat. 


\title{
STIRP IV $M$ aduerfarianowa. \\ SO NCHVS CASP ER A,Vulgiflore Hieraciy, foliys Dentis Lconis, alins \\ Diplacios Ladtuca, an Diofcoridis A R BORESCENS \\ $S O N C H Y S$ tenerior latifolia?
}

\author{
Gérm. Genfizoiftel. \\ Ang. Sow thistle. \\ $\{$ Ital. Cicerbita. \\ Gall. Laifferon \& Laiteron.

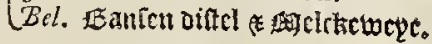

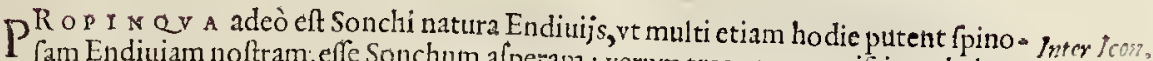

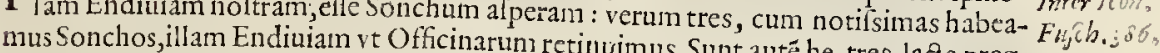
nantiores veræ Sonchi Græcis $\pi \alpha \rho \dot{\alpha}$ Tò $\sigma \widehat{a ̈ o s ~ x e ́ v ~ q u i a ~ f a l u b r e m ~ f u t e ́ ~ h e ̨ ~ t r e s ~ l a c t e ~ p r e g-~}$ eftrofas ftomachi lancinationes \& Hepatis biliof falubrem fuccum de fe fundant, ad bitam Latini \& Itali ctiamnum vocant Genfsoiftel obftuctiones vtilifsmam, Ciceroiftel Germani: fune fpināanferinā, fpinof̧ nullis ferèvifitur. Ouarum dur fręum hor ridulucula aculeis, quędam perpufillis aut bus \& vinetis : minor,minus obuia \& not maiores fponte, cultis \& incultis, fegetibus \& vinetis : minor, minus obuia \& nota. A pera que vocatur, è radice prolixa, fubflaua,fipatu fibrarum comofa, caulcm erigit concaum, quaternum \& fenum cubitor bene adultum, alatum, \& floribus donatú, luteis pappofis, Senecionis, aut Hicracij minor bus. Folia ab imò numerofa, laciniofa, Dentis Leonis vbi folo fquallidiore oritur, fin verò latiore aruo \& pingui, lątucacea funt: Dipraci maçnitudine leuiufculis, per arn bitum lacinijs \& fpinulis afpera, cunetifq; fwi partibus adeo tenerefcit \& frucicat, vt arboream fenun, feptenumue cubiterum proceritatem ęquet, cibo etiamq; tunc fit mitior \& aptiol: : quare multò commodius ftatuifent, iftan efie Diofcoridis arborean, cum dux fint adhuc notiores, \& aptiores ad explendum Diofcoridis trium Sonchi ditferentiarum deferiptiones, quan Endiuiam illam Officinarum, de qua fuperius. Er faueret coniecturæ plantz huus teneritudo, ac foliorum latitudo, quam dicinus contingere. Soli bonitate acrifuè \& regionis varietate, quemadmodí in Cichorijs \& lactucis, quz cum agreltes funt, hirfutiores \& finofiores proueniunt : cum verò folicius adolefcint, tenerafcunt, miaufq; horridz funt. Verum Enduria illa nec tenerefcit, nec vnquam ef culenta fit,potius amarefcit, \& farnentofa euadit, fimul ac foruit.

\section{SONCHVS L AVIS, laciniatisfoligs.}

\author{
Ger. Zafentot.

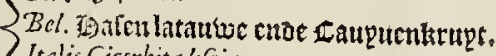 \\ CItalis Cicerbitalifiar.
}

\footnotetext{
( A Lt e R A m vero leuem dixerüt, etfi folijs fit magis fcabris altioribus, $3 \mathrm{n}-M a t h .497$. guttioribus $\&$ inconditis lacinijs, longioribus, minus tamen multò fpinis horridis caulé ambiétibus: per quoldam quafi genicularü cxortus recét Aratum, rubellum, concaum, lacte turgidum, Horibus pappofis Senecionis aut Iacobex habitu ipfo, foliorum quadamrenus Papauer Corniculatum

Varietas. prefert:Oleracea tametfieffe potelt, tamen quia non colitur non manditus.

Diuerfam quandam ab vtraque fuperiore, parsim ijfám in locis, vinetis Matbofgs, \& fegetibus obfcruauimus: teuuiorem totam \& foliorm incifura, atc; fifuitune Papacris erratici (quemadmodnm fuperior cornuti) circumfufa, imo cauli é Radice parua fibrofa,pcdali \& cubitali Hieracij modo ala-
to \& Aoribus luteis non diuetfis,
}

$$
\text { H.ij. HIERACIA。 }
$$


NO n fecus ac Elaphobofcum à Cerno, Chelidonia ab Hirundine, Perdicias à Perdice, permultag; alix plantx mutuarum eft nomen Hieracium ab aue cognomine, qux libi huius fucco aciem calligin ofam colluftrare confueffet, aliòquin è generc Sonchis non diuerfo fed proximo eft omne Hieracium, cuius multæ vel differētix, vel varictates funt: \&: omnium frequentifima qua maius vocatur.

$$
\text { Maius. }
$$

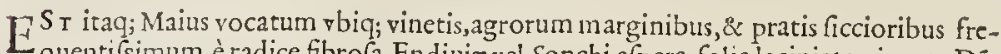
Luentifsimum, è radice fibrofa, Endiuix vel Sonchi af́pera, folia laciniata pinnata Détis Leonis vel Sonchi diuifura promit, caulis inanis ftriatus nonnihil interdum rubens pedalis \& fefquicubitalis flores Senecionis vel Sonchi ex luteo pallentes funt. Tota laae turget non fecus ac Lactuce \& Sonchi.

\section{IIIE RACIV M minus premorfa radice, folijs acuté laciniat is fore liutes.}

M! n v s Hieracium pratis montofis Anglia admodum familiaré, cauliculos fundit iunceos, laues, graciles, fefquipalmares:è radice parua fibrofa, plantaginis aut Succifr modo pramorfi, eog; plebeculæ Hybernx, Morfun Diaboli vocatū. Folia pinnata anguftius laciniofa, delicatiora, minora, vti etiam fores lutcoli, in pappos enolantes.

\section{HIER ACIVM slind minus, non laciniogum forijs Pilofells.}

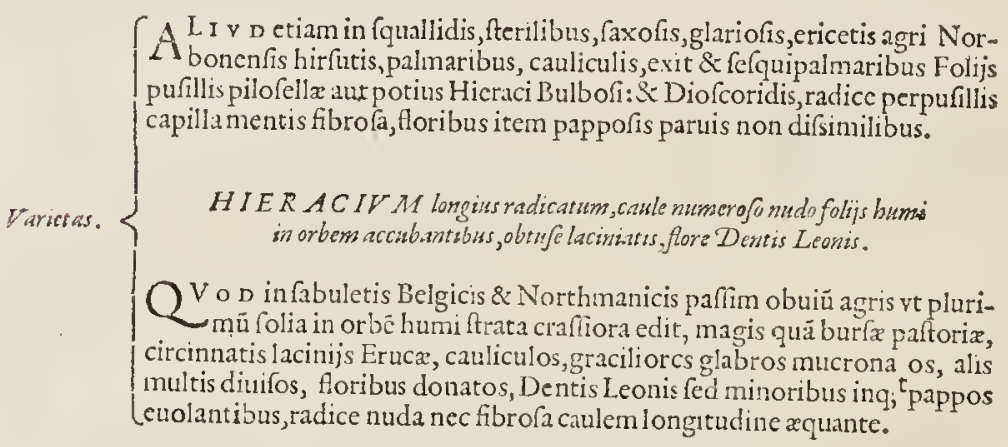

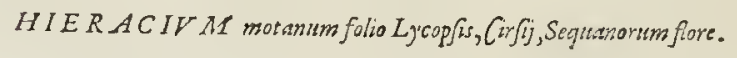

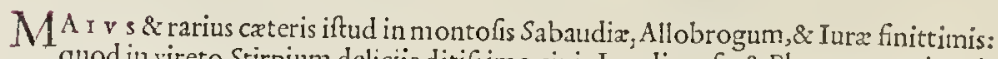
quod in vireto Stirpium delicijs ditifsimo ciuis Londinenfis \& Pharmacopei peritifimi Hugonis Morgani flores edidit Iunio Cirfij lutzos femenq; hirfutum Tragopogl,ortus \& caulis aliguantum Carduum Benedictum afsimulant aut Cirfium, cuius etian eft folijs obfcuris per smbitum crenulis peracutis afperatum \& acrius, nec perinde
vt fuperiona lacteum.

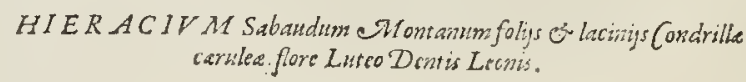




\section{STIRPIVM aduerfaria noona.}

EI I em Morgano fornit altera Hieracij fpecies Iulio \& Iunio, Condrillæ cærulex folijs altutus incifis, viridrbus, in caule flaccido \& molli glabro. Flores Dentis Leons ali; quantò minores, radice Tragopogi.

\section{TRIDACHE $\dot{S}:$ fut $L A C T V C \& E_{\text {: }}$}

\section{2} Vemadmodum Seridis recenfuimus multas fpecies fubalternas quarum qux dam longins, queddam verò propius à fe ipfis abfunt, fic poftumus conftituere Lactucam illius Endiuix fpeciem quam Lactuceis follis donatam ex diofcoride defcripfints. Quippe Lactucę nonenclatio, à lacte ducta \& diftin ća fuit (peciei huius, quia plus lactıs refudaret cæteris Endiuijs \& velcentibus muliercu.

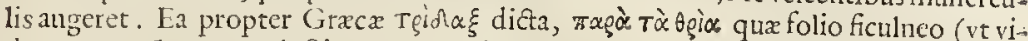
detur) vocarüt, vtpote, lactis nou expertia. Cum auten latuca hortenfi efculenta nullum olus frequentius aut notius fit de cuius collatione Sylueftrss laktuca nofcenda fuit \&icenfenda recentioribus.

\section{LACTVCA AGR EST IS: Scariole bortenfis folio, Lactucaflore, Opj Odore vebementisoporifero os virofo.}

NA $\mathrm{m}$ ea Seridis fpecies qua folia habet Dentis Leonis ritu incifa, quam propter \& proceros caules \& frequentes aculeos Sonchum arborcam Sylueftremué quidã putarunt, nihil lactuce funile habet praterquam lac \& femen. Foliu adeò intybaced fune ve Pliamacopoos vbig; etiamnum cä in pertinacia alat qui hancee pro Sylueitri Eliduia agnofcunt \& vfurpant, tun Syrupis, tum Styllatitij liquoribus Horum plerify; adeoq; ciam Lostis prxceptoribus noftris, vi Rondellctio \& Affatio maximo ftyrpium Norboneufum indagator1, altera lactuca non minus peefettim hic in Anglia frequens quam illa, fed longe proprlus accedens quaibet fui par te ad lactucam vel ad Ceridis latifolij vulgo Scariolam laetuca fimillumam, ferucntibus folibus Norbonz locis apricis huius lacteum fuccum exuberantis $\&$ pro copi? tranffuents dum colligeremus, vix foporiferum ferre poteram? odorem qui teter 8 ingratus vt opij. Caulis bicubitalis, glutinofus. Flores lacucx, femen aliquantò minus nigricans. Eandem feuit in horto Morganus Londinenfis Pharmacopœus perituis, vi à fatılia fpecie ditherfam facile difere ac meminiffe par

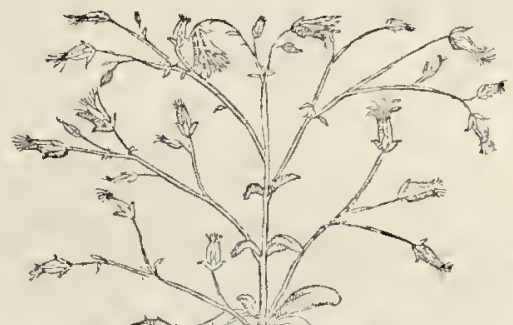

Lactuca Sylites stris vert.

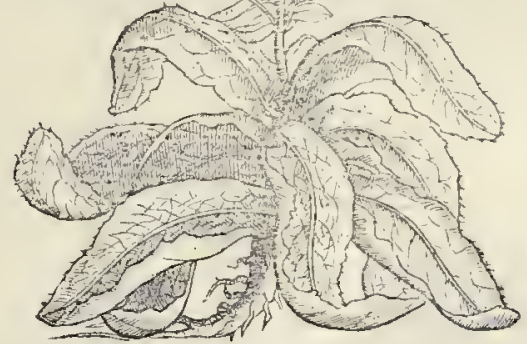

eft, ne cultx quidem foliorum rotundam oram, ac pro fui magnitudine latam, amplam, neclaciniofam; (qualem vult Theophraftus \& Diofcorides) Dentis Leonis modo inefo fe,vt Endiuiz Officinarum prafertim adultx.

\section{LACTVCA SATIVA, Folio Scariole.}

ET fativæ quidé laçucx notius nihil, cuius varietates complures funt nô fecus ac Braf ficx. E Radice fibrofa Endiuix caulem, cubitalem \& fefouicubitalem, rectum alis dirifum, \& lafte pregnantem edic, cui infunt follia feridis fatiux fimilia. Flores copiofi H.iij. 
pufilli lutcolj in pappos abeunt. Semen pufillum album teres compreffum Phalaridis lexuius,anguftius.

\section{IACTVCA CRISPA, non capitata.}

E L E G A N T I A ftudiofi Olitores, in hortis colür: quamplures huius Lafucx varietates, nempe Crifpam, qux eadem cum fuperiore effet, nifi illieffent folia reduction, contractiora \& bullatis, rugis crifpata : vnde tota tenerior \& olere gratior habetur. Semine alioqu \& reliquis partibus, à fupcriore non differt.

\section{$L A C T V C A, \operatorname{RO} M A N A$ dulcior, nigriore os Scario- la bortenfis folio, envine nigro.}

RARI $\mathrm{PS}$ hæc in Gallicis \& Germanix hortis colitur, frequentiffima tamen Italicis, Romanis præfertim, vnde Romana vocata Sattiba varietates. $\{$ fuit : nec à vulgari diftat, nifi quia nigriore folio, nec perinde fcabro femine nigro, tenella tota, guftu dulcior,eoq; gratior, aptior ventri mouendo, quam merito putet quis fcitè illo Martialis carmine de-

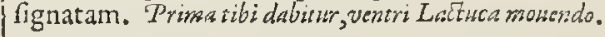

\section{LACT VC A fativa, fepilis, fiue eapitate, rugofis crispis Braßuca folys.}

CA r I A T a verò qux vocatur, propter glomum foliortum conuolutorum, atq; ftipatorú in fefc, quafí multx tunicx mutuò appreff $x$, ad xmulationem Brafsic capitatx \& fefsilis vocatx, quia vixdum à radice exiens foliorü globo, infideat humi, qua dc nota eft cuinis notifsima, ac tenerrima: prime in acetarijs commendationis, albicat . Si qux funt preter ea Lactucx minus verè dictx nomine, vt Theophrafti marina, vel laEte, vt Tithymali, fuis locis dicentur. Permulta alià experiuntur Lactnca mangonia fcitè conuenta veíuti \& Brafsicx, quibus facies \& fruitio, in olere non admodum difpar.

$$
\begin{aligned}
& B R A S S I C \mathcal{A} \text {. } \\
& \text { reAlba, Sejults, glomerojn, aut capitate, Lattuca habitu. } \\
& \text { Eadera conicolinta o arcti occlufatapud Belgas, rubro colore, enernitib. } \\
& \text { aptior. } \\
& \text { Sabauda, Vulgo Sanoye, patula o minus occlufa, faris virens, mins }
\end{aligned}
$$

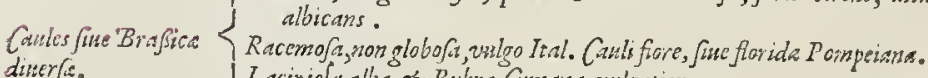

$$
\begin{aligned}
& \text { diverfis. } \\
& \text { Laciniofa alba, or Rubra Cimana, vuloatior. } \\
& \text { Nigra undantibus, crifpis co lacino is folys. } \\
& \text { Marina wultiflora, Syluesiris, monofpermos. } \\
& \text { Caulorapa,braßica peregrine, medio caule turbinata cu rapaia. }
\end{aligned}
$$

VOL IM $\mathrm{O}$ s fuperius Raporun generi comparare \& fubdere Brafsicas, propterea quiz mutua fit quxdam amicitia \& affinitas veriufuis feminis, vetuftioris præfertim, vtramus plantam generandi, vnde antiqui Græci Raphanum Brafsicam, vel hanc Raphanum vocitabant. Attamcucommodior occurfus, aliarum plantarum fecit, vt hac

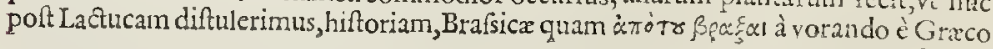




\section{STIRTIVM aduerjarianona.}

dictã verifsimilé êt. Eftur namq; tota à plebecula tú cruda, tum co\&a, vcl muría ferua-

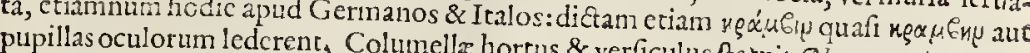
wis oculis inimica corambe. Tan ctfi placuit hortus \& verficulus ftatuit. N unc venist qum-

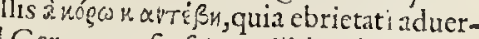
tifsina, quare nullum cit opcrc pretimna apud Germanos, fi vfpian alibi.Scd vbiq; nofuturum, quòt cultuvel eucétu alio varios fubi vulgarem exactius notis defignare, fatis gere. Eft ouippe omnis

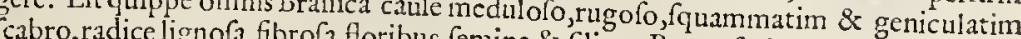
fcabro, radice lignof, fibrof, floribus, fenine \& filiqua Rape : folia ortu \& afpectu La.
etuce, cuius etiam varietatcs initatur. Caterum Brafsicam marinam fuc Soldonèlam, magis vfa \& nomine quam re funi-
lem, inter volubiles dicenus.

\section{BR A S S I G A alba Seßilis glomerofa, aut capitata Lactuca babitu.}

uésulok

$$
\begin{aligned}
& \text { Gall. Chou cabu, blanc. } \\
& \text { Ger. Kappiftraut } \\
& \text { Belg. Witte fluptkeolcu E Eabntrikgolen, } \\
& \text { eAng. Cabbuge. }
\end{aligned}
$$

NI I I fimilius Crifpęcapitatæ Lactue quam hæc Brafsica : folijs etenim adnodum crifpis, dence inter $f_{c}$ conuolutis, intus forif; albis teneris, interna parte concauis carinatis \& quafi media cofta, extcrius verò neruis venofis, digitum craffis medijs \& fecundum longitudinem hinc inde curfantibus, aut obliquantibus, cuius in olere apud Italos \& Gallos prima commendatio.

$$
\begin{gathered}
\text { Eadem conuoluts cuaté occlufa, apud Belgas, } R V B R \dot{R} O \\
\text { colore, enematib. aptior. }
\end{gathered}
$$

HE n nif colore, à fuperiore qui ex putpureo elampelino, in cortulcum languet dif

fert.Vtriufq; nufquam maior proucntus \& fętura quam apud Belgas vifitur, qui naucs onuftas in vicinas Gernanix, Anglix \& Hifpanix, regiones denehunt. Hyeme cibis funt gratiores, cnematib. valdè accommoda, quare fxpifśme mifcent, Germani \& Belga medici. Vere primo panduntur folia \& in caule bicubitali, tricubitali unciam craffo erü-
punt flores, fliiqux \& cornicula Rapi fimilia,

\section{BRASSICA PATVLA, Sabauda vnlg. Sauoge,Intus Albidis, foris virentibus folys.}

Ne minus fpeciofa quam Sabaudam recentiores hodie rocant, à fersili Capitata

diffdet tantum colorc. Capitulo patulo,minus claufo, \& floribus albis. Impatiens friģoris admodum, quare in Italia, Sabauda, maritima plurima, rarior ad Septentrioné, vireliquæ brafsicæ frequentifsimé coluntur \& cduntur.

\section{$\mathbb{2} R A S S I C A$ florida.}

ELEGANTI $E$ peregrinx cft qux vocatur florida, aut potius racemola, vil botritis funt enim quãdam gcrminula florum, qux denfifsimis, mufcofifq; albidis, olca crumpunt : oblongis racemis èmedio quafi foliorum centro, vbi quafi vtero, conduntur za fouentur,femine Rapa, guftu in olcre dclicatiore.

$$
\text { H. iiij. IRASSICA }
$$




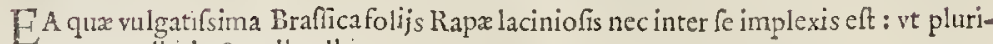
mum exalbido \& pullo albicat.

Eademq; in hortis Rubro colore ex cxfo, crebra vifitur. Cui interdum carnex coft carinæuédorfi foliorum rubent fol $x$ : Interdun folæalbæ funt, reliqua foliorun tunica purpurante, aut vodante, oris \& fimbrijs crifpantibus.

\section{$A N G L I C A M I N I M A \mathcal{B} A S S I C A$.}

M E M N I M v s,ctiam in Anglix hortis pugillam brassicellam, totam niuxam fræe terquam extremas oras laciniofas fimbriatáfq; plicis crifpantibus, \& vndulıs rugofis, purpures, afperfas maculis, quas etiam ad corollas \& olfactoriola nectenda: dum tenella adlatic eft in hortis colunt,

R E GI ON I в v s ad meridiem quibus prefertim oleum abundar, hæc multum familiaris in olere quia fuauifsimo guftu elt, oleo prefertim vel condita, vel elıxa, aqua mixca : folijs cft quam fuperiore vulgata, nugrioubus, viridioribus, \& rugofioribus.

$$
\text { Trafaca, } \rightarrow A R I N A, S Y L V E S T R I S \text {, multiflora, monofpermos. }
$$

PR E T R R hafce elegantias, fimbriate, crifpate, \& Aloridę, Brafficę:quxin Be]gio, Francia \& Anglia,magna copla feruntur : elt etiam porquan pulchra Branica Sylueftris, Diofcoridis fpecie diuerf ! locis oriunda Anglix maritinis, a.t ortlandian infulam : fed quia inculta, ne. gleats, Hifpidior tota \&x predura eft, eymę inrratiores multo, cibo toleräda tamé. Cuius fenine iam diu Medicus Anglus hac parte cxercitatifinus, Turnerus nos donarat, eāq; mono enulu $\mu v v \sigma \pi \varepsilon \dot{q} \mu w$ vocandam,à femine fingu larivolebat. Suntenim in florum pallentium aborum congeric elegäti, denfa \& vmbciloa, multisinamis filigux breuiores crafsiufcula, quibus fingu is fingulum inett femen, paulo minus Do, Soldonellę, aut Orobi equale Folia cade nu fermè que Braficę nigrę, fed craffiora \& lariore afpecta, \& fimbris vndulatis plicifo;

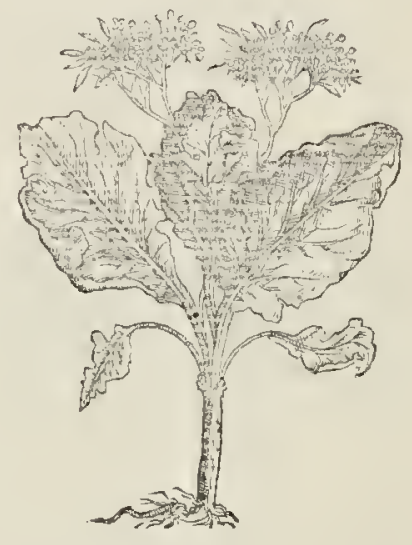
adinodumartificiofis.

\section{CAVLOR AP A, BR ASSIC A peregrina, maedio caute turbinata of Rapata.}

SVPER EST mirificx illa Naturæ lufus recentioribus, Caulorapum vocata, plan ta pe"regrina, c̀ Græcis, hortis noftris ingulina: Rarior Septentrionalibus, vtpote, cuelo tigidioriminime affucta. In tralia nob s, Florétiz, Pazatii, alij f̧; locis vifa, folia illi vulga ris lbx tum aquutx Brafica, per ambitum latius finuata, radicx lignofiore caulem effert:nou alciorem pede, qua folı oriuntur, quorum exortus ambunt \& inuolume : pro tuberanten bulbinfar capitatú, funfofa carne Rapum, vnde nomen Caulorapum cóflatum, vti natura upfa. Quod tuberofum Rapum, Caulı reliquo concolor eft, \&c fapore, medula codem quo caulis. 


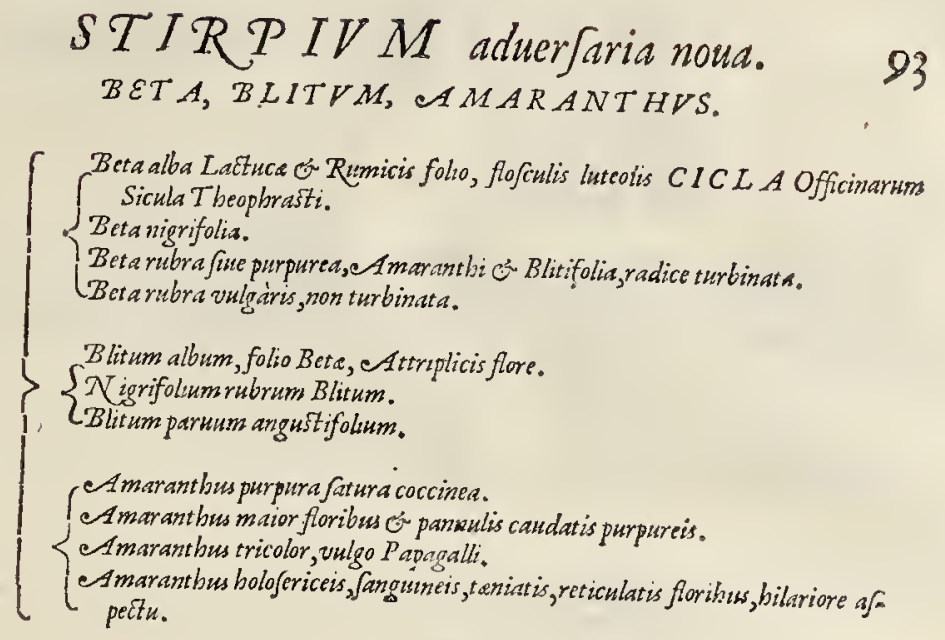

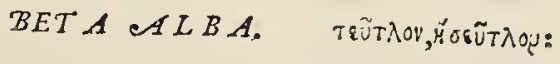

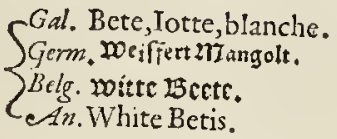

Q Vo modo non fruftra optent probi primates, in qualibet re publica benc inftiruta, ne exercitati,qua fine corum modo fidi \& induftij, fed etiam fimplicium cognitio. tifsimos qui fe vocari cupiút, \& qucus ef aut fcelus, quando hodie videas corum periter Blitum \& Betam neclecend quafi medici cui famulätur Thefeos qui quid interfit in. Sed vtrumlibet pro altero accipiunt proter gemto oculis manuué difcernere nequeãt. fimilitudiné, tametfite accipiunt,proter geminam nempe nominum \& folioriorun

$m$ diftent inter $f c$.

fo litera proxma prime, deprimitur fta fic dictam volunt, \& canit Lucius Columella, tur vocatam, quia in proceritatem am,jifidis pede candida Beta. seṽ $T$ rep etiam opinanamplisimung; ambitum impellantur folia \& caulis nis Cicla detotto nonine a , qux maior, vtilior \& vfitatior, cxtcris ef, vocaturq; Offici lus hortus caret honine a Sicula frue Scicilia infula vnde primum nomen habuit. NulPIantarinis maioris Caus Lactucx per inicia magna fimilitudine, deinde Rumicis aur res copiofi ex viridi luteoli \& femen nigrupedali ftriato angulofo alis diuifo in quo floueftris modo occlure lique mul tò nitrofior\&mordix digitum craffa fefquipalmü longa fibrofa. Hxc quam recior difcerni poteft a B mordacior cft, muccum elicit naribus ficcus : gnftu quia mordaleram faciunt quemaditis, qua funt ignauiore, infulfo guftu, magis humentes, ct cho. tatcm expultricem cunodum Cucurbite, Pepones, qux dum nequeunt excitare faculq; ventriculi motiones excitant, tatumunt cibum,ipfiq; corrupti romitiones turbidar-

NIGRA BETA.

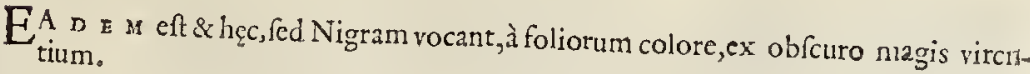

$$
R V B R A
$$


94

\title{
ST IRP IV $M$ aduerfarianous.
}

\author{
SAing. Redde Betis. \\ Sall. Bete rouge. \\ SGer. Koter inangolt.

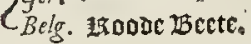

$A B$ illis duabus diftat hxc radicis effigie, medio fui ventriofa \& turbinata, Napi modo, foris intufq; tota rubet, fanguineo cruore fuffufa, edendo fuauior, nec perinde falla eft folijs, caule, floribus \& femine fuperioribus non difsimilıbus.Hæcrarıor.

\section{BETA RVBRA Vulgatior.}

NE c hxe differt ab alba fiue Cicla, nifi colore faturo rubente.

BLITVM Mairs albuns.

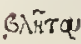

$$
\left\{\begin{array}{l}
\text { Gall. Blette. } \\
\text { Ger. niager. } \\
\text { Ang. Wilde fine orrggt. }
\end{array}\right.
$$

I S C E natura \& figura finitima Bliti ab infulfo fatúoué fapore qui in eo percipitur

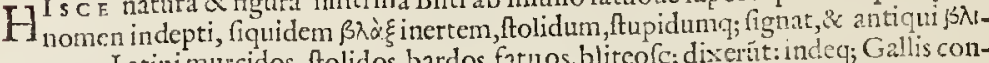
Trs quos Latini murcidos, ftolidos, bardos, fatu os, blitco $\Upsilon_{\zeta ;}$ dixerit: indec; Gallis con-

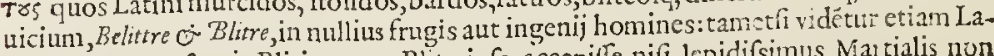
tini Betam, pro fpecie Bliti aut pro Blito ipfo accepife, nifi lcpidifsimus Mastialis nun bene norit diferimen illo difticho.

$$
\begin{aligned}
& \text { Ut fapiant futue fabrorum prosdia Bete, } \\
& \text { O quan sepe petet vina piperg } \text { coquss. }_{3} \text {. }
\end{aligned}
$$

MA A O R I \& vul gatiori radix gracilior eft, folia fere Ocimi, aut Atriplicis glabra, cinereo, colore, floribus item Atriplicis \& femine pufillis Vrtice, compreffis pericarpiis Betrinclufo in caule trium quaternumué pedum, inuifa aut contcmpta Olitoribus, qui eam eruncant extruduntq ; è fuis hortis.

\section{BLITVM TI INVS albuks.}

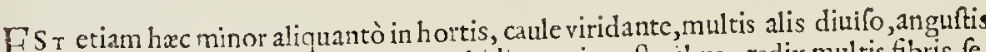
folijs triplo, quam Betx minoribus, rubidis ex nigro floribus, radix mul tis fibris, femen aggeltum vt in Atriplice.

\section{BLITVM RVTRVM.}

Mar.effig. 453 NE c diuerfa ab illa elt Rubrum Blitum, nifi quia intenfê rutilant fanguineo Caules, \& folia ex rubro liuent : Semine fermè concolori.

\section{BLITVM RVBVM MINVS.}

M I O R hac fponte etiam inter olera, fed puriotem \& faturiorem fundit cruorem,

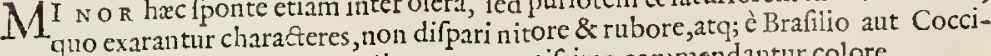
nis baccis. Folia etiam X erampelino exuperantifsimo conmendantur colore.

$\mathrm{AMA}$. 


\title{
STIRTIV $M$ aduerfaria noua. A $M A R A N T$ HVS Porpuretus, faturo Coccineo.
}

\author{
Clal. Fior velluto. \\ Ger. Bamat bluom is Danfent feloos. \\ $\{$ Gal. Paffevelours. \\ eAng. Flover gentill. \\ Belg. frouberblocnet.
}

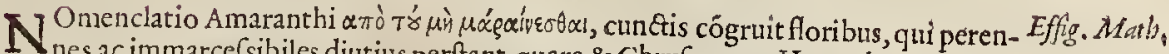
o,alijf; pertinacis coloris \& decoris attributuare \& Chry? come, Heranthemo,agera- $1047 \%$ pultitu cuinfmodi eft iftud Blitum:perpulchra florum purpura nitıdum, nec fęnis, aut feptenis annis vietum, decolorg; futurü, eoq; Taßseuelours Gallis vocatur. Quod an Theophraft, Diofanthos, \& Phlox, in Adonide herba dictum.

Vulgatior.

Elegantix ftudio apud Italos, Gallos, Germanos, \& Anglos, in hortis multis feruntur, \& coluntur, quę non difficile è fuperiorum cffigie percipi poffunt. Hæc autem eft latis Bliti Solani, aut Ocymolongioribus folijs, per interualla binis, fecundum qux fpicx pannularum oriuntur afpectu blande, holofericum mollitie, vellere, ac nitore pronocantes, femine nigro, pufillo nitente.

$$
\begin{gathered}
A M A R A N T H V S \text { G } A I O R \text {, floribus pannulis } \\
\text { Jpicatis purpureis. }
\end{gathered}
$$

NE c huic difsinilem, fed fioribus fuperna parte luxuriantibus, multis pannulis fpica- Blitmm maius tis inflexis, fe mutto implicantibus, incundifsimo fpectaculo, fed obfoletiore cocci- $M a .452$.effig na:cuncta reliqua uon difsimilia fed maiora, caulis octuum aut denum pedum ftriatus,
\& folia niaiora multò.

$$
\begin{aligned}
& \text { A } M A R A N T H V S \text { tricolor, vulgo Papagallisitné, T HEO M- } \\
& \text { BROT }
\end{aligned}
$$

$H^{V}$ i v s venuftas non de flore ed è foliorum triplicis coloris, maculis fcitè diftinetis, pendetur . Sunt enim Ocyni, aut Bliti, interdum luteo viuido, vel purpureo, nunquam etiam triplici viridi, luteo \& fanguineo concolori, Pfitacorum alis: quare plebecula Flandra Papagalli vocant. Scme \& flores Atriplicis aut Bliti:Hæc omniu rarifsima,

\section{eA MARANTHVS Holofericeis, fanguincis, tenistis, reticulatis floribus, hilariore af pectu.}

$S^{E}$ D venuftatis eximix illa qux rarior in hortis Italicis, vberem prouentum forum nularum, caudis vereto, in arcum flexis, \& quafi fe mutuo dccuffantibus ligularum, vel pannularum, caudis vegeto, \& pleno rubro cruentatis, ,emine plurimo pregnantibus. Mag næ apud mulierculas comnendationis non modo voluptatis Coronarien ergô, fed etiam matricis renumq; prolluuia fanguinea \& vicera fanie manantia.

\section{A T R I P I I C E S.}

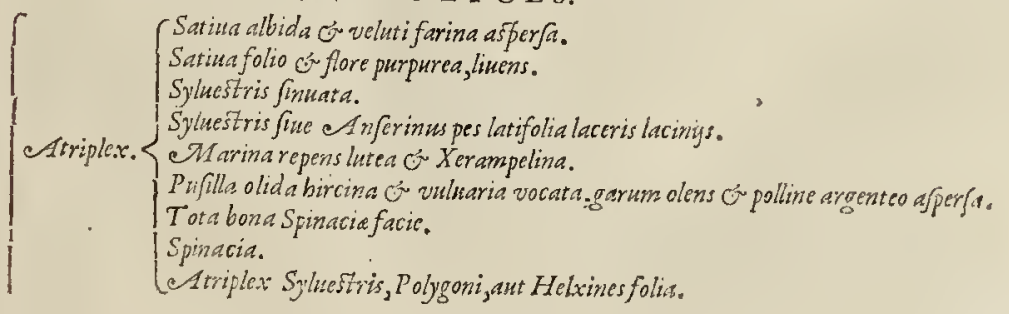




\section{STIRTIV $M$ aduerfarianoua.}

Helxine Parietaria.

$\{$ Halxine CyJampclos, inecr Volubiles.

$\left\{\begin{array}{l}\text { Pbyllon thelyganum. } \\ \text { Phyllon arrberogonum. } \\ \text { Mercurialis }\left\{\begin{array}{l}\text { mas, } \\ \text { formina. }\end{array}\right\} \\ \text { Cynocrambe. }\end{array}\right.$

Heliotropinm $\left\{\begin{array}{l}\text { mains, } \\ \text { minus reperss. }\end{array}\right\}$

Tornefol, vulgaris Vermucaria, of Tricoccum Heliotropium Tli. Hoiterfe fine Holeraceum.

Veficariwm, fime Halicacabum.

Veficarium loguminofum, fune cordatrem pifum inter legusine? Sonmferum \& Lathale.

Furiofurn.

Solunum $\{$ Somniferum Math: Verticillatum.

CArboreum, fue Amonmm Italorum, Maniacum, an Stramonium?

Cacubalum Pluny, quafi maleficum.

Circan.

Vua Paris.

inhandragoras $\left\{\begin{array}{l}\text { mas, } \\ \text { formina. }\end{array}\right\}$

Hyof hiamus $\left\{\begin{array}{l}\text { albuss. } \\ \text { luters. } \\ \text { niger. }\end{array}\right\}$

Melongena fine Melazena.

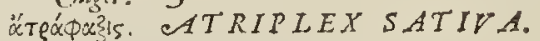

Gall. Arroche.

Ital. Atriplice.

Hip. Armoles.

$\{$ Ger. zan zolten fire milten.

Eelg. Itame nuclor.

Ang. Urrage.

T TO n ninus multiplex Atriplicum genus, nec illis adeo difsimile eft ortu, facie, fapo:e, olere, \& incremcrti celeritate, vnde retinuit nomen è Græcis apud Latinos,

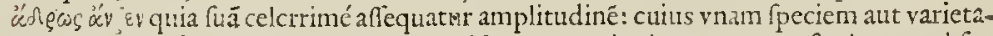
tem Chryfolachanon vocarunt Diofcorides tum antiquiores, tum pofteriores cui folit quin marcéfcrtia c̀ luteo vel fauó in aureum vergunt, aut $x$ crampelino corrufcant. Tametif hxc aptius congrucret narino, cuius multa fafta mentio apud Diofcoridem, quem \& eius coxtlos fcriptores tacitè videtur negligentiz arceffere Pliniusin Chryfoliachato Hore aureo, folijs oleris tantum indicato. De Chryfolachano(inquit) non fatis dici fcio,nec plura reperio. Hodic tamen notifsimæ quä plurime Atriplicis differentiæ, Sylueftris, domefici, maritina, Cunctis tamen quadantenus Bliti folia, ortus, modus, profertim domeftic funt : radix fibris capillata, rectos fapos enittens, proceritate hominis friatos, 111 ino terctes, fuperius angulofos, ramulis divifos, Ifatidis foliofo femine onuftis: poftuam luteiflofculi numerofi Eftate \& "Autunno defuerint, folia funt lationa ad bafim quam Betr, fed albida atq; farinaced, puluere nufcido obduta.

A RTIPLEX SATIV A altera, folio Co flore purpurea, limens.

Huic domeftica prorfus eaden eft ca qux ex liuido purpurafcit, aut rubet, caule \& fore, alioqui non vlla firi parte, difsimilis. 


$$
\begin{aligned}
& \text { STIRTIVM aduerfaridnout. } \\
& \text { aA TRIP L EX Syluestris finuata. } \\
& \text { Germa. Woilo moltent. } \\
& \{\text { Gallis. Arroches fauuages. } \\
& \{\text { Belgis. milide Ageloc. } \\
& \text { lang. Wilde orrage. }
\end{aligned}
$$

SY I V E S T R E M diftare fpecie à domeftica,præter cultum fruftra tentatum, folia etiä docent, quę nigricant plumbeo colore Solani(qui cum lubens fochatur in viarum mar ginibus ) ideóque antiquis atıum olus putabatur dicta : vbíque locorum circum mcenua \& fimeta multa, nota \& negle ta fylueftris A triplex: luxuriat foliis minoribus, anguftoribus obtufe per ambitum finuatis vel dentatis, floribus iten ex luteo herbidis,

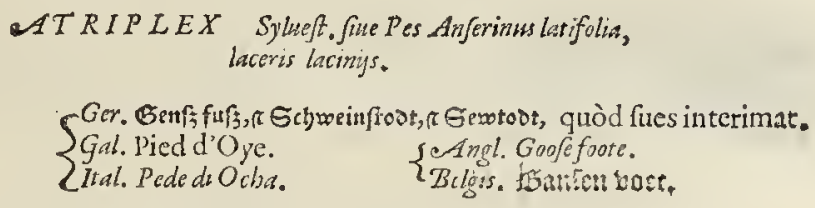

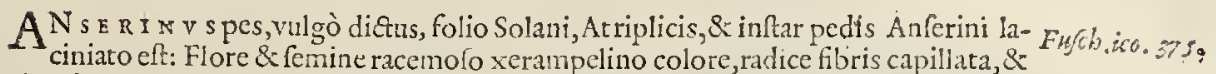
circa hortorum \& viarum fimeta palsim non fecus ac Atriplex obuia. Nullius in Offcinis vfus; fues interimere fertur,

$$
\begin{gathered}
A T R I P L E X \quad M A R I N A \text { REPENS, } \\
\text { lutea, } 6 \text { xerampcling. }
\end{gathered}
$$

MAr I r m is Mediterraneis, \& Adriaticis nufquàm nō obuia humi frata Atriplex, Caule, femine foliis laciniatis Sylueftris Atriplicis \& Spinacix, interdum colore, fed cralsioribus, latioribus xerampelino, interdum \&x lutco, fapore falfo nitrofiore.

$$
\begin{gathered}
\text { PVSILLA ATRIPLEX OLIDA } \\
\text { Hircina, Vuluaria vocato, garum olers, } \\
\text { polluze argenteo aper } \sqrt{a} .
\end{gathered}
$$

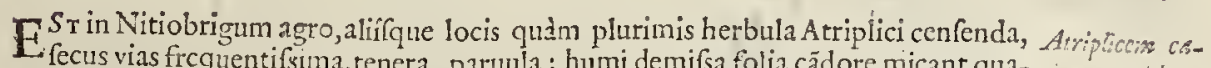
Efecus vias frcquentifsima, tenera, paruula : humi demifsa folia cãdore micant qua- ninsis gridem fi polline interperfa. Hanc notifsimam fecit odor, \&. fermè infamem : odoratu nám- disterunisani c. $\vec{z}$ que Hircus tetérque fpiritus oplet nares, quo imbuti quęruntur permulti fe meretri- ex vrm, C. cum impuros loculos fubodoratoseffe : planéque referre odorem illum virofum quem crafíniourraik proftitutr libidinis forta eximpura colluuie congefta fpirant. Inde vulgò futuariam twi. dictitant : atq̨ne autunmant, hac illitas veftum mulicbrium plicas cancs figire, at tque arrefto veretro Veneris $x$ ftu a fos illas amplexos cupere inire, præfertim in templis vbi tetrius odor firat, \& ininus ventis diffatur. Hxc vulgi funt, tota cibis abdicanda.

$$
\begin{gathered}
\text { TOTA } \\
\text { Bonus Henricus. } \\
\left\{\begin{array}{l}
\text { Germa. Euter Zoinrich. } \\
\text { ering. Englyh Mercury. }
\end{array}\right.
\end{gathered}
$$

SE D T O T A B o N a perquàm optima, magifque vfu quan vlla peritia re- Fuch. Rumicis cepta, Mercur̃alis credita fuit iamdiu à plebe muliercularum, aut illis non mul- fertimn gerases. to peritioribns Pharmacopois Anglis, quam adhuc inferiam magis pertinatia tertikngents
quàm vila racione fouent, quia fauit illis cuentus. Siquidem eft huic planter

$$
\text { I.i. . deter- }
$$


deterforia facultas multò quàm Mercuriali, tutior in morbis feruidis, nec tamen eft ignauæ in attrahendo facultatis, cibis verò multò Mercuriali gratior, tametfi plufculum flatuun habet, \& non ita procul à Spinaciis naturadoeife videtur.

\section{$S P I N A C I A$.}

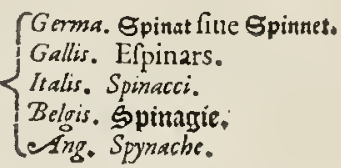

I'I N A C I A filie Spinaceum olus à fpinofis feminum acul eis diatum Latinis videtur. Foliis eft primo pullulatu triangularibus \& fagittr modo cufpldatis, deinde laciniis \& pinnis dentatis Atriplicis longioribus, fapore Betę, femine aculeato, flofculo caduco viridante Blitti, cibo quàm Beta alimentum fuauius prxbet.

$$
\begin{aligned}
& \text { ATRIPLEX STLVESTRIS POLYGONI } \\
& \text { at Holxines folid. }
\end{aligned}
$$

N vinetis \& agrorum marginibus non rarò occurrit anguftis folits Lithofpermi $x$ qualibus Syluefris Atriplex, fpargens humi ramulos ftriatos, cubitales \& fefquicubitales, folliofo femine Ifatidis, aut Atriplicis hortenfis, \& flore mofchofo onuStos.

$$
\text { ¿ोंin? HELXINE } \begin{aligned}
& \text { PARIETARIA, VITRIO- } \\
& \text { la, fue Perdicinm. }
\end{aligned}
$$

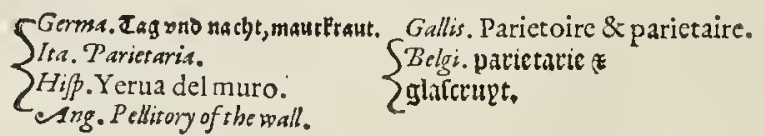

NO $\mathrm{T}$ is s i м A de facie natalibus, \& herente veftibus, femine \& foliis, vnde nominis occafio, Helxine. Nullius enim regiones parietes mufcidi vetuftioráque rudera Wathe effgi. hac non fcatent : qux etiam femel hortis adulta vix exigi potelt, folium \& facies Aals. maranthi, aut Mercurialis, cauliculis è radice fibrofa rubellis teneris fucculentis, folis afpera hirfutie pilorum, \& fenina Betæ, obuium quemlibet pannum arripiunt. Flofeuli mufcofi herbidi pallentes, multi vfus tota ad encmata, \& balnea abfterfioni accommoda, guftu item vt fuperficie abftergente nitrofo bliteo,cui admodum fimilis. Ciffam pelos rero Helxine in conuoluulis dicetur.

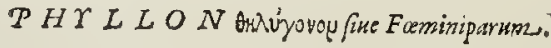

TAM E I I I diu vexarit exercitatiores illa difưuifitio nempè foretnè idem Phyllon vtrúmque cum vtráque Linozofide feu Mercuriali herba, tamen cum samdiù ex ftirpium cognitione defcriptionibus collata fatis liqueat in cognata generis claffe multúm ipfas inter fe differre, hî́c commodùm omnes vtpotè congene res fubdemus. Nec enim aptiori loco poffunt hę dur quas damus Phylli fpecies, imò fermè nullo alio collocari quęunt : adeò námque funt fimiliftruftura \& partium partibus habitu refponfúue vt minus mirum fit autores ad res confiniles defignandas iifdem ferè vos comparationibus \& vocibus qux opinionem fecerint recentionibus (Hondum repertis plantis, ) bis eiufdem rei inculcatæ mentionis. Atqui fecus eft multo, nec iftud caput, irreptitiım, deprauatúmue effe magis videtur, quàm alia multa, quæ non minus negotij propter ambiguitatem faceffunt. Enimuero Diofcorides non plantas quin fint, qualéfue fint in dubium reuocat : fed dumtaxat ambigit num, fexus optionis compotem quem- 


\section{STIRPIV $M$ aduerfarianoua.}

piam faccre potis fit earum vtráuis, nempè maris aut fominx, quod Crateuas prodiderat, \& fabula affine efic Theophraitus monuerat. Diofcoridis igiturfunt defcriptiones non Grateure, aut faltem non folitis, fed exalijs Diofcoride mutuante autoribus. Diffede, cui folia $O$ cimi fuperis, cum vtriúfq; inter fe,tum potifsimum cum vtráq; Linozoftqutor dicit: At Phylloficie \& crenulis in ambitu, habitus \& facies Parietariæ vt fcitè tion dicit : At Phyllo quod Eleophyllon, olea folium nuncupat \&itidem florun erup talcs, Gallix Norbonen fis fufpendij paulóc; vlteriu Monfpeli, fecus vias \& ad collem fquallidum \& glareofum qucntifsimum Phyllon cuins pontem Caftri noui, alijfó quám plurimis locis, frcprimè \& fingillatim obuerfx funt:nem manifeftx dux differentia, vtríq; Mercuriali ap- . cralsitie \& figura:Portula diora incana numerofa: Caules inx magnitudine, glauca \& quám olex vel falicis pallilcres in multas did of modum pufili dicuctos Polij modo alas, quas iuxta \& folia florcs mufcoft oliury; in ola tefticulorum ritu \& in fpeciem iun ed a do, quibus per Auguftum \& centibus \& un fem \& vt minoris Heliotropij exiliunt remina immatura albida, matura vero Cyaneo nitent colore rotunda, \& quả pa paueris naiora, guftu feruida \& nonnihil pinguia. Radix lignofa exilis.

\section{PHYLLON CHasferearbene. gonum Mariparum.}

HV I v s fxpius fruftrá conati fumus femen aut intueri, aut excipere, \& mirati fumus rícemulos mufcolos in pediculis porrcetis oblongis, olex floribus, iam narcidis \& caducis non abfiniles pallentes vel potius Mercurialis fominz, ex luteo inftar nucamenti colurni aut

PHYLLON Aunv́yoroy fiw: Fominiparkm.

MAS. F OE MI I $\mathrm{N}$.

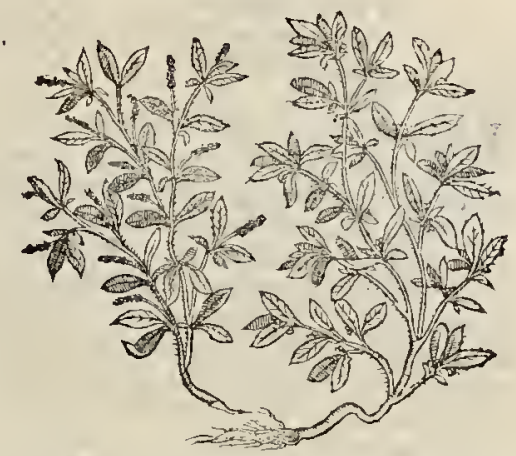
Phylerex, nullo confpecto feminis veftigio defluxiffe. Cxtcròquin eadem planè fominx eft hac,nec in inus calida acria guftanti foliz,aut deglutienti vel tantillum, tametfi non perindè feruorem primoribus labris, \& lingux atq; gutturi inurit : Qux omnia indicio funt nobis haud temerè antiquos hafcè varijs nomenclaturis \& orationis picturis repreentalle. Hincq; vires fubducendi aluum, quas in Mercuriali nouerant minimè afsignaf ficun feciffenc diuerios, \& fi quid hucfacit, etiam Phyllon femine donatum, fominificun fecife. Maren verò fé́ Marificum femine caffum \& orbatum \& frugiperdun, non Mercuriali fominæ, quippè oui erali fonina floribus contingit: \& tamen contra euenit Plyllo tamen Seram diuerfum ineft.

Senenfis planta nutanti conicctura, \& deferiptione mutilla buc adducta an fit $\mathcal{N}$ oli me tangere Italonm, videndum. Sed quòrfum ferratum folium, \& Mercuriali breuiús afferendo Arthenogono olex folioineffe? Deindè fi non noris primum \& præcipuun nempè Theliogonum, quî potes affeuerare \& dicere: quafi iam non dubitet, plantam ait quam re peri effelegittimum Arrhenogonum. Saltem accurata defcriptione \& icone patefecifet, fed pleráfq; alias vel notifsimas alienifsimo loco appofuit: vel quæ nufquán fuere in natura, vel illi nufquam notæ fuerunt,præterquam de comentariorum figura, lectione vel
auditione mera.

$$
\text { I. ij. Phyllon }
$$


TH E o P H R A S T I verò Phyllon ob prolem mafculam, fominámq; propagandam, vt idem inquit, fic vocatum videtur Mercurialem propius defignare, quam Crate ux vel Diofcoridis Eleophyllon cum quo propter prolificas illas \& mirificas communes $\vee-$ triq; dotes commune nomen fit fortitum, vt alia palsim non parum multa in authoribus : \& aliòquin Ocimi folia, feménq; dydimon,non fomine vti Phyllo Diofcorides at-

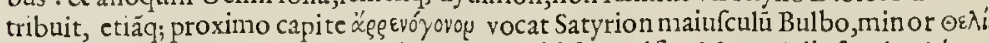

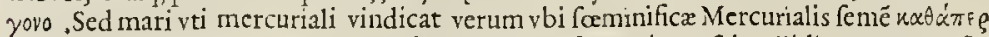

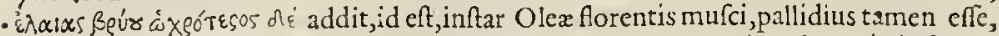
\& verba \& res Eleophyllon Diofcoridis magis accedunt,neq; enim Mercurialis femen

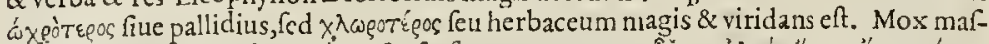
culificij femen olex primulü cे mufcofo flore emergente oívą غи Tò ßeúr ijfdem penè verbis quibus hîc feu Crateuas feu Diofcorides defignant fum: Eóq; dignior venia Plinius, eúmq; recentiores fequuts, fi ex ancipiti \& fortè in vuam có. flatam diuerfa gemináq; defcriptione vnam confarcinarint, \& notionem confunderint.

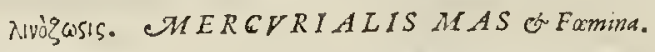

$$
\left\{\begin{array} { l } 
{ \text { Ital. Mercorella. } } \\
{ \text { Ang. French Mercuty. } } \\
{ \text { Ger. Bingelfrat. } }
\end{array} \quad \left\{\begin{array}{l}
\text { Gal. Vignoble, feu Mercuriale. } \\
\text { Belg. Bimgelctupt }
\end{array}\right.\right.
$$

Dod.effig. I I NOSOS I D E M Ceu Parthenium \& Mercurij herbam altérutram qui norit ambas cognorit,adeò funt per omnia fimiles \& duntaxat femine diuerf $x$, ()cimi \& pari etariz folio, plurimis geniculis maiufculis perficarice, multos teneros holeraccos caules quadratos \& alas cingentibus: fubnitrofo fapore \& nonnihil virofo ficco multo porraceo purgante \& medicato, ad multa perquám vtili vti tota herba vbiuis gentium notiffima \& vfu maximè recepta, vt pluribus ad cognofcendum nihil fit opus cum id abundè dudum capite de Phyllo quænam foret \& quantum differret fit dictun. Linguagotix Monfpellij prafertim Pharmacopoi multum vtuntur melle Mercuriato vocato, nempe fucci exprefsi libris tribus incoquunt mellis boni $\mathcal{L}$. if, vel. $\mathcal{L}$. ij. ad enemata \& muliebria encathifmata. Huius locu hic in Anglia vbi non minus frequens, fed tamen non xqué nota fuperiore feculo vtebantur Tota bona feu bono Henrico dicto quem etiamnum vulgus Mcrcurialem appellat \& putat errore quidem non paruo,fed ad vfum Tora bona An-non manno incommodo, prafertim fi ad enemata tantum addatur, minus enim calefaglis Aercurialis cit, lenius lubricat:at olere vel ore, aliouc fumpta modo nonnullos multum torfionibus, vexat vti diâm inter Atriplices.

CrNOCR AMB E, quafi dicas Caninam Brajicam. Mercurialis mas, Syluestris.

Qod.effg.s9. OVe pafsim in Europa tota fecus vmbrofas vias \& in Syluis vdifuè locis prefertim feptentrionalibus \& minus calidis copiofirsima oritur \& vulgò Sylueftris Mercurialis vocatur, tantam cum mari tota habet fimilitudinem, folijs per interualla binis in geniculis indidémq; femine didymo è pediculis lógis, caulibus quadratis tenellis, vt quín vera fit mulli dubium: rectis tamen binis, ternis $\&$ interdum quaternis, non alatis cauliculis pronenit: folia fubpallida funt Mercuriali longiora, fapor, odor, holke raceus \& fubuirofus. Radix latior humíq; ferpens fparfa, tota facics Mercurialem docet : vfus nullus tametfi optimus futurus ad ferofos \& Melancholicos humores educendos.

HELIOT ROPIVM, whotgow:op, officinis Verrucaria fcorpioides. 


\section{STIRP IV $M$ aduerfarianona.}

O VA $\mathbb{Y}$ is permultx fint ftirpes qux Heliotropir, \& Heliofcopix dici merentur, -quia Sole puro colluftratx, quafi illius fruendi auid $x$ hient: eóquc Ccli medium tenente pandantur prorfum, deinde abeuntē gyratione quapiam, atque quafi in eum nutu pronæ \& conniuentibus floribus profequantur; illius abitu \& defiderio fere motantes (quod in Narcifo Calcndula, Tragopogo, Cichoriis \& quamplurimis aliis cernere elt. )Tamen hifce Diofcoridis Heliotropiis, id nominis particulatim congruere videtur, quia Solltitio tan tü florere author eft Theophraftus, \& obferuatio. Serins quippe fponte prodeunt \& florent.

$$
\begin{gathered}
\text { HELIOT ROP IV M masius, Solanifolio, fore Echi, } \\
\text { adunco, candato corpioidis. }
\end{gathered}
$$

HO r v м maius vocatum v bique Lugdunenfis, \& Norbonenfis Gallix,cultis \& incultis marginibus aridis obuium, nec non in Italia \& Pedemonte. Pedem altos, caules crectos, foliis donatos, () cimo aut Calaméthi montani, Solani maioribus, albidioribus, hirfutioribus, quibus fingulis in fummo elegantes infunt florum feries, faftigiaud racemofa, culudicullas infexás fcorpionis, aut Echij fcorpioidis imitatę albidx, feminis plene miliacci oblongi pufilli virentis,ad tumorcs ftumofos verrucas \& vlcera phadagenic veluti eft tota planta magni experimenti. Anglix in hortis \& Francix.

\section{MINVS HELIOTROPIVM repens.}

WOn facilè reperitur iftud nifi paucis in locis \&x frobibus lutulentis, Grammontizfylux, Monfpelliacra inter Pulegios ceruinos fubter Tha marifos, \& Lunellam intcr \& D. Egidium:quibufdam paludofis forbibus, Surculis multis tlexultbus, teneris, gracilioribus reptat: folia rotondio:a, triple minora quam magni Hcliotropii, numerofa \& fimillima toréfque âsimiles breuio ribus auultò glomcratíf; fed minus rcflexis caudiccllis nulla ferie, iam intra, iam fubter folia pen. dulis vt in Tornelole, necper interualla foliorum finguli totis ramis alternato fitu qualem non de-

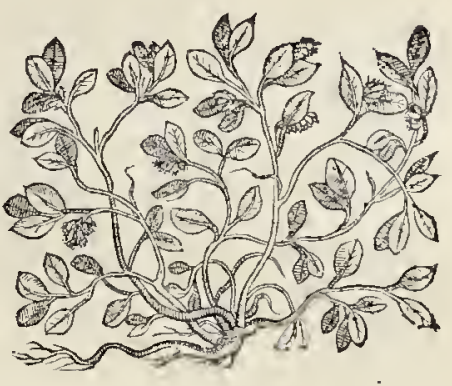
friptum, fed male pi\&um, aut multò à vero diuerfum Commentator habet, radice pufilla fimplici vfu iucognita adhuc, etiarnque de facie, nifi amicis quibufdam Lugdunenfibus, \& Antuerpianis, quibus eam eiu\{que magnam feminis copiam mifimus, non valde dırsimile à maiore Heliotropio, an autê illis fatum creuerit incertú habemus. Hic Londini nobis Bruma fẹuiente periit \& Motgano noltro.

\section{HELIOTROPIVM UnlgareT OR NES O I Gallorsm, fine Pliniy tricoccon.}

NO n modo de vernacula voce Gallorum qui Tornefol hanc vocat, fed etiam Pliniana lectione qui eandem Tricoccó Heliotropion appellat, cuilibct innotefccre potelt huius plantx figuram, \& Hiftoriam Heliotropiis deberi: tanietf Drofcoridi videtur præterita,aut cum minore in vnam defcriptionen contrąa. Folia huic facićfque tota maioris Heliotropij, n igtiora viridiora folia Calament hi montani, aut potius Solani floreslutci exilcs, olcx, facilè defuentes. Semináque tricocca capfula Tithymali aut Cha= mxlex proxima, fed f́cabra, ex viridi nigricante affrictáque pannis, aut chartis, virorem viuacem impertiente, qui mox in coruleum hilarem \& purpureum mutatur:magno quxftu colligun t ruftici Lunellx, Mafsillarges alif́lque Norbonx traftibus oliuetorum, vbi plurima maturáque Septembri funt, qux diftrahunt mfectoribus, \& Chirurgis nonnullis, huius plantix vires ad medica prafida fupra quä dici potef efferentibus,

$$
\text { I.iij. }
$$


de quibus nos in felectis remediis dicemus, duce \& aufpice Chrifto. Romani agri vinetis etiam faniliare, Belgis, Francis, Germanis, \& Anglis in hotris. Pannol $x$ lacinix, qux in Officinis nomine Tornefolis veneunt, ad vinum gelatinas \& alia medicamenta coloranda, pereleganti purpura huius fucco vinóque remifto creduntur imbuta.

$$
\text { SOLANI GENERA. }
$$

SIRYCHN oN viteum, capreolum, vitem vel acinum, aut tale quidam fignat, in Solanorum claffe qubus cunctis proprium acinos plures vel pauciores habere, nifi quis

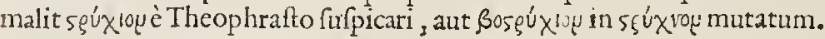

P I v A quam Diofcoridi reperta hodie genera, verütamen non Diofcoridis omnia:nullí ensm manicum foliis Erucxad Pxderôta Acanthi fimilitudinem \& coryn:bolum, quale eft apud eundein vipiam auditione vel infpectione innotuit nobis, nifi fit Stramonium yocatum quod inferius poft Somniferum perpendetur.

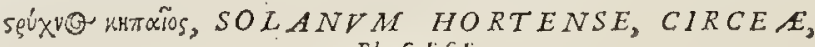

$$
\begin{aligned}
& \text { ant Phafeoli folio. }
\end{aligned}
$$

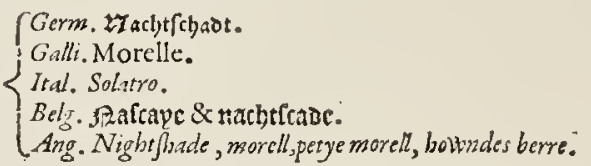

CETR OR Y M Omnium holeraceum dictum hortenfe vulgatifsimum fue Meridianæe, fiue Septētrionalis gentis viarum \& hortorü, cultis incultis fcrobibus marginibus \& areis ramulos edit multiplices, lentos, fruticofos, pedé \& cubitũ longos, foliis latioribus flaccidis fucculentis, Baflici vel Atriplicis fylu.nigricantibus, donatos Iunio : Iulio flofculi, al bidi, ftellati, plufculi pręeunt, bacculis fucculentis quafi in corymbum Circeę noftræ collectis, initio viridantibus, deinde nigris; fufcis, alize rubris purpureis, alias fuluis rutilis. Pufilla in fummo cefpite radice albida, fibrofa, fub hyemem moribunda.

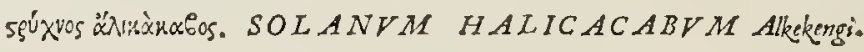

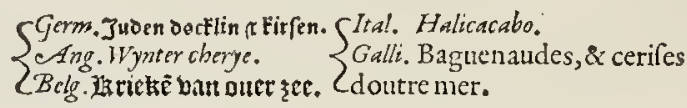

$\mathrm{V}^{\mathrm{B} \text { I }}$ i s vel pueris notifsimum qui etiā in Helueria, Sabaudia, \& Pedemontium fe-

Fufc.eto.396. bri, etrámque hyeme ineunte feptentrionalibus, quibus ideo Hyberna Cerafa Whter Ceris dicun tur * acini qui femine la tiufculo, compreffo, fubfuluo, Leucoii, vel potuus siliquaftri pregnant. Folia item Solani hortenfis, aut Phafeoli maiora viridantia in farmentofis caulibus fefquicubitum altis, flores maiores pallidiores Solani folliculis herbaceis, deinde phceniceis cordato Pifo peregrino fimilibus, quibus acinum fingulum inclufum cærafo parem \& fimilem defcripfimus: reptrıce radice, \& reftibili fobole fefe quotannis reparante, Celeberrimus huius ad calculofos lotiumque ciendum rus.

SO MNIFERVM, o LATHALA. An Mandragoral Theophrafti, Belladona Italorum.

Serma. Dolfraut, Geufraut.

$\{$ Belgis. Broote naftarc $\{$ Wulcturc.

Ceangl. Dwale, oreare Morek. 


\section{STIRP IV $M$ aduerfarianoud.}

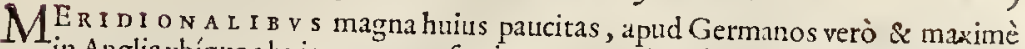
in Anglia vbíque obuio prouentu fruticat : tota Solani facie virgis longis, rectis ni- $F u / c h$.ico.39. gricantibus ternos \& quaternos cubitos longis, digitum munimum xquantibus, foliaque gerentibus atra aliquantùm hirfuta, \& vtrôtuis Solano maiora, nonnihil ad Man dragoram florum calathis fufcis, afpcetu mæflis \& obfoletis, é quorum fingulorum cz. uo enicat bacca nitida cerafx, aut potius vux Paridis par \& concolor.

Radice non modo annotina fobole rediuiua, fed etiam adeo viuaci $\&$ importuna vt fcmel in hortos afcita, vix exigi deleriuè queat : imo vel tantillo fruftillo relicto, aut infoffo repullulet. Prafens nex efu hec cerafi, vt multi noftra menoria morte funt experti, pueri prafertim:namque Angli adolefcentuli qui per imprudentiam peregrè fitibundi in via efitaffent, lymphatici fed fomno femi fepulti interiere. Etiamque Antuerpix non multis abhinc annis quidam impuberes, huius æxum morte luebant. Menoranda huius radicis facul tas qua nugiuendi $A g y r t x$ in Italia plebecu$1 x$ attonitx concurfum plaufum \& pccuniam captant : tantillum nanquc radicis admodum fitibundis conferux Saccharatx Rofurum, violarum ue cuilibet addunt, atque deglutienda dant citifsimo aduerfum fitim, etiámfi quis ea propemodum enectus foret leuamento \& refocillamento, fed nequifsimo : Atuperatis námque vt reor faucium in teroribus neruulis ad æfophagum imum, languet prorfum appctentia præfertim po solanum Som tus \& interdum cibi, vnde poltea malè habent nifi repentè colluant aceto quippiam Abfynthites vini, aut Theriacx deslutiant. Cxterum ridiculun iuxti ac Matbeol. Fotio. pertinacem commcntatorem fe prxbuit Senenfis lo dcclaratum Solanum, nedie 1071. aliícue quám Solanum, nedum probatum ftudiofis obtrufit, verticillatis floribus, viribus alıốquir fimilibus : prinè congruere nullus inficias it, pratul it.

\section{STRAMONIVM PEREGRINVM ANSOLANVM Manictim ? Sule Poma pinofa Recentionum, Metelltalorum.}

I м quamuis putarint Stramonium, vel Strychmonium illud peregrintim ab Stry: chnodeductunı \& idem effe cum Diofcoridis Solano Manico, dueti nonnulla pilu-Fufc. $1 x$, aut pomi echinatifimilitudine, tamen non parum differre vel ipfadocent folia,nedùm fruetus pilulauè, (Suntenim hortenfis Solani leuius per ambitum finnata nonnihil) qux fquamulis (pinofis multis compaetx fune; quadätenus nucis Metel Offcinarum, vel nuculx Cuprefsi, aut rugofa gallx immaturx fimiles, fed echinatx fpinulis. Folia autem pilofa \&ad Solanum hortenfem accedentia,florum calathis volubilis maioris, aut Scammonij albis ex folliculo Hyofcyami, fed odorem fuauem Illij halantibus, vnde pilula in caule pedem \& fefquipedem alto, hirfuto, non profun da nec magna radice, Horentem vidumus plùfquam duodecim abhinc annis in horto Patauino \& in Belgio. Verütamen multa defunt huic ad explendä rcliquam deliniationem, nifi fit illa luxata, vt quidam fufpicantur, qui in Stramonix foliis veternof quiddam agreftis Laculcę, aut Meconij odorantur, affectúlque non difcrepantes experiuntur, verim ne fic quidem vnquam facient fidem, \& multo minùs perfuadebunt, qui Chriftophorianam, tametfi Corrymbaccis floribus \& baccis, follo multum diffecto fit, cuius venenata facultas maiorem opinionem huius Solani, quam Stranio. nix facere potuit, $v t$ in Elleboris dicemus.

\section{STR TCNODENDRON\& A MOMVM}

Pli: vulgo lialorum, putatum.

Solinum arboref cens Belgarum, an Theophraft. Solanum foligs

$T$ it bymali, fructu rubro, radice rsbra.

$$
\text { I.iii, } \quad \text { EL }
$$




\section{$S T I R T I V M$ aduerfarianona}

PL E r oy E Itali,Galli, Germani, Belgxq; in viretis aut Adonidis penflibus hortis voluptatis canfa ferunt peregrinam Indican baccam,ex qua fruticat pumilla trinum \& quaternum cubitorú planta arborea Perfici, ant Amygdala facic, \& fronde, fore per Aftatem \& Autumnum, Solani hortenfis, \& baccis nitidis coccineis, aut miniatis paribus \& concoloribus Alkekengi, nec intus gygartis diuerfis in Brumam etian \& Ianuarium menfem vfquè aduerfus frigoris fxuitiam edurantibus, colorímquc tuentibus. Amomun quidam Plinii putarunt : re\&tius alij Strychnodendrum vocarunt.

Recentiorum, planta, Alfmes maioris facu baccis Solmi,

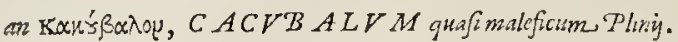

F S Y I v os a s vdis Germanix, Flandrix, \& Anglix, in hortos tranfmouerunt HerbaErij quandam fruticoram plantam, reptantem humi, ortu Rubix tenellis ramulis \&e fractu facilibus. Folijs per interualla geniculata pallentibus, Rubix, \& Conif medir quadātenus. Flofculis albis, Holoftij aut Alfines, fruetu nigro,Solani hortéfis:radices im portuna viuacitate etiam erutę repullnlat, non fecus ac Solani Somniferi, \& nihilofecius manfu interficere dicunt.

\section{CIRCEA}

Germ. Jelenger ie lieber \& らynfcbftaxt. $\{$ Gall. Solanum ligtiofum.

$\{$ Lati. Amara dulcis, ZBelg. Altranke.

I S T E quam Solanum ligneum vel lignofum vulgò,Herbarum ftudiofi Lutetix, \& EMonfpellij prafertim vocitabant ? Videtur fane eadem, nec nulladum cognita nobis, propius accedit. Et vt non effet, tamen merita eft huc fuffici, tum ob faciem haud ita difparem, tum propter vires non contemnendas \& illi cum Circxa communes: deinde qua notifsima, \& plurima vbíque regionum fecus fxpes, viáfq; vliginofas luxuriat \& Monfpellij etiam in ruderibus,macerijs \& macillentis,portx Latenfis Solanis ad iungenda fruticat, flagellis multis farmentolis non prolixo reptatu, fed innixu harétibus ternos quaternófque cubitos xquantibus, rotundis, lignofis : folia Solani \& vt Similacis, vel Sigilli marix, fenfim accuminata obfcurè virentia, Solani fuperficic quibus infernè vtrínque appendicula vna quafi auricula vel pinnula ineft, acetof minoris, aut Saluir nobilis modo. Flores quamplures violaceis faturiores Sycomori Venetorú, aut Afarch darace, quínq; partitx appicello in medioluteolo, vnde acinuli conferti primuIum virides, deinde maturi hortenfis Solani rubri oblongi, \& teretes granulis intus miliaceis comprefsis, ita racematim conditi:qui foli quoninus hanc planè audeamus afferere Circęam, diffuadent:tametfi non dicit Diofcorides cornicula, fed velutı in corniculis femina, nos tamen vt cuitus exploratam habemus naturam, hanc malumus quam nullam, nec vnius aut alterius notulx penuria, fortè peruerfione, aut metathefi vnius voculæa apud Diofcoridem lubet illico refpuere, dum facultates quadrant. Eft quippè nonnihil ficca, moderatè calida, aut potius frigidiufcula,næd!nn vt feruida fit quod nonnulli rentur, \& Diofco. pcrfuafus fuit, fortè propter amaroré, \& tantillum acrimonix. Nam fi plufculum amaroris primum guftanti exhibet, non proinde fit calida magis quam Endiuia, Cichoria, Hyeracia, \& Rofa : eius quippè quantü percepimus, calor \& acrimonia illicò abeunt, perftunte dulciculo \& imbecillo quopiá fapore mandendo radices \& virgulta, farmentofa, lignofa, medulla albida, amarore ingrato, primü \& diu linguam afficiunt:tandem dulcedine multa Glycirrhize ingratiore faftidium pariunt, magis, nu agíque dulcoré offundendo, idcirco Germanis vocata Je lengar ie lisber, Anglicè Suytbitter, Latinis Dulciamara.Vnde vires mirificas \& penè Circęas coniicias : nam admotam foris inflammationibus, \& decoctionibus epotam Solani vires expleuiffe fcimus: ad internos autem affęus refrigerata calfacit, calfątáque refirigent, eadem ctiam qua Alkekengi fiuc Halicacabus pollet facultate, moderate enim citra virium difpen- 


\section{STIRT IV $M$ adierjaria nowa.}

difpendium vifcerüiè incendium egerit per fudores vrináfq; aquas, atq; obftruetiones demolitur qux füt Teteridis \& Hydropifis præuiij \& alumnæ, qua item facultate lac māmis fuggerere fructus potis eft, non fecus atg; multa qux exficcando ferum \& defocan do fanguinem illuc vrgent puriores benignioréfq; partes. Sic foniculum, fic Bryonix turioncs tenelli cum ijdem duriores \& acriores potius lac populentur, \& abfumant, quod difcrimen ef inter menfes cieutia \& lac generantia. Eóq; forbiliones parandas iubet Diofcorides, non iuffurus nifi vefa forer. Et Circæam dixerüt nonnulla vt par eft cum Mandragora fimilitudine virium : quippe Circæa Mandragoræ nomen fuit, \& forfan vtriúf $q$; ad amatoria vfus fuit veluti Diofcorídes de Mandragora innuit, nempe Phyl tro illo frigiditatiodor $x$ coniuncto, cuilus ad amorem amiciriáq́; ferruminandas vis mira \&c adamantea vel magnetica. Hæc interfuit Commentatoris Senenfis enucleare, at hîc vbi quid cómentetur.oblitus nobis elapfus eft in Plinuj perorat lapfum iandiu nota tum \& confoflum al orum criticorum obellis, \& fortè immeritò, fieri enim potuit vt i- Math. 1282. ta legerit \& verterit ex quópiam Botanicorum:nec enim, vt vult Senenfis, ex Diofcoride 100. pro Vit femper necefiun aut confuetum fuit illi mutuare, nec verifimilè vt cuius nufquàm men- Syl. tionem facit, alióqui candidus \& multus in ciendis \& laudandis fuis authoribus, \& non raro Diofcorides Galenus plurimìm atq; ex vtróq; \& Eineta cæteríq; Graci meri funt, dumtaxat aliorum recitatores, non fecus atq; Plinius, qui fé́ ex alio quàm Diofcoride accepit, vel quàm è Diofcoride verterit, feu aliquid peruerterit,ferendus homo Romanus \& aulicus non minus quam Diofcorid.qui Saluiam extingere femen, contra quam Ariftoteles \& antequi in Problemar.prodidit : \& aliogui pronus valde eft lapfus in virium attributis,quod vulgò quotidiè enenire videmus : fic Cafsiam filiquam propter affinitaté nominis, ducere menfes putarunt, at fiftit, vt fi quis Circæam, Mandragoram lacinhibere audiuiffet, \& idem huic quade mentio fit Circxx cognomini funilirudine deceptus attribuifet. Doctus Plinianus Ecclefiaftes fic Plinij verba legebat. Semine lac monet (vulgati codices minuit) vino aut mulfa aqua pota, fic Diofcorides $n \alpha T$ øo $\tilde{x} y \mathrm{rra}-$ here, allicere, vel mouere, extremis námq; tantum non item re differunt, tractio \& protrufio. Nos hæc his femel tametfi pluribus quàm voluimus, quò faceffant ifti maleferiati Ariftarchi, adq; rerum commentationem cognitionémq; accuratiorem vires ingenij contendant.

\section{SOLANVMTETRAPHYLLVM, fine HERBAPARIS。 Vua Lupina, Pardalianches puttata.}

Q V i B v s nondú notæe eifent primi Aconiti differétix non abs re vua Lupina verfauè à̀ recétioribus dięa, Pardalianche Diofcoridis credita fuit: quaternis näo; eft vtí- $F u / c h .48$. q; herbula folijs decuffatim aut ex aduerfo fibi mutuo exortis, fummo ferne é caulc e- Math. 1093. natis nigricātibus rotū dis oblógis, tenuib ${ }^{*}$ : cauli rotúdo gracili,fefquipalmú al to fubeft fibrofa varièq; fparfa cefpite fummo radix, vnico in flore ftellato, \& ex luteo herbaceo, aciuus Solani Maniaci fimilis, nec difpar eft. Natales amat vmbrofos, frigidiufculos Sep tétrionales, cuiufmodi Germanix propè Bafileã,aliífq; Gallix, Belgix, \& Angliæ fyluofis Hãc qui Aconitũ coniectabãt venenatä prodiderüt:noxianè fit nondùm certùm habemus, tametfi fxpius collegimus fepi isimè dedimus canibus \& agnis nullo percepto incómodo, quin potius raro \& perquam iucundo fpectaculo meminimus fuiffe nobis amicífq; noftris Barhonix Heluetioru, dum Thermas illic inuiferinus : Etiámq; Lugduni antidotum qualem mox defcribensus ex hac potifsimùm aliífq; nonnullis conflatü. Canum par vinct um loris meminimus, vtríq; vi \& bacillo in fauces intimas indita fuit Arfenici $\&$ Mercurij fublimati añ. 3 . f. carnibus aditam (neq; enim nifi inuiti vorarunr)é vefligio vtérq; canum ore patulo aerem captabant,fpumas elidebāt, anxióq; \& crebro conatu fed irrito vomere nitébantur : latratus edebant ore \& affultu rabido, ructúq; minaci proximum quémq; inuafuri videbantur. Hora vix exacta coptus vtérq; frigidior \& quietior fieri decubuit moribundus. Tum pulueris huius 3. ij. ex Rubello vino infurf fuerunt in fauces vnius, ac nec tum quidem quicquam euomuit: quin potius aliCapinafiliqua nö ducit menfes, quantò 


\section{6 \\ STIRPIVM aduer Jarianoua.}

guantò poft quim focius periculi iam enectus effet hîc nobis attractantibus vifus fuit ca: lefcele itáq; coepit orc reptare, oculos referare \& animum viréfq; adeò repcntè recipere,vt hilaris \& ludibundus aliquò thoris poft conam fub menfa coperit, planèq; conualuerìt, Idem euenit ad Badéfes Thermas canibus quibus data fuiffet cum Arfenico mixta nux vomica:fed hi vcrtigine vcutriff; diris cruciatibus afti fefe in gyrum indefinenter verfabant. Pulueris hac defcriptio.

Rec. $\left\{\begin{array}{l}\text { Vtriúfq; Angclicx(innuit)damefticam,\&sylueltrem. } \\ \text { Vicetoxici. } \\ \text { Valerianx domefticx, } \\ \text { Polypodij querni. } \\ \text { Radicum Althex \& } \\ \text { vrticx. }\end{array}\right\}$ añ. drach,iiij.

Corticis Mezerei Germanici. drach. ij.

Granorum Herbx Paridis. N 24.

Foliorum eiufdem cum toto N. 36.

Ex maceratis in aceto radicibus \& ficcatis fit omnium puluis.

Herba Paris refrigerat infigniter, ideo arfenici vim reprimit.

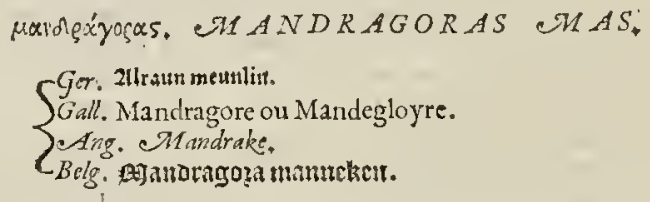

Mat.160.1076 O VI A antra atq; fpecus vmbrofasvtpote Solis feruidionis impatiens, Iubens fectareutur Mandragoras dicta fuit. Mandire enim aprica loca quò fe recipiunt \& ftabulantur armenta etiam hodiè Itali è Grxco frgnificant, \& ad anatoria non panm poffe olim credita fizit $\&$ vocitata Circra à Circe inuentrice magica Solis filia Pytagoreis ctiam $\alpha \dot{\nu} \theta \rho \omega$ nómopфos, quod humanum truncum \& artus nonnihil adumbrarent radices implexx ciura bina \& clunes quafi difparata oftentantes, quàm ad interpretationem alludit non infcitè Scptentrionalis nomenclatio, qux Mandragoram quafi Man \& draghen : virigeram fuuè homigcran cónotat. Duum generum hodie Italix, Prouinciæ, Norbonæ, \& Hifpanix hortis foren malág; maturat, fcminc aut radicibus ex Candia \& Cycladibus infillis aducctis. In reliqua Gallia nonperindè tameti fuperiore anno florem pomáq; apprimè matura nobis dedenunt Briftoix Occiduo Anglix aprico \& tepidiufculo horto, trima aut quadrima non fert, fed iam anicula poma dat autci odore fuau fopiente Mas, Mefpilo paria medulla ctiámg; fermè granis latioribus comprésis pullis, folia humi ftrata numerof Beta, aut Lactucx, virétia, rugofa, crifpa Dipfaci olida:flores in gracilibus pediculis Beilidis, (caulc námc; vacat) candidicant, vcl purpurafcunt,Malinfani non difsimiles.

\section{$M A N D R A G O R A S$ FOE MINA.}

Mat.Ico. 1077 FOE M I N A м quafi minorem, vel imbecilliorem fexu, hanc propter pallidius malum atg; altero tanto minus Sorbo pufillo lutefcenti par \& concolor rotundius, mdice minore, duobus tribufuè Empufix caudiculis crurum ritu humanorum claniculatim comifsis \& intortis. Folia vt omnia mari minora. Augufto maturant Francis, Anglix, tametfi multo longius ab æqualorc abst Iulio \& Iunio meminimus.

TH ELONGENA, vel Mala infana, exotica. $\left\{\begin{array}{l}\text { Gall, \& } \\ \text { Belg. }\end{array}\right\}$ veramgenes $\}$ Ger. Alelantzani 


\section{STIRP IV $M$ aduerfarianoua.} A F F I N I A cum effent Mandragoris hac cortulo purpurea poma finc aliud ab Eetii num fufpicarieffe marem Theophrafti Mandragoram, éque efu læthalem rati, infana Matbeol.effig mala vocarunt. Sed apud Theophraftum multa le Zionis labes, fortè non diftincta ftirpi- 1078. um deliniatio, ne dică farrago omniü congenerü,è quibus hæc eximenda eft \& Cucumerú faniliz, aut potiùs Mandragoris \& Hyofcyamis afcribenda : folis Cucumeris eft afinini hirfutie molliore Solano Somnifero Hyofcyamo albo, vel Mandragora proxima iu caule hirfuto peden al to recto, cui inedio furfüm verfís è pediculo breui appenfa fores \& mala funt femme pario congefto pullo vel fuluefcente \& fufco. Radix fummú cx́pité fibris anplexa colitur, viridariorü voluptati \& guloní aniditati, qui interdum hofeè frudus vti Cucumeres in acetariis helluatutur, vti Romx, Genur, Neapoli, n12iore voluptate quam v tilitate: deterioris enim fucco vel quolibet Pepone, aut Cucumerc eft.

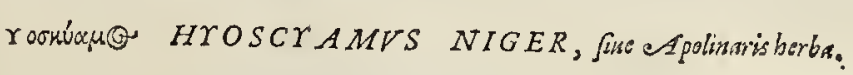

Germ. Bilfomen Getobon.

Italis.Inguiamo.

$\{$ Galli. Iufquiame, \& Hanebane:

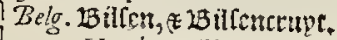

LeAn. Henebane, Hernegrale.

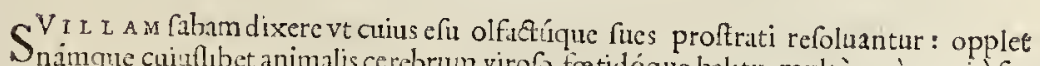

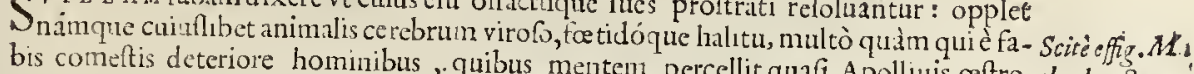

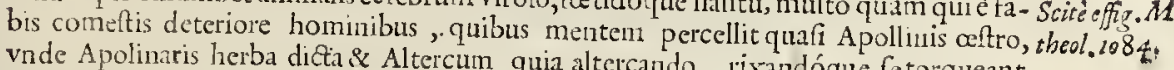
vnde Apolinaris herba dieta \& Altercum quia altercando, rixandóque fetorqueant Hyolcyano demètati: tametfi meminimus mulierculam inuenem cui dentium dolor fotu Hyofyanni fedatus fuiffet tridum penè totum lætan \& temulentæ, non tamen morof $x$, fimilliman fuilfe. Admodum notx lam funt tres Hyofcyami Diofcoridęi differentias, quarum familiarifsinu calidis \& frigidis campeftribus vbíuis Europæorum niger:per amplts foliis hirfutis verbafci, fed Acanthi laciniofis, pedis Anfcrini diuifuris flaccidis crafsis, fucculentis, in ramofo frutefcente caule fparfo, hirfuto bicubitali , tricubitali nu. merofo, qui medio fui flores è fufco pallefcentes in purpuram cæruleam triftem vergettes (fruftra negante Comentatore) calathi fimiles promit, quibus menfe Augufto feminum pullorum Papaueris plenæ pixidulæ fuccedunt, cy tini effigie przfepiolis difceptę \& fupernè, afperę cufpidatz: radixalbicat craffa crutu facilis, \& perquàm ad anodina viti lis,minúfque quám folia foetens, \& obnoxia putredini.

\section{HYOSCY A MVS Albus, mitior, birfutior.}

NO w æquè notus albus, ac proindè in hortis Pharmacopcorum colendus. Ei penç Tratheo.effef: eadem facies \& magnitudo, nifi frondes latiores, rotudiores, mollores, 3 albidiores, foite. 106 s. \& hirfutiores forenc. Floribus iuxta folia \& in fummitate non ver ficulo, colore albo, lan-
guido, alabaftriculis minus afperis, etiam femen albius alterius fouentibus : radice minore minúfque viuaci. In Norbonęad Aurantinm, fiute Auraicum \& inferius cis tránfq; Rhodani oftia variis fatorum \& veruactorum fecùs vias marginibus fpontè adolefcic: Belgio, Anglix, \& Francix in hortis feritur \& moritur quòtannis. Mitior \& tutior mul.
to huius vfus.

\section{DVBIVS HYOSCY A MVS luteus Solanifolius.}

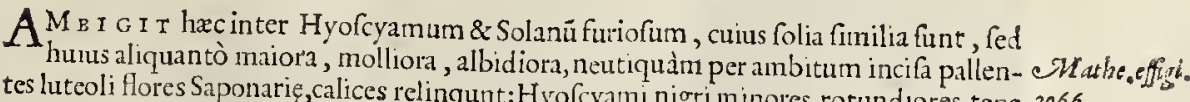
tes luteoli flores Saponarię, calices relinqunt:Hyofcyami nigri minores, rotund iores, tene 2066 , riores, femen fubflaum Irionis \& pufillum : radice tenella, \& quòtanıis inltauranda in. hortis vbi dum taxat vidınus, neutiquàın vfu recepta, aut explorata : guftu tamen acre femen nec odore, aut calice videtur Hyof cyamum prą̧ferre. 


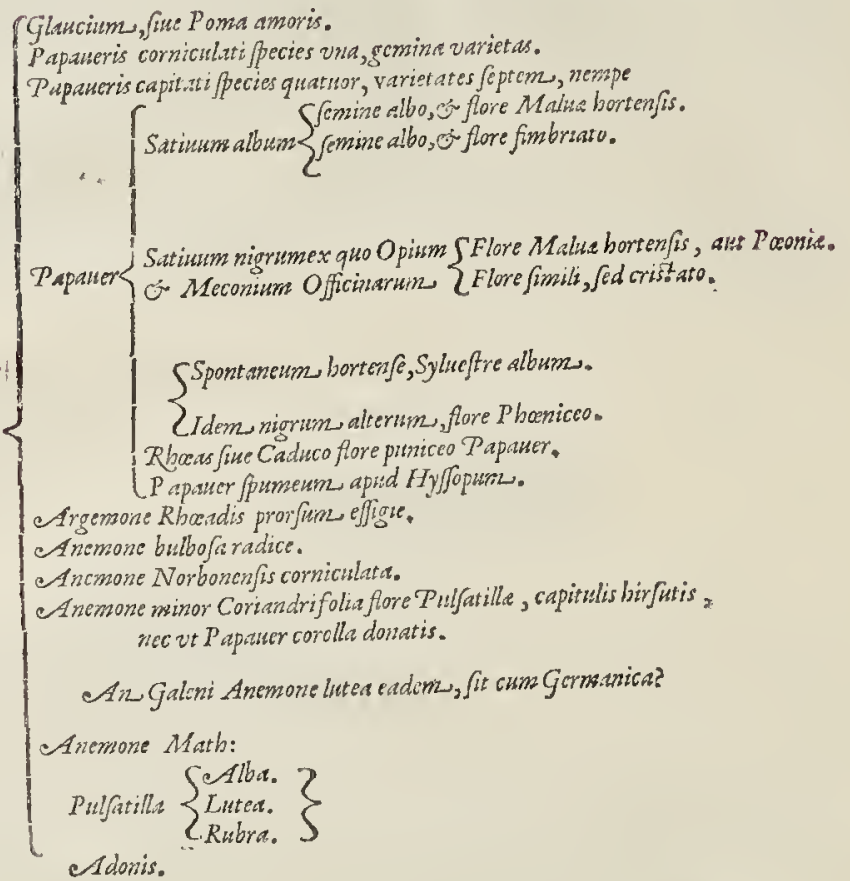

PO MA AMORIS, \& Pomuns aureum Lycoperfoum quorismdam, an Glaucium Dioforiális?

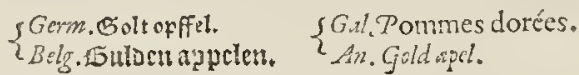

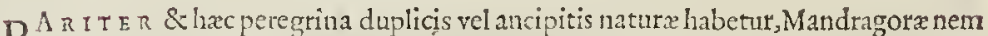
$P$ pe, Solani \& Cornuti Papueris, inter qux igitur fuit adducenda, vel etiam quia tú hanc, tum Papaucr Cornutum, nonnulli Glauciü putarunt, tametfi fi non fit hxc: Glau cium, nequit eff earum vlia quas croceü fuceum fundere noumns: non Cornutum $P_{\text {a- }}$ pauer Diolcoride moneute, non maitus Chelidonium facultatc exulceratrice refragrante: Et inter conathx fpecies qux maxima ex radicibus fuccum luteum remittens, calorc ctian pollet. An vero potius fì quæ Amoris malı Pomáue vocata fert? nè id quidem fatis liquet:non enim exDiofcoride nif van, aut altera nota fuppetit, foliorum \& fuc ci.Acfuccus haus quidem valdéqum oportunus incipienti epiphoræ fluxionibúfue oculorum feruidis glaucona facturis, fi per initia admoneantur, vnde nomen Glaucii: nifi ve Plinio placct, à foliorum fuperficie rquori \& aflatu maritimo concolori dicta fueric. Non nodo enim imentis humoris infultum compefcit, fed etiam calorem modeturur, fxpius periculo ì recentionbus fafo. Quinetian erifipelatis, ignibúfque facris vehementcr oblnctatur, vnde firigida nimium \& penc̀ uarcotica putatur etiam ipfa tufa : verum fuccus edu\&tus è concrematis furculis enatis in Syriaco folo \&c feruido, 


\section{STIRP IV M aduerfarianoma.}

ficri poteit ve tum mitior, tum crafsior \& colore faturiore euadat : ef enim aquens \& dilutus pomi prafertim fubfauus cuiufnodi Meloni, \& alioqui folia haud ita difsimilia,

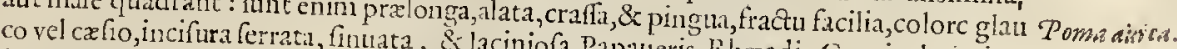
Tcneriufcula vniuerfa planta, fucculenta laciofa Papaueris Rhoendis Corniculati ritu. cuins fimiles flores luteos ex tis pronta \&uni reptã; , Cucumeris agreftis in modum, tudine \& modo vifitur, torulis radiarim : fructus vero cum maximus Aurantij:magniculi centro ad appicem porrectis. Color deductis in ambitum quafi fectiunculis à pedipureus, cuiufmodi Charantix, vel Alkek renidet nonnunqquan fuluus, interdim \& purfimilia. Ital is nonnullis cfitantur Alkekengi, cuius ctian femina compreffa, flauétia, funt planta teter firitus, paruo emoluma, non fecus atq; Melones: fed quem halat vninerfa

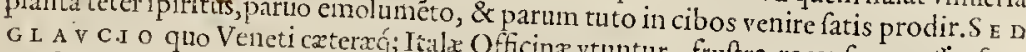
præftant:quia inquint ruffefcit fuperficieflicina vtuntur, fruftra recęnfiores allenfum Glatci, Suc bus notis Diofcoridis refpondens : Qu shaut intus, amarus, odore ingrato, feré omni- daucm. nummi ingenio Hcbreorum Syriacorum liceat, Glaucio nouando, vafro \& inexplebili undis, odores, colores, faporéfó cmentiri, vit ian quod in non parum multis alijs deprateft tamen \& hic per bonum vfum praftre vti iam tum Diofcoridis xuo faitatum. Foum erit : Quin fi mihiopren tutum \& vtilc tametî non fir é Glaucio, non tamen Glauci

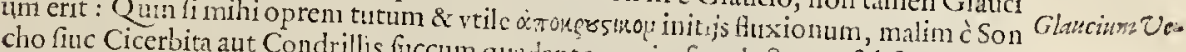
cere, \& in permixtum admoucre, ad ca quadantcnus virofum, latteun, fubfultum cl i- netorum. ccrtiori commodo, idem effecerum aqu Diofcorides Glaucio fanat, non minori fed paner atg; Glaucium reprefentare videntur.

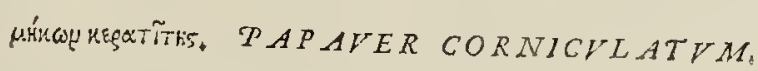

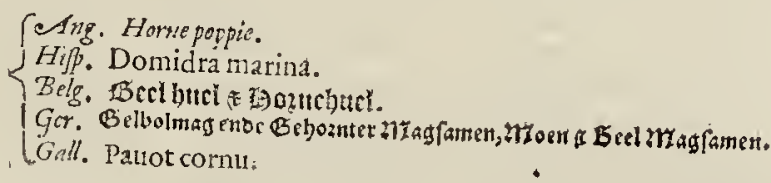

NI s I monuifet Diofcorides, quofdam deceptos foliorum fimilitudine ex ifto $\mathrm{Pa}$ paucre feri Glaucium putaffe, putafernus \& nos è Papauerum genere effe Glaucium, quod Plinius congener Rhøeadi, fuc erratico fecit, eorum fortè perfualus lectione quos Diof corides hallucinatos dixerat: nafcitur (inquit) in affatu maris, aut nitrofo loco,vnde nounen Paral lion, etiam alio nomine aflumpfir. At Diofcorides inter Papafquallida on thon tacuifict: aut fuo capte omifffer. Iftius autem $P$ apalueris natalcs funt nie, Nor mantima, cuinhibet orę fiuc Oceani frue Mediterranei, tum ad calidos Hifpafores colore iam luteo ia , Genux : tum ad frigidos Anglix, \&Hibernix tractus: vbi ctum cornom futeo, iam phenniceo, purptreo legimus fępins. Etcnim vulgatius dinis Iunio forer.Folij duifurolj, ant Chelidonij maioris, feminis nigri Plantaginis plecrifpati, fparfo fcapo mult is al is, glaters Rhceadis, aut Argemones, crafsi, hirfuti, rugofi,

\section{$P A P A V E R$ CORNVTVIM flore Phaniceo.}

Varietas. SAd Frontignanam Norbonx,\& portlandiam Angliz, aliáq; in afflatu maritimo loca, flores fert aliquanto minores, colore non luteo pallentc, fed pho niceo in purpureum languente, fucco, nec alia fui parte difsimili, nifi quia
tota delicatior cft planta.

$$
\text { K.j., Papaner }
$$




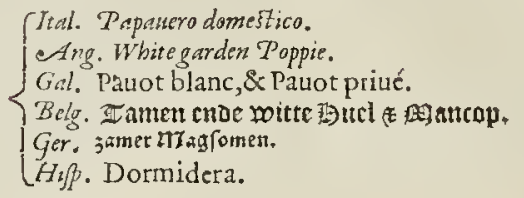

VA M v s hanc Papauerum recenfronem concinnius Iafucis añnecti pothit, qui-

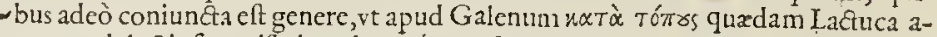
tra, \& amara ob lactis foporiferi copiam $\mu$ úkcwis fiue papaueracca vocetur : tamen nec intcmpeftiue hî́ fuccedet, \& nos plerunǵ; nolentes aufert commodior 2lizrum occurfus, nullibi equè oportunus poftea ád feriem plantarum continuandam futurus, eóq;

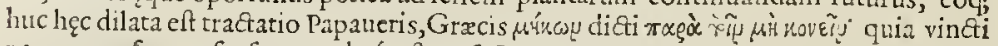
papatierco forore fenfus, membráq; ltupefacta, nequeant quicquam agcre: nifi dictum fit eadem qua Cicuta notione: kaviop enin à vertigine \& calligine quam inuchit vtrúmq;, vt de Cicuta liquet, \& de fucco huius dicebat Andreas apud Pliniū,excxcar protin is oculos,nif is fuerit adulteratus Alexảdrię. Tritę admodum cognitionis omne papaueris genus, fed difficlis dignotio ab anemon:, cui fimilitudine tanta coniungitur Rhœas vt planè eadé iudicio multitudinis fint, nif́ fic diftingantur. Calidorü, \& frig darü regionü fatu in lortis maximus Papaueris prouentus, prafertim aruis maritimis autaffatu maritimo obnoxijs, quibus impendio oblectatur, vt ad Lio infulam Venetijs vicinä, \& Septétrionalibus in Hollandı̨̧ propè Oceanü aggeribus, vbi totæ habitiores lacte plurimo fcatent ad Meconium conficiendum:capitáq; ferunt magnitudinis confpictę maioris pomi Nymphex, malum Granatum non mediocre etiam ęquantia, difiepientibus interdum calicem membranulis tranfuerfim fe decuffantibus, femen copiofum, album, rotüdü,fuaue amigdalæx,aut Melonis fapore ad placétas \& medicamëta vtilifsimú farctis. $O$ leum ctiam premunt Officine dulce nec amygdalino abfimile, albidius tanë \& tabidis commodius: Iunio flores latioribus quaternis plurimum folijs candidis, Maluæ hortenfis aut Rhoadis Papaueris caule vnico:fed alis dinifo infunt, rceto, ternum \& quaternum cubitorum, quem totum folia ambiunt Scariolę hortenfis, aut Hyofcyami nigri lacinijs tencra, fuccum lafteum fractu remittétia: qui effufus rna aut altera diecula polt flauefcit, radice cxigua Lactuce..

\section{Finbriatum album.}

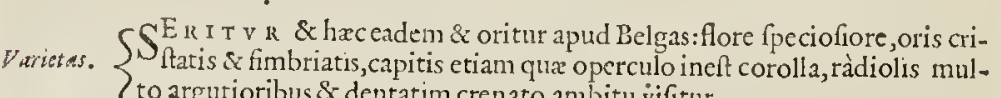
¿to argutioribus \& dentatim crenato ambitu vifitur.

$$
\begin{gathered}
\text { TAP AVER } \mathcal{N} \text { igrum Satiunm flore M Malue } \\
\text { bortenfis aut Toconic. }
\end{gathered}
$$

S A I v I alteram fpeciem alune, nigrumq́; à femine vocant nigricante, turtiore ín SySrupum de Papauere quan fpontanei hortenfis femen, quod virofius eft. Flores emicant fanguineo faturo Pœoniz, non diuerfo tempore, folid autem \& capita tanta funt Imilitudine, vt ea nifi effracta nefciant dignofcere pharmacopoi qui feucrint.

$$
\text { SATIVVM NIGRVM CRISTATVM. }
$$




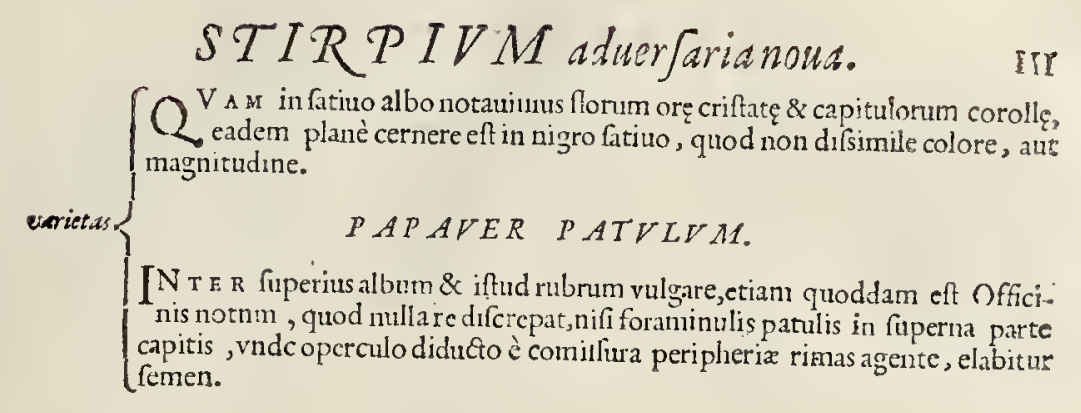

$$
\text { OPIVM. }
$$

P P A Y R R M eft lachrymaliquorúe,guminan; vulnere aut fponte emanans; quem dam fommúm ó \& óm dam fommúmq; concilian dum, \& ftupefaciendum decantatifsimis, \& verifsimis, etiamnum hodie, prafertim apud Turchas, Mauros, \& Perfas, vbi vfus tan frequens \& fecurus, vt id quafi quoppiā nepenthe ad aninni corporífque exhilarandas facultates, largius \& fxpius efitent, qui verò aflueuerint cfui,fi prorfum abftineant, moriuntur, aut periclitantur valde : ac rurfum fi largus efitent, vt factitant fontes quos txdet vita, aut manet grauius, fupplicium mancipia : extinguntur. Effe verìn \& merum iftud quod Officinæex Syria \& Alexandria habent, nec Glaucio addito calidius acriúfue \& amarius factun (vt Commentator fomniat) certum eft : nam quidam Pharmacopoi Veneti, \&e alii non pauci alıbi, ad Theriaces fimplicium delęuni exceperunt Opium è fativo $P_{2}$. parare albo, prorfum idem cum peregrino Afiano, vbi ex albo tum ex nigro fatiuo fit: quare corumi Amphiam effe Opilln Grxcorum, liquido patet, noménque indidem commutatum fuiffe vtrúmque perquàm amarum: veliemens odore, acre gultu, \& fauces quadätenus accendens, lumi nibus obie Qum Hagrat;etiam deterius \& nigrius iftud in Officinis noftratibus. Namillud Venetum, purius \& vt Alos pellucidum, fed glutinofum fuit, laqteum eximiis viribus, acrimonia $\&$ amarore, infigni. Quo minus fut cominifcendum Senenfi propter imniftum Glaucium, acrius \& feruidius Opium effe; etenim Glaucium nullum verum hodie cognofcitur, nec etiam calidum fed frigidum à Diofcoride proditur.

\section{MECONIVM.}

M E C O N I v m verò non modo ex vtróque Nigro \& Albo fatiuo, fed etiā Lątuce fyl: vera contufis foliis \& exprefsis, partim habuimus, partim etiam parandum curauimus: facultates comparabuntur \& expendentur cum opij viribus, inter leqtaremedia noftrà.

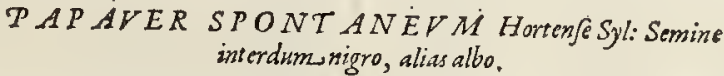

PRE T E R E A fponte in hortis prouenit,quædam fpecies foliis minoribus, foribus dilutè nubentibus, obfoleto afpectu, capitulis triplo minoribus numerofis, femine in terdum nigro, alias albo, quandóque hiulcis of culis, quandóque ocelufis, cohibentibus femen, quod parum gratum, aut probatum habetur, prafertim nigrum.

MŔkcay ğósxs. RHOE AS, fine caduco flore puniceo P apaner.

$$
\begin{aligned}
& \text { Germa, Kapper kropen. } \\
& \left\{\begin{array}{l}
\text { Gallis. Pauot faumage, confanons, Poncean, \& Coquelicot. } \\
\text { Ital. Papuero }
\end{array}\right. \\
& \text { Ital. Papanero. }
\end{aligned}
$$

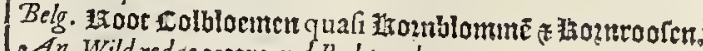

$$
\begin{aligned}
& \text { An. Wild redae poppye and Red weede. }
\end{aligned}
$$

I I H I \& frequentius ifto in fegetibus, quod vocarunt authore Diofcoride $\rho^{\circ}\langle\alpha s$, à códitione fluxa floris quem parum diú feruat.Folia hirfuta, incifa, altius lacinofa, 
Eruce, Ambrofie, aut Burfá paforis, ambitu rutilant ex atro cruenlati flores minores, tenuiores, flaccidrores, fatius, nigris, in medio apiculis villofis, per initia occlu fi introlucrohirfuto herbaceo Cucumeris Afinini pulilli effigie. Capitala funt 'Pfendo nelanthi magnitudine, fumlitudine, Sefupernè etian vertice coronato, feminis plena $\mathrm{Hy}$ of cyat mi,aut $P$ feudomelanthij. Caulis afper cubitalis \& fefquicubitalis; radiec non magna. qux attrectando quippiam illinit manibus eruenci, aut fubpurp rei, ad morbos eordem proficui quos iuuant Syrupus è flonbus, \&ftiliaticia, magnx apud nonnulios $\mathrm{Me}$ dicos, \& Officinas commendationis.

\section{A R G $M O N E$.}

O I a huius fuccus argemas \& nubeculas oculis difpelleret Argemone vocata fut, - cui cum fylueftri Papauere, \& Anemone perquä fimilis tota facies, folia, color, no dus:has tamen vt inuicem difcernercmus, fecit uatura difsunilitudinem ouädam, \& varietatem in fimilitudine, qux exercitatis oculis, tametfi notis adduct ts à D ofcoride, tum incuitu facilè inotefient; tamé g̣uoniam potius antiquor um quàn noftro ftan dum eft iudicio, nunquam perciperemus planè aut rem, aut euus difsunititudinem, nifi verba qux funt rerum indicia intelligamus. At illa videntur hic vno, aut altero loco, aut mäca, aut minimè vera: nä quorfim híc de Eu patoro cuin illis fpactat collatio, nefciunt doati: proindè ex rationis illatione fatis liquet non Eupatorun, neúc Agrimonian, fed Argemonem eo loci legendum. Sic enim. ait, Anemone, of Riseadi capitsht

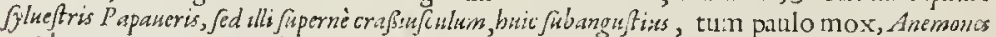
hooliey caicre. Iam fi codiu eft eapitulum, aut pixidula qui clauduntur femins: (quod D I A c o D I v u nomen videtur in(inuare) negabit eidé adeffe Capitulum, quod illi paulo fuperius afferebat. Ergo fichabendum, $u \in+\alpha^{+} \lambda \wedge \alpha$ capitula hîc alıd effe quam Codia (quodinterdum etiam Theophralto Fabx cralsius gibbum indicat) natura magis quain yocum vfu docente : $v$ in Papauere, vides caule fummo Capfulam rotundain teretem, cur fummo fuperficiei med io crigitur cupulus caliculúfue Punici mali in modú. Iftum híc Diofcorides codion ununcupat, eóque magis ver. quam fcita diftinctione eundem Anemone abeffe indicat, vti infpectio etiam teftatur, qux quemhbet hxe monitu facilè germanam differentiam docebit. Ifta Intererat accurati \& probi interptxtis po: tius extricare, quàm meras aliorum icones congerere, aut Ruellio huus hiftotix pa renti bene-meritò notas imperitix inurere.

Effe quädam Papaueris, Rhoeadis fpcciem, cui fuccus flauefcens preffu cxtillet in Plan Defript io gua tarum diaris, \& memoria habemus:an verò radix illi rotunda haud fuccurrit memorie, qubufda gemi- nectamen cuilıbet fe prodit intuenti color iftus Papaueris, quam Árgemunem putanis locis extat, mus; vti neque in Rhoadis radicibus, quas fi digitis fregeris, aut Papyro affricueris, non nifi una eft: non in radice fed in cute colorem purpureum, vel fanguineun untuebers: hanc guhbet fedaltera plätä, paulo gnauior, qui multas Rhoadis plantas collegerit facilè animaduerter. Flotes vealter.z pars vires rò interdum a deo Caturi flamneínc coloris funt, vt atrorem preferant Adonidis Horiprofeguitur. busparem.

$$
\text { A } N E M O N E \text {. }
$$

PER 3 I M I L Is Rhoeadi Papaueris, Anemone, quàn quia primo euíq; afllatui venti flores pandat \& referet, fic appellatam volunt. Potuit etiam non inconcinnè a corsnati affectu Rhoadis floris perfimilis, cui deftunt folia cito, fiue ilatu, fue fpontè,vnde vulgò dicebant Pulfatille, \& Herbă Venti: nam hiure pateréque llantibus ventis por xftatem, permultis vfu venit herbis. Deinde quotquot Ane:nones vel eultis, vel neglectis locis legitimas agnofimus; oportet perquam fimiles effe floribus, prefertim Rhceidi Papaueris, \& Argemone, Diofcoride monente :alioqui fruftra folito diligentius Diofcorides hafe interfe collatas difcreuiffet, monuif't tque Anemone fuccum \& calycen deelle, dumtaxat Afparagi pullulationémue cacuminolam ineffe. At Rheadi \& Ärgemonefuccum tum Codion fiue calycem fum efte.quas cunftas differentias, qu 


\section{$S T I R P I V M$ aduerfarianoud.}

in Romano agro Norboncnfi volucrint animaduesterc,illicò deprehédent. Tametfr raillis Ranunculis, \& Napellis, quas quidà falió $A$ amen certiores \& notiores multò funt 11etijs virentem é Syrio fcmine prognatum cuulfimus.

$$
\text { A N E MONE, Bulbofuradice. }
$$

FL o r es funt Papaueris Rhceadis aut Monfpelliacx Anemone pares, fed colore faturatiore viuidiore qual.s Adonidis, cauliculis multis fefquipalmaribus \& pedalibus, teneris hirfutus, folia Coriandri aut Pulfatillx, radix tuberculus eft quătus Doronici ob.
longus, aliquuannultis fibris capillatus.

\section{$\mathcal{L} O R B O N E N S I S$ AAncmone maior, corniculata.}

NO т I S I M se verò apud Norbonenfes dux, ptimo intuitu Papaueris Rhceadis florem oftentant, in cultis prafertim, quarum maiot folia habet eciam Coriandri divifura: fed Papaneris Rhœ?dis modo hirfuta, in caule pedali \& fefquipedali:fores verò ex ru. bro in purpureum violaceum deficiunt, quos perquàm tcnellos Papaneris Rhœudis ritu vel Icnifsimus aurx appulfus celeriter aufett, remanente tereti hitfito lon giore corniculo, comuti Papauris non difsimili, fed minore \& gracilore:quafi natura alludere vol uiffet, itto defcripto ad Papaueris cornuti feliquas, \& altero ad Argemonæ glomerata cupitula, in acutum faftigiâta non operculo munita, vt Papauera omnia funt,

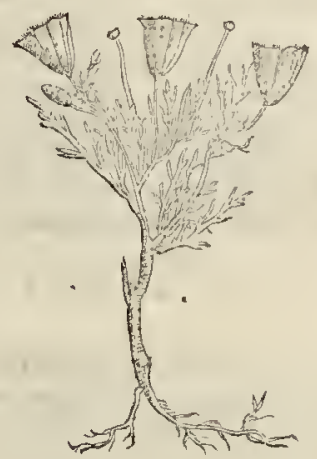

$$
\begin{aligned}
& \text { CII INOR A A EMONE, CORIANDRI folit, } \\
& \text { fioie Pulfatille capitulis birfuris,nec vit Prepaner } \\
& \text { corollu donatis. }
\end{aligned}
$$

$M^{\mathrm{I} N \text { o }}$ R autem delicatiore caule non difsimili,minutiore folio \& dinifura quam Coriandri, valdè quàm hirfutis; \& fatis rigidis, hirfuta capitula,flore elecanti relinquente multo minora quadantenus fimilia Rhoadis Papaucris, fenine nigro Hyofyami, radice pufilla fuperiori haud difpari, quibus fi tubercu lim adeffet, nullix notx dceffent: ac fi non fint Anemones, fanè vix fint vllæpropriores aut illis, aut Argemonx, aut noux putanda fint, vel fufpicandam capite de Anemone duo genera defcripfifie Diofcoridem. Quorum vnum radice fit tuberofa, alteram non difsimili Rhœadi, quod videntur inuere verba initio, deinde confirmare, vbi difcrimen ponit Papaneris, Argemona \& Ancmonc, hrius tuberculi nulla in-

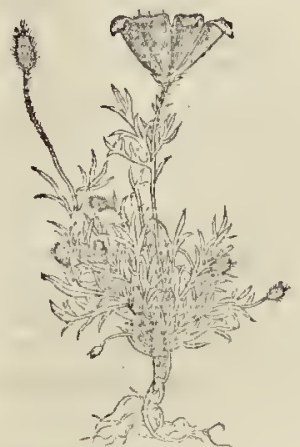
git, quod Drabradici, qux alicubi tuberofa, aliubi plana \& xquabilis vifitur. Idcirco

$$
\text { K.iij. àMon- }
$$


à Monfpeliaceis Medicis verx putantur, frequentéfq; inibi oriuntur in vinetis ac veruaciis,præfertim iuxta prædium Praceptoris \& harum feduli veftigatoris D. Affatij, qui cumalijs nultis opinabatur illam Germanicam \& recentiorem Anemonen, fellatis Iuteis Ranunculi floribus \& femine, radice multis bulbilis tuberofis Bulbocaftani donatam, fpeciem effe Bulbofam Batrachij: nam tametfi eiufdem flores interdum albidi aut purpurci fint, tamen nihil fermè habet tota quèd quadantenus prxferat Papa-

An.Gal.Ane mo Lutcalib. 2.

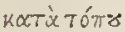
eadem fit Germanica. uer Rhcas: funt cnim folia Geracij columbini ant Ranunculi, cuius vrentem facultatem itidem habet:qua propter illuc nos referëdum duxifiemus, nifi à Galeno memorata Anemone luteo flore nos fafpenfos fententix de hac planta magis quàm certos retinuiffet.

\section{ANEMONES Mathioli.}

M. icorres.617. PO R R o côplures A nemones ve non neceflàrias, ita parum notis $\&$ locis expreffas ad618.619. ducit Mathiolus, quarú parteñ nunquam vidimus, partem verò bis inculcatã puta-mus, nempc hic \& in Ranunculis;quas tamé vltimas ponit, veriores intermedijs coniect:mur,potius quam afferimus:qua ex illo profufo magis quám profuturo picturarum apparatu, nullò aut perparca verborum explicatione, locorú defignatione, \&utirpiú diftinctione fubnixo, nịilil penè certi capere valemus.Vtinam tantus Herbariorum diča. tor, potius pofuifet operam noftro defiderio difcendiexplédo, quam Ruellio, Fufchio, Brafauola, Manardo alíf́c; viris neritifsimis carpendis cum alibi crebro \& falfo tum hî́c in Pulfutille \& Venti herba qux apud vulgus complures herbas denotat, Othonnæ pannofa atrofa folia, Solidaginem minorem, Pulfatillcm, \& alias.

\section{TVLS AT I L L A, an Sylucstris Ancmone.}

T $V$ y v s comofi \& tremuli fcminum pappi quia huc atq; illuc vel leuirsino quóq̧; fa$\mathrm{H}_{\text {tu pultarctur, Pulfatillam barbari vocitarunt, Anemonem }}$; conie\&tantes \& vertentes Vétí heı bam pleríc; dixerunt: \& fanè meritò non multun vifa fuit abeffe à Sylucftri quibnfdam doetîsimis. Quippè folijs eft Anemones tuberofx, Bulbocaftani aut Coriandri, rigidioribus, hirfutioribus, nigricantibus, crafsiosibus, durioribus, caulem palmarem \& fefquipalmarem hirfutum Geranij amplexis, in quibus flores Papaueris Rhoadis aut potius Anemones, quinis \& fenis folijs purpuro cærule is, c̀ medio quorum excrïtur apiculi ftaminánc lutea Aquilegix aut herbx Trinitatis fiue trifolij Hepatici,à quotum delapfu fe prodit cafaries villofa, cirris ctebribus, \& cincinis calamiftratis pennas delicatiores fericeas pulli coloris implexas, aut curminatum bon?bacis penfum referentibus, cuiufmodi in Caryophyllata, Scotino, \& fpongia Bedeguari:quibus conditur femen ex. iguun Afcle piadis: Radice digitum crafta non admodum acri nec feruida. Quare inuerecundaratione incufat Fufchium erroris Conmentator, hancog; recufat quia cum priinúm erumpit,emittat hirfuta folia laciniata, qux acrinonia fint Ranunculi aut Flammulx : inferius tamen paulò, dulcem faporem radicis idem Senenfis agnofcit,non acrem cuiufmodi in caule \& folijs: At Diofcorides vult vtramq; Anemonem acrem \& acriorem illam cui folia nigra funt, qualia funt huius Pulfatillx, qux cruftas emarginat admbtis folijs,quemadmodum de Anemone dicit Diofcorides, qui introfumenda folia ptifana elixat, quò dcponant acrimoniam : ip $\int_{a}$ vcrò radice vt puta mitiore cruda manfa, pitritä extrahit. Flore albidam, pallentem, Mendini nontes, \& Auernix, dant. Pedemont tiū Tau rinenfes, interdum lutean ferunt : ex Alepo Syrix rubram etiam habiimus. Non procul Bafilęa in Heluetia meminimus frcquentem hanc cxruleam \& purpurcam, qua propter Mathe. ico. qui Rifus A pium Diofcoridis hanc autumant, rifum potius quam rcfponfum mcrcitur.

RECENTIORVM A DONIS, aUt A DONIVM Poetarum, fpecies Anemone, non Eranthers. 


\section{STIRTIVM. aduerjaria nosia. \\ Belgis. Bstutetteketris.}

E r I I v s etiam augurarentur, fi eximix pulchitudinis forem iftum vulgò adoni- Effig. Math. dis rocatum, vel Adonium qui etian inter fegetes pafsim in Gallia, Germania, \& An- 906 . glia reperitnr, $8 \mathrm{in}$ hortis coronaria habetur, ad Anemonas retuliffent: Etenim Eranthe- Erantbemum num cur non fit, diximus inibi, cur autem anemones fit, \& eadem cum Poctarum ado- Dod. Fol.140 nide videstur, faciunt flores punicei anemones Galenicx aut Germanicx, intenfo cruore faturati \& alıquántumnigricando lucidi. Folia, caulis,ramuli, \& radices Cotulx, aut Anemone Monfpelliacx: : menen in pufilis oblongis racemofis, Ranunculi longioribus fafigiolis, afparagi primum pullulantis, vt fignanter monuit Diofcorides in Anemone : tota guffu fubacri, vnde Monfpellienfes eruditi pleriq, in anemones potius quám Eranthenium ducendam voluerunt. Sententix quorum fauentetiam è Nicandrj Theriaco cólecturx, vt qui hanc adonidis cruore genitum, Anemonem vocent, \& Ouidius itiden

Curn flos de fanguine concolor ortus,

Onalem que lerio celunt fub cortice grantum

Punica ferre folent,

2Lmia lenitete caducum,

Excrutiunt iydem, qui perfant omnia, venti.

Vbi vides anenonem, \& vulgi nomenclaturam, herbam venti adumbratam.

\section{APA THI, fiue R VMICVM genera.}

\section{C $V M$ Paulo uperius Lapáaij differentias cunctas Atri- plicibus \& Betis, in ferere confiliü fuiffet: Nec tamë id} apte fieri potuißet, quod nunc poßumus proxime eas bic adiun gemus: Deinde vt quxá fe e offerent fimillima, ita proxima ferie ad bunc modum erunt collocanda.

Oxylapat bum praterife, \& Paludofum folio a cute mucronato.

Pratenfe alterum obtufiore folio.

Lapatbiolum, fiue parutm fontium.

Hjidrolapat hum magnum.

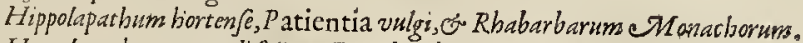

I A A- $\int$ Hippolapat bum rotundifolium, Tfeudo Rha Recentiorum.

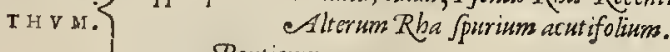

Rha $\left\{\begin{array}{l}\text { Ponticum, } \\ \text { Barbarum. }\end{array}\right.$

Lapat bum Janguineum, Jiue Sanguis Draconis Recentiorum,

Lapat hum Oxalida, fine Oxalis.

Oxalis Gallica rotundiore folio.

Oxalis minima.

$\left\lceil\right.$ Bistorta. $\left\{\begin{array}{l}\text { Maior } \\ \text { Minor } \\ \text { Minima }\end{array}\right\}$ Draguntia Pliny quorundam,an Britannica?

K.iii. Rha. 
Rha capitatum Centaurij maioris facie, Enule folio. Pulmonaria maculofis Betc folys an Britannice?

Britannica altera Gefneri.

Herba Doria.

Viran Aurea.

Solidago Saracenica.

Tripolium.

Limonism vtrumóg.

Pyrola.

Sanicula altera Primula veris.

Cochlearia cum Frifia co Anglia.

CAlifma fue Damafonium que Plantago aquatica.

Saditiaria.

Alifma recentioram, \& H. Morgani.

Calceolus Marie.

Ophris, fine Bifolium.

Vnifoliem.

Plintago. $\left\{\begin{array}{l}\text { Maior lavis. } \\ \text { Maior pilloja. } \\ \text { Quinginerwia. } \\ \text { Rofea. } \\ \text { marina. }\end{array}\right.$

Potannogeton,

Folivim Indum Diofe.

Foliuns Malabatri,

Tombul.

Butre.

Gentina. $\left\{\begin{array}{l}\text { Maior. } \\ \text { Minor Crutiate. }\end{array}\right.$

Nardum \{ Celticum.

Cardum \{Celicumalterum:

Nardum montanum cum valeriana.

Elleboru albus. \{ Flore racomofo albo,

Elleborine alba.

Saponarici.

Perficaria mitis.

Perficara Hydropiper.

Capficum fure Piper indicum mains,

Balfunine famira.

minus. $\}$

Costius hortenfis, vulgo Cocq \& Baume, Tragi Alifma.

Noli me tangere recentiorum.

Lepidium ïginet a, fute Raphanus fyl. vulgi Gallorum, of Belgarum.

Raphorans maginus Rusticanus.

Bolbonac fue Raphanus agrestis recentionum, non est Diofc. Armoracia.

Violamatronalis.

Fioln Marinza, an Medium antiguornm?

Trachelicn flore. $\left\{\begin{array}{l}\text { cartuleo, } \\ \text { albo }\end{array}\right\}$ maius of minzes.

Campanul. borten/is, P byteuma CNathiolifollo.

Pes Locista A Aricema, frue Rapunculisminor.

Rapintirm mains, eAlopecoricomofo flore. 


\section{$S T I R P I V M$ aduerfarianous. $L A P A T H I V A C A C V T V M$.}

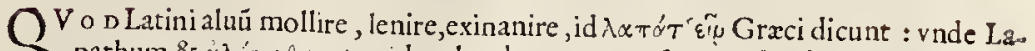
pathum \& $\alpha \lambda$ is $\alpha \propto \alpha$, vt quidam legebant, vocatæ fuerunt. Herbx notifsinax \& lu bricand 1 vi donatx holeracex, cuius permult $x$ funt differentix, cunctæ vbiuis abundè prouenientes : vt eftea quam adhuc hodie L A P A T H I v M A C v T v M fine acutifollum vocant. Pratis nufquam defit, foliis Acetof nigrioribus, Betę longioribus, anguftioribus in caule cubitum \& fefquicubitum alto, rotundo, profundè frrato, purpurafcente, alis pluribus donato, quibus flores múcofi, \& femen triquetrum. in folliculis Atriplicis, vel Acetof $x$ concoloribus paribus non difsimilibus. Radix fubeft peden longa, vnciam craffa, flaua vel fulua, foris ad lotiones, fotus \& lininenta, etiámque, intrò in decoctis vfurpari officinis folita, totius nomine Lapathii acuti, non reiectis ramulis rel folis.

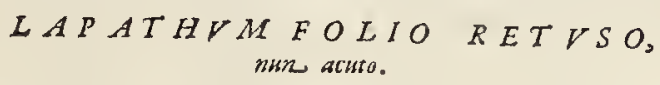

NO diueri generis, Officinx vocant non acutum, quoddam Lapathium foliis fupernè retufis, breuioribus, rotundioribus, iifdem locis circa ruder $\&$ areas zquè familiare, ac femine, caule, flore, \& radice a fuperiore vix difcernendum : vfu minus receptum,propter fuperius acutum vocatum.

$$
\begin{gathered}
H T D R O L A P A T H V M \\
\text { fune aquaticum. }
\end{gathered}
$$

Q I a frequens in aquis, necalibi fponte exiret Hydrolapathü vocarunt iftud, etiam tota facie Hippolapathum fatiuum referens.folio nigriore, non difpari, vti neque caule \& femine; radice dumtaxat breuiore, fibrofiore, foris nigriore, intu s vero ru briore, cóque ad Behen Rubrum ementiendum aptiore; Hancenim quiden Antuerpiani, \& Galliaudaculi Seplafiariiad Medıcos vfus fufficiebant, Behen rubro, cuius facultates \& notas non minus adumbrat quam Limonium.

\section{PVSILLVM FONTILAPATHYM, C) Lapatholum vocatumu tenellhm.}

$I^{S}$ r I etiam aqux funt natales, fed non nifi lympidx \& fontanx, trans quas è fundo - exerit cauliculos teneruficulos, faccidos, graciles, non abfquè hunc inde filamentis, vt cæteræaquatic $x$, ftipantibus \& pendulis : folia funt item admodum tenuia \& molscella, nectamen aqux inuatantia ritu Potamogetonis, fel erecta viridantıa ex atro Lãceola, angutiora multò quam Potamogetonis, qux nufcenda colligebant fedulo, qudam Pharmacopœi Norbonenfes, prafertum Namaufi(vbi hxc, nectemere alıbi, reperitur)ad vnguenti Martiati nominum \& rerum farraginem confufísimam: tuebantúrugue femper iden nou aliud generis Lapathii mifcendum effe slli vnguento.

\section{$S A T I V V M$ Hippolapatbum latifolitm, wh/gi, Rhabarbarum Monachorum.}

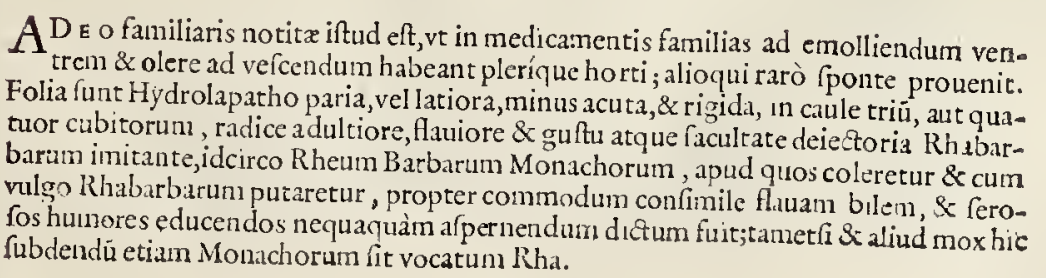




\section{STIRPIVM aduerfarianous. HIPPOLAPATHVM ROTVNDIFOLIV $M$,}

PSEY DORH A recentionum.

PA v c 1, \& diligentiores Herbarit vt Antuerpenfes Pharmacopei iftud colunt, \& agnofcunt, quafi multò cognatius vcro R heo Barbaro, quia folio fit rotundiore, de fuperno ambitu retufiore, propioréque ad Perfonatam, ant Petafitem, quibus fermè magnitudine xquiparatur, nec tamen maiore, aut ita diuerfa radice Hippolapatho, vfúue, aut natura dissimili.

\section{RHA CAPITATVM Centatirigmaioris fucie, Enula folio,}

MVI I s etiam abhinc annis aliud Rha exfemine Turcico habuerunt nonnulli, in MhortisGallix \&. Flandrix, quod magno ftudio cultum, non parum diui inibi perennauit; foliis etiam Bardanx, fed non perinde latis, longioribus, Enulx, vel Phlomi, ambitu ferratis, \& fimbriatis, læua \& aduerfa fuperficie virentibus, auerfa autem glauca lanugine pullis, caulem rectum fefquipedem \& cubitum amplexis, capite faftigiatum, foris fquamulis loricato, ac per maturitatem ftamine purpureo pleno, cuiufmodi in Cynaris, Carduis purpureis: femine dam circa Iunium \& Iuliú maturuit; Cétauri maioris, vel Carthami longiorc: Radix etiam fungofior, maior, \& Rhabarbaro fimilior quàu Centaureo.

\section{PONTICVMI RHA Antiquorum? \\ RH $A$ iPortiflumine cognomine $R h a, \mathrm{R}_{\mathrm{H}} \mathrm{A}$ v E D Seniè Chinarum In- dia feu Rlobbarbarnm Cholagogonu.}

A P v D Arabes \& recétiores, duplex radix peregrina nomine Rha defignatur;fed quia cuiúfnam vtráuis, ftirpis fit, hactenus doctis ignoratur, \& numnam eiufdem ambx fint plante ambigitur, paucis \& perfpicuis refeetis turbulents argutationum aceruis, \& anthoritatibus; lis ex rer m infpeetione \& accurata collatione dirimenda. Qui fixpius manıbus \& òre verfarit radices háfce quínque nimirum Rhapontici, Rhauedeni, Centaurei maioris vtriúf,; \& Hippolapathi Monaftici, facilè percipiet omnes parıter \& v nam quamlibet interfe, tum fimiles effe, tumetiam non parum difcrepare. Quod fi harum tres ift $x$ indigen , nobis tam partum notx forent, ac ill $x$ duæ peregrina funt, Pontici \& Barbarici Rha, facilè quis leuiufula coniectura addita adduci polfet, vt Cen taurium Rha Ponticum crederet, atque Hippolapathum Rhabarbaro idem, aut congener faceret. Nunc cun lixc duerfa efie fatis conftet, nullus nifi apprinè veris argumentis fretus,afferere debet, Rhaponticum idem effe Barbaro Rha. Eft enimillud non modo molcfum tyrom leftori, fed etiam impedimentum ad fimplicium percipiendas qualitater notas, varietates, differentias, \& vfum; quin cauillis \& ad oftentationem concinnatis fophifmatis contrarix, fermè naturæ i es exdem effe probantur. Quíppe fi quis iftud Rha Diofcoridcum, nunc poftremo cognitum guftu exploret, primim pauculum amarorem, vehementem aftriftionem, glutinof um vifidúmue quippiam adiunetum,acrimonia expers, inodorá, leue, manfu nó, cuiufnodi Rlıbarbarari, Croceü deprehédet fed croceorum, tramitu, colocem, atriorem, tamen \& ferruginem aceto dilutam oftendentem, fractu facilè, adeo vt minutim etiam non attritu in fruftula diuellatur; intus

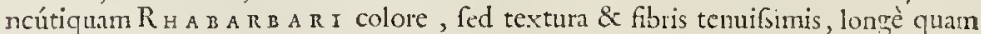

Rhabarbari o Rhabarbaridelicatioribus, à centro inambitun radiatis, colore cinericio pulloue, veRhapontici dif-nulis träfuerfis pallei coloris. Crafsitudo radicis maxime nobis vifę quäta Cêtaurei maiocrimen. ris; mediocres pollicé zquant: recens laxioris folutiorífo; fubftantiz magis quả Rhabarbarum, etiam vetuftate cariofum \& minus graue.Longèal lud eft ab illo quod Mathio. in. nuit; Anguillaræ A ppoliníf; monitu, nam merito hi cöiectabant; vti res erat, fuam illam radicem effe tantü præcocé \& præcifam à iuuencula Rhabarbari planta: etenim anno ferme is $6 \mathrm{I}$, miferät copiam iftius in Italiă, \& Rhabarbarai Pontici nomine donarant: flaua crat grauis \& mracilis radix, fed vetuftior, \& teredenibus exefn, leuior, pallidiö, magni tamé tunc ha bebatur, quia in Math.cómentaris celebrabatur, etiāq; vt afferebüt nönul: li purgabat, plufculü fumpta, vt videre meminimus Florétix in Nolontrophi officina; \& 


\section{STIRP IV $M$ aduerfaria wouda.}

etiā Venetijs plerifq; locis alijs. Q no verò anno I 64 . Math.in Bohemia, eius verò com métaria pralijs Valgrifsianis Venetijs lærebät Sequinus Martinello doctus \& perquā in hac Palxfra verfatus, iftum alterum poftremum fratri Albetto ad Angeli fymboin mi fir:quod Mcdici Veneti nulla nota reclamante Theriacis addiderunt, \& ad cxteros affeEtus in vfum deduxcrunt:prafertim Lugduni in Gallia, Medicus fingularis Dalefcanpius: neútiquam purgabat, ed aftingebat \& duntaxat prottabat ea qux de codem prodiderant antiqui.Sic \& Pharmacopcei nonnulli, vt Valerandus Donrez infulanus valde ingeniofus, huius non femel fecit, \& vidit periculum factum. Caterùm parum folids pedicis fulcit Anguillara fpuriam illam Pontican radicem, quam fi quis huic noftræ vellet aptare, longé magis aberraret : hanc etiam cum magna copia recentem habuerimus: (pendebant tamen $\&$ in fingulas vncias ducatum ad Theriacx compofitionem Pharmacopoi) femper leuiufculam corticibus crafsioribus, \& abfolutis, vti fupra difum obferua uimus: cum potius debuit grauior effe recens quàm adulta, aut arida, contra quàm An- guillara putat Raued iftud purgans. Frultra \& ridicule faceffunt negotium, dum quibus cx orbis regionib.aut emporijs Venetias adưehatur anxié a nquirüt: nam alijs nauigationibus ex Indijs Orientalibus, ad Septentriones a coli volucribus \& Neptunis Hifpanis Vlifsiponem indeq; Antuerpiam deuehitur: venumá; exponitur dimidio fermè minoris quan Venetijs. Maguus Mathiolus magna profequitur veneratione, Apollinem iftum Iambicum, qui aquo anino forat illius falfa \& afperiufcula nonita, nec conucium in illum regerat, qux tamen nee lacefsitus in alios doctifimos folitus eft congerere:verú prudenter \& catè fic fáctum vt filuerit: \& vt puto ne iftam Mathioli laternam luftraret, aut vaft a commentaria Cuis illis radijs Iambicis conficeret, \& vreret.

\section{$L A P A T H V M$ fanguineum.}

Belo. tDesacten bloct, aut fanguis Draconis vulg,

Gall. Sing de Dragon.

SETENTRI ON IS hortis f Ponte hrcetian oritur, rarius in calidis plagis, quam 3 quifpiam putafet Limonium, cum quia Blited illi fint folia, tum etiam quod neruulis, \& venis crebribus fanguineis cadem fint intertexta: qualia quidam in Limonio defiderant, cum apud Diofcoridem veveorad ह̀ nuncupatum legunt, id eft, nerueam, aut neruis donatam : verum è Lapathorum eft lıac genere, quod habitu toto ipfo præfert, tametfi nitrofiore guftu, \& Bliteo folio \& facie, vel Lapathij acuti anguftiore, longiore, numerofo ranguineis, purpureis, faturatis extantibus neruulis, aut venis cruore plenis, quoquouerfum fparfis, \& labyrintheis du\&tibus, folij fufcum virorem maculantibus. Reliquáq; omnía funt protfum Lapathij acuti, aluumq; cient iufculo, aut expreffo fucco fanguineo to. tius plante, quan idcirco Dlaticu bloct Germani vocant.

$$
\begin{aligned}
& \text { OX ALIS, fine L AP AT HVM OXALID A, Acetofaffi. } \\
& \qquad \begin{array}{l}
\text { Gall. Oufeille. } \\
\text { Ger. Saurampher. } \\
\text { Belg. Sutkclc. }
\end{array}
\end{aligned}
$$

OX A I I DES tametfi non perinde nif nomine expreffęfucrint à Diofcovide, tamen quin fuerint Lapathi quartum genus conftitutz nulli dubum: nam quod cuipiam Effgr. Dod.383 minus placere poffet, femen of tirr,acidum fue aigre cum acri confundens : alioqui cur illi notifsimum, vt femper fuit vel mulierculis, non putemus? \& Oxys feu Oxalidis vox, non modo foliü, fed etiam faporé connotat, qui acutus ab acie cultrorum proportione \& fimilitudine dicitur, Oxis fiuè acutus, quibus etian Lapathum vocatur Oxalis, vt fane eft: folijs quippè acuti Lapathij tentuioribus, delicatioribus, \& magis holeraceis, ima bafi latioribus, lunatis \& pinnatis Spinaciam, \& Atriplicem teferentibus: caulem multum friatum, rubellum, fucculentun 


\title{
STIRTIVM adverfarianoua.
}

ambientibus admodum acidis : radice ex Crocco fluct fibrofa, femen angulofum acutum, in folliculis Lapathijs cxteris non difsimilibes. Vbiq; pratis \& hortis quòlibet anni tempore viget, ${ }_{2}$ ippetit Officinis \& culinis ad embamata.

\author{
Oxalis T ENVIFOLIA, finuata Verrecine. \\ selg. Scaepg futkd. \\ TGall. Surelle, on Ofetlle de brebis.
}

DE 8 s r M I r huic, E tanto luxu fabulofis Brabantix, Picardix, Nortmanix, \& Anglix importuna, vt fegeres enecet, vires aut incrementum prapediat, fufco purpureo feninum catium, \& foliorm colore folum ipfum operiens. Guft etium acida pecori non ingratz, eóg; for tè vocata Belgis Schaep surthet, id eft, Acetora veruecina. Minor tota \& gracilior,palmum \& fefquipalmum alta : radice exili \& tenella, plurima etian in collibus quibirfuis fquallidis \& macilentis.

\section{Satiua $F R A N C A$, rotundifoliarepons.}

GR ATISS I M A \& tenertimu holere hxcin Fräcia Iutetiam, \& Aureliam circum:

tam hortis ad intindus ciborum \& medicamenta, quim fuperiores dia relicuis regionibis frcquens : acideò Romana vocati, qua cunctis proferreretur,guftu \&accidtate delicatiore. Quámuis \& in montibus Gallorrouincia glareofis multa fateat, for-

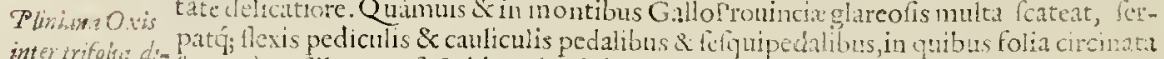

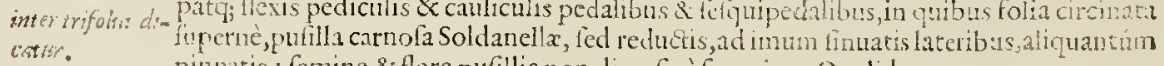
pinntis : femine \& flore pufillis non diucr fis à fupcriore Oxilide.

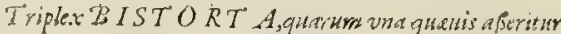 BRIT ANNICA.}

PR I M $\mathrm{M}$ intuenti vtrámuis Biftortam, videntu illa è Rumicum fylneftrium fami-

lia, guate ä de Diofotidis foliorumq́; comparatione Britannica iudicata fut, Sed maimas mulcò commendationis antiquorum Pliniíq; elogio Britannica olim fuit, quam hodle fit cxploraix notitis. Factum quippè videtur negligentiufula recenfione, fortè \& va immitata vocula, aut funè labecula in radice exprimenda, quod vfu venit noftra \& auorum menoria, vt quam peı ditam aut ignoam duceremus, vfin tritam quotidiano, nomine fub alio inuugatam, funiliaren admodum habeanus. Qune qui Biftortam nolunt,propter iadiccm $\lambda$ eтTkv, id eft, tenuem menoratum, neq, nihil penitus dicunt: neq; tancin tantum incommodın addncunt, vt cum cæetera onn exquifitè faueant tum figurx,tum vinum figna : cumiphi nihil nquè commodun, nedum melius afferant, fit il.lis illicò cictcondum: totum quippè difceptationis monentun in radice vertitur: aliogui

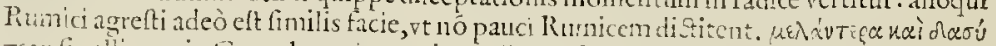
Teps fi vellicant, in Gracula notione trita calligät : faturiore quppè \& quafi purpura ni-

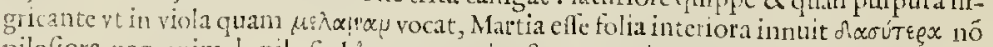
pilofiora, neg; cnim de pilofis hic comparatio eft, neq; notio e. commoda hic eft, fed rigidior., hiita, \& firmion. Beaxlap, id eft, brenem, fanc videre licet ctiam cum Lapatho, atut minoribus collata. $\lambda \in \pi$ thv, tenuem fanè, vt non lubet, ita inuitus dico, for tè quod verifsimum eft : at illum minoris Biftortx radicem intellexifte, qux non admodum crafis eft, aut quenpiam amméfem, qui brenem radicem legifet, tenucn è crafo mutafie wax" in $\lambda$ st Tiv, nempe rei ignarus, ratus id aptus congruere, (quil qux funt brenes radices vt pinimum funt tenucs : tnnetfipfis etiam autoribus eaden excielere pofunt crata lenimfula, humanx Mincrux. Vt vt fit, vfus \& fructus Bifortx naquit extorqueri illis, cuos rigintianos,eeq; plus toifi: Britannica fedula difquifitio : quit fiunt ijfem plane viribus, \& longè plucibus, quă quot atribuert: Diofcorides Britunicx, pollere. Quarú expondio retince nos in eadem fententia colubentius, quod nullam plunevideamus, quir $x$ -
quicongrtat. 


\section{STIRTIVM aduerfarianoua.}

M A r o R enim promit folia, Rumicis acuti fimillima, alignanto minora, nigriora, ple Effrg. Mr.this. niora, rigidiora, ambitu tantillum laciniofo, aut alicubi reducto, auerfa cxefia, te- 946 . neros, glabros,pedales exiles, \& in fummo fpicatos flores purpurzos Betonicx, aut $P$ erficarix, caules edit. Radix nigra, inftar contorti, in tróque reflexi pollicis digiti manus, intus ruffefens, lapore perquam auitero, aftringente, quandantcnts Tormentilla, foris fibrofa, nigra."

$$
\text { Bistorta } M I N O R \text {, o } M I N I M A \text {. }
$$

PR o R S r m eadem prima minor \& minima, etiam quò loci onnes vnà fponte oriunitur; fed hifce folia anguftiora, lęuiora, continuíf̣; oris: breuiore item implexu conuoluta, minórque radix, \& nullis penc̀ fibrillis. Celfr mótes \& frigida pratéfia has alunt on nes, vt Baldus Veronenfis, "̈x colles herbidi multi in Anglia Occidua. Vbuis etiam colunt horti Pharmacopceoú efficacifsimas omnes ad vulcera effienè ferpentia, \& ad fungofos polyporú in naribus, \& palato interiore Aagellos abfumendos, aqua ftallatitia, qua etiă ad hepaticam fanguincámque refudationem plurimum pollet epota:

\section{$B R I T A N N I C A$ GESNERI \& Lurdsrenfirm}

Q V e enim nobis primum indicata, ab exercitatifsimæcognitionis Valerando Dorrẽ Infulano, vt non parum foliis, \& radice re(pondercre videtur; ita plurimum IIlis aftritigendi viribus \& oris fauciúmq; vcl tonfillarü vlcera iuuandi, defici, haud obfcth rú:\& veheméter amara, atq; nonnihil calida eft: Conizx quiddam odore, \& fapore teftatur. Magna copia Lugduni etiam ad mœnia, is intra po męria peninfulę herbidis amœn $x$, quãalluüt, \& difterminät duo nobilifsima flumina;hinc Rhodanus ab Oriente, illine Arar ab Occidente, \& vocant vernaculè Ayne?. Caule plurimum fingulari, rotundo, duriore, pallente, cubitú alto: iin genicul is folia ima nonnulla emittéte Morfus Diaboli minora, aut Conizę nıaioris, Bellıdis, nónihil niggricātı. Flores in pufillis alis fummis lutei, circinati, Conizę miores, fed non abfiniles, abcïtes, maturo fenine, in pappos:nec femé difsimilc Conizę maioris. Radix breuis, tenuis, albicaus; fibrofa, minor, radice Succifx aut Bellidis par. Qualitates quales diximus, vfum nefcinus. Hanc tamen non difplicuiffe Gefnero \&\& Dalefcampio, magni no:ninis medicis, forte de facie dumtaxat, eandem iudicantibus certum.

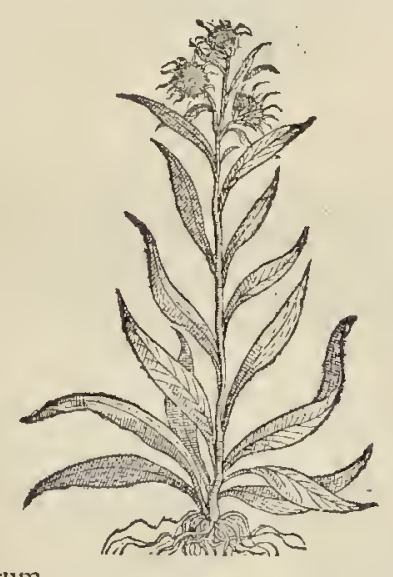

Pulmonariã reccntiorü Britân ñ că hodie putatam;quia folio,effigic, floribus atq; muc. Pulmonaria an co Symphiti eft, retetus illic ponemus, \& difquiremus, ccquid à Britänica vera difcrepet. Brisannica.

$$
\text { COCHLE ARIA duplex, Britamica, \& Batana. }
$$

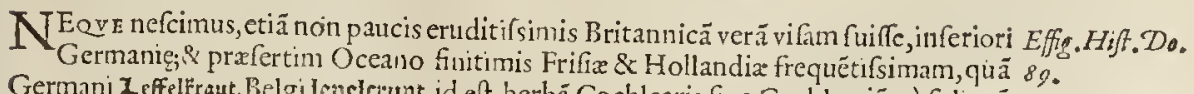

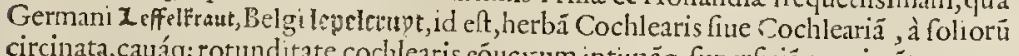
circinata,cauáq; rotunditate cochlıaris cóucxum intinăqq; fuperficié exprimčte, voca- AN BRITANrunt; Pliní́que Britannicamu cenfuerunt: quia eodem loci, iifdémque dotibus comper i- naca Plsay? antur, quas Cæfaris milites trans Rhenum promotis caftris aduerfus luem illam, \& dentium, ncruorúmquc noxam, edofti à Frifis colonis experti funt : vt idem fufus narrat. Verum cum hre neittiquam illius Plinian $x$ defcriptioni congruat, \& permultix alia fint plantie aquaticx, vt Nafturtia \& Sion Cardamine cidem perfini-

$$
\text { L.i. les }
$$




\section{2}

\section{STIRTIVM aduerfarianona}

les guftu, nec admodun difimiles habitu,idem remedii dent, nullum inde certum fuppetit argumentum, quo hanc Britannicam affeuercnt. Sunt enim folia prima pillulatione oblonga Pyrolx, aut Ophioglossi, móxque cralsiora, \& varbilicata enadun \& nonnihıl cau, Rorellx Solis modo, fcd magnutudine Soldanellx, nonnilit aınbıtu angulofa, cochlear aliquantum pręerētıa; Ho culıs Cardamine albidis, in cauliculıs palmum \& fefquipalmumaltis; per æitatem femen ferie gemina,in vericulis filıuo is con ditur, Thlapfi minus fufcum, compreffum: radix tenuis albicans, parum fibrata, guftu acri, herbaceo, Nafturtij, aut Sifyunbrii Cardımine.

\section{COCHLEARI A Anglica, Atriplicis folia.}

O V I Frifiam Cochleariam antiquorum Britannicam profitentur, cómodius fuam opinionem tucrentur, fi fcirent in Anglia ad amonifsimi Tamefis fuenta, quà Londinum præterlapfuselt, etiámque in Briftoix finu Occidui Occani, quò allidune per ftat2 incrementa vnd $x$, aliam effe congenerem, \& fimilem ill 1 , flore femine, $\&$ fapore; fed foliis non æquè vinbilicatis, aut cochleatis, potius Atripliccm, ant Lapathiolum effigiantibus, vnciam latis, inqque fefquiuncix, aut vnciarum duarum longitudiné porrectis, crafis, denfis, \& fucculentis, guftu \& colorc alterius Cochlearię; Radice maiore, vt qualibet fui parte, minus tamen altringente, nec commoda ad ea qux fux Britan uicx Diofcorides attribuit: tametf æquè vt fuperior, laudata ad Sto machacen, Scorbutum: quibus vehementer aflictos xgros aliquot huius ope iutos vidimus, fupcriore Vere.

\section{PYROLA BPyrifolio: LIMONIVM Germanicum. Germa. $\$$ oulo mangolo, a fylueftri Bera, cuifinilis.}

XT $\mathrm{O}$ defuerunt etiam qui aliä iftis fimilem, fuperiori, \& inferiori Germaniis adeóNque vniuerfo Septëtrioni notä,Britanican deuinarint: quòd effet foliis Betx \& lapa thioli : obídque Limonium hodie autumant, nomine ctian viliditatis perennis fuffragante, 50 intergruyn Germancè, fue hyemis virorem fon ante, quippe xterno viro:e penè atro aduerfum Brumæ rugorcs perftat, montolis fyluofis, \& frigidis vdis, præ qubus tepidos hortorum receffus, locáque vrbana, \& mitiora viridaria alpernit;inque illis quafi inuita xgrotut, ac tandem emoritur. Proinde Chirurgi, Germanici prefertin Theophraftini Heluetii, \& Lanfqueneti, ad potiones vulnerarias fibi deAlpibus fintimis, aut montofis lectam curant, principémq; vnam è vulnerariis ænemis, \& vulneribus ferruminandis addunt;Brabantis in $15 \mathrm{crchem}$ Sylua Antuerpix contermina alí́qque Belgii fyluofis, rarior Ital is, \& Gallis meridionalibus. Exigua de radice \& tencra, fubruffa, nonnilhil ru gofa,caulem dodrantalem \& pedalem magntudinepromit, floribus in fummo albis , \& èmedoftamina, apicéfue emittentibus, odoris Lihi Conualii land difparıbus : \& in imo compluria quina, fepteñ , o.tonáue folı, rotundiora, minora multò Betæ; $P$ yro pro piora, nigriora, viridiora, non fecus ac cunctx partes ficcitatis, \& aftriatutionis vehemétifsimx, cuidentis frigefactionis. Vnde non defunt coniecturx quibus fententiam Limonis foueant Docti nonnulli, qui illud prius Behen defcriptum non norunt;propterea quia minus in pratis, aut littoribus herbidis, totius Oceani Germanici, ant Anglici reperitur.

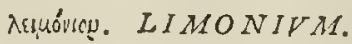

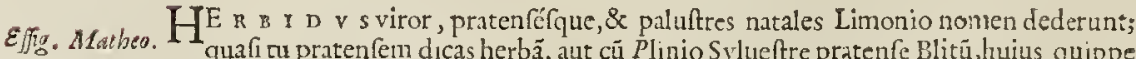
g. etiam videtur, ant fpecies, aut perquả affinis nigræ Betx, quả efu etian fiftere aluú Diofco-autor eft. Verim recentiorü fedulitas complures huic defcriptioni aptauit pratenfes palluftréfue plantas, forte non infcitè: tamen nulli congruit magis Limonij \& nomen 
\& notio, quam ifti pratenfir \& naritimo recepto : cui folia funt Beta nigræ magis affinia : Senuen copiofum, oblongum, ruffefcens ex cæruleo: flores purpurei,cærulei coloris \& guftu fubaftringun, radixq́; rubefcunt, magnitudine Lapathij acuti, cui totus accedit, \& qui vænum Lugdunum duxifent, copceis anfa porrecta, vt Behen rubrü nuncuparint, rum non paruo pretio \& noftro drolapathi. Non nifi locis nerbidis \& Norbon cenfenus: cenfemus:tantum indagare voluimus, quid cæteris difcreparet: quæinternotiones, funt

\section{PARVVM LIMONIVM NOrbonenfe, Oleafolium.}

$\mathrm{H}^{\mathrm{V}}$

VI c alterum prorfum fimile, fed minus multò, inter falebrofa Jittora, \& rupes montis Ceti,\& falloProuincia faxofis oritur reques, quod Empetri feu foniculi marini afiocia tur lubens, folijs minoribus Oleæ, aut Myrthi pari bus, humi radici proximis : circui pedales caules, $\&$ cauliculos graciles inflexos, carulcis mufcofis flo ribus fuperioris non difsimilibus onuftos, folia logeminora foniculum Marinum, fue Empetrum fatis exprimunt.

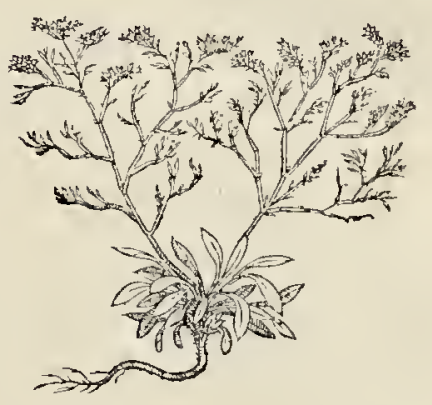

Matbioli Securdum LIMO NIVM.

DV o namq́; cum appinxerit, nihil diftinxit, ac ne quidem monuit,neutrumné, an y- Matb. $g 8 \%$ trum effet verum:fed quafi rerum nefcius, ne verbo quidem explicat: \& tamen certò doctis conftat fecundi ab illo defcripti, flores non ita pafsim videri inter nulta millena
plantarun.

TginóNop. Litionim TRIPOLIVM.

FE R v N T fic vocatum à ter, fingula die, mutato forum colore, quod quidem fieri pof-

fe cquidem iam luber credere, qui videa mus è naturæ Officina multò mirabiliora euc niuerfi penè littoribus, \& nefcimus: illud fcimus, in Maris Meditcrranei, \& Occidui $v$ fimilen Limonio prino : crtcró of tijs: plantan copiofe pronenile, non ita folijs abternä coloris interdiu : catcróqui Tripolio exquifitè congruentem, quæ non quidé \& purpurei in Phœniceü, interdué experiatur: fed quia duplicis eft floris, nempè lutei pernè defuete primum folit a dum \& caruleum vergétis, litea foliola radiatim afsita fi \& putpurea vel albida cerni, a bus,albidis, \& purpureis fuperftitibus, loris:quod idem nonnullis ftirpiü Scatent hac Norbonica, \& Anglica littortu alio cótingere modo, iamdiu obferuauimus An fit Dama Jonism, Pbleg. magogum of Cholagogum Macelirempi? ris eltus, inundant vbi fermè ribus, défis, leuibus, fufcis, crafsis, circa caures comparet, folijs Glafti aut Limonij, ininoramulos diuifos, multos, crasis, crica caules fefquipedales \& fefquicubitales in fummo etiā craffa, fibrofa, fores medij fubteró nó magnitudine, fed nónulla fimilitudine, radice ueŕa multú afteri Attico vt latius monuin? cap. L., ij. de 
de Aftere Attico \& alibi : In Turbith diximus effe Serapionis Turbith. Radix depacta fibris crafla, non tamen aluum ciet decocto \& fucco pota $a_{2}$ nec apud nos Gummofa.

\section{Norbonenfum $D O R E$ A quafiaurea, quam per peram $D O R I A M$ vocant, folys Limonij ant Rumicis, flore luteo Tripoly, aut Iacobea : an T beo- phrasti $P A N A X$ Chironium \& $P$ ling $T H A R$ - N $A C E Y M$ ?}

NE v т I Q a м Dorix duci triremium clafsis Gallicx, \& Imperatorix prafecto, qua Ir exoticx huitus repertx laudem verè affernnt Herbarij quidam: cum hac fit Gal lo Pronincix \& Norbonæe amnibus non admodum rapidis, \& ijfdem etiann natalibus oriunda, quibus Limonium, cuius multa fimilia habet, \& inde in hortos Belgij \& Anglix trandata fuit, ybi etiam hac xftate, Lódini Morgano noftro creuit: perquàm pro. cern \&: elegans feptenum \& octonam cubitoruin fcapo recto: radix gluam pro ftirpis magnitudine minor, maximam Helle borialbi æquat radicem : ctri ctiam compluribus filamétis, reEta prolixàque fparfis, ch habitu toto fimilis cft : à qua, \& reliquo caule mox fupernè furrigitur numerofa foboles fuliorum, $\mathrm{Hy}$ drolapathi longitudi1]e, crafsis \& obliquè extancibus purpurafcēribus neruis trāfuer fim : \& qux valde angufta in imo funt, pal ma latitudiné, fed me dia fui partè xquant, virore intenfo,rigida, \& craffa vt Limonij, aut Tripolijpexfertim in fummo caule, qui

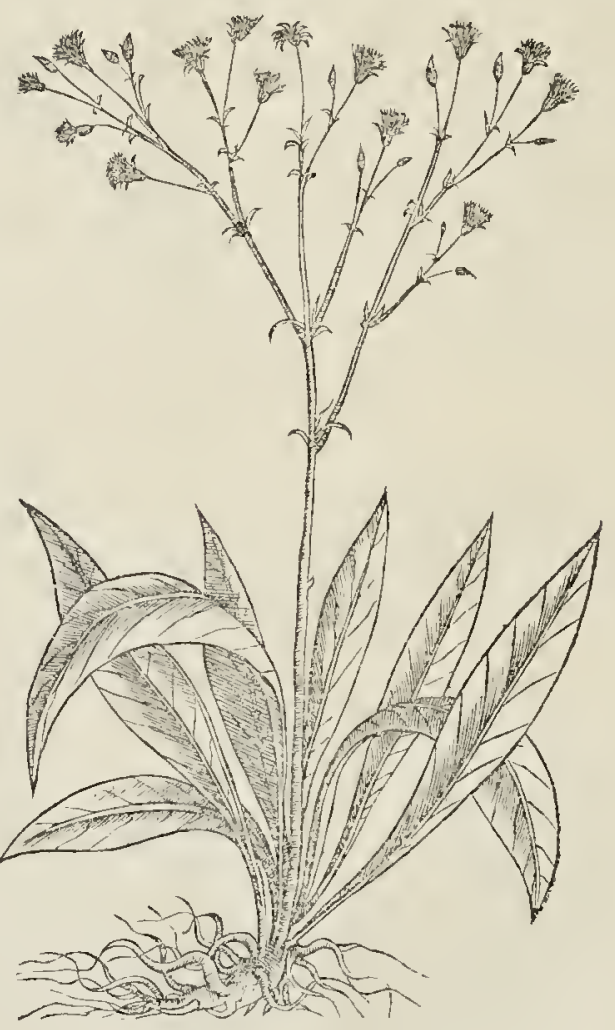
procero homine proccrior eft, rotundus, craftus digitü, Lapathij modo in fummo turiones habet varix lögitudinis, quibus" fores Senecionis aut Tripolij marini, in pappos abeuntibus, Sapor,odor, radici \& fol ijs aròmatus \& medicatus Angelicx Syl. \& nó nihil nitrofi,minime acris. Plurimum hac vtütur vul nerarij curfores, plurimíq; faciunt quidam Medici : qux coniectura cæteris congruentibus notis, magis perfuadet effe Theophrafti Chironium, Lapathij fimile : aut fanè vnum corum, Gूrae ad Theophraftum Plinius retulit, vt Pharnaceum. 


\section{STIRP IV $M$ aduerfarianowa. \\ CONSOLIDA AVRE ANemorum, Limoniifolio, non Alifma montamum.}

\begin{abstract}
IN A V R E I I a Gallicx fyluofis denfifsimis quæ noftro H. Morgano perelegans floruit hoc menfe Iunio Londini, radiatisniultis in ambitu foliolis; Nardi Montanæ, aut Doronici florem \& colorem fimilem habentibus, foliis nigre Bet $x$, aut potius Limonii, atrius virentibus, carnofis, aliquantum hirfutis, crafsis, venofis, Dorex fimilibus, amplex is pedales Doronici cauliculos binos, ant ternos; floribus radiatis Doronici, aut Calendule, \& concoloribus fitè pectinatim confertis, \& comifsis foliolis,antequam pandantur, eleganti fpectaculo, radice inultis filament is albidis fparfa in cefpitem fummun,Bellidis modo: fapore Medix Confolidx, tantillum acrimonix prodentis, aut Herbx Dorex, cuius etiam vires\& quandam aromaticitatem æmulatur.
\end{abstract}

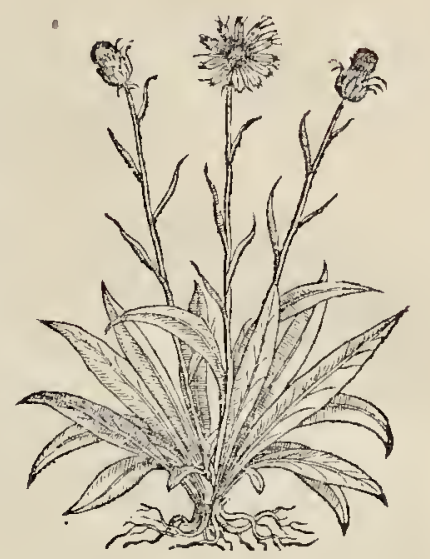

AYREA VIRGA Fillanouni, Limoni, aut Cofi bortcrsis foly,
Doric floribus, an Lcucograpbis Pliniy?

JE c minus celebris hxcapud vulnerarios Autea Virga vocata, nec non multum $f-$ milis fuperiori; fed multo frequentior \& notior, prefitin Germanix, Francix, An- Dodon.10\&. glix, atque cateris Septentrionalibus nemorofis \& faltuofis opacis, vbi multò maxima copia. Caulem gracilem lauem, leniter rubentem, cubitalem \& fefquicubitalem foliis ambientibus inmmum perficx latioribus, temuibus, tantillü crenatis, Cofti hortēfis modo, multò anguftioribus, \& reliquo cauli; qui multos in ramulos diuffus vifitur, Horibus cófer tim ornatos aureis Doriæ, vel Confolıdæ Suracenicæ, in pappos dıfparétibus: radice fufca fibrofa:fupernè rubcila Cofti hortenfis. Conizx femine, vi aftringendo efficaci, fed ficcädo multo efficatiore, mirùm quantùm calculo exterendo laudata, atque finguini fiftendo vlceribus vulneribúfq; cogendis; eapropter perfunfun nónullis hodic Leucographin effe $P$ linii ; qui tamen fibi notam non modo negit, fed ne lectam quidem apud quempiam autorem, mitatur; quä(inquit)adco effet vtılis. Et Virgx aurex nulla vfpiā linearum veftigia infunt, qux nominis argumento refpondeant: vires autem non tam ad $\mathrm{f}$ ftendum fanguinem in tro compertas habemus, quam ad alios affectus admirabilem ex. perti fumus.

\section{SOLIDAGO Sarracenica.}

CL A V DER E iungcréue, aut cóferruminare, vulneris labra, confolidare Barbari Chirurgi dicunt, vnde hæc vocata Confolida, cognoniento Sarracenica; quod Turcx Dodon. 107. \& Sarraceni opinionem magna peritix, in medicamentis vulneraris præfertim, effent apud Europoros affequutı. Et finè hxc eft perquàm accommoda renibus, hepati, inteltinífọ; vlceratis, atq; diffolutis. Foris verò nihilo fecius ad vulnera vtilifsima. Iifdem fermè natalibus nemorofis, quibus Aurea Virga, fed magis vdis \& deprefsis, apud Septemtrionales : apud vero Meridionales, montofis vdis, inter Valerianas fylueftics fruticat , è radice pluribus $\&$ crafsioribus fibris capillata, caulem refun erigit, trium, aut quatuor cubitorum, rubellü, rotundü, caumm, fecundü quem totü, folia Lyfimachix lutex, aut Amygdali longiora, parū quid crenata: fünis alis \& floribus palidis virgä Aureä æmulātur 


\section{STIRPIVM aduerfarianowa}

in pappos etiam perduntur, vnà cum Conizx femine. Vulueraris in hortis viret.

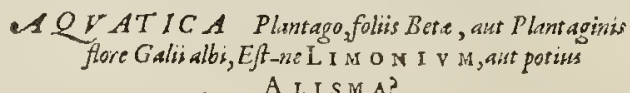

Gorma. Doafler roegrish.

$\{$ Gallis. Plantain d'eaue.

$\{$ Belgis. soater wegeble.

An.Water plantaine.

QVI SPI A M pofsit intexpratari dictum $\ddot{\alpha} \lambda \mid \sigma \mu x$, quia in aquis nafceretur \& iactare-

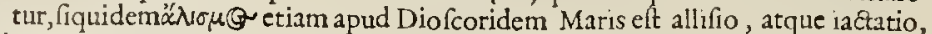
qualis vulgari aquaticx Plantagini contigit. Sed enim Recentiorum fatagentia malure quippiam diuinare, quàm quod certius erat fequi,aut tantifper retinere, dun quid melius obuium haberet. Itáque aquatica Plantagine contempta intruferunt Bifolium, fcù Ophrin alî̀, alii verò Limonini, nonnulli Saponar am; quidam Calceolum Marix vocatum, eft qui Epipaztidem Hellebori folis, ac non nemo Commentator, fed Mufis plane iratis Botanicis, qux fe vti nos quxruntur delufas, quafi praftigiator quidam, vifus aliquid(faftiditis cxterorü iudiciis) \& reicêto Alifmate fuffeciffe, nihil tädé nifi nutä plantz vmbrä, ideft pieturä plantę indiąe, ne fcitur cuius, reliquit nobis hiätibus, atq; aliquid fal tê noui, fi non veri, audiêdi auidis, \& repęte fe fubduxit. Cui autë animo fuerit, hafce omnes ftirpes de veris cunctis notis \& accurata collatione expendere, nullä non pocul à Damafonii deliniatione literaria Diof, tī vcrò \& natura, \& facultate agédi abeffe, pręterquã vnā iftā aquaticā Plantaginé vocatā, quę minus iftis morofulis placet, quia fortè Greca litera nonnihil labis, aut hiatus perpefia eft; veluti vbi sєvó Tę̧ $\alpha$ :id eft, angu ftiora folia habetur, idé potuit effe fignificatus, \& voculz permutatio; cuiufmodi in He$V$ t in fumaris. lenio, Meo, aliífq; nô paucis. Quin locis aquaticis, quorúindigenã facit hanc Plantaginé, nufquã gentiū aliā videas plantă, qux quicquã ferè aut vultuss, aut viriñ expleat: vires fî quidé perquàm congruunt fermè omules, verū Galenus qui legiffet, radices huius acres eóq; redemata difcutere; fuo more nỏnihil Diofcorid. tacitè aducrfatur: de cætero verò illi affentitur, féque reliquarum facultatum, vt frangen di calculi, periculum fecife tefta tur : cóque non acrimonix, fed abfterfioni, calculi expulfionem acceptam fert , qux de radice verùm effe experimento \&ipfi fcimus, equiden melius quàm Plantagin is, cuius folia, \& radices fimiles habet; qux cóferuntur Helleboro: ac è follis etiam qux unámevo

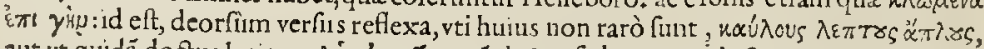

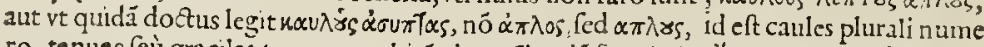
ro, tenues feù graciles, teneros, cubitúaltos: Sicetia funt huius éx habens Thyrfi fpecie capitula, cuiufmodi fanè habet, nondim explicatis, egrefsífue flo-

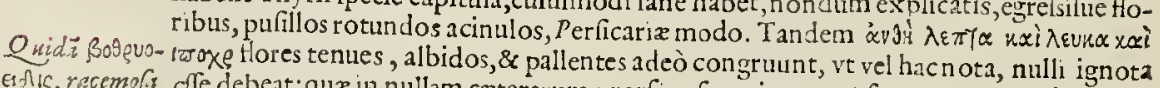
antls, racemofis cfe debeat: qux il nullam cæterarum prorfim fuperius propofitarum, conueniunt.
capitshla.

$$
\begin{gathered}
P I S T A N A \text { Magonis, fue Plinit, } S_{\text {A G I I T A R I A }} \\
\text { aguatica: and Stabe famina? }
\end{gathered}
$$

PE R M Y 1 i I s hxc amnibus ac leniter labentibus in Italia, Gallia, Germania, \& AnAratheo.effigie. glia; fubter aquas è fundo vadofo, radice multum capillofa, \& prolixa, albida, non$173_{3}$. $\quad$ nullis oblongis fibris crafsis $\&$ bulbolis adnatis, pediculos prxgrandes, triquetros viridantes glabros exerit:fingulos fingulo folio donatos triquetro, vtrínque pinnato, reductis lateribus inquè mucroncm deficientibus, \& prorfum harundinem cufpidatam effigiantibus, cauli felquicubitali medio lxui cauo, molli, ternx aut quaternx pllula echinatx Vnedonis, aut Ricini non difsimiles, aut Caricis, quibus affinis videtur : pót florum delapfum, qui tcrna foetura prodeunt, totidémque foliolis conftant cádidis, èmedio pauca ftamina emittentibus, Maio \& Iunio in Anglia prope Oxo- 


\section{STIRP IV $M$ aduerjaria noua.}

nium, ponè mœnia, in amœnifsimis illic refidibus, fed lynpidifsimis aquis:etiam Lon dini $a \mathrm{~d}$ arcis Regix vallum, \& in Tamefis crepidin bus palludofis guftu aftringente:ficco, non ingrato.

$$
S A G I T T A \text { Minor. }
$$

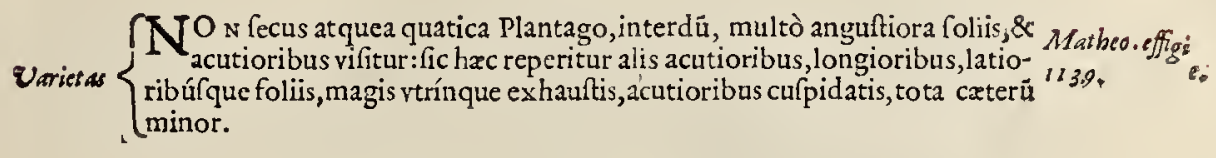

$$
\text { BIFOLIVM } \underset{\text { videturOphris Plini: }}{N O N} \text { EST ALISMA, }
$$

Thrc quod effet foliis Plantagineis, locíque humentibus familiaris, opinionern

Damafonii quibufdam fecit:aliis, \& quidé aptius, Pliniana Ophris dicta fuit; 110 quia fuperciliis fucandis, aut lenocinio apta comperta hattenus fit, fed à binis vtíque foliis vnde żųblat, id eft, Bifolium dicit Germania, vbi fyluofis in pratis, \& vdis frigidioribus plurima , caule rotundo, glabro fefquipalmari,cuius ab ımo duo fibi vtrínque vnum ex aduerfó furriguntur folia Orchis, \& Plantaginis aquaticx, viridantia,\& fecundum longitudinem neruul is intexta; deinde à medio fermè, fummo tenus flores funt deinceps, vtrínque gemina ferie, ex pallido herbacei , mufcx, aut volucellæx plumis exutx, nö multum ab Orchii diuerfi ; radice huc \& illuc multis fibris $p$ parfa, facultate nec aftringente, vt fit Damafonium, tametfi alia dote vulneribus \& frafuris proficua fit, \& Alifma \& Ophrin alıquantùm adumbret, neutra tamen afferi poteft.

$$
\text { Mơó́QuMop, RECENTIORVM. }
$$

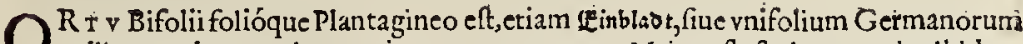
nulli opaco luco, vel nemori non oscurrens, per Maium flofculos promit albidos, Galii \& fimiliter odoros,vnde acinuli pallidi rotúdi rubelli , dum maturucrint; ;guftu amaro \& ingrato, fed facultate ad neruorum farctus eximia. Folium vnum per initia in imo, deinde femine iam perfecto, aliud fe prodit folium minus in fummo; vtrúmq; $P$ lan tagineum \& neruulis donatum eft, fuperne acutius, \& nonnihil ad volubilem accedentibus:cxtera prorfum fimilia Lilio Conuallio dicto, antiquis nó memorata : tranfuerfirz radix gracilis geniculata excurrit.

\section{Recextiorum CALCEOLLS Marie, fiuè}

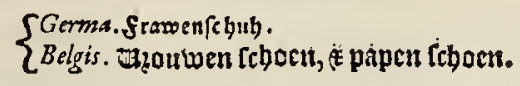

PR I s c I s etiam pręterita videtur illa floris larua perquàm fpectabilís, etian Plantagineis foliis, aut Bifolii, quam nonnulli Alifma opinati funt, vulgus Septemtrionalium, Jnzer vzauwen [chacu, vel panen [chaen, id eft, Virginis calceum, vel Sacerdotis Effigie Dod, de crepidan vocitat, à floris effigie, qua quatuor conftat foliolis dilutè purpurantibus, $z^{2}$ flo: 77 . rubentibus, fui è medio promentibus vtriculum quendam purpureum, intus vacu. um,rotundum Fuci,aut Afylonis cadauer, vel Vnedonis caliculos florum nonnihil referens, fed fupernè,aut latere vno patulum, inftar crepid $x$ oræx patul $x$, quà inferitur pes; foliis Plantaginis, aut Alifmatis in longitudinem venofis; radice tranfuerfa, nec altè depaeta, necmultū fibrofa. In Heluetia \& Oenoponti finitimis Alpinis opacis, habuimus。

$$
\begin{aligned}
& \text { ágroyiase } P L A N T \& G O \text { latifolia latis, } \\
& \text { SGerma. we werich. SItal. Plantagine. } \\
& \{\text { Gallis. Plantain. ZC1n, Plantayne. }
\end{aligned}
$$




\section{STIRTIVM aduerfarianoua.}

$\mathrm{V}^{\mathrm{E} \text { L v } ~}$ I Ophioglofon, Cynoglofion, fic Arnoglofion, quafi Agninam tu dicas liguam, vocarunt'Plantaginen Græci: ab omni memorid peruagatæ notionis, ex vtilitate $\&$ feracitate vbiuis gentium penè immenfa, cuius varietates \& nomenclaturas, foliorum magnitudo, \& modus, diuerfas conftituit.

\section{MAIOR LATIFFOLIA.}

Q V s námque latifolia maiórue Plantago, nulli negata regioni rotundioribus elt fo liis, \& fuı medio plenioribus, latioribus, humi accumbãtibus, è radice lateratim fibrofa, candida, \& in medio prxcifa, fiue mucilata; Morfus Diaboli fermè modo:floribus fpicatis, caudicellas murium imitantibus, obfcurè purpureis \& pullis: Semine Portulace pufillo, furco, ant rubigineo.

\section{$P L A N T A G O$ Incana.}

CVI vcrò folia incana fuperficie pubent, rigidiora, crafsiona, inquè ambitum humi neruulis magis extantibus refracta:radix crafsior, longior, minúqque fibrata, rectioribus, altioribus cauliculıs, floribus breuioribus, fed magis fparfis \& fpeciofis, albidis caudatis, Iunio \& Iulio defluentibus.

$$
P L A N T A G O R o f e n .
$$

OVA. A M autem voluptztis ergò in hortis Belgicis, \& Anglis colitur merita ; que pofteritatı Cripto, \& icone innotefcat : Ei omnia Plantagini maioris fimilia, præterquàm cauliculis fummus, eleganti ambitu, multis foliolis fibi xqua foric mutuo in cumbentibus, atque fenfim in faltigium countibus, $v-$ biquafi imbricatim, fquammatimue fefe decuflantia folia, vmbellam elegantem, quafiflorem conftituunt herhidum, vti in quadam fpecie $P$ rimulx Veris fermè cernere eft. Semen è mediis foljorum interltitiis exilit, fed priori fimile.

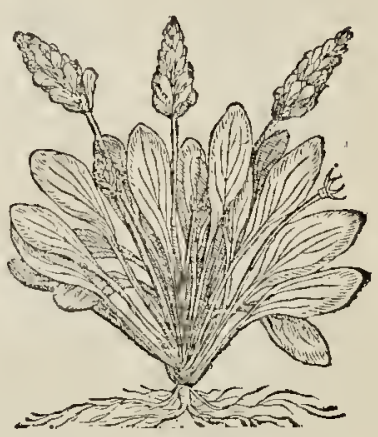

P L ANTA GO Quingue Nernia, Lanciola, $\{$ Germa. Spit\}iger woegrich. $\{$ Belg. Dontribbet. $\{$ An, Ribbe Worte.

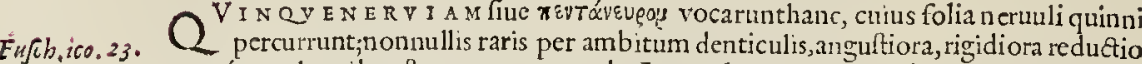
percurrunt;nonnull is raris per ambitum denticulis, anguftiora, rigidiora reductio ra,vtrínque lateribus \& mucronata, vnde Lanceolam vocant Barbari. Radix, rotundior, breuior, pluribus capillamentis depacta, emittit iunceos angulofos cauliculos, floribus albidis ftipatos, 111 glomerofis \& breuioribus fpicis. Sicciore eft hxc, \& commendatiore dote ad vulncrarias potiones, vnguenta, \& hernias: nec minus vbíque obuia crteris.

\section{PLANTAGO Marina.}

D. A r s s Plantaginem putant, Marinam quandam herbulam, foliis crebribus anguftis, exilibus, Porraceis, tum colore, tum confiftentia; Etfi fxpe littoreis Norbon $x_{2}$. \& Anglix vifa \& animaduerfa, nullídum certò quxnam fit affeuerare licet; nulli tanế finilior vmbellis, quàm $P$ lantagini, aut Coronopo.

$$
\begin{aligned}
& \text { P O TAMOGETON, fue Fontalis, of pirata. } \\
& \text { 5хxútтs. Gal: Efy ydcane. }
\end{aligned}
$$




\section{STIRPIV M aduerfaria nona.}

NON folum fuuiorum elt høc vicina, vt cius nomenclatura fonat, fed etiam alumna Eff. RLA.2137 perficiei frata, quafi humo viferetur, folijs Plantagin, aut fegnius labentium, earú fuaut Perficarix, duriufulis nofis, in plo lis caducis, quibus fpicati infunt flores pcdiculis à multis flexilibus geniculatis caulicuIunio \& Iulıo. Radice flexuofo anfrofurtx, aut Perficariæ finiles, obfoleta purpura trans a trans aquam fundo immerfas, è quo alimentum fugit, vt in Malabatro ftatin dicetur: guftu aftringente ficcante.

\section{Nostrate FOLIVM, MALABATRVM est.}

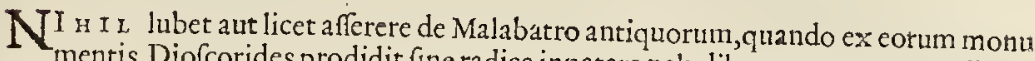
mentis, Diofcorides prodidit fine radice innatare paludibus : cum tamen nullo of piam angulo totius Indix illius, qux noftrx atati multo notior eft, quam illis fuerit fua Gracia,comparuit hactenus iftud folium, quod nec exprefsit fatis Diofcoridcs: vnde gemina hrfitandi occafio, primùm notúmne habuerit : deindequi pofsit fieri, vllum vt fit folium non modo fine caulis aduiniculo, fed etiam fine radice, id eft, fine ore : \& $t 2-$ men folitum fit filo traijci, quia odorum,n1agnum, craffum, \& humentis natura: id eo folitum filo tranfui ad ficcádunn. Quare fatius fit de illo fateri nos nefcire quam de Prifcis minus bene fentire, aut à nuperis parum gratiæinire. Illi namá; adeò laka notionie rern fignarunt, vt quid capias, nefcias : \& hi dum vt cumulo fidem filciant, authoritates aceruane, plus porrò quęrendun relinquunt, nofq; inopes inter ignotas opes deferunt. Naın quid obłtat quò minus vnū fit è tam multis, præfertiin quatuor nobilioribus, illud Malabatrun imitantubus. Quod fit quidem verum, fed eius ortts \& natales aliquantum deprauatè tradätur, vt in \& Earico videre eff. Quare id fanè fuerit iftud noltrate $\mathrm{Ma}$ labatrum, iamdiu Arabibus cognitum \& hodie Italis medicis vfu receptum, non modo quia in Malabar Indix regione cognomine oritur, fed etiam quod proptcr cximias vires, plus proportionis habet cum plantis aquaticis, quan illa folia Cinnamoni, aut Caryophylli, quibus folium laurinum fcrmè eft. At illud folium crafsiufculum cuiuf, modi Nymphex eft : fibrę verò fecundum dorfi longitudinem duetx, cuiufmodi Potamogetoni, qui propter figure \& natalitiun fimilitudinem, nonnullis ineptè folium putabatur: Nobis fecus, cum huius folia apud Anguillaram \& alios harum rerum confultifsimos, non multis abhinc annis vidiffetmus, quibus adhuc hrebant lignej pcdicelli: \& quafi furculi è ramis effracti (anin potius integros ramos meminimus). Cinnamoni auté folio \& Garyophyllis facies ferme eadé, nitidus lawor, aromaticus, fuauifsinufó́; o. dor. Temperamentum, crafis, modus \& vfus uon ita difparia funt, \& halizum commendant omnia vt Diofcorides Malabatro attribuit, de quibus commodius alibi. Obijcient literatoces nobis Diofcoridis verba. FOL I V M A CVIS INNATANS SINERAu i $C E$. An vllum folium, aut oriri, aut viuere fine radice, id ef, fine ore, qucat, quilibet nouit:nam Lenticula, Semperuinum, \& etiam Muha, feu Opontia, aut radicem habent, aut quippiam radicis loco. Quin \& Lenticulę plantarum minimz, nec radicellx fux defunt, \& illis fubfunt quædam terræ fordes \& quifquilix, quibus aluntur \& fulciuntur.

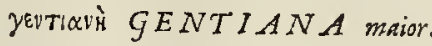

$$
\begin{aligned}
& \text { Germ. Bent;ian, Bitrer Dorts. } \\
& \left\{\begin{array}{l}
\text { Belgis } \$ \text {. Ano. } \\
\text { Gall. Gentiane. } \\
\text { Ita. Gentiane. }
\end{array}\right.
\end{aligned}
$$

VS v s \& celebritatis notifsimx à Gentio rege Gentiana Illyrica, Helleboro albo fo- Dod.223. lijs \& natalibus adeò pr.sxima, ve minus exercitatü eminus eludat: vti nos adnodü Fufc.ico.11\% inuenes qui defessi \& potaturi,cum in poculum vino plenum radicem Gentianz qutam 
130

\section{STIRPIVM aduerfarianous.}

ad lafsitudinem difcutiendam, \& apetitum excitandum commendare audifenus. Huius loco Heliebori radicem fimilitudine foliorum hallucinati immifimus, at penè perijmus. Putredinis hxc hoftis infeftifsima, \& veneni mors: Pefti adeò remedium prxfens, vt non modo hoinini, fed e tiam brutis incolunitaté tueatur: \& anifiam inftauret, eóq; folita Heluctia plebs iftam cum fämula porcis, \& olim Monachis propinare, ne anima in viuo cadauere puteret.

Non nifilin montofis querenda fponte exiens Gentiana, qux alióqui repertu facilis: \& frequens, planèfronde $\&$ afpectu ante quä forcat, fimilis Plantaginis, viridätia, aut rubé tia folia, venofis ftriatum piicis extantibus, è radice craffa pedem longa, intus flaua, fapo re perqunm amaro:caulem cubitalem, quem fummo ornant flores, verticillati, lutei,oblongis $S$ aponaric caliculis, Leucoij femine ruffius, exilius, necmedulofum.

Gentiana $M I N O R, C R V C I A T A$, recentionum.

SGer. MToodgert Gpeetenfuch.

\{ Bel.

Dot.224.

FA N C D o c T I non pauciGentianx fpeciem faciunt, facie \& facultatibus duEti. Locis tamen non ita arduis, ac Gentiana, multa \& palsim oritur, vti propè Bafilcan, Maconium Burgundix Gallicx, deprefsis collibus inter Chamædrin exuberans. Huius tamen non flores lutei, fed cærulei diluti, radix verò fecundum longitudincm tripartitò aut quadripartitò fifì, ynde cruciatam putant, fed folijs potius crutiatim cauli incumbentibus, nominis etymon debetur.

T NEV MONANTE Cordi. Gontiane minoris fecies.

Ger. Xungeublums.

Cordus.162. CRvi IA s fimilis aut eadem qux in pratis etiam montolis oritur, folijs anguftio. ribus, minorib.flore cxruleo Calathi modo, radice fibrofa, neutiquam incifa:à Mathiolo graphicé defcripta.In Pedemontanis pratis propè Sufani, \& Ríuoli multá.

$$
\begin{gathered}
\text { GENTIANELLA CAMPANVL } A F L O R E \\
\text { purpureo, Feluetis. }
\end{gathered}
$$

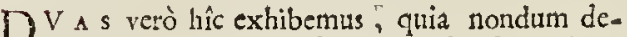
fcriptz tamen elegautes füt. Altera eft radice exigua fauefcente fibrofa, foliola conferta numerofa, imú cau lé ambiüt circinatin folijs Olex, aut Plätaginis fimilia, minimx Gentianx colore \& modo. Cauliculo vix palmum alto,folijs fermè exuto, nifi proximè florem: vbi minuta bina ternáue vifuntur. Purpurafcit calathus figura \& magnitudine, \& colore Violæ Marianæ, raldèquam amara. In Patauinis collibus \& decliuibus, vbi viperz capi folita funt etiamq; in Heluetia.

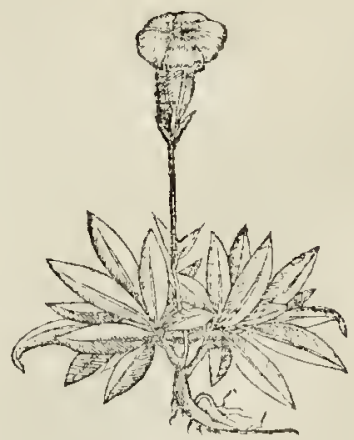

\section{$G E N T^{\circ} I A N A$ minima.}

M IN I M a qux omnium fpeciofirsima in montibus arduis fruticat, Centaurij minoris modo, quem ytcumq́; refert, plurima in çelfis verticibus montium qui Dannubio in 


\section{STIRP IV $M$ aduerfaria noua.}

Septentrionem, Orientalem, \& Athefi rapido in Italiam pręcipitante originem dant; prope lacuftres voragines, \& monrem Nıcolai, pufilla tota, palmo procerior, foliolis, \& radice Centaurei minoris, mulrò minoribus, \& modo, ex internodis geminatim oriútur : \& cauliculos exiles ftipant;partim ab imo, partínque medio exortos, quorum fummis caliculus folliaceus Caryophyllex forma, \& flofculus cxruleus, cxlefti atque incomparabili purpura. Amarifsima \& hæc, vulne ribus commendata, \& idcirco confenfu curforú Genrianella dicta, nobis alióqui Centaureo minori, aut eadem, aut æuula.

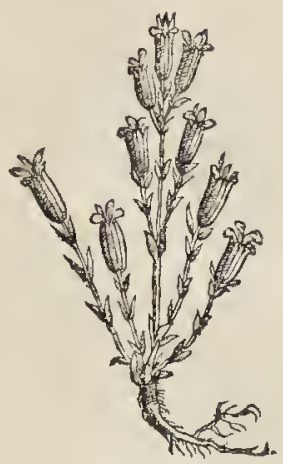

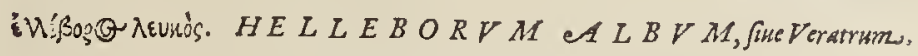

Germa.Doeif5 Zziefwart3.

Gallis. Helleboire blanc. Hifp.Yerua de balefte.

Italis. Helleborobiance.

Belgis. \$oit Nielccupt.

VD A M O N T I vं A Alpitinque iuga, huius funt foracisima, præfertim qux frigidiffima,celfa, \& pratéfia, quibus Gétiana maior gaudet;vti alıbi Hellebori ltipatu \& có uiftu, cui adeo fimilis folia eminus inruéti, vt non rarò oculis illudat: præfertim cum $x$ fate cxtero prorfum gramine arefacto, vel manfo, vtríque pecus pręamarore (pura)parcat. Radix quamplurimis fparfa humi fibris, qux fuperıè medio quafi rrunco, vel nodulo colleftx funt, non abfimiles Plantaginis, fed maiores, cui etiam fol ia mul tum accedut; tametfi maiom, rigidiora,ftriatíque fecundum longitudinem liris acutioribus, \& media coéia eunre liner, mutuò implexu, quafi runicę conuoluta, humi ftrara, partímque amplexa caulem concauum, glabrum fucculentum bipedalem, è cuius medio, fummo te. nus, alternis pediculis furrecti forú thyrfi hapsíue, Botrys modo, racemofis floribus onufti, colore albicante vifuntur. Quibufdam in hortis Belgicis videre eft, floribus purpureis: Maximi atque certifsimi vfus, herba vniuerf Europæ fatis nota, vulgo -Veraire.

\section{EPIPACTIS, fine $H E L L E B O R I N E$.}

NO $\mathrm{x}$ inde quia fimilis foret Helleboro videtur Epipactis dicta Helleborinę, fed propterea quod Helleboris mifceretur, \& iifdem locis nafceretur, forétq; quâl frenum impræfsioni vehementifsimx pharmaci Helleborati ; eóq; Diofcorides ad venenata cómendat, iecoríqu ue amicam ait:néq; vtri Helleboro fimilem fecerit contat, imo ne fecilfe quidem, non magis quam deneutra Sefamoide. Eapropter quid hîc Commentator harioletur, qui volet videat, \& rideat. Eius nos commentitiam Helleboriné, quam è Tragio mutuatus fuit, nec talenı effe docuit, conmmodiori loco ponemus.

Necalia de re Helleborinx vocata fuit, quàm quod illius femine Hellebori al bo addito vomitus cómodius cieretur, vti de verbis Theophrafti liquet Libr. 9 Capit vndecimo, vbi Helleboriuem iftius commodi vocat herbulam, vnde nonnulli noftratem Herniariä autumabant. Sẹmen cuius, fuccus, \& folia, hepatis obftruetioni \& renum lapillis, magna dote pollet : quin fi quid huc facit, minus comperta qualitate fternutamenta ciet foli- Herniarix. MA orum pollen. Quod fieri potuit, vt mixto cum Helleboro fuerit ftimuli vice ad facultate legram Centeproritandam: quemadmodum proditum et, antiquos folitos mifcere falem \& acetum, grana. quo celerius exigeretur Helleborus. 
A T Recentiores nominis fono illecti, putanint herbulam Hellcboro facie fimilem in A terpretandum, éque duplicen vtrique nim rüulbo, 8 nigro Helleborofuam affinxerunt : qui fi quam pracipites ad afferendum, tam feduli ad inueftigandum fuifent, labuiffent cx Theophraft.q to fe ab errore vindicaffent: Is quippe Lib q. Cap. I I. huius femen Helleborifmis propotifinífue addi folitum ait,quafi calcar futurum vomitorio me dicamento, vocátque her bulam $\beta$ otávo', quare vti dudum monumus: Helleborine quafi veratrulü, nó perinde vt Cardamine à Cardamo Gmili, dicta fuit, fed Epithymü, \& Séamoidem, non propter fimilitudinem, fed propter vfum, Helleborum vocitanut prifi. Et Senenfis arbiter, decernit nobis $\mathrm{E}$ pipactide pictam, nec defcriptam;vt folet innumeris locis, vtpote aliunde mutuatus, nec ftirpem confpicatus: at ficubi fuerit naetus brafsicas aut vrticas defcribendas, vel alienas inuaferit deliniationes, enecat verbis, aut Crambere cocta. Sed rariores, \& cognitu digniores, piEtori mandat; \& illico elogio illo centies inculcato addit, Eff fmilis prorfus nullis reclemantibus not is: fubditg; nonad nott am cognitionem, fed ad fui oftentationem, non quidem fe fcre num Helleborine fit; fed tamen Epipatida elfe:ridiculè perinde ac fi dicat quis, incertum effe num fit Helleborum, fed tamen certum e ffe Veratrum. Quin etfi quis largiatur illud, nimum propter fimilitudinem fuperius collată, Diof. intelle fum fuife Helleborum, quis dıinabit? cum nè nunc quidem vti docuimus, Hellebori nigri vfquequáque defcriptio congmat. Verim nos quo confulamus cognitionis auidis vtrámq; recentiorum fubdemus, albo affinélic, alteram commodius ni gro Helleboro inferius.

\section{HELLEBORINE fue EPIPACTIS, Recontionum $\mathcal{O}^{\circ}$ Belgarums. \\ Germa. Co Belgis, wolldt wit ßRictertit.}

d.it.1 235. M V z o propius faltem faciead album Helleborzm accedit, qux Galliæ, Belgixáue locis, nemorofis, vnbrofis, prouenit:caulë reêum, pedalem, inuolutú Arnogुloŕsi, vel albi Hellebori foliis anguftio ribus, floribus fummú conueftientibus, albidis, vel purpura obfoleta, medio pertufis, notífice partim luteis, partímq; coccincis diftinctis, atjufmodi in Digitali interiore, quam etiam repræentat. In filiquis fenen pufillum Digitalis: Radice quàn Hellebori albi fibris paucioribus, variè vagantibus, nigricantibus, durolibro, \& amaro.

\section{NARDYS CELTICA, Saliunca.}

T I D E montofis iifdem fermè Gaudet Celtica, aut potius hodie nuncupanda Ly1 guftica Nardus, nec Gentianellis admodum abfimilis folit aromaticitate, ipfóque ha bitu,quam S E L L I G A, vallefii vernaculè quafi Saliun cám dicunt : nec dubium quin fit ea, quam Maronis verfus innuunt: $p^{\prime}$ uniceis bumlis quantim Saliunca roferis, Iudicio noftro,tantzum tibi cedit Amyntas. Pufilla námque herbula, aliquantum proferpens, deinde fe furrigens, cauliculo palmum \& fefquipalnum alto, ad quem imum folia cefpites fummos conflant, exigua tenuia Gnaphalii montani, aut Gentiancllæ minimx , pallida \& fublutea, infernè anguita, quà radicis ceruicis fquarof $x$, aut fquamulis tuniceis obfitæ, fpicatim digeft $x$ innituntur; fubtérque multx fibrx, fufcx, villofęque propagines A fariodore, \& modo in terram fparguntur:acri, amaricante, aromatico Spicam Nardi fpirante: in Genuenfibus, Lygurixque Alpinis ftarilibus, non procul Sauona vrbe, vnde Genuam Iucelli caufa

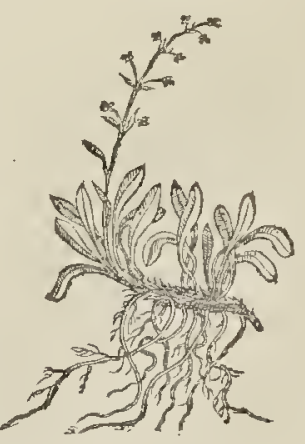
ferunt Coloni. 


\section{STIRP IV $M$ aduerfarianoua. \\ CELTICA EAltera.}

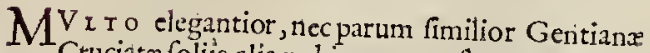
Cruciata folijs, alia nobis reperta eft prope Conobium guoddā,inter Dei viridarium \& Calcaris mötes in agro Narbonenfi, magni \& vulgati nominis. Radice eft Valerianx maioris, paulò minore, geniculis Doroni ci modo diftineta, humi ftrata, acri fapore, erodente, aromatico $\&$ amaro, Nardi $x$ mulo, folijs Saponarix vulga ris flaccidis, ex flauo pallefcentibus, fenis, feptennífue, Gentianellix adeò cognatis, vt primo insuitu eandem putes. Caulis cùm maximus cubitun altus, mediocris fefquipalmum : fore radiato, auteo, Buphthalmi æmuIo. Hanc Rond elletius Nardi Gallicx fpeciem effe coniectabat:tunc temporis cùm Canobium fortè effet nobis hofpitium in illis defitis locis, cuidam è lignipedum Canonicorum dyffuria laboranti, \& noftranı opem obnixe pofcenti, potinnculam ex hitius Meió; radicuin decoßto parandam iufsimus, vrinæá́; copiam elicuimus.

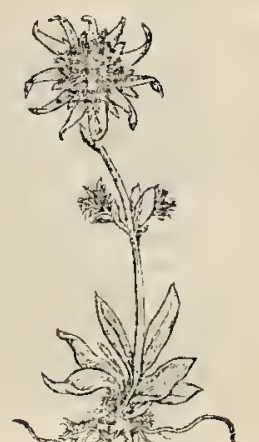

$H I R C V L V S$ 。

$\mathrm{R}_{\mathrm{A}} \mathrm{A}$ OR multò Hirculus, quem nunquam nobis recens vifum fatemur, \& lubenter affentimur, gratiamq; habemus de illius affertione, ftirpiū exoticarum peritifimo, Carolo Clufio, gui hunc nactus inter Spicz Celtica fafciculos, pofteritatifcitè patefecit, in fuis è Garcia Lufitano Medico verfionibus.

\section{S.APONARIA vulg. foliss Plantagineis, akt Gentiand, foribus O C I M O I - DIS nonest STRYTHIM DIOSC, SIVEARAB. CON- DI S I, de givo in Hippoplosto, co. Hippo:}

$Q^{\prime}$

V A u v Y s permulta plant x etiámnum Struthia vocarì queant, à facultate vfúq;

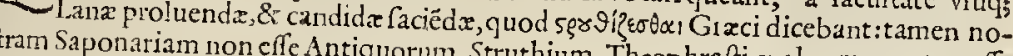
guippe eful entum can effe Antiquorum Struthium Theophrafi verba monent : effe quippe efulentum caulem, lanuginofum, \& ferulaceum, nafci vbiq; A fia prafertim, fpon qux conditur ad proluendas, curandan folio Olexx inodorä, femine nullo: radice imagna, quit cula barum curandi exoleuit cófuetudoapud noftrates fullones, lanas radice aut fucco her barum curandi, nefcitur iam qquodnam illud fuerit ş夭̈日op. Et fedula plebecula lotorum apud Belgas hodie, non herbis aut fuccis, fed Sapone, I.anx primü carminata, Oleóq; a at Butyro delibuta, candoren niueum, \& fericeam mollitiem conciliat. Nonnulli conicQant hodie Ocimoidem illann. quam Papauer fpumeum etiam dietităt, quia fit folijs $\mathrm{O}$. lere, effe Struthium: verim abeft a facultatibus, \& plurimum difcrepat reliquis indicijs. Hxc verò vulgi Saponaria, quafi quis dicat lotricem, aut purgatricenı, tametfi nitrofuni extergentémue preffu remittat fuccum, emundandis pannis aptum, tamen non in afperis aut fqualidis, fed fecus herbidas amnium conualles, \& deprefos apticorum vdosum margines fruticat : multis virgis crebrò geniculatis, teretibus, gracilibus, cubitum, fefquicubitum furrétis, multis binis è geniculis fipantibus, folijfón; venofis, crafsis, pinguibus, Gentianx cruciatx dietx, aut Plaztagin is, horfun reflexis, fpeciofis florum oblongis caliculis Lychnidis, aut for is Conftantinopolitanj obfoletc purpurantibus, \& albidis framinulis egrefsis inter quina florun foliola :radicibus multum diuifis, \& $f$ partis, diu durantibus, gundo in hortis colitur Regionum Septentrionalium, vi bi non perinde fpor tè obuia fit. Non igiturfit Arabum Condifi, fi non fit Grxcotum Struthium: quia hac duo nomina, eandem defigilant plantam?

$$
\text { M.j. PER. }
$$


PEREGRINA voce Piperis cum vernacula apud Gracos isflop, conflatum nomen Dodice. Hydropiperi fuit, feu tu dicas aquarum Pipcr: pronenit ctenim vbić; fcrobibus aqux ftillantibus in herbidis vdis, caulibus innmerofis, inq; ramulos diufis, Perfici fronde nigricăte ex virore: è geniculis finúg; foliorum: \& alarum flores Iunio, \& A A ugnfo permult1,albidı \& purpurafcétes, caudatis fpicis, racemofis Biftort $x$, aut Potanogetonis,ra. dicibus plurimum fibrofis:fenıen fubnigricans, latiufculum, minutum acre Sinapi,aut $P i$ pcris fapore, vbiq; notifsimú: Gallis Culraige vocatū, vt cuius folia quı quis podici(honos fit auribus) abftergendi caufa affricuerit, inurãt rabiem clunibus, fue vt loquätur Legulci, culo. Vnam hanc Parafcelusille ter maximus, per aquam frigidan traiectam, quibufibet vicerum lancinationibus, \& laniationibus remedio fummo cælitus parato fore affimst: Cui cun fidem habniffet nuper quidä amicus, dicebat illum Apollonij Thianxi apud Philoltratum $\not i \lambda)$ úf́úx

\section{PERSICARIA mitis.}

Dodico.de for. 269 .

A Lien a Diofcoridi,vt verifmile fit prxterita, tantópere huic effigie, loco habitúq; toto cóucuit, vt neutrā ab altera queas difcernere, nifi faporc: qui plané facit, vt diuer fe fint, nec exdem planè putentur:eft namq; is frigidus, ficcus, \& nonililil acidus:infolij fu perficie media nonnullx macula confpiciuntur nigrx.

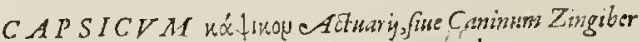 Auicenne, Calecutium Recentionib.}

Effi.Dod. C OE P I t noftra memoria ifta perpulchra plantaadferri ex Gon, \& Calecutijs oris in Europam,vbi Piperis vicem explet, \& voluptati in hortis,penfilibúfq; vafis apud Gal los, \& Germanos eft fpectatori triplicis differentix, non tamen admodü magni diforimi nis,nifi fructu. Eft enim caule quadrangulo, pedali, fefquipedali, fufco, fparfo, folia in pedicellis habente Solani, aut Perficarix, aut Amomi Pliniani:nigrioribus, acutioribus, floribus cädidis, pufillis, Solani, vel Vincx Peruincx, exiguis foliolis, quorum cétrum tenet, afterifcus, herbidus, exiguus : deinde filiqua fuccrefcit nitido virore \& lauore, per inaturitatim rubidx \& miniatx, purpurex, oblonga, mucronata, crafsiora, cotiacca, cui infunt multa granula lata, compreffa. ex luteo pallida: Iufcula, \& condimenta colore crocco,\& gultu Pipereo commendat.

Vaginulis tion difparibus filiquofis, fed minus crafsis, longioribus accutio-

varietus. $\left\{\begin{array}{l}\text { Vaginulis tion difparibus rofris, candem planè, tamen ijfdem in valis alunt hanc. } \\ \text { Interdum \& multò breuiores, rotundas, turbinatas,codem fcmine pragnan- }\end{array}\right.$

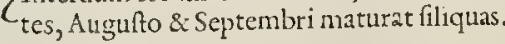

\section{B ALS AMI IN A fomina, Perficifolie.}

A Sc t y 1 T hac percgrina vulneraria credita, eandem quam Balfanine Cucumerina nomenclationem, propter eafdem facultates, \& fruetum nonnihil fimilen. Alióqui Ptipites crafli, turgentéfq́; fucco, Mercurialis habitiores füt, folia \& facies admodum Fer ficariam vtrámuis referunt, quare etiam hunc Perficariam nonnulli dicurat: tametó ron minus propter vires confimiles \& vulnerarias, quales in Perficaria recćtio: es agnouerüt, dicta putari pofsit. Flores fubter folia per interualla penduli, purpurei, ciliati, incarulum vergétıs, Dclphinij Cófolidx effigíe caudatx, vel Noli ne tágere rocatæ, qua esiam multùm huíc funilis: pufilli fructus penduli, ctiā funt Augufto nuclei Pruni vtrinq́; acumi- 


\section{STIRPIVM aduerfarianom.}

nati fimilitudine, primú viridante, deinde luteolo, \& fcris fcabro dehifcēte, per maturitate:n femcn Erui, aut Rapi elidente vix digitis fummis tacto, ritu Noli me tangere her-
$\mathrm{bx}$.

\section{PERSICARIA Silicola, fme Nolimetangere.}

T N I G E A hre montium colliu'ngue Gaperiorü Germaniẹ, \& Gallię Słlsaude, quan $3 a \lg x$ alunt frequens, vocantque vt Germani Sp:uct Fraut, quafi erupt-icem fue falientë, zut fubálienté hzrban, propter

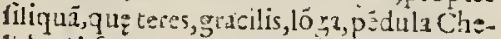
lidonij, femin ? p trua, ro: $\mathrm{d}_{\mathrm{d}}$, Balfamine fe

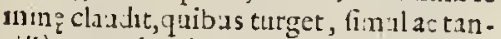
tillum tangitur in vultü proximicuiúfq; quafi impetu.vindicabud, \& fe tangi quęribüa excludut. Idcirco Nolun: t. igere, vulSus herbariorú vocat, qua notá \& nonine notifsima iam diu. Folia, faciéfq; \& virgulta Balfaminä, Mercuriale, \& Amaranthü exprimüt:qure cauen lu ne quis Mercurialé putet, eánguue in vius eofdẻlegat, vt nonnulliballucinatifecerunt:quippe venenatanı q̨uidan a:ıtumant, pręitaréque explo. ratis, quàu incerta hacvtimonät. Tanate alios ad effectusmerito laudent.

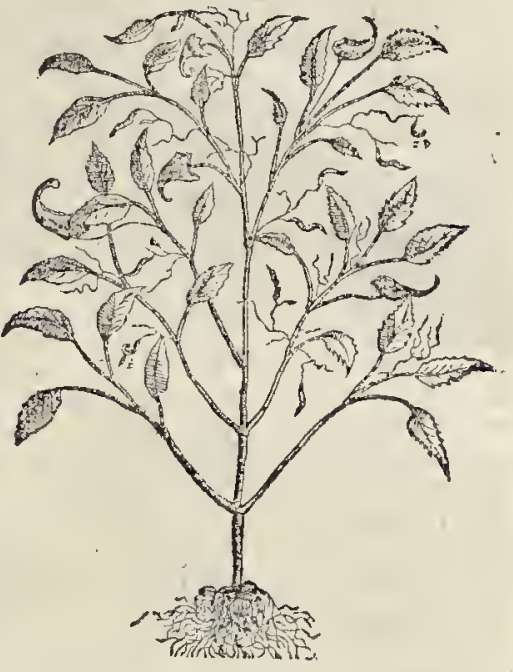

$R A P H A N V S$ Syl: Officinis Francis, ơ Belgis.

LEP I D I M Eginete, folys quan Lakrimaio ribus, fort bius, racemofis Galy albs.

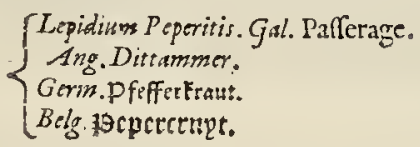

V A m potuimus aptè ab altero Pali ex Diofc rride Lspidio minore, fu: Cardamantice difcreuimusiftud pagina 77.oltandimúfque inultò vrentius effe, \& efficacius illo Democratis carminibus celebri. Perquam notum eft ifud regioniba calid is, $\&$ frigidıs, vt Norbonx, Belgio, \& Anglix, ad decliuia riparum fruticare folitum, plebecu-
Ixque Raphanus fyl. \& Pafferage vocatum, id eft, extrema rabics, propter feruorem igEgri.Matses neum, qui etiam teltatur hanc legitimü Lepidı̃ : folis námq; Laurinis. latioribus tanțil lum crenatis, ex pallido virentibus, Hyofcyami quadätenus lutci, aut Colti hortêfis, in flexilibus, ramofis virgis, cubitum \& fefquicubitam al tis:flores albidos mufcolos, Iunio \& Iulio edentibus, feménque pufillum:perreptat fubter humú radix, \& quotannis noua pullulatione fe reparat, ad ifchiadicum dolorem efficacirsima tufa, \& axungia exicept

\section{Crafaradice, $R A P H A N V S$ RVSTICANVS, Lapathiifolio, videtur M O I Y B D N A Plinij.}

Sinapi Perficum. Germa.mIectretich k ketn.

POT IS T Y D O P I P R dici etiam hæc, aquaticis, \& fubftillis pratenfbus fruticans, quain inulti Lepidium Pauli, \& Plinii dixerunt : vt cui fint folia latiora, circinati, ferrata, longioráque Laurinis, \& rigidiora , viciniora tamen Al.ij. Hip- 


\section{-136 STIRTIVM aduerfarianoud}

Hippolapatho, à radice craffa longa, acríque tufa vefcendo in condimentis Sinapi fapore. Floribus albidis, Sinapi aut Braflicx ninoribus, in ramulis, fectundĩ quos harenz frliquulx Erifini, aut Rhaphani, cum quo fimilitudinem quandam haber, ećque vocatus fuit Raphanus rufticanus à Plebecula.

$D E N T A R I A$, vel Dentillaria R O N D L L ETII, Co Norm bonenfutrm, E G I NEIT LEP I D I V M itidam putatum.

NEc abs re Lepidium quoppiă feccrunt perelegantem iftam plantam, Norboncules praceptores noftri, Fruticat ea pafsim in Romano,\& Mórp sllinco agro prope feves \&e fata, radıce lógiufcula, caule bicubitali, turionibus nultifida, folia ima maioria cauli Ifatidis, Drabruc ritu incumbentia, pufillæ viola modo.Floribus purpureis, dilatis, extremo caulis ambitui confertim asgeftis, quibus defluentibus, femin a gemmeis, \& vilolis hirfutis, \& aligua tum tenacibus pericarpisis includütur nigra, acri vuiuerfa planta guftu, \& vrentis facultatis, qua tantôpere pollet,vtetiam volę manui vibicem callúmue inurat furutm, aut plumbeum, vnde viros Do Glos in opinioné duxit Molibdenä effe Plinij, ant Lepidium. Eginetę. Dentillariam, ant potius loctariam vulgus ftudioforum putabat vocatá à Ron delletio, qui vt Pyrethris, aut finili-

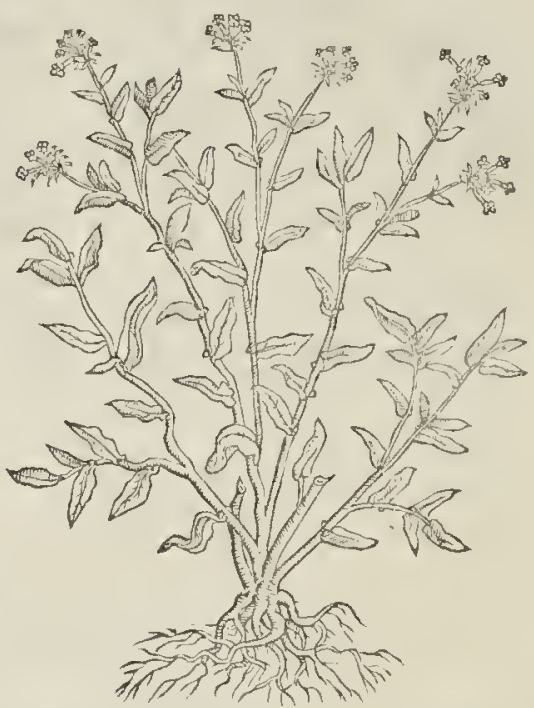
bus vrentibus vtebatur,ad rabidum dentium cruciatum placandum; etiámq; in Balneis filius Re zis Sapor.

$$
\begin{aligned}
& \text { HORT ORVM Coftus Cafsinni Basi, Mentha folio, ant Lepidig. } \\
& \text { SGerm. Sraumentrat id eft, Herba D. Marix. } \\
& \text { Gal. Coq. } \\
& \text { CBelgi. Jasticme, id et, Balíamum. } \\
& \text { Offic. Mentha Graca, ¿ Sarracenicat. }
\end{aligned}
$$

Dodo.179.

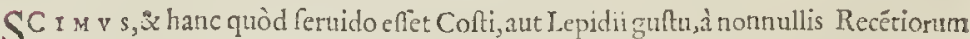
Lepidium putatam, quan Mentham Gracam Pharmacopci, \& Sarracenicam qu1-

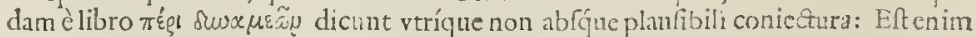
foliis Lauri, fedinterdum maioribus, ferratis, viridibus, pallentibus, molliufculis, radice fibrofa, infexa, \& fummo cefpite fparfa, caule cubitali, fl sribus luteis Tanceti: hor tis familiaris, \& nota confoicua amaritudinc, feruoretamen non fuperioribus inferior. Vulnerariam curfores Chirurgi, \& mulierculx cicisim opis experimuntur: eóque "Banrre apud Gallos, id eft,Balfamum vocitant.

B V L BOS A folliata, Officinarem B OL B A A C, I, V N A R I A

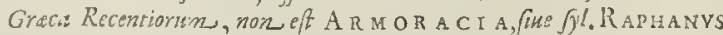
Diofcori. aut T H L A S I lati-folitus Cratetes: vt ipagina 75 . lighet. 


\section{STIRPIVM aduerjarianowa.}

$C^{V}$ hrac in Alpinis, Galloprouincia conterminisć; Pedemontij oriatur,apud Flan-Dod,deftor, 36 . fe Barbari, à radicibus bulbofis, efculetis, oblongis, cr, rectius videntur Bolbanac dixifdantenus Afphodeli, aut Poeoniz, fed minus prot, crafis, longius porrectis, porofis qua aut Violam latifoliam nuperi quidam. Erus protuberantibus, guam Gracam Lunariain, ciz \& Pedemontij conterminis fcimus, \& indidem fortè contibus Alpinis Galloprouin glia, radicibus exilioribus, ffaccidioribus indidem fortè coli in Flandrin, Francia, \& AnAfphodeli Lutei, aut Leucacanth $x$ Monfpelliacr protubcrätibus, fed finilibus \& fparfis ramis multis donatos,foliác; pauca promentibus, obidis prorfus carnofis, caules teretes, tronalis, virětia, in ambitu parum promentibus, oblonga, latiora multu quá Violæ Mabx purpureis, \& fubcerueis, poft onata, foribus, primo, Vere, Dentillarix aut Violæ al quafi membranula cópacti,pellucidi, femina cuaterna aut folliacei oriuntur, ex triplicì pè difsepiente, candida cutıcula fericea ipfa quaterna aut quina complexi, media nemfo cernitur, vnde PE N N I N C K Brabanti, id eft, effigie femina, non fecus atg; in Alyfnariam.Calido,ácríq; guftu eft, prafertin fenine, fed tanen radiceant, \& quidam L tia, manduntur, nec perinde funt acres, vt Crateux Thlafpiradices traduntur, vt Rapun

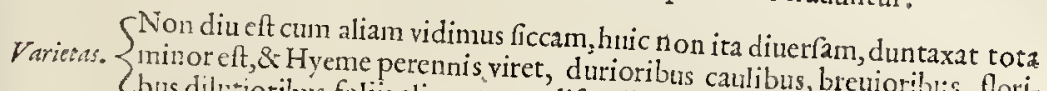

$\left\{\begin{array}{l}\text { bus dilitiotibus, folijs aliquot non difparibus, caulibus, brenioribus, flori- } \\ \text { bution }\end{array}\right.$

CH ATRONALIS Viola, aut Damajcena.

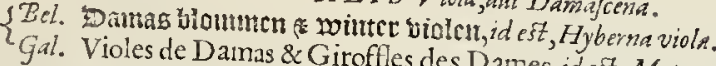

Gal. Violes de Damas \& Giroffles des Dames, id est, Matronalis viola,

NEc confultius faciunt, qui iftam fimilem illis plantam, Marinam violam, Damafce-

nam, \& exotican vocitant, cun in Nitiobrigum nonto Mas \& Veganijs fyamafceamó; Anglix in pratis fruticet, vnde horti habuerunt : cेtofis \& Veganijs fyluofis, eti- Dod.deflor.24 lijs eft Drabæ, aut Erucx, minus Iaciniofis, nigris, crebribus a imo fabro, denfa, ampla foles \& fefquicubitales ambientibus A prilij, Maio, \& Iunio, ab imo caules rectos, cubitadido purpureos, \& rubellos edétibus Saponarix aut lunio, flor un caliculos multos ex cã. pi funt, vbi femen acre, fu fcum, aut ruffefcens, \& Erucam, Il corniculi filiquarum Syna tota fapit, quibus idcirco affinis natura putatur.

$$
\text { MEDIVM, afI CMARIANA HIOLA? }
$$

M I v v s mirum etiánnnüc Medium effe nullius aut ambigur lectionis, cú codices \& autores fuerint valde variæ lętionis. Qui namá́; cū vulgatis Diofcoridıs codicib \& \& Plinianis, Iridis folia legebant, fuperioribus illam tionem in Meo fecimus, \& iconem, plenamg; defcriptioné in Iride, cuius vt nouę mêintcr quos pręceptor, \&D. A Aatius, Callotus, atc; Diofeorides Barallius $M$, ftatuebant: 129. Sed nonnullax notæ magnitudinis \& figure, potius qucorides Barallius Monfpelliêfes. candidifsimus Gefnerus, \& deinde Italorum doctirsimi virium, refragari vifa funt. At bus, \& hos fecutis Grxcis authoribus Seridis folin himi nonnulli, qui alijs in codiciabhinc monebant nos, Violan $M$ is Seridis folia haberent, iam plufquam octeniun tamen poftremo fibi notan feruitor Comm A M dictam, vulgatifsimam plantam, quam Medium,vt fi qux alia planta referre, quorum fentiebanur, quia Iridis fylueftris nullius men lectioni \& fententiz nos co lubentius affatiua, nif magnitudine diuerfa fint, nônullíó The loiofcorides, necfylueftris folia à

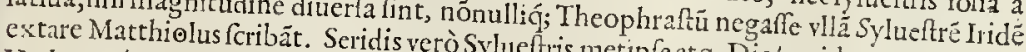
Violx auté Marianx, \& Mariæ diêx à Belgis (qui muneri at $q$; Diolcorides meminerint. derunt Macix Hungaricæ viragini illi Heroinz bellicis elegantix florú caufa, primi de. tatx) noftra etiam memoria, cultu hortenfina bellicis fafcinoribus, \& incendijs nobiliM.ï fpeciofirsimis tantá mag M.ij]. nitudinem 
nitudiné affequú tur, yt inftar calycis aut poculi poturis voluptatis caufa, vinú contineât. Sunt nanć; nol $x$ oblongx effigic, nonu ullis lacinofis crenis, cærula hilari interdú purpu rafcéte, interdü dilutiore, \& candicãte, emergentibus ab ino calyce, quibus reflexis, aut elapfis in vtriculi, \& forü bafi Rapútio, aut Trachelio a fimili claudútur:triquetra numero fa femina Acetofx, colore, \& parilitate. Bicubitales caules toti, \& al a hirfutx, \& hirtæab imo folia habent longiora, latiota, tunicis hirfuta, rigida minus quá Licopfis, aut Pulmonaria vulgaris Intibj fu Seridi domefticx potius quä Sylueftris, qux laciniofa eft. Radis autem candida, tencra, efculenta palmum longa Rapútij frmilitudine, vtifemen \& Fores fed duplo maior, nec guftu multum difpari:fiquidem in acetarijs Rapuntij modo efitauimus verna quiadragena Belgix prafertim, \& Couentrix Anglix, vi etiam in Syluofis cu $\vec{x}$ plurimis enata, fecl minor \& ftrigofior, eò poften incrementi progreditur, cultu in hortis pafsim, vt lougè maior adultior, fuauiorq; edendo fit. Calidioribus Italix, \& Gallax infetiori infrequens, magis figura ad Medium quam facultatibus alludit, figuidem dulcisacriufcula minine altringen percipitur.

$$
\begin{aligned}
& \text { EGIMkidop. EPINEDIVM. } \\
& \text { an Epipetron \& Eptrzetron Tlin? }
\end{aligned}
$$

ATQ y $\mathrm{E}$ arduum fatuere Epimedium quznaim fit Planca, \& an hodié noftro orbi Europaocognita. Quippe perpauca fant plantre caule donatx, quin flores, aut quxdm eo:um ru dimita $æ$ dant, vti Filic, Ficus arbor, \& alia nonnulla. Qua de notafi in hifce regionibus nafceretur, facilè cognofceretur Epimedium quod fuf picamur, efle Epipetrum, vt Plinius legiffe videtur Theophrafto memoratun libro 7. capite 0Et wna cum frn ctauo (non vt vulgo legunt Épimetrum.) Siqui, Et u, forum pem dem fuxis, \& petris innafci affirmat Diofcotides. prodegere. Cui fi idem vfu venithic atq; in Bechio, Diktammo, Onofmate, fortè \& Cynogloffo, iam facilius accedemus peritiorü Herbariorum fentétix, quam non femel fuper Epimedio(atq; de hac ele ganti,\& noua quä pictan damus planta) rogaui mus. Antequan in fonicetijs inter cremia ena$\operatorname{tam}$ fponte, non procul Piftoia, in Florétina pre

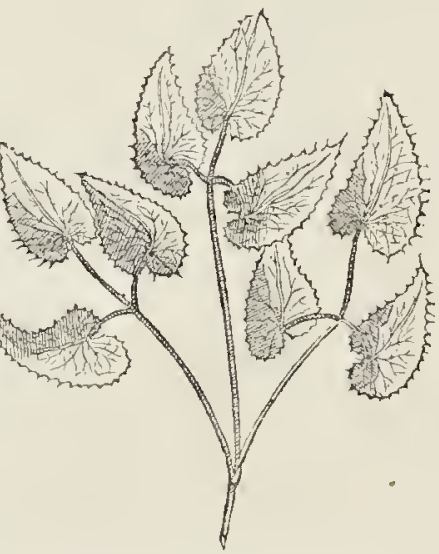
feEtura vidiffemus, virentem dono acceperamus à Ioanne fomello Veneto Pharmaco. poeo non vulgaris peritia, ad Buccentoris fymbolum, qui in hortis colcbat, \& alscunde e proximis Vincentix, aut Patauij agris habuerat. Hac etiam nos donauit clarifsimus Bononienfis Doetor, \& profeffor medicus Cæfar Odonus. Viticulis efl quafi iunceis, non crafsis, fed nitidis, afbidis, prolixioribus, tenellis cubiti, \& fefquicubiti exilibus nutätibus, fparfis per fumma finguli in ternos, quafi pediculos diuifis, in quibus fummis quafi in alis multó tenerioribus ternis pedicellis, terna infunt folia, id eft noué, aut decem mag nitudine, colore, letrore Hederacco, fed tencrion, ad Theophrafti Libanotide accedentia auerfa parte glauca vel albicantia, \& extrema ora nonnullis denticellis fpinofis ferratim extantibus: radicem non vidimus, fed ab ijfdem auditione accepimus: iam tum defloruitre femenó, amififfe, virofo odore: \& prolixis ambagibus radicem incuruari atq; in latera diffundi, fubaftringentis, \& ficcontis guftus effe:etiam unuc poftremum dum literis mandaremus nobis guftantibus folia multum amara, guftu fermè Chamælea percipicbantur, per quam rara.nec nobis vfpiam, pręterquam in Italia vifa,

Tęaślicu. TR ACHELIVM, fus Cernicaria of Vunlaria. $\left\{\begin{array}{l}\text { Belg. } G\} \\ \text { Ger. }\end{array}\right\}$ ald braut. 


\title{
STIRP IV $M$ aduerfaria noina.
}

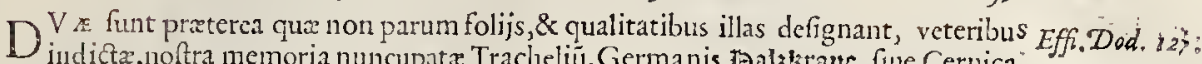

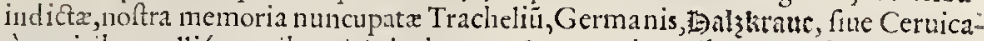
tix, àcerticibus colliq́a; partibus vicinis, internı \& externis, quibus tumefactis, \& vıceratis multum opitulantur:vnde Vuularia ab vuula etiam dicitur . Maiori harum folia funt quadantenus Bolbonac aut Vrtıcę,Hifpida, rigida, latiora, ad Imum, fupernè acutá \& ambitu crenata, Vrticę habitu \& fuperficie:floribus albidis, plurimùm cęruleis Viola Marianx minoribus:radice alba tenera Rapúculi in acetarijs apta iciunio Verno prafer tim.

$$
\text { TR ACHELIVM, minus. }
$$

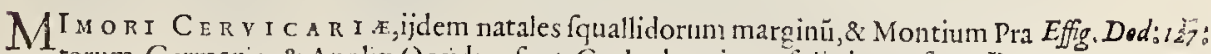
torum Germanix, \& Anglix ()ccidixx funt: Caules breuiores, folia iten afpera Rapuntij aut Saluix, pilola, flores denfi pulcelli fuperioris funt, Rapuntij fapore, primóq;
vere acetarijsetian adduntur.

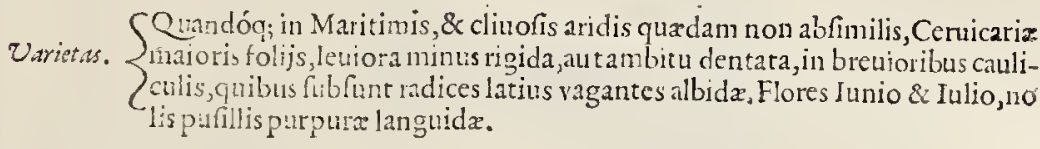

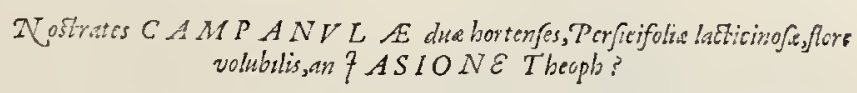

O B I O N G A, angufta, \& obfcurè virentia folia, imum caulem cubitalem, atg; radicem Effi. Dod. "jC. $_{j}$. ftipantia funt caules refti in longitudinem ftriati in quibus totis infunt fiorum ca. Iathi,vel nolę Cxrulex, albide, cxruleis etiam vel albis cxplicantibus fefe nounullis fta minibus, anibitu conftantes \& quafi vnico folio, fexangulo, idcirco putatur meritò Theophraft Iafone:capitula infunt foraminulis peruia, quod impofuit Commentatori Snenfi, qui idcirco illicò pu tauit, \& fanxit effe Phyteuma. Horti voluptatis caufa habēt: tametí in olere mandi queat.

\section{CAMPANVLA Minor.}

E A D E M fponte propè fcrobes, \& rer es pronenit:multò minor, caule breuiore : folia funt ad inum ftrata, rotundiora, \& volubilem viarum propius accidentia, flores puro purei, \& radices exiliores.

\section{R A PVN TIVM paruum, vulgo' Tes Locksta Anicema.}

\author{
SGal. Refponce petit. \\ \{Ger. Clen Kapunizlein. \\ ¿Bel. Tlecn anapoucllen.
}

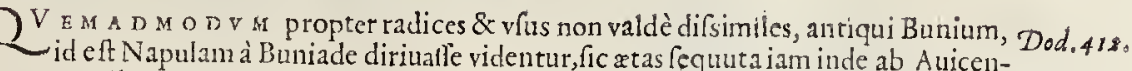
nætemporibus R:puntium fiue Rapulum iftam vocauit:fue quia inde ab Auicendem aut congenerem, fuse quia ad vefcend $\vec{u}, \gtrless$ ad afpectú, Napum aut Rapulam prx fe fert radix: Eftenim pollicis lögitudine \& crafsitie Rapi in morem, aut Raphan oblongà, \& medio fui nonnihil ventriofa : fed multò minor pellucida, candida, tenera, acetarijs vernæ Quadragenx longè quouis Rapo aut Raphano delicatior. Inter namó́; primas,prima rüm erumpit, folijs Olex, Gentianella, aut Campanuls hortéfis brenioribus, in caule gracili,nec huic difsimili for es cralei quatuor foliolis, vt Lini, cópacti fed refex is campanule modo : femine in oblongis theculis pufillo. Non modo hor tis \& fatis tamiliare vbinis, fed etiam fyluofis \& fẹpibins tum frigidarum, tum calidarum regionum.

$$
\text { M. iij. Rapun- }
$$




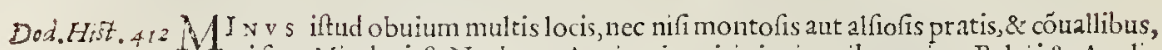
vti funt Mindeni, \& Norbon $x$ Aquitanicx vicinis pinguibus, etiam Belgij \& Angliæ numerofs. Figura, radić́q; maiore Rapuntium imitante, \& comofo flore purpureo cæruleo multum diucrfo à Ravis, Napis \& minore Rapuntio. Folia enim per initia latiora imò, fupernè acuta Hederx, aut Trachelij, fed longiora in caulc recto, peden fefquipedemá, altw, geftante denfun comofung; fpicatum, ex corniculis crebribus in quatuor foliola fupcruè dehifcentibus, Melampvri forem cxruleum purpurantem,iam glatcum, tam pallidum. Inlio, \& Augufto theculas relinquente rotundas, Rapuntij marfupiolis non difsimiles, vti \& radix non difsimili guftu \& figura eft, vnde dicta videtur Rapuntium,tamet neutra inter Rapos collocanda.

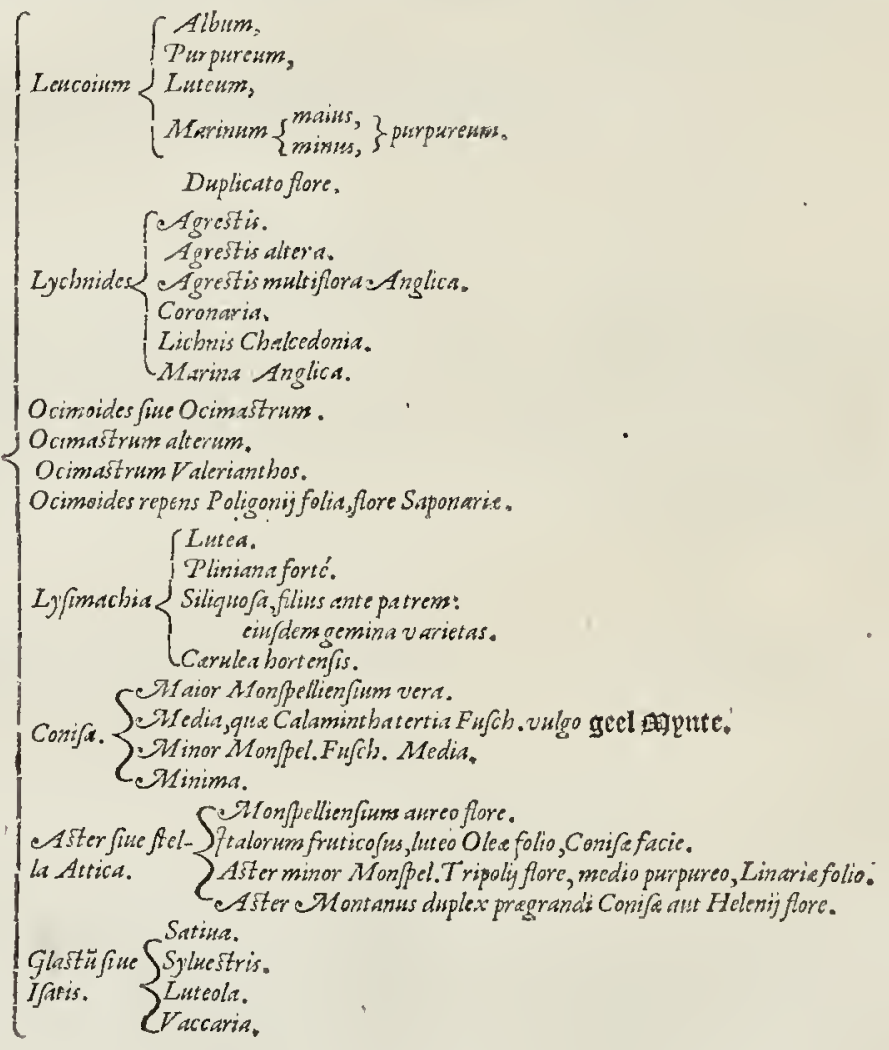

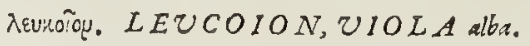

SBel. thiolierent.

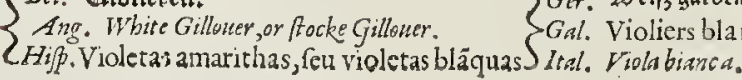

2 Ger. 2Deifs garoen Diele.

Gal. Violiers blancs.

Violx 


\title{
STIRP IV M aduerfarianou.
}

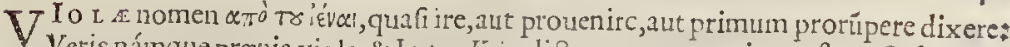

Veris námque præuia viola, \& Lutea Keir dict?, quarum capti yenuftate, \& fragrantia, vt vfum ad coronamcinta fic nomen commune fanxerc, pofteáque magis confuetu- $E$ fig. . Aathio?. dinem, aut florum fimilitudinem, quam rationem fquuti, multos \& varios flo- 876 . res Violas nuncuparunt. Idcm nomen varíis atquc longè diuer fis plantis inditum:quippeapud Theophraftum Viola eft bulbofa, nigra \& alba:quas nos fuis quáque locis exequuti fumus. Hic vero Leucoium fpeciem duntaxat lcuitcr perftringemus, qux non aे Hotum albedine, fed foliorum canitie, cinericióuc colore dieta alba videtur. Etiamnum hodic, vti Diofcoridis xuo, vulgatifsimæ cognitionis illa triplex è floribus varietas: vbiuis propemodum gentium. Ditisıma peræquè omnium florum foctura.Sed alba \& purpureacxrulea non nifi fatı.

\section{LEVGOIVM LVT EVM, KeriA Anal.}

\author{
Germa. Beel gatoen veiel. \\ Siral.Viola Talla: \\ Gol. Violes de muretz. \\ An.Waile Gyllofer.
}

LV T E A verò parietinis prafertim,etiam fpontè lata foret \& vernat, Februario \&

Martio, hreque ve frequentior, \& odoratior, ita nó parum vtilior Medico vfui, cuius Effg. Maxbio?. femen etiam efficacifimum compreffun in filiquis, fed minoribus multò, atque Erucx $87 \%$.

fylucftris paribus. Folia ctiam anguftiora, vircntı Liguftri, vel Phyleree. Caules farmentofi,refi, complures, radice lignofa, fibrofa cómifuris \& rimis partetum incuneata. Hîc in Anglıa v ti pleráfque al ias Nataliciis Chrift frpius floribus luxunıaté vidimus, ctiz̄ hocanno:non tamen perennat.

SV r finilis \& vnd dumtaxat, quæ plurimum albos, fæpe purpureos, interdum, præfertim arotina flores, exolcti coloris in cxrulcum vinaceú languefcent is fert : Cornicula Vorietwi: quanta x́cuufmodi cornuti Papaucris, geminú item feminum ordinem, membranula fecundị longitudinem intercurrit. Folıa accedunt ad Calendulam albicantia, è radice Jignola : Hxe non perinde feruet guftu.

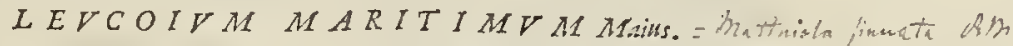

$S_{\text {D }}$ Maritina, qux plurima Mediterraneis SNorbonx littoribus, rarior nultò, Thlarpi guftu \& fapore videtur. Flofculi altate quaternis folılis dilatx purpura:filiqua \& femine fimilis, fed folio ad Cichorij, vel Erucx modum diuifo, cralfo albido, cócolori, \& pari hortéfís.

\section{LEVCOIVM MARI- num, minus.}

II S D M locisnonraro pufilla duplóque minor oritur, \& ab hac differre videtur: vti Thla fpi munimü,à mediocri: vehementius tamen a* credine vellicat linguam.

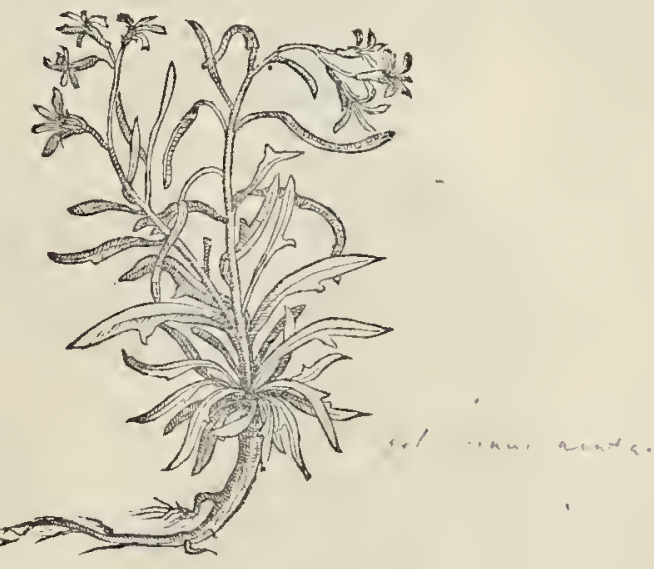

\section{LEVCOIA DVPLIS FLORIBVS.}




\section{I42 STIRTIV $M$ aduerfarianous.}

MANG oN r o holitorio repetitáf; creỏiore tranfplátatione, tum lutei, tum purpdrei,flores macnituduc luculentam affequantur : imulaplici finguli prxgnanti foliorum foxtura, Rofam mofchatä æquante: Sed vti viold Martia foribus donara, femase orba fit.

Auxvis, LICHNIS Coronaria.

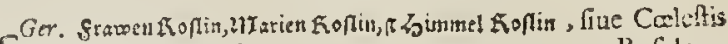
Sal.Oeillets, \& Oeillets Dieu.

Rofuli.

Bel. Lbittus oogben.

An. Roje Campior.

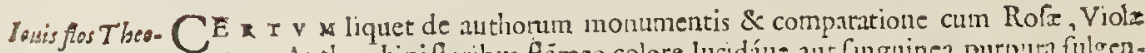
ph. non Pblox, atque Anthyrrhini fioribus, fiämeo colore, lucidíus, aut fantruinea, purpura fulgenwhe finments tibus, dietas fuiffe Lychnides, quafi lucidos luculetofúeflores, qui elerintizillecebris in Plitr.

Variets., coronanenta venerint. Eiufinodi elt Viridariorü delicix lectisimusflos, Ocellus vocatus, Gallice Oeillet, fohiftus anghen Flädricè, cuius tres quatuorúc num erantur differentix: quas omnes huius arço notionis ambitu cóplexi fumus : Satiuę radix fỉorof, longurfula, folia faccida, crafsiora, tomentofa, vti Ethyopis, magnitudiné Leucoii, vel Saluix xquante. Incani item caules furrecti, teretes, geniculis atque ramulis pluribus donati, qui finguli, flores explicant, è calycibus Pfendomelanthii amulı, Rafea purpurarutilos, atque nitore flammantes, oculorüq; acien interdum perfteingentes, $\bar{p}$ yropi, aut lapidis Iychuidis modo, vnde nomen vtríque cömune fut. Hæe vt omniuin pulcherrina, ita colitur fola, éque flores adeo confertos \& ingeminatos fert:ve femine pofter orba fit, exhaufta nimirum formæ vi, \& pabulo in forum cónodum abfumpto: curiufmodi in Viola Martia exemplum videre eft. Haud difparnatura earu'n q̨ux ruri, interdum fponte oriuntur, aut in hortis negliguntur. '’rxterquam quod floribuz candidıs paucioribus, minoribus, \& femine donantur.

\section{LCCHNIDESSTLVESTRES.}

A Fy r e s etiamum tres, quarum dux pafsim fecus fatorum fxpes exeunt:radice non ita magna, gracilioribus, ac paucioribus, tum cauliculis, tum foliis, \& mollioribus, nec perinde tomentofis, fed ex pallido herbaceis. Alteri flores rubelli dilutiorífue Rof $\boldsymbol{x}$, alteri vero niueo candore renident.

$M V L T I F L O R A$. Pariens

TR A r s V C T e vtriúfque in hortos cultu adeo fores foetura luxuriant, ve anaximum Affricanum florem, vel Ro(fam xquent,aut fupereat.

Ang. Doble Roje Campion.

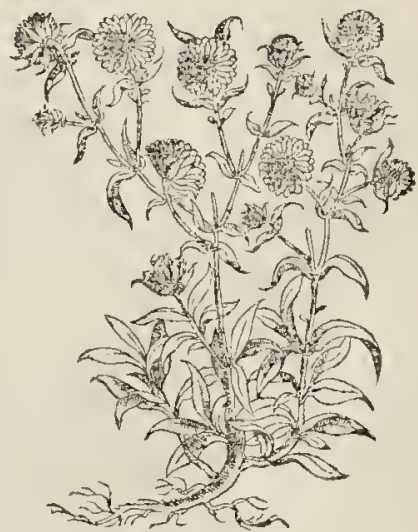

ZYCITNIS MARINA, ANGLICA. 


\section{$S T I R P I V M$ aduer aria nowd.}

A L te Ra quam hic pictam damus, in aggeribus maritimis Vectis Infulx Anglix, totóq; illo littore frequens. Herbula eft ab ina radice multis folijs cincta,crafsis, minoribus, \& anguftioribus quàm Portulace Marinx. Caules creberrimi, Hexiles, huni fufi, cubitales \& féquicubitales: in quorum fummo caliculus albus Ocimaftri, aut Lych-
nidis eft, cui hrent
elegantes, Ocimaftri non difsimiles, apiculis
intus nigris. Semen in folliculis furcum Lych fummo caliculus albus Ocimaftri,aut Lych-
nidis eft, cui hrent
elegantentofculi candidi perquàm
intus nigris. Semen in folliculim furcum Lych fummo caliculus albus Ocimaftri,aut Lych-
nidis eft, cui hrent
elegantentofculi candidi perquàm
intus nigris. Semen in folliculim furcum Lych nidis, aut Ocimaftri.Salfo eft guftu, non tamé 7 . Th, infurui, efu tenera: non nifi inter filices \& Brafsicas marinas quà ferme vndxa all uunt enatam videas. Floret menfe Iunio, Iulio, Auguno, \& Scptembri.

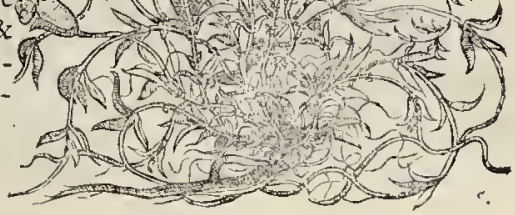

\section{IrCH NIS Ch̆alcedonica, fü Coilstartinopolitan aminiata.}

FA C I e harum pulcherrimam elegnntia prouocat, aut fuperat florum delicix planta Chalcedonia illa, cui florem Conitantinopolitanum nomen indiderunt.Huius ra-

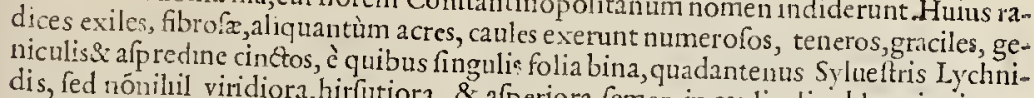
dis, fed nonililil viridiora, hirfutiora, \& a periora, femen in cauliculis oblongis nigrum purco, rutilo fulgentibus, viuidioribus, quàm in Martagone vel Cannesti, \& minio purquia inodores funt ifti coronarijomnes quam in Martagone vel Canna Indica, adeò ve merito hic Lychnis multò omnium pulcherrima fit habenda.

\section{OCI MO I D ES fine Ocimastrum. facea alba Monjpcl. Herba T unica Gordony.}

NON tantim propter foliorum cum Ocymo fimilitudinem, fed etiam adeóq; multò apt:us ob vires aduerfum viperinos norfus exploratas, cui maximè confert $\mathrm{O}$ cinimin, Ocimoides, ant Ocinaftrum vocaffe videntur. Cuius non parum plenè omnes cxplet notas ifta planta vulgatx cognitionis, qua nufquam non inter fegetes, \& viarun marginumg; gramina vberè luxuriar. Radix alba crafsitietu digiti æquans, tenera non-
nullis fibri fouffi : exiles rectofó, nonnihil hirfuros, nullis fibri fparfi: exiles rectofóp, nonnihil hirfutos, cubitales exerens caules, per interualla geniculos habentes, è quibus fingulis folia maiufcula Ocymi, aut Lychnidis fyl
ueftris hirfuta bina, \& plerumg; quaterna, nouis fuccrefcentibus binis pufillis, in fummo ternos, aut quaternos folliofos calyces ventriofos fupernè anguftos fert : vbi femen fuf, cum Pfeudomelanthij, Hores Lychnidis fylueftris albi.

\section{SPVMEVM Papamer vulgo, est Ocimaftrum alterum.}

X E c minore prouent u, nec alijslocis oritur hæc,vulgò Norbonenfum notifsima,

\& propter fpumeam fputeámue afperginem, qux non rarò albicans foliorum, \& Behen albusz geniculorum finibus infidet, fpumeum Papauer putata : fuperiori Ocimatto admo- Cor Polemonium
dum fimilis, cunctis fuip dum frmilis, cunctis fui partibus, fed caules leues nitidi hirfuta, ad Tunicem magis acce- Belgarum:nerdentia: vnde nonnullis practicis vt Gordonio, Tunica herba dieta, radix nec folia fractu trum tammera ve-
facilis, nitida \& pellucida magis. 
Dearciffur Virpilu e Columel- - alunt herbarij Belgx : radice tamen aliquantim crassiore, habitiore, \& inagis tereti

O N G If hacfloribus pulchriorem, alioguin folijs, caule, \& facie non ira difsimilen, leforté. $\quad$ què alba, odoratiore. Longiora,maioráq; aliquärò tum folia, tum caules funt. Flores verò creberrimi, elegantifsimi affatim in mufcarijs propendentibus, \& ex pufill is caliculis Valeriana rubra oblógis congeft, Valerianx partim, \& Iafmini.Vnde illî́ Valeriana Rubra vocatur. Purpura nanq; diluta nitent flores, Iunio cxeunte. Vnde etian Rubrum Behen vocitarunt idem:non nifi in hortis penfilibúfq; puluinis, \& figlinis enataın vidumus.

OCIMOIDES REPENS, Polmgonifolin, flore Sapontaria.

TO $\mathrm{N}$ modo Taurinenfium ad Padum collium vmbrofis, Syluofis, \& iuxta fapes lixe frequens oritur, fed etiam Seuenx Veganij herbidis, \& vmbrofis marginibus, fecus riuulos \& fuenta proxime Afarinam in faxorum commnifuris. Ecauliculis gracilibus, geniculati s, reptantibus, teneris, flexuofis Alfines maioris, folia exeunt bina, iuxta geniculos Olex fylueftris, Myrthi, aut Polygoni, ,ed paulò lationa. Flores ver ò in caliculis oblongis Saponarix concoloribus, multo minoribus : radix exilis, vfus hodie incomperti \& neģlectr.

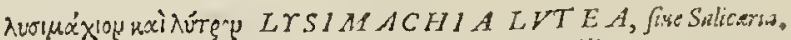
\{Gal. Perçe boffe. Soufy d'eaue.Corneille. $\{$ Ger. Geslabibrich.

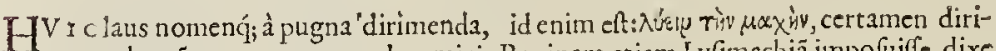
merevel pacë componere, quod nominis Reginam etiam Lyfimachiä inpofuiffe dixe runt. Eft tamen ea plantx vis, vr etiam belluarum animos feroces, \& mutuos hoftiles congreffus pacet. Faceret vtinam rerum arbitra, \& hera Proaidentia, ve quàn nota eft hodic lierba Lyfimachia, tam effer nobis copia illius coleftis Lyfimachix, quze eft Paracleti interpres, \&alumna pacis gratia, qua rabies, \& rerum humanarum æftus, atc; infania plufquä Cerberca, ad lenitatê perpetuumó; perennis annicitix feedus, teducerentur. Tametfi tres pofteritatis fedulitate animaduerfar funt Lyfimachiar fpecies, Diofcoridi indictz, tamé vix vlla carü vfu hactenus recepta fuit. Eapropter lutea notifsima, vfúq; frequentior. Mefsibus flores lutcos elegantia vifendos, in ramulis, Hypericonis modo edit, inodoros, multos, cófertos, folia auté frondis Salignex, aut $P$ erficarix, pallentia, in caule bicubitali patum angulofo, geniculato, quaterna ternać; fibi ex aduerfo fita. Radix cépire vagatur, la . tius fparfa, editó; teneram fobolem purpurafentium turionum. Semen rotundum Coriandri, pallhdum. Marginibus hac \& ripis minuswvdis, atq; merfis, quàn reliqua tres aquaticx. Vbiq; Anglix, Gallia, Germanix, peruia, quä Officinx nultam ad gargarifmata, \&c

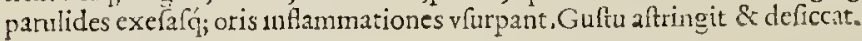

\section{LYSI M ACHI I E furt' Tliniane.}

SV N т qui Plinio mentionatum Lyfinachiam diuerfam illi fpecie arbiträtur, quippe qui

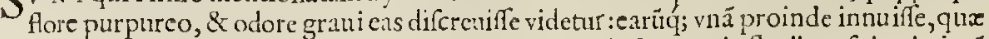
nufquä emerfá confpiciuntur:è riuulis pigris, \& palludof ts lacunis, loribus, fpicatis, inté fè purpureis, palmuın \& fefquipalmü longis, è Sertis purpureis femine conclufo in anguftum deficientibus, Viticis aut Lautendula ritu.Caules geniculatos, \& folia Lute $\approx$ fimilia, aut Salicis anguftirohx funt, ex interuallis bina fubpurpurea. Radix maior quàm Lutex, \& fimiliter turiones, quotannis tencros promés, lignofa, nigticans:nó tamể odore tetro. Quare tameți non magni noftra referat cuia fit $P$ linianáne an Diofcoridea, tamen fubo-

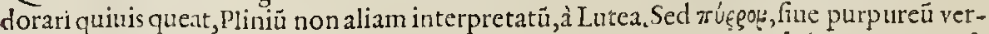
tiffe, aut wóppupos legilfe:\& graucm odorem habere, quod quando adoletur, verum afferit Diofcorides. 


\section{$S T I R \mathcal{P} I V M$ aduerfarianoua. Lr S I ACHI A Siliquofa, Filius axte patrom.}

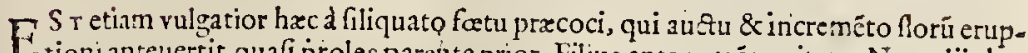
E. tioni anteuertit, quafi proles parente prior, Filius ante patrē vocitata. Non aliis hẹce natalibus, fed multồ vberiore \& variato prouentu oriunda,caule \& foliis hàud diuerfa, nifi quia anguftiora \& leuiter crenata. Flofculos foliolis quaternis conftantes purpureos, pitulos: Geranii colúbini, quibus quafi caliculus foret, fub funt teretia exilia \& longiufcula cornicula, que femine perquàn minuto Conizę, aut Dentis leonis, vnà cum pappofis inuolucris, dum filiqux hialc $x$ \& bifid $x$ difparantur,perduntur,

H $\mathrm{H}_{\mathrm{O} \text { I }}$ s filii ante patrem in Bel gio, fed in Anglia facillimè,variet2s duplex obferuatur, non iifdem tamen locis femper, attamen vmbrofis, faxofis, aut minus vdıs. Frequentior eft omnino folio, filiqua, caule iifdem, fed magnitu-

Variets $\left\{\begin{array}{l}\text { dine inferior, \& tenera adeò,ve vix filiquam forénıq; fulcire queat. Flos verò } \\ \text { propius Caryophylleam Tunicã dietam, paulò ninorem, rubeum exprimit. }\end{array}\right.$

A L T E R a varietas cernitur in floribus, pallidioribus, quadripartitis, anguftionbus foliolis, ex aduerfa cruciatim, aut decuffatim afsitis, in parli fin Liqua, cui catera omnia fubfunt fimilia.

\section{LXSIM ACHIA CARVLEA borrenfis, Veronices RECT A guorundsim.}

E Thrc non abfimilis folio, Filii ante $P$ atrem, aut maioris Veronicx, fed longiore, craffiore, fed tota ninor, cubitum \& pedem al ta, \& quafi exvtraque Lyfimachia mixta: ramulos in fummo fpicatus, floribus cocruleis, nitidis Teucrii, Germandrex, aut Lauelldulx longioribus: pluribus exiguis marfupiol is contentum fẹmen minutum: exigua \& fibrofa radice nititur. Rarior hæc etiam hortis:Londini hoc anno Iunio \& Iulio floruit in horto H.Morgani noftri:Belgicis etiam fyluis dicitur crefcere fponte. Parcior,aut ra, rior harum omnium vfus, pręter quàın Lutex, vti dictum.

\section{CONIZA MINIMA fime Pulicaria:}

I quadruplici differentia eft Coniza, quarum Media \& Minima vbiuis'Gallix, Ger1 manix, \& Anglix locis lacuftribus, \& humentibus aruis multa. In Benardgregn ara \& fofsis, altcro à Londino lapide fruticat minima, inter Camęrmillam Romanam, inter \& Pulgiun Regate : fefquipalmum caulibus fuperat, multis alis donatis, hirfutis, pul. Iis vel cineritiis, rotundis, rigidiufculis,quos folia àmbiüt ab imo crebra, incana, S. Phyli Thelegoni fermè paria,aut Gnaphalii vulgaris, quem habitu \& colore tota refert, fed maiora multò \& obfcuriore ob foletioréque lanugine. Flores rotundi, bullis Agerati vel Tanaceri, fed minus vegeto colore \& cóprefsi, quibus elapfis fermen fubeft Anthcmidis, acerofum ninntü: exigua lignofáq; radice, minime omnium hac glutinofa, minúfque quàm Media foetida, quam dumtaxat veftigio olido ţefțatur,

\section{$M E D I A$.}

EO D : M loci fecus Regiam viã atq; humentes fcrobes, Media illi prorfum fimilis, fed duplò maioribus fol lis, crafsis, denfis, virentibus, apperis, rigidis, fquallidis, caulë bicubitáé \& alas multas ambientibus, ima falcata, bafi Glafti Dentillarięúe modo. Radiatis floribus, luteis, Chry fanthemi, aut Buphthalmi,femen haud difsimile, radix pufilla, halitum virofum, \& quiddam Cimicum, aut foetidę Cotulx eflat.Parum autminus mu!tò quàm maior, \& minor glutinofa.

\section{CONIZA MAIOR Vera,}

$S$ Ev maior tẹpidiore Auftrinóq; ccolo \& aëre maritimo oblętatur, cuiufmodi elt Hetrus-

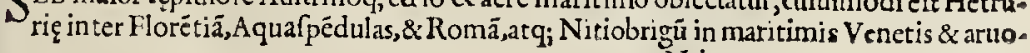
N.i. rum mas - 
Yxarginibus Lunelle, Marsilit ges, Mófpellı. Binú trinúnue cubitorum frutex, multis propagatur virgultis, reetis, rigidis, rotundis, foliis multis cohærentibus, denfis, ex viridi pallentibus,crafsis, pin guibus, Olcx fimilibus, ant Afteri attici Italici. Extremi caules nultis ornãtur fecundủ lógitudiné floribus, Luteis, rotundis, Hieracij, aut Senecionis, in pappos euolantibus: nec non femen exiguu, vt Hieracii: radix lignora, fibrofa. Prxftatior cateris mul tò hxc,cùn odore vehementer fuaui, tú viribus, necminus Ledo Chifto olutinora tangenti, cuius odorem, fed cum ca quam mediam iam delcripfimus, nónihil confufum imitatur, adeò ve omnes norit,qui ambas, mediä nem pè \& iltă nouerit. Adeò funt inter fe coufimiles, \& Diof coridis lineamentis affabrè bellè congruentes.

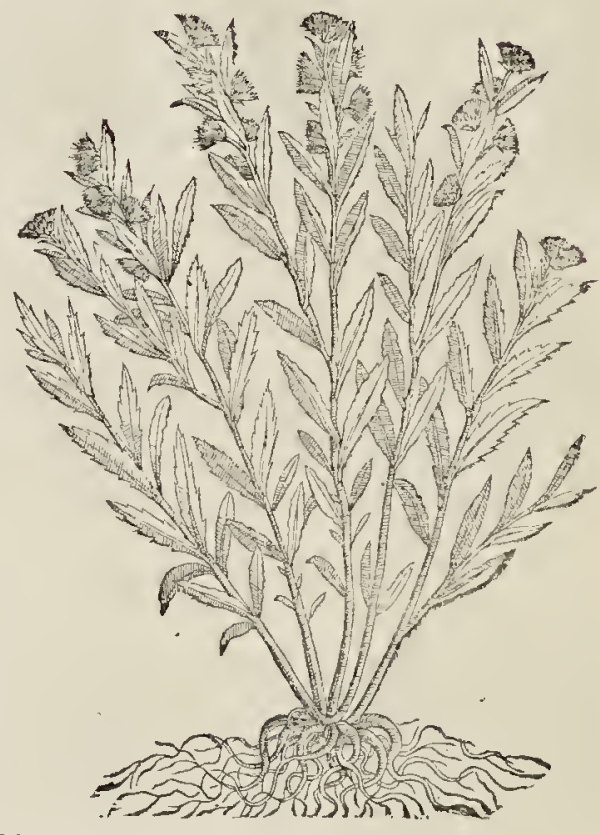

\section{CONIZA MINOR Vera.}

HV r ctamen præcæerisafsimilatur natalibus, viribus, odore \& facie, quam minore Dofcoridis aftruemus. Qux prorfus eadé foret, nifi proceritate \& caulium luxuria viticeretur. Vnico fed enim eft vtplurimum caule, gr.cili, cubitali \& fefquicubitali, paucioribus, ninoribúqque foliis Lynarix, vel Chift Ledi anguftifolii:color, odo:, modus, femen, tum illis, tum florbus, haud diuerfa:radix exigua. Gramuntix fylue fintimis agris, hanc non modó, fed etiam publica via maiore, in deprersis Sylue lacunis minimam, non femel,

Conifamior Pulegii Ceruini conuigricé, legimus : Mediam AI stbiolo fallo verò palsim vbique locis vdis, fic inubi omnes tratit:. fudiofis paulò exercitatioribus iamdiu notx: quibus rifui fuit Senenfis audix commentum, Aronpell. Bac- qui longe diuerfam, vti in Baccharide dictum, caris.

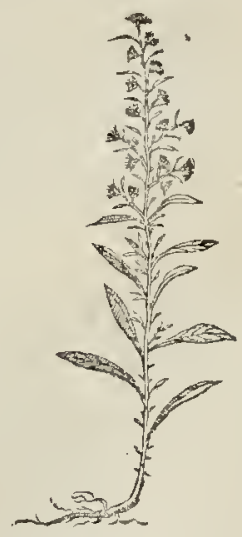
plantam, Nullis reclam,antibus, vt ille femper affirmat (vti nos híc omnibus aduerfantibus)notis, intrufit huc. Parum certè illi notam, \& quod minus fcrendum, nō defcriptā. Spirat huius nãque radix odorem, non tetrum, fed arromaticú Garryophylleum. Caule, \& foliis Verbafci, aut Blattarix non Olex, glutinis nihil pentus habentibus. Flores ex luteo purpurafcentes: cætera etian planè dirsimilia, multò magis viribus : quare nunquám Senenfis dignitas noftratibus mulierc: lis Galloprouincix perfuadebit, vt fcopas euifcandis, \& enecandis pulicibus,cx. Baccharide potius quàn valgata illic Pullicaria colligant. 


\section{$S T I R P I V M$ adudrarianoud.}

ASTER, fue STELLA ATTICA Monpellionfinm, amrofiore.

A T T I C A flellix nomen, fi non à flore, fed à foliolis forem in fella morcm cingentibus, fictum fuit, ve Diofcorides videtur exprefsife : inon alian hodic plantam comgro, prope pratorum margines, \&onfpellicinfum Aferem vocatam inibi Noibonenfi areum, circinatx, fed comprefr $x$, nee admodum perfaniliale. Florem etenim edit altate auaut Cliryfanthemi, quen ambiuce admodum extuberantis rotunditatis, Buphthalmi giufcula, Stellam marinam pifcem, quina fenáue foliola angufta, mucronata, rigida, lon ni, duri, lirfuti, qubus totis infunt folia obum referentia:caules pedales terni aut quater oris, pilofa rigidiufeula, viridia in fulla obloga Lychnidis aut Verbafci Saluifolix tenuigente, amaricante, non acri,nec ita ing a bo cura. Radice capillofa, fparfi. Sapore aftrittembri in Francix, Belgij, Germanix \& Ato. Semine anthemidis Augufto naturis vel Seppurafcunt quibufdam 111 locis florum foliog hortis. Nam ruxi illis non pronenit, Pur-

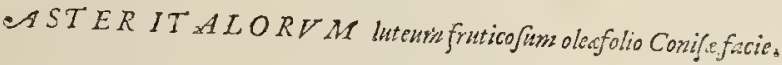

ES $\mathrm{I}$ cifud non modò Italia faxoris \& aridis valdè frequens, fed etiam Galloprouncix Norbone,prafertim via Aucnione Nemanfum petenti ad læuam, inter Anguvocati eximia monument; menifentix rudera, ruinofać; triplicis fornicis pont is Gairl amne!n ad pontem. Virgultis nuamplurimis duriorib, \&ecus Lantm Monf pellicum quipedalibus: folia Olca Conifa, yel Myrthi durioribus, nigricantibus, pedalibus, \& ferteo,pappofo circinato foumulis acerof foris fioris, aut potius Conifa facie \& flore. Lut guftus vnituer $x$ fubaftingentis \& ficcantis for fepto, in Iacea morem. Fibrofa radice, commodi hactenus incerti. Incertumá fits parun quid anmarooris arrcinatici \& odori: meli veri, neq; Diofcoridis Afteris opinitne A melus Virgilij. Videtur cquidem neq; Ajpfas, \& vtriufg; authoris lectioni dicat liquet.

$$
\text { CASTER CMINOR Norbonenfum tripoly flore, Lynaria folio }
$$

NI s i hic (non in pratis) locis aridis \& collibus faxofis prouenirct, vt funt Oliuera

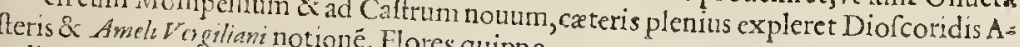
radiatim invltis galiani notioné. Flores quippe purpureó purpureoq; mixto fulgore micantes Tripolij. teo Diolcorid prigitur aliquid purpurci luteo immix tum, vt videre eft quando dicit,forti partem purpuream bubonis pięfidio effe, Sic eninivertendim elt, \& vertit dostifsimus Marcellus. In gracilibus virgis, numerofis, rectis, pedalibus \& fefquipedalibus ab vno radicis fibrofx cefpite:foliola oblonga, anguftiona quàn fuperiorum, Lynariam referentia. Similis tota, fed minor \& gracilior Tripolio, guod A M EI. $\mathrm{V} M$ I irgilionum fignantius exprinit, non modo quia fecus fluenta \& pratorum riguorum contalles amoniores, vt padi, fitie famigeratif fimi Eridani prope Ferrariã, Patauiū, \& palsim in Lombardia : fed etiā quia tü forü \& foliorü, tü cauliü fuperficics, interdü cx virore purpuraf
cứt,fpeciofamó; radiantium Stellarum in lutco

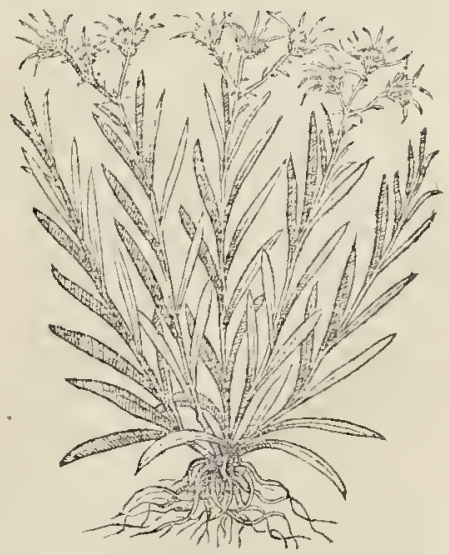
AST ER CMONTANIS duplexpregrandi Heleni flore. N.ij, 


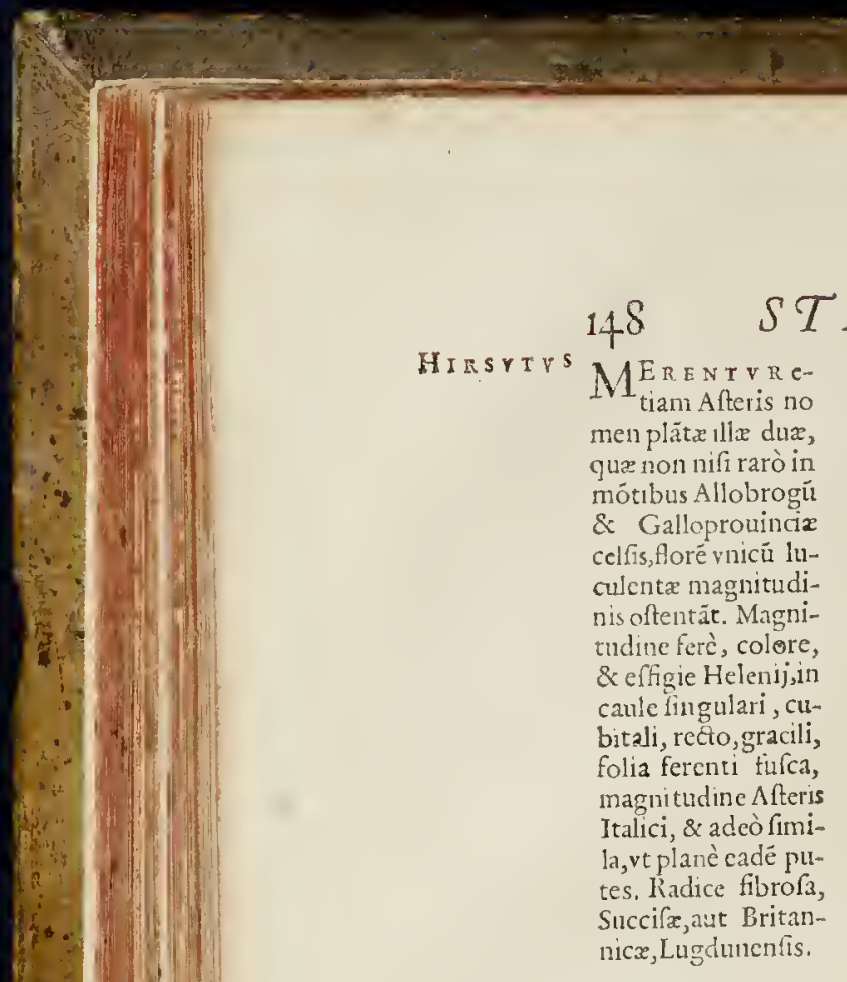

\section{STIRP IV $M$ aduerfaria noua.}
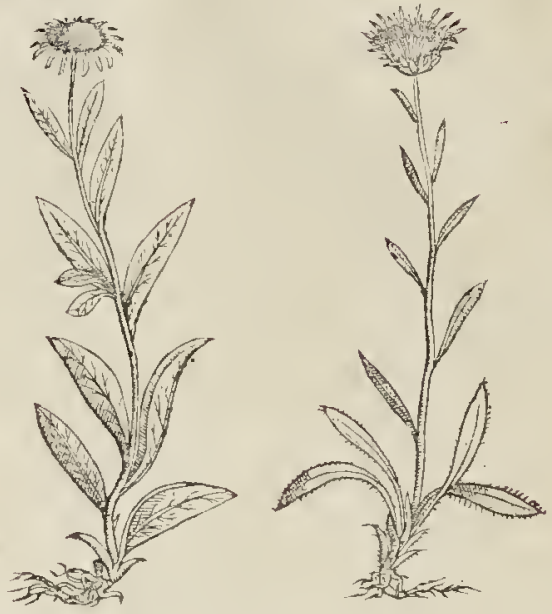

Alser folio of caule birytir.

A Lter proceritate, \& flore non abfimilis, fed caule, \& folijs hirfutis, longioribus, Cynoglofsi noftri parui paribus, \& fimilibus: radice verò minus fibrofa.

\section{GLASTVM Satiusm.}

$H^{V x}$ v s fatiui \& longè omnium optimi immenfi tractus confiti Tholofana mitant Efj.Ma.634. Hegionem, vbi virens herba Guede : tabefacta autem \& putrefacta, inq; mola tru-
fatili espicfla herbacca fanies, in prxgrandes glebas aceruatur, \& Pastolvernaculè voca

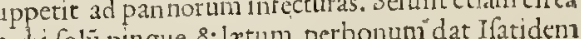
Infulas Belgij vrbem, \& in Germania vbi folú pingue, $\&$ l $x$ tum, perbonum dat ifatem necinultum Tholofana inferiorem. In Italia minus frequens, eoq; minus mirum ir doEus. Anguillara fe noffe neratit, \& aliam Norbonenfem fylueftris Glafti fpeciem, pro fatiuo Glafto defcripferit: quam nefcio cur Lodoneus Vaccariam vocarit, cum apud nos

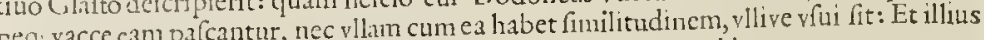
confuicua differe titin ab vtroq; Glafto, quibus tamen congener videtur.

Grium infecturx commendarione vbig, notum eft. Aruis pinguibus erifur quotannis, exitóf; folijs ab ino totos caules cubitales \& bicubitales rectos ftipantibus, crassis, pinguibus, anguftis, atrocaruleis aut virétibus Cynogloli, aut Thlafpi latifoliz effigie liarentibui,in fummis ramulis numerofis, Maio men/e, \& Iunio flores lutei, pallidi, aumcrofi exemt, fecundum quos thecul $x$ ccmpreff $x$, acut $x$ in lingux figuram $e-$ P emen maturane nigricans. Radix albicat, non altè depacta.

$$
\text { GLASTV M fise IS AT IS Syluestris. }
$$

Matb.535.

SY L V E S T R I s fegetibus obeft, \& multò procerius priore luxuriat, folijs Endiuiam i-

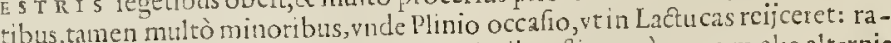
dice exiglia, caule lignofo, tceto, ab imo folijs compluibus fipato, è quorum alis alternis nterua is propaganturfores, fed in funmo multiplici conferti, melino diluto colore. Galloprouincix plebeculæ coronaria eft.

IS AT IS fyluostris Ocimulistricaliculo, fore exiguo pallido, Vaccaria dicta Norbo.

SY L Y EST I I a utem fue Vaccaria, \& Ocimoides diEtaimportnno prouentu Triticen feretion folia promés, quàm frlueltris Iftis, Ocinaftri, fiue papaucris foumci funilia, rarion, in caule cubitali alis forfo, \& or nato floribus pufillis Ocinaftri, aut Pfoudomelanthij, alabaftriculis albids, \&i pallentibus, nec fomine difpari: non vllius adhuc commodi comperti. 


\section{STIRPIVM äduerfarianous.}

LVTEOLA.

MA a o vfui \&emolumento eft Luteola, recentioribus tantùm cognita, ad colorem fuluum aureúmue pannis conciliandú valde expetita, prefertim in Belgio, vbi magua copia: tameti aliis ctiam pleríque locis Galliz, \& Anglia ruderibus, \& \& femitibus occurrat. Hæc tertia Glafti fpecies conttitui recte poteft :radix oblonga, folia habitiora, Ifatidis figura, fed anguftiora, fufco virore, caula reto, féfquicubitali, Thyrfum mufcofum gerit, ex multis fofculis, lutcolis, pallefcentibus, Olex fimilitudine, \& magntudiae, decuffatim explicatis: Semen nigrum, Vrticr Romanx, fed minus.

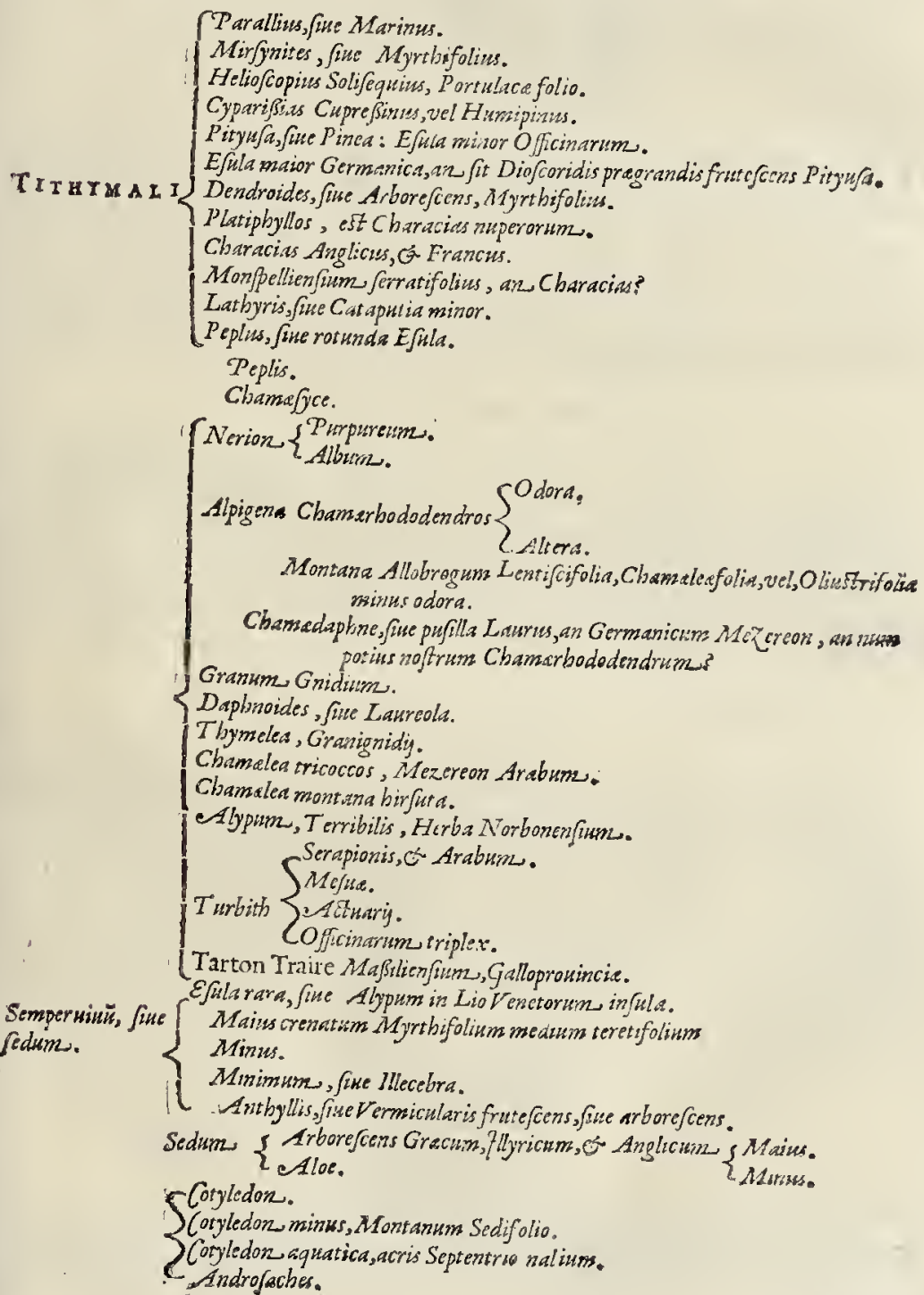




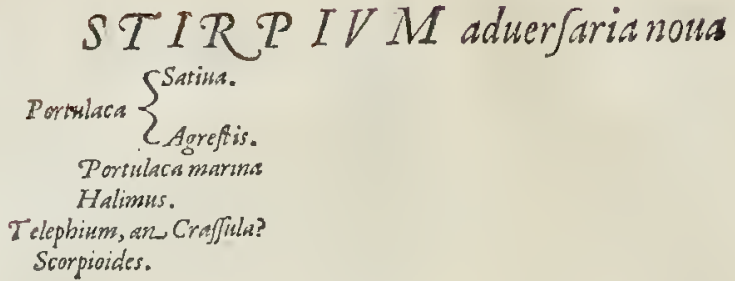

$\tau I T H Y M A L I$.

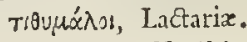

Germa. Doolfynilch.

Galls. Tithymales, ou Herbe au laiet.

$\{$ Belg. moollsurclek.

A Svecolacteo quo turgerent differentix cítę, nomen factum cômune Tithymalis, vel per diphtongü potius, Tithoimalis, quod mammä, fute papillă vberis exitiofan virofánue non infcite interprxtatur. Plures hodie quam apud Diofcoridern extent, habeinus; quarum partin confufas à Comentatore, nec verbis defignatias, partim affictas orationi non intellect $x$ Diofcoridis, quamlibet fins indicis illuftrabimus, \& paucis emendabimus: Diofcoridis oratione quafi filo Ariadnx du\&t, fed nofrum ordinem fequuti, accuratiorénque ex infpectione defcriptionem:quò quxlibet planta cui prox pils quadret, Magis perfpicuum fiat. $P$ aralium primum ponemus.

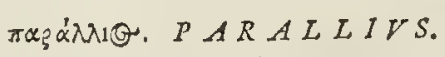

P. $\mathrm{R}$ A I I I os fue hac maritima appellata nufpiam hic nifi fabulofo fterilíque littorum folo Mediterranei, Occidui, \& Germanici maris, vbi quäplurima exit, virgis à radice, re \&is rubelis, taztui glutinofis, foliir denfêftipätibus, fubnigris, Lino latioribns, Alypi terribilis paribus, \& fimilibus. Flofculs ex herbaceo luteolis in fummis pediculis circinata foliola media traiicientibus, ficćue vinbellam efformantibus \& fenen edentibus tricoccum, Ch?nılex, aut Latirid s non difsimile, minis \& contetus:intus medullofa tria grana funt vcrucarix Tornelolis : radice fimplici,prolixa, lignofa.

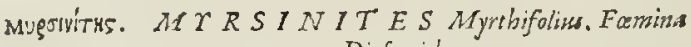
repens Diofcarid.

PRox I a a illifaciehrc, fed breuioribus pedalibus, piuguoribus, reptat humi furculis, quos folia prorfum Chamzlex latiora, Myrthi, vel Rufci,mucronata crebra ftipant, ve Paralium,pallidè virentia, \& in fummo magis fparfa Sedi maioris, aut Iatureolæ ambitu, è quo trans folia concaua \& vmbilicata, difparantur quaterni, aut quini pediculi Inuio \& Iulio, floles luteos, herbaceos, pufillos, mufcofos geftät, \& fenma tri quetra Paralii Augufto maturant, maiora, qua itidem tribus compacta lateribus, in tricarinas valuulas dehifcunt, fingulas fingulum granum, teres, oblungum, fufcum : medulla alba acri non ingrata. Anglix, Belgix, \& Francix horti hunc fxpius alunt: 11ec alibi natum vidinus.

HAvonon!O. Helisfopirs. T ITH H $M A L V S$, Solife. quins Portulacifolius.

Germ. Gonnewende walfymelct.

Gallis. Reucille matin fuiuant le Soleil.

Belgis. Croouthens clutut.

ang. Wertgrafje, cowerworte.

CVnc Is gentibus familiaris híc \& notior, foliis Portulacz minus crafsis, Halime breuioribus, ambitu nonnihil crenato vt nolter Charatias, caules naruos pedales in burnuga 


\section{STIRT IV $M$ adwerfarianona.}

humut flexos, quaternos \& quinos, rubellos, cingentibus floribus ex luteo in pallidú languentibus, inque vmbellam collętis, ienine non diuerfo: fed Norbonx, vbi maturuerit plenè,adeo fpiritu vapido tırget, vtı foli relıctum, quafi fe motaret, exilıat, mediüque crepet; pueris raro fpectaculo elt, quemadmodum Thamarifci femen.

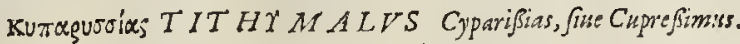 vel Humipinus.}

A P r I M referunt huius denfi ramuli rubëtes, fefquipalmares, pofitu ortu, effigie,2en A quabili circinatóq; habitu pufillã Cupreflum: folia auté ariguftiora, longiora, \& mültò quam Chamzlea, aut Thymęlea, Pino propiora, molliora : femine alioqui in fummitatibus, pixidata foliola trấfmistentibus, nec à fuperioris, nifi quia minora funt, diuerfis: vicinioribus tamen $\mathcal{P}$ arallio Tithymalo, \& Pituife. Crepidines fabulofę flumunu, \& vici- - llo fromentius hane alunt, vti funt Ligeris ad Aureliam, Btturiges Gallix , \& pellio, alibíque pafsim Maio, \& Iunio, quuni interdum errores albent folia, \& minor tota reperitur, etiam in Leúctiam totum habenus Parallium, \& Amygdaloidem

\section{ir $A$, fue Pinea, Offici. Efula minor.}

1 Tithymalus, nomine \& facie, viribus, natalibus, \& foliis alleret afstmilatio, Dio?corides diuerfas effe fpecies movideri poffet nna quæpian Cyparifsię Tithymali varieamen hic non vnituerfum habitum, \& lineamenta Plante, adit. Quare conie tura fert verifimilior, Pityufam efle la minote, qux etiam Efule vox, quafi abfcifa a Pityufula, r. Palsímque cognofcitur, cum Linarix collatione, de ver- Efule Laitefit, fine lizto Linariacrefoit.

us, $p=d$ : \& cubito maioribus, per interualla dilparia Tolyauciora prométibus, Ofyridis, fiue Linarix, longis, acutis, tm qum Cyparifo propinquioribus : cui etiam flofculi a theca eadem:radix digitum minimü xquat,albicâs, cuius ru'o lignco exiteratus vfui Officinis, nec fructui eft lentis scoridushabet, cui potius mendum fubeffe fufspicamur, m fufiragante \& monente perpenfione: \& fane aut nullum prorfum noftratium \&uy w. aloum (quo um omnium inter ipfos eadem, \& triquetra pericarpia, fiue inuolucra funt, ) fuitillis notü, vel defcriptum, aut amanuenfum incuria (nolim Dicfcoridis) temerata fuit, luxatáq:le ahig tnot locis germana lectio: vt mox fufus monemus: hinc fimul ailendx, fimul pudend $x$ Commentatoris commenticix, Tithymali, $P$ arali, \& Mirfynitidis efigiature, quas non c̀ plantis ipfis expinxit, fed vti in Antirrhnifloribus, Trąacanthi fruétu, \& capitulo Gnaphali marini, Poterio; atọ́; quáplurimis aliis locis, plaufibilis iconis mendacio, polteritatis theatro illufit; ex quo exercitatifsimo cuíque, \& cordatifsimo viro furpicionem fecit, \& fout meritò, non vno loco fidei classiciauthoris illum fregiffe tefferam,necilli deinceps, nifi benè re perpenfa, in medicatoria pollicitatione credendum. Pratorum margines, \& fepium, iftam frpiug alunt Efulam. In Francia, Belgio, \& Anglia, non nif horti Pharmacopoorum,

\section{ESVLA maior Germanica, en fot Diofcoridis preagrandis frutefcens Tityufa?}

$V^{T}$ vfu crcbro apud Germanos, \& Belgas Pharmacopcos hæc recepta eft, Efula maior, fic fanè nulli Tithymali fpeciei quam $P$ ityufx propior videtur, $\&$ alioqui nifi huc acN.iiij. com? 


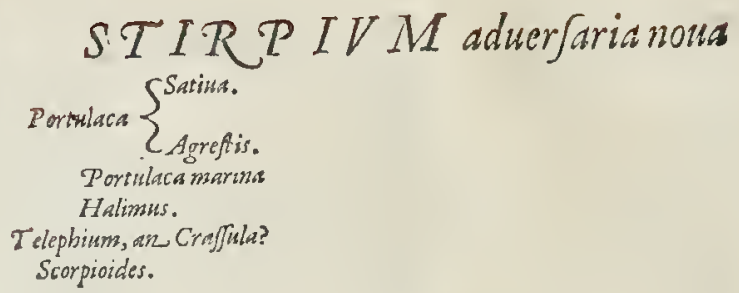

TITH $M A L Y$. төงนúx si, Lactarix.

Germa. Dolfyunilch.

SGalls. Tithymales, ou Herbe au laie.

$\{$ Belg. noolfisucles.

C.Ang. Wilde fpurge.

A 5 vecolacteo quo turgerent differentix cüs TITHY MALVS Myrgites. I 50 vel per diphtongũ potius, Tithoimalis, quod virofámue non inlcitè interprxtatur. Plures hoc habemus; quarum partim confufas à Comentat Etas orationi non intellect $x$ Diofcoridis, quamli emendabimus: Diofcoridis oratione quafi filo fequuti, accuratiorémque ex infpectione defori pius quadret, Magis perfpicuum fiat. Paralium $p$

$$
\pi \propto \rho \alpha \lambda \lambda 1 O . P A R
$$

PA $\mathrm{x}$ A I I $\mathrm{r}$ o sfue hrc maritima appellata torum folo Mediterranei, Occidui, \& Germa radice, re Ais rubellis, ta:ui glutinofis, foliir denf Alypi terribilis paribus, \& fimilibus. Flofculs ex circinata foliola media traiicientibus, ficáue vi cibus tricoccum, Chmmxlex, aut Latiridis non di lofa tria grana funt vernucariz Tornelolis : radis

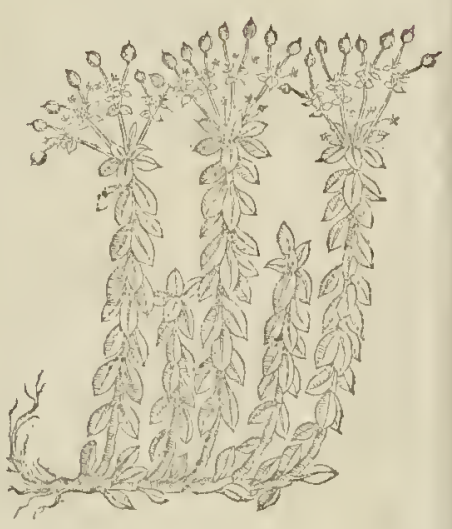

MขgsiviTHS. TIRSINITE:

repens Diofcors

PRox I M a illi facie hæc, fed brenioribus pedalibus, pinguioribus, reptat humi Purculis, quos folia prorfum Chamalex latiora, Myrthi, vel Rufci,mucronata crebraftipant, vt Paralium, pallidè virentia, \& in fummo magis fparfa Sedi mioris, aut Inurcolx ambitu, è quo trans folia concaua \& vmbilicata, difparantur quaterui, a ut quini pediculi Iunio \& Iulio, thores luteos, herbaceos, pufillos, nuicofos geftät, \& femina tri quetra Paralii Austifto maturant, maiora, qua itidem tribus compacta lateribus, in tricarinas valuulas dehifcunt, fingulas fingulum gr:num, teres, oblingum, finfum : medulla alba acri non ingtati. Anglix, Belgix, \& Francix horti hunc fxpius alunt : nec alibi natum vidimus.

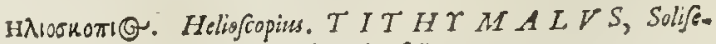
quius Portulacifolius.

Germ. Sonnewende wolfymelcF.

SGallis. Reucille matin fuiuant le Soleil.

Belgis. Croonitens contet.

esing. Wertgraje, cowerworte.

CVNC T Is gentibus familiaris hic \& notior, foliis Portulacz minus crafsis, Halim breuioribus, ambitu nonnihil crenato vt nolter Charatias, sules paruos pedales in humuga 


\section{STIR P IV M adwerfarianona.}

humut flexos, quaternos \& quinos, rubellos, cingentibus floribus ex luteo in pallidú. languentibus, inq́u vmbellan collectis, lemine noul diuerfo: fed Norbonx, vbi maturuerit plenè,adeo fpiritu vapido tırget, vtı foli relıctum, quafi fe motaret, exilıt, mediüque crepet; pueris raro fpęaculo eit, quemadmodum Thamarifci femen. Kumaguroixs TITHY MALVS Cyparißias, fime Cupresimuss.
vel Humipinus.

P P I M E referunt huius denfi ramuli rubötes, féquipalmares, pofitu ortu, effigie, 2: A quabili circinatóq; habitu pufillä Cupreffum folia auté arguftiora, longiora, \& mițtò quam Chamælea, aut Thymęlca, Pino propiora, molliora : Semine alioqui in fummitatibus, pixidata foltol trä́rnisten tibus, nec à fuperioris, nifi quia minora funt, diuerfis: vicinioribus tanen $P$ Parallio Tithymalo, \& Pituife. Crepidines fabulofe flummun, \& vicini colles frxquentius hane alunt, vti funt Ligeris ad Aureliam, Buturiges Gallix , \& Norbona Lani, non procul Monfpellio, alibíque pafsim Maio, \& I Iunio, quun interdum propter anni \& loci rigores, vel feruores al bent folia, \& minor tota reperitur, etiam in maritimis:çucmadmodum caruleü ctiam totum habenus Parallium, \& Amygdaloidem fanguineum.

nurissoe PITXVSA, fue Pinea, Offici. Efula minor.

Ir I I A D о affinis hæc Pinea Tithymalus, nomine \& facic, viribus, natalibus, \& foliis

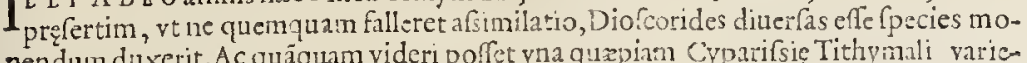
nendum duxerit.Ac quâquam videri poffet vna quxpian Cyparifsic Tithymali varietas, quales aliquot notauimus, tamen hîc non vniuarum labitum, \& lineamenta Plantę, fed dumtaxat folia Picex effe tradit. Quare coniefura fert verifimilior, $p$ ityulam effe candem cum Officinarum Efula minore, qua etiam Efulę vox, quafi abfífa à Pityulula, nempe $P$ ityufa minore videtur. Pafsímque co z of citur, cum Iiarrix collatione, de verfificatoris carminulo rithmico. Efula Lautefcit, fine luste Linaria crefcit.

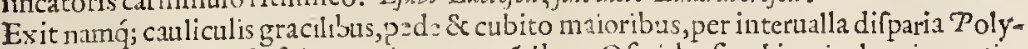
goni mo:e,ramulos, ¿ Eolia paiciora prométibus, Ofyridis, fipe Linaria, longis, acutis, anguftis, \& nuili Tithymaloru:n quan Cyparifo propinquioribus : cui etiam flofculi prorfus, \&e feninum triquetra theca eadem: radis: digitum minimü xquat, albicăs, cuius cortex ace to maceratus, \& torulo ligneo exi teratus vfui Officinis, nec fructui eft lentis forgu, cuilinodicodex Diofco:idis habet, cui potius mendum fubeffe fufspicamur, quàm fandum putamus, reerm fufragnte \& monente perpenfione:\& fane aut nullum prorfam noftratum Tithymaloram (y:o um omnium inter ipfos eadem, \& triquetra pericarpia, fiue inuolucra funt, fuit illis notī, vel defcrip tum, aut amanuenfium incuria (nolim Dicfcoridis) temerata fuit, luxatáque aliğtot locis germana lectio: vt mox fufus monemus: hinc fimul ri.tendx, frmul pudend $x$ Commentatoris commenticix, Tithymali, Paral i, \& Mirfynitidis cfigiaturx, quas non è plantis iplis expinxit, fed vti in Antirrhınifloribus, Tragacanthi frustu, \& capitulo Gnaphali marini, Poterio; atớ; quãplurimis aliis locis, plaufibilis iconis mendacio, polteritatis theatro illufit; ex quo exercitatifsimo cuíque, \& cordatifsimo viro fufpicionem fecit, \& fout meritò, non vno loco fidei clafsici atichoris illum fregiffe tefferam, necilli deinceps, nifi benè re perpenfa, in medicatoria pollicitatione credendum. Pratorum margines, \& fepium, iftam fxpiug alunt Efulam. In Francia, Belgio, \& Anglia, non nifi hotti Pharmacopoeorum,

\section{ESVI. A macior Germanica, an fit Diofcoridis pregrandis frutefcens Tityufa?}

$V^{T}$ vfu crebro apud Germanos, \& Belgas Pharmacopocos hæc recepta eft, Elula maior, fic fanè nulli Tithymali fpeciei quam $P$ ityufe propior videtur, $\&$ alioqui nifi huc acN.iiij. corn: 
commodetur, Diofcoridi, art minusno. ta, aut praternití fusc. Ex ampla multíque adnatis inplesa radice, craflo, dcnföy; pullo incice amitza, innumera furriginntur virsultá, minimü digitú cralfa, \& binü cubitorum proceritate viridātia, folia fercnia Latyridis crebra, aut arborefcentis Tithymali, nec femine diffimili:fed partim fecundú caulis \& foliorú interualla, partim in vmbella, fed minus lata, \& minus in orbem collecta, cxtera non difsident à reliquis Tithymalis. Verùm rarior hxc in Italia \& Gallia, \& Anglia, nifi in hortis colatur. Germaniz verò fuperioris, \& inferioris ad Rhenum?.

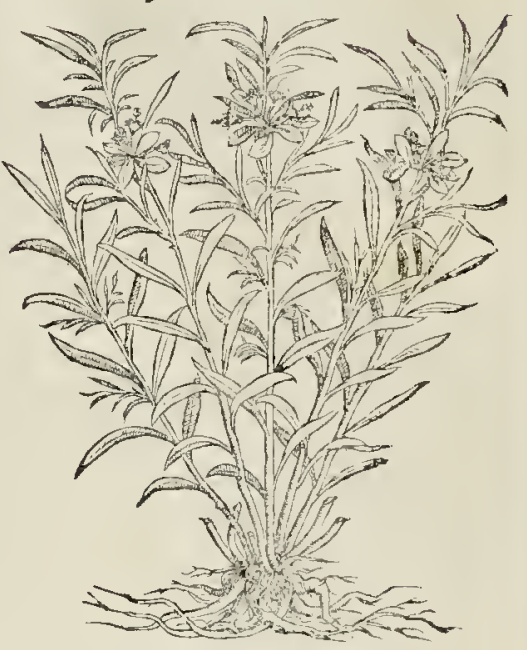

\section{$D E N D R O I D E S$, fue arboreus Myrthifolisu, Myrebei Becie non a folsis, fed frutico:}

CA I D I o r I s foli collibus apricis, \& faxeis, flue afperis, fecus fuenta Norbone, Hetruriz Romanixque prouenit Arboris zmu!atione, ab vno ftipite pollicis crạfitic, plurcs einitit amos,amplos, bicubitales, digitú craftos, Efule maioris folia paria \& admoglum fimiia, veluti cuneta planta:quan radix exilior, ftipes crafsior, \& vmbelIa maior, ab Efula maiore diftinguit: vti etram arboreus vultus, quem hæc præfert, vnde illi nomen.

\section{PLAT IPHXLLON Characias Mathioli, Vullaris.}

POs т e quàm habemus plures, quàm quot Diofcoridiannumerato fint Tithyma: lorum fpccies, \& huic præ cæteris folia inefle latiora, vt Plinto ctian vifum, ad Violx albę, \& minimi Sylueftris verbafci accedentia, fimilitudine, ortu, \& 2 parilitate, videmur tutò affrmaturi, latifoliun hunc Tithymalum dicioporterc : \& pirfertim cùm duos infuper finus nacti, quos fi nouifet Commentator, Characiâ fecifet, nolq́ac hoc labore lcuafiet. Qnem igitur Characiam noftra ętatc fcriptores putant, nos Platiphyllum opinamur, quemamodum Platiply'llon Iteam, fiue Salicem appellant illi. Eft namque latioribus, longioribus cxterarum foliis, ramis fefquicubitum \& duos altis, alióquin Dendroidi, aut Pityufz maiori afsimilatur. In Norbonx Galloprouincix, Lugdunen fiq́; prafe fura , ac aliis quàmplurimis Gallix, \& Germanix fyluofis, \& fiuentum rupis, nihil frequentius. Floret, Maio \& Iunio, vnicaulis, vt plurimum hîc:eóque Dendroidi cognatior.

\section{$C H A R A C I$ A $S$ Anglicus of Francks.}

HI c almodum fimilis Platiphyllo, fed minor caule, \& foliis. Frequentior etiä in Ger. manis, S Francire Aurelia vicinis frluofis, quàm calidiori folo: Nullibi quàm in $\mathrm{An}$ slia copiofior. Frimo Vere floret, cauléfquc complures à radice lionofa, fufca, rubentes enittit. In quibus folia multò minora, purpurantia Amygdalina frond is effigic, Paralij maira. Lntefcente folculorum fotura, \& paritura, per Iunii meftes trilateram, \& tri-

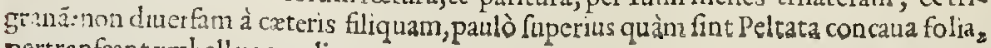
pertranfeantvmbella ramuli. 


\section{$S T I R T I V M$ aduerjaria noud.}

AIONSPELLIENSIVM SERRATVS TITHYMALVS, sut Caracias.

No N temerèalibi (ne in Italia quidé) quàm

Norbonenfi agro iftum reperias, qui inibi vulgatı_simus, \& à foliorum crenistenellis, ferra tus vocatus: exeüt à radice alba, Etingij fimili, pingui corticc,carnofa pulpa, pollicé craffa, pro lisa binü \& ternū pedü, gümneo \& percosto fuc co pregnante, coó; Turbit fúpicionem faciente: exeunt furculi plures cubitales, \& pedales viridantes: Folijs Mirfinitidis, anguftioribus, aut Myrthi maioris, crafsioribus, pinguioribus, \& elegãter per ambitú, fed leniter,crcnatis:in füno ramulis fpargitur, \& donatur vmbell 15 vmbellicatx rotunditatis, folıola traijcientibus, forem, \& thecam hand diuerfam ab alijs, eftate. Si villius horum omnium radix affabrèemcntitur Turpeti Alexand rini radicem, fanè hęc foret.

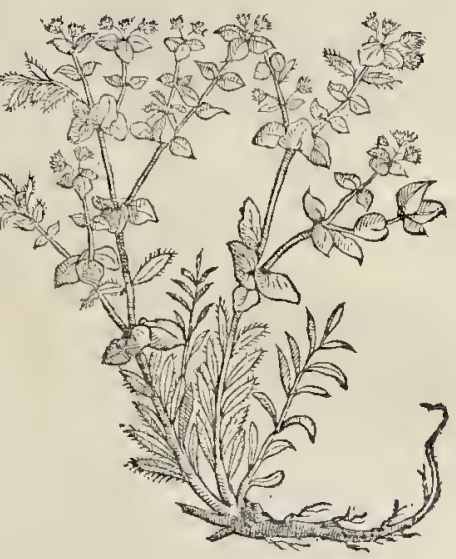

\section{LATHYRIS fine CAT.APVTIA minor:maior eSt Riclints.}

POS т в мvте omrium Tithymalorum notifsima, \& vfitatifsima Lathyris,cui sp-

pcllatio indita videtur, qux congenerem quidem, fed efficatioren?, \& $\mathbf{r}$ irofam magis

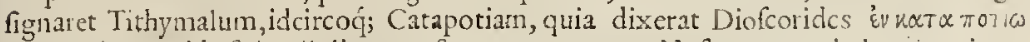
$\lambda_{\alpha \mu \mu \beta a v o ́} \mu v v_{\alpha}$, id eft, in pilulis grana fumpta purgare. Nufquam non in hortis, ctianq́; in agrorum Anglorum, \& Galliz marginibus occurrit, caule fingulari, bipedali, fed ramofo afturgit : quem per interualla ab imo bina cingunt folia, Rhododendri, aut Platiphyll Tithymali, craffa, pinguia, fucco lacteo virofiore glifcentia. Flores zetate pufillos, $x$ femen edit Augufto, \& Septembri,maius Tithymalis cẹteris, non tamen diuerfum, tricoccum, trilaterum, exprefsiore ternum granorum commiffura, qualis Chamelex, qux maior, \& figuratior, \& angnlufior magis, ideo confpicua. Idcircoó; plenius, \& fignatius à Diofcoride defcripta, aliorư Tithymali pericarpia, \& femina nó pcrinde. Qunare nobis fubfribente natiua rerum imagine fuerunt inter dum imm utand $x$, interdumć; cxprefins poncnd $x$ defignationes, non vt faciunt ifta mancipia mendaciol um, qui ne videantur ignoralfe, malunt ignota blaterare, fibić; ipfis \& naturæ monftra commentari,

PEPLVS, fine ROTVNDA ESVLA.

Q Vo o ramulorum ambitu, \& quafi rotundo amiẹtu, vclum efformaret, aut tellurem operiret, $P$ eplus dieta, nifi potius ob purpuream foliorum fuperficiem, fine serampolinam, qux huic in vinetis nafcenti, \& Peplidi in maritimis fabulctis degenti, vt plutimùm ineft. Peplun namq; fuiffe purpurei, vel phęnicei coloris, cum multre hiftorix, tum faüneolum teftatur, fic à flammeo dietú colore. Germanijs \& Gallijs pafsim Peplus fpóte protienit, fecus fępes, forsimenta, margines hortor um, \& in vinet is. Radice prolixiore, pufilla, fibrofa, ramulos promit fruticofos, fefquipalm ares, complures, graciles, tenellos:fo liola Rutx, Alfine, vel Heliofcopij Tithymali minora, bina, \& poft fofculos leteolos iuxta exortum fingulum, marfupiol um exile tricoccum, nec diuerfum à cxteris Tithymalis: tametfi exile admodum, fenine intus medulofo eandicante Papauerino. Succun laetcum tota fundit planta, planéc; Tithymali f peciem fatetur.

\section{PEPLIS.}

V'T nomine fic effigie hęc Peplum pręfert, \& proprus adhuc etvmun Pepli, vel flammeoli exprimit : idcirco $\theta x \mu v 0 s \dot{\alpha} \mu \phi i \lambda \alpha \phi i s$ Diofcoridi defignatur, quia fruticat 


\section{4 \\ STIRP IV $M$ aduerfarianoua. \\ vberiore vndequaǵ; ramulorum comofa concinnaq; fobole in Pepli fpecien collecta, Eff, Mat v2so phæniceo colore purpureoúe, nitentibus viticulis fefquipal maribus \& tolijs minoribus, numerofioribus quàm Peplij, Chamxfyce inter \& Porrulacx agreftis(cui quàm fimilima tota) forculi item pallentes exluteo, \& femen tamen maiufculum,tricoccum, Pe plij aut Chamæfyce, Augufto edıt, lacte turgidú acri : Littora Norbonenfia Thyreni \& Adratici maris hanc reptricem abundè fundunt, ignotam al ioquin Septentrionalibus, nifi hortis.}

CHAMCESTCE.

E'T hac facilè deillis duabus cognatis nofci poteft, Eartor ramen multò, nec vfpiam Iralix aut Germanix, fed duntaxat in Norbonenfis Gallix oliuetis vinetif́, , vbi plarima, pręertim aridis fabulofis, non procul
Monfpellio ad patibulum via, \& tractibus maritimis. Ptilchella tota \& tenera, ramulis \& foliolis numerofis, humi reptätibus, ex pallido virétibus, non difsimilibus ant difparibus Herniaria, fed lactefcens, vti dux fuperiores: \& fimile femen, thecam \& flores, fed cuncta minora.

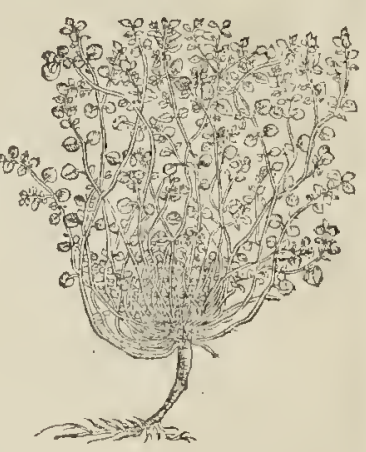

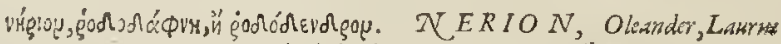

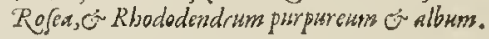

SGal. Rorage.

$\{$ Ger.\& $\}$ Olcandre boonte.

Ang. Oleander.

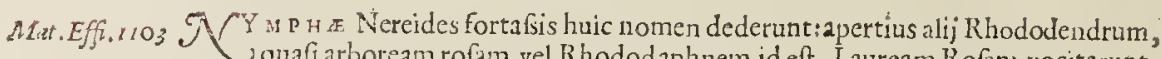
qquafi arborean rofam, vel Rhododaphnem,id eft, Lauream Rofant,vocitarunt. Non admodum frequens, nifi tepidioribus ad meridiem mareq́; vergentibus fuentorum crepidinibus \& littoreis, cuiufnodi ad Olbiam Galloprouincix, Genuam Ligurum, \& Lybornam arcem maritimam Thufci Ty rrheníue maris, vbi fruticat fparfis latè ramis furrectis, in alios minores diduetis, \& denfo ftipatu foliorum amictis, qux Laureolæ vel 0 Icx anguftiora, longiora funt, Laurinis anguftoribus, acutioribus. Sillquas bifores \& lanu gine pappofa quadantenus vicetoxici farctas: femine fufco, longo, leuiore. Flores rofea, diluta, purpuriffa nitét Augufto Amygdalinis aut Malı maiores, quos interdum rubellos, interdum albos memini tum in hortis Italicis, tum in maritimis. Tota afpecta lata, coq́; in feptentrionalium hortis coli folita : aliogui vfus afpernendi, ant metuendi, nifi aduerfum venena, ad qux prodefic, authores funt, poft antiquos, recentiorum quidam Practici, nó fecus atq; Vicetoxicun, foris etiam poteft prodeffe docente Galcno.

$$
\begin{gathered}
\text { ALPIGENA CHAMCERHODODEN- } \\
\text { DROS, odora. }
\end{gathered}
$$

QV a Oenoponte Tridentü, Veronamá; quis proficifcitur, videre eft interdŭ vniuer mötis deuexa latera, ifto frutice, quafi tapeto purpureo operta, prafertim Iunio, Iulio: quü Hores eminus coccineo enicát fulgore, cópacti raccmatim, pufilli, foliać; pcieunia purpurafcŭt rubêtớ; Xeräpelino cópluria, rigida, crâfa, déra, bux ea, \& Rhododédrí muitò 


\section{STIRP IV $M$ aduerfarianoua.}

multò minoribus, breuioribus. In farmentofis, precduris furculis deprefsis, fefquipedem, \& dios altis : fed alicubi penè accubantibus fixo, vel glarix fubftrat $x$. Pinguis eft tota, fuatis odoratu, fuauifsimóque afpectu. Alpini illî́c Italo-Germani $A$ iprofen vocitant.Bacculas A fparagi,vel Taxi pares \& concolores, Septembri edit.

\section{$\mathcal{A} L P I N A$ ALTERA.}

CE r s s s rigidifsimis cautibus huius quadätenus effigie,floribus purpureis, perquä exiguis : Ericr foliolis perennantibus, nec deciduis prouenit : humilis tota, à nobis tantùn ficcata aridáque vifa; cóquc minus accuratè deforpta.

\section{MONTANA ALLOBROGVM Lentifcifolia, Chamelexfolin, vel Oleaftrifolia, minus odora, $C H A M A R H O D O D E N D R V M$.}

PE n e metiam, fiue cubitum fruticat, lignofiore, crafsioréque multò ftipite, \& furculo recuruo, brachiato, rugofo cortice, \& intus ligneo; Lentifcino, vel Gragel Germanici : folia planè Oleaftri, aut Lentifci leuore, colore, magnitudine, rigiditate, crafsitie : fupernè virentia, fubtus ex pailore ferruginea, ex v no principio ferè per cacumina cxorta, proximè fructuun corymbaceas vmbellas, eleganter quinque partitis apiculis, coronata, Ruta modo oftentant: flores perpulchri funt copiofi, Chamęrhododédros odoræ fimiles. Cunctus frutex eft guftu nonnihil aromatico, plufculum aftriationis, \& aliquid moderatę calefactionis retinet:tempera mento Lentifci,\& ferè guftr, non-nihil odorus, attritu non pinguis.

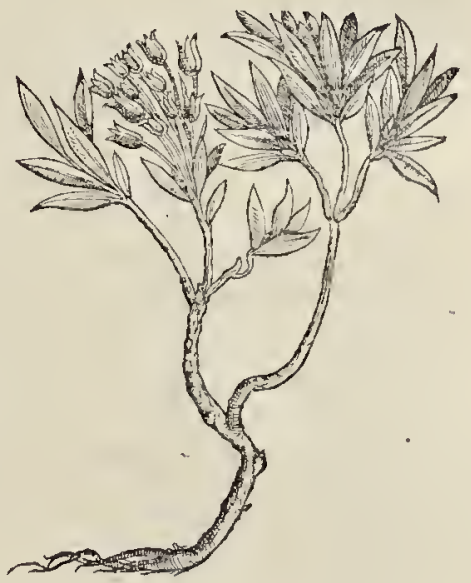

\section{CHAMA DAPH N E, fure pufilla Laurus, an: Germanicum $M_{6}$ Zereum, an-num potines nof trum Chamarbododendrum.}

GT huic pariter Lauri effigiaturam vindicat nomenclatura Chamędaphire, id eft, humilis pumilęúc Laurus, cui duos nouimus affines vul tu frutices, alterum Germanicum vocatum Mezereon, alterum noftrum dudum defcriptum Chanzrhododendrum. Sed vtra alteri prxferenda fit,ambigimus, propter nonnulla quxipfi nobis obiecim us inter legendum, qux de viribus Chamædaphnæ à Diofcoride, Galeno, \& Paulo produntur: alioqui aptior Gernanica foret:fruticat fiquidem binûm ternûnque pedim, ramulis firmı, fequacibus, cortice \& foliis obfcurè viridátibus, \& Laureolę, vel Liguftri, \& Olex; fecundum quos Perfica flores fubpurpureos, minores, \& grana $P$ iperis rugofi, nigri,iam vietx maturitatis, per initia tamen viridia; deinde ruber euadit cortex, qui exemptus detegit medullofum granum Canabino, aut Lythofpermo maiori finile : guftu ferui-Granum guididifsimo, \& fances, afophagúmque adurente, diu multúmque vexante imprefsione, polt- bim. quàm deglutiendú dederint agyrtę numm petę foren fes, vt affolent, rufticis fpectatum confluentibus, aut potius illuftrialicui potori, quem vinum nequeat temulentum facere: nam qui vel vnum grannlum vorarit, nequit quin \& vfque vinnm inuergat, quafi in ventriculi vtrem, guttúrque colluat, donec Baccho temulentiáque defipiat. Proindéque vocitant $P$ iper Rufticum, \& Gniduun Granum 'Pharmacaria infcitia, quan fouitiamdiusenenfis, decipítque deceptus, qui hafce plantas fupina ignauia difcendi \& inue- 


\section{STIRPIVM aduerarianona.}

ftigandi,fibi incognitas, horfum prot fum confudit. Plurima hec cim in Germania, st Heluetia, tum in Allobrogum, \& Lygurum, Taurinorum, Delphinatúfque montıbus \& collibus Syluofis, opacis. Martio floret, fenenq́ue maturat rubrum Angufto. Non minus hxcper aluum deilcit craflum vifcidúmque $2^{\prime \prime h}$ leğna, \& inteftinorun raméta abradit, quàm Laurcola, cui non difpar, fed vehementior facultas ineft,cademqque in aceto maceratio ad corrigendum debetur. Sic enim vtuntur etiam Medicorum quorüdain pracepta Pharmacopoca, quare facit hac virum expenfio, vt minus quis putet Chamadaphnó

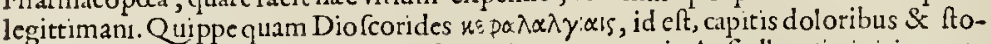
machi ardoribus mulcend is commendet, vt interpres vertit. At fi vlla ratio iniri queat, qua tam feruida planta pro Diofcoridis Chamadaphne agnofci queat, e a interpretatio-

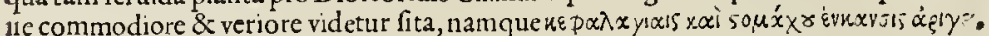
id eft, capitis doloribus \& ftomachi vftionibus accommodat, vertas, non incommodo fenfu intelliges, folia tufa admotáque capitis dolori, puta à frigore, vel flatu, mederi: Stomachíque vftionibus faciendis admoueri, ad diuturnas fluxiones fiftendas, aque ftomacho auertendas: vt Paulus ex antiquis docet faciendü,libro fexto de ftomachi vfltione, ferro vel cauftico non vrente actu, cuiufmodi funt fungi, aut nigri ag.rici, fruftilla, aliąque inibi fcripta, quibus non fecus atque follis huius vi fant antiqui.Sic Diofcorides magnum prafidium putat Arabicam vocatam vitionem à Gracis, qux fieri folita fuit fpirillis caprinis Oleo feruenti immerfis, \& pollicis cauo inuftis.

\section{$D A P H N O I D E S$, fue Laureoln.}

VT nomenclatio, fic natura huitus,prorfum pufillam Laurum imitatur, frondibus pattlò fuperius quàm à medio caule furfum verfús obfcurè virentibus, nitentibus, craffis, denlis, Laureis prorfum, femper virentibus, \& Bruma, quemadmodum vifcus, fores prométibus denfos, multos, quafi oblongis, gracilibus, ftellatis, calathis ex herbaceo albos vel Iuteolos: bacculas media ęftate virếtes, deinde maturitate affequutas, nigras, Lauro eafdem, fed minores:ramis flexilibus, pluribus, binûm aut ternú cubitorú , cortice obductis perguàm tenaci \&: laceratu difficili madix longior, \& durior, durat etiam in hortis facilè perpetuo frondium virore vegetiore quàm Laurus, quam adeò tota prx fe ferr, Laurcole Pin-vt etiam plebecula vix confpectam,pufillam dietitet Laurum: Vbiuis fermè Germanix, gera'a. Gallix, \& Anglix, prxfertim Mulomedicis \& mulierculi clinicis nimifquàm nota, vt mirum fit, Commentatorem Senenfem tam ieiunc̀ \& manca defcriptione hanc defignafe: certo inditio non tam negligentiz, aut con temptus, quàm ignorationis: quippe figurä, quam nullis floribus dat, quemlibet alicuius arboris (fortè Mizerei Germanici) furculum pracifum refert, quàm Laureolam, cuius mutilam defcriptionem, vt quam fubdit proximam, \& plurimas alias, exfripfiffe videtur ex iftis authoribus meritifsimis, quos hîc lacerat, \& infcitix traducit.

\section{TH HMA L $E$ A, grani Onidii.}

COG n a t \&. figurx \& natura funt Chamzlea, \& Thymelia cùm inter fe, tü illis dudü defcriptis : fed frequentior,notiorq́ue Thymxica, qux non modò in Galloprouincia \& toto Norbonenfi littoreo trątu, fed etiam Italicis montibus longiufculè à mari Thyrreno difsitis, vt funt Mons Diui Iuliani, \& P ifani, Lucenfeff́ue colles, vbi nufquam Chamzleam vidinus. Quin etiam in Occiduo Oceano, Gallia Xantonicx, ad Rupellz Infulam, des Ratz vocatam, id eft, murium, (quorum Oftreis \& radicibus victitätium eft alumna illa angufta Infula) frutica Thymalea multat, cuius nomenciatio effigiem naturamçue quadautenus adumbrat. Vidétur qui ppe Thithymęlia, quafi Thithymal \& Olea mixta facie: Eft nam q; virgis, rectis, mul tis, fefquicu bitalibus, partim ab ftipite, partim ab lignofa radice, habitu, fitúque Oleaceis anguftis foliis, admodum vif́cidis, pinguibus, inter Thithymal u, Cyparifsiam \& $\mathcal{P}$ aralion, corticofo amietu tenaci cincreo, t fumma ad imum deglubenti fequaci, in ftar Laureolx corticis: fummis in virgis fores albidi, puGetli, frequentes, Iunio ftellati: Augufto demùm grana,2ntiquis $G$ N I D I A Yocata, 110- 


\section{STIRPIVM adwerfarianous.}

uena aut dena, primulú viridia, deind e ex flauo rubétia, tenella cuticula, fircco aqueo turgida, vnú meduliofú gygartŭ amiciěte, foris n!grū, intus alba mcdulla, in qua fer nor ille gur fitus in G nidio grano,vt expendenti verba Diofc.liquet, ad cuius imitationem pcrperã edoctus cü Pharmacopocorá plebe Commétator, qui hãc nó nouerat, Mezerei Gern unici granú feruidius multò, \& pland cruftas inurés, tum foris, tum intus, nobis, qua folet fidu cia,fugillata tum Diofc.tum recentiorú omnilu doctorú fententin temerè obtrufit. Nam nó coccú ipfün rubrü dat, ait purgare afferit Diofc.fed Pericarpio cócluf medullæ.interiori,cui vni(albam nuncupat) vin deijcicndi Phlegma \& cholerá attribuit, \& abundè explicat, quãdo vigunti granorú internã parté, qux fanè medulla elt, $\mathrm{Pe}$ ricarpio gygarti nigro fepta, pracipit dare. Vnde nec ipfas plantas, nifi fuperba animi inductione à Senenfi incertas, \& codi cis Diof coridci nulla nifi truiali leftione, cuius tamen admodum accuratum vindicē fe fore voluit videri initiò, affertas, magno multorú detriméto, qui illi" freti comnentis ad Hydropem funt vfi, rati effe Diofe. veras Thymxlens, Chamaleas, Daphnoides \& Chamzdaphnes, quarū nullã nec legédo quidē, nedum facie,vel

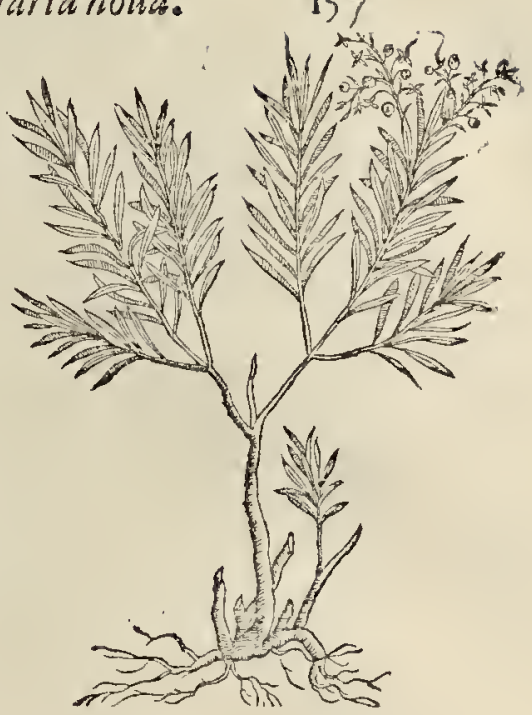
virubus cognită habuiffe tautum hatoré Senëfem, cuilibet ve! Pharmacoporo iam liquer, CI EZEREON eArabum, Chameleatricoccos.

FE r v I D I etiă fquallidifi; foli, faxofi, maritimi, Chamelar,id eft, hamilis Olea vel Oliuclla nuncupata, ab ea qujadmodu exprefia eft fortita cum Olea facié, folijs louote, labria, ramis, fub quibus in Oliuctis cultis prope Frontignaná Norbone vherè fruticat, nec nifi collibus vicinis, arčctibus, faxolis, fponte enatä,perinde facilè eft :eperire:nec quidé in Galloprouincia, vbi tamē nafcitur, multo prodit prouêtu. Ran orü bicubitaliü fobole magis famét ofa ce rugof, lignofa, intorta, quàm Thy mel eæ. Folia latiora, viridiora, nigriora, lenticulis lógiora,augutiona,propius referút Oleaftum \& tcuuifolian Phylerea..Flores luteoli,pallıd, Laurcolæminores, ęltate xftúc; fummo: Augufto verò promir virétes, demamć; rubétes bacculas tricaccas, Tornefolis fue Heliotropij vertucarii, aut Tithymali fimiles, nifi quia ofsiculis eft preduris, lignofis, guftäti medullam feruddà \&e pręficcả cxhibétib? :radix lignofa, inutilis. Magni taméfuccivfus totius plătx ełiā hodie, prẹertim Mófpellij, vbi Pharmacopœi pręîư ficcatíró; habèt,monéte primú Rōdel.cuius imitatione \& nos fépius défati fucci recétis $3 . j$. \& 3 . ij. dedimus perfe, \& aliàsalijs catharticis Hydragogismix tas, perbono fanè euentu: fề nó admodù multü excer-

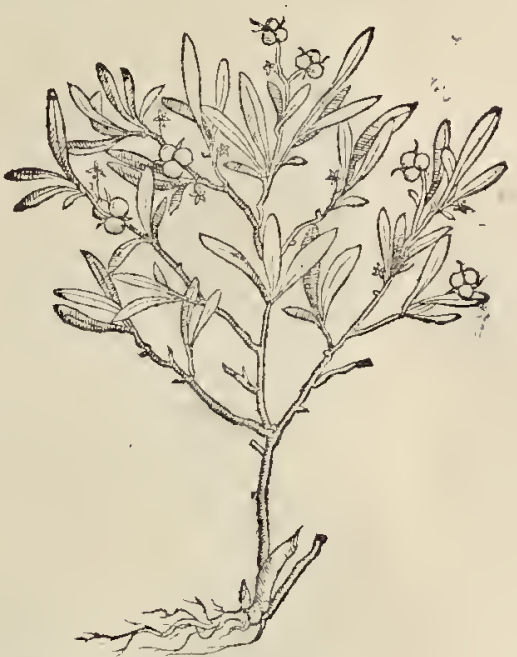
nit, nec vllo effreni motu, vt folët Laurcola Mezereon Germanica, Gratiola, \& alia.Quin perparü, aut nihil inter dü, mouet Chamelex fuccus cócretus, nif remix tis quibufdá leni entibus, aut fimilibus catharticis. cuidã arthritico habitiori, torofo, procero homini, trés dragmę nullü excrementü mouerüt. Pueris ctiä datus, nec tormina, nec vomitiones facif fed aquas educit \& ferú. Admotus pubi \& abdomini Hydropico, nó vllü prę̧átius ad vri nas prolıciédas, quo modo lubétius v tebatur Ródel. Sic etiā Thymelex fucco, qui tamen difficilius pramitur \& clicitur, propter glutinofü virus:nec nifi tepéte affufo vino, aut có fimili quopiã liquorc, vt factitãt dum fuccú Brafsicx marinz educüt, quilibet vti poterit. Tundútur tenella lolia, flores, diu \& veheméter, fępiu sá; tātillü tepétis vini affüditur inter tundendum, túc prxlo ligneo vehemé tius vrgêtur, dum trăs colum expiret:tunc igne lento aliquãdiu bullit, dum Loch crafsitiem affequitur. Demúć; Soli feruido obiectum du refcit, addito faccharo, ne mucefcat:fić́; cóchis recüdebamus nos illic dum ageremus. 
PERQYA A fimilisgufu, facie, viriPus, folijs, \& virgultis ligneis, gracilibus, concoloribus, rugofo cortice anniEtis Mófpclliacz Chanelęræ: facilè tamé $2 b$ hac dif́cerni poteft, fructu nimirú Me zerei Germanici, Oleaftri, aut Phylerex nec tricocco, \& foliis fummis, non airo virentibus, fed tenui,molliq́; incana lanugine obductis: quenradmodum \& flo res pallentes è lagenulis argêtteis, Strammonij fimilibus, fed minoribus,conlpiciuntur. Commanducata fauces inurunt, non fecus ac Mezerei Germanici grana. Ideoǵ; etiam plebs, Rufticum Piper vocat: Mafticata folia lentorem remittunt, vti Soldonelia, Thymelza \& Chamelæa Norbonenfiü. E Lemanni \& Allobrogum vicmis Alpibus folum habuimus.

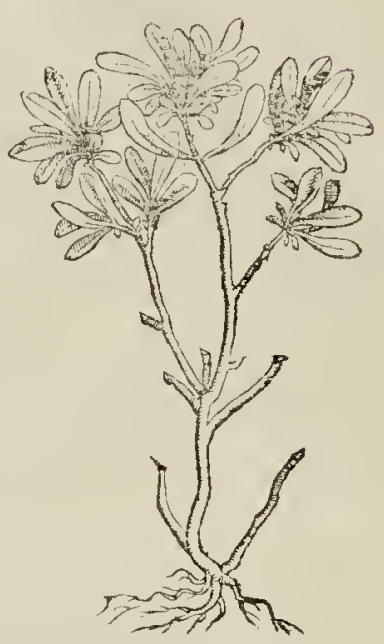

ALYPVM Montis Ceti Norberrenfium. Herba T erribilis vilgo.

NOM I is ducta videtur intellectio, contrario quàm fe habeat planta fenfu: Alypum quippe quafí indolens inoffenfumq́; \& expers moleftix remedium, Sic fella Gracis glycea, fiue d:1cia, ¿c Holoftium, qux herbula eft teneriufula, per antino mafiam dicta fuerunt. Sed nalim coniectari "'xurn, id cft, filfam, vel maritimam, plantum nuncupatam, quia fecus mare, vt Diofcorides nemorat, oriatur. Tametí oportunum fit calumnix, ftatuere vllam certam plantan hodi - pro vero Alypo, propter Arabuin \& Grecc:izurorum fcriptornm diuerfas, ant planè contratias opiniones (quarum quę Actuarij,album "urbith cum Alypo vel Alypia Diorcoridis ic̉m autumat: Mefux verò Thapfian vel ferulæ genus laEeeí quoddam,deniq; Serapio Tripoliun) tamen cùm nullü hodie noftra norie xtas,cui Diofcor:dis Alypú afsimilari queat, neq; plantã vllam habeamus quę ęquè bené, imò vilo

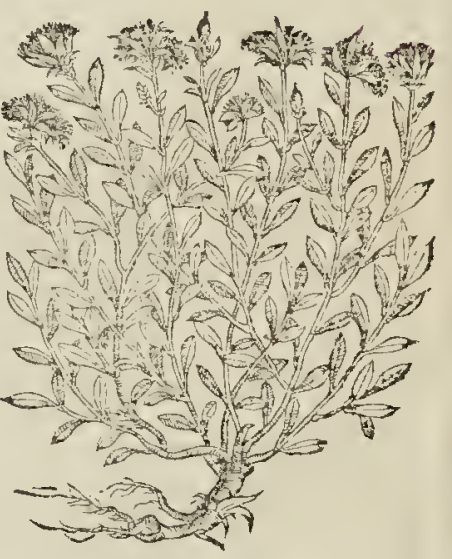
modo(pręter færulas)A Alypo cogruat, fiue lineamentis, fiue efficacia purgandi, atq; hic fru tex maritimus: Fanè hanc quò minus affcramus genuinum Alypum, vna notula non tam obftepit,quàn deeft, foliorum nimirŭ: quę non fuerüt exprefia à Diofcoride, aut fortaffis fuerür labecula codicis peruerfa mutata népè voce $\mu \alpha \beta \alpha$ T pos in ìregóteos, vt fit nó fubruber, fed foeniculaceus frutex. Hincr; Mefuę fun Turbith fęrulaceum fecerit,vel Thapfiatn cum nonnullis, qui eitus radicibus qúotidiano viu in Gallijs \& Hurpanijs purgationes pituitę, craffés; \& Melancholice blennę moliuntnr. Verim, fi vti nonnullis exuditis perfuafum fuit, Arabes vocitarüt Turbith, quodlibet phleg magogum, saulò vehemeiafius pituitam educenr, meritò \& ifü fruticem, quem picum damus, polsit quis Turbith rocare: 


\section{STIRP IV $M$ aduerfarianous.}

rocare, nec enim minus malè ominato nomine quàm Turbatorium Turbith vocat ifta herbam Terribilem vulgus Norbonenfium, vbi impoftores valendinis cauponatorcs im pij,atq; tribades inulicrcula terribiles, vt vocant, illic moliuntur purgationes, iftius terribilis fruticuli foliis, floribus, \& femine. Siquidem virgultis crebribus lignofis, fefquicubitum Ex duos altis, cortice tenui, ex fufco purpurafcente, denfc cingentibus concoloribus, numerofis ab imo fummo tenus folijs exilibus pufille myrthi fimilimis, minoribus Thymelex aut Chamelex. Singulis in virgis fummis finguli infunt tenuifsimorum florum purpurafen tiun glomeruli, nonnihil fimilibus fed exilioribus \& breuioribus delicatioribusá; Scabiofr ftaminıbus. Radix digitum craffa, fufca, lignofa. Cuncta planta perquàm amara, \& inamono Thymele $x$ aut Chamxlex guftu,aut rehementiore, etiamnú dum hxc commentanur, fexto abhinc anno,autlfa in monte Cxto Frontignanę \& Mafsilix, faxofis prxruptisq́; vtrobiq; ad mare \& Auftum deuexis natalıus: quam fi Senen fis prorfum filuifet, nec pingendo depraualfet, \& melius fuo honori leftoriọ; confuluiffet : hanc enim capite de Tripolio, fibietiam ignoto, vbimulum ineptit, \& Alypum plantam tenuibus ferulæ folijs effe dicit, non iftam, Diofcoridi imponit, Braftauolæ \& alijs do\&tifsimis conuiciatur \& obtrectat,argumentis ab illorum monumcntis mutuò fumptis, etiamq́; veftigatore ingenuo, qualem immerito haftcnus fefe nobis gloriatus fuit, indig na prorfum \& vecordise plena verba illa inferuit: Nó referre cuius plantæ fit radix Turbith Alexandrinum, cùm eius facultates à Medicis optimè fint perfpectx. Sic caprimulg um, fcam: nidicum, vel aratorem, non commentatorem, loqui decet.

\section{aALEXANDRINVM Officiserhm T urbith.}

PAR fermè controuerfia de Turbith atq; de Hermodactylis, quarum plantarum viti aut certè poffefsione non videmur carere, veriora tamen quxnam fint, ambigimus, quia anbiguæ fuerunt fententix antiqux. Ac de illis fuo loco, híc verò pauca de Turbith. Arabica Semimauráve Orientalium nomenclatio vaga eft, vt non paucæ illius gentis voces, fignare quamliber lacteam radicern vehementius pituitam deturbätem, voluiffe vifi fun $t$, propterea vt quælibet vna magis arrifit, fic eam arripuit.

$$
\begin{aligned}
& \text { SSerapionis, T ripolit radix Diofc.vt liquet è defcriptione. } \\
& \text { Mejue, Herbe ferulacee laite turgentis. }
\end{aligned}
$$

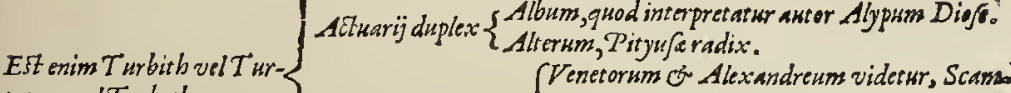

$$
\begin{aligned}
& \text { petrm velT erbeth. } \quad\left\{\begin{array}{l}
\text { Fenetorsm of Alexandreum } \\
\text { mony anthiochenifpecies. }
\end{array}\right. \\
& \text { Officinarum triplex. }\{\text { Cineritium, à colore, Radix T baphe vulgaris } \\
& \text { Nigrum, deterioris quidem note, fedalioguin } \\
& \text { eiufdem cum Anthiocheno pecici. }
\end{aligned}
$$

V V L g ^ в Officinarum Alcxandrinum cognominatum diu nos torfit,cùm enim audiffemus de Guillaudino Patauium Alexandria reuerfo, nihil aliud effe Turbith Alexandrinum, quàm Myrfinitem Tithymalú, omnes Tithymali fpecies erutas, ficcatasq́; habuimus, infpectione \& exploratione expendimus, fed non ita habere deprahédimus. Etcuim, Tithymali ferrati quæ fimilior eft Turbith Alexädreo, cortice elt rugofiore, trifti ore afpętu,fungofa, lruioreq́; concretione, guftanti virofior \& feruidior, minus firma, \& qux facilè non afulatim aut fecundum filamenta in longitudinem dehifcit, duraq; non elt, nec perinde purgat vt Turbith, cuius exemplum fumi poteft in Benedicta laxãte,cui mifcetur Efulz radix, \& tamen blanda benedictać; habetur.

Porró fub finem capitis de Scammonio, de Turbith quid \& quur coniectemur radicem Antiocheni Scammonij, dicemus.

Quodq́; fuperius monuimus fuccis Chamælex, Thymælex, Brafsicæ marinx, \& alijs vfu

$$
\text { O. ij. venire }
$$




\section{$160 \quad S T I R T I V M$ aduerfarianone}

vonire, vt tninus, aut fermè, nihil per fe purget, nifi remicesntur imbecillioribus, fed lenientibus, aut al to modo purgantibus:id idem admodum perfpicuum fit in hac fadice Turbith.Sıquidem non arò neminimus datis infufo ternis, quaternífue 3 .cuidam non aduodum aluo arétz, nihil penitus eduxife, in alis excitafie quofdā torminofos murmurillos, aliis aluum femel, bífue citaffe. Quin nec in fubfantia ọuden admodum purgar:vti in electuariis Diaturbith, Diaphœinicum, de Citro Solutino.

$$
\text { T A R T O N-R A I R E Gallopro, A1agillengium. }
$$

NOr a noftrx xanti,iuxta ac elegansafpzctu hęc etiam maritima Cathartica, có 7 ; vernaculo vocabulo Mafsilienfium, Tartonraire vocata, ab exuperanti effreníq; purgaudi vi, quęnon rarò dyfenterias fluxú?q; immoderatos alui accerfit. Pręęctim fi quis minus peritus, huius folia in puluifculü ducti, vel q.opian liquore dilut $x$,propinarit:vt fa Citabatille necator Thunifo, qui nobis primìm cam,eiúfque vires, vt dicebat, a"camas detexit. Circum Mafsiltam locis ad mare denexis, prafertimácue coliem vulgò Mrud-rond vocatü, fqualidi, aridü, glateofun, plurina fruticat, tota pilchella, tenui incanáque lanugine obfita,candidıs, nitentibus, argenteis foliolis crebribus, ab imo ad fummu Chatnlęex, \& Thymelea:prorfum $\mathrm{fi}$ $t .18$ magnitudine Alypo proximè defcripto

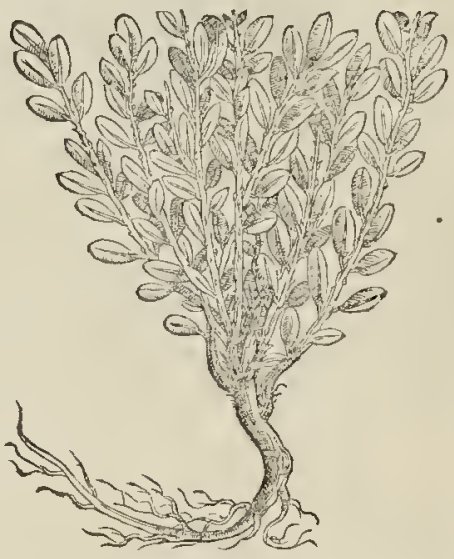
paribus: edit virgas rectas, crafsiores, vicenas, tricenas, aut plures, admodu n lentas, \& frątu contumaces, nec adcò lignofas, cubito lö. giores, flofulos in fummo pufillos, \& (ni labat memoria) pallidulos ex albo, femine pullo, rotúdo Arthemifę, aut Ambro, ię: radix prolixa pedé, fimplex cortice atbicăte foris, intus candid, Iineo a.pe\&u, \& fibris dura, lignofa, guftu non admodum calida, nec amara,nec ingrata, nonnihil tamen caloris imprefsi poltremò relinquente,\& quadantenus Turbith Ale xandrinum, fiue vulgare, refcrente, inodora, tota lacis expers.

\section{ESFLA RARA in Lio Venetorum Infula.}

COgnationis cófequatione fibi hunc vendicat locí hęc fupcrius proximè dalcriptas, \& Efulá, quam vocant maioré, fiue Pityufam : cuins eft hæc Venetis Me. dicis, \& Pharmacopocis fpecies : cóq; hac, vulgatx communis Efulx viccin fupplent in Benedicta confectione, \& pilulis $\mathrm{Ca}$ tharticis: purgat etenim non fegnius Efula communi, eónue putabatur à quiburdam Alrpum Diofcoridis, \& alii, quàm bene, viderint ipfi, nigrīi Turbith, qué Pityufam Actuarius autumat, opinantur. At Pizyula non hree eft, fed perquàm fimilis, ideo vtraç; Efula à nobis vocatur. Sefquicubitum duófque longos caules, fungofos, rugofos, fufcos, craftos minimú digitum, ramulis multis diuifos emittit, pedalıbus \& foliis fitu binis, perinterualla maioribus quàn Terribilis Alypi,ad Gly cyrrhizá pro ximis, lentis, pinguibus Thymelex: flores pandulos, promãtibus par-

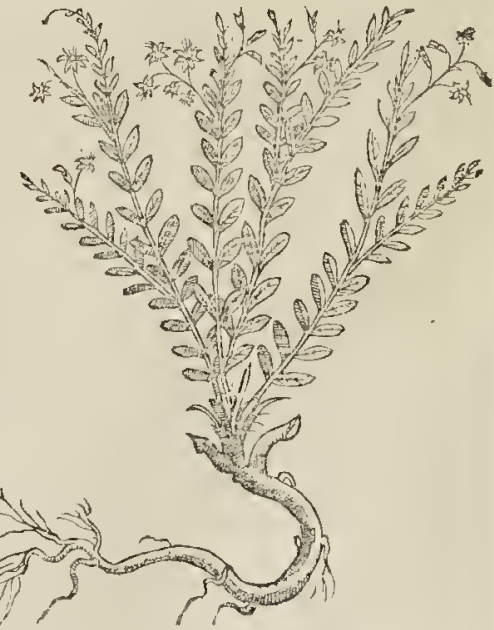

putafcentes 
purafcêtes, \& fufco obfolcto ariftolochir, vicctoxici effigie. Radix foris pulla, intus villofis lincisć; pelliculis, cniufmodi in Tartonraire, cinereis, fefquicubitum longa, digitum minimú craffa, fucco diftenta: vniueŕ́, planta Iadefcit, \& prorfum Tythimali paralii, cui conuictrix fermè femper vifiturx quiparatur. Sed non alibi quàm litoribus, \& Infulis finus Adriatici facilè reperitur, \& in Lio Infula exigua, quęobex eft maris allifionibus.

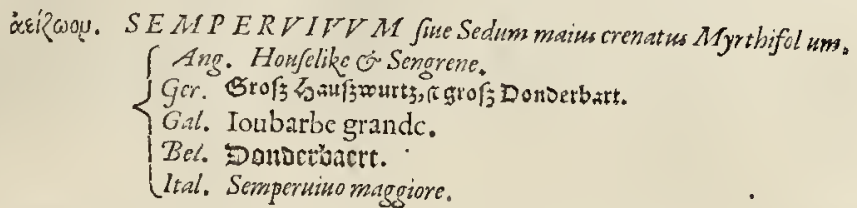

$\mathrm{N}^{1+x^{2}}$

I f I I vfpiam gentiú vulgatius, vfitatius, viluatiúsue, Sedo frue femperuiuo,fic nun- Effi. Fufch. cupato, de perenni vegetoọ; folioní virore, que hyene \& aftate in parictibus vel im- Epurh. i7. bricamętis, ctiam nullis, vti videtur, radicibus nixum, aduerfus quafibet colli impreffiones tuctur: Ccfsili circinataq́; bafi \& ortu pertinacius haret fubgrundijs numerofa fo lia fquammatina digefta, ęuore fuccoú; pellucida, admodum carnofa, mucronata, \& lingulas piciu unitata : catilis promitur rectis verfibus flipatus, quifores Iulio \& Angufto febribus cumandis, profertim purpurafcntes, \& rube!los geftat. Hnius a quam tillatitiam febribus curandis, prxfertim tertianis, \& Caufonibus propinant mulic:cula, edoetzalin cuius monitu \& initatione:nam non paucos curant.

$$
\begin{aligned}
& \text { AגO'́, CALOE. } \\
& \left\{\begin{array}{l}
\text { Ger. } \\
\text { Bel.o. }
\end{array}\right\} \text { Bitter eAloes. }\left\{\begin{array}{l}
\text { Gal. Perroquet. } \\
\text { Ilal. eAloe. }
\end{array}\right.
\end{aligned}
$$

I a in maritimis Aloes fponte nafci proditur, non abs re quis fufpicetur nomen il li fatui à falc vel falo fiuc mari,cuius afflatu imprimis gau det, fortè itidem \& nonni Eff. Matho hil foris falfedinis continet, vt cxteræ maritimx. Peruagat $x$ cognitionis \& vfus, nti anti-683.684. quis,ctiamnum fuccus, ipfać; planta : qux plerifo; Europæ locis in hortis penfilibus foxfano Hetruriævireto, \& Mafsilex in fabuleto depacta adolefcit,floretć; : fed quæ 11 Pictihorto vifebatur meritò non peximè Noum portum in Præfequân folijs tum mucronem cxtremo fin, bickibalibus, vnciam \& fofuiunciam cralsis confabat, guis dquilini politi, non adcò annci olten tabat, nagnitudine, rigiditate \& colore vnprope intcrualio digcft. Caulis bu. gix, in cuo flores crow purpurei c̀ tricubitalis, digitum craffus, Haftulx Rcamara : cærcra altcri fol quidem recenti ex Hifpanijs in Fandre, vt putanus: Neutri enim infignis amaror,nein Flandriam, Angliamq́; allatæ, pbi tamen Aloes factitari nondum folibus perco fucco multo aqueo ofus, vt Bumali tcmpore, minimum amarus eft : quod cxtcris inde maturitu ftrna dulcis eft, rrimefla, cida. Succorum prima fuluef Iam hand opus of rixari

periculis facis certum fir fort ptum fuccum, illis prefertim qud hotum claudere, \& fanguinen fiftere, intrò vcrò fum. re, deducere ad venarum ofcul, hemoroidibus vexantur, fanguinen attenuarc, calfacefucci non pauci faciunt, vt Porrip fíq; adeò vaforum extrema ieferare, non fecus atc; alij

$$
\text { O.iij. SEDVM }
$$


$S E D V M M E D I V M$ teretifolü, fue minus Scmperniü̈ Officinarum. Ger. ZKlein bauf joutt menle, it Hein Dondetbart.

Ang. Trickadam:

$\{$ Gal. Petitte Ioubarde, \& Triqucmadane.

Bel. Elcyu sonactunet.

Llat. Semperutuo minore, Jeu Pignola, í folio tereti Pinci.

Effi. Fuf $\mathrm{Ch}$. Epith.18.
Fufch, Effig. $E_{p t h, 20 \text {. }}$
FT I A M ijfdem natalibus admodum frequens \& notum proucnit iftud: tamulis à radiceperquàm exili nuultis,gracilibus, edentibus foliola anguftiora, rotundiora, nino ra,teretia,carnofa,mucronata, acuta, Salicorniæ vel Kali colore \& modo: flofculis aurcis, ftellatis: tota ciufdem figurx \& facultatis atc; mains fedum.

\section{VERMVCVLARIS. CR ASSVLA MINOR Offinarum, fine $I L L E C E B R A$ mitior. \\ GGer. Mlein baufswut watible. \\ Ang. Wylde prickmadam.

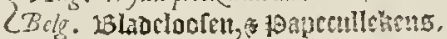

Fufc. Epith.19. SE P I s I M E etiam hac colligentes fallit proptcr natales coldem, fucienć; adcò minoris fedi fimilem, vt mirum magis fit prorfun contra ria pollere, ne:mpe calticicidi \& vlcerandi facultate: tamen difcernitur foliolis rotundis, teretibus, oblógis, carnofis ma-

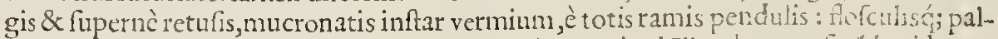
lidulis, vcl albidis:demumq́; quia non femper virct, eò ad Illecebra:n reféda videtur, cuius elt facultate. Supina admodü negligêtia Commétator nofter nólis hanc fortè pro fecundo Sedo dedit : ncfcius, vtvulgus ignarum, facultatun, \& inmemor verborum Diofcoridis, qui, freuti monuimus capite de Telephio \& ?ortulaca, quia neclêper vircret nec refrigetaret, non aficrit hanc genus Scmperaini, fed tantum cognationis \& funilitudinis caûa proximć fubdidit, videriq́; fpeciem dixit.

aI NIMVM. ILLECE B RA, Seditertiumgenus non Semper virens.

SGer. Ratjentreuble.

SeAng. Stone crop, or Stone bore.

¿Gal. Pain d'oy feau.

IS I A m pufillam reptatricem pulcliellä floribus aureis ftellatis, vulgò notisimam vbi-

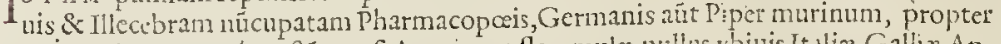
acren cxulcerantemó; gufü, quaff Aronis ant flammula, null is v biuis It aliæ, Gallix, Anglix, \& Germanix nó nouit:pufillis namq; ramulis parietes faxofasá; moles \& colles a. ridos amplexantibus, gracilibus, reptat fed potissimum guftu cognitu perquàm facil $1 s, 8$ qua inauditam focordiam Commentatoris arguit, inq́; ro herbaria par ü exercitatam, vel mentis, vel oculorum acič, qui hanctam valdè vulgarem(tamctí idë of čtat ille frequës) vbiq; Italiæ, Pifis accerfat, Guini preconijs \& literis affertionis, \& quafi in lucem erutä, ac ceptä ferat, Quin in Diofcoridis lectione hxc falebra nulla eft: dec ve enim quanplurimis locis, non pilofun, fute hirfutum, fed denfun rigidum vel compaqum fignare, capite de Britannica, Hypericone, alibió; non raı̀, reperiats.

$$
\begin{aligned}
& \text { A R BORESCENS Grecum, Illyricuri, o Anglicum, } \\
& \text { fune maritimum. }
\end{aligned}
$$

MV I I I s ablinc annis huius multas plätas Veronx, Patauii, Venetijs, \& iu Hetrurix hortis vidinus, chm admodri exoticafq; putabamus : Poftea fingularis fidissinufa; anicus Vallerandus Donrez, pafsim in maritimis Sclatuonix fue Illyrix circa Ditachiu virentcm collegit. Nof́; demum in Sinus Briftoienfs Anglici Oceani Infulis vocatis H o $\mathrm{s}$, aunlfimus copiofum, fed in faxofis, nec perinde carnofum aut ramofum, tamen ftirpite ramif́; fruticat lignolis, duris, multis, lentis: folijs, paribus, \& fimilibus, vulgare maius Sedum fitu \& ortu amulantibus, minus crassis:inter vulgare Sedum mains, Laurcolam \& Tithymalum ambigentibus.

Gracum 


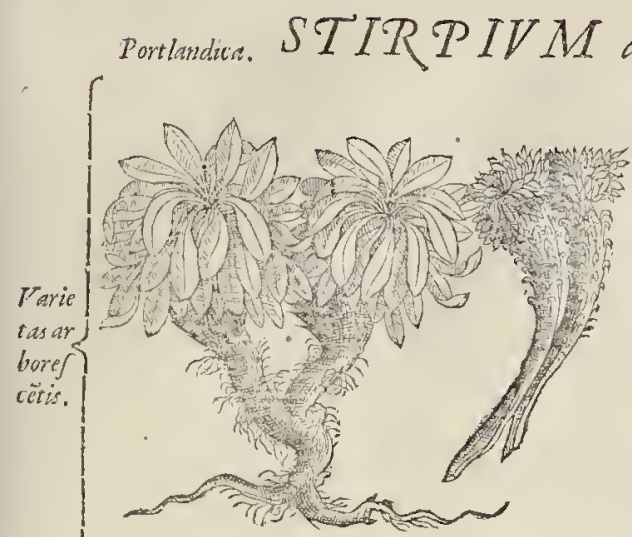
. taxat vna aut altera planta reperta

nobis erat, rati efe ex Tithymalis, aut ex iftis prolé degenerem, incertäọ; ftirpem,
nihil certi de ea prodere aulf fuimus.

SEDVM PETREVM Montanum.

A VERTIA Mindenis \& D. Ioannis Mauri AlloArogum, montinn rupibus \& conuallibus hanc pulchellam fippius collegilnus, nomineq́; Sedi Petręi donauimus, quod faxis fapitsinnafcatur : folijs pufllis vno exortu circinatim Sedi ritu, vel potius Cotyledonis minoris montani, fed multò angufioribus, rigidis, quafi ligulis mucronatis, è quöum medio cauliculi pufilli, binos digitos \& palmum alti,excunt, exi guis flofculis lntcis Sedi minoris onteti, quibus fuccedunt clypcoli Thlafpi quadantenus. Cur hanc nónulli Phyllon Diofcoridis ftatuerint nefcimus: gutm proprior multò fit facie \& ortu Sedi generibos, guftu aftrin gente, exficcante.

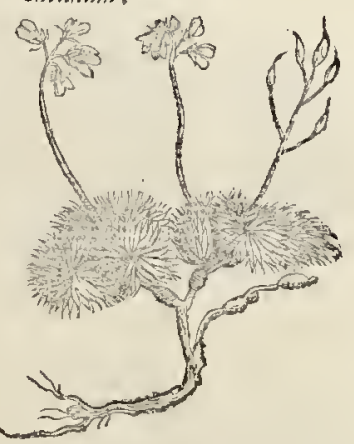

An CHAMaEPTT HIS maior Diofc. fon altera vermiculata Sedieffgizo.

CHAMPYIDES, quas natura fimiles Aizois fecifet, \& Diofcorides iifdem arsimilaffet, hic anneftendas duximus . Fruticat maritimis litoribus at-? q; infulis Anglix \& Zelandix, nec non in fqualidis campis Aralatē inter \& D. Acgidij oppidü, non procul à Rhodani fluétis, vber rima perënans, Verniculata dięa, nónullis Anthyllis altera putata, propte: necefsitudine, quam cum Aizoo habet.Sem per viret namg; inibi, virgultaq́; promit cubit 1 \& fefquicubitum æquantia, crebra, incurua, lignea, colore cinerco, folijs multis, denfis, obfcurè viridãtibus, \& inter Sedum minorem ato; chamapithim marem medijs. Radix multum dura , fibrofa. Flores oblitifumus, puto herbaceos, \& nielinos, albicãtes, mufcofos, Olex.Salfo guftu \& fapore fuccoó, Kal i etiam procul à mari, natæ, vti Aralate. Quam vt nouam, nec notam, crercitatis ingenijs expendendam magis proponimus, quuàm yerä aftruimus.

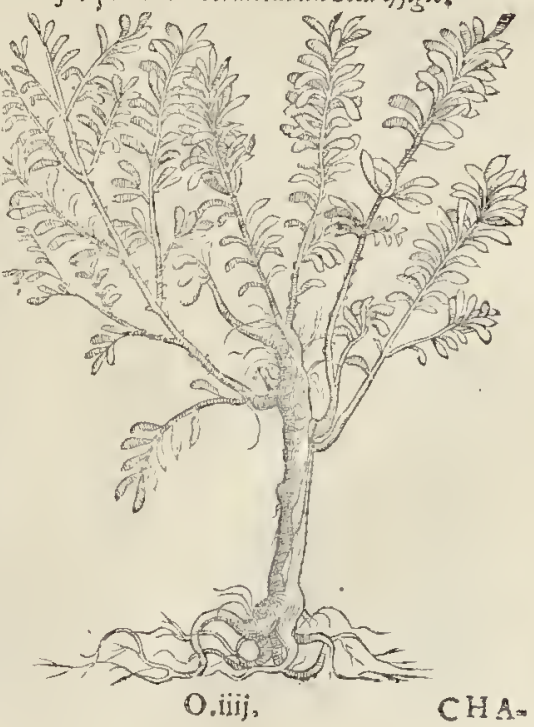

In Auftralıs Angliz Infula Portlandia, pufillam, nó multü diuerfá ab ittis forma, ortu, habuimus: led quia inter Tithymalos orta \& dun

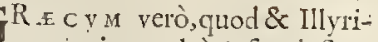
um, inaius multò \& fpeciofius, nato 2 cortice foliorumq́; circireolam imitantibus, crafsioribus, ribus, breuioribus, fuccutis a dali \&c cubitali, lignofo Laureolx crafsiote. 


\section{Ió4 JTIRPIVM aduerfarianoua. \\ AINGA val CHA AT ETT'HIS mas, Ding. IV A artbrytica.}

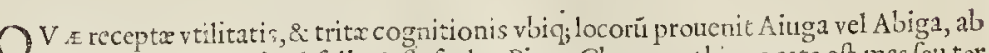

- Abicte propter odore, folia, 3. Hofculos Picex, Chamept this vocata elt, mas feu ter tia Diof coridi, nó prima, vt Cómentator ftatuit. S.buleta, arida, lapidofać; vineta \& oline ta amat Norbonx, ybi perquă odora, furculis gracilibus, hirfutis, infexis, numerofis, Pini tolijs vel Pfylij, minoribus, incanis, confertis, refinofis: exiguis interfertis fecus flofculos melinos, Veronicx focminx: Sed feminc oblögo, tereti, fufco. Germanix, Gallix, \&Anglix ruri fpote pertia, fed paucis in locis: eoǵ; in hortis colitur, ad Medicos tamen yfus odore \& virb ${ }^{9}$ ignauior. Radix fibris durituculis, lignofis, amaro fapore, medicato, fubacri, neu

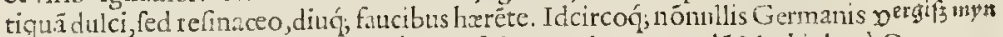
nichrid eft, ne mei obliuifare, fortè dieta fuit: quod etymum dü Marhiolus à Gernano Tharnacopoo, \&z Braffau ola adductum er ror is inct fat, immeritò facit: \& imperitius inul to labitur, cùn aliam vocatã ze lenger ye lieber, id fonat, quó diutius cio amátius, aut gratius,(quod Anaredulci fiuc Circex mericò quadrat) infcitè in hanc tranffert.

$$
\text { CHAHAEPTTHIS mima Diof. odoratior. }
$$

$A_{\text {I }}$ v s nota hxc, \& paucis obuia locis, magis tanen odon, collibus aridis $\&$ aruis $x-$ Nitioributs, Nicæ Sabaudx, \& Genux Liguftica, circum vrbern Penem in Italia, fruticat, ve quidã affirmant. Quin etiam eandé vireta nonnulla Beigij feculò colunt. Radice fibrofa, Sonchi, aut détis Leonis minore: ramulos palmum altos, humi ftratos, \& foliolis feptos, Semperuiminoris, aut potius vermicularis, minus carnofis, fed incanis \& hirfu-: tis:in quibus flofculi ex melino albidi:Suatriorem fpirat odorem,interdum vliginofum, vti vfaea mucúfue Quernus, aut Cedrinus.

\section{A Mofcata Monpeligest, ANTHYLLIS Chamepytoides.}

$V$ E. in Olimetis \& aridis aruorü marginibus Norbonx ac Galloprouncix fruticat, Hec alibi temerè nota, Mofchata etiā vulgò vocata fuit, cötrariæ fragrätix, fignificatü (ironicè népè) eft enim odor $a$, fed olfactu minimè grata,nec Finüredoléte, verę \& odoratæ Chamxpy tidicog nata, furculis tumé rigidioribus, farmétofis, lignofis, fed breuiorib": copiofa folia, latiora, lógiora, leuiter incifa, Coronopi aut $P$ fylij modo emittit, plur lanugineinca na,inters Hores maiores purpurcos, \& femé hirfutic ftipatū Chamrpytidis.Lignea radix, guftu amaro, ingrata tota, \& nonnihil fiptico, Abfynthiüreferente:capropter Kali fpecies illa, aut potius Sedi marini fruticantis, de qua inibi dięú fuit, neutiquam ad reni faciet, fi conferatur cum hac, Hirfuties, flores, color, odor, fapor, qui híc falfus non petitur, defint. Adde odoris grauioris, \& amaroris aromatici, non falfuginis notam:quan in medicamentis primæ commendationis ad comitiales plerifq, animaduertas, vt füt Vngulæ Afininæ, Alcx,\&

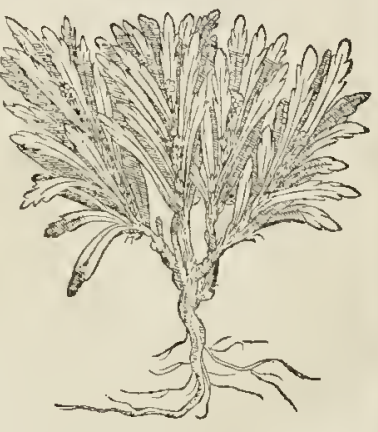
operculü onix dictum, multóq, grauiore odore, Caftorcum, \& huivfnodi nidore, potu \& fuffitu excepta, \& quarum dotes fibi vindicat multò adhuc certiores.

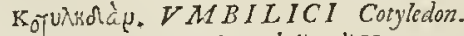

$$
\begin{aligned}
& \text { Ital. Cope, trituole, Umbilico diVenere. } \\
& \text { SHip. Scudeter. } \\
& \text { ¿Gal. Efcuelles. }
\end{aligned}
$$

Eff Mat V I g a r I s iam notitix Cotyledon, fic difum à concâno folio, acetabulun aut vmbilicum imitato, circinato, \& nonnihil crenato obtufe, ixuore plirimum glauco 


\section{STIRP IV $M$ aduerfaria nowa:}

virente, interim purpurafcente, craffo,carnofo, fucculento Telephii, aut Cochlearia:radix bulbee Buni Cyperi rotundior, aut fumarix Plinii, nonnullos pediculos foliorum \& cauliculos teneros florum herbaceorum ex caliculis parit, in quibus femé Portulaca, minus fubrufum : guftu tota glutinofo Portulacx, ted vix acerbo, infipida, frigida: non folim in Italia, Prouncia, Languegothia, fed etiam in Anglia occidua ad Briftoram, plurima.In Francia tamen \& Belgio, rara, nif fata fuerit : exit autem fenine, tota hyeme. viret, marcefcunt reftate folia.

\section{COT'Y LED O N Minks Sedifolio, Montankm:}

$M$ E Rito hanc Sedifoliä appellanıus, tätoperè namque cum Sedo quadrat, vt propiórne illi fit quàm vmbilico, ambigat vulgus: cóque apud nonnullas gen tes Sedum montanum appellitetur. Rarior multò fuperiore, nec nifi quibufdam Alpinis Allobrogü \& Pcdemontii, Sabaudáque ORenfi valle vocata, \& Mindenis montibus Auernix \& Germanix nobis vifa. Maio \& Iunio flores albicantes, minoris Semperuiu, in cat1le fefquipalmari plurimú vnico, ex radice fibrofa, nigra,tenui, perfoliorun, quafi centrum, eunte: foliorum lingulas oblongas, crafsiufculas, imitantium, \& tantillum anbitu crenatas, albo vel glauco lęuorc,colot e, carnéquc Semperuiui, minor is guifu.

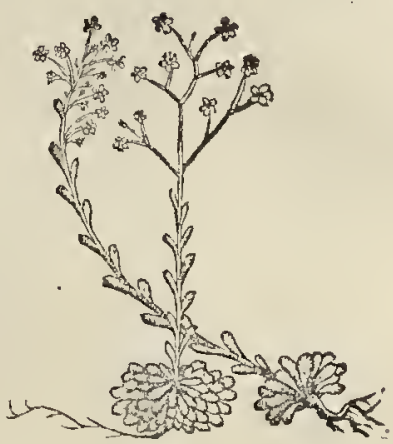

\section{AQV $A T C A$ Coryledon acris Septentrionalium.}

WV s p i A M Italix vel Norbonæ meminimus hunc, in Anglia verò \& Belgio \& Nortmania admodum frequentem, riguis deprefsífue pratorum conuallıbus, \& fcrobibıs, vbi torpuerunt per hyemem refides aqux. Fibrias exiguas, multas, cauliculóque teneros reptantes, humíque fufos habet, folia pel tata, ambitućue circinato, \& leuiore incifura \& obtufis dentibus: criftato medio centro, nomihil depreffo, vmbilicum imitante, fed teneriora:flofcult albidi, penduli fubter folia: Iunio \& Iulio vifuntur, guftu calido,acri, linguamq́ue vellicante, inodoro : quem infitia ctiamq́; penuria Cotyledo nis indunt indocti Pharmacari Populco vnguento.

\section{e $N D R O S A C E S$ Cotyledon Marinum berbafolliojum.}

QVEMADMODVM nominis etymo Androfaces, vel,ve nos putaremus, $H_{y}$ drofaces, feri lotióq; in abdomine, quafi vtre, alííque è corporis ductibus,eductionem pollicetur:fic videtur hic proximè Nympheas defcripta à Diofcoride, propterea quia non mil $f_{f}$ in aquis, \& pot:fus magna cum Nymphex fumilitud ne, tametfi multum difpari magnitudine crefat. Nec vllialis, vt genuinx, Androface acquiefcit animus, præterquam ifti, ex Guino fummę erudıtionis profe $50-$ re Pifmo:in Mathioli commétariis quadruplò maior (vti folent, qui imagines, non plantas viuas, viderunt) ipfa planta depicta, nec tamen ab co defcripta. Perclegans eft, fed perpufilla planta hrc vimbilicata, \& videtur è genete earum quas parafiticas feftuè quis dixerit, propterea quia non nifi al ena quadm vefcitur, ci-
bo, \& difco.Innafcitur ferme femper dorís ftriatis Cham $x$ conch $x$, qux humi obuolut2 fit 


\section{I66 STIRP IV $M$ aduerfarianoua.}

ta fit y 2cu2 hofpite fuo Vefco apud Italos Cape tondo vocato : ${ }^{p}$ edicellis cirrífue, glabris, nitidis, exilibus, vncias binas altis, crebribus, furrectis, fingulas fingulí cly pcolum medio centro fulcientibus, circinatum vmbilici, cum ouracis appenfis in memoriam reuocant-bus, rnde Monfpeiliēfes præceptores Vmbilicum marmum vocitarunt:notifsina quippe illic Pifcatoribus ftagni Magalonenfis \& Later accolis . Frontignanzetiam reilux itagnantiff; aqua falle innumeras plantas obrutunt. E fundo quippe inç; aqua, non in aere, crefcunt \& viuunt vt Mathiolus pinxit. Virent enim primun ex fqualido cincreóf; colore:Pofteà egefti vndis, exceptić; litore, albefcút, vti conchilid \& corralinx vocat $x$, quas guftu fubfalfo \& a nato æmulazur: nec dubiun quin vrinas ciat, \& materiam articulis impactum digerat. Semen nufquam vllum vmbilicis claudi non putamus, certè nunquam in multis mulibus obferuauimus. Ventrem fiftere fcimus, vt hunc fcrupulü eximamus doEto \& candido Anguillar $x$, qui nefcio qua de re Senam \& Cafsitham hariolatur verifimiles quia emphyla aut aphyla planè contrarix notæ legatur,potitsimum quia aluum foluunt, quod hic nec; expetitur, neq; verifinile fit: tota plantula ficcior actu \& tactu quàm calidior eft, \& multun diuretica, cuare Galeno aut cius codice error, qui aftruit humidā, ex Egineta \& Plinio req́; ipfa expungendus.

Fuir quando Tragum ijfdem fere maritimis oriundum, hanc Androfacem opinati fuimus, fed nos retinut $P$ liniana verfio, qux accuratior hic, quàm quxuis alia videtur:delineatquippe fine folijs in cirris follicalos, habentem, \& in hisfemen, albam anaram,

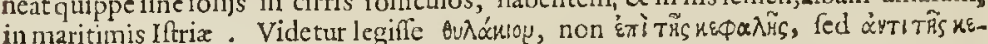
$\phi \alpha \lambda \hat{s}$, quafi dicat folliculum, pro capitulo, feu verterit ex Diofcoride: feu, vt verifiniluus, rterq; ex codem authore. Cxterùm Cortufi munus valdè leuideufe fuerit, fi Morlüm gal linx vel Alfinz, foliolis neutiquam nudam, non ex Syria, fed è veteri quapiam macer 12 decerptam, quis patefaceret Commentatori, qui proinde non aufus fuic oratione reprzfentare.

\section{Aydéxing PORTYLACA Domestica.}

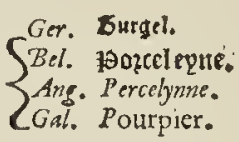

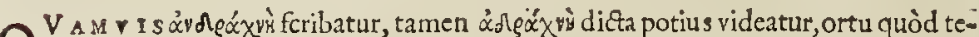
neritudine quadālzta \& carnofa luxurient, ramuli foliać; albicent, quadä fpumofa fuligine fue tenui quapiam afpergine cinerea, qux in marina euidentius multò cófpicitur, vbi nec colitur, \& aura fpumea aflatur quam $\alpha$ xuhv dicunt. Tribus autem differentiis, quot nouimus penè eadem facies eft,przfertim domeftic \& \&ylueftris: quarum tamé contrarix facultates \& effectiones vidétur principiis genericis differre, \& $\&$ tabilire noftru docendi modum,qui figurarum priufquàm facultatü annectit feriem. Etenim quamuis Diofcoridi Satiua Portulaca refrigerat, Sylueltris tamen calefaciat, \& eadem exulcerat. Nec tamén inficiandum, multas effe plantas, quę quamuis polleant contrariis aftectionibus, tamen eodem generis ambitu cenferı debent, vti hæc marina pläta $P$ ortulacæ foliis, \& facie, quam Crithmum Diofcoridis putarunt: nam nihil videtur illi obefie, aut deeffe quò minus $P$ ortulaca fit. C $x$ terum, non aftringit fed refrigerat, legendum elfe norit qui attentius caput de Portulaca apud Diofcoridem à carcere ad calcem luftrarit, ea e nim

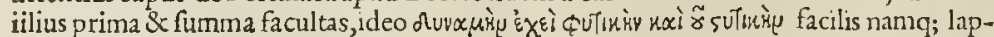
fus rerum ignaris amanuenfibus. Et qulibet etiam ex illa vi, qua hxmediam dentiúmve ftuporem aufert, minimè aut minimùm certè aftringere deptehendere quit in quotidianis acetarijs, quú vulgo efitantur tenell $x$ Cym $x$, \& folia craffa, carnofa, Thel ephij \& Scor pioidis vulgaris: fucculenta to ta, rotundis teneris viticulis humi reptantibus, florepufillo Sedi: femine in theculis feminis Papaueris nigri plenis cauli hærentibus.

STLPESTRIS. 


\section{STIRP IV M adverarianona.}

Q V I Doneticam norit, Sylueftrem non poteft non nofe, qux minor dun taxar tota, locisq́; fquallidioribus, vinetis glareolis, viarumó; interdum ftratis reptat:ramulis rubentibus, folio Oleaftri, figura cxtera dupló minor tota : fed guftu acidiore, \& non refri zeante, fed potius acri calfaciente, vt in Norboncnfi agri vinetis \& fatis, vbi acrior multò, quàm in Anglia, aut humétibus frigidis ad Septentrionem:quin etian exulcerat,

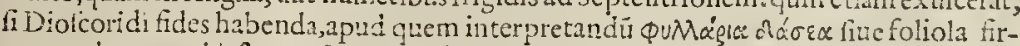

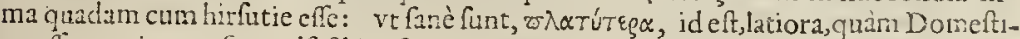
cæcfe:ncutiquam funt,nifi fibi ipfis comparata, quia funt bretiota \& latiufcula, quaf rotundiora: aut fit fortè inmmutatio ill a apud hunc qualem frequétem \& Theophraftuщ latioris \& : ingutioris folij, in Helenio, phlono, \& alijs non pancis monumus.

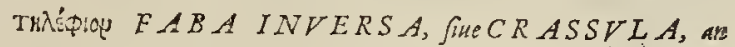 \\ TELEPHIV M?}

Ger. Woundraut, thaben Fraut, fot; 3 mang, ond fortzreyn.

Belg. mot!sen Utupt, $\$ 1$ tretwottcle.

\{ltal. Fabagraffa,

Gul. Reprife, Ioubarde des vignes, Fene cfpeffc.

Ang. Orpyne.

VA G Y \& pluriuocú fuife Tclephij nomć, ex Crateuæ \& Diofcoridis geninatis deferiptionibus \& varijs plantis accommodat videre elt. Cratenæ quippe notz, vti re- Eff.g. apnd Do centiores dofiores fcitćmonuerunt, Scorpioidé, qua Dioforidis libri 4 . calce penultima do. Epi.4l. appingitur, exprimere videntur:ncc funé abs re, nam facultates illi ineffe eximias ad diffepulotic \& \& inuiga vlcera, non modò lectio, fed \& animadnerfio facti periculi crebra, tefta tur. Infuper duobus locis duas plantis Tclephio nomine infignit, non parum tamen fi- of e. Telephikrs miles: alteram hoc capite, alteram libro $3 . q u a m$ Romanis Illccebram nuncupatä dicit, Cratcua. vtrāq; facie \& viribus vulģo nota:P R I O R C R A S S I A dicitur, quia folijs craffis, car nofis, Portulaca hortenfis non abfimilibus, floribus albis, luteis vcl purpureis in vmbcllis Drabx:cretera prorfum Portulaćé fimilia, radix alba, carrofa, tuberofa compacta, Dentis Lecnis bulbofi, aut Leucacăthæ Diofcoridex, vinetis, cul:is, fyluofis, marginibus, fixofis, Anglix,Sabandix, Gallix, \& pafsim alıbi abundat. Hanc r-gidi cenfores pro Telephio faftidiunt, \& inquiunt calore \& abfterfone carere : refpondent periclitatores, illam multis dotibus polle re, \& plura prętare quàm quæ Diofcoricies fribit:addinus nos, calo. rem illi non deeffe, neq; ficcitatem, quantã Galenus \& $\mathbb{E}$ :ata prodiderunt, nempè prinui ordinis, id eft, guftui vixdum perceptibilem. ficcitateñ verò cuiurmodi in Semperuiuo: Abfterfioncm quale farina fabarum \& Portula z $x$, qua :amen videntur potius lenire muccofo glutine, cum primo adpulfu linguam tangunt. Sed fruftrà fæpè monemus, iftos defici modeftia \& peritia. Etenim fi calefactione, ficcitate, $x$ abfterfione, Telephia curarent vılnera, numnä id præfarent prệentius, quæ multò tum calidiora, tu m magis abftergentia funt? Sed curata putamus tum potiunculis, tum pulticulis, \& fomentis ex ifta paratis, ad acrimoniam faniei erodentis, \& opus natura prepedientis retudendam,ac cacochymiam corrigendam intus \& foris.

Alternabatur Diofcorides, vti videtur, vtri effet afcripturtus Illecebram Romanis dictam herbulam, Telephij ne generi,propter vfum \& nomenclaturã an femperuiui, prop ter faciem \& figuram : \& quia videtur optionem feciffe Le \&o:i, vtrum mallet eligendi, nos Telephio affribemus. Siquidem non femper viuit $\&$ vrit, 2tq; eadem praftare poteft que Telephium, aut qux in Telephijs \& Cacocticis vlceribus fanandis defiderantur:tametfialio modo, vt exercitati operum exploratione norunt, iciem affectus diuerfis, \& interdum contrarijs, expugnetur. Sic in vulneribus, capitisq́; fracturis, vtimur calidis exfic cantibus, vt Ifide, \&e de Minio, vel frigidiufculis, interdum humentibus, vt fanguine columbino \& Roficeo, ad mitigand um, digerendum, \& expellendum excrementa à parte; 


\section{STIRTIVM aduerjarianona. SCORPIOIDES, anCrateue TELEPHIVM.}

Mark. depicts non defcripta, pes.130s.

R E C E N T I oR VM verò \& Monfpellienfium Portulacz foltam Scorpioiden, vulgò fic dietam à filiquofis corniculis Scorpionis caudx inftar reflexis, Galegx femine plenis, dostiores, qui Telephij [peciem coniectabant, non infirma ratione nicebantur . Eft quippe folio Portulacx foreluteo, non tamen albo, Medica aut Trifolji parui, pratcnfis lutel : guftu item \& facultatibus non multum diuerfis. Monfpellienfibus cum fatis, tum vinetis, Latrenfis portx admodum familiaris.

Crithmum Diolcoridis, an Pottulaca marina?

Empetrum, vulgò Foniculum marınum. Ang Sampere, Perchepier. Capea.

$\checkmark$ Halimus.

Chryfanthemum marinum, Math. Crith.tertium, vel fecundum. Kali.

Salicornia.

Blanchette.

\section{CRIT HMVM, fen CRITHAMON, ar Portulacs MMarina? $B$ AT IS Pliny.}

PL в z ey funt maritimx ftirpes qux Crithmi defcriptionem quadamtenus dea fignare valent, nulla autem penitus explere. Quod quidem non vt nodum in firpo quxramus, fcribemus, fed potius vt hafee tricas expeciamus, que animum quo minus verum ftrtuar,irretitum tenent. Et paucis vniuerfuin negocium componi poteft. Si ftare lubet antiquis herbarum defignationibus, vides hic fruticofam dici plantim ì Diofcoride folijs pinguib. longioribus, \& latioribus, quàm Portulacx, albicantibus, falfis, \& cxice Huic defciptioni habemus plantam quandan, qux malius congruit, quàn $F$ os-

F O N I C V-! tera. Huic derciption habemis plà herbarijs hodie Crithmum putatum, quod neun I $\vee$ M marmu, N I C $\checkmark$ I $\vee$ M Mam Portulacx, vt Diofcoridi placet, fed potius facie tota \& vmbellis Foniculo, vt infue EM P F- fpectio ipfa vulgus ignanum vocare docuit. Et folis non albent, fed virent Porraceo coI R V M vulgo fpectio ipla vuigus igna itur \& pafsim efitatur, ideo fit Critlimum habendum : ctenim

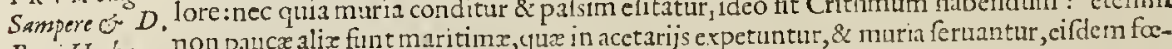
Petrifterbs. non patucxalix funt mar pollerecreduntur. Atilla, qux à fimilitudine PORTV I A A Math.Crith. niculo itto facultatibus pollere credibus \& longioribus quàm Portulacx, atc; albicantipremui,effi.489. M A R I N A dreta ful, folis, adeoǵ, faxeis, maritimis, copola, cuius flores albidi, herbidi, P O R T V L A - Atriplicis : multò propior eft vero Crithmo. Cxtcrum, ineptiufcula audacia eius eft qui

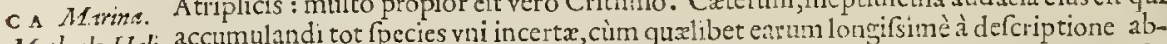
Matbaslo Hali-acc : alioqui curnon \& tam multas Kali fpecies, neci defcriptas, nefcio an notas Diofe. m:s kr/garis. non pofsit quis vnam accumulare, \& pro Crithmo vindicare : nam fermù omnes naucleEffg.i6o. non poibum cedunt, nobis etiam in mare Liguftico acetarijs manfepenuria inelioris cibi,non pefsimi faporis vifre fuerunt.

Et fciunt exercitati, fecundum Crithmum Commentatoris planè $P$ aftinacr aut Eringij guftum, odoremá, prafe fe ferre, vnde Arabum Secacul opinionem fecit, vulgus Paftinacam marinam vocat. Vtrumg; litus fuperi inferić; maris Italici hac planta featet, ne non putet Senenfis fe munus leuidenfe à Cortufam magnificentia accepiffe, quod pueriliter folitus eft iactare, \& inculcare putidinfcula infantia. Tum tertix \& quartz fpeciei ab illo depiâi, quid negocij aut fimilitudinis cum Crithmo:tertij, e tiam flores lutei Jontanum E- funt, radiati, vt Clnryfanthemj,quó tetulunus: catera cius delineatio, nihil ad Crithmun. ringium recen- Quartum demum montanum eft, non nłaritimum, guftu \& odore Enngij, radice fiulvoorum. Ies funt, Crithmo valdè difsimiles. Hinc videre fit ea qux meris affertionibus, non rationibus, aut veris infpetionibus, afferta ab illo funt, eadem facilitate dirui, atg; ftabilita 


\section{STIRPIVM aduerfarianowa.}

fuêre. Hxc fi oculis \& manibus verfafies, vti nos fccimus, non tam fitiliter affeueraffes fe ${ }^{n}$ tentias neq; veras, neq; perfpicuas, qua magno detrimento funt non modò Tyronibuss fed doctis quàmpluribus.

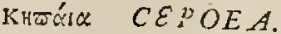

CV n haceadem Domefticx Portulace figura, vna aut altera vagula notula radicis \& colorisadditis, quafi fatis foret nota, \& redditæilli facultates, qux fatiux confiniles funt, mentione etiam incerta, de Afparago Myacanthino, quem proxim ¿ Portulac $\mathrm{c}$. put,appofuit Diofcorides : Videtur \& hac nihil aliud quàm hortenfs, vt pox T:śáce teftatur,Portulacz fpecies, qua illinc huc irtcpferit, argumento \& methodo hic non veftigandis. Eoq́; Galenus fortè ratus è Portulacis vnam, eam tacitam preterijt. Marinam Portulacam, fpurium Halimum,Becabungam, Crithmum fecúdum Mathioli flore luteo, denig; medij fpeciem huc licuit adducere, fed nihil libuit affercre. Neq; ingenuos dece $t$ tyrones, cuiufmodi fumus, tantū fibi indul gere in Naturæ doctorumq́; theatro, quantum fibi arrogat ăuTos é ф̀̀ Pytagoras alter Herbariorum Senenfis nofter, qui vt folitus, hanc pro filio fuo Odorico Melchiorio, pro ętate fua non imperito fibi inifiam, nunc tandem, cognitam alfeuerct: nec tamen vllam notam addat vel figur $x$, vel naturદ̧, nedum locorum quę nos certiores faciae, illï Capeam hancadamufim fuam congrucnten certam explora tamq́; habuiffe. Hanc nosfuperius dedimus inter Portulacas,

$$
\text { ¿̈inuos HALIMVS. }
$$

ANNo 1563 . OCtobri menfe, quidam Botanicus Italns, qui ex Sclaucnia onufas raris plantis redibat, quandam locis maritimis lectam fruticcm nobis petandun dedit, Cilti magnitudine \& modo, folijs O lex albicantibus, Portulace marinc, fue Halimi vulgaris: fed fenine \& fore tunc orbus crat ramus, quem adhuc habemus Antuerpix. Hanc cuncti Herbariorum Scnatus. Venetorum Halimum affimabant: Et Lco illc famofits a5y"rta dicebat, fe feppius quordan, qui in acetarijs teneriorcm efitarint vidiffe: cui ne nunc quiden magnoperè r efragamur, nam falfa erat, \& maritima. Sunè planta videtur elle falfa, vel nominis vel natalium argumento, Halimum.

Quid fi negationem eximas, \& dicas, Diofcoridem dixiffe fpinas habere,nam vt quid inter fpinofas \& vallatorias \& finitimas, maritima cum fit, recenferct:nam que vefca fut \& holeracea fecundo libro differunt ur.

KALI magnum Sedimedif folio, femine cochlento. Soede, Gallis.

Q $V$ AM $V$ is tres plant $x$ fint inter fe congeneres \& inaritima, que Crith mum, vt dudum diccbanus, adumbrare poffent:tamen nulla videtur antiquis nota fuife, aut certè defcripta,tantim abeft, vterhifes 5 A I iftud, vocatum apud Arabes K A I I, exifarum vna vfta, \& quod mirum, fufa fieri nouetint, vix tacituri fi fiuifent. Quaic vt nomen,fic \& pläta, \& modus falis iltius parandi,videmur Gręcis rccentioribus, ant Arabibus Philorophis Chymiftis \& yalurgis deberi,qui ex ifta, quam argutè effigiatā danus, copia, per initia Autumni aceruatum fuper fcrobe, cuiligna infunt decuffatim inftructa, rt accenfa meta herbæ Kali dum vritur \& liquatur, inq́; fundum fcobris defluat, $\operatorname{cog} 3$ thirq́; in glebamaut faxum pulli nigrican tIs, vel cinerei coloris, illi vocant Kalli, vel $S$ O D E ad vitrum conflandum in Italiam inq́; Septcntrionem cx Gallia Norbonéfi \& Aqquitania deferunt. Vrit non fecus ac

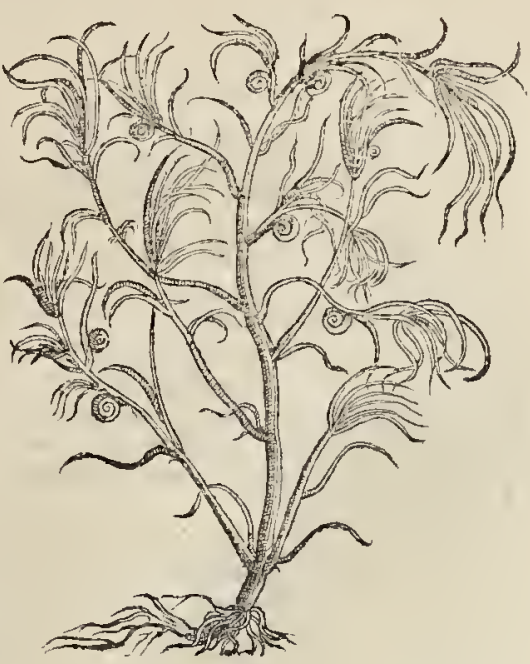

P.i, 
caufticü. Hæc fpccies \& notior in maritinis Gallia Norbonenfis, vbi tum (ponte, "tü fata, cäpos maritimos frequentia, cauliú rubentium operit purpura. Fruticat etenim caule cubitali \& fefquicubitali,carnofo, Portulace concolori. Folijs item denfis, anguftis, fimbriofis, Sedi medij fiue Semperuiui minoris teretifolij duplò longioribus, acutioribus, inter qux femina Limaccm pufillum fpiramúe imitantia, colore fufca, follıculis Malux feminıs ritu occlufa. Minus obuia hre Septentrionalıbus, imò nufpiam fermè.

\section{BL ANCHET T E Norbonenfum, fine}

Kaliminus.

FOS D E M ad vfus [ćdulò colligunt maritimi coloni Norbonenfes, ijfdem nátalibus, folijs, \& caulibus minoribus multò, minusć; carnofis, anguftioribus, necita rubentibus, fed ex pallido virentibus, vnde vulgo Blanchette, quaf Kali album vocatam. Semen exiguum, nigrum, lucidum, Vrticx aut Acetofe. Non folumicalidioribus regionibus hxc, fed etiam ad Septentrionem Angliz, Normanix \& Belgij faniliaris.

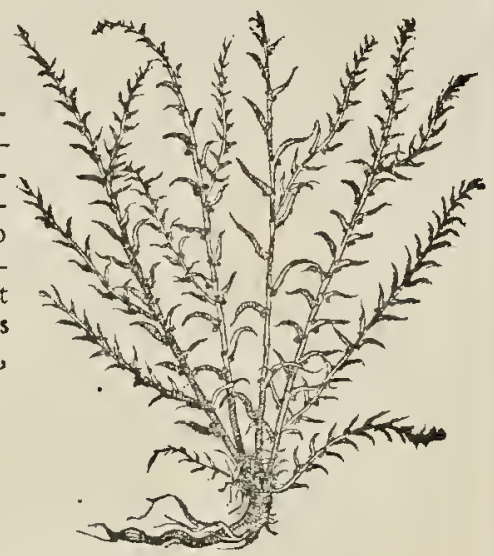

SALICOR NIA, fine Kaligenieulatum vermiculatum.

$M$ L 2 r o frequentifsima ad quaflibet IVI 1 maritimas otas tum Oceani, tum Medircranei maris: fed effigic multò rarior, \& cui folia videntur teneri turiones ramulo:um: femen nullum. Sunt enim è radice fibrofiore quàmplures cauliculi bicubitales, recti, geniculis multis donati, extremis quafi folijs crafsis, pinguibus, carnofis, teretibus, rubentibus, per crcbros gcniculos infertis, \& pyxidatim,quafi alabafticuli,quadä cum Equifeti frmilitudine, \& cornun I ceta obtufius mucronata imitancibus: guttu non infulfo, nec temperaméto aut vfu difpari à cæteris, verùm rbiq; neglecta.

$$
\begin{aligned}
& K \text { ALI Jino- } \\
& \text { ofum Capite de } \\
& \text { Tragano. }
\end{aligned}
$$

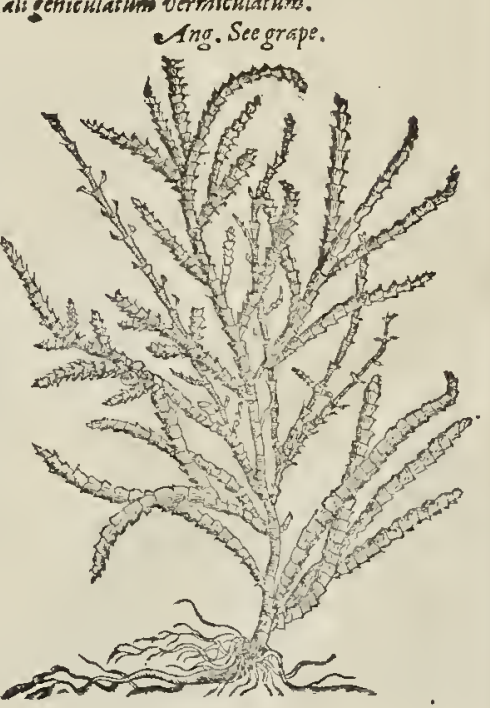

LITO- 


\title{
STIRPIV $M$ aduerfarianoua. \\ Litorenm CHRTSANTHEMVM flore Bupbthalmaiaut Conifra, folys \\ Kali, aut Ine muscata.
}

IL $L_{\text {I }}$ s accenferi debet hxc, quam putartnt nonntilli Crithmum, quia non nif mariti-

mis gaudeat, Dore pereleganti, radiato aureo Afteris ant Buphthalini : foliss pluribus Effig. Mar.49j perinterual:a caulen ređum cubitalem \& fefquicubitalem anbientibus, ftellatim cin-- Jub romme gentıbus, rectis, piuguibus, exviridi cinercis, vel pallidis : 'guftu falfo, nec alio quażm vna Chritbms. quapiaul fuperiorim.

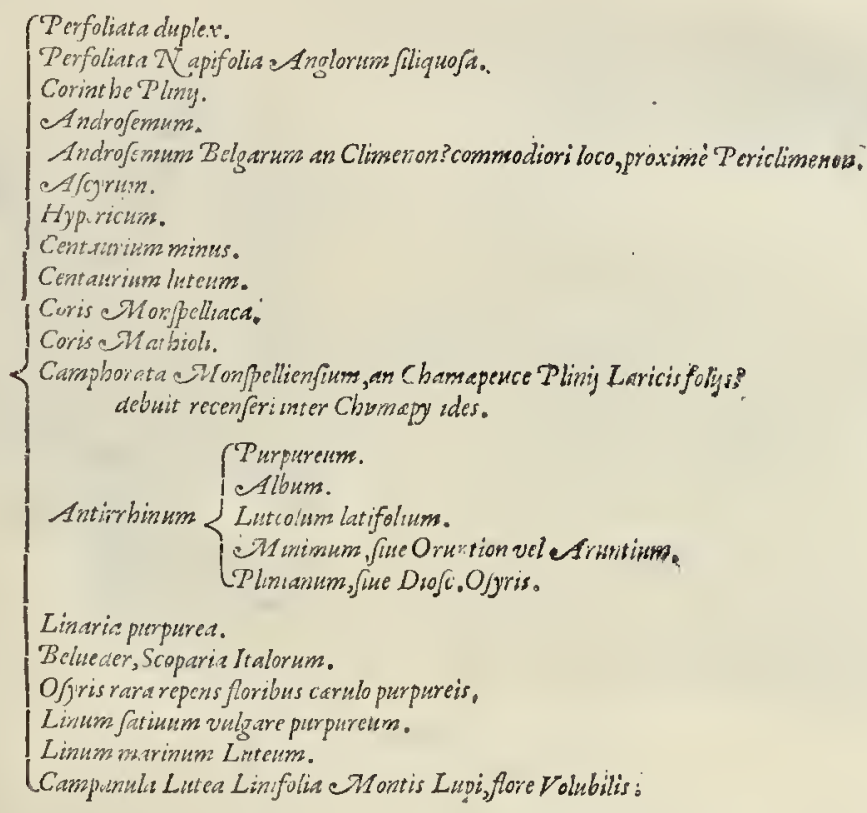

\section{PERFO LIATVM vulgatins, fore Luteo, folis Vmbiliculo.}

\author{
SAng. Thorow waxe, \\ Bel. Duertong. \\ CGal. Perfoliata,
}

F N Burgundix,Sabaudix fegetibus, \& latis,alibiq́; Gallix Germanixq́; hxc occurrit, Effig.Dod.

è radice vnica, fimplici, fibrofa, multos graciles ramulos promens, quz folia tranfmit- Eptr. 172.

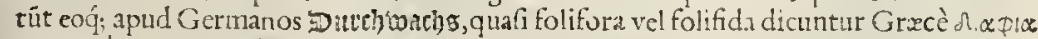
\& dix $థ i n \lambda \alpha$. Sunt enim rotüda,cana, Tithymali ampliora, tenera, exucta, nec pinguia,colore ex glauco virentia, \& lxuore Plinianx Cerinthes, cui multum finilis. Per Auguitum fores funt in fummo pufilli, ambıtu radiato ex aureo pallentes: femma fufca Saxitragia hircinx pratenfis: guftu non amara, fed manfu refin ofa, hyperici aut Clymeni.Co:itur eti am ì Chyrurgis ad fraturas, vlcera, \& hernias vtenda. Variantem hanc iam pridem \& hoe anno vidimus in Morgan hotto, floribus fpeciofiore fitu \& fertis vmbellatis el egätiores.

$$
\text { Dij: SILI }
$$


VANDA it item donarút recentiores Perfoliatx nomine, qux tamen ambigux naturæ videtur inter Barbaream Buniadem \& Perfoliatan, non minus frequens, fed fxpius in montibus calidiorun regionum, occurrit folijs matoribus, longioribus, afperioribus, habitioribus, rigidioribus, aliquantum finuatis Dentillartx modo, filiquas angu lofas Leucoij pralongas, exiles, feminis Brafsicx plenas aut Leucoij. Gufu neutiquam acri.

CERINTHE Pli.

ZA C v L T A T e, guft, \& effigic,illis \&

Hypericoni, nó ita abfimilj, fed hilariore nultó afpectu ea eft,quã Cerinthem apud Pliniun cóiectarunt recentiorum doetísimi nó pauci,minus tamen incertis admodum indicijs : colore ex vegeto viridi, glauco \& cerulco, oculos oblectàte: folia funt oblonga, non difparia fuperioribus, nec gultu ingrato, fed tamen medicato, \& quafi Climeni fiue Androfeni Belgarum vocati, veluti fi quis guftatet ceram nouam melliufcula'n. Etiaunü hoc nenfe Augulti in horto peritifsimi Pharmacopoei H.Morgani, Horibus Iuteis Androfemi vel Hyperici prag nans vifitur, femineq́; didimo, foris atro, iutusmedullofo Canabini aut Raphani. Eius Aloribus apes capi \& oblectari putarint, litt enim vt venufti, fic nó infuaues, \&. guftu fubdulci: fol ia autem cum manduntur, ๆuiddä ceræ nouæ, aut Erithaces vocate, fapiunt, vnde dictam fuife veriflmile elt.

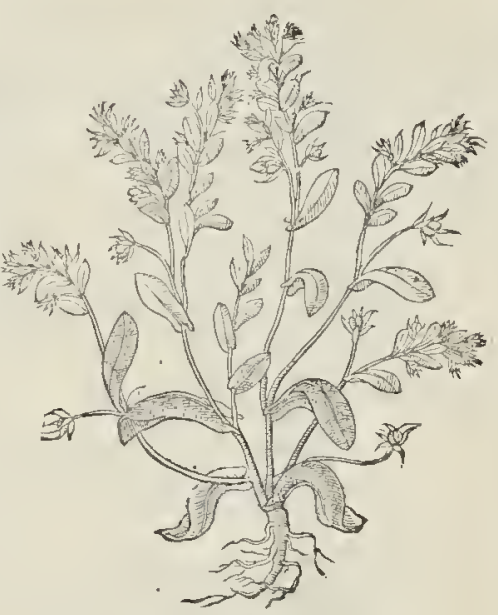

iTEกIXUN. HTPERICVM.

Ger. S.Jotjans tratt.

Belg. S. Jaus cttipt.

$\{$ Ang. S.JobnsiVorte.

Gal. Millepertuis.

Ita. Hyperico

Hip. Coraioncillo.

Efi. Dod.Epir. NVS I A M de elegantiorib. iconibusHypericum, Afcyrum, \& Androfemum, con-

hiftoria veró iam tráflatitia \& vulgatior, tum quia accuratior Diofcoridis defcriptio, tum quia plantarum inter fe tanta cognatio, vt vna duntaxat nota, ceter l.utere que:nt, fi copia adfit, neminem. Vbiq; vulgatifsima \& vfu tritifsima medico \& chyrurgo Hypericum dieta, margines fatorum, areas defitas, \& ruinofa feetans, ctiamq́; letiora loca. Tota planta multum ortu, rirgultis, folo, \& têpore, fed rotundis, rubentibus floribus \& folijs, xmulatur Centureú minus: fed huic nomen Perforatx vel Milleforx, quòd folia obuerfa Soli, innumeris ferè poris, acu quafi traiectis, aciem tum noftram, tum Solis tranfmittant radios. Flores odori, pingues, glutinofo contactu hxrent, atc; chartas fanguineo Anchu five cruore inficiunt. Semen in pericarpijs copiofum, odorum, refinaceum, amartum, \& ingratï guftanti, ad vulneraria balfama nulli fecundum, multo Chyrurgor un peritírsifnorum Monfpellienfium experiméto, vbi etiam oleum vernaculè de T rejcalan vocatum, quotanuis paratur longè optnnum ad hunc modum.

$$
\text { OLEVM HXPERICONIS. }
$$




\section{STIRP IV $M$ aduerfarianond.}

Accipit fummitatú Hyperici\} $\}$ añ. $\mathcal{L}$. ij.
$\&$ olei communis.

Myrrhz

Gummi Elemni \}ań. vnc.ij.

Terobinthinæ. vnc.iiij,

Aloes. vac, j.

Thuris

Maftiches. $\}$ ań. vnc. f.

Infundantur, bulliantó; in diplomate cx arte. Ad IQterum ctiam \& Calculum rtilitas confpicu2.

\section{ASCIRVM.}

SE c v N D ₹ M Hypericum eft Afcyrum notifsimum,amnium \& riguorü riuulorumq́; Effi.Mak, 937 pratenfium amans valdè, quadratos rectos viticulos è radice mul tum fibris fparfa exiles erigens:alterius folijs paulò maioribus, venofis, punctim poros peruios habétibus, \& floribus itidem luteis, coccineum cruorem affricanti illinientibus. Semen cdore refinaceo fui indice, nares feriente. Haud difparis, fed infrequentioris yfus.

A $N D R O S E M V M$ excelleritus dittum, Jsu magnum.

$V^{\text {Texcellentius, fic rarius, nec nifi opacis \& fyluofis gadens, verius Androfemum vo } E f f, \lambda 1 a t h .939}$ catum, quòd non modò Horibus, fed etiam folijs tritu \& preffu muriceum remittat fuccum, quo vno pre cxteris Androfemum agnofcas, \& difcernas, par eft: Procerior maiorć; tota, \& altero tâto niaion folia, pauciora, quàn Hyperici, cui etian fimilius fore \& femine: Procerioribus, bicubitalibus, gracilibus, rotundis, rubentibus ramis. In collibus \& nemorolis pone Riuoli Pedemontana arcem : Norbonenfibus ctiam Senenis pafcuis \& Sylnofis, etiamó; in Anglia aftare fuperiore prope Briftoiam:In Vincentij prarup.
tis \& fyluofis trans fumen.

\section{A LTERVM tomentofum.}

IN agri Monfpelliaci locis natura rdis \& fubftillis, fed feruidioribus Solibus exuctis, f $_{\text {- }}$ pius Hypericú occurrit palmo non maius, \& humo pronius, folijs item minoribus ex interuallo rarioribus: flore \& femine lutcolis pallidioribus, tota cana \& hirfuta, minus o. dora:non alio fapore, fed imbecilliorc.

\section{$C E N T A V R E V M M$ parum.}

IV I I i non norifsimum Centaurium, Hypericoni omni fui parte fimillimum, nifi Effi.Math.6s? fore rubro \& inligni amarore( $v$ nde Fellis terræ nomé) difcerneretur facilè. A ccuratiores nimiò figurarum aut defcriptionú exactores, qui Centaurij minoris notas expreffiores defiderant, nodum in fcirpo quærunt: vtinam non multo plures deterius infignitas haberemus.

\section{CENTAVREVM Luteum}

$Q$ v I D verò de ifto altcroluteo fentient, magnoperè fcire anemus. Quamplurimis tum Galliz, tum $\mathrm{An}$ glix locis, ifud luteum nuncupatum: prope Rondelletij \&. Afratipradia, multa Monfpellij: collibus vrbi Brifoix eninentibus, inter fegetes itidem . Radice exigua, folia ima proximè humum pufilla \& ftrata,vt in altero . Caulis fefquipalmum alrus, ex interuallis bina folia, aut potius rnicm binis apicibus vtring; donatum trijcit, non fecus atç; Periclimenis videtur huic \& fuperiori contigific: nam Periclimenon alterum, traijcit folium, prafertim fupcrits, prope fiores: Alterü, bina diftincta folia, Floribus altcrins, fed aureis

$$
\text { P.iij. intenfè }
$$

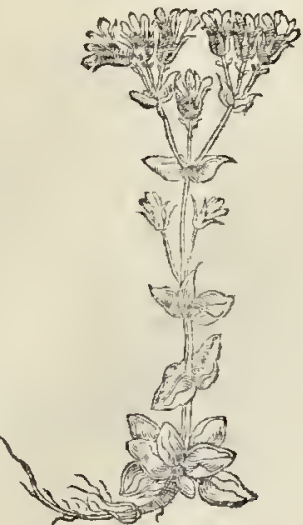




\section{STIRPIVM aduerjarianowa.}

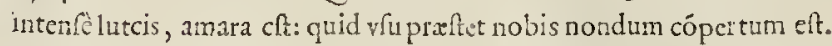

\section{COR IS Ronpelliaca.}

$K$ og̀s, alit potius róg', virgo, puellàve dici potuit, quia tota pulchella \& perquam hilaris vultu hác noftra: vcrum Hippocrates \& antiqui, hogh, id ef, pupillâ, vocarunt, propter femen oculi pupillæ, feu anteriori humori cryftallino anbitu fphrico, haud abfimle, cuiufmodi in hac cernitur: quan quia nufquam nifi Monfpellij \& Frontignanæ ad radices Ceti, \& prope Magaloncin, reperimis, nec alibi notam audiuimus, ideo cognomincm fecimus vrbi, lectifsimis nobilitatx ftirpibus. Hanc autem perraram nifi huc appofitiśsimè quadraffet, Erică minimam putaffemus, aut nnedia cuiufdā inter Hypericũ propter purpuriffä, \& Aiugæ propter folium naturæ:Ian non aliò, quàm ad Corim referri poffe arbitramur. Fruticat quippe ramulis multis, défis, curiufeulis, furrectis, ro-

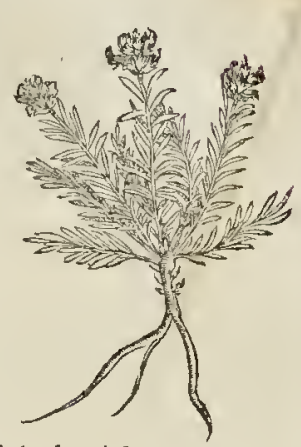
tundis, palmú altis \& éfquipalmú, lignofis, cuius etiam foliola denfè ftipata Ericx maioris, \& condita, forum purpureorü tyrúlis confmilibus, purpurea, coerulea, nitudiore \&amœniore decoris fpeetantur. Semen vtricul is mollioribúsve alabaftriculis conclufú, rotundū thanarifci par, glaucum vel pullum, tenuifsimis tuniceis gl umis inuolutú, quafí occli pupilla tutior inde futura forct. Radix multò fanè maror, longior, \& crafsior, quàn pro plantx modo, Anchufa minoris par \& cócolor. Tota namque planta rubelía vificur, \& fucco purpureo radicis pannos imbucndo cómendatur:amaricat guftu fubacri,non in odora. Eauropter Corin nö dubitarunt profiteri Kódellctius \& Affätius, doctirsimi Prxceptores, \& in Academia fimpl ciü indagatores, quibus frequens affentiebatur auditorū corona. Cuius tamen clegantia li minus capiantur ift morofuli plumbei ccufores, quibus nihılpcnè à noftra mediocritate profectü plicere quit, arrigăt aures attenti, magni Senéfis de Cori hiftoriam percepturi, qui fic infit, vbi nuda Diofcoridis ycrba recitauit, \& in Italia(vt nillies rcpetit) uafci dixit: Sed quòd de Corimentionem feccrit Galenns

Marbioli Coris. in fimplieium cenfu, mithi ineompertum eft. Qux denique nogis, Gracè, Coris ctiam Latine, St Cor1 Italicc vocatur. Hactenus eft cómentatus ille maximus Mathiolus, cuius fanè mirandum cùn in cateris plerifque, tum masimè in hac planta cómentanda aeumen, quo Italis rerum nunquan for tè auditnum,nedü cognitarum nomina ernit nona, \& literis mandat. Et porrò pittori negotiun relinquit figuræexprimendx, fi viuan, nó pietä vidiffet,melitis fortè noftrx cognitioni \& fuo honori cófuluifete. Cófulamus igitur nos huius figura \& natura repręfentanda, illi operof molis; volu nini plerumque nuto.

\section{CAMPHOR AT A Morpel, an (HAM EPEICE fue bumilis Ticea Plinit?}

SA I I adumbrarevidetur $C$ H $A$ M $A-$ P E v Ce M Monfpelienfibus Câphorata lierba vocata, cmitrit quippe è radice lignofiore cauliculós plures, grtaciles, rectos, pedales, foliolis Laricinis dêfeftipatos. Guttu deficcáte, infipido, Nenıa fërs Amphitheatriangufa antiquitatis in liulcis parietibus, per vetuftatem rimas agentibus, hac prouenit, nec non alibi prope Namaufum \& Monfpelliú, inter pontem Iuuenalen dictú, \& Portam Latrenfen: in Gallia verò, \& r reliqua Italıa, rarò occurrit.

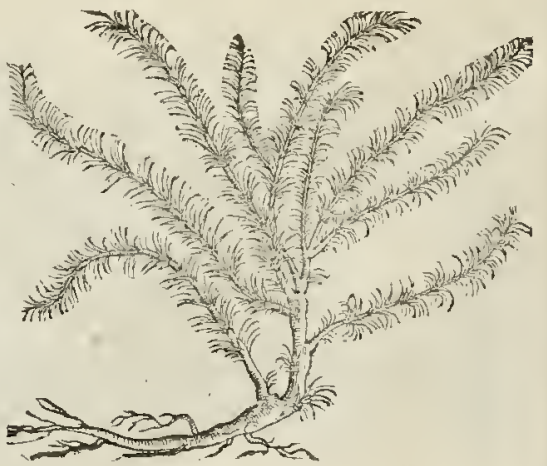

A NTIR- 


\author{
SGrm. Drant. \\ $\left\{\begin{array}{l}\text { Angl. Calfes frowte, or fnap dragoin. } \\ \text { Gal. Moron violet. }\end{array}\right.$
}

STIRTIVM aduerfarianoma.

Aútięgrop A NTIRRHINVM. Vulgo Caput canis cru caput vituli.

N ON potuit commodiore, veriore, infignioréve nota prodi hæc planta, quam Antirrhini, fiue naris Vituli nuncupatione: nulla nāque ftirpiü $\mathrm{eminis} \mathrm{innolucro,caput,}$ vultum, nares, oculos, adcóque hiatum oris vitulini exprimit, atque hæc, qua in Italiis \& Galliis, preffertim Frouincialis \& Norbonenfis, admodum obuia inter oliueta: Fori- Effg. Dod.epit, bus confpicua purpureis, ex rubro violaceis, oblongis, vel rofeis, vel albidis, calathum 2 l 9 . effigiantibus, fed fup ernè buccas flaccidas, riatúque Leonini oris æmulantibus, \&: conniuentibus, non patulis, quò fedulx apes inde nellificaturæ, fi fortć irrep ferint, rurfum quafi valuulis occluduntur. Et folia \& cauliculi fparfi, fragiles, Leucoii, lutei, fiue Keyri, nec radice abfimili. Semine nigro, nigri papaueris minore, hortis Belgicis, Anglicis, \& Germanicis , florum decoris caufa colitur, nec ruri oritur.

Varietus. $\left\{\begin{array}{c}\text { Non diverfa nature aut figur } x \text { eft luscum floribus Antirrhinum, fed dun- } \\ \text { raxat folis latioribus, brevioribus, nec in agris pcrinde frequel1s, hortis düa }\end{array}\right.$ ¿axat folis latioribus, breuio

\section{AI INI MVRI forfan Archigenis ORONTIV AA, vel Aurantiun quo auriginem morbum fune leterum leuat.}

E Thüc Antirrhinä effe docét capitufa mëbranacea vitulinx, aut Simix caluarix, prorfï

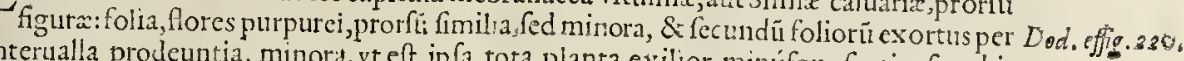
interualla prodeuntia, minori, vt eft ip fa tota planta exilior minifgue fruticofa, vbiuis tum hortorum, tum incul torum marginibus fponte plurima, apud Germanos Orant vocata, nomine, vti videtur, perfuafo \& deflexo ab Archigenis Orontio. Iam minor, iam maior \& latior prodiens, folia anguftiora multò lini ant ofyridis. Quapropter nonnullis hanc Pliniano Antirrhino eandem effe, vifum fuit,

\section{covgi,. OS R R I S ant Linaria, que vrinaria, ant Plinii antirrbinum, vel Bicluedere ftalurum, Scoparia?}

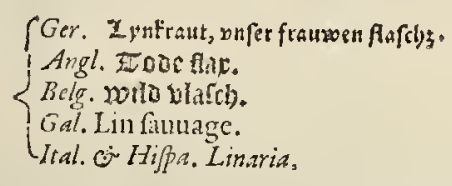

IN T E R P R E T A I I nomen clature videtur herbä fignare diureticấ, fiue vrinariam, Effrg. Dod.egit。

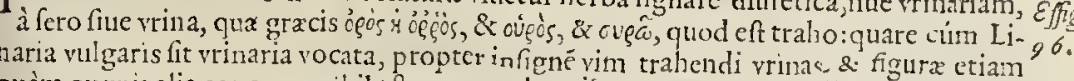
quàm quxuis alia concors, nihil eft quur exploratifsimam fintciamus, illam inccrtam \& facultatis peregrinam praferamts, quia verrendo fit aptior, quafi non quàmplurimxe fint frutices, quorum è virgultis pofunt fcopx concinnari, neque tamen ideo of yrides fuerint: nec Galeni quicquain fufiagatur fententia, quippe videtur ille $\&$ Paulus, $\mathrm{f}_{-}$ quutus nominis fignificatum, quafia verrendo aut purgando fuifer conflata appellatio, Ofyridem fiuc Scopariam fignificaffe. Et vbi quis feuerius expendat Scopariam, feu Beiuıdere Italonum, videbit folia longiora effe, quàm Linarix, \& mumerofiora, non amaia, qualem tané Galenus \& Paulus volunt, nec vllius certi commodi ad ea qua efficacifsimè \& verifsimè Iftericis fermè in bydropem dednetis præftat I. inaria vulgaris, vbique freguentif ima, \& Lini fimilitudine notifsima, Efulan minorem adeo imitata, vt prudentiores barbari ifto verficulo vtramque neceffareo diftinxerint: Efollalatef cit, fine lacte thinariacrefoit. Flos tamé clt Linarix elegantior, \& inaior. fecundum fummos caules inP.iiij. fundibulis 


\section{STIRPIVM aduerfarianona.}

fundibulis,quafi caudicellis Lelphinij, aut Regalis con [olidx, fronte vero Antirrhini riEtu \& arpetu.

\section{$L I N A R I A T V R P V R E A$}

VT fruticofior,fic elegātior multò \&: rarior, \& propior defcriptioni, ea Linariz fécies, quam primùm ad Veganij Norbonenfis montium radices, in cantanetis Syluis inuentam, in Flandriam amicis ferendam multis ab hinc annis miferamus: verùm, quia vires exploratas non habemus, paucis notis duntaxat oratione pifam damus: non enim nifi tolus paucioribus, floribus purpureis, ramulis gracilioribus, nagisque P.cxilibus,pedalibus, \& fefquipedalibus, vimineis, etiam verrendo aptis,differt:alioqui primo intuitu Linariam pates.

\section{SCOPARIA,BELVEDER Italorim.}

Nor

O $\mathrm{N}$ perinde bellula hxc aut fpeciofa videtur re, atque eft Italico ifto nomine, fores ctenim perexiguos, racemofos, obfolcti viroris alis, iuxta quas nafcuntur, cócolores fundunt:virgx nume: of $x$, fparf $x$, crebribus foliis, Lino duplò longioribus Pfyllij, totä $x$ Iratem virentibus: \& propter raritatem exoticam apud Italos in hortis \& in penfilibus figulinis vafis alifolita, hodie perquàm yulgata.

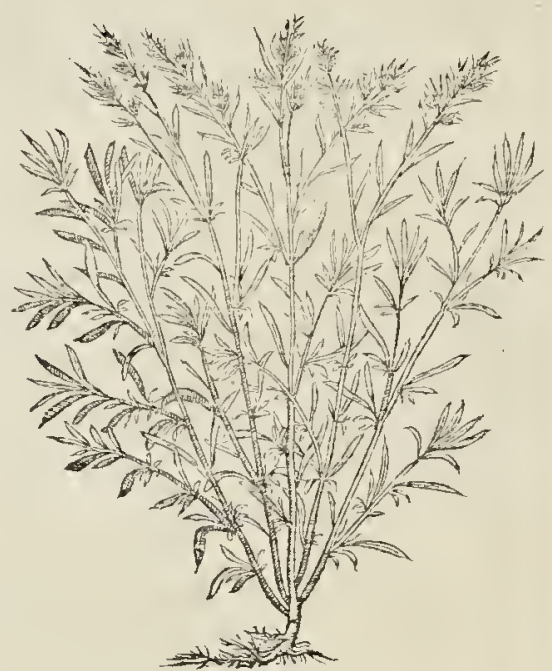

OSXRISPFRPVRO COERVLEA repens.

PR O R Y y Aimilis harc flore \& folio Linarix fuperiori purpurex, cui anuectenda venit, cauliculis tamen gracilioribus fefquipalnaribus, non erećtis, fed humi proftratis, Polii, Coris Monfpelliacæ, aut Sefamoidis primæ ritu : flores cærulopurpura hilariore nitêt, Cori coocolores. Tota herbula guftu eft annaricante, nonnihil acri. ti ane nufquam vidimus, praterquand is $>$ in ttu sunrt H. Morgani.

$$
\begin{aligned}
& \text { L INVM SATIVVM, vinlgare cerulcuma; } \\
& \left\{\begin{array}{l}
\lambda \text { woy. } \\
\text { Gorm. Slacbfor in lein. }
\end{array}\right. \\
& \text { Gal. Lin. } \\
& \left\{\begin{array}{l}
\text { Gal. Lin. } \\
\text { frai. Lino. }
\end{array}\right. \\
& \text { Belg. zalarch. } \\
& \text { Angl. Flsx. }
\end{aligned}
$$

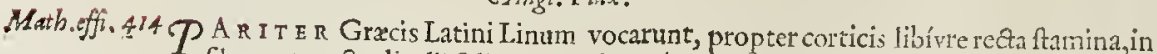
filamenta recta diuclli folita, qua etiam $\lambda$ íwo dicebătur:vade Linea \& Libeili, qua directiones 


\section{STIRPIV M aduerfarianoma.}

retiones angulorum \& parietú fruequra librabantur. Sic ctismnum hodie filum fabri lignarij dureforium Lineam vocant: fic \& pifcatores, filum, chi annexus eft hamulas, lineam. Tam frequétis olim \& hodie notitia planta, vt pręterquàn quèd de linaris iam defcriptis facillimè pércipiatur, etiam fuperuacaneum fit lineamenta depingere : qux hanc fuis fträgulat anplexibus inter Cafithas relata fuit. Theophrafto vifun fuit, Linum degener factum, in Lolium abire. Noftates coloni fibi vifum pernegant, aut anditum.

\section{$L I N V M I A R I N V M$ Lutcum.}

V V r a prata \& litora herbida Norbonenfis maris, ac inter ftagnum \& mare fruticat, 1 pedalibus \& fefquipedalibus ramulıs rectis,numerofis, gracilioribus, pancioribusquc $M a r b$. effig. quàm Inini folijs, lentis, corticećue ad nendum commodo, flore non difsimili, fed luteo, minore, Iunio, Iulio. Semineque \& pericarpiis minutioribus multò: non notum reliqux 416. Gallix, Germanix, \& Anglix.

$$
\text { C A MP ANVLA lutea Linifulia Montis Lupi, fore Folubilis. }
$$

PEr ar a m elegans in denexis Montis Lupi quà ad Septentrionč vergit, Linifolio aut Poligalx, palmaris herbula, Hore luteo peramœno, maiore quàm pro plantx magnitudinc, lafione aut Volubilis donata, quã hî́c piQam damus, ve ftudiofis illic innotefcat, quia rara eft, nec alibinobis vifa, fic vfu minus cognita.

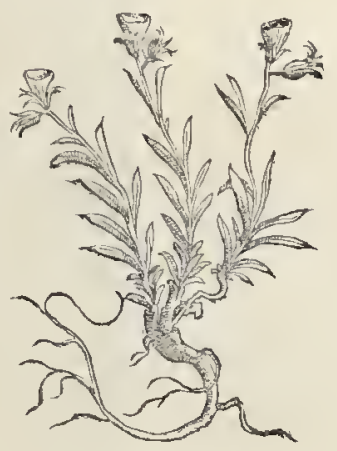

\section{Reponendabecproxime Telepbium, vbiomifa fuit.
ROS $E_{A}$.}

$$
\text { RODIA RADIX. }
$$

R OS F A M vocarunt prifci hãc radicem, rimofo cortice \& frequenti, fed pufillo tubere infignem, rofcoq́uc halıtu fragrantem, odoris liofei prærogatiua, quem manfu aut attritu nullă radiccm, ac ne ftirpem quidē, f pirare (pręter peregrinü illum $A$ f́palathü, cuius meminimus inter frutices)nouimus. Ex Allobrogum \& Delphinatiü faxofis, mótofis,nec non Taurin is Alpibus Pedemótium, iam du in viretis multis Be]gicis, Gallicis, Anglicis, \& Iralicis, Iulio \& Imnio vmbellas edit, luteis florculis pallentibus \& herbidis, Drabr, aut potius Crafulx, quam tantoperè pre fe fert, caulibus pluribus rectis, \& foliorü multi lici ferie, ortu, pofitu, fitu, diuifura, crafsitic, imò \& quadantenus radicis loco natalitio, raxeo, macilento, corpulento, rugofo, \& difparili coal itu, vt cógencres fint putand $x$ :minora tamen huius folia dentata iminutim, Tithymali ferrati proxima, \& radix maior, tortlis \& vberofis papillis rugofisqúue infignata, foris fu $c a$, intus albicat virens: Sed vetuftior \& ficcior, cöcolor eft adeò Schanæ peregrinæ, vt inftitores interdum fallāt frufta adultioris, quam guftu excefsíve vllius qualitatis vix fuperare videtur, eoque nobis ferè perfuade tur, non procul abeffe à Rofr aut Crafulx temperame nto, quamuis non nefciamus Gale Radix Hippo-
num, eumću fequutos, fecüdi caloris gradu donafc hanc:

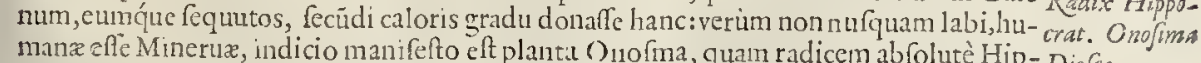
pocratcs cum vocaffet \& defcripfiffet, magnus ille interpres Pergamenus nec Onofma effe fufpicatus eft, fed feorfim duobus in locis, quafi duo fuifent, ynã eüdem bis, \& vifdem planè 


\section{I78 STIRPIVM aduerjarianoua.}

planè verbis, de Hippocrate mutuatis, defcribit plantam fine caule Anchufa fimilem. Fit hodie nulli in vfum vt propter Medicorum ignauiam, \& fuccedancorum ad Chephalalgias copiam veniat, vt Rofex, Roreacum, Nympheæ, confimlisć; facul tatis fimplicia, qua huic proximè f́nbdidit Diofcorides, vade de facultatibus conięura cliciéda lectori.

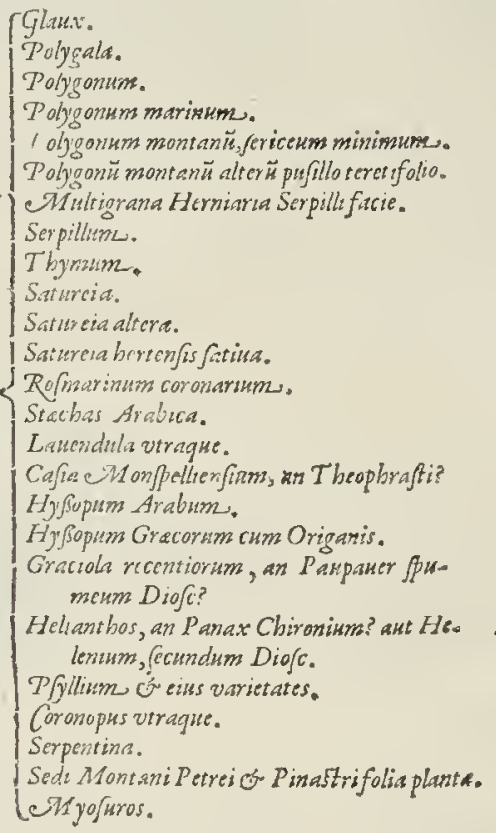

$$
G L A Y X .
$$

F V E S C s \& leguminofis fuit etiam Glaux, à colore foliorü, qua auerfa glauca fpec. tãtur, vti faligna, quas fulices Poeta canit. Galax etian, glax, \& eugalactó, quafí Lactea, vel Ladifica drcta, vt quæ lactis vbertatem efu fuggereret. Iam verò cum huius frequétior defitus fit vius, minus licet ftatuere, etiam fi veram nofles, quxnam fit hodiehabenda, \& è multis, qux Glaucis emétiuntur, aut refcrunt natură, vtı'a vtri fit praponédu, incertum.

$$
G L A V X \& X I G V A \text {. }
$$

Dodefg. 3 8. F X I v a tamen illa herbula maritima, qux nonmullis Glaux rocatur, non perperam quadrare videtur: folculos enim promit Tunicis, Garjophyllex aut Leucoij, exiguos, florum calices dilutè purpurafcentes, inter foliola Tribuli, aut Lentis, vel H rniaria fimilia, crafsiora:caliculos complures partm reptantes, partim \& furrefios, teveros, holeraceos, Pottulace aut Sedi,palmum \& fefquipalmum al tos:cefpite fummo, rads x gracilis fibrofa:Zelandra \& Anglix plerifque mari coterminis, falfis lacuftribus couallibus reperitur : Morgani hortus aluit. Alteram Glatico affinem putamus è Leguminun fanilia, códemque reiecimus.

\section{P $O L Y G A L A$}

Anathoir Poii. O VA M I s ob lactis vberi prouentum, quem fpondebat nomenclatio, debuiteffe gilt. notifsima Polygala, tamen nullam dum habet noflra ætas quam afferat. Quam auté plantulam guo argmmento Senenfis Polygolam legittimam vindicer, piget referre, 


\section{STIRTIVM adverjaria noua.}

funt enim normæ Lefbix \& plumbexillius tăti herois ratiocinationis,quas cuilibet aptes afscri licet adamufim congruent. Sic hic huius Aftragali putati, \& alterius huic confimilis, tacitas defcriptiones fi pręteriit ille, quiduis libnerit cóminifcatur , \& illi fanè per nos fides habeatur: addemus verò nos defcriptionem eius, quæ feritur, \& pecoris fagina dici, tur, nō item affeueremus audacter incertifsimam rem, quod eft fupinx ambitionis.

$$
\text { NOSTR } A \text {. }
$$

LE'N I I C Y L A foliis \& facie crafsioribus pufilla \& tenera planta in Galloprouinciz pafcris montofis prouentu mul to feritur, flofculi fune lutei, minores Cityfi autAra ci,filiqua \& femine minutis, qux lactis augent prouentum gregi \& armentis.

$$
\text { RECENTIORVM Poligala. }
$$

Q V.e tamen dottis Poligala, aliis Onobrichis vifa fuit, non minus placet, fi aquè pabulo cedit:duriufculis tamea eft ramulis, non leguminofis, aut holeraceis, fed Geriftellæoblongis aut $\mathrm{Hyffopi}$ angufti folij : purpurei, pallidi flores, albidi interdun $\mathrm{Fu}$ -

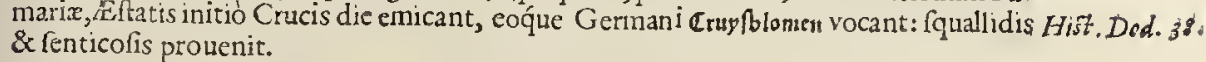

กoxúgroę

$$
\begin{aligned}
& \text { POLTGONVMMAS vulgare. } \\
& \text { Sunguinaria, Centurenadia. } \\
& \text { Angl. kirotgraße. } \\
& \text { Sier. wetgrafie. }
\end{aligned}
$$

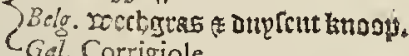

$$
\begin{aligned}
& \text { Gal. Corrigiole. }
\end{aligned}
$$

SANG INARIA centinodiáve, innumeris geniculorum nodulis, a folis riataceis, vel Hyperici, nihil oótemptius aut vulgatius habét compita \& rura, fecus vias, areas, fepulchreta, inuitıs durna diuturnaǵ; proculcatione \& neglectione reftibili fegete lafciuit, totamq́ue xftatem humum infternit virore, reptatu ferptuq́ue ramulorum exiliun viticulorum, qui innnmeris flexibus fe implicant, femengíue fubter foliola in geniculis condunt numerofum, triquetrü,pufillum, Runicis iam defuxis puniceis, aut purpureis Proferpinucs. flofulis vel albidis. Rubella eft radix, prolixiusćue fibrata, vti planta ferpit,vnde Proferpinaca dici potuit.

\section{W ARINVM MAXIMV Maltum.}

$\mathrm{N}$

O NYSQY A in in Adriatico, Veneto \& Anconenfi litoreis fabuletis, fxpifsimè autem in mediterranea Norbonenfi ora, ab vfque Marianis aquis, ad Cetum montem aut promontoriun dictum, polygonum iftnd oc currit longè mains, \& multò fpeciofifsimum: quippe fubter foliola rutacez, candida, glabra, licida, fecundum nodulos $\&$ fores candidos condita, partim etiam maiora, longiora viridia, Galegx aut Portulacx marinæ habet : radice \& viticulis alterius, prolixius reptantibus, humiliusq́ue inftratis arenofis fiticulofisqúue fabuletis: tota planta albicantibus. Semen ad geniculos in foliaceis thecis candidis nitentib.Sal fo \&aftingente guftu. AlibiGallix, nec Anglia, \& Belgix,
nufpiam vifa nobis.

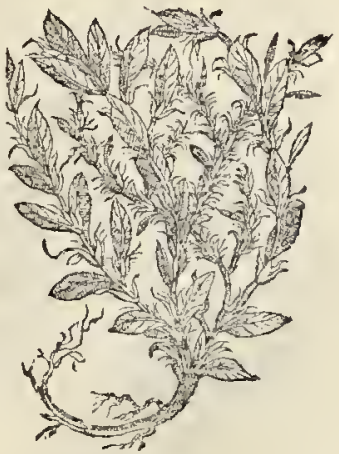

$$
\text { ex } O N T \text { ANV M minimum niнeum on } 5 \text { cricium. }
$$

$S_{\text {D }}$ vfpian toto illo collium amœnifsimo procurfu comparet quicquam rarius, âpeEu, aut attrectatu \& obferuatu dignius, ifta minima, fed pulcherrima argutáque natura foler- 
180

\section{STIRTIVM aduer faria noua.}

folertialaborata plantula:vix vncian \& femunciam $x$ quant denli eófertique ramuli farmentofi, duriufculi,denfifsimis genieulis, \& foliorü quafi denticellis, Herniarix aut Thymi tenuifolij foliolis minoribus, per interfticiola vifu vir difcernenda. Eximio vellere ferieco \& niueu candore Iucētibus glomernlis foliaceis, delicatifsimis, tenuifimisque membranulis contexti flores vniuerfam fupernè plantam ornant \& oculant: exilis radix lignea quàm \& eaulıculi longior. In aruo cui fubeft $\int \mathrm{pe-}$ cus Frontignanenfis eóeameratio \& fornices hæc non ita i Chameiride difsita. Mirabundus Pręeep. tor Afsiatius \& Iaco. Vtenhouius Gandauenfis, commilitones mul tò doctifsimi, iam tum Polygonum rebantur : feminula acerofa Ery* throdani maruzi, vix vifu eapiqueunt prx exilitate.

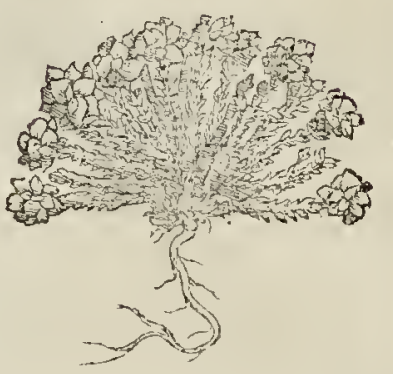

$$
H E R B A T V R C A \text {. Herniaria multigrana Serpillifacie. }
$$

SEMrisı feracifsimam hanc nó inf́citc̀ vocer quis multigranam liumi reptricem herbulā:innumeris quippe feminulis in furculofis cauliculis, fufe fparlis, denfirsimis, luxuriantibus, a ua oliuetaque Norbonéfia featent ad rus Boutonet, altero 2 Mórpellio lapide, \& Riuoly Pedemontiun, feeus cafrum. foliolis eft Serpilli, fed Alfna minimx minotibus, crebribus, creberrimis \& feminulis, vt Po Iygonú(ideo mille grana dicta)media inter \& fubter foliola aecrnata, Atriolicis Centinodixve mino ra: fofeuli luteoli plurimi. Tribuli terreftris multò

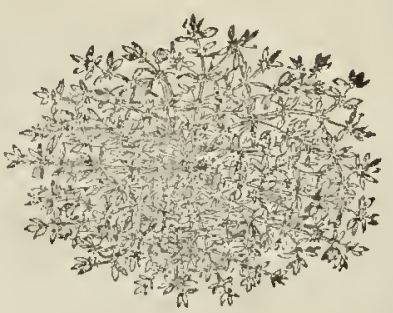

Herba Tkra. minores nec difsimiles: vinerfa ex herbaceo Auct. Herba Turca vocitatur, commenda. túrọ!n ad viperea maleficia, venenatáque extern, tum foris tumintus vtenda:ad herrias enpiaftris fidem fuoerat, ftillatitia octiduo liepatis obftruationes \& ICteritiam perCanare proditus. Eapro p ter nonnulli He!leborinem fecerunt, vt fufus illie monuimus.

POLYGONVMA alterum pufllo virmiculato, ferpillifoliola.

V I s nonita difsimilis hac nomine eft, etiam (1) eòdem tradenda videtur, quiarara $\&$ indict. lactenus fuit: nobis autem induftrij iumenis lacobi Reiiaudcti Mafilienfs Pharmacopcei primú inno tuit.Ramulis \& cauliculis furculofis, prolixis, gracrilibus Serpilli, humi fparfis: collibus maritumis Galloprouincia, non feeus ac Herniaria multa luxuriat, è genieulis foliola pufilla, teretia, fucculenta Aizo: vel Illceebrx, Thymo paruo noftrati xqualia \& fimilia. Radix pralong, lignola, fapore amaricante, calidiufculo.

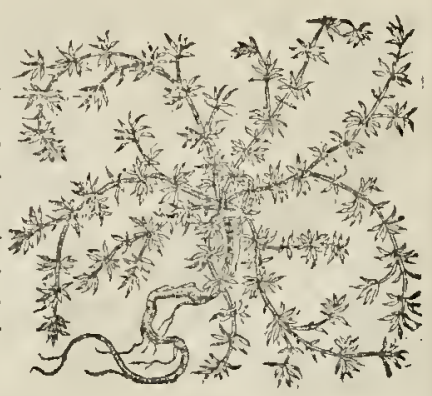

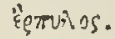

$\left\{\begin{array}{l}\text { lital. Serpillo. } \\ \text { Germ. Quenoel, (t buener foei. }\end{array}\right.$

LHyp. Serpoliso.
SER P ILLVM.

$\left\{\begin{array}{l}\text { Gal, Serpolet. } \\ \text { SAnol. Wildtime }\end{array}\right.$

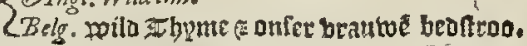




\section{STIRT IV $M$ adinerfarianoua.}

A SERPENDO D I C I Y M SERP 1 L I. v M,hodie quoddam fatium, quod habitius \& grandius, quoddam fylueftre, incultis marginibus, fierilibus of collibus gaudens: Facies vtriq; Thymi noftratis vulgaris: flores \& folia fimilia, fed maiora, $7_{\text {nf fore variefas }}$ in gracilibus cauliculis duris, lignof is, reptantibus; in capitulis Thymi vilgaris: fofculi Mat. Effr. $72 \%$ purpura rubentes, nonnunquam \& albentes. Vtriufy; notior facies quầm vfus: vfus nempe medicus, non efculentus : fi namq; adeò excalfacit \& ácrimonia ficeitateó; tor fiones ventris difsipat, quî poteft non magno difcrimine dari hepati inflammato, aut etiam cerebro admoueri phrenetico?Id innuiffe videtur Diofcorides, nó infammato, fed phlegmone ex fanguinea pituita conflato hepati profutu um : Initio quidem ipfo, aut potius declinante affectu, neutiquam ftatu fummo: vti nec phrcneticis, dum furia cerebrumobfidet. Hæc methodico Medico rcfponfioni fat erunt, verùm non exploratori auidiufculo animum explebunt. Dicet enimrille, fe Stnapifniós admouiffe fpleni hepatiq̣; inflammatis, ficć; morbum curaffe, auerfa nempè inflammationis materia à centro, \& per venarum ductus ad ambitum tranfvecta, fićf; digefta:Cuius quidem therapeutices nonnulla exempla etiam apud clafsicos autores t'eperias. Hac rationis vnbra fefe ab. dunt qui oleo Vitrioli infammationes \& vlcerationcs rentmm fanare profitentur. Sic carpis \& ceruici cauftica admouentur febribus periodicis eucilendis. Sed ha delitix com mentatori Senenfi: nos Botanici fumus. Serpillum refrrgerare putatur corpora ętu Solis feruida, non fecus atq; Allia, Ceepe, croteraq́; acria vefca. Rationis quadam veftigia videre eft in diuini Maronis Bucolicis.

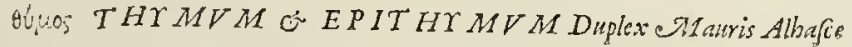

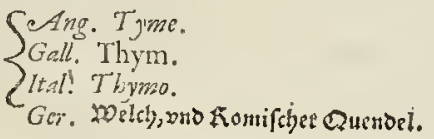
I Mathiolo magno licuilfet vidiffe \& meminiffe illius maioris Thymi, folijs Tymbre
aut Hyffopi, cuius furculi capitulis ficicatis, Stxchadis ritu, floribus operti ex pallido purpurafcentibus, atq; numerofa cirror um fibrarúmve cæararic implicantur, virinmó; prę ftantiorum commendatione, ex Syria Venctias afportautur : deinde Norbonx nuritimis collibus pufillum Thynum vulgatum, folio \& flore Serpyllirigidiore, pafsim itidem Epi thymi cincinnis \& capilanentis delicatifsinis obuolutum : perfuafum fanè fuiffet v trig; Thymo innalci Epithymum. Nei]; cnim(ut Mathiolus fcribit) id Diofcoridcs nesat, fed tantum maioris, è quo prodit iftlęc foctura, meminit. Monfpelienfes Medicí ifto minori Thymo innafcente, frequentius, coq́; hubentius vtuntur, quia ibi recentius \& copiofus, quàm illud Syriacum, iam diuturna \& difsitifsima tranfveatione femiexoletum. Minus quidem mirum, cim vel plebeculx noltratis cxperimento Thymum vulgatum Melancho liam educat. Et maiorc conatu quàm emolumento inftanrat demortuas concertationes Mathiolus, noftrumne feu Arabum cum Diofcorideo'fit vnum : Idem certè eft, non quidem quo ille ancipiriargumelito affcuerat, alioquin non folùm plantæ \& ftaminum flores Epithymum forent : fed etiam omnes plantæ partes, vi purgandi Melancholiam donata. Notioex rerum diftinctione perfpicua, atq; Diofcoridis lectione. Eft enim nihil aliud Diofcoridi, quàm capitati flofculi gemillative, quibus aptantur caudicella, capillament inftar, coloris fufci,vel rubelli nitentis : flofculi interdum candidi, nomunquam herbacei: Thymo verò v troq; purpurafcunt, quibus etiamnum Veneti recentiores', Pharmacopoi, vel nominis, vel etiam vfus argumeto, Epithyni loco v tuntur, \& fuis Theriacis mifcêt. Nomen quidem id præfert, \& vius facilè fert: tota namq; planta, nedü flores, purgat. Cur iftud Europxum, feu minimum Tirymum, non curarit fculpendum Mathiolus; viderint critici,aut potius Cratenfes, quorum Thymum Craticum distum appofuit.

\section{(n)}

-

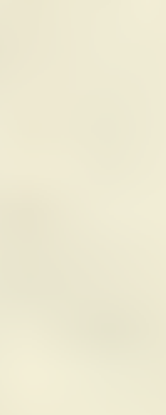




\title{
182 \\ STIRT IV M aduer Jarianoua.
}

IN Thyrenimaris afperis \& falebrofis S.Iuliani He1 trufci,magno prouentu oritur afpectu perquàm elegans Herbula,quam nullus non fatctur Satureian veram. Pifanis ctiam ve:naculo idiomate TymbradiSmto Iuliano dicta. Virgultis cxilibus, palmum altis, farmen tofis, lignofis; folijs ab imo crebribus Thymi Crætici, fcd anguftioribus, longiufculis, fpicã teretêfümogerêtıbus, flofculo copiofo in tertexta : Guftu acri \&t odoro, rniuerfa ex obfoleta purpura albicat, Thymo naiore minor, minori fermè par, Hec Diofcoridis germana videtur: Cęteræ verò duę etfi non fpicatę, vfu tamen Satureix nomen indepte fuerunt vulgo: cui in condimen tis \& lucanicis loco piperis eft : Ea prefertinı, quę in rnont of \& \&axofis Narbonenfibus \& $\ddot{P}$ edemontanis vbertim grifcit.

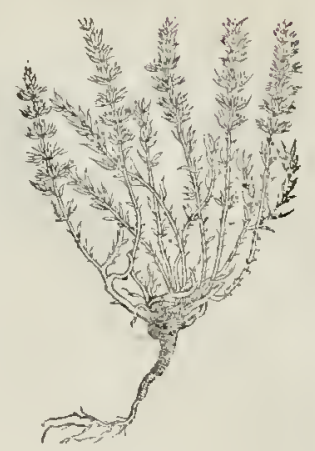

Dod. Effig.epit.

$S A T V R E I A$ fue $\mathrm{T}$ Y M B R A altera.

332.

HV I c folia rigidinfcula Thymi maioris, yulgaris Hyfopi aqualia, afperiufcula,nigricant fupernè,bina quaternáve oriuntur ex internallis, \& indidem flores promuntur purpurei diluti:lignofa radice:guftu elt Piperis tota, coć; vulgo Piperella dicta.

\author{
$S A T V R E I A$ Hortenfis. \\ SeAng. Saworie. \\ Scrm. Kunbel, fropbel Zorfop. \\ Ital. Satoreggin. \\ Gall. Sarriette,Samorie.
}

Mat.Effr.723 A LTER A rarò ruri, vt plurimùm in hortis vifitur, folijs quàm hac mollioribus, anguAtioribus, paucioribus, tum folijs, tum floribus. Belgis \& Anglis quotannis feritur, \& moritur. Fubis cum Selino incifa \& infrixa edulium gratum illis frcquens habetur.

Quam Mathiolus pictam \& germanam reli nquit, videtur potius Polium formina Re centionm: nec vlla fpica donatur, aut in cibis commendatur: denig; nullam nifi vagam \& incertam eff fortita notam.

\section{EPITHXMBRA, EPITHT $M V M, C^{2}$ \\ CASS I H A Plini.}

E T E R y м, Epithymbra non modò hifce omnibus, fed ctiam in F“ yfopo Serpillo aC.ijsć; non paucis congeneribus clauiculis in nétitur, eớ; meritò ambigitur, fuzpténe adoleuerit radice, atc; finitimis plantis furrecta fefe implicuerit, vndc alimentum vbcrius nacta, illi radicula exarnerint.Sed ex fimili ratio facilè liquet. Cufcute enin oriundi \& arrependi conditio par. Ortu namg; primulum \& amplexara vites Norbonenfes, tam multis ofculis, per quandam quafi fynatth omofin, corum fuccum populatur, \& gcnium defraudat, vt radices fui muneris minus iam neceftarij oblitæ, fcruore arefcant, \& abrumpantur, (non fecus atq; auraci cxarefcunt, foctu cxclufo, \& mutato alimenti dinctu) pendulis illis capitulis â ftaminibus Cafsithæ in Virimm ailarúmve ftirpium amplexibus reli$\varepsilon x$, vbi ideo putätur enatx. Sic nobis deprechenfum in vinetis, \& femine collecto \& fato non pauci prodijffe fciunt veram Cufcutam.

\section{$S A X I F R A G I A$, fine Saxifraga antiguro:uxe.}

I AMS x P I V E T N ECESSART O monuimur, Saxifragx vocem apud Authores effe multivocam, nec vnius cuinfpiam ftirpis indicem effe, fed virium infigniorun efficatıácue qua funt præditæ, ferè omnes vulgo Saxifragæ vocaræ, quę 
Grecorum Lithontriba pofient dici, vt non pauce côpofitiones. Eoǵue Betonicāa Galeno, Paulo, \& áliis clafátcis, Saxîgan vocatam, ¿ Kcítrum, cü Mcoleginus, quia vtrúque Lithontribü effet, feu tu dicaslapidum serebran, aut,vt Plinits, viriculum. Sed quando opera noftra naturx ditand $x$, illuftrand $x$ Hiforia ftudet, nilhil attinet an sxius fcifcitari, irrepferit ne huc caput iftud, quafi intrufum cuiufpia Latini amanuenfis imperita audacia, vel intempeftiua commentatiuncula, fortè ad Codicis margine:n, prope Tribulü marinum affcripta, deinde inter Tribulum \&:Limonium inferta. Sanè non videtur capur iftud adulterinum cenfendum, aut infititium, quia Latina, vtiquiritantur, nomenclatura Græcula praierit; quippe illa in-

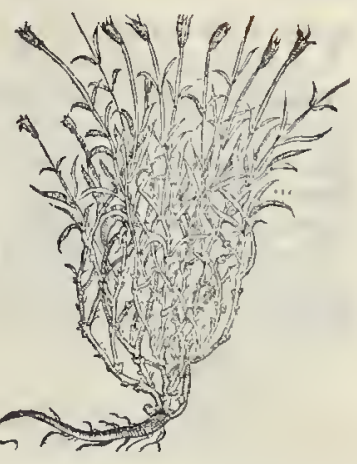

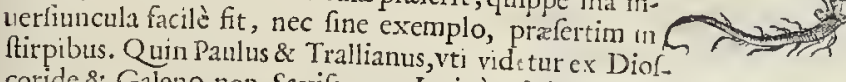

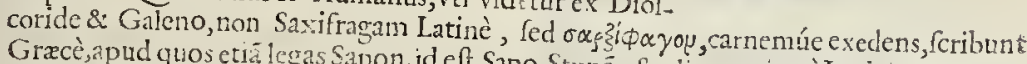
Græcè, apud quos eträlegas Sapon, id eft, Sapo, Stupä , \& alia nomina è Latinis mutuata. profiteri. protero e tan varia Saxifragarum tribu videmur polfe Diofcordis genuina préertim Patzamos, ction hodie, Cuius laus \& pràrogatiua penes Italos, \& V Vnctos, pręertim Pataumos, ctiannum eft. Quàmplurimi traetus ariả, cretacci, montofi, faxofi, lia,Gallix Delphinatu, \& Anglia fundüt: Thymú,prouenit: Huius magnã copiã in ItaSerpilli ramulis, contortís gia, fundut: Sparfis pedem altis, multis, creibribus, exilibus geniculis, vti Poligonatü, iadiceparnimplexis in imo, vbi multis gramineis exafperantur

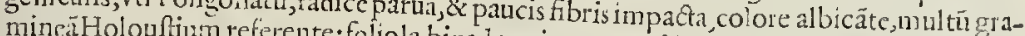
brx Pifanx maonicenterente: foliola bina, longiora, anguftiora, Tunicis, aut potius Tympillaribus, reqis \& fparfis, fingulis fingul goniculss, in viticulis farmetofis, exiguis, cdnicis, fumma ora fimbriolis, vel apiculis tenuibus forlum oblongum quadamtcnus Tutüdum, exiguum. Hxc vt pofterius vfu s roubus crcnatum: vbi femen fubrubrum, roItalis prafertim hodie credita tum propter faminc Saxifragx recepta, fic potior \& verior, pter arêam, quan cum Epithymo videtur famigeratifsinam facultatê, tum etiam procerta ifthxc fimilitudinis conicetura, vuam Commilitudinem : verum non vfquaque tifsimis arriptit : namcue valdè varii codices inmentator ex recentioribus exercitamum, \&alicubi nentium habent: Sicuti vider interdum Thymum, interdum Epithycufo anno 154 . pagina. 370 . Eapropter min cf è caftigatiore Grxcolatino Lutetix exnds,alteran' I hrmo, alteran Epithopter minime oportuit illas, quas idem ftatuebat biHetufis reuellere, vtijfdem rimis tertiaminangef conftantia) improbare, \& è faxis $\triangle N G L I C A$ SAXIFRAGA.

CHE c eadé operit Iulio \& Augufto accliucm Varietas tari acgeftum inter Chipm montem, arte mili$\{$ glix Brifolin inter Chipnam \& Malburú AnPus, Briftolicnfi à Londino via, fed variat floribus, qui longè ninores albidi, mufcofi, non fecus ac toti planta.

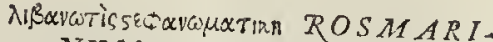
NVM CORONARIVAT. Ital. Rofmerino Coronario. I Ang. Rofemary. Hip. Romero,

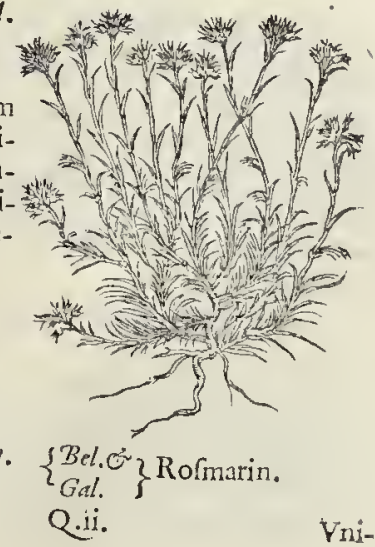




\section{STIRPIVM aduerfarianona.}

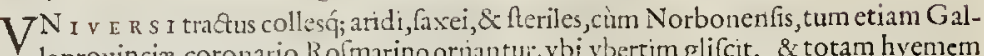
loprouinciz, coronario Rofmarino orriantui, vbi vbertim glifcit, \&s totam hyemem vernat,floréfq; ex pallido coeruleos alit. Tanta fuppetit copia colonis, vt etiam clibanis calfaciendis, focoć; domi aleado fuccendatur. Verum inibi minor muitó quàm plerifq; locis Germanix \& Anglix, vbi cultu luxuriat, adultior \& procerior multò perennat. Nó tamen vfquam menfas, cytharáfve ex illius fruticis refecibus, radicibus, furculífue farmentofis vfquam illis in regionibus concinnatas nobis videre licuit : quin penè Commétatoris fide freti,fabros illicillud fcifcitati ludibrio fuimus. Oleú parant diftillatione perquàm odor $\overline{1} \&$ vtile ex furnmis virgultis \& floribus Paraclyticis \& induratis articulis Schyrro de tentis. Aqua ftomacho amica \& cordi.

\section{$S T$ ECHAS.}

Gallis \& Officinis Strchados.

$\{$ Ang. Frencb Lauender.

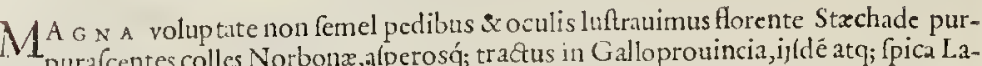

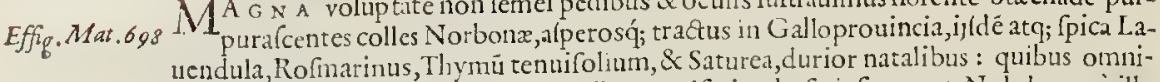
bus tanto prouentu fatet, vt etiam clibanis calfaciendis fatis fuppetat. Nobiles verò ill $x$ \& rarffimarum ftirpium alumnx Stæchades infulæ, huic cognonines, non ex aduerfo Mafsilex, vt perperam ex Diofcoride perfuafun eft(bidui namquc itinere \& litore indidemalyfunt) red è regione Olbix, vulgò Hyeres, vrbecula olin tagn lauta, quàm nobili, à qua etiamnum hodie Infulx stæchades nomé retinent, non Mafsilex, dicuntur namque Hyeres Infulx. E radice lignofiore cauliculos emittit cubitales \& fefquicubitales, lignofos, in quibus copiofa foliola oblonga, Saturciæ hortenfis longiora, albicantia, incana, anguftiora, \& minora, quàm Laueddulx, aut Rofmarini coronarij. Capitulis fpicatis in fummis virgis Thy ni Cretenfis, fed maioribus, è quibus flores folliacei cærulo pur purci exeruntur. Semine fubfufco Vrticx aut Lauendulx ficcrefcente. Aduerfus omnes capitis morbos à frigida caufa efficaces, vfus frequens comprobauit.

$$
\begin{aligned}
& \text { SPICA. LAVENDVLA, ITALIS } \\
& \text { Spigo o Nardies lialica. } \\
& \text { Stal. Lauanda. } \\
& \text { SGal. Lauande. } \\
& \text { ZBet. 至aucnoer. } \\
& \left\{\begin{array}{l}
\text { Ang. Launder } \\
\text { Ger. Iafanoer. }
\end{array}\right.
\end{aligned}
$$

H A v Dabs re nomen Spice Latinum \& tritum ad Stæchadem allufit, idem enim fignat

Strchas Grxcè, quod Spica Latınè; nempe propter finilitudinem totius, prinùm

Effg. Math. 31 facie, deinde faporis, odor is \& loci. Vtrauis vtriq; fimillima, neque fpecie ditierfa. Folio \& fore fpicato Lyfimachix, aut potius Viticis purpurco,alias albo: hoc tant ùm difcriminis intereft; Spica fragrantia maior, grauior, folia maiora \& latiora Stæchadis : Lauendul $x$, aromatıci, \& gratix plufculum: eoq́ue affectibus matricis fener \& folia commendatiora, tum fomentis \& lotionibus, tum pulucribus dilutis intrò fumptis, ad fuffocationem \& afcenfum ex vaporibus putridis, \& ad partus accelerandos.

\section{CASIA Poeticaciongellicrfum an Theophrasti?}

PO E т I C A M Cafram, qui cum Cafsia fiue Canclla \& Cinmomo, nominis fono du\& \&i congerunt, nulla vt dd facerent fuerunt rationc illecti : tanto minus ftirpium ve iti-

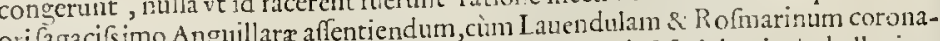
rium Theophraft Cafiam cenfet. Nec non Gullandinus, indefefs laboris vir, hallucina. tur dum Chamaleam Cafiam effe putat. Neuter id dixiffet fi vidiffet, plantam Romano Nor- 


\section{STIRTIVM adwerfarianout.}

Norbonenfiq́; agro vbete pioutentu oriundam, Sparthi caule, ftriato, colore Polemonix : folijs Thymelez, aut Stacluadis, vel Lauendule: Cocco copiofo Cneori, vel Afperagi marini amulo, gintinofo admodun: cule fefquicubitun \& cubitum alto: Flofculo multiplici Olex, ex viridi flaucfcente. Hanc Præcepior Rondelletius, Pelliferius Magalonéfis \& Monfpellienfis Epifcopus, perquàn e:uditus,commilito nétq; noftri, Cafiā fecerunt, quia in Diofco. deerat \& in Throp. Fupererat. Floret Iunio, femer rubet Auguito, ad ripas Lani prope ponten Caftri noui, \&alibi pafsim in Galloprouinria iuxta fepes \& oliuetarum margines.

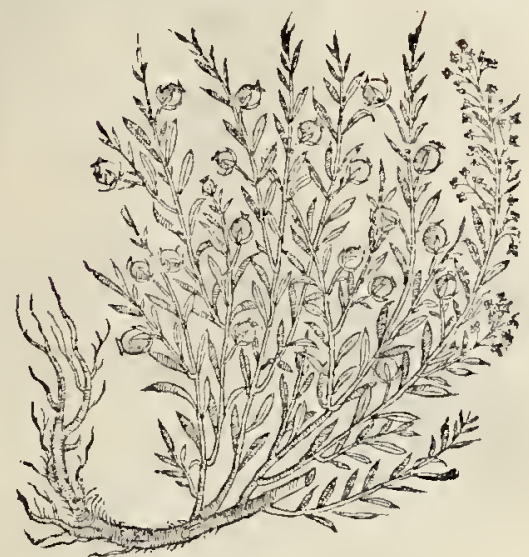

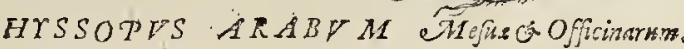

$$
\begin{aligned}
& \text { SGer. brliop. }
\end{aligned}
$$

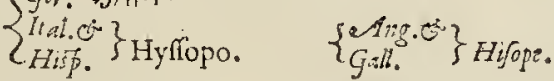

VT in Hyffopo Græca diximus,tametfi hax vera non fit Diof .tamen iamdiu cómuni confenfu recepta ifta Hyflopus fuit, quia valdequàn viribus efficax eft, coğue in O: ficinas dedncta Mefux antoritate, qui Hy (Topun ramis Thymi atg; folijs, fed nucoribus, facir.Eiq́; occafio fortè ex Symphito Petreo hallucinandi fuit, cui Origanü (fimile nép ̇̀ Hyfopo) \& Thymú cöparantur. Nec mirü iam tü ita perfuafum fuiffc hâc lectioné A rabibus,cùn Senenfis, extra crrorisalean Cómentator, côdem impegerit: vbi nō foliun de nouo à fe reperto, fine probatione,Symphito, fibi plaudit:fed etiam folia Thymi contextui, \& Symphito reperto affingit:qux neq; Grxco codice, neq; Latinis verfionbus vfquä coparent.Collibus afperis Romanix \& Veronéfi traetui,prafertim fecus Athefim, ad anguftins faxorum \&arcem munitifsimă, qux Imperatoriam à Venetorum ditione difcria minat, èregione montis Baldi, fponte fruticat hac, nurfpiam al ioguin nifi in hortis.

HISSOPUS candidus efinglonum. varietas. $\left\{\begin{array}{l}\text { Eadem hortenfis in Anglia nullo māsonio dımidio fui folijs \& ramulis adè } \\ \text { candefcit, finelanugine, ve quanlibet niuem aut calcē facilè protoocet, femiffe }\end{array}\right.$ Zaltera viridi remanểe. Horum vtrüq; montibus, collibuss, \& hortis oritur. GR AT IOL A recentiorna, aN SPVMEVM P APAVER?

$\mathrm{H}^{A}$ C T E N v $s$ non parí vexauit multorü ingenia huius plantę afsertio : Saponariam Hrath.eff. 60: quippe alii,Behen album \& vulgare quidam, frte Ocimaftú aruorum, deminn Giatiolam Spumeum Papauer fecerunt. Huic enim (prxterquam quod Olex vel Struthij foliis, \& florıbus albis donata eft) etiä vis ftreunuè purgandi fupernè \& infernc̀ ineft:radix mulciplici flexu, crafsiore propagine, fummo fparfa cefpire, Pratis montofis oriunda, rarò tané fpumea, fed quadantenus albicta foliis eft herba, amari \& ingratifsimi guftus.

$$
\text { HELIANT HOS, fineflos Solis, an P A N A C C I RON I V M, }
$$

o H H L EN I Y M Jecundilm Diofc?

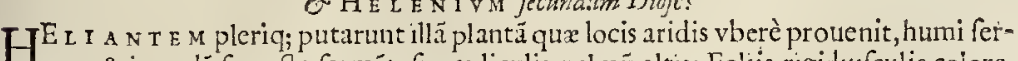

1 pens, \& interdü furreeta, farmétofis cauliculis, palmü altis: Folijs rigidureulis colore, crafsttic, \& effigie Cyfti parti, fed minoribus multó, quẻ Helianthë, fue Solis florê, vocarūt,floris aurei Potentilla vel Pentaphylli fimilis cómendatione. Qui quia finilis recenfeturde Chironio, ideo Chironiü putarüt. Nos in Helenio mentioné huius fecimus. Mófpellij Cifti partui fpecie m faciebât:fed crefcit hîc in Anglia \& alijslocis pấsim, vbi nulla Cyrtus.Aftringendi ficcandiớ; vi pollet:acrimoniam nullä prodiț eod; minus Chitonij opinionéfacit:fed faciet fortafsis magis Centaurï luteum vocatum, efligie cum fit \& viribushand procul recedentibus, \& quòd acrim onia non caret, non nihilq́; odorum eft.

$$
\text { Q.iij. }
$$


186

$$
\begin{aligned}
& \text { STIRPIVM adnerfarianons } \\
& \text { Jún } P S Y^{\prime} L L I V M, \text { Puliceris berba. } \\
& \text { Gall. Herbe à puces. } \\
& \text { Jial. Thillio. } \\
& \{\text { Belg. Al'op cart. } \\
& \left\{\begin{array}{l}
\text { Ger. Piflien frant, flobeliaut. } \\
\text { Ger. }
\end{array}\right. \\
& \text { Hip. Zoigatona. } \\
& \text { L. Ang. Fleworte. }
\end{aligned}
$$

Cintus muccofo a modum \& refrocräte, lubricante, quod vuiufnodiluec duefumeft Ef.Mat. 1067 in farmentacca ftramineać; planta trifarian variăte ccpiofum habctur. Ea autem fponte 1068. Norbonéfia \& Galloprouncix veruacta profcifád; arua operit \& in teruit. Qua auté frequentifsima exilioribus ab ima radice exigua, fibrof, ramulis totuma caule pecialé ambiẻsibus crebribus fruticat folijs anguftis longioribus Scoparix, Belnider aut Coronopi, in canis, hirfutis: Imbricatim compate globulis, fquammofis, oblongts, $P$ impincllævel $S t x-$ chadis Arabict prinulum Horentis, quos apiculi ftaninei candicantes ambiunt frequentes Coronopi vel Plantaginis. Hac ctiam inter oliueta fabuio fasć; (crobes Monfpelijagri protenit.

$$
\text { Mrarinum. }
$$

Farictas. QVon littora fabulofa maritima lubenter fectatur, habitiore, fed non difsimilinfpeatu, longiorbusahquantò ramis fruticat, \& folijs muitò prolixioribus nagíf; denis \& hirfutis, minus incifis: cuius etiam non aliud femen, vcl fiores, vel vfus.

\section{$\mathcal{P} L I N I A N V M$ fort maius,radice perenti.}

I I DE M in tra\&ibus, fed marginibus \& fquallidis oliuetorum incultis collibus, farmé1 tofius lignofífq; prolixa foliorum \& furculorum caudata, comofáq; focura denfísima implexa fruticat, \& reptand o cefpitcm ornat latiorcafpectu, fed hit fut te ex viridi albi căte. Semine haud difsimili, fed maiore fufcó, fine caftanea corticis colore:radice lignofa, dura, fibrarum procurfu prolixa. Eiden vfui iu medicumentis arteriacis, \& bilem fiue pręparantibus, finc educentibus:nec aliud ab iftis innuit Plinius $P$ fyllium, vt nonnulli mi nus accuratè cius de lacte gumníve fententiałm expendentes opinantur, Tithymalı́; quoddã genus Pityufa dictum, interpretätur:neutiquä id feripturi, fillis venifiet in mentem feminis \& herbx muccaginofum \& laftei cremoris fimilem fuccum, ad purgandam choleram (etiamnum à nofrỉ Medicis hodicnis conmendatum) plinio vocatum fuiffe Lac vel Gummi, lasiore interpretatione, vt non rarò hic autol folitus eft.

$$
\begin{aligned}
& \text { Kogcútrous CORONOPUS, CornuCorizum. } \\
& \text { SGitl. Corne dc Corf, P1cd de corneille. } \\
& \text { Angl. Buckborne. }
\end{aligned}
$$

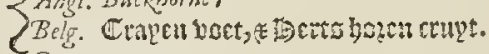

$$
\begin{aligned}
& \text { Germ. Kritenifs. }
\end{aligned}
$$

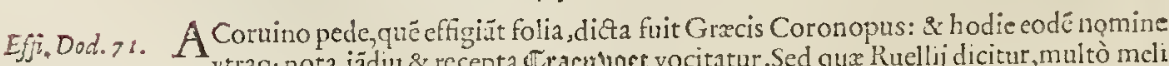
vtraq; nota, iädiut \& recepta $\mathbb{C r a c n}$ troet vocitatur. Sed qux Ruellij dicitur, multò meli us Coronop fpecies habetur, qułm illa Serpentaria Math. qua incerta cft, \& folijs longè difsimilior: tü huins vires exploratiores habétur, quas Medici multi admirätur, dum videntintro fumptam, aut pracordijs admotan, accelsiones febrium, qux originem ab obfructione duxerunt, quafi fafcinio amoliri, prafer tim ab imperitis Curforibus: Inaud tamen difficilis caufæ veftigatio, quæ ab codem principio pendet, quo cater $x$ planta congeneres, fmiles effectus febrientibus admotx, edunt. Serpentaria verò potius Holouftii fpecies eft, quä eò adduximus. Fol. I 7.Quinetiam vulgatior \& magis obuia è maritimis in hortos Bclgarum, Anglorum, \& Germanorum, tranflata ad acetaria, \& calculum, folijs Pfyllif aut Plantaginis marin $x$, crafsis, pinguibus, hirfutis, vtring; fifis \& laciniatis, comicum vngues ant certinum cornu preferentibus. Verc in thyrfulis graciltb.hirfutis dodrantalibus Rorcs, \& fpicx Plätagins aut Boloftij Monfpelliaci fimiles, concolores, fed mino:es. 


\section{ITIRPIV M aduerfarianowa. $\quad 187$}

minoics. Radix tenuis, , modicum antringens, cum nonpulla calfactione, çalculofis hodie cxpetur, non fecus ac totins herber ftillatitia aqua.

Cornu Corui alterum vnelgi.

CORONOPIS REPENS Regelly, echinato feminuminuolucro, an Theophrafin?

Varictis:

I V a E N s hxe inter Polygonam proculcatis itineribus, fed humentibus oritur, facie, Effg. Dod. 1 ?

folio cum fuperiore eodem prorfum, flore albo in cauliculis fersilibus, reptantipus: Semina in folliculis orbiculatis, ambitu nonnihil fpinofis, catera fimilia, cognitu peruia.

CORONOPI \& SEDI montani media plapta Mafulienfium.

II A c nomam antiquis \& neotericis indictä, vifum fiätfibdere, cum propter nonnullam inter fe fimilitudincm, tum propter eoldem natales maritimos. Collibus \& cautibus Mafsilex vicinis ad maris allifiones, intcr Tragacanth ü pafsin luxuriat denfirsmo '́par fońue foliorumftipatas Scdi minimi faxei montani, vel Pinaftri ritu, pofitu, \& rigiditate, innumeraetiam fobole cauliculortm dotrantalium, femen pufillum $F$ lantagrinis, aut Serpentinz vulgaris, fpicisincludentiú. Radix longinfcula, lignofa, crafsior, guitu nonnihil calida, aromatica.

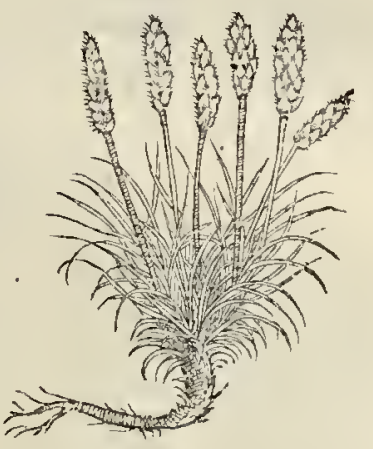

SERPENTIN

SV prar v s diêu fuit Serpentinxplantam \& nomenclaturam recétiorum effe, neque

Coronopum ffe, fed potius Holouftium : eft uuim follis Gramineis aut Vetonicx fylucftris hami procumbentibus, radice lignofa Vetonica Garyophyllex, femine \& f fica

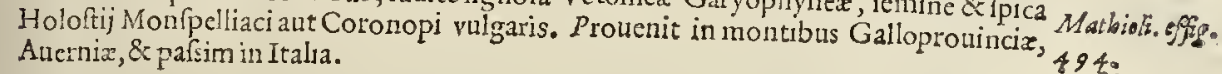

Farietas. $\begin{aligned} & \text { Superrorifimilis tota, nif habitioribus foliis, flofculis, cauliculis } \\ & \text { pertu \&acilis. }\end{aligned}$

$$
\text { Mvosoúgo: CAPDAMVRIS: }
$$

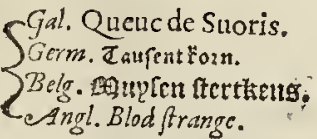

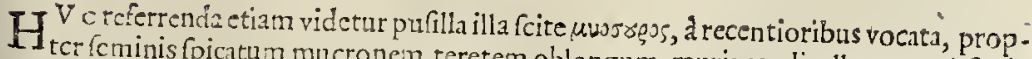
ter (cminis fpicatum mucronem teretem oblongum muris candicellæ non abfini- Efig. Dodo lem, forculis per Maium \& Iunium albidis, crebribus, palmaribus breui mareefcen. $\varepsilon_{\text {pit. }} 18 \mathrm{~g}$. foilola funt gramminea angufta, pollicé \& fefquipollicé alta,rigida, guftu plantaginso.

$$
\text { Q.iiij, Nofrats: }
$$




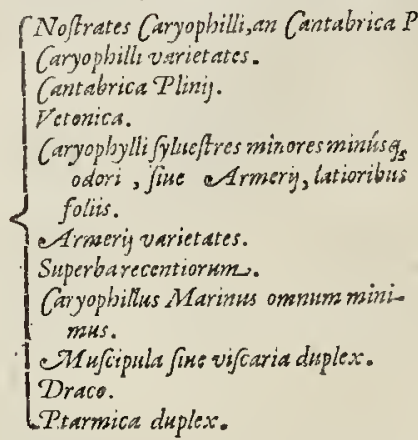

CARTOPHILLI Rostrates an Cantabrion Plis.

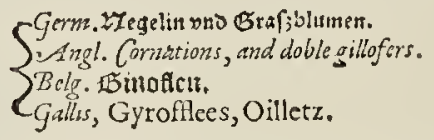

Effig.Dod.cpir. A N I I ev I setiam indicti videntur florum clegantia nominatírsimi Caryophilli, ob 18. A 2 eam quam cum Cariophyllis exoticis habent odoris cognationem, ac nonnullam caliculorum cum Anthophyllis fimilitudinem, quorum funt differentix dux, nempè fylveीris \&r fatiua: varictates auté permultx. Qui namque in hortis colitur,cx intortis geniculatis cauliculis ealices teretes glabros gerit fenis foltolis, fed multiplis conflatos, per extremas oras feitè fimbriatos, odorem Caryophillorum, aromaticü fimulante, è medio ftaminulis exortis geminos apiculos oftentantibus, triplicis varietatis, in penfilibus vafis aut torulis hortorum fpeetantur : nempè aut purpurafcunt dilutius, aut intenfiore cruore nitent, non pauci ex albido, nonnulli punetis quafi afpergine purpurea verficolores funt, cunctis diutiúsimè florentibus, folia per interualla bina, glauca ề geniculis caulium teretium \& gracilium iunceorum: Semen item ninutü, pręfertin fylueftri, qqux quidem

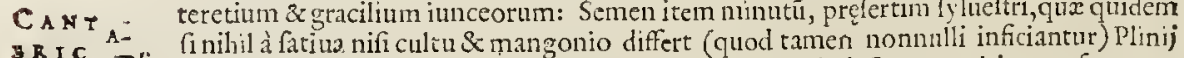
\$ R I C APli. fi nihil à fatiua nifículiu \& mangonio differt (quod tamen nonmuli inficiantur) Plini) le iunceo pedali, in quo flofculi oblongi, velut calathi, in his femen perquàm exiguum: qux quidem defcriptio nonnihil videtur quadtare cum VET O N 1 C A, inter nothad Diof co:ide relata delineatione hac: Montofis pratis \&e cultis nafcitur, radice rubente to-

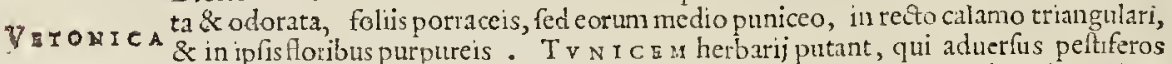
affe\&us mifcent in antidotis:tametfi dotifsimus Bernardus Monfpellienfis Polemonium Belgarum fiue Ocymaftum imperat, vt cuius radices plurimùm commendantur de eadem dote.

$$
\begin{gathered}
1 R M I E R \perp A \text {, minórue Caryophillus fylueffris, } \\
\text { mainus odorus, follis latioribus. }
\end{gathered}
$$

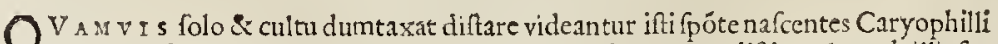
ì fuperioribus, tamen etiam dum coluntur in areis hortorum, diftingǘtur ab illis fo. liis latioribus, cauliculis humi ftratis, in quibus fingul is flores confertim numerofi consefti, Saponarix in modum funt calyculi, \& fores minores, fimplices, vt plurimùm cruore coccineo rubentes, nec odore perinde fragrantes, atque fuperiores, nec adeò ferò prodeunt, fue in hortis, fue in agro: eft enim plurimus hic Caryophillus vbiuis in petreis montofis \& fyluolis margimbus calidarun \& frigida: um regionum Aprili \& Maio.

$$
\left\{\begin{array}{l}
\text { Angl. Tinkes. } \\
\text { Belg. 19lumntitus; }
\end{array}\right.
$$




\section{STIRTIVM adwer/arianoua. i89}

H O в r m eadem, quam in fuperioribus diximus, colorum varietas cernitur, quippe Dod. Effig.epir notuls candidis purpureis cruor intermicat interdun, interdum aute niuei arperfo 191 . diluta purpura nitent fores, qui ctiam argutioribus fimbriantur crenulis altioribus, aut laciniolis:anguftiora etiam funt folia, caules pedales \& cubitales, odor is fuaui: elegantix Varietas.
caufa in hortis habetur.

A R MOR $A R / A$ Syl.pratenfis.

Ger. Gauchblum. id eft, flos Cuculi.

$\{$ Belg. 0 rapenblomkeng.

$\mathrm{S}_{\mathrm{D}}$ in vliginofis pratis Anglix, Belgix, \& Normanix prouenit Sylueftris Armeria vo$\mathrm{S}_{\mathrm{Cata}}$, inodoro fore, fimpliciore, altius crenato, foliis breuioribus, latioribus, Centau- Dod. Effig.epit. rium minus, aut Vifcariam fimilātibus. Venenis commendant, qui putant Tunicem effe: 192.

nec prorfun falluntur, quia non fruftra opem experuntur : \& nonnullis Pracicis A T V N IX. bibus etiam Tunix vocatur, non fecus atque Polemonium Belgarunı fiue $O$ racticis Ara- $T$ unicis vox viquod eft Gordonij Tunica.

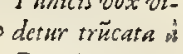

Betorica.

\section{$S V P E R B A$ Recentiorum, $₫ G e r$. bocbinut.}

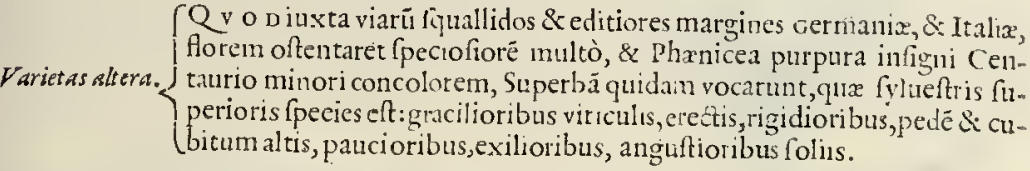

N Agri Norbonéfis montofis plantula eft non inelegãs, quẹ huc refercnda videtur,nam 1 fefquipalmarem \& pedalem erigit eauliculum geniculatum, ftuperioribus confimilem,
nec flores difpares gerit, aut ealyce ita diuerfum: fed femen Scabiofa, aut Carthami,nigrum, pellucidum, quo faeilè quilibet plantam rariorem hane à Caryophillis difcernere poteft.

\section{CARYOHILLVS MARINVS Omnium minimus.}

H A r v M onnium minima, fumilis \& quadantenus cognata videtur illa, quam Belg $x$ Herbarij Moly marinum indigitarunt, alij Holoftum, vtrique potifsmum propter folia graminea. Sunt enim rigidiufcula, quamplurima, fparfa humi, colore glauco, fimi- Effig dod, epit. lia Caryophilleis. Cauhculi graciles, imncei, dodrantales, \& palmares, in quorum fummo 377. vmbellæ compreffx Thlafpi Caudri, autSchænoprafsi concolores. Radix illi fubeft prolixa, tenuis, ruffefcens Serpentinx aut Caryoplillex. Hac arearũ margines ornant Bel- Moly matraü. gx \& Angli, apud quos in maritimis frequens oritur: Calidis \& Mediterranei maris litoribus, non perinde occurrit.

S E D conuallibus Calearis Seuenx montis, pafsimq́ue alibi in Gallia Lugdunenfi locífue à mare difítis, prorfun eadem reperitur, nifi plures funderet cauliculos pedales, folia item quadruplò maiora, \& reliqua grandiora : quxnam fit planta apud antiquos
iam non occurrit.

A V SCIPVLA, sueVISCARIA.

P Rarer has, hic geminas damus pietas, quas plebccula Mufcarias, Vifcarias, frue Muf cipulas yocitat, quia glutine quopiam muccóue adeò vifcido fint perlitæ, vt non folùm 
manum, fedetin!n mufcas \& papilioncs pixteruolantes minimo contagu implicet. Oritur apud Norbonenres in locis fquallidis \& fegetum marginibus, folijs Armeriz fyluctris, pratenfis aliquanto longioribus : flore \& caliculo Centaurij minoris, ant Vetonicx fuperbx dicta: cauliculis plurimis cubitalibus, femine pufillo Lychnidis.
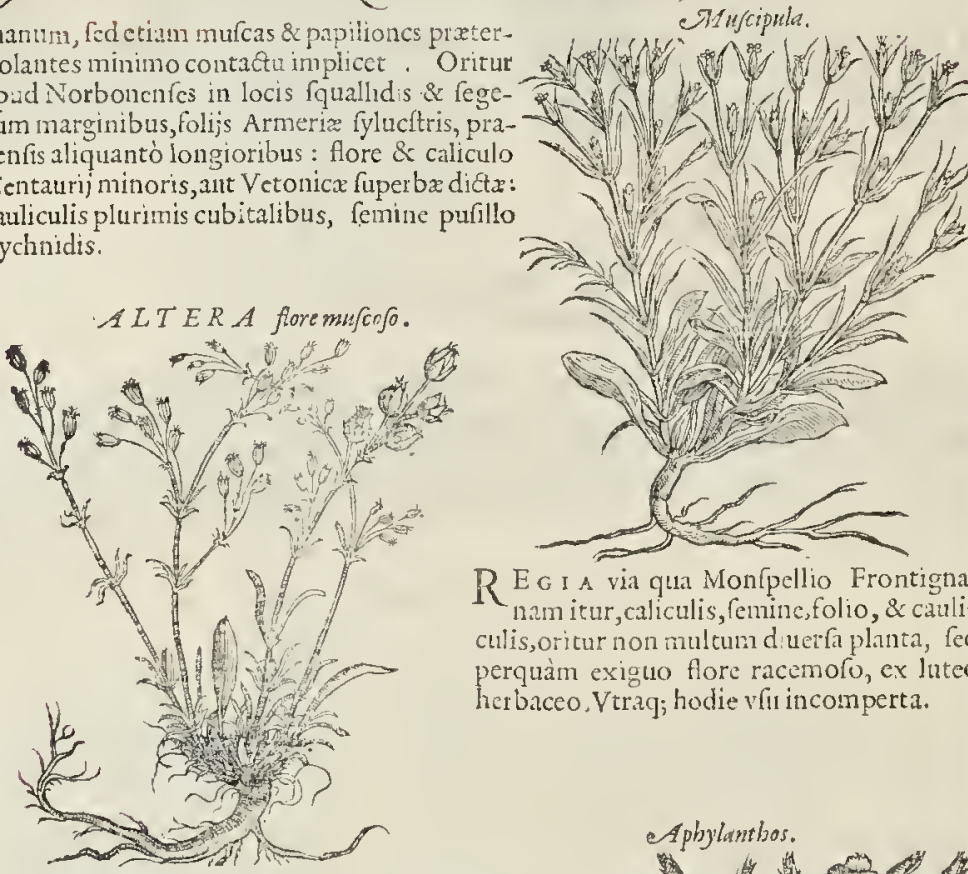

REg I A via qua Monfpellio Frontignanam itur, caliculis, femine, folio, \& cauliculis, oritur non multum diuetfa planta, fed perquàm exiguo flore racemofo, ex luteo her baceo. Vtraq; hodie vfit incomperta.

APHYLL ANT HOS Monfpellienfum.

E M I s v s hodie notis ca elt cui nomëAphyllanthos fecernnt fudiof Herbarij Monfpellienfes, non quia nulla folra enittat, fed quod adeò fint exilia \& iuncea, vt vixdum emerfa are fant, \& feftucas preferant,paleásve, pallidiufculo colore in imo cefpite è fibrofa Iunci radice: cauliculis féquipalmaribus plurimis, iunceis, gracilitus, enodibus, olabris, per aftaten fores dencatos carulcos, Lini aut fy heftris Caryophiller minores, in glumofo acere gc?antibus: guftus tota planta amaricantis,uontihlitcalidi: Flurma glariofis Atrigofisć; Ilicetis Norboile.

$$
D R A C O \text {, autfotius } T \text { ARCHON Symeonis Seti }
$$

\section{Apbylanthos.}

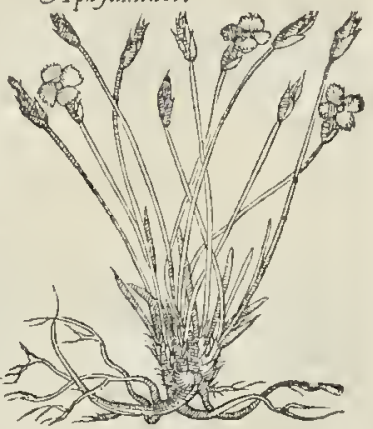
cinicerne.

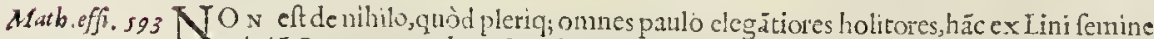
cuipiä Cepacxant tuberoßx radici inferto,emergcre affirmant nam tametfi nó temerè cuilibet ex perienti cedat, iciǵ, oftentum, \& euentus rarior fidcm penc̀ abroget, tamé fi quis in afflatu maritimo \& natalibus Squillx nou aulf inferat, op tato voto nó fruftra bitur, vt nobis affer ebant quidnm Lygures \& Hetrufci herbarij non pauci. Idem euenire tradutit, fi in Raph no aut Cępe foramintilo fąto adigatur Lini femen: \& argumento vtütur faporis, qué falis 3 aceti vnà mixti quodāmodo pręert: in acetarij frequentifsime efitatur, Nafturtij guftu, \& ritu: Nec vpiam niff in hortis vifitur: èq; radice in varias partes diuulfa pr opagatur $\&$ plantatur:quia femen, quafi fpurium, $\&$ nou genitabile, exiguum \& cuanidum eft. Folia angufta, cufpidati, cralsiufcula, Kal avt ARcir marini, fed lon- 


\section{STIRTIVM adturfaria nona.}

giora $P$ tarmicx, non tamen crenata Betonicx modo, vt quidam decepti fimilitudine P ta $F$ micr tradüt: flofuli lutei, in ramulis fparfi:caules cubitales:radx Scordei aut Gratiol $x$, longius vagatur per fummum cefpitem, exigua.

$$
\begin{gathered}
P T A R M I C \text { A folio } T \text { araconis } \text { Jed crenato, focello, } \\
\text { vmbellicato, candido. }
\end{gathered}
$$

Q V A v I s perplures plantæx, quę ciere fternutamenta olfątr valent, Ptarmicx hodic dici pofsint : tamen hac id nominis pre cunctis hodic eft apud herbarum peritos affequuta, quum Pyrethrum nuncuparunt, quia effet guftu feruido, diuó́; linguam vexante Pyrethri modo : nonnulli Prarmicen coniectabant, quòd odore ingratiufculo \& aeriore nares ferirer, fternutanentaq́; cieret, quibus non æyrè accediunus, quando aptiorem $P$ tarmicam nondum nouimus: Nam quas alias mox fubdemus, longius multò à Ptarmicis abeffe putamus. Huic fiquidem flores in vmbellis Anthemidis, Cotulæminores, aut Stratiotidis millefolix, folia longiora Taraconis, fed ambitu tantillum crenata, in multis gracilibus cauliculis pedalibus \& cubitalibus. Radix fibrofa, repens.

\section{PT $A R M I C A$ altera Gallorum.}

COGNAT IOREM multò Thlafpis putabit,qui guftarit aut olfecerit hanc, quàm Pyrethro aut Ptarmicx: Ef enim gufftu ignauiore, quàm vr Pyrethrum æquet: \& $0^{-}$ dore penè nullo, aec fternutamentum ciente: Quare non magis hac Prarmica fit, vr quidam cóie êbant, quàm Terribilis vocata,inǵ; caput de Alypo relara. Etenim Monfpellij enatam habuimus in horto eruditifsimi profefforis Regij Laurentij Iouberti, folijs, facie, virgultis, \& floribus concoloribus Candiaci Thlarpi.

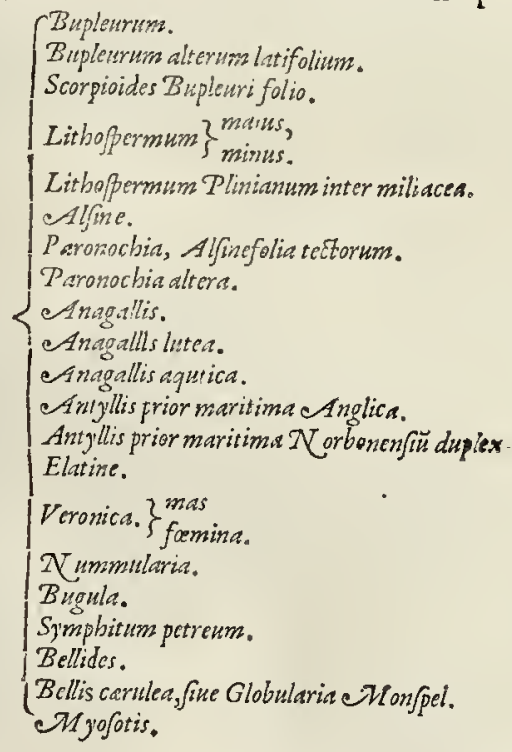

$\mathcal{B} E$ VPLVRVM.

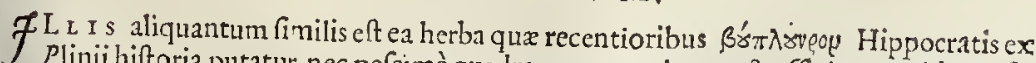
Plinij hiftoria putatur, nec $p$ ofsimè quadrare nomenclaturæ \& effigiaturx videtur:folijs namq; Ingis, angultis, quadamtenus Graminis, Lachrym $x$,Iobx, aut Gladioli,multis itrijs, lirísve rigidis, quafi coltas in folijs fingulis effigiantibus, \& laterum modo inclu. 
192

STIRPIVM adwerfarianous.

fis, vt de Heptapleuro loquitur Plinius, per lógitudiné fquibris, in caule fefquicubitali \& cubitali admodú geniculato, Lcuabro, rotundo, rigido, inq́; ramulos abeunte, quorú fum

Dod.Epit.373. ma vmbellis pufilis, fpurfis, lutcolis Anethi donätur, \&-femine Anifi aut Anethi oblógo, longiore, graciliore: lapidofis \& ftrigofis Ilicetis cocciferis Norbonz pafsim floret Iulio \& Augufto: Radix digitum minimum æquar, nigricans Peucedani figura, guftu, Ro odore, cuiufnodi \& fenen:quo etiam magis retinemurin veri Bupleuri perfuafione, Nicandri \& Plinij autoritate, fi forct planta hxc cibo idonea. qualem Hippocrates commendat : fam in inedicaméntis, vt placuit Glau coni \& Nicandro, non incommodam dicet, qui faporem \& odorem quadantenus Hyperici deprahendet, temperato calore, aliquätum ficciorem.

$$
\begin{aligned}
& A L T E R A B V P L E V R U A \text { iongener latifolia, AVR I C V A A } \\
& \text { Leporis dilta,nonest EI A P HOBO SCV M. }
\end{aligned}
$$

Variesas. $\quad$ IS DEM in locis non proncul Gramontia fyluz, longè frequentior hxc reperitur, qux Dod.cpit.37 4. I plane cadem cum Cuperiore ctt, natalibus, figura, viribus, vmbellis, \& foribus: folio alioqu latiore, rigidiore, latiufculo in medio, \& fupernè in angufłum deficiente, nonnihilq́; concauo ant in! exo. Vindejllic fudiofi c Surculam Leporinum vocitant, alij Elaphobof cum fecerut, auia it folio aliquantum, vti putant illi, Therebinthi:atqui Diofcordis collitio cxprinte pritium folij latitudinem digiti, deinde modum \& pofitum Therebinthi, fimilitudine plätæ Ferulacex, qualem dedimus alibi inter Paftinacus:nan de Plinij liquet illuc conferendum, qui Olufatri folium Elaphobofco dat.

$$
\text { SCORTIOIDES repens Bupleurifolio. }
$$

$\mathscr{Z} \mathrm{N}$ oliuetis \&aridis montofis Monfpellio vicinis frequens occurrit hæc, alibi rara J planta, nec nifi in hortis vifitur, vocaturq́; Scorpioides jropter feminis inuolucrum, quæ tel na hærent hirfutic obduka in fe conuoluta, \& aliquantum Scorpionis caudam amulantur. In caule caduco, teptante, fefquipalmari, \& interdum pedali, folia c̀ geniculis promente Bonpleurilatifoliz fimilia,reflexa, minus rigida.

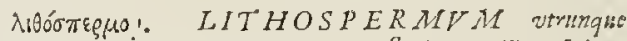

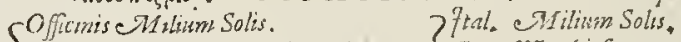

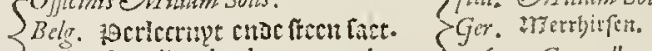 ¿Gall. Gemil. \& herbeaux perles. Sering. Gromell.}

API DE A duritic \& Herculea feminis vi nuncuparüt hãc Heracleiam plantä:notiEffig. Dod, epit. I tix peruulgatx omnes differentix, quẹ à maginitudne, habitu, \& folijs quxruntur. Paf 317. fim in Gullijs \& Anglı locis incultis Lithofpermum minus, magisć; obuium fit:ramis \& Mat, epit. 46. alis duris, rectis, afperis, rotundis, albidis, folia angufta, acuta Phylirex aut Liguftri, vel Polvoonati nigricantia, rudia tactu, fqualida, flofuli albent in alis \& fummo fecus folia. Vniones lucidi, læues, rotũdi, albidi, aut pulli pralucidi Milio aquales, ideo Milion Soler, id eft,montiü, dictü potius quã Solis. Effractum multü ficcitatis,abfterfionis, nonnihilaSoler melius quă crimonia habet. Locis frigolis aut quibus coli defitum, femen minus, nitióum, fed rugoSolis, vede in S: 1 nm \& afperum, vti ctian folia. Maximus huius vbiq; in officinis vfus, $x$ ftate coll 1 gunt $\&$ lere Montaro venum ferunt mulierculx:in Anglia plurimim fponte.

Variecas. $\left\{\begin{array}{l}\text { Eft vbi minimum videas palmum altum, foliolis Lini anguftis, fecus quę gra- } \\ \text { 1ula puflla, rotunda, polita, \& prorfum minora. }\end{array}\right.$

\section{LITHOSTERCMUCHA mains.} Dod.epit. 339. Sf fermè fitu, a b imo crebra cingút folia logiora, aç, hiora, latioraç; minoris Lithofpermi nigrican- 


\section{STIRP IV $M$ aduerfarianona.}

nigricantibus, afperis, quibus occuluntur hirfuti ģafilli, \& f cmen idem, fed durius \& maius, defuxis purpurafccntibus flofculis, oblongius s atq;; calculo exterendo, lociòq; mouédoefficacius multò, minus tamé vfurpatum quàm minus, quia minus frequcns, minorq́; rupperit copia, nec perinde feminis eft fercx. Belgio \& Germania hortenfe vtrumq; Mófpellij propter Sellæ notzx pontem \& decliuibus, fixofis, vmbrofis, fylluofis, fpötè multü.

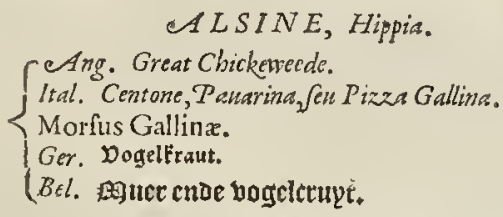

A L s I o s is non modò fed etiam parietinis, \& inbricamentis oblectatur Alfine, que

Auricula muris vocitata fuit antiquis ob foliorum admodum artam fimil itudinem, cum genuina Myofotide, teneriufcula fiquidem herbula ef, Gallinis \& a aiculis pabulo Morfus Gallinas grata, coó; vocata plebi morfus Gallinæ. Plurimos ramulos gcuiculatos, rotundos, foliofos, Angallidis vcl parietarix minores minusć; hirfntos fiofculos etiam ex capitulis Anagallidis, vel Hollauftij explicat albidos, ftellatos. Scmine exiguo in pericarpio oblotigo,guftu infulfo aqueo refrigerante.

\section{A LSINE Minor recentiorum, fue Hippia minor. fAAng. Aniddle Chickewecde. \\ $\{$ Gall. Morgeline Mouron.}

PE r S I M I I I s fuperiori,fed minoribus tü foliolis,tú ramulis, humi procumbenti- Dod.effig. $\cdot 37$. bus, propiusq́; ad Anagallidem, quàm Parictariam eformatis, cætera non difsimilis, neq; oriunda diuerfis in locis.

\section{Ang. Little Chickweede.}

$$
\text { ALSINE Minima. }
$$

$E^{\mathrm{T}}$ hac proximè defcriptem Anagallidem admodum prafert,verùm tota tcnellis ca- Dost.effi. st; pillaccisq; ramulis, exilibussq́; Scrpilli ienticula vel tenuifolij Thyıni,numerofioribus: non difpari loco, fitu, aut effectu, notisims.

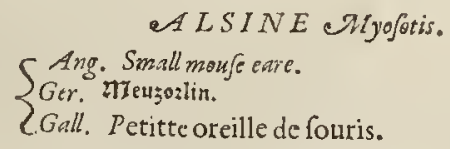

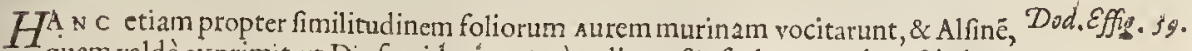

quam valdè exprimit, vt Diofcorides innuit:à radice cafsiufcula, rotunda, reetis item multis viticulis crefcit,femipedem $\&$ peden altis, foliolis auriculas murinas vel centaureù minus imitatis, binis, ab imo nultis per interzalla. Fecundum qua in capillaceis pediccllis flofculi exigui Gallij vel A parine cartulci flofculi. Rarior hæc, nifi Italix Gallog̣; pro uincix herbidis marginibus \& campeftribus, nullo excellenti guftu.

$$
\text { MTOSOTIS Hirfutarptans. }
$$

A DM OD v m familiaris hac hortis, vinetis, fegetibus, \& pratenfibus, vnlgo Phiarmacopocorum suricula muris minoris nomine notifsima, \& aptifimè fic vocata, propter

$$
\text { R.j. hir- }
$$




\section{STIRPIV $M$ adwerfaria nowa.}

hirfutiem effigiemq́; auri murinæ haud abfimilem, repit humi tota ramulis palmaribus * hirfutis, mollioribus, Scorpioidem minimam vel Anagallidem referentibus: fofculis albidis, 2: femine non difpari, radice multis fibrillis fparfa.

AN AG ALL IS Phaniccamas, co Caruleaformina.

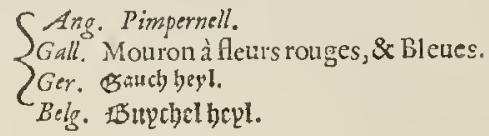

Effig. Dod. $60.6 \%$.

G.Mis dicebatur Græcè Hyacinthus, vnde à colore hyacin theo Anagallis nuncupar

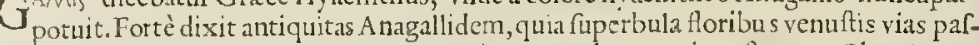
fim ornet, colore oculis grato \& anico. Antiquorum duas nouit noftra $x$ tas, Phocniceam \&. Carnlcam, qux neutiquam effigie dinerfx funt, fed duntaxar colore atq; effectu. Etenim Phoniccam fue marem illitu fedem euocat, quam prolapfan reprimit Cxrulea,vt Diofcorides ex aliorum hiftorijs recenfet.Vtrag; antem pafsim fruticat teneris cauliculis \& folijs Alfinc, copiofis floribus \& femine pufillo in pericarpijs Lini.

Cærulca autem, pratc:quàm quòd nois perinde freqnens, variat colore \& acrimonia, ealoréve remifsiore ett, fi antiquorum hiftorix ftandum.

\section{ANAGALLIS LITEA.}

TV т E a quàm vífu pulchra \& rara tranfmarnis regionibus vti Lugduni, tam crebra

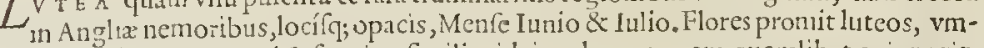
bro'fis gaudet, cætera mari \& foeminę fimilis, idcirco harum vnam quanlibet qui norit, primo quoq; intuitu cxteras duas nofcitabit. Superiore ętate maximam huius eopiam nacti fuimus in quadam denfa \& amœna Sylua Coucntriz proxima : itenq́; dum hæc commentaremur, altero à Briftoia lapide, in Northonij Equitis nemorofis pafcuis propè denexum Auminis Danem. Hallucinatos planèfuo more queritatur $S$ encuís, qui herban vocitatam Tharinam Barbaris In fubribus, Hetrufcè verò Ccntone, Anagallidem tradunt: atqui fi fciret vtrang; harum Timpernell plebi Pharmacopoot î \& mulicrculartun hîe in Anglia dieitari, ne ille multò grauius fibi ferendum putaret? Quafi veró non vulgi fit peruerterenomenclaturas, veteres delere, nouas fuo, non noftro arbitrio, cudere \& cö-

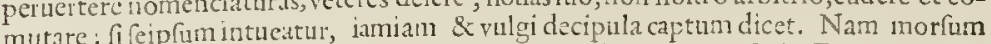
Gallinx, qui eft Alfine, Anagallidem hanc vulgi more hallucinatus fecit. Et vtimam non nemo bouus renins illi in mentem non Diaboli Morfun, lutic loco prorfus alientim, fed potius errores fuos, \& fupercilium faftu Cerbereo elatun fibi fpectä́da immififet. Quin houc Succifan, tmetfi iamdiu Trago \& Fufchio monentibus, híc non pauci imperiti Pharmacopei \& plebccula Scabiofam dicant \& vendan pracipiant: lllise fi difulifit, multò confultius feciffet : nam fortè Scabrof fpecies eft, \& faltem ad fabicm multum pollet.

MORSTS GALLIN AE Folio Hederule, floreffgurac pericarpiss e Anagallidis.

\section{Belg. Lacnoctucet.

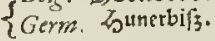

Eff.Dod. Epit. F I Q y e pafsim iusta fepes reptat cauliculis hirfutis Alfnes Myofotidis, folia pufl-

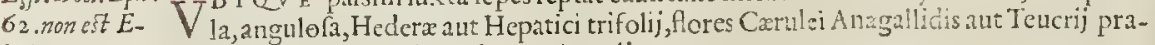
lating. tenfis. Semen paruum inciufum pericarpijs. 


\section{STIRPIVM aduerfarianoua. CA $N A G A L I S A Q V A T I C A$, fur Becabuenga Germanorum, non eft Capers \\ SGallis. Berle. \\ \{Belgis, zoaterpumighit;}

$\mathrm{G}^{\mathrm{A}}$ L L o R r m plebecula hanc Beruland dicit, fed confultiits recentiores Herbarii Anagallidum vnam, vt cuius folia \& vires uon parum initat ur, nec non natales fectatur vdorú, fecus pratenfes rinulos in pigris aquis, aut fabftlliis; folia edı: leniter ambifir crenata, fruticofis ramulis, teneris, carnofis Portulacx \& Núnularix in humü, deflexis ac ramulis crebribus, foetura diti florun coeruleorum Anagallidis finilimm, ftipatis: Radix multis fparfa fibris albicat, \& Nummularix modo fubtus ferpit, tota guftu acriore Nafturtil, odore non ingrato, llec inin ore ope apud Frifios \& Germanos vfurpatur, aduerfum indegenam morbü illic Scorbutum nuncupatúr, quem iuuat, non fecus atque $\mathrm{Co}-$ chle.ria, Cardamine aquatica fue Bcrula, $\&$, alix quas alibi diximus. Porrò Cxpean non videri,inter $P$ ortulacas differuimus.

\section{A ATH L L IS PRIOR Leinifolia \\ Peplins cffigie, maritima.}

O V A s I floridulx, lanugine cana qua pubent Anthyllides dietx videntur, aut potius i thofccliorum evilitate, quales cernuntur gemmci perelegantcs, pufilli, in Anthyllide hacMaritima létifolia dieta à unbis dcpiata. Ac tametri per notas mintus accuratas ne nacto quiden veram primam Anthyllidem, integriln fucrit certò affeuerare quanam Diofcoridis prima fit, tam=n quoad eius fieri quit, vt confulamus rerum Hiforix, non poenitendi iudicii conicctur $x$ aptand $x$ funt tum defcriptioni, tum plantz ilt, qua non perperam inter fe quadrant. In Angliz infulis Auftralibus, ca prás crtim qux $P$ ortlandia vocatur, litore Norhtmannicobuerfo, plurima quam hic damus, pufilla prouentic in fabuletis \& arenofis vadis deprefsis, \& apricis: geniculis, \& ramulis palmum trésve vncias longis, angulofis, pallentibus \& foliis, Lenticulam, Alfunem minorem, vel Peplin referentibus. Flofuli fummis infunt ex buxeo herbacci,dentatim ftcllati, Sedi minoris Iunio \& Iulio: Semen Tythymali in perexiguis Chamacyfx triquetris thecis alit: prolixiore, cxili,geniculata radice, rabulo altè inforfa Soldonel-

la modo:tota falla, guftenti a maricat \& parum quiddam calfacientis indicat. Nec hefitationilocus ian foret, fi quam certum habenus facultates hanc fortitam effe, quales prim Diofcorides afferit, tam confidenter decerncre auderemus effigiem planè eandem effe : nos monet tamen non partum Alfine quæ quia huic, vt fariè eft, cum fimiiis admodun foret, eodem nomine Anthyllidis vocata donataq́ue fuit, vt apud Diofcoridem videre eft. Et multò aptius congruút huius nouẹ maritima foliola legumıni Lenticulx, quàm paluftris Lenticulx. Quare comparatio videtur accipienda de Len-

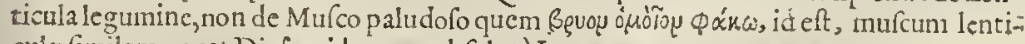
culær fimilem, yocat Diofcorides, non abfolutè Lentem.

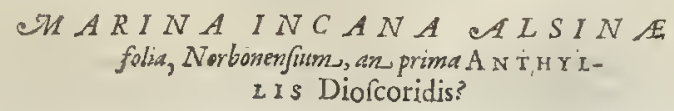

R.ij.

Exis 
T I A m maritimis agri Nitiobrigi ad Perass \& L.3teras reptat hac pafsun, vti fuperior, ramulis comenticula, fed per interualla quxdam, quafi circum geiculos cxortis, numerofis: copiofifsimis item flocell is fummo aggeftis, mulcolis, albulis, foridum quafi noAnthyllidis oftentantibus \& teftantibus, feminis trofo, calidiufculo.

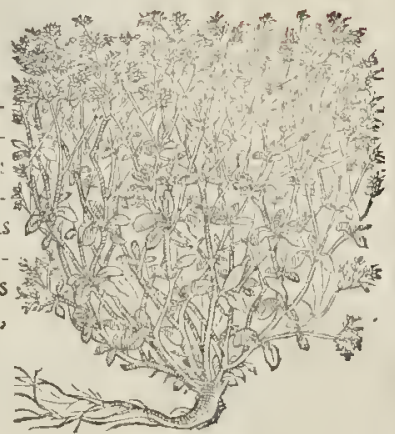

eANT HYLLIS Marina Norbonenfium altera,admodum,

faljo-acida, Chamasycaficie.

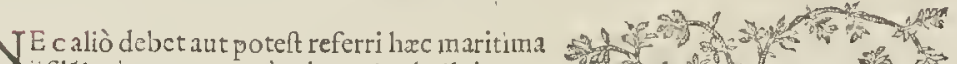

iffélocis reptans, quàm inter Anthyllides, vt ux aliis mul tò faifiot fit. Foliis \& facie eft Hernia aut Chamr yycę: flofculis pufillis fubter foliola - albo purpurafcêtribus; femina in florü calyculis àm Clitopodij minoribus multò occluduntur. ota guftu falfo, acidulo, lactei fucci expers, \& xucti: nec proinde Chamefyce ftatuendi, ve quiqui ficcan tantum in fuis muleolis viderant, odiderunt.

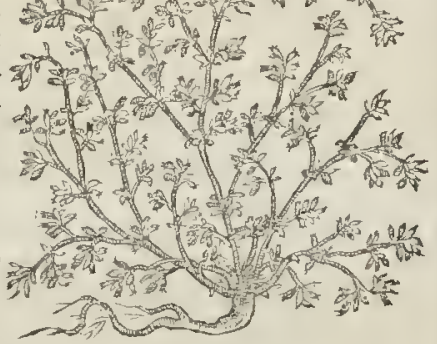

TP ARONYCHIA Aljmefoli..

V I A ei vnguium affectui medetur quem Grxci Paronychiam, Cicero autenn redu-

uiam dicit, $P$ aronychia di\&a fuit: hodie minus fanè nota, propter multas plantas, qua confiniles funt, eandemq́ue adumbrant apud Diofcoridem, magis quàm preffè delineant:inter quas tame in tectis \& parietinis reperitur vna, vt fi qux alia, Paronychiam imitata defignationem. Pufilla eft plantula tota Alfinx figura, non multis folis Alfines vel Lenticulx, nec difsimilibus donata, fed exorta ad imum cauliculum aut pedicellum dodrantalë,albidum,admodú exilé, quaiis Callitrici Apulei putati: in quo fummo flofculi candidi, \& theculæ minimi Thla!pi pares, fed comprelfæ \& foliacex : guftu aliquantum acri, eoćue opinionem fouente corum qui $P$ arony chiam autumant. Nam illa capillacea, quam Commentator iactat, non perinde poteft $P$ aronychiis prodeffe : effećue guftu \& facultate Capillarium ceterarum, monuim us alibi.

PARONYCHIA ALTERA, FOLIO Rutaceo, flore albido.

Convictrix in parietinis locísq; mucidis, petrofis, vmbrofis, vbiq; cum fuperiore obuia etiā eft hęc; cauliculis dodrantalibus \& padmaribus,crafsiufculis : foliola Rutz bifida, interdunú; trifida incíura, magnitudue \& parilitate quadamtenus cernuntur, colo. 


\section{STIR P IV $M$ aduerfarianoin.}

colore pallidula \& fubrubra, fucculenta ; foribus albidis, feminula etiam in thecis Scorpioidis Myofotidi non difparibus: vtraque excunte hyeme Vere prino flofculos edunt: deinde ninimo $x$ ftu marecfcunt, vt nufpiarm toto anno compareant.

\section{ELATINE DIOSCORI. Veronica \\ fomina Fufch,}

$Q^{2}$ V I D hîc carpat aut balbutiat Commeutator nefcit, neque fcire voluit nos, fibi ignotam fuife veram Elatinem, cultates verò reticet, nec quid fibi volucrit,hifccre audet:Genuin ne omnium nuperorum fuffragiis, viribus 2 Scriptores, Doctifsimus prefertim Fufchius, Veronican fominam dixerat, quanquam alius generis àmari Veronica.Plurima in fegetibus Norbonæ, Gulloprouin

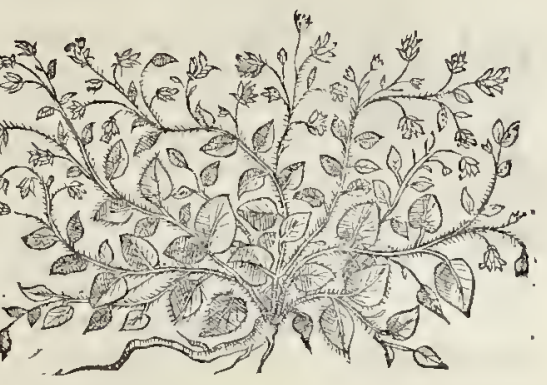
cię,Delphinatu, Germanix \& Italiæ quibufdam locis:rarius in Bclgio, \& Anglia conparct. Pedalibus ferpit viticulis, tenellis, flexilibus, pluribus, ab exili radice: folia Hel xine minora, rotundiora, fed pilofa \& incana,ad Nummulariam vulgo dictä accedentia, promunt : flofculi Hedera terrefris, aut Anchirrini, fed perpuflli, albidi, \&s fomen exiguti, nigrum, fubrotundum, Anagallidis parac fimile. Aftrictorix non modò hxc facultatis, meritò diffentericis, tumoribúsve feruidis prodeft : verùmetian tanti fit hodie ad cancros, carcinomata,maliqúte humoris vlcera,vt eucntus fuperct, aut temeret fiden: Nafum qui decreucrant abfindere perdoeti Medici complures, præceperantćuc eiufdem fententix Chyrurgis valde exercitatis id faciendum, quidam mifel lus Barbitonfor, qui de quopian fuo hero cximio Medico hanc dotem didiciffer, diffuafit : luuius litu \& potu effecit, vt nec nafus abfcindendus foret, \& vt reliquo corpori in Iępram prono optimę efiet : amaricant folia aftringuntćue ficcitate non exafperante.

\section{VERONICAVERAĆmior.}

Germa. Lrestibrifs is Brunbeyl.

Belgis. Letert prifis;Laudata nobilium.

$E_{\text {T hxcetiam nominatifima, nec vulgatx commendationis ad vlcera, vulnera,ac ple- }}$

raque virulen torum affectum. In fyluis Septentrionalium pafsim, fed editis \& möm Betonica $P_{a}$ ât tofis Meridionaliun collegimus pufillam, ramulis crebribus, villofis, purpurafcentibus, Dodo.2x. gracilibus, pedalibus, ftratis: folia nonnihil ad Teucrii vel Chamædrios crenis accedüt, fed lenioribus, \& Berberidis quafi effigiätibus folium, fed hirfuta Pilofellę : flores dilutè purpureos fummi turiones edunt, Germanicæ Germandrę̧, feu Teucrii pratenfis effigie; fed aninores:in marfupiolo comprefio grana minuta. Fibrofa, nec prolixa radix.

\section{$M I N O R$ Serpiliffolia VERONICA,}

NE chac nifi tractubus Septentrionalibus etiam in hortis fpontc multa ferpit, Alfue vel potius Serpilli ritu \& habiau, coq́ue non nullis putabatur Serpilli fpecies. Verùm crafsiore multò ct folio, ncc crenato, aut hirfuto albido, vt Veronica mas, cui nihilö minus foliorum ordine \& ortu, viticulis, floribus, \& feminis vtriculis permultum fimilatur, fed magnitudine inferior. Radix tenella, fibrof, fubtus repit:calida nonnilil \& deficcans, ad Serpilli guftum infipidiorem accedens. 


\section{$S T I R \mathcal{P} I V M$ aduerfarianous. \\ NVAI $R Y L A R I A, C E N T I M O R B I A$, num, Ereffed:anum, Theoplaraff?}

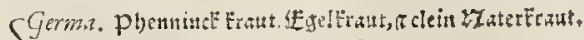

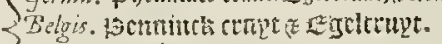

Laingl. Hearbe tivo perace.

Centrmorbin.

P A C'I \& riguis gandet, fed regionum Septentrionarnm, \& frigidiortum potius quàm calıdiorum(vbi puca)indigena eft Nunmulara, à folioru circunata rotun ditatc numum initante dicta bud exeun thxc, exaduerfo æquis, fed crebribus fpacis viticulorun humi repentiü, Elatina longitudıne, \& ritu : colore \& habitu quadātenus

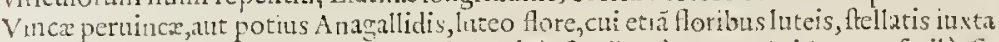
foliortum exortus, etiom gemino ordine adeo fimilis eft, ve per initia non facilè fit difcenere: fed Anagallidis lutere progreffu tempors longinfeula fisnt, \& in ino nonnihul finuantur:nce fenen drfsimile. Non modo unfigni quapian altringendi S exficcand: dotc in gargarifnata recipitur, fed etiam tot ad atrecus vtilis tantoperè habetur, vt Centimo:bia fic dicta, \& nppellıtetur hodie: Anglix, Germania, Bclgio, \&Normănx Gallia vmbrofis vdis,ad fepes familiaris.

\section{ST MPHYTVM Petraum.}

YMpнyr Petræi quxadübrarent delineationé nou defuerüt plantẹ pleræque: at non Sfimilitudinis, aut figure caufi, fed viritm \& nntırc, quá glutinädi vtriq; inefle fcirent, v-

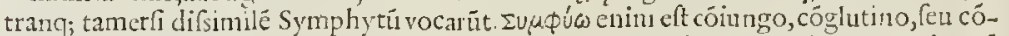
mirto. Sed nos potius ad quãpian Cunilla, id eft, Origani, Thymi, Serpilii, Satureia, vel Coris Monfpel.cögenerẻ deducebat Diof.lęto:in Petrofis enim lignofum, furculofum totü \& odoratú oritur, ramulis Orıgani, folis partis, capitulis Thymi, vti Plinis, vel vt

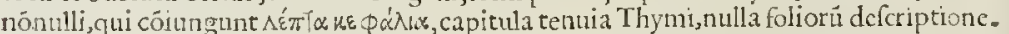
S.liuam cit, tum fubdulcis elt, purpurea radix, longa, digitum æquans:quorum fimul fubducta notio facit, vt nondum vilam queanus ftatuere ftirpem Symply to vero eandem. Coris verò Monfpeĺlıenfú, atq; Sideritis odora pufilla, fpicatoflo:e nos poterant adducere ad Symphytiperfualionem: verum morofis non omma penitus quadrare vide. buntur. Et Senenfis plaufus praproperus, capite de Hy Topo, repertam elfe ian perfua-

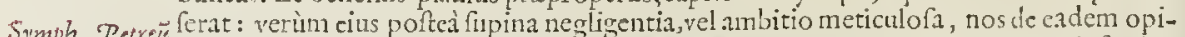

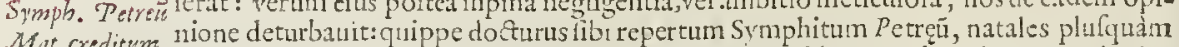
Hat .creditum, prolixè cnarrat, pichritudinem celcbrat, in terea nilul addit qux ad certiorem probatio. nem faciát, nó faciei, non viriü, aut vfus quidquam. Quarequid vul fibi, vt affentiamur, fi nihil explicat, extricat, aut docet? Vidimus iamdiu plantan, quam putamus ab illo reprefentatâ, prope Fernardi celfos Sabaudicos montes, \& de Anguillata audiuimus, cur nó aufus fuerit, vt in quamplurimis, defcribere:audere id igitur poftunt, qui viderunt. Eft ea floribus purpurea confertis, fpeciofis, Ericx maioris, fpicatis, foliis pufillis Chamxpiteos, breuioribus aliquantü hirfutis Pilofellx modo, in furculis pedalibus, 1 gुnofis:fed inodora,radix lignea, non purpurea, nec dulcis gufu planta,nec faliuaris. Quan ille cum fe reperife, Deofecundo, exul tabat, foliis Origani \& HyrTopi, non animaduertebat Hyffopo Diofcoridis folia effe Origant:\& Diofcoridem nó folia, fed caules Symphiti, Origano afsinilafle, vti \& Plinius: folia verò parua diftinetè, sx feiunctè dixifle.

\section{BVGVLA, quidum Pruneliam.}

GA I I I s, vt Rucllio \& aliis, vires illx decantatx aे vulnerariis Medicis \& Empiricis, ad foris intisque multos morbos curandos, qui Sy"mphito inele folia Origa nilegerant , anfam dederüt opinandi Buglam vulgò vocată,aut Bugulam, effe Symphytú Eetraú : eft fancmirx vis cum Sauicula potionibus vulneraris: quare velito nomine \& certi- 


\section{STIRTIVM aduerfarianoud.}

certitudine malim, vt Symphito vti,quàm Mathio. incertż cóiecture acquicfcere.Confolidum mediam, id eft, Symphitum, Chyturgi vocarunt, feu Solid. yुinem \&: Bugnlan. Sed huius finilem $\mathcal{P}_{\text {ruinel }}$ an vocatam, aut Confolidam minorem, eodem nomine do. naant, propter vultum \& vires hud itu difpares, aliognti natales Bugule vel medix confolidx funt vda prata, \& fylux, \& horti: farmento is rants, cxihbus, flesilibus, humi reptantibus, \& foliis Becabningre vel Antgallidis aquaticre, \& alicubi deprtis, vnde ali eri: guntur furculi, angulofi, fe fquipaimum alti:quibus folia crafi, rotunda, oblonga, leuiter ferrata, \& a uerfa parte Hedere Pruníne modo, aut granati colore puniceo, (vnde fortaffis vtenuis Gallis $\mathcal{P}_{\text {cunella }}$ promifcuè diaz) flores iuxta folia ì medio fum no teans verticillatis fpaciis ccerulei elegantéque prodeunt, interdun niueo can lore. Radix fibro. f., tenera, maior quàm Prunellz.

\section{PRVNELLA STMPHITVM Pctraum.}

PR V N E L e e enim pufilla, fed prolixior fobeft radir, vitgultis itemi reptantibus, quadratis, hirfutis, palmü \& fefquipalmü longis, inflexis: foliis longroribus, fupernè acutioribus, Pulcgti regii,vel Origani, vel Trifolii, fpicatis \&x parpureis comis longioribus.

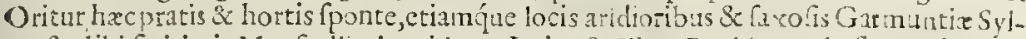
ux, \& alibi fintimis Monfpelliaciagri, inter Lados \& Ilices Baphicas, vbrfores dilutic

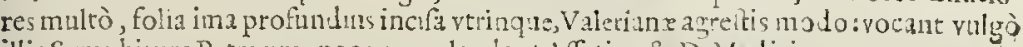
illic Symphitum Petrrum, nec parum latadant dfatius \& D.Medici.

$$
\begin{gathered}
\text { CONSOLIDA minor Officinarum,an B E LL IDES } \\
\text { Tlinimin? }
\end{gathered}
$$

SGalls. Marguerites, Pafquettes.

Pital. Primofiore.

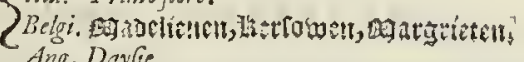

$$
\text { Ang. Dayjie. }
$$

ETfi tacitns Bellides pretetiit Diofcorides, tamen qux apud Plininm extant perpauca CMathio.g's. Ler vagt, perfuaferunt pofteritati hofce lores, qui in pratis abunde primo Vere erunpunt, Bellides effe: Nan inquit ille; Bellis in pratis nafcitur, flore albo, a hqu utenus tubente:cui conie turx farret nomenclaturx expenfio : Potuerunt nanque functle ille Beli Danai hegis quinquagintx natx (qua totidé nuptx maritis, cos quxxlibet fuú iugu1arunt nonen dedife, vnde fortè poltea iftos flores vocarint, qui. multi vifuntur gregztim và̀ \& belluli, vnde vocautur vulgò Marguerites : funt quippa glomeruli multi forí quafi vniones, fiue Margarita, è pediculis crebribus, palmaribus, teneris, pilofis, en umpentibus è medio foliorum, qur Pratenfi ninori frequentiori infunt multa, vilidia,crebra,cralsiora, Olex aut $\mathcal{P}$ ilofella. Radix pufilla $P$ lantaginis.

II V I v 8 autem differentix varietas in florum colore \& magnitudine : Eq enim flos frequentius albus, medio luteus Anthemidis. Interdum \& purpureus. Nec qux in Varetessi hortis coluntur a d coronamenta, differunt, nifi cultu:annua enim \& frequenti tranfplantatione maiores, habitiores, confertiores, duplicati, \& triplicati, \& elegantiores euadunt forcs. Hiî́ potifsinùm vtuntur vulnerarii, vndc Conolidæminores dietx ficicunt,

\section{$B E L L I S$ CIEDIA.}

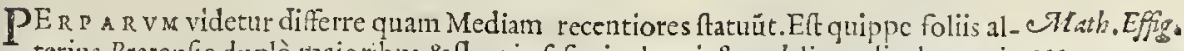
terins Pratenlis duplò raaioribus, \& Hore in fefquipalmari \& pedali, pediculo graci- $27 \%$, li, nec diucrfo à frupsriori. Hancà fe lectam in Syluofis montibus Germaniz nobis conzmunicaut D. 'P ennius Anglus.

\section{BELLIS Cerulea, GL OIYIARIA Monpellienfurn.}

$$
\text { R. iiij, A.F.Q }
$$




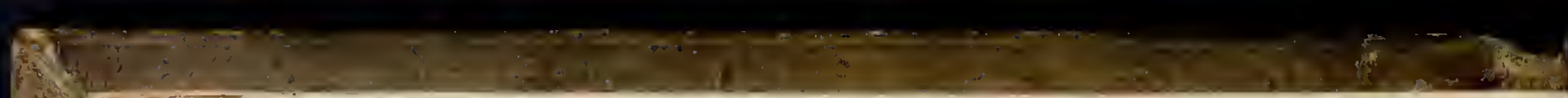

A F I O R M glomerulis globiste Globularia recétio- ty ribus vocata, Monfpellienfibus prafertin, apud quos Gramuntix fylux vicinis deuexis pratis oritur, foliolis Bellidis vulgaris, nigrioribus, fed iuxta pedicellos rigidiufculos palmares \&-fefquipalmares anguftioribus. 1 lores cxrylei, pulchelli, in orbè glomerati,Scabiofę mótanx modo \& colore. Radix lignea, fibrofa. Rarior hæc Italix, Germaniz,\& Francix.

$B E L L I S A A I O R$.

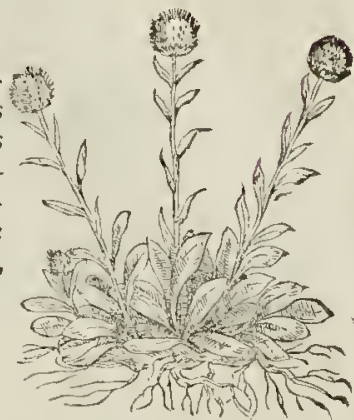

CONSOLIDA MediaVuntrariornys.

$\left\{\begin{array}{l}\text { Germa. Benf5blum. } \\ \text { Ang. Greate dayfie. }\end{array}\right.$

C V r recentioribus maior Bellis vocatur, caules emittit graciles, lignofos, plures, teretes, cubitales \& pedales, Iacobex fimnles, è fibrofiore \& fparfa radice, in quibus flo res nedro luteos, \& ambitu candidos Buphthalmi, aut $\mathcal{P}$ yrether vulgatis; folia Senecionis, ferrata:fecus margines agrorum \& pratorum familiaris.

\section{PILOSEL $L A$, Auriculamuris;}

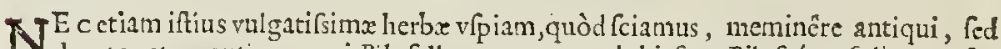
dumtaxat recentiores, qui $P$ ilofellam vocarunt, ab hirfuta $P$ ilofáque foliorum fuperficie quadātenus albicante, oblonga Bellidis, fed aliquantum fupernè concaua, auricu lam murinam effigiante, vnde Myofotidem quidam dixeruut; tamet [i alia fit Diofcoridis Myofotis : Pedicelli iten hirfuti, graciles, palmares, \& fefquipalınares funt: Floréfq; edunt æftate Bellidis, aut Hieracii pallidufculi concolores: vniuerfa aftri\&orix facultatis quadam tenuitate calida mixtx, cuius ea eft vis, vt fucco decoetóue acies chalybex cädentes fxpius merfx, quarnlibet duritiem lapideam, ferreámue pracidant \& demoliantur, nectamen retundantura aut hebetefcant. Vi etiam eft prafentifsima ad calculum.

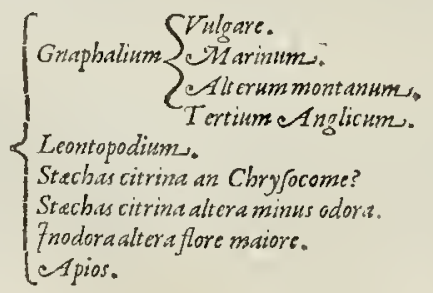

$G N A P H A L I V$ M marinum: Cotonaria vulgi.

Bombax ha. INA milis. tergere, concinnare, \& interpolare, vnde Strutio \& Graphalion, quod Romani codein Pette Coton,. fignificatu Centumculum nuncuparunt, \& Tomentariant, ac Plinius Chamæzylon (fic enim emendamus, quod omnes etiam recentiores legunt Chamæzelon) appofitè dixit: nulla namque planta raritate, elegantia, \& v tilitate propius imitatur Gof sipium, imò nibil aliud, quanta eft, nifi tomentum videtur, fi tadicé exceperis, \& intimam forum fuper- 


\section{STIRPIVM aduerfarianona.}

fíciem, corymbos enim Abrotani fœminæ aureos, numerofos, mulk fidis caulium furculis, quos fupat lanugo candida, aut cinericia perquàm denfa, cinguntćue folia quoquonerfum multa, fungofa, eadem pube obducta, taciuique vniuerfa planta valdè quàm blanditur, holofericı attrectatu, fefquipalmum pedémve alta fruticat, du riufculis virgultis, farmentofis, tomento craffo incanis: radice lignca, recta palmum longz, inflexa, Aizoi me. dii vel Paralij Tithymalli fimilia ortu, fitu, \& figura, fed minora. Vniuerfo litore \& fabuletis à Marianis aquis ad Ceti noótis radices \& lacum plurima, alibi haud temerè occurtit Norbonę. In Adriaticis littoribus non vidinnus, S. nonnullas plantas primùm oftendimus Venetis, \& Veronéfibus Bellicoco \& Caffcolario: Corcufio verò Patauij charticeum Herbarium fpectandum cum dediffe-

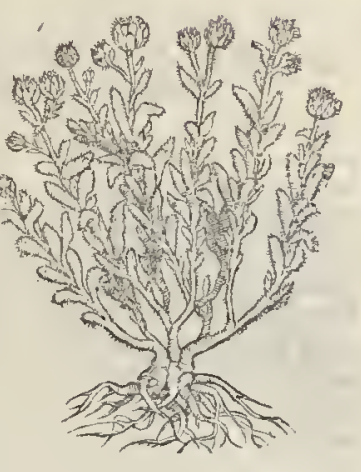
mus, huius củ $P$ olyrhizi Ariffolochı, Thymalli ferrato, floribus Opontix, plantulam nobis periiffe animaduertimus, nec multò pòft eafdem depictas Mathiolo fto muncri mifas fuiffe, quo lubentius perfuafi fuimus, propterea quia neque defcripfit in poftremis commentaris, neque quxnam \& vnde oriunda foret, monuit, nec flores appofuit piator, quia illi noftrx flos fentenq́ue tunc defuit: triquetrum enim, pufillum, acerofum, oblongum, albidum. Afringit magnoperè \& deficcat tota planta, nonnihil falfa, nec tumen ingrata, aut ama ra, aliquantum aromatica odore, quadamtenus citrine Strechadis; vel gummi Elemni: Inlio foret.Sxpius vfi fumus furculis pro cliclniis, qui viuide al!n: flammam, Olci quippe catcriọue pinguis liquoris potrix eft.

\section{$G N A P H A L I V M$ vilgare, Filago Centurculus.}

$\mathrm{V}^{S}$ Cy Equấque quidem Gnaphalium iftud vbique aridis \& ferilibus multum \&e notum, videtur foliis \& cauliculis innitari maritimü, differt tamen cum fol is, floribus; Ianugine, odore, cādore, tü fpeciofać; : s hilari afpectu, Gnaphaliü fuperius, à Filagine, que potius ad Strecliadem citrinä referenda fit, aut certè cognitionis vtilitatif́q; caula, fit cü̆ profuuiis imnoderatis non parum accommoda. Herbula flago eft plufcul is cauliculis, pullis vel cincriciis, lanugine tectis, gracilibus fefquipalmum altis, fol iolis crebribus, aduol utis, breuioribus quàn Strchadis citrinę. Floribus glomeration oriētibus:partim mediis è furculorum duaricationibus, partim etiam extrenis furculis, fubluteis \& pallentibus:molicella tota \& pufilla, frequentior $I_{12}$ chac delincatione occurrit.

Varictas GER MANICI maioris \& fecundum folia floridi.

ZN TERDVM \& aliă vidimus in Germania maiorĕ fláai. né etiā roliis\& caule Strchadis citrina:\&inodorã, alibi etiä flofculıs non in fummo, fed inter foliorú interualla pafsim fecúdum longitudinë ortis : quemadmodü oriuntur in ifta, gquā ve nondum planè notam, hî̀c appinximus.

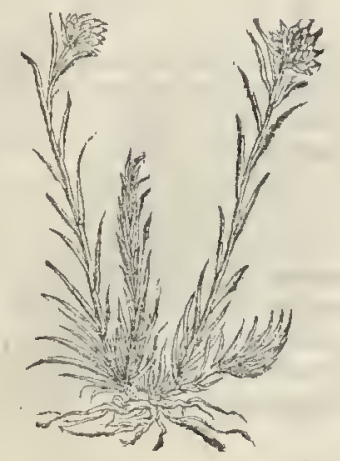


ANGL I CV MI folio longione perperass
Leontopodium alterum Mat.

Graphaliü teris Anglicum

R ACI I I Ys \& rectis virgis, nullis ff$\mathrm{U}_{\text {fú al is, proceritateq; } 2 \text { quat Abfinthiủ, colore }}$ etiä \& figura refert: folia ab imo cefpite, radiq́ue capillace t, duplò longiona \& latiora quàm Stxchadis citrinx, fermè Salignex effiginn, toto reliquo caule $P$ fylio longiora, anguiftior, fed partciora, prope qux media in pedicelliz exiguis vellicatun tern quaternive flofculi, 'pappoli, è Buxeo pallidi Senecionis, vel Srechadis citrin $x$ hẹrêt aftrıngit:nönihil amaricat, multí exficcat. Tertio à Lódino miliari opacx fylux cliuns multam alit, cis Tamefim.

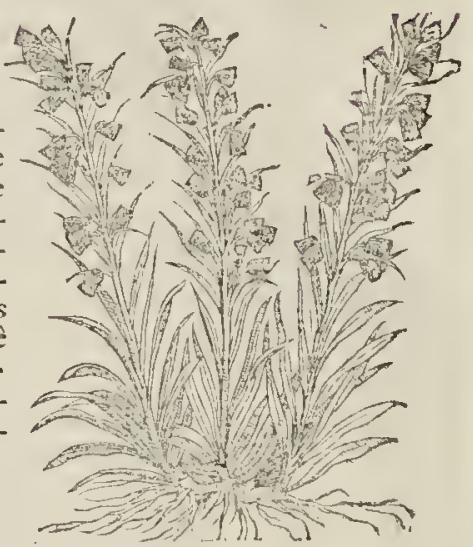

$G N A P H A L T V M M O N T A N V M$

Purpuream o Allum Pilofella minor Fufo's.

MYosr I r I svel $P$ ilofellx minoris effigie oriture hec arduis frigidis, iugis, \& quo loci Vaccinia nigra, aut Ided Theophrafti vitis putata, foliciter proueniunt : vix fefquipalnum æquat, perexigua radix, reptäs fibrillis. Folia incana, mollia, ad imú penè tota, vti in Bellide, reliquo caule pufillis, perpancis \& exilibus, flos

Fisietas. fummo fingulus globulus eft, Scabiofx feré, fed conpactis fofeulis permixtis partim purpureis, partum can didis, hîc rarior, frequêt ins quippe occurrit flore albo: valde quàn aftringit, \& exficcat, guftu infulo. Rauiburgi Germaniz \& ad Calcaris montem Norbonz prope paguin fxpe collegimus.

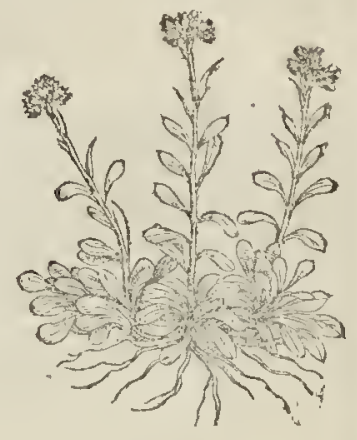

\section{LEONTONPODIVM SIVE \\ Pes Leoxinites.}

PE D E M Lconinum propter villofam foliorum \& flornm effigien crus pedi annexum Matbio.1/g3. Caliquantum referenten, dixerunt, quemadmodum pedem Leonis, Leporis, Vri, Columbx, Corui, \& Gallinx, tum antiqua, tum noltra ztas. Iam inde à நtunftelfi Ger-
manorumque aliorum de te Herbaria meritifsimoram feriptorum temporibus inuenta \& defcripta herbula montana, quæ non parun foliis Rofam, feu Rotellam imitatur. Eft quippe folits angutis, oblongis, hifutis, fed incauis, præfertin in imo, duos noljices logis, Gnaphalii, Strechadísue Citrinx latioribus: In canle fummo itidem hifpido, ternos, quaternósvedigiros alto, geftante flotes, nigracantes ex fuico violaceo, \&: capitula latiufculo, fed denfo ambitu fparfa, ac nonnihil quibufdun foramiuuls inpreffa, quafi Leonis veftigium, vel foleam imitatis. In Germaniz arduis, adcoque Italix Alpinis \& Baldo Veronenfi inucnitur, fed rarius, idcircoque quid pofsit aut praftet nondum fcitur. 
CHRYSOCOME aureatie coma. STACHAS CITRINA nostras, fue Luteus eAmaranthus.

SeAng. Gold flawer.

SGer. Mrattenblumen, Rlyeisblumen.

¿Belg. Aacunblocmentmotteis cupt,

CONSPIC V a forum corymbaceorum aurea coma nomen dedit Chry focoma, qua hactenus nofie non potuit atas noftra, veri Hylfopi Diofcoridis ignoratione, cuius corymbace is com is afsimilantur huius flores aurei. Iam cum Hyfopum veram inferius oftenfam \& affertam à nobis, corymbis comparamus Stæchadis Citriuæ diqæ, reliquasó: defcriptionis \& virium expendumus notas, perfuafum planè habemus, Stxchadem iftan verani Chryfocomen, quam etiam Luteum e Amaran bum vocarant Graci, à colore \& fulsore penè immarcefsibuli, cuiufmodi in iftius plante floribus

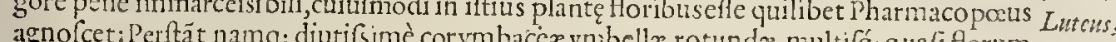
agnofcet: Perftát namq; diutifsimè corymbacex vnbellx, rotundax, nultifq́; quafiflorum bullatis glomerulis, fparfim tumultuarieć; códitæ, Origani non abfimiles, aut Hyfopi Diofcoridis à nobis data, lucente nitenteq́; permaturitatem coma aureo pallorc, \& mollicello vellere, pufillo intus femine Masoranx, fed exilion, ruffo, acri, odorato: In cauliculis, rectis, albidis, nonnihil incanis palmum \& fefyuipalmum al tis: folijs oblongis, anguftis, leui hirfutix incanis; Stachadis, vel Linarix Ofyridis, quam doctiores ninus rectè Chryfocomen antumaruut. Radix fibrofa, gracilis, nigra foris, gummi Elemnium vel Cyperum rotundum Syriacum, redolens vti flores \& tota planta: guftu ctian aro. matico, medicato, acuto \& feriente, non nimio feruore fubaftringéte : cuíus amicorum quorundam doetiorum imitatione expertifumus, admodun infignem vim, ad iecoris ex glutinofis fuccis ac vaporibus crafsis intra tunicas difcurfantib!s, diutu!nos affectus. Pulmonibus verò infammatis non impunè dari menninife par eft, fed affuxu pituita acida, ferofx vel falfx calefatis aut erofs: Eoq́; tutius vertifet interpres, pulmonarijs vel peripneumonicis, quàm inflammationibus pulmonum. Praftantior hxc \& fpeciofor Norbonenfis Galloptonincix, \& Hifpanix aridis \& petrofis, vbi odoratifsima \& plurima,ęfate, radice perenni. In Gcrmania ad Rhenum, reliquać; Gallia paucior \& inefficatior. Eapropter nihil quò minus veram Chryfocomen ftatuamus obltare videtur, nifi verbulum vnum ant alterum, quibus fubeffe quippiam labeculæ Monfpellienfes noftri pręceptores liondelletius \& alij, qui hanc Chryfocomen vocabant, íamdiu fubolfecerant

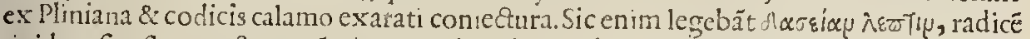

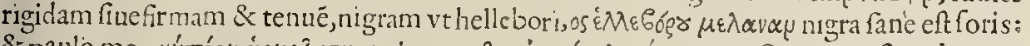

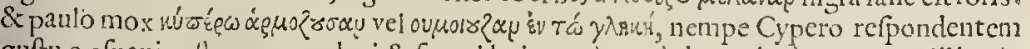
guftu ex fuaui aultero, qux odori \& fapori huius quàm quod maxime congruere illis vifa fuếre.

\section{$S T$ EECHAS Citrina Altira.}

VEMANSIIET MONSPEI. I. I I meminimus al teram huic fimilem, fed graciliorem totã, nigriorem,fquallidiorem, cincritiam, pluribus cauliculis viti ccis pedalibus: Radice cxiliore minusć; fibrata, quia raro niff in rimofis ruderibus \& mœnijsvrbium victitat, fufca foris, minimum odora. Florum corymbi finguli in fingulo caule, nec aggefti, vei fuperiores. Semen tamen fimile, exile, fufcun, quod Londini fat no nobis floruit \& annuè viguit.

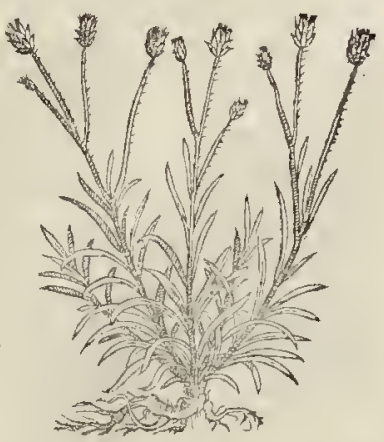


RA D I c s indiciocognitu facilis apios, qux rotunda, turbinati coni pyrum initallTenetijs ap nfula erutam, ill $P$ yrariam vernaculè vocatam, ftudio fis quàmplurimis detexit. Deinde nobis ato; peritifsimo Plarmacopœo Valerando Donrez vifendi attraetiduć; copiam ecit plantulan Crpacea radice, ['eonix breuiorem crafsioremq; vnnm è bulbis fimulan te,concoloré,pullámve foris, fed intus albicantem, iann aridam, rugofam, aliquot emergé-

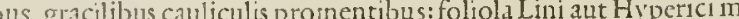
vuftiora, Ilofculis, pallidis, Tithymali minoribus. Hæc quin effet vera Apios non ambigebat ille vt cuins vis purgatricis periculum non femel fe fecille aicbat, grauis \& minimè triuialis peitix vir: chi eò lubentius affentiebamur, qutòd nullāaliam viderenus figu-

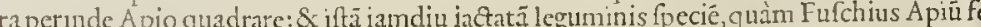
cit, tã lógè abefle à legitina Apio, cuàm difsidet Cyclamé à Cicercula, ctüus eft fermè ef Gigies illa Fufchiana radicibus quidé bulbofis, fed nentiquá purgãtibus, imò ab O pilion rmanis, vt in (a)

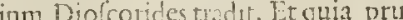
of

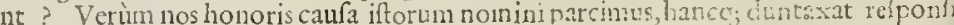


Calambir ba montwita Tolegro jrailis Nepeta vocitta.

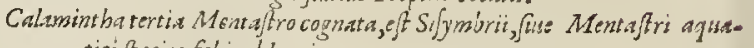
Cartaria. ticipecies folis ablongis.

Polycnemon, (Iue multitibia an Calaminebs aquatica Belgarum? Alterafacue Clinopodician Polycnemon?

Apiastrum fure Me :yopbyllusis.

Mrelifophyllum T urcirum, , Iue Moluca duplex.

citelifa Turcica, Sidoritides fucre flore carrico.

$\{$ Cardiaca

Cardizca eingue varietas Apera vocua Mclota, fue Molusa. c Marribirmb.

Marrubium Creticuis.

Ballote, fine Marrubium fartidume.

Galiop is.

Lamium.

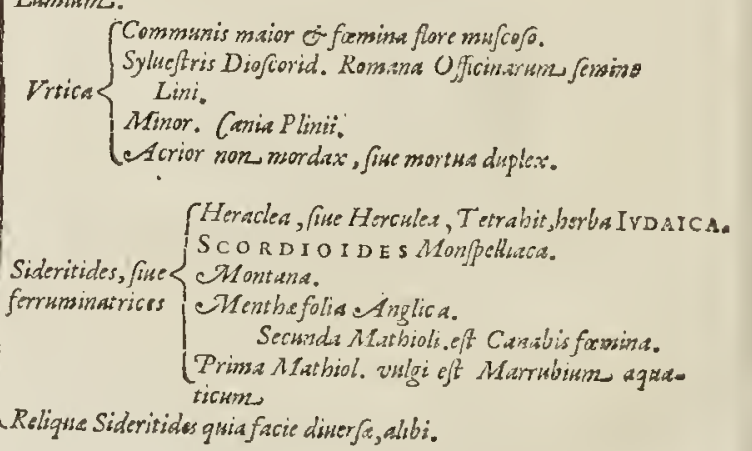

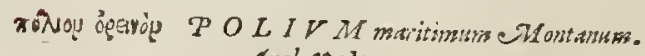
etngl. bolcpe.

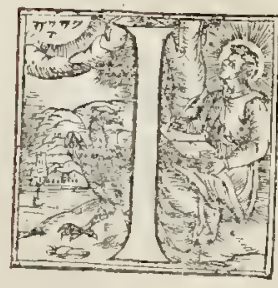

NTER LVSTRANDVMCVNCTASHETEArum gentilitates, \& fimilitudines, nullam tribum videmur congruentius poffe annetere fuperioribus quàm hanc : cuiug figura, habitus, \&quafi modus, magnitudóue non longè $a b$ illis abfunt, \& foliia dútaxat ambitu dentato, aut crenato, ferratóue diftant. Eft autě Polio nomen inuentum à canitie, canís ve capillamentis \& tomentacea hirfutie, quæ non modo capitula corymbacea ( $y t$ ait Diofcorides) fed etium vniuer- 


\section{$S T I R \mathcal{P} I V M$ aduerfarianou.}

fim plantam incanam reddunt,pcrinde ac Gnaphalium,prefertim locis maritımis , \& deucxis collibus, \& arenofis litoribus, cuiufmodi ad Ceti montis infulan \& Magalonum Norbonenfis Galliz, vbi fpeciofius \& crebrims, quod idem Maritimum \& Monta nü dici poteft:ab radice lignofa, tecta, fibrofa, ftatim numerofis fruticat culliculis, rot:in dis, feffuipalmeis, éque fpatiis crebribus folia oblonga, Gnaphalii letritfculis impref$f_{a}$ crenulis, rigidiufcula, quaz ex aduerfo vnà caules cingunt : inćuc fimmo radiatin circinatínve flortm giobulos corymbeos effigie Serpilli candidos, effigiant:vti \& vniuerfa planta tomentofa lanugine pubet incana.Iftud pre cæteris oloratius: fed cuticlda acutum \& gtauiufculum naribus vnà cum fuauitate affat. Semcin paruum \& tcres, oblongum.

$$
V E N E T V M \text {. }
$$
Q Vo n minus multò crefcere meminimus in Infula Lyo Venetż ditionis \& clientele,

$$
\text { CRETICVM. }
$$

NE caliud videtur quod Creticum dono habuinus : nempe huic magnitudine par, la nugine \& habitu maritimo Monfpelliaco fimile.

$$
M I N V S \text { \& mediterraneum. }
$$

PA s s r iftud etiă locis perquàmà mare difsitis Allobrogum, Lugduni, \& Valenti glareofis, \& afperis,falcbrofis, montofis, \& planis fruticat, viticuläsque palmares ctiGit crebras, tenues, foliis crebribus ex interuallis enifsis, anguftioribus mul tô \& luę mofcatz, fed minime incifis, Icuiufculis tantum denticcllis in ambitu extzntibus:a!reriu£ fores pallidi albidiúe:non diuerfum femen eft, nec odor, fed ignauiora.

\section{$L V T E V M$.}

PR O E Aquifextias quibufdam fuperciliiș collium \& clinorum luteis occurrit floribus, fpectatu iucundis.

$$
\begin{gathered}
\text { POL IV M Lauende folio, fof fullis pallidis, } \\
\text { Fomina Recentiorum. }
\end{gathered}
$$

V r nondum in maritimis verum $P$ olium nonerant, iftun plantam $P$ olium fecctút: Siquidem perfimilis etiamq́ue congener Poliis eff:tametfiodore pcnè nullo, gu-Cord..125.vbi ftućlie cun plaftico \& ignauiore:quam Polium Fœminam ideo quidam dictitant:nec lo- minus veré qua ca maritima amat,vti Polium getmanum, fed montofa, glareofa, Sabaudix, Delphina- dam. tus, \& Galloprouincię: Reptatq́; Serpilli modo, lignofis füculis, dodtantalıus, inflexis, crebro geniculatis : \& numerofis foliis incanis, Stachadı, aut fpica Lauendula: Rofculis etian confertim è calyculis Rofmarini:crafsiufcula \& duriore radice.

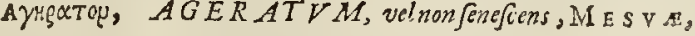

$$
\begin{aligned}
& \text { Eupatorium, Officinis. }
\end{aligned}
$$

Ital. Herba Giulin.

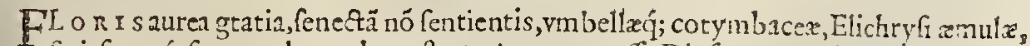
fatisfupcró; fucrant docendo nofteate Agetatum effe Diofco. genuintım; quibus de notis etiam notifsimú vel Phatmacopœotŭ calculis vbiuis gentiü iandiu fuit:nec proinde opus fuit iftis Herbariorü rabulis, \& triuialibus declamator ibus tam mul ta acenare, vt nullius momäti obiętiones diluerent: potius inter parandum Mífur Sirup!ım de Epithymo guftallent decostum, aut folia Agerati Norbouncnfis î plunè filuifent : eft

$$
\text { S.ij. }
$$

enims 
enim non modò valde acre \& amarum, fed etiam ad ciendum vrimas intrò fumptum, forísque fuffitum, admodum efficax : odor etiam fuauis quadamtenus Romanx Chamamilla fragran tia, index certior eft racultatú emolliendi vulux duritias, vrinaf́́ ; nidore eliciendi, quas Diofco.memorat. Præterea collatio cum Origano híc valde oportuna eft, fue totam fruticem, \&r vmbellas, vt Diofcorides, fiue etiam reliquam planta faciern perpendas. Sunt enim he bullatz vmbellx, vt Elichryfi, Origani, Hyfopi \& Chryfocomx, quas inter fe confert Diofcorides, qui tamen hic foliornm non anemint: vti neque Chryfocomx, quam Hyffopo afsimilat:Hyflopum autem Origano. Quid fi etiam Origano folia alsimilaffet propterea iftud nofrate Ageratum periffit? neque enim adeò procul abfunt folia ab Origano: quinimò quibufdam Norbonz locis \& Tú 9y rictas Can- caniæ fqualidis, fed deprefsis, videas Agerati fruticuli folia multò minora, \& tamtillum
dia. crenata, rigida, dura, pluragucue virgulta, Origanis variis inibi fruticantibus, toto habitu non dif similia.

Agerati vifitur interdum etiam illic ipeciofo candore, nitentibus florum bullis, hand tamen de catcro, ab illo diuerfum.

\section{e $G E R A T V \cdot$ M Septentrionalium of Anglicum

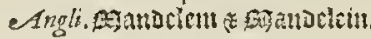

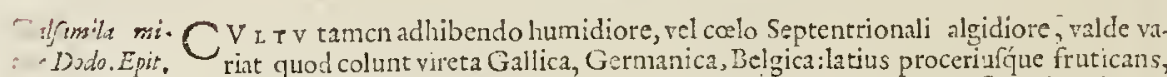

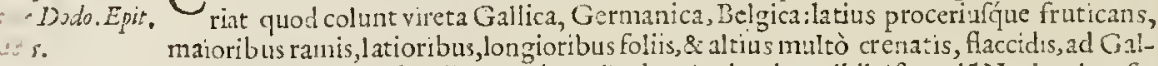
li criftum herbaccedentibus. Sed Angliz hortis viuacius nihil, ito ctiá Norbonico femine fato, ramis caducis, magísq; ferratum foliis, diu perftans, admodum diuerfum. Idé contigitetiam Althex arboreæ Prouncialis, qux in Maluam abiit trienniò pòft quàm in Anglia hortis feueramus, hirfurie canitieq́; exutis: guafi foret fpecics diuerfa. fftud M E S v a fpontè enatum clarífíma Monfpellienfum fchola 8 collegium Venetorü Medicorü syExpatorium. rapo Epithymi \& Mefußtarum compofitionibus, vt legitimum Eupatorium addunt: Agrimsniw: Gracorum autem medicamentis, noftrain Agrimonian. Quod inftitutu fi cui munus arridet, ifta vtatur moderatione, vt vtriusq; nempe Græci \& Arabici Eupatorii ẹcuils porto:nes mifceat, vti in Antiballomenis monuimus:przfertim vbi vtrius fit gentis compo. fitio, incertum fucrit. Neque arbitrandum Eupatorium Mcfux effe idem cum nofra Agrimonia, Diofcoridis Eupatorio recepto, vt non nemo autor minimì malus, ncc indoftus Belga nuper perfuaderc voluit : cui lubenter aftipulabimur, cum hafce notas a Mefua Eupatorio tributas fuo, noftraticonciliarit : qux fic habent: Herba lungutudunis ch-

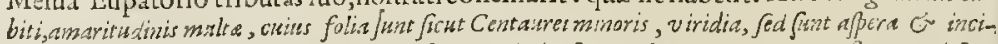

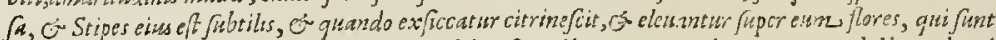
ficur fubcitrini, longitudinis prucs. Qux A rabica fimplicitate, exprimunt tum delineationé Centaurio proximă, tum perquàm amaram \& Abfynthio fimilem, Choleræ purgatricem facultatem ( neutiquam Gratiol $x$, impendiò effrænis $\&$ vifceribus hoftis) palilò fuperius recenfitam innunt, aliaq́ue non pauca indicia, cuiuis plante potius, quám $\mathrm{A}$ grimonix afcribenda: eapropter fatius fuit $\mathrm{Agrat}$ fpeciem retinuiffe, ob eas rationes quas adduximus.

$$
\begin{aligned}
\text { Truxplop } \quad & T E V C R I V A . \\
& \left\{\begin{array}{l}
\text { Germ. Brof5 Sathengel, } \\
\text { Gallis. Groffe Germandree. }
\end{array}\right.
\end{aligned}
$$

CDV I A N I Iemionitidem alii:nos porius Spleniü Teucrii inuentoris cognomine do$P$ natum a Plinio, \& hanc Diofcoridis preteritam, qux tamen fplcni optimè facere nata eft, \& nihilo fecius ad Teucrum inuen toren rcferri poteft, per Plinianä Hiforiam: cum conftet neutri harum proiecta exta adhæfiffe, nedum fanguine exinanita fuite. $A c$ tametri Tencrii notio minus certa videtur propterea quod deforiptio aut malè aut mu- 


\section{STIRPIVM adwerjarianoua. $\quad 209$}

tile prodita eft. Verùm huius vt \& confimilium Chamxdris \& Germandrix dierx deuo. luta eft ad pofteritatém cognitio, adeò vt etiam qui deforiptiones nullas norunt verna* culè omnes vrio nomine Germandreas vocent. Nec ambigendum guin le gitim $x$ fint. Ac primun Teucrium faxofis multis aridisć; montibus fruticat, virgultis multis, reêtis, lignofis, qux procerizare dupla Chamedrin vincunt. Folia vero fimilia fed crafsiora, alia quantis minus incana, rugofa, \& afpera: fores confimiles minori Gcrmandrex, fed pur. purei faturior is cx interuallis \& ex auerfo Chamædris ritu, vti ü forcs oriuntur.

\section{TEVCRIV $M$ pratenfe. Offici.Germanie of Batanias perperam Chamadrys. \\ $\left\{\begin{array}{l}\text { Ger. Etiam Bamanoer. } \\ \text { Ang. Wilde Germander. }\end{array}\right.$}

IN nemoribus \& pratis fubfruticula,cauliculis exil bus, nec duris, fe fquipalmum a'tis, radice lignofa, fibrofa, folia ex aduerfo \& interuallis bina, qquaterna, fcna, caulem veftút in ambitu ferrata, modo 8 magnitudine Chamædris maioris: fpicatis Thyrfir: ramuli cau lium fumni donantur caruleis ex purpura Aoribus Anagallidis concolor bus, $H$ yacinthe modo. Nondum Chamædri vtrauis nota vtebantur Gcrmani Sep!afiarij ifo, fim!litudine quidem decepti, fed viribus ducti qubus, ad viferum obftretiones, Cacochymiam, virginumq; foedos colores, miris pollet \& certifsimis hæc flantula. Et hanc vnä duntaxat Germandreaın tum vocitabant illi:quam nomenclaturam vulgus pofea impertiuit Cha madri, etiam apud Anglos \& Gallos.

$$
\begin{aligned}
& \text { CHACH AED R IS Querquela minor. Tristgo, fure Trixago. } \\
& \text { Stal. Quercinola, O Calamandrina. } \\
& \text { Ggall. Germandree, ou Chefnette. } \\
& \text { CGer. Gamander leyfar Batbenge!. } \\
& \text { eAng. Germander. }
\end{aligned}
$$

$A_{\text {culæ, vbiuis locorum pręlettim apricorum adolefcentis. In Chamæedrys, fiue Qujer- }}^{\text {B V }}$ bus vuiuerfos quafi tapetis videas ftratus purpereos \& viridantes opund acıs vero criltipos, quantum cft inter Chxlonas (vulgo Chaion)\&- Machaonem. Radice exigna, furculofis virgultis,numerofis, pedem altis; folijs in amisitu ferratis, binis, numerofis, vt quercus, fed profundè minus. Flot ibras pumpur eis exiffdem interuallis vt Teucrio.

CHAM $M D R I S M A I O R$.

$S$ E quæ Antucrpix horris vifitur folijs eft maioribus c ãdidioribus, \&: flore crfio pallefo cente: vbi etiam niues imbıéfy; brumales afpernit. Illa contrà breui marcefsit .

$$
\text { CHACK EDRIS ontanafrutefceris, durior. }
$$

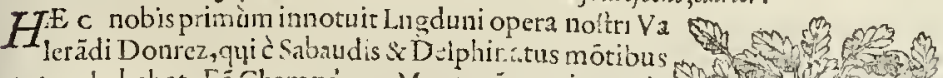
crutam habebat. Eä Chamxáręos Montanú nomine, quia by the the mæxdryos vel Scordij fimllimis \& paribus: fed auerfa parte Potentillx fue Argentinx diatx nodo, incanis, \& in iquali exortu, nó vcrticillatim binis, prodeútibus, Cauliculi verò duriores,lignofiores mul tò, maiori Germâdrex fiue Chamxdryos, pedales, humi fpurfi, colore ex fufco rubentes, Aly po Norbonenfi concolores, Radix lignes, Tota nonnihil amaticat, Salicis guftu.

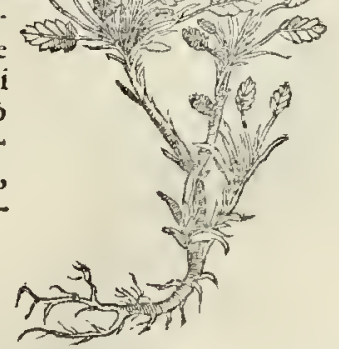

CHAM EDRIS miniwa.: Fomina Doulonci.

S.iij. 
TER в у д A M iftam olim Germani herbarij nomenclatores dixerant al teramChamxpytim, quam floribus \& odore quadantenus rcfert: fefquipalmü alta multiplici cauli culo quadrăgulo, lanuginofo, inplexo humiç, in curuo: Fumarix Plinianæ non Chamrpyteos: folia numerola,parua, déla,multú incif̂, a bfynthij aut Quercus ritu, fed longc̀ mi nora edéte. E quorum interuallis, flof culi purpurafcentes circum emicant. Scmen pufill inclufum capfula, nigrú, Calaminthe montanx modo. Radice crafla multis capillamétis.

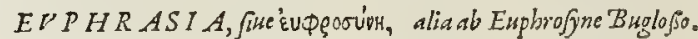

Ocularis.
Balg. Dogentroon. $\begin{aligned} & \text { Ger. 2lugentroft. } \\ & \text { Gall. Eufrafe. Eufrafia. }\end{aligned}$

$A^{P} \vee D$ antiquos Botanicos nulla extat inentio vllius Euphrofynes, præterquàm Bu-

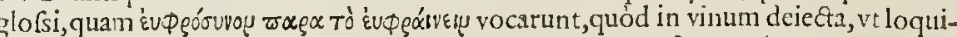
rui. Plinius, animi augeat voluptates. Ac tametfi non paucx pofsunt eaden noméclacione infigniri, vt Verbena (cuius decocto afperfa cænacula la tiores conuiuas reddit,) atq; Melifia, Pimpinella \& alix, quibusimbuta pocula animos voluprate denulcent : tamen hęc herbula Græcam originem teftata, ducentos \& é plus annos,iam pofteritati Euphra fix fiue Euphrofynę nomine innotuit, ad oculorum caligines \& morbos pituitofos perúagatx comnendationis : vnde Germani 2 ugentroft, oculorum folımen: Anglis Eyebright, oculorum lumen, dicta fuit. Nec abs re fanè, vt cuius puluere fẹpius ingefto, per [c, vel cum Aloe,ex aqua foniculi aut Verbenx, mirum quantum opis prętetur oculis, fluxione, aut caligine vexatis. Vino autem cui multa Euphrafia inicta fuerit, quantumuis magn operè commendetur à multis, non perinde fidendum: vt cuius potu tantum trimeltri in Heluetıa viun focium \& cómilitonem noftrum, meminimus penè ambobus orbatú oculis, \& fuxionibus modó non oppreffum:quum dütaxat antea leui cataphora \& lachrymatiunculis laboraret. Quare puluere, aut decocto, citra vinum, tutius vtetur quis, \& e a præfertim, qux ftrigolo folo pufilla $\in$ ft, palmaris, hilari afpetu, facie, cauliculis \& folijs crifpantibus Teucrij parui, aut Veronicx fominx, exilioribus: flofculis item pur fillis,cx luteo albicante, \& purpurafcentibus. Pratis frigolis gaudet, ¿apore amaricante, deficcante, calfaciente.

sućgolion. SCORDIVM, Trixaga Palustris.

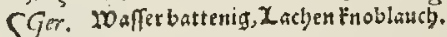

KGall. Scordion \& Chamaraz.

ang. Water Gormander.

Itwl. Chalamindrinu Palustre.

A B omni memoria celebrem fecêre Scordiü Allij teter odor, \& alexiteriacü nomé:fed tamé penc̀ perierac Cuperiori fẹculo cücto ignota pläta:vix enim vigefimus hic eft an nus cim primitun cadenix Pharmacopœisá; Monfpelliacis innotuit verum Scordium opera Epifcopi Monfpellienfis Gulielmi Peliferij, Rondelletio Pręceptori in Pifcium ftır piumóf vcftigatione Thefeo \& riuali.In herbidis namg; \& amœnis maritimis agri Monfpelliaci animi caufa dum vnà fpatiarétur, inibiọ; allium fubodorarentur, illicò herbulä virdum arreptam, \& eminus confpicati Scordiü efe deprehenderunt. Indidéć; varijs plä tis in Galliä \& Italiam mifsis, amicos verũ effe Scordium monterunt. Illi facies vniuerfa protfi Triffaginis, radices numer ofiores, fibris crebribus fümo ce fpite fparfis : folia craffiora, denfiora, fucculentiora, nonnihil tomentofa, rugofa, afpera, viridantia, vt Mentafiri.

SCORDION alterum Tlini, latioribus folys, Mentustro fmile.

SOfficinis faluia agrest is of faluis Dofci.

KGer. Doito Galben.

Ang. Woodjage.

Bel. soiloc fanc.

Alterung 


\section{STIRPIVM aduerfaria noud.}

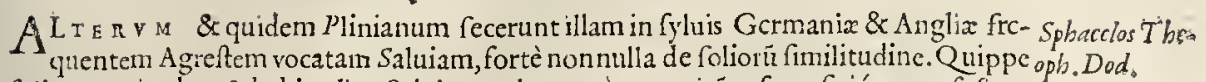
folia magnitudine \& habitudine Saluiam, colore vero atro, virēte, fuperfieiéq; rugofa Scor dium Mclifámve referunt:etiamq́; odor quiddā Scordij, non tamen prorfum Allium, fapit. Herbacei ex luteo funt flores Saluix, aut fylneftris Hornini nó abfimiles, minores vnaớ; \{eric ad eafdemó; partes penduli,vti Digitali, luteì:rotundum \& fufcum femé eft: $\mathrm{fa}_{\mathrm{a}}$ cultates Rubix, ad fanguinis grumos dirsipandum.

$$
\begin{aligned}
& \text { ORIG ANVM Heracleoticum, Cunila. } \\
& \text { \{ial. Origano. } \\
& \text { Ger. Wolgenuot, Kotto often, fiue Coftents, } \\
& \text { Hifp. Oreganos. } \\
& \text { Ang. Organe,nr wilde Margerome. } \\
& \text { Gall. Mariolaine baitarde, Origan. }
\end{aligned}
$$

QVAs $I$ cliuofos,editos, montofosq́: natales amaret çéryovou appellata fuit hęc, quatin iam haud nobis difficile noffe ex Hyfropo alibi ind cato ép probato, à quo non variant Origani fpecies tres, nifi magnitudine ¿̈ vmbellarum difparilitate. Heracleoticumı autem eft !l ud Hifpanicum in Flandriam faccis plenis quotannis dcferri folitŭ, \& ab inftitoribus diftrahi:vtuntur enim vulgò Piperis \& Satureiæ vice ị̣ obfonijs. Belgx hanc plantam colunt,pedem altam, folijs \& virgultis Maioranæ maioribus, quibus fummis nó in vimbellain circinatam collecti funt fores, fed in paruis thyris, fpicatis, ternis, hinc inde difsipatis ve Thymi, edore Maioranam prouocantibussprefertin in Lufitania \& Lucania enatio.

\section{ORIG ANVM ONIT IS Gollopronincie,mains, co minns.}

MON spe L I I I circum inǵ; Galloprouincia, notifsima funt duo Origana, maioris \& minoris difcrimine duntaxat difcrepantia : nifi quia huic Amaraci tacics \& folia, fed minora \& rotundiora Heracleotici fermè : Caules recti, pedales, fruticofi, ramulis \& faftigijs breuribus, coactis, fpicatis, confertim in vmbellam collectis, floridum corymbum imitantibus, \& per aftatem purpurafcentibus, admodum glutinofis.

$$
\text { M AIVS. }
$$

Ef hoc quidem maius, \& fruticofius, hirfutius, fed viribus, fapore, \& odore contemp tius alioqui: perquàm fimile, \& pafsim occurrens.

\section{STLVESTRE Origanum Syriacum.}

$V$ E N E I I Pharmacopœi \& Medici c̀ Syria aut Creta Origano vtütur longè optimo. Cui cauliculi exiles, folijs paruis, capitulis numerofis, collectis, ambitu vmbellam imitatis, Onitidi proximis, red non perinde accumulatis, albis flofculis. Guftanti grata tota \& aromatica,Di\&amni \& Piperis acrimonia. huius fafciculos multos habebat feduli \& pro bi Pharnacopœi Martinelli Officina ad Angeli Symbolú. Scd Scplafiarij nó pauci illic \& alibi in Italia, veras Theriacas ementiuntur \& nundinantur iftius micella, \& veræ precio diftrahüt,non tanto errore, quanto flagitio: eft quippe efficax \& gratum antid otum diffoluts veneno viribus, aut fomachum dolentibus,

\section{CRET ENSE apudVenetos T ragoriganum, fiue Hircinum.}

H I R C I N y videtur nuncupatum quafi pabulo gratum foret capris, vt Onitis AGnis,potius quàm hircum foeteret: grata enim \& mitis Tragorigani potio, Diofcoride tefte, cuinfmodi huius, qui furculis dodrantalibus \& fol jis paulò quàm Thymi Cretenfis matoribus, denfis \& rigidis, floribus per interualla \& verticillos, purpureis, Clinopodij modo fruticat : fapor feruens Piperis, aut Thymi illi, qua \& foliorum áddita coniectura, Creticum Thymum id vocarunt Origanum recentiores, quod nos Tragoriganum putamus. Cìm inter Thymi Crctenfis fafciculos \& quifquilias iftud femé repertü hortis cres ditum fuiffct, foliciter adoleuit Italiz, \& Flandrix hottis.

$$
\text { ALTERVM TRAGORIGANVM. }
$$

HE R B l A illa fruticofa, quamiádiu decerpfimus in horto Antonij Cortufij Patauini magni Mathioli pręconis \& feruitoris, nulla melius videtur genuini Tragorigani R.iiij. effigiem 
212

effigiem \& facultates explere potius quàm Mati, quo nomine ifti nomenclatores prepro peri illam donat unt, nam Fruticulus eft fefquipalmum altus, al bidus, multis caulicuhs tenuibus Setpilli folijs, vel ifins Tragorigani proximè defcripti: flofculis fubter folijs purfurafcentibus, faporis acerrimi, odorefragrantifsmo \&s vrente: tritum namq; digitis cminus non fecus ae Flammula percellit nares \& cerebrum ferit. Multas licuifet Tragorigano aptare, fed nullas reperimus iftis duabus veris aut commodius quadrare. Non effe Marum, femidefcriptum à Mathiolo foliis ferpillis, odore Pulegij, fuo loco dicemus. Vid:tur fpecies altera Calaminthe.

Genuina HXSSOPVS Grecorumfulio Origani, vmbellato fore.

CLA R \& \& notífind dim Hyfopus, fapientifsimi Salomonis meta altera Sermonum

Naturalium, qui euncta differuiffet à Libani Cedro ad vig; Hyfopum de pariete enaf centem: jifi non fit eadem Palxftina, qux Græca: vbi tamen perixde comnita, \& quali ío -

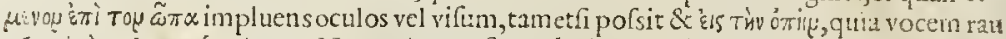
cá vnicè pulingnésq; iuuat. Ne aperiamus fores declamatoribus,paucis, \& apti: Hyfiopi lyftoriam perfiringimus: 1 am non minus vulgaris notitiz Hyfopus fuit olim, quam funt hodie varia Origani genera in Galloprouincia: \& in Romanix afperis Hy fopus vulgaris hortenfis fponte fruticat: fed quia duplicem facit Diofcorides, \& notiolua ait quàm vt defcrbatur: nobis hinc inde emendicand notx, quæ Criticis iftis declanatoribus clandät concionandi valuas. Alioquin quod chartis illinent fenper habiturts. Proximo Stectizdis

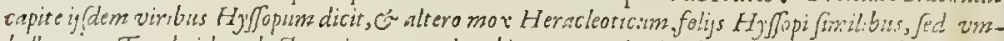

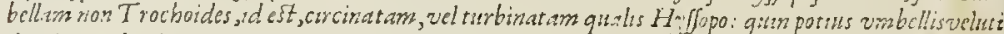
diutarn, vel aifprantam: o in extrertis virgis femen nor den/um. Denuò putilò nox Onitiden candiciore folio, \& fimiliorem $\mathrm{Hy}$ fopo,quàm Heracleotico. Semen non culdem effe corymbos fed it a coniunctum vt fpeciem corymborm prębeat. Primum quando ex Philo fophix preceptis l'bronix tacito duau à notioribus vniuerfms noftram cosnitioue hau ftan fuife docemur, nobis quippiam certi fatuendum \& cognofcendun, cuius ope \& perficua notione in caterorum cognitionem prouehamur. Ea de re cum fit Serpillum non minus frequens quìn cettum \& notum, eiq; à Diofcoride foljis \& tamulis () riganủ collatï, cui quiden suthor iden $\mathrm{Hyffopum}$ alsimilauit folijs \& vnbella: Nobis minutias Iftas accuratius perpendentibus, neglectis neutiçuam facultatibus, nó magis videturiam ambigendmon de vera Hyfopo, quàn de Serpillo aut Origano. Quinetiam Maioranam hortenfem'certifsmæ cognitionis Botanicus Cratæuas, Ifac Serapio, ¿ Mefues finilé faciunt Hyfovo. Intuere iam comnunioris \& vbiq; Gallix, Belgix, (vbi Anglieü vocatur, quia in Angl a plurimum lxtius, \& cibis aptī protenit, prafertin in hortis) vmbellam ha bet circinatam, turbinatámve, denfam \& congefam cx multis flofculis, purpuream. Eins dim fofcul maturefount, Semina frequenti pericarpiorum ferie ac glomeratione con iunguntur in Corymbıxulationé, non fecus atq; 11 Maiorana cernere eft, nee non in Origano Onitide, \& vulgari. Quod fi ad folia, vires, vmbellim, tot:an deniq; effigiem refpicias. Hyilopum fanè,nif loret Origantm, futurü dicas. Ef igitur if a planta prorfum congrua tot notis, cuot poffunt \& opus eft adferri ad geminx Diof. Hyffopi cognitioné: odor fuauis, Origani Hilpaniei, Heracleotici putati, acrinonia mitiore: Nec quicquam vi decur differ re ab illa pläta quàn Doctor Treuifinus Patauinus in horto fuo colebat:putabántq; Doftı Hyfopum, fulio Origani vel Orjgano funilê:omnia yuippe frmilis huic, acrior tamen:de Horibus \& femine nhil prodimus, quia nondum planta, vtpote recens allata, foribus feminéve donatid etat. Corymbi auté vox Plinıo \& pofteritati fraudi fuit: nam legenti tria femina Hyfopi mederi Epilepticis, ratus nf fi è Corymbis ifis baccas: hafce pro feminibus hallucinatus accepit: Siquidem vmbellis attribuutur femina, Corym

$$
\begin{aligned}
& \text { CACM AR ACVS vulgatior fine } M A I O R A N A \text { nostrass. } \\
& \text { Ger. maioram, mzeyeron. } \\
& \text { Bel. Elariolrynea. } \\
& \text { Gal. Mariolaine. } \\
& \text { Ital. H C Naiorana. } \\
& \left\{\begin{array}{l}
\text { Hifp. } \\
\text { Ang. CMarierom. }
\end{array}\right.
\end{aligned}
$$


CIm I I Dictamno facie Pulegiń, fic Latinis dicum à pulicibus, quos nidorc fugat ir ne-

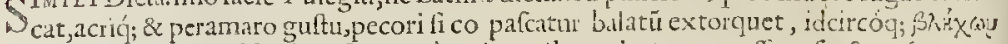
nomen factumilli, nifietiam fit quac̀ pulmonibus pituitam crafan farcamóne extundit. Hodie regim \& vulgatum Pulegimm immeritò, fed folito more rufpunt publici cenfores, \&ration is ne nican quidem addunt. Plinus non nifi vnum genus deliraat Maris \& Ecminx mentione, quod idem elt \& Diofcoridis. Eft ommibus facultittibus efficacirsimum receptim Tulegium, in hortis quidéfloribus purpureum, vtplurinum: at Pedemontis planitie itinere mcdio adlxuam, quà Ryuolio Taurinun itar circa margines $P$ ulegioflorente obductos, non pancas plantas tloribus candidis, viuidis Icrmus : ac dende idem aliis locis repertum, Cortufo \&V Venetis quibufdan ftu diofs oftundmus : folys vtrüq; Sy fumbri, aut Organi, toto caule cx interuallis cum Mas Proriffoflo ribus verticilios alteritis planè inodo contintibus: vires, odö̈, piorfus exdem.

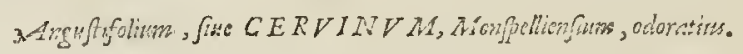

MIN I m miram Ceruinum Linguagothicum nulli dum fuiffe defcriptum, aut piMetum. Nam tanetí Norbonx Monfpellit eftvbiq; obuium, 3i nulli non cognivum: tamen quiahaud temerc facilè occurrit in Italia, Gelmania, autaliis Galliæ Regionibus, illis ideo videtu: fuife ignotum. In luco Gramontio pone conobium, $\mathcal{E}$ in primo adiru ad lutofis ferobes multa fruticat crebribus furculis, inultò quäalterius ereetioribus \& ri gidioribus, dodantéaltioribus: foliis ninoribus, crebri bus, Satureix amulis, \& xqualibus: ex interuallis per verticillos diftinctis, è quibus florú veluti purpurafcentes globuli orimntur. Radis verò difsimilior alteri $\mathcal{P}$ ulegio, fummocefpite fparfa \& multiplıci flexu multorü quafí afparagorí bene adul torú, Gratiolę vocatę modo. Huius fapor, odor \& vires mult to quàm alterius gration, wehementiora, \& probationa : vtriusq; cnim cum maximacopia fuppeteret noltris præceptoribus Regiis \& Monfpellienfibus profeforibus, tamen itud

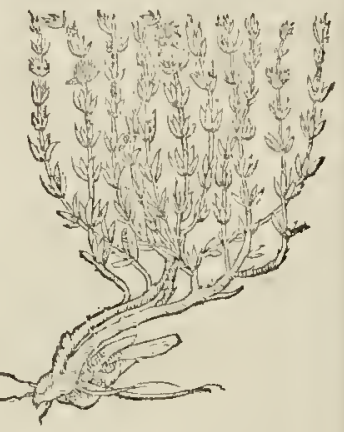
pratitero, Pharmacopais accipiendum imperabant.

\section{$D I C T A M N V M F$}

V.Vr,Cretenfis Idx montis qquali ocello Ditzxo vocato, debentur nomenclatio educatioǵne decantatifsimi Dietamni, P ulegio adeò affnis, vt nonnulis agrefte fit dictum pulegium. Huitus 10 ita inağno precio multa an copian cumunt non modò Italicx, fed ctinm Bclgica \& Anglicæ Officinx hodieno dic, tametin non paucis ab hinc annis lloribus donatum perrarum \& charum erat : quippe perpaucum olim, idque floribus orba. tum adferri folitum fuit : Idcircoq́ne flo:e caffum effe Diofco. veriùs quàm antiouis, de co prodiditum fuiffe, credebatur.Iam planta cognita, lis ifthx reliquela maleferiatis : foribus enim fpeciolis, purpureis, multis, trans hucidas concolores fquammas fpicatas, cmergentibus, Streliadis modo, copiofum ad nos afertur. Quinimó, vt fertur, Pifunz ore \& Liguftice afperis deuexis fatum, creuit, \& flotuit,exili femine, ik plantam paris pulchritudinis, çualem ipfi vidimus : tertio tamenvel quinto pòf anno, in fpurum abire audimus.

PSEVDODICT AMNVA foribus serticillais. 


\section{STIRPIV $M$ aduerfarianoir.}

IS T r D quidem Pfeudouocatum audiebamus de quibufdam Ital is in monte Nigro diEto Pifx \& Libur nx contermino \& aliis loćis mar timis nullo fatu oriri : nec verò illic vnquarn data, aut in affinem fpeciens degener facta videtur;nam caules mul tiplices cubitales,recti, terni, aut quatern : Colia ex interuallis bina,paria, \&v vt caulis incana: omnia denćue fimulia, nifi quia fores cófmıles, difsimulı modo \& fitu orıuncur. Sunt enim non ex fpicis, fed ex foliorum pediculis.

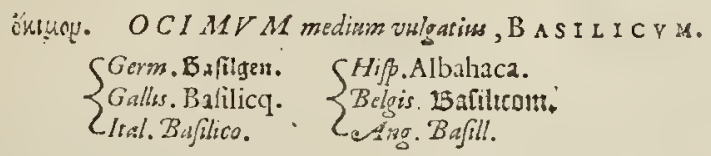

Q VA w y I santiqui excufi, tum calamo exarati codices, vbique Ocimum, non Ocy- MYash.s33: -mum, aut Ozimum habeant; tamen quia herbula hxc eximiè odora cercbrun feriret \& fternutanenta cieret, cam primulùm Ozımum vocitatam, id elt, odoram fuiffe, natura \& do tis nos affentiti par elt, odore enim mirum quanta fragrantiz effe Ozimun Troglodyticü \&\&ylueftre nafci iamdiu notum eft. Nec ocyus cateris quàmplurimis o. riri certum: quare id Ocymo farragini leguminum tribuendun fuit, vt poftea dicemus. ANEDIFM

Ocymi autem vel Ozimi.vna fpecies eft, varietates tres notifsimx vel mulierculis, qué vulassims. odoris \& oleris gratia in figlinis vafculis colunt, aut in puluillis areolísve viridariorum:frequentifsnum autem Ocymum vulgare, fiue Medium dictum, quod quidem duplex odore habetur : vnun quippe vilius \& abietius, odorem fuanen etantilla grauitac mintum, A p12itri modo fpira : radicem \& cauliculos pedales \& folia Mercurialis Parietariz, vel Agriorigau, fed nirzrior a mittit: Hofculis è calyculis verticillatim caulé ambiä. tibus:femine puillo nigricante, quadamtenus Tlilafpi.

\section{Medium Citratum.}

A L T R v mullatenus difat,proterquàm odore gratiore ac cordi amabiliore, quỉ corticem Citrii mali redoler; idcirco Citratum vocitat vulgus , non i Citri folio, th falfo fcribunt quidam.

$$
\text { M AXI MVM Caryopbyhatum ac Citratum. }
$$

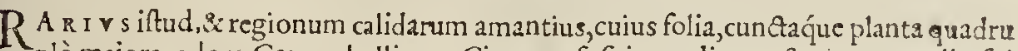
plò maiora, odora, Caryophylli cum Citro confufa iucunditate, fennine nec vlla fui parte alioqui diuerfs.

$$
\text { MINIMV M Amaracifgrya Caryophylldtum. }
$$

IT n diuerfa huins facies, fed minor tota dumtaxat, quz Caryophy!li halat fragrax tiam, eapropter vulgus, qui in tefful is \& penfilibus figlinis, alit Caryophyllatum vocat, \& gentilein, quemadinodum rofam quampiam Canellatam, à Cinnantomo, \& Mofcatâ,ì Mofco dicere cöfueuit. Hic afpectu pulchellus, interdü crıfpantıbus; foliis \& cöuolutis in glomerum: vitrex phialx, cui infit aq̨ua,angufti or is, intrufun, viuit angeturq́ue radice aque potrici, diu reliquia herbula virente. Complures alix vel differeitix, vel varietates \{ponte oriri produntur apud $\mathrm{Aby}$ bsinos, quas nobis non planè notas hî̀c filemus, fufius alibi dicturi, qux de Ocimi natura culta, $\&$ viribus penè prodigiofis, tum ab aliịs prodita, tum à nobis comperta fuêre.

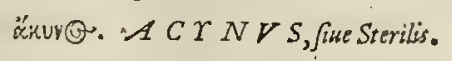

N O s tantùm perfimilis, fed \& congener Ocimo videtur äxuv $\widehat{O}$, ac per y proferéd $2 ;$ quòd fterilê infoecundamq́; fignat plantã: vti etian Plinius fortè interpretatus fuit; qui hanc herban coronarum \& ciborum caufa in Egypto feri, nunquan florere, alióque nomine Epitreton vocari, aut potius Epipetron(vt Theophraftus habet, qui hanc inter ávaryłs cenfet) feribit. Quare cum illi flore non negaffet Diofcori, ,ciú sque ftudicfifsimus Ruelitus Ocimurn, fiue minus Bafilicum, poffe effe Acynon, ni obftaret Theophrafti Pliniigue mutula Hiftoria, dixiffet: Senenfis candor confuetris hac arripit, \& qua: 


\section{$216 \quad S T I R P I D M$ aduergrinnous.}

fi fua obtrudit exorobutçue doçtis, nec interea leftori quidquam commodi molimur:tamen explofo Ocimo llo minimo, Calancnthum illud inodom vian vbique frequens \& contemptum, à Manardo iandiu addustmm profert, illicue nulla probatione prafert. Sedenim qui acrins menftrufóue ciendis aptum Calanenthum iltud norit, neutiquam affentietur. Et alix funt planta qux multò aptius quadrarent, ni aduerfarentur vires, nempe fiftendi menftrua, \& izu facromedendi; fi conguerent etiam folia, \& rami floribus vidua, ex Theophralt \& Plini Hiltori: , quod nufquan tra-

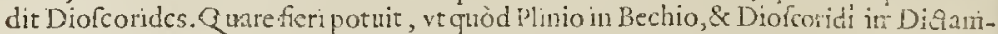
no contigit, idem vlu venerit Theophra. nempè vt nullum agnofceret florsn in Acyno; quem poftè Plinius fequutus fit: apud quein tamen legunt nonnuli Acynon non penitus flore carere: fed in hortss no u llorere. It fi coronaria fuit, verifimilius eft Anres hzbuife. Sed quemadmodí Bechio \& Petalitid, quia preproperè florent, \& citifimè deflorefcunt, deefe florem quidam putant : fic fortèifti, quia obfcurius \& ferius Hores promit, ac fxplus interdum cmerfos anittrt, intempefta Antumni qualibet minima fxutia:ficutividere eft in nonnullispufllos Referorinos fores edentibi1s. Aut aliud forte fit Theophrafi Acynos, à Diefcoridis, vt vidinus in Teucrio, Tragio, \& alis. Nam llia, quam nouimus huic locoadmodum congruam, folculis pulpureis, verticillatis, ramu lis quadratis, ficcis, \& exilibus, foliis hirfutis, lauugınofis Ocimi, multa fecus fepes viari fruticat, nonnilul aut perparum odora, \& guftanti multò ficcior quàm Ocimú, tantilo calore fubaftringente, ve Bethonica. Qunre poffe filtere menfes, fi à partium imbecilita. te flun : poffećueigni facro mederi perfpicuun eft cùm mo teratè repellat dizzerendo, ¿uo pacto Mentham ficcam, tametfi calidim, admouent intiannatis partibus noltri zonfores Empirici, \& breui difcuticndo deprimunt tumores tim calidos, tum frigidos.

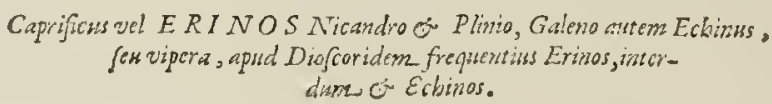

X $О$ м I I s etymon notióve veriloqua Erini, vel Erinei, fatis perfpicuè infinuat ob 1 lacteum fuccum, quo plurimo turgcret, hanc plantan fic nuncupatam futle. Eft quippe Erinos ficus pracox fugaxçue, lactc turgens primo aut exacto ian Vere, Rorum vice, quo caret femper ficus feu fylueftris, feu domeftica, onatu : quam feisuitus gentilitatem Plinius, proximè Caprificuin fubdidit. Et inquit, Palsso altan: contsculis

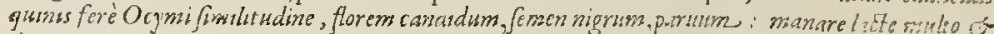

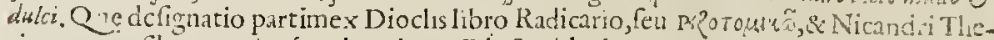
riacarus verfibus, partimúue de vulgata Diofcoridus litera collesta eit. Cui qudem ve nunc aptarenus non infirè quandam plantam nobis notam , tanetfi diu elaborausmus: tamen proprer hiulcam codicum lectonem, atque è Galeno notan Erini, in Echinon variationem, Iubuit nuilam certó afferere; fed dumtaxat vnam aut aiteram, n:* *ul gares \& pracxteris aptiores, in medium adferre exercitatiorbus firpiun veftigatoribus. Quxdam plantula eft in montium deprefsis decliubus, \& conuallibus vdis vel ri-

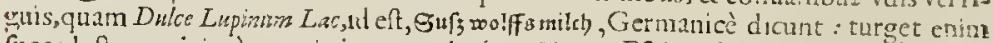
fuccolatco, minimè aut minimum acri,cóque Tragus Efulam dulcem vocauit:foliis 0 cymi longioribus, radicibus genicularis implexis, \& altius deptetis.

\section{Altera ESVL:A Syl. Tragi, folio fimilior Ocymidentato.}

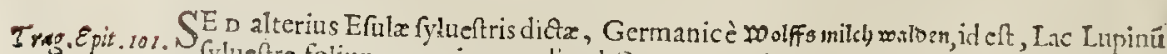
fylueftre, folium proprius accedit ad Ocymum ambitu circinato \& crenis Latioris folii. Cxterum, vtrius vel vires, vel factes magis quadret legitimo Erino, indufrii efto lectoris: crius etiam híc Cómentatoris impudentiufulum commentum liceat doprehendere \&cridere. Is namque quam fibi vifam \& lectam ad riuulos acinacum adco lacteo fucco mananten, vt co manus inficeret; palàm \& audacter affeuerafet, non verbizalssus fuit defcribere:fed pingendam curauit plaufibili in yulgus? ?harmacopoorum icone, 


\section{STIRTIVM aduerfarianona.}

quinis nec pluribus ereetis dc eclpite caulibus: Ocymi folio, bino, nónihil crenato per interualla donata, nuilla addita prorfum qux dubiam vel fidem, vel plant ã fulciret hiftoria: cuius picturx quum eum puduifft, poftremö de vltinis commentariorum interpolatiomibus curauit ex pungendam, 1tullam interca in huius mifella fubreptitiam locum fuffecit,ac ne verbulum quidem fubdidit, qua id de caufá demfrffet.

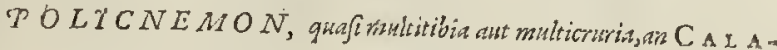 M I N T н A aquatica Belgarum.}

A E Q E nos habuit anxios conquifitio $P$ olycnemonis, quafi tu dicas multitibiã mulfuram, aut geniculatain plantam : fruticat enim multis geniculis intercepto $P$ ulegij caulc, folia origani cdčte, nec vmbellas, fed corymbos, odoratos \& a cres, Diofcoride all tore. Clit fuccinetx dclincationi, quătum coniecando licet, vnamquampiam aptare oportet medir cuiurdum habitudinis ke effigiaturx inter Origanum, Pulegium, \&: Clinopodum. Quales aliquot adeò fimiles habcbamus, vt quàm cui antiponeremus, aut veran prodcremus, ambigcremus. Ea propter vnả aut alteram exercitandi caufa Candidatis proponemns, qux nulla non nota congruunt:ve eft fruticofa quxdam non ita magna Itirps, exigna radice, caule gcniculato, folijs Origani vel Pulegij, rnde Pilegim agre fte, propter odorem \& folia fimilia, dicitur, flores Corymbi fpecic carfi, vel Pulegih, tota in cana. Caulis multiplex, incanus, geniculatus, quadratúfq; Pulegij, Q ' farmentofus, prefcr-

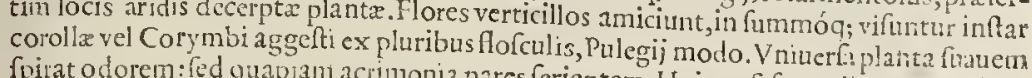
fpirat odorem: fed yuapsam acrinonia nares ferientem. Huius vif funt olim Belgæ Pharpíf; agrorum, pratorum, in Belgio prowenits in illic retinct. Inter veruacta \& fata ritati fcimus profuiffe:Syderiticam efouenit \& in Anglia. Stillicidıo \& vrine difficul-

\section{ALTERASERPYLLI O CLINOPODII figura, an Tolycnemon?}

Q VA D A M etian Clinopodij \& Serpylli facie plantä videre meminimus fuperior amo in Morgani hortis, quam quondam rebamur Polycnemon : furculofis enim ramtlis, geniculatíf; Serpylli aut i pulegij crefcit, vix lefquipalmo longioribus, ferpentibus folys Origani min or bus, Serpylli odore non ingrato, acri guftus.

$$
\text { KMrronódlọ CLINOPODIVMI aut Lectipes. }
$$

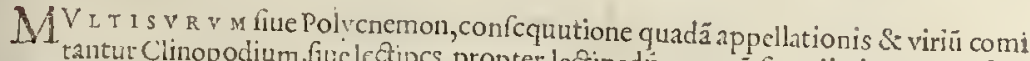

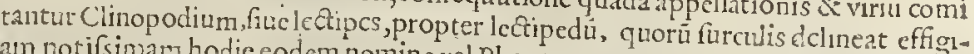
aturam notifsimam hodic eodem nomine vel Pharmacopcorum vulgo apud Monfpeldos namg; \& glarcofos occupar veri Clinopodij exprefsionem vix elt quod op:es. Aridos namq; \& glarcofos occupat tractus, furculis plufculis, fefquipalmú longioribus, radivel Ocymi folys partis Serpyllum aquantibus, cui \& funilia vel Calamenti montani, vel Oymi minimi, nonnullis leuiufculis in ambitu crenis apparentibus. Cauliculi complures farnentofi, præduri, crebribus ab imo fümo tenus geniculätur verticclis \& alabaculis Calaneethre. Calida planta, calorem non ita cula totidé exprimétibus, purpureis flor a toré funte!n fuirat Serpylliqualurem non ita magnú guftanti prabet, feil ficcitatem, nopodinn exprimat, inuerics nullam. Marum fi propius figuräintueare, qux malus Cli rum vocat, Maro quadrat aptius : nce vertirellis quppe, quam Maftiche plebecula Galloditis vel digellis, nonninis arous inçc vertıccllis aut foribus Marrubij tam concinnè conditis vel digeltis, nominis argumentum nempè Lecticx vel Triclini pedem refer $2 t$.

$$
\text { T.j. Ge. }
$$


Belg. 15? 2urubevlige, feu fufea facra.

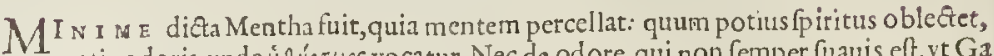
gratia odoris,vnde vid ḱc $\mu$ os vocatur. Nec de odore, qui non femper fuauis eft, vt Ga lents etiam notauit,aut illius contrario fenfu: fed potius quia $\mu$ in $\theta$ a effet concolor, aut

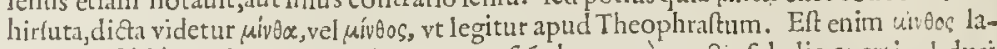
nugo mufcidáve pubes humentibus 8 putrefcétıbus penè cunctis fub dio apertis obduci folita, qualem cernere eft in fuccis \& decoetis herbarum diutulè feruatis \& pafsim in oletis \& fterquilinijs:cui hand abfimilis tenera illa hirfuties pulla, qux in, Mentha agrefti, fed precipuc in Calamentho vifitur, vnde dicitur Calamentha, quafi pulchrior Mentlia, mufcida \& pubens, funt autem fpecies dux \& totidem altrinfecus obuerfx varietates.

Binx namg; Menthxrotundiore funt folio \& fufco purpurante, minus hirfuto, caule quadrato: Sed vni flos fecundum totos ramulos Sifymbrij fiue menthx aquatic $x$ modo, per interualla flores infunt purpurei Pulegij.

Alteri verò omnia planè eadem, nifí quòd folia ex aduerfo bina, rugofa, alterno fitu decuffatim \& deinceps infunt harentia,quadam crucis imitatione, vnde đe rupsanum, fuc Crutiata Mentha dicitur : flore etian diuer fo fpicato mentaftri, procumbit humi vtraq;, \& ex agris videtur in hortos tranlata.

\section{RO $M A N A$ Officinarum fure prestantior anguffifolia. \\ Ger. Epiths stunts, fpicata.}

R OMAN.E itidern geminx non nifileue difcrimen:vtriq; enim folia oblöga, anguftiora, albidiora, hirfutiora, odoratiora, efficatiora foliz, ynde Romanx nomen \& Ballamex: cui Hos Spicatus Cruciatę menthx prorfus.

\section{RO MANA anoufifolia, forc coronato Jue Cardiaca Mentha. Ger. Jertzizunt.}

A L T E R I flos glomeratim in verticillatis ramulis, purpureis facrę Menth $x$ fimilis, odore \& vi peramica cordi ac cerebro: Ideoǵ; Germanicè bettecaut, fiuc Cordis herbä vocarunt. Omnes vulgatęcognitionis, \& opis multiplicis: humentia amant, nec femine, fed radice \& furculo propagatur.

$$
\begin{aligned}
& \text { A } 2 V A T I C A \text { fine S I SXM в R I A Mentha, rubrofolo, of fore } \\
& \text { nigrae Mentha. Balfarnine Officharum. }
\end{aligned}
$$

CVM effet hre cognatior menthr quàm Sifymbrio, rectius huc à nobis dilata fuit. Eft

fiquidem foiliss' (ed maioribus) facie \& odore menth $x$ fufcx, quam idcirco qui norit, minus mirabitur fi legat in Sifynbrium abire, vel hoc in illam redire fponte, cultu, a ut ncgleEtu. Iuxta \&e fubter aquas leniter labentes passim: radix menthx nigra ritu reptat, non alto folo depacta : caules quadrangulos, ramulos numerofos amiciunt glomers li forum purpureorum Pulegij Regalis,odorem menthæ, fed vehemétiorem, non ingratum vibrantes.

$$
\begin{aligned}
& \text { CNENASTRVM. } \\
& \text { eAng. Horje myte. }
\end{aligned}
$$

VT appellatione defluxum à mentha, fie e tiam afperiore \& crnfsiore habitu odoréq; grauitfculodegener videtur Mentaftrum, quod vbinis fecus monia, vda, \& fcrobes vrbiu fatet, maioribus, crafsioribus folijs, rugofis, incanis fuper \& fubter, hilpidioribus, leniter crenatıs, Menthx, cuitus confimiles flores ficatos fortitur, caules ambientibus quadratos caducis ramulis, ealore \& odore ignatio. 


\section{STIRPIVM adverfarianow. \\ Varietas Anglici cinerei $\mathrm{N}$ I V Ex.}

CVL I I R E S horti in Anglia Mentaftum quoddam alunt, vulgato longè minus

$\&$ odoratus, cuius folia partim funt viridı colore, partimúue niaco candore, \& $\$ x_{-}$ uore nitidifsimo, cuiufmodi in Hyffopo \& Saluia euenire notauimus. Balneis \& compofitionibus Officinarum, vt Pulueribus Diacalaminthe \& Diacymini, hanc vtpote gratiorem,nec minus efficaccm, præltaret indere.

\section{$\hat{C} A L A M I N T H A$ Montana preftantior.}

V a s I elçantiore afpectu odoréq; delicatiore eflet quàm ARetha, Calaminthe voca ta fuit:certè hilariore nitidioreć; habitu effe nullus inficiabitur, qui Vincentumam \& Veronenfem viderit. Et vtinä catera omuia periude paucıs \& f́itè expediifet Diof.aique Calaminthx differentias fignauit: næille multos fcrupulos nobis exemiffet. Et quäuis tam perfipicuè oftenderit, tamen non diu eft cùm primim Ofícinx peritiores $\mathrm{Ca}$ lamenthum à Cattaria dignouerunt, \& vfurparunt, cóniciente adhuc ignara quorundam Pharmacarioníngnuia, qui fciunt quidem iftud verius \& eflicacius quàn Cattaria, ied labori aut nummo parcunt. Neque enim obuium iftud montanum, nifi Norbonenfis Se. uenæ vmbrofis, faxofis cliubus, \& in Romano atque Patauno agro, vnde memininus quofdam medicos Taurinenfes dottifsimos curaffe quottanns magna vi acccrfendum, cuius aqua ftillatitia ad menftrua cienda vterentur, fperato fucceflu: cft cnin guftu $\&$ olfatu fuarter acri. Exian dú eft viride plurimi fit apud Italos:arefieto non alıd ad the riacam illam myficam preftantius, virgis riget quadratis, nitidis, cubitum altis, \& quam Menthx gracilioribus: folia edentibus Ocimi, ant Melitfophylli, fed nuinora, fyeciofiora, hirfutiora: flores item Meliftix, fed purpurcos, femine Portulacx minuto, odore Amara. cino, Menthx fuauiore.

\section{$C A L A M I N T H A$ altera, folits raculofis odore grani Pregis; Diojco. Nepeta.}

A P R I E fedulushíc Diofcori. hauc Pulegio fumilé facit : vt certè eft, foliis quippe

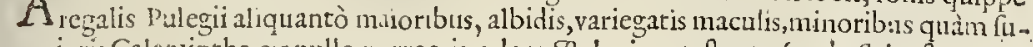
perioris Calaninche, ex pullo porraceis, odore Pulegium teftante, (vnde Sylueftre pule- Perperam $M$ a giun antiqui diserant) fed vehementiore ingratioréq; , præfertim feruidioribns trąti- thio. Icon. 677. bus, fquallidis, cliuofis Italix Norbonx \& Galloprouincix, vbi nonine Calaminthe, fue Montanum. Nepetx Officinis vurpatur, non fecus atque Cattaria alii illic vtuntur: $\&$ in reliqua $G a l$. Jia.Luzduncnfi pracipuè, vbi ctıan totam æetatem flores purpurantes pallentesćue verticillatim virgas cubitales amicientes, fundit.

\section{CU ENT H AST RIIEOLI A aquatica, hirfutat, Calminthe Drof.eft Sifymbriifpecies quedano recentiorum.}

Fi c i I is huius dignotio Mentaftrum intuenti:vtraque enim aquofis viret marginibus fatotum aut pratcrum, huius caulis cubitum \& fefquicubitum æquat : foliaque Menthaftri aut Sifymbrii edit, incana: Alores $M$ entha foicat os purpura obfoleta, odoris grauis Sifymbri,nec guftu minus calfaciente.

\section{$C A T T A R I$ A, fue Mentba Catio}

Germ. Katigen munts.

Gallis. Herbe au Chat.

\{Itals. Gattaria,feu herba Gatta?

Belg. Iatten crutut.

LeAng. Cattis Niynte.

$T, i j$, 
F Calamenthæ Mcliffẹcue participe tribu eft ifta prxtans viribus herba, antiquis for te ignorata, quam Cattariam plebecula vocat,peramoni fpectaculi argumento:vixdun Von ef Nepe: enim confpetam vbi olfactarit Cattus,amplexatus \& diffuautus fuerit, lafciuiendóm. anirgrorum. illi ian accedendo, iam recedendo fefe verifque pedibus dus \& multü affricuerit, colludédotãdé miris gefticulationibus vniuerfan andè ligurit, fed auidns fi ea ex agris in hor tos fuerit tranfmota:tenerior nanque tunc eft, odoréq; nó perinde vehementı, alioqui agrefti fimilis, quadratis, numcrofis, rectis culmis, duriotibus, ftratis: foliz iuxta interualla promentibus bina, incana, Mclilire, aut Martubii æqualia:flores intra \& circú fuperioram foliorum exortus tamulos ambientes, \&extrema fpica caudata decorantes, Menthe aut Mcntaftri: cuius etiam vdıs natalibus gaudet plurimam nihlominus viarum \& cultorum margines dant: Strentia cilfuciend \& attenuandi dote, fed eximia prxrogatiua ad conceptus facilitandos, prolificunı́que vterum reddendum.

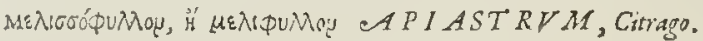

$$
\begin{aligned}
& \text { Germa. Woutuzenfratut. } \\
& \text { SGallir. Melific. }
\end{aligned}
$$

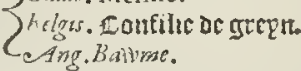

NO nulò pratuntior aut difsimilior Prifcorum Melifsa, qua non fecus atque Catti fua mirè capiuntur $A$ pes,quibus alpergebant Coloni diumi pracepto Maronis,

Tuiuffos apperge liquores,

Trita Ascliphylla, Co Cennthe ignobile gramen.

Citraginé vocauit pofteritas quòd fimiliter Citro fuatuè fpuret, \& cordi profit: tametfi nó nullis c̀ locis leta, quiddī pxỏoris aut cimicū ciusgratiz odorxafcitü fit, \& idcirco dubitatum ftt, vera nc effet, an aliús fpeciei noftrâs hæc, qux nulli regioni in hortis deeft, fed in quibufdam Italicis \& Pedemontanis hortis meram fuam fibi halat gratiam, Bafilici aut Citrii,eximitqúte quamlibet de odore argutationem, quippe de catero nulli non cognita:fol 12 Menthz, Ballotx, aut Cattarix, rugofa, afperi, fed viridantia: ramulis quadratis Marrubii,edentibus orbiculatim flores albidos,copiofos, in verticillis Ballotx aut Cardiacx: teneros tufos turiones excipiunt muliercul $x$ outis, facharo, \& r ofacca, placentu lasć; pinfunt parturientibus, puerperis, \& enixis, quibus vires impendiò deicctæ fuerint, aut fecundinx non probè eductx: ftillatitix ad cardiacas confectiones, multa yfio.

\section{MELISSOPHYLLON THECLCH:}

TA В TS I he nares quidem muccofas latere potclt huius eximix plantæ odor, qui Melifix Citrcúmve malum adcó imitatur, imò \& fuperat, vt illicò cui fit aficribenda claf́si moneat, \& penc̀ præ nimia framrantia faltidiun faciat, illo exuberanti halitu permixto, qui à Cimıcú foetore haud longè abeffe fubolet nonnullis: tamen merita eft imprimis vel accuratifsimam delineationc, propter vifendam venuftatem, \& vires non contemnendas. In viretis duntaxat futricat, radice non magna,caule quadrato, fefquicubitali,nt maiori, foliis Chamadris vel Scordit, fcratis, in acutú definćtibus per interualla a b imo fummoq́; tenus, multarum alarum ramulis ambientibus verticuJis feptenis oftenísve ex fpinofis caliculis, radiatis, congetts, in quibus fores purpurei, cærii, Teucrii aut Triftaginss. Semen Augutto aut Septembri nigrum oblongun, Pfylii, a picello donatum albo,

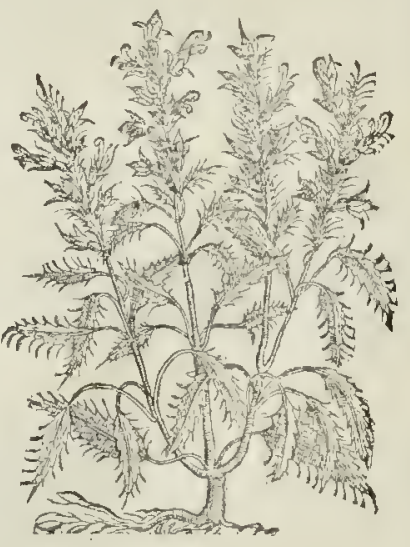
quà furfunn tendit. 


\title{
STIRTIV $M$ aduerjarianona.
}

$C A R D I A C A$ :

\author{
SGer. Ђertfsgefperr, yno bertsgefpan. \\ $\{$ Bel. Betreghelpart. \\ Ang. Miorberworte. \\ Gall. Agripaumć.
}

A D hanc daffem fpectat genus illud Marmbij,cui recentiores Cardiace nomen dede-ri eximix dotis \& cordis affectibus amicx merito. Radix eft multifida, in terram fexi bus fparfa, quadratis caulibus fruticás. Marrubij folijs herbaceis, crebrioribus, longioribus, \& altioribus multo fifuris, quàn Acutæ fpinæ vulgaris. Florcs item purpurei verticullis caulem ambiunt, odoréq; quadantenus Marrubium præferunt.Vires Meliffophylli,fuppares.

\section{$C A R D I A C A C M E \dot{L} I C A$ fue ${ }^{\prime}$ ioluca Syriaca.}

DV a s etiamnum Melıfophylli congeneres \& inter fe perfimiles(tamet fi peregrinas \& minus cognitis) virium commendatione $\&$ odoris conjectura hæc xtas Cardiacas vocauit, nomine etiam quadantenus eôdem alludente, nam Melicam \& Molucam appellät; non ab Oceani trans Tropicum noftrum infulis Molucci:fed nomine cum planta miffo è Syria Venetias Martinelli Sequini opera, anno ferè decimo exacto. Harum maior (quam Antuc pian primum doetis amicis dono mifimus, deinde Narbonæ \& Londin feuimus) duos tresúe cubitos alta, multas fundit propagines è radicelignofa, fibrofa, nuultifida, albicante: caules item rotundi, crafsiores, culmofi, intúfq; caui, nonnullis obfcuris friarum fecundum longitudnem veftigijs, \& æquis fpacijs femigeniculatis porriguntur, vtrinq; exa aduerio bini, exiles, fed prolixiores pedicello, totidémg; folia fulciëtes, circinata vt Me liftre, diuifiris minus quàm Cardiacx noAratis, profundis: Proximè pediculorum exortum geniculos amplexa fublunt fpinulx prętenues, quas operiunt patud lx fenæ oftonxve campanulx, multiangulx, tcines, membranof $x$,albid $x, \&$ rigidiufculx, adulta: Summa ora lunatx \& pinulis horrentes, quarum è nedis centris purpurafens albidúfve fos, Lanij, aut Cardiacx nofuratis non abfmilis exit, fuccedente remine angulofo, Pyramidis effigie, cunci bafim apicémg; conftituentibus, albidis, alterius Cardiacx. Gratiorent hẹ quàm Melifia odorem fpirarc videtur his quos minimè inuat, ille impendiòfragrantior, \& quafi fitum putorémg; cimicum redolens, A pia!tri odor. Hęcnāq; Citrij prodit,fed mitiorem.

$$
\text { MOLVCA CASPERIOR. }
$$

jV I v s varietatem fepius alnimus in amiconm hortis Monfpallij, quam nunc afpetam Melicam aut Molucā dictitant: v tpote afperiurculis caliculis tantum duerfâ, anguftioribus infüdibulis, , $\mathrm{ed}$ acu

MELICA vel MOLVCA afperior Syriaca.

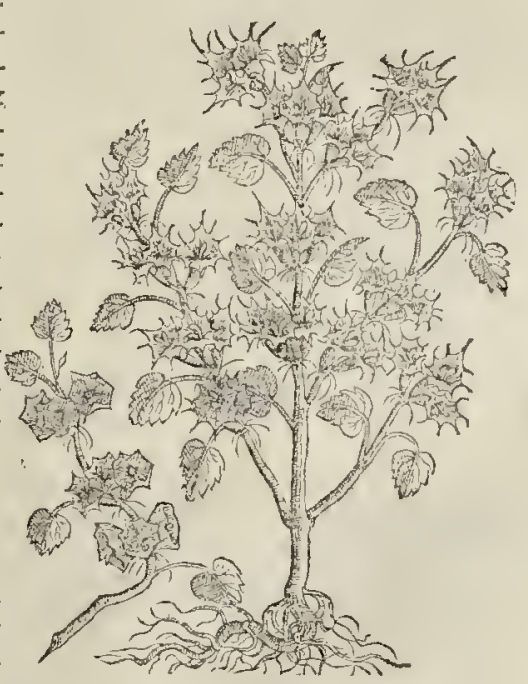

Ramultis MOLVCA fue Cardiace minus alpere Syriace. cis infeltioribus, rigidioribus, longioribus leptenis vel octonis, caule quadrato \& leuiter canıculuto. Sed par cuneiformæ triquetrú vtriq; femé, infundibulis fufcis, nó ita albis, aT.iij. 
iperalıæc dista Cardiaca, cuius vires atq; natales quid differant, nobis incompertum.

CHARR R BIVM.

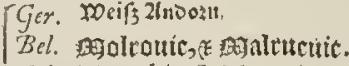

$\{$ Gal. Marrubin \& Marochemin.

Aing. Horebounde,

Offil. Prafsio.

V I I E I V R Prafsinus viror, aut certc̀ virofus odor, appellationem impertifie Marrubio tum nigro fortido, quod \& Bullotx dıcitur, tum al bo odoro: vnde Plinij anfa hal-

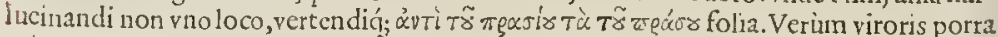
cci nitor melius quadraret Melyffr. Duo auté Marrubia, etian Theoph.volente, eiufdé füt nominis, effen tix.\& figurx: duntaxat hoc diffrepant, quia Ballota plufculum ad atrorem fufcum por raceum vergit,odoreḿ̧; granem \& foetor cm vibrat: Marrubio verò fuauis odor, incana \& candidiora folia, tun fores, non ita Apiaftro abfimilia, nifi lurido viroréve è luteo vítuido, \& odore longc̀ fragrătiore selifa donaretur. Omnibus canlis quadratus, verticillis florum per intercapedines diftinctus, fefquicubitalis, fores purpurafcentes, lioquin reliq̨ua dun taxat magnitudine aut exilitate differentia, matgis albicat Marubij flos.

$$
\text { C } A R R \text { R B IVM Creticum angistiore folio, odore gratiore. }
$$

$\mathrm{M}_{\text {Creticun, vt credere etiam libet, nuncuparüt }}^{\text {In s hastenus peregrinum Marrubiü }}$ Cretenfes inftitores, qui Venetijs oráq; Thyrenica negociātur(vbi dono habuimus ab ingenuo \& perito myropola Vencto Iohanne Pomello ad Bucin toris infignij officinä)Fruticat caule contorto, gra cili, rotundo, al iqnammultis exilibus alis do nato, Polij nontani non difparibus, \& quàm Prafiij noftratis multò candidioribus, teneriufcula la nugine obfitis:vti \& folia anguftiona, oblongiora, \& lcuiter ferrita, in anguftum abcuntia Meliffx Turchicx equalia, cx interu!llism:Itò argutiorcs \& minores verticelli, Syderitadis aut Tetrahitnon difpares hroét. Flofculi pregtenuesindidem cmicant albid: Marrubij, quod quunta quanta eft, odore \& lantigine profert.

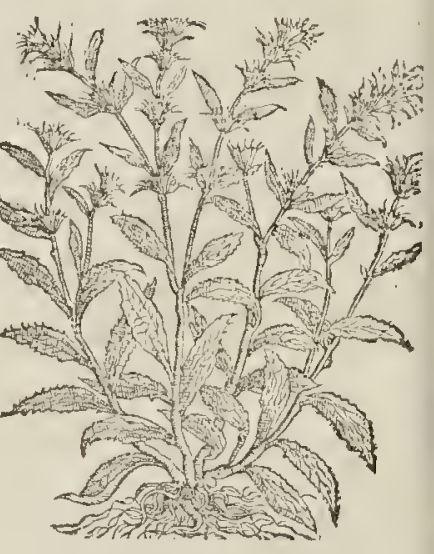

$$
\text { raxiśtis }
$$

Vrrica, non mordax, mortua, deplex. $\{$ Galiopfis vulgaris factens purpurea. I.amium Plinif \{fuc vulgi Archangelica. Flore fábaceo å Luteo. Mila atela ltalormon.

A F L OR y u effigie Galeata, vel potius Muftellæ facien \& rietú quadantenus exprimé-

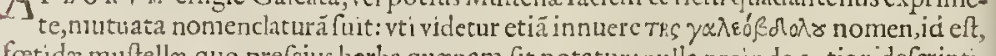
fotidx muftellæ, quo prefsius herba quxnam fit notatur: nuila proinde aptior "defcriptionı, quàm vulgaris Vrtica mortua fœetida vocata, cim quia vfquecuaq; vitican ant foctidum Marrubium prefert folijs \& caule, tum ctian quod lloribus purpur:is, exilibus, oblongis galericnlis, aliquantum muftellina effigie exprefsis vifitur, dcinde iuxta fepes, rudera \& vras oritur pafsim, vbi non item vlla alu vifitur quę nonnullä opinioné Galiopfis

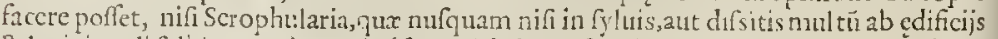
\& locis incoli folitis, reperitur: minúfq; multó foctet, \& minus Vrtices afsimilatur quàni ifta vrtıca mortuil, cuius vires praclaras ad ftrumas \& carcinomata, gangrẹnás,non folum 


\section{STIRP IV M aduerfarianoua.}

antiqui,fed etiam docti barbari pofteriores experti funt, \& literis mandarunt, qui Vrticrá, mortux \& fortentis nomen indiderunt,q qua nota facriè dignofcitur à congenere Lamio \& perquàm fimıli.

\section{A MIVM sime Archangelica, albo for:.}

Ger. Tootitifich

BCl.Đeconte=

$\checkmark$ Rticeo etiam generï primo intuitu hanc affignat vulgus: eft quippe folijs fimillimis

Vrticx, \& canlibus quadratis. Galiopfy fimillima, multo tamen procericr tota. Floribus oblongioribus, maioribus, fabæa aut matrifilux: qux per interualla folionū verticillatim quafi anfe inflexx, \& laruatam cuculo adumbrantes Lamian tribadem, (vnde Lamium fortè diđta) caules amplexätur, minus grauè olentes, albidi vel pallêtes: Adnodum etiam nota hxc: tametif lubentius fenticetis \& fepibus, quàm domum ruderibus vicina accolit.

\section{LAMIVM Luteum:}

NE c hæc in fyluofis \& opacis videtur fpecie variare, nifi proceriore caule, numerofiore, hirfutiore: folio, flore pereleǵanti, luteo, \& alioqui nó diffimili nec alilis viribus,fed innltò efficatiort bus ad vulnera, vlcera, \& tumores, vnde Sideritis putata, \& noftris auiș Archangelica vocata.

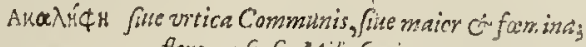

$$
\begin{aligned}
& \text { flore mufrofo, Milingemine. }
\end{aligned}
$$

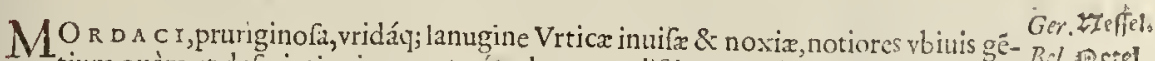
tium quàm ve defcriptionis egeant, cóq; duntaxat diftinximus à flors, fentine nus

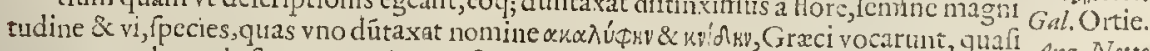
non tangendas, quia frum punctorix vftion is dolorem inurerent, cuiufnodi fermè ve. Ang. Nertelo fparum ant a pumi aculci:tametis miranda magıs iniuria, cimm perqquàn exilis, mollicella, nec pcnetiare potis if thx videatur lanugo.

Maximo importunóc; prouentu cuncta fcatet Europa communi fiuc maiori quàm ceteræ, latioribus folijs, nigrioribus, \&2 interdum purpurantibns, minus altè ferratis, procerioribus:caule \& ramis, femine in racemaceis filamentis Milio minore fubruffo, culus in Officiniş Borealium, Penuria Romana vulgò dietæ, plurimus vus.

\section{$V R T I C$ A Jyituestris, fue Romana Officinarum, fimine Lini.}

TAMET I I hec non nifi calidioribus regionibus, vt Hifpanix, Norbon $x$, Italix, \& Romanix frequentior \& vulgatior: tamen Romana non eft dieta ob natales, fed prop ter feminis maioris maiorem efficaciam, quod menfe Augufto \& Inlio maturum pilofis villooísve pillulis, Echinum referentibus, è pedicellis, ,n caule flexwofo, folijs donato, al tius quàm cęteræ Vrticæ fimbriatis colligitur,ad gluten pituitof ú incidendū, extergëdum, quum opinionem afthmatis \& orthorpnex verx facit, vilifininum: non tant um enima pręparat vifcidum farctü, fed etiam delectu educit clementius, Chartami feminis ri. tu \&: Dófi:Rondelletio in magna commendatione,

\section{$V R T I C A$ minor fiuc Cania Pliny acrior.}

$V$ V L G A I I S I M A minima in hortis \& fatis vbiq; gentium hxc, admodí mordax, fi milis planè maiori communi, fed minoribus folijs \& caule breuiori, tameti magis vrida vi: Ornium vtilitas hodie corticis libriq́; Vrticarum aqua diu macerati in India Ori. entah apud Callecutios \& Goas multa, ad lineos pannos delicatiores, quos illinc adferunt in Occidentem \& Septentrionem, quidem conrmodo intitores precio, eleganti tenuifsiráque textura, fed non nagaix durationis.

$$
\text { SIDERITIS, fine ferruminatrix. }
$$

VOCABVLO QVOD FERTOSAVCIATIS PABTIEVSOpem promitteret, nobilitarunt primi mortales complures plantas, Sideritéfo; vocarunt potius viriun confuniles effectiones fequuti, quàm vultuum affinitates generiT.iii). Eáfves 
cáfve differentias, fic clorę̈тss terra, ars, \& lapis Magnes, dicta, quia fer:o vel aduerfarentur, aut vterëtul, vel confentirent.Sic plebs Gall ca Car pentariä fue fabrorum vocat, qui bus frè̀ vulneratis remedio eft: nec al ia notıone Stratiotides fiue militarcs, vocat $\boldsymbol{x}$ fuerät. Sed cun huc fẹculo diuerfi admodum generis, nec minus excellétes, \& multò plures innotuerint, quàn qux huc vel pofsint vel debeant cögeri:noftrā coptam viam infiftentes, guảstet hac dote \& nomine claram, fuz addemus claisi: alioqui Hclxine à Diofc, Sideritis dicta, \& fexceta aliæ tum Sideritides tum Stratiotx poffent huc aceruari. Hanc itag; Sideritidem Heracliam, fine ferruminatri $\mathrm{com} \mathrm{Herculeam,} \mathrm{Loeti} \mathrm{Barbariillam} \mathrm{nul-}$ to experimento compertan \& vocatá Tetrahil, fiue Iudaicam, effe fanxerunt: non modo propter vïes efficacifsimas \& pla. nc Herculeas, fed etiam quia quàm proximè delineationem Diofcoridıs, fi quęalia, reprefintat. Strigofa enim vel fabulofa, arida perpetuò amat, inć; Autumnum perdurat: Iulio \& Innio floribus purpurantibus, pafsim in Maritimis \& montofis Italix lufubræ, \& ad Apenninos móres, Venerijs ad Lio, inć; Gallijs Norbonéri \&e Lugdunéfi reptat.Virgultis peda!ibus iam

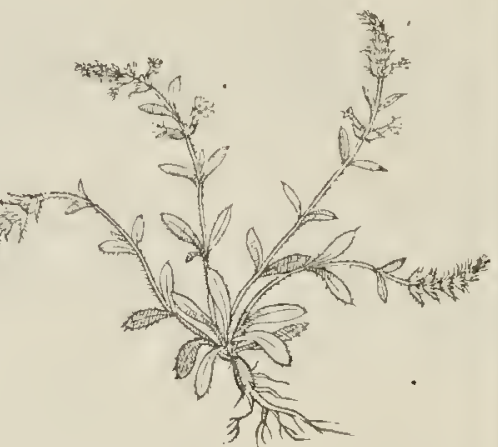
furrectis, iam deprefsis, quadratis, duriuf-

culis, ternis aut quaterns, verticellis crebribus per interualla donatis, firm is, a fperis, pun gentibus, planè Marrubij Cretici fimilitudine, etiámq; floribus albicantibus ex diluta purpura.Iunta quos \& fubrer folia funt longiora, angųtiona Marrubij itiden Cretici, in cana, \&, vt totus caulıs, fabra \& crifpa, ambitu laciniato vt Chamædris, aliquádo laciniofd durifura obfcurius ap paret in quibufda folijs, que puto caufa fuit vt Dinfcorides iam quernx fródi, ian Saluix \& Marrubio cótulerit. Radix lignofa Marrubij, min us fibrofa: iandtu valdè magno emolumen to cognita practicis quibufdam Iudęis \& Maranis curfori bus, qui hac enterocellas \& alba menitrua curant . Vehementer exficcat nonnihil odora, aftictione infigai, nec ingrato fapore, ad vulneta nata, \& prorfun tanto Herois nomine digna. Quòmagis dolet peritis \& candidis plantarumarbitris, Commentatorem noftum eo fecurıtaris ignatax progreffum, vt cum quxıam elfet vel I talicis Judęis Indaica herba, fe nefcire quererctur, quã fcitè, vt femper omasa, Ruellius, \& cx eo Fuf́chius exprefsiffet, tamé in verumg; de tc herbaria optinè meritum infitia calumniam impegerit: \& Cenfu ftudio planè deprauaro plaufun è triuio captarit. Huicq́; herbę de fua clafie vulfe, fibi miffas, ve femper iactat, nec tamen nif mutile defcriptas, alias fuffecerit, fci Mambunm a- licet Marrubium aquaticum vulgi.Cuius natalitia, folia maiora, latiora: caules cubitales, guaticum vmloi, nec a perillum huius prioris fortè pœinituifet, ei alteram multò adhuc confufiore facie, quafi fubfidiariä dat, herbarijs Canabim fomină vocatä:quam inter Vrticas, Lamium \& Syderizis : Galyopfim referimus: folijs namq; facie \& verticillıs I_amij, Horibúfq; purpureis, nec ni-

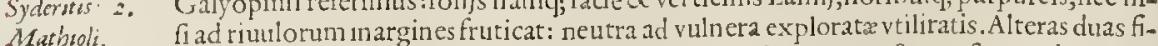
guras cquidem parum notas, cur idem autor pingendas curartt, \& prorfum tacitas praterierit, non iam quarendum: potsus ferendum fui malx confcu oftentationis fudium ducimus. Nos alias à viris nultæexercitationis non parum approbatas lí́c damus, quò expendantur, \& non vt afferantur defcribimus: nec vllius affenfum ancupamur.

$$
\begin{gathered}
\text { SY DER IT IS Monfpelliaca Scordioides, } \\
\text { fine Scordiyfolio. }
\end{gathered}
$$

O R R o preter hanc Iudacam, Monfpellienfum fchola aliam fpecicm Syderitidis no$P$ uir,palmum \& fefquipalmum altä, viticulis anguloris, reftis, pluribus,aridis, lignofis, $\operatorname{com} 2$ 


\section{STIRPIV M aduerfaria nond.}

coma \& verticillis Hytropi, foliis \& facie \& colore Scordei Diofcoridei, fed minoribus, magísque rugofis, rigidis,crippis,pilofisçue, quàm Tetrahıt Iudaicum, nec minus laciniofis, fed hirfutioribus:flofculi Satureix vuIgaris dietx (quę tymbra eft) ad foliorú articulos \& verticillos, amaricante exficcantéque guftu, nonnihil asomaticifuauifque halant,quod Chamædryn aut Bc. toniam referat. Ad ripas deucxas Patibuli Monfpel liaci, fqualidósque margines \& colles prope vrbem, \& nouun Caftrum \&'alibi Norbonx multā meminimus.

$\operatorname{MONTANA}$

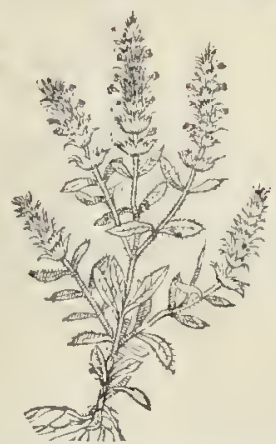

IN nvs T r r ville \& gnzrus materix Medicx cunEt $x$ Valerandus Donrez, ex Sabaudiec Alpinis hanc fibi lcctam, vnà nobifcum vnam Syderitidum opinabatur: \& quideta fic fatis bellc̀ quadraret Heraclex Syderitidi, ni folia anguftiora multò effent, viquue efficatiore carerent: eft quippe cxteroquin verticillatis cir cis afneriufculis, pallidis Marrubii aut Tetrahit, pluribus verticulis, tenuibus, lignofis, nec quadratis, binum palmormm: radice flexuofa, prolixa, lignofa, pulla, amaricante gtftu,praficca,riec ingrata:viu nullo explorata.

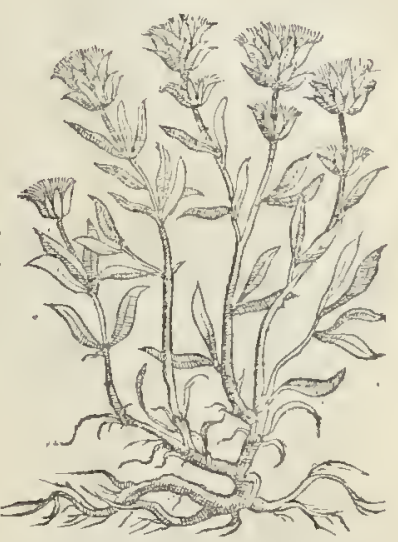

$\int$ Cannabis $\left\{\begin{array}{l}\text { Mas. } \\ \text { Famina inforcunda. }\end{array}\right.$

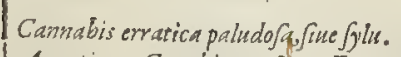

Aquaticum Canabimum Mas, Eupatorium dictum Auicenna.

Canabnum Eupatorium aquaticum dittum Farninam Sepsentrionalium.

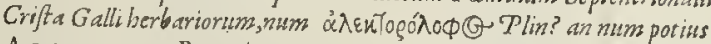

A L I. I A R I A Recentiorum, ó Pes Afini Pandedtariy?

Stachys, ficat is circinató que ambitu cinct is floribus purpure is $\&$ luteis.

Stachys Spuria folio Echiy, aut Calthe, Belgatrum.

Herba Venti Rondellety o Monfpellienfum, pannofis, flaccidis fub Hyes mem folys, an Othonna Diojco?

De flore Africano, fute Othonna Italorum inferius.

Betonica.

Betonica aguatica Septentrionalium, an Climenon Diofcor?

Climenon Italorum, fue Ciciliana cum Periclimeno.

Scrophalaria.

Serratula.

Herbafacra, recta, altior eft Verbena noftras: fed Perifferion, fute Cow lumbaria dodrantalis, in aquaticis eft longè alia, qualem Egineta memorat : jitre Scabioja minima? 


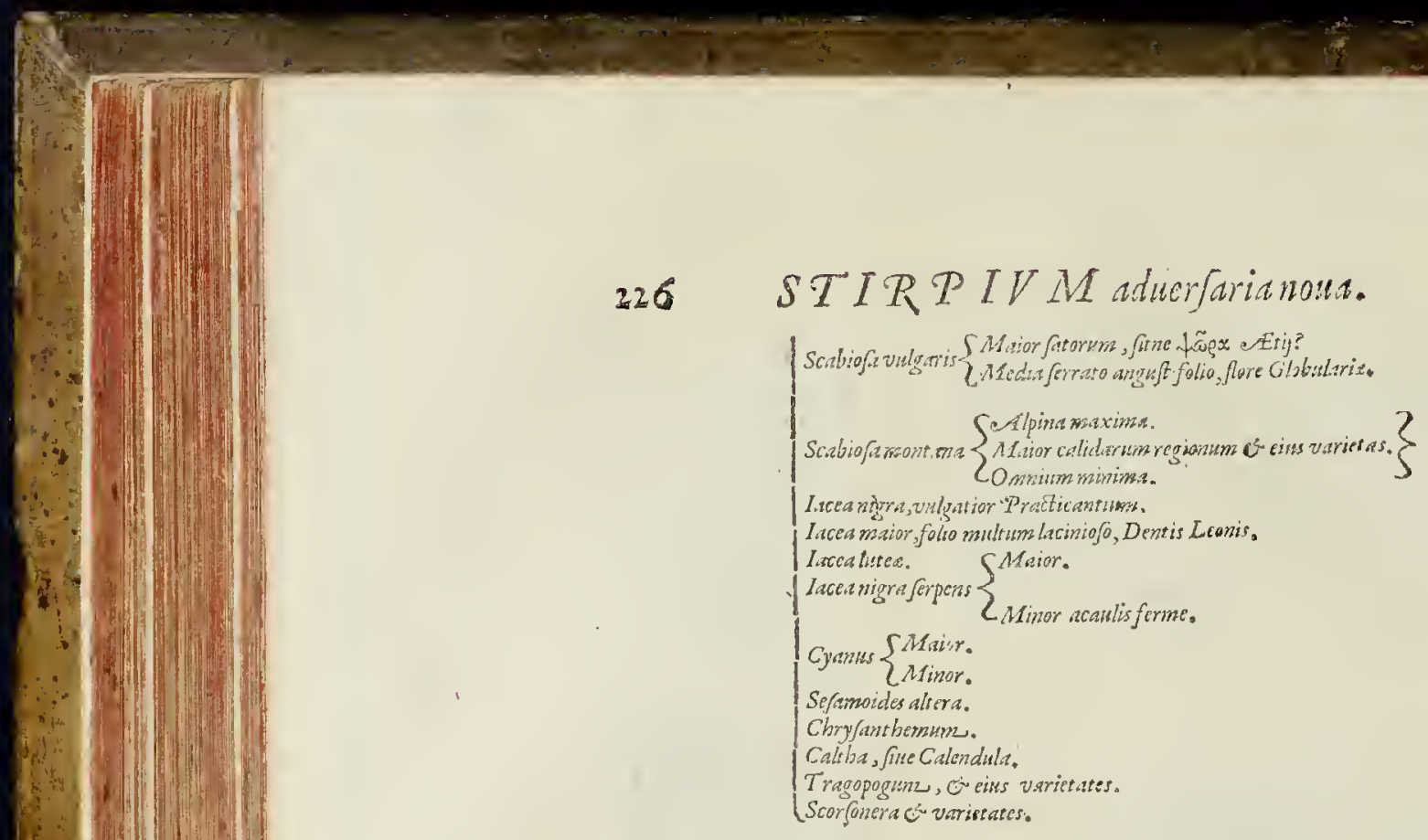

\section{$C A N N A B I S$}

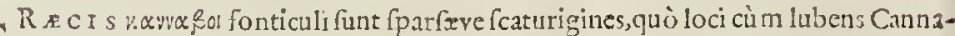
Gbis fpontè \& fata luxuriet, videtur id nominis indepta:glifcit namque feges Cannabina rectis culmis, quadratis, ftriatis, horridisq, ferratis, nigricantibus foliis, Vrticä, aut Sideritidé quadantenus exprimétibus, fed feptenis aut nouenis ć fugulo pediculo diuifuris Lupıniaut Ricini, mul tò notior quauis defignatione: nou difparis yfus, fed in immenfun vtilior quàn Vrticx Molucx. Cunctis enim populis penurıả Lanæ, Liui, Xyliç; refarcit, ad veftum ftragula, velorum, Papyrum, quambibet denique fupellectilem. In inarem \& fominam feninis duntaxat foctundo prouentu diftingunnt : Nam ex codern foło pingui, vdo,alut riguo enatx, qux inolliore culmo, delicatiore cortice, aptioreć; ad nendü \& rextrinas, fominä faciunt : cuius florü feminísq; fpes in firü mufcofum \& puluerulentum, quafi filicis, perit. Qux verò robuftior, horridior, fruticofior, rudentibus \&e capiftris torquēdis nata, Mas habetur mulierculis, adagio iocantibus foeninā potıorem mari. Huilus autem fem $n$ eft noli parüad mul ta proficūi: exeodem Oleum prelfum tumoribus \& fcirris opitulatur, lucernis alit lychnis \& lucem. Lac etiam vel pultes ciufden macerati, aut iufculis decoeti, Huxiones filtit diuturnas, dolores repentinósque flatuum vortices, \& humorum fuctuationem compelcit:foinnum confliat. Vfus tamen nimius molefto fopore perfundit. Tritu capiti, vel pedibus imis admotum, haud abs re Icteri humores, vapotefq́; tenues à cétro auerterc \& cuncare putatur. Radices podagricis tophis proficure. Odoré graué \& nônihil virofum eruftat, \& vel capitis in eo decubitu temulentos facit. Succus verò foliorü certa pernicies in fectis interzaneis, \& vulnerum putridorü alumnis: II n qua facultate idéfoliorum Perficx, aut Tuglandium putaminis fuccamétum efficit : fed vapido tetróque fitu, odore, \& exficcandi vi, qua alïrentum praripit illis \& populatur,excrementis difsipatis: multum alimoniz fuggerit Gallinis, Cortalibúsque; fed hyeme focúdiores, poltea fteriles \& quafi pinguedinis mole obrutas reddit. Auiculisetiñ cibus eft, ac tantü faginę adfert, vt aut enecet, aut cantıllandi adimat alacritatem \& facultatem, vt Carduellis, Linottis. Lacunis aut forobibus aque plenis metguntur vtriufque fexus fafces \& manipuli, vbi macerantur eluunturćue multum \& diu: deinde ficcantur Sole, vt tundantur, ac demum cortices ft minei rundendo velluntur, vt Lino fit ad filum \& telas. Sed lacuftris aqua, cui intabuerit, tantoperè viru nocet, vt epota pręentifimo fit fitientibus exitio; nullis enim an tidotis quantumuis têpeftuè datis oc curripotut fato Marquifii Arboii fratris Guiforŭ,eúíf ; vxori \& quảplurimis genero_ IIs, quifuperioribus annis prope Olbiam $1 n$ Prouncia aftates feruidas cum tranfmitte 


\section{STIRTIVM adverfarianoua.}

rent,imprudenter fontanam lympidam, fed occultis mxandris \& fubterraneis cuniculis indidem in fontem illapfam haufiffent.

\section{$C A N A B I S$ erratica, paludofa Syl.}

A L i a non eft hac à Satiua,vt etiam de Diofcoride difcitur, nifi quia illius proceritate vincitur . Hac tamen crafsiorem caulem Brifinalux parem indicj affequitur : vmbrofis lacunarum marginibus Cicutæ fociatur, itemq́; cxnofis, fœtidis, fecus villas \& mœnia. Flaccidiora folia, fed hirfutiora aliquantùm \& Sideritidis fimbriatis or is: floribus purpurillis \& albicantibus. Radix compertifsimi commodi ad tophos, \& f pretas remedia durities.

$$
\text { A Q V AT IC A Canabina, Eupatorium ditta, eMas. }
$$

P A s s i m ijfdem natalibus \& Canabina facie oriuntur dux plantx fimiliter difcret $x$ fexu, quas proptcr amicas hepati vires, for tè \& ob folı, Eupatoriumu vocarunt, marem \& foeminam. Ille rotundo fubpurpureo caule, intus medulla alba referto exit, duos tresúe cubitos æquante, aliq̨uantum hirfuto:vti \& folia crenis fimbriata ${ }_{3}$ nigricantia, afpera, $\mathrm{Ca}$ mabinis ortu \& fitu a deò accedentia, vt permulti Thar macopoi, Bel gx prafertim, Eupato rium Auicénx foli js Canabinis proditum, vocitent. Glomerofos villofosć; in fummo fert fores, ex diluta purpura albicantes,inq́; auras papp $n \mathfrak{l}$ abeuntes. Radice fparfa latè fibris. Amaricantis guftus, odoris nö minus fuauis quàm Betonica vel Agrimonia, cui viribus $x$ quiparant Medici \& Pharmacopoi illic:ac quoties pręfcripto vtrumq̨; eodem pręcipiunt Diofco: ideum \& iftud intelleetum iri volúr. Nec f pretui habebit is qui noterit nonnullos ad affęus iflus decǫa non modò nó cedere Agrimonix, fed etian excellere: impacta hevati ac fpleni referando non multa calfactione setiamq́; fanguinem temperando \& cun ctis partibus concoctioni dicatis tonum, roburǵ; conciliădo. Obcfx nimis naris aut Rinoccrotides erant,qui fotere dictitabant. Quippe fuauiter fpirat manifeftó:ormnium fers mè reģionum ad aquas alumna.

\section{F OE MIN A Canabina Septentrionalium, ftellato ci odioro fore}

N() $\mathrm{N}$ itcm tot regionibus frequens, fed Bore alib us magis, \& ipfis in vdis aut medijs riuulis cúctantius fluentibus viuut hxc, viuida radice, multis prolixioribus \& gracilibus aquaticarum modo fibris, caules promentibus cubitales \& ferquicubitalcs, fubpurpureos, rotundos, ramulis inultis, diltributos exinteruallis, \& è regione fibi Canabina folia magis taméferrata latiora not perinde hirfuta.In extremis foliola vngules role os imitara, ftellata, luteos vmbilicos atris pütiis mact:latos afterrs attici ambiētia, odoré Gümi Elemni ant Refinx, aut Cedrini ligni quod adoletur, cdunt. Semen Pyrethri longum, comprefü, \& hirftitie veltibus harens. Minoris hac notitix. eóq; minoris vfus: vulneribus introfumpta prafcrtin plurimùm confert. Et eadem qua luperior potis eft. In Anglia vbiq; vdorum, pręfertim Londini \&x Auxonę.

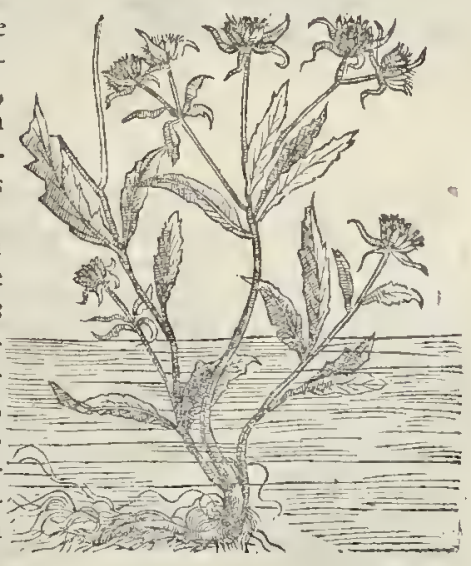

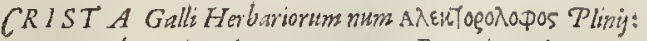
an nitm potives $\mathrm{A} I \mathrm{~L} 1 \mathrm{~A} \mathrm{R}$ I A Recentiorum?

Galls centrum inferius adducitur. 


\section{8}

STIRPIVM adner Tarianous.

P R Op re R folia qux criftr Gallinace ęquiparantur $\alpha \lambda$ entó $l$ nietiam Plinij xtate dicebant, vnde noftri fortè iftan pratenfem luteorum florum partormn 2 folonm denfo anicu faltigiatan in Crifts modum multipla \& denfe ferocioris Gallinacei conectarunt, aut retinuerunt, folijs vtiq; magis fuadentibus, quæ ex aducr fo bina ambitu diuifur'x prorfun criftatx funt, fenfinq́; à medio lariore in anguftius definune crifteritu . Caulis tenuis, pedalis, fefyuipedalis, refus è radice exili, pratorun pracipue amantis. Semen in vtriculis foliaceis vel filiquofis, tencriuculis, Pfeu donelanthij, fufcum, compreflum, rotundum : nullodum tamen experimento oculis prodeffe, aut in cos indi compcrtun habemus : Vulgus etenim non iftud, fed Scarleç lxvius \& lubricius folet genas inter \& tưnicam inferere femé, \& huc illucq; oculü verfädo, ducere, nullo moleftix fenfu. Hanc etiam Centrum Galli dicunt, quibus ad duellum fie incitamentum, \& fi flotes non parum ad crifx nomenclaturam alludant. Nulli non pratorum \& agrorum marginibus multa, guftu fubaftringente.

\section{ALLIARIA, Pes Afini Pandectari, an Alectorolophos'Plin?}

PER I N D E vulgarishæc, itidem Diofcoridi prxterita putatur,quòd neminem odor

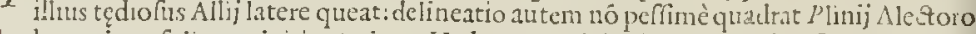
lopho:quippe folia per initia circinata Hęderx terrefiris lógiora, altiúg, ferrita euadüt, funbriats, acutis in ambitum denticulis, tota planta Vrticam referente, preterquàm filiquis, Napi femine plenis, nigricante, vt vult Plinius. Flores multi, albidi Ironis : alba radix, nultos caules bicubitales fundens . Tota gufn calidiufculo, humente melioreć; odore \& gratiore quàn Allij: Quò fir vt mulic reulx, pręfertim Anglix, folia fucculenta, tufa, fal fancutis \& intinctibus frequenter mifceant, multumǵ; ad incolumitaten annuam tuendam primo Vere comedent. Quare fi quis vires confulat, hanc certiorem dicet quảm fuperioren,cuius vires multun abfüt ab Alliaria. Hæc auté Erifinum aut Erucam facultate refert:quare tufsientibus magis proderit, st placet Plinio.

Cæcerim Septentrionalium ftrigofa macilentáq; prata montofa Norbonenfium palpedicularis A- maren pufillan quandāhabent, floribus Alectorolophi fuperiorís, plurinùn rubris, inlectorolophos. terdum albis: nosinte. Filipëdulas dicemus, quorum folia \& facies imitatur: Sed facultatibus virolis, pratis in felta, \& pediculis holtis, quare quidam Pedicularem vocant.

\section{ST ACHYS, fpicatus circinatoóg, ambititu cinctis floribus purparis culacers.}

DE culmorum floruná; verticillatis fpicutis extremis dictam fuiffe 5 x́xup fiue Spicam: certir eft: vinde coniectura non perinde vera vt folerti periloctus \& modeftus Anguilfara Spicam Lamendulan opinatus fuit: Senenfiautem hic mod:ratio defuit, qui fornendo meliora rum iudicia, tum plantas, ftam intrudit Stachyn, Marrubio quidem non ita difsinilem, fed neutiquam fpicatam, nec adeò congnum, yt eft ea quam Germani fels 2kidozer vocant, id eft, Sylueftre Marrubium. Eius fiquidem eft perfimilis, procerior a caule quadrato, craftore, candidiore, \& hirfutiore : tumq; folijs longioribus, nonnihil ad effigiem \& incifuram Betonic $x$ vel Ballotxaccedentibus, plefculis alarum ramulis quadratis, quos flores purpurei partim verticillato ambitu, Marrubij ant Lamij ritu, difinguut, partion fuperiora fpicant Hyffopi vulgaris aut Betonicx modo, quan Dioforides fpicatam fummis caulibus Satureix funilitudine dicit:Hxc pasim f conte in Norbonæ afperis, non procul Peras \& Magalona occurrit : interdum purpureis, aliàs luteis floribus:odoratior, gratior multo illa quam Senenfis prioren \& Germanam ratus fuit * 


\section{3e STIRPIVM aduerfarianond.}

cant, vti Betonica. Itaque verifimile antiquuos fuum Ceftrite quafi Betoniceum dicas vinum foribus \& folis, non item radicibus inditis parafie, eóque fic faciendum hodie illis qui cafcos longè faluberrimos \& fapidifsimos hic in Anglia \& alibi parant,aththores fumus, non modò enim renibus innoxii funt tunc futuri, fed etian profuturi.

Quxdam enim nature maximè eorum fu iuuantur, \& muccum pituitofum in lotio mingendo euetrunt. Eft enim diuretica \& Litontriba, vti Galenus libro nono de fanitate tuenda innuit, qui inibi $\sigma \alpha \rho^{2} \phi \dot{\alpha}$ yog , aut Saxifragam nuncupat. Sicplatearius Ceftrum Meum dixit, ob confimiles vires diureticas. Betonicas aut Vetonicas, tum $\mathbb{E}$ ginetæ, tü recétiorü, Tunices, feu Garyophylleos vocatos, quia multò diuerfí funt clafsis, fuis quamque familis reddemus. Gens enim Vetonum ducrfis plantis, vt res \&̈ occafio ferebat, nomen fuum accommodarunt, vt de Plinio \& proximo capite liquet.

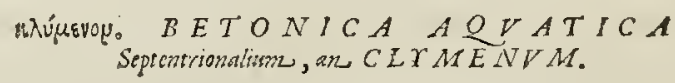

Angli. poater betone.

O V A $\mathrm{V}$ I s inclyto Regi Clymeno illam cognominem decreuerint, Cicilianam feu totam Sanam Gallis vocatam, dequafufus alibi diximus, tamen \& hanc Clymenon putatam, experimentis celcberrimā Vigoni Chyrurgi, tum opinione percelebrem, decuit luc adduci. Eam enim defcriptam is autor mpente collaudat, ac eius natales propé Genuā, cuius ciuis fuic, ad fonrem Labromadore, fnie equorum aquato: rium difum, indicat. Amat quippe non fecusatque Betonica vmbrola, fricida, fed magis humentes elices \& crepidines fof arü, qui hacfatent, in Northmannia \& Angliz przfertim, Idcirco Waser Betony, feu Betonicã aquaticã vocant $A$ nglı. Edit quadratú, ruf cum caulem, bicubiralé, geniculatum, canum, \& rectum, crafium Bctonica: foliz ex viridi nigricant,ambitu, figura \& crenis Betonicæ, aut Scrophulariæ, fed maiora: alæ nonnulla in fummo funt, Horibus nigricantibus purpureis pufillas cafsides imitatis; vnde femina pufflla in lagenulis Blattarię, aut Digitalis purpurex. Fufca radix,multú fibrofa. Clymenon etiānum hodie propter infignes vires putant, nifcentó; vulnetariis \& vlceribus prauo humore imbutis, deterrimiqque humoris \& dolore fauciis. Vulgुs Chyturgorú fua mundificatiua, quz ruptica vel abfterforia dicuntur, ex eadem parat. Cruribísque cute erolis admolent foliz.

$$
\begin{gathered}
\text { SCROPHVLARIA MAYOR Millemorbin, } \\
\text { Ficaria, Ferrarin fiue Caftringnala. }
\end{gathered}
$$

$$
\left\{\begin{array}{l}
\text { Germa, Baunzoutts. } \\
\text { Belgis. Stcentruyt. } \\
\text { Gills. Grande Scrofulaire. }
\end{array}\right.
$$

X $\mathrm{O}$ potell non noffeScrophulariam à radice factoćtue vocatam, qui proximè díEtam Betonică nouerit, non enim ouo ouum fimilius: fed radix tuberculis afpera \& capitulis papillofis donata Fabar1æ, aut Alabaltritıdis corraliux diet $x$ : alba, folida, ftrumofa, incondita, fubtus porrecta cefpite, obltat quò minus interdum ctiam exercitatiores inter legëdum vtramuis pro altera euulfam accipiamus. Huic tamen foilia longiufcula natales fylua \& nemora vda, vmbrofa, monto 2 . Calidior etian hac vtrauis Betonica \& vlceribus ftrumolis, cauernolis, cadauerofis, carcinomatis, atque depafcentibus fideratis oportunior. Tuberculis infuper ab humore frigido glaciatis, aut fclurris carcinomata minantibus, difcutiendo \& emolliendo opitulatur.

$$
S E R R A T Y L_{1}
$$


conte tr.t, Verb=n

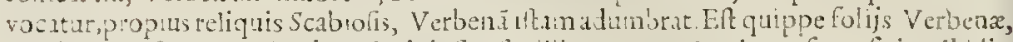
melurs per fumnaltiorbus, laciniolis, limilibus tumen, se altcra fupcrficie albidis, ad terrun ttatis, latioribus, mums fertutis. Caule plurmum afurgit reftó peden \& cubi tum alto, rracili, fupeñè in ramulos rcetos fparfo:hilarillores, rotüdos villofósq; cx crefio coculeos vel glaucos, Morfus Diaboli: femine comprelfo, radicc pufilla, quantus paruus digitus, paru n fibrola.Propè Monfpcilij Egidi.um portan ad riuulum, \& agrorum margincs Norbonx plurima. Etiam in Apcninis Bononix meminimus: eandé Angli \& Belgi hortı habêt. Hac plurimùm vtuntur Monfpellicnfes Phar macopœi, propter inibi matoris Scabiofx penutiam, non modo ad fanguineum ferum putrudum edncendum, dcfecandumá, \& Thoracem pulmonéfq; congerie pituitola expediendum: fed etiam ad Morpheas Arabicáf; Elephantiales, \& Græcorum lepras fquammulásve, reprimendas itcm impetigines ex aceto Fumatia incocta, facri ignis cxcrctiones, pruritus, cutisć; fcabres fochs: quas dotes fermè omncs Drofcorides Columbarix vcrbenx iudicabat, nólö; enar 1auimus, ne fi minus placerent lectori illius tanti viri contecturæ, noftráq ; commentatiuncula, raltem planta huius $\vee$ tilitas tanta foret accepta.

$$
\begin{aligned}
& \text { SC AB IOSA mitior, Satorems tulsation, finte } \\
& \text { tãgx Astin? }
\end{aligned}
$$

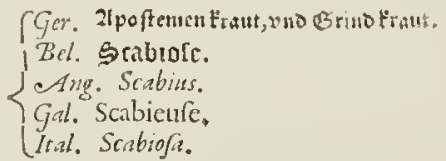

Vuloarem non nonit Mathio

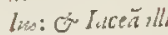
nigram maiorã lairiofamine cons luffect .
ET quamuis pluribusplantis pofsit accommodariscabiolçnomenclatio, (non fecus: atq; Pfore E tij) vt Iacere, Morfu1 I.)iaboli, fimilibus facie \& viribus: tamen non eft de nihilo quod vulgus tan diu ittis Scabiolis id noninis vindicarit: vnde propenfior eft animus é vt auguretur quampian harum Etıj Pforam effe, quamuis nufpiam extare apud antiquos meminerimus.Sed maior Scabiofa notior eft apud omncs, quàm vt delineationis egeat, confinili fuperion is vultil, fed latioribus folijs, pullis, hirfutis, inç; terrain repādis \&recumbentibus, \& altioribus incifurts, necperinde Verbenam Sacram, vt maiorem Valerianam cxprimentibus. Radix fimplcx, longior, caulem plurimùm fingularem, cubitun \& fefquicubitun altum fundens, \& fornm cęfariem villolam Cyaneo purpurẩ imitantem, in fegetibus, planis, \& decliuibus letior dcgit.

$$
\begin{aligned}
& \text { Media SCA B IOS A ferrato,anguntifolio? } \\
& \text { flore globul rie. }
\end{aligned}
$$

I S S M I I I o R aliquantò hxc maiori Scabiof $x$, quàm priori, minima Verbenx putat $x$ : in marginibus agrorum Septentrionaliü lxtior multò, \& maior adolef́cit, quàm: in calidis. Caulis è radice exiliore, fimpliciore, cubitalis, alis diuifus, folia Iberidis aut: criftæ Galli, aliquantun ferrata. Flores Globular ixautScabiof

Scabiofa $A L P I N A$ MAxima,montis

InYA Co SaleHe.

Parum 


\section{STIRTIVM aduerfarianoud.}

TOn parü fpeciofiorem \& maicré hanc èiugis oriun. dä Iurę \& Salanę nobis imperti uit fingularis amicus D. Penni 11s, ea Morgano hac seftate flores perelegantes cafios velleris inftar fericci,ftaminulis crebribus amiciétibus globulos echinatos, Dypfaci, rotúdiores, minores, alpectu hilares, \& $\mathrm{Sca}$ biofx vulgaris duplò maiores : folia ité Scabiofe, altero tanto ampliora, altius incifa, \& Ccntaurio maiori Belgatú fimilia, penè pariasangulóos ab imo \& numerofos bicubitales \& tricubitales caules, multis alis duuifos amplectétia, per xquas intercapedines, iuxta fingulos exortirs alarum, cano protus berante \& rorem excipiente, Dypfaci more: guftu nihil diuerfum à cxtcris percipitur.

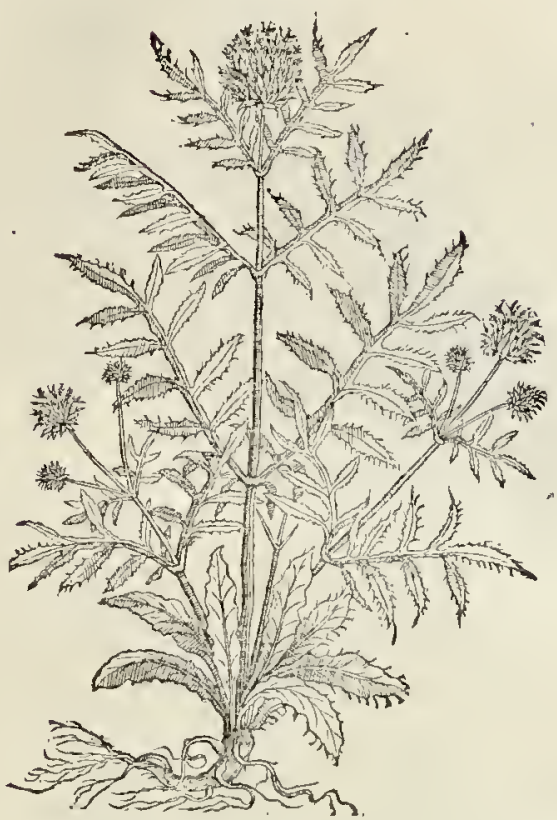

MOTANA calidarum regionum maior.

$\mathrm{CO}$ I I E s A M A T hac plagx temperatioris,vt Pedemontis propè Riuoliam, \& CNorbonz, ybi montanam vocatam Herburii folio angultiore, albidiore, partm hirfu to lenuifque laciniato ad imumi caulem Verbenacx, aut vulgaris Scabiof $x$ : faperiora verò in ramulis plufculss, gracilioribus, altius diuifis, \& flores per Iunium \& Iulium promentibus purpureos Scabiof $x$, parux, aut Jacex capitulis fquammatim compactis, vbi femen tıjolii Afphaltitidis, pullú, copiofum, inuolucris membraneis arguta cócinnitate effictis, angutiis plicarum fornicum pufillorum cohibentibus.

Iandiu eft quando in hortis Herbariorum Belgarum quandam nultò maiora fundere Verietres. folia, teneriora, crafsiora, fucculenta prafsina caulibus \& floribus, duplo maioribus, nec iam elfécne diuerfa fpecies ab illa, fuccurrit.

\section{LIONTANA onnium minima.}

HAr $v$ M omninm minimã hanc animus fuiffet verbenä paruam facere, nifi in montibus cretaceis $\&$ iacultis obuiaforet. Nam fefquipalmum pedalésve paucos edit cauliculos, folits in imo fxpius donatos anguftioribus, inter Sefamoidé \& Scabiofam minimam, floribus dilutx purpuræè fquamolis capitulis alterutrius non diuerfis,

V.iij.

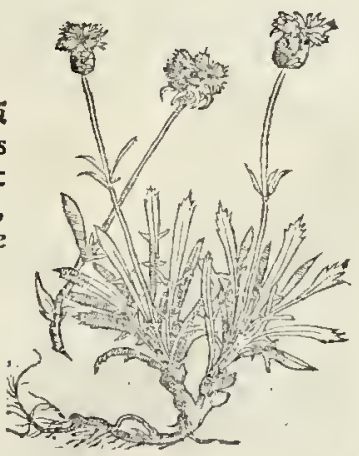

IA 
I ACEA NIGR A vilgatior Praiticantium: Alba MTonpellienfum in Ocymorde dict a furt.

Hrosciais Plis.

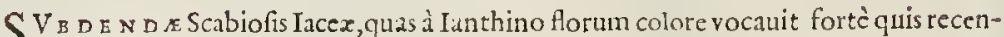
tiorum Grxcorum : tanctfl barbaris Practicis duntaxat notæ fuife videntur, qui nihil præetantius ad hernias inueniffe lacea nigra narrant. Errat oppidò Senenfis, qui hujus facuitates Violx flammex afferit, \& a Scabiofis difcernerc nefciuit, à quibus non minus diftat quàm Morfus Diaboli ab illis: \& Iaccæ fapor non perindc ingratus, fubdulcis aftritio, ficcitas efficatior multò, calor prope nullus: fed dccepir illum nomenciatura

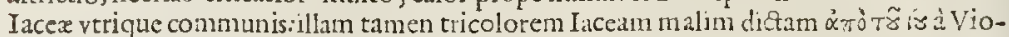
$I_{a}$, vt etramnum vocatur, quàm quòd plurımum humi iaceat, vt quidam autunans. C.xterum, qui hanc Plini Hy ofciridcm duinant, fereadi funt: tametfi pluris ducant viriu'n quìm effigici coniecturam, cùm vtraque confentiete fit opus. Intubo dicit Plinias fimilem, minorem, taftu alperiorem: vulneribus contufam preclarè mederi. Q:tx ve nihil certi de figura afferrent, tamen quandan plantam finilen opis iftufmodi, indicant : neque enim Serides funt tantx ad vulnera laudis, quanre ifta I o v I A Seris pliniana, zut Iacea noftra eft: quam duplicé, nimirü albam \& rigram prafici vfurpant, frequentior multò nigra, notiorque, pratis \& inculcis malta fruticans, folis nizricantibus, hirfutis, rigidis, à radice multis, fed in caulibus cubitalibus, \& fefquicubitalibus obtufioribus laciniis diffectis. Flores ex purpurco nigricant, in ventriofis posulis Equammulis compactis, femini Cyanci, aut Cartami.

\section{ACE A maior folio multum luciniofo, Dert is Leonis, mainf Culi varculis, floris putpurei, of lutei.}

SE G T r M hæc potius quàm pratorum eft, in Gallia \& Anglia plurima al tiores cubito $S_{\&}$ fefquicubito caules edens, circum quem folia multa inultumq́ue laciniofa Hiel scii modo funt; globulos duplò maiores, communiores, turbinatos, fquāmulis loricatos gerit,apicibus fiorum purpureorum obductos Cyani maioris. Radix dıgitum xquat, lignofa.Semen item Cnici, minus : horti Belgici hanc vt præftantiorem ad vfim Medicum colunt : tametfi in Anglix fegetibus Couentrix conterminis abundè proneriat.

\section{ACE A maior lutes.}

ONT E R DVMeandévidere eft in legetibus $M^{\circ}$. fpelliacis, floribus luteis, venuftis: Carthami

Farients. fylueftris nullatenus diuetfam, capıtulis, foliis, aut caulibus : Nifi quia tota afperiufcula; quam qui malit Plinit HYOSCIRIDEM, nobis fecundis, liceat.

\section{CAPITVLIS SPINOSIS} I A CEA.

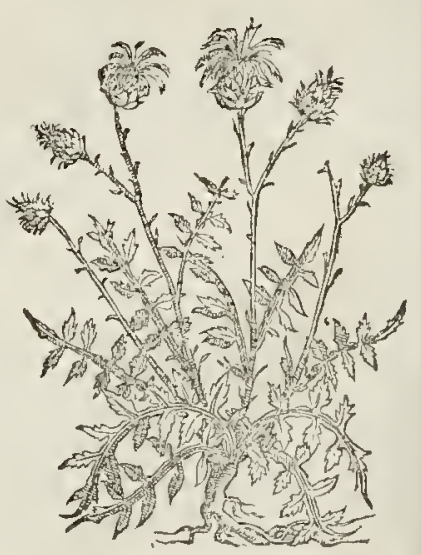

Varictis,

A D Cellam nouam \& vicinis rinetis Monfpellii minor fponte vifitur alia, nigra eadem protfum radice \& effigic: duntaxat triftiore afpectu, florem cdit purpurenm interdum album, in fquammofo \& fpinulis horrido capitulo, Calcitrapa haud abfimili. หúavơ 


\section{STIRP IV $M$ adwerfaria noua. \\ I A C E A pumilla, bumilis, ferpens, acanlis fermi, flore \\ Cyaneo or albo.}

R A R I s occurrit hxc, \& ferè Norbonenfium eft:

inarginbus fatorum ad Pontem Monfpellio milliare difsitum, via qua Frontignanam itur, obuia eodé in aruo, vbiftudiofi folebant $P$ hallarides colligere, folis eft paruis, laciniis Hieracii, retufioribus, minoribus, vnà cum cauliculis dodrantalibushumi fratis : flores \& capitula Cyani prorfum, cerula minus obfoleta purpurantes, vel albidirradix crafsior, \& femen cęteris non abfimile.

\section{Incandaltera C Y A N I aut I A C E e, capis} tulis of flore.

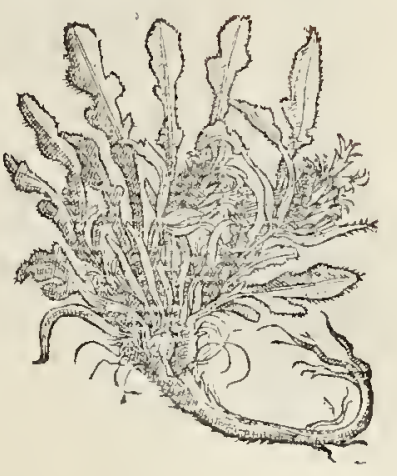

PR o p I o hac Cyano quàm Iacex: vtrique tamen had abfinilis, quam quidam $P$ tarmicam, fiue fternutariam arbitrati funt, propter $f_{2}-$ porem acriorem, annarum, halitum q́; tetrum,cerbrolternutamenta interdum extorquenté. Non ita multi funt ann , quum prinum in Linguagotix vinetis, $\&$ cis Cellix noux $M$ onfpelliacx $P$ ontem plurimam, iamq́ue in hortis plerifque Anglix v berè pro pagatam videmus, ab viza radice $d u$ riore, plures caules emittente, totam hirfutie pilofam, incanä, Gnaphalii foliis triplo maioribus, crebribus, leniter ferratis, ab imo multis ad vfque fumma, oblongiora, acutiora, graciliora, fquãmulis albidis compacta capitula Cyani, aut Iacex apicibus villofis, ex purpurante paleo colore in pallidum languentibus.

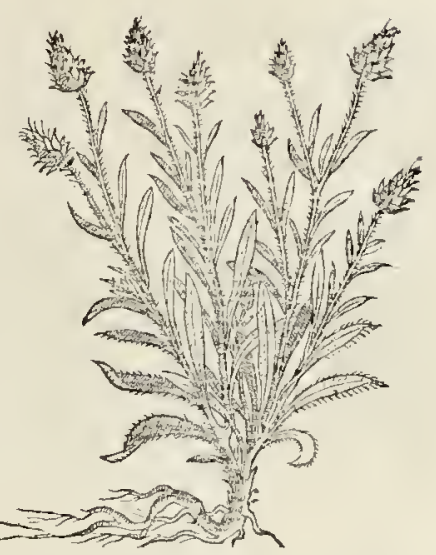

\section{MORSVS DIABOLI.}

$\left\{\begin{array}{l}\text { Germa. Zeuffels bifs. } \\ \text { Gallis. Mors de Diab. }\end{array}\right.$

Gallis. Mors de Diable.

CAng. Dewellesbit.

N O n video quid negotii fit hanc non effe è Scabiofis vnaun probaire ; quod quidatr contendunt:verùın adeò Scabiofis eft fimilis,vt plerunq; pro iifderi accipiatur : eurdens tamen difcrimé in radice, ä qua tota ¿euffels bif nomen Herbarii retinent, nam antiquis non debetur. Cùm itaque fit multis crarsis fibris fparfis, depacta, precifa apparet quà crafsiores coëunt fibræ plures, quafi pramorfa foretà quopiá cacadęmone: tametfí idé férè cernatur in plâtagine, quare malunt alii diçáa ab vrida vi qua mordicat bubones \& carbunculos peftilentes, quibus magno lemamento admouentur. In pratis \& viis quibullibet occurrit multa, cnbitalis \& bipedalis : foliis Scabiofx vulgaris, fed rigidioribus, nigrioribus, hurfutioribus in imo, in fummo autem caule aliquantum ferratis(non profundè incifis, vt fcabiof $x$ ) : Horibusitem prorfum $S$ ca. biof $x$, fed purpura fufca, triftiore a $\{$ pectu.

$$
\text { V,iiij。 }
$$

Grm. 
Germa, Coznblumen.

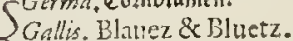

Zital. Fior Campeje.

\author{
Selgis. Eascinglaener. \\ SAngl. Blew Bottell.
}

CE z e T is carulc̨ xmulus color flori inct Cyaneo, fic vocato ctianı apud Pliniti:

Blaptifecula vulgo, Bluctz \& Blareetz dieta Gallis codé à colore: etiạ̈̂, Gernanis Coz:1= blumen, fiue fegetü flos: quiaimportuno luxu fegetes vbiq; prater câteras Secalis palsin Frrague propin- propemodí cnecer, prxfertim frigidiufculis terris. Hutus diuerficates infigniores Erragutor Scabiofis tici \& Hortelis. Ille in caule angulolo cæfia albicantiáuc folia, angufta, in arctum deciné\% iaccis, guam tia, acutislaciniis finuata $S$ cabiolx, aut Dentis Leonis more gerit, capituláque oblonga 7ntybis. calycis effigic fquämatim foris cópacta, exaccrofis tefsilis nitidis, è quorum inedio cxrulei erumpunt flores fenis plurimum foliolis, fenen fub meffem relinquentibus, angulofum, acurum, oblongum, \& hirfutie obductum ghuca.

\title{
Cr ANVS Maior bortenfis.
}

$V$ E a alterum Cyantm alnut horti onidam in Gallia \& Germania,non ita diuer 13 eft folis, fed muoribus, latioribus, flaccidis, minusq; laciniofis, id Lychniciem, aut Flomam paruam lirfutie \& mollitie accedentibus. Nec flores diuerfi, fed maioles, fpeciofiorcs, faturioréque im purpureum vergenti cornlco:radix longior, \&e viuacior, quàm fupcrioris.

$$
\begin{gathered}
C Y A N V S \text { minimus viticulis Spartcis firiatis, copiofis, perpufllis } \\
\text { caliculis, flore purpureo objolcto. }
\end{gathered}
$$

TOR в O N E N $s$ I s itcm opulentix videtur hîc Cyanus, nec perinde obuius, nifi ftrigo 1 fis, aridis, propè Monfpelliacum patibulum \& Caftrum noum. E radice lignofa ramofos valde cmittit \& vimineos graciles fparteos pedales, duriores, lignofos, multis alis divifos, pilofos, incanos, vti \& folia pufilla Cyani, aut Iberidis, aut Scubiofx parare montanz diuifura : fores afpectu triftiore in cornulis pellicula fquammatim confertis quadruplo minoribus,numerofiotibus. Calycibus Stxchadis citrina alterx paribus.Cyanco guftu, now perinde, vti fuperior, amara. Semina non difsimilia,

$$
\begin{gathered}
C \Upsilon A N V S \text { peramarus, repens, copitulis foirarofis } \\
\text { Sefanoidis parui. }
\end{gathered}
$$

M I N v s obferuata hxc non aliò quàm ad Cyaneü aut Iaceä referëda, fed habitu ipfo \& afpectu fuperficiei proximè fuperior is fimilior occurit (nec nifi qurenti) fubterque Sefelı pratenfe mulos ad Sellan nouam \& al ibi agri Monfpelliaci reptando latitat: foliolis oblongis, angultis, Lauendul rigid is illius planta, quam incan is, albidis Cyani \& Jaccæ mediam, vna interiecta planta, proxinè defcripfinus, fimilibus in cauliculis gracilibus, viticofis, pal maribus, pedalibus, \& fefquipedalibus: quorú fingulis fummis ftaminci flores finguli Iacex, obfoleta purpura, è poculis fquanmofa infertione conflatis prodeunt. Radix digitum parum æquat, Tota planta guftu perquàm amaro \& ingrato.

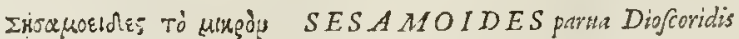

$$
\begin{aligned}
& \text { fquammogis lucidis capitules } C \text { yaneis, flore carulco. } \\
& \text { Alind o primi Diofcoridis rutaceis foliys, cim Hamala } \text { Or }^{2} \text { Rutis. }
\end{aligned}
$$

E X A C r E poteft rquiparari Cyaneis Sefamoides, à feminis Scfami fimilitudine, adeog̨ue vfu, vt nos putamus dictum. Iamǵue multi funt anni quum verum minus notum 


\section{STIRTIVM aduerfarianona. 23 s}

$f_{\text {uit fcholx Monfpelliacx profefforibus eximijs }}$ Rondelletio \& Afratio. Siquidern lineamenta perpendas, folia funt Cyani parui prorfü, incifura $\&$ orth Coronopi, lurfutiora, maiora(tanetfi fortí $\mu \alpha$ uote $\rho x$ legendum, vt alibi crebrius monumus) fores radiati prorfum Cichorij concolores \& finniles fupernè, fubtus capitula fquãmulis compilta Chamælei lęuis Theoph. Cyani aut Iacex modo habentes. Semine intus Sefami aut Cardui minoris : radice Tragopogi, exiliore. Cómentator nofter cum fuis Belle ast pulantibus om. nibus ex imagine aut potius ignaiuię, notis, huic Phalaridis flores \& capitula commentus eft, \& affingit, fuo ne, an fui Thefci errore, nefcio $:$ fortè quia qui ill pettam mi ferat à nobis Patauij ficcá habuerat: Tametfi in Italia Longobarda non infrequentior qquànn Norbonéfi agro plurima fqual Indis collıbus, ¿e etiam herbidis ad Lanum.

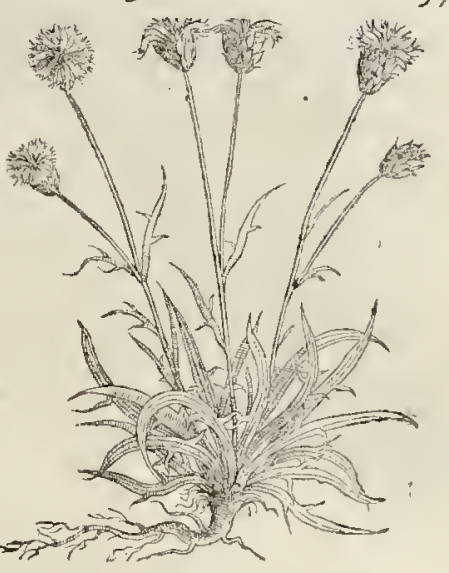

CHRTSANTHEMVA fegetum folio multriesßo.

CONs:1 cv v m aureum florem ifthęc fatetur Chry fanthemi appellatio, ciufmodi eft fanè ille, quo fegetes frigidiorum tractuum Gallix, Germanix; \& Anglix fcatent; fauam por mefles Cererem ornate, ac mà cum Cyanei a Papaucris Rheadis foribus in fternente, magna fpeetatoris voluptate, quafi tricolori tapeto. Regionibus aftuofis rarius. Caulesilli tencri, glabri, vitentes, plufculi, rotund, fefquicubitales. Folia crebra ab imo fennunciam lata, toto ambitu Arthemifix modo \& crebrò incifa, pallentia, tenera, viridätia. In fummo aurex orbitx nonnihil fulgentes, latiores, comprefsiores, Anthemidis; bollidis matoris, \& calendulæ fimiles. Oleracea eft guftu $\&$ nomiluil caloris indicante, ei tamen parcit pecus in Anglia,nec item olere manditur: ac illis fignis deficitur, qux in Calèndula graphicè Diofcoridıs Buphthalmum exprumunt.

\section{CALTHA Poetarim 0 CHRTSANTHEMON ocrulatum verius Diofcoridis, Calendula Offici.}

V I P P E noftrâs Kalendula quin fit Poetica Caltha nullus neget, qui in Georgicis ĹtuteQ olum Caltham, \& 111 Plinio grauiter odoratam leget:Columella auté Buphthalmum hanc innuere videtur, vbi fanétia lum ina Calthæ canit, nempe aureum rutilumáf; flanorem, \& orbé circinnatum vunboneós in centro extante cófpicuo, luminis, fiue oculi jin fpe ciem. Vride Cachlan, id eft, hiantuian \& apertann dixerunt:fić̣; Caltham putet quis decifim à Calatho (vt Melyphylló à Melifophỵllo)qui quafillus Latinis, Seruio tefte, poculum \& calyx eft, cuinfrnodi oftentant fingulis fermè Calendis Calendulx flonm pocula flaur: : cuivs \& nos funus fententix, à quo hifce falebris permultis perplexi, difcendi caufa Monfpellienfem Epifonpum Gulieinum Pellifierum, DiofcorideæPlinianxó; lectionis mirun quantum auidum \& pertum, Magalonx audire meminimus (inter comp'urà loca partim hiul ca, partimć; luxata, qux ille interpolabat) diftinctius legentem, liunc in

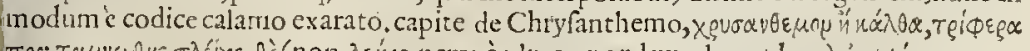

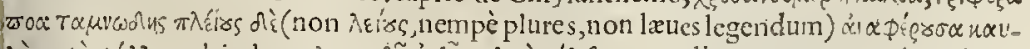

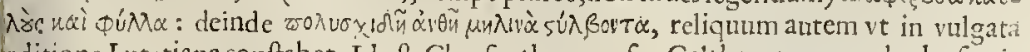
feditione Lutetiana conftabat. Id eft Chry fanthemum feu Caltham tenera: herba fruticofa plures (in vulgatis læues) ferens caulcs \& foliz: tum multifidos, id eft, crebrò, aut

ฉวinu- 
2,8

minutim fifos frorcs lutcos, admodum ́plendidos vel rutilos, magnos oculos (non bouss) exprimentes: circá́; oppida eandem nafci, \& olere mandi. Quam hac cẹfura literam Calendule feu Calthx rulgatre componëtes, tim plenc̀ \& exacè vtramq; vtrauis indicari, vt nec herba alterius de: criptionis, nec detcriptio alterists plantæe egere vifa fuerit. Etenim fruticar Caltha Galloproumcix \& Norbonx cum multis in aruis \& incultis propter feretes \&s oppidorum rudera, tum Monfpellij,paulò viterius figido fonte aruis vrbi conterminis. Caules c̀ radice parua, fibrofa, complures, fparfi,tencri, læues: foliáq; Leucoiji flores cxinio fulgore nitentes edüt, vel ctiā rutilos (lic enim súd Boy Cicero, rutılum Murtis ful goren vertit) oculi anplum orbem effigiantes, argutis minutifsimisq́; crenulıs

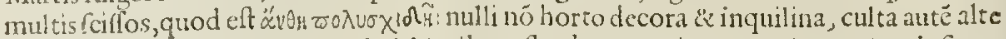
ro \&ertio tăto plcrioubus \& habitioribus flotibus paucis coronarionum tpeciofitate fecunda. In cibum etiam cedit \& iufculis inditur, guftu \& odore nóingrato:acetarijs etıá

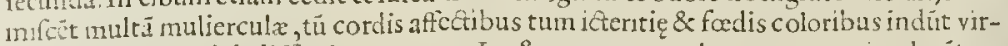
gunculx, refpirandió; difficultate vexatx. Ius \& tencræ cymx luteo ouorum in placétam cxccptæ \& manfa, ninis inenfes fluentes fiftere, cunctantes autë impellere compertü eft.

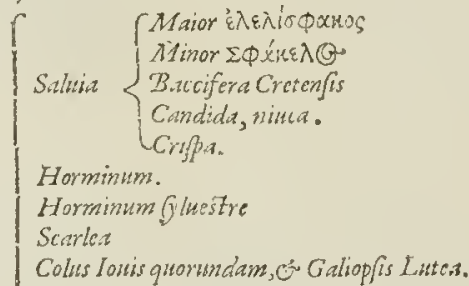

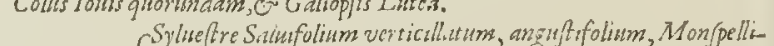
enfum, an Phlomos Lychnitis, fure Lucernaria Diofo.

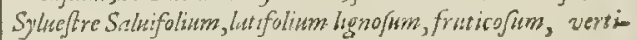
cillatum lutcoum.

Verbizcum Saluifolum purpuretion.

chas.

Fomina.

CMaximuin odoratum.

Nigrum odoratism Luteo flare.

(qpurpurens Ericiefolims.

Attryopis.

Blattaria Pli, an Chrygoronum

"Primule Veris an antiguorum Plslomides ine Terbafcull?

Primula Veris pratenfis

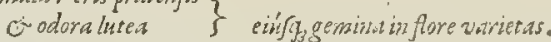

Trimula Syluarum, eius triplex variectas.

Sanicula altera Alpina fine Auricula Vrfiflore purpureo albo es luteo.

Baccharis.

Digitalis $\left\{\begin{array}{l}\text { Purpurea. } \\ \text { Luttea. }\end{array}\right.$

Helenium.

Helenium fccundum alibi.

Buglogium Diofc. Fute Borrago recentiorum.

Buglosum vulgare anouflifolium.

Borrago fempervirens.

Buglo Sum peregrinum radice mult if da Tulmonarie.

Bugtoßsum erraticum, Echioides apperum.

Anchuse $\left\{\begin{array}{l}\text { Onocloides. } \\ \text { Litea, } \\ \text { Tertia, } \\ \text { Quarta, , ff Lycopfis. }\end{array}\right.$ 
Valde variat etiam iu Anglia, vbi farmenta quedam \& palmites eiufdé plantx partim fpadiceo colore, partim candore plufquam niueo vifuntur \& folia quafi pellucida. Qu $x$ nonnullis etiam rugantur, \& fimbris inultis in ambitum crifpa cernuntur, non fiue vo luptate.

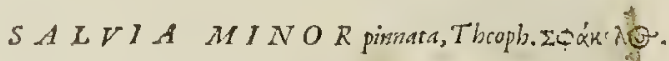

Germa.Clcin Galbey, edel Gnlbey.

Ftal. Saluin minore.

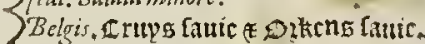

CAng. Latle Sage.

I I E R A rerò differentia, qux auritis, aut pinnatis eft ad imum Circex modo fo$A$ liis,minus fquarofis \& coriaceis, ninoribus nuitò:eó́ue nobilem dictam, \& $S$ phacelum putamus, nec vllam eius varietacem nounıus : nullum en aut odore elt.

"ॄsurop. HORMINVM.

$T^{V}{ }_{M}$ Satiuum tum fylueftre notius hodic, quàm vt pluribus aferendum fit : nedum in

hxfitationem reuocandum: vtrunque inedicatum cft:fed vehementius Sylueftre ad

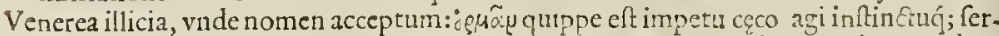

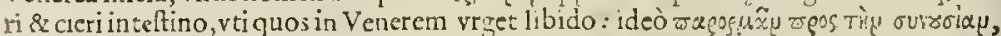
in Venerem laceffere dicit hîc. Nufquan, autem nifi in hortis cultu Herbariorum vifitur Satiuum, folis Pfeudodictäni vel Marrubii ex interuallo binis \& in fumno purpurafentibus, collectis vt in Dictamno:iuxta qux tota circum caules quadratos, pedales \& cubitales, flores funt verticillatis pyxidulis purpureis ad cæruleú vergétibus:qur hiantes per maturitatem deorfum nuunt pendulę: fcmine papauereo masore, nigro, ablongo, muccaginem aqux merio, vt $P$ fylium, emittente:ętate floret.

\section{STLVESTRE HORMINIM}

R V DE R A \& prata macilenta fectatur fylueftre difum: foliis maioribus \& aliquantùm laciniatis oris Blattarię fimilitudine \& colore: quadratis \& paucioribus virgultis, fefquicubitum altis:per internalla flores verticillati in fpicas longiores abeunt, dcorfum inclinatas, cegruleas purpurafentes: nigro, nec abfimili priori, femine glutinofo. Vtrique radix lignea: $S$ ed illius odor nullus, huius verò $S$ carleam redolent flores.

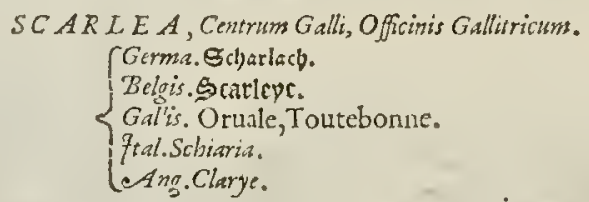

Fs $\mathrm{x}$ auten quam vulgus Gallicum Orualle, confpicus ad Horminum allufione, \& cófimulide dote rocitat notifsima: Germanicè \& Belgicè satle quafi dicas,oculam clarificans, mixtis latina \& Germanica voculis. Semen quippe palpebram inter \& oculum infertum, atque diutulè retentum, quantum eft fordium illic, illico euerrit \& rapit, quotidiano etian vnlgi experimento. Seritur, \& oritur anno poft, Iulio \& Iunio: flores edit cęruleos \&albicantes Saluię vel Dictamni : in quadratis caulıbus folia pręgrandia Verbafci, afperæadmodủ hirta, rugis \& veluti verrucis nónihil hirfuta, Éthiopidis aut Verbafci pube, \& fylueftris Hormini fimilitudine: fed mimor radix, durd \& fublutea. Semé in

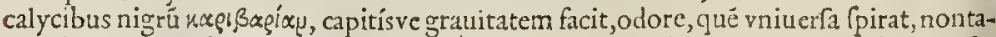
men ingrato : coq́ue magni vfus quibufdam feptentrionalium ad Zyti Bicréque confecionem: Lupuli namque vel penuria, vel vegetioris potionis faciende caufa, cortinis feruenti- 


\section{STIRPIVM adwerfarianotad. 241}

uentibus addunt; fitćue temetum, quo non multis depletis poculis temuienti funt, hilaritate propemodum infana: in nonnullis tamen, rifu qualm mifcratione magis digna. Menftrua \& fecundinas ducit, \& Venerem ciet, quare minus, quin ft Ho:mini fpecies,
refragandum.

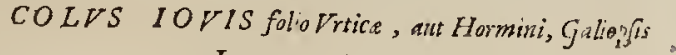 \\ Litera reccationum.}

HIs meritò accenfenda videtur ea, quann nefcio qui rei Herbarta noméclatores, Galio pfin lutean dixêre, \& Colum Louis: fumno caulis faltugio colum fluzo penfo inuolutam, nonnihil effigiantes: facie quippe Hornino propiore quàm Vrticx, ant Ballotx. E radice Lamii fimili,caules edit non multos, cubitales \& fefquicubicales, quadratos, hirfitos, quibus folia Vrticx, aut Trachelii albida, ad bafim finuata, latiora, Latia, Gallitrici minora:flores in verticillis lutei, Saluix ane Scarlex. Scaturigines vdósque fyluarum mar. gines amat, Gailix, Germanix, \& Italiz. Guftu nounihil calido, exficculte.

\section{$V E R B$ ASCVM Sylueftre Saluiternifoliun Norbonen furm, an P н о М OS LYCHNIY IS Dio?}

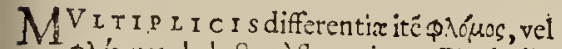
$\phi \lambda o_{\gamma} \mu o s$, deductus è fammis, aut Elychiuis, qua liuius tomento bombaceo concinnätur \& alütur, Tupfum potins maius dicunt, aut Taxú practici, quita toxicis aduerfetur: tametfi cogna ti cuncti faluiis facultate \& facie adeò funt, vt fylue itrem faluia plebs vocitet minores fpecies montofas,inter quas frequentifsima plerifque omnibus agri Norbonêlis collıbus glariofis: Mó fpellio vicinis, fruticat hic quê Phlomns Lychnitidé videtur innuere Diof. rarus alibi Gallice, vel Italia. Peramœeno afpectu florum luteorum Fabęvel Marrubii , in verticillatis circinationibus fecundum foliorum exortus hinc inde porsectis, pallidulis villis faminum, folia fcabra,crafia funt, denfa lanugine cana, afperáq; tactu \& crifpata, Saluiç Anguiftifoliz anguftiora, fed lógiora, \& ad Elychnia valde accommoda : vnde videtur Diofcor.Lychnis dicta,

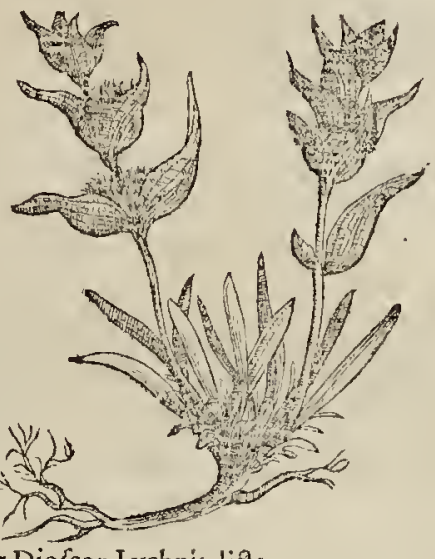

\section{STLVEST RE Saluifolium, fruticofum, lignofum.}

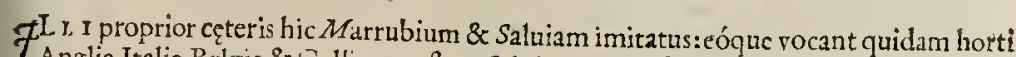
Anglię,Italię, Belgię \& Gallie, agreftem Saluiam: foliis fcabris,albidis, aliquantum hirfutis, quadrangulis, in virgis lignofis, breuibus, bicubitalibus, per internalla foliorü flores promentibus luteos, Marrubii vel Archangelica modo, verticillatim hçrentes, vifu pę iucundos.

\section{DERBASCVM Nigrum Saluifolium, purpureoflore.}

PR a I I s fabulofis familiaris hic Saluifolius, præfertim non procul Taurino $P$ edemó tium : pariter Germanix, Gallię,Anglix, faxofis pratis herbidis \& ruderibus. Folia quàm maximè Saluiam agreftem, fiue Scordeun Plinii,aut Horminü zuiulantur, fecundúmque caulem \& ramosab imo quadratos pedales \& fefquipedales nunerofi forcilis verticillati, purpurei, vel cxrulę, per forniceria.

$$
\text { X.i. PYR. }
$$


PV r P V R E v M Erucx foliü Anglix \&. Gallixe tiam obuin hxe tum pratis, tú ruderibus, quam horti quidam alunt in Beigio, cognitu \& deftin fu facuim, fol horú laciniof or Eruca, aut potius cor nuti papaucris ditifura, \& colore nigriore, ramofos cales $\alpha$ cauliculos ambiunt:fores per interualla Saluia aut Hormini modo \& colore, tora viridante \& hirfuta fuperficic. In mole templ diruti Bathoniç Angle prope Thermas, videre erat fuperiore anno.

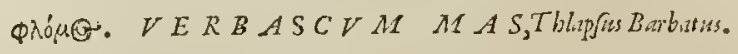

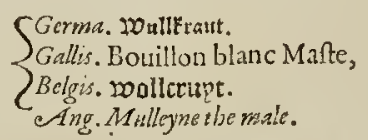

V r obfentarunt muftellas conflixife cum ferpente, peneque eneetas \& victas, pifas iito Thlapfo, \& factas denuò alacres, duel! inftauraffe, Taxú vocarút:aliogui luculenta folır ù magnitudıne, \& videndi vbiq; confuetudine, nulli nó cognitü. Folıo pręgrand, fimili, \& pari, Enulx, pube obduEtum multa \& leni \& incana, quali in Gnaphalio \& Ethiopidc. Caulen admodum procerum, trium cubitorum, î fui nedio fummo tenus fiorbus luteis ftrpatum, thyrfumque, fue funalen exprimenten, wiendum, vnde

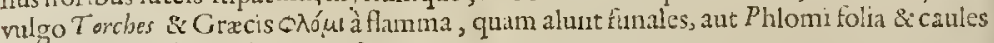
in lucernis. Radix pollicen cratsa.

\section{FOE $M I N A$.}

HA s c fr albidis cxcat floribus, \& fenis foliolis diuifs, foeminam vocant, alioqui folio confimili \& pari.

\section{MAXI MVS odoratus meridionalium, T blap bus barbatus.}

FX c e r. L I T hîc vt magnitudine foliorum, fic etiam odore fuaui, omnibus Verbafcis: tametfi varictas tantum videtur defcripti commmis $P$ hlomifominx, vel maris: flo ribus quip pe lutcis \& interdum albis exit, [enis foliolis:quę arantur rubris lineolis, odore fuauifsimo, folio longiore, latiore: radice craffa, nec aliulo difsunilis to ta planta. In Belricis, \& Gallicis Northmannis hortis alitur. Pedimontani verò agri, Norbon $x$, Anglix \& Italıx, occurrit pafsin in campeftribus.

\section{NIGRVAI Latifolium Luteris.}

FT huius omnia penè fumilia, foliis namque Enulz inter \& Digitalem vcl Symplitum nigricatibus obfidetur, paribus, fcabris grauiter olétibus, nec incanis, flofculis ex herbaceo luteolis, ftellatis, minoribus: femine item Papaneris minore, Digital is ritu inclufo: c̀ radice xque cxter is magna, caulisgracilior Blattarix cubitalis. Praris Brabanticis, fabuslofifque \& herbidis, atque in Francia, \& Anglia, Iulio \& Iunio fponteprouenit.

\section{AET H IO P IS Qhoú́ors, fue Pblomitis.}

HV c nomenclaturam Magica futilifque mendaciorum magifta fupcrftitio comméta videtur, quòd iniecta flumini folia quantú effet aqua exhauriri crederetur: tametfi verifimilus, quin optima ex Ethiopia adueheretur: nifi fit dicta, quafi fuliginora cine-

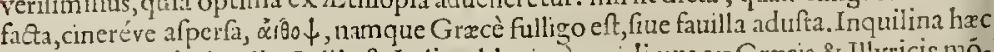
hortis Gcrmanie, Anglie, Gallie, \& Italix:vbi primum vidimus ex Grecis \& Illyricis mötibus maritimis allată, iamá; fatis vulgatä effe, \& cognitu facile, Thlapli barbati admodú fimilë, cóftat, Magis tamé incanis, mollioribus:carptaq́; delicatiore lógiore lanugine, cufinic, cof tat, Magis tame incanis, 2Ccu- 


\section{STIRPIVM aduerfarianoti.}

accubantibus, \& ambientibus quadratum, hirfutum, binum pedum, \& fefouicubiti, mil tas in alas fparfum, qux fecundum lógitudinem verticillatim flores anbunt Scarlex at Hormini: fed albidi, \& femen non dilsimile. Radix cognatā Verbufei naturam teftatur

$$
\begin{aligned}
& \text { CHRTSOGONVM, an potius B I A T T R I A Plinit, } \\
& \text { quam recentionm } \mathrm{T} \text { O } \mathrm{R} X \mathrm{E} \text { N I I I L A? }
\end{aligned}
$$

A 5 aurca florum fetura diatum Chy fogonum credere par ent : Eapropter fi Blattaria longius Chry to gonum Diof coridis non eft; nulla ram planta me menoria cit, qua nou longus multo abfit a Chryfogono, quàm hęe Blattaria. Quippe denefiruticat, unultísq; fimms ramis, \& rigidis fefquicubitalibus, \& duos cubitos altis, re Q is: foliis Quercus, aut Vcrbenx : flores adeò Vcrbafco, foliorumq́ue quinario numcro, \& colore accedunt, vt $\mathrm{v}$ tralibet pro vtrauis accipere facilè fi , ctiă monente Plinio. Vcrims Buattariz flawo faturiore, \& magis rutilo, initio prafc:tim, folia non perinde incana, aut litfuta, fcd obfure viridutia. Scmen pullun, inclufum pericarpiis Lini, ant potius Digitalis purpurcx. Radix Napi aut Raphani fylueftris, alba, digitum crafla fed xtate excunte per Autumni initia, exatro foris intúsque rufercere quidam amici affrmabant; nempè excocto ab $x$ ftu alimento : quemadinodum Carduo Benediato vfi vevite videmus, \& quidem minus nodo in Bclyii \& Gsllix Habari han nodo in Bclgit \& Gallix Hcrbaris lortis, fed ctian in Taurini \& Rimois marginibus campeftribus herbidis. Amara admodum, calidaq́ue \& ficca gintanti; quare qua alliciac blattas \& tineas dote arcana nalim fcire, quim non potius (quemadinodí Abfyntho, A brotano, \& aliis amaris arcentur)ab-actum iri idem animalculum fufpicari: farctis vifcerum meferaicarūć; expedire certum: incertún verò quid ad morfus venenatág; pof- Toamesrı. fit. Eapropter qui pra hac Tormentillam feptifoliam, inter Pentaphyila memoratam, mauult Chry fogonum facere, ob radicum ( tamet fi perparim rufefcant) effigiem fores \& foila, ac denique vires ad venenata plurimi faciendas: funè per nos optionem habeat, dumnodò halce noftras coniectationés fic accipiat, vt eas; qua funt lubenter ceffura potioribus veftigatoribus, non ignauis obtreEtatoribus,

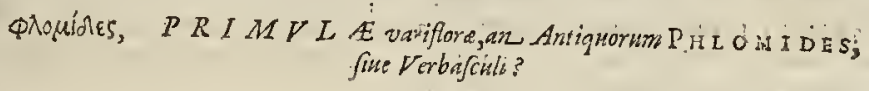

A Verna germinatione, forumque quafi rediuina vernatione, vulgus $\mathcal{P}$-imulas veris, A quia primulum tum erumperent \& forerent, vocitauit. Huius plures varietates,preertim in Anglia, lautitix \& florum delıcix amantifsima, quàn alibi confpiciuntur: quarum qui vnam duntaxat noucrit,cunctas cognitas habebit: diftant quppe Aloribus dun-

\section{PR AT ENSES Due, Pallida, Lstea odora, qua culta fit maier c flore multiplo apud Anglos.}

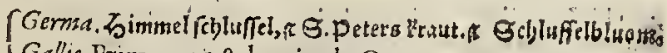 Gallis. Irime vare \& brayes de Cocu.
\{tali. Brachediculo, of for di prima vera: Belgis. S.10cters crupt.
CAsing. Colvelyppe.

VB I QV \& Is pratis vliginofis \& riguis, prxfertim regionum minus calidarum, vt Sabaudix, Flandrix, Gallix, iNorthmannix, \& Anglix, primo veris tepore florent: è radice albida, fibrola caulem nudum, rotundum, aliquantum hirfutum, palmarem se refyipaimarem, quem fummum \& nutantem vmbellx inftar, florum calyculi copiofi ornant, non difpares pulmonarix, fed lutei,cera noux odorem \& colorem amulantes. Folia

$$
\text { X.ij. }
$$

maiora 


\section{STIRPIVM aduerfarianous}

msiora Betonicz, neutiquam ambitu incifa, Digitalis purpurex yuadantenus, rugofa, ad imum ftrata, aut parum furręta: guftu non ingrato, in olere, placentulis, \& acetaris: adıodum vtilis capitı, neruis, \& humorım ex decubıru putredini,aut infämationi,eóq; vulneraria habetur.

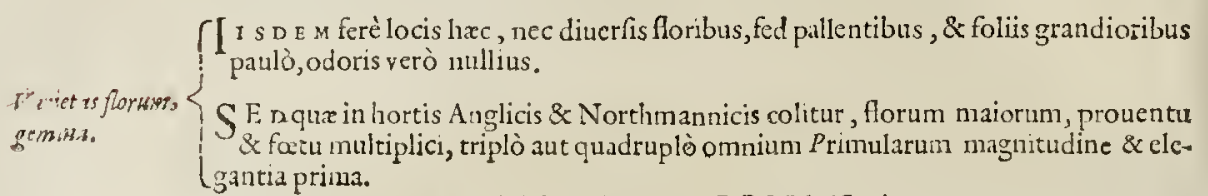

$$
\text { SYLVARVM PRIMVLA. }
$$

$H_{\mathrm{N}}$ c non poteft non noffe qui vllam fuperiorü viderit: differt enim flore duntasar,; qui fingulus languido pallore, pufillus, palıno breuior, quafi cauli fummo ineft. Folia, fapor,odor, vfius, non difparia, fed lubentius hxe nemorofa vmbrofaf́que conualles feqatur: vti in Anglia, Delphinatu, \& Subaudia. Flandris \& Gallis hortenfis.

CV A R I A T hæc in Anglix hortis fpeciofa forum duplicatione \& incremento, Lychnidem coronariam duplicatan rquante:coloris etiam diluti lutei.

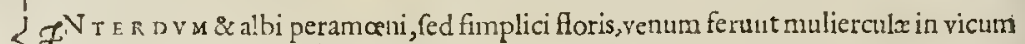

Fariotas

$\{$ Tercatorium Londini.

T 1 a m fimbriatis foribus, rugofif́; plicis, \& coloris obfcurè virentis, $P$ rimula quxEdam Londini hortis frequens, alıoqui afsimilis cxteris : quam fudiof Herbarum Antuerpiani, vt nonnullas fuperiorum indidem habuerunt, \& nos monuerunt quāpiam Primula!n in Angla extare floribus purpureis: fed nobis fruftra quxita, \& $\mathcal{P} u l$ Lmonaria putata, vt doctı simus Turnerus dicebat.

Harum omnium cùm fint folia ambitu rotundiore quàm maioris Verbafçi, \& caulis nonnullarum foliaćue lint hirfuta; cur neget commentator non effe Phlomides?nuliam nifi oftentationis futilis habet rationem: vires quippè \& tota facies planè Thlapfi, contrà fuadent, confenfúsque experimenti apud om nes reyiones, qux modò rnam quampiam harum habeant, P aralyfis herbam vocant, quo nomine propter infignes facultates fuit etiam Phlomus donatus: igitur \& ha Phlomides.

\section{$P A R A L Y T I C A$ sipina $S$ A N ICV I $A_{2}$ Vrfíauricula recentiorum, figura Promisla, fed fioribus purpureis.}

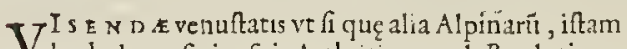

herbulam, fatius fuir Arthriticam vel Paralyticam nominalle, quàm Saniculam, tum proprer peculiarem cxprefsioné affectus Arthritici, quem admolitur, tum maximè quia Primulis anuumeranda videtur: tametfi amat hæc fumma item montiú pracelfa, \& præruptarú Supercilia petrof, qualia funt in Claudii cautibus, Clauenê, \& Oenipontis finitimis, vbi ferc̀ to tã ę tatē perénat nix, qua inuita exadto Vere hæ Primulx pratenfes fingulari cauliculo, quafi flores in pediculo molliore \& inflexo punicantes, ant ex rofeo albicätes, vifum exhilarantes dant, fuauiterć; fpirantes: folia autem albida, virentia, crásiufcula, carnofa, \& lęuiora,quàm Primula Veris, nonnihil repanda, \& limbo crafsiore tantillùm

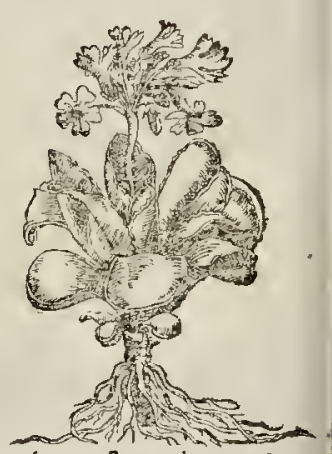
fimbriata $\&$ circinata:radice multum fibrola \& cognata $F$ rimula: guftu pariter multum exficcante \& aftringente, vulneraris potionibus quzefita, \& foris vulnera glutinante, $v n-$ de Sanicula. 


\title{
STIRTIVM aduerfarianona.
}

Variesas. $\left\{\begin{array}{l}\text { Alibi montium interdum frequentior } \mathrm{m} \text { \& } \mathrm{maiorem} \text { vidinus folijs, cau- } \\ \text { liculore, qui tamen nô purpureus, fed luteus, ant albus, \& furcedinc pul- }\end{array}\right.$ Clus eft.

DIGITALIS PVR PVREA.

\author{
SGr. Singerbut if finger Fraut. \\ Belg. Tinger bart etriet. \\ Gall. Gant noftre darne, doigtier: \\ Ang. Foxeglout:
}

R E g I O E S quxad Aquilonem funt, feracifsimx funt Digitalis purpurex, qux Me= ridianis calidiufculis ferè deeft. Sed in Francia, Belgio, \& Anglia, nulli non nota,vbi id nominis vernaculè affequuta fuit, nec enim antiguis memorata, quorü calathi oblógi, picti, cellative apparent, in Digitalis fue digiti ad fuendü nunimenti fpeciem, el egant1 ferie cauli bicubıtali harent vno ex latere,penduli,folij paris, cócolor is, \& fimilis, Cynoglof́i vel Symphiti maioris: fibrofa radice, vifcida, nigricante, fenen in pericarpis pufilum, $V$ erbafci, odore putidiufculo, se qui Bacharim dicebant, opinioné refcllecte gufu ingrato, exficcante, difinautum calido, \& valnerario: quarc plurinifit ad omnia vulnera fananda.

\section{DIGIT ALIS Luted.}

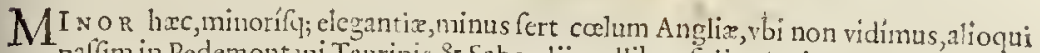
palfim in Pedemont tuni Taurinis \& Sabaudijs collibus, folio nigriore, angufto, Blatta rix aut Plantaginis, latu, nechirfuto, non perinde hiluriafpectr fortm, qui palliduli lu. teo fquallent, anguftiore nola,nec pernde punetulis impreffa.

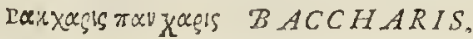

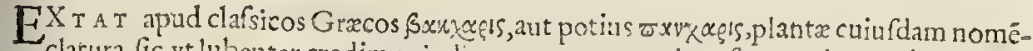
clarura,fic, vt lubenter credimus, indita, propte; cximian frugrantize gratiam Cinamomex radicis, ex qua cùm multa alia, tun ynguen confebat, item tarkes's apud Atheneuna diatum, fertáq; concinnabantur, quibıs tempora cinzebantur, ne Fat nocen malalengua futuro, vt cant diuinus Maro. Eam ob ren licenius abntuntur lectoris p2tientia, qui iltud capue ¿̀ Diofcoride quafi fpurium expunfâ valunt, fiuftáque probare fatagunt, vtramq; plantant, Baccharim nempe \&. Afarun, \&r vtriufuis defcriptioné(paucis qux irrepfere demptis)eadem effe, cum quilibet iam cernar legendo non propius abefe Hederam à Saluia, quàn Afrum à Bacchare. Altringt hxc, infanm tionibus \& ignibusfacrisproficit, fomnifero eft odore, fronde inter violam pluta alban \& verbafcunn. Illa contrà impendiỏ calfaciens, difcuti ens, hederaceo folio. Nó parum itac; diferepant Plinio autore: 'qui quòd co:onis non additur,dietun tradit Afarum. Labes hæc profecta è fragmentis Crateur, vbi Baccharis Diofotidis Afarum vocatur \& defcribitur. Quod qui dem nos monet, fedulam appeliationum perpenfionem nentig̨nam neglectui habendan effe accuratis viris, veri fidis venatoribus. Imm verò de multis, fi optio detur, nullă perinde congruã videmus, acilla, quă olim barbarotü doctiffmi genuinā putabant: multó enim propuls, quàm illa Mathioli fpecies verbafci odonati, ad Bacchare accederc certü efi, Hzcc quippeffrtuticofa, appendıcibus donata, foliisć; afperis, nigricantıbus, Primula veris, vel Saluix latifolix magnitudine, caule bicubitali, floribus purpura obfoleta glomeratis, in pappos defluentibus, Cardui modo. Radix fummo cefpite fparfa, difufis fibris, garyophyllatx modo, cuius odorem prêfentifsimum halat, vel cinamonii:cui contulerunt antiqui Baccharis radicem, qui Garyophillos non noffent. Planta yalde frequens, valdćq; ifto nomine nota Monfpellij circum, \& alibi non paucis locis Qui quatuor Conizx fpecies nouerit, (earum namque inter fe non parua fimilitudo, fore, Luteis omnibus, odor grauis, gluten dum attrectantur) cur Mathiolus iftam Baccharem odore Es fore 
nobilem Conifam maiorê fecerit, \& Verbafcum ei fuffecerit, haud facilè dicet. Vetbafcü quippe eft odoratum, cui interdum flores Ittei, interdum purpurei, v t Blattariz maioriq́; Verbafco interdum continoit mutari. Ronn cum valde auidi, ve femper foliti fuímus, \& freti fide Mathioli complures quos fcifcitabamur herbariæe rei peritos, nihil aliud quàm Verbafcum putabant:idemá; in Flandria alijsć; non paucis locis ortum, non eharta agGlutinatam plantam iftam Mathioli, qux potius figuræ, quàm odoris, colorísve notas retimet. Sed iftud confuetum illius dignitati, res verbis a ut chartis affertas, non item infpeeticue exploratas literis mandare.

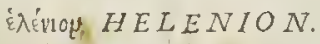

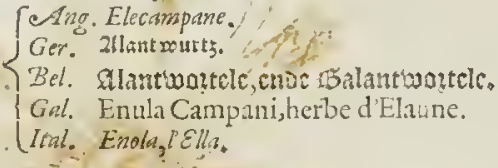

T JEL EN E Iuctu aut fátu clarius \& notius pofteritati fictun eft Elenion, quàn vt fufiole delineatione fit opus tamet \& 8 ab infula Helena dici putatur, vbi longè optimun Juxuriet numerofa \& pregtandi fronde Digitalis ant Verbafci latiphylli(non an guttiolij Verbafei,vt mendofe codex (J⿸ens) Horem Buphthalmi aut medie Conize anreü ftellatü Innio \& Iulio fundẻte fcapo fümo, rcêto, tres an quatuor cubitos procero: radicis amplæ,crafioris, curpum ferè æquätis, perquàm odorę: in piatis villarum \& pradi orum Anglix, Germanix \&- Galliz, etuı primo Vere folitæ. Qua quiden vtendum intrò humenti \& recêti ad animi paranda eommoda lætitiamq́; inuchendan, \&n nofitiam necädam: de qua dote plurimi fecerut eam antiqui, \& nepenthe illud Esyptium ex ca vna confequm opinati funt: ficca verò benè facit foris: fin intrò fumas, hurienti atq; recenti vendum, prxfertim in pulmonis affectibus eronicis. Iftud tamen Pharmacopoi non eft, fed periti Mediei.

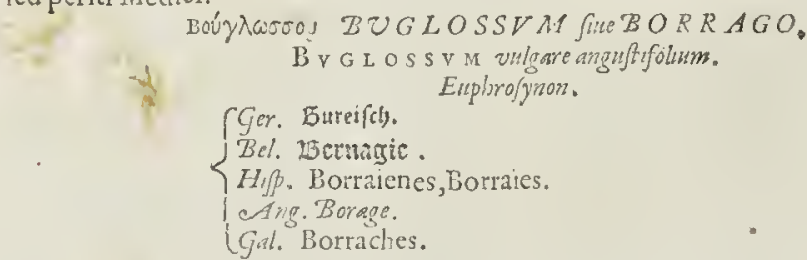

BOR R A G I N M quafi Bouaginem vulgus dixifle pututur, verfa \& deinde peruerfa d Buglofa vocc, çuod tan verum videtur, quam nulli in dubium ian vertitur, noftram

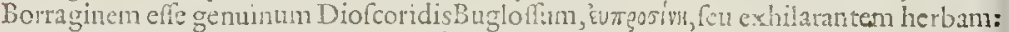
cuius poftea xas recentior nomcn confudit \& commune fecit, viribus \& nonnulla duea funilitudine, anguftionibus folijs, \& aliquantum diuevf $x$ plät $x$, non Borrazins, vt nỉe, fed Buglofix tune diftx. Ian verò notior vtraq; etian plebeculx quouis ofufculo: fed minus vera, verum retimuit nomen. Lacifolìa \& germana, non Buglofla, fed Borrago tantù dicitur.Vtrag; foecunditate importuna hin hortis luxuriat. Genuinum \&latifolium folijs

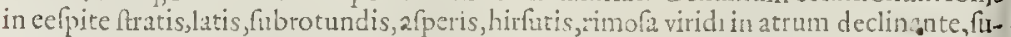
perficie Symphiti naioris potius quä Verbafci. Huius radix extima albicat, minor Se breuior nec perennis. Alterius contra foris nigra, perennis, prolixior. Vtraq, tane gitutinofa, edëdo medendóq; nata: genuine flores fellati quinis foliolis, esimia purpura, coruleóq; nitentibus, interdum candids, nedio quafi centro coroniden circinican, fufeam, exilem cohibentibus. Semine nigro Anchulx aut Lycopfis: Sed alteri forcs concolores, Primula Veris modo aut Anciufx: Scmé maius, nunus nigrum, folia lögion, angultıra, Echio aut Lycopfi toto habitu tam propè aecedentia, vt ni defuifce rubellus radici color, Lycopfin doneffiean facturifuifemus, qui cuia nigricat, potius Echum incicat,aut vtrufo; anceps natura. 


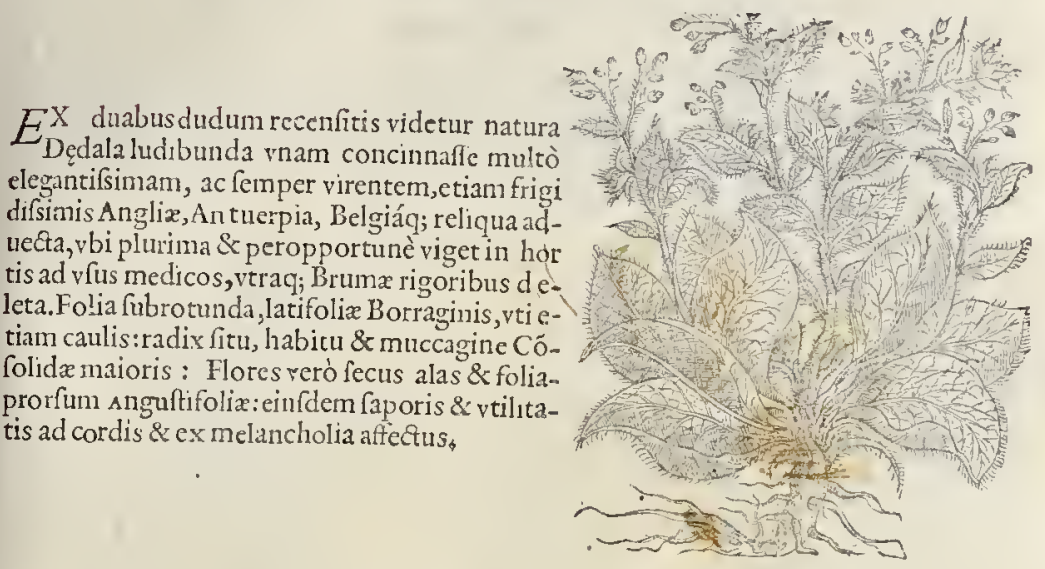

BVG LOSSV $M 11$ peregrinum radice multifida Pulmuonaris.

$\mathcal{F}$ noftris firpium fportulis quedã arida adfhuc eft Buglofin facie planta, quam ex- hortis Bononienfibus habuimus: in pilis denfis, horrida \& afpera funt, anguftius definunt temporis anguftiam expendere non licuit.

\section{Erraticum BVGLOSSVM aperum Echioides,}

ES T \& harc perquàm fimilis qualibet fui parte fupcriori,\& penè par,macilentis \& fabuletis Autuerpla vicinijs parsim fponte, ctiam in hortis lucum faciunt, vtuntúrq; Bug lorsi penuria Pharmacopœi, quibus Sylueftre Bugloflum creditur. Admodum horrent hifpidáq; funt folia, fetacess, pilis rigidis, \& bullis prominulis, tantúmq; \& fimili differt modo à fuperiore, quantum Labrum Veneris à Dipfaco hortenfi. Radix gracilior, Iignofa.

\section{BVG L OSSVM Echioides Luteuns.}

$V^{\Lambda}$ I D E cognatum huic eft facie, natal, bus, vfứg. Pluris faciunt hăc mulierculx Angl $x_{1}$ quàm Bugloflum, vocantó; Innguam Bouinam luteã, propter luteos flores Sonchi fimi les, in afperis caliculis collectos. Fol min item DipfaciSylueftris, nec minus fpinofum, an. guftius aliquantum. Radix alba, vifcida, oleracea, vt Buglofî, cuins eft fpecies.

$$
\ddot{x} y \times r \propto \text { CANCHVSA. }
$$

SOff. Alcann $x$ radices.

Ger. Koat ochfen jung,

¿Gal. Orcanette.

Ang. Alkanet.

F V c o pigmentísve illinere, Græcis ảy x́roẹ erat, vnde Anchufa dica à radicisilluftri cruore, coloréve florido, cui plantre totius cognitionem debemus : vix enim alioqui innoturfent, tum propter cum Echijs, Lycopfide, \& Buglorsis fimilitudinem, twm etian

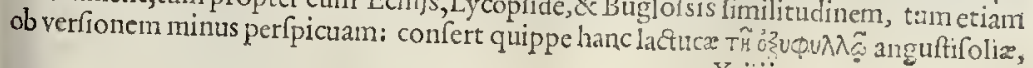
X.iiij. 


\section{STIRT IV $M$ adwerfarianoua.}

vel acutx, \& vti videtur agrefti, qux hirfutior \& horridiur. Quatuor animaducrtimus differítias ex Aoribus, fol riss, \& magnitudine. QuæCalys feu Onoclein vocatur, maxim $x$, fre quentifsima Gallix \& Anglix, aruis lætis, fed glareofis, vel argillaccis. Radix iutus ligneo corculo, libro corticéquc craffiore amięa, äguineo fucco fädalinóve digitosinficiente: digitum xquat, fefquipalmum longa,guftu Buglofix. Folia copiofa Echij aut Buglofsi anguntifolij, lanugine foinofa, incana, cefpiti incumbentia:caulis plurimum fingularis, rotîldus, fquaber, cubitalis, tirfulis florum cæruleis ad punicem yergentibus, Echij non diffimilbus:fermen exiguun, oblongum, pullum.

\section{Luted $A N C H V S A$,}

RARI o R \& elegantior multò quiluteis foriRus,fed ramulis ninotiLus \& magis collectis in fummo: folijs item numeroforibus, lanuginofis, albidis magis: caulis pedé aut cubitü eqquat, \& femcn alterius. Radix tamen viuidiore multóc; delicatiole nitet purpuriffa, fucculentior priore, Norbon ad aqua: Marianas, vmbrofo \& pingui folo. Etian in afperis,non procul Athefi flumise, \& Baldo Veronenfi, collegimus,

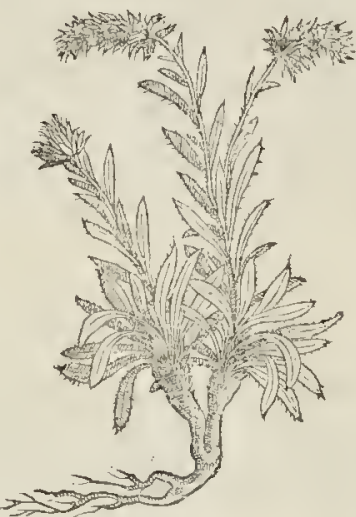

MINOR fen eflcibiadion vel Onochiles.

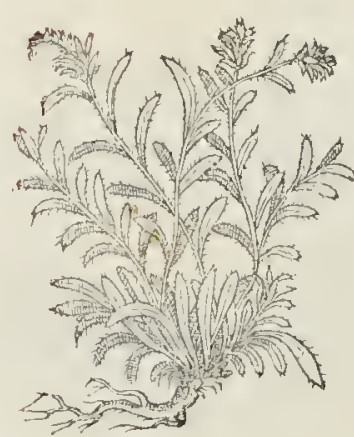

No I s s i M a hæc \& copiofffima in Nitiobrigum agro, vnde Pharmacoperi Monfpellienfes \& Lugdunen fes Lugdunĭ ad nüdinas quotănis acferfunt: nos è vinetis \& fabulofisaridisá; collibus Grämuntix Sylux,propè do Etoris Afutij prcdici,eruendã curabamus. Prolixior namq; \& carnofiore plenjoréq; eft radice cxteris. Catera tota mi nor, anguftiora folia, multo ntumerofiora, viridantia Bugloffi. Complures fundit cauliculos teneros, graciles, foribus ninoribus, Buglofiminoris anguftifolij, puniceis. Senen cinereum, oblongum, paruum. Sapor Eugloff,nó ingratus, acrior tamen \& ficcior.

ANCHVS A LIG NOSIOR angufifolid. $\checkmark$ Lr I a hęc \& minima omniü, tamet fi vix Anchufa ha benda fit, vt cuius fit parum aut nihil purpurea radix nofos Satureiz: foliolis oblógis, Alcibiadx Anchufe mino ribus, minúfg; hirfutis: florcs item nó multum abfimiles, pufill, cxrulei. Radix lignea ex fufco ruffefcens, parír aut nihil inficiens. Marginibus agri Frontignani \& Valerix Sylux hxc interdum occurrit, Alibi nobis nufquam vifa.

LY.

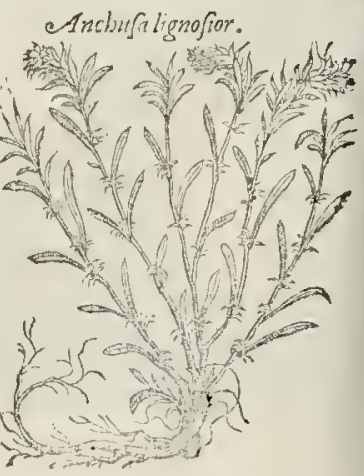




\title{
STIRT IV $M$ aduerfaria nowa.
}

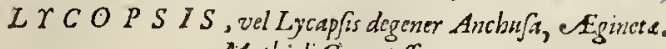 \\ Matbioli Cynogrojpum.
}

NI I $\mathrm{I}$ habet hre Anchufe, proterquam radicis fufcum ex purpureo colorem;à quò Lycopfis deriuata fuit, id eft, fufcedo obfcuritásve, qualé ante lucanum vulgus inter Canem \& Lupú crepufculü yocat:nifi fit ab hifpida caulis foliorï \& florum inpexaque hirfutie, pedem imitata Lupinum:qualem non procul à littortbus Frontignan $\&$ DoCoris Griffii rute nobis primú oftenfa fuit à 'Profeffore D. Affatio, praceptore exercitatifsimo, \& de Medica nateria benè merito.Satam poftea habuimus Londini in Anglia: folıa dum per initia erumpüt, cefpite inftrata numerofa, bullis \& villıs afperat2, Eclui, palmum longa, pollicem lata iacent, neq; toto anno aflurgunt, aut caulem florénve edunt; fed vno ar interdü al tero anno pòft, xftate caulen fefquicubitalé, rotundun, hitfutis alis multis diuifum. Iuxta quas \& folia erumpút ex interuallis: flotésq; Echni fimbriati, diluta purpura,exili ftamine. Semen Borraginis, minus nigrü: radix cralsior digito,rufefcit, lignofa : parumm aut nihil attrectantem inficiens.

Hæc ab ea qux hîc in Anglia via qux Bathonia \& Briftolia Londium ducit pet meftes lata \& multa hilari vifitur alpectu, flotibustantùn diffett: quos non fecus foliorum $\&$

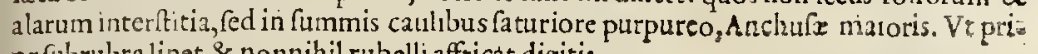
or fubrubra linet \& nonnihil rubelli affticat digitis.

\section{"xiò ECHIV M, Buglofum agreffi。 \\ Gorma. Woilo ochfen 3 urg. \\ Gallis. Bugloffe Sauuzge. \\ $\sum$ Belgis. motioe Dife tongbe. Ang.Wyld Buglof the lefer.}

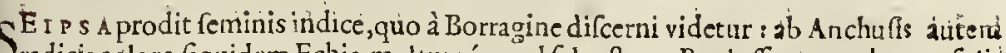

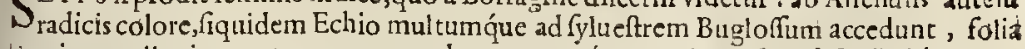
per interualla circum teneros rotundos quaternósve caules rełtos fefquicubitales, alterno fitu plurima hirfuta, retnas, quaternasve vn cias longa, pollicem lata, fubnigra ctá$\mathrm{fa}$, è quorum finu emergunt per interualla flotes copiofi, ex puniceo cxrulei, in pufillis $v=$ trinq; incutuis ariftis digeft, plumatas fummitates effigiätibus: hifce afperiufculis \& fpinofis te zumentis euolutun clauditur femen, viperinum caput argutis; fed exilibus oris; luminumọue veftigia efformat.

\section{O NOS M A, Jue Ononis.}

NV $x$ r y s eft paulò execcitatior, qui illicò percepta Ònofriatis ex Diofcoride delinea tione, nó opinetur eam effe è cenfu Auchufarum, Lycopfrd niinirum cognatam, anchufámve degerneren, quam fecreuit Diofc. nomine \& familia : ve fuo obfequutus inftituto frugiperdis abortum faciētibus infereret, cuiufnodi funt Securidica, Nymphea, ADpleniun, Hemionitis. Eóque bis foliorum fimilitudinem ad Anchufam inculcat. Res verò ipfa indicat effe, quemadniodunt arbores non paucx, qux foetx fuerunt primùn, poltea exhauftis viribus biennio aut trienno florem fruftu mq́ue edunt nullum. Sic duo aut tria genera Echii putata meminimus, triennio primùm nó nifi folia, poftea caule n $\$$ remen promerc quibus pet frigota amifsis, non nifí biennio aut triennio interiecto, turá fum incaulem \& llores erumpete: alıas anno floruife primo, aut altero, bien uiúmq; interdun totum quafi effortas \& fteriles, caule orbatas fuiffe, fufpicionen'que feciffe femi 4 nis, florun, caulisquie fua natura expertes effe:cù n tamen denuò rediuiuas repara tis caule flore atq; feminibus Ly copfides animaduet tiffemus: quod potuit itidem inde iftis euenife, \& id vulgo perfuafife, quia infoelix, atq; fotus certa pernicies, non fecus atque filix alıáque haberetur. Huc exempla Bechiı \& Dictamni ftudiofi arceffant. Cynogloffuna zutem iam hîc nobifcum perpendant. 
Kuróyncioroy. CXNOGLOSSV M.

Germa. bunityunte.

$\{$ Gallis. Langue dechien.

Belgis.

eAvg. Holindes twrige.

Crnogrosfum, Pufillum Norbonenje.

$\mathrm{H}$

$A \vee v$ difpar de lingua Canina hafitatio, fedqux minoris egere videacur difquifitionis \& probationis, æquis arbitris attentius rem ipfam expencicntibus. Etcnin nifi nullidum cognita eft Cynoglofta, aut certè ea eft planta nominis interpretatione, vfu, caninz linguz afsimilatione, confenfui vulgato a deò probata \& recepta, vt nullus fit ex iftis malè feriatis nouaroribus,qui xquè bonam \& congruani, medum potiorem, mciagare quiuerit. Ef namque ca foliis mollicellis, lenibu,s, lanugine pauca, ad tactum minime afpera, mollicie \& effigie lingue caninx vel Glafti, non hil venofa, albicantia, llantagirm latifolia at Giora,prefertina aridis \& fabulofis Linguagotricis, v bi pufilla vix fefquipalnu \& pedem excedens: caulis rotundus, incanus : in alas diuifus, quibus flores prinicci anguftifolii Buglofsi:paruum femé lappulis, hirfutísve cly peolis contentü, vefribus, vt Ágrimonie vel Caucalidis pertinacius hærés. Finguibus tamé \& humétibus aruís Ferrarienfibus \& 'Patauinis maximun glafum fuperat, eò proccritatis proorefla;vt vix fuifimilis fat : viridiora namque folia ima \& latèhumü operiétia: dilutiöresflores, obfoletiorésy;, quos fert nullos nullưmq́ue caulem nonnullis annis, pracipuè vnubra falignea aut fepibus vicinis opácata. Qui in Hérbaria cognicione cólenuerat peritior quàm iactantior Barallis, Diofcorides Monfpellicnfis vocatus, afferebat Rondelletio nobis audicuribus fibi non femel in Lemouicibus \& Auerniis obieruacas non paucas tri $\rightarrow$ ennio 3 quadriennio quotănis bellc̀ reuiruiffe, $c x$ terò nullum caulé promfifc. Quin fi vires fpectes, magis arrideat tum planta, tum feritentia noftra, qua doctiori lubenter cedet, quunı potiorcm Plinio,Cynoglo, indicarit Cynoglofum. A mbuftis fiquiden opitulari, vel muliercula fciunt, refrigerandi f́ilicetmanifefta qualitate, exficcante, doloremć; Ieniente, \& majoré affluxú probıbente ; præfertim exungia alliquefała feruidáve infitilata: ité Allopeciis de acri \& erodente hum ore capillis defuêt!bus, cófert. Nec nó emolliet aluü eius vis malactica \& muccaginea vino incofta \& frigore retufo. Radix Symphiti eft magnitudine, muccore \& colore, odore penè foporifero, maximi hodic vfus ad acres \& tenues fuxiones: magis tanien incraftat quàm refrigerat. Hæc P’linii lappulas fercns videtur: non enim Echii, att Anchuræ, aut Lycopfides ferunt. Quare, $f$, vt pleraque omnia, è quopiam Herbario vertic Plinius, caule ferre \& femen, vt qui obfernarit fortè eadẽ que nos fcriplimus: infcitè finul 2 tc; perfidè erroris fodi traducitur, \& Ruellio pererudito calumna impingitur non ferenda ab illo cius perpetuo plagiario præfertim:qui nifi híc tantus fuifiet, nunquam ille cóméntatcris opinionem fuftunuiffet. Porrò cum nifi tumultuari gloriolamq́ue aucupari fitis perfpicuum, cùm nihil interim doctiores nos vfpiam relinquat. Cur nó docebat, qua de re Trallianus eximus Græcus addiderit radicis cortices pilulis, quas de Cynoglofo infcripfit? ศua apprimè pollicitationi ftant, nec vllus Medicorum hodie aliam vel addit, vel nouit. Etenim Mathioli hanc, cui natales Romæad molen Adrianifacit, nufquam non locorú paulò calidiorum Nopbonę \& Hetrurię multa, nec alio quàm diximus modo in Lycopfide \& Onolmatc, illic caule viduacernitur. Proinde, qui nec hanc quidem probè notam de facie haberet Senenfis, paucas \& confufas notas pofuit: vires verò, quọd ininimè decuit,fuo more reticuit, \& tamen legittimum afferuit. 


\section{STIRP IV $M$ aduerfaria nown.}

\section{$C I R S I V M$.}

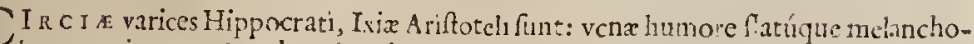
Iicopominentes S tuberofx, dolore interdum fruo purten vexutes, quibus quia hac planta medetur, id nominis aftequuta fuit. Genuinand atem plurimam propè piltrintum oliuarum, \& ponè molas farinarias, in locis vadofis Lani amins Monfpellinci, \& pratenfibus lacuftribufque littoreis à Grammutio luco in meridicm deuexis, quà maris alluuionłbus \& folibus feruidis longè latéque patentes plancies iale niuco opertas pedibus tcrebamus Iunio I 56 . Radix \& ima folia Dypfaci modo \& ortu, Buglofsi anguftifolii acutiora, \& leuibus hivucis fpinisq; afperiora fitgularis, binos, ternos, aut quaternoscubitos $x$ quat, angulofus, rectus, incanus, tener, Sonchi modo. In quo extrcmo forcs, rotüdis, oblogis capitilis, fenecionis, aut Cardui, purpareis denfis cöllati ftaminbus, vnà numerofi \& cödri. In pappos defueatibus

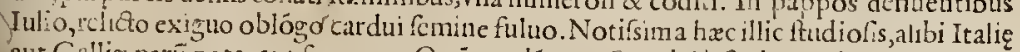
aut Gallix parī nota, aut frequens. Quä cande cum Guni Cirfo in Mathioli cónentaI's eleganter depictam, intuitu, quoad licet, coniectamur:propterea quisa idem Senenfis vtique fui finilis, nullam defcriptionem appofuit: Rucllio alijfóue dofus, qui patarint hanc Brigloifun anguftifoliun effe, neutiquam parfurtus: fi virentem, florêtemó;, vti nos, vidifict. Sanè vix villa in Diof coride plcnius defcriptioni refpondet is ficultatsbus, quàn - hxc,floribus non quidem Buglofsi,fed pappofis 3 : lanuginofis, eumidis, caducis.

\section{$A L T E R V M$.}

I I c Londini in horto Morgani, etiamnum ineunte hyeme, huic aliud Circinm credi- tum creuit, cognatum foliis, floribus, \& radice, facie tamẻ Cicerbitz, foliorumóue pofitu in cauliculis teneris, canis, minus hirfutis, vti ecia folia paulo breuiora : fed Hos purpureus, \& fingulz cyma fingulus pappofus:ea ạnum fermè vegeta viruit.

$$
\begin{aligned}
& \text { SYMPHYTVM Alum, Seu Alus. } \\
& S^{G} \text { rlis. Confyre, Oreilled dafnc. } \\
& \text { SAno. Cumfrey. } \\
& \text { ¿Confolida maior. Hip. Suclda matior. Ita.Confolida maggiore. }
\end{aligned}
$$

PE r A P o s I r e iftud Symphytum cótulit Bugloffo, id eft, noftrr Borragini Diofcorides: quandoquiden tratus amat lætos, riguos, interdum \& hortentes iftud, non

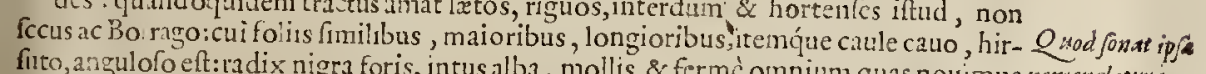
futo, angulofo eft: adix nigra foris, intus alba, mollis, \& fermè omnium quas nou , him s nomenclarurs. maxine vifcida: fapore oleraceo, vel infulfo, qux carnium fru?t, fi illi incoquantur, ferruminare, glutinarćue meritò credütur. Quàmplurimos ad affétus certifsima ope códiutur, ad vnguenta fpiffatur, tota namq; folio \& radice vulneraria eft: Buglofsi guftu \& muccagine, fed mul tò pluri \& efficatiore ad vicera ferruminanda, eóq; Confolida maior vocatur : \& qux mas vulgó dicitur, floribu\& purpure is, efficacior habetur: qux verò albidisfloribus, fomina. Luteis etiam floribus obferuaumus quandam, qux folis putaretur Borrago, vbi de foruit, nifi radix fubeflet tuberofa nigricanfq́ue : quare minus vet è quidam opinati funt, Indicam occiduam fanctam herban, Symphye wextou apud Diofcori.
effe, vrunox oftendetur.

$$
\text { Ináorum Sana SANCT } \dot{A} \text {, fue N I C O I I A N A Gallorum. }
$$

IMPVDE N T I V S C I I s Herbxrix obtrectatoribus, ignauiam lixe, fi loquatur, exprobret, ingenuisautem veftigatoribus fedulitatem gratuletur, qua factum eft vt non multis ab hinc annis ex Hefperię Indię nouo orbe Portugalie, Gallię, Bel gie, \& Anglia
facta fuerit inquilina : maioréne au certiore commodo, incertum.Siquidem non modò 
Symphyti de figura \& habitu upfo conferenda eft, fed ctiam effectionibus ad inteñ \& ex terna incommoda, cidem \& cuilibet Pannaci decantatilsimx preferenda. Non eft ramé Symplyyti fpecics, tantò mi-

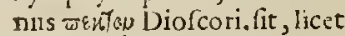
vifum fuit quibufdan : at illudeft noftrum Symphytum vulgi magnü, tametri iffdem riguis, nempe pinguibus \& apricis gaudear, proueniatá; folits pragrandibus, oblongis, hirfutis, Symphyto magno,!atioribus, rotũdiorib ${ }^{9}$, Bardane Hyolchyamoluteo concoloribus, nult is c̀ radice cxili Laequar, multum fibrof2: fcapus exit trium cubitorum in Fräcia,Belgio, \& A nglia: fxpirsimèquatuor \& quinque proceritate, quum mature fatum fencen in calidioribus tractibus Aquitaniẹ \& Linguagotiç: florum calatos Augufto fert,

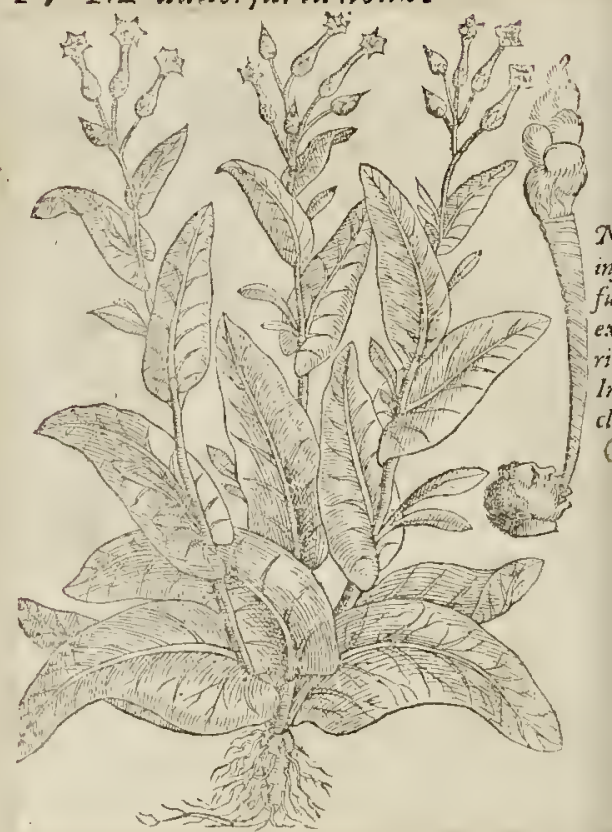
herbaceo pallore nonnihit punicantcs, vncialcs: femenćue maturat in calyculis exilibus admodum, \& fimilibus

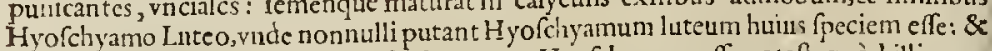
fanè verique plufculum caloris ineft. Quare nec Hyofchyamus effe poteft; quòd illis perfuafum fuic, quia vidifent non paucos huius fumo haufto tenulcntos fieri. Vidcas enin naucleros plerósque omues qui ifthinc rediunt geftare pufilla infundibula ex folio Palmæa aut itorea confecta, quorum lateri extremo inferta funt conuoluta folia \& comminuta ficcata huius plantx: iftud ill accendunt igne, atque hianti orc quantum plurimum pofiunt, infpirando fumum fugunt, vude fibi famen fitimque fedari, vires inftaurari, fpiritus exhilarari afferunt: fopir qque iucunda ebrietate cercbrum, dictitant : incredibiIcm pituit $x$ copiars plerumque cduci: Quod ipfi dum haurirenus, experti fumus : non tamen citò inebriat, nec frigore dementat, $v t$ Hyofchyamus, fed quadam aromaticitate vapida ventriculos cerebri imbuit. Hyofchyani illius lutei nullú factum à nobis certum periculum, Iftus verd Sanctx herbz vocatæ iarn vbique increbuit fama : fanè ad vlcera, vulncra, thoracis affeetus, tabemć; pulmonú, ea nihil noui nouit ex nouo Orbe noltra $æ$ tas prafentius, allt cfficacius, quemadmodum inter remedia dicetur.

PVL MONARI A, maculofa folio Borrag. floribus Primule Veris,purpureis.

Gallis. Herbe aux Tulmons.

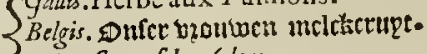
LeAng. Sage of Ierufalem.

ON 5 y I I I s huchæc fuit dilata,non enim magis dieta Plinii Pulmonaria ob effgiem foliorum, quàm propter vires pulmonibus non fecus laudatæ atque Symphitü, cui cougener $\mathrm{eft}$, nec parum funilis, hirfutis cal yculis forum Prinulx, nrima vernatione eleganter purpurantibus, in cauliculis mollioribus, fefquipalmaribus : folis itcm fuper- 
tem fuperficie \& hirfutie Symphiti aut Bugloff, maculis Iafteis \& nigris afperfis, femina nigu relinquentibus Borrary, nis, ab imo crüpentibus, fuperne actris, radicc quàm Primulæc crafiorc, fufca, vifcida: guftu nó ingrato totius plantæ Holeraceo. Iufculis mifcét fo lia mulier cula, aut tura ex ouis in placentas ducunt, adq́; pulmonis affectus, \& coráis vires conferre pradicant, coó; in hortis habent ex vmbrolis montofis. Quibufdam regionibus vifuntur fine maculis.

\section{PVL $110 \Lambda^{\top} A R I A$ Gallorum, florc Eicraci.}

V A M v I s fit hxc Pulmonariz maculofis folijs' \& nomine donata, propior tamen videtur Intubacco generi: flore nempe luteo Hyeraci, in parietinis \& dirutis, mufco obfitis, Lugduni, \& Monfpellij Gramütix fylux, emicat tcnello cauliculo, Intubacco, pal mari \& fefquipalmari, gracili, è radice exiliore Betonica, nonnihil fbrof. Incerto adhuc $\checkmark$ fu,vti planta parum nota eft:quidä tamé cóferrc paronochijs \&

$$
\text { MONT ANVMI Artion an Perfolatn Pliny? }
$$

TAM E I I nullufdum fcriptor ARC'ToN, fue Vrfam, vel Ar Eurum Diofcoridis nouit(neq; enim liuellij vndequaq; doetifsimi manes, ant fétentiä de Xantho, infectari, animus eft, aut fas ducimus) tanen id putamus factum ignomatione, non tam plantx ipfrus, quàm Cumini Sylueftris fue parui, cui confert Diofcorides Areii femen:iliogui folia ampla Phlono rotudiora,cauléfig; teneros \& longos promit hęc, quæ vt nosninc \& ordine apud Diofcoridem, fic facie magnoperè cognata elt Perfondta fiue Apuéle vnlzari, cuam Vrfam interpretamur dită, vtrãq; âfcmme, vti videtur, hifpido, villolis cchinis, qui hu ius Araij funt molliores, propiúfg; Cuminum partum fiue Sylueitre fimuintes : Cemine etiam non áfimili. Quare nec abfmili vero ratione videmurafieruife hanc Arction veram. Hac nufpiam nobis vifa, nifi celfis \& Syluofis montium opacis, vt Veganij I ugis Norbonx \& Saleur mótis, alijsć; Pedemontis \& Sabaudix finitimis. Radix longa, tenera, candidrá, foris \& intus, cdendo non ingrata. Folia, fubtus ptafertim,admodum incana, vtivngulæ caballina vel Petafitidis. Plinius hanc Perfolatam nuncupaffe videtur: fed defcriptione confudiffe ( vt fapè facit) cum Perfonata, non leuis fúpicio eft: tum quia folia vtriufq; comparat Cucurbitæ, \& tamen fingulari diftinguit Perfolatam à Perfonata capite \& radice. At Diofcorides Vcrbafco comparauit, ä hafce tres, nempè Arcion, Aretion \& Petafitiden, admodum inter fe fimiles, ferie coniunxit, nec tamen aliam alijaffimila nit, cum tamen Petaficidi fimillima Perfonata fit.

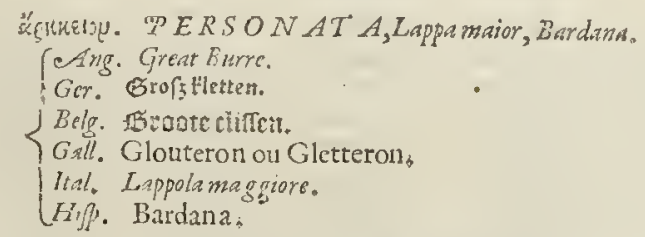

PR O P T E R eandem quam cumvillofis hirtíf; vrforum capitibus glomentiones cchinofæá; lappæa haberent fnilitudinem, nomenclaturä cófmilem accepit Arcion \& Arction.Perfonate autem fortè, quòd folia pregrandia vultui, larux, aut perfonx obtendi facic folita effent. Et Perfolata, quia galcri vice Solis xfum à capite arceret:vade etiami
Petafitidi nomen factun.

Nimis quàm frequens \& vulgaris lappa magna vbiq; gentium fecus vias \& vibium pomeria, luculentæ magnitudinis, Cucurbitæ emulis folijs, \& Echinis, mordaci hæu veftes canéfq; arripientibus, puerorum frequenti lufu nulli non notifsima. Radix grancis, carnofa Aretij fue $P$ erfolatx, fed foris nigra:conditur faccharo, \& cum grata tum vtilisima ad calculum \& dyfenteriam habetur, Vencris etiam incentiua. Idem femen pollet, fed. multò efficacius calculo fis:

Y.j.

$X A N$ - 
$O$ I O R I s eognomine fie dicta, quia ruffit capillos, quemadmodum hodie vulgus tinctorum luteam \&: Kermes, finte Kermefinum dieit, cuilibet regioni fermè xquè nota ac maior lappa, fed non perinde feraci inuifoq́; pronentu abüdat, loeis \& ferobibus arcfactis, quãdo imbres arnerint, gaudet, orta \& fructu echinato lappofóc; Platani aut potus clycyrrhiza alterius filiquof $x$, folsa gerentubus caulibusfefquipedalibus \& pedalibus, incifura, figura, \& colore Attriplicis vel Torncfolis, Bardanä etiam alicuantum adübrante:vnde Bardana ninor dieqa, radice non profunda, fibrofa, meritò, vti fernen ipfum, laudata ad tumorun ftrunarumó; pertinaciam delendumfrequenti admotu, vade Xopadió-

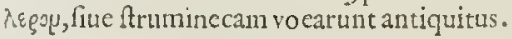

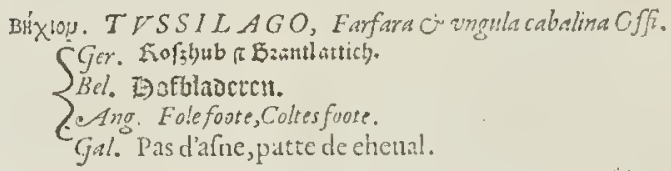

A.COM chum Gracis, Tufsilago Latinis, vel vngula cabalna recentioribus. Folia quippe pro mit ab imo in pedieulis fefquipa!mum altis, rotunda, fed latcribus fenus, , Ceptenísve angुlos aeutos elandétibus, auer(a tomentofa incana, aduer fa virentia cainofa, Petafititli adeò aceedentia,vt per initia nifi odor(qui huic granis)difcerneret, eïdem putares, Flos illi aureo pallore, radıatus, dentis Leonis æmulus, qui Februario \& Martio nondun egrefsis folijs repentè floret: parump cr perftat, \& celerrimè in pappos dehifcen:. Radice tenera, can dida, earnofa, g niculata, humí fparfa, cuius cmm folijs eft vfus notior, quàm vt longioriegeat oratione.Vda fata, ercpidinéf́; fluminum amat.

$$
\text { - Detasiths Tetafes. }
$$

.

ReAng. Butter Burre.

$S$ E o \&vtiq; fimiles fui negotium es negotio ferunt ftudiofis, qui Tufsilaginem affe-

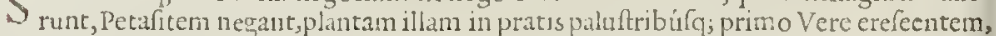
atq̧; thotudum fol ijs ortis caulena erigentem tenerun, cumofum, eoncanum, fe lquipalmum altum, () robanchr limilem, foribus in funmo denfis, pufillis, multis, mucofis, racemofis, olcr, in purpureum eonum compactis, fpectatu amoum : nullo femine prxgnantem, fed fleremarcefente \& defluête, fpēetiâ feminis perdenten. Folia pedieulo eubitali, craffo, carnofo, quali appenfa medio fui centro, pendula infar Petafi intrerfi vifuntur, maximä Perfonatiam fuperantia:fed rotund:i, fubter parun incana, fingulis pediculis fingula, medio fermè totins puntto hærentia, vbi finus definit profüdus ad vf(y; folij ce ntrum actus, qux fi profín elanferis, fungi penduli modo fulciri dixeris: fimúlg̨; Conmentatori filentimm indixeris, qui dum nilhil habet quod illinat paginis, in minutijs iftis obftepit bo nis viris, nec quid quóve modo fcrbat, de faculiatibus notífve eertioribus, quicquam penfi habet. Grauis enim \& prorfum ingratı eft odoris bxe, guftanti verò perquàm amara, \& ingrata: deficcat item magnoperè, quapropter morbis epidimicis vtilisima habetur \& comperta Medicis Gernanis etiamq́; plebi, qux ea de dote vocat 杼fitlentic mozrcle, id eft, peftis radicem: qux valdè crafia, foris pulla, intus cădida, \& plurimùm ver.

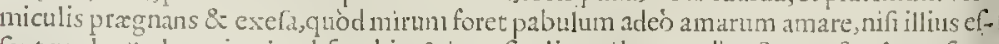
fent proles iz alumini:vt in abfynthio, \& in veficulis, quibus condiza \& repofta aloes a por eatur,cernitur, qquam interdun ctiam mures ligurint. Radices complures coutice exutas 


\section{.. STIRTIVM aduerfarianona. 25}

\& exenteratas ace to indunt quoad viribus inbutum fuerit, excye illo cum Rutx fucco \& Theriaca propinant,præfidiutnǵue rulii fecundum affirmant. Leuitufculo argumento deceptus fuit, qui rebatur propter communia natalıtia \& forum ante foliorum egrefitm; effe cafdem,quafi non idem contingat Trifolio Hederaceo, Croco Syluefri, Ephemero, \&:aliis.

\section{$C A C A L I A$.}

Ac multum Petafitidi afsimi

Hlatur,foliis prçlertim:an vcrò

fit Cacalaa ambiguum, nec tamen vlla alia vllä opinioné vere nobis fecit, nedü vt animum expleret, prxterquàm ilta. Alpinis ingis opacif́́; fupcrcilus prope fagos \& aquarum fortuigines velfuenta plurima, alibi tara. Ternos cubitos xquat catlis: ramulis quiburdã diuifus,flofculis albicatibus \& aliquantun obfoleta purpura afperfis,incóditè cógettis \& pãrıofis mufcosifve, vti in Eupatorio Canabino, aut Virga aurea, radix albi $\mathrm{da}$,fibrofa, crafa Garyophillatx, vnde pedicul1 furgunt foliis permagnis leuiter laciniofis donati Petafitudis:quàm etiä odore quadantenus imitantar. Gallix Norbonenlis celfo monte Calcaris núcupato primùm vidimus, pro pe illurs montis verticé qui Dei Paradifus à plebe vocitatur. In Delphinatu vel Allobrogum finibus Montes qui Pilati monumento $c_{\text {. Jgione vifuntur, iftam }}$ habent, ${ }^{3}$ de quidam amici Lugdunenfes peritisimi habuerunt;

\section{A L TS SO $N$.}

FV r t hæc Thlapis \& Lunariz Græcę focianda:fed operarum properatione huc intrufa eft, licet non abfimilia fint folia Echiis:in hortis cultioribus habctur, \& nonnullis $L_{u-}$ naria vocatur: fcd nulla melivis Alyfo Diof.quadrare videtur:eft cubitum alta tota, incana, afperiufcula, ac nonnihil tomeritofi; radice exili,foliis in imo Coniz $x$, vel albę viola, plurimum vnicaulis, roturidus, hirfutus, puffllis alis diuifus, in quibus alternatim foof culi lutei orimntur Irionis, \& folliculi oblongi clypcoli comprefsi, qualis Lunarix Græcx, quem duplicatum facit membranula difsipans verinque feminum feriem duplicem, que funt Leucoii fimilia, fed maiora.In Belgio vidimus, in Italia dono habuimus, Möfpelliiq̣ fatam \& enatam guftauimus, fapore longè Porro aliud eft Gale ni Alyfíon putatum à re. centioribus, Bugula nempe fiue media Confolida, iamdiu fuperius adducta:

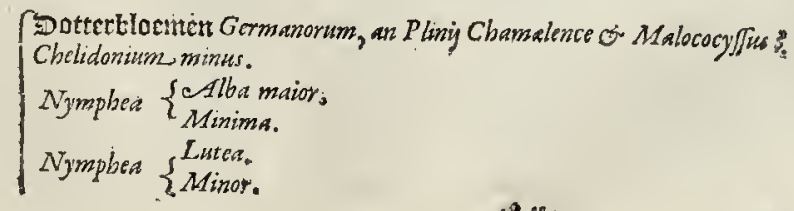

R.if: 
muliarculx not attulerint \& oftentarint. Folia non fubter incana, non angulofa, non caulis tome!stofus, fed potius atro virore polito, vti Afarum, Nymohea. Radix fibrata capillamentis, acris guftu eft, fed mo 'eratè:nondum tamen vfu exploratx facul tates: quod magno pudori eft iftis andaculis affertoribus, fed masori detrimento Mcdicina tyionibus, niaximo verò nocunento xgrotis, quos perdit infitia, \& feelerata glorix fames.

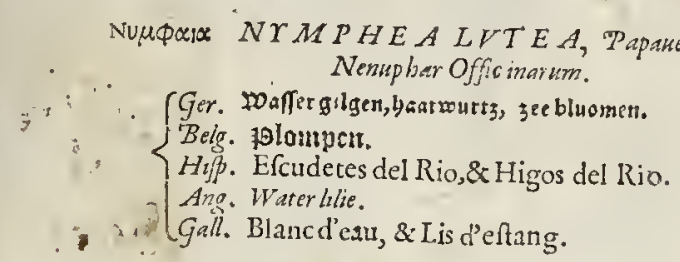

A Q v a Lymphx feu Nymphx antiquitùs vocatx, natales \& nomen fuppeditaruns Nymphea, qua nufpiam nifi in aquis leniter labentibus emergunt, parum extante folio peramplo,Bechij aut Dotterbloemelt, circinatz totunditatis, lxuoris, denfitatis, \& inagnitudinis, 111 caule glabro, quafi pediculo, quaternum quinúmye cubitorum, flore fpe ciofo, luteo micante afpectu, $\nless$ ambitu obtufore, quàm alba Nymphex.

\section{NYMPHEA alba.}

A L т r a M fpecië, quæ major vocatur, vix quifquanı difcernat, nifi floris emaculato cãdore Lilium prowocante: radix viriufq; craflecie cruris humini, nodofo \& frumofo corio clau am imitatur, guftantı infipida quin adhuc humens, ficcatx nonnihil fapit alimétof. Lutca albus eft, Cand:dx autem nigricat cortex, vtriufq; amaricat: femen \& flores nonnihil od ori albæ: Flagrantifsimi lutei, \& guftanti nonnihil acrimoura pręferment, glutiníq; quippiam habent, quem, nifi condantur, arefaciamitınt, ficció; efficiuntur, atg̣; nullo aut pufillo calore digerunt: qua ç perpenfone facilè quis componat tumultuarias Arabum \& Neotericorum inter feperorationes. Atq; qum attoniti mirātur Arabas q'jandam fpeciem Nymphex calidam tenuantemq́; putafe : non eft fanè quod conuicicilir, ant ineptè è capite de Sedo accerfant fubfidium: nam fi Nymplica inde fit dita, quil Lymphis Nymphísve eft conuictrix \& accola, potuerent Serapione antiquores Cal iam nobis dudum Paluftem dictam congenerem fecife:natales quippe, folia $\&$ fores af uitate haud vulgati, etiannum perfuader 1 dé quibufian Pharmacopers, qui no fris medicamétis non femel fubdiderunt hanc,illarum veriúais loco:vocabantá; Nymphxam liteam. Quin ni nobis forent notx Nymphex, certè hanclegittimam Nymphrama ietore, quoties potiores vel rationes, vel plantx acconmodatiores nos deficiant.

$$
A L B A \text { extinor. }
$$

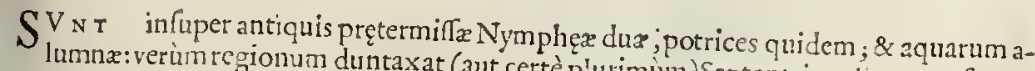
Anglix, via cux Londino 0 duntaxat (aut certè plurimim) Septentrionalium, prafertimi griores minuff; profundas, numerofü Briftoiam ducit, fecus \& trans aquasviarum pilibus folium, fere magnitudune Chelidenit hxc in tenuioribus pediculis $\$$ non difimi men vocatę:defluente fore candido Papaneris minotis, aut Paluftris Caithre, soctcrbloc sa fuperfunt, crafsiufculo cortice obduat a

NXMPHEA LVTEA minor Scptentrionalium.

$$
\text { Yiir. Minus }
$$


IV ${ }_{105}$, èlimolo item tundo, rraijcit lymphas iuncess pedicuiss, tcrnú \& quatenrí cubitorum crafiúnculis portulace, fingulare folium in fummo geftantibus, duplò mains quàm fuperioris: quare ha differentia fibi ita $c x$ aduerfo altrinfecus opponútur, it hec maiufcula lutea, albę Nym phex Diofcoridis refpondcat, $\mathrm{fu}_{-}$perior vcrò minima conucniat: cú maiore lutea. Floribus ex vno quati incco exortu Primulx, minoris chelidonij ftellatis, iuxta amcenifsima Thamefis fluenta, in $v$ dis fcrobibus \& kacuftris pratcfib us: gututu plufculumn caloris v1detur habere, \& ficcior elfc quàm fupcriores.

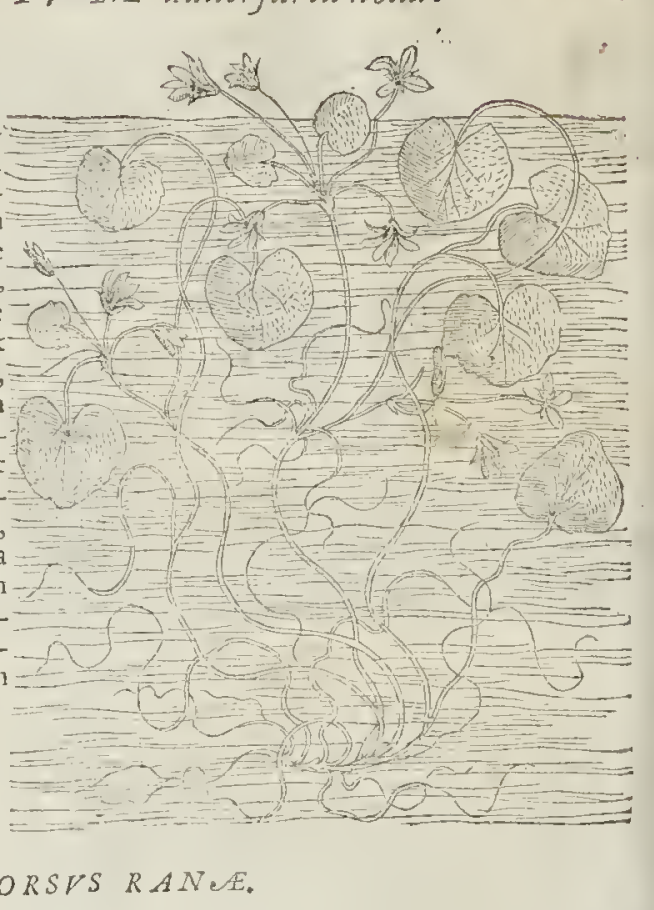

JN ComperTa M \& hanc Grxcis, Septentrionalcs, apud quos(rarius in calidis)pro-

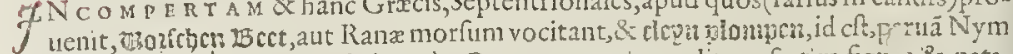

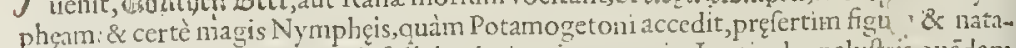
libus, ncmpè torpcntibus aquis foliola plurinsa innatant, in Lenticulæ paluftic juädam effigicm, ant potius pufilla Nymphęx albx, circinato paritcr ambitu, fed mino "Cappa

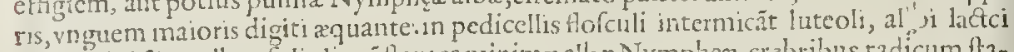
aut ielini füt, tribus foliolis côttantes minime alb.e Nymphex, crebribus radicum flaminibus, longus fe porrigentibus in fundum lacuftrium, ftagnantuimg; aquarum, vbi ranx lubentius itabulantur, vnde nomen: ad arcem Londini regian \& monia, Flurima Iuho \& Iunio, guftu Nymphęz aut Lenticulæ paluftrss.

Teisnos TRIBVLVS CAguaticus.

SOff. Tribulus marinus.

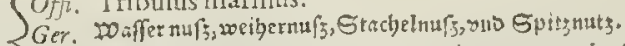

Belo. matctuoter. Hif. Abroves cor Abrollos.

Gal. Efcharbotz, Saligotz, Chafraignes d'eau, on Truffes d'au.

BO R. A a i z v s, vt Belgix, Germanir, forsis, 3. pigris fluentis, prope Nymphęas aquaticus Tribulus, qui ctian aduerfo filumine č Francolno Ferrariam verfus na!:igan ti, nonfemel occurrit, adqúc ipfus \%rbis Ferrarix monia latcritia in altè deprefsis val. libus \& fcrobibus. Pancis hæc frmilis effigie, cóg̨; nullī laterc quit, qui muricatas uces caltaneásve criquetras,duras, tcrnis plurimumat taiaternis mucronibus figétes, norit: zucleo albido, Caftanea fapore, quo plebecula hubéter viectrat, Caftuneáfy: aquaticas appelitat. Semirotunda, crittito leniter ambitu, fulia Soldonelle \& Vmbilici fimilid, fed 
ciafsion, c pediculo longiore, fuperiore fui parte nonnihil protuberante, cannofo, fucculíto, è caule breui Porulaceo fonfm definètc in 1'adicen, comis vdis, \& albicantibus capilla ment:s, prolixis, fiblatas, continenter in aquis partim natantibus, partim in fundo rcptauribus î merfis. Quarc videndum meritò cur Agrip pęvinguento addiutur nuclei, qui bus etiam ciuplaftica, ołftruendić; vis, aluuin conftipantc.

\section{COLOCASSI A, fue EATPTIAFABA,

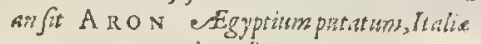 \\ muperingulinum?}

SI $Q^{y}$ Is ad fruetum varietatem rcfpiciat, latius hodic multò patet ambitus genèris fabdcei, quam quuin Diofcorides Gracam fabam \& Egyptian duntaxat memorabat:nam \& noftras vulgaris ncutra illarum eft, \& complures ex: India tum Oricntali, tum noua Occid htali confequur fumus, quotum fructus aliquantum fabx rquiparantar, fronden autem \& reliquam faciom, fillie abfit, nullus agnofcat fabx . Eaproptcr illa cum primis egregia Egyptia huc pertinere vidctur, vt que paluft is foli humentis gleba fit foboles, vndeapté Liofcorides Cibotij fiue Aruilæ eruiz ethymon, quodinmeri- tóquidarin carpunt, vti dicctur pofteà . Et frondesilti funt quantę arborum (malim verti Peralitidis, vt c̀ Gręco poteftelici, equè Thiophralti \& Galenilectıone.) Radix harundinacea, crafa, cruda vel cocta eftur. Quarc apprimc oliminnotuife Theophrafto \& Diofcoridi, certum eft. An verò fit ifta, quam Commétator fibi, al 1 fị; perfinafit, fides fit penes Bizantiam pifuram: quam ifam critici audaculi fub fanät, ac mulfant Dracontio Aconito, alífg; nonnullis, ita nefcio quid talis eueniffe. Cortè multis annis ab hinc per multas credebamus plan tas nobis vifas iftus in plcrifq; Italię locis(nam nullus crat hortus paulò celcbrior illic cui deeflet) verum poftea monucrunt nos forcs $S$ : bulbi, tanet complures vnà adnati, A ronis fpeciem efic. Sunt enim nultz conferta \& quafiappendicibusaliorum bulbortm aude, tuberofe, oblonge : radiccs effigie quidem Ari, fed triplò aut quadruplò rnaiorcs, fimiles, \& cócolores illi radici, quĩ Apium falfum cfie monui mus: fed fucculenta, tenerx, intus forisć; fufcedinc rubigin ofa : folia 12obis creuerunt Nymphex maximx magnitudine \& ferè funilitudine, crafsitic, colore, fed liræ, venulx, neruluć, \& fupcificics fuerunt Aronis, vti \& guftus: florem nullis blanditijs poturnus prolicere, neq; diligentiores cultorcs, Pifis, Bononix, $P$ atauij,, bi Triuifanus Medicus habuit : nech Lio ille forcufs Philofophus Venetijs parum fudijhuic impendit: in Bclgio fatan hymis fxuitia deleuit.

\section{eARON CAGTPTIVM qui co Theophrasti,num \\ fitrocchtionim Colocafia?}

S i igitur, vt non nolentesaflentimur, fit Arum Egptium ifta planta, quam dudulnt Sdclineauimus, non Colocanta fue Egyptia faba, cognationis notis qubufdan potuit impofuife cum recetioribus, twm antiquis authoribus: nam Palladius, vbi buibos Col locafta ferendos peccipit, videtur fequutus opinionen \& nomcnclaturam Cypriortm, qui Collocafsiam appcllationem huic impertiunt, vt cft apud Diofcoridem. Et vtiuam otium non defuilfet Mathiolo, quum illi oftendebatur Tridenti vera Colocifsia, na ille accuratius tain vifendã ftirpern, ciúf; natales, conditiones, magnis, vt par crt, votibus her bariorum expetitan, nec citra laborcm \& fumptum aducetum, verbis expreflinet: Sed non tarò inftituti obltố magnum virum tranfuerfi agit perorandi libido in quoflibet, gui nequent fauere linguis \& lilere, cuiufmodi hic dactísimus Guillandinus, nodeftiffimis Anguillar, Matthiolo maltix Vercellenfis A pollo. Itaq; ob fimiliudincm caulis \&

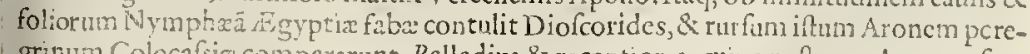
grinum Colocafsia companarunt Palladius \& recentiores, cuius nofitum Aronem foe-

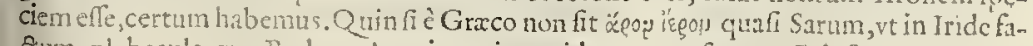
fum, plebecula, qua Darban Aronis vocitat, videtur agnofcere, ex Palrfino vernaculo 
\&. ornamäto Axronis Pontificis. Et alij foudius, fed fignatius, côdé ferě alludentes, Sacerdotis veretrum, aut mentulam vocant, in conum mucronatum racemum illum purpura punicante miniatulum acinulifg; ftipatum, ad milig Indıci faftigiat $x$ fpicx effigiem: vbiq; vıarun margimbus \& pratorum ripis volis obuiü, vixdü hyeme exıou folia pediculo edète bipennis eftigie, quale fagittarix aut Boni Henrici, virorc lurida \& pallentia, maeuhs nonnullis niggricantıa, vnde etiam Dracontiam vocant: radice hermodacty li ferè oblógıre Satyrij Erithronij Geneuenfis.

\section{$A R I S A R P M$ Veronenfum. Plinig ARIS.}

$V O$ c i s atgumento, non tantum effigic \& viribus perfpicunm Aro congenerem effe Arifarum, quem vocat Galenus \& Plinius Arim: quę vox Hippocrati, inttrumentum Chirurgrcum oftendit, vnde fortè accommodatum nomen : aut potits à vigetiore acrimonia qux huic ineft, quàn Aro, \& qua difcernuntur: alioqui non nuf magnitudine difcrepantes \& in Egypto nafcentes à Plinio traduntur. Nobis tamen qux notx funt fpecies duę, non folum minores multo funt, fed etiam rotundius folium vni eft, cuius virentis magua copia nos donauit Francifcus Calcenlarius Veronenlis in primis perstus Phamacopœus. Eä puta-

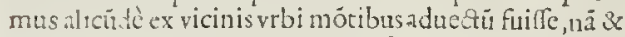
alıbi non procul Thermis Lucenfibus habumus: \& ide bulbi, quos vna in capfula cum Moly \& Colocalsia afferen dos curaftemus,in Belgio fati ipfa Bruma in foliú erupête, paulò antè Ari exortum: in pedicellis loreis Cyclaminis modo, folia fingula Hederacea, nultó minora, Ari molliora, \& delicatiora. Flos fuit er:a fingulis vnus, vuo foliolo conuoluto, oblongus ápeciu Arifto. lochix, c̀ lateris rimula enicante fibra ftaninca. Radix quanca Fumarix Plinianx, fed foris fufci, albida intus, tantoperè feruens, vt ifta Agyrtx: ridiculum quidem, fed nou perinde iucúdum, evcitent plebi fpeftaculum.

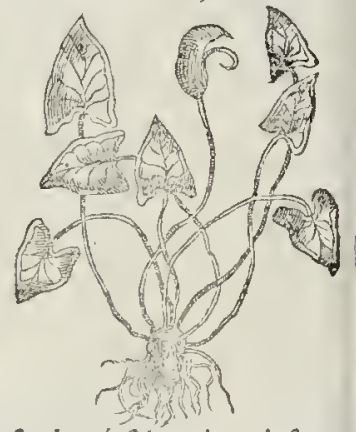
Quippe alicui è turba oftendunt nuculam auellanam, perfuadentć, falten ip os inferat, ff deglutire non lubet: tum impoftor, cclcritatc munus, cun valct, inferie hianti ruftico vnum ex ifts bulbıllis, moxq́; illı eomprimit futces, qua xetutum inufte bulbi imprefsione, contratis fibris, \& tunica palati,convelluntur. Manetí; mifcllus riftu didúcto, ore hiante, ridenti fim lis : Sed mavusígevoy Homericum edente.

\section{A RISARUAI Norbownte.}

HO u v v c o quidam Stephanus Barallius vocatis, nobis perfumiliaris, p:opter $\widetilde{\text { fu}}$ mam firpium Norbonenfum peritiam, in qua confenuerat, \& uomen in Academia indeptuserat Diofcoridis Monfpellienfis, non femel duxit nos ad riuulum quédan ponè conobium Funecinctorum, vbi in fulicetis \& herbidis vdis eruebat radices huins, interdum vnam aut alteram fimul,interdum plures adnatas, maiores quàm Chelistonij mino ris: folia emittentes longiora, anguftiora A faro, righidiufcula, coć; cuneta plantula adeò a-l rida, ve fruftra fapius cupierimus flo:es \& fruetum videre, maturius marccfentes prz: folibus feruidis. Nam illic quibufdam annis, humidioribus pręfertim, nonnullæ fe prodút. plantr, qux a liàs aliquàm multis annis contintò âtate recurrente pręficca, nufpian cóparent: vt eft legumen illud Ferro Causdo Italicè vocatum, nec non aliz multre,

ARISARUM anguSfifolium, Orbinogali luteifacie, 


\section{STIRP IVM aduerfarianond.}

NE CY I E millius anguftifolix Aricari, quod in

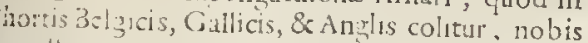
form vilum aut lemen ha temus vilum. Quod quidê eò mugis optibamus, quir fufpicabamur Orithogali luteicougencrem. Eftenim in erıcctis \& filicetis, Lig!nrixpreferim, anguito folio, porraceo, aut Ornithogali lurei, palmari, in anguftum quafi pediculum, prolixŭ, ad imum duficlente, è ceruice bulbi Auellanz nuculre puris, jur Serpentarix maioris.

$$
\text { AIVGVINA DRACVNTIA. }
$$

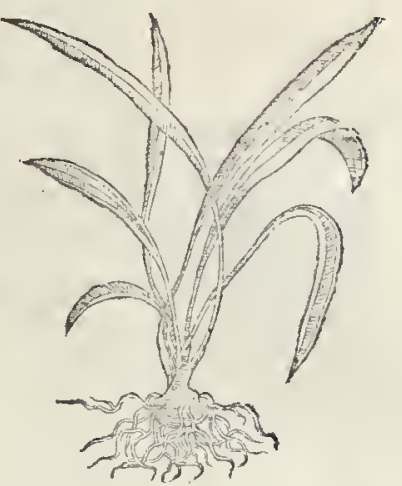

SERRENTARI A w ifam maiorem,quam cunet horti norunt, E ager Monfpellienfis

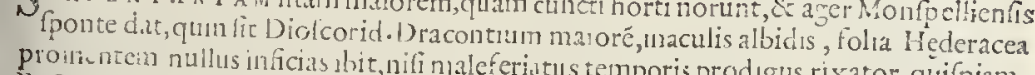
proinntan nullus inficias shit, nifinalcferiutus temporis prodigus rixator chifiam. Rectu quipoe caulis, flaber \& politus, extima cute anguinum ferpentísve extuium, ma-

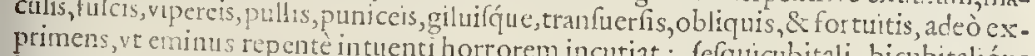
primens, ve cminus repentè intuenti horrorem incutiat: fefquicubitali bicubitalique In fum no è vagioula enicat, congeftus in cono racemus plane Ari, cui radicem ctian non abliamem, rotun lam, maiorem, feque lateratim propaganter. Qni igitur foliorum comparationem negant veram, quòd non fint hederacea, actum agunt, nempè monét, propter confequtionem \& aretam finilitudinem, folia Dracótii dietu fuife hederacea, cun potius debueraut hederacea illa Ari dici, quia huius poftea conferun tur cum folis

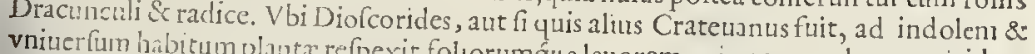
vniuerfum habitum plantx refpexit, fol orumq́u lẹorem, virorem, colorem nitidum fuperficiei contulst; quia elfent perquam affines pluntx, vt vides in collatione etiam radicis:vbi fingularis numeri, nulla exprefsione maioris, a ut minoris Dracontii, bis repetit collationein. Nec vniticifo tractu Græcra, à nofris amicis iamdiu luftratæ, vlla alia vfpia Serpentaria, quàm ilta, quę etiā non procul ınceniis Möpelliacis inter egetes, Gladiolos \& Hyacituctios lata exit, alibiciue in pinguibus aruis, non diucrfa nifi xtate, quando decufsis funinibus \& fimmitatibus effactis à prxtereuntibus, frequenter repullulant nouellre que potuentut Plinio perfuadere, plures vt confitueret fpecies Dracunculi,mifcerótq; Arı, Afari cognatıs differentias, vt in Bechio, alirfó; locis illi contırit. Nec alterius DRAcostrov plante videtur geminata defriptio apud Diofcoridem, fod ab alio quopians, paulùm di Matbiob. uerfè, vt fere fit, defcripta. Lubenter nos \& grati illam à Senéf Rapi fffigie adductam, nee tamen defcriptam, fpeetatum iuiflemus quo loci ille dicit, vbi faplus frultra fcifcitati filnus: 17e vquxm libt vi fam : negabant item Cortufus \& Anguillara nobis anxic̀ fcifcitantibus.

$$
\text { AQVATICA ANGVINA, fue Dracunculius. }
$$

IV $\mathrm{x}$ T A riunlos \& labentes aquas frigidarum ac calidanm regionum, vtin Beigio, Nort'mantia, Apulia \& Hifpania Granata, fponte iftum emergere afferebant nobis, gui in hortos fuos indiden tranfplantarunt: cauliculis folia haderacea gerit, maiora Ophioglofsı, fupernè acuta: in caule humili fubpurpureo vix palmari flurem rubellí, odorum, tọ abintenile Serpentarię, è radice fibrofa, geniculata, latius ferpente, \& multis fibtis hum: depafa,nullo bulbo appenfo aut annexo, vrente gufti \& crufas excitante.

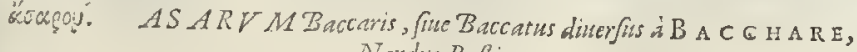
Nardus Rufticn. 


\section{STIRP IV $M$ aduerfarianona.}

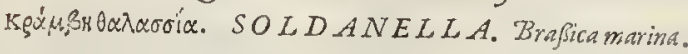

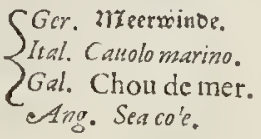

VV I G A T IS S I A hæc non modò meridionalibus litoribusmaritimis, fed etiam ad Septentrionem Anglix, Belgix, \& Nortmanix, abundè prouenit folio A fari minore, craffiore, in riticulis pedalibus \& cubitalibus, humi fpatfis: flor e pulchello, purpurante, Volubilis, nolæ inftar. Semine nigro, duriufculo, angulofo, Pooniæ minorc. Tota muccagireo fucco pragnat, qui denfutus Hydropicis, cùm intró fumptus, tum abdomini admo. tus, multum commodi praftat, notiore quàn tu tiore experimento.

\section{$G R A M E N T A R N A S S I$ bederacerem recontionm.}

PER ? v с с н A herbula,foribus candidis, Ranunculi, venulis fufcis, palientibus depictis, in viticulis dodrantalibus, femipedem \& pedem longis, infernè rubellis, \& à me dio ad radicem, folia Cochlearix adolefentis, vel Chelidonij minoris ant Hedera, fed multò minoribus, nitidis, virentibus:radice cralfa, tcnera, multis fibris reetid depacta, in pratis \& ydis pafcuis Anglia ad Oxoniam, Pedemontium, Belgij \&: Northnaniz : femen in vericulis, fubrufium, exile, legebamus per caniculares dies dictos: fipor fubdulcis, gramineus, tantillum acrimonix prodit:magis congrua defcription facie, guìn vfu cóperto, gramen Parnafum fanxit hanc herbariorū Germanorum Senatus, Lá ras yont naltus yocans.

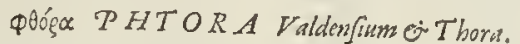

NON infcitè quis inferet huc illam iftis perfinilem herbulam, qux palsim mótium Alpiüć; accolis vocatur Thora, interdum nulla adiectione, interdum Valdcnfum. Etenim multum diứq venatores illius Alpinz gentis vti funt, vti ctinnnum mul ti alij,ad ferarum cap tură,quibus folo fucco exp: cfo, \& fpiculis illito certam citamc; paraut perniçiem, qua namģ; hreferit telum, aut vuluus fecerit, fubic repentè vitus, quo illico ona vulne ris (níi pracifione antevertant) corrüpuntur, putrefcút ve:vnde Phtora nuncupata, veltigio manifefto de Grxcis relicto:quippe $\phi \theta . s \alpha$ cormuptio, nex, venenum, aut mors. At hi quibus multis periculis notx funt vires earum omnium herbarum, qua vulgo nuncupätur Sagit tarix, cuiufinodi cum multis A conitis, ctiam Heliebori funt, Hifpanis vocati bicrua de los abaleftricros, praut i-

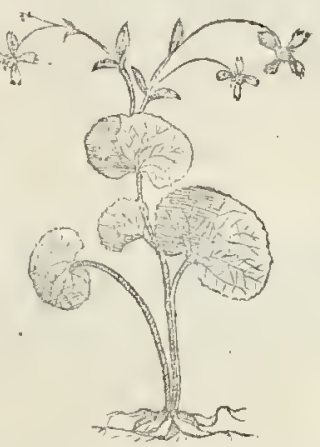
fta eft,cateras propè elumbes \& incertas ducüt. Huius verò ineunte Vere ius premitur, atq; veficulis, aut potius vngulis \& cornibus touill is recondium emitur mittiturć; vent̆ ad emporiafinitima, vbiad vfus anmuos venationum fibi comparant fera:um infidiatores, quos vicini Del phinatcs, Allobrogi, \& Prouinciales vocät, Be prers vil Lobatiers. Qui quidem mouere potuif:nt ifum Pfeudocommentatorem, ne Pfendoaconitum aftueret, vt qux funefta dote fuperet quoduis A conitum \& toxicum. Hanc nos ex nontibus Genenx conterminis primum Italis plerifq; oftendimus: Cardanóq; quil tum primum fuo de venenis libro,multam ilius mentionem fecerat, neq; dum nouerat, dono tulinus, cü huius antagonifa feu hoftica anthidoto, Antithora etian vulgò fic dicta. Sefquipalmum viy fuperat caulis, glaber \& iunceus, cuius è medio \& fummo fape vnum, larò bina, rarifine toto caule terna aut quatcrna folia or $x$ circinat $x, \&$ tantillum criltatx: fuperficie 


\section{6:- STIRPIV M adiverfarianona.}

giabra se rigidiufeula non harfuta, leuore \& coloreviridante, nounihil ad Cyclamen acce. dunt, Toribus luteis Pentaphylli, Tormentilleve. Radicellis aliquammultis quafi corul is

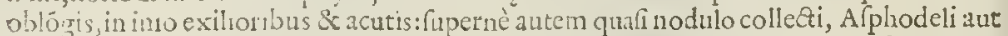
Lenicanthe noltre fimtitudine \& candore ccfpiem amplexx; quafi Cancri forcipulx,

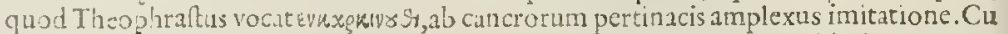
iufnodic q qan è celforibus Sabaudı Alpinis val d' Engroigne, yocant, híc damus. Nam in hortis Mechlinix caulıculo fingulare fingulum florem $\mathrm{R}$ anüculi dedit, Anico ftirpium perquàm fudiofo Georgio Rienti.

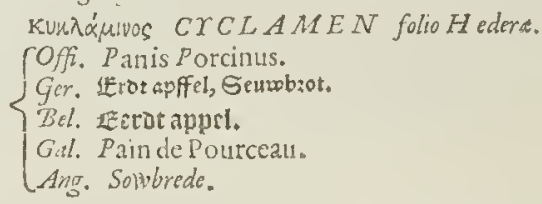

6. N S I N Y A T Cyclamini voxtum folij ambitum circinatum \& circulare, tum etiam J orbiculatum radicis bulbum, vnde facilis dignotio vulgatioris Officinarum: Nam ex montıbus Aipinis Rincticis in Italıam proficifcentibus, locis vdis \& Gaxeis itineribus obwa pafim alia, qux non folio circinato vt Afari aut vulgati Cyclaminis eff, fed potius rriplici nucrone diftuneto, herbę Trinitatis aut Hedere Helicis modo. Eadem etia Norbonę rignis montibus $\&$ hortis crebra. Eius radices que vetuftiorcs magnitudine altcrius funt: qua noucllreadeò exigur, vt Anellane magnitudinem vix fuperent. Adultioribus catuis promitur exilis, tcneriufculus, \& in liumum prontus, è quo prælongis pediculis folia fur. recta faftigium verfus, vbi funt flores purpurci communis Cyclaminis prorfum frmiles, purpurei: nomnunguam \& luteos Verno tempore exortos nondum folijs emerfis memi nimus nobis attuliffe commilitones: Florent cnim Vere \& A utumno interdü odorati, alı̀s non. Huius vires communi pares, \& vus ficquens Norbonéfibus ad Hifpanicam lu $\mathrm{e}^{\mathrm{m}}$. Doetor Scnenfis vbi cx Mc fux maior m \& minoren facit, tandem dixit fe minorcm vidiffe folum vno tractu:cam tamen ncq; verbo auticone docuit. Decuit tamen illum finere 110 f cire quæn am ifta effet radix, \& an ab hac noftra differret, quando multa minus vtilia varijs locis infcrit.

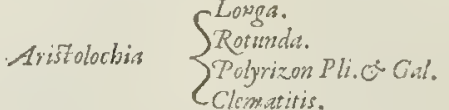

OMPLVRES iamfunt annicim Academi. \& Pharmacopoci Monfpellsenfes quatuor Ari folochias notifinas, \& vifu receptas habucrunt: quas hic propter ardeliones, qui temerè res fibi nec vifas, nec auditu cognutas peruertunt, potius quim produnt, operxpreciil fucrit oratione \& iconc perfpicuis notiores faccrc. Ac primú animü huc aduertat veftigator, tantan effe trium, Rotüde, Longx \& Polyrize Plinian $x$, folljs, caule \& florc fimilitudiné \& parilitatem, ve ne perfpicatiori quidé, \& exercitatiori interdủ lıceat nó decipı: na a foliu cü tis circinate rotunditatis, magnitudo fer nepar, caule lento flexili:florib color partim ex luteo ni rricat, torma omnib? cadé, vnde dilcrimé vel attentius intucnti vix patet inter ipfis tres A. riftolochias:ac nifi radix certiorem ficeret, nullï nó fallerc poffet.Id tamë intereffe depręhendes, $\tilde{i}$ quando loca vbi ontues magna copia nafcutur, ve

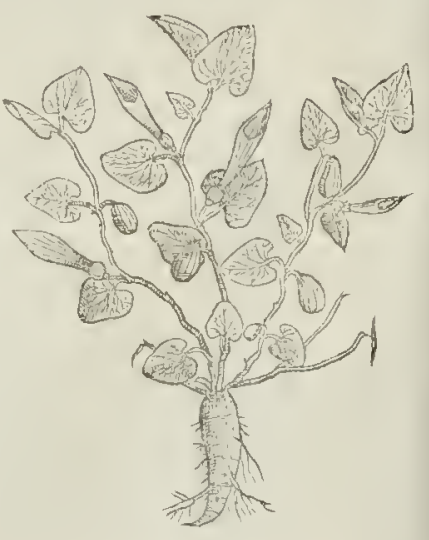
toto Narbonenfi tractu, luftaris, Piftolochia to:o labitu aliquantò ninor, neq; folii, neq; 


\section{STIRPIVM adwerfarianowa.}

florum aut pomorum differentia nulla,vti ney; feminis, tadice tant ìm differunt, gux Lo ia gx, forma digiti,cum pufilla,qualê videtur defcribete Diofcorides, cùm verò prouecta , quadruplò inaior, foris colore fufco vel atro, intus fanet Centaurei inagni colore.

POLYRH I Z O gratior odor multò \& aromaticitas; radix mult:s fibrofacapillamentis Hellebori modo, prolixionbus tamen, \& fauentibus ex atro. Rotunda veriuis perquàm fimilis; verùm folia aliquantum rotundiora, \& nigriora Longx Ariftolochix, non Piftolochix, vt plurimúnan fitu nutari polfunt \& folent:flores itide, vt folia,obfcuriores, \&r per meffes turgent lagenuix, nucis mofchatre pares, femine fufco pragnantes, ad bafim compreffo, śapice donato; ea cadenj planè quxinter marem Myrifticam \& feininam nuces intercedit difcrepantia. Rotundx auten radix iam valde nota, Itiliz \& Gallix Norbonentis ; fed non perinde in vfum deduet $t$, ac potius Chirurgis, quàm

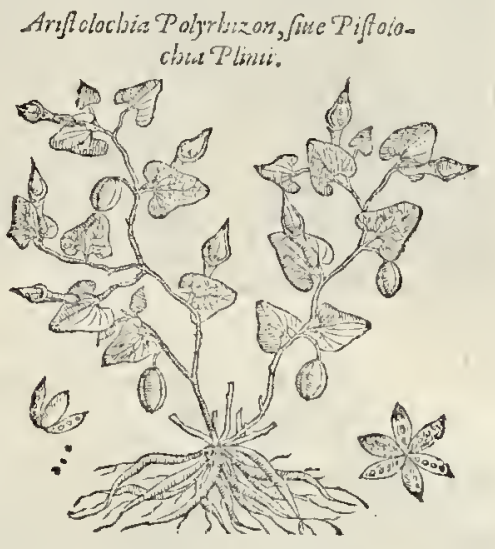

$\operatorname{ROS} N D A$

Medicis, magno fanè dedecore artis, \& incommodo egrorum : Quibus commendamus Indicas merces, picrumque tempore viet $a s$, aut cariolas: $h a x c$ anté noftratia recentifsima ignorare $110 \mathrm{n}$ pudet. Tam efficaces quippe funt Löga, \& Polyrhizon prafertim,vt radices vtrufque pari monento, partiun intro dato, partim in peffario admoto, elicuerint footun, iam fefquidiem fruftra erumpere conatum, foctufque inuolucra lacerata, enixan puerperan, tridui cruciatibus penè enecatam : eóque multus omnium vfus apud Monfpellienfes. Poly rhifx guidem Arffolochix, indictx Diofco.\& incognitz Commentatori, radices, in vfum liondeletius reuocarat, propter plantæ ignaratio nem iamdiu defitum, se tainen praferendum reliquis duabus, tim fuau aromaticitate, tum medicata efficaciore facultate;cuius merito Andromach. \& Gale. Theriacis aptiorem pra Rotunda \& Longa prxceperant:at vtranq; de odore \& fapore exploranti, multò ignauior comperitur Clematitis, quam falfò tenuewa apud antiquos Theriacre fcriptores vocatä putabant Itali : efț enim ifta implexa multis viticulis tentioribus quàm Afparagi, aut Clematidis alterius carulex:fed non difsimilibus, quale ms in Olinetis, fegetibus ficcioribus, nos, comilitonéfque noftri toties videbamus \& eruebamus, quoties Mórpellio Botonetū vcrfus \& Cafrú noum prodeambulatum ibanus. Inibi etiam locis pratenfibus \& vdis Rotunda luxuriat. Longa verò prope rudera cucrobiorum, via quæ Frontignană ducit plurima. Procœemifcuc adeò vtrauis, item Rotunda \& Lóga in pratis ad oppidum Villa noux, vt vix difo cernere queas,

\section{CLEMATITIS:}

No s parum notiorem \& frequentiorem Clematidem, tum vinex plurimam, turri \& arua frigidiora dant in reliqua Gallia, cuncta Italia:deing̣ue Germania , \& Flandria fponte habent: multò proceriore fruticat viticeo farmento, cubitali; flore luteo, caule cus bitali, fruetn oblongo, magnitudine parui oui: femine intus lato, radix exilis, odorata. Huic viresignauiores cętéris, \& viú obfole tiot; praterquàm apud omnifios A ppolli; nem \& Mathiolunz, fecutos facé Pharnacopœorum; qui cùnuLongam \& Polyrhizon nunģuam vidilfent, \& Italiz nilhil y fpiam plantarü deeffe à $M$ athiolo perfuafi effent, ili facilè \& falfô perfuaferunt, Clematidem effen genuinam Longam. Hincq́ue tot morolxe. Laureati Appolinis difquifitiones, gui cum hanc in Biblioteca pictam ex authoribus. fruftra quafifet, \& Mathiolo fcribenti, prope foffas emergere, fidem habuiffet, illuc illum fequntus ; dum venatur, phà fizo more, in foffas lapfus eft. Res ipfas 
qui infpectione notas habuerit, \& tum mente, tum manu concinnè digerere nouerit, facilè ex voculis perperam afferiptis, fefe \& lectorem extricabit, \& perplcxas accruationes iItorum declamatorum aut ridebit, aut declinabit, nec fe rebus, fed frbi res fubijciet.

Piftolochia Fufchij,quam Plinij Capnó effe, nuilus ian ambigit, plurimú aberat à $P$ olyrhizo: hincá; licet documentú videre humanę imbecillıtatis \& fatagentix, quz eri.um optimum quemq; \& veriamantifsinum, ve fuit Fufchius \& Dodoneus, non tarò tranfuerfum agit: modeft a horum tamen potius gratia!n,quàm cenfuram merita elt : Alioqui vides Piftolochiam à crebra radicum propagine prolixa fic nuncupatä, \& deferiptä. Conrra Capno vtriq; rotunda vel glomerofa radix:maioris, quanta Caftanca nux magna, infernè concaua:minoris, nuci auellanx par. Fumarix folia lationa, caules, fores, fapor \& odor,cxtera fimilia, vnde Capnos: \& vides quid profuerit error : etiamnum hodie clinica \& Chirurgi Bataui ifto errore imbuti, ad vermes necandos, \& vulnera ytuntur, non infolici tamen fuccellu.

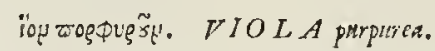

gGor. Blauso Deielobermzertzen violen. eAng. Fiolet.

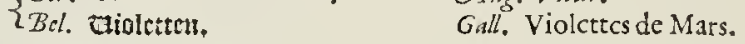

VT Cerè prima ortu, fic in prima cőmédatione vtilitatis \& delitijs inter vernos flores Viola purpurea, fic Grecis vocata ab Io vacca fabulofa, cui pabulo hre fuerit. Nihil frequentius \& vfitatius vbiuis gentiü, tum officinis, tun plebeis cömodis, to to vertēte anno, foliorum virentium, \& fornm recentium, Vere prafertim. Exinia namque fragrantia blandiuntur qux faturiore purpura nigra lucent(flores albx quippe vbiq; etiam vulgatiores, nullo aut fanè languido, placent odore) ad Cordiales condituras, Syrupófo; \& cathartica decerpuntur, vfurpantur, aut ficcati vmbra feruantur. Nillibi Europæ cultuluculentiores, magnitudıne, fragrãtia, colore, \& prouétu vifuntur, quàm Antuerpix officinis, quibus parant creruleum violaceum Syrupum ex pluribus infufis, faccharo addito, Soli 20.aut 3o.dies expofitis. Angliz horti delitijs,ędiumq́; ornamento \& olfactoriolis alüt. Sed feminc caffam orbámve fecit hanc duplicé vocatam Violam, florum luxus, fraudato reminis genio. Etenim fi rurfum negligatur, nec frequentius tranfplantetur, ad ingenium redit, filiquofa , focundać; feminis albi, toutundi, pufilli, miliacei, mollioris , medullof, ad purgandum vtilis, fed calculofis vtiliffimi.

\section{$V A R I E T A S$.}

VE M A D M O D V loci \& frequentis tranfmotionis occafione, flores maiores; colo. ratiores, \& femina nulla edit:fic in nemorofis, vmbrofis, frigidarum regionum, qualis Anglia,Belgia,vel calidiorü mótibus arduis, ficuti Veganii \& alii Norbonenfes mó tes, ramofos cauliculos emittit, fefquipalmares, teneros : \&ex interuallis folia oblongiora, altius ferrata; filiquafó; in tres filfuras dehifcentes, longiores: flores concolores, inodoros:nonnihil tota ortu \& pofitu Violam flammeam imitata. Neq; tamen fpecie, aut natura diuerfa à Martia, ne tantoperè fibi plaudat Cómentator, qui inuenta Labruíca, infultare videtur Baccho.

VIO LA, FLAMMEA, coloria,calids.

$\left\{\begin{array}{l}\text { Germa. Sreplesmitrut. } \\ G \text { allis. Penfees, aut menues penfees, }\end{array}\left\{\begin{array}{l}B \text { elgis. 19entect. } \\ A n, \text { Hertys eafe, Loue in ydle pan- }\end{array}\right.\right.$

Feristas. S I c e I O R I I v s hortis pratísque fiticul ofis hxc admodum fimilis viola fruticol $x$, fed anguftioribus, longioribus, laciniofifáue foliis, caulibus quadratis, tenellis, fucculentis, reptantibus:florü tricolori valiegati elegantia \& magnitudine violæ Martıæ æmula. Sedula etiam culturx opera, nitidiore bicolore purpura, cädore immixto, intermicant $A$ äwieis violaceif́çue foliolis quinis \& quaternis, guftu fubacris tota elt.

SAXIFRAGIA ALB A Chelidonioides. 


\section{STIRTIVM aduer ariañowá. $\quad 26 \%$}

$\mathcal{F}^{\mathrm{N}}$ ferenda huc eft hac, magis firurze merito quàm tcmperamento, ant vi calfaciendi \& Fincidendi fua, vnde radicem ad calculum laudant, \& Saxiftagum diêtant, illius cuim albx Strumof \& grandinofa nigrx filamentis \& fibrillis hrent pendula exigua quafi granula, qualia Chelidonii minoris, fufca \& obfcurc̀ purpurea, acria, amara, à vulgo femina falfo putata, propterea quia obferuarit féfe propagare ex aliis atque a. liis bulbillis, noua fobole fuccrefcente:folia nonuull is ima erumpunt c̀ pallore virentia; in pedicello pillofo, rotúda, criftata,mollia, minora, fimilia A farinzaut terreftris Hederz: Caules etiam villofos, pedales, \& fefquipedales, quibus foliola for nonnulla fummatim habent albicantia, Nallurcii quadantenus colore, effigie, aut Eruce. Magna copia \& magni nominis lıx in fterilibus, \& fodinis lapidei carbonis, via Bathonēfi in Anglia, Belgio etiã \& Northmannia, acceruant mulierculx grädinofam nondun florētis piantx radicem, vocantó́ue Saxifragiæ femen: peroptimum ex vino vel polline ad calculum pel-lendum, farcúsque renum, vreterum \& vificæ extergendos.

\section{$S A X I F R$ AGIA AVRE A Lichomifacic conatali.}

HV I v $s$ videtur fpecies illa herbula palmaris \& perquàm fimilı foliis: funt enim rotunda, \& fimiliter carcinata, crafsiufcula, nigriora:fed radix tenella proiixoribus \&e comofis fibris, mul tos hiąc inde cauliculos emittens, in quorum fumuo forculi emicant aurci, vnde vtriculi femina per maturitatem pandunt hiantes, rotunda, jarua, rubella, fapore herbaceo, frigido,infipido, \& prorfum eiufde tum figurę, tŭ naturx, qux Hepatice aquatic $x$ ? qua cum Mattio \& Maio bellula in Anglix Northmanix \& Pelgii humentibis aut I ichenis faxeis \& parietinis fubftillijs \& manătibus floret. Vfum putarim non alium quàm Hepaticx aquaticx, aut Iichenis.

$G A R Y O P H Y L L A T$ A, fine G EVM Alpinkm Recentiorsm folio Hederaceo.

NOstris herbariis hanc Alpinam Geum quoddain facientibus, 110 aduerfamur, quia nefcimus, fitne potius ad Saxifragas fuperiores referenda. Folia quippe in imo plura, Hederacea, nonnihil criftata,circinnatione Afarinx, aut Saxifragiz albx, fed maiora funt. Caulis è radice geniculata, cx fufco ruffóve albicăte, reçus, gracilis, cubital is, fummo ramulis diuifus, \& flofculis albis, ftellatis onuftus: tota nonnihil calefacit, exficcatq́ue guftu Caryophyllatx, aut $\mathrm{Sa}$ hicula.
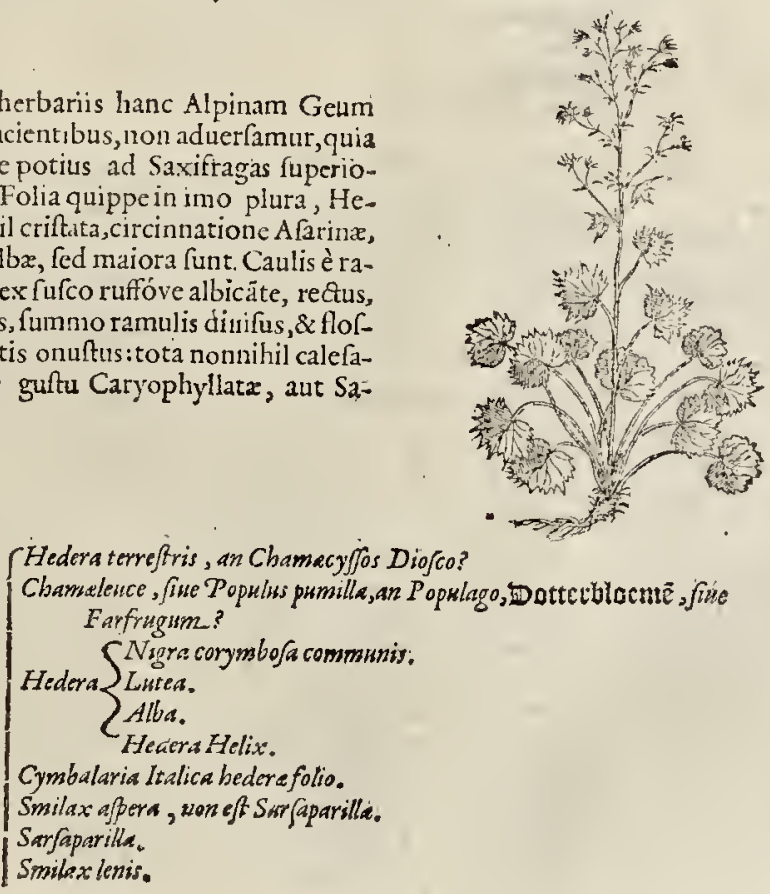

Z.ij: Scansm 


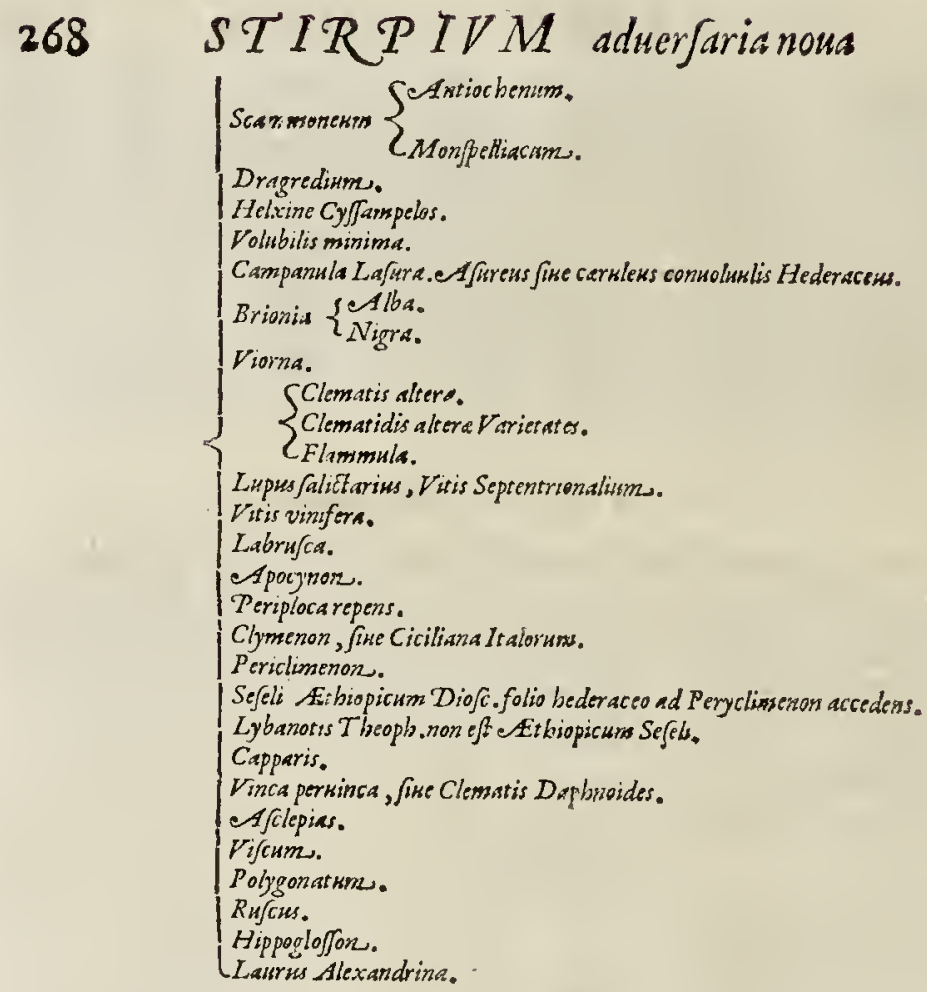

\section{$H V M 1 L I S H E D E R A$, Hedersla, fue Chamaciffus.}

E F F I G I E $M$,vires,atque nomenclaturam plebeiam vulgaris heder $x$ terreftris expendenti, vix vlla fe offert planta qua zqué fcitè quadret Diofcoridex Chamæciffo: fic dicta (vt verifimile fit) ficut Chanępeuce, Chamxdris, Chamacipariflus, \& Chamxpitis, quia hederam pra fe ferret, fpecie tanue differret, vti facit terreftris Officinarum Hedara , qua amarore \& viribus Diofcoridi me moratis, ad obftructiones difculfu perdificiles, nec nó arthriticos affétus valere, Barbarz praxis crebrum expermentü teftatur. Verùm qui malunt litigate quàm inuenire, obiiciunt folia Macrotera, vbi nos Microtera (qux tranfmotiuncula vnius literulæ frequentifsima eft)legendum fufpicanur. Refpunt etiam flores Leucoii minores: atqui refpuerent potius in Anthirhino, quem Violx Leucoii afsimilat Diofcori. funt \& huius purpurci caliculi filace is fofculis non ita difsimilibus. Reliquxq́; notæ adeò fuffraguntur, vt qui hanc hocloco excludunt, dum nullam fiue potiorem, fiue deteriorem fufficiunt herbam, parum gratix incant à rei Medicx candidatis, \& à noftris Practicis meritò ambitionis pracipitis in fufpicionem veniunt. Parsim abundè hac prouenit, \& nofcitur ab omnibus, iuxta foffas \& culta, vt Diofcori. monet. Qui etiam flores candidiores quàm Albx violx defiderant, minus accuratè vulgatos legifie videntur codices, qui non habent album florem. Nec fi Plinius Splcatum tritici forem habet, illicò idcirco fequendus, quando Diofcorides nullam facit mentionen, \& $P$ linius folitus eft non paucis in locis permifcere notas, vel audacius Latinè vertere, vt proximo facit capite de Chamzlence : quem tamen nos lubentius excuranus, quàm incufamus, hoc fęculo alienæ famæ vorand $x$ auidifsimo.

$$
\begin{gathered}
C H A M A E V C E \text {, fue Popklus pursiths, } \\
\text { an Populago? }
\end{gathered}
$$




\section{STIRT IVM adwerfarianoui.}

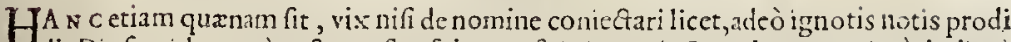
dit Diofcorides:ver im fi qux fit vépiam noftëis in terris Topulum proximè inititił folïs planta, ea erit, quam vulgus Gernanorum Đottcrbłsemē vocitat, Latini autem, Farftugum: qua pratıs nihil notius aut frequentius eft, vicina, amula, \& conuigtrix Chelido. nii minoris,prope quam collocaumus. Ad renum lumborumáue dolores epota mulcere poffe, fi quideun cralsıs \& flatulentis muccoribus fint oppleta, facilè credet, qui guftarit, Frara quadae: A \& nouerit partin vrinas ciere, patrim etiam in alinentum ades̀multum \& laudatum melo Vorgilio, abire, vt vacca prino Vere palta, lac perbonum efficiant, \& inficiant birtyrú luteo colore.

K1000;. CORTMBOSA HEDER ACOngmunis.

Germa.售plye. Gallis.Lierre.

$\{$ Belgis. Cievl. Ang. lwi.

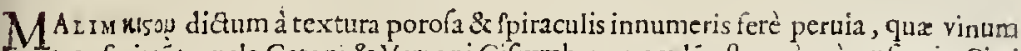
tranfmittút, quale Catoni \& Varroni Cifsymbion poculì eft: quàrra à pufionis Citti faltätis in Hederā Poëtica defornatione à Baccho verfi, vt fabulant Gracı. Kiskp̧s iterm

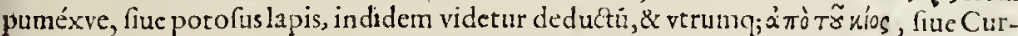
culione, qui cufpidula, aut acu, potins quàm ore triticum hordeumq́; terebrat Latini ab edendo Hederã dixerunt: Etenim arborü importuna amafia, \& vel uri affentatrix, cortice rmo ${ }^{\prime}$ impacta, maceries veruftiores demolitur, \& radicatis propagationibus arbores amplexa, enecat \& exedit; prxfertim illa fpecies qux maior \& arborea vocatur:non item qux Helix. Nec plures duabus nouit noftra etas differentias genericas' : tametfi quainlibet multas dixerit fpecies Diofcorid. qux fortè melius decernentur varietates, quales agnofcit quaternas quinasse è duplici fpecie vulgaris arborex, qux cunctx genti notifsnıa, virere criam inuita Bruma folita eft: Fronde in imo per initia arcuatis, \& femilunatis angulis triquetra, ve funt Trinitatis herbẹ diax: Vetuftiora autem in editioribus viticulis circinata, qualia Cyclaminis : floribus congerie mufcarii glomerofi $x$ ftate defluxis, corymbos botrósve glomerofos ineunte hyeme matuerefcëtes, Ligultro fimiles, cernere vbique viatun eft:ité circa vda, \& ripas humentium regionum frigidar í ac ternperatiorum; nam \& calidifsimarum impatiens eft. Huius multz varietates funt, qua antiquis perfuadere potuerunt, vt plures differentias, fiue fpecies fatuerint : tametfi difcrimen è Baccis duntaxat Diofcorides accerfat, vti in Malis, Nucibus, \& aliis fructibus valgò fit. Arborea Hedera recta.

Quinet iam atborefcit quadam, fuapteque ftat ftipite, nulli innixa pedamento, qualem in fyluofis qquibufdam Anglix meminimus, Orthocifum antiqui dicunt. Interdum etiā quibufdam locis xerampelino colore folia nitent. Pifis nobis oftendebant herbarii corymbos cafii \& albicantis'colotis. Melinos fubfufcos corymbos plereque planter fata in hortis Italicis \& Germanicis ex Campania \& Apulia, hodie maturant,

\section{HELIX, Suse prossolnta, fterilis Hedera.}

HVmr r is planè hæc minor \& infrequétiơ cöcinnè vocata Helix fuit,quia fecundüfar. ineritofos funes exerat clauiculas capreolófve viticeos, qui humi pangütur, \& propagatione quadam quafi in fpicas \& anfractus prouoluitur:interdum etiam ferpendo mufcidis truncis \& caudicibus aduoluitur gracilioribus farmertis, folia minora altius triquetro fegmëto finuata, edentibus, planè fuperioris, fed minora minorisć; vfus:nec eninn vel folia huius decerpuntur, vel Gummi vllú officinę ex hac colligunt: Quin nec fruetus quidem villus in ca obferuatur, vnde fterilis putatur. Verius autem hẹc nǘcu paretur terre ftris Hedera, quàm illa Barbatoruni, niobis paulò ante afferta Chamæciffos Diofeo.

\section{Cr $M B A L A R I A$ Italita, Hederaceofolio.}

VE N E $x$ x I s , Patauii, \& vicinis pagis pafsim in zdium parietinis Hedera, ant Alfines modo dependet iftxc, folio finuato, Hederaceo, mollicello, lęuj, in fexilibus, cxilibus \& tenerrimis, capillacesis,pedalibus \& fefquipedalibus Cafsitz caulical is. Flofcul 
luteouirentes Elatines, fiue Veronicx fomin $x$ pares \& fimiles. Illic Pharmacopœi,penuria \& ignoratione Cotyledonis veri, inilcent Fopulneo vnguento.

$$
\begin{aligned}
& \text { SAILACIS ASPERAE, \& SALS EPARILLA } \\
& \text { figura on natura diforimen. }
\end{aligned}
$$

DI F F E R T hæc à laui vuis foliis, fpinis, radice,lloribus, viticulis, atque viribus, denique natalibus. Quippc non nifi montofis \& collibus feruidiorum tractuum, Romanix, Hıfpanix, Linguagotiç, vbi plurima, horridts aduncisq́ue crebribus fpinis, Rubi ritu, iouplicat mordicus proxima quxque, affurgitćue vltra fupraç; parietes \& fepes vicinos. Folia Hederacea, longtora, Bryonix nigre ambitu \& fuperficie : non incı $\sqrt{2}$, $\sqrt{e}$ d lçuia, \& in medio, fecundum ftrias neruulonım, fpinulas habentia atrouirentia,acinosć; rubros, racematim copiofos, Ribes magnitudine \& modo:nec flores difs miles Ribes vtrufuis ra cemofi, fed albi.Radices tametif longius excurrät fubter humum, ter nis aut quaternis vlnis longrores, non tantæ tanen cum salfa-parilla fumilitudinis fortitas fcimus, quantum hactenus perfuafum doctı quiburdam fuic:qui fcriptis mandarunt Salfaparula ean dem planè effe: cuius tamən conf́picux intuenti patent, à Smilacis radicibus, difie. rentix. Sıquidem Smilacis geniculatx, articulatıs fegments radices, candidx, foris nitentes, Graminis carnini, aut Harundinis valatori.

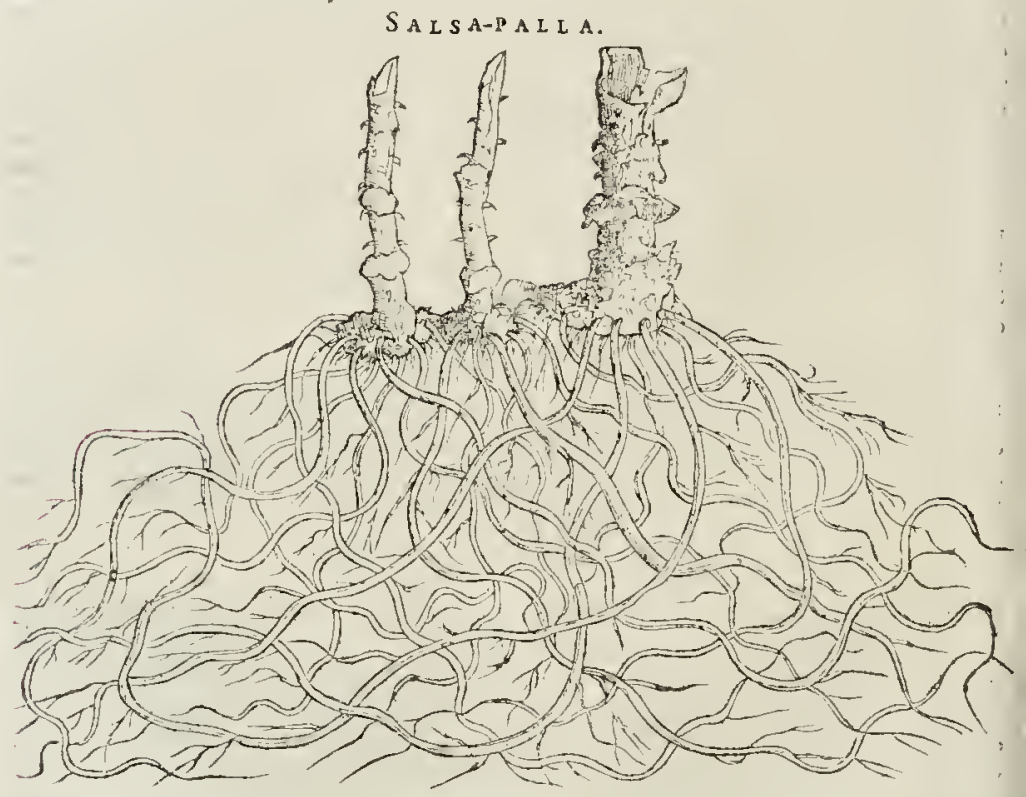

At Parill $x$ crebris loris prolixifsimis, ab rno trunco radicis magno, pręduro, frumofo rugoff́çue capitibus, hinc inde fubtus, vt in Afparago, vel Rufco, oriuntur numerofi concolores lori, zquabiles \& fine geniculis vel nodis; recti, Hexiles, cortice duruficuculo, pullo, rugisftriato in longitudine, quam vicenum pedum interdum metiti fumus. Intus farinacea medulla, non ita ingrata, fed vifcida, nonnibil emplaftica, amaricante, nec tamen calorem prodente. Eapropter perfpicuum eft, non magis effe Smilacis, Rubi, aut Clematidis alter $x$ Viorna dictę, quàm fint Cinnamomi, \& nonnulla arbores, 


\section{STIRP IVM aduer/aria nowa.}

tum Indicx Oricntalis, tum $\mathcal{P}$ er unianę noftra Laurus: Tametfih $x$ c pofsit nonnulla cadem : qux illa præitare. Neg; fi Colutea fimilhnna eft Senx, ideò contınuò cadem aftruénda. Sed ftipites quos habemus $S a l f x$, ex eodem radicis preggrandi \& capitito nodo lignofo, intus flauefcente, Ariftolochix rotúd $x$ tuberof $x$ magnitudine, \& colore, exeuntes, pollıcé,aut maximum Rubā crafsitie fuperant: fed præduri lignosiçue , crebros nodos adinodum extantes circa articulatas cómiffuras crebriorum vncialium, frequentiumçue interuallorú, atq; aculeos adūcos deorfum verfus nōnihil depreffos, rigidos habent, Ǩ valdequàm Rubü imıtantur afpectu, potius quàm Snilacé:verum guftu neutiquam aftringente, fed fermè infipido, nec vt radicis emplaftico:cóqque, vt certò fcimus, mininus efficaci: Folia tamen quidam amici, qui viderant, affere bāt non admodum abeffe ab Snilaceis. Optima habetur quę plenis medullofisá; eft Hagellis,folida, cādida intus \& habitior, quęquue facilus in zquas tota fui longitudine partes diuellitur:huius namque libr:un femiffem plus virium habere experiuntur, quàm alterius ftrigofx \& gracilioris, nigriorıs, decé 2uit duodecim vncias. Debent tamé inttituı decoctıones non minoris quantitatis, quàm 10.aquxlıbrarum, ad vncias duas, tres, vel quatuor radicis : non, vt quidam Medici noftrates fcripto imperant, aqux libra 3 . ad vnciā vnain radicum. Citıss namq; diffarit aqua ( nifi 11 diplomate id praceperint) quàm radıcum vires bulliendo eductr fuerint, Radicis namque medius torulus vel corculus, qui lori inftar eft, durior eft, quàm ve tam citò vires deponat. Vnde quilibet facilè percipıet, quàm parùm comperta fibi $\mathrm{ex}$ alienis paginis in fuas tranfferat \& pofteritati offerat Cómentator, qui eximii ingenii \& Italorü fuperioribus annis doctifsimum Medicum Fallopium mendacii infimulet;atque iftius de Salfa-Parillę, atq; ciufdem fententix, adinodùm incert $x$, authorenn faciat Gunnum fuum praceptorê, quem virü auditione, dum Pifis effemus, accepimus tantoperè flagraffe rei plantaria cognitione, vt etiam nihil nô luftraffe montium, nemorum, praruptarúmye rupium Hetrufcarun1, \& Tyreno vicinarum infularum, quò minimas quafque herbulas indidé aduectas, nec dum fíbi notas, in chartas ipfe conderet, \& affabrè pingendas curaret. Quare fi fuit illa pluribus abhinc annis Tufrorum Prıncipi allata planta vera Salfa, (ac nó potius, quod periti nonnulli fubolfecerunt, Hifpanica Smilax afperat) mirú videtur $\mathcal{P}$ hi lofophici \& nobılis animi Principis,principes Medicos Guinum \& alios iftā non curaffe reprxfentandam; falté illas fatis cópertas, \& valde varias notas, quas fuperius oftendimu\&。

\section{CONVOLVYLVS maior Plin. Smilar lanis velleris. Volubilis maior vulgi.}

$V^{A}$ L D E quàm laxus Smilacis fignificatus, qui quafdam cognatas, vel fimiles alias, tamë admodum difcrepantes, \& viribus penè côtrariis pollentes, defígnat, vt $S_{\text {milacé, }} T_{a x}$ um virofam, a fperan $S$ mulacem venenifugam, fraxinum anbiguä:demum hanc non valdècertam, vt cuıs vtilitatem nullam, fed duntaxat incommodum turbulents infomnii parcere Dior, autumat : eapropter hanc hîc noftro more difcufsimus confufam fignificationem, ne vti Plinio, imponat nobis. Quod autem ad Lęuem Smilacem iftam, vulgò receptam at tinet, quia nihil omnino reclamat:praterquàm collatio fe rs inis luvius anguloff, cum Lupini rotundo, compreffo:qux fanèineptior eft, quàm vt Diofcoridis fit putanda:conectamur nos voculam dégur quippiam deprauationis perpeffam, qux genuinam

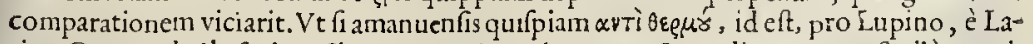
tino Græcum ép̧òy faciat : Sic extrito primo elemento, \& medio mutato, facilè potuit,

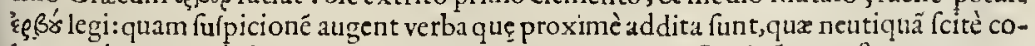
hærent; hrc nempè. Semes vetuti Lupini parumm ơ nigrum. At Lupinú non elt paruum:nec nigruın.Salté quxpiam fubeft labecula, cuiulmodi my riades plures expunetz funt in authoribus Græcis Theoph. Atheneo, \& aliis : \& in Galeno nonnullx:in Paulo \& Tralliano complures voces Latin $x$. Eapropter hanc eandem maiorem Conuolluwlum retinendam arbitramur.Eft quippe non modò farmentis viticeis, mollioribus, longifsimis, \& aptiffinnis ad fornicatas opacationes: Foliis itę lęuibus, hederaceis, aut alterius Cóuoluuli Ciffampeli maioribus, mollıbus: cętera tŭ flore, femine, farméto prorfum Cifampeli noftri, fed maiora:radice item longa, fparfa,flexuofa, fed paucioris lactis, nec comperti cómodi. 
PA y c afunt plunt $x$, quas de facie \& facultatibus penitus notas habere, magis intertaria fan foriá yolut ( neceffaria, vt tanetli nonnul! a infamia flagraret, tanen nulladum fit inuenta, cuius vlla ars, fuccus, vel excrenérum, tam pufilla nole tantum cómodi preftet, aut ve vicária huic e nofcendum impoftorumóuc fraudes detegendum : fićne aurior \& folcior foret $\mathrm{Mc}$ dici opera. At vix hodie millefimus quifque Medicorum plantam vidit, nifi fortè pictam, hinc cuilibet fit in procinctu veram \& nofe, \& alere, orationis ambitu pingenda, quam olo penicillo Cómentatoris pietor exprefsit. Anno fexagefimo primo aut fecundo fupra quimilefinum, indefeflus ille herbarú nounu veltgator Venetus Pharmacopecus Seminus Martinellus, ex Syriaco Alepo miferat plufquam centum libras glebx Scammo cas Lachryma plenas, feu Diagredio antiquorú, cum feminibus angulofis Volubilis. Hęc emina tum Patauii \& Venetiis primo Vere mâdata, in luculentā Volubilem, feu Voluuu abiêre, adeò finuofis Smilaceis foliis, triquetris, vel potius Ciffampeli, foliis, floribus, \&e em Bryonix radicem $x$ quante ato; teneritudine fimulante fors ericia,intus albida arne: et probatioris I v R B I T H of ficinarum : verum facilius aliandé pottea A ntuerpir quò femen miferanus ferendo men forbus \& viticulis quinum \& Cenum cubitorum, prorfum nihil diuerfam, cuius Guillielradicumólue pullulationes excifas exficcatasque ofteutabat, adeò Turbith A mentita, vt difcriminis perparum, aut nihil percipi poffet.

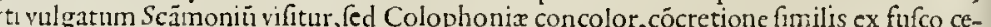
ruleus erat. Quare non fecus differunt quàm Meconium, fue fuccus expreffus, ab Opio, qux fuit manans liquor, feu lachryma. Sed Scämonii lachryma cinereú habet coloré: O. pium fiautum \& limpidiorem. vtpote e capite, vbi defęcatior, non è radice fiuens. Verum quia nauca lachryma aut mera, aut hodie vfurpata Europeis vxnit, nó enim poffer tanto vfui tam paucafatis effe:opera ponéda, vt fucci probe teneanus exquifitas notas, \& vaetates, quu minore mortahu detriméto, logè maiore emoluméto eo vtamur purifsimo, crimen.Videas namq; non rà̀ idem corpus, eadenu de inorbi caufa \& planè eodé modo affectum, aliquot granis fumptis fxpius facili duetu, nulloó, cruciatu bilê, pitnitofamó colluuiem excludere, tnm ex eadem prorfum gleba effracto frulillo, mul tò plura grana 


\section{STIRP IV $M$ aduerfarianoua. 273}

data minus educere, multum tamen cruciatum cicrełnempè difpar molis concretio alicubi plus, alibi minus, alterius cuiufdā lact is Tithymali, aut Cataputire accipit: vnde difparilis vacuatio tam æxpè confequitur:fi namq; foret purus \& merus fuccus vniufmodi, nequaquam tantæ dof sop effent difcrepantix,quantas cim antiqui tum hodierni Scammonii animaduertimus: quandoquidé etıá lodıe quidã nihil aut parü excernüt forupulo vel 3.S.quàmplurimi verò minore portiuncula, quia vt plurimum temiftú eft Scâmonium, çux mifcella neutiquam improbäda videtur, vt vociferantur humorifta Galenici, namq; if eft pro eo ac debet, equabilis atq; correcta, valdequàm eft vtilis, dú minore $\$$ mo Ie \& mor 2 ed ucit, anteuertió; inıprefsioni caloris, qux fieri folita cft à medicaméti curicta tione: maximä enim nouimus vtilitaté in huius cathartici celeri notu cum delectu:nam fufflonum Agyrtarūóq vitrū, flores, fiue farinę ftibię, impetu \& nó difcretu humotes quoflibet obuios pręcipites dant. Tametfi vinü purgans ex radicibus Scầnonii Diof. parat, $\&$ fi homini Græco iftud demenfum folitü, lane plus purgat aliis additum : fic videmus additum Diaphrnici Catholic \& aliis, vt fucco Rofarum, plus moucre, vt Braffica marina Thymalli. Ac nullun Scammonium hodietnum affertur non adulteratú, \& tamen fottấsis commodius, quàm Diofcorideú fincerũ, cuius êuo fi fuit dofis recepta, par eft putare alicuius vehementioris fucci additione, tantillä quantitatẽ tantum efficere nunc, $c$ tiā nonnulla portione farina, colophome Refinx addula:nimirum refina ad pelluciditatem coloremq́ue taurini glutinis ementiendum : farina verò, ve cuius interuentu refina cum Scämonii lacte aqueo focietatem coalitumá; inire queat:Iento tum ıgne rudicıs la verfando quantum plurimum pofunt optimè agitant, donec indurue rint, coaluerintque, in compodx nixtionis glebam. Cuius dignotio $h x c$, fi non admodun ferueat ote, nó multum virus redoleat, nec nimiū tenax fit terēdo: 11am leuitatis albefcentis atq; taurini glutinis pelluciditatis hodie vagæ, nec certænotre funt : nullü fermè hodıernü videus Taurino glutini aut Bdellio trăfparens \& nitidü , nec laktex albedinus, fed liucntis \& ad cxruleum dilutum quadantenus vergétis. Pharmacopci è Mefue \& Greccis cy tonii cauo inditú coquere in clybano addereq́; maltichem foliti funt:minuló́; prudēter cytonia abiıciunt, quibus träfmiffa vis \& potior \& delicatior fcảmoniı remanet: Quare dehine fciant mifcendam etfecarnem cythonii compofitioni, vel ifto Venetorum modo parandum, ne maior iuftò moles medicamenti inftituto officiat. $P_{\text {ulueratũ fcammnni L Lib r. fucco }}$ cytoniorū depurato operiunt, leniterque \& blandè, non fecus atque. Mefues fuú de fucco rofarü Flect. excoquŭt, dum induruerit, vbi cautio, ne nimio obruär fucco, quò vires fcãmonii nimis reprimãtur,obtufave penè langueãt,plerüq; plus nocitutx quàm profututę: Nam $M$ cfue meritò multum fucci rolarü Scammonii incoquit, ve quo retundatur quidem impetus \& acuties, fed non deleantur vires à fucco Rofa roborantis \& purgatricis

$$
\text { Monpellienfe SCAMMONIVM. }
$$

$\mathrm{CO}$ м м м is Pharmacopocorum confen Cus Scámonium etiam facit ıllam Marinam volubilem, copiofifsimam toto illo lito re $\&$ rabuleto, ab víque Rhodanioftio ad Aquas Marianas \& Sinum Agathenfem, cuius fucco lacteo concreto, (quo inulto tota turget)purgatıones moliebãtur, fed maiore do fi,minore effectu:quippe fucco nihil additú erat, fed coctione coactus, niger vel' fufcus erat. A volubilium omnium floribus differt flos huius, multos namq; pufillos, ftellatos, candidos, confertos fert Iunio \& Iulio: folia rotüdiora, A fari, breuiora,crafsiora, firmiora, latiora, fuperius albida, acuta, \& bafi falcata, nec angulofa Apocyni, aut Ariftolochia frmilitudine \& nognitudine; ex pedicu lis \& loris reptantibus \& ftcatis humı viticulis vel pifcatorum attegiis \& Tamarifcis

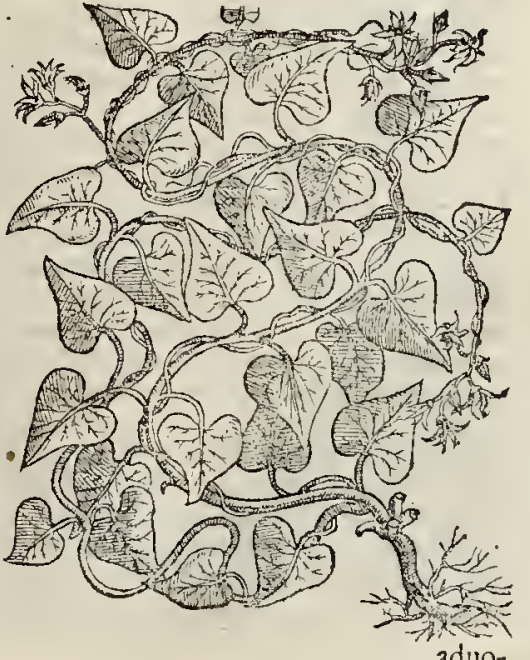

aduo- 


\section{STIRTIVM aduerfarianoma.}

aduolutis quaternum quinúmve cubitonum: femen angulofum in vtriculo minore quàm Ariftolochie:radix digitum xquat minimum, longo reptatu multiu fibroL2, alba, fucculentä, veluti relıqua planta.

$$
\begin{gathered}
\text { CONVO LVVLVS minimas Spice folins, vel Stachadis } \\
\text { citrine, ant Lisaria. }
\end{gathered}
$$

$\mathrm{R}$ A r Ivs inuentu hîc aliis regionibus quàm Galloprouinciæ, Aliobrogum, \& Norbonæ, ad margines aridos fatorum, \& oliuetorum:vbi Iunio, \& Iulio floren delicatiorem fuperiore, fed confimilem,vnifoliü, -angtrofum, diluto colore purpurafcenten $;$ femeng̣ue haud difsimile, angulofum, compreffum, promit exilibus in viriculis, reftis, crebribus, à radice lignofa, ferquipulmunt lo nga, albida, à qua partim folı, partum à cauliculis féquipalmurualtis, exeruntur,angufta, longa ad Linariam, aut Stæchadcrn citrinan 'Phiteuruáve Norbonenfe, etiamó, colore \& canicie accedentia: guftu exficcante, nonnihil calfaciente.

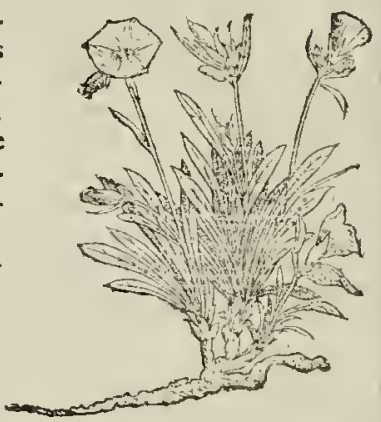

ASVR EVS $\mathrm{S}_{2}$ ine ceruleus Conuolunlus Hederaceus, vel fmilaceus, exoticuss.

HE c omniü.huius clafsis rarifsima \& pulcherrima,nec nif hortis Italie, Gallix, \& Belgię nota, vbi amona purpura porrectis attextísq; fecus parietes \& pcrtıcas funibus vi ticeis, gracilibus, vmbracula cócinnant, atc; fornices, vifu periucüda: vifenda quippe floribus, è pediculorú calyce exeütibus, Iafmini, aut Vincx peruinc $x$ fimilibus, fed ora cuinis ftellatım prominentibus angulis, nolę carulex vel afurex effigie:vnde Campara Latura Ltalss. Folia teruis angulis fingula, in teneriufeulis pediculis, Ciclanıen, Hederámve anna fam imitata, nomihil hirfuta:longa \& gracilis radix, rulla fui parte in Medicorum commercia venit.

$$
\text { HELXINE CISSAAYPELOS. }
$$

Sโ м ४ \& Ciffampeli nomen, frmulque collatio \& foluendi effectio, teftanturabundè Hel xinem effe vnum quein pıam Voluulorum lątariorü, pafsim propter fepes, inter fegetes \& vites oriundum:vox fiquidem E $\lambda$ vete, trahere, harere, vel arripere configrificat, viticean, voluulofamáue propaginem, prçertum in Ciflampelo, \& Hederæe mixta fignificatio, folia fatis repręfentat: Verum cum Volublorum, plebi Volubilium dictarum, quat. 10 f finr differentix, mox fubdend $x$, que vixdum effigie, viribus, verò neutiquam diftinctä hactcnus fuerüt, nobis can fanciendả Cy flampeió, qux cum co,quod notis \& matalibus magis quadrat, tum etianı pre cæteris euidentius purgat, quanrvnan dutaxat ficultatem illi reddidit Diofcorides, cui potius affentiendum quàm polteris illius duntaxat amanuêfibus, \& exfcriptoribus, quos modeftix caufa nó nominamus. Scimus igitur Volu bilem illan, q!ı inter vineta Múchatelina, maritimaique fepes, Thamarifcos,propefegetes ad Fronrignanam Norbonx \& Lio Venetorun,inter mare \& hortos, alibiçuc palsim viticularum prolixifsimis flexulibus fefe aduoluit,aluum foluere fucco \& diluto. Eft hæc non diuerfa a Volubili vulgari maiore: fed folia aliquantùm anguftiora,crafsiora, dilutè virentia, in exilibus pedicellis \& prælongis viticulorum loris, quibus ettan intricat fepes, penaentia:prope qux, ex iiffem intertallis, fed in aliis pediculis, flores infundibuli,nolave effigie, à latiore labro ad mucroné ductisleuibus ftriis, latera nónihil intrò inflexa, finientibus, candidos, tenues s̀̀ cuius ino cétro prodit vtriculus angulofi feninis plenus, Ariftolochir rotund $x$ fimulis, fed dimidio minoris, Scammonex Antiochenę paris. Succo etiam tota,tum radix, tum folia turgent lacteo. Candida radix, prolixa, fragilis, hucillucreptans, minimum digitum aquat. Hacplerique impoltores Phamacarii, prę̧erim re. gionibus 


\section{$S T I R P I V M$ aduer Jaria noua.}

gionibus maritimis,vbi hxc adultior, adınixta fucco Tithymali Taralii \& refinx Colo. phonix, quæ nigricat, ementiuntur Scannmonium.

\section{CISS AMPELOS, ALTER A, Arripliciseffigie.}

$H_{\text {A s c iamdiu à doctis perfuafi, huic tamen aliquantùm difsimilem, putaramug }}$ H legittimam Helxinen: frequens namque amplexibus multis vites rripit, nec fecus aut arêtat,aut enecat, vel lifde pabulum furripit,atq; Cafsytha. Foliis e chederaceis, ob. longis, in anguftum Atriplicis facic \& modo defnentibus: Flores itein Atriplıcis albicất racematim:femine triquetro, nigro, Selami Theoph. fed minore; radice exigua; vbiuis ina gno protentu vinetis, frigibus, ac fepibus adnata. Sed de ficco vel facultate fubducendi aluum, nobis ignota, nifi quis Atriplicem putet, coque lubricare poffe aluun ftatuat, mul. tò tamen imbecilliorem illa maritima certum.

\section{VITIS ALBA, BRTONIA.}

Germ. Gtichwurts. Gallis Couleure, Ang. Bryonie, Wille vyne co wrilde boppes.

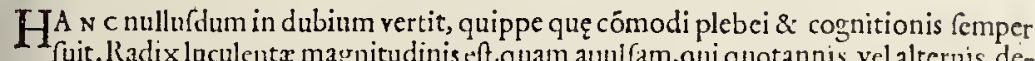

$H_{\text {fuit. Radix luculcntx magnitudinis eft, quam auulfam, qui quotannis, vel alternis, de- }}$ orfum verfa bafi pangunt, altero tanto crafsiorem efficiunt, tenerarn, Raphani colore \& concretione: In viticulis pręlongis, teneriufculis, clauiculis multis, obuia quxque prahendentibus, folia vitıs, aut Balfaminę, incana, flores palliduli, ftellati: acini parfi, tubentes, magnitudiné Afparagorum fermè æquant, fucculentr, acriores, vti tota planta: cuius turiones \& a paragi pullulantes etiamnum hodie quidam in acetariis efitant. Ifchiadicis cataplafmatis radix peroptima, \& Pfilotris:immixta \& cótufa taurino fanguini, ad Scirros \& carcinomata inirum quantuin profit.

\section{$V I T I S$, vel BR YONIA rigra, Sigillwm Maric. an Ciclaminos altera?}

$V^{E_{I}}$ tacitus plebeius confenfus iftam vitem effe fciuit,vocauitćue nigram Bryoniam; vti cx Diofcoride Galenus \& Paulus, cuius tametri quiddam levioris momenti, vt color rubens in acinis, ac buxeus internus vitibus defit : tamen hederacea folia, Sinilaci a fpere quàm finillima funt, citra, \& fentes flexuofi gyri, viticularum multiplicicapreolo, \& clauicella proxima quaque amplectente: racemi multis aggefti acinulis, virentibus primulim, deinde rubellis, demùm viterius maturitatis quafi vietx progrefsi, ex fufco rubore in fufcedinem atram vergunt : catera, vti radix (qux Bryoniä magrnitudine, figura efficacitate \& teneritudine imitatur, foris nigra, intus alba)planè tam vcra,quàm vulgo notifsima funt : vbiq; fiquidẻ in Gallia \& Germania Syluofis \& afperis dumetis, arbores, fepéfque fcandit, \& ruis, fpeciofis, oblongis, floribufque mufcofis Labrufcx, vel Oleę pallentibus conueftit. Compertum eft, vel nulierculis, vehementius vrinam, renunique fabulum, \& menfum faburram, impellere potu: verum Veneris tantoperè incentiuam effe, non perinde affentiuntur quidam Commentatori; quin potius experti eidem conuiciabantur; conquefti lumbos eneruare, fan guinem, renéfque inflammare, plurísque effe fibi vnam aut altcram Cynaram, quàm incertaın \& periculofam fuam Bryoniam:quam fi propter calorem, Venerem accendere vult, haberet fibi vni, aut Flammula vefceretur, ad fui Satyrii Erithronii vires enerues fupplendas.

\section{VIOR N A VVLG I, fortèVitisfylueft. Diofcor. O'T heoph. Atragene.}

Y $V$ I I locoaptior Viorna vocata Gallis, qux nufquam non frequens \& nota (fortè quia viarum fepes ornat) quàm huic:Sarmenta quippe cxteris Clematidibus proli- Lib. S.Cep. it. xiora, duriora, crafsiora, rugofiorn, vitiç; Labrufce vel Viniferz Vitıs colori fimiliora:folia etiā funt Solani hortenfis \& maiora, atq; fingulis clauiculis quina, quibus lubens obrepit arboribus, atque Hederç xmulatione editiora fulcra fcandit, ,ed interdum ambitu 


\section{STIRPIVM aduerfarianons.}

fupernè ferrato ternis autquaternis dentibus, vt un Solano nonunquan vifntutu, que laciniata pedem Anferinú vocatum!, Atriplicis fpeciem, tam bellè refcrune, v1x ve dificr-

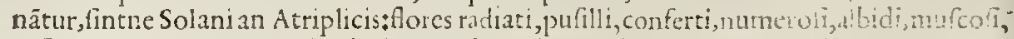
\&ftamineis apsculis ornati, odori, Mavo \& Iunio : capilliceo tomento cin Lntur capte Januginis albide, lęuis, qux etiam in multam hyemeri perdurat, folis aini(sis:acini autem complures confertim ftipantur ab vno pediculo, aptr, rotudi, rubentes cs fulco, comoref

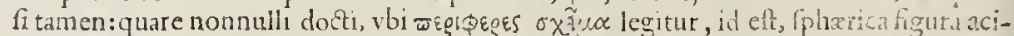

Atrarine $T$ beo phra.vitis Syl. Diofe. Dalejc norum vel granorum, ซixtiфegs leuiufcula immutatione \& commodiore fenfu legi volunt, id eft, rotundam compleffan figuram. Actamerfi conectura hac nobis non fatis animum explet, tamen multò minus refoondebunt, amara Dulcis vocata, aut Biryonia nigra quas fuis locis commodius \& neceffariò aptaumus, notis. Alteram fcilicet neuriquam viticeam, farmentofámve, rugofam, limnofan, rimofan: llam verò conununem, iplam nigram Bryoniam.

\section{CLE $A A T$ IS perigrima Ceriela porpurat.}

TT O n abfimilis eft hax cxulea peregrina noftrati Flammulx ciematidi, ortu \& f.exu, porreftuque viticularum atque foliorum habitu: (unt tamen maior, flaccidiora, fir-

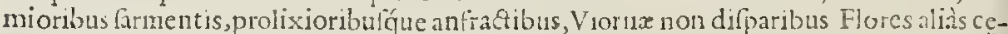
ruli,aliàs purpurei, ab illıs \& multorú foliorú figura fitnóg multü diuerfi , cxpanfis quateruis altriufecus \& ex auerfo fitis foliis, Pufatilla effigic \& colore, munoribus tamé. Seme \&radex Flinmulx. Nufpiann nos vidile meminmus, nifi in hortorum delitiis: Quin fuperiore tantùm anno Angliæ inquilina fuit, foruitque in Morgani horto:vt malè it iltis bambalionibas rizotomis, qui doctifsimo Bodonge hanc passim yiarum \& agrorun in Anglialuxurare perfuaferunt.

\section{CLE M AT IS altera, vicns, vuigi Flimmult.}

F Clematidum viticearúmve generi affinibus plantis, nulla eft, qux perinde quadret

facie, vel viribus, atque Flaminula, piebi fic vocata, quia non fecus ac hammeus feruor cuti adpreff, veficas, cruftas, vlceraq́ue inurat:Quin eius eft tenuitatis calor, prxter mulıa qux vrunt, vt fpiritú vridü dü digitis fricantur folia, eminus in nares pręertim iaculitur. Cerebrumğue \&. Cenfus repentè unagnoperè percellat, quòdexperiendo notıus, quàm gratius nobis tuit, tametli idcirco ad facultatem nolcitandam adımento fuit. Quippe feruor ille non in centro, intinifǵue terreis partibus, fed in leuioribus extimis, ind:cium faciunt fues Norbonx, \& alibi, qui hac innoxia, tum viridi, tum ficcata, vefcuntur etiam çfate, figinariq́ue creduntur mulierculis. Quin \& fuccus, \& ftillaritius lıquor primus, quali è vino flammeus eft. Folia multùm colore \& lęuore Peruincã Clematidë praferüt: fores item ftellati, fed minores, albidi, \& pufillis in medio faminibus, vt in Hypericone. Radix ab vno principio multas fpargit fibras Hellebori modo: nefcio an etiam purgent, vti de femine prodidit Diofcorides. Eft autem fubfuluum, vel fufcum, rotüdum, convereffum, in angutum definens, copiofum, ferie quadam \& corolla coniunctum: Norbonx \& Galloprouincir fpöte \& in pratis maritimis humi fparfa,tenera, \& humils vifitur, aut foe nicecis falce cadit, deficitur quippe fulcris, quibus inntatur: ctiăǵ; plurima frucicibus o fepıus inuixa, alifóque pedamentis, fi quę nacta lit. Belgi \& Germani cultiores fcita tex^ tura huius, Campanicl lalur $x$, \& peregrin $x$ Clamatidis carulee, depactas ftirpes frondofásque vites porrigunt, ad parietum fornicumq́ue vmbracula, variegato implexu, retia culatógue, tricoloria. Nec cnm minus fandit, nec difsimiles vites habet Ialemino: ne tantilia unicularum ratiücula à Cóméta tore tanto adducta, quufpiam deinceps audeatinficiariveram alteram Clematiclem effe hanc,cui pratulit Senenfis idem Viornam vix a* crem, nedum vientem, aut vlcerantem.

$$
\begin{gathered}
\text { LYPVIVS SALICTARIVS, Spontanos: } \\
\text { Luprenfalidarino or witis Seprentrionalinm, }
\end{gathered}
$$




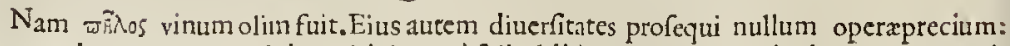
quando varictatem accipit mulriplicem à foli códitionc, more, \& Solis ab xquatoris inclinatione. Neq; enim Aquilonium cœlum fert, aut certèfructum profert immaturum, ferotin um, minimim fuauem.

Spontanea nec culta profundit vires infana lafciuia, \& in farmentofam, arboreamọ́; penè lobolem luxuriat, prol ixitate anfractuum, vnde fterilefcit, aut minores minusć; fapidas \& maturas vuas fert : Qual is in $P$ rouinciç \& Norbon $x$ maritimis, Gallia L ugdunen $f$, Italiẹ́que plurima, fquallidis agrorum marginibus.Sarmento duriore, cutég; integitur rismofa \& villofa, Viornz, aut fatiux vitis modo.

\section{DOMESTICA.}

D OMESTICA autem viti,amputatione \& interlucatione farmentorum proftatur ne fuccus farmentis \& palmitibus impendatur. Eóq; mitiores, maiores, \& elcgantiores botrifüt, fuauiores acini, vberioresḉ; latice manant. $P$ almitum decora magis fronde, habitiore, latiorc, diuifura Platani aut Aceris.

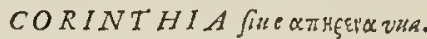

COr I N r i a quavocaturvua, nomen patrium teftata, effigie nihil planè differt à communi : Scd algidioris coli impatiens, gracilitate tantim racemorü \& exilitare aci

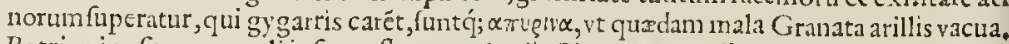
Botri enim, fue racemuli i pri, conflantur acinulis, Pipcrina aut Sābucina grana aquátibus. Ad topiariorum pergulas \& fornices deducutur hodie in Italicis \& Pedenontanis hortis vites huius.

\section{ASCLEP I AS Vicioxicum.}

VANDO ifti morofuli Critici, potius quàm Commentatores, nullum modum carpé di,immutandi,improbandive aliena placita,faciunt, noltrá ; expectatione \& $\mathfrak{x}$ quanmitatc abutuntur, exerceamus dehinc nos met conferendis plantis nobis plene cognitis, cum antiquorum defcriptionibus : inuitis illis rigidis cenfuris, ad quas fi vniuerfum opus herbariü Ceucrius exigas, vix cétefimam guamg; plantan legittiman dicas.Minus verènegantVicetoxico noftraci deefie Hedera folia, caq́ue lögiora: floremć; graueolew tem: quos potuit doccre vel infpectio merx piaturx, qux folia hedcracea prafert: $y \mathrm{cl}$ Diofcoridis ctiam lectio, qui Periclymenum \& Ethiopicum Sefeli Hederæ folijs commitit: additç; quantitatis dementionen, luempè longam, $P$ ericlymeni modo: \& idem hic Hedera cea facit, fed lógiora. Stirpi aüt pict $x$, a ut chartis affixę, fi odorem negăt, fortè affentior, fin florenti in montibus, dicam effe illi narem obefam,aur nunquam virentem vifam. Tametf txdet tot repetitionu de odoris incremétis \& amifione variis in locis \& plantis. Infirmum enim argumentü, quãdo multa apertiora \& potiora fu ppetüt. Quippe Vicetoxico vulgus practicantiü nomen fcciffe à dote qua aduerfum deletcria pollet, verifimile: vti \& Afclepias nomine tanti Medici nobilitata propter confimile facultatem videtur. Radix porrò huius innumer is fermè capillamentis fibrata, caules fexiles, vimincos, lẹues, fefquicubitum prolixos, edit. Folia quidé Hederæ rigida, ex atro virentia, fed aliquätò longiora, \& quafi fuper nè mucronata: florem cxiguum candicantem, odoris grauis, ingrati, quibus fuccrefcú toblog $x$, teretes, Rhododédri aut A pocyni perfimiles filiqux, femen fubfuluum, Sefami aut Apocyni, lanugine obuolutum cohibentes, A pocyni ritu. Huius radice vfi primùm periclita. tores, cùm aduerfus venena, tum ad vlcera, magnŭ fibi \& plantæ nomen peper crunt. Neq; pofteri potuerunt poftea adduci, quin pro Afclepiade agnolcerent \& vterentur. Siquidem illis etiam natalitijs, nempèmontibus aut aridis collibus, prefertim Narbonx \& ad Li. gures Taurinos propè fruticat. 


\section{STIRT IV $M$ adierjarianoud. Situe Diojco. AP O C $N$ N $M$, Periploce Greca, folius latioribus bederaceis.}

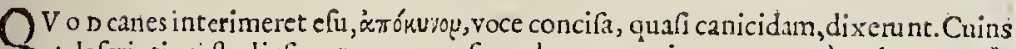
defcriptioni ftudiofi poterunt conferreduas non minus raras, quam clegantes \& apprimè quadrantes plantas, quas Patauii iamdiu ctiamáue non multis ab hinc annis in Pifano publico vireto videre memininus, \& adhuc dono feruamus à Medico longè peritifsimo Andrca Acroaria Cifalpino. Earum vtrique nomen Periploca erat. Alrera fuit flexilibus furculis vimine is, gracilibus, leuibus, pediculos vtrinque habentibus, longiufculos \& exiles, in quibus folia Hederacea, molliora, viridantia, lxua, tenidentia, \& quàm Vicetoxici rotundiora, nonnihil in funmo acuminata : fores tenues candidi mufcofi Valerianx, aut Drabe inter folia exeruntur : fuccedentibus Augufo menfe filiquis corniculatis, mucronatis, rectis, Afclepiadis maioribus, cliudentibus femen nigrius depreffum, pappofa lanugine obductum. Succus fiauefcir, ingratus, \&, vri tota planta, virofus videtur. Hac fi coni nex fir deuorata, A pocynum effe \& liuius fore a ntidotum Vicetoxicum) valde probabile eft.Certum nos exploratumq́ue habemus iam diu, faltem aliis venenis à cane deuoratis antipharmacü fuife: vti Thorę Anthora, \& Paridi, herba Pardalianchis, funt.

\section{$P E R I P L O C A$ Jerpens, anguftiore Tericlymenifolio.}

A L t e R A veró Periploca repens vocata, prolixioribus \& lenioribus viminibus ferA pit,variisque flexibus arripit \& amplectitur obuios caudices, Periclymeni modo. Foliz vtrinque ex aduerfo bina, Periclymeni potius, quàm Hederx æmuli, fed apice vt Vi-i

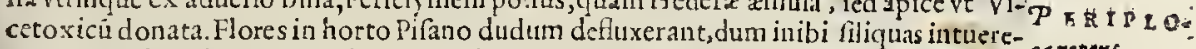
mul : qux folertiore contnexione inutuis erant coniunetx quafi roftris, vna è for is bafi, feu calatho, vtrinque repandz, fummis \& imis infertz mucronibus, Rhododendri quadantenus in morem.

\section{$C L Y M E N O N$ Italorum, fiue Siciliana, non eft Androfemons \\ $\left\{\begin{array}{l}\text { Gallis. Toute faine. } \\ \text { Ang. Tutar, }\end{array}\right.$}

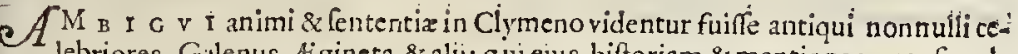
lebriores, Galenus, Aigineta, \& alii: qui eius hiftoriam \& mentionem quafi nula lam, aut incertam, taciti prateriêrc. Acian tum Plinii xuo variabat defcriptio \& confufa ex Clymeno \& Periclymeno, alia Grxcis, aliaque Latinis erat. Quò minus nobis lubi tum fuit prorfus aquaticam Betonicam, eiúfve affinem Scrophulariam,verum Clymenú affeuerare, tametfi vtriuis nec facies ita difpar, \& vires nentiquam fint appellatione Clymeni indignę, Quippe funt hæ non ninus vulgatis Chirurgorum præconis nobilitatx, atque planta Clymenum, Regis Clymeni cognomine. Verum non minus inclito nomine fuit donanda ea, quam vulgi Gallici confenfus Toute fatre ( quafi Panaces omnibus remedia ferens affęibus) vocat. Sépervirens hęc, virgis exit vimineis, fangnineis, nttentibus, reQtis, fexilibus, nonnihil angulofis, aut recundum longitudinem ftriatis, Periclymeno, fcu Matrifylux con coloribus, \& perquàm fimilibus. Etiamćue folia bina ex interuallis, auerfa, cæefia, fupernè faturato virore, multum finilia, nifi quia è geniculis emicant, nec, vti illa, virgis trailciuntur, eóçue pufillis interuallis, binis per eadem fpatia foliolis; Audrofęmum referunt: verùm non perinde fanguineum cruorem vel fundunt, vel allinunt affricta chart $x$, vti dietū in Androfęmo vero: flores lutci nó difsimiles funt, \& bac culç primùm rubrx, deinde nigræ, cruore nitente, purpure o, \& feminibus minuris, fufcis turgidę. Radix foris fufca, intus alba, lignof, fragilis, pedem \& fefọuipedem longa ; giftanti refnofi, lentoris expers, nee tota planta ingrata, no nnihil gummi Elemni, aut trifolii odorati fapit : moderatè aft ingit digerendo, \& deficcat, pauxilla, aut nulla calfactione, Vulnerariis remediis, Balfamisadeóque potionibus \& oleis nata, vfu A a.ij. nuli: 


\section{STIR PIVM adwerfarianoua.}

multò laudatifsima \& plurima Anglix fylus, lucis, \& nemoribus, prefertim Briftoix \& Gloceftrix contermituis. Flandris horten fis eft tantum, \& Androf emum nuncupatur, falfóque prodıtur foliis cruoré fundere, vel refudare cöprefíu fanguineú fuccum. Patani ctiä in vireto Senatorio alebatur fudiofe : vbi non nemo ardelıo ambitiofior perfundere fruftrà nobis conabatur, hanc folius Sicilix indigenam al umnamáue effe:eoque Italı plerique omnes Sicilianam vocitant.

$$
\begin{aligned}
& \text { пер̧ікийщвиo. } \quad P E R I C L T M E N O N \text {. } \\
& \text { Offici. Caprifolium, Materfylua, Lilium inter fpinas, Volucrum mains. } \\
& \text { SGerma. Beyfjblat wnoe fpect gilgen. } \\
& \{\text { Belgis. Bbcyten bhot cnoe axentumckens. } \\
& \text { Gallis. Cheure fueille. } \\
& \text { Itali.Vincibofco. Ang.Wod bynde. }
\end{aligned}
$$

A M I G A T quamdiuvolent, qui Matrifyluam in dubium reuocant, negan tq́ue effe

Tericlymenon, quia radice non fit rotunda, \& crafta: fruftri erin inquirunt \& exqui-

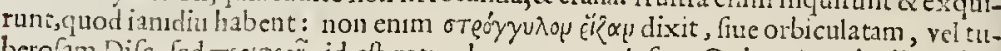

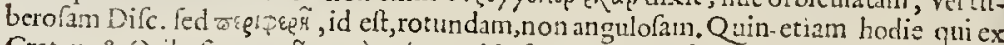

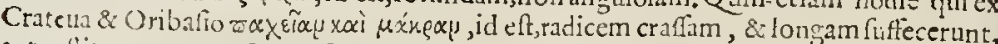
aut reltituerunt, pror fun aufam quamlibet rixandi praciderunt. Videtur autem A pocy-

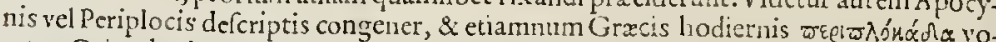
catur. Cuius duplex obferuatur variatas ex folio. Quòd folium Italic $\&$ Norbonenf vulgatior i furculis farmentísve, voum cùm fit $\&$ continaum, gemini tamenifpeciem præbet, quafi vmbilico medio traiefum, vtin tuteo Centaurio \& Tithymallo ferrato: coque $\mathcal{P}$ erfoliatun diEtum, quafi pertufum,perforatum, aut perfufum, vt Cicero loquitur. Extremis verò flaxibus caprcol atis, folium acetabuli forma, vel v mbilici circinatum, forum delicias continet, ex purpura niveo candore nitentes, \& alicubiluteo afperfas, fen fim in longitudinem porrectas, quafi promufides elephantium, aut lagenulas, floribus fabaccis multum fimiles, fed fragantia maiore, \& apiculis luteiso:natas. Senine rotundo, coccineo,Bryonię, fucculento.

$$
P E R I C L Y M E N O N \text { non porfoliatum Septentrionalitum: }
$$

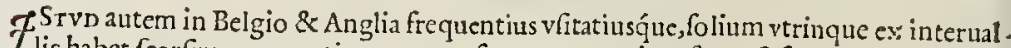
Jis habet feorfin non continuum, nec farmento peruium \& perfufum, neq; cupulo foliaceo erumpentes flores. Alio qui prorfus idem.

$$
\text { ALLOBROGHA Periclymenumalserum, Cornus form int effigie. }
$$

SVN T qui fruticem quandam, vel arbufculam in Allobrogū fyluofis crefcentem, Cornus foeminę facic, $\$$ baccas in pediculis binas tefticulorum fitu, \& nonnihil oblongas. ferenté, Periclymenis iungunt. Cuius acinos Heluevii, vbi plurima hęc, butoent titfent, id eft,cerafa canina vocitant, necdefunt qui eadem Matrifyluam autument : quippe folia huic perquàm fimilia, bina, \& fimiliter parū cxfia, aut glauca, binífq; in exilibus petiolis flofculis, oblongis, necita abfimilibus, fed minoribus, candidis, nulta ftaminea exerëtibus. Qualis Belgix hortis colebatur à Guil. Dries optimo viro \& Pharmacopœo Antuerp. Fed fuo hrc caudice fulcitur, non(vt altera) indiga adminiculi vllius, \& habitu fufagi nis frutıcat,aut Cornus fominę, quatuor quinquéve cubitos alta. Facultatú incerti furnus.

$$
\text { SESELI AETHIO PICVM. }
$$

Q V o r genera Sefeli à Diofcor.recenfentur, tot eademq́; collegimus in Galloprouincia Maisllix circum, arque prope Ceti montem ora Norbonenfis maris, non procul $M$ onfpellio. Indidemó; nonuulli fudiof ftirpes quafdam deferendas curarunt I.utetiam, Antuerpiā, adeóq; in Italiä, vbi nondum innotuerant vel doctis. Qüin ne nunc quidem noraseffe Senenfi Commentatori, in iftis poftremis Imaginum recufis \& mutatis fententiis, magna iniuria facta $P$ harmacopcorú plebi, videtur, Medicifóf; ignauis. Et fanè mul tò maiore fux dignitatis dettimento, id contigiffe magis dolendum, quàm 


\section{STIRT IV $M$ aduerfarianoua.}

ridendu noderatis ingcnijs. Quti norint non vulgari moderatione \& certa prudcntiz illus quantum licurt lapíbus vno loco tam mult is occurrere conatum: Cùm enim per opinonem tıım fiducix, tum etian emúctx cognitionis, guam illis de fe iandiu excitarat, Iicuillet(illi fi lubuiffet)nó folú picturis mendofis, fed etiã verbis fubdolis perfuadere, piQuris tanie cötentus fuit, \&̈ filentio fux dignitati confuluit. Si qua tamen vfus eft vafricula iutuerfincula, eft illa leuius ferenda: Non enim nouerat aptiores:aut fi norat, fe tantoperè deceptum fateri, cius dignitatis non ernt. Igitur quas potuit, dono puta emendicatas, ideo nec recens animaducrfas, aut defcriptas, in paginas congefsit eius pįtor, perperā quidē illas omnes cenfitas, fed tamen carum vnam fermè correctam iftam, qux êt $S$ efeli Et thiopio cü verum:cuitus effigiem mutuatus fuit à Dodonęo Medico multùm exercitato.

Ea Saxeis illis deuexis Mafsilex \& maritimis," tum etiáad Cœti montis cclfi radices, qua in Lací vergit, fruticat vberi prouéru Iulio \& Augufto valde quã fpectatu elegans, multis prouenit virgultis rectis, ligneis, ni. gricantibus, rigidis, binos ternófve cubitos altis, in varios fur culos didhetis, folia crafta,rigida, \& lęuore viridária,vt Hederæ, figura oblöga, propior Periclimeno prométibus. Luculëtas in fümis gerit vmbellas, luteis florib' Anethi, quas femē ftipat fufcum, oblongum, copiofum, foniculi maius: nonfolum femé, fed etiam vniuerfus frutex guftanti aromatis faporem acrem,medicatum, \& fubamarū, fed gratum imprinit, fuauemó; odorem fpirat à fummo ad imä vfo; radicem, qux lignofa eft.

Eximiz vis eft huius fenen, cu ius copiam mifimus amicis Venecis \& Iugdunenfibus ad The riacem, guod etiā, vti Diofcori des innuit Mafsiliêfi multò odo ratins \& efficacius eft . Quod

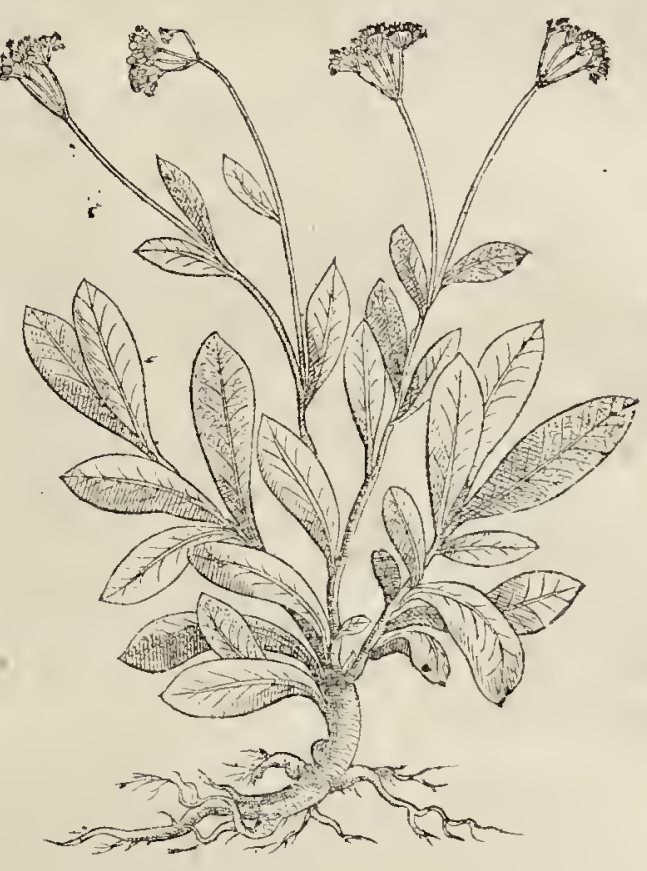
Sefeliffivt pietum in Dodonęo, ita viuum in agro vidiffet Cömentator, lubens \& volens fuffeciffet in locum illius plant $x$, cui videtur poltpofuifle:eft enim illa non frutex, fed herba, quam Recentiores Libanotidem Theophrafti prodiderunt, viribus \& figura aliena ab

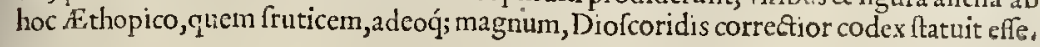

SGer. Kappiet.

$$
C A P P A R E S \text {. }
$$

KHip. Alcapparas.

Ang. Kapper.

Gall. Cappres. F R v I C A r ruri inora Thyrrenici maris, Norbonĕfi, \& Hifpanica Capparis vberi pro dat, decerptus, \& muria conditus magno femper vfu fuit. Flos ei candidus inert, Rof $x$ aut Mali Cotoncx: \& femen in filiqua oblonga ruffum Milij Panici, medicamentis vtile.MaAa.iij. iores 


\section{STIRPIV $M$ aduersarianoua.}

tores \& ninores Emporijs varüs raneunt, fed minores in prims funt cömendatione, fextićlq; pluris c nuntur, quàm maiores:vulgo nunq; lazbentur meliores, quia palato gratiores paruz. Sic palatiftudium fullit ingenium, valetudinis difpendio : nam qu fapor illis percipitur, afcititius eft i muria, vel ab aceto:alioqui vtraq; acerrimi \& teterrimi guftus eft,feu viridis, feu matura. Proindeq́; minor, perpaucr carnis \& fucci, facilius \& penitius imbuitur conditura, quam maior: qux melioris fucci \& aptioris ale ndx carni eft. Culinx proinde error clt, minores maiotibus perferre. Sed hic cófuctus inoleuit, mos. Nam,vt fci tè dicebat $P$ hulofophus, nihil nagis aduerfatur valetudini, aut Medico, quàm bonuscoquus. Itaq; voluptati coq̨uus emat minores magno precio, frugi œconomus emet ( fi nos audiat)maiores minoris multò, bonx tuendx valetudini. Radices eff́c adulterinas quidam imperiti Medici ridiculc̀ non minus quiritantur, quàm ille qui conquerebatur,perperam fieri hodic, quòd Santalum citrinum adultexaretur ligno aloe:nam hac radice nihil vulgatiusaut viluss, etiam in Hifpania.

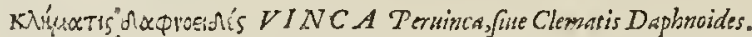

Ang. Peruincle Bel. Uintroute Emterioc patme?t. Ger. Eingruen,

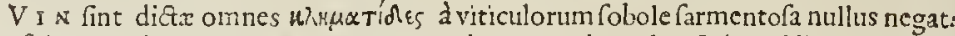
Q Iftá auté vbiuis Gernan' $x$, Galliz, \& Italiæ, nemoreis, ymbrofiś́; trątibus, \& fentice tis, marginibus gaudentem, veram prinam Clematidem, tun facies, tun vires iamdiu, \& fępius compertx teftantur:tametfi pauci memineriat, huıc ineffe quédam calorem, quó ab ftergat educatọ́; foctidā menftruor ü alborum illunie: ac rurfum aftrictionc inibi rcliça, \&s robore parti reftituto, eandé lupprimat. Ac mirúa lánè magnú fit, fi dútaxat cöolla ex hac cótexta, capiti, aptata fanguinem è naribus fluentē fintet, aut inguiuis regioniappreffa, mee. ftrua cohıbet, abor tumǵ; inhibet, vt author eft Mathiolus commentator. Cæterü cuilibet hax notaclt, fronde laurea fenperviren ti:lẹore, colore, magnitudine, \& facie Liguftri,ex intcrual lis bina exaduerfo, in virgis viticulofis, flexilibus, virentibus, fparfis hunit,\& caducis, nec obuias plantas irretientibus: numerofis, guftu amar is, nonnihil calidis,aftringétibus. Flores calyculis conttāt quinis, foliolis Iafenini, paulò maioris, minus aut nhil odo ris. Fibrofa radice, flauentc.

\section{PERVINCA maior.}

MA I O R a multò, nec nifi Norbonx, non modò vmbrofis, fed etiam apricis \& reftuofis, oliuetis, oriańdam meminimus eandem, qux tamen non nifilętiore habitu pro: ccritateǵ; diftat.

\section{iß̧ $V / S C V M$.}

Ang. Mişelie. EV O C E

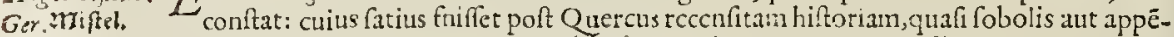
Gal.Guy. Ital.Pifchio. dicis menuniffe. Nectan rarum, quam nirum citra vilas radices pafin in arborum caudicibus totum vertenté annum, adeog; Trumali tempore Vifenm Fronde vircre noun, quens non fus feminat ar bos, vt canit Maro. Quò minus verifrmile fit, acinulo illo pallido \& pellucido feri hüc, fed potius'ex fucco elaboratiore aggefto, ad cortices librófqu; brachioru1n exlialätc, \& vapido, vnde fit ve alimentum nunquam dcficiat copiofum, nec folium defuat: \& oriri multa feminio nullo, nulli mirantur,qui ijfdem natalibus Polypodium, Dryopterim,

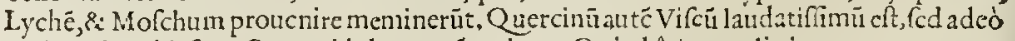
rarü vt vix millefimę Quercui inhęrete cóperiatur. Quin hî́cin anglia innumเras quercus nobis intuentibus, vix vna aut altera comparuit, vbi perpancú $\&$ magno ftudio feruatü in crat. Cuius tamé fapor, color, R̈ odor, nihil prorfus variare videntur. Vcrú nẹn abs re antỉ qui Hyphear ab Ixia \& Stelite, (qux catero-qui natalibus tantum diferre videntur) difcreuêre. $P$ urgat fanè vifcum quernum, melancholicü \& pituitofum fuccü, vnde vertigino fi: cerebrif́́: epilepticis piamentum quafi inucheú fuit, \& cclebratum olim, ceu facrum anunlctum, ă Gallorü myftis Druydibus, qui è quercu vif́óq; querno vaticinati fuêre. Nec minus Clyymiftis eius qui vocatur Sol is Aucupiun feu Illicium experitus fpirtus : qux myfteria prophanis neutiquam referanda. Q12afi to pici medicamenti, necintrofumendi 


\section{STIRTIVM adierjaria noua. 283}

mentionem fecit Diofcorides: vfus tamen, tum potiunculis, tum catapotijs valdè tutus: fo ris verò exploratæx vtilitatis adeò nouimus, vt è penitioribus finubus collęum pus, trans fpatia mufculorum \& denfas eartilagines eliciat. Eft namq; cpipafticum nullı fecundū, vt quis experiri poteft, qué iuuabit vires nofce Emplaftri vifcini, ab Scribonio Largo laudati.

moniyóvatoy. POLTGONVA maius.

SAng. White roote, or cely fala. Gel. Galonions fegel.

$\left\{\begin{array}{l}\text { Offi. Sigillum Salomonis. } \\ \text { Ger. weify }\end{array}\right.$

NOM I I Is àrgumentü radix, geniculis cópluribus pyxidatim cöfertis, Rufci modo protuberãs, digitú minimú craffitic æquãs, innứt: qux vagatur cefpite fummo, multum fibrofa,eâdore pellucido, marmoreo, Alabaftritidis radicis afpectu, guftu infuaui dul cedine, fubaftringente. Caules emittit rectos, rotüdos, cubitales, virides, quos folia ambiunt Lilij conuall lijvel Bifolij, vel Lauri Alexandrina, Ellebori albi modo, liris vel rugis reEtis venofa :è quorum emiffu pedicelli prodeút: flores Vnedonis,feu Arbuti dieti, ex candore herbid, Lilij conuallium lougiores:quibus excuffis, Maio \& Iunio, bacce virides, de inde nigræ fubnafcuntur, Corrudæaut Liguftri.

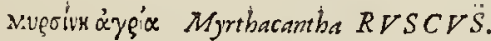

SAurina fpina, fine Myrtus fylucfris. SItal. Pongitopi:

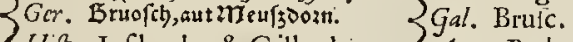

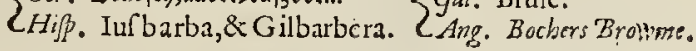

TA s e s r Myrthum humilem, fylueftrem, \& aculeatam vocarunt Rufcutn antiqui, quafi eiufdem naturx, vt figurx erat prorfum fimillimx: tamen differre inter $f \mathrm{c}$ indole \& natalibus certum eft, eum ad Septentrionem populis nolla fponte nafcatur Myrth is: Rufcus autem calidis \& frigidis peræquè multa fcateat, facie folijsç; planè Myrtheis, fed rigidioribus, mucronatifq́; fupernè, quibus medijs ritu Cocci baphicre haretet fin:ulis baccx fingulax, ruberrimx, duriores, maioréfq; quàn Afparagi, nucleo ofea plane duritia, vixq́; vlli frangenti iqui cedente. Floribus pufillis, in fruticantibus multa foboles virgis, praduris, bicubitalibus, \& tricubitalibus, rętis, ftriatis, viuaciffmis, vt \& radices, qux quàmplurimos annos perennant, fuccrefcente qu:ctānis noua Afparagorum fimillima turionū propagine:aromatica, aliquantum amara, vifcerum \& duetum faretui vfitatifima, nec feus ae in officinis A fparagi v̛́rpari folita, vel Bonifacix, cui nó parum fimilis. Semen ea tiam mifeetur eodem fcopo Benedicte laxatiua \& Litontribis.

$L A V R I$ CA LEXANDR E E Diofcer. (quet Theophrafto Rugcifoits

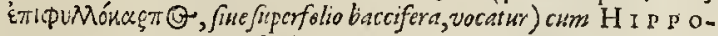

G I OS S O fime L I G V L A I A difcrimen.

A Ĺr a m effe Alexandrinam Laurum ab Hippoglofto, aunis in promptu eft de Theo. phrafto \& Diofcoride nofce : quippe fructum fiue baccan coccineam medijs in folijs harere, nullius ligulæ facta mentione, vterq; afferit:folliać; molliora, mai ora, \& albidiori quàm Rufci inefié Lauro huic, Diofcorides fubdit, virćfq; diuerfas teddit, \&: radicé maio rem, molliorem, odoratam.

A T Hippogloni fiue Linguat HIP POGLOSSF $M$.

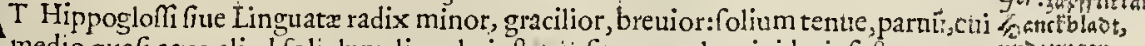

medio quafi cauo aliud foliolun, lingulx inftar, infitum:aculeo rigido, infefto, muero oxso $y_{\text {thitgen }}$ natum vtrüque, inter quę baccula etiā rubra Rúci vifitur, ftrfpiciendo naturæx, propter sa-

ritatem, opere. Quare verfioneni Plinianam legenti, fatis liquet diuerfas effe plantas, le- $B c l$. In onger

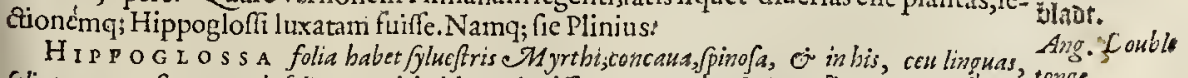

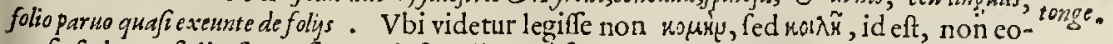
mofa, fed caua folia, fiue inflexa euiufmodi planè fút omnia noftratis Biflinguę fiue Bonifa cię:hortis iādiu fatis notę, \& viribus ad calculü dyffuriáfq̧; eximijs celebris:prę̧fettim fpöte

Aa.iiij. 


\section{4

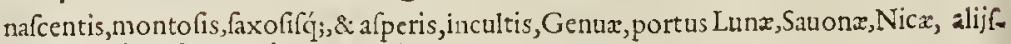
q́; Alpinis fterilibus calidiorum trąuum.

Matb. Laurus Senëlis nofter, qua ingenij eft opulëtia \& liberalitate, vbi cxteri friptores putarăt defcrip Alexan.com- tionem, noméclaturamć; geminam effe, duntaxat vnius \& eufdem plantx, non folum dementitia. dit, vt par fuit, Bonifaciam pro Hippogloflo, led infuper duas fcitiffimè equiden cómentusfuit. Alteri nempè affixis affabrè ligulis, quàm poltea pudcntior factus, delendam curauit : Alteri datis in petiolis longis baccis, quam sigillum Salomonis meritò fufpican* tur, in illumq́; quafi impoftorem ignarum debacchantur morofuli ifi critici,quód toties, rotq; annos, cum verlarit hafce quifquilias, tandem non animaduertcrit Theophrafto \& Diofcor.Lauro medijs in folijs fruEtum, non in peciolis ineffe:fed illam denstam, quafi foret à fe fietam commentarijs penultinis, commodiorem multo fuife : quippe cui fimilior eft ea, quam cyuidam herbarum peritifinni in hortos colunt, \& veram affirmant Alexandrinani L aurum.

Cucurbitc.

Cucumis fatiuns cf culentus.

Cucumis flexwofus fue Angwinus.

CMelo fue Cucumis antignoram, Diofcar. Melopepo. eiusvarietates.

Citrullus officinarum, Anguria, fine Batecba, fomine nigro Auicenna, wh

Pepones oblongi,onales vinloatißmi.

( $M E L O P E P O$ ? eiufdem variet ates.

Chcurbite varietat es. $\left\{\begin{array}{l}\text { lagenaris mior. } \\ \text { minor. }\end{array}\right.$

Colocynthis. cinf $\dot{g}_{3}$ varictates.

Cucumis Elaterijflueftris.

Momordica, Ballamina.

Doronici,quorünullus eft A C ON I I V M Pardalunches.

Doronici varietates.

Xylon.

Malue.

eins varietates.

Bamia.

SydaT heoph.

Abutylon.

Alther.

Althea arbor.

cAlces.

Alcea Veneta.

Geramia.

Pes Leonis, fur Alchinullos.

Sanicula.

Epipactis.

Ranunculis.

Ranunculus flore albo.

Ranunculus gramineus.

Flammula

Aconita. Luteum.

Nespelli. \{ Lycoitonust.

Mufce Nepelli.

- Anthora. 


\section{$S T I R T I V M$ aduerforia now \\ CVCVRBIT A Sycbia. Succha. síms.}

TA s T a elt Cucurbitarum, Cucumerum, \& Poponum inter fe cognatio, rt antiqui

Greci \& Latini,nedum recentiore s, minus accuratè nomenclaturas difcreuerint. Euthydemus fiquidem in oleraceo libro Syciam Indicam nominat Colocyntidem: puta poft Hippocratem : cui vei ctiam Theophrafto videtur, quamlibent varietaten \& diffe-

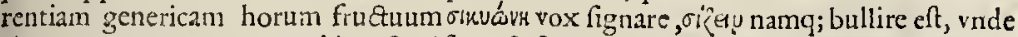
oikus, qux vas, ollam, \& pyxidem fignificat, \& fanguifugum vitreum, aut cornu inftrumentŭ : indeq́; fortè Latin is Cucurbita, tametfi Varroni à curuando diqa putetur. Ariftoteles etiam Sicyas pepones appellat:\& Galcnus'Pepocucumerem. Quare quò facilius percipiantur \& difcernantur ab inuicem, qua hodic in vfum culinariū \& medicatum venerunt, genera cuncta non incommodè oixús, vel Cucumeres, vocamus : quarum duo fumma faltigia fint Curcubitz \& Melopepones, varia nomina adepta, propter frudu. um, foliorumǵue varictatem.

\section{CVCVMERES SATIVI OंEforlenti.}

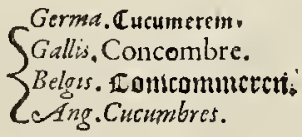

NO I I s i m I funt, tum Meridionalium, tum Septentrionalium hottis Cucumeres, qui \& fuzuifsmi cfu \& frequentifsimi, prefertim crudi , at muria conditi, dum adhuk funt tenelli, merito habentur. Foliis hifpidis, fcabris, viridäisus, fimilibus Brioniç, aut Vi: tis:maioribus,minoribů Bardanę \& Petafitidis: flores ex luteo pallent liliacei, conninétq́ue noctu, aut marcefcunt,Volubilis ritu : reptantibus multis vitibus \& claniculis, proxima quxque implicantibns, fiuetumq́; dant teretem, fenipedalé, oblongü, cortice teneriore, maculofo, cx obfcuro virore in flaum maturefcente, interdum fpinulis molJiufculis, afperato, \& leuiter fecundum longitudinem canaliculato, vel fulcato: femine referto albo, Melonis adeo fimili,vt neutiquam, nifi quia angufius , \& pufilo apiculo fubtus protenfo donatus cht, difcrepet:medullalactef́cente, admodùm fuaui, \& multi vfu Officitis, non item Culinis.

$$
\text { CVCVMISfexuofies, fine A N G V I } \mathrm{N} \text { V } \text {. }
$$

R A R I O hic,\& nifi in hortis herbariorum infrequens, prorfum fimillimus fupetiori Cucumeri, Hagelliz, flore, foliis, \& clauiculis, fruetu autem faclè difcernitur, \& ag* nof citur, qui incurua gracilitate anguinum flexum, \& longitudinem \& crafsitiem $x$ qqua vnde nomen:tenera cute, nitore herbido.

\section{L O vulgi, fue Cucumis Antiguorum, Diofcoridis M E L O P E P O.}

$$
\left\{\begin{array}{l}
\text { German } \\
\text { or Bel. }
\end{array}\right.
$$

IL I I s affinitate foliorum, florum, $\$$ fructus proximus hic, fimillimo etiam, ve diximus $s_{A}$ 1 emine, inclufo tamen in globofum fruetum, magífque ventriofum, \& fecundum longitudinem altioribus liris, \& torulis fulcatú. Cortice duriore, nónihil hirfuto, rugofo, pul s lo, vel cincreo. Carne fulua, fapore \& odore mellito, vel faccharato, cuiufnodi in gulx de litiis crudos fuauifsimos habet vniuerfa Italia, Galloprouiucia, Norbỏnenfisqúc \& Vafconica, Gallia, Hifpaniz: efitantur cum pauco fale \& pane Iulio \& Augufto. Cxteris regionibusad Borcain, vt Francix , Belgio, \& Anglix, rgrè aut infipidiores proueniunt, ncc plerumque maturitatem affequuntur, pr $x$ imbrium copia, \& caloris inopia. Semen etian vnum officinarum habetur, inter quatuor maiora vocata, primz commendationis 2. frequentioris vfus, 


\section{STIRT IV $M$ aduerfarianoms.}

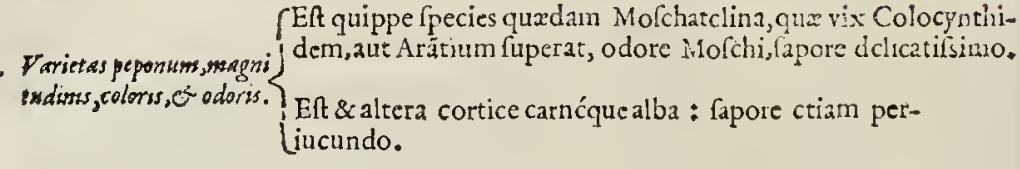

VE $~$ hoc vrio argumento quilibet afíeruerit Melones noftros, fue vulgi Italici Pepones, effe antiquorum(prafertim Diofcoridis)domeflicum Cucunerem, fiue Sicyam fatiuam, quia odore eximix fragrantię, \& cytoniı mali, aut pomornm redolentium, $x$ mulo, reftauret vires languidas \& reficıat, [piritúfq; difsipatos reuocet animo lapfis: wt idẻ Diofcorides author eft:coq́ue Melones, quafi Pomofi, neritò vocati fuerunt i recentioribus Gracis, quòd ori ac ftomacho cibus fint gratísínus, omnium huius generis.

$$
\left.\begin{array}{l}
\text { CIT RVLLVS Officinarum, Angerin } \\
\text { fure Batecha Anicenna Jemine nigro }
\end{array}\right\} \text { Melopepo. }
$$

Z Mrta arva etià Citrullus maioré alique Melonce effigie \& carne folidiore, fragili: fed fapore vefcendoq́; magis Pepones vulgatos refert:vnde Melopeponé iftü nomenclatura, vt ancipitis naturę, dictú de vtroq̨; mixta putamus, népe Mali, frue Melonis circinnata ro tunditate, non tamé torulis fulcata, \& fapore magis Peponem, quàm Melonis dulcedinê melleam referente:qquibus ctiä,monente Galeno, difcerntur à Melone. Scmẻ verò vnum é quatuor vocatis maioribus eft; inaius Melonis, minus Peponis, duriore corticc feptum, nigro,omnium durifsimo: alioqui tota planta fimilis P'eponum plantæ, fed folis alticribus, laciniis Colocynthidi proprioribus. Seritur etiam \& manditur caro cocia vel cruda, \& plerifque Pedemontis I talixque hortis enalcitur.

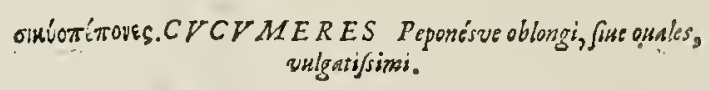

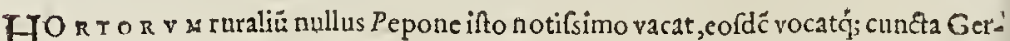
mania \& Anglia Pepones magnos, admodum $M$ Aeloni, vel Citrullo fimiles : flexuofo fagellorum, fed proceriore reptatu, foliss latioribus, profunda Citrulli laciniofác; diuifura, fore maiore, frutu teret, oblongo, oui ftruthii fimilis, maiore multò, flauo in. terdum, interdum \& albicante cortice obducéte. Semen Citrullo latius immerfum carni Jutex, qux hyeme fuper aut fubtus camino fumóque arefcunt, iifceque tenuis fortis plebecula vefitur.

$$
\int^{2} \operatorname{COMPRESSI} \text { roturdi, Melonis effigie. }
$$

V A R I A N T verò folio minori minúsqueinci[o, alioqui finili,nec difpari flo re,aut fructu,rotundo, compreffo, Melonis effigie, nonnihil ite orbiculatim ftriato. Corticc delicatiore, glauco, rel albido, nitente. Semine albo Citrulli,

$$
\text { Zirietas }\{\text { LATIORES Ciypeiformes. }
$$

NI н I I prorfum difsimilem in ramis \& foliis alterum horti alunt fructum latiorem, rotundo Galerifpecie, aut Clypei vmbilicati, \& a mbitu rimofo, atque plicis funbriifq́ue rugofo cortice:delicato \& concolori fuperiori, nec diuerfi faporis à fuperiore. Vtrumque in taleolas fcifsos, frietósq; in farta gine, \& farina alperfos, fuatues admodum mandunt, in Belgio, Gallia,\& alibi.

$$
\text { - ST RVMOSPS. }
$$

PERE I E G A S hic \& rarus, foliis alioquin ficulneis proximis, fructu Mclonem mag: num xquante, fed Limunia mala exprimente, tuberofoque cortice,papillatim variesato : fecciofa item tricolori frumarum buliatione. Semine non aifsimill. 


\section{STIRTIVM aduerfarianona. CUCURBIT $A$ fine Zucchs.}

A D s o D r M verifimile fit, Zucchæ nomé(fic enim Italicè vocant Cucurbitam deprauatis elementis)owixy, aut duxiay (vtrog; enim modo fcribunt nonnulli Graci) defignare:nam ok $1 \alpha$, vnde etiā ficus Latinis deriuatur, generaliffima fut appellatio Cucurbitaram, Cucumerum, \& Melopepopum,vt fuperius monuimus.

Quarc Cucumerinæ familiæ maxim $x$ vocari poffunt Cucurbitx, \& conmodiore etymoà curuando deduci,quafi curbando, vt loquuntur Vafcones \& Pyrenei, Notiffima \& condituris aptiffima, qux anguina vocatur, omnium maxima, in arcum flexa, tcrnum fenumọ́; pedum longitudin is, cute polita, albida cx viridi ; teftaớ; duriore quum arida fuerit. Carne alba, el ixa non ingrata. Semine longo, lato, nonnihil quadrato. Folio Cucumeris ro tundiore, minore, flore albo, in flexilibus caducífq; humi loris \& capreolis, topiarias ridicas \& pedamenta implicantibus. Hầc maxima copia in taleolas longas diffectā , faccharóq; conditam, Lufitani Hifpaniọ́; adferunt venum in Septentrionem,vocantọ́; Carbafade. Siticulofis $\&$ aftu febrili vexatis gratiffima offula funt.

\section{$L A G E N A R$ Y A.}

$\int L^{A} G$ E V A R I A M vocamus, vt qua peregrè proficifcentes lagena vtuntur, prafertim in Gallijs, Hifpanijs \& Iralia:commodius namq; geftatur vinum quam vitreo aut.figlino vafe, qux oneri funt $\&$ facilius franguntur. Semen illi minus quàm fuperioris:folim alioquin, flores, \& reliqua non difparia.

\section{varietas. $\{L A G E N A R I A$ maior.}

$A B$ illa tantim differt fruetu minore, lagenulamq́; concinniorem exprimente, eóq; lubentius commodiusớ; geitatur itinerantibus, Semine, folio \& \&lore, delicatiore, non diuerfo.

COLOCTNTHIS, fine Cucurbiula amara, Catbartica,

SGer. Coloquint Offflein.

$\left\{\begin{array}{l}\text { Bel. Quint appcl. } \\ \text { Ang. Cologuintida. }\end{array}\right.$

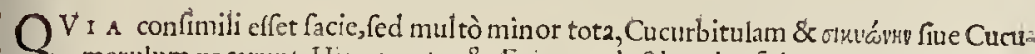
merulum vocirunt Hippocrates \& \& gineta, ducti potius fol orum afpectu, quàm planè contrarijs facultatibus, quibus infigniter pollet: \& documento eft, fub ijfdem foliorun florúmq; lineamentis, cognatarum fpecierum plerumq; effe perquàm diffimiles vires:qux quò melius innotefcant, plantx ipfex funt ux ta fe ponend $x$, \& defcribcnd $x$, vt frequenti intuendi in eas confuetudine \& experiendi, periti earum euadamus. Idcircóq; vti fuperius femper, fic \& hîc nos hunc Cucumerê, \&alin̈ agreftem vocatü, fuis gentilibus fubdemus. Hanc ferüt Herbarize voluptatis ftudiofi Vere, in Gallia, Germania, \& Anglia, frutámq; decerpunt Septembri, fed fubflaum, virentem, virofúmg; nec purgationibus perindè aptum, vt ea quę ex Gracia Hifpanijfque defer untur Poma fiue Cucurbitz, exépto corticc flaucfente candidę \& fungofęl læuique concretione, amarore virofo \& exuperanti,\& horrendo, fauces vifcera inteltináq; ladente. Ortu \& natalitijs humentibus penè Cucumeris fatiui par, fed folio minore magifquc laciniofo, ad Citrullum accedéte, luteolis nec diuerfis floribus. Semen item fimile, fed minus, durius, pencạ́ue lignum eft, nó tanta virulêtia ad purgandū, quàm caro ipfa fiue medulla:dedimus namque multò maior $\mathrm{cm}$ dofim quàm medullæ, maiore commodo, nullo aut longè minore tumultu.

Satx Colocynthidis in hortis Batauis, Gallicis, \& Italis, vidimus triplicis aut quadruplicis varietatis: fructum nem pè pufillx Cucurbitæa aut Pyri \& lagenulæ cffigie, ex fufco viridantc: cortice nonnihil maculis variegato, reliqua foliorum facie Cucumerem fylueftrê referente: teterrimi etiam faporis tota liacc eft: videtúrque $S y$ lueftris f pontére nafcentis ea fpecics, quam mortem, fiuc exitium in cacabo, vocabant quarıbundi Prophet $x$ illi, qui a- 
pud Elifum fume prefi, cum multi degetent, \& cibum caperent, iuffúq; effet quidam incoguere pulmento olera, collect:m magnam huius copiam, ratus elic Cucurbitam efculentam, ollæ indidit:Illi verò vt efitare cepcrunt, amarotem iufeftum, quafi morté deteflati funt:nec porrò vorare potuerunt, tü ad P rophetam protinus exdamare, \& Mors,incuiuut, Dimine, ef m cacabo, nec poßsumus ve/ci. Vates autem Elifeus muraculis potens fretufq; mult tis, farina adieç pulmentum Colocyntıdáfq̣; fyluctres dulcerauit, edendoqúc cómodas reddidit: quare oportuit effe amarifimas.

Meminimus criam cxatè fphericas, maximum Arancium aut Citrium, vocatum Adami Pomum, requiparantes, etiam nonuihil variegato cortice.

Videas \& nonnulquam compreffx rotunditatis, fubflaui colticis, quarum omnium exdem vires, \& dirus anaror.

Sxpifinc̀ pufilli, Peponis oblongi cffigie, outum anferinú aut olorinum çquantes, , corticis durioris, ex viridi in atro \& cinereo maculati funt.

\section{CVCV $M 1 E R$ Elaterijgi。}

Ger.dviloer Cucumer.

Sal. Coucombrefuuage.

LAng. Nolime tangere, ¿wilde Cncumber.

TO vimmeritò Cucumerem agreftem vocarunt hunc, potius quim Afininum aut fy.

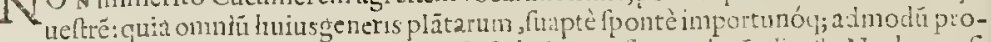

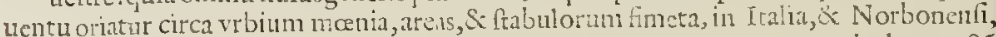
Prouncialique Gallia, vbi vel puetulis notiflinus, qui fructum turgenten visdum tactú digitis ludibundi in faciem inuicé eludunt fenuna, fíccóque peranaro à virofo os oculófque perfundunt. Rcpens \& humilis, non topiaria elt, tota Cucumeris fatiui effigie, minoribus folijs, marifque fabris, \& crafioribus, cineritijs, ab imo denfe futicantium cauliú tencriorum, fucculentorum: quibus exeunte ęlate, poft Hores luteos, pallefcentes, Cucumeruli in pediculis per interualla infunt, pruni intar oblongi, hifpidi, cincrei, coloris qua datntenus Papaueris gemmantis glomerulos imitantes. Scmme pullo colore, vel cinereo, nigricante, Colocynthidis non diffmili, fed minore: radice craffi, Raphani aut Bryonix,aliquantun fbrofa. Medulla candida minus quàm fructus, aut folia, ingrata:quæ præertim Solc ficcata, flanmis admota, tota deflagrat vrendo. Vode primum robis conicetura fuit ex / linio, monente etiam P ræc ptoleaccuiatiffmi iudicij Rondelletio, E L A T E R I V M verim ex hac plurima, \& pauca ei hrente muccagine nedullofi, non exipfis Cucumerulis parndum effe. Perquám celebre fuit antiquis Catharticum, vt de Hippocrate \& Thcophraftolicuet, Elaterjun, quafi dicas exagitans turbáfreciens medicamentum: vehe menter namque fupenèe, infernéq; aluá citabat, pufilia do fi, nempè oboli, vei forupulo, femille, por fe, vel adiecto falis altero tanto, \& Stibij, cuod colorando fatis eflet . Probauffmum fuit, læue, non afperum, nec ponder of um, fed aibun, nec aridum, vel exuctum, vehementcr amarum, \& lucernx obic fum facilè lagrans. Qux notr lećcori plantarủ con fulto, non risandi, fed cognofcendi cupido, facile retegunt plauc peruam huius loci in Theoplua!to \& Diofcoride falcbrofi intelleftionem : cim nanc; ex Cucumetulis iftisfuccus effluat admodim tenus, viridis, aq̨ueus, ignéq; denfatus inæqulis, nigricäs, ac obiectus lumini ncutiquam fammam alčs, paucíf; aunismucidusputíf ; futuros, verifunile

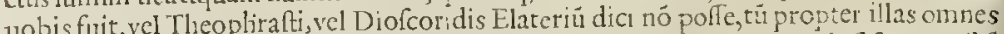
iam quos diximus, reprobi ind tia, tum quia nec dutat, nec fagrat. Qmare ip fi fliperorib" anais cum in Gallia Norbonenfi paraffemus Diofcoridis \& Theophrati inetituto, curaffe músc; parãdum multis unodis: tandẻ maximã Cucumerulûn copiam colligcudá curatiimus, èquibus fuper cribro incifis, femins tufi, \& crebro manibuspefti, nedullam fure mucçainem Pfilij finilë fubter cribrum tranfmifiam crcepimus, Cucumerulorum enrüdem fucco affufo, \& aquz fontane nonnihil, quo facilius -luzen renitterét trans cribrü: iftud partim Soli fub dio expofitü nigricans hubuinus, partun verò ione aut fub cineribus exficcatú, albidū, \& pullỉ. Vtrumq; tamen lucerna admotï actutum flam:mam dabat \&ale bat fua pingucdine:quin etiam, quale nobis adiuc in mufcolo longè aridum fupereft, faci- 
Varietastcrita PRIOR I propior tertin eft, fi prorfus eadem fitetian fuffigio Herbarior í, qui magnitudine duntaxat diftare aint: nam hic multus collibus nemorolis Taurini \& caulis fefquicubitalis : alioqui fimiles inter fe funt adeò hre tres, vt Cyperorum ritu dicrepent. magnitudine tantur , fitu, \& numerofa Cobolis propagine. Iam neutiquam pus fit nuita difquintione ad itatuendum, ecquid fit difcriminis inter Theophrafti,

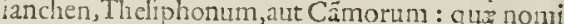
es.Sed tamé paulum quid variat Diof . de radir phraftus verò cadaueri toti cöfert. Id nó contininò alius creneris firpem aituit : fed ean mon explorata, labpleraque mnia in Stiroium hiftoriaillum accepta ferre Theophrafto. Ecquid loci fit in comto Pardatianche reliceum, dicent confultilsmis a fispium exploratores indefersi I alorum doctifsimi, qui nullum vfoiam fibi vifum, vel anditione cognitum pleri-

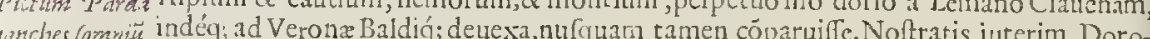
nici plurimum diuerfis locis obuium habuife. cón cón ifum Senenfem commcntatorem, cui impofuifet brc lcuiufcula, guam fupra arnoumus, differentia, quafi vnam quampiam nouam \& fui generis fanxiffe. Indicio of e, quoties curauit rccudenda illa commenta, toties variatam Iconcm : nec nifi $\mathrm{V}$ Palpare faftu,afu, \& palpo manni nominis eruditis inculcet illud $P$ alpato or videre, quoniam Mathiolus non fribit mendacia, fe ridere \& mirari : fore tamen iam, ve fenior eónue oderatior factus, fateatur fe laplum, lugeatq; Doronici, fibi ignotu anteà, quod fcelefte

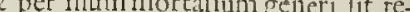

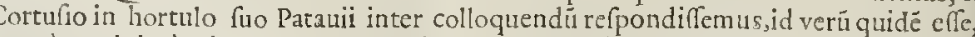
crterum minimè mirum : vt qui cxperimento certum haberemus, Aloe faluberrima iu terfici vulpes, eardémque eneotas amygdalis amaris ex Plutarcho meminiffenus, annuie 
ille Italici cuidam compatri fuo Pharmacopero, qui vulgatume exemplum de nuce vomicafubdidit, ea nempè feles, canes, auć́f; in terimi, qux tamen tuto a magno commodo aduerfus lethifera \&: Epidimicos mor bos in Electuarijs L. berătis, datur homini. Immeritò

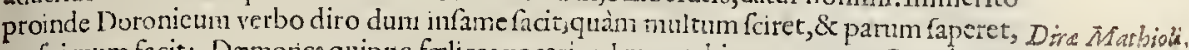
perfpicuum facit: Dxmonics quippe foelices vocari, vel monachi nor unt, qui Cacodęmones haud atrociori conuicio incellunt, quàm ille Doronicum è tepublica Medicorum exigere nititur. Tantillam ren, tain valdè vulgatatan, captunı fuperafie tanti Commentaton1s, ftupet vulgus, qui Plilomelis, Alaudis, Hiridinibus,alijfó; delıcatioribus auiculis non folùm nó noceat, féd interdum cibus, fxpiffinè remedium vnicum č päehrafton fit. Q 11 ă multis tu Principibus, nos pauperibus, Doronici ignoratione, exitio fuiffemus :quantam ftragem plus quingentis abhine annis dediffent Medici, freti electuarijs de Cemmis \& aromatibus \& alijs Cordi amicis, quibus frequentiffimè vfi funt, téq; monere polfunt, Doronico ne tantoperè conuitiêris, fed potius dofim metiaris:alıquicroci, Morchi, finiliumạ́ue da to quaternúm drachmarum demcnfum homini, \& comperies Dęmonium tǘ.

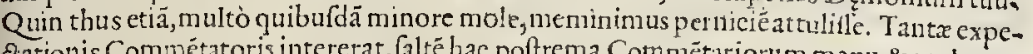
Eatrionis Commétatoris intererat, falté hac poltrema Commétariorum manu \& mole, an Pardaliāelie eodé neçrct modo, quo cæatera Aconita, exquirere: quippe fi nominis etymó \& Seriein Sympthomatum perpendas, videtur,aut fola(aut certè comite veneno) fträ gulatione, id patrare:çuemad móciun fungi, pap, ofaç; cxcrethenta Typhr \& Cannarum, qux belluis,pracertim ficcis \& anguntis meatibus, nec ruminantibus, fi cum efca pauca mul. tum confertim vorarint, moste moliủtur fuffecādo. Quin non fenel audiuimus venatores affirmătes, fe fruftrà dediffe Napellum, Helleborum, \& alia toxica, à feris ftatim vomitu reiecta: at vbi pauxillī Taxi addıdificnt, prorfum nullü animal cuadere, quippe naufeare, fed euomere nulil Pereunt igitur partim vencno, partim occlufo fpiritu, puta ad fauces, trachcam, \&: daphragma: plerumg; etiam euomere bilem, muccum, cibum, veneni auté nihil, nifi ob ficcitaten, ferò aut perparum. Non igitur refpuemus nos Doronicum, fed vtemur moderatè: fi non vt aromate, faltem liceat nobis vt Theriaca \& antidoto quapian : cuiufmodi inftituiffe vides in Degemnis Mefue, \& aromatü Electuario, celebres Medicos,q̨uos temerè infeitix \& feeleris rcos facis. Sed hæc fufíus paulò mox, in Paride \& Napelli mufcis, non muribus tuis, quos multi equè catti herbarij, atq; tenon minus fagaces, nequicquam venati funt. Iftx dudum defcriptær radices, à nobis Aconita cenfita, vt omnes cógeneres, fic faporc penè codé rüt, népè igntuluiore fubdulci, \& emplaftico. Qno magis addueimur,vt cre danus Diofcoridis lcgitimă effe Adoninis, quippe afcêfet ille, oculorü fcilicct remedijs blandis temperatifọ́uc calorc \& craffi nonnihil, emplaftica, pauxilla aftrictionc, digerétc

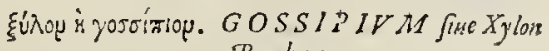

$$
\begin{aligned}
& \left\{\begin{array}{l}
\text { Ger. Baumwoll. } \\
\text { Ang. } \\
\text { Gal. o } \\
\text { Belg. Cotton. } \\
\text { Ital. Bombace. }
\end{array}\right.
\end{aligned}
$$$$
\text { Bombax. }
$$

QVE M A D M O D v M fedulitate Europęorum factum eft, vt fericun fit iam valdè plebeium \& pafim emolumentum exco multum fentiatur, fie Goffipiü prifcis ferme ignotum,adeò creuit notto æuo, vt ex tractibus \& infulis A a abicis iam non opus fit petcre:multis enim mediterraneis littorïbus alitur, \& venum inde deuehitur. Vidımus $T^{2}$ atauij \& Venctijs, aliquot abhinc annis in Treuifani \& publico horto fruticanté eubitum altü caulê, aliquot furculis \&"petiolis cinctú. In quibus folia Alcex aut Vitis, fed minora, molli ora, incana: Flores lutci,nónihil in medio purpurafeêtes, nuculáfģ; relinquunt, aut potius mala exigua, pullo colore, Ariftolochiærotúdæ magnitudine \& ritu radiatim hiảtia, dúóg:

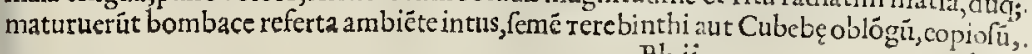
$\mathrm{Bb}, \mathrm{ij}$. medulla
męoslogu, coplofu, 


\section{STIRPIVM aduerfarianow.}

medulls plenü alba, oleaginofa, non infuaui gufu, Pnea, aut Anrygdalırũ, præfertim dum recens eit. Ex guta radice, fibrofa, alimenti perboni : pulmonum \& thoracis congcftant ma teriam ad excludeudum \& detergendum apta: hepati \& renibus amica,ftomacho haud perinde, aut capiti. Dy fentericis etiam opitulari noumus, cóq; lubenter voluiffemus quōo dam hanc Diofcoridis facere Gnaphalum, aut huius fpeciem, \& per deifcriptionem licebat:mollia namq; \& incana fint folia, vfus in tomenta optimus. Verim Theophrafti pofteàloco moniti, ad illius lanigeras vites referendam agnouimus. Sic enim ille: Infulam eße Tylem ( gualem bodre narrant nawigationes) non illam guidem algidam o cymeriam Septentrionalem, in fint CArabico ad Orientem, feracem arbortum, aliarimgque multrarum fir pium lanatarum, quibus folum ineft vitis, fed minus. Et frulu quidem orban, (intelligit vefco)

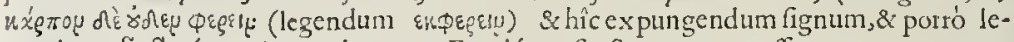

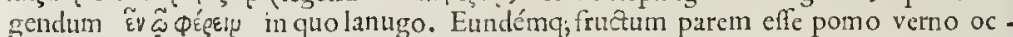
clufo, maturo veró pomo, cuelli eximić; lanuginem, qua texunt veftes, partim eximias, partim plebeias. Eafdéć; plantas in India \& A A rabia oriri,vbi etian eafdé $l^{\prime}$ linius recenfet, tanetfi foliorum non meminit. Et, qui mos illi vertendi, paulum variat, aut alundè mutuatus fuit: Senenfis veró tantus veftigator negat vfpià faetam huius mentioné à Græcis anriquis, nec tamen iftum luctlentum adduxit locum: alioquin velitationum ex Manardo, Braffauola, Ruellio, \& Fufchio importunus inerífq; interpolator \& proxencta:fed impofuit illi verfio Gazx, qux videtur innuere(negle $q a$ diffunctione) Xylon arboremeffe: atqui ne deinceps riftui fit criticis iftis, qui illum ne Latinè quidem, nedü Grxcè fcire inciuiliter negant, adeat Græcum codicem Theophrafti, \& difcet non arbores folun, fed etian communi nomine ftirpes, lanigeras inibi memoratas.

Apricis maritimis ad Auftrum iam multis, prouenit femine: quod fuillo ant vaccino fercore tridum macerari olitores Candiotzafferebant nobis. Sic enim vberius \& feelicius enafci,nempè celerius emergit, copiofiúfíf; fert, anteuertitá; frigoris tyrannidem, \& fęuitia. Sic enim induftrij plcrique omnes herbarij, etiam minus tepido \& commodo cœlo plantas vel morofinimas aftuefaciunt citò \& uberè ferendo.

Sylueftris $M A L V A$ vulgaris procerior.

CGer. pappel.

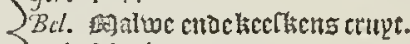

¿al. Maulue.

Ang. Mallow.

CV I I I E E r genti notius nilil, aut vtilitus Malua, appellationem ob precipuam emol-

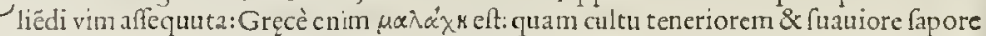
frugi antiquitas in hortis efficiebat, famemq́; ea explebat quotidiano olere, \& ventrem

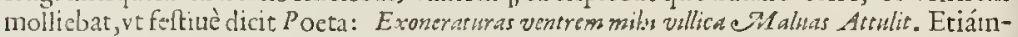
nü hodie primo Vere vnà cùm $A$ fparagi pullulationibus plebecula in agro colligit, \& efitat eius turiones teneros: $n$ am hor tis exulare, iamdiu iufit luxus i pram, \& officinis vtendam reliquit quotidiano ad varios morbosprafidio: vbiq; viarum \& arearum propc̀ vrbes luxuriat, caulum teneriorum flexili fobole: folijs quàmplurimis, craffufculis, ambitu nōnihil laciniofis, vitidantibus, circinatis, partim \& initio, partim \& poftea angulofis: flores tota aftate patticulatim exeunt, colore fubpunicante \& ex purpureo pallidi : edentes clypẹolos aut orbıculos feminum:radice pufilla, longa, digitum æquante, lignofiorc.

\section{eX ALVA Sylueftris.}

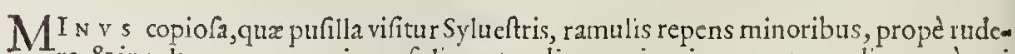
ra, \& inculta pagorum, minore folio, rotundiore, mitnutius crenato, radice penè pari fuperioris, flo fculis purpurantibus, albicantibus, vtilitate aut facultate non diuerfa.

MN $A L V A$ arborea Sylueftris. 


\section{STIRPIVM aduerfarianouta.}

FVEnrr huic Maluę quod Ficilici Sedo A rundini,atq; alijs non paucis plâtis,vt etiä nô cultax arboreã proceritaté, durationê, \& ramorí magnitudiné affequätur. Etenim quã meminimus in conobio D. Spiritus prope Venetias, \& aliis locis maritinis Thyrerix orx, nóprocul Sationa \& Arbenga fponte adultas, Perficam arbufculam xquabat, altrtudine \& crafsitie ftipitis, qui ramis fparfis, frondis lxuore, virore, inò toto flore, femine, $\&$ facie Maluam teftabatur:fed crafsiorem totam \& habitiorem, qualem Gallobelgix, Anglix, \& Germanix horti hodic colunt, qua driennium, quinquenniumqque cdurantem, lignofiore prægrandi radice, \& folido trunco, duritic lignea, fenum \& octonum cubitor $\bar{u}$, facultate non diuerfa à Malua vulgari : nec tamen olitorum induftria, vt falfò Senenfis atbitratur, fed folo natiuo deberi hanc differentiam fpecificam, è natalibus manifefum fit: nec enim vulgaris Malua ftudio, aut fortuitò in holeraces s hortis cult ta ${ }_{2}$ ffpiā vifia tur arborefcere, aut tot hy'emes trunco perennare.

$$
\begin{aligned}
& M A L V A \text { ROSEA FRVTICOSA, an Galeni } \\
& \text { Anadendromalache? }
\end{aligned}
$$

$\mathrm{V} \approx$ autem foris Rofei elegantia \& fimilitudine à Scptentrionalibus vocantur winter tojêt, id eft, hy emales rofẹ, vei Malux rolex, videntur ex equo cü Althea iftis Maluis cognatæ: qujp pe foliorü \& cauliculorü incana fuperficie, molliore, ruccagineać; radice Alricaun referunt, ambitu vero Ficulneo, aut Maluaceo, \& fcapo arborefcentem Maluam penè affequuntur,fed Althxę pofitu \& modo oriuntur, quotrannis etiā moriun. tur, radıce deniò primo Vere fefe propagante, culmófq ; edente ternum \& quaternú cubitorun.: fecundum quos ferotini prodeunt Augufto flores, nagnitudine,effigie, \& elegantıa tricolori Rofam ip $\mathrm{am}$ prouocätes. Trifariò enim variat hortis Septentrionalibus flos, qui mul tiplicior, confertiorq́; foliorum fcrie ftructuli euadit, vt plurimum $P æ o n i x$, punicæ faturę concolor: Sed cãdidus non rarò: interdî̉ dilutè nubet, aut vtrify; confufís coloratur. Semen illi etiam fimilius, fed grandius, Althæę: cuius loco vtuntur plerique, nec enim etiam radıcu huius difpar facultas ab Althæ2; quare efle halce Galcni Anadersi dromalachen certius quis affirmet, quìn arboream fuperius adductam.

$$
A L T H \text { A } A \text { IBISCVS: }
$$

Germa. Joifci.

SGallis. Guimalues.

Belgis. colittc buentt, w witte nalue

CeAng. Maithe Mallowe.

R I t e medicatricể vel medicã vocarurit Gräci lanc, vt qux fit certilsimi \& ferc̀ ingen tis commodi ad quàmplurimos affectus morbidos:c̀ Sylueftrium $M$ aluarun $f a$ milia, ficuti etiami monet D of corid. effe,cuilibet primò intuenti fatis oftendunt folia Maluacea, lenia, fed oblongiora, incana,nonnihil tomentacea ad Populneam frondem accedentia : flores albidiores, \& femina prorfum fylueftris $M$ alua:radice tamen multò habitiore, carnofiore, tot2 muccagine pragnat, \& in multas fibras digiti cralsitie diuaricatur, ac pratenfibus maritimis lubentius fponte propagatur, nec ferc̀ alıbi quàm in afflatu maritimo:idcirco afferunt quidam Pharmacopcei auuifas radices è maritimis, \& procul tranfmotas in hortos in Malaã vulgarem abire. Medici \& exercitatiores Veneti Pharmacopoi, c̀ muccagine radicis, ad tenues in pulmones defluxiones, offulas, mor fellos vocatos, diuriufculos ex facharo excoquunt, vfque mouendo, ne vrantur, nec enim cuiufuis êt, propter lentorem, benè parare.

$$
\text { Bb.ijj. ALtis }
$$




\section{4}

STIRP IV M aduer Jaria noua.

\& $L T H$ EA arborea Olbir in Galloprosinc.

$\mathrm{NO}_{\mathrm{N}}$ fecus atque Malua Arborefcens à vulgari, differt hęcab Althex cómnni:fed paucioribus locis, \& feruidio: re cxlo (quale in maritimis Galloprouinc.ad Olbiam) prouentu tanto fruti$c a t$, vt ad fepes conftituendas fat fit. Mul to autem folidiore fcapo eft, quàm Malua arborea, Salignx quafi concretionis, inqúte arborean texturam fermè verfo : flos item Malue vulgaris, aut Althex, nec difpar femen : quod in Morgani hortis Londini fatum, hacaftate plantam ip. fam peperit minus incanam, aut hirfutam, minírfque fpeciofam: tantum abeft vt cultu aut mangonio arboream euafiffe quis argutetur: perdurat etiam hic in Septentrione aliquot hyemes, nili fo lịtò fint fruiores.

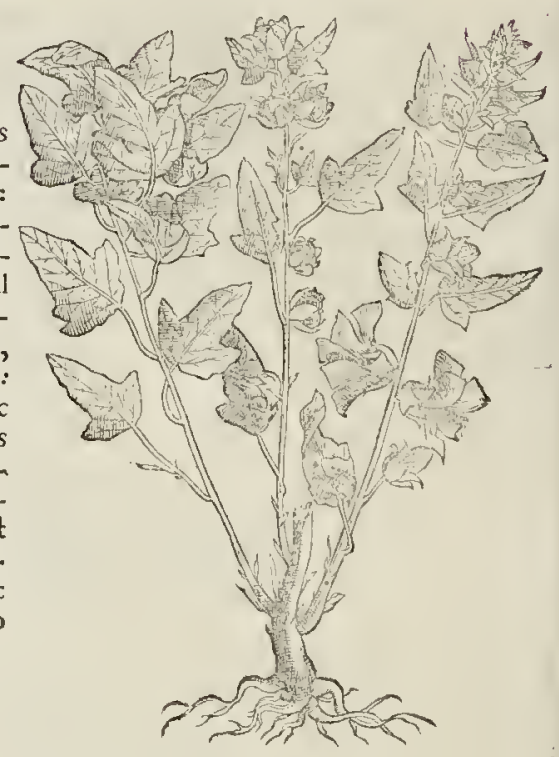

Alebea palufris, Cytinifore, Ariffolochic viriculis, $S$ I D A Theop: rafti putatur.

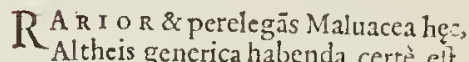
Altheis generica habenda certè elt, ctisimis $S_{\text {I D A Theop exiftimara, cui }}$ quidé, vt fi qux alia, exactè æqui paratur. Nam zíd Græcis dicta fuit à flote Balauftio concolori,nec abfimili, qualem venuftum imprimis oftendit hac planta,florere folita in locis riguis, lacuAtribus agri Ferrarienfis, inter $\mathcal{P}$ atauium \& Eridanum flumen, Radix hortenfis Maluę : caulis cubitorum duorum. Folia Althex, fed oblongiora, laciniis acutioribus. Flos illi purpureus, faturior Peoniz, aut Malux fatiux, aut Cytini:iuxta \&in fummis cauliculis vifuntur tempore vindemiarun vtriculi rotundi,oblon gi,phęo vel pullo colore, Ariftolochię ef. figie, pręgnantes femine Smirnii,aut Milii colore \& magnitudine.

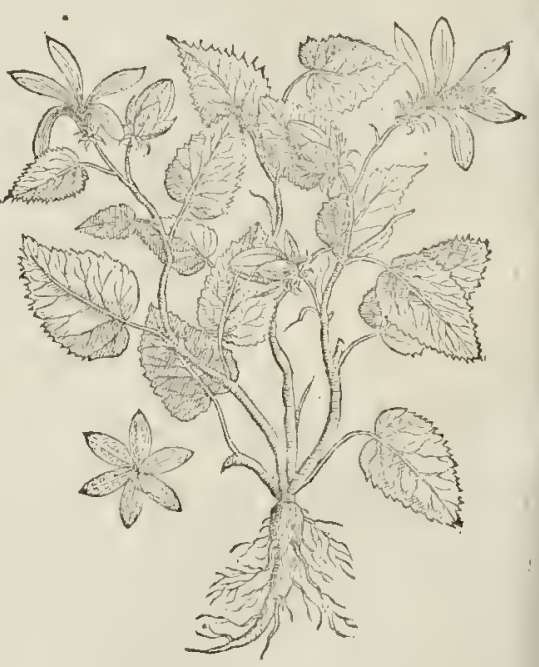

Sencifis videtur

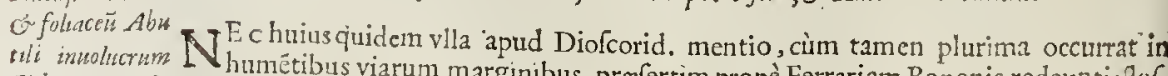
Side appinxtfé Stde appinxtye culis Iunio \& Iulio luteis, Potétillz aut Althex Venetx, per Auguftum \& Septembrem fesafe. 


\section{$S T I R P I V M$ aduerjarianous}

fis radiatim fefe pandentibus : radice Maluacea, folióque Althex, fed longiore, leniore, flaccidiore, fupernéque acutiore;vt Sidx:nec guftanti ab vtrauis diuerfa, nifí quòd nòn a-

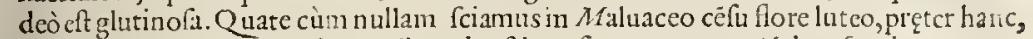
zquè tuto Lbifcum, vel Altheam Theophtafti profitemur, atque Althex fpecicn.

\section{EXOT IC A Maluaces, Bamia Eben quibufdum.}

IA M I v eft quum rarifsimam hanc primùm Veronx in veceis penfilibus vidimu s:pofteaçue Monfpellii fetrimus, \& virentem habuimus anno 1555 . in hor to Regii profefforis perquàn eruditi Iuberti.Et tametfi facic fí Malux, fed arborex nondum adultę; ncinpè folio crafsio:e, rotundiore, ininúfque finuato, \& magis ad Sidam accedente, tamë incertum nobis adhuc, fitne Maluacco geneti accen fenda: florem quident nullum prompfit illic, \& hyeme prinı fxuiente periit nobis: Semé auten à nobis tertæ mädatum,allar turn fuerat Alexandria aut Baratho, Malux \& Althex difsimile, teres, rotundum, pullum, Erui aut Orobi par: for tuita quadă ex Atabiftis codicibus, vt videtur, cóiectura remotios re,quidam Bamian Eben diuinarunt, quz fpecies Malux videtur.

\section{$V V L G A R I S$ ALCEA.}

QV A I cxteris robultior \& efficacior foret,videturantiquitas hanc etiam fylueftre

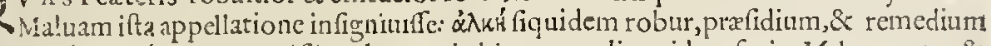
Gręcis elt: multò auten notifsima hxc ruri vbique:prodit quidem facie $M d$ lux, ortu, \& cavliculis, fed altius incılis, quinque purtitis foliis, qualia funt $M$ aluz vetuftiori, pufillx, aut Geranio, è radice prorfum Maluæ, \& virgultis féfquicubıtalibus, numer ofis, fené rotundum, orbiculatĭ, compreffum edentibus, poft forem copiofum; fed particulatim fiorentitu, vtrüg; item Malue, calidis pariter \& Septëtrionalıbus familiaris:plurima in Anglia, prope Conentriā vrbent : magis digerit, muccaginis minus dat, quàm MAalua aut Bifo malua.

$$
\text { FRVTICOSIOR AlceaPentaphylifolio. }
$$

PER M.v L T I Herbarii habent hanc, prolixioribus magísq; vimincis furculis fruticanTem,diuifura a!tiore, qui 1 atia, \& crenulis exiguis, planè rubrú Pétaphyllum, aut cannabuna folia exptimétibus; purpuräte flore: nullatenus difimilis fuperioribus tota hers $\mathrm{b} a, q u a l e n 1$ meminimus aftare finperiore in hortis videre.

\section{PEREG R IN A Alcea Solijegun, an T beopbrafii Malua?}

V A M N Is quidam hanc Italicam \& Venctam dicant,tamen nufpia meminimus in Q Italıa,nedum Veneriis, nifi in hortis viduffe, \& multò plutem Herbarii Septêtrio- An Argemonte nales habët, quàn Itali. Emicăt in fummis fefquipedalibus lent's virgultis peruenufti flo. alterafunch. res, aliquotó; foliolis conftant, foris albidis, medio \& intus purpurantibus, Abutili effigie $\&$ folliculo, è medio flotum emergentē croceum cuneolum, teretem, oblongiufculum occulentes;nifí quando $S$ ol ferè meridianus cęli noltrum verticé fcandit, runcenim, quafi fideris iubari inhiantes, fe pandunt, vnaque aut alteta horula pòlt, illıus veluti digreffu \& defiderio mofti, marcefcunt \& occluduntur, vnde quis Theophr. fufpscetur $M$ aluam effe Horariam, quam Columella Molochen videtur intcllexiffe illo verfu: Et Moloche prono fequitur que vertuce Solem. Radix exigua, tenera, folıa ab imo terna quináve, Pentaphylli aut Papaueris Rheadis vel Alcex:Alexilibus cauliculis, hirfutis: flores Malux vel Anemones; Capita numerofa, fecundum caulium longitudinem, lanuginofa, mollicella, ftrigata, membrancfa, hirfura, operculo tenui, radiato, clypei forma, obducto; vbi femen nigrum, Nigellæ ferè. Admodum rudis eft Cómentator, qui Rutx folia huic effe contendit,oculis teclamantibus creteris notis, 8 riris doctis monentibus ac negantibus, quibus feroculus infultat. Et quod deterius eft, fibi nobíque difcendr auidis, imponit, dum huic vires Opii afferit; nam guftanti potius infipidum quiddan \& ignauum lingux relinquir, 


\section{STIRTIV $M$ adierfaria noua.}

ab Opio prorfus alicnum amarore horrido: qui explorannt guftu, humidum tantùm \& calidum fecundo ordme, Fucile dicent.

\section{GERANIVAT RobortianmL Syderiti Achilleadon, ant congener.}

ROS r R A I capitis Gruiui cum preferrent effigié cuncte huius faniliz roftrata femi-

112, nomen obtinuerunt Geranii : quot um non ralde peruia funt, que duo memorix prodidit Diofcorides, multis Europaregionibus, vi nihilofecius vbertin tres quatuórve luxuriant dufferentıx, eiden \& plenfuue prifis indicta, fortè 1 ec into nomine cogntza : nam etıanfi iutiles putaffent, non tamen tacuifent, cum hîc alteram defcri-

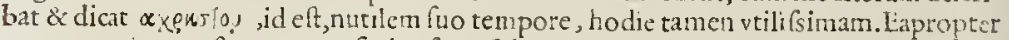
operæ preciuni nofter conatus facier, fi perfpicuas omnes fecerit, atque cum inter fe, fitra etiam ab aliis,nempè A nemonibus ranunculs \& Napellis difunxent, ne deinceps ty. roniimponat, néve negocium facefcar multuplex concors \& hallucinatrix parilitas.

Quôcungue acien verteris multis in ruderibus, parietinis, \& imbricamentis, icl fnggrundis tectotum, dentque fegetibus \& aruis videre eft, tres nociores differentias herbule Robertianz vocatę, fummo cefpite virentis, cauliculis gracilibus, fpatfis, multis, retrò deffexis humi, hirfutis, purpurafcentibus vel xerampelino vel phoniceo nitentibus, finzula teneriufcula fermè folia educantibus, Pentaphily, Arthentifį, \& Ranunculi duifu:a, fed profundiore:complures flores quinis itcm foliolis in furnmo confant, pupputei, circinnati, qui deftuentes roftratos mucrones, aut acus, è latiori bafi \& rếcum definétes, telinquunt, vbi femeil pufillum. Sapor non ingratus,aftrirgens; vulneribus perefficax; odoi teter \& vehementior; notissima \& vilisima:radix ex flato viret.

H a c duabus adhuc differentiis donatnr : quarum altera floribus maioribus vifitur; varietas foliorumć, altioribus mcifuris, cætero finnllima. Tertia ite Robcrtiana pluribus, caulicuRabertiani. lis, teneris,nonnihil hirfutis, reliquág; fimilis: duntaxat radice difsıder fanguneo prorfum foris $\&$ intus colore, longinfcula, flore item rofeo colote \& ambitu. Ef hac tertia, quam Achilleam vocat Diofcorides fub codé Svileritidis ambitu, tum quia def criptioni quadrat, tum quia p:aftat planè ea qua cidé Diofc. reddit, cóque 3 lutwuitż Germani vocant.

\section{P'ES Columbinus, fen Diofcarides alterum Geranintu.}

RE C E N T I O R xtas iftud rerutile agnofit, \& pedem Columbinum vocauit, ve cuins folix circinmata Alchynilla vel Sanicula fimilia, fenis octonífveincifuris Jaciniata, flaccida: fingula in exih caule appenfa, finilibus fof culis Angallidis minorıbus, purpura dilutiore, è quibus calicnli feorfim feninula oblonga colubent, \& acus exerunt pratenus, fufcas, $\&$ nitentes. Balneis percommodä afferme practici(tametí Diof cor. fua memoria inute) \& ad inteftanorum tormina vtilifsiman fcimus. Cultis \& incultis parsim inodornm.

$$
\begin{aligned}
& \text { MYRRHID A Plinü, Roftrum Ciconic, feu Aus Mofchata } \\
& \text { Officuarusi, ci paftoris. }
\end{aligned}
$$

PA v r o minus obuia ifta, canliculis ité gracilibus, cópluribus, è radice exigua fub pur. purcis \& hirfutis, preffertimadul tis, è caule nedio apice tenus folis enafcentibus Myrrhidis aur Cicuta, pofitu Tanaceti, in plumam tarfúmve deductis: in fummo flo fculi fupe rioris, qui caliculos in fuis petiolis relinquunt foras intróque reflexos, collum ciconiz effigiantes, ftylüque protendentes exilé, tenuem, \& longun, vnde nomen, \&acum $A$ of tam yulgus etiam dixit,ab odore fuaui Cicutarię verz aut Myrrhi.

$$
\begin{gathered}
B A T R A C H I O D E S \text {, fue magnum cormlewm odoratum } \\
\text { Gratia Dei. }
\end{gathered}
$$



$\not{F}$ A $\mathrm{m}$ feciofus iftud $\&$ calidos trąus enitans, amantius multo frigidiomm, pratis \& monę magnitudine, confpicua: Folia rotĩda, fiffa, peramplis multífq; diuifuris, Ranuna li aut Aconiti viridantia, \& interdum maeulofa, è unceis ramulis apta, glabris, pluribus ab-vno caulium internodio ortis, qui copiof à radice propagantur, \& variè inclinantur: prorfum horlumć; procumbunt cauliculi: è pediculis ambiunt verulos craffiores cufpidéf vetridentales, adduncas, breniores quàm fuperiorü, apicibus dehifentes, nonnilil inficxas, cum iam pra æate marcidi nutant deorfum flores : guftanti ficci, nonnihilqúc aftringentes, minus amari:odor quiddam Rofæ Mofchatx non abfimile refipientes, cuiufmodi ineft Acui Mofcharæ Diofcoridi indictx. Sed vul gus iam Plinij æuo Myrrhida vocabat, vtidiAum:adeò efficax eomperta vulneribus eft, vt 500 rgnas Germanis, Dé́ve gratian nomen
inuenerit.

\section{BVLBOSVM Dioforidis primum.}

D I eft cum quidam Pharmacopous Oenoponti, nobis iftud Geranium pro Anemone venditabat: verum animaduerfis poftea roftellis, qua huic roti fpecici peruia funt, facilè calculum reduximus, \& radicem pallidam, fubliuidam,lotundam, fapore infipido, infulfo, vel vefco animaduertimus, in petiolis prælongis, folia ab vno centro quinq; partita, \& diuifura Geranij Robertiani donata. Flores non ita in tenfè purpurei fucrunt: nos primî Diofcoridis Geranij agnofcimus, tametfi nullum periculum illitis fecimus. Rarò enim in Italia \& Gallizobuius nobis fuit.

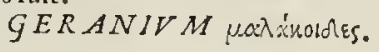

A P v n clarifrimü, ni labat memoria, Cáfarem Odoné Bononix iftud vidimus, etiamq́; Florentix Thomas Tranfyluanus fumma fpectationis Iuucnis, in quopian vireto nó procul ab vrbis ponœrijs nobis cómonftrabat, priufquàm luculentú prouétum naeti eflemus ad Monfpellij menia, porta Egidia, \& via qua ad arä, dirutumć; fanü itur, in colle amoniffimo, nee non via qua itur Mö́fpellio Befiers, 3 . aut 4 . ab vrbe lapide. Molicella tota,caulieulis \& folijs, Maluæ inftar humi fufis, fed longioribus, ex viridi pallent ibus: flores minores, albicantéfq; purpura, acus, verulíve Venerei pectinis, fed breuiores:Radix cuiufmodi Fumi terra. Senenfis Commetatotis arguere videtur(vt non pauex alix) hac planta fupinam fecuritatem, quippe quam pauló fuperius titubans in hortis fibi vifam, \& Momordicam herbarijs quibufdam nuncupatan dicit: eandem pofteà rerum incertus, quafi alterius generís pläta foret, vt Calciolarii donñ,defcribir \& appingit. Sed fraudi illi fuit, nolens tamen, illo qui à Sequino acceptã illam, quę magis albida \& tomentofa erat, mifit: nec noucrat eam ipfam effe que Bononi hortis fata, magis glabra \& minus cädida cerni tur.

$$
S A N 1 C V L A \text { o Diapenfia. }
$$

$$
\left\{\begin{array}{l}
\text { Ger. } \\
\text { Rel. \& } A \text { Ang. } \\
\text { Gall. Senide. }
\end{array}\right.
$$

A Potiore Medici munere, fanandi nempè,nomen factum Saniculæ:Sante quỉppe potu vulnera, \& prærogaciua quapiam interiorum excrementorum commotionem inhibet, frfitć; , ne in partes imbecilliores corriuentur,corruantó;. Hre Septentrionalium \& mótanarum regionum, Syluofarumq́; vdarum amantior, quam ealidiorum. Coptofrfoma \& notifima Anglis \& Germanis. Folio quina dunifura altiore, Ex apprinic compto, crenatura fimbriata, Geraniy columbini modo, rotundo, viréte, \& ex atro polito lavore, nume rofa, nngula è fungulis purpurafcentibus quafi pediculis, ab ima radice multum fibroG, Ellebori nigri aut Epipzctidis, for is nigra, intus alba:è qua caules cubitum aut pedem alti folia fuperant,glabri, teneri,graciles: Hores albos quafi vmbell a collectos: femine hirfuto, afpero, \& mordaci lanuginc, Iun io Iulio etiam in hortis chirurgorum \& muliercularum Belgarum floret. 
$T 7^{M B R}$ OS A etiam montofa \& rigua editiora hacamans, celebre Alchymiftarum pr conijs nomen indepta videtur, \& Germanis Chirurgis, qui hanc multum vfurpant, Ma!or fanicula vocatur: ncc abs re fanè, eft enim admodum affinis viribus \& facie, haud ita fol ia difímilia, latiota tamen, \& multò minus altè incifa, rotunda, angulofa, Malua, fed virentia, polita, fenis pluribúfve angulis, quafi plicis donata, \& antequam erumpant,vnà farca \&r conuoluta, argutis crenulis fimbriata:intérq; hirfuti cauliculi exeruntur, féquipalmum \&pedem alti,albi, rotüdi, quibus ftellati, luteoli flofali,vel herbidi,racematim congeruntur: \& in tuniculis her bidis femen exile Portulacx vel Papaueris:radice crafla, fibrofa, foris nigra,minúf,; calida quàm Sanicula,fed admodùm ficca \& aftringens, vulne ribus, fi inflammationis fufpicio ad dit, admodim oportuna.

\section{ALPIN A Eleborine Sanicule, Elebori nigro facie.}

E Elcborine aut Epipatide, multa Icctoré monuinus in albi Ellebori calcc pag. I 3 1: iftun verò, vtpote Saniculæ \& Ranŭculis propioré huc adduximus, ijfdem quippe móolis, vmbrofis, fed celfioribus \& Alpinis oblectatur: è radice fibrillıs vno nexu appenfis donata, erigit pedicellos teneros, glabros, flexiles, in quibus fummis folia quinq; partita, diuifa, \& parun crena ta, Gcranij Columbini ant Sanicul $x$ diuifura infit t: Flotibus radiatis, foliolis fenis, guftu non ingtato, fed acriorc, Ellcbori nigri radice: quare nonnulli voluerüt Ellcborum nigrum effe. In vallis Oftenfis faltibus, non procul à Iouis monte, aliquot plan as collectas fcrumus.

$$
\begin{aligned}
& \text { B } \alpha T g \dot{\alpha} x \log . R A N V N C V L I \text {. } \\
& \text { CGer. Zarenfufs. } \\
& \text { Bel. } \text { Bancmuoct. } \\
& \text { Gall. Baffuet \& Grenouille。 } \\
& \text { Ang.Crocfoote. }
\end{aligned}
$$

VIEVSDAM è Geranijs non parùm fimiles funt Ranunculi,quos cognomines Ranis fecerunt, quia ijfdem lacuftribus obleftarentur, \& floribus vt plutim um ranatis,ve loquntur Grxci,id eft, lutcis herbido permixtis,infignirentur, vnde facilis cognitu fuit Cemper planta. Eius autem multò plures differétias \& varictatcs quàm D iof. notainit po Acritas. Et vulgatifima quidem eft vbiq; pratenfis à Brabantis ritè botterblom vocata, ve qua tenera flotibúfq; onufta nult ü paftx vaecx, quá ad muleträ veniunt vberius lac dant: idó; colore pallësaut fubluteú, odore priıç bonitatis\&notç: folia initiò rotủda, in ambitu Geranij columbini,deinde incifura Coriandri, maculis paucis, fufcis confperfa aut fertugineis. Flores lam effigiantibus, aurei. Semen in racemofa, fiue Adonidis fimili cógeñe, grumofa, minus vrente guftu, necinfuaui odore, quem etian lafi impertire creditur:pafcuntur enim hāc pr $x$ cxteris armenta, quia gratior \& pratis pinguioribus vfque cunctis copiofifima.

\section{PRATENSIS Ranunchli varietas.}

FV N D E M fere videns ijfdémq; penè pratëfibus \& germinofis vdis marginibus hnnc, fed minorem totum, folio altius \& minutius diuifo, Coriandrinis frmili, $\&$ in cauliculis pedalibus fummis multò tenuius incifo, flore aureo \& capitulis congerie non diuerfis.

TOLY ANT HEMOS, malifform, fims Holeracems. 


\section{STIRP IVM adverfaria nous}

FT hunc putet quifpiam duntaxat fup crioris varictatem, fed florum fceturã perelegãtés multiplicé fortitü cultu hortenfi : vide 'Polyantliemon Plinianum arbitranturrecentiores. Nec fanè non alius videtur à vulgari pratenfi, nifi quatenus cultu mitior \& tenerior factus, qubufdä in holere manditur. Angli horti quendam habitu rotundiore Geranii folto habét, floréf̣; duplò maiores, \& fẹpè geminos, népé inferius medio ferè, canles, latiores, quos medios tranfadigit cauliculus, alter um in fummo minorem florem oftentans, aniceno in hortorum deliciis fpectaculo.

\section{BVLBOSVS Ranunculus, hirfuro muricat ofemine.}

WEcinfrequens hic, fed amantior multò fatorum, aut fabuletorum, quàm denfi com pactique foli pratenfis: folio paucioribus, fed altioribis incifuris, fuperioris Ranunculi finili, fed feninis inuolucro vilis af periufculo, lappofo \& tantillum echinato, Xanthii aut Caucalidis modo, radicis bulbofi Geranii,fubtus fibrofx.

\section{$P A L V S T R I S$ rotundiore folio, Jemine Ecbinato, effine Apitur Risus?}

I Nullam magis quadrat Ranunculi nomen,quàm in hane, vtpote ranis conucerricem, \& aquarum potricem, quafi refocillationis \& frigidioris egeret alimenti:quia omuium Ranunculorü habetur calidifsima, eóq; Apium Sardonium Difcori.putatur. Et certè rarius quidem, fed tamen alicubi in anontofi ftrigofićue agri lacultribus vifitur, foliis albentibus, 1nonnihil pilofis, Aceris, aut Pampini penè diuifura. Plurimùn tané eft videre vulgaris vbiq; torpentiü, autpigrè labētiü aquarum, folia fubluftri virore nitentia, Smirnii, aut $P$ aludapii, quẹ idcirco ex Diofcoride nonnullis perfuaferunt effe A pium Rifus, nobis ncutiquam inficiantubus, fed hrentibus aliquantum, propter caulem huius, qui vix fuperiores aquat: eft hac aurco flore \& femine fuperioris, cateroquin acrimonia rutis excitandis, \& liemoroidibus referandis, fi in Oleo Violaceo maceretur, aptifsim a propteres dica Homeroidum Herba.

\section{Flanmers $R$ A NVNCV LV S,aguatilis, angufti folius, Taraconis effyie,}

PER ev A M familiaris hic riuulis \& propter fteriles tradus fegnius fluentibus Belgï," Francıx \& Anglix, non perinde calidis tractibus, quafi frigidiufculo fucco \& aëre gauderet, quia feruidirsimus: enecat quippe edendo pecora, \& ideo arcent fedulò pecus opiliones, ne eo vorato infāmentur prxcordia, indidémq; moriantur, vt vıdere eft in balantum extis, qux huius pabulo ambufta fuerant: \& fummi foris quidem calyculi aurei lucentes Ranunculi funt: folia tamen angufta, oblonga, carnofa, nitentia, Ly fimachix rubre paria, ambitu aliquantum ferrata, in rubellis geniculatis reftis pedem ac cubitum altis, caulibus concauis, capillata radice, albida.

\section{Pumilis $R A N V N C V L V$ S, gramine is folit Goniculatus.}

PA R v obuius hic, duntaxat Norbonæ pratenfibus ponè publicú diuerforiú montis Lupi,\& in arduis Mindeni Ruthenorum pafcuis nobis repertus : afpectu latiore, \& flore quidem, radice, ac femine racemofo, prorfum Praten fis : verùm folia pauciora habet, \& adeo exilia, vt vix nifi floreat, à gramine dignofcas, prẹtertion locis illis ftrigofis, vbi caulis palmum \& fefquipalmum non excedit.

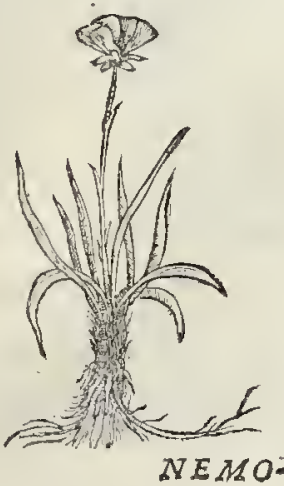




\title{
STIRPIVM aduerfarianous.
}

\author{
Nemorofus $R A N V N C V$ LVS fare albo, ficllato \& luteo.
}

VI x nif fyluofis, itut frigidufculis \& montofis reperire eft pufillos iftos Ranunculos, primo Vere florentes, luteos interdum, fapius candidos:foliolis ftellatum dehifcentibus, caule palmum alto, folio, diuifura Napelli aut Anthore, plerum que vno, nec pluribus, radice Filiculx, fiue Polypodii, minore tamen, necimprefsis cotyledonibus,

MINIMIVS R'ANVNCVLVSS Septentrionalium, herbidomufcofoflore.

VN A cum Ranuncult iftis \& Vnifolio, in iffem fyluofis \& vimbrofis, frigidiufculis Anglix, Belgii, \& Northmannix, non femel reperinus quandam tencllam, petılis gracilibus, vicidantibus, flexilibus, palm2ribus, folia laciniof fulcientibus,peryuàm fimilia Fuma rix Plinianx, vel fuperiotis Ranunculi fyluofi fed nitentia, expillore virentia; in cauliculo parter Fumarix, feminum glomerulus apiculis aliquantum verrucofis compactus vifitur, etiam radice aliquantum afperati, fquammolis grumulis candida, pellucida; fapore Gerdnii Kobertiani, tion ingrato.

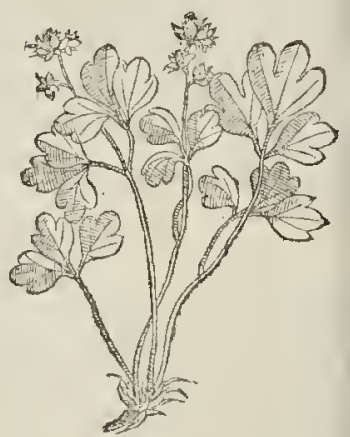

A CONITVM Batrachoides, anfot Diofco albo fiore Ranuaculus?

FA c I T aretifsima Ranunculorutn Aconitis finilitudo, vivtri fint referé dx quxdim plant $x$, alioqui apprimè nobis not $x$,nefciamus : E quibus eft. yna hxc in moritubus Veganiis Norbonx, Aruerniz \& Sabaudia fatis frequés, iux ta Cacalia, \& in mediis ritulis in Maio promentibus ramulis, canlis fefquicubitalis \& bicubitalis, flores candidi, delicatiores, Ranunculi effigic , feminum capitulo non abfinsili. Folia fingula, quinquepartita è pediculo, incifa Aconiti, Ranunculi , aut Saniculæ diuifura, ambitu parü fertata, pallentia. Radix - cauo cauli fubeft, in multas inaiufculas fibras difparata; acris ve Ranunculus. RA N $\mathrm{N}$ CV- Quem quartum non Mathiolus de-
lits quartius his quartius fcribit, fed elus piclor oftendit, totus eft
Marhot?. oritur. Radice Hellebori nigri , floribus albis, Ranunculo maioribus: caule fefqueubitali , foliis diuifura Napelli.

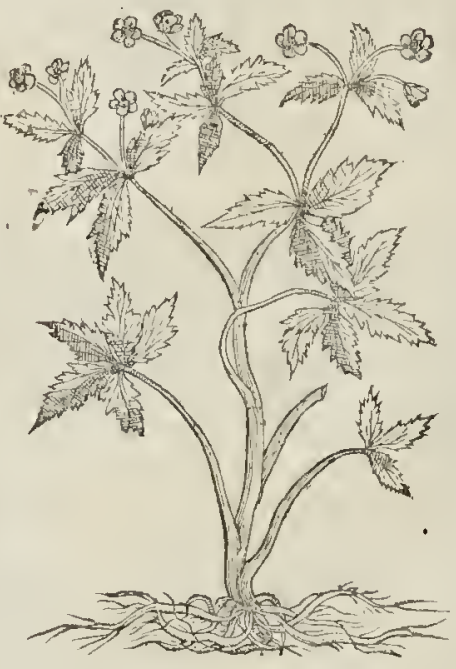

$$
\begin{gathered}
B V L B O S \cup \cdot S \text { unifolius ant Bifolins Batrochoides, } \\
\text { Elleboraces berbula. }
\end{gathered}
$$

FN $s$ or E E I I O R E effigie, hanc Venetiis in mercatu holitorio primùm à mulier7 culis herbilegis emimus, pofteaque Patauio vicinis collibus, vbi vipera capiuntur, e- 
tandem euulimus. Recto, vno, gracili caule furrectam, palmari \& fefquipalmari, in medio quafi centro, fingulum item folium (aut non plura duobus) fulciente, quod mulcs \& aitis incrfuris radiatim diuifum Aconıti foliü refert, cuius in medio, quafi vinbilico, flos vnicus, hetbaceus,pallénfqg;, A prili \& Maio vifitur, Hellebori prorfum:filiquofumó; femen relinquitur, etian feellatum, \&e effigie Hellebori: radicis bulbillus, quantus Ftumarix Pli nij,adınodum acris guftanti, etiamnum nọuem abhine. annis erutus.

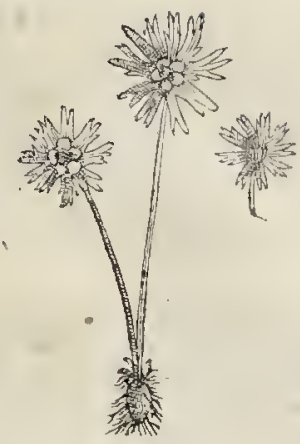

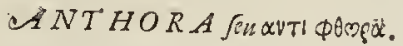

Is D E x prorfum natalibus, nempè Rheticisatq; Sabaudicis alpibus,emicat aftate Anz I tithora, quam quiodam proudentix munere aduerfum Thorx pernccabile virus compatatam rentur Taurini Ligures, \& Lemani accolx, quorum opera plurima radicum copia ccepta Venetias adferri plufculis abhinc annis. Agyrtis plurimi fit, ad omnium venenotum amoliendi nocumenta, dum plebeculam panagyricis declamatiunculis excitam praftigijs illis oblectant \& illudunt; etiap purgationi apta elt, educit namq; muccofos ferofofq; humores \& putredinem cotrigit aut exugit, lumbricifó; cxactis, mareriam futuris prafcindır. Amaroten auetfatur plebecula illic, aitó́; fí quidplä peramarū guftarit amarius eff: Anthora, id eft veinaculè $L^{\prime}$ Antboro: tametfi f́imus etiam alijs eos hanc nomenclaturã indere. Quàm Thoro paulo alror caulis huic, rotundus, ftriatus, alterno foliorü ab imo fummo tenus exortu, fingulari, multiplici, folio altè \& tenuiter incifo, quadantenus Delphini, Nigella aut Napelli: cuius floribus fimiles, fed luteos, minores, cuculatos, \& riftu hiante, habet galericulos, geminas radices Cyper aut Orchis, foris rugofas, folidas, fufco colore, intus albas.

\section{ACONIT VM LHteum Ponticum, Lippicida, Canicida.}

$A^{L}$ i \& \& natura \& facics alterius fümi A coniti generis, cuius differčtix plures quàm recenfucrit Diofcorides noftrum nouit xum, tametfi ambigux medæúe naturæ inter Ranūculos, Hclleboros atq; Napellos videãtut earum nonnullæ. Ponédæe ex primùm quorun vires certiores, exploratioréff; euentu reprêfentant facies, vt ćux folijs scit viticcis altè incifis, nigricātibus \& Geranij maioris, ve fimilibus fic maioribus edit. Cullem rotundü tenuem, bipedalem, lentum atque nonnihil fexuofun,petiolis nudis, alterno fitu folia gerentibus donatum, flotibus ornatum luteis vel pallentibus Linarix colore, \& effigic:fitiquulis fubnafcentibus, feménq; angulofum \& arrum cohibentibus. Radir fexuofis \& numerolis, nigricantibus fibris cyrrifve implexis, montofis, \& opacis faltibus auiffo nemoribus oritur:in hortis Gallix \& Belgix colitur, proq́ue deteriore catcris veneno habetur à venatoribus qui Lupicidam vocant: non quòdidem non faciant alix, feć quia hęc citius \& certius:quin nonnullis in locis adultęflores vel folo marfu fauces linguámg; tunore il lico excitato adurunt, \& vertiginem cient.

in

NAPELL'VS verus, Caruleus.

CETE R A Aconiti gencra tametfi Diofcoridi nomine tenus duntaxát prodita fint; tamen quantum ex firpium collatione \& virium obferuatione affequi quimus, Na-

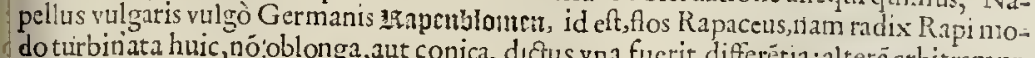
do turbiriata huic, nó:oblonga, aut conica, dıctus vna fucrit differétia:al teră arbitramur, Cc. j. quan? 


\section{STIRPIV $M$ adwerfaria nowa.}

quan Satuen $x$ Monfpelliacx accola perperam Thoram,nempe vaga cun creteris nomenclatione vfum propter, vocitant. Huic folia \& facies luteo Pontico non difparia, fed minutroribus plurıbúfq; incifuris molliora:è radicc tereti,ngricante, \& quam Anthorx graei * lore, fed longiore, ima parte recía, obtufa, caulem cubitalem, fingularem exerit. Flores \& femẽ in corniculis Aquilegıx Napcllíve modo. Edeuexis horti Dei Linguagotticis nemotibus nobis Canonici Lignipedes illic venationis callentifimi oftenderun, huius copiam in hortos Monfpelliacos tranftulimus: vixit du in Hermeti $P$ harmacopci viridario ad Egidiam portam.

Wapeths. Illud verò iamdiuctiam hottis præfertin Germanicis \& Belgicis peruulgatum, \& florum amcenitate duntaxat mulicrculis expetitum, quos propter fimilitudinem Brabantij emuntiscappen, id eft, monachi cuculan dicunt. Germania fuperior itappenblomen, ex radice \& flore contlata nomenclatione: infignis quippe radix, infignior \& flos arguto naturæ opere : prx fe namq; fert cucullx hiantis aut caffidis fpeciem, cuius anteriore media parte demiffior pauló frons in faucem proniffam inferiorê vergit, éq; medio exerit linguJam gcminam, paulum quid inflexan, multis indidem porrectis villofis ftaminibus, quibus extremis puncta lurida, vindiave infunt.in thecis fenen fimile nigrum \& angulofum veluteo. Radix orbiculata $A$ pij modo, vel Dracontijoblonga, emittit caulem tricubitaletn,petiolófö; gracilcs,prælongos, folıjs nigris donatos, multis magnifq; incifuris, quadantenus pampincis, aut Platanı. Huius videas accliues montium faltus Iunio \& Iulio pcrquàm cicgantem \& luxuriantem fundere vbertatem in Rheticis Alpinis, cui tumen cuncto illic arrofo gramine) parcit quantum cft pecoris, pręfertin fecus iter, quo Confantia Nafaretum verfus itur, vbi à quouis animaliü illibatum perfat, præerçuan à muf́cis, qux illi turmatim unfident \& aduolant, \& floribus fortè innafcuntur, funt cnim fermè concolores, maiotes, quàm communes, a lis capitulifq; ex lurido viridíve cafio virente, quali cantharides, vel cincedula, hafce attentius obferuauimus quidem continenter de fioribus ro ftello dchbantes:catcrum murem Napelli fruftra diu \& niultis aunilis plantis, quafiuimus, \& an vidiffent opiliones percunctati, nufquam fibi vifum negebã : $\mu$ ú fiuc rnurem è

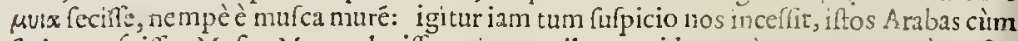
fcriptun fuiflet: Mufca, Murem legiffe: quippe nullam antidotum è mure parant: c̀ mufcis prattantifimam aduerfum funefum Tatantx morfum atque. Epidimicos noibos, cuiufmodi hac.

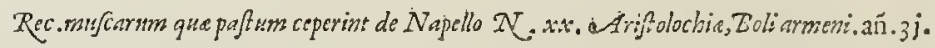

Nec in vlla planta huic congenere,mufc $x$ h cærulc r infidêt aut viftitant, quiò certior eft coniccura iftum Napellum effe Arabum, idémq; Diofcoridis vnum ex Aconitis: nam quòd qui perfunctoric̀ paginulas perpaucas A uicennx lnitrarunt, argutantur illum diucrfis capitibus quafi diuerfis de plancis fcripfife, quàm non multx, neque acclirata fint lectionis,indicio funt tan multa capita vnius rei, quas ille ant propter varias nomenclaturas putauit \& deferiptione fecreuic,aut quò incertus rerum qua parum plenè commenratus effet exactiorc opera profequeretur . Sic Serapioni non vno loco contigit:quin \& Diofcoridi ipfi non paucis, magno flagitio eius dignitatis \& difpendio pofteriratis. Senenfi veto,cùm fẹpe vt alibi oltend ımus, tü autem, quod mirum magis, ifto etiam loco, eafdem plantas bis térve inculcare, nimirum nomenclatura diuerfx ignoratione \& fuis imaginibus delufus. Quas enim imagincs fe dono accepiffe iactat, eafde fpectádas dat, nec def crip tiones, quod illi familiare, apponit, fed meris, nelcio quàm veris, piaturis, dütaxat oculos, non item animos pafcit.

$$
\left\{\begin{array}{l}
\text { Elleboraftria Confligiziss. } \\
\text { Elleborus niger. } \\
\text { Chriftophoriana. } \\
\text { Aftrantian nigra. }
\end{array}\right.
$$




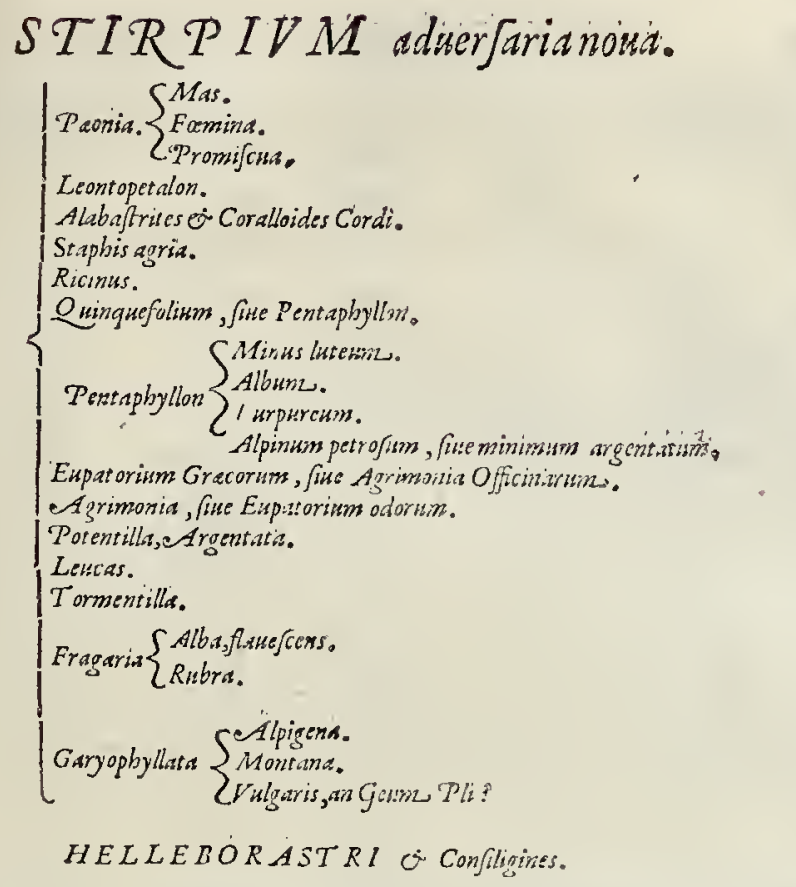

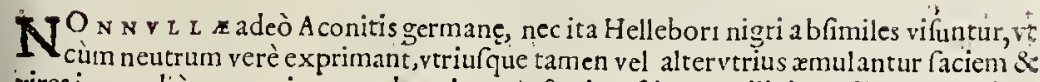
vires impendiò purgatrices : vnde quis coniectari polsit Conciligines dietas primùm, quòd cierent aluum,non folum quia fegetibus conferereıtur,aut adnafcerétur. Sic enim interpretatur Conciliu m, fue Cöuoluulum Plinius, quia Venerem cieat, tatnetfí inter fegetes luxuriet frequentifsinus. Geminam auten Confiliginem nouit atas noftra,nempè fegetum fociā, quæ pafsim Biturigas circum, \& Beauciæ variis aruis, Gallix Aquitanix, \& Norbonenfis exit: yt iux ta Lanum amné Monfpellii, omniü maxima, foetura luculentá foliorum, florumq́ue: caules feíquicubitales, geniculatos:cute ex virore pulla, vel atra, fquammofa, multas femiuncialis lat itudinis fundens alas, qux denfa pleraque folia fulciunt, fingula feptena, leuiter crenata, digitata, Lupini, Platani vel Viticis diuifura,figura, \& folio, fed longiote, cralfo, rigido: colore, odole, \& fapore, ferc Laureolæ. Porriguntur indidem multiplices petioli, qui in flores herbaceos, Buxcófve, pallentes, rugofos primùn explicantur, Garyophyllatæmontana, Tithymallíve Heliofcopii modo:dcinde fuccrefentibus corniculis membraneis, pallentibus, quadantenus Aquilegix, remen teres, atrum, \& oblongum, grano tritici minus recludentibus, Sole arietem ingreffo. Perennis Bruma rigidifsima etiam Septentrionalıbus peritat, floretque Círıfti fermè Natalibus: Anglis à figura

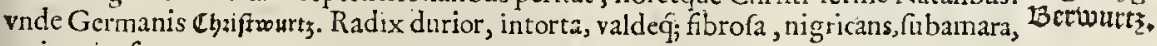
acris, virofa.

A I T E R A, quir minor tota,paucioribusć; caule \& foliis, fed maioribus \& latioribus, flaccidioribus, magifáue ferratis, è pediculis fefquipalnum pedémve longiss, eductis, qui H E I I E в ójn tenuem fibrä porrectū florē edunt, \& filiquam \& femé,cuiufmodi proximè defcriptä, vafti duplex diffed non perindè copiofa; codé tamen fidere \& frigore: verùm fyluis hxc \& vmbrofis gau-ferentin: det:fibris nigricantibus implexa radix, vti Vicetoxici, vno quafi oblongo nodulo aptis, Hæc propior nigro Helleboro, illa Aconito, viribus \& facié. Hæcóue, quafi fui difsimilis foret, fi ferius, vt Februario floreat, procerior: fin citius, multò minor fit, tametfi codem folo \& tempore fata : quin, vt crebrò notauimus, ctiam clementiore hyemc, folutág,, nec gelida tellure; qua minot, elt florü partione alteri,menfe,aut fefquimểe ante-

$$
\text { C. c.ij. uertic; }
$$


Yertit. Dudum monuimus, noftra memoria $P$ harmacopcos harum vtraque vos fuite, Hellebori nigri penuria \& gnoratione: nonnuli etian veri Hellebori ni-gri perfuafione: qui tametfi non parum accedunt, tamen illi neutiquam tuto vtendo fuffici queunt.

\section{HELLETORVS NIGER.}

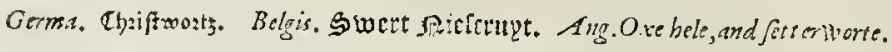

$\mathrm{N}$

I $\mathrm{G}$ E R verò Helleborus ( nam Veratrum nigrum qui dicat, videatur \& dicere poflé atramen tum nigtum, vi Se(quilongobardus ille ineptiebar) iam plurimus ex lyyreneis \& Alpinis in hortos tranfuectus, qui ineunre hyeme, itidem paulo polt brumam fores dedir ex candore Roreos, interdum albos, nonnunquam purpureos, necè folis, aut caulc, fed è pedicellis ftatum à radice ortos, cuiufmodi Cyclaminis. Folia fert in fingulo pediculo minora, breuiora, rotundion, \& retufiora, fupernè qua duntaxat pufil. lum quid crenata funt, diuifura feptena, Peponix fominx, aut Smynii fermè modo. Viridantia exatro, minus cralsa, aut rigida Radixintexta, intricat, innumera fibrarım'atrarum fobole, eodem fermè fuperno complexu appenfa, amara valdè \& ingrata. Morbis penè inuictis, non modò Melancholicis, fed etian nerè pituitofis \& fanguineis eximium pręfidium effe, certum habemus. Prater namque vertiginofos, amentes, $2 x$ cancro vexatos, etram paralýfi de fanguinea pituitofáque materia fpurieu partim obftruente,partimq́ue neruorum \& fibrarum tonum vigoremque laxante, correptos, valetudini reftitutos fuifle fcimus: \& quid Arelateli cuida Monacho,colore \& habitu vegeto, viribus athleticis, repentè Paraly fi \& Podagra perculfo, Rödellecius prętiterit, in memoria etiamnü habemus. Vocabatur Apis Monachus percuàm notus \& fcitus aulicus ille, id eft, Abeille, vernaculo Narbonico. Nec tarne ac albus, eft perinde formidädus hic: nam decoctis vnius libræ purgātibus \& mitificantibus, Melancholıă drachma duẹ trésve radicū, infufo addebantur:quin \& nonnunquam albi \& nigri mixti,ana 3 ij. addidimus. Quòmagis accedimus eorü fententiæ, qui primum è Pyreneis Perpignanx, \& Salfas Hifpanię cóterminis, cruti Hellebori periculü fecêre. Pofteà nobis colleqû̉ idê in Apenninis Bononie accliuibus, \& valle Auftêfi Pedemótana, ad Iouis mótisfaftigia \& ardua circü,nigrumó, nigri Hel lebori opinionem auxit:alioqui minus cógruit Diof.delineatio: nulli enim huic fores ra cemofi, femë Carthami Sefamoidífve eft: \& caule glabro lęuiq́;, nó afpero, aut nifi mauis in

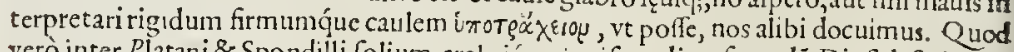
vero inter Platani \& Spondilli folium, crebriúsq;incifum dicit, ferendü Diof.defcriptioni:non enim adeò rigidè ad normā minima quęque exigenda: verùm in floribus, femine, alif́que nounullis, luto hxrendum eft. An fufpicandü luxam hîc lacerámve defcriptio-

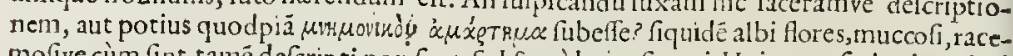

Crsstopho. molive cùm fint, tamé defcripti non funt, fed fortè huic afcrioti. Huic excufationi venia rionts. defit, verifimile fit, nos illo antiquo carere veratro. Idcirco CHR ISTOPHOR I AN A N illä, Aconit um racemofum nonnull is cenfitan, Helleborum nigrí, non femel arbitrati fumus. Radix quippe atra,confibrata, quàmplurimis appendiculis, morfus Diaboli aut Ve. rarri:Folia crebribus incifuris, effigie Napelli lutei, ferratıs, longioribus, pendulis, atrovrentibus, Spondylium, vel Imperatoriam aliquantum præferentibus : caulis fefouicubitum altus, gracilis, geniculatus: è quo extremo Hof culi racematim cohrentes, Olex, aut Helleborine albę, albidi, Corylli nucaméto maiores:quubus dılapfis, bacculx Laureo$\pm x$ haud difpares, acinorum modo in Botrum congeft $x$, cuiufmodr in Liguftro. Iunio fio ret: al tibus montofis \& dumet is gaudet. Prope Taurinum in Pedcmontanıs Träfpadanis collibus, vbi \& Laburnum vidimus:verùn cùm hanc tan toperè nocuan accepiffemus, in ægroto vllo periclitari vires, religio fuit.eóque vulgarem retinere confultius vifum fuit: erratum rati non in re, fed in Diofcoridis codice.

\section{ASTRANTIA NIGRA.}

TA N r o minus illi quadret Aftrantia nuncupata Atra, German. Schwatrs 31;tenty, ooes mutermozts, quám periti Saniculam alteram putabant, alii Helleborum nigrum,leuiufcula 


\section{STIRPIVM aituerfarianoin.}

niufcula fanc̀ coniectura. E radice nulumm fibrofa, aliguantùm Helleboro nigro fimili, atra,cmergunt complures petioli \& cauliculi glabri, graciles, quibus folia cuinis diuifuris Pétophylii, Saniculáe modo, per ambitum ferratis, obfcurè virentibus:fores aceruatim glomerulis collecti,mufcofi, Bellidis, Succifáne modo \& colore:Iuteum vniuerfa fúdit fuc cum, cuiufmodi Aftrátia maior, cui hæc etian alijs notis meritò affimilatur:idcircò nigra Aflatntia vulgus dicitur.Sed enim huic cum Helicboris cognationis: montana tamen eft, fedvulneraria.

$$
\text { POEONIA fomina. }
$$

A VspicAT ISSTMo Apollinis cognomine, 2 foclici ope prętanda, Proonia notiffima, cuä quafi fexu diftincta foret, marem \& forminam fecếre:vtramị; Geneua A. pinis \& Nor bonx arduis Veganij culminibus, \& indicem fyluofis non procul alio celciri i monte Lupi vocato, foeminä ernimus Verc forentē \& ineunte æftate tamen notior fcemina, eó́; vfu frequentior. Qux när; proftàt Officinis s Fomine funt, ACphodeli,Cyperi maiores, aut Oenăthes, vno tuberofo nodo pëdulæ, laté fparfx, glädulofé, ruffefcentes, oblögx, \& tenuiores, quàm promifcux $P$ xonia: calles primulum pullulantes

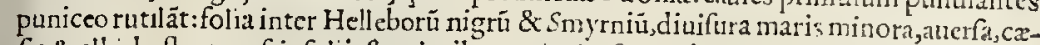
fia \& albida:flores rofeis folijs \& calycibus maioris, faturatis, vt Malux hortéfis, fuccedéte terno folliculorum foctu, Amygdala putamini fimili, \& pari fermè, concolori, delififcente per maturitatem, Hell ebori nigri filiq̨ua ritu, atquic pandente purpureum feninis partum rutilum, oblongum, nitidum, teretern, ferie mirabili ttipat $u m$, acinis Punica non diffimile: plenè maturum, nigrum, lucidum, medullofum: fapore medicato, acri, fubaftsingent, nonnulla dulcedine cum amaritudine.

\section{$M A S$.}

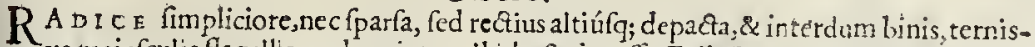
ve maiufculis flagellis, odora, intus al bida, foris ruffa. Folia Iugläds f tu \& ambitu mi nora,craffiora, ad Tercbinthum aut Staphylodendrum accedentia. Flores, Gliqux feminas fimilia, fed fernine exquifitè rotundo, concolori.

\section{PROMISCVA feu Neutra.}

V k.nondü mari Pronia reperto à nónullis Mas credebatur herbarijs, nobis Promif cuum, quafiớ; vtriufq̨; cinnus effet, \& neutrum, vifum fut appellare. Quippe quantum à folo extat, fi perpendas, Mafculum dicas. Sin erutas radices intueare, formina iudices: nifi quia pleniores $\&$ habitiores. Hæc Plinio Mas fortè eft, tamen id excutere noftra haud magnoperè intereft, nec ocium eft, nec lubet anxius prof equi, nú idé author errarit, dum maré folijs ait redolere Myrrhă, cuippe cùm Smyınium Myrrham redoleat, perinde

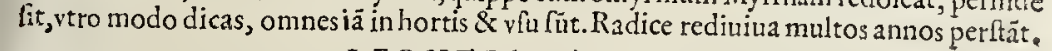

\section{$L E O N T O P E T A L O N$.}

MV I I I s abhinc annis qui complures radices tubcrofas proftare quibufdam Venetis Pharmacopolijs fẹpius vidiffemus,putabamus effe Cyclaminis adulį̧ aut vietx, pri mo intuitu. Poltmodùm felfcitati inftitorem,relpondit effe Leontopctali radices:cúmcque multis poftea in hortis accuratius viuam perperderemus, flores $A$ nemones vel Ranunculi,in filiquis femen, caulem non ita procerum,adeóq; radicem magni Cyclaninis aut rapę foris fufcam, tuberofam, vti Diofcorides prodidit, memineramus. Cater im folia tametí. ampliora multo, tamen finuofa \& circinato ambitu diuifa, P:xonia modo:non Brafficr fimilia, aut Papaueris diuifura obferuabamus. Iam inquilina cum fit Icalı \& Gallix, le fo $^{-}$ ri integrum crit nihil affentiri, vfo; dum vires exploratas habuerit.

\section{2emoralis eAlpina Herbarinram ALABASTR $I T E S$, CORRALOIDES Cordi.}

POTEST ItIDEM Pentarhyli Vocari E a, Qye in vmbrofis faltibus Taurinenfis agri, Calcaris montis Seuena, \& trans Rhenum non procul

$$
\text { Cc.iij. }
$$




\section{6

Bafilca reperitur. Folio è fingulo pedicul o quino $\&$ fcpteno, Ellebori nigri, aut potius $P$ coniæ, ferrato, in pediculis gracilibus, glabris, è caule fin gulari, fefquipedali, innixo radici craffiori, minimum digitum xquanti, tranfuerfim dcpactx humi,qux crebribus articulatur portiüculis, fruitillifve marmoreis, \& Polypodij modo radicem acetabulis infol ptam, effigiem Coralli albi præfe rentibus. Flores in fummitate plufculi pallentes infunt Maio, polteà filiquora vaginula erumpéte, maiore Erucęaut Chelidonij: femen pufilium claudente, gufu tota hxc amaricante \& calfaciente.

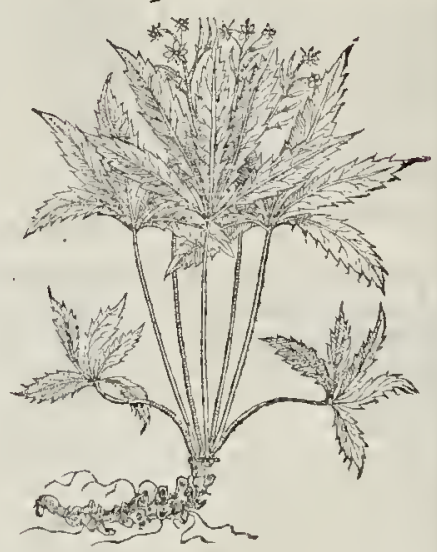

RICINVS,

Ceruarnaion.

CataphitiamaRicinus:appellatione dedit, vti Echio, Pfylio, Ve rucarie. Ceruam maiorem fue Cataior. Granum Re putiā palfim officinxappellatt. Granũ regiü Mefux:Palnıam Chrifti vulgus, propter fródis ginm Mefue. digitatam effigiem, qux volam palmamć; expanfis digitis quadantenus zmulatur, oriPalma Chrifi. untúrq; ex cauliscrafi, caui, 5.aut fex cubitorum, pixidatim confertis geniculis, depreffis, alterno fitu folia in ficulneo pediculo hxrenta, feptenis \& nouenis altioribus diuifuris, Ficus, Platani, Caltane $x$ equíve Staphidis agrix vel Ellebori nigri, fubnigra aut fubcoru lea, pinguia. Siliquato fecundum fumnitates faftigio, racematim compatis foribus luteolis fuccedente, vbi conduntur plurima ternis coftis, aut loculamentis, confpicua concep tacula orbiculata feninis tricocci medullofi,multúmq; olei preffi reddentis. Vix alibi qua in hortis videre eft, tamé tum calidis tum frigidis, lata tota ex cærulco in fufcum languet, annua clt, nec rediuiua.

Lat. Pediculit-

ris.

Gall. Ponil-

leufe.

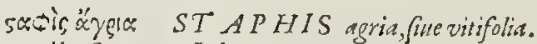
Ger pediculos illitu \& fuffitu abigendos : macerate namg; \& tufe in aceto vegeto, grana fi affricentur intcrulis, quantum eft pediculorum vel Icndium enecant. Ad quod bellum pediculorum, in prefidijs ipfa planta alitur vbiuis gentium, \& uufquam vltro prouenir,caule cubitali, furrecto, fufco, folia ab imo in pediculis pampineis laciniofa, crebra, profundác;, Aconiti, Ricini vel Vitis duifura. Cxruleos autem flore ftellatos, Rapótij, Lulio \& $\mathrm{Au}$ gufto dat. In oblongiore filiqua, multis coftis compacta, dehifente, femina crumpunt tri quetra, pulla, amara, \& vrida, oleofa. Radix non ita magna, annua eft.

$$
\text { QVINQVE folium. }
$$

F O L I o R V m numero quinario notum Pentaphyllon, perinde vt Ârgentina cognata, frequentifimum vbuis itidem marginum \& viarum vdis cuiullibet plagx. Folia crenis \& afpectu $\Lambda$ grimonix vel Potentill $x$, in lorulis pralogis, flexilibus, purpurafcentibus, quifefe nouis, qua folum fubierint, propagantibus Fragaria, Potentillæ vel Vnicx peruni cax modo quinq; partita effigie digitata, Ricini, aut Lupini, ad Saniculam etiam accedétia, Argẻtina lute is foribus. Radix quanta minimus digitus, lóga, pur purea, vel Cétaurci major's colore, quæ arida facta, quadrata cernitur, veriffimè monente Theophrafto: gua etiam nota, aduerfante Bat barorì pertinacia, manifeltò diftare à Tormentilla cuilibet in promptu fit noffc.

Huilis 
Huius aninaduerfa iamdudum quadruplex ant quintuplex varietas, in magnitudine Horum, colore, \& folijs fita.

$$
\text { 'P ENTAPHTLLVM MinusLuteum. }
$$

M I г м у $м$ omnium differt $P$ entaphyllum luteum \& minus vocatum, rarius tamen nifi fyluofis pratis \& herbidis mufcofis occurrie, vi Tormentilla, quã gracilibus tum folijs tum viticulis, fimul ac pufilla ftatura (necfefe defixis ramulss propagante, vt prior) admodum repręfentat. Folia qua terram fpectant, albicant.

\section{PENTAPHYLLVM album}

NEc multum magnitudine fupetatur, commune luteum Pentaphyllon ab hoc, cui 1 iem quinq; partita \& Helleboraftri modo digitat \& antcrius duncaxat crenata folia fubtérq; in cauliculis hirfutis, fores conduntur albidi, radice multis adnatibus huc \& i]Iuc vagantibus. In Belgix \& Gallix hortis meminimus vidifte,

\section{A LIVD album, C T Turpureum.}

$P R$. omnibus procerius \& fpcciofius iftud, quod in pingui parcuâm folo vel pratori Sauen $x$ Norbonenfis Iunio \& Iulıo flores edit candidos, interdum purpureos, \& in caut Jibus ab imo, rectis, firmis, pedalibus \& cubitalibus folia funt quinq; partita, fed altioribus \& crebribus, Coriandri Geranij Robertiani vel Alcex modo:foris nigricat radix, intus rubella, digiturn lata, palmum longa, \& fefquipalmú. Etian in A pénino I taliæ purpureo flore, perquàm af́pectu amœno, legebat peritus Pharmacopcus \& amicus non vulgaris, Iacobus Rainaudet Mafilienfis:Belgx \& Galli,in hortis alunt.

A $L P I N V M$ petofum cominimum Pentapbyllum.

WE hoc quidem adhuc defriptum, quippe non frequens occurrit, nec nifi celfioribus montium iugis gclidíf; cautibus, qualcs funt Sabaudia, in Auftéf valle, \& Norbonx ad Calcaris hortió; Dei ardua, \& in verticibus editifrimis Mindenij. Foliola funt circinato \& integro ambitu, quinq; partita, tenuia, \& fubtus candore nitido luccntia, aduerfa, viridia,Saniculæ tenellæ multü fi. nula, fed minora. Flofculi ftellati, racematim collecti, candidi,interdú \& putpurafccntes, AJchymillx fimiles, defluút ventis êta te, in gracilibus admodum cauliculis, è radicibus fibrolis capillaceis, furcis, purpurafcentibus. Quidam Tormentillx annumerāt iftud, cui multum $\sqrt{2}$ né fonile cft: Incompcrtatamen facultatis, nifi exficcantis \& altringentis.

$$
\text { Incana Pentaphyllieffigie, an LEVCAS Diofc? }
$$

NON penitus nihil rentiebant doctiamici noftri Valerandus \& alij, qui hanc plätam intuiti,Leucadem cenfebant: non modó enim tota incana eft, ve flagitare videtur ipra noméclatio, fed etiā Triffagini folijs eft, qualem oportete efle, facit fufpicionem confequutio. Folia funt terna aut quatcrna, cte bra diuifura \& magnitudine Triflaginis, furculis bre uibus, crafirs, lignofis, fubrubris, ngofis, furcis, vt Pé taphylli, quod inęquali à radice exortu multis depa-
cta portıúculis quodá habitu adübrat:item cx fufco purpuralccntibus, in alias fibras diuifis, gufu etian Pentapliylli vol Tormentilla, aftringéte,exficcãte. Q uare \& fortè non minoris quàm illæ dux efficacix -

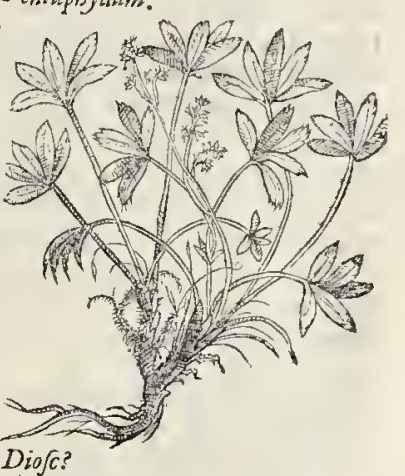
aducrín venena eft:qux caufa fuit, vt illi fortè vires radicú experti,aufi funt Lcucadê haroları. Etpræetat(quädo nulla eft Diofcoridis delineatio) hanc perpulchrä plantã noffe \& Cc.iiij. expe- 
experiri, quàm nullă,nililq́q; periclitari ad eruditionis fuppleméta. Admodùn inuentu ra: ra, nec nobis lecta, nifi propé Allobrogum deuexa,planitie in arida, glareofa.

Ger. Dostre: nig, $20 \mathrm{rt3}$. Ang. 20 A. Gall.c Srimo Bel. Sine.

\section{EVP ATORIVM Grecorum, Agrimonia Officinarum.}

TA м т s I quofdam nouimus in Belgio \& alibi,qui Agrimoni , fue vero Diofc. Eupa torio in morbis hepatis, lubentius Canabinum aquaticu n, ̀̀ nobis fuperius inemoratum, fubdant, vfur pentq́; frequentius, tamen quia non rei ignorationefaciunt, fed viriü: maiorum exploratione freti,eos adeó nó incefímus, vt potius laudemus, fi veterü quıpia fimplici perbono aliud melius vfu comprobarint. Agrimoniä autem noftraten fatis cum norx cunctx, tum nomen Argemonz in Agrimoniam detortum, (non Arthemifum, vt fub capitis fincm Diofcorides monet) verum efle Eupitorium fatis teftantur. Quin vires nultó magis, fed inultò plures funt, quă quas Diofcorides enarrauit. Eftó, notitix vulgatæ planta, frequentiffin i commodi, vbiuis gentium in pratis ficcioribus fatorum, viarü inarginibus fruticat cubitum \& fefquicubitü alta, friatum, angulofum, fubpurpurcum, hirfutü, durun, lignofun \& vnicú fxpiffimè caulempromés, multis ransofis nerunlis, folia quấ pediculo innixa, ad Vlmariă, Potétillă,aut Rolanı effigiata hirfutie, nönihil incana, foréfú; in fummo exig:ios, luteos, ftellatos, Pentaphylli minores, fecundum totam fummitatis lon gitudinë edıt, vbi feminum feries Lappofa hirfutáq; pannis hxrétc, quos vel tactos mordicuśt tenet:medulla intus albida, fa pore non ingrata, viti nec odore tota planta. Radix craf for, foris fufco rubore, dura, exficcante, \& moderatè aftringente, adco apta foris \& internis affectibus,vt decoctum dilutúmve colore lyn pido vinı gilui, placeat: \& potu vifcerum, hepat is prxfertim, toum reftutuat, intempriemç; omnem fermè corrigat, obftructiones referet. Eoque fuccum officinæexpreffum in Trocifcos ferusnt. Xantis Pictauę Gallia finitima fylux eandem Agrimoniam edunt, quam odoratam vocitant, propter odorem multo Bagrantiorem,etiamó; in hortis colebat fuperioribus annis, \& dabat nobis illie eruditus Medicus Iamoureus.

Ger. Srenting. Gall. $\mathrm{P} \cdot \mathrm{Ar}$ Bus. Sutine

$$
\begin{aligned}
& \text { eA R } G N T \text { IN A fue Potentilla. } \\
& \text { AAng. Wilde Tanfie. }
\end{aligned}
$$

TANTOPER eft hæcaffinis facic Agrimonix, vt \& vulgus Sylueftrể rocet Agrimoniam, I \& non rarò mulier culas A grimoniam fe collegiffe ratas fallat: difcernitur verò reptata viticulorum teneriorum, gracilium, Fragariz vel $P$ etaphylli, cuius fores funt fimiles, \& concolores, lutei: foh auten fupernè virent dilutè, aucrfa auten argcnteo fplendent nito: re,vnde Argentıne dicta. Potentilla pariterà viribus,quibus eximijs pollet, ad frangendä: calculum, interiora vuluera \& vlcera maligna, \& dyffenterias, vifcera roborando, fimiliter Agrmonix:cuius, potins quã Tanaceti, têperamento exficcäte, (iuc calore modcrato eft, fed antrictione fuperat:multum fanguinë grumolum potu cullloluit. Viarum, vdarum pręfertin, nulla amantior, frequentiórq; alumna vbiç; genrium dignü obfcruatu. Hanc inditan peluifrigida aqua femiplenx, \& operculo occlufe deftillare, fine vapores in concauă opciculi fubuehere, quod fublumare vocant, ferüt. Huius ftillatitiam ad lëtigines, pänos, \& maculas, fufcumó; colorem Sole contractum delendum, Angla muliercul $x$ adhibent.

Ger. Brictinurt; rub rot beyt 2xurti.

Gall. Tor

Ang. SmenBel. Still.

$$
\text { TOR MENT I LLA velH E P T A H Y L L O N,an Cliryfogorum Diojc? }
$$

O V I Pentaphyllon nouit, non poteft quin norit Heptaphyllö, à feptena foliorum diui furafic vocatum: Tormentillam verò, quia tormentum, cruciatínve dentium fanifinum placat, atc; venenatorun quorundan rerum compefcat furam cruciantcm. Ncmorofa,montana, ficciora, inacilentiorać; prata fternit, furculofis, gracilibus, fenis vel ofonis ramulis, folia Quinquefolij minoris lutei, fed fe ptena diuiftir, farfis, rubellis, nitidis ab radice exortis corpulentiore, \& craffa,pollicem ferè xquante, Biftort $x$, \& colore intus rubro, foris nigricante: Fofculis Potcutillx, vel Pentaphylli lutei minoris.

$$
F R A G A \text { Fragaria. }
$$

$7 \mathrm{O}$ I $\mathrm{T}$ a dinct fa ortu \& habitu ipfo vifitur in fyluofis Fragraria,praterm:fia etiam Diofc: fed verfu Maronis fignata: Quilegitisfores co bums nafectia Fraga. Fragrat nam. 


\section{STIRP IVM aduerfaria nou}

mamịue non modò fructus \& flos, fed etiam ftillatitia ; prafertin fruf qua nuliercula Erifypelaceas \& furturaceas lentiginofáfque facien fordationes leniunt \& abigint. Ad calculofos\& inflammationes epota optime facit. In bellariis, prefertim cul tx plätz idé vfus, fed quàm Idej Rubi delicatior fructus. Humilis herba, fyluofis familiaris \& viarü marginibus, primo Vere foret, \& tota ętate fructú fert, purpurei, fanguinei dilisti cruoris faturum, folia terna Rubi, aut Idei,adeò fimilia, vt nonnulli fomniarint eandë, differt verò herbacea natura, ( tanetfi hyeme perfante, quando etiam Erunz tempore femioperta niue in Anglia, niora efitaumus nonnulla ) viticulis exilibus, enodibus, numerofis, pilofis, nequaquam fpinofis, ab radice tenu, fuperficiaria fibrola,prodicunt ibus: floribus in fummo albis, Rubi, fed minoribus.

\section{Iulgaris $G A R$ TOPHLLAT A, an GEVMPlinit? \\ Germa. Benedicten mo:t5. Gallis. Galiot. Ang. Auens.}

NV T R I V N \& \&yluof vulgarem hanc,illis non multùn abfimilem, nec item Grxcis \& Latinis ( 1 if fucrit Geum apud Plinium) dictam, cuius tamen radix eximii odor:s nullum latere debuit, qui olfeculfet: quippe Nardi Garyoplylíve fuanitatem Ipirat , multum capillofa, rubella intus, caulem pilofum, fubpunicenin, fefquipedalem, \& bipedalem emittit, alis aliquot duifum, quibus fummis fores 'Potentillz, aut Tormentill $x$ infunt, \& pilulę deinde oblongx, fcabra hirfutic mordaces, in pediculo fingula ad imuın folia ferè Alchimille, in fummo Fragarlx; fed hirfutie \& fimilitudine Agrimonic, cuius qualıtates ferè eft affequata:calore \& ficcitate temperatis : ad vulnera intus forífy; vifu laudatissimo; quare $\&$ in hortis vbique herbarii colunt.

\section{Septentrionalism, rotundifolia Pappofo fiore G A R Y O Y Y I I A T F.}

BRA E A T I E fyluofis conterminis Mechlin' $z$ \& in Northmannia frequens ifta, in Anglia verò plurima: quę magis totius plantæ habitum perpendenti, quàm foliorum exprefsionem, aut radicis, Garyophyllatam reprafentat: funt etenim circinnata, \& aliquantim criftata, ambitu Hederæ terretris, in petiolis exilibus nonnulla foliola admodùm exigua habentibus, vulgaris Garyophylx modo:radice crafsiore, minus fbrofa, minimú digiti æquante, Geranii mofcati momordicie dicti, nec perinde Garyophylam, aue Nardum halante: flore fpeciofiore, \& caliculo pallidiufculo, relinquente pappofam orb tam,quafi plumeis vadantıbus, quidantenus Alcex Venetx radiatam.

\section{Alpina Pentaphylea CARTOPHXIATA.}

N Rheticis Alpinis nó procul Clauenia,hanc primùn nà cti,putauimus effe Tormentillæ, aut Petaphyli fpecië:verùm radix Geranii fibrofior , forifóue rubiginofa, parùm quid fuaue redolens, Garyophylatam teltatur. Quinetian trigit caules pedales, cui hęrent folia quinquepartita, amoitu Cerrata, Penthylli, aut Tormentillx , flore luteoo pallentéve, ftaminulis lanuginofis, croceis, pappois, minoribus Garyophylati.

\section{VERO NENSIVM Garyophylata,flore Sanicule Vrfina.}

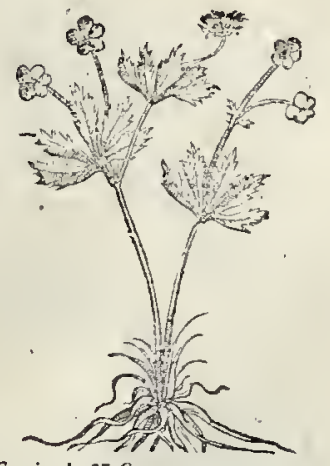

IN $\mathrm{T}$ E complures infigniores plantas, quas apud Veronenfium Pharmacopororam peritifsimos, Francifcum Calceolarium, \& Andream Bellicoquum, partim in Officiiis, partim in hortis videbamus 1563 . fuit quadam peruenultis florum quafillis, pufillis, 
ortu \& fimilitudine Primule, aut potius Saniculæ Alpinæ, intus luteis, foris purpurant bus, nitidis, èmedio filamenta crocea oftentantibus, \& pluribus in fingulo cauliculo, glabro, gracili, è radice numerofa coma donata,quę permul tos petiolos ftatim fundit, quibus cunctis fingulí foliü Geranii, Maluacei, aut $S$ aniculæ, rotundü népè: fed per ambitú altius finuatî,,minutimó, crenatī,afperiufculü, flexï humi, \& fufus aliquätò fe pandens, ritu Geranii. Qualé meminimus in hortulo pone ædę Iacobi Cortufii Patauni Patricii,rei herbarie perquàm periti \& auidi, cui \& nos vicifsim quafdä tranfalpinas \& Norbonenfes plantas, partim dono, partim fpectádas dedimus; fapore ex aftratione ficcante.

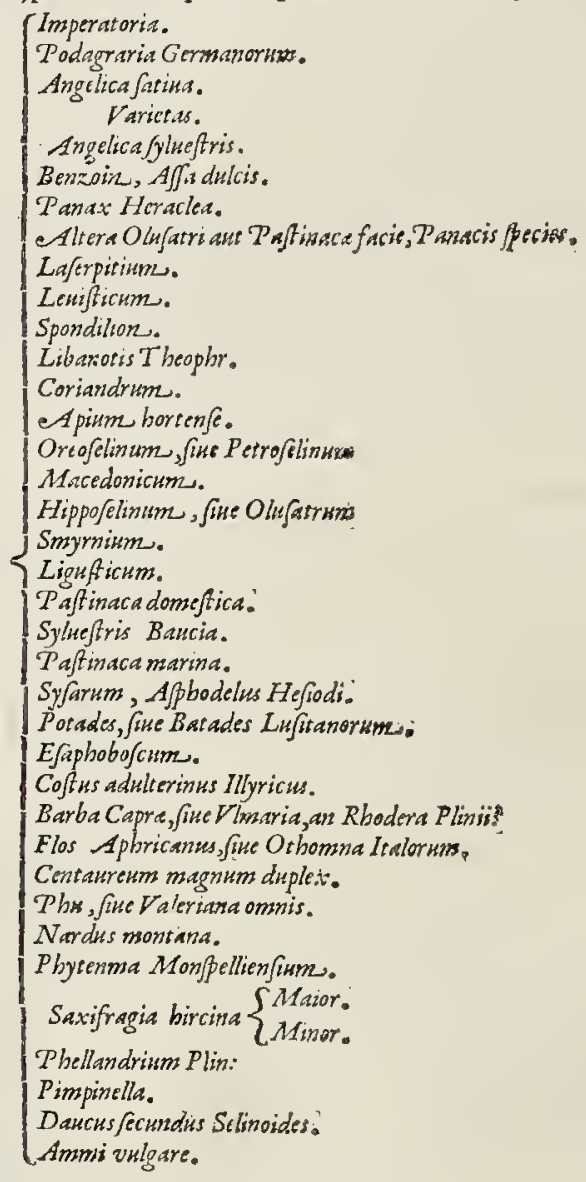

\section{IMPERATORIA.}

$A$ Vóvsto hęc propter raras facultates donata fuit nomine, ceu quxpiâlectẹ mercis in dicatura. Affinior auté eft facie fatiuę Angelica, quàm fyluefri: folia tamen propiust Spondiliü \& Hippofelinü zmulantur, vt plurimù terna, ftatim $a b$ humo cauliculis fubuectu:gracilis caulis, nodofus, fefquicubitú altus eft: rmbella $\&$ femé Angelica fylueftris, vel Anethi: radix digitú $z$ quat, mulcis fibris in terram fparfa, foris fufca,albicans intus: 
multò veliementicris \& acriorịs facultatis, \& odoris quàm Angelicx. Iifdem gaudet na* talicijs.

PODAGRARIA, German.

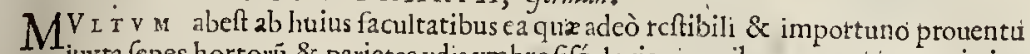
iuxta fepes hortorü \& parietes vdis vmbroffíg; locis pinguibus prouenit, vt vix indepolfit radicitus deleri. Pedem alto caule, candida vmbella, Imperatorix, minora folia \&r radix odore minus fuaui,quo \& viribus quadantenus ad Ebulum accedit. Ea propter plebecula rata ESul um efie, vfaiam diu eft,ctiamnumó; experiturad Ifchiadicos Podagricos optimè facere. Vocitántquc Belgx f flctcintrupt, id eft, Podagrariam. Sanc̀ facultates Ebulo quàm Imperatorix fimiliores fortita eft.

ANGELIC A.

$V_{\text {bêdas }}^{\text {Ix }}$ credi par eft noftrates Angelicas Indici, delitijs aut przfidijs neuticiuam pofthabëdas, Antiquitati noras, niff fint apud autores veterinarios Gallorum Laferpitia methorata:nec enim filuiffent illi tam diuinam fragrantir gratiam, \& vicarias diniriæ Beneficentia vircs, fiue Angelicas, triplicis noftratis Angelicx. Quarum qux procerior, radice crafla \& aliquantum fupernè tuberora, multis appendicibus humi merfa intus candicat, foris pulla, odore perquirn fuaui, aromatico, pinguem,gummofum, flauumque fuccum remittente. Caulis bicubitalis binum triúmve cubitorum: ftriatus, pallefens, ferulaceus. Folijs latis, Hippofelini, Simonijve æmulis, ex virıd in pallidum langnefcenti bus, mollibus, vmbelle funt Paltinacæ, donefticx, luteique flores \& temina foliacea, rotunda, com preffa, \& albida, acris guftu \& odoris eximij.

Varietas.

NOnnullis in hortis hic Londini, Antuerpixǵ; vifitur alin, tota minor, cuilus fuauiorem odorem radix fpirat, prope quam folia ima ex purpura rubefcunt: fupcrna autem ex rubore virefcunt:vmbellx cateráq; femina fimilia. Cclfos vtraque montcs gclidáq; amat iugaj vel uti Imperatoria dieta, cum qua in hortis colitur in Anglia,Belgio, Gallia.

STLVESTRIS Angelica.

$S E$ D qux fylueftris rarius hortis, fcd fxpius vliginofis, pratenfibus locis frigidis, gaudet; radicc pluribus fibris, odoréc; czteris multo minore clt, guftu non ingrato \& Paftinacafermè:minoribus folijs,acrioribus, paucioribus, minúfq; incifis: graciliori \& humiliori cauli,vmbcllę albicant magis. Cuilibet hæe nota;in Anglia, vbi lubenter vtuntur, quia aptior edulijs condiendis. Corrigit enim prouentum faburamq́; craffortin \& vifcidorum humorü, atq; foetidum halitum emendat tetri f piritus, expraua concoetione manantis; copiofsor etiam \& gratior eft.

$$
\begin{aligned}
& \text { A SS A fotens, an fit fuccus Cyrenaicus mixizus. } \\
& \text { recentiorum, non ef fuccus Cyrenaicus. }
\end{aligned}
$$

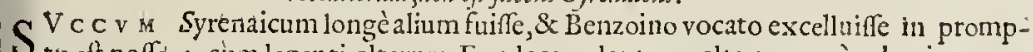
$S_{\text {tu eft noffé : cum legenti,alterum Ferulacex plantæ, alterum vetò arboris proce- }}$ ræ multo fuauifi tumn cxcrementum cff: tum etiam facultates,qualitatésve exploranti, qux guftui in Benzoino, neque feruorem in intima fefe dantem, neq; in corporis meatus peruadêtcm,fudorélve affatim cienté exhibet. Capiteauté de Lacca; Benzoin inuentum re-2 centioribus, \& à Cancamo differrc, differuimus. Actametfi Syrcnaicum illud celeberrimum iam tum defeciffe Plinif xuo affentimur, non tamen prorfum: nullum extare in naturx familiaLafcr pcrfuademur.Præter enim quàm quód fpeciem nullam penitus poffe interire docét Metaphyfica dogmata, tuim verò nob is fuppctit Affa fẹtida, quả potis eft Syriaci, A rmeniaci \& Lybici laferis opinioné fuftinere. Solitú enim erat ittud nota deterioris mixtum Sagapcno vxnum vehi. Sagapeni enim eft odor Afię foe tidus affinis, quod $L_{2}$ feri nondum ficcato foliti erant remifcere,ficó; venundarc, Diofcorłde authore, cuitus recenfione doceri oportet Lafcr non adcò celebre fuiffe, quia odoratiffimum, alioqui primo libro recêfuiffet, alt hî́ vfum tam rari odoris addidiffet, velfaltem odoratiffimum dixiffet: atqui dútaxat Syrenaicú laudat, quia aptius cibis, maiore conmodo, minorc odo is faporífq; faftidio efitetur. Odore nó fuauẽ, fed intenfî̀ vegetúmve cómendat, quo mixto fải aut condimétis, oris fơtentëhal itü corrigit, vt puta Liguftico Imperatorio. Zeduaria, Leuiftica 
non fuani,fed gratiore quàm naturx placeat odore. Hune Serenaico temperatiorem mul to $\mathrm{ffe}$, \& os co imbutum minus vehementer fpirare. Ipfis fubductis, fi quis duplicem af fam meminerit Arabibus dictan, al teram dulcem,alteram fotidan, vires noffet fic fati: quadrare: odorem verò mitiorem illius, quæ dulcis dicitur, agnofcet, vt cui minus aut ni hil additum fit foetidiśagapeni, aut alicuius confimilis gummi. Fotidam verò $v$ bi multi fit remiftum, eoque fit vt interdum liquidior, liuidior, subicúdior, remiffior cernatur, pro ut mixta, recés aut vetultior fuir, neq, dum exaruit, cuiufmodi interdum vifere eft in rancidis officinis.

\section{$P A N A X$ Heradium Herculea, fue Heradia fronde Pafinace.}

D Ixim v s antea Panacis nomenclaturam communem fuiffe pluribus plantis, qux neq; inter fe fucie, nec planè viribus fimiles effent, magnx tanen celebritatis commé-

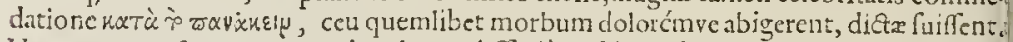
Hanc antem etfi Herculis nomine claram difficiè nof citare fit, quia alıquàm multis, quas noui nus in nofro coclo orjundas, effuat mullus fuccus, tamen non defunt qui quandam in hor tis coli non ita diu coeptam,nobis etiā (commōftrante Doetore $A$ fatio) rurı lectam) veram afferunt. Verim permul ta funt alia huic nulla dote aut nota inferiorcs: radix exigua nimis videtur, dumm cubitorum caulc ferulaceo enim, folijs quadantenus Smyrni, aut Imperatorix, fcd lacinijs ambitúq; magis circinato, viridis pallentifg; coloris, rigrdis, \& leuiterhirfutis. Radix non pcrinde fucculenta Liguftei vel Angelicæ, vm bella lata, floribus lutcis. Creuit fuaptè fponte in illo faxofo colle, qui Frontignana redeunti Monfpellium ad lruan eft, propè aut pone Saccllum dirutum, vt nos monuit multiplicis in-a duftrix atq; indefeffi laboris hac in parte Doftor \& profeffor Monfpellienfis Affatius: fed ftudioforumaccurfu, qui auidè iftam plantam in chartis feruabant, deleta illic feré fuit.

\section{$P A N A X$ altera recontior Olifariant Paftinace facie.}

T E N E T OR V M quidam potiores, etiamćue Lcopilli circulator, alebant \& oftenta-

bant quandam Panacis f peciem ferulaceo eaule binum \& 3,2 utem 4 . affurgere cubitorum, multos in ramulos fupernè diuifo. Ferulacea auté folia fquabra, afperiora, in fingr. lis petiolis,geniculis, fingula prodeunt, ampla, tharfi, plumatimve ex interuallıs $x$ quis pofieu $P$ uftnac $x, R$ folijs conftans multis in vno petiolo, oblongo: Africani fermè Horis iuteoli aut pallentis: flores in umbellıs paftinacx aut Baucix, quam etiam affmilat tota planta hirfutie incana, radice longiore, albida,nec ita difimilis:in Venetis \& Flandria lortis meminimus gufu aromatico, calfaciente, \& digerente, gummeo, oponaceum fuccum redolente: quare merito putetur hac, vt fi qua alia, $p$ anax legitima.

\section{LASERPITIVAL.}

COnTra quàn fithodicabiftis autoritatum racematoribus, mininè nobis luber intitas aceruare fuper hac hiftoria paginas ex vetcribus, quibus ne nunc quidem fi viuerent fortè eifent ipf $x$ plante notx, Laftupitij dico Sagapen, permultarúmque ciufmodi cummificaum, qua videntur Diofcoridi \& Theophrafto non vifa, fed lectione aut auditione accepta. Eamobrem non multa hic verborum velitatione, vt moris hodie, fed fed la luftratione \& peregrinatione opus effet, quando antiguorum manca fape, fxpius nulla recenfio extat. Igit:ıripf quantums infpectione affequtifuimus, candidis amicis lubenter impertiemur. E regione Mafilex, \& non proeul infulis, quas videtur vocaffe Diofcorides Stxehudes (qux tamen putantur hodie illx èregione Olbix, à Maffilea fermè dicinauigatione, vti capite de Stachade dictum fuit) inter multas raras nafcitur ferulacea 


\section{I STIRPIV $M$ aduerfarianous.}

nem nufpiam cur non fecerit facilè fubodorari. Foliis Lactuce fylueftris, fterilis, ort caule, flore, \& feinine, Theophralto memorata, nufquam nobis vifa.

\section{CORIANDRFM.}

$V$ B I $C_{y}$ e hortornm peruinm Coriandrum, à cymicum putore, aut potius cicut $x$ foe tore virofo, \& confinvili facie, nominatú tametfi \& finili, vt videtur innuiffe Diof virj

Comfule Diofro. bus cognatum. Cuius fententiam fiaccuratius fubduxiffet Senëfis, non quidein iam con mantator, fed Diofco.immerentis defertor, neutiquam tam nultas farragincs ex Galeno Auicenna, Ruellio, Brafiauola, in fuas paginas conuafaffer. Quin potius, quod folertis in terpretis \& candidi eft, à veritate Diofcoridéque ftetiffet, neque noftra delufa fpectation fic, ninil docendo, el aprus abiifet. Licuit enim cuilibet Philofophiz mediocriter imbuto. dımudio paucioribus verficulis non parú lucis huic difficultati afferre. Et decuit etiä vedt cum doctum hunc adınodum pauca difierere: Coriandil autherbam totan, aut fe men in vfun vt plurinum venire: \& cius qudem, aut aridi, aut virentis : neque tan multis rixis, fed inultiplici experimento, \& antiquorum certísima obferuatione, ew exprefum fuccum herbámve contufam, illitu tumorum feruorcs cópefcere; femen vero ftomacho multis de caufis proficum, concoctionem iuuare, vaporum furfum eruptio nem fatıumóue impctum fiftere, temperatxq́ue qualitatis alimentum effe, vnde fant guinis feminisque incretncntum, ac ne quidem corredum prodeffe, ne tantoperc̀ alierfer: tur illud meticulofi ifti declamatores : cùm quifque Pharmacopcorum, aut etiam i plebecula quotidianis epulis autmedicanentis correqum mifceat, nullo inde percep. to nocumen to. Plerumque etiam illud faccharatum officinarú, neutiquam correctum eft: nifi putes faccharo, igneǵ; : igitur non aceti frigiditate, fed potius feminis ficcitate \& tenuitarc. virus fortidumque fpiritum abfergi putandum.

Rationis fubducio igitur hac eft: Coriandri herban pręertim fucco frigidam effes adeóq; nonnulis in locis, A rabum teltimonio,cius fuccum epotum exitio effe:quod de Hiulca recentiores etian exploratum habent:Herba nempè vefca \& bonialimenti, fuccus cuius, hominem necat. Quapropter \& facris ignibus illitus reprimet fuccus infammationé, exceptus polenta panis medulla, quam Galenus haud reiciet, vt quilibello de paratu facilibus, exantiquis doceat hordei farinam polentam panémue \& fimilia addi folıta, non tam quò agant, quàm vt agendorum fuccorum vires excipiant. Tametfi videntur etiam inuare digerendo, \& ficcădo, vt hordeacea, aut etiã demulcendo, vt medul1a. eAtque huic reiponfio eruenda obiectioni de ftrumis: multa namque fuat non calida, qux ftrumas incipientes difcutere valent: eóque hic farinam frefa fabx addi vul t Diof. cum exciplendo medicinam, tum etiā iuuando action: : Digerit namque faba, cumć; Co: rianári fucco mixta noderatè repcllit exficcando : qua ctiam vi teftium phlegmonibus opitulatur: ficca enim optimè ıd praltare, modò modicè refrigerent \& difcutiant, prafertim initiò, Methodus Galenica docet: fic'Plantago etian Diofcoridi, fic capilli Veneris frumas difcutiunt.

$$
\begin{gathered}
\text { APIU } M \text { Hortenfe. } \because \\
\text { Germ. Pererfilgen. Gallis. Perfil. eAng.Terfele: }
\end{gathered}
$$

M A I m equidem selinon quafi Lunaticum dictum, ab illo fotmidando affectu, quem accerferet efu, quàm à paluftri folo, vbi non femper nafcitur. Fi autein non defunt : vires quædam Coriandro analogx. Siquidem eadé fermè vtrunq; pręltat, experimen to \& Diofc. fuffragio non tamé cùm dicimus analozas, eafdē aut finiles, intellectū iri volumus: fed lic loquimur, vt enucleemus iftus authoris fcitủ folérfq; ingeniú,pauci eloquii \&r veritátis amicilsimú.Vt quid nó argutetur nüc criticus ex Galeno, hxc $M$ ethodis aduerfari, calidü nempe Apiü? in

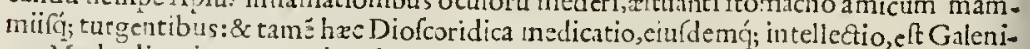
cx Mathodi anima, perquàm digna cui nauet quippiam operx fedulus Senenfis: Sicque fe expediat, effe prxfidia non parum multa, qux contrariis, aut yalde diuerfis polle - 


\section{STIRPIV $M$ aduerfaria noid.}

ant effectionibus, \& tamen eidem medeantur affeetui eiufdem incrementi \& modi. Id in capitis fracturis atque vulneribus facilè de Galeni Celfíque lectione, \& medicamentorum collatione difcas: quorun hic fiecantibus frigidis; ille verò calidis diger entibus;etiamq́ue humectantibus foeliciter vfi fnêre: fić, 't teftiun numoribus violaceun farinis exceptun leguminofis quidam,al!j ve rò Cretenfí feruido vino exceptum Cunnini pollinem medêtur. Sic hic nihil mirum Coriandro ficco refrigerante, \& paulùm quid aftringente partim diffipari,partimq́; repelli materiam eiúfq; incrementum,vel A pio calefaciente digerentéq; in halitum per poros hatos difiari. Multa cùm fint Apij genera,omnium frequentifinum gratiffimúọ́; cibiseft domefticú, é́q; merito tacita cóiectura magis quàm certa vlla expref-Varietutes. fa figura, verum antiquorü putatur. Nam illud perelegans \& rarum, quale viruit in hurtis CR1SPArva fuperiore anno è montibus allatum, nihil diftat, nifi foliorum crifpatis oris, argutioribuf- Apium. que \& minutioribus incifuris. Iftis haud abfiniles cxteræf fecies, viribus tamen efficatiores \& medicatio magis.

Paludapium vocatum fatiuo quidem mains, fed ingrati tum faporis, tum odoris, vt fi PALVDARXY M quod A piü meritò fuerit Chryfippi Dionyfijq; confilijs Medicorü, à cibis abdicarĭ, quia propéfius päroxifmum epileprscim exciter, acieiq; obfit: iftud paluftre fit merito cenfendum. Eft tamen efficax valde, eóq; Arabibus \& Pharmacopois nonnullis vfitatius in fyrupis ad obftruetiones, Bifantino \& s.radicum.

\section{OREOSELINVM, fine Tetrofelinum.}

$\mathrm{O}^{\mathrm{R}}$ EOSE I I N Y M verò radice eft craffa, longa, alba,odorata, acri, aromatica, quàm quà caulem promit, capillamenta curdam in ambitu habet Libanotidis modo. Folia à Venetis reperto Macedonico Petrofelino fimilia \& xqualia: caule non procero, fparfo: Semen \& ${ }^{\circ}$ vmbella non diuerfa. Rarius iftud, nifi montolis Lugduni, prope Sequanam, \&
in yalle Oftenfi Pedenıontana.

\section{MA ACEDONICVM.}

A D o M E S I c o perparùm diftat effigie Venetorum Macedonicum vocatum: Folia

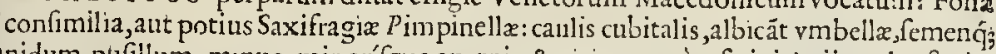
euanidum, pufillum, mınus, mirioríque energix \& virium, quàm fatiui $A$ pij, multo ftudı coptuni eft coli, quiararum, nefcio an verum.

\section{HIP POSELIINU M, fiue Olufatrenso}

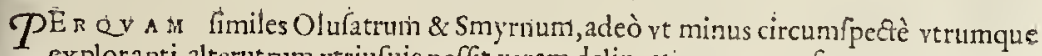
exploranti, alterutrum vtriufuis poffit veram delineationem repręentare: at cui vtraque planta viridis prx oculss, atq; deicriptio non item. Magis confpicux differentix funt hx. Iftud geinus, quod plebecula frequens efitat, prxfertim primulùm afparagos dum pro* mit, vocitató; Macedonicnm yel Alexandrinum,vt Angli, in hortis coplofiffimum, vbiradix illi craffior,magis fuccofa, vefca, \& tencrior, quàm fuapie fponte nato. Foris color pul lus, intus albus, odora, guftu grato, \& nonnihil medicato. Caules edit aláfve multas ftaţro à radice, \& folia A pii paluftris, fed maiora, rotundiora, viridantia cx atrore, vel lurida:caulis ftriatus, bicubitalis, concauus, A pij: vmbell $x$, chorymborum inftar, pédulx vifuntur mitturitatem affequute, onuftx feminc copiofo, atro, vnde illi Olufatram, pleno,graui, femifphęrica figura, fed paulùm quid vtrinq; retufa in bafi, medicato guftu acri ad Smyrnum ac cedcnte. Doctiff. Marcellus $\&$ Braffat ola efle verum Hippofelinum afferucrunt, quod qui

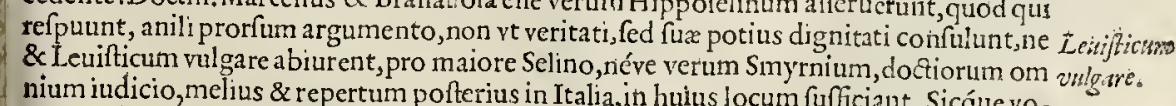
nium indicio, melius \& repertum pofterius in Italia, in huius locum fufficiant. Sicóue voplaudente. Virgilius Marcellus tibi peruerfus intcrpres immerito videtur, quippe hoc
plocto Dd.ij. noti 
non eft peruertere, fi radices foris nigras, intus albas in quopiam non tibi vifo codice aut exemplari legit \& fcripfit. Peruertcret autem, fi contrà quàn author innucrit fenfum expromeret, atqui $f$, vti tu vis, Diofcorides nulibi meminit, igitur nec aduerfatur, nec $M$ athiolus meritò Hippofelinum verum auerfatur. Quod tamen vulgus Italorum audiffimè expetit in acetarijs, non fecus atque Germanortun, Anglorum \& Græcorum, qui etiamnum, vt iam tum tempore Diofcoridis, cum Smyrnio confundunt. Valde familiare "olus eft, alit bene \& prẹtateaden qux Apium, fed efficacius. Sic Angla plebecula $p_{\text {ulegium }}$ Origanum, Anagallidem antem Timpinellam facit. Et Hippofelinum Alexandrinnrn, Apium vocant. Leuiftico aút eft femen multùn dinerfum, fapor,odor, \& tota vmbella:nul lus fermc̀ $v$ fus in acetarijs, non enim oleracea eft, qualem optat Diofcorides, fed ingratiflima \& acerrima guftu.

$$
\text { SMYRNVM. }
$$

F A $x$ in procinetu ruerit vera Snyrnis cognitro, \& cum Hipporelino ac Icuiftico diftinctio, cui nota fit illa planta mul tis iam diu Belgiẹ \& Galliẹ hortis enata. Cuius radix cófmilis Hippofelini, aut Ferulx : folia pauciora, maiora, craffiora, ima retufiora, fum in o caule circina tæ rotunditatis: quo quidê traiecta, vt Perfol ata herba dicta, ccrnuntur, proxime ranicellos amplexa, vmbellis A nethi aut Perfoliate donatos. Floribus albicanti bus, aut pallcuribus, vbi femen fuicum, fubrotundum, Raphano minore, Brafficx par \& li- $^{-}$ mule, prorfum Myrrhā fpirans, acre. Commentator conmentatorum Sencufis, mor ofè ni mis, cum in fuperiori fuo, tum in hoc Snytnio femen Brafficx exquirendo fatagit, lectorem feque intricat fuo more . Nam \& illic paucisinteriectis lineis fibi refragatur, \& hîc(quia, pt fermècius omnia, emendicatam habuit plantulam, radice nancan, vmbellis feminḉ; chartis fortè appteffis, eóg; minus exątx cognitioni aptis ) Braffice fimile fe. men ncgat, nec quicquam melius indicat.

\section{LTGVSTICVA1.}

SI quis Genuaitinereterieftri proficifcatur Sauonam, \& paulùn ad lxuam Auftrum narére verfus deflectat, magisani copian ridebit huius Lyguftici,inibi propemodum $\checkmark$ bi Saliunca vifitur oriunda:verü illie, vnde nomen habuit, apud Lygures, quibus nummus fermé Numen eft, non folum hrc, fed ctiam pleręque multò prẹftantiffimę firpes negleEtui habentur. Vniuerfo illo tractu maritimo reperitur hxc, cuius femen fulcun, odorum, Fonıculi fermè, vefcum êt, multoó; ;vfuillic mótium accolis, Mei fimile \& par vmbellis,è caule Fcrulacco, alis diuifo, folia ferentibus anguftiora, Galegra aut Sileris:radice Panacis, odora.

$$
\text { PASTINACA Dumegica. }
$$$$
\left\{\begin{array}{l}
\text { Ang. Perfenippe. } \\
\text { Gell. Paltinades. } \\
\text { Ger. mozen. }
\end{array}\right.
$$

Q V 1 a fponte hac in agris nafcitur,quamq́; quxliber paupercula gens pafcitur, Paftina

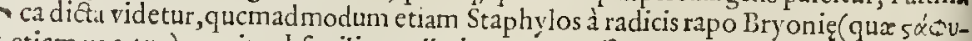
os etiam vocatur) non ita a $b$ (mimili,appcllationem traxiffe potuit. Tametfi non effe figura diuerfan à fatiua $P$ aftinaca, $f c d$ viribus duntaxat ignauioribus quàm Sylncftris, ex Diofcoridis oratione non liquct:tamen, quia poifcritatis confenfu, \& nulto vfu ifta recepta eft,idcò vt genuinam agnofcere vifum eft. Similis Sifaro facie, fimilior tamen Elaphobofco, Syluefiri Pattinacx, fiue Baucię officinis diç̨, vifitur: Iutei namģ; funt Bauciáfores, \& radix coucolor, \& eiufdem faporis. 


\section{STIRTIVM aducrfarianoma.}

STLVESTRIS, SYLvesTris fimilis eft tota Carotis, feu Danco, eui Galeni Paftinacam fylueftrem fuccecandicant. Ea [eatent arui \& fat $a$, minor multò fuperiore, \& radix eundein guftum, ièd, medicatum exhibet: minus tamen cibis expetitz .

\section{SIS ARVM Angl.fyrret. Gallis, Ceruys.}

NOst r a t e Sifaron retinet cópicua veltigia appellationis \& fimilitudinis Sionis: 2lioquin ex deferiptione antiquor rum, quibus notisimum fucrat, non fatis notum, nifi hac nomenclature \& radicum conieatura : ideo quòd vulgò frequens Norbonenfi agro (non perinde in Italia aut alibi) vefcendi eaufa alitur, legitimum putatur. Snpor illi

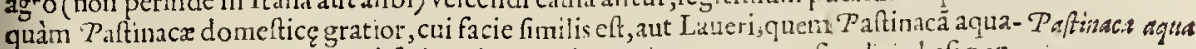
ricaun fecerunt: fed in radicibus difcriminis plus: fint enim ex vna quafi radicis bafi peln- tica. dulx, buibofx, teretes \& oblongx, Oenanthes A fphodelíve moto; qux quia vefex funt efféntne illie ab Hefiodo ftultis exprobrat $x$, vt quondam ambigcerenus fecerunt. Nanı Hefrodi AfiboDiofcoridis Afphodelus non homun , fed pecont potius, aut fui alimentum cedat. delars.

$$
B A T T \text { A D ES, Tgnames. eAng. Potaites. }
$$

H V I C Sifaro non parùm accedere videntur radices

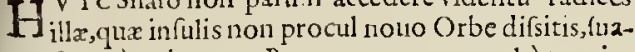
pte fpontć oriuntar. P O T A I E s vernacul è tum indigenix, tum Hifpani illic vocant, quibus hxc in patina \& Vencris illicia freqéns veniunt:finguli bulbi teretes, oblongi, Napum vtrinq̨uc obtufum æquant, color pullus illis foris, albidus intus, fapor gratus valde \& tener, quafi Milii delicatioris, ant fabę frefæe, cóque guftu infillfx funt, nifi condiantur: faléque aceto \& oleo interdú eduntur, \& vino perfunduntar, nonnungulam $\mathrm{co}-$ Ex prunis. Hifce congeneres funt \& perfiniles qux $\mathrm{ab}$ Hefperia, Ethiopia, \& Guinea afferuntur, Ignames vo-

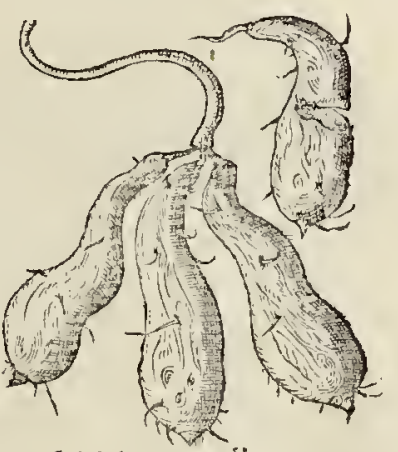
cat $x$, quales aliquoties efitauimus:folia vtrifque hederacea \& Maluacea audimus,

\section{AST IN AC A Marina, an Secacul CArabum?}

E R v I a s huius radices in maritimis fabuletis Norbone inter Eryngia, dum cfitat plebecula illic $P$ aftinaca Marinam vocat : funt enim prorfum eodcrin fapore, nee longè à figura abfunt, nempè longiore radice Paftinacx aut Eryngil; caulem fefquicubi- talem, ferulaceum, ftriatú, Eringij fundens, quem mult $x$ al $x$ c̀ geniculis emergentes ambiunt per interualla vtrinque: folia cra $\oint_{S} a$, mucronat:, pinguia, 1 quo fummo albicant î́. res; quxdanq́ue rudimenta vinbellarum effigiant : vbi femen fpinulis refertum murisatum \& Calcitrapz, aliquantò Paftinacx gufu, fed falfo.

\section{Bancia, an EL ATH $O B O S C Y M F$}

DVAS PAS T I A c A S Sylueftres, alteram ex Diofcoride, alteram ex ArabiDus, fcitè ftatuunt plebs Pharmacopoortum. Illam Diofcoridis, vt iam monuimus, pro Dauco fubftituunt ex Galeno. Hanc A rabum, qux difsimilis eft(quippe foliis,facie, Baucis, floribus \& caule fimilima Domeftic $x$, fed radix minor, guftu tamen magis vegeto \& medicato, \& paucioribus folis) B A v C I \& nonine difcernunt, quam fi attentius expen das \& cun Elaphobóco Diofcoridis conferas, nihil prorium erit , quod requiras. Mon fpellienfium autem pabulum Ceruinum Elaphobofcum putatum, multun abẹt à veris notis, vt fupcrius diaturit.

$$
\text { Dd. iij. } \quad \cos T \text { VS }
$$


$\mathrm{H}^{\mathrm{v}}$

$\checkmark$ c etiam pertinet noua \& perlegans illa, quam quidam vocant hodie Cofum Illyricum : folia cnim funt lineamentis $P$ affinacx maioris, terram fermè radenzia, inçue ramulis caulem fefquıcubitalem foniculaceum amplcxa: vmbelle fummęin cögerie ramulorum lutei flores fuut: radix pollicem crall, admodun amalra.

$$
\text { Babicapra orV L M ARI AVulgi, an, Rhodora Plmit? }
$$

MArginenses herbidi,ant prata vmbrofa, vda, lxtion, téperatiorü regionum Gallix, Germanix, Italię, \& Anglix, vix elegantior é habent herbaın ifta, quam recentiores vocant Barbain Capre, propter ramulos forum fotura racemofa amictos, in prxlongas quaficomantes barbulas effigiatos, aruncos, [pirilló qque caprarum imitantes : candore unueo, puniceo, rofeóve colori intermixto, vifu \& odoratu perincundo: folia Caryoplyy late, fed fitu aut Agrimonie, VImi foliurn admodinı expriment 1 , fuperficie, $t_{\text {tugis, }}:$ ambitu $A g r e f$ is Valerianx, vnde vernaculam nomen:nam recentiorum eft herba, nec cnim de antiqus nofcitur, nifi pro Rholora $P$ linij habeatur, quòd fludio lî́c relinquimus, nee alibi in alis excutiemus, vtlectoris exercitationifimul \& ludicioid relinquanus.

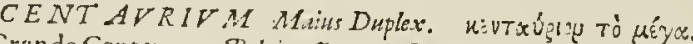

Gallis. Grande Centauree, Delgis. Droote Scutory. Ang. Grat Centorye.

E F F I G I E \& natura abeffe Paruum Centanriü à maiorc, fuperius patuir in illius clacradice,que vtrique, cùm mexima, foliorum incifura dü taxat differre vidétur, magis quàn co, fubruff=f diculo,ve in alio,fed medio vtriufq; cadé: folia verò ex vno oftona, aut fepiena, non pedè laciniofa : radices cófor ferratis \& profunzuc. Iam vtrauis nullo difcring, qux ficcatæ, vtrinis Rhapótico, falfo cxdë olin putaban. tricis fordibus educentibus, lare critici, gnam cius Centaurii Dodoneus, quen aptius poftent híc croris infmupotuit decipi,Arabas Cequauri maioris iconem, vt non legittiman, recurare. Nam illic runt, hîc neutiquam Viretatus, quirires maioris \& minoris ferè contrariis confudeoptimas, \& nulla nota à yul aratiore, gica plurinas huius Serratifolit alunt plantas, vfui mile \& par,iu capitulo fquatiore, nil folus Iuglandis, diferetas. Semen vtrique Caici fius, Belgicis hor tis frequentius: lacex nigre maioris: flos purpura albicat. Hoc pofterietiam fpontè.

$$
\begin{array}{r}
\text { O T HONN A Italorum, aut fos. Apbricanus, an Iycoperfion Galeni? } \\
\text { Belgicé, , Shutis ulocuteu, }
\end{array}
$$

EX Aphrica, Italix, Gallię, cunctífque ad fcptentrionem hortis factus eff inquilinus flo licepecior, quàn falubrior: quem idcirco Africanum vocant, vel Thunctianum Folic mitatur: in ramulis fumis fof a ferrato anbitu, quadantenus Valerianam fylueft em irutilant, hol oferici enmla gratia,fed tetro putenc Lychnidis maiores, iutus fiumo miniatóc

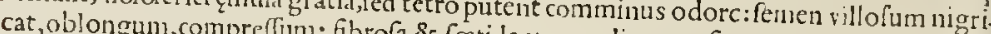

Farietas, ta venenata non immerito credicur \& fatida atem radix, non fccus atque muiuerfa plannounullis, vt audiuimus, credicur, vt culus efu porcis tumeat rofrum \& fauce , ac reus, \& tantó pulchrior , exitio fuetit. Cuius potius varictas eft, ille duplò maioratacoronamenta; quia aut minus atroli ithonnä decernunt: horti in delicis habent ad multò maint; quia aut minus, aut perparùm tetri fpirat : foliis, aut caule, non diucrfis, fed vifum oblectantes: calida guftu vtric maiores \& confertiores cernütur, aureo fulgore diximus in Othonna Monfpellienfi.

$$
\begin{aligned}
& \text { An } V A L E R I A N \text { E noftrates fint Dioforidis? } \\
& V \text { A LER I A A maior. } \\
& \text { Del.Sperctupt. Gal.Valeriane. Aiz. Setwall. }
\end{aligned}
$$




\section{$S T I R T I V M$ aduerfarianous}

IMPEN $\mathrm{I}$ o morofiores funt, qui noftratem Valerianam maiorem negant effe $T$ hu apud Disforidcm; nam formm Narcifsi collatio, quam vnam ifti vellicant in Valeriana, potus autoris incufare diligentiam videtur, vel uimis frequentem illam inuerfam, aut $\mathrm{P}$ н $\mathrm{p}$.

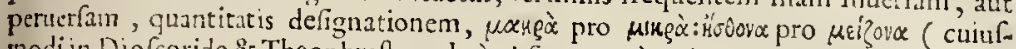
modi in Diofcoride \& Theophrafto crebrò obferuatur:) quam Val erianam inprobare, vtpotc gure cæateris indiciis quadret, \& plenè refpondeat antiquorum $P$ hin facnitatibus, quibus multis valet, vnde Valcriana vulgò vocatur. Eius hodie nofcuntur qiatuor differentix. Qux in hortis vbiq; maior \& notior vocatur, caulem enittit bicubitale, ghl.brum, concauum, eq́ue geniculis folia pręl onga altius frnua ta edcntê, Erucre aut Paftinace diuifura: flores funt nó inuenufti, in fummis ramulis vmbellatim collcki $\mathrm{i}$, purpurantes per initia, odori: radix tranfuerfa, humi immerfa, craffa, pollicé xquat, calidiuf-

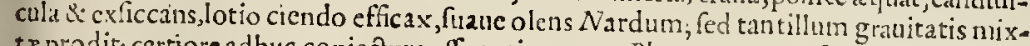
tx prodit; certiore athuc coniectura effe antiquorum Phu; quam poteft quifpian feftiuè dića putare à putore grúíve odore nix to Nardex franitati, quem $P$ hu, fiue Phy, aduerbio admirantis \& ablorrentis auerfarentur fubodorati; qui lic appellarunt.

\section{VALERIANA Sylueftris.}

SV N r \& fylueftris in Northmanix \& Anglię humentibus nafeentis,caulis, ortus, \& $N_{\text {Aores Domeftıce mult tum fimilia:quin etiam radix, fuanitas, Valerianain teltatur, folia }}$ autem in longitudinem pedem \& fefquipalmum porreeta, altius incifa, \& crenata mintatim funt, Sionis, Laueris, aut Barbæ Capræ ritu, toribus candicantibus, penè Eupatho-
rit Canabini.

$$
V A L E R I \text { A NA MINOR. }
$$

f.S r a etiarn gâdent fyluofi riuuli, humentésve rra taq́ue effiziemaiotem Valarianam fatetur, minor ramen multò, adque imum folia aliquàmmulta promens, Nafturtii aquatici quadantenus; in med co caule minora habet in. cifufiperioris Valerianx fimiliora, Hofculis fyluelt. Valerianx, aut Nardi Montanx radice lougiore, geniculata, reptandóque fefe propagan te.

$V A L E R / A N A$ Peregrina Belgarum, of Hertariorum.

E $Q V$ r D E nefcimus nos,nec fciunt fortè qui huic Valerianz nomen impertierüt, quid Haxc habeat Valerianx praterquàm exiguam cum foliis finilitudinem, aut potius cum Aftragalo:funt enim in cauliculis \& pullulation ibus confertim enafentibus, teetis, folia pennarin gemino ftipatu concinna, ferie neruo medio harentia, minutius ac eleganrius quàm in Aftragalo, exiguis flofculis, multis, cófertis, vivida cartrila placentibus, eq́ue medio brenia ftaminula aurea cmittentibus: poltçue fenten altate media nigrum pufillü in filiquula oblonga, creberrimis filamentis radice donata. hort is rancei, Belgii,\& potiffimùm Anglię familiaris, ad concinn andas ædes, olfactoriola, \& coronamenta.

\section{$P H \bar{V} M I N I M V M$.}

PR E т в R relatas hafce eft quxdam harum omnium minima, flore \& vmbella ex candore purpurafeente Thlapii, \& foliorum diuifura tertix fimill, fed adeò exigua, vt vix minoris adiuga foliz zquent, palmum alta, radix candida, exilıs admodùm, \& Nardi penè infimis fibris fimilis, odore tertix:interdum moutolis locis fa:sorum commifuris, interdú un regetibus, ve propè Monfpellium, adolefcit.Nec non fxpe nobis vifa \& enata in Anglia.

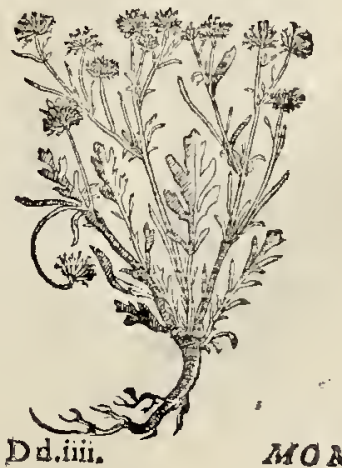




\title{
STIRPIVM aduerfarianona.
}

\author{
MONTANA Nardus.
}

DE Rontana Nardo Anguillarii iudicium \& defcriptionem fequimur, iftaque planta admodùn obleQànur, quan inuenimus tum mótibus Mindeno cóterminis, tum Veganiisarduis accliuibus : natura paruula eft, Valerianx minori perfimilis, flore \& folio, fed purpurafcente, Erucx diuifura, \& Valerianæ maioris: radici bulbi, bini,oblongi fublunt Orchis ritu, è quibus caules féquipalmum alti.

\section{PHXTEVMA Norbonenfiurs,}

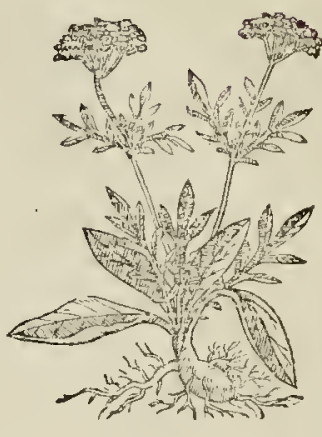

$V$ A $S$ I foret ad amor em ferendamóne prolem apta, Plyytcumz, vocata fuit: fortè etia feminis pertufi occafione, quale etiam covio Fum in fingulo pericarpio, fed cxiguú Hyofciami par, rotundius tamen,pertufum imprefsumúe foraminulis, vifitur hodie in Galloprouncire, \& Norbonę oliuetis propè Monfpelliurn: vbiftudiufis admodùm notun eft ifto nomine, effigiećue Valerianx minimx: verùm folia illi in imo infoctoriæ luteola funt, fuperiora auté diuifura \& magnitu. dine pufillę Valerianę:plufculi funt floresalbidi mufcofi olex: femina pufilla in tarq́; vnionum rotunda: fed quà paululí cernuntur compreffa, veftigum foraminuli in fculptum habcntia, inclufa Plinian $x$ folliculo Rhefed $x$, in cauliculis palmaribus \& fefquipalmaribus, reptantibus. Radix exigua Valerianx minimz.Tametfinon nefcimus c̀ tan concifa defcruptione nulli fermè integrum effe quodnam Thyteuma, verum fit afferere. Tamen pudentius duximus iftud coniectari, quàm vt $/$ /athiolus Campanulam quandam, à Fufchio \& Dodoneoiam. diu depietam, intrudere.

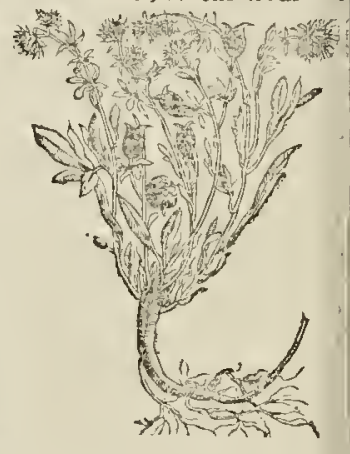

$$
\text { PI MPINELLA, aut Bipinellt. Ang. Burnet. }
$$

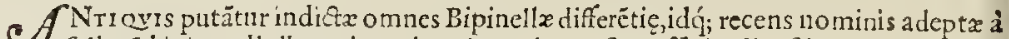
foliorü binis ordinibus piunatim, plumatim tarfive effigie digeftis:cuiufmodi $\mathrm{Fi}$ lipendulx funt perquàm fimilia fanguiforbx Bipinell $x$,eóque hic recenfend $x$ \& diftingundx quodam cognationis \& confecutionis filo. Eft itaque Bipinella qux minima, frequentifsima ruri \& domi notifsima,pedem aut cubitum alta,exili radice, exiguis Pentaphylli, , fed numerofis \& teneribus turionibus, oleraceis multis foliolis, aquis fpaciolis Chamedri vel Eufrafief fimilibus, ambitu crenatis \& bini ex aduerfo pofiti: Summis in cau libus rotundi flofculortum glomerulı mufcofi, interdú punicei ex candido, interdü fubfului infunt, qui floribuselapfis Adonidis, vel Mori fruetü exprimunt. Pocul is gratiă con ciliat fapore \& odore aromatico \& vinofo, quodammodo Melonis : nec minus in ace tariis expetita, ex oleo namque fale \& aceto Belgi, Angli,\& Galli libenter efitant. Peramica vifceribus, Hepati,Cordi,\& pręfertim fpiritibus, perhibetur: magnę commendationis etiā ad Peftilétes morbos, vt cuius fucco etiā abigútur febres exitiales, locis gauder incultis,aridis \& fquallidis collibus \& marginibus: Aftrictoria vi \& exficcante pollet citra mordacem vellicationem: Eóque internis \& externis fanguinis eruptionibus \& vlceribus opitulatur : vocaturǵue Bloctusutţ Germanicè, id eft, Sanguinaria vel Sanguiforba.

$$
S A N G V I S O R B \text { A altera, maior, fine Pinpincli. }
$$




\section{STIRTIVM aduerfarianoua.}

$H \notin$ c tametfi natalibus differt, \& plufquam cultu, contrà quà̀n nonnulli arbitrant tur, tamen quanta quanta cet, vt maior multò, fic fimilima ef.. Folium interdum Betonica par. In alis \&r caule du um, triúnwe pedum alto Capitulis item ijfdem, fed lógioribus, riffefcentibus, femine angulo[o,triangulari: herbidis, montofis lubens oritur, \& plurinia in Anglię Northamptonię pratis \& pa fcuis prope Aighlot:vtriq; vires exdem, fed hortenfi gratior \& potior eft. Suavem tamen \& maiorem vino merfam meminimus illic.

\section{Bipinella Saxifraga vtrag, an T HELLAND RIVM Plis \\ Ger. Beuernel.} Q Vra Saxifragix nomenclaturaplanè diuetra genera notat herbarum, \& perquàm natas claffes, vel cognitioni mutux accómodas, facilè diuelleremus: ton enim magis hifcé cú Liof́coridis aut Italicis Saxifragijs cógruit, quàm diureticis Rufco, Polıgonato, ycl Afpe rago. Harum aút notiffima hircina, nonnullis Bipunella, cuilus folio aded fimils cxit, \& 8 facie, vt endé planè putetur: nec eas féper pilis difcernerc eft,vt putat verfificator: Timpinella babet pilos, Saxtraga non habet villos: nam eodé proximè loci tractu vadere merninimus Saxifragam foliorum interna fuperficie pilofa: nullos tamen in Pimpinella, Sanguiforba, ve hortenfi videas. Anné non folıjs innatos, fed inter frangendum traetos villos, tenuiffináve \& fermè Arachnea ftamina, mnuit, qualia in Scabiofa animaduertas? In cank rotundo; glabro,cauo, è geniculis, flores in vinbellis, albi, Dauci femé, acre, Cartii, fed calidius, acrius. Radice multó acriore, albida, Dauci Sylueftris. Germanix, Belgix, Gallix, Anglię́q; in pratis ficcis, fecusfepes. $M A I O R$

In fyluis vero tota maior \& vmbrofis pratis, fcd minus acris feruidáve, quàm minor, \& folio longo propius exprimit Apium, quàm Pimpinellam. Crebcrrimus vfusapud Bela gas v triufq; feminis \& radicis calculo frangendo lotiog̣; proliciendo, velementior fiquidem vtrumque præftat, P roindéq; nulla magis Pliniani $P$ hellandrij opinionen tuetur. Ruta quippe pratenfis dieta, \& Parifiéfibus noftris preceptoribus Phellandriur putata, multò minus quadrat, multóg; ignauius præftat id muneris, quàm Hircina ifthxc, neutiquani à virofo hircúng ; olente fic dicta(Dauci namq; Paftinaca vel Liguttri quiddam, nec infuaue redolet) fed quia illa a dulti hirci, eo quo docent Practici modo, fanguis \& carnes ca ximium fint calculofis prę̧idium. Etiamó; I Itericis \& Hydropicis. Petrifindula verò vocatur etiam eadem pręrogatiua.

\section{D $A V C V$ S fectundus Selinoides.}

$V^{\text {E }}$ E T I Pharmacopoi quam Matheolus Daucum alterum facit, Saxifragam dicunt, illiç; vires confimiles frequenti experimento afferunt: nihil tamen obftat quin fit Daucus alter Diofcoridis. Folijs namque Coriandri,aut Petrofelini Macedonici veri, do natur. Semen illi in vmbellis oblongun, angulofnm, Foniculi modo. Radix aroma olet fuauis guftanti, fuperneque comata,Mei modo.

\section{VVLGATIVS ammi.}

$Q_{\text {I в }}$ v r is foffarum ripis, nec folum inter olera fponte Gallix \& Angliz videas vulgare iftud Officinis Ammi Iunio \& Iulio, flores puffillos, in fümis albicátes, rüdia tos, vimbellis Carui geftareffiméǵ; Augufto exiguum, pullum, fed nulla aromaticitate, acrimonia pauca,amarore ingrato, \& proinde verum Ammi inficiante: caulisfefontipedalis, \& bipedalis e it, rotund us, in alis folia oblonga, bina, terna, \& quina, fingulo quafi pedicu lo, \& al a pufilla latitis fparfa, Hircinç planè, Saxifragię, aut Sifari, fuminas vmbellas obfident: radice Cicutę, albida.

CAnifum.

Carum.

Cretichm verkm.

$$
\left\{\begin{array}{l}
\text { Deucus niger T heoph. Fue Carotta rubra. } \\
\text { Carottafyl.fuce Daucus Officinarum. } \\
\text { Cerefolium. }
\end{array}\right.
$$




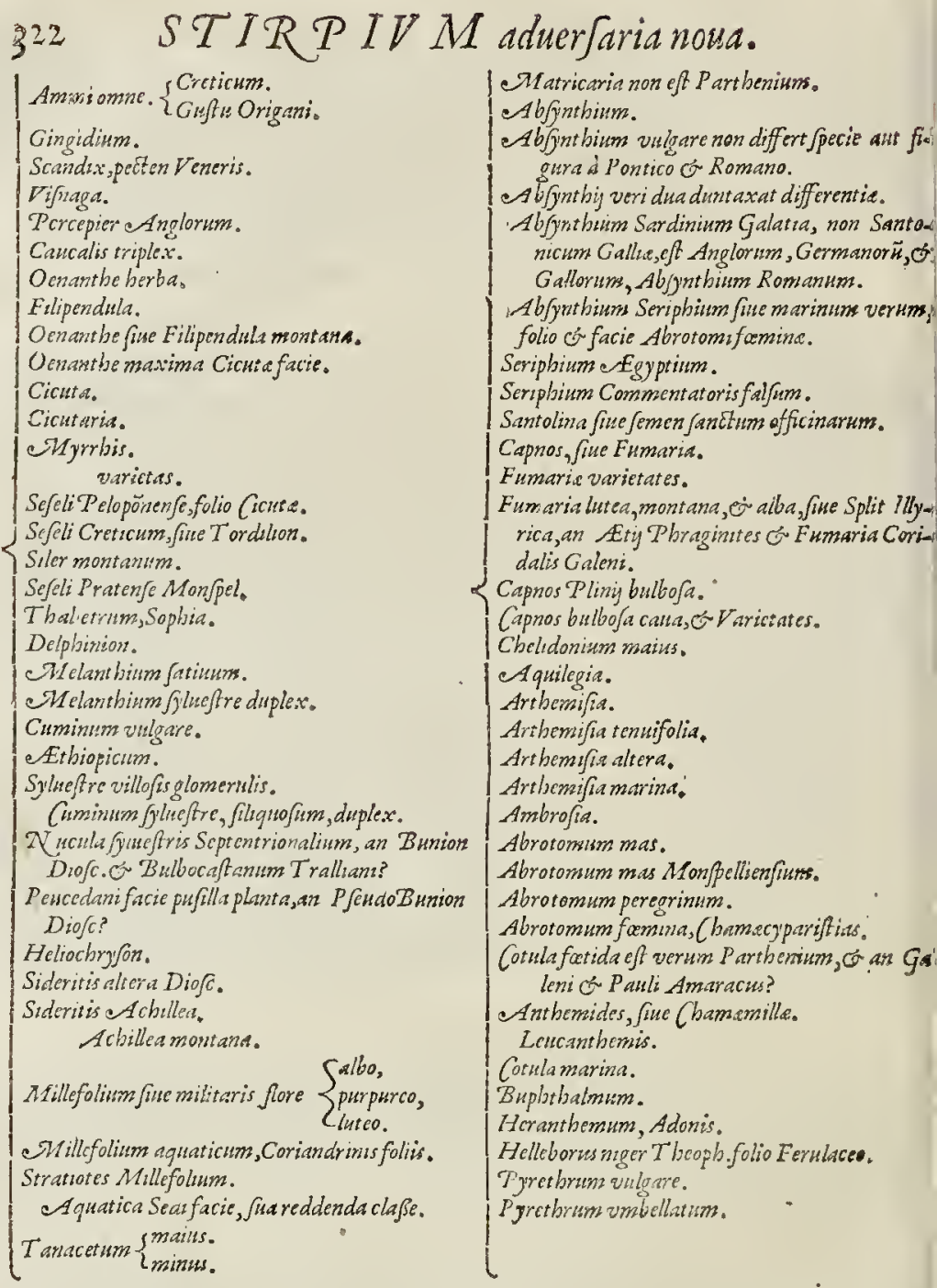

\section{ANISVM.}

MAG n fuit olim Anifum antiquis, prefertim $P_{y}$ thagoreis:non modó quia cibi ap. petentiam reuocaret, vnde Anifü \& Anicetum dictum putant, fed vt verifinilius óri $\alpha$.

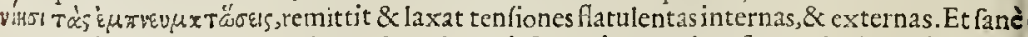
nullum è crter is flatum emittentibus oleraceis feminibus gratius eft ventriculo, minus habet acrimonix, aut plus fuauitatis, quàm iftud femen, qu od neutiquam, vt ex Diofc. Galenus arbitratur, 3.gradu hodie guftanti apparet calidú:nifi quia ruri rarò aut nufpiam apud nos vifitur, in hortis verò vbiq́; gentium etiam Septentrionalium, vt Germanix \& Angliz prouenit, cultu \&: folo nonnihil deponat caloris. 


\section{STIRPIVM aduerfirianoia.}

D AVC A S Cretenfis Veris Diofó.

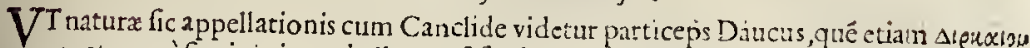
vocatum, à feminis in vmbella quafi furfutaceas yerruculas \& afpergines oftentan. tis effigie,à qua \& viribus communis noméclatura tuit, diuerfo aliogut folo à Daucis elt: nam quod primum defignat Creticum vocatum Diofori.à Selinoide non parum differt, nec tamen id fola Creta fert, quippe Germanicx Alpes no:n mo:to, fed ctiam Genuenfium colles, \& Geneuentium circa Iuram rupes, hoc Cretico abundant, vnde Lugdunum atque alia ad emporia hodic venum defertur: cóque pluris enitur etiam Venetiis, quia ad Theriacan \& fimilia an thidota efficatius eft, quotis alio congenere Dauco, cuius folia exilia,inter Foniculï \& Carottä media funt, vmbellis cädı̀dis, Horibus A nethi, copiofum femen, oblongum, vt Cumini, fed lanugine albidum, guftu acre, odorum, \& cuius vfus potifsinùm eft:vfui etiam tadix, quę Paftinaca minot, gultu feruidiore, \& odotatior. Huic, quò minus fit Creticū, fi quid deeft, folum, cẹtúmve erit. Sanè effigie nihil , viribus auté perparú abelt. Quno tempore Senenfis cómétabatur iftud, Pataı inū viretū ynam aut alterā plantäalebat, vnde ille habuit, quod opinioné illi faciebat non nif́ in Creta oriri.

VE N E I I Prarmacopci quam. Mathiolus Daucú alterum facir, Saxifragiam dicunt: $S$ A x I F R Aillique v:res confimiles frequenti experimento afferunt: nihil tamen obftat quin fit Dau gia venetorum cus alterú Diofcorıdis, foliis namque Coriandritaut Petrofelini: femen in vmbellis ob- $\mathrm{D} \mathrm{A} \mathrm{r} \mathrm{rs}$ longum, angulofum, Fceticuli modo:tadix albicat,atoma olet, fuaúsque guftanti eff, fu atter pernéque comat, Mei modo.

$$
\text { DAVCV Sniger T beophrafi, C A R o I T A Vulgari. }
$$

FEc r т fimilitudinis cognatio, qux Daucis cum Carotis intetcedit, vt Theophraftus

hane Daucum nigrum cenfuetit. Elt tamen duplicis ì colore radicis differentix $\mathrm{Ca}$ rotta:ithxe namque flauet, alteta purpureum atrum remittit fuccum elixa frixáve; cuius vt pluriminn gulx irritamento apparatam efitat vulgus. Medix vidétur inter Däu-

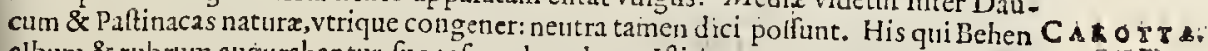
album \& rubrum auguraban tur, fro tefpondetur loco. Iftis nomenclatura indita fuilife videtut, ab illa quam cum Carui fimilitudine \& cognatione fortitę fuetunt.

$$
C A R V I \text {. }
$$

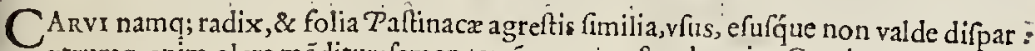
vtrumq; enim olere māditur: femen tamé vegetius \& odoratius Carui, prefertim eo qui pratis Ontélis vallis prouenit, albis floribus \& vmbellis, caule pedali \& fefquipedali.

$$
\text { Vfratius D AVCV MOfjicina, inter Coryotam of Paftinacam Sylueftr. }
$$

NV L I I s i huirts defit copia Officinis Italix, Gallix, \& Germanix, qux iftud frequétus Ctetic penuria vfurpant, duplumque nonnull, fubdunt, freti Galeni fententia: tametî non parum facultatibus \& effigie à Diofcori. Daucis abfit : edunt hinc loca tuni frigida, tum calida,fragofa, \& margines fteriliores : è radice lignofiore \& minore quàm Carotis; cui multum fimilis, caule cubitali, folis latioribus, hitfutis, Coriandrinıs,ad Bauciam accedentibus:rmbellis albidis, \& femine.

\section{$A M M \dot{I}_{\text {: }}$}

O к R í V R I A Ammi genera,qua parsim vbique hortorü obuia, neque planè difplicent, quia Ammi nefcitur effigies vera; neque tamen placent, quia multa in femine defiderātut. Quippe áuu appellatio videtur perpufillū quafióf; arenaceú exilitate \& colo-

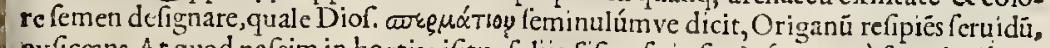
exficcans. A t quod parsim in hortis vifitur foliis Sifarı, fatis fuperọ́; patet è fuperioribus.

Et rurfum illud quod in Pataninis hortis culturn, etiamó; non procul Ageno \& Garumna in Aquitania lectum ad huc feruamus: foliis \& vmbellis Dauci Cretéfis, femine \& radice hortenfis $A$ pii,neutiquam illis in Ammi femine viribus expetitis praditnm eft.

I G I T v R quod femen plufenlis abhine annis cœptum fuit denehi cx Syria, aut Creta Venetias, hortenfi Apio par,fed flauo;guftu aromaticum feruidum Origanum 
pręfert: fxpius fatum, non vietum, aut marcidum, delufit nos, \& in eam fufpicionem coniecit,quam quidam nos monuerat, fieri porfe ad Theriaca Veneta myfteria, vt quifpiä hebrxus mango, Cretenfiú \& Sytiacorü portuü Telonarius, decoctione dilutóve femina maceranda merferit : ficq́ue compendii caufa cum Phamacopcis Venetis non parum gratizinierit.

\section{$G I N G I D I /$ pecies videntur.}

MV r, т 1 iam funt anni cùm induftrius Pharnacopœus Martinellus nobis hanc allatä cx Syria afferebat:fed cötrà, nos effe indigenā plantä memincramus, \&્ bicnnio pòt magna copia in vinetis \& fegetibus, inter $P$ ifa fylueftria \& Caucalides crefcentem vidimus: quam fi facie \& viribusad Gingidium alludit, tamen ex Diofco \& minus accurata defcriptione nullus aufit pro Gingidiocertó affercre:Planta enim eft Caucalidi natalibus $\&$ facie eadem, folio tamen longiore $\&$ anguftiore: illi wmbella candida, femen hirfutum, odore paftinacę fylueftris. C'EREFOLIVM.

Cerefoliü tamen, vt pro Senēfis cömétatoris Syriaco deferant Medici multi \& muliercula, nunquam efficient ipfius perfuafiones: eft enim cibis gratius, efficacius \& multò exploratius, quod hinc amotum, quò relegandum cenfeat ille,pe ruelimus fcire.

VIS N A G A. Vifnagam verò peregrinam, vt folent pleraq; fibr miffa videri, multis Italizlocis, pręfertim via Pefaro Romam, \& Aquitaniz Ageni, fecus Garunnam \& Burdegalā vidinus \& $x q u e ̀$ bene poreft congruere deferiptioni atque cętcra: nam de vmbella, nulla montio in Diof.Foliis eft paftinacx fylueftris tenuioribus, \& caule, fed nudo, \& minore diuifura prægrandi,adeò \& rigida ymbella, vt dentifcalpris fit apta, flore candido.

\section{$S C A N D I X$}

I quid conicturx captari potelt, cuiufmodi planta fuerit Scandix, id fanè ex capitum

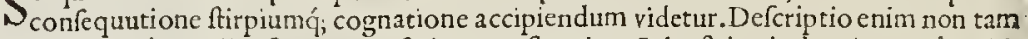
ambigna quàm nulla eft. Hæc tria fetie recenfira olera Sylueftria; vixdum innotuêre vlli, propterea quia incertis $\&$ paucis, partim etiam nullis verbis defignata funt. Nam Peeten Veneris, Fumariä guftu, foliis, \& vfurepr $x$ fentat:vul gus Pharmacopcorum ctiam VeneTESTEN V E tiis,putat \& vfurpat. Acrimoniz verò \& amaroris eiufdé momenti funt argumenta, quameris. lia funt Galeul de Fumarix acrimonia : quam fententiam meritò docti viri vellicant, \& ipfa reclamat res. Sic Chelidonii minoris, Ari \& cæparum experimur multò mitiorem a-. crimoniam, quam illis tribuerint antiqui.

$$
\text { P E R C E P I E R Anglorwm. }
$$

$\checkmark$ I Percepier Anglicum probè perfpeftum habent, harum duarum itirpium vtriuis fimile effe fciunt, \& neutiquam iifdem viribus fecundum : amaror etiam \& acrimonia in eo percipitur, \& pafsim valetudinis caufa olere manditur : Figura ci Ceref́lia nupernati proximi ; fed herbula femper eft, nufquam Spithamęo adultior, to to anno fuapte fpontè erumpit, arido \& trito folo luxuriat, fine caule, flofculis herbaceis:vehementer \& repentè vrinas ciet, muria conditum feruatur : \& ex co aqua fillatitia magno vfu elicitur. Hanc plantam proponimus magis quàm afferimus; quia Herbariis nó valde notã, nequedü quod fiamus defcriptä. At Angliẹ tamen Briftoix araibitramur, fr equen tißsimo apud mulierculas vfu reccptũ eft.

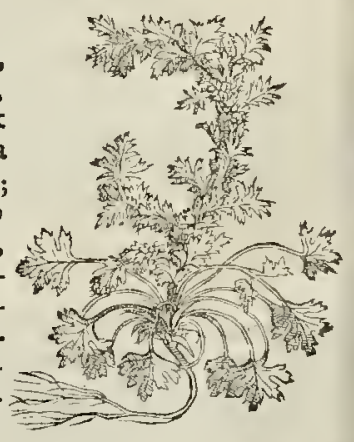

$$
C A V C A L I S \text {. }
$$

PO r v I r dici Caucalis à feminum effigie, qux vafcula oblonga \& femifphxrica imitantur aut cùm praarida ftrepitum edunt hæc femina ventis concufla, vindemiis $\mathrm{cx}$ actis. Et fanè luxata videtur lectio Diofcoridis, aut quifpiam non imperitus videtur or codicis 


\section{STIRP IV M aduerjarianosa.}

codicis hac verba,folijs Apij fumilibus, adic cifie, qux poft è̀ in contextü Latinum irrep ferint:nam noftris Gręcis exem plaribus de liderantur, \&e etiam fuperuacanea vidétur, vti vir magnx fedulitutis \& exereitatx $\operatorname{cog}$ nitionis Anguillara an notauit. Eam plätam quam ille Caucalidem autumat,nos iamdiu collectam in praruptis S. Specus y ocati, ad Fanú Magdalenę in Prouincia Norbonenfi hic cappingendam curaumus, \& liberum $f_{2}$ cimus quid cuilibet ea de re vidcatur. Eft hac caule Fæniculi, \& folijs, \& diuifura,cu bitum alta, vmbella al bet, \& odorata eft, radix vnica, recta, humi paeta, candida, rapore paftinace. Ver ùm hoc magis placent vulga res Caucalides, quia fit caule, fol ljs, vinbella \& femine hifoidis, eog; magis congruut verbis Diofcoridis.

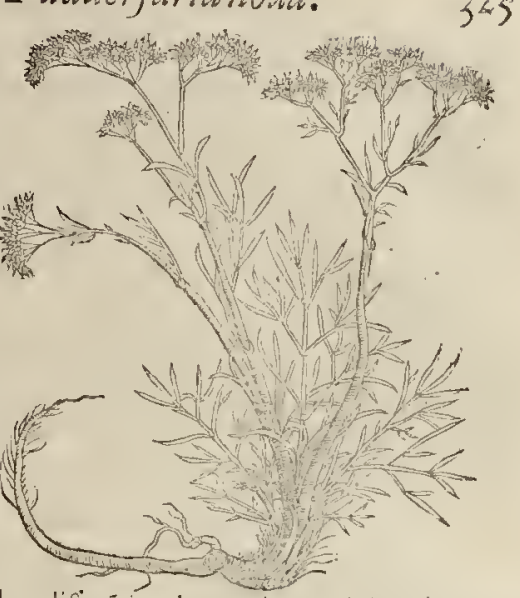

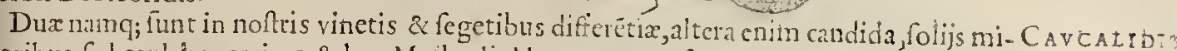

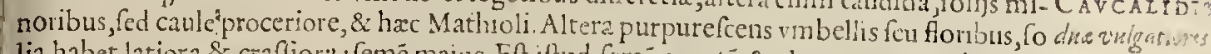
lia habet latiora \& crafliora: femé maius. Fft iftud femé argutü \& elcgans, nam triquetră

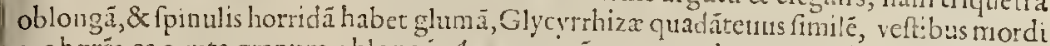
cus hæres, ea exuta granun oblongị Auenz, exeâtenatzinodo cernitur, haud guftu infuaúe:qua quidem fatis expreffa nota infigniut Câcalides Diofe. \& finilibus diferesit. $O E N A N T H E$, flos wineies ant vin zatits. $\mathrm{N}_{\text {dantenclas }}$ Colore non diffimules. Ex funt Labrufea fiue fponeanca vitis, \& eius cognominis Vitis fylueftris, primx florum eruptiones \& germirationes fuatie quiddan halätes,

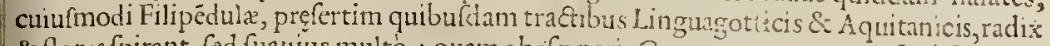
iz flor es fpirant, fed fuaurus multo : quam obefe naris Commentator non refpuiffer, nec doctiorum fententiam fpreuiffet, fi verba Diofeoridis prefius perpendifiet, \& locis aridis petrofilque plurimam eruifet: Hie enim in Anglia, vbi libenter vtimur, non procul Briftoia ad Vincentij rupes \& cautes deuexas, ctiam in Germanix aridus, plurima Iunio \& Iulio, floribus candidi:, exiguis, ftellatis, confertis, Brionia \& 2 Rutx fitu. Semine mufcofo fquammofo, rotundo Pimpinellx, cui folijs etiam fimilis, $P$ aftinacéć; fy lueftris dudufura:eau lis cubitum \& fefquicubitü altus. Radix non altè nnfofä, fed latéf farfa \& ampla, è pendu lis fibris multis pilularum, Cyperi, Panja tominę, aut Aiphodel modo: qua perbellè qua

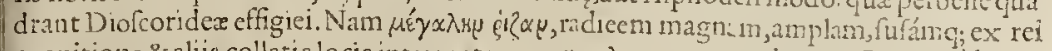

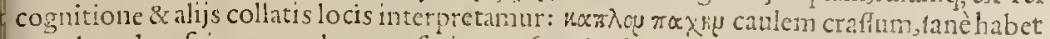
pro alutudine fui,quem palmar cm facit: cunifmodi eft la ac noftra, nontullis glariofis mon

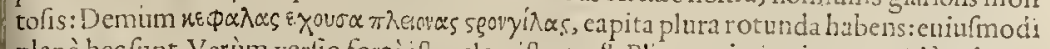
planè hçc funt. Verùm verfio fortè ifta calamiftrata, \&s Pliniana imitatione oppidò tuberofa illufit fortè Commentatori, aut eius Thefeo Tridentino, adegit́f; vt Arifo! ochire rotundẹ \& adultę,perquàm finuilem facic radicë aftuerit:quęab Oenanthe tã̃um diftat, quàm Bunium vel Bulbocaftan um Tralliani à Filipendula: quod plebecula Gallica, Germanica \& Anglica eum monuiffet. Illa enim Faucrotte, Germari vociat, vtriç; à nuce, caftanea vel bafilica fapore \& fimilitudine:neque enim cminet tuberculis, nifi valde vetus,vti Arifoloclia rotunda. Et Kipper nuts opilionü nucem fonat, quia ${ }^{\text {Bulbocaftantm }}$ illis cibo cedit: eft enim oleraceus bulbus, edendo totus i gratus, Caftanec fapore : folijs Gingidif, vel Scädicis vei fuperius diximus, in pediculis \& mollicellis eauritutis, tcineris \& $\mathrm{ca}$ ducis: froribus ité pufillis, albis in vmbella, adcò eidé, vél leâini Vencrei, fimilibus, vt ciufdë nature videatur. Semine Cumino aut Foeniculo minorc, odorato. Arua \& pinguia vmbrofa amat. In Hollädia, \& Anglia plurima,pręettim ad Pagum Clefton prop̣c Brifoiä. $O E N A N T H E$ vulgaris.

F Ilipendulx nomen affecuute funtitidem plante due qux vt Oenanthes non ita diffini les, ita híc commodè referen dę. Ac fi natalia fpeQtes,minimè Oenante dicas hari duas?

$$
\text { Ee.j. aiterum }
$$


alterum quippe plurimùm folo vliginofo \& pratenfi, \& tanen Commentatoriflis nomen infcripfit Oenanthes, Filipendulx ademit, qux praterquàm quäd viribus, etiam ratalibu montofis \& faxeis,vt diximus, magisquadrabat \& recentiorum confenfu.

Harm qux minor \& verx Oenanthe fimilior, radicibus amplis, globulis oblongis, pro. lixis, filimentis:pendulis:turfiones promit, imaq;; folia A pio hortenfi, teneriufcula, faturi virentia, cubitalem \& fefquicubitalem caulem, genıculatum, al is folıjf̆́; \& vmbellis Anif vel Coriandri,fores albidi, pufilli, $x$ ttate in conuallibus herbid ss aut verrucis pratenfibu Anglix:Mö́pellij etiam prope pontem Cellenoux, Magalonæ inter Narciffos, atg; Gram muntiam fyluulam circum,

$O E N A N T H E$ fue Frlipendula altera CMontan.

R A R I O r multô qux hî́ depieta Fúlipéduli, nulli dum

$\Omega_{\text {memorata fcriptori. In celfium montiun verticibus, }}$ vt Norbonx ad Veganiú, in Dei paradifo vocaro, Calcari contermiuo, nobis eruta, radice non æquè fufa vel ampla aut cirrofa:fed proxime caulé bulbofis, teretibus, lógiufculis, $x$ qualibus fermè proceffibus, modicè protuberanti $b^{y}$, Corriudx annotinx partibus: Pęonix modo radicata, Caule afiusrgit fefquipalmum alto,crafio re, rotundo, nómihil ftriato \& \&ulcato, imò medióq; fui folia alterno fitu emittente Filipëdul $x$ inter \& Millefolij, exigua Cornucerui duifura:extremum flotum, thyrfum album, fpeciofum amplexa, cuculatis galericulis, crebribus, cófertis, conflatum, in Criftx Galli, vel Chynoforchis, vel Napelli \{peciem.

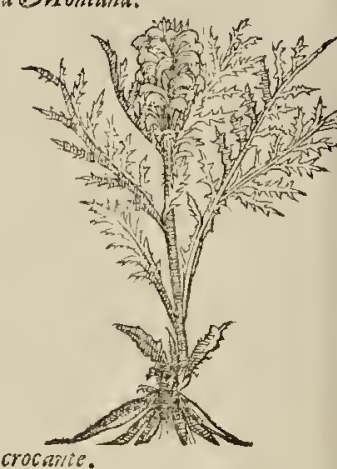

$\checkmark$ Ec quidem admodìn nota hæc, nifi $N_{\text {Borealibus prxfertim Anglix, erumpic }}$ riuutis, lutulentisúe \& riguis ripis, vbi $P$ alt dapium, cui folijs non abfimilis,vel Rutapra tenfi fimilior, nulto pullulatu, virore tetro, colore \& facic Cicutx. Caules bicubitales fpargit, è radice in pares Afphodeli albi bul bos multiparta, \& quafi brachiata, nullius ' $\mathrm{fi}$ bra vinculo aut mnteruêtu (fecus Mathioli) coutinuos, tencios: guftu acres \& ingratos, fucco lactco primü, deinde flanefe ente viio fo \&iexulcerante pregnautes:Vmbella cici tx:cuiaffinem autumant, qui maleficiopare expcrtos fe afferit. Vfos namq; in acetarijs nhil factum fuife provins guàn vt interirent,aiunt, alios, qui efitafent: vertigine tenebricofa palantes, nutantes, attonitos,inć; gyruin verfantes fe vidıfe. Et certè tam non elt Oenäthe,quá ab ca diftat Ruta pratenfis autCicuta. Ijs igitur \& quibus $x$ grè lotiū it, fecundinzíe cunctantur, fuadente Senenfi,

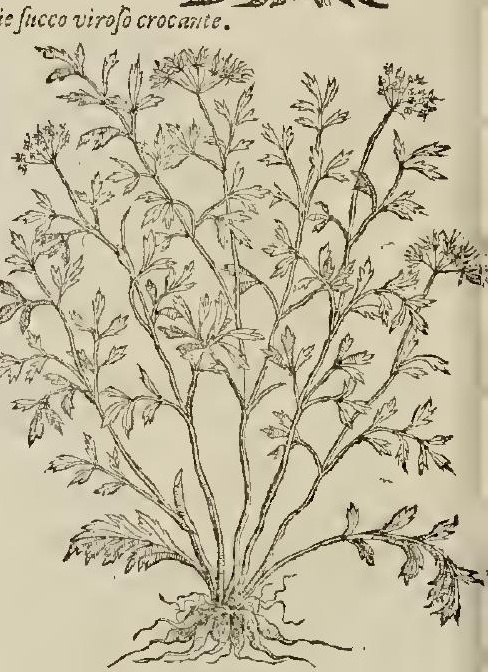
dato,\& Themifo non Medicus radies:tantominus epilepticis, analepticis, atq; vertigino fis propinabis, quos tamen eximia quadă pręrogatiua magnoperè inuant Filipenduli radices, qua calcul ú è renibus, muccú è vefica diffîpare atq̧; excludere mulierculis, ne dú no Ang.Hombis,creberrimis com pertum experimétis.

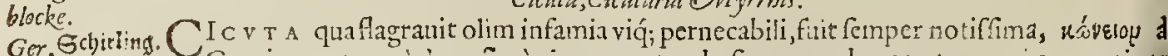
Cecuta, Cicutaria Alyrybis.

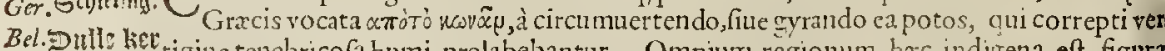
ur!. Gal. Cigue. 


\section{STIRTIVM aduerjarianons}

Cerćcolii, fue Paftinxcę fyl. aut Myrrhidis, \& figura adeò cognata Cicutarięvt indifcreta penè fruilitudo, necis occafio fuerit nōnullis, qui efitarăt, etiä noftra memoria.radice etenim finilı, alba, breniore, crafsiore, caua fuperius, quà caulé alit, qui plunè ferulaccus, quatuor aut fex pedes procerus eft, cauus: dêfe admodum geniculatus \& maculofus interdum, rmbellis dëfis, forculis nimutioribus, \& angulofo Arrifi femine: odorequàm quauis alia nota, difcernitur à-Myrrhide:tum parua, quę Cicutaria non fœtens vocatur: tum ab odora Myrrhide vera, \& faluberrima.

CICVT ARI A F ATV A que minus Foctida.

NE quéquam fallat, quia nó fe prodit odore hęc,aduertendus cius color,qui atrior aliquâtò, nec maculofus eft, nec adeò putorê halätubus fcrobibus, vmbrofic, vdis exit, fed ad margines \& fepes paulò editiores \& ficciores:alioqui nó minor copia fecus vrbiti ag. Far àeras. geres \& valhü fepes vifitur. Equidé noxia \& inuifa olitoribus \& hortis, vbifpontè, viridiorq́; \& nitidior,pręfertim minus feruidis, Tetrofelino propior \& cócolor, \& minor tamen vera Cicuta.

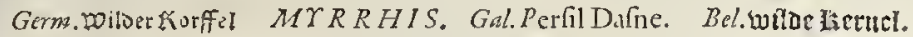

Dorat am hanc, fiue Salubrë \& efculentã pofsit quis vocarc Cicutä, quam $M$ yrrhidé,

fiue Myrrham, propter fuzueolentian, quiddà Myrrhẹ refipientẽ, dixerüt. Nec hace perinde frequéns, vt fuperiores, aut procera occurrit, fed rarior, \& in pratis, vel germinofis marginibus:etiam olitoribus ad vefcendum in Yelgio multa colttur: \& efitatur in iufculis Cerefolii vice, cuius nomen apud Germanos affint, vocant enm solto fietuel, id eft,fyluefte Cerefolium,quod odore faporífue incunditate imitatur, ctiamćuc facultatibus diureticis: facie verò eft Cicute, albicâtibus ramis a folis, tenella hirfutie, $\mathrm{Pa}$ ftinacā fatiã̃, aut agreftem referente:radix prægrandıs,altè depaça,prolixa, nec facılè auellenda, Ferulę aut Paftinacx efculent $x$, quam fapore \& odore, fed magis medicato, \& ad Smyrniü accedente, repræfencae emen admodum longum Cerefolit, duplò maius, ftriatum, angulofum, fufcum, odorum. Hæc etiam Myrrhis ìlıniana videtur: folis Cicutx minutioribus, caule breui, rotundo, faporis \& odoris iucundi: quam o1 ta confufione à Geranio odoro, Myrrhidé Romani perperä faciebant:vudequifiam Scandicé vulgarem oleraceam merito fufpicetur, aut illius aliquan fpeciê:nam Syriacam Scádicem valde variam prodire certü eft, \& Adagio cóftar. Varia enim olera in Syra ali dictitabat plebs olim.

$$
M 1 Y R R H \text { is Alters. }
$$

CIcvtarta odore, fiuc Myrrhidis, affinis ea admodü oft, foliis \& ramofis vmbellis minoribus, delicatioribus tamen, \& femine oblonģo, Dauci Cretici, exiliore, nó hirfuto, necita abfimili fapore:è Geneuz \& Salcux viciniis mötibus: peritus iuxta ac anicus medicus Pennius Anglus Londini ferendam curatit, nobífque impertiuit.

SES EL I I eloponnenfe, Folio Cicutre.

A $D$ montem Lupi \& iuxta çdes Sacrificuli, in decliuibus falebrofis Infula montisję̧ti,quà mare fe pandic, eft plăta quidem copiofa, , fed nó ybiq;obuin, cuius radix magna, intus alba, foris nigricans, recta \& altè porrceta, Ferulx Thapfẹve modo,odorata, \& aliquantum acris. Caulís digitun xouat crafsitic, fefquicubitü altus, fert. laceus,à guo promuntur alæ turionésve cóplures in ambitum fparfi, vbi folia multa, Cicuta magnitudine fed incurta , pilofa \& crifparugatać:Vmbellę nultę Anethi luteę funt: femé latūi folliaceun, compreffum, Angelicx figura \& unagnitudine, fed multò minus grauius:color illi ex pallore flauefcst:odor fuauifşimus, Ethiopici adeò fimilis, vt ftatim odoratu, cùm primùm vidiffemus, Pelopönenfe conie\&tarimus. Et conic Et!-

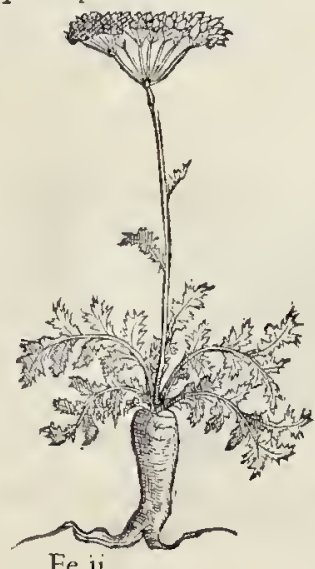

Ee.jj. ram 


\section{STIRTIVM adkerfarianona.}

ram certioreexploratione notal um \& virinm preceptores Monfocllienfes fulcier unt,vt nullus illic ambigat de cius affertione; cum tamen antea nonnull Thapix frecien fufpicati fuerint. Verum Thapfia, oux veriat multa in Aquutunia Vafconims, mul to ab hac diuera, colore \& vultu.

\section{SESELI Croticts, Tordilion.}

PA s s r m in regetibus Norbonz fccufoune vias occurrit furcu'o $a$, hirfuta, rigida, afpera planta,folio rotundiore, Cerefolii, vmbellis albidis purpureis, paruis:quibus luccedulat femina copiofa, circinnat, quafi torcumatis elabortta, vnde fortè nomen peculiare fuit, orbiculata, comprefia, atque geminis valuulis, vt Ferula femen, contata, clypcoli fpeciemreferen tia, gufu Myrrhidıs. Numnā hçefitilla,qua fe deceptü Cómentator conqueritur, cum ille feribere aut nolit, aut non aufus fie, ambigimus: voluimus tamen hanc non ignobilem plantam ftudiofis notain effe, vt houm iudıcia ad collationes accurraciores excitaremus:ne deinceps faftui commentatoris, qui innumeras propemodum, aut non nouit, aut perperam prodidit, aut filentio abdidit, affuefcere dıfcant; luculento enim detrinéto cius ignatia, aut ambitio Tyronibus fore certum eft, quemadmocium \& nobis mul tos annos per initia nimium credulis, furfe meninimus $\&$ dolemus : non tamen ili infultamus, quin potius veniam danus, fi docere non potuit quod nefcierat:liberéq; profitemur, nos dehine non modò non liber ius quicquam animaduerfuros in iftis pannofis centonibus \& commé tationum aduerfarifs, fed potius fi minus de re licrbaria bene meruit, \& melius voluit, gratia habituros, \& melius in pofterú bonas horas colocaturos: po tius, vt certa prodamus, quìm ve incerta, ambigua, ambitiofe emendicata munera, fur ta, verfuras, cenfuras, iurgia, fimultates, obtrectationes, conqueftiones, A pologias, Apomaxeis $\&$ recantationes, retegamus.

\section{SILER MONTANVMA Officinarum.}

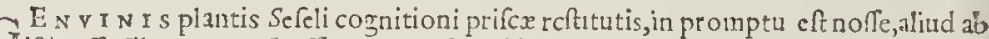
Giftis effe Siler montaniı ofticinarum, fruc Sifcleos, qué retinuerunt bono quidem confitio, qui Neotericis anfam errandidederunt, atque fanciendi mhil aliud cffo Siler, feu Sifcleos vulgò dieñ̆, quànı Diofcoridis Mafsilienfe Sefelı:bono inquain confilio vfi funt. Eft quippe planta multò mator is acredinis \& efficacitatis quàn vllum Sefeli, éó nenftruis cierdis valdequàm commendacum. D û́m eR cubitotum terulacens caulis:radix odorata Liguftici, folıa terna, nó modó féniculo, vt Marsilicnfi Sefeli maiora, fed vel '?eucedano latiora, ac paulò minus Ligufticum, vel Coronarium Rofmarinum aquantia, mollia:vmbellę prę̧randes Angelica: quibus fené foliaceú, longius Cumino, colore pal. lido, quod guftu ctiam faccharo conditum, acrius quàn Ëthiopicum cft:antò magis, quìm Mafsilienfe,cuiacrimonia prefert Diofcorides $K$ thiopicum.

\section{PRATENSE SESELI MOnpollienfinm.}

STrosi Lutetiani \& Monfpel.planti illam qua in pratis freguentior occurric, saxiSfragię tenuifolię frmilis,vocät Pratére,Sefeli. Radix illi Dauci, wel i eucedani:foris nigra, odora,caulis bicubitalis, folia Sileri montano minura, anguftiora, rigıdiora: vmbella

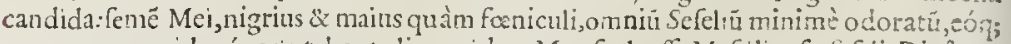
perparum acre, ideoque putabant olin quidan Monfpel. effe Mafsilienfe fefeli Diofcor. Angloram verò Pratenfis faxifragia, ne cui fimilitudıne imponat, lutuic quidé fimilis, fol tamen \& diverfa, vt monuimus fuo loco.

$$
\text { Situe Soplaia Chirargorm } T \text { H I I C T R V M Diocoridis. }
$$

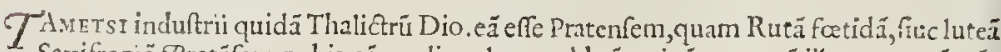
Saxifragiä Pxatéfem;nobis cómodiore loco reddıtî opinétur, tamé illa magne cömédationis 


\section{STIRPIVM aduerjarianouta.}

dationis \& meriti vulneruria Sophia vocata, a pud Septentrienaics precertim, cim propter figuram, tum vel potiffumum propter exinias fa:sandi claudendió; vlcera antiçuata \& ma ligna,vires,aptins forfan Thalitro conferrettr, \& e aden tuto affer eretur. Qua quidem in admodum fuccincta, nec fatis diftinfta, foret Diofc. deforiptio. Eft enim, Coriandrinis ramulis, folijs, \& incifuris, fed tc nuioribus folijs, albicätibus, A brotano non nbfimil bus, virgultis fefquicubitalıbus, gracilibus, rotundis, rectis, lignofis, pallıdulos vel luteos flofarlos, Erucz vel Synapi fylueftris, nec filiquas diffimiles, fed exiliores edentibus:Scrrê exile, rubellurn, clsudentes:multa in parietinis \& areis propè vrbes Gallix, Nottmanix, Belgix, \& Anglix: fed rarior calidioribus ad meridiem. Hac pollicentur Carboniuori 1 arace!ffit $x$ nullum non vlcus fe percuraturos, cuus curationis cognitionenz, nó item fatuam promittendı fiduciam, didicerunt à Chirurgis practicis, qui ætate Guidonis \& Petri Argelatx vixerunt. Caterum, quod fapius inuiti nonuinus, hic etian inculcädum rurfum ell:apud Diofcoridem collatronum plerumg; exceffits non de pläta, qua defcribitur, fed in ea cus confertur accipiêdos:vt hic, Cotiandrum pinguiote folio effes \& fuperius aliquet retro capitibus in Cotyledone fecundo, prioris Cotyledon is foliz latiora, non anguftora : fie in proximocapite de Vetbafco,fic capite de Enula, \& alibi frequens.

$$
\begin{gathered}
\text { An Confolida Kegia, fiue Calcaris flore recentior, fot D E LP H I N IV M. } \\
\text { vol Sofandivum Diof?? }
\end{gathered}
$$

Certitterfiners Ang. Larckes

Q V A MV is nufpiam:vlia mentio Delphini apud elafficos authores extet, tamen non claw.

illico neceffe cet liane Diofcoridis codicirrepfife. Fieri namgue poteft, vt ifta appel Gall. Pied'd'As latio, quam foliorum (aut potius forum cucnlla intundibuli) fimilitudo plantic inucnit, louette. autore Diofc. indita etiā fuerit Sylueftri Cumino, ficó́; duo pluráre nomina à diuerfis fcrip toribusaccommodata fuerint propter varias faculiates: quod idem non parum multis alijs contigit plâtis, vt diuerfá defignētur voce à nimium communi totıus Cumini fpeciei: fiquidem indicio funt, non modò notx fatis perfpicaz, qux defcriptioni quadrant, icd etiam virium, qux vtrinq; fimiles prodütur, nempè adueffus venend \& alia incommoda:çu dotes in Calcari equitis nondum plenè coinpertx, in Anthora Arabun \& rccentiorumexpluratifinz funt:vtriufg̣; hîc mentioncm fácimus, vt ifta expéfione iudicium excite mus Itudioforum. Eft enim Calcaria folijs minutim profundéq; incifis, exilibus, longis, virid an t,bus, confertim, quafi exinteruallis, nafcétibus, yt in equitis calcari. Flores iten purpurei, corniculis repandi, in morem Nupelli difpofrti. Hx itaq; due, duas Delphinij delineationes explere poftunt: quarum Calcar in fegctibus frequens, Anthora verò non nifi afperis mótofis, ner tamen inibi frequens obuia. Prope Geneuam \& ad Allobrogum Delphinéfum Alpes nuilta.

$$
\text { CHEL ANT HIV M, fme Nigella. }
$$

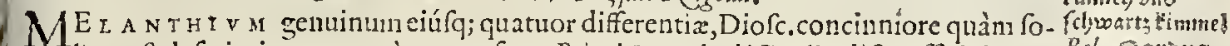

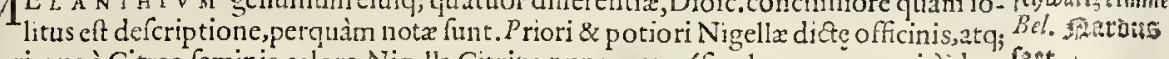
al tcri, quę à Citreo feminis colore, Nigella Citrina nuncupatur(fi colorem exceperis)iden art. odor, fapor, vis, vfus. Folia, capitula membranulis intercurfantibus difcepta.Flores purpu Gall. Nielle。 rei,pallentes, femen multum, pingue, odorum, oleóq; efficacifinno reddendo aptim, quo puerperx muliercula ex cludendo partui arq; fymprhornati ifterico propellendo mul tum vtuntur. Vocitātó; vulgi perfuafione Nardinum:nempe odoris fuauitate \& efficacia haud difpati.Iftud oleum prxlıs expreffum, 11igro fed lympido colore, pauca quătitate hauftü, fplenis tumores duritiéfq; deınolitur:ficó; foris illitum. Citrina ex Syria alijfúue Orientis Cotrina. Emporijs adtięta nigella Itali multum vtuntur, etiamć; in condimenta, in placentas fynapiq́; addunt. Anglis iam \& item Getmanis hort is copiofior quàrı Italicis:vbi qux odo re creteris excellit, Romana quodam nommis eulogio vocitatu r: nam alioquin Rome vel in hortispauca.

\section{STLVESTRE duplex.} QVEVERO INTER SEGETES NORBONE PASSIN OR ITVESYLA
ueftris ab Hortenfinihil nificxilioribus folijs \& odorispraftantia difcrepat,ncrimoniaq́ue vincitur, fed Capitula \& flores in folo natiuo aliquantum maiora funt. Se-Syluefris alson cunda auten fylueftris, quam in Normano agro inrer Drudum \& Carnutum

$$
\text { Ee.iij. leginuss }
$$




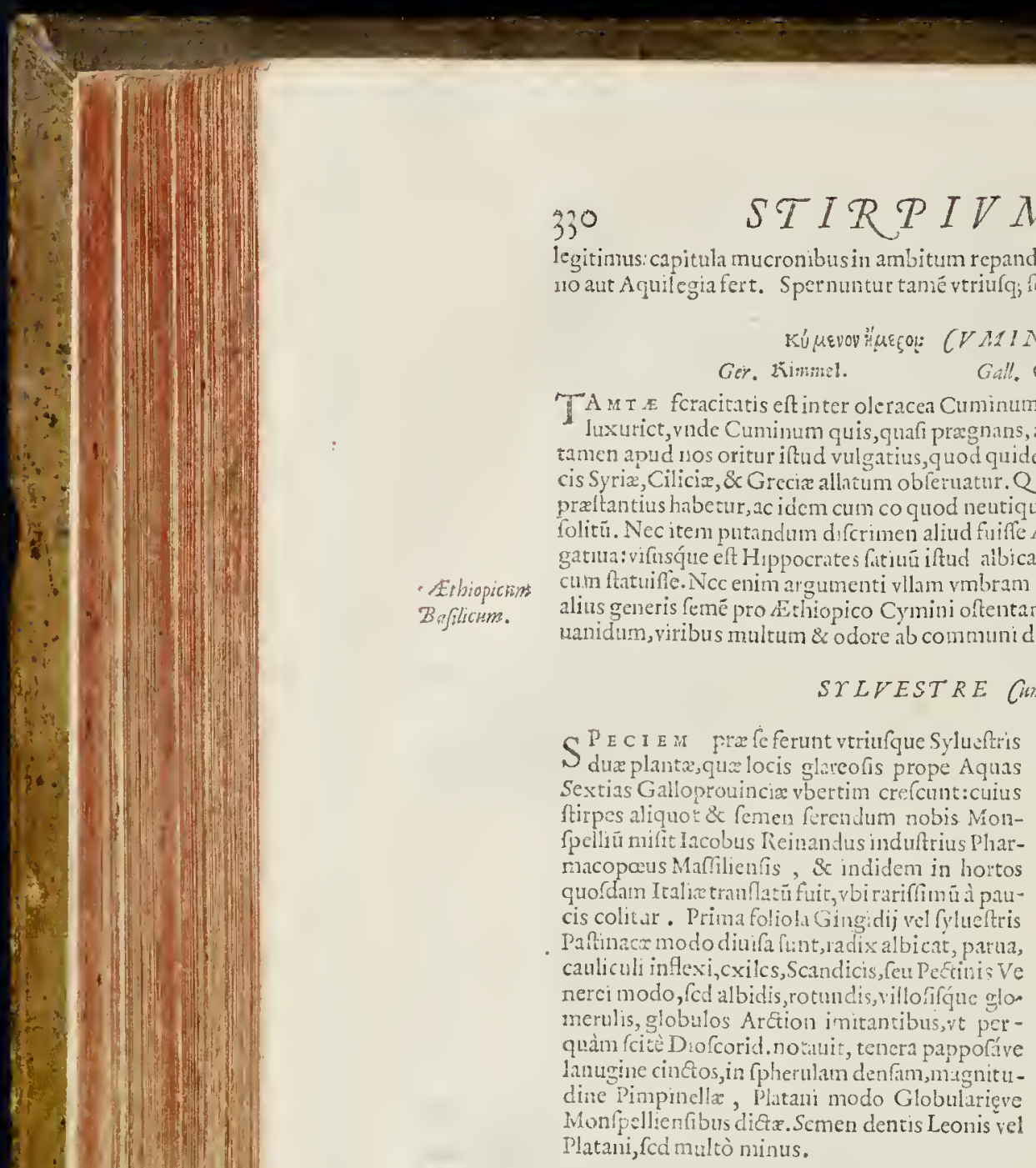

- Erbiopictint Bafilicum.

legitinus: capitula mucronibus in ambitum repandis retróve nexis, cuiufmodi in Ly coctono aut Aquil cgia fert. Spernuntur tamé vtriufq; femina, cuia \& meliorü copia fuppetat

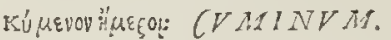

A M T E fracitatis eft inter oleracea Cuminum,ve etiam maledigis fatum v berrimú Iuxurict, vnde Cuminum quis, quafi praconans, à rúc verbo manaffe putct: nec fponte d quidem aliquantum diuerfum diuer fis è loor. Quod cnim albicat, hirfutumá; eft femen, Firfutum eft, apud nos feri \& virere

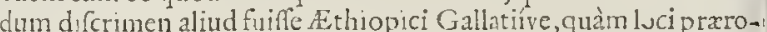
mabent Patauini quidam herbarij, chm alius generis femé pro Ethiopico Cymini oftentant, pufillum enim valdè eft, acerofum, euanidum, viribus multum $\&$ odore ab communi deficicns.

\section{STLVESTRE CaminiDior.}

S PECIEM præ fe ferunt veriufque Syluafris $S$ dureplantro, quælocis glareolis prope Aquas ding nacopous Marfilienfis , \& indidem in hortos quordan Italix tran!atü fuit, vbirarifimu ì paucis colitur. Prima foliola Gingidij vel fylueftris Pafinaca modo diuifa lunt, ladixalbicar, parta,

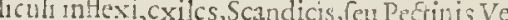
quàm fits Dofcorid no init tenem papofáve lanugine cinctos, in foherulam denfam, murnituPlatani,fcd multò ninus.

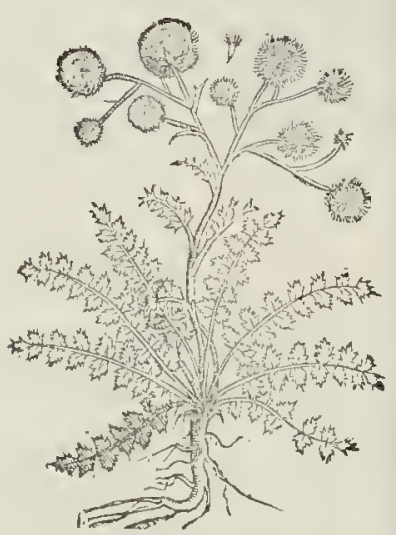

ALTERV MI Diofc. Siliguofm.

A L T' E 1 I verò Syluettri dux funt plantæ, तux effigie Aic fatis \& peræquè congruere videantur: Ea namquc quæ tninus cognita, exigua \& pulchra, nó procul Aquis fextijs oriunda, complurı gerit cornicula, filiquofa, adüca, Scorpiodes diex modo, fed crafliora, fenune intus prefepiolis diftincto, colore fiauo, oblongo : cauliculi graciles, teneriúculi, \& folia parua, Carui aut Scandicis. PcEtini Venerei Fumariæué incifuris, profunds: exigna radix, Inteiftores Maio menfe, Chelidonij maior aut E-ruces, led minore.

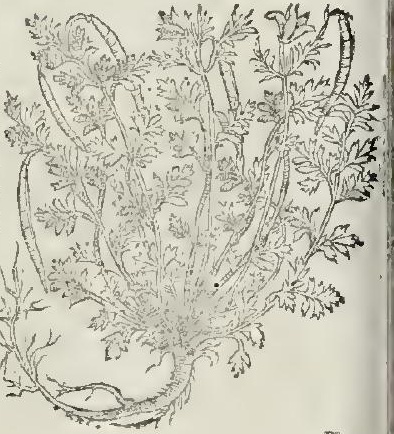




\section{STIRP IV $M$ aduerjarianoia.}

ET eidé̉ îfdemáue natalibus filiquora perquàm fimilis fociatur altera hęc, nec niff folio tenuiore, anguftiore, Sefeli Maffilienfis diuifura, \& ad imin radicis albidx Cerefolij plunimùm nafcente diftat, cauliculis fermè glabris, filiquağue maiore, femine inibi contento, Galegæ, fubfuluo.

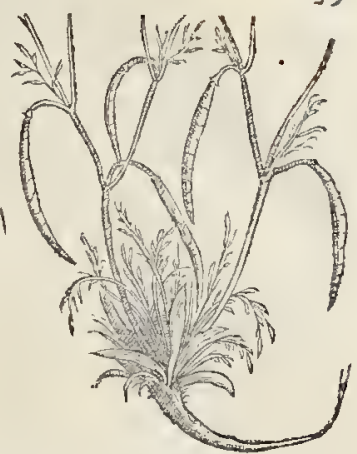

$R$ E G I A veró confolida alibi dicta, Cumini folijs, floribus purpureis \& interdum candidis, fpeciofis, coronarijs, Calcaris antiqui in fpeciem, è quibus cornicula oblonga, 1ecta promútur,fernine Nigellax nigro, adeò hortis mulierculifó, familiaris eft,ve minimè notionis dilucidroris egeat:hafce itaq;, ceu veras, nó mutiș pi\&uris, fed ver bis voluimus fubdere, vt cuiq; quod vifum fit de illis ftatuat. Cùm cnim Cumini Catiui fapore odoréve gratu non polleat, nedum vt id fuperct, dubium eft vlláne fit Sylueftre Cuninum. Alteri nam luteł flores infunt, \& femina Melanthij defunt Sola horum Regia, quam proinde herbam culcariam, Delphinium inferius dicendum, Cófolida rocata, videtur adhuc Cunini fylueftris conicturam poffe foucre: tametif vfus medicamentis aut cibis vel nullus, vel incertus.

\section{NVCULA terrefiris Septentrionalium, an fit Bunio: Diof. co Builooca, farizm Trallan?}

Bel. eteróonotut. Sabandis. Fauerottcs. Ang. Kippernutz,

$V^{\mathrm{B}}$ I fuperius diftinximus Bunion à Buniade, maluimus pra cunctis alijs hane Bunium Diofco. afferere, vt cuius nomenclutio relį̧uam Diofcoridis defcriptionem expendenti, videntur à finnilitudine radicis bulbofe Buniadis, frue Napi, appell ata, \& vfu, quia frmiliter vt illa editur à plebecula:vnde fortè Trallianus Bulbocaftanum, quali caftaneá Bul bofarn vocauit : alioqui nimis tota facies à Buniade diffidet: Anethi enim eft conis, folijs imis, aliquanto latiorbus, ad Coriandrum accedentibus : floribus in vmbellis Anethi, fed albis.Semine Anifi minore: Radice rotunda, Cyclaminis, Caftaneain wquante, fufca foris intus alba, guftu Sifari.

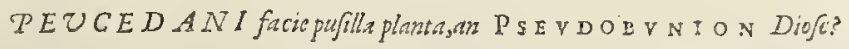
NEc non concinnè huc quadrat pufilla illa paimatis
plätam, Peucedani facie folijfq; , fed breuioribus \& ad Foeniculum tortuofum Nefeli Maffilienfe accedentibus, ramulıs intortis latius, in alas fparfis, cócoloribus: vmbel la cxigua, candida, Ancthi femine, Anifi breuiore, exiliore,guftu grato, aliquantìn acri:radice craffiore, comofa fupernè,guftu Oreofelini, non lóga, parni napi, craffiore quàm pro fui paruitate, cibo idonea: Qualé Briftoix in Anglia, ad rupem Vuncentij, nobis primum magna copia Iepertam, \& icone damus.

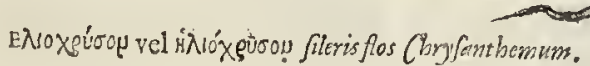

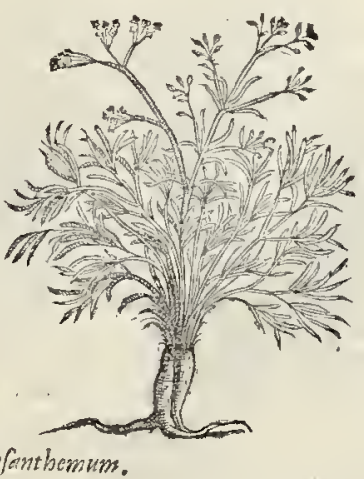


I Ex y ockryso eximium aurci foris decus, coronamentis, vt Theophraftus innuit,adcii -1 folieum,adque radiorum Solis repercuffum, corufcam lucem \& vegetan intuetibus vibrantes, corymbi nomendaturan fpeciofam reliquerunt, nobifque fignarune certifima illus cognolendi indicia, qualia in itto rulgato cernuntur,vmbell $x$ Corymbace multis bullis extantibus circinat $x, \&$ aureo afpectu micantes, Tanaceti \& A gerati diuturnam colo ris gratiam tutantes; in ręts virgis, gracilibus, viridätibus, pedem \& cubitum altis, duris alis \& folijs per interualla A brotani, vel tenuifolię Arthemifię: exili \& lignofa radice, Nicę ad Thyrrenum mare, Genux Lyguftica, \& in Galloprouincia afperis, macilentis conuallibus, \& defertis inculcis, fruticat: pollet multum ad podagras \& vlccra maligna, humorum impetum illuc incitum \& ruentem reprimendo, lotium dcritrando, \& faburran vehenen tius impellendo: \& eadem fermè qua Millefolium promittit.

\section{SID ER IT IS altera Diof an noftras Sangrisor ba Bipinella,}

A Pennatis pediculis \& foilj quadantenus Filicis, noftram efre dictam Pimpincllam, ve Etynon plebeium teftis locuples eft. Efle verò vulneribus valde accommodam, nullus non noute, qui audit vocatam effe Sanguiforba:cuius'cunctas partes fi Diof coridis conferas defcriptioni,nihl plané deeffe, nihilúe faperefe facilè inelligas: quin qui nob:foun fentiunt \& faciunt doftiores, nartant etiatnnum in Chio infula Sideritidem vernaculo adlauc fuperftite dici.Sanè folia incifura prolixóc; neruo, modo, fitu, vtring; pinnati, Filicé faten tur. Deinde in ramulis gracilibus \& longioribus, tenubus viriculis fphæricos vlomerulos, fupcrnè cacumine afperiore capitatos geftanti, vbi claufum eft femen:onnia demú fuftragantur, \& nobis inuitis Senenfem precipitis infcitix fpecimen dedife clanant: vbi carpebat quoldam, qui $P$ impinellam hanc 3 . Sideritidem autumabant. Nam folijs, inquit, Cot $\mathrm{i}$ andri. Atcui unullutra tanı infcium putamus, quin facilè videat, cum tertia nihil prorfun, fed cuin fecunda penitus quadrare Pimpinellani:quam prẹltitit retinere, illámq; nec defcriptã,neq, capitatan, fortè, neq; notam, magis fpectandain, quàm percipiendám, proponere.

\section{SIDERITIS Robertians.}

R A T E $v$ E Herculca eft noftras Robertiana notifima \& vuineribus fanguiníque eruptionbus non folum, verùm etiam vlceribus, adcóque potionibus valnerarijs certiflimi prafid ij exploratione merita nomen hirfuta Sidcritis: folijs Coriandrinis, qualem Geranijs recentiortun affcripfinus, eft.

$$
\begin{aligned}
& \text { SIDERITIS EACHILLEA, LHE, odora, } \\
& \text { erbapurpurea cadcm. }
\end{aligned}
$$

IV I C Sideritidilaudatus Chirurgus Achilles, Chironis difcipulus, nomen famamq̣us dedit, y t uua Telephij vulnera medicatus fuiffe creditus fit: Ac quò citius quituis noffequeat vel ab intuitu folo(quàm in Recentionm vel intempetiuas, vel falebroras, vel confufiff mas pedicas impingat)quid diftet Achillea hæc Sideritis à Militari(rectus quàm à Plinio millefoliü) vocata, fic difcernat: Achillea hæc multò procerioribus cft fcapis, nume roforibus, pedem \& cubitumaltis, \& folijs tenuioribus, magif $;$; ac profundius incifis, Atthenifix tenuifolia fimilitudine, mufcaria congcta, gercntibus, pufillis fofculis, denfe numerofis, \& quàm Militaris maioribus, albidis, odorem medicatum fpitantia, Arthemifia vel Matricarix, cui ctiam fimilis eft, in xtatem duratura: radice fibrofa, lignofa: tota odore \& fapore Matricariæ, vel non fotentis cotulæ, fed minus amaro. Solum in aruo edito amat pingue \& lætum:cuiufmodi in Italiæ Romano \& Tufco agro, \& non procul Riuoli, Pedemontis. Et pafin etian'Galliz Lugdunenfis ac Allobrogum.

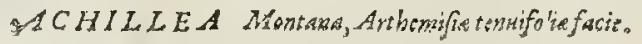


collationem, aptius nulli quadrare poffe quàm illi Millefolio in aquis nafcente, eiufdena cum iftofpeciei \& facie, chius folia quimplurima à media ad imum fciè exprimuntCh-

Miriophy - minum fyluctere, ant Cor andrum: fupcriora verò funt Leniculi, féd tenmiona, delicationa, lont. molliora, vti aptè etian quædam habetíetio. non amaraci (v t falfo lcgunt) led Maratri. reliqua minora, fed fmilia fupernè Horibus Millefoli: vnde perfpicua fupini Commentatoris fomnolentia, dü vfque \& vfoue car pir hunc \& illmm, iple carperdus \& ridendus magis, quinon videat hanc neutiquam foliis effe Semperuiuo maioriba; nagifque refrige rantibus, fed potius Cuminu fylue. Coriadri, \& $M$ Taratri, qualcm ipfus Sencnfis bellè ninxit.Vmbella etiam huius elt Millefolii, aut fylueltris Cumini, cui hic Diof confert, polt fa. tiuum fuit Mathiolo expendenda: vbi ctiamnum animi pendenus nos, fi non cfluxata orationis fories

\section{ST R ATIOT ES, fue Mrlitaris Aiznder,inter Aironfpecies reddende fuit Diofcaridis.}

EN I M verò fi huic funt folia Séperumo fimilia, fed miora,noménq; eidem inditú fit, quia incubet aquis, Diof interprete, \& innatando latiore éfsilı́; bafi fuas occulat radicesfubtus, vel, vt verifinilius, propter facultatem vulncrarinm, militi neceffarian \& nota, (nam alioqui effigre, imò omnibus notis, difsidere videntur : nifi quis harioletur militarem, quia fine radice, quafi fine lare \& re, vt miles, vifitet vitam incertan \& fuctuantem) fanè nequaquam illı Commentatoris erit Stratiotes.Scd diuerfa facie à Millefolits potius vera fuerit illa, que multis fuentis pigrè \& fermè ftagnantibus riuul is in Belgio nó procul Antuerpia \& ad Lifam Rumen prouenit, Semperuiui maioris figura, maioribus multò foliis, mucronatis, ag guftes, Lanceolx, Plantagmis longioribus, fed extremo anguftiore \& rigidiore ftilo: E medio autem foliorum \& ad latera exortis pediculis non longis inf dent flores ternis foliolis, quadātenus Ranunculi albi, fed medio lutei, \& pillis hirfuti, è carinula, aut forcipula cancri marini trifida emergentes. Ei fubelt contractior radix, foliorum fefsili latiori \& quafi bafi radicem compreffam obtegente, fed indidé tenuifsmx \& penè aciem fallentes fidiculx trans aquan humi demittuntur, nlimentumáue latenter fugunt, vermiculorum fpecié cmenticntes. vnde plebi mentiuntur felerata fcamundicorum collunies, qux mulicrculis iftıs radiculas in aque plena Phiola, quò maiores appareant oftentatas, iactat fe eduxiffe ex intehinis vermes, vt docifsimns fpectat $x$ modeftiz Dodonęus affirmat, \& Ioannes Crutlmanus Mechlinienfis, fibi vifum nos ccrtiores faciebat. Huic ten peramentum effe $P$ otamogetonis, ficcădi \& refrigerandi, ccrtum:quare facultates funt dıfparcs(ne dicã cötraria)fuperiori Millefolii:quod renibus fanguinem potius prolectaret, dü vehementifsimé vrinas mouet, cruenta ducit, vti nos feimus.

\section{PEDICVLARIS Alectorolophos, PedicularinTragi, an Stelophuros Plinii?

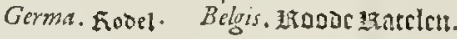

SVPERIV in Gallinacea Crifta hanc minus quadrare Pliniano Alectorolopio, \& inter Filipendulas aut Millefolia reddendä cenfumus; quò d illis nó abfimilis fit ortu, \& foliis ité minutim diffectis, in tencllis, palmaribus, gracilibus cauliculis,partin ereetis, partim humi fufis exeat : propter auté fores Crifta Gallinacex, purpurcos, aut albos, Aleftorolophon \& Criftam Galli, fecerunt recentiores: vfu alioqui hatenus incomperta.

\section{T ANACET Y AT Millefolii, folits, floribus Abortani fomine, ant Agerati.}

PRopivs Millefoliis quàm Arthemifiis, aut Parthenio, eft T anacetü diEtü. Folia fiquidé emittit pinnata Millc folii \& Filicis media :Caules èradice lignofa, reptrice, fibrofiore,plures, fufcos, ferquicubitales, rotundos, geniculatos, nónihil ltriatos, per fumma alis diuifos, quibus forcs aurei in vmbellis Agerati, aut Menthx Corymbiferx infunt, femécue Seriphii Abfinthii, aut A trotani fominx: quo vtuntur muliercula ad rermes necan- 
dos \& vinx fillicidia: gnfu fubacre amaricantis,cum grateolentia. Nafcitur pratofis marginibus, \& iuxta fapes \& foffas agromm.

Illud idem in Anglix lortis in delicijs habetur, longè,argutioribus fimbrijs, minutiori- Varietw bus, \& latioribus folijs.

Tanacetum non odorum Sylueftre, in Gallię Delphinatis fponte, prope Valentiam frequens oritur: nullo odore præditum, floribus Matricarix, quibus à fuperiore difcrepat: alioquin cuncta fui parte prorfum fimile. M AT RIC AR IA noftras, non refpondet Parbenio Paul.co Plin.

$A B$ Y N DE differuimus inter Anthemides, cur magis quadret vulgi lotula, Parthenio

Pli.Pauli: quàm herbariorum Matricaria, quäuis fivfum odorémq; refpicias, quibus virgineis morbis Matricis opitulantur, vtraque poffit Parthenium dici:verum hanc,quia longius ablit à Diofcoridis lineamentis. poltponendam illi duximus. Fruticat autem ficcis vbiuis viarum, \& hortorú marginibus fquallidis. Folia Arthemifięaut Abfynthio Romano propiora, quàm Coriandro:flores Chamæmeli Iunio \& Iulio edit, 1nultos fed odore Cotula, radicefibrofiore.

$$
\text { A B SY NT HIV M vulgare,non eft alinda }\left\{\begin{array}{l}
\text { Romano os } \\
\text { Pontico. }
\end{array}\right.
$$

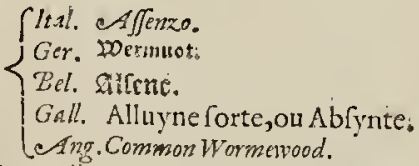

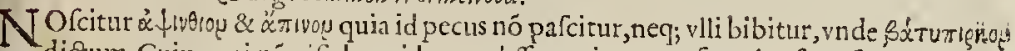
dictum. Cuius ve i nó nifí dua videntur differentia, tametf multa funt fimilitudines: Quod namy; vulgatius \& amarius cit, fponte natum vel cultum, caule fruticat ran ofo, folijs, figura, Arthemifir 1 ncifura: incanis, fofculis, rotundis, aureis, racematim aggeftis: Pon ticum eft, tum antiquis, à præflantia \& regione cognomine, tuin recentioribus barbaris ab aftictione, quàm illi Ponticum faporem fua, 110n Latina voce, appellät, quem laudabant in $A$ blynthio Pontico'Diofc. Cuiufnodi eft vulgatiffinum vbiq; peruium noltrum, fed Natalibus Capadotici, Tauri montis \& Pontis, vtpote purioie cuelo \& aere perflato commendatius, magíque aromaticü, vt pleraq; alia idem author \& Galenus eadem cômenda tione celebrauerunt. Et inter $A$ rabas Mefues interpres,'cum Romano Ponticitatent vin'dicaffet, id eft, aftrictionem ficcam, \&; valde Medico vfui oportunam, idem Ponticumatc; Romanum effe, nihil fortè huiufmodi meditatus, veriffimè literis mandauit: vnde Phar macoporom tam fedula huius Romani conquifitio \& exploratio etiamnum durat. Romanum enim,id cft,optimum, vti Camonillam Roinanam cæteris prẹfantiorem \& gcnuinamsexpetunt. Quin ne Barbaros iftud nomen Romani cómentos fe ignorare conque ratur nofter Vercelletis A pollo, feiat Romanum iftud commendatifinum inter paucas herbas \& facrü plebi Romana fuife, quod quidé victori fantatis pramio, \& quafi omine faufto propinabant,vt Plinius author. Et quod vofto xuo in Romano agro antiquisć; ru deribus paffim vifitur, non aliud à noftro eft, \& vtrumque Pontico idem eft, Quare non oratione defcripfit Diofc. quia vbiçue regionum copiofe fruticaret, tantum indicauit quò loci præftantius nouiffet, eodem enimillo monte cætera duo defcribit \& commendat, nó quód non paffim alibi, vt ian dictum, nafantur, fed quia ibi potiora, Necitidem vllü foecie aut figura difcrimen afignat Galenus: fed tantùm Diofcoridis fiden fequutus, vt plurimum folet, vires prafentiores, non diuerfas, Pouticú habere air:nec natura, fed loci prarogatiua, quam etiannum multis in regionibus vulgatum obtinet. Eft enim v bi odore non infuaui, vbi odoratum, \& vbi ferc̀ foridumpercipias. Sic A grimonia odora locis non nullis vt Xantonicis, alijs igitur autem expers odoris, qui vni gratus.alteri fetet odor.

"Folia verómagnoperè doctos torferunt: nam vbi legitur Ponticum minora habere folia, legebat codice \& rei exploratione fretus pręceptor Rondelletius, maiora efle, qu Metathefis, vt facilis, ita nimifquàm familiaris fermè omnibus de plantis fcribentibus. ex tat fxpè in Theophrafto, fxpiffimè in Diofcoride, vt capite de Helenio, Meo, \& alijs:inter dum \& in Gal.non fuo, fed amanuenfum vitio. Sed quò d Eveioliak obijciunt, dum obijci unt, nihil efficiunt:nam fi magis'odoratum, igitur \& odorun erit al terum, cft द́vadi $\alpha$ non 


\section{STIRPIVM aduer Jaria noma.}

minutim crenatis, teneriufcula lanugine incanis, vti Gnaphalium fum mo tenus obfitos: v bi extrema capitula aureis floribus bullata fulgent:femine patuo, copiofo referta, fimi . litudine Tanaceti,fed minore: tota, candida, fapore \& odore illitis quod Romanú \& P On-

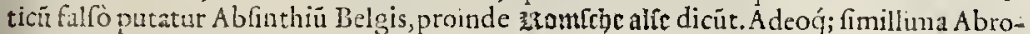
tono Foeminx vuigari, hortorum (Francis Cypres) eft, vt haud facilè itramuis ab altera difceruere fit: nifi quia hac tota minor, odoratior, candidior, tomentofa, quod alteri deeft, cui folia breuiora, Fapor non adeò ingratus, aut vehemens. eAtq; hoc non ansbitióê, cateris è fua clafle anotis, huc inferitur', fed quia propius eft Abrotono fomi$\mathrm{n} x$, cui comparat Diofcorides, prafertur, propter fumman affinitatem, qua vix credebamus differre à Fcemina Abrotono, nifi vtrumq; contulifemus Frequentulsimum Nora bonenfi Nitrobrigum agro fponte frutefcens \& eadem Londini Satain horto Hugonis Morgani \& enata, neque quidquam murata, vidifiemus.

\section{Gelatiun Sardonium, perperam Santonicum vulgi: eft Officinenum Abfjn- thiun Romitum falso creditum.}

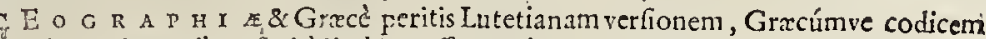
Aldinum legentibus, facilè licebit noffe, neutiquam $A$ pes Gallicas in Xantonum 2gro, vul gò Santonge exiftere, vbi crefcat cognomen Abfynthium Santoncum:fed fecundum eAlpes Galatix, vernaculo cognomine Saddorum, Sardonium vocatum. Sic enim etiam hodie legitur \& reftituitur, facili intellect ione \& proximè fequentis capitis repetitione, vbi in Galatia Afiatica Abrotonum,vtpote cógener,oriri dicit: \& quot Abfynthii funt fecies, tot iam eodem Gafatize \& Cappadocizloco commendat Diofcor. vt ratio nulla fit hafitationis, aut in Santonicü Gallicü deprauationis. Tota Pläta Abfynthio fimpliciter diEto fimilis eft, fed minor, minúfque candida: feminibus non adeo multis, toribus exiguis. Nonnullis Germanix locis frequens: in Flandrix \& Angliz hortis copiofa, is vfi multò expetita, illic rocata taomíche Alíctue, id eft, Romanum Abfynthium. publica períuafione. Quan fequutus Senếfis(fi Efculapio placet)in Hügaria, \& Bohemia, Ponticum, ifud feu Romanum fibi repertum prædicat. Nans sacontrbe gifene Conferuam, in officinis Antuerpianis \& Belgicis paratam, muliercula Mulomædice \& clinicz lubentins emunt, quia non ita amaram, facilius deglutiunt. Decepta quidem, nam fi ca. rct amarore, igitur \& facultate amica, \& grato calore. A tqui Ponticum verum, Teu vulgare, vivis argumertis docuinis amarius effe: \& Diofcorid. Seriphium ac Sardonium dicitaliquantu m(non multum) effe amara. Nec minus Romanum poffe,quam Seryphit odor \& fapor indicio funt.

\section{Gallis Barbotine, Belgis Semen Zedoarie.}

F C V I D E M femen fantum,vel Contra, officinarum aut Santolinü diđum, horum triū $A$ bynthiorü, nullī efle videtur:nam tametfi nonnulla amaritudinis \& figurx fimilitudo illis interfit, cunEtis:tamen non adeò funt plenè adulta horum femina, aut horridè amara. Et fatum nonnullis in locis vidimus femen peregrinum iftud, ex quo fruticulus furculofus enatus fuit, vndequaq; feminibus glifcens, pluribus fermè quàm foliis. Quodáue fement nondum, vietun, fed plenum \& recens qui fit nactus, fi fęrat variis locis, Fäcilè plantamarsquetur.

\section{Alind Peregrinum, fine A A G P T IVM Abfynth.}

A G Y в T I M quoppiã vocatum Abfynth. Pollitrici forma, foliolis albis,alterno fitu digeftis, digitum, altis apud Gefnerum iamdiu, \& pòtt penes Valerandum Donrez. ficcum viderainus, infirma aut certè nulla coniętura, $\mathbb{E g y p t i o ~ c o g n o m i n e ~ i n ~ f c r i p t u m ~ \& ~}$ à quodam herbario miffum, qui ex hoc femen fanctum produci conie etabat.
Ff.i,
CA: 


\section{STIR P IV $M$ aduerfaria nona. CATNOS FVMARIA. \\ Germa, tzrotrauch, Katsentioinel. \\ $\{$ Belgis. Befrecon cutoc Dupucketucl. \\ ZGal. Ang. Fumetere, Fumitere.}

A s N o N , fue Fumum, fumidam, fumariamq́ue è Græco dixêre Latini, quia fucco oculs illito, non fecus ac fumo, exprimercnturvellicando lachrymę maximo ho die vbique vfu \& veris reltibili prouentu notifsima herbula eft inter fegetes \& proxime margines, ramulis fibrofis, \& fruticofis, quadratis furculis, cxviridi in cinereum pa!lorem langueintibus, emergens: folia diuifura Coriandri : Fofculis purpurantibus, interdum al'oidis, \& interdum rubellis : femine rotundo, viridante ex fufco, \& aftate colligi op portuno; viret vero \& foret herbula Vere, quum fuccus illi efficacifsimus, \& exp:ini fo litus ad Syrupos, eletuaria, \& pilulas Officinarum: amaro guntu \& fubacri.

\section{VARIETAS.}

FN Norbonenfi agro minor multò, fed minus frequens inuenitur quadam Fumaria 7 ramulis \& foliolis palmaribus, Scandicis, nec procumbentibus, Ce furrectis, 2 albicantibus, tuin folis, tun floribus: adice exili, guftu amaro. Monfpellii rurc propinquo Boutonet nuncupato, aliifúue aridis glareofis vere ctiam vifitur.

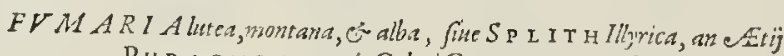

$$
\begin{aligned}
& \text { PHRAGMITES, CoraleniCORIDALIS? }
\end{aligned}
$$

NOr I I I т A V I T hanc raris laudibus noftra ętas, eharamque etian fecit hortis \& no. tam carsindi metus \& paucitas, płucis namque locis obuia, nce nifi calidiorú Regionum montibus Illyriw, Dalmatię, Hetruræ \& Norbonę Galloprouincię. Seriùs nempè quàm vulgaris Fumaria fores luteos, ftellatos, Chelidonii minoris, Iulio \& Augufto edit: folia vero Fumarie bulbofx, vel Chelidoni maiotis, minora multò, glauca, cineritia, exilibus cauliculis, pluribus, fefquipalmaribus, \& pedillibus : è radice latus fparfa, fibrofa, Robertiani Geranii. Senine rotundo, depreffo, atro nitente, in corniculis Fumaria bulbofx, vel Chelidonii maioris, minoribus mul tò, cui admodum fumilis facie \& colore eft, vndè fcitè coniętet quilibet cfe Ẻapmun, fiue Chelidonium Phragnitem Etii. Quan Coridalim Galeni qui affenerant, propter colicum dolorem, cui opitulatur, nimis ancipiti vtuntur argumento. Quippe noitấs etiam Fumaria idem interdum non infrenuè prętat, digerendo, difcuticndóque vifcidam pituitam, è renibus elíciendo faburram, qua non rarò colicum dolorem efferat $\&$ cmensiatur. Quin Coridalim videntur vocafse potius Bulbofam Fumariam, ab effigie $A$ laudx auicula, curus capitis galericulatum verticem amulautur fores criftati, turbinataque cornicula. Husus fapor fermè qualis vulgnris Fumarix, fed efGcacius videtur farctus tenuare, atque incifos in lotium deriuare, vnde laus magna ad Hydropen. Robur ctian addit vifceribus, reỉiquáue præfat quę Mefues de Fumaria vulgari narrat, de qua quod ille dixit, contrarium de hac dici poffet, fcilicet ratitatem auxiffe opinionem, at vulgatan copiam noftratis Fumarię laudi offe. cilfe.

VARIETAS-

QV s. via ducit Florentia Tiftoiam \& Lucam Tufcam, hanc eandem Fumariam fo. ribus albis fert, vt ferunt quidam a mici noftri admodum periti nobis tamen nullibi illis in monticulis, nec quidem in Iuliano, vila vifa fuit fuperioribus annis.

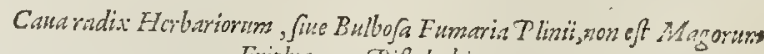

$$
\begin{aligned}
& \text { Friplya, nec Pifrolochia. }
\end{aligned}
$$

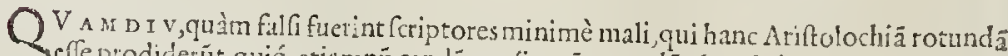
"efle prodiderút, quić; etiamnü cnndē quafi verā rotundà vfurpät, in Clenatide obiter diximus: nomen autë occafio plantz huic, \& eroris ifis fuit radix, quz rotunda cum fit 


\section{ST IR P IV $M$ aduerjarianoua.}

bubofáq; \& perinde vt Ariftolochia rotunda faciat, ad vermes \& inaligna viceta, facild opinionem illis fecit Ariftolochix, qui verain nondum vidiffent. Scd diffuadendo fat fue gidioribus erumput purtio \& Aprili in vembrofis decliuibus \& nemorofis faltibus frjgidioribus erumput purpurei \& aliquando albi, more, \& fimilitudine Fumarię vulgaris, ad cuius folla multum accedit lauore cafio \& diuifura foliorum, maiorum tamen : femer pellucidum eft in corniculis in hortis autem Belgij alitur frequens, \& reliqua Germania,
vbi etiam è montibus oriundarn habent.

\section{$F A B A C E A$ radice, altera $C A P N O S$.}

\section{Bel. Boontiens bolwortclc.}

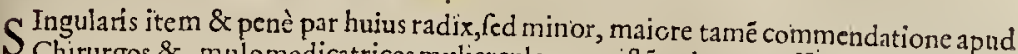
S Chirurgos \& mulomedicatrices mulierculas, qux iftä puluerem efficacioren \& delicatiorē ad lumbricos interimendos pradicāt. In Belgio, Germania, \& Subaudia, vti Gene ux aruorü quorundan fepes $\&$ margines hac fearent. Meminimus ctiam:in Veganijs hortis Dei nos eruiffe:non vlla totius facie nota, prxterquàm radicis exilita te, nuila infignita cauitate difcrepans, ctiamó; natilitijs, nam inibi nufplam fuperiorem reperias, quar alioqui
multa occurrit, vbi neutiquam hrc.

\section{CHELIDONIVM mains, Hirundinarie maior. \\ Ger. Brofs folwutt5, Scbwalmentraut. Bolowurts. \\ SBel. Boumotele, etroe Broote Boutue. \\ Gall. Efclayre, \&Chelidoine, Felongne: Arg. Celoridine.}

PR I m a hirundinum tranatione, vernaq́; noftratis coeli ternperie oritur maiof Chelidonia,non fecus atq; minor, à qua tamen multum al ia eft, aliać; occafione dicta, nem pè cùm aciem oculorum fuccus illius acuat, hirundinulisqúue fuis occacatis vifum reftituere credantur herba ipfa matres: radicem etianó; totam plantam in hortorum fcrobiumóg; marginibus multum obuiā, \& fucco croceo, fuluiore, virofiore quàm Papaucris Cor nuti glifcentem, neminê latere quit, tota reliqua facie ad $P$ linianum Capnun vel $A$ quilegiă comparata, folijs cafijs, \& filiquis tenerioribus, non ita diuerfis: lutei autem funt fores Keiri viol $x$, feruidıore tamen acrimonia \& foetidiore eft,minimè guftu aut odore grata:ra rius in trò vtenda, commodius foris ad impetigines \& pforas puerorum, necron nietallo. rum chymicas medicationcs.

$$
\begin{aligned}
& \text { A } 2 \text { I I IN A, Aquilegia recentiorum aut Columbina, num fit } \\
& \text { Ponihos T beophrafti, fiue Defiderium, Gazs interprefe? } \\
& \left\{\begin{array}{l}
\text { Ger. 2letilet. } \\
\text { Gal. Ancholies, } \\
\text { Ang. Columbine. }
\end{array}\right.
\end{aligned}
$$

S I hac antiquis innotuiffet, non dubium quin illis coronaria futura foret, eft enim non vulgarinec intienufta florum clegantia, crerula purpura nitentium, aliquot calyculis cornutis aduncis vtring; gracilitate ceruicem \& roftella columbarum adumbrantibus vnde Columbina Anglis dicitur, \& doctiflimo Aldrouando Bononiêfi profeffori Ротнos Theophrafti, cùm illic verfaremur,putabatur. Frigidiufculos Meridionalium tractus amat,pratenfis etiam eft Francix \& Anglix, fed fqualidiore minúfq; hilari afpectu non cul: ta, nam in hortis duplò, triplò, \& multipló flores denfioribus \& nitidioribus caliculis ftipätur, triplici varietate coloris feorfim confpicua, aut in codem vno fore dintinta, al-bo,purpureo, \& cxrulco. Reliqua foliorum totiúfq; facies Chelidonij con par \& fimilis:muior \& fimilima Pliniana furnaria: femine itélucido in folliofis recurus infundiblilis Confolid $\boldsymbol{x}$ Regalis aut Melanthij, guftu tantillum aftringente, temperatx cx calore ficcitatis: cóq; ad faucium pharyngis \& trachex incendium \& vlcufcula vtitur p'ebeculá

$$
\text { Ff, ij. } A R T E=
$$




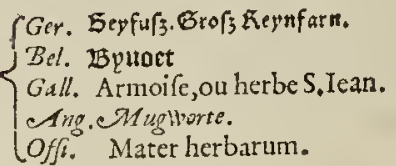

OGNITION Is ordinifá, confequintione Ablynthij generi Arthemifix fuccedunt tribus hodre quatuoríe differentijs diftnctx, quas, valere iuffis oftentatorum velitationıbus intempeltuis, perfpicuè paucis fecernemus. Qüæ vulgaris cognitıonis \& vfus perpetuò fuit Arthemifia, plurima vbiuis locorum fecus fepes, \& initerum margınes, $\mathrm{Ab}$ fynthio vulgari, feu Romano, fimilima fruticat, procerior tamen, \& folia maiora : fupernè nigricantia infernè incana, habet:Semen item illi Abfynthij, \& floresalbidi, odore non infuaues, apor minus aut par ú amarus. Viribus hæc exploratıffina, quia in vfu aut fola, aut frequétiffima, \& vtiliffima Sed \& eaden quibufdam locis inaufpicatx telluris \& pręaridıs J'arictas. adeò ftrigola, parua, \& odore quadam grautate feriente vifitur, ve alia prorfum putetur: vti Ablynthio noltrati \& Pontico folo nafenti euenire monumus.

$$
\begin{gathered}
\text { ART HEMISI A tertia Diofcoridis } \\
\ddots \text { Leptopbyllox. }
\end{gathered}
$$

HV nutiqui Diof coridis vnicaule nuticupaffe videntur herbudam fefquipalmum, cubicumáque altam: folijs minutis, Abrotoni mari fimiliter incifis, paruis, virentibus ex atro, lignofis in ramulis, Hot ibus, feminḉ̧, quàmplurimo refertis, paruis, \& ex virich luteolis, $\mathrm{fl}_{2}$ uefentibus. Prope culta \& olimeta Mó-

Abrotinums mus Monspel. alecrups. fpelijalifíf; quàmp̧luribus Norbonx locis multa \& rota:fed vulgo quodpiam Abrotani genus credita. Equidê per Diorcoridē licebit ficappellare, quia nó de fua fed quorundam fententia, hane inter Arthemnfias receufet. Odor tamen illi nou Abrotani att Abfynthij, fed Arthicmifix prioris eft, \& prorfun eadem videtur, quæ Leptophyllos tenuifolia, feu Lepto. carphos, proximo capite indicata, $\&$ in culcata, duntaxaz explicationis caufa: \& facultatesıauté vidétur à quopiãauthore, cuuss oratio multò cultior, É pollicitatio maior de Arthemifia eft, quarm qux Di-

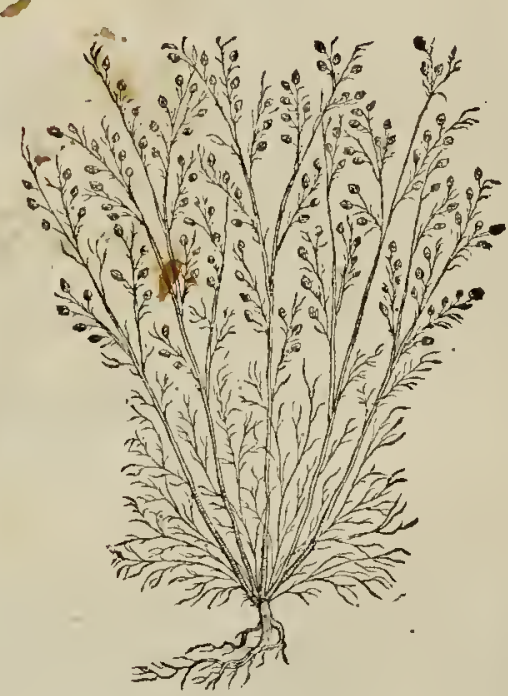
ofco. conueniat.Sed ille potius deceptus non pauca fimilitudine odoris \& foliorum, indicaffe videtur herbam illam fruticofam; odoris fuauifsimi \& Sampfucum imitantis, quam fecimus c:m doftis Abrotanum mare, vulgus Picardorum \& Francorum, Herbarn \& lignü S.Iohannis vocitant, cóq; in coronamentis \& Iüborum fuperfttiofo cinetu ad epilepfiam, morbü D. Iohannis putatä, auerrun canḋa expetüt. Hinc D. Ruellio dubitädi aña iudicij hallucinati, quam factiofè, vr folitus 


\section{STIRTIVM aduerjarianou.}

eft illi improperat ille Bambalio commentator, qui omnia conuiciis híc mifcet \& diruit, docct verò $n$ : hil, aut dicit.

\section{ARTHEMISIA Marine.}

TA M nufpiam in mediterraneis, quàm frequens in maritimi iffam reperies, ećotte merito martimam voces. Pluribus fruticat farmentis ab via radice lignofa, fibroła, furretis, aiternis interuallis, cineritii colore, mufcofóquie fernine' fimiliori Ablyntho communi, guàm Arrhemifiz: fiores item lutei, numerofi funt. Folia ima \& ferrić humi ftrata, paucioribus, fed maioribus inc furis: media verò, aut fuperna, anguftiora, minora, interdum vna, aut altera incifura, Portulacę marinx, aut Feniculo marino non abrimilia, canofu, albentia, vit rnime-fa planta, qua gratuin de fe cnittit odorem, $A$ brotani maris ferm:̀ fapor fubfalfus, perparùm anarus, cuiufmodi Arthernifiz prioris. It finus 1 driatici littoribus ad Lyo infulam \& Vouctam ṕlúrima.

\section{$A M B R O S I A$.}

EXimiz fra grantix gratiz etiam Diuis expetita, nedum coronamentis, Ambrofix nome Efinxst:apud nos autcm nufpiam nifi fatiua Ambrofia vifitur, coq́uc procerior merito eft, quàn qua fpontè oritur: Nec quifquam argutator noltratis magnitudinem obiciat, quam tripalnarem Doforides facit: multis enim, nec magnis de caufis, incrementum decrencénnve capit hic fruticulus: cubitum altos edens complures ab ima radice caules, ranulof'que toto è caule multiplices, ftriatos, graciles, à medio fermè fummo tenus: fenine \& Anofulis quàmplurimis alternatim dissitis, luteolis, mufcofis, furfurcísie acinnlis, ve olex, racemofis, fed rotundis femper, nec latuus féfe aperientibus. Quiburdar: inter foliz è pediculis vtriculi emicant, angulofi, Echinati, minures \& fimiles tribulo ter reftri. Semen aigricans, rowundum, ant potius Gygarti vax xmulum, gütanti non ingratum. Folia Rutę frmila, \& circa imum xqualia, fed fupernè marora, maior buf̨̣; duifutis, Arthomifix, vel Abfynthii, teneriora \& tenuiora : vniuerfa albicat planta, odorćnque

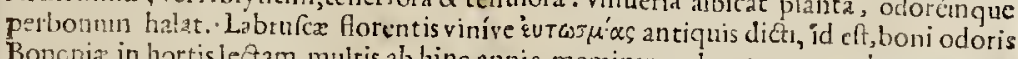
Boncnia in hortis leatam multis ab hinc annis meminmus lanc, quę eadem etrannä viret Londini fata, radix gräcilis, palmi vel fefquipalmi.

\section{AB ROTONVM Farnina.}

\section{- SGerma. Garten Exprefs. \\ \{Galis. Petit Cypres \& Gardcrobbe.}

C. H a m crparis sos,ceupumilla Cnpreffus diea, vulgo Petit Cypres; in hortis Cfrequens colitur, \& Gallix Norbonenfis Nemaúenfi vinetis\$ campis patentibus fru-

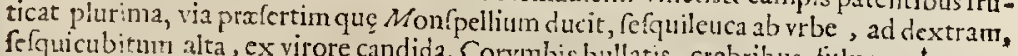
fefquicubitum alta, ex virore candida, Corymbis bullatis, crebribus, tuluo colore reni mentbus. Menfe Inlio eft crtera hortenfi fmilis, fed odoratior, lignofior : hujus feminenecant lumbricos quotidiano experimento muliercula effe: Idcirco Abrotonum fe. minam minimè anbigimus: tom quia notis candoris, amaritudins, fruticis arborez habiru, Corymbis aureis, refertis folis, minutıfsimè incifis, Seriphii modo, quadrare videtur:tum quia viribus fcimus iifée, nec ignauioribus pollere, quas Dief. \& Galenus illi vendicarut. Huic quàm bellè cógruat Diof́. gemina collatio Scrıphiı \& Abrotoni. Siquidē Senélis Seriphió nultis noti̊ \& authoritate confirmatū, nó foret verum. Folns enim Arthemifix eft, aut Abfynthii vuigaris, feu Pontici , cui Diofcorides \& antuqui difsimile facuunt iftud viribus \& forma. Etchm afferat Galenus Seriphio \& Abrotono vires confimiles \& noxias effe, etiā feruorê, acrimoniā ingratã cum falfedir e: nempè vbi nari propius oritur:vtrumq; autem viribus \& forma Cẹpius comparet, Scriphiumǵ̣; vltimo loco

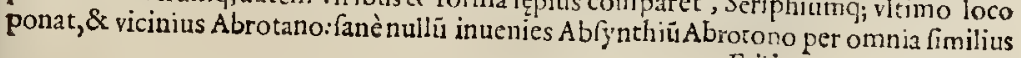
F.iij. Dodo- 


\title{
$34^{2}$
}

\section{STIRPIVM adwerfaria noua.}

Dodonxo refponfum, in procinctu illi non eft:meritó ambigendü fuiffe fuper Abrotano, cui perperam fuiffet agntum Seriphium:nan qui explicationem Abrotoni defcriptio nem haberct,potins ex ifto de Seriphio, quàm ex hoc de Abrotono iudicium fuum eliceret, aut confirmaret: illa enim Arthemifięfpecies, potius vulgare refert, foribus, folitis, \& femine,vt metipfe fat etur:minutifsimis incifis foliss, Seriphii modo nentiquā elt:ideo non Seri phium Pontico contulit Diofcorides, fed fempcr Abrotono fominz.

\author{
ABROTONVM Mas. ¿̇şótovoj. \\ Germa. Stabwutt;, Scbefwutt;, fen Bertwortz.
}

AVR O N Eallicè vocata, \& hortis ruríque oriunda, Mafculum Abrotonum meritò cenfetur,farmentofum duriusçue : Feninibus tenuibus, odorum, fubalbidum, amarŭ, folis fœeniculi modò minutim incifis, paulò latioribus, crigendis hortis \& deambulacri3 concinnandis coluntur:flore lutcolo, Abrythii, minore.

\section{ABROTONVM Teregrinum CapreßBifoliss.}

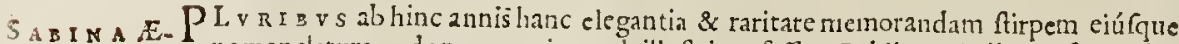
Syetra. re Bononix, gqui hanc Sabinam. As gyptiam vocabat, huiusq; mentio fąa capite de Sabira, exigua radice, ex vna ftirpe plufculos viticeos, caules rigidiores, nigricantes, folia $\mathrm{Cu}$ prefsina, aut Sabinx, textura reticulata effigiata, longa, anguftia, \& per virgulta crenatis extremitatibus denuculatis foliis.

$$
\text { Anthernis vulgatior, fue } C H A M A M I L L A \text {. }
$$

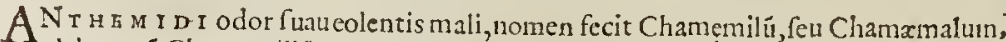
plebs au té Chamomillă, \& Cotulam non feridă vocat:huius è floribus \& odore quadruplex eft confpicua differentia, nominibus fecernéda. Et Europæis regionibus freq̣ué-

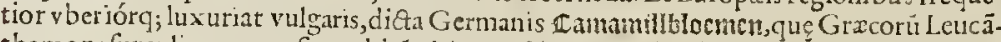
themon: furculis numerofis, cubitü altis, erectis, in alas diuifis: quibus ab radice pufilla

PYSTRI. folia crebra ninutim incifa \& perangufta diuifura Anethi, vel Coriadri, viridia, tenuia hærent : flores in funmis cauliculis numerofi, candidi, Bellidis, radiatim bullatum glomerulum luteum, quafi modiolum, ambientes, Cytonium malum quadantenus iedolen tes: femine pufillo, luteo, incunte ęftate fcgctibus tam frequens \& fatis, vt non partum incommoda fit: ingentis hxc commodi \& vfus Gallis, Italis, \& Germanix nonnullis locis, quibus defit copia alterius Leuchatheni, quem iam dicemus.

$$
\begin{aligned}
& \text { A Mhenis fue L EVCANT HEMVM odoratins, Romanorum. } \\
& \text { Belg. } 19 \text { oomiche samblbioneit. }
\end{aligned}
$$

VT fuanius multò, quiddamq̣uc aromaticú Amaraci, aut Abrotani halat Romana hæc, fic multò ad a peetum hilarior \& comptior efte ea deniq; notrone dictu, qua Bafilicas pręftantores plantas vocare foliti fuerant, vti Romanum abfynthium, \& Bafilicum a paragon:T enellis cauliculis repit, haud diucrfa foliis, \& Rorbus vulgatex fylueftri, reftibili iten fertilitate \& perenni radice, qua fefe inftaurat, \& fundit propigationes proculcationis contemptrices: eóque voluptatis ergò totum vertentem anhum in Anglicis viretis attondetur, fecus puluillos \& toros infernens \& ambulacra: negleeta namque, protrita, \& refecta, foelicius \& vberius vernat \& luxuriat Siquidem Anglio vniuer $x$ hatud alia fe rmè nota, vel vú recepta quàm haxc: Ruri miliari vno aut altero $a b$ vrbe Lódino plurima, herbidis, aridis, vbi fpótè orta flor ü capitula \& folia gracilitate elegátiora à cónuni difcerni queunt: Gallix \& Italię tneridıonilibus (tametli Romana dicta) rarior fontè. In Belgio \&: Northmannia ad Druidum vrbeculam, quò loci religionis ergò cóniffun fuit funette \& cruentum pralium, multa. Qui fyrup:is huius floribus, fircco, Er vino albo confit, mul tò ad fplenis \& ieterum hydropis pręfidium optimus. 


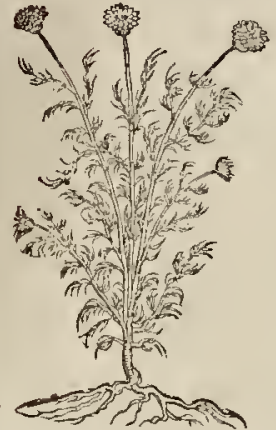

BVP HT H ALI N, Oculns Bouis. Millefoly folio, (bry fant bemiflore.

HE c Gcrmaniæ, \& Anglix hortis inquilina. Romano autem agro, Hetrufco \& Galloprouincie prope Olbiā ad ma re Hicres vocatí, fpontè fecus vias \& margines fatorï, cubitales \& fefçuicubitales crebros fpargit ramos, graciles, teneros: fo lia fimilia,fedlatiora, ad Co:ulę \& Tanacetum? nonnihil accedentia, crebctrimis n inutifsimisq; plumatim \& fcitè du ctis diui furis Abrotami, Arthemifix concolor, floribus Anthemidis prorfum \& odore: fed intus forıfáue luteis , vt Chryfantheni vulgaris, aut Calëdulę: quos xftate, etiāọ; in vfque brumam híc Londini vegetos v1dimus in horto Morgani,\& Briftoix.

\section{BVP HTH ALINVM alterum, folio of facio Cotwle Eotida.}

TO $\mathrm{N}$ inelegans iftec nobis reperta feeus A Arantiorĩ lucos Olbix in Gallo. prouincia maritima. Caules promit Hexuofos, cubitales, \& duos pedes altos : quos ambiút folia tenella A nthemididis, lætiora, Cotulx fotentis paria: flores funt radiati, lutei, Chryfanthemi aruorum, aut Calendula fpontè nafcentis. Hanc etiam nobis repertam in agro Romano meminimus.
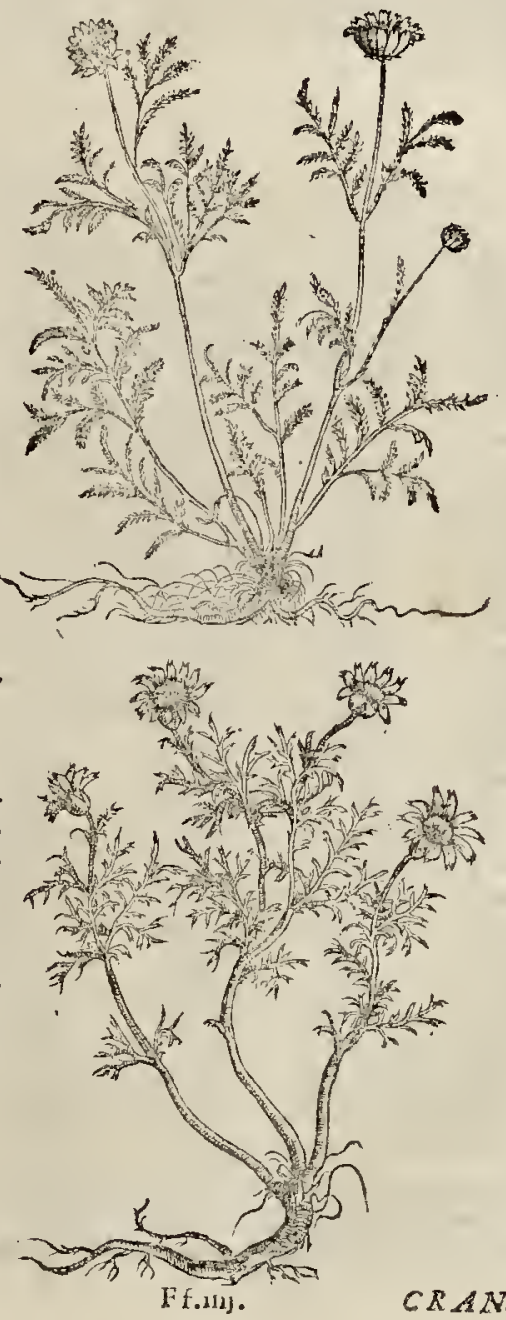


\section{ERANTHEMON.}

V A M plantam Eranthemon Gefnerus, cui oftendimus, opinabatur, quia aptior hafenus defuit, etiamnun veram effe coniectamur, finilitudine \& viribus Antiemidis perfuaf : eft enim Anthemidis facie, fed maior tota, \& Cotula fin lis, vel fpecies, lacio ribus maioribusq́ue floribus, Bellidis maioris, infernì rubenisbus ex purpura, lupernè cä doreintermifto, inclinaquc bulla med ta, interdum inter alias Cotulas fatis enáci folct fapor ingratus illi, odor Cotul $x$ : Tametfi pericul of $x$ eft ale $x$ res, de icone lectionéve duntaxat notas,illicò propter nonnullam fimilitudinem, quar nam fint, cer tó ftatucre, Anicus quidan Pyrhetrum vulgare tuebatur Eranthemon genuinam, ob foies fubtus patpuraf́centes, \& folia Anthemidis haud abfimiliav erùm radicis figura \& fapor, vrens fatiôs,nos dedocuerunt.

ADONIS. TAN T o minus fit Adonis,vt nonnullis vifum fuit, vt cui bullx luteol $x$ medix, flores 1 autem Anthemidis, fomen \& fucultateslongè abfint : quare commodius nos inter Ancmones.

\section{PARTHENIVM, velf'irginea, eft Cotula fatida, non Matricaria.}

CALARACYS vinl.sinuli.

7. $\mathrm{O}$ nefcimus morofulos iftos cenfores leuiufcula plerumguc adductos notula a au$\checkmark$ tores perbcnède re heibara meritos, infitiz traducere, atque irridere plesunque, ridendi ipfi cum forent:ıdú; in Parthenii dı́quificione liquidò videre êt, grod nolint effe Cotulan, fed Matricariam autumant, propter duntixat Cotiandri folia:at te-

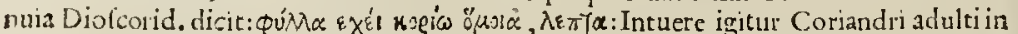
ramis media î fumma folia, \& fatebere collationé apprimè cógruă, imò omnia Coriandri funt: folı confimili diuifura, rami, fitus, tenuitas, figura, pręterquàm ima perpauca folia, qua latiora funt Apii aut Ocnanthes, quibus eadem foltorum difnarilitas contigit, eóque fcitè addidit $\lambda$ ém/ $\alpha^{4}$, nimirum vt collationem nó ad inı, fed ad me. dia plaraque folia factundam in auer. Matricarie cnim nequeunt elfe Coriandro, $\& \lambda \varepsilon^{-1} \kappa_{\infty}$ feu tchiva : funt enim ipfa Coriandro maiora,nedum tenuiora, Arthemifie \& Abfythio propiora pariánue reliqux plantx partes, floribus duntaxat Anthemidis. De anaro:e autem quod blaterat , indıcat in legendo fupinam negligentiam, atque in guftando fatuun palatum: eft enim Cotula amarore inamceno \& perquam ingrato, vti Parthenion:

Matricaria verùn híc nulla exupetantix adieftione, fcetidan fubuirofánue \& amaricanten dicit,

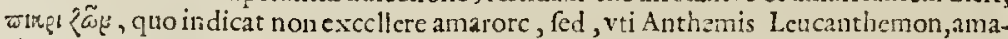
ricantefapore effc. Cui etiam, quia fimilis erat Partheniú, feu Cotula,idem nomen factä Leucanthemidis, è Graco contextu difcas. Iam vero fi ad facultates \& vfum animum aduertas, quod intererat Senenfis Commentatoris, neutiouam vlterius inficias ibis, $P$ arthenium effe Cotulam fotidam. Memininus namq; quod probènonit clarisima Agatho. polis Schola, Rondelletium aliófque profefores præclaros, frpius addere Cotulam fortidam decoetis, ad ferolos, aduftos, falfos, melancholicofque Elephantialeos, \&: mali mortui vocatos, per inferiora educendos: purgat etiam aliquantùn fuccus per fe iufulis inditus, magnoperè in fyrupo,abiifdem laudatus: cnia thoracis 3 pulmonum farcus, lotiun euidenter ciet, \& tumores emollıt, digerendi vi paulöquàn Chamamill vegetiore. Sumus \& nos vfi percommodè totum hos fexenniü Rondelletii imitatione, mul toñt cómodo. Eapropter multuin nocuit, maleq́; ąum cum ftudıofis hątenus, quibus perfuafe-

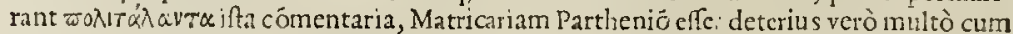
xgrois, qui herbx dustaxat ad menfes ciendos vfurpatæ, purgatoria (caterùn ananroris

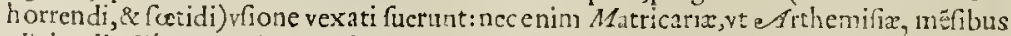
cliciendis alísve matricis particularibus affectibus prærogatiuam, fed tantum ad duritien \& Phlegmonas commendat Parthenion Diofcorides.

Varietas. TA R T E I I igitur, feu Cotulx, varietas duplexà magnitudine \& odore. Notior \& frequétior qux foetidior, caulibus \& alis teretibus, fuccofis, teneris, viridlobs, crafsiori. bus, longioribus, quàm Leucanthemidis agreftis : foliis veró \& floribus illi adcò all udenti- 


\section{STIRPIVM adterjarianona.}

bus, vt vel exercitato, nifi nares confuluerit, illudat:attentius tamen intuëti folia latiora; \& Horum medix bulla depreffiores, latior es, ij fdem fatis xftate cum Chamanelo Leucanthemo floret.

Inodora Cotula.

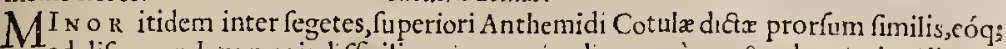
ad difce-ilındum magis difficilis, quia magnitudine penè par, \& odore imbecillo aur nullo eft. Flores tamen latiores habet \& teneriores caules:radix quotinnis regerminat. COT $L L A$, fine Partberion marnim minimum.

$A D$ Cetimontis Norbonenfis radiccs, non procul pifca torum attegijs, hxc frequens oritur: \& Cichorio Bulbofo lubens affociatur. Exilibus palmaribus caulieulis humi fternitur, quibus folia infunt 13 uphthalmi vulgaris paria, di uifura Bellidis maioris, carnofa, odore feriente, putidulo, Cotula vulgaris: Floribus item non ita abfimilibus. Vires autem nec inferiores, nec difpares.

\section{BVP HTH AL MVM, Oculus Bonis.}

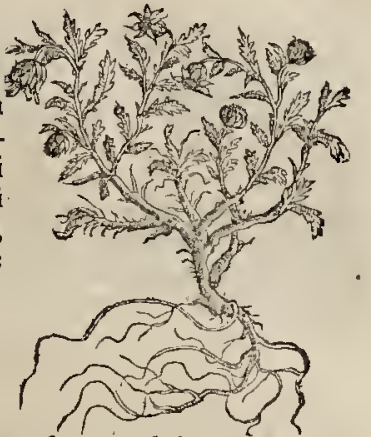

FN I M V ER O Galenus \& Ëgineta,quafi Chryfanthemum foret Buphtlalmü, aut nomine tenus diftarent, nufpiam Chry fantheni meminerunt fed Buphthalmum ijfdem quibus Diolcorides verbis pofteritati fuæ mandarunt, peneq́; perfuaferunt commentitiŭ vel fpuriuin caput de Chryfanthemo efle, vel cuiufpiam amanuenfis induftria nowinis \& ordinis quadam cófequtitione illecti,illuc inter Chry fogonum, Chryfocomen, Heliochryfon \& Ageratü apud Diorc. afcitū, eodémq; penc̀ orationis filo \& viribus, quibus Buphthal mum. Tum v troq; pofterior I'linius, videtur vnã tantùm defcriptioné legiffe, vel, quod verifimilius, vtramq; ratus eandế, Buphthalmi vná delineationé conflaffe \& Chryfanthemi. Buphthalmos, ait, fimilis Bouú oculis, folio Fœniculi, circa oppida nafcens, fruticofis cauli bus, qui \& mandütur decoSti, quidā Cachlā vocant, hæc cum cera fciromata difcutit : Vbi

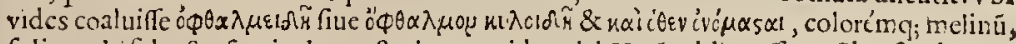
folia mulitifida, fcu foniculacea, \& circa oppida oriri. Verü addita effe ex Chryfanthemo, caules mandi decottos. A beffe verò illi fores vehementer fplendidos, caules lẹues: variante nimirum nonnihil defcriptione ex Buphthalno atq; Chryfanthemo conflat: . Hæc fatis vifa fuerunt non paucis doctioribus ad aftruendum, non nifi eandem vnamq; planta $m$ \& defcriptionem vitumg; effe. Qubus fanè \& nos affentiremur, ni \& ipf ftirpes, quafi fe amoias fua tribu \& capite diminutas quererentur, Junc poft liminiò reduces fefe nobis offerrét, atq; lectio paulo vtrobiq: attenfior liquido praluceret. Siquidé Buphthal no caules funt teneri, tenues:folia Fœniculi fpecie, flores lutei,finiles \& maiores, quàm Anthemidis (nempè Leucanthenii)oculi imagine. Chry fantheno a utẻ fruticofa facies, lęues caules: Fo lia multum incifa. Flores vehementer fplendidi, vel rutili, \& caules holcracei, efculéti. Qua a propter oppida, nó itẽ in ağis, oriri tradit. Qux quidé varietas cü par ipfis in pläris cernátur, facit v't arbitrentur, Galenú, quê fequitur l’aulus, recéfione hac fuper fediffe,dú ex Dior coride exfcriberet, quia plätas inter fe non comparaffet: aut, vt lenius dicamus, Chryfanthe mi hiftoriä eius monumentis intercidiffe: quemadmodú in vulgatx cognitionis Iride contigit. Facultates præterea fi quis argutetur cafdem vtrifque red ditas, iden factum in Sch - $_{-}$ nanto cum Calamo, Myrtha cum Bdellio, lbcride cum Cardamine, Cichoriis cum Hieracijs, \& non paucis alijs. Ea propter exercitatioribus binum damus Buphthalmum, \& totidem Chryfanthema, quorum acceffione faltem naturæ familix duæavctiores locupletioreff; funt futuræ.

HEL LEBO KVS ferulaceus. Buphrbalmum Dod.

THeop. Helleborus ferulaceus folijs foniculi, huc accetfri extcapite de Elleboro:ferpla cet Doct. Dod.fed flores nó ita congruü. Facultates minus multù catharticus enim ef 


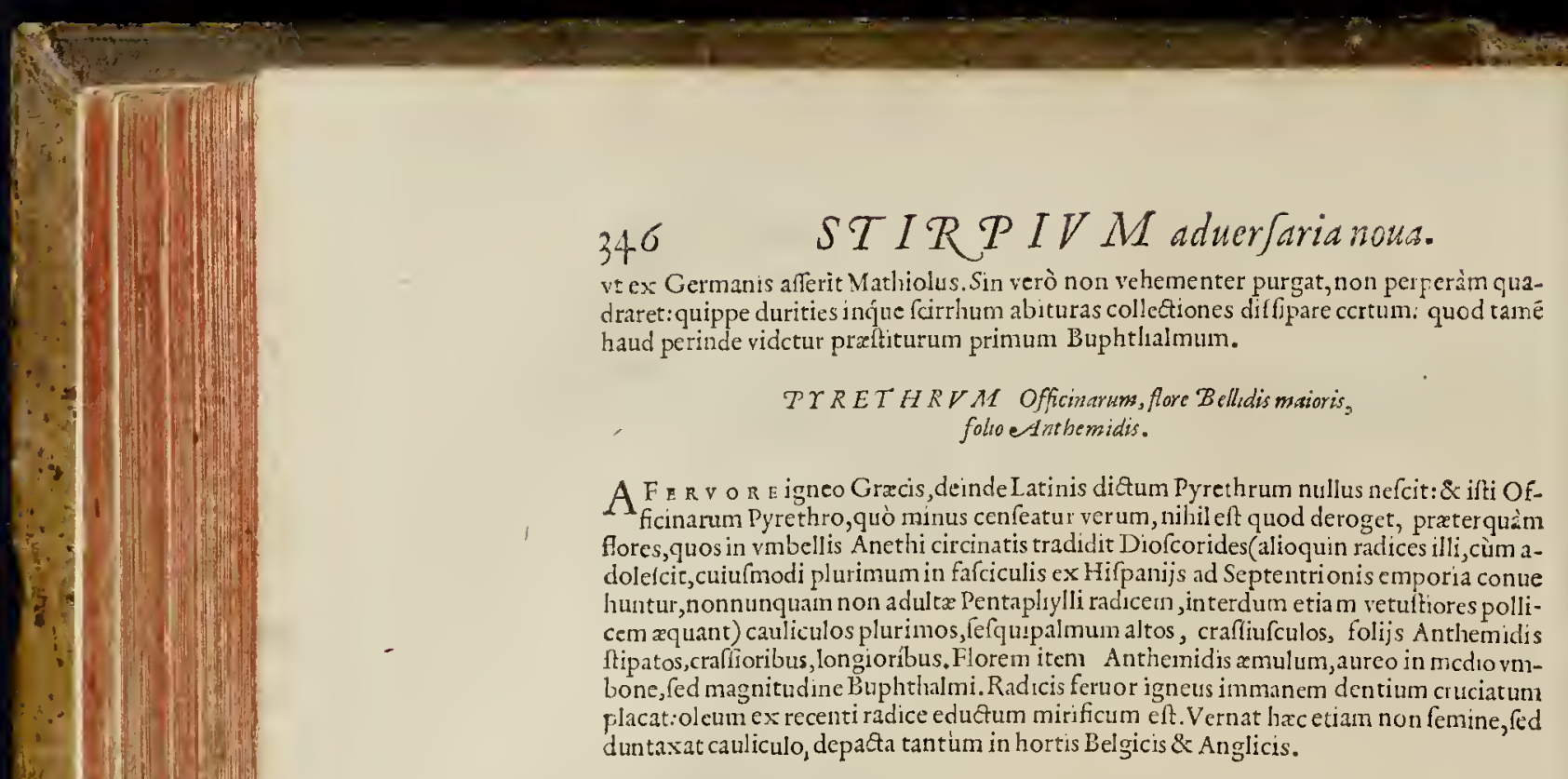

\section{$P Y R E T H R V M$ alicrum.}

A L I a m plantam Pyrethri veri nomine donabat Guillandinus, \& alebat in Patauino horto, cui radices \& folia Cotul $x$ fortid $x$. Vmbell ab yno quafi centro multis pedi-

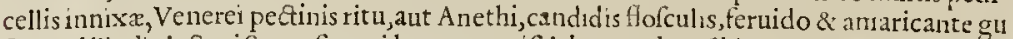
ftu. Sedilludit lectori Sencnfis, qui hanc non nifi labore arduo fibi comparatā,neq; omnibus cognitam aflerens, quafi inuideret nobis tyronibus cognitionem, aut metueret criticorum reprehenfionem, tacendo docet, nifi quxnam illa effet, nó perfpectum planè fuerit illi. Et fanè minimè habet hac alterius illius mirificas vires:vt neque nonnull alix, qux quia guftu feruido funt, \& nonnullam foliorum fimilitudinem fortit $x$, illicò ab intempefiuis herbarijs $P$ yrethri nonen accipiunt, quafi id praltacet Pyrethrum fertore tantum, acnon potius alia comite facultate.

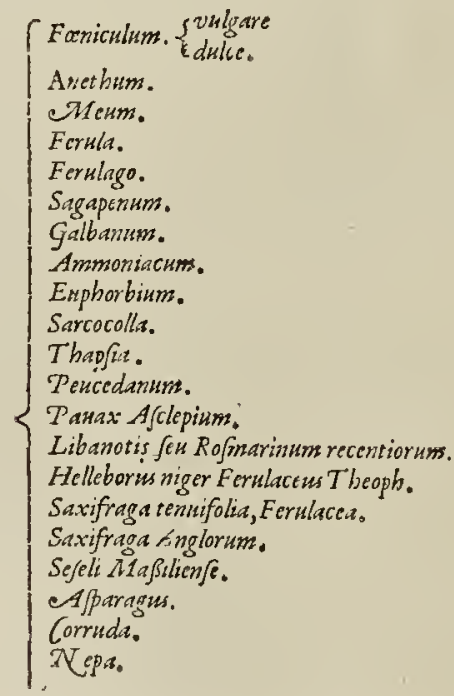




\title{
STIRT IV $M$ adueijaritnows
}

\author{
[Myriophyllon vel Matriphyllow paluftre. \\ Myrioplyyllon Equiferi folium funiatile. \\ Polygonum fermira. \\ Equtfetum onnu, fue 'Hippuris. \\ Traganos. \\ (scorpio Theoph.
}

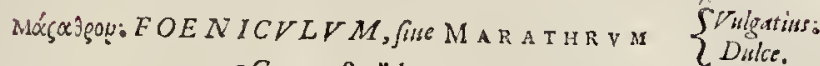 \\ Sorma. Sentel. \\ $\left\{\begin{array}{l}\text { Belgis. Uentikel. } \\ \text { Gallis. Fenoil. }\end{array}\right.$ \\ CGailis. Fenoil. Ang. Fenell.
}

Vo s a m multus vfus un cibis Foniculi emarcidi \& arentis, Marathrum quidam mes arefactum \& marcidum reponetur, foen è Gracis Latini, quòd quafi fonum in hyemes arefactum \& marcidum reponetur, foniculum dixerunt.Id autentapud nos in tripliciffentia vifitur: $\downarrow$ uigare, \&omnium vfu fiequentifsimum apparandis cibis, Dulce vocatun Officinis, femine maiore Cumino, guttu An fi, dulci, parandis cibis, Dulacri,breutoré; caule \& exiliore; folia itidé funt $A$, minus D v L c. Hyenresitud conor ne è Gracis, aut Syria allato. Vulgaris autem nec perinde frequens ferit ur, vtpote femimenfis, ficcior, fquallidus.

Hippomaratiri auten ab antiquis proditi fyluctis, femine prefertim ab ifo diverfo, Hipposaracnius plantam, qux aptè rcfpondeat, fin: ilen equidem habemus nullim, Guilli. Dricfel shum.

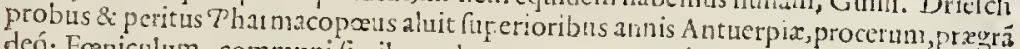
deć; Fơniculum, communi finilc:caule ternum, quaternúmve cubitorum, folin breuioribus, aliquantò rigidioribus, albicantibus Conndx. Semen par, aut paulúm mus al. tero, rotundus, \& Anifo propius. Ilt Hippomarathi llomen fecerunt.

$$
\begin{aligned}
& \text { A } N E T H V M . \\
& \text { Germa.Dyllen, Gallis. Anet. Ang.D.ll, }
\end{aligned}
$$

A NHTON, quafi ànkeTey dictunz volunt, quia appetentian cibi cxcitet, fed etian

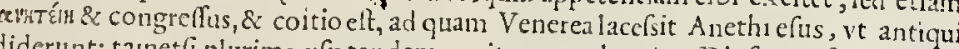
prodiderunt: tanetfi plurimo vfu tandem genituram exhauriat, Diofcor، tefte, diffatç; quippe èfomacho crafim fpiritum, quen tentatum in intima \& vafafpermatica viget, fed demum populatur. Hortis hæc frequentifsima, fponté interdum nata, etiam in Anglia \& Nortmannia:tcneræ conæ in uffculiseficantur à quib ifdanı calculofis, quibus nó parum prodeffe certum elt, fed cibo, parum grato fapore: tantoperè Foniculo finile a. libi diximus, vt ipfo Pharmacopoco interdum deiudat, niff fupore Facile difceneretur; ingrato, calidiore, \& colore obfcurius virente Anethum.

\section{CH EN. Germa.Bctriuntt,}

$\mathrm{M}$ E r veri plurimas frpifsimè vidinus plantas in Germaniæe, Italię,Gallię, Hifpanixáue locis Alpinis: Qun nuper etiam da hac meditaremur vireto peritifsim ?halinacopoi Londinen fis Iohannis Riccii, Radix odore fuau fpicx, vel Angelicx, caule \& folis Anethi , vmbella candida, Iunio \& Iul io floret Semen Hippomarathri, odoratum. Eadem in celfísimis montium iugis fterilis Seucur, prafertim loco cui nomen Gallicè s' Epperon, id eft, calcar latiuè, monticolis eftre nuncup atur vernaculo nomine, *i Platearii \& Pandectarii æuo, cui nulla doctiorum omnium fufiragio deeft nota veri Mei Diofcoridis. Cuims etiã

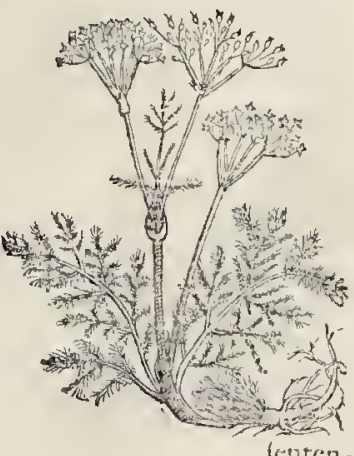




\section{$3+8 S T I R T I V M$ aduerfarianowa.}

fentiz eft, nofter eruditifsimus Turnerus Anglus, qui in orę Septentrionalis Alpibus Che ueorıcis Seotia finitımis, magna vertate fcatere hanc ftirpem nos monuit. Vix enim Fesiculum tor-quadrienniū eft, cum-primum hac planta Venetis Pharmacopcis innotuir:nani tameti

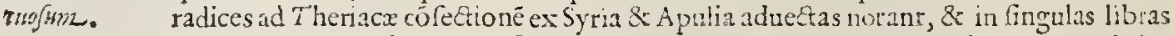
fingulum aureum ducatum infitori pendebant; tamen exoticam putaliant, nec vllo loeo Italix oriundam, ve qui neque caulem foliáve vidifent, \& Herbariortm Senenfis dičatorıs, fummi placitıs aequseuifient. Hicenim Mafsilienfuñ \& Mófpellicnfun Ancthum foniculumve tortuofuin, tortuofo errore verum Diofeoridis Meam aftruxerat,anfamq́ue illis errandi prębuerat. Quia ne nune quidem, vt crroremaut tegat, aut fousat, in iftrs poltremis Commentationum recoctionibus atque reeantationibus, nifi inuitus hane genuinam effe fatetur: Ir fatali fua modeftia argutatur, odore quadancenus viro. fum, folin non eAnethi, fed A fperagi, radicibus non adcò tenuibus; Tum paulò mo: fubdit, Appult Imperatricem vocant: quo quidem vocabulo, vbigue fermè locorum isnara herbarun plebs folita eltaliculusincognitx phnta exinium \& gratum odorem \& viresinfignes fignare:Sic enım vulgò etiam Angelicam Imperatricem vocät : alioguin Angelıex, aut Imperatorię, cum Meo nihil eft afficitatis, nifi oforis, qui in Meoperiade incú dus eft. Et peritis indicio efteutn neq; multas radice huins eruife, neque folia planè nerfpecta habuife; (unt enim fitu \& fimilitudne Anethi, non Afparagi, ve alfcric:cti etianfi effent finiles, tamen anbitionem fie fuam magis prodtcre: \&paiagun nand; metipfe feniculo afsinilat \& Anethum adeo fimilem fænieulo fuo capite aficit, vt plerumque colligétes fallat. Ne porró in mel tò reconditionbus plantis deinceps fallamur abs te, nos tyruuculi,catio vna \& fumma erit, non temerè tuis argutis inductionibus picturísve credere. Penè enim nos fefelleras libri initio de Iride fylueftri, quam Medio ex Plinio cóparabas:at nónis pòft lógè aliud Mediü dedilti, quam inibi prêt te ferebas. Hîe porrò de Sefeli, Androfache, Sr aliis permultis plantis, fanere lingruis eonfilium eft. Qui non nefeiamus, te tantum Dictatoré iandiu fupra al eam humani iudicii vel erroris fummo ignauo-

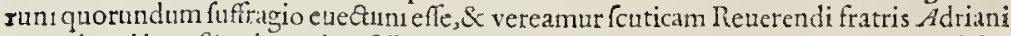
Veneti, qui in vafti tui operis veftibulo \& Priuilegio, dieit totum volumen, tuum à fua Paternitate examinatum, approbatum, \&rab omnifupieion e erroris liberatum.

\section{Náp̧т\}द FERVLAC Ferulugo. Hipa.Cananheia.}

VEMADMODV NógTh? virgulum, thyrfum aut baeillum Graeis fignat, fic Ferula La tinè à ferendo, quód illius frapi pedamenta frutieibus, \& fenibus pedum ac feipioneseflent. Plurima \& procera in Galloprouincia o Norbonenfi Gallna, prefertim illis rupibus praruptísque faxis prope fubterraneas ery tas, via qua Monfpellio Frontignanam itur ad reetam:itidem in celfis fqualidísque faxorum finubus, qui foles ętiuos \& feruidos exceptos totú fermè fouent diem, propè oppidulum Rochxve Calturum vocatum, quà ad auftrum vergit:quinúm eubitorum caulis, radix magna, refa \& altè in faxorum commiffuras hiantes rimaz dz fcendens, euulfu aifficilis, candida, lacteo pinguig; fuceo turgida, odorem vehementem vibrans, folia foniculo maiora, pirguiora, crafsiora, vt \& cauIs: vmbellx pragrandes Anethi, Iunio \& Iulio Hofcuiıs luteis defluentibus. Semé folliaceur, compreflum, oblongum, rotundum, Angeliex fermè , duplò maius.

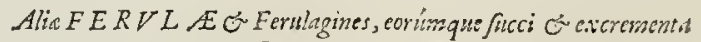

SA G ADEN V AS.

SVNT etiamnü dux in herbariorũ hortis huius elafsis, naturx \& fimilitudinis plantæ, quas idcirco Feruldgines vocant. E videntur diftare duntavat eultura, ftatura, clecãtia \& fucci co pia,prout funt natę radiees arunm aridun, magísque excostum, fub cxlo fudo \& feruidiore, vt in Aphriea, Media, Cyrene, \& alibi.Quare, minus mirum eft Diofcoridem paucas \& obforras notas de Sagapeni, Galbani, Ammoniaci, Euphorbii Ferulis, alísque permulitis gummifers fcripto reliquilfe : cum ne nune quidern fint nobis eognita,poftquam à noitris hominibus terra \& mari luftratx funt Lybia, E thyopiać; eun- 


\section{STIRPIVM aduerjarianou.}

Ea,multoó; plures regioncs, \& magis diffitx noftro orbe. Equidem Diofcorides videtur agnofcere ferulam candon cfle atque Sagaj cnum:nam è radice Fel ula fuciata manare Sagapenum primim dixerat: deinde inferius, quafi fuperius nihil dixifiet, alteram plantă Ferulaceam docet, ex gua alius generis Sagapenum effuat: quæarguunt potus fuccos ipros agnitos illi, quàm plantas. Quippe Plinij ctiam Sagapenum in Ferula oriri tradit: fortè quia eádem plantam cum Ferula vulgari putauit. Cum autem multıs c̀ plantis, gum meus, pinguis, \& refinofus fuccus cxeat, vt Coniferis, Amygdalis, Maftiche, Tet ebintho, Ce rafis, Hedera:herba Rutha, Dragacantha, Ix ia, \& alijs non paucis: tamen omnum nobiliffimum excrenentum medicamentúmq; videntur Ferulacea remittere: \& earum quxdam parcè, nec nifi alicubi, vt Foniculum in Hifpanijs, Thapfia apud nos:de quorum nati ra, viribus, \& mixturis, commentationem plenam inftituinus inter fuccos medicatos, vbi facilius cum cateris liquoribus concretis, pinguibus, \& cognatis comparabuntut. Nunc tantium fi qux faciunt ad hafce plantas veltigandas, pauca leuiter attingemus. Diximus haud dudum in Lafere, ad quan vocem alludit Affi forés, foltü olm nifceri Silphio fue Laferi Sagapenum, cóque, tum propter alias rationes, videri nobis cognatas plantas: quã cóiecturä fouet Diofc.qui Sagapenú nef́io quid mediū inter.Lafer \& Galbanū olere affir mat:idó; fenfuü perceptio hodierna confrmata, ideo namq; fimilia colludüt ad nos, vt ex ercitato fit op us oculo \& nare fagaci ad ea inuicem difcerneudí. $P$ urius fiquidem Sagapenum \& illud recens, quale nó multis ab hinc annis cœperüt Venetias afportare infitores, concolor eft Affę purior, odore item ingrato, Porrum iefipıentc, vel Galbanü, quum prxfertim recentiffimam \& efficacifimam intucris gleban lachrymis thuris concretam.

Quin \& Galbanum Ferulx item Syriacx fuccus gummeus; Aflam multò propius afpectu imitatur: odor tamen minus teter illi, \& Gpoponacis quadätenus cognarï videtur:cuiuf modi habemus hodie ex Officinis Venetis quoddä ruluã, molle, Ceram nouam refereus: cuius grumos glebula lúc lachrymis pinguibus congeftas feruanus, alorumq; multorum lectiorum gummoforü fuccorum fpecimina,vt quiddam iumenti nobis afterant,ctian ad plantas ipfas nof citandas, intérq; ipfas diftinguendas. Siquidem verifimile fit, fic in uicé hafce Ferulas fe habere vti ipforum gummi funt aut diuerfa aut affina. Nam Hammoniaci gummi, quod perquam recens optumum $\&$ copiofurn hodie adfertur, tametfi plantam ferulaceam effe, ipfa fruftilla fcctucafúe harundinace corcicis, qux inter glebam reperiütur, fidem faciunt, \& Diofcorides affirmet: tamen longius abeffe videtur ab illa communi ferula fpecie cuius cognationé Affam, Galbanum, \& Sagapenum fufpicabamur. Ifta etiam fe mina latinfcul2 ferulx, quẹ inibi immixta glebis confpicuutur, caulifq; , vti dixim ${ }^{2}$ ruftitiz, arguunt ferulam diuerfam quandä, fed tamen congenerem : tamé vides ipfü gummi alio odore, figura, \& copia multo maxima. Ad́de quód Euforbij ferulaceam, arborem etiam tra dit Diofcorides in Mauritanix Achlante monte, cum tamen ipfe liquor concretus non pa rum difcerpet à fuperıotibus gummis, finilior multò Sarcocollax. Quare vtris credendum fit, meritò hxremus, Diofcoridíne, qui ferularum, aut ferul $x$ arbori fimilem tradidit: an recentioribus, qui iftos cunctos tractus Mauritanix ad modī exploratos 'habent,' ipfatuq́ue iplantam Euforbij frequentifima fibi vifam codem quidem loco vbi Diofcorides, fed lon gè alia fpecie repræfentant. Nempe fpinofam plantam- $A$ cantho aut Cynarx fimilem, cuius radici innafcuntnr cumerorum effigie fructus prægrandes, fucco ifto feruido turgentes, quibus per maturitatem incifis, lac effluit, colligitur except quod habcmus Euforbium. Verùn qui fxpius ob feruauimus inter glomerulos $\mathrm{\&}$ aceruos Euphorbij multa femina tricocca Chamælex, Lathyridisúc modo, gultu acria, lubens audi remus, num hac fint eiufde femina plantz, quod tamen minus videtur, fi ca fit Cynaris fylueftris fimilis. Nó aūt effe Euphorbio congenerem Sarcocollā tametfi admodìm fimilia ipfa grummi grumofa fint. Diof corides monet \& ipfe feruor in Euphorbio, amaror autem in Sarcocolla, tum facultates diuerf $\approx$, quas nos profequemut, quo loco polliciti fuimus.

THAPSI A Turbith Gallicum, \& Turb.th cineritium Officinarum.

Gg.j. Potuit 
PO T v I t dici Thapfia, nó folum vt pla cuit Diofcoridi, à Tha pro infula cognomine, qux vna è Sporadibus eft: fed criam propter flanmeuin calorcm, quen corpori admota inurerct, adeśq; cminus, prxfertim aduerfo flatu fpectanri. Valdequàm fimilis Tapfia habitu toto \& viribus:tanet fi vfu multo preftantiore atgi; purgatrici vi. In Aquitanix macilentioribus montofifq́; fqualidis inuentam nobis dedit preceptor Rondelletius,prope vadum quà traijcitur in Hifpaniä, tun ad radices Pyreneorú, non procul Pcrpignano vrbe:craflior radicis cor tex, fufco foris colore, intus pallet,fuccón; multo glifait Iattco, gummco, fed inibu!loci neglceto: caulis $P$ cucedani gracilior, quä Ferula, foliaćue Foniculo latiora, breuiora, in vmbellis femen Ferulx minoris, oblongum, anguftius, montani Sileris. Merito defita cx iftius fucco purgandi antiquis

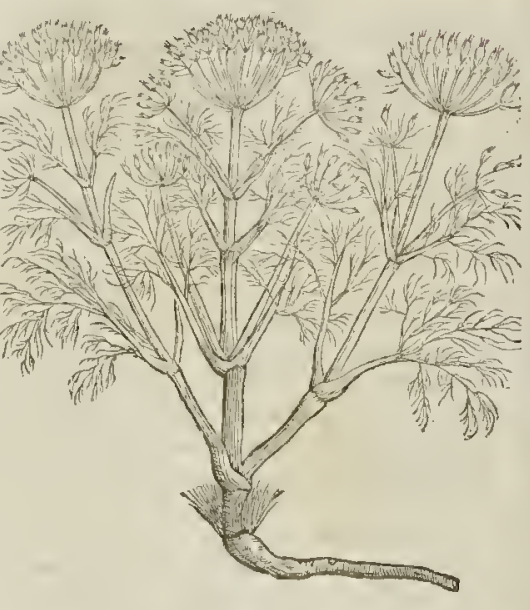
confuctudo, vt quo multum noceatur præcipuis vifceribus, \& tormina dira interdü excitentur. Verum fiquidē mifcentur leuioribus \& naturx anicioribus, proderit Sarcocolla, Hanmocami, Turpctiúc fucci modo. Nec Ferulx Peudanique fuccis gummeis defüt vires purgatrices: verùm tü quia planta tum fuccus fcetidus cerebro aduerfatur, idco non correQta plus difcriminis inferret. Sagapenü vocatur gummi ex Ferula cductú,vti Hämoniacú, Galbanú cæteriq́; congenercs ex Ferulis confimilibus, fed tanen pro fuccorum natura inter fe diffecrentix eliciuntur, de quibus paulò mox.

\section{Howbariorum T' H AP S I A Vulgari, Carote effigie.}

$V$ a M V I s fit hixc vulgatior Thapfia officinarum verior cxiftimata \& fupertori Thap Q fix radicenon parum afímilis, tamen certum eft longius à defcriptione abeffe:'eft enim folijs potius Carotx, fiuc Daucl agreftis quä Ferulx: $c x$ Italia iandiu hortis Belgicis \& Francis tranflutitix notitix. Sed quia Aquitanica radice vtuntur plexæq; omnes Offici næ Septentrionales, ideo fe putêt vti iftius vul gatioris radicibus, quia nó ita füt abfimiles.

$$
\begin{aligned}
& \text { PEVCED ANVM. Foeniculim porcinum. }
\end{aligned}
$$

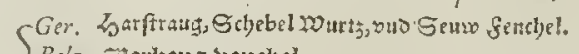

$$
\begin{aligned}
& \{\text { Belg. Auerkens venckel. } \\
& \text { ZAng. Horeftrange. }
\end{aligned}
$$

EFERV LA. COGNATIS hxc, cui radicisfucciq; gummens, tefinofus, piceus

fortor, $P$ eucedani nomen fecit: Apuleius Pinaltellam, tametfi potius horrendum amarorem \& foetorem apud Poctas Tevued avos pox fignet. Multum crefcitlin Italiæ Hetrufcæe xftu ofis atq; Norbonx glarcofis collibus, præfertim in Luci Garamontij adiru \& circú intcr \{entes, lumas, \& dumeta. Radix profüda nigricat foris, intus virefcēs, fuccúć; remittit gummeum, flau um,odore grauis \&: fortentis : comatớ; fupernè denfo capillitio fufco, ambiente caulem gracilem, fefquicubitalem:mul tis inrerdum ab imo furculis diuifa, in folia terna Foniculi modo, quàm Ferulæx duplò latiora, Iongiora, minus craffa, vimbella latiorcs, luteis fofculis prægnantes fem inc Angelicx haud abfimili, ingrato. Sic \& purgandi vi donata fuit radix herbáve, fed propter fortorem vtriufq; minus in vfum deducta. P AN AX Afclepium Forula facie.

J Ec diuerfi gencris eft Afclepium $P$ anaxà Ferula,nec"item figura abfinile, prafirtim is autor admodú notas plantas oratione prolixiore profequitur, rariores auten tacitas preterit, aut nomine tcnus indicatas pietori relinquit, nos potius dubios quàm cetiores 


\section{$S T I R P I V M$ aduer farianonia.}

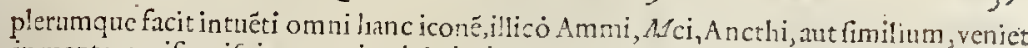
in menten, nifi quifpiam aperiat defcriptionc concinina, fintue folia fonictlo minora, odoration, hirfutiora, qua vmbellx, quo fore donate, fic paucis Cómentateris of ficio \& pollicitatione defügcretur, præclarè oppra pofita, nec muita: quæ tamê multum plus tibi honoris , \& vtilitatis nobis effet allatura, quim ex A urhoribus, nui peiuii funt ftudiofis, paginas fuas infarcire, vt plebi mialta loguutus videatur, quum dixerit aut docterit nilii. ExIllyrio traetu, cui Hiftriæ nomć, hodie plätas non paucas af portautinduftrius Valerădus Infulanus Lugduni Pharmacopœus, quib multa cü hac Panace affinitas, ouas in Hor to Doctoris Iuberti Monfpellii feuinus:Ferula fimilis crat effigie, fed multò ninor magnitudina. Semine tamen non Fenıculi, fed vt Ferula, lato: folits \& Horibus haud difsinilibus, caule \& radicc, magnitudine atque fimilitudine Anethi odorato.

\section{ROSMARINVMI ferwacenm, Fertile Dioj.cuins Scmen Cacbris dicitur.}

DI r e R S I admodùm generis plantæ Libanotidis appeilationé ar cinerunt,ob odorem quem firarent, quadam fui parte Thuris quadintenus zemulum, criufmodi prima Libanotidis radicem olere Diofcorides author eft:quidem a Theophrafto quandā Libanotiden nemoratä, cuitus folia agrefts Lactuce amarx ciadlidiora, afperioraradice breui, harrat. Nobis autem nulla hodie plenè imnotuir Libanotis è tot Ferulacei- qux vulgò Libanotis T heö Libanoides putantur, perinde defriptioni confona, vt hxc, quam ?'atauinus olim ha-phra. folijs La bebat hortus, quex et iumnum hac ineunte hyeme lata virebat Londini in horto Iohan- Etuca, apud Dio nis Riccit, hon vulgaris peritix Pharmacopoi. Surrigit ea caulen quinum \& fenum intet dum cubitorum, feniculaccum, aut ferula, nitidun, obfcurč viridantem, alı multis e flteram vide \& ranulis diuifum, c̀ nodofis geniculis exeintibus, foliaq́ue gcrentibus crebra, Feniculo prope Olug vatrits? crafsiora, Cotula maiora, a uerfa, virore cefío \& glauco, ymbcllas per aftatcm latiorcs Ferulæ, ant Tapfix,floribus lutcols refertas, \& femina Fraxini, folliacca, oblongiora quàn Ferula, \& Cucumerino femini maiona, côprefsiona, ftriata, acerofa, refinaceti, aut Tht:rcunn lialitum dum fricantur, Sileris Montani,aut Pelopónenfis Sefeli dantia, manfućue os refinaceo \& Thurco fapore compientia, acriora: reliqua planta tencra, calidiufcula, fed non ingrato holeracco \& Smini guftr, quo quidem facilè dignofcitur à Ferula : nam alıoqui lacte multo turget tota, vti Ferula,fed albidiore \& minus feruido, aut graui odo-
re, quin potius odoro.

$$
\text { HER B A RIORVM Soptentrional, notion Liburiotis. }
$$

DO n perinde Libanotidi congruit hac ferulacea, cuam multi Herbarii horti in Galn lia,Germania, \& Anglia fouent: tametfi caulc gracili, reeto, Mei, aut Anethi,ftriato, atrouirente, bicubitali fit, paucis alis \& geniculis douto : in quibus, imis prefertim, Pencedani prolixiora folia, freniculi tortuofi, antruftiona Sixif qugie Anglica, medio \& fupcriore caule pauciora; Vmbellis \& floribus pufillis, cand ddis, Mei: Sed exiguum femé, fub hyemé maturäs, minus Carui rotund, ferê Ammi officinarum par, quod neutiquarm poteft conuenire Rofmarini fertilis Diofcoridis fem!ni, Cachryn, aut Cancryn vecati; quia grano hordeaceo eflet fimilc, aut potius quòd vecntis facultatis cùn cfet, fimilems efcaram inurebat cuti, atque pilula Cacri propterea ab antiquis vocata.

\section{NIGER HELLEBORVS Theophraft.caule of} foliis Ferula, radicibus nigris.

EThî́c cogimur ctiam affentiri doctoribus inculcantibus nobis iftũ Senenfem toinus verfatum ftrpium in infpectione, aut acthorum clafsiconum lectione:nam vbi Tragii veftigatoris pertísimi $\&$ Gefneri indefcrsi laboris viri iucicium, vt vanum vlerüque incufat, nę ille quàn non effet mult $x$ exercizationis, aut lectionis, liquidò prodit. Saltem debur monuife, Theoph, fortè \& Hippocr. Helleborim defcriprife Cotulz \& folis 
ferulaceis nigris radicibus, albi fïmilibus: vfun qualem nefsius $\&$ a aius pfeldocónentator, ifts preudohelleboro attribuit. Rad $1 \times$ quamplurimis, nigris, $t c n$ mbus neruilis, Hel leboro finilis,ternos quaternófve crigit cauliculos, peden fermè altos: foliis denfis, tenuiter incifis, virentibus, Ferulx $\Lambda$ donidisve potius fimilibus, chius flore etiam æmulos fed luteos \& maiores Calthx paluftris, aut Ranunculo propiotes, fuboriente confertim crebribus confluto feminibus pufillis capitulo orbiculato, oblongoque, Morum imirante, fimili eidé Adonidi,vel Ranunculo: In variis Hzlratix locis oritur, \& hor tis colitur. Iam veró fi neutiquan Hellebori vires habere vere tucntur \& profirentur obferuatores, non fit igitur Helleborus: fioret tame viretq̣uc Bruma, Ianuario \& Februario, vt Helleborus \& Ferula.

\section{SAXIF R AGI A Ferulacea Italorimn.}

Q V r d A s horti Italici, vt Vrbini \& Florentix, alebant Saxifragiam bicubitalem, foliis fcrulaceis, aut foeniculi,minus aut minimè geniculatis, tenuioribus follis, obfcurè virentibus: foribus vmbellatis, albidis, Mei , cuius videtur fpecies. Radices albicant, $\mathrm{Pa}_{2}$. finacx fapore.

$$
\text { S AXIF R A G A Anglorsm, facie Sefli Pratcofis Manfpellienfutm. }
$$

$A^{B}$ eximia dote in frangendo calculo, Saxifragam fcitè dixerunt Angli hanc plantant, pratis vd1s familiaren: folis foniculi latioribus, pratenfis Scleli ninuributs. Rud dx odora foris nigra, intus alta, $P$ eucedani facie. Flo res in vinbellis candidi : Tenen foncucu$\mathrm{li}_{\text {; }}$ caulis fefquicubitalis \& cubitalis eft: hac ftillatitiä parät muliercule clynice in Anglia.

\section{SESELI MASSILIEN SE, folio foraiculic crafiore.}

PAss I \& \& verè crefcit Mafsilienfe Se-

feli illis in tractibus qui Mafsilia AMuafextias ducunt, tranfq; Rhodanum in cta, via qua Roma Senami itur, propè collesoppidi Mörfuffone, vini optimi Mufcati commendatione, potoribus magis noti, quàm Botanicis ftndiofis. Radix illi alba, foeniculi effigie \& magnitudine, altè humi depacta , \& euulfu difficilis, quàm feeniculi odoratior \& calidior:caulem vtplurimùn fefquicubitü ferulaceú, hincindealis multis ex geniculis prodeuntibus reflexum emittir, pręd:ırum, rigidum: Folia pauciora, fed firmiora, craffiora quàm foeniculi, \&albida funt:vmbel l $x$ confert $x$ Anethi floribus candid 1, \& femine, Anifo fimiliori quàm foeniculi:gus ftu fuaui,acri, \& medicato, cuiufmodi Nei aut $\mathcal{P}$ anacis guftu, $P$ lanta illic valde nota, færiculi tortuofi noméclatura:fingularis

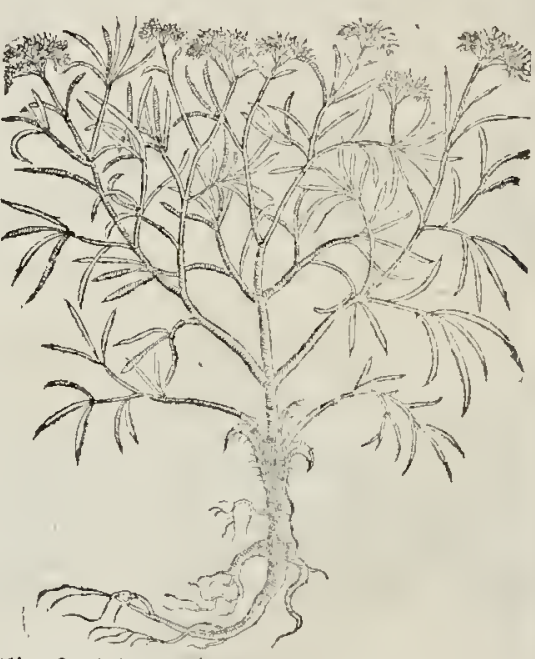
induftriz amicus Iacobus Rcinaudus Mafsilicnfis cinis \& Pharmacopous primus hane Lugdunenfibus medicis, etiamque Valerando Donrez illic Pharmacoposo, huilis cognitionis fuprà quàm dici queat confultis, miferat, ad Theriace exquifiá confccionené, cui etiam Monfpellienfum Doctorum inftituto, Rondeleti prxfercim, adóitur, cnius fepten tiā non raıò fequimur. Neque quantü illic locorŭ eft Marsilix circum funtranti, vilam plantā videre eft, qua magis quadret Sefeli, proindeç; hallucinantis conmétatoris TriAn flic Mon- dentinú Sefeli neutiquanı genuinú effe quit:quidverô fit, cimm ilie defcribere non aufus

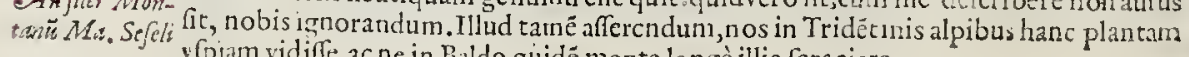
vpiam vidiffe, ac ne in $B_{\text {ald }}$ quidé monte longè illis feraciore. 
bortengibiboleraceo.

Ang. Sorrage, or Sperache. Bel. Sonacl crtut. Gall. Afperges.

TẼ E L L .z \& prinùù à fatione erumpentes holeraceorum germinationes Afpa-

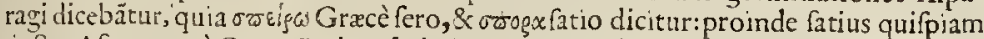
conicctet Afparagos è Græco Latinis deductos, pace multifcij Varronis, quàm quia exafperis virgultis le rerentur. Dux autem differentix, qualcs antiqui fcripferunt, paffin vul gònofürtur, \& in hortis feruntur: nam fpontè natæ potius gaudere videntur maritimis lo. cis: fed ea fpecies qua vulgaris fue altilis elt, depreffiora decliuioráq; pratenfia martima amat: iam ad nodum nota \& frequens primo vere $A$ fparagis punetin enicantibus, multis crebribúfy; tcnelis thyrfulis, caud $x$ Equinx quadantenus fimilibus, efu in aceta. rijs admodum quæfitis: aftęa poftea ętate \& 2 ftate, multis fruticant ramulis caules adulti, proceritate termin \& quaternûm pedum, denfffimis foliorum exulium comis Foniculi aut Anethi, flofculos edentibus oleæ luteolos, qui pariunt bacculas rotundas, Rufci duplò minores, pares frufu Ribe.

\section{CORRPDA differtabaliti A Aprago.}

E D crim Corruda magis mon. Stofis \& collibus ii deuexu \& affa tumaritimo delectatur, pcrperámq; à noltris Herbarum Doctoribus hodie cum Altili confunditur, cùm eademputatior: tametfirarior inultó occurrat,neq; enim Veneto traAni maritimo, Germaniæ, Gallię, $A$ nglixúc maritimis vifitur, vbi nihilofeci ${ }^{9}$ altilis frequés oritur. Facilis autem ì fuperiore dignotio, quia hac tota cä. didior \& rigidior eft, \& ranis diuari catis funditur per fepes. Folia acutiora, breuiora, \& magis in ordines fi pata: flofculis olex luteolis, crebribus, fubter alis enicantibus: \& femé illi, nó vt Altiti, Coralli colore, fed vbi maturum nigricatex vir:di,magnitudins alıquätó inferius, guod glo meratim proximè furculos adnafcitur:quas fi fcorfim fpecies gencricas vidiffet $\&$ obforuaffet Commetator, nec falfus ipre:nos fefelliffet,nec Cor rudam appofuiffet, non illius loco $A$ fparigumaltilem \& vefcum fponte erumpentem illi fubdidifet Is yuip

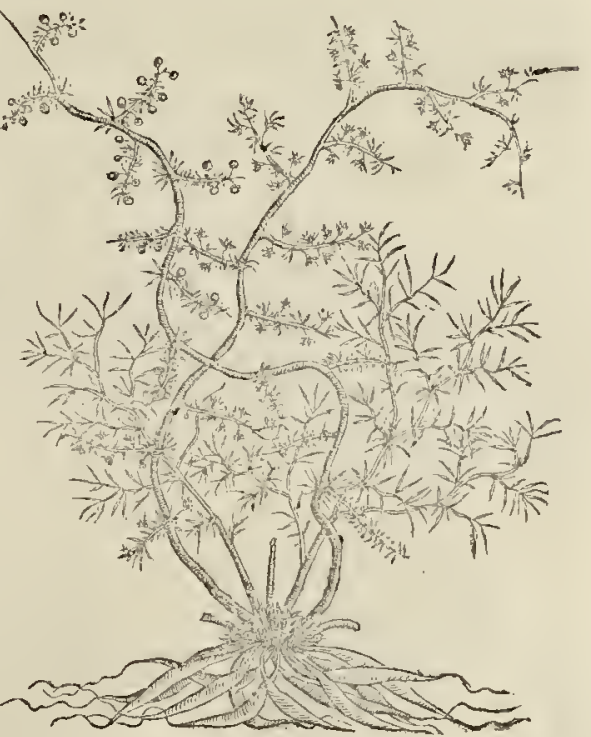
pe nulla re prorfum quam tranfplantatione aut cultu, à feipfo hortenfi difat. At cuid differat ab horum vtroque Corruda, fatis iam liquet, wbi Altilis \& maritim bacca coccinex funt:Corrudx auten ex nigro virides femper, \& Afparagi marini bacc $x$ multo maiores quàn Corrudę.

$$
\begin{gathered}
\mathcal{N} E P A \text { aprd Theoph. disserfa eft is Scorpione, quam inter } \\
\text { Cali collocatam oportuit. }
\end{gathered}
$$

HV c autem properatione non ita incommoda irrepfit Nepa:quippe cui fpinæ horri$\mathrm{d} x$ \& infefta, nomen commune fecerint cun Scorpione, qui etian ab fpinis punctim

$$
\mathrm{Gg}, \mathrm{ijj} \text {. }
$$




\section{STIRTIVM aduerfarianoma.}

tangenten fauciätibus dietus eft: \& frimiliter Ne- +4 pa vocatur cognomine ab animalculo caud $x$ ictu metucndo. Hancautem fermè indifcretx fimilitudinis effe cum Corruda prodidit Theophra ftus: qualem plantam paucis adhuc notam, nullidum recentiorum defcriptam: tum ub fui cognitionem, tum ad Corr ud $x$ collationem apponemus: non pauci enim funt, qui ad eanden quan Senenfis falebram impegertnt, rati Corrudam ni hil aliud effe quàm martinum Afparagŭ,pafim locorum prouenietem, vt fuperius diximus. Sed enim qui no:serit hanc, Corrude fimillimam dicet, non item Afperago: Eam nullibi pręterquàm in Prouincia vidimus, locis montofis vberéfruticantem, prafercim propemontium radices, qui Magdalenx celebri Fano \&x .pccui faneto n uncupato finitini funt, via qua Aquasfextias itur. Iig nex funt radices, nul tiplices, implexx, tenues: à

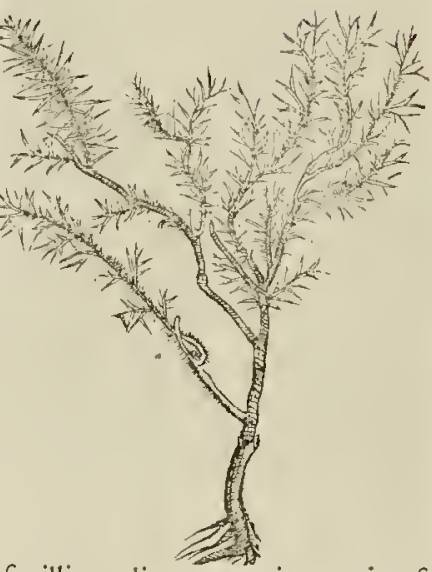
quibus mox or $x$ fpinulx, rigidulx, den $x$, Corrud $x$ frmillim $x$, al iquanto maiores, vnituerfa virgulta fummo tenus veftiunt, ficq́; tota planta denfis horret aculeis pro folijs:\& faciem, Corrudx prafert, guftu amaricante, Locis faxeis \& aridis, \& Stercllai montis decliuibus, ac propter argenteum amnen, Argens wilgo Galloprouincix dietum, multa.

CIYRIOPHYLLVM aut Maratriphyllums paluftre.

A F F r e s nomine plantas Militares, fue Diofcoridi dictas Millerolias, feilicet Semperuituifolio Stratiotem aquaticá, \& Filicifolım terreftem, ac Cumini fylueftris folıa quamlibet fuis alibi notis difcreuimus:à quibus iam hanc fouiculi foliam diuerfam agnofeere in procinctu cuilibet eft. Quippe quam fxpius reperies in leui agmine fluentibus aquis \& palufribus, innumeris folıorum capillamen'is exilibus, è neruis per xqua interual 1 pinmatim exeuntibus, teneritudine \& diuifura Foniculi pullulantis, aut Corrudæe, mollioribus, colore ex viridi fúco, mollicello, teneró qi caule in aquis fuitante : eq́ue radice exigua, euulfu facili, pallidula, lutea vmbella enicat, guitu quadantenus paluftris Equi feti. Quighic nulla de caufa Matathrü vocem difpungunt, ve Amaracum fubdant, gnauiter in nihil agendo, \& fibi moleftiom afcifendo, fudant:nec vident nomen à Marathro dedu\&um, monente ftirpis effigie 2 codiee.

\section{Migriophyllum Eguigetifolim Finuiatile.}

$\mathcal{F}^{S}$ r v D Diofcoridi partermiftum, medix figurx in ter Hippuridem \& My riophyllum aquaticum cxittit. Caulem fiquidem edit cauñ, friatum, \&r glabrum, duum trinumúe pe dum: Pofculis albidis, confertis, faftgiaturn, Vatturtij aut Cardam aquaticr fimilibus. Aquarum refidum \& riualorum vadofis inna fcicur lubens: folijs multis, flaccidis \& languidis, Huitantibus, caudatis, aut fetaceis, Equifeti, vel Millefolij foniculacei.

\section{POLTGONON Fomiza femine vidua.}

PR o p r E R crebras geniculorum cómifuras Polygonon diqum liquidù conftat, fic vul 1 gus diceret nultinodiam: propior tamen \& finilior hxc fpecies Equifetis, quàm mafculo Polygono videtur, natalibus, culmis, folijs, crebribus in genicnlis, per interualla fermè aqua exortis, tanta cognatione itidem vitium, ve non valde fit difpar aut mo dus, aut emolumentü veedi. Habet fiquidem ternos \& quatemos caules, fed letiores, glabros, neq; frijs afperos, reftos, folia angufta, lógiufcula, fefe per radiatos cxortus, \& articellor ü pixida tasinfertiones fipantia, Equileti, aut afperulx anguftiora. Radix albida, longius propaga$\mathrm{ta}_{2}$ \& de fe nonnulia gernina Afparagosúe promés, tener. Vliginofas cónalles \& quas riuuli 


\section{STIRPIV $M$ aduerfarianona.}

interluunt,ctepidines feetatur in herbidis ydis,ad cellam Noum Monfpellio excuntibus occlirit. Rara tamen illic \& nec multum alibi, nota: ficca \& aftringens valde.

HIPPVFIS.

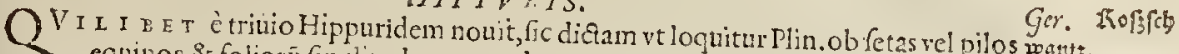
equinos \& foliorú fimlituducm caudx equin \& fatnrum marginbus, plurma ccocung. iueri vdis, humetubus pariter gaudetfrobibus Ital. A/perellu, tur. Equifctum iftud notius, culmos arundineris obuiu fit, \& in duplici diferentia cerni- Gal. Queue genicula tos, \& ficcitate firmores, detergendx om nigenc fupcllectili titos, initio edit, exiguis articulor floribus oblongis, rotundife, afparagi nougs per initia, \& racemofis in fummo donatos: Aing. Horfe fu ex vertebrofis, tim cinount multiplices exilium commifuris, quas in ambitu per intercapedines radialifs, Myriophylli aquatici coun lijs, Myriophylli aquatici conns, aut Equinam caudam fatis ementisntes. Minor interdum \& fpicatis donatur ramulis, comos, teneros, fummos, non clauatos, fed racemulis longis, CMinor fontalis HIP PVRIS.

PR o D r т \& iftud fubfillis \& fabulofis aruis, vti in Anglia paftemè vinis jpfis fcatutiginibus trans vindantem aquam etupens prepe Cafell Cary : eftétue fccunda Diofcorid. fpeçes, quã autores implicuiflc \& confundifte vidétur. F $1 t$ en 1 céo caule, crafficre, magis cauo, habitiore:per interualla carnofes exortus foliorum multo brcuiorun, albicantium \& teneriorun edente: radix nigticat, geniculatis articulationibus \& fibtis donata: viribus videtur impar fuperiori.

\section{An racemofa Equijetifacic planta fit T $R A G O S$ \\ vilTragonon Diof c?}

CErearem frugem multum acerofam Tra gon vocarunt, qua ratione nuncupari \& hane innuit Diof : cuius v triufuis origine vocis nequa quam ad hircum intelligas allufum, fed potius

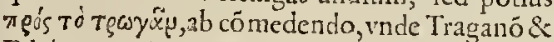
Edulen, \& Tragernata Bellaria Latinis dicta:Gal lis ctiamnum dragee. Sic in T rafi dolce $\mathrm{V}$ cronenfi, quia edendo effet, eadem vocis veltigia temanfe rüt. Elt aüt Traganos, qué hic rerum profitemur, fruticulus raritate \& elegantia in pritios cognitu dignus, nequedum vlli recentiorum metnoratus, qué primùn in fiticulofis arenis oræ maritimæ ad Ceti promontorij Agathëfis finus radices, \& finitimis aggeribus arenoils, inter mate \& fag num Lateréfem, tres quatuórve Lcucas Mófpellio diftantem, legimus, eiúfq; fruAtü, fiueacinos, quos hic Diofc. ¿́xyos vocat, ex granulis tritico parib" congeftis, ternis aut quaternis, mori Bati effigic,

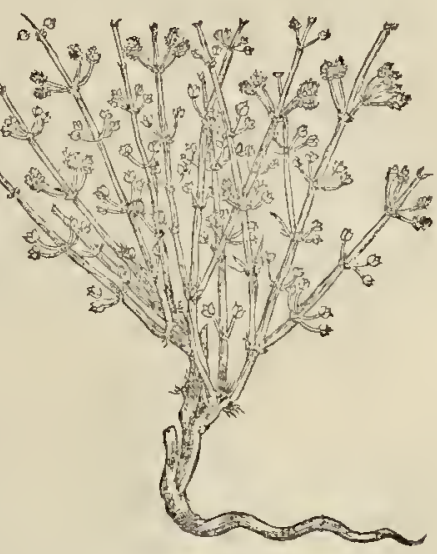
vinaccis aut arillis perçuàm aftringentibus, magna cum voluptate efitauimus: vbi vulgus pifcatorü \& naucleri accolæ, etiámq; ftudiofi Monfpellij Rafins de mar, feu marinā vuã vo cat. Luxuriatinibi tanta vbertate, vt ea plauftra oncrare queant. Folionum prorfum expers eft, farmétofis, gracilibus, copiofiffimis, \& confertis viticulis, iuncum, aut potius fpartum, partim \& Equifctum referentibus, ramofis comis, humi accubantibus, cxcraffiore, duriore, ruffefcente breui ftipite, arenof fuperficiei multis anfractibus immer fo, \& radici continuato, qux in fenos octonofúc pedes tortuofa excurrit, genicula rufta, graminea, 

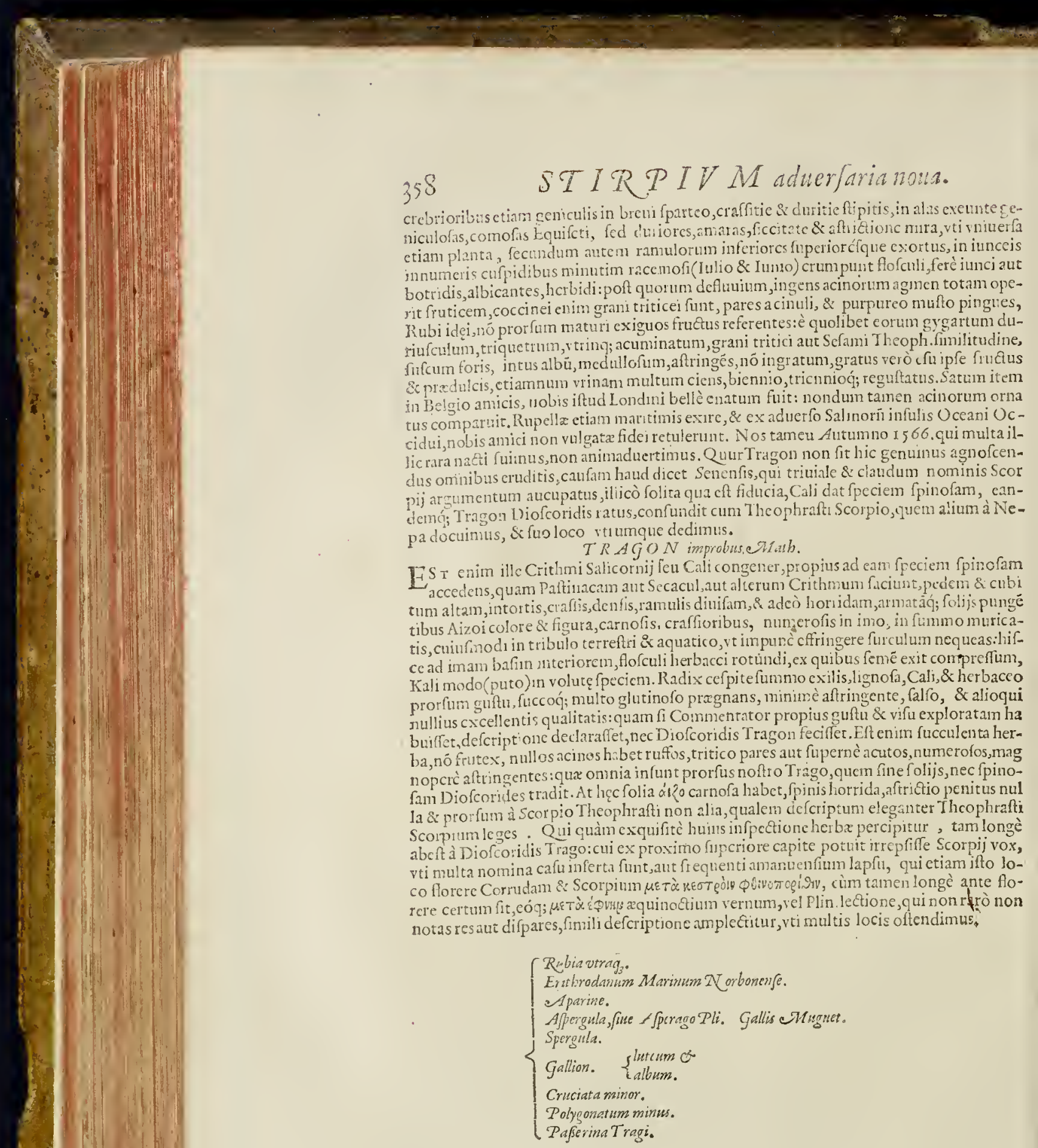

RVBIA viraque, Erithrodanum marinum. Ang. Mhadder. Gall. Garance. Zelg. Grappe. 
$V^{B}$ E r I tum prouentu,tum quxefu oritur \& colitur Rubia vbiuis locorum, prxfertim in Germania \& Belgiz Infulis vrbe dica, vbi radices prolixissimas \& numcrofas, Aexibus multis humi fparfas, rubentes intus, forísque Coralli nondum perpoliti colore: Ang. Madder erutas hyeme ineunte, menfe Nouembri, ficcatas trapetis fubdunt, confringuntćue, quo
commodius ad extera emporia compendii caufa venum vehantur. Infecturæ lanarü coriorúmve impendiò expetita, necnon officinis medicis notifsima : hre maior \& melior
vocatur.

Altera verò, vt minor, fic deterioris eft notę, minus afpera tota, cuius radices è ru-Sylueftris $R_{u b}$ bi bello in luteum languent, forcul nec luteo pallent, fed candicant, folia minora, nu- Minor. merofiora, geniculos frequentiores tadiatim ambiunt, cauliculofque triquetros, femine rotundo, prorfum maioris Rubix fimilitudine, vfus rarior huus,

\section{RVBIA MARIN.A Norbonenfum.}

PA v c I s locis otiunda fpectatr elegantiẹ pianta, quam non temerè nifí in Norbonæ Maritimis, \& fquallidis:fabuletis Magalonx \& Perats circüiectis reperies, nec conunodiori quàn huic loco referas. Radix pedem aut féquipedem longa,nuda, farmétofa, arida, rubra, Anchufe colore, modo,\& magnitudine: intus ruffet obfoletius cuiufmodi Iuniperi,aut Ccdri ramenta: graciles numerofóáne cauliculos ab imo furrçtos, teretes, geniculis crebtibus cinetos habet: c̀ quibus folıola Saturei aut Rubix minoris, tenuia, rigida, mucronata, fed incana, vt plurimùn quaterna decuffatim promütur, qua fuis axillis acerofos glomerulos foliorum pufillorú códunt,deinde fummis in cauliculis c̀ mediis iftis glomerulis forculi prode. unt ex herbidolutei aut pallidi, magnitudine Amaraci,\& lafmini modo oblongi funt.

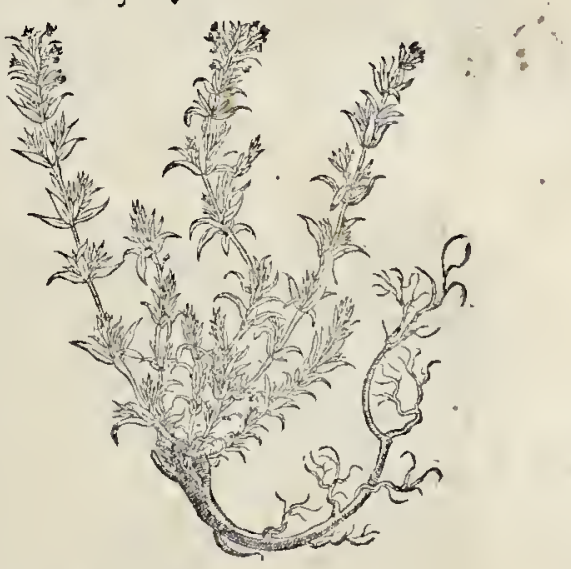

eA $P A R I N \ddot{E}$.

E R y t R O D A N I vniuerfo generi videtur congener Aparine:valde quippe funtlis, \& eadem penè fylueftris foret, nifi intercederet feminis difcrimen, tum etiam fabritia hirfuraćue cuticula caulium \& foliorum, yubus fefe veltubus pertinaci applicat hęfu vnde Philantropos, feu Hominis amans, vocitata fuit. Semen vero vmbonis vmbilicíve figuram calatam medio fui habet.

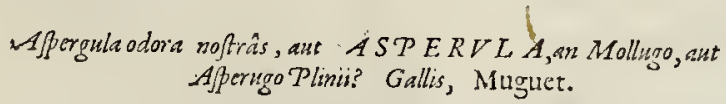

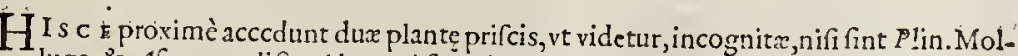
lugo, \& $A$ perugo dictz. Altera, Afperula vocitata, tamen non eft nifi femine aliquantùm afpera. Caulıculos complures quadratos geiviculis multis cinetos edit, circum quos ftellation foliola Aparine, latiora, magífue virentia, feptena vel octona funt: foréfq; exigui candicant in fummo, Valerianx xmuli tuta planta odore fuau cuiufmodi Lilij conu2li : femen rotundum \& nonnihil afperum. Rarò alibi qquàm in hortss, vbi odoris com. mendatione colitur, $G$ allis Belgis pertamiliaris.

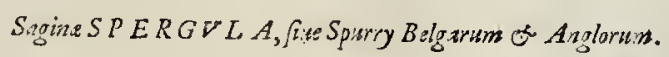

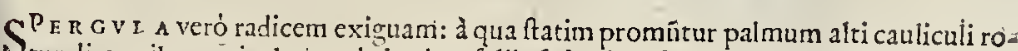
Stundi,graciles, geniculati, crcbrioribus foliis, fed exilioribus, circum in ftellæ morem ra- 


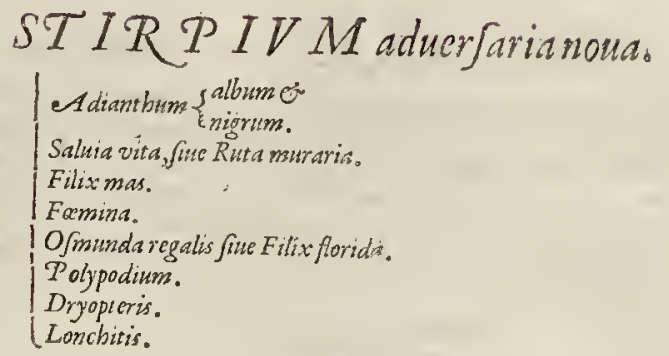

PHYLLITIS o Hemionitis.

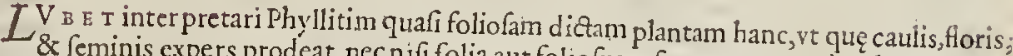

\& feminis expers prodeat, nec nifi folia aut foliofus cefpes apparcat: èradice namque multi s capillamentis fibrofa, nigricante, capilli Veneris, eriguntur fenx, octonx, vel déné frondes, crafliores, rigidiores, Vulgaris Lapatij cffigie, paffim viarum parictina \& fyluarí

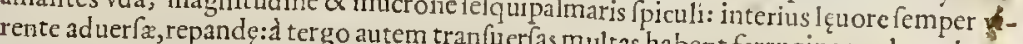
tim exiles Ineolas, aut liras extantes, ab ima \& latiore fui parte, plumatim fecus medium nenum digeftas, fummo tenus quà in mucronem Lapathij vulgaris,aut lingux oblonga fimilem deficit, vnde Ceruina lingua Officinis vocatur:quarenentiquan iam ambigitur, Phyllitim veram effe lianc, fapore exficcätenon ingrato, \& acerbo, fubaftringéte, mul ti ad fplenem vilis.

\section{HE MIO NIT ES fine fterilis.}

$S$ E denim parum adhuc nof citur nū ea qux à nor nullis recentiorum pingintur non item defcribitur Hemionitis, fit ne fpecicdiuerfa, ab vulgari lin
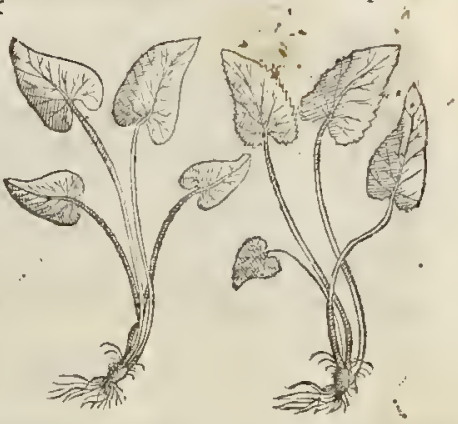
gua Ceruina dicitur, quam idcirco fecerant docti quidă Hemionitidem, frue tu dicas mu. lariam:quamuis eam mulæ depafcàtur:malim taméfterilem ditam, quòd feminis, caulis $s_{3}$ \& floris fit expers, cóq; perçuàm affinis \& germana noftrati lingux Ceruina nobis videtur. In quibufdam Iralia hortis eandém hanc, fed aliquantum loco latioré, diuerfant, me minimus, hortatuq́, quorundam Italorum fruftra hanc Romx quxfuimus, quo locinos bis indicarant illi in augufte anticuitatis ruderibus $x$ dium collapfarŭ, quas, etramnumo nacule Septe Sale, id eft, feptem triclinia, illic vocant . Qui fcif́citantibus nobis negant fe: funt enim maceriz tanturn illic $\&$ crinentom in vinetis vicinis Hemionitidem vidifuido minimè alendis plantis, nedum Hemionitidi, dintz moles aridiffim $x$ a prx fole fer quàm fedulo A nguillarx, qui nos idem quoq; d, aptæ. A ttamen nihil difitenutr viro per buiffe, fed ad eo ob curis, qui idem quoq; monlierat:nempe plantam indidem fe halingua Ceruina. Nec enim minus fibrofam perparum aut nullatenus differre viderctur à vel fuperficie harentibus, huic ineffe: folia radicem nigricantibus villis, fummo cefpite obliquis lirisalterius fimilibus: bafin tomentem anerfis exarata declinibus lineolis, feu lum fal catam arcuatanúc Volubilis modo. latiorcm habere \& vetfum circumg; pedicu cidua, ad rupes antrofáfót: cautes $D$. Vinodo. Hæc ille. Sed aliquot annispòft, in Anglia ocBriftoia, vberrimè luxuriantern quandamcentij,vno aut altero miliari ab vibe peramœna ternis quaternifúe folijs, minoribus multó: vi lingux Ceruitıx, plantam, inuenimus: fed dine excedunt:minımè craffa, aut rigid, alias plantas capillares, alioquin te rigida, fed mollicella, quafi Achanthi veri, inter quem \& 


\section{STIRTIV $M$ adwerfaria nowa.}

turis afpetata, ad mucronelaterimbus vtrinq; ad mediú finuatis, \& redu\&is: bafi latiore, lunata: Cermento quafi vtrinq; interius recuruo. Londinum in hortis plantandos cefpites mifimus, fed parum diufuperftıtes fuerunt : adeó namq̧; tenuibus cirr is radicis, \& folijs de licatuls iniuriz oportuna eft, vt vix fe attrectare citra lacerationem patiatur: guftu tamen neuticuam à lingua Ceruina alio eft. Hanc nonnulli Flandri amici, quibus dono mıfimus putarunt effe aliam fpeciem à Phyllitide, nec tamen effe illam quam depinxit Mathiol.

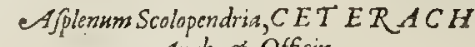

SEM E E item rullo oritur aut donatur herba Afpleniü dicta, nataq; Spleni iuuando, quam etiam fignatiffima \& perquàm fcita collatione docuit Diofcoricles folijs donatam effe finilibus Scolopendrix, infefto animalculo, quod lumbricum putidı literatores, cum ron nouifent,aufi funt Ceterach negare, aut lapfus Diofcoridem infimulare. Iam vtrumq; notius, quàm vt pluribus opus fit, etiam vniuerfę occiduę Anglię, quæ fcatet Phylli ride, Hemionitide, atque Scolopendri.

\section{$L V N A R I$ A racemofa, Ceterach folijs,racemulis Ophiogloji.}

TPER E E G A N T M hanc antiquisindietam, recentiores Lumariam vocarunt, à folio-

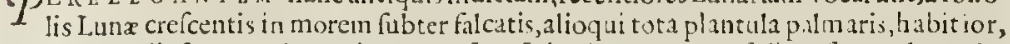
crafitie rigidiufcula, Scolopendriun prefert:fed vnicum tantum folium fert, colore, violat $x$, gemina acic vtring; quafi fecuriculis vnd tis lumatum, c̀ medio caulicula Ophiogiof fi tenello:qqui furrectus, fummus ramofum forem edit, A inbrofix, aut Botridıs cónexione, quadantenus O phioglofi, quam ipfo afpectu \& facultate eximiè vulnera ferrumiundi, vlcerać; \& luxata cogendi, vel æmulatur, vel fupcrat guftu praficca \& aftringens. Ericeta ftrigofa, fteriliaque montofa amat: è Mindenis iugis etiamnun habenus, \& poftremò in Anglix collibus, qui Grennici Regijs ædibus, \& Tamefi inmunent, fatis multü reperimus.

$$
\text { Ophiogloßs fue Encapbyllum. }
$$

MV r t o frequentior hae, fed aliquantò minor:cui foris argutula cufpis, lingulam fer pentis exercam im itata, O phioglofi nomen impertiuit apud antiqguos, \& noftri herbarij Lunarian dixerunt. Pratis \& quibufuis, in conuallibus familaris, nec parue ad vulneraria prafidia commendationis: perquàm exili radice, tenella, , tenerum cauliculum promente, cui fingulari fingulum folum oblógum, Pyrolx, tut Cochlearix,craflufculü, ex viridifubluttre, aut pallidum infit.

$$
T R A G I V A \text { alterim SCOLOPENDRI folimir. }
$$

NI M I Q V A M anxiè multis abhinc annis Aloifum Anguillariam, materix medic $x$ callentifimum, modeftıimumq́ue, Ferrarix conueniebanus, de Lonchicide, Scabe, tertio Dofcoridis Diftamno, iftóq; Tragio, fentétiam eius rogaremus:qui cùn multa alia doctè \& amicè nos moneret, tum iltud Tragium fibi non femel vifum Scolopendrix diuifu ra, hirfuto folio, radice albida, interdum Drabz-nonnihil tuberora, \& nonnihil Rapuncit lum accedente, non procul à Pifanis montibus. Nobisć; literas dedit ad cuendam per bonum \& indufrium Lucenfem Pharmacopceü: qui tamen plantam neq; ipfe potut, neq; quifquam alsus, illic quo loci effet, indicare. Tametfi balncas aliáque circum loca, \& $\operatorname{ran}$ dem montem Dui Iuliani Pifas \& Liburnan vfyue tranfmiferimus. Neque ex eo tempore vllum contigit audire qui viderit:aut aliam videre, qux planc deferiptioni feceric fatis. Lunariz ctenim minori hircinus deeft ad or, radices exiliores infunt :Lonchitides auté non mağ 1 huic, quàm nó fuo quadrant capiti. Quare ni potiora fefe affer $11 t$ dun ad vmbilicos properamus, hafce in coniectauea noftra fyluamóue amandare, ccitun eft. 


\section{STIRTIVM aduerfarianom.}

A D IANT HV M, fure Capilitus Vencris verus,

$Q^{n}$

VI

rz precium non vuigare erit, propter iftos rabiofulos \& prolixos comnentatores; qui dum rabie Cerberea ad Dryphada fe mutno profcindut latratione, nillil llited guam tyroucs nos, noltrofque commilitoncs, hre noícendi perquàm abidos, torguent potius quàm docent: $v$ t quibus fortè feripturicntibus non res ipfix prx oculis, ear unve cogultio, fed potius oftentandi deciamandi juc in anmo ambitio cffet.

Primò Adianthum verum Diofcori multibi quàm Norbonenfi tractui frequentius, faxis \&̈ ricuis vmbrofis petroff́çue, Veganio, fterilis Seucni finitumis, ac rupium, fontium, \& putcolum labris vel afperginibus Monfpellii Namaufiḉ;: rarò alíbi in Gailia, Gemania, Bckgin,\& Anglin,ant nutquam pronentt: quitu ne Italix quidem locis multis, aut multum videre men?!nibus; duntaxat quibufdam in puteis Riuoli vrbis Pedemontanx 1 egionis, idǵue perpaucum: fibrillis vciò capillo fis, pl uf́culis, fufcis hreret, vno omnes amplcxu aperis, ynue panduntur mumerofi cincinni iuncéve loruli pratenucs; prolix:or:bus fed tenuioribus quàm Trichomazes ftamaibus, pul

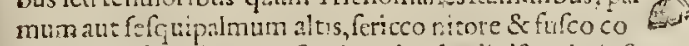
lore nitcrebles: colta Anifi vel Coriandri diuifura, latiuf-

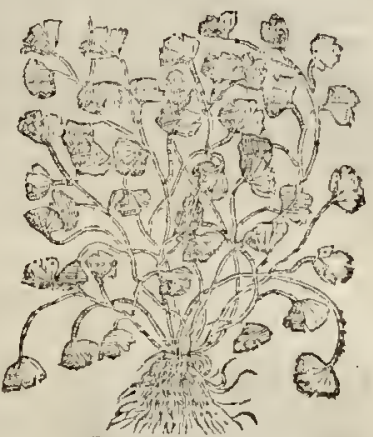
culis alterno fitu cirrulis appenfa, penc wrum pra tcinistatc falfentibus, tenella, rtrinque later bus receis claufa, trianguli foccic; fó fupernc̀ ambitu laciniato \& circinato. Hę omnium prattantifsima, que indidem L.ugdunum, Iutctiä, Antuerpiam, inć; cốtera Emporia cclebriora afportatur, caroqúc à Seplafiariis cmitur, al Capili Veneris Syrupi diEt apparatum. Galtıx ditiorcs \& aulici Ǵbi curant non rarò Mónfpellii conficiendun, indéque adferendum, quo recentiore, \&i prafentiorc viantur: mirumenim quantsm thoracis affeetus, hcpatis renumg; iuuet. Immadidus, ven fpecies cxtere, in aqua perffat incrfus, quaf fuis efict in natal:bus, 8 tamen ficcius creditur, aut potins ambigitur ab illis me. ritò, qui ex huius exprefía libra beffon ferpué fucci promanate afferunt.

\section{TRICHOMANES, Palytricun.}

ZJI I I V S \& fapore proximushuic Triohomanes, \& Polytrici nomcaclatura officinis non confuetum minus quàm cognitum: vbique Belgix, \& Angliz parictnis, glareo. fifógue opacis viis vberrimum, radice fibris nigricantibus comante, crafsioribúfque \& breuioribus capillamentis, fufcis, nitidis, rigdiufculis, gcmina vtrinque foliorum feric, Aftragali Tribulive terreftris amulis, ex atro aduerfa parte virentibus, fubter veró macli. lis ferrugincis fignatis.

$$
\begin{gathered}
\text { ADI ANTHVM ALBVM } \\
\text { ON nigrum Plini. }
\end{gathered}
$$

PL в R e Q E omnes Batgix, Gcrmanix, Bưrundię, Prancia, Sabaudiaćue officinx, non modò hoc zuo, fed etian ab omni memoria Adianthi duas differentias hafec habucunn ; quibus femper vfe funt albi \& nigri Adianthi vocabulo. Radix pufilla, filamentis crebribus compaeta, atris, rectis, crebribus iunccis,paulò crafsioribus \& prolixioribus quàm Trichomanes; exhcrbido pallentibus aut albicantibus: foliolis vtrinque \& altrinfecus plumatim dif́ritis, Filicis maris diuifura \& fitu, fed nultò minoribus,

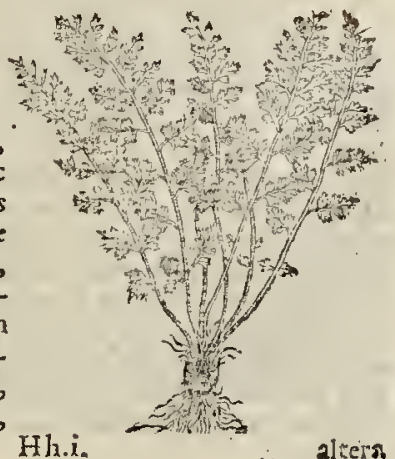




\section{STIRPIVM aduerfarianoua.}

altera facic virentibus, altera in glauco punctulis rubigincis feries geminas habent, fefqupalmum eóque plus alta, lixc alba, imò vtrąue, quę nihil planè differunt:qua nigro Adiantho cauliculi neruulive nigricant politiore nitore, foliaçue funt faturrore virore, vires cxdem prorfum, quas etiam doctis multis, nedum nolis, cxploratas fcimus ad quotidanas \& confuetas potiones multis annis, magno commodo, nullo detrimento. Vttandem conuciari dedifcant ift tenebricoli commentatores, yui hafe Dryopteres virium rgnoratione autumant : nihl cnim acis, neduin caiftici , bx innoxix capillares habent: nam Dryopreridom alıarn efic fcimus, \& fuo loco dicenus.

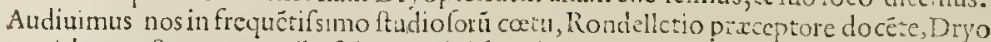
pteridem noftram nonnullis fuis agrotis (dum in Allobrogum ad Thodanum vrbibus factitaret medicinam ) exitio fuife ob Pharmacopoorum flagitiofm infitian, qui non parum Dryoptcridis Potiunculx medicatx loolipodii vice mifuifient : Hafce proinde, coniectura certaducti, PInio menoracum vtrumque albun \& nigrum Adianthum, foliis Filicis, imíque cauliculis fúfis \& âperis, ar bitramur.

\section{Herbariorit S ALVIA VIT A, fue Ruta mitr wingnoneft Pororychia Difc. Belg. Sorrit liapti.}

NV I I herbarum tribui cognatiori quàm buicaccenferi giat, en quan plebs, preCertim Batauorum, \& mulierculatum clinicarum in Gcrmania, s.luam vitam, fet

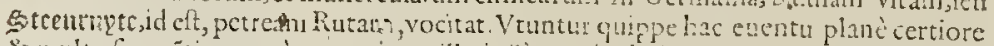
\& multo frequétiore, ciàm quauis capillari. Cum enim huius copianultafuppetat illis, fi quando pra hyeme cá icrarum vlla defir aut victa fit, hanc fubdunt etiam Tharmacopoicxercitatiores : quibus nulla vnquam calaniftrata oratione vllus perfuadebitcó. mentator effe potius Paronychiam, quàm cì Adiarthis ynam, lifdem enim inter Ceterach, Adianthum, Polytricum, cęteráfque capillares, locis faxcis Iubcns prouenit: pufillaradice, cauliculífgue tenuibus, non ita difsim:libus Adianthi, cuius foliolactian non parum refert, fed minora huic,crafsion, \& incifuris pluribus atque altioribus.Palmum vix eqguat tota, \& albicat colore pallido rutacco, ad Rutam accedente, nonnulla etian folorum fimilitudine, vnde nomen vernacula'n Ruta. Caule demim, flore, \& femine orba,yti cateræ capillares, guas prorfum exprimit guftum confulenti: vndecommodipetendi conięura fuit, ad tufsmomfeftum è vifcerum vitio atque $\mathrm{Hy}$ -
dropes.

\section{FILIX MAS, O FOEMINA.}

SGerma. Walofarn mennle $\pi$ meiblitin.

¿Gal.Fengiere mafle, \& femeile. \{cArg. Forne the male and form.

F I L I c is tametfi ferilis plantx, nullus tamen trafuss paulò incultior non fer acifsimus : adeò namque viua, reftibili vertate luxuriat, ve ctiam sole ferudifsino \& Syrio vicinis encetis plantis, tamen ipfa non marcida perfet. Diftinetę autem funt, \& trita cognitionis mas \& fermina, vel ipla mtégodcs Graca voce (quę crpanfe ala etfigiem 2dumbrat ) Earis indicante: $M$ as quippe crebriores, c̀ radıce crafsiore, nultis cónoluta\& implexa appendicibus, emittit prolixiores, bicubitales, vel proceriores pediculus, plumatim folıofos, alx figuram, inde nomen, cxprimentes. Fơnina verò vnum fxpius promit caulem, nudum, multis diuifum è nedıo ramis : minore radice, digitum equante, prolixè fparfa, nigra foris, in qua non tranfuct fo ductu, fed calamatim incifa cernunsur quali cmblemata, effigien aqgila, aut fimilis alitis, alis \& cruribus expanfa, affabrè mentientia: quan Aquilain plebs,aut ei fimiles quaten Ciomiftx iaćtität. Vtraque feminc nullo oritur \& moritur : tametf rudinentum quoddam fominjs edant puluerulenta foliorum fimbria, rugofe, \& ifta atomos admodum exiles, tcnuifsimis arachneis filis, de fummo Filicum ramo pendentes, pafsim lilicis fominx femen dictitabant, \& piebi perfuadcbant : quæ non facilè quid vtriúque folia diftent, difer-
nere nouit. 


\section{STIRTIVM aduerjarianona. \\ Recentior um OS MVND A Filix floridat, luteolis fute foofulis or racerrofis ligulis.}

M I v s verò nota Italicis Gallicífue traçbus meditcraneis ofnunda, Filix diq Regia, regijs fanè ac prxclaris viribus. Mulia hęcin $P$ iftauinm nemorofis fyllis. iténgue Belgio \& Angla plurima. Maris Filicis radice quafi coftis compada multis, \& folijs ijfdem, fed nentiquam crenatis. Caule ftriaco, quem bicubitalem folia nonullatarfum 2 lāve imitantia :quis ex interuallis ftipant, latertinq́; cmittunt palmates \&e fefquipalmares thyrfos, \& for ü ligulas oblongas, denfis racimulis, Lunarię \& Ophiogloffi rmulis, aut potins Tamaricis Norboncnfis nuper erumpéti,qux ex ferrugineo fucefunt, inćue cariofum \& puluerulcntum fitum fatifcunt, feminum fpeciem aut fpem oftentantes. Radices autem amplex $x$, \& tóruli complures coltis fimiles, fquamatim fibi incumbüt, ad Hernias, ad vicera exploratifini commodi. Quinetian colicis \& fpleneticis plurimin conferút. Nonnihil calida eft, \&r a cris guftus, odoris non ingrati

$$
\text { EORUTódloy TOLYPODIVM. }
$$

EI v SDE M claffisfunt Polypodium, Dryopteris, Lonchytis vtrar, ac Polynodium aui Bel. DocBm ba

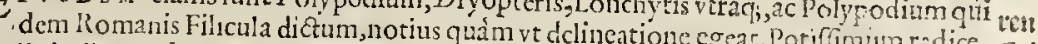
prolixioribus anfradibus, nodulis acetabulifo; donata \& flagcllis?olypi pif́cis fimilibus, Gal.Polipode, cuiufmodi ferè coralli albi funt:craffitude digiti minini, anclis ?olypi pifcis fimilibus, aitringens \& fubdulcis, querna præfertim hac, fola in viu, in tus porraced, guflu nonnihil cilo cilentius nacta folum, gracilior, trigofiorçue fiat. Sic ctiam quibufdam opacis nemori bus paululü folio eft adultiore, ncutiquam tamen fpecie diuerfa, ve fruftrà faciunt quidä.

\section{DRYOPTERIS, aut guerna Filit.}

HA s c de vultu \& dequercu Dryopterim, Filiccm quernam dixcrunt: folia huic Po lypodij funt prorfum, ant filicis Fomina, minora nulto tanê (nó minoribus lacinijs) delicatiora, tenuiora, $\&$ tencriora: exilibus Iuncis pedem altis plumatim foliorü exortus ex aduerfo exactè gerentes: auerfa item folia,notulis afperfa, non cxtantibus, rubiginolis, fed candidis, ap- ys pictis, ferie gemina, fecus folij ncrulum medium. Radix verò longa, variè inflexa, hum decurrens, fuf. ca, fübhirfuta, \& villic -irrífvefibrata, Polypodij(nifi quia gracilior multó)perquàm fimilis. Hinc anfa Pharınacopois minus perıtis erroris ple etédi fuit, au huius radices dilutis decoeis sq́ue mifcuifent, à medi co inftitutis, rati Yolypodium hä́c effc: qua exitio fuit agrutis, vti fuperius in Pliniano Adiantho monui-? mus. Radici fapor acerbicr multò quàm Polypodijs, non gratus, \& ficcitas nonnihil calida, cuiufmodi in Tormentilla apparct, fed huius exitiofa.

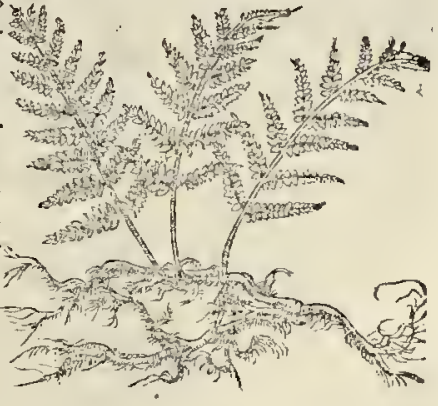

\section{IONCHYTIS prima:}

A TRtangVia SEM NE, CVSPIDE, LAN CEOL av E inucrone, dictafuit Lonchitis, fed hactenus ignota prorfus illa galericulata, qux mitum quatum torfit \& tranfuerfos fui defiderio egit animos veltigatorum melioris frcigis, Guinun, Marantham, Anguillaram, quin vel Commentatorem ipfum pepulit ad Montes Itälos, \&

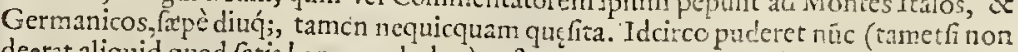
decrat aliquid quod fatis bene quadrabat) noftan tenutatem, multum impendio minoreın, quafi foliciorem aut diligêtiorem, llius Heroicis conatibus intempeftuè prxferre.

$$
\text { Hh.ij. Yerumi }
$$


is altera afperáve nuncupata, quæ Polipodij folijs minoribus, tcnuioribus cifis, palmos binos alta, pufilla Polytrici, Cetcrachúe radice eft. Locis nemoro currit, vti nobis in Anglia, Bclg:o, \& Bafilex, prope monté arduñ, vno ab vibe mulcoli apiculi, vermiculorum in modum, præfertim prouefta $x$ ftate, émq; \&fpeciem dant foninis lutcoli \& racemofi, Olez fermè:tametfi fint euanida rudimenta, vti Filicis.

\section{$C A R \mathcal{D} V \mathcal{H} \&$ Acanacea.} vetcribus. Quare lubuit, fi qux poffent ad antiquam cognitionem referri, ita expcndcre, vt interim alias complures fpecies \& varietates indifas ncutiquam tranfilercnus, coque hanc recenfionem feorfim aufpicari \& digerere commodius duximus, quàm Sonchis (quibus cum tamen plufculum fimilitudinis fortita videbantur) fubnectere. Sunt quidē vtraq; fpinofis folijs, latis, \& ferè holeraceis, fed Carduis ful generis peculiare difcrimen ftatuunt capitata muricataúe cacumina, vnde Acanacca dicta fuerunt.

Corduorums frequentisimi, hi funt.

Reriores funt.
CAcambiun maius, viarum.

Acanthus hartenfis ofyeftris.

Scolymos viraq, ine Cinara.

Sylubum 2eu Cardwus Marice engentatus.

Calcitrapa fue my acanthos $T$ beoph. vel Ruell. Tribulus ex Theophr. Atractylis, fue Cnicus fy'lueftris Galeni, Pauli, T heoplor.primus. Cardurus bonedactus, fue Cricus fyl. fecundus Theophr. c.t Ruclio putatus.

Crocodilion Fufch: Ritro, Jeu Rutro T beoph. Anguillare, fen Echinopus Gefneri. Carduns peregrinus Dodoniai. Afrone Anguillara.

Acontbium Illyricum.

Chamalcon $\}_{\text {niger. }}^{\text {albus, }}$

Cramaleon non aculeatus Theoph. Fou Carduns pinus Mon/pellienfurs. Spina alba. Arabibus Bedeguard.

Spino alba nltera Anglica.

Spina A Arsbica, Mauritanis Sucaba.

Lencacantha, radice (yperi, an (hamaleon niger Monfpellienfum?

Eringium \{cAlpinum carsileum Genenenfe,

Montanum,Illyricum or Italicum.

Chameleontha Monjpellienfum.

Scolymos Theophraftts (eu Eringiwm luteum Monfpellienfum.

Spina Solftitiales, quia Solstitys poft Jectas fegetes in Norbonenfa agro, infeftis muricibus totos operit trectus,

Picromos, feufrequens aculeata parua Solonenfis Crete, vulgo Crau. Carduccllues d racices montis Lipi. 


\section{STIRPIVM aduerfarianoita.}

[Echinomatocactus Terenianus, magnitudinc of off. gis

Aselonis, vallatia Julcata, frrats.

Hippophacs Hippephofion.

AK xvoloy. $A C A N T H I V M$.

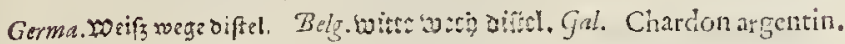

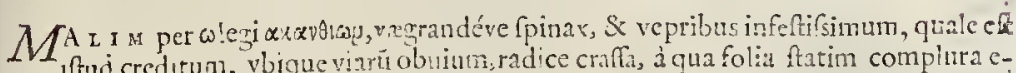
${ }_{1}$ tud credıtun, vbique vimú obuium, radice craffa, à qua folia fatim compluta emergunt magna ferrata, in finu lanugine obducta, \& aculeis horrétibus donata:caule cral fo, \& itriis, fpints, Echunato capizulo, friminibus purpure:s referto, \& refertis fentibus armato, femine Cnici, fel comprefsius, Carduo Mariz non abfinili. Hxc folis vtcumque accedit ad Carduum illum Bubofum, quem Lencacantha conicetumus.

$$
\text { ACANTHIVM ligiusL. }
$$

SVperiortevs annis indefefsi laboris Pharmacopous fingularis amicus nofter valenandui Dorrez Fiander Infulanas, ex Sciauonia rediens, huius femé attulit, \& Lugduni in Gallia feuit,vnde miræ altitudinis Cardius foliciter adoleuit. Folia Acanthi magni, vel Sylibi maiora funt; procera caulis fpinofinalta hominen duobus tribufque cubitis fupeat:capitella Acanth amplum, foribus ltipacü pupureis fert : femine Cnicl farctum. Vniucrfaplanta magnutudine [pecie m prxfert arbulcula, \& a adeò aculeos quo quò verím protendte, vt uullus fubter impunè tranfmitere pofsit.

$$
\begin{aligned}
& \text { ACANTHWS SATIVWS G Sylneftris. }
\end{aligned}
$$

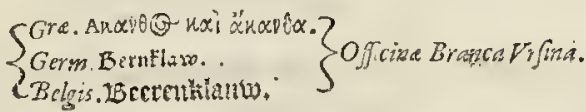

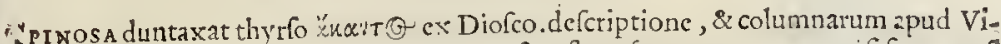

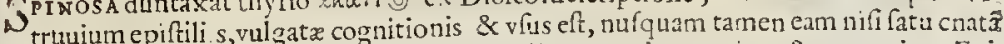
vidimus, prxterquàm inter oliueta Mófpelliëfibus manis proxima, \& exeunti ex Ägidia porta, inter fontem \& riuulum, prope murum, vbi Pharmacopoi colligere folebant ad xnemarum emollientium decotiones, cui folo vfui duntaxat etiannum in hortis fatium habetur :nihilǵne differt ab illo, nifi mollicie \& magnitudine. Videtur Galcnus, aut eius amanuenfes, quas facultates Diofcorides $\Lambda$ canthio attribuit, $A$ cantho huic afs gnafe: cuius tamer, vel diurno \& diuturno vfu tefte, radices emolliunt, vninerfácue planta muccaginofa eft. Et vbi interpres vertit luxationes, aptius diceret torfones, ligamentorúmve tractiones, cui medentur, initiò fuavia malactica dolorem fedando, \& leniter digerendo, fi quid doloris appulfę parti infuxerit. Nam luxatis artubus potius oberit, fractis \& conuulis proderit.

$$
\begin{aligned}
& \text { Kúvagx. SCOLTMOS, feu Cynara, Cactos Theophraft. } \\
& \text { Germa.errobiloon. } \\
& \text { SGallis. Artichau: } \\
& \text { Betg.antici)aits. }
\end{aligned}
$$

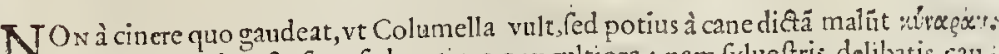

Hums compluria vefa fune, fed gratiora qua cultiora : nam fylueftris delibatis cau. libus teneriufculis, \& capituls no ndum in fores erumpentibus, vti afelli, vietutant etiam ruftici Itali. Cultu adeo adolefcunt \& tenerefcunt caules \& coni, vt gulonibus etiam tra. gemata mnimè fpernenda fiant. Nec funt Cardui illi, nomine Cactơs Theophraft. aliud quàm Scolymi, quorum defcriptiones, vires, \& mangonia iamdiu notifsimafunt. H.iij. 


\section{6

SCOLYMOS STLVE. fris, fure Chameleonthit Mon. pellsenfinm.

O VAN T y squantuseft, fpinis re fertus eft ille, vfu,quàm nomine celebrior, Carduus fylueftris, coagu latorius, Norbonenfi agro plurimus:quem, quia tota facie Scolymú refert acule:tum, Cinaram fylueftremappellamus:Hoctantim interelt, quod foliis anguftioribus, aridioribus, \& nultó denfioribus fpinis fit. Flores item eleg ınti pur pura multi,conferti lanugine; quibus coloni, ancequam in pappos abeant, decerptis, lac coagulant, nul li viui alii illic feruit: tametij non infuauis guftu, nec abfimilis Cyna. ræ. Capita altero tantò quàm Sco lymominora. Semine Cnici, com . preffo, aut Sylibi. Chamxlcontha vocabant praceptotes noftri.

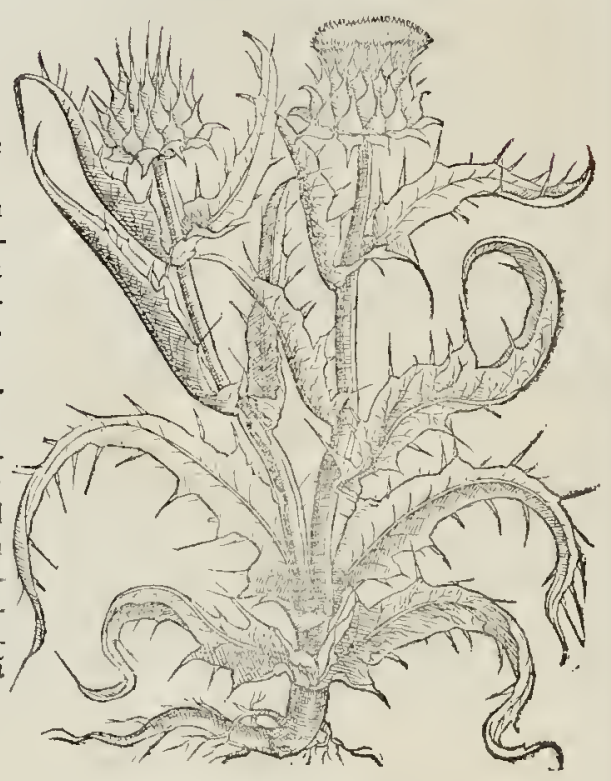

\section{SCOLYMOS THEOPH. Fen Eringinn lutenm Monspelliensum.}

SE D Theophrafti Scolymos haud parùm à Diofcoridea abeft, vt facile animaduertere Se o y os eft exvtriufque lectione, \& illius plantr infpectione, quam Monfpelli Eringium luTheoph dinerga teum vocant, illiufóue loco monnulli fufficiunt locis à mare remotis. Frequens hæc locis a Cyara ci Ca maritimis Norbonx: radix pollicen xquit, magnitudine Raphani, fed fuluefcensfuc870 . co pregnans lacteo, vti Dens Leonis, cux cruda vel co\&ta eftur à nónullis: numerofos fun dit caules bicubitales, in ambitu circú fparfos, folits obduetos, ciulem ambiétibus, que in imo maiora funt, longioríque, viréntq; intenlo virore nigricäte, \& maculis lactess paffim imprefsis:adeo tota horret aculeis præduris, vt quà arripias, nefcias. Cinare conum profert, Nucis Mofchata magnitudine vbi fores luteoli, non Cnici concolores, fed fio miles:Semen compreffum lquamis coni coercetut.

$$
\begin{gathered}
\text { SILYBVA, CARDVVS Marix, O Ladeus. } \\
\text { Germa. Mzaryen diftel. Belgis, Onter vęontur oifel. } \\
\text { Ang. Our Lady thiftell. }
\end{gathered}
$$

LA c т e o Carduo, vel Marix dicto,adeò folta Chamxleontis albi fimilia funt, vt non parum multis doctis perfuafum fuerit Spinain alba effe, quam illi afsimilat Diofcorides. Sed quia feueriores animaduerfores, folo magnntudinis arguméto, inficiancur, [al tem, puto, pro Silybo non refpuent, quæ lata fpina proditur : cuiufnodi eft Marix Carduns, foliis pregrandibus, latis, fpinofis, tnaculis \& ductibus lafters, crebribus, afperfis, viridibus. Caulis bicubitalis, craflus, fpinofus, \& echino donatus, foinis cineto, puppreo fo re referto:femen Cnici comprefum, lapidi exterendo optimum, etia mulievcularu experimento. Inum caulem pullulanten delibatum, \& radicem in acêaris aliâs cfitauimus in Italia, ybi rifum Getmanis mouimus. Plebecula mulierculatum copiam lactis 


\section{STIR P IV $M$ aduerfaria noua.}

lius e fu prouocat. Dodonęi fedulitas, vt multis aliis locis laudanda, ita plerifø; minus té. peftiua, vbi ignotis plantis facultates certas afferit, quas è Diofcotide accepit, magno detrimento xgrorum, \& experimentatorum, qui quod videut il viro bono, \& veritatis anico fcriptum, illicò ve verum arripiunt, \& per experimenta mortes agunt. Sic virpius \& eruditus Turnerus Anglus, in fuis herbariis Alphabeticis Anglicis.

\section{Herbarionum Carlina, é varietne, non genere duplex, non of Leucacautia, fed CHAMALEON ALBVS, Diof.}

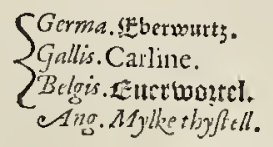

PL E R I Q Q E omnibus officinis perfufum eft duplicem effe Carlinam:quipp-quam gummi fubfaum verniculofum, nomnhil pellucidum, odore virofo guftu $\&$ vifufy; plorafient- demumǵuc eadem adice \& forelucidum, odore virofo, guftu \& vifu ex- IX IA. plorafient - demumq́uc eadem radice \& florecaule donatam, alias verò caule carendonatas, obfruafent, voleutes fenten enatas, partin caule viduas, partimq́ue vtroque donatas, obferuafent, volentes fententiam mutafent. Id́ nos accuratè expendimus, non proculab arduo \& gelido dicto D. Bernardi monte, atque etiam via qua Ifbtitgo itur THEOPH. CHAMALEON non aculeatus, interdings
acaulos, alsís caule donatus.

$S I$ c videas $M$ onfpellio finitimis locis glareofis, in ter Cyltos \& cocciferas Ilices Carducellum foliis Scolymi non aculeatis, radice nigricante, digiti pa:ui crásitie; cuius caulis palmum, fefquipalmun, \& pedem altus, linibum fert intus florum, multis purpureis aggettis \& collectis ftaminibus, foris fquamulis lucidis, albicantibus, fibi imbricatim incumbentibus, complutum, vifu pulcherimam Hunc fapius oly. fculi itudio í cómilitones inibi copiofum colle pimus caule carentem, \& eoden donatum : flos tamen, folia,radix, nुufus, omnia eadem: quin \& nobis tunc mirantibus, difun fuit, lunc caule catentem, cultum; caulem promere ptimoprowentu.

\section{IXIA, fine vifcum Carline.}

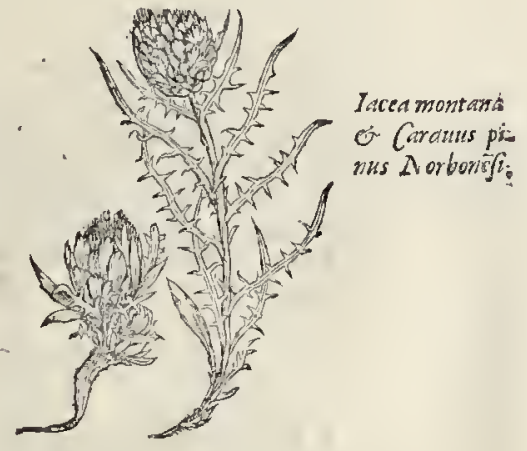

GVM M I verò Ixia di\&um, Carlina caule viduæ \& donatx radiciexudans virofum, \& id afferere poffumus quod praftaret iftis noftris ampu vnam effe plantam vtranque Cirlsnam, vti didum: nec Maranthis turbate; neque ctiam Diof cori. Viforibus docere, quàm cógelie authoritatum omnia Charaleönger lius illius noxix vis meminit. Vifcum vllum in nigro Chamæleonte agnofcit, aut vl- Pictus, eft Diofs. de Ixia nofter Plantarius Sen que pariter noftram fulciunt fententiam. Quid balbutiat gensmus. neni,nlibi dicemus, vbi, fitne illud ne quidem a Ruellio doctus difirentiam vifci \& venamq; \& ingrato animo faltidire videterium intrò ingeftum, difcutiendum. Immeritò fibi muneri miffum. Nam, inquir, fotur Marnnthx Neapolitani Chamęleontépiâum, rubet caulis, nó exefa, non acris, nec flau radis maculis nulla liabet, ron variegata, nec Quafi veró ifta indicia ei, quem ille Senenfis alerum non dicritali crafsitie videntur:

$$
\text { Hh.iii. }
$$


Qui norunt Galcnum mutuatum è codicc, potius quàm de Diofcoride mera \& metipfaverba, vt pluminum iufpicabuntur nifeutfe ilim albi cuin nigro facultatcs, hujufque radicem renenatam prodidife:quod neutiquan de ifto, fal de albo, propter, it

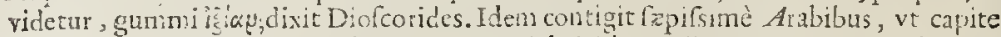
de Contaurco, \& alıbi nonnufau Galero,vti de Iride \& aliis:nec tame vilam Theoph. venenatx qualitatis facit metionem, tantum canes interincre pofie ait Sic pofunt multa cani \& pecor notia dici, qux funt falubria homini, tt nux vonica, Doronicum, \& alia. Cum autem stynon huius Cardui Chamaleontis, Diofcoride interprete, ì coloris \& folorum varictate deducendum lit : planta fit oporter varicolor, varis in locis, vti Chamzlco, cuivs cutis cuicunque folo incubuerit, concolor fit, iam nigta, viridis, aut albicans. Quantum vero conteftari licet, nulla eft planta, cui maģis hac Diofco-

ERYNG A. ridis nomcndarura faueat, quàm ER Y N G I O val garı, nam montanus totus cxruleus fit, campeitris albus, interdum \& pupurafcens, vtı etiā in maritima ora Scianon: $x$ inuenitur, \& adxdes virginis manufactx I auretanx, vernacule Lorette vidimus. Albus verò fecus Rheni \& Sequanæripas, in Germania, \& Burgundia prope Maconem, aliofue trafus.

$$
\text { CROCODTLION. }
$$

NE c miltum liquer nomenclaturæ luius Cardni ratio, ncque defcriptio aninum explct : \& Carduorum tam latè pater fam:lia, tantíguc incft fimilitudo, ve vix ne antiquis quidé probè aut diftinctă, aut cognită fuilfe putemus. Nam antiqui, GaIcnus, ()ribafius, Paulus, duntaxat verba hinc videntur mutuati, aut è Cratema, à quo Diofcorides \& Plinius, qui locis non fyluofis, vti ille, fed fabulofis, codicis errore, non fuo, orrifcribit. Scd in Cratenæ fragmentis defunt verba paucula ifta: nai ภ inftar afpidis fer pentis in fpitam vel gyrum conuoluti, vt effet guradam allufio nominis argumentiad Crocodylum, nifi forte cò allufifte nomenclatores videntur, quia Crocodylion aquaticum fit, \& ripis fuminum plurimùm degat. Ideóqueab \&ito mentio faCta fit magnx Crocodyliadis iuxta aquas nafcentis,ad dolorem capitis. Quin neutiquam

Crocodys. p- puto iftam vim tacitos ptętcrituros antiquos fuiffe inter Elenchos hæmagogorum rees magra Atiy mediorum, fi plantam familiarem notamąue habuiffent. Nam pucrili acclamatione foe lices ominatur in Italia Medicos futuros Senenfis Commentator, fi hęc inibi nafceretur. Potius gratulandum foret Empyricis circulatoribus, \& vulgo Scamnidicis vel Moxtutsb.ncis, quàm emunctx naris Medicis, qui cum c̀ naribus ducendus fanguis eft, longc̀ tutrora \& potiora remedia in procinctu habent.

\section{Anf CROCO DY LIV M, niger Chamaleo Murantha?}

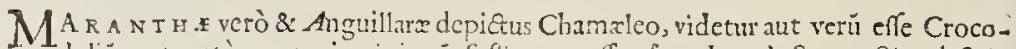
dylí, aut certè germani opinioné fuftinere poffc, viquedum doetis exactior defcri ptio,aut planta Crocodylio aptior occurret:adeo enim defcriptioni accedit,vt illis nigrú erfe perfuaferit Chamxlcontem. Qui vero fanguinis è nabus prolectionem defiderar, ferò Crocodylion agno fcet,quia probationis incertus modus, cxperimétủ etiam periculofum \& incompertum doctis, non tacituris, fi nouifent. Calduus verò quem Fufch. Eol.835. Crocodylium ftatuebat, huc pariter poffet afferti.

$$
\begin{aligned}
& \text { RITRO, fa RVTRO Theophraft. Crocodylion Fuch. Echinopus, } \\
& \text { fou Cardibus Echinatus Gefneri, Spharocephaios Cordi, } \\
& \text { Spina Pcregrina Dodonei. } \\
& \left\{G e^{\sim}\right. \text { ma. Dolfche siftel. } \\
& \text { ZBelgis. Aroomiche aiftel. }
\end{aligned}
$$




\section{STIRT IVM aduerfarianoua.} H E $\mathrm{c}$ intcr fpino fos carduos valde quàm elegans, du-
plicis differentiæ vifitur, \& (quæ nanc; ; in $A$ Anconéfi, Ronano, \& Norboncnfi agro ac Auinionenfi, habentur, dupla magnitudinis füt) Chanæleontis ritu variat. Etiamnum ficcas habemvs, radice exigua, pollicem $x-$ quan te, fol rjs Chamaleontis albi longe minotibus, cau le nullo, inter dum exiguo, nomnunquam palmum \& al âs cubitum al to. Folijs femper proportione exiguis, \& Spinz alba modo profundè incifis. Echinusilli cæruleus, cximia cærula purpuref́és, orbiculatus, fpectatu iucundiffimus, \& magnitudiwe, quanta fpherula luforia.Semen \& e cus glumx fimilia Spinæ albx: 11ullas tamen furfum reass procul vaginulas aculeatas porrigit: tanetff fint acerof $x$ intus $\&$ lanuginof $x$, vti in fina alba. Rutrum fiuc Ritron Theophrafti cenfet Anguil-

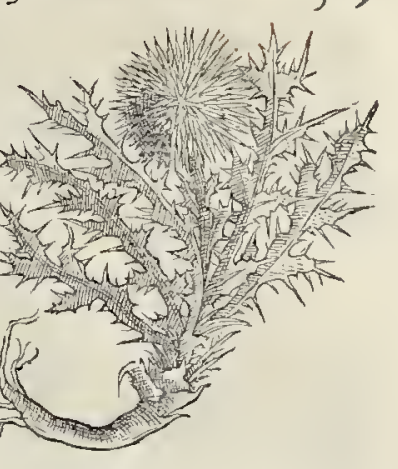
lara:qui tamen proxime,vt videtur, immemor defcriptionis, candem fpinæ albx notis ac-
commodat, iffdem fermc verbis,

Altera, quan Crocodilion FuIchius putauit, proffus genere eaden huic eft, fed magnitu- Fufbiy Crocodis dine impenfè major, vt pl urimum, vifitur:In fylua tanıen Valcna, qua Gangem oppidum itur, collegimus cxruleã, \& hanc excaulem, \&i caule palmū alto pręditä,qux alıbi ad duos, ternos \& quaternos cubitos afturgıt. Echinus cädidus eft, 1100 cẹruleus, \& cim maximus \& rotund us, magnitudınem mediocris Arantij affequitur: femine alterius, fed naltò mas iore. Cauli imo fecundum longitudinem ftriato, adnafcuntur permagna folia, \& Acanthu firmilia, ,pinofa. Belgici horti\& Britanici hanc fpedaculo alunt, vbi luculenta magni-
tudine Spina peregriua dicitur.

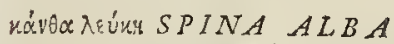
Bedeguard Arabibus.

A RABICO idiomate Spinam albuin Bedeguard vocánt, nec ta men vllis nots notiorem faciunt Meftues aut Serapionis interpretes. Quxnam auté vel:or fit ex permultis, qux prodit $x$ funt, paucis dicendum. Plufculis fuperioribus an nis in horto Patanino illuftriffimi Senza tus Venetorum, indicante Melchiore Guillandino , inibi præfeto (qui un itirpium hiftoria quantę fit peritıx, \& indefefii laboris, non uifi perdocti norunt) vifus fuic Carduus totus albidus, infernèlanagine incanior quā fupernè:folia Chamęleontis minora in regionibas ficcioribus: nam quen in Anglia feuim:Is, latiora aliquätó habuit: fuitg; caulis bicubitalis, interdnm tricubitalis, digitū craflus \& incanus totus: Echinos marinis fi niles, rotúdos habet: quando florent, exalbo

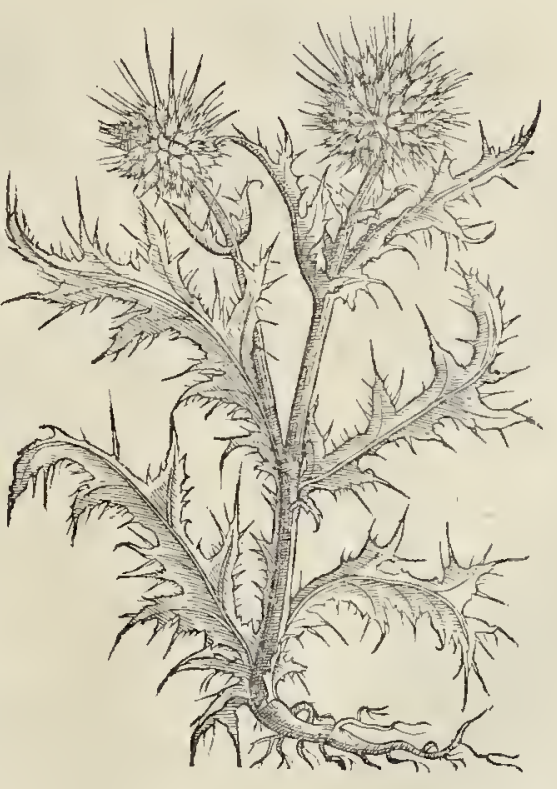




\section{STIRPIVM aduerjarianoua.}

puspuafcentcs. Inter quos defluenres fefe in fummo multò altius erigunt ternæ, quaternxue pappofx glumaz conferta, rigidis, mucronatistunicis, femen claudétibus oblongú,

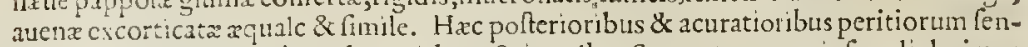
tentijs onnum maximè guadrate videtur $S$ pinxalbx. Semen tamen cuiufmodi diximus auencaut Secalo fimlius, fed rotundius Cnico. Non eft hxc, quam fibi miftam olim Pata uio Sencnfis dat, cateris omnibus iugulatis fententijs, ve fuam ambitiofe intruderet ridédis argunentis, \& plus momenti allaturis ad fuam ipfius, quàm ad aliorum refellendam.

\section{SPINACARAB ICA, fue Suchaba Mauritanis.}

CNszey r i o doccthanc Cardum quëdam Arabicum effe, non arborem: nec Contùn natali folo, fed potius facultate diuerfam effe ab Alba fpina: \& tamen híc quidatn proligati pudoris fcriptor viros lectone \& omnium artium exercitatione cultos gratis incommodo pofteritatis lacemat : doceret potius, cur non fit hac fpina Arabica vna ex Agyptijs, aut cur non pofit congener efle, Diofcorides fimilem albxfpinx, natura nempè dicit, quia aftringei a afert. Illa vrinas ciet, conuulfionibus prodeft : hec fi aftingit, flamenta duáfíq; fibranım rugat, \& conulionus caufam impingit, inculcátg; mate.

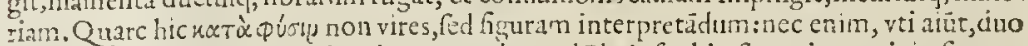

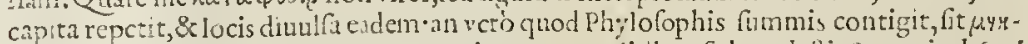

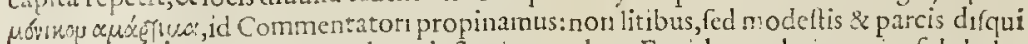
frnonibus dirimendun. Cuando virifuf, vires crden. Et videntur huc potius fubdi debuife fuccednum Bedeguardiue Cynorodi glomeruli ex varij coloris filamentis conuoluti, quàm illi:nam aftringere hanc fignanter notat:illä potius digcrere.

TO IIENTOSVS cardurs Anglicus, apriorne videtur deforiptiani eAcarthe Leuca, quim fuperor Pataluries?

NE $\mathrm{c}$ longius abeft à genuina DiNofcoridis Spina alba hxc, quàm fuperior memorata, facic, caule ternum quaternámve cubitorum, inca ma lanugine obfito,Spinxalbx Patauina, aut Scolymi fylueftris fimilibus. Florum capitula rotunda,compreffa, Echinum marinum, (quum nondum hiat) bellc̀ referunt, aculeis mollioribus, villofifo; quafis Aracha neis fericeílve Filis concinnè riticula tim implicata. E quibus per maturitatcm ftaminea purpurea florŭ, Cynarx aliquantè minorum, excrütur, fuccrefente femine Sylibi, rotundiore, corpulentiore. Radixmagina, fufca form, intus alba, Perfonatze fimilis, guftu non ingrata, diuretica. Frcqués hxc in Angirx collibus Itrigofis agriSommerfeti, iuxta ædes generofi huius hiftorix perquam auidi \& ftudiof Eduardi Saintloo.

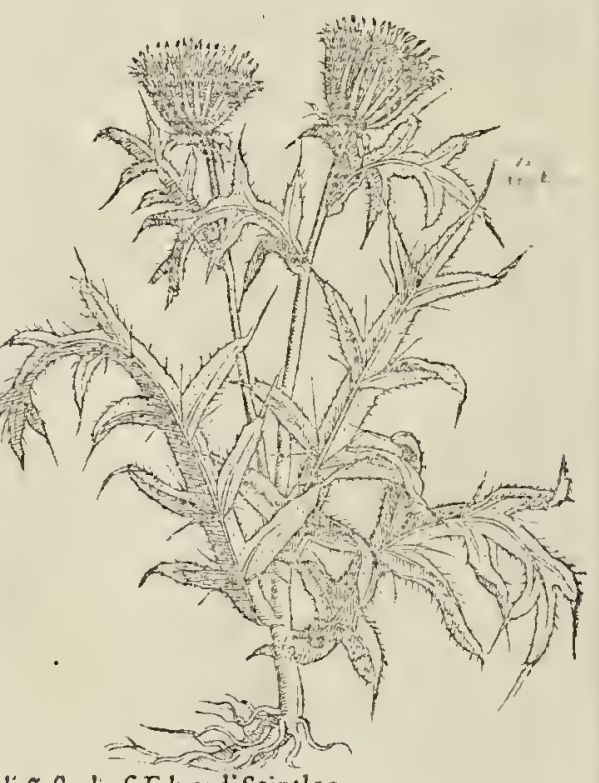




\section{STIRPIVM aduerarianonis \\ GAR DVVS bulbojus Monpellicenfum, an for Lencacantba Dior?}

PAvi o fuperius fpinam Albam, proptcr folia candidiora quàm albi Chamaleonus fic dietã,e Patauinis hortis recenfui mus: vnde liqquethanc Albam fpinam ab illa non parum difsiderc, contrà quàm nónullis perfuaferat vocum parilitas : ilius namque defcriptio fatis plena, buius ferè nulla, pręterquã radicıs qua Cyperi deferi bitur. Tametii ex Diofcondis ferie \& aliis cójęturis dignofitur hanc cffe fpinofum quendam Caiduum, non arborem folıdo ligneóg; trunco, vt audet affirmare nuperus quidan fcriptor, nó inuenuftus $P$ hilologus medicus. Hanc altem Monfpelliacam híc depictam fr Mathiol. nouiffet; potius puto,Albāfponãopinatus eflet, quàm Carduun Argenté̆ Mariane dictum, cui radices Cyperi nullę, rcliqua indicia aquè incerta omnia. Locis vdıs $\&$ pratenfibus Mófpelliū circú Cardus hic oritur frequen s, in:ter Narciffos \& Ariftolochias, cui folia palmum alta, pinguia, aut crafsiora, in ambitu laciniofa \&e ferrata A canthii modo vifuntur, tenuibus fivis ambientb. Caulis binos cubitos altus, gracilis, cui in fïmo capirula, floribus purphre is ftamineis oppleta, femine Cnici,fed minore. Radices multę, confertę, x v vo quafí nodulo aptę, in multos oblogos globulos diductę, Afphodeli, Cyperíve modo. Qua nobis perfuaterint guftu explorantibus, \& etiamnum hxc icribentibus, nullan ftirpem propius accedere ad Leucacanthāämandenti multú glut tinis exhibet radix, nonnihil caloris \& tenuiü partiü, tametfi amaroris penè nihil. Sed nualumus vera \& nobis cóperta prodere, quàm rerum naturas apparatu mendacionú a noft ã gloriam detorquere, aut apros appingere Sylự:":

\section{CARDVVS Prateris Tragi Acanthifacie.}

GN T E R Acanthum \& Acăthiü, medius videtur Carduus ille pratenfis, luculenta inagnitudinis \& venuftatis,pratis Heluetix \& Germania familiaris : Folia namq; haber Acanthii, fiue Brancæ vrfina fimilia, dinifura \& ortu paria, fed molliora, faccidiora,pal lidius virentia funt, in caule quaternum quinúmve cubitorum fo res congefti pappofi, Senecionis maiores, ex litteo purpurantes: feménque Cnici multó minus. Radix prolixa,craffa. Morganus nolter Londini alebat in horto.
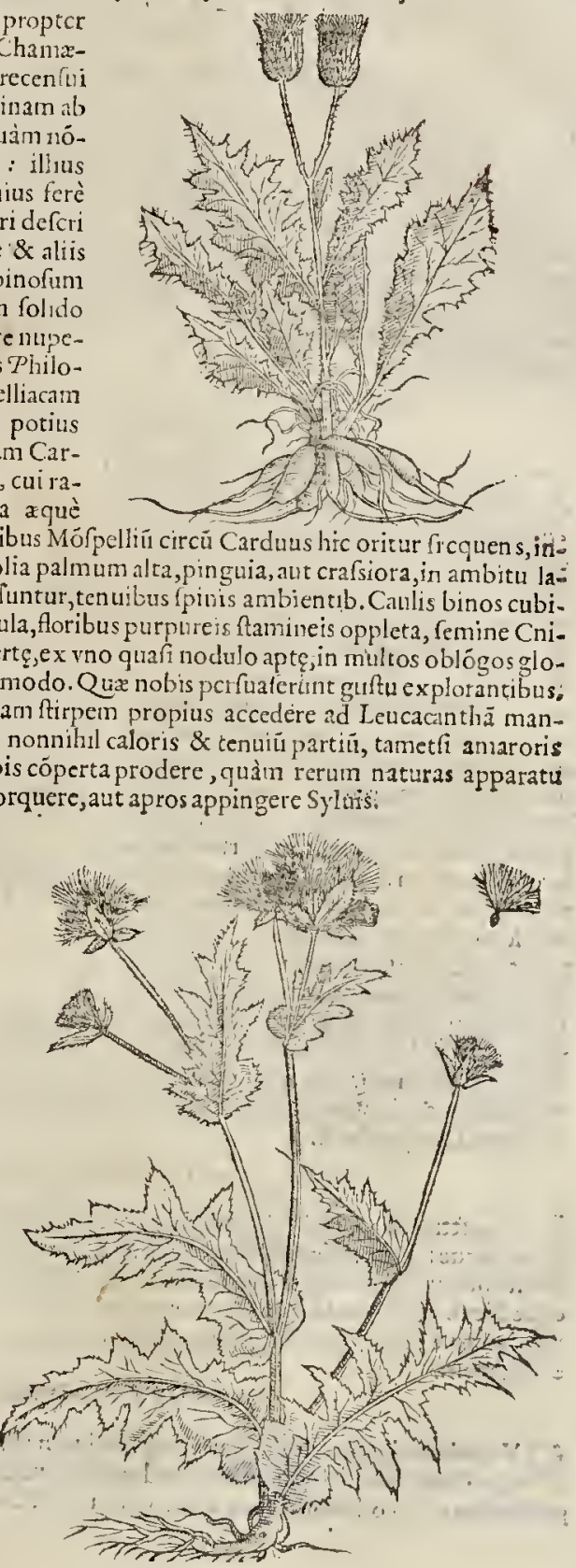


\title{
STIRTIVM aduerfarianona.
}

\author{
CARDVVS STELLATVS, Ser Calcitrap o Tribulus Ruellia \\ Coronopus.
}

9. $\mathrm{O}$ minus notus quàm infeftus Calcitrapa vulgo nuncupata; quia non manibus,

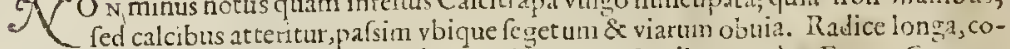
Jore fufco foris. Folia lanuginola, lacinia, vndulata, profundiola, quàm Eruca, Coronopi modo, caulis friquipedem altus, muitos turıones promit, qut raciis fteljation dilincti, mucronati, acutiśsmi, Calcaris f́peciem refcrunt, Goremáuz Atradiudi fumié purpurcum claudences.Semen exigum, rotundum, compreffum, İenticux funie. Decodio huius radicis plüimum vtuntur plebei åd calculum exter endum, vrináfoue cicadas, vti \& fcmine contufo, cui tanta vis, vt etıam anaftomofi facka venar um emuirentium, aut vreterum cruentum lotium proliciat. Hanc non nouiff, aut ncglc fur habuilfe, multis in locis contemptum Medici parit. Tantò minus decuit ıfuñ Mcdicum \& Conmenzatore indictam pręterife.

$$
\begin{gathered}
\text { SPINA } S O L S T I T I A L I S \text {, Airioles } \\
\text { Prowincinlibus, an Plinima? }
\end{gathered}
$$

CTE L I A T O Carduo fimilis, nec minus Snobilis Spina, feu Stella Solfitialis. In Galloprouincia tanta feracitate luxuriat, vt fegetum inctemen to nó parum officiat, \& melforü manus pedéfq; fapifsimècruo- $\$$ re \& vulnufculs afficiat : radice parua: 0 It incana, lanuginofa, caules multiplices fecundum longitudinem ambientia,pinriatim vtrinque furrceta graminis magnisudine, quafi penne fux arundini affixx, aut innatæ, \& quxdam ftriarŭ tentaméta: murices tribulı terreltris maiores füt, Carduiftellati fimiliores, fului,lucidi, rigidi, pú gendo valde quàm infefti, prefertim Solftiṫo exacto, quim maximè cxarucrút, tunc en im fepes harü aggeribus foliti funt arma re coloni. Flores Cardui ftellati, fed filaméris luteis:femine Cnici paruo, paleo colore. Balneis admifcentur ad tineas \& Lichenas: fillatitiam dicunt tuberolas laringis glandulas \& ferophulas tine dolore difisipare.

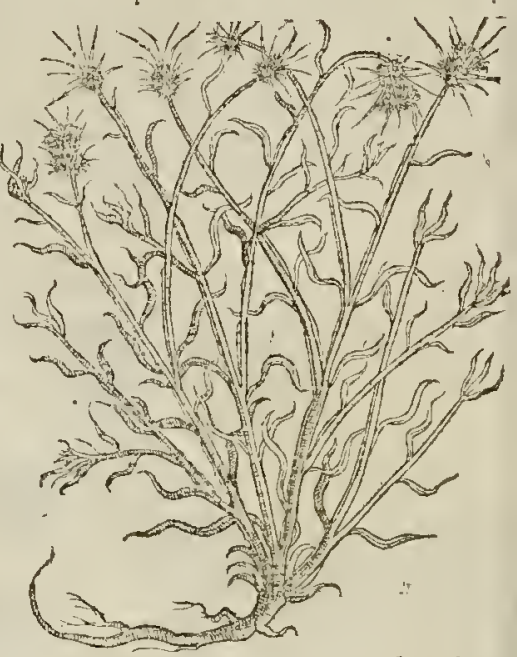
Empyrici etiam eiufdem ftellis crura pratumida frequenti ifu aperiunt, \& fanguinem vilnufculis cliciunt, vti idcm agifolii ramis foliti funt, ipfi meriti vt non crura, fed terga liagris lacera geftent.

$$
\text { ATTRACTILIS. }
$$

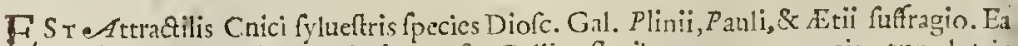
plerifonelocis,prxfertim Norbonenfis Gallix, floribus tum purpureis, tum luteis. spontè oritur. Radix digiti crafsitudine, folia longa, ma anis incifuris \& aculcis in ambitu: caule bicubitali, fpinofo, cauo, \& capite fpinis horrido:flore ftanmineo, lutco, vel purpu-

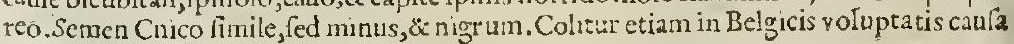
\& fimbrofis.

\section{$C A R D$ VYS Boredintus.}

V V $M$ benedifum, fen folicitatum Carduum plebcius confenfus nuncupanit, alteRram Cnici fylueft. fpeciem effe iamdiu doftis nobífyue ex collatione perpendentibus perfuafum eft, ea omnibus v fu \&z vifu cognita eft. Hanc colunt magno fudio Chyminta 


\section{STIRPIVM aducifarianona.}

Ec clsici,morbi Gallici linitores. In ardnis alpibus Gallopronincix prope Monftrias Marignols vocatis, vbi vndic; effodiütur Cryftaliuz, Irides, \& varij coloris alij lą̧ides, cref cit: is fummo montis rigıdior \& aliquanto minor hortenfi. Senćfis fuo more nordct, \& nihil doect. Nam eius Attractilis nullis depieta aut aflerta verbis iacet fpectanda, non vt nos certiores, fed vt dubios reddat: parti enim Diofcoridiscicfoription autreceptz Attractildi accedere vidctur:vtrū veró illius filentium,an piEtoris in cxprinēdo folecifmus \& cacolilia,incufäda fint, viderit lector. Fortc̀ huc nullodelectu intrufa fuit, quia in penu! tims ilis Commétarijs abfuit, nec dum vlla cerca, v t videtur, authori non fuit. Ideo fuo more, ne nuhil ibi erife videretur, velitandi anfam arriput :ait Attrafilidé non che Carthami fylueftris fpeciè, duntaxat quòd argumento truniali fanguneü fuccū nö remittat. Hæc iamdin fibi feripturo obiecerat Ruelius: \& refponde-st, no yuonis ani tépore, fed meffibus prafertin, nempe maturo \& copiofo fucco, id depręhendi:tunc enim rominil cruenti coloris emanare. Quod etiam Luretix in vireto Ioannis Hebrei fugularis Rhifo tomi meminimus iam multis annis oftenfum nobis in Attrafullıde: criangic Monfpellıj in benedieto Carduo \& Carthamo idé cóperimus: nam florā \& fuccorü colores, odores, aliíq; accedentla incrementa, decreméntáque, afequiunturaijs locis \& temporibus alio modo Quinmulta fucco funt aurfuluo, aut purpureo, in quibus non nif affretu, maturatione, naceratione, ant cxpreffonc percipitur, vt in findrofenis, lihcacis, Papaueris radicibus incifis, Verrucaria, fue Tounclole, \& alijs pierifg: Scd tcenam ambirionem prodit imprudentia, nam qui vidiffet antiquis claficis medicis nixum Ruellium, Galeno, Dioforide, Egincta, Etio eorum fententias, contrà quàn folius elt, in capitis calce reticuit.

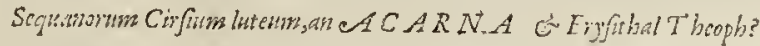

$\mathcal{F}$ N V L T Is \& aridisEricetis vifitur carduus quidam, quem Acarnam Theoph, aut Carlinam Sylueftrem, alıj Eryfithalem nuncupant. Exıgua radix, folia Carlinæaut A ttractilidis, minora, fpinofa funt. Caul is gracilis, rotundus, cubitalis, quo tria yuatuórve tu bercula cchinata aut aca nacea gerūtur, radiatis ftimúlıs cineta:è medio patuli, Echyni ex eruntur florcs, cx luteo pallidi, [cd multo minores. Hanc Anguillara Ery fithalem fecit, Sequani Cirfum luteum vocaut.

$$
\text { PICNOMOS Creta, Salonengis Galloprouincia. }
$$

VT pufillus ita pulchellus \& rarus eft Carduus, qué fol h̀m in arida fpatiofác; maritima planitic, inter duas antiquas vrbes Arelatem \& Salonem, cur quia, vt conicctura fert, cretaceum folum fubel, nomen vernaculum Crau indit eft. Edicula media in planirie eft olim D. Martino facra, propè quā cx aduerfo minoris diuerforij hic Carduus nobis pri mü leftus fuit, vti eriā alijs pofteà locis incultis \& dcuijs. Radice eft exigna, manfu quidpiam glımoli praferens, longa folia fecus longitudine cauli adhxrentm, Chamalcontx Mófpelliefis modo, fed anguftiora multo, in ramis magnirudine Calcitrapes $\& i_{1}{ }^{9}$ modo

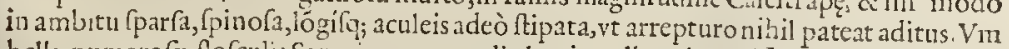
bcllx numerof, flofculis Senccionum xtulis, luteis, pallenrıbus cöllarx funt, qux in pap pos duriufculos Attrabtilidis modo etolant, femenćtre cxiguum Cnico finvile relinquüt palcaccum. Hac quò fit referenda,nefcinus, nifi inter nigri Chamalcontis fpecics. Picnomon non affeueramus, fed quia fpinis munitiffima eft, fignificationi alludentes, ita vocitamus.

\section{$D I P S A C I$ fatiui Fullonum, $\leftrightarrow$ ponte nafontis $L A B R I$ $V E N E R E I$, difcrimen.} VAs I fitibundus potórve vocatus fuit hic carduus, quod foliorum iuxta caulem
alis \& cauo plerumgj; roren aut imbrem excipiat \& fernet. Eius autem varietas

$$
\text { I1.j. duplex }
$$


dup lex hodie nota vulgo eft. Nec enim videt ur folo cultu cue niffe, vt Fullonun Dip/a a cus aculeis aduncis, recurtuis \& rigidiorıbus, à Labro Veneris fponte prodeúte tantū cultu dittet. Nam pleraque omnia culta mollıora \& teneriora, minúfq; fpinofa euadere folita funt: at hic fatiuus capitibus eft reductioribus, oblögis fpinis, crebribus, aduncis, ter ram verfus reflexis, adeò rigidis, $v$ t ftamina carpendo \& vellendo filamenta non facile effringantur.

\section{VIRGA paftoris.}

$S E$ Dälter mollioribus, miıoribus furrectis, nec aduncis, longioribus multò, imbecillio$S$ ribus: folija itë mollioribus, minoribuc, haud diffimilibus, capitula crebribus, \& bituminofis trifolio fimilibus. In Anglia Cantia fccus vias \& fuburbia Rhix Sandricium.

Tertium \& minimum, non adeò frc quens, vfui incompertun nam cętera duo refrigerātis \& ficcantis funt facultatis. Cancerofis vlcerationibus multùm conferentibus.

\section{C.VICVS Carthamus.}

MOrdacem pungendo fpinofüq́; carduum Cnicus fignificat, purgatricem autem eius 1 facultatem Carthamu: Non eft autem regionum Septentrionalium nifi culta \& inquilina:vbi tamen lxta adolefcit, fed nö parum virium purgantium femini decidit. Nam Orientale multò facilius \& v tilius minori quantitate purgat. Norbonenfe,vt quod Mafßs! Larges quatuor à Monfpcllio leucis colitur à Pharmacopoeis, imbecillius multò eft, vtćue quod non minore quàm duarum vnciarum, fed faltcm vnius \& femiflis mole, atuum fubducat, nec obftructiones meferaicarum ६què probè referct. Quia fatis innotuit plura adde re non'operxprecium fuit, chm etiam de Carduo Benedicto congenere fatis cognofatur.

$$
\text { CARDVNCELLVS montis Lupi. }
$$

$\mathscr{F}$ Norbonéfis agri montanis, ad montis Lupi ima, Meridié verfus oricur prope pufillú amuem aut torrentem hæc Cardui fpecies omniü minima, eợ; Cardủ cellus nobis nücupata. Plantulx huic radix eft implexa, altè humi depata, à qua mox foliola pluffula, exilibus $\&$ altis diufuris dentata. Caulis vix fpitameus, lęuis \& gracilis: humi demifus, flos feu caput, maius quã pro foliorum refponfu, fpinis horridis, foliofis cinctum florem claudit purpureum Attratilidis, cui etiam folia ipfaq́; rniuerfa plinta valde fimilis eft, fed longe fimilior $\mathbb{E} t 1 j$ Attractilidi,purpurea flore vocata, forte e eadem: vfus incognitus, quia planta vix nota.

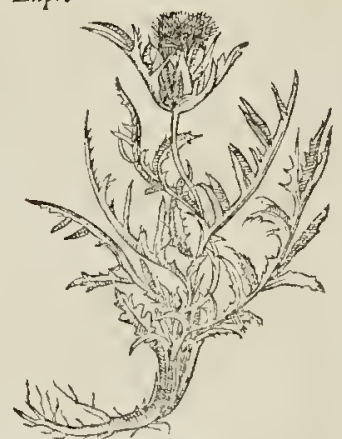

Vrigo eAftone Italica Anguillare, Spinum Canoton T beoph. tametfi multa nef radicis not a vaga.

PAtauino agro fubter humú prolixè propagătur huius radices. Folia fimilia, fed fpinofiora quàm Sonchi:caulis ftriatus, cui fummo infunt paruuli mnlti Echini purpureis Itaminibus florentes, $\&$ in pappos vbi maturuerint euanefcentes: Semen paruum, \& fimile Cnico.

ACVLEOSA Gase, an Polyacantha T beoph?

Arduus ille tritæ cognitionis, qui fpinofifimus Polyacãtha merito videtur:adeo enim quafi denfis villis fenticofis obuallätur tum caules \& folia $\&$. fol orum capita,vt quacunq̣; intueare, multas fpinarü phalanges animaduertas: flos illi puniceus \& purpureus. Capita echinofa, oliuam equantia. Caulis fefquipedem altus : folia fpinofa Acanthio,minora, nec lanuginof, fed $\mathrm{cx}$ atro virentia, radix fibrofa, numerofa: $H x c$ tamet $\{$, vt plęrif q; fpinis refertifimè aculeofa frue Polyacantha dici poteft, non tamé continuò Theoph. fit aut Gafx, qux yidetur ex fubfruticum genere:Tametí putet quidam Polyacantham. 


\section{STIRPIVM adterfarianowa.}

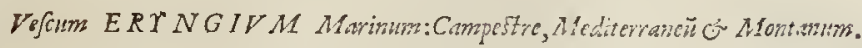

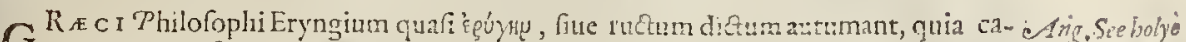

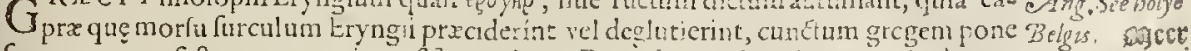
fequenten quafi ftupore attonitum filtunt, donec Eryngium ruetu rciecerint. Quàm pa- bostrtcle. rum perfpicuè calamus humanus, etiam res minimè fuapte natura obfuras defcribat, vel hincliquet, quòd cùn Diofcorides oratione dilucida Eryngiun reprafentatit, tamen nondum liceat ftatuere, vtrúmnc Marinum dictum an valgare Montanum infinuarit. Omnia tamen indicia propius Marinun referunt, quàin vulgi Montanun, duntaxat loci mentionem excipias, notam lubricx fidej, \&k non adeò magni momenti. Ma rini primum folia teneriufcula funt, neque ftatim aculeata coć; in acctara veutunt, quemadmodum Critlınum aculeatum, feu Paftnaca marna, huic natals bus proxima : Deinde lata,fpinofág; fiunt, extremo aunbitu minus p: ofundè finuata \& a fperiora quàin montani guftu ctiam plus gratix \& aromaticitatis habctit, ambitumćue alperum : adolefcenti fpinx fuccrefcunt:\& cauls magis fphxrica capira infunt, rigidioribus'aculeis nteliatim circundata, ve vult D of cor. color vero verique variat, fed vul gari non nifi variante loco. Ma- Montanumizs rinum ipfi vidimus ad Aquas Marianas \& alıa compluma iitora, colore cærfo, albo \& viri-cornlorme. dante: Radix eilongifsima, \& qua denos duodenófve pides excedat, crafsior etiam quim Montani, odoratior, cibo, medicamento gratior, efficatior:nen enım nifi hac deficiente vtuntur docti illa, non perinde freti viribus illits. Alpen Maritim ú amat, editıra:vix nunqum enim in monte Cetı 2 . firmilibus inter ædita farofa occurtens, fed femper deprefsis, afperis, vel arenofis, incultis locis, interdum fefunimuliare à mari remotis. Cam-Cornofofte. peftrem veró fuperius cum Chamxleonte, cui magis accedere putabanus, contulimus, \& obtulimus iudiciis em unctis:tanet fiab ifto, colore, \& folı rum laciniata altè incifura magis,quàm natura diftet.

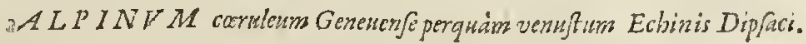

HV I v s Eryngii infpedio tantęvolupta$H_{\text {ti eft homini plantarum nofcendarum }}$ cupido,vt facilè, non modò labores herbarios intempeftiuc̀ improbos leuare, fed etiä ad magis indies veltigandun excitare valeat : mirre namģue elt elegantix. vnituerfus reuidet colore cxfio, caleitnx purpura, hilariore multò, \& quì̀n in vulgari moncano vuidiore : tadix Entltre penè par, Eryngio concolor, funilis, \& finiliter odorata: caule erecto, ferulaceo, fefquicubitali \& bicubitali,ftriato, qué folıa per interualla exgeniculis orta ambiunt radıatim, ftipernè mollicella \& delicatiora, quadantenus Etyngii Cäpeftris, Cpintilis pluribus, fed ignauioribus. Ima autem ftation à radice exeït folia hederacea, ambitu delicatius ferrata, lauia Trachelii, aut Epimedii à nobis devicti. Capitula echinata, finulitudine \& magnitudine Labri veneris, fed colorc foris crruleo. In arduis montofis Iuhx pra-

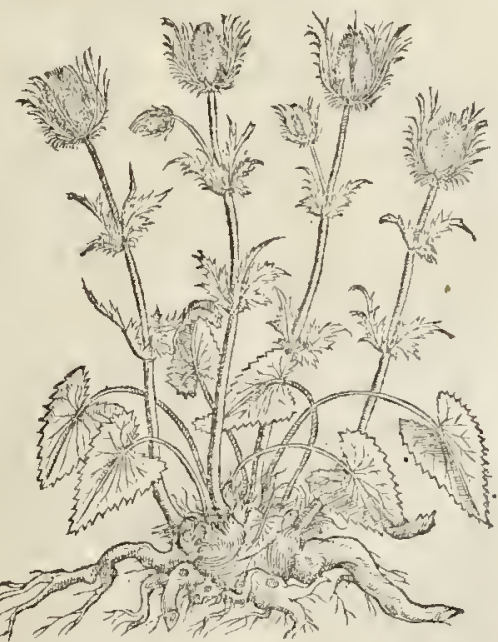
foris cartileo. In arduis montofimon Geneux imninentum montiun iugis, atque criam Claudii celfis reperitur:radixnigra foris, intus candida, boni odoris, gu?tus Eryngii.

\section{- HIP POP H AES Hippophefterm.}

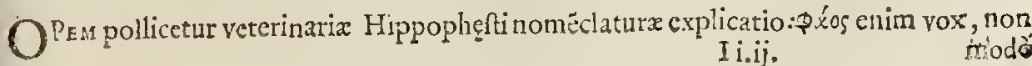


modò lucem, fed etiam falutem, profídum \&c remedum fignat. Hanc fullonian Diofcorides tradit ac fcite fic delıneat, vt nullí paulo diligentioren vefitgaiorem, fiquidem cam nactus fuerit, latere queat:quò factum vt iamdiu defierimus quxtco do nos torq̨ue:e, cùn poft luftrara multa litora, prafer tim Tirrheni $\propto$ $N$ Norbonenfis maris, vbi quidan fpicilegul fcriptores oriri fibı \& nobis falfò perfuaferunt, nullibi aliffve amicis magis fedulis comparu erit:aut vfpiam in velu cffe fullonibus Mediterranei, vel Occidui m.ris accolis at1dire à quoquam licuerit : fidem tamen gratianǵte habemus fidifsinio nec vulgari amico, hu us hiftorix peritifsimo Anguillarx, qui fibi hanc vifan coram verbis nos ecrtiores fecit.Sabulofis Pelopónenfis maritimis oritur, vocaturq̣e vulgò, inquit, Spina Purgatorin: radicibus palmum longioribus, hactenn fuccum frangendo fun lentibus, amarifsimum,

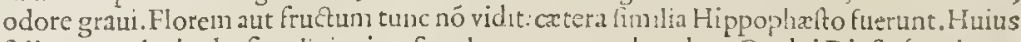
fullone mu! ta hodie frnplicia vices fupplerent; quemadmodum Cardui Dipfacive plante fatiui fullonibus vbique iden commodi prxfant, quos tamen autiquitus ad vellendos carpendófve pannos vfurpatos fuiffe, nuilla in Diofcoride mentio: huius verò multa, cùm apud alios, tum apud Theophraftum, qui Hippopheos, non Hippophaes vocat , \& para-

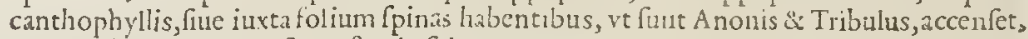
quod indicium certiuseft, noftro in folo non prouenire.

$$
\begin{aligned}
& \text { HIP POPH ESTV } M \text {, nominis vfu, fortè cं cfrgiciquiddam } \\
& \text { commune cum fiperioj i habutfe. }
\end{aligned}
$$

$S E v$ haud perinde nota fuife vide tur, atque fuperior fuit antiquis hre : quippe cuius Salenus \& Paulus non meminerint : Cùm tamé hic Hippophẹtú exferipferit ex Diofcoride, qui ctiam paucis verbis incertífque defcribic, cauliculo floréque viduam, [pinofis fo liis plantulam, fullonis fpinẹ fpecie, qualem è $N$ orbona aducetam fe viduffe, eruditior autorum lectione, quàm ftirpium infpectione, vndequaque literatifsimus Ruellius, fuis cōmentariis mandauit. At eandem nos putamus illam Norbonenfem fpinofan Echinatä, Ritro Theophrafti inter fpinas dietum: qua de re iudicium peritifsino cuique deferimus.

\section{ECHINOMELOCA- \\ ITos, fime Melocarduns \\ echinatus Indse occi- \\ dithe.}

$V E$ M non iuuat in hoc mirx raritatis \& venultatis Carduo, folertem Nature opu lentiam contemplari, is fe putet auerfo natum ingenio à lautiore Philofophia. Hanc autem fpon te edunt noui orbisinful $x$ occidue, pręfertim ca que Dituæ Mar garetx facra cft, vnde reduces naucleri Anglicisoris, Morgano peritifsimo \& perquàm liberalis

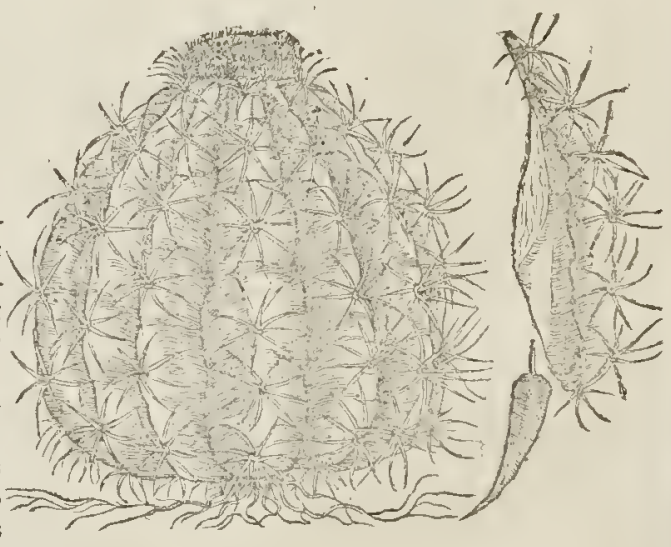
ingenii Ciui, \& Pharmacoporo Londinenfi, attulerunt : in cuius officina iuftrefisima, plerxque ciufmodi ftirpium nouarum delicix fertantur, quales fuis locis appinximus. Sit ne celi Europxi patıens huius femen, nondum fcinus; fed primo Vere experiemur.Videtur autem hic quali quidam naturx Cinnus, ex Pepone,Melone, \& Cardio coaluife cóque nos Echinomelocafon, fiue Melocardutim Echinatü, frgnata magisquàm recepta nomenclatura vocauimus: Turb inata illi metx effigies, torulis, callosífune quatuordecim quafi coftis canuleata, à fefsili \& latiore bafi fecundun longitudinem in conú obtufiorem coëuntibus : ex quo, quafi vertice, emicat tomentofa, vin in Cyara, cericea 
bombax admodìm farcta \& delicata ferè quafis lapidis Amianthi, gua inuoluuntur mu: cronatæ vaginulx, filiquof $x$, fanguinex, Capfico concolores $\&$ fimiles, fed perquàn exiles.Semine pufllo, rotundo, Amarāthi plena, multus fetis croceis fipernć fele exerentibus, fed rigidıs \& pungentibus.Dorfa autem fumma friarum, quà latius protuberāt, exerunt infeltos veluti Iftricis aut Echini aculcos aduncos, corneos, denos, \& duadenos quafi hamos, radiatim feptenas vt plurimum ftellas effigiantes. Adeoǵ; vniuerfum corium armant, inftar Echini, vix vt inultus manu pienas . Eft autem cutis externa callofior, crafsiorquiue tota, Aloes aut Cucumeris colore \& concretione. Caro fubtus albicat, pinguis, fiaccida, Meloncm aut adipem referés. Guftu infulfo \& acidulo, non ingra to, aqueo,refrigerante. Cuius fuftrum ex eaque decoctum experiendi caufa vorauit \& haufit innoxiè, vir impendio doctus, \& pius D. Foxius Anglus. Quafi autem Melo foret interiore \& fuperna fui parte, qux forifibeft $A$ canaceo, carnein firmiorem dife pitsmein brasula per medium iens, fellulamqque efformans, ferè qualis Cucurbiize. Sed feminis vi fungofiore minúfq; compacta medullan inibi inuoluit. Eius natales qui viderme tum naucleri, tum familiares quidam, maritima fabuleta effe referebant: cum maturitith $p$ eponem mediocrem vel maximum Melonem æquans, nouemá; \& vnius triétem libras pen: debat lięc. Humi feflilis eft, nufpiä cóparentibus nequidem fol iorum veftigijs in ipfa pla nta aut.radice, que exilis eft, al 1 quot appendiculis vimineis, pullis, prolixis, firmis, nec fractu facilibus, fparfa.

$$
\left\{\begin{array}{l}
\text { Poterion. } \\
\text { Tragacantba: } \\
\text { Ononis. } \\
\text { Varietates. } \\
\text { Natrix } 7 \text { li. Recentionms. }
\end{array}\right.
$$

\section{POTERION ant vovęód.}

O V o D neruis peramica fit gvovéód $\alpha$ vocarunt, \& Poterion fortè, quia potrix paludiofi riguiḉ; foli amans fit, vt dicit Diofcorides, qui fruticem hanc ramulis \& folijs Tro gacantha aptè confert : eiufmodi namq; primìm vidimus multum in quadam areola horti Patauini, opera erudiffmi Guillandini. Deinde ex auftrali tractu I'edemontanæe regionis vulfú nobis mifit peranicus iuuenis doctus Pharmacopous Mafilien fis Iac. Rainaudetus. Sparfa \& latè porrecta fruticat, multis cauliculis exilibus, cortice nigricante, tenui veftitis, etiam aridis, non rectis vti Tragacanthum, fed vltrù citroćle fexis \& ordinè intortis, vti in Nepa aut Corruda. fic etiā fpinulx nulla ferie digeft $x$, f $\mathrm{c}$ d multob delicatiores, quàm Tragacătha, \& minores, paffim cancellatim \& reticulatim implicantur folijs nudx. Foliola non albida, ,ed nigricãtin, qux non ex aculeis, fed è caule fibrillis delicatiffimis, triplò quàm Tragacāthr minoribus Lenticula modo vcl Aftragali exeút: 5 cmé pufil lum, rubellum, Sumacho fimile, \& minus. Hunc receptum fcimus vir is Doctis. Nec mitamur tantoperè vifum fuiffe accedere ad Tragacanthan, vt congener effe videatur $\mathrm{Man}$. thiolo, qui fuũ Poterion Conftantinopoli, nen.pèvédibiliore \& plaufibiliore loco, fibi ab Oratorel mperatorio miffú dat. Cú nihil aliud quàm Tragacätha fit, aut ex cius icone de pictutn: non enim fpina, non cortex fimilia, neque in fpinis folia, neq; multa alia à vero diffídentia. Ideò vir prudens fuo honori pobè confuluit, cùm deferiptionem tacuit, ves rolitus eft: verumtamen dicir effe Tragacanthe fimile, fed verius dixiffet eadem effe.

\section{TR AG ACANT HA bircirlos fpicillos} orunces imitata.

$$
\text { Ii.iij; }
$$


VE a Tragacintha, cui fpinularum barbulx vindicant nomcr piurima fruticat in

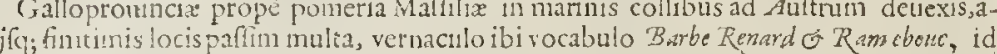
eft, vulpina barba, \& furculus hircinus vocatur. Frutex humilis, denfus, totus ca ndicat, vo cefpite multa copia aroettus. Radice albu, longa lignofa, craflitie disti, prolixis flcxius fubter humum mer [a. Ciulis cim procerrimus cubitalis, $\mathrm{x}$ quo fpicula foliata vtrincandidus, quen eftiunt fpine foliatæ, veprisus rigidilimü, ftellis horridü. In fummo inter fpinofa folia \& emina cxilia, albicantı includuntur, Smapi masnitudinc angulofa. Tllic planta neillio , led negocium dedmus cuidam lilic amico, vt radices vilncract, acfi cuippiam Jummofideflueret, fermare fic nos in Terebintho, Lentifco, inibi lacrymas compercri-

$$
\text { O NO IIS wht Anonis Afmaria, fue nockin Ofic. Angfa bows. }
$$

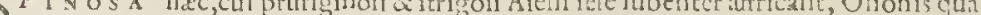

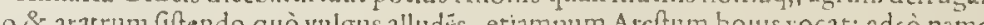
lenè refponder defcription infiantur ipfi fi non ro ovor ridendi cartè inuciles balbutiores \& nocui bouis fudij:, fin bed1. Quauis in plaga calida frigidaue fruticat flexilibus pluribus, fefoucubitalibus icubitalıbus furculis, per initia cum adolefcunt proximè \& fubter folia nónilhil genicu -

uxdam occurrit in pratis maritimis \& vdis Anglix, prafertim ad Briftoiam \& prope ondmum, folijs maiosibus, \&rantillum crenatis, frmil bus fuperioris, fed floribus lutes, urin floribus, alicubietiann no o exeunte in hac pofteriore, guăuis in agro fruticante \& in hortis eam obferuauerimus

HA r v r V T r I v I s perquàm fimilis inerba illa incer fe gctes e crepidines cultorum Monfpellif frequens, ce via Bouromet ad nounn cantum, Radix punlla, caules pronic gis multis Fee attraftantiliceat fe intcrdum extricare. Odora impendiò eft hac, fed quippiara minime rati foirat odoris forte vehementia qui quiburdam Conizam fatida fapit Flores illilu ei pallentes Aronidis:è quibus Delphinij cornicula, femine plcna, fed pullo colore Häc atricem Plinij conicétabant non nulli: quibus autē argunentis non vacat ariolari, neq per $2 u$ thorcs incerta fpe quarendo vagari. 

fimilitudine hiltorias, decreueramus graminis \& triticex frugis recenfione abfoluta,cे veftigio hãcquafialteram graminum familiam illi proxime anncciere, aut inter confimiles alias plätas alicubi quàm cómodè fiecri poffet, inferere:fed nufpian occurrente fatis apta fatione, in hunc locum, vt nó lubenter, ita non inuiti eam diftulimus. Quare fi cuivifun fucrit ad calcem graminum vel harundinaccorum referte, illi liberum relıcui mus. Hîc porrò häc ita fecuim ${ }^{9}$, vt quòuis reponi queāt: \& fic exequenur, vt loco \& folijs potius quàm ferie aue vfu difare videantur, hac duo fumma graninis faftigia : eftenim par penè cognatio collatióq; acuti folij graminis ad triticum, atqux trifolij graminis ad leguminum. Nam vt frugis voce à fruendo, tum triticum, tum legumen complexa fuit antiquitas: fic graminis appellatione, non modò qua foljjs triticcis excunt, fed etiam que leguminofis, defignauit, vt funt trifolia Loti, gramen Parnafium folio hrderacco, Hore alboiapud Diofcoridem, \& Cerinthe ignobile gramen apud Marorem: perindè enim vbe. rè glifcunt ifta gramina, cefpites herbidos prectergrediendo, inçue pabulum cedunt peco. ri, vnde Galli hodic Medicarn, fonaciam vocitāt, \& fonum Burgüdiacum faginandz vere rinz imp endió laudants

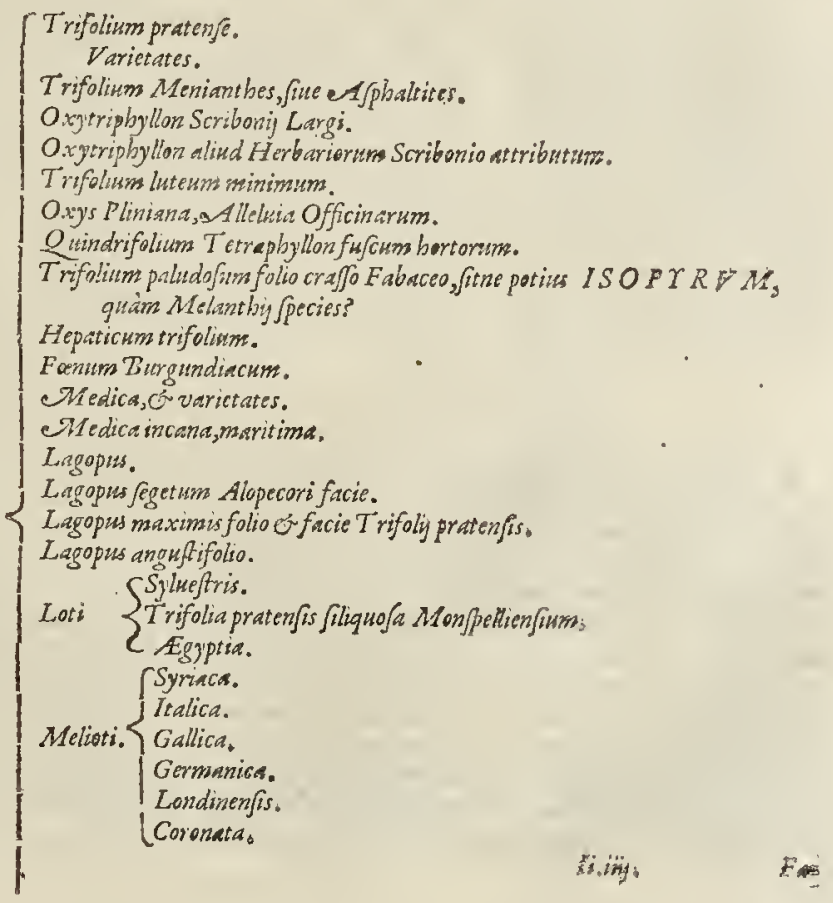




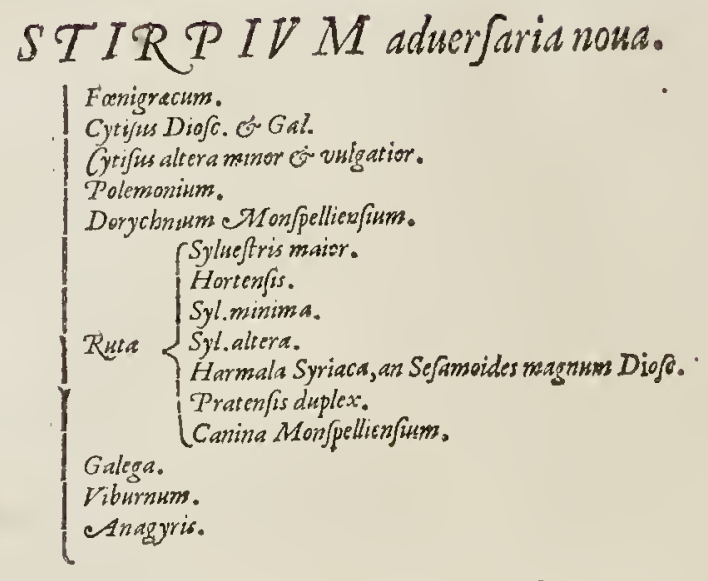

TRIFOLIVM PRATENSE \& cinis Umictates.

\author{
SGer. 20 , fentlee. \\ Bel. Claucr. \\ Cal. Treftle. \\ Ang. Herbe trifolie.
}

JVfpiam igitur đefit trifolium pratëfe, trifariam floris colore, variäs, quippe quod tore purpureo purpureum, \& albicăte al bü dıcitur, \& maiorıbus etiam fulijs difcernitur : vtrouis nihil notius, frequentius ant vtilius pecori veterinariæú faginandæ. Nec aliud ab ifto eft, quo mortales miri, Hybernię delitias, irritamentáque palati fpreti placentas, lagam na \& panes pinfunt, exque butyro fu bigunt, quæ jatranti obtrudant fomacho, nonn unquan trıduum fame exercito \& penè rabienti. Sed hæc tollerantia prædonibus præfertim confuetaitemq́; militubus. Inter quos fuperiorbus annis nobis noti generofi cùn militia mercrent propter defectionem latronum in Hybernia, mirabantur eos probè paftos, cingulo arCtiffmo cinctos, circum vmbilicum tamdiu effe, quoad proximo triduo rurfü cibum ingurgitarent. Quine prxproperc̀ elaberetur,perfuafi erant multum profore ad roboris \& alimenti fupplementum, fi vinctu cinguli quàn diutifinè inibi coetceretur. Idq́; natura docente potius quàm Scy tarü imitacion cactu:n reor, de quibus idem prodidit graus author Plutarchus. Indigenę enim infula cú fint hi \& longillimè abfint, Hęcquę uis vbiuis gentium prata alüt, ambo fapius guttatis \& falcatis fuperficie foliolü maculis.

$$
\text { ASPHALTEYM. }
$$

A Sphaltcum feu Mœnianthes Diócoridis non temerè alijs regionibus quàm Sole feruidiore luftatis,vti Monfpelij \& Maffilex in Norbonenfi \& Galloprouincijs, videas. Quin nc Longobardis quidem ant Venetis, $n$ if cultum in hortis reperias, vbi incúte Hycme non fecus atque Flandris \& Anglis vtplurimum interit. Fruticola eft, fefquicubiti vel duńm cubitorum. Surculos preciuros rigidófve multos exiles in ramulo, hcbetes,cxiles.quibus in viticeos fermè pediculos excuntibus fingulis, fol a terna infunt, nec plura, In imo \& per initia circinatæ rotüditatis, fed in pediculis fuperioribus adulta, oblōga,an guftiora, \& in mucronem definentia, lanugine horridiufcula, hirta, nigricétia, vti \& virgul ca, interdum albida. Flotem purpureum, compactum, in oblongam gloncrationem vilofa textura fert.Semen pullun, afperum, fupernè mucrone pilofo claulum, tetro odore, cuiufmodi vnue:G planta, quan ou legranum bitumen non norint, fi odorentur,vix vnquam olfacient poftea bitunen, quin illico etiam nondum vifun agnofcant, Confimi li Afphito, fed excellentiore, quod mirum magis eft, dote, thrn occulta, tum comperta, 


\section{STIRPIVM aduer farianous}

nim \& Theriacis mifcetur prefidio non vuigari: \& for is admotum, multò vehementius \& euidentius prima etiamóue I pecifica vi venenum è fummo cotpore reuellit, fecumónue eductum, quafi vin£tum, idé coercet :quodó; fan parti appreflum, virus non minus fxuum inurit, quàm erat infictura ferpens, vt puta Vipera, aut quxpiam alia : non illud fuo fibi infito nocendi vicio, fed alcititio reneno: quemadmodin capite de Anchufa, vel Echio,liquidò patet.

\section{OXYTR IP HYLLVM Scribonii Laroi idem videtur cum fuperiore.}

foS r v d Afphaltium non aliud effe quàm Scribonii Largi Trifoliñ acutum, Oxytriphylz lúmve dictú, piopter mucronatun extremum, quafi eminentem aculeum, quem habet, \& lanugino fa, plenioráque folia, vti author delineat, duum pedum fruticem, grauiter odoratum, montibus oriundum, fed Siculis plurimum, Italiæ rarum, nec nifi ad Lunæ portum, qui eft Thyrreni naris ora, inibiọ; fibi repcrtum profęturus in Brstanniam cum fuo D so Cafar Claudio, facilè fibi perfuadet qui meminerit fuperius dictum, haud facilè лifi eftuofis regionibus prouenire,uifi colatur, vt in horto Patauino \&salibi. Nec quifquam pute: aculeatum intelligi debere, fed folii extremum in anguftum quafi aculcum porrectum, cuinfinodi vifitur in ifto. Et de vfu ad quem commendat, nolcas certius,

\section{OXTTRIPHTLLVMA niterum Scribonii,Herbariorum.}

TV B N T E a senfi effemus nofrisperdoetisanicis,quos fentétiam rozaramus fuper alio trifolio, in fyluis aridifque collibus frutican. te, que primum tum vifum Scribonii Oxytriphyllum autumabant: nempequia proccrius, lignofius, atqus hirfutius vifitur, furmento \& folitis alioqui funilibus, fed minoribus, ternis \& quaternis, albicantibus magis, \&obiufioribus: fores non adeo in Siobum comprefsi, fed hiantes inzSis, ir deprelsi, atque albicantes : 0 dor aut nullus, aut pere riguus, nedí vt graucm tetrúmve olfacias, vti in bituminofo fuperiore: quod idcò huic preferendum ex cribonii verbis cxprefsius, ducimus. Prope Lugdunum \& Taurirum, etiamó; $M$ ori fpellii iuxta Gramuntiam Syluam iffud abundat.

\section{Trifolinm lutenm minimum.}

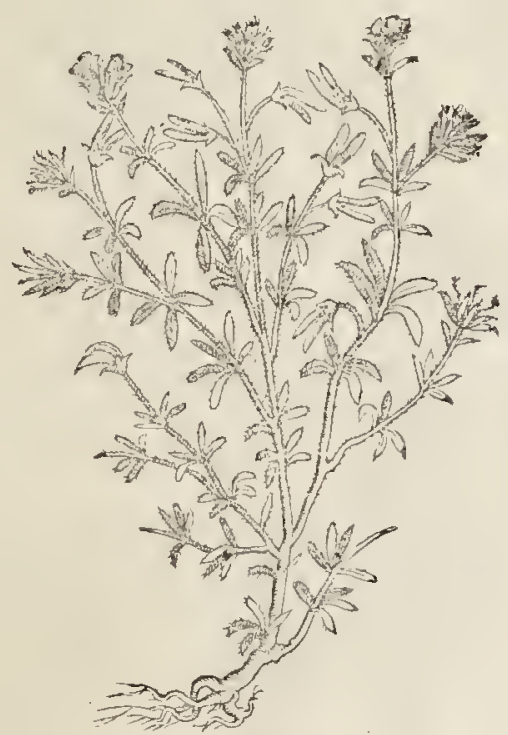

ES Jutenm minimum omnium, \& non ita peruium, gracilibus, pufillis, reptantibusiunceis, folio tcrno aliquantum crenato, luteolis floribus, in orbem compactis, in pratis \& cultis vifitur.

\section{OXYS PLINIANA, Panis Cuculi, Alleluya Offic. Trifolum acetofum.}

TRtroz a Oxys Pliniana, Oxytriphyllum itidem vocata fuit, non quidem folii acutie, 1 fed potius aciditate, qua cumvtilifsima, tum notifirima ef, pufilla videtur Lotus, opac2 vmbrolaqúte fequens, radıce ima fibrola, fumma mediaçue fquanıatim loricata, è qua plufculi 


\section{STIRTIVM aduerfarianoua.}

pluf́nli exeút pedicelli iuncei, ylabriq̣; \& prxtencri, quibus fingulis in extrem stria aptantur folia ret rò \& mutuò inflexa, qux turbinis cordifie picturam prxferunt. Flos ftelia tus, candidus, nonnunquam \& luteus, vti femen lutcum, in thecis oblongiufculis, \& perpartis.

\section{QV ADRIFOLIVA Plogtion fufchm bortorum.}

W E foret huic generi proprium vtique terna habere folia, fatum ne Naturx inftituto, I anc mangonio, incertum nobis: nam que fpectantur in hortis voluptatis potius quam vtilitatis cauGa,è pratenfium genere, tametfi quaternis, quinis, adeóque feptenis donata foliis, non difparibus Oxy Plinianx, cernantur: fed colore phxo, vel liuido, rabente: flores quales pratenfis, albidi funt, reliquíque non diuerfa.

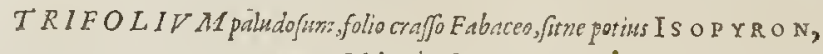

$$
\begin{aligned}
& \text { gramu Melinihiffecics? }
\end{aligned}
$$

PE R QV A m frequens paludofis riguif́uepratis Anglix, \& Belgix, \& Germanix, alibi non item,aliud trifolium: quod quia non nili in aquis viuit, aquaticum vocanc. Radicem, vt plęreque aquatic $x$, crebribus geniculss diftuctam, \& fibris merfam halset : folia craffa, viridia, tenerı, vt Phafiols, aut fabe, tetna, in fingulis ped ıculis crafsis, canis, \& porolis, viridantibus, è geniculis egrefsis radicis:indidemọue caulis confimilis, concolor, cubitalis, in cuius fummo flores candidi, ftellatı, Ornithogali vel Sagittę Plinii,alterno fitus vifuntur, de quibus mediis nonnullæ prodeunt fibræ, codémque tempore floribus defaxis glamx, pufilláve pericarpia,Hyacinthi fimilia, fenen fuluum cohibentia, Milii, fed minora. Hurc, cur, quafi potius Ifopyron, Mathiolus quoddam Mclanthium pratulerit, vix conicetarı licet:quando ille quà maximè opus effet, muffat, nec hifcere audet, in tritæ cognitionis rebusaliogui tantus hiator: elt tamen hac multa \& vocata Biberklee, quafe Caltoream Germanis, Belgis, 3 oxbedirer, id elt, faba hircina, ab odorc ol do.

\section{HEP ATICVM trifolitm, fue Trinitatis.}

IOS D E M fermè hxc natales \& vires, necita difsimilem vnltum fortita el, cum Oxy Pliniana,pręterquàm quod acidum non eft trifolium iftud: Quibufdam Italix \& Norbonæ montolis locis vmbrofifque fyluis \& vdis obuium \& inultum, præfertim Taturino collibus Eridanóque Circumpıdano conterminis. Rigida lyeme Ianuario ineunte, vel exacto, primulùm pediculi Violx martix, aut Bellidis, piloti, tenelli, palmum alti, floribus cæruleis, pallidis, ftellatis, Chelidonii minoris nó difparibus donantur, qui inu to inrerdum frigore, trans niues fuperftratas fefe exerunt, nondum foliis enatis, quę in diuer fis (vt violi Martix) \& fingulis pendula pediculis, diuffura, colore, \& fermè magnitudine Hedera helicis, aut potius Ciclaminis hederacei, etıam vrgente niue perftant. Semen ininutum capitula cohibent, apiculis herbidis, fuicis, conflata, conulimodo, aut potius $\mathrm{R}_{2}-$ nunculi.Radix capilloøa, fpara, nigra.

\section{FOENYM BVR GVNDIACVM O Medica. Gallis. Foin de Bourgoingne.}

F. Mrde regionis pafcuis iftud trifoliú habuit \& coluit Grxcia \& Italia, vnde vocauit Medicam, veluti etiã $M$ edicú malú citriū dicunt: Quare potuifet fœenú Burgundiací

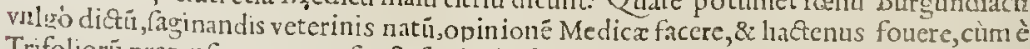
Trifoliorı̆ pratenfium genere fit, \& folliculü filiquofum, cóplicatum, orbiculatum gerat: feminc Fonigręci aut potius $M$ eliloti prægnantem. Flores ex cceruleo purpurafcentes. 
Scd cum aliud fit Medica tres in femine varietates. genus Trifolij longè pecorigratius \& antiquorum notis aptius, nobis ex recentiorum veltigatorú fedulitate geminæ Suppetent Medicx: quarum prior \& certior eftea, quam vulgusin Galloprouincia vocat Lauferdo. Ea fatiua propter v tilitaté, llic eft trifera, trifolio prorfum fimilis,prolixioribus tamen caulibus, humi fparfis, vbi magis foctaluxuriat, in quo rum alis frequentes
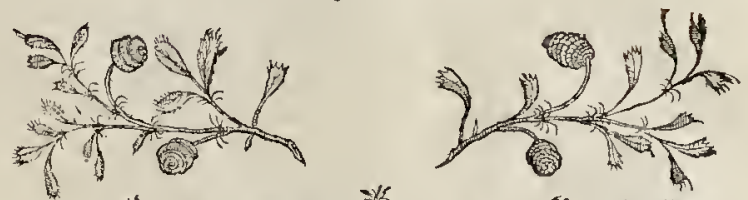

funt folliculi orbiculati, qui dum digitis infpiras expandütur,volutz figuram exprimút, dum autem contrahuntur, nummos exiguos multiplices fibiaggeflos pueri dicticant. Interdum filiqux hifpidx fune, interdú fpinofx, qux flores lutci, exigui, ternić; funt. Vifitur \& quibufdan locis tantx proceritatis,"vt dupló maior excrefcat, liliqua vero glomera tur in nucis gal bulumúe Cupref̣ ferè figurä, cui femina Geniftę femen fetè xquantia infunts

CHEDICA marina.

HA c S s p I v s vidinus illis perquàm fimilem maritimis paftim oriundam, Venetijs \& in mari mediterraneo, fuperioribus tota 11 inor folijs, \& filiqua \& fe mine : caules verò humum prxreptant prolixi. Lutei flores funt:caules \& folliculi denfiores, omnia tométofa lanugine obducta, vt Gnaphalıu \& alia maritima pleraque. Hanc cur refpuant viri docti haud indignam vel animaducrfione vel defcriptione, caufan habét nul lam,neque cxemplum: fi namque antiqui hac ignauia fuam ignorationem aut pofteritat is ignauiam fouiflét, longè plurima defideraremus, quorum beneficio plurimùm profecimus. Hafce enim infpectione \& vfu præftat notas habere, quàm nullas.

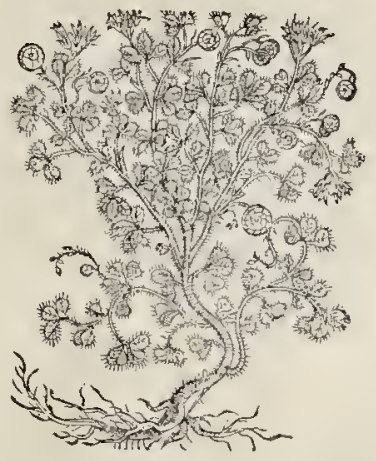

\section{AGOPVS.}

LAgopyrő, quia inter triticeas legetes nafceretur,quafil leporcum aut leporinum triticí iam tum Hippocratis tempore vocabatur : Diofcoridisautem æuo etiam Lagopon quafi pedem leporinum, propterea quód in pilofa fpica glumas villofafq; quafi ariftas mol licellas, Leporini pedis, hirfutič \& coloré xmulantes haberet. Sic enim in libro de vlceribus concife, fed fcitè defcribit Hippoc. Replet maximè cócaua, pura vlcera Lagopyros vo cata, Elt aūt triticcis, aut, vt alij legút minus aptè, furfuribus fimilis, quãdo aref cút, foliü pufillum, in tar olex folij, \& minus. Vnde non difficile conieftari ittam plantam in aruis 


\section{STIRTIVM áner aria nowa.}

inter fegetes frequentem vinuerf Europ $x$ valde vulgatam, \& gramineis Trifolijs accenfendam, efle genuinum Lagopum antiquorum. Siquidem tritieea eft fpica, inter triticum, melampyrtun, \& Alopecotum naícés, quibus êt nomine \& facie finilis lanugine \& pilis, mollicic \& fufcedine concolor Leporino pedi: folia Oleæ, fed multò ininora \& terna, è viticulolis cauliculis, pedé alt is, in multas alas diductis. Semine exiguo Sefemi,ninore, Sophir pari,glumulis obfito triticeis, aut trifoli $j$ bituminofi. Non parum huic aftrictionis, ficcitatis veròtantum, vt mirum feminis profuuio laborantibus præftet prxfidium. Eapropter vlceribus canis, fed iam deterfis is mundatis, non dubium quin carnis prouentum, \& cicatricem acceleret, vt vult Hippoerates, tumoribus veró inguinum \& laxis Hernijs colibendis peropportuna.

\section{$L A G O P V M ⿻ M A X I M Y M$, folio of facie trifolij pratenfis.}

To w perinde frequens, fed tamen inter eafde plantas \& fegetes nafcens gemina liuius differentia,altera cuus folia planc̀ eadem, minus tamé acinta, \& trifolij pratenfi propiora, caules fimpliciores, enodes, ferè rectos, cubitales ambitit, [picatas item lümitates gerétes, bunos pollices lóg: $2{ }_{3}$ craffiores: pilis \& lanugुine hifpidiores, villofis floribus trifolij pratéfis, purpura rubelis, fufcis, fceniceis, pailentibus. Häc Veganij, Norbonéfis in pratis,

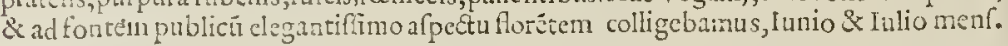

eALTERA mguftifolin.

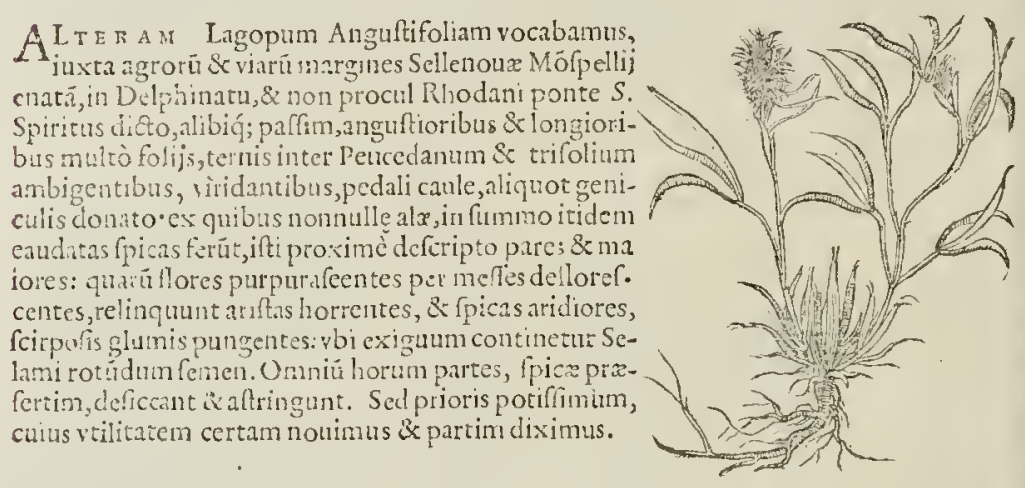

Hortorum odorit LOTVS, efiverior DiofC.

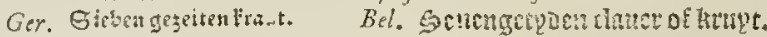

VMarbores, fntices, \& ali , fpeeie, facie, frnctu, \& foribus difierentes plant $x$, Loti diCantur,quapiam boniratis commendatione, potius quam inter fe contenientia, videtur hace noméclatio huic trifolio actributimquafi quod cxteris trifolijs excelleret, inć; paradifis \& letioribus locis oriretur, dietum foret Trifolium $\lambda$ Gr ou, Gue volupe \& voluptas, dे verbo $\lambda \omega$, vt fit adlufum ad $\lambda$ crspóy ys Vliffeos. \&- Epitherum apud Homerum,qui vocat rofcidum Lotum, Deorum lubeicentiam. Proinde conie Aura piena fert, veram Vrbanam illam verè dici J.ozum, qur domi hodic in Belvia, Germania, Anglia, colitur, decer piturs; ad oleum conficiendr̆,celebratum valde tumoribus contumacioribus, \& topheis demoliendıs, à tharmacopcis prafertim, qui vernaculo nomine vocitanc hanc senegetpoe elaucte, quafi fepties mutans die nempe odorem, quem illi aniffife, Se denuó recepiffe fingulo die arbitrantur. Sefquicubitalem leuiter firiatun ramofum ì funmo a dimü vfg; videas eaulem.Pediculos \& folia è geniculis edu\&ta, cuitufmodi Trifolij pratenfis, Fa

nigreei 


\section{STIRT IV M aduerfaria nous}

aut Melilotigermanici, fed ambitu obliquè dentata, pinguia, crafsa, habitiora, fubpallida: flore \& glomerulo pallido, Áphaltidis Trifolii, femine Milii palleo. Eximii odoris Metiloti,nonnihil gummi Elemnium redolentis, vnde mulierculis Balfanum dıctum, \& fand vulnetibus paranicum. Digerit quippe leuiter, \& infämatıones ingruentes reprimit mo deratè, robur parti tutando,nec fanè mul tò difpari vi quàm Fonigræcum aut Lotus oculis opem laturam putandum.

\section{LOTVS STLVESTRISDiofco.}

PA S s I m plurimáque quę dicitur erratica Lotus, fecus Lanii amnis Monfpelliaci 1 pontem \& crepidines pubet, in Anglix etiam vdis fcrobulis. Graciles, numerofos, bicubitales \& tricubitales fparfos multis alis promit à tadice lignofa, fibrofa, caules, quos nroxime ambiunt folia terna, mo!lia, rotunda, fufco virore, lauia, fores lutei, Genift $x$ aut Meliloti veri modo è geniculis imis fummíque copiofi, quorum caliculi poftmodum fouent numerofas vaginulas, teretes, oblongas, rectas, tubentes, nitidas, intus femine Sinap pari, cinericio colore. Sapor, qui leguminum quorumbam \& medicatus, vti Lupino, Phafeolo, \& Cytifi, quos odore ctian refert. Verum non intereft cuius fit odoris ifta, fed quàm bellè referat Lotum bicubito nnai orcm,nultis donatia alis \& Loti praten fis trifoliz

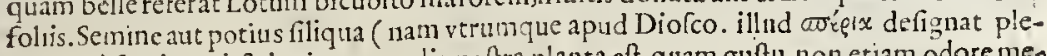
rumque) fonigræci, fed minore, qualis noftra planta eft, quam guftu, non etiam odore mes dicatam optat Diofcorides.

\section{LOTISS TRIFOLI A pratenfis filiguofa, Monfellienfium cus a Btmilatur Juperior flluefftris.}

T O paucis locis Monfpellienfis agti \& decliubus pratis Lanio Grammuntieque Sylue interieftis bumilis filiquataque Lotus inter Ariftolochias, Scordum \& Narcifcos repit, angulofis cauliculis, ge. niculatis, pedem longis. Folia in pediculis per totuni canlé terna, pauca, fubrotunda,crafsiufcula, fribpallida. Extrema caulia gcrminibus nónullis, mt:ltifida, 'uteum flo rem, buxcú, fabx fimilen fingtılú lingu- lis alentibus : ctian cuilibet, filiqua fuccrefente quàm foenigraci maiore, fed reCta \& fuperius retufa, quibufdam fecundum longitudinem imprefsis ftriis, fœnigraci flauefcens femen dum maturuit diffiliente \& oftentante.

$$
\text { AGYTIA LOTVLS, vel NILOTICA, }
$$

$V$ T I $D_{E R}$ M $\vee$ T A funt qux nufpiam in natur $x$ ditione ditifsima $\&$ inexhaufta cretare fuipicari aufi effemus, priufquam vidıfemus:ita plerum que fit ve nonnulla ctiamnum hodie arxiè minus venemur, qux aut prx oculis \& pedibus lacent, fed malc̀ aut mu tilè literis mandata, eoǵue incognita funt, aut nufquam terrarum, prout hiftorix produnt, oriantur. Idq́ue cùn noftratibuı non paucis, tum vel maximè peregrinis in ftirpibus agnofcendis nobis vfu venire veri fit fimile. Hafce enim non vifu, fed au ditione plesumque difcere foliti fuerunt fcriptores, eóque fidem liberandi caura $\$ \propto \sigma i$, vel źóke, aut finilc quippiam addere foliti funt, quafi non alferant, fed duntaxat hiftorię rexendx gratia inferant: Quod videtur vfu veniffe in hac Loto Theophrafto, fufiorem

$$
\text { K k.i. }
$$

enim 


\section{$386 \quad S T I R P I V M$ aduerfarianoua.}

nibus repetiris, que fufpiciptionem dar,omisisis foliis \& contrariis feminis comparatiomas videas firpes plupious locis aciunt luxat $x$ liter $x$, aut recenfionis mendof $x$. Plurimas videas ftirpes pluribus locis obuas, mò \& menfis, quarum aut perperam ant fabulofe Jium, Quercus Larix perennis, vel ipfa Exemplo funto mandragorz radix, filix, trupoetian perplexius minuaris a ne longius abeas, nobis quàm multa \& frè̀ relata funt, rifue plantis vulgus, \& interdum eruditos confulentibus, nis etiam viris qu a tione tenus prodita? Necidie, mniltis enillibus pauca, ninus accurata, aut vera, audibus, aut lection bus que ftotels, huius Alexiod Diolcoridi e Crateua, \& Theophrafto huic contigit ex Aririç fuerunt.

$$
\text { MILILOTVS Syriacs. }
$$

MEI I I odoris ir coloris gratia Mcliloto,fue Melita Loto dicta, coronas texuerun prifa, quibus caput redimendo, non voliptas modo peteretur, fed etian aftus febriléfque difemperses arcerentur. Omnium quas nouimus huius familia longe aftus feclegantisina, qux è Syriaco Alepo ferricepta fur \& coli hup ranilix longè optima 3 1552. \& tertio, caius etram a ad Angelum ofticini. Copiofs fefertos proftare meminimus Venetiis, in Martinelli tun alis, geniculis cobribus diltuticat ramofifque cauliculis hine inde deflexis, cubililotive communis, minuribus diftinetis: vnde emicant folia in pediculis terna, loti Metaferia \& modo, vt in Securidaca, aultum ferrata : \& fores lutei pallidi, fipati certiori bafi, in mucronem aduridaca, aut Aftragalo. In fummo vaginulx hamate S è Jacomprefsius, exilius oducum exeunt roftri Pfytaci non difparem : femen Fonugraci cendx, fed multò odore Meliloti Germanicx, vel Gallıcx, hîc proxime diIalic Melilo- natiuioblita, nonnihil corniculis min dccennium perdurante. Sata Patauii,quali foli tus. Illlc nomen retinuit Italicz; vbi tamen falcatis, lunatis, \& ignauiore odore degenerat : Supplemento eft.

Germanica o Gallicas,

No S T A T E s verò dux germanicx, Gallicxúe nuncupat $x$, odore quidem inferiores funt, fed multò proceriores fruticant, ternos nam que cubitos æquant virgulta crebra, teretia,ramofa, lenta, crebribus folis in exili pediculis ternis, fonugræco aut potius Buritipant complures, Ixniter dentatis, carnofis, fubpinguibus. Cauliculorum fummitates nianæ, fed ininores, flofuli, ferie apti, penduli colore \& modo geniftellx, fiuc Luteola P Iinianæ, fed minores, interdum \& cani. Semen in vtriculis, lutcolis herbidis exile, \& perpaucum. Vbiq́; iamdiu huius inoleuit vfus, propter facultates compertifsimas emoli\&eptico, naturx amico \& altrictione moderata.

Llotses altera pu- Lon fuperat \& $\mathrm{r}$ in horto amici cuiufdam alitur huic per omnia fimilis, nifi quia cubitum filla. tus, Syriacz gratior: fed quia alis Araci modo, femen non difsimile habet, vtrique odor gratus, Syriacæ gratior: fed quia aliis de 110 tis plufculum differunt, hafce putarim corollis non adeò expetitas fuiffe. Illis tamen ueutiquamad Medica commoda cedere.

\section{MILILOTYS CORONATA}

WON DE N I H I o erat, quod quidam perfuaf fuerunt, illam Lotum qux faltem pro Melilotis, viarumq́ue marcinibus lrtatur, Sertulam elfe campanam, aut accedit, etiam filiqu ofa ef, \& floré perguppe praterquam quod nulla propius ad Syriacá vnde plebi Gallicx Corona Rere pcrquam hilaré,,corollæ aurex fertíve perfinule habet, Kamulos fpargit hinc ind 


\section{STIRTIVM aduerfarianout. $38 y$}

terius trifolij pratenfis cxfis caule enatis plurimuin quinis, $\mathrm{cd}$ in pediculis ternis, vti in Loto fylueltri. Flores lutcoli vel mclini, nondum explicati ex flauo rutilantes, pifi effigie radiatin \& zquis fpatiolis diffiti Coronidem exprimentes, Sapor qui leguminum ple-

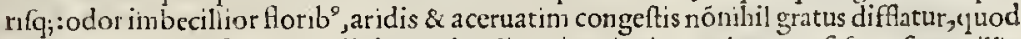
mellis odorem pręfert, quen linimen tis relinquit, vti etiam colorem:vfi fape fumus illitione ad vifcerum feruidorum materianı concoquendam in tertianis nothis, ex floribus oleo imbuto, quod etiã oculis op timè facit. Ea Pharmacopceı Galli prę̧fertim, plurinuùm vtuntur xque tuto atque Meliloto, nufquam non Anglix Galliæ, belgiæ frequentiflima. Siliqua LoziSy'lueftris,

\section{Trifflinm FOENVGR PCV M ditum.}

$\mathrm{R}$ A $\mathrm{R}$ o aut nứpiam nifi cultu:nam quod ruri ortū putatur Fơnugracú, quiburdam locis itı Italia,ambigit inter Lotos. Et Fonogræcum hodic adeò notum eft ve qui lotos norit, neminem latere pofit: duntaxat differre videtur fillqua, qua maiore magifque adunca, acution ftyllo eft fonigrecü, albicant flores parui:inq; caulibus partum ftriatis, cubitum \& féquicubitun lógıs à teretibus folla funt, ternis è pediculis, loti $x$ thu\}a, alig̨uantú crenata. Seminis fului angulofi Securidacx, fed rotundioris, maximz in re medica vtilita tis focta cornicula. Quo pararur oleum viribus quam quifquam credat maioribus, ad inteftuorum latétes fcrr ros diffipandos, \& frumis perutıle,

\section{CYTISVS}

TRifolius ifte frutex Lotufice gentilem cognominis infule

Cinthyfe qua: vna è cycladibus eft appellationem fatetur, vnde reliquę Grecix Latiog; factus conmus nis fuit. Et mirum quanti putatus ad pecoris paftiones, laetis \& prolis prouentum, Quare qui wut:-., hoy ex Poetis legunt, polfunt apte interpretarifocurtium fonum, quod multum ranguibis viriumą feminis abfóue quo friget Venus, fuggertit. Din nos anxios \& ambi gos animi habuic Cytifi veri hiftoria \& expenfio. Verun fubduEtis hinc inde rationim momentis \& collatis varijs plantis, quas refpuebanus fiperamus tandem pto barum iricandidis arbitris. Qua quis Roma regia via Florentiă adit, oppidulo, cui nomé Aquapédule, (ni perperä in Pàlinxefto her bario notauinı') decliui \& depreffa etiam planitie feracifima Cytifum fruticem 5 . fexúe cubitis pro-

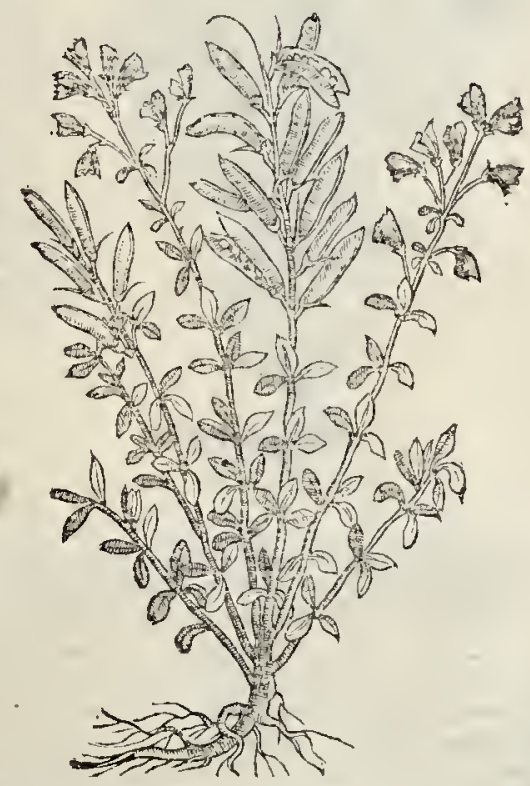
ceriorem Genifta farmétis pluribus, gracilibus prædutis, ftriatis, vidinus ftatim ab ino aut paulo ftuperi' lignofa radice c̀ te nuibus pediculis: folia terna, non ita numerofa finnilia fcenugręco, anguftiora, habitiora, rutacea: geniftx vel Sparti aut pifi fores Iutci, fed mi nores: Siliqua Genifte par, cinericia, gracilior, comprefsior, intus loculis funt difecpta fe-

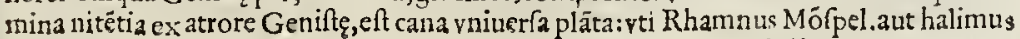

Kk $\mathbf{k}_{i} \mathrm{j}_{\mathrm{o}}$

Sapots 
Sapor Ciceris aut fimilis leguminis odoris fanè iam non fuccurrit : aridam enim \& inodoram duntaxat habemus uulfam Norbonę,prefertim, ad radices mótis Calcaris prope Veganiú:minus procera tamen,fed tenerior pabuloǵ; aptior eft, fortè quia dum in mon tes abigunt pecus, vt quotanni: faciunt, paftionis latioris, atg; $\mathfrak{n}$ ftus conuallium declinandi canfa, ineunte Maio \& Iunio, Sole in Arietem ingreffo, teneriufculos germinationum foctus, florum filiquarumć; fpem liguriunt oues, \& capellx. Eóq; Pocta venuftè ex Theocrito canit. Florentem $C_{y t i f u m}$ Salices carpetis amaras. Hæc, vt fi qux alia apprimè quadrat Diofcoridis, Gallenique Cytifo : na!n ecquid cadem fit Theophrafti haud magnoperè folicitos facit nos, quando ille in defcribenda minus folicitus fut, qui de Lotis alicubi monuit, plerumque vfu venire.vt eadem voce plurimum diuerf $x$ plant $x$, effigie tradantur. Qua propter vti Antiqui Cytifum yocarunt Fenigrxcum, Lotum magnam, \& Trifolium, propter figurx aut naturæ coninnctionem, fic ex varijs confimilibus fruticibus Anagyridi, Labırno, Colnteę, incertum vagumque vocabulum remanfit.

Ternatiem predesm binc folit, fed pictor, guiz emarcherat, minus arimaduer. tit.

\section{Nonfaters.}

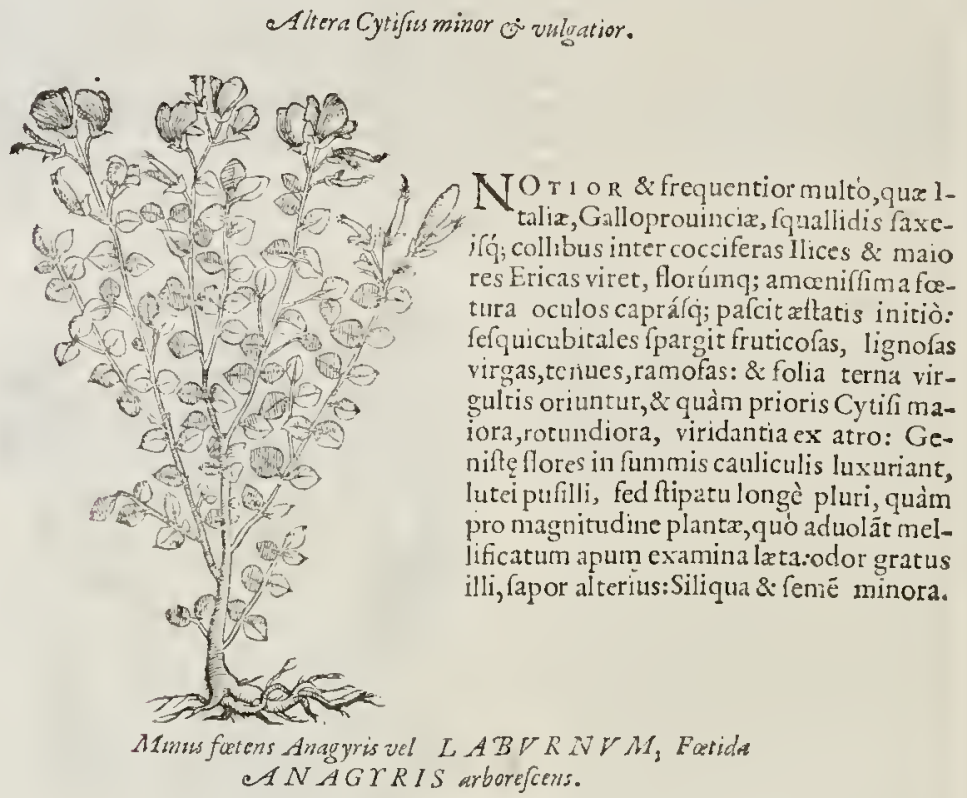

$A$ V T regio aut putor quem ciet, huic nomen fecit, locúmq; prouerbio, Ne moueas \&ُygen yúphn dedit:idcircò nauteam, à naufea, quam mouet, $P$ lantus vocauit. Cognati antern generis videtur, fi non genericx differentix, Anagyris whtuofis conuallibus \& riguis, prafertim Galloprouincix oriunda, cum illa montana \& alfiofis Alpinis proueniente, quam Laburnum \& Anagyridem non fotidam nonnulli autumant. Plurima hæc Taurinis mon tofis \& collibus Pedemótanis, Vere ligulis vel pannulis confpicua luteis, pralongis, pen dulis, congeftis multa flofculor um ferie, Sparti Geniftellæ aut Cytifi non diffimilium : folia tern Afphaltidis trifolij, Cytifi,aut Polemonij longiora, ex pallore viridia, filiquulis, multis Geniftellæ aut Cytif, vл: pedicello hærentibus, minoribus, minúfq; latis: femen item Cytifi aut Galegx,oblongum, vel Genifx: fruticat ad arboris proceritatem, prædura materia, rufticoáne inftruméto nata, intus nigricante, foris Fufarix colore,ex Alpibus Heluetijs in Germanię \& Flădriæ hortis florentem vidmus, fed perparum aut nihil fœeti dam,tainet fi fœeteat yernaculo folo: effe Laburnum Plin, vt non magnum operaprecium puta- 


\section{STIRPIVM aduerfarianona.}

putamus probare, ita ct valde verifunile fed huius Romani ne imparatiores minufóuçaccuratx fuerunt in hac hiforia tum fynopies, tum veriones, vti lexcentis locis, ac proximo Anagyruds capire, nranifeitum fic.

$$
A N A G T R 1 S .
$$

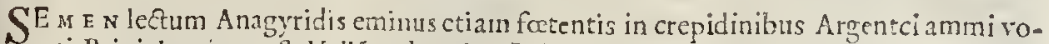
cati, Biniolam inter \& Vallü vrbeculas Galloprouiıcix, in Belgio creuit,etiamó; Londini nobis prouenit in Morganı Vireto: folia item terna virgultáque Memantis Trifolii: minor tota fruticat, minus dura materia, cortex nigricat, flores in mufcolis thyrfis racemofi, Napi ant Raphani, aut Braffice, lutcol, filıuis longioribus, latioribus, fencn cohibetur, renis Phafcolíve effigic, durifsimum, pullum, nitidum, fubpurpuretm. quin fit vera nulli iam dubium reliquit femen \& foctidísimus odor, vnde nonen illi \& Adagio locus,

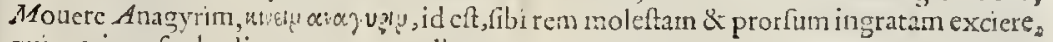
quia rarior, vfus hodie paucus aut nullus.

$$
\text { DORTCNIVM ETronffollienfinm. }
$$

$\Delta$ gérwov, quemadmodum toxicum, quibus fpicula cufpidatáve tela infici folita fuerant, quò celeriorem unolirentur perniciem, nominatum fiutle par cft. Mulrum verò abeft iftud hic appictum ab illis dia abus, aut tribus plátis, quas uñulli hariolabätur fore Dorychnion, quxífue nullum o perxprecium conmemorarc,vt1 ?hyllereă, Veficariú co:dis effigtelegamen, \& alia: Nam iam Jiu Rondelletii Praceptoris, \& Scholx clarrfsim Nitiobrigum penc̀ cunEtx familix diuturna conectura, iftam plantam Dorychnion ftstucbat: creberrima quippe illic \& in Gallo. prouincia fruticat (non perinde in Italia) farmentofis, lignofis, duriformíị; virgultis, tenuibus, flexilibu s, rcetis, fefquicubitum, \& binos altis;numerofa alartum fobolc è zcriiculis imis fummo tcuus per interualla folioJa habente, incana, cópluria, Rutaceis, Chamęleę, aut Olcx nuper pullulätis multò exiliora, mulcis forculis mufcofis Olcx , vel Quercus, per cacumina candicantibus, ¿゙ in radiatis quaf vmbellis relinquentibus theculas vel folliculos albidos, inembranofos, rotúdos, oblógos , terctes, Loti fylue-

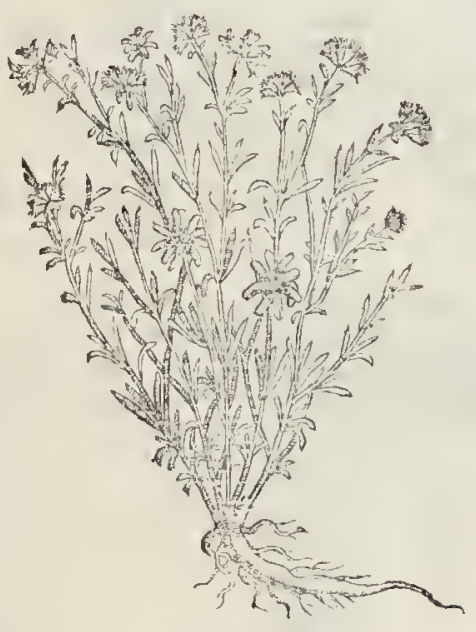
ftris femina quina, aut fena, nigricantia, arentia, A raci fylucteris, aut Loti fy'lueftris condentes : radice lignofiore, gracili, prolixa, faxofis fterdibus id Frontignanam \& maritima Norbonx oritur. Guftu cit infipido fermè plantu, \& vt rcor, refiggerantis, non humeEtantis facultatis.

$$
\text { POLEMONIVM MAOrfollienfium. }
$$

$H_{\text {V I y }}$ s eft finilitudnis Polemonium, quafi dicas bellatum \& bellicofum, H cuins inucntione fibi vendicanda certatum inter Reges fuerit: Quippe qux herba effet $\chi(\lambda r o d v$ swas vocata, id eft, mille viibus predita, authore Diofcoride. Nullidum recentiorum nota fuit Tolcmonsa, ac ne quidem illi nouo huius çui tadiato Appollini Vercellenfi Math. alioquin amico non vulgari, \& hac in palęftra riuali: ac nc nos quidé fortè nouiffenus, nifi Rondelletii præceptoris \&: Guiltielmi Peliferii Monfpel. Epifcopi, \& A frati faraci veitigatione, factun fuifet, vt non multis ab hinc annis vnicierfa Acadenix illic fucrit notitiz vulgatifsimx, etiam viribus explorando compertis : nam frutex iple vndequaque exquifite quadrat delneationi Diofcoridex. Virgultis multis, lignofis, retus, rotundis, gracilibus, cortice pullis ex virore, ternos \& quaternos cubitos altis, Kk.iij. 
in quibus ad vfyue funmum hęret viringue pinnatim ramuli \& folia tema Cythifi,aut liutx,maiorn, fatutè virenth, crafsiufcula \& rigida. Flores Maio \& Iunio cm icant lutei, pufilli, rt Ialemini, qui cedunt baccis nigris vnà circinnatim collectis, plenis, paribus liguftri,aut Corni fominx, fucco hyanthino; vel atro purpureo inficientc pregnantibus. Radice prolixa,tignca, implexa, \& vaiio flexufparfa, intusalba, faporis nennihil acris \& amari, etutfu difficilis. In Monfpellio agro,ad Caltri noui aridos colles $\& \mathbb{x}$ fuofos margines oliuctorï \& in luci Grämîtii cäpeftrib? faxofis quamplurima. Gal lis, Belgis, \& Anglis hortisian quidé.culta, fed putata \& vocata a b illis genifte peregririẹuedäfpecics. Pueriliter hic nönulli am-

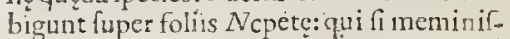
fenreffe fpeciem Calaminth $x$ Pulegii, planè folis fimilibus, \& paribus, lubenter de Behen albo \& rubro steriusineptire definerent: Suntenim Pulegii, Rute, \& Polygoni,

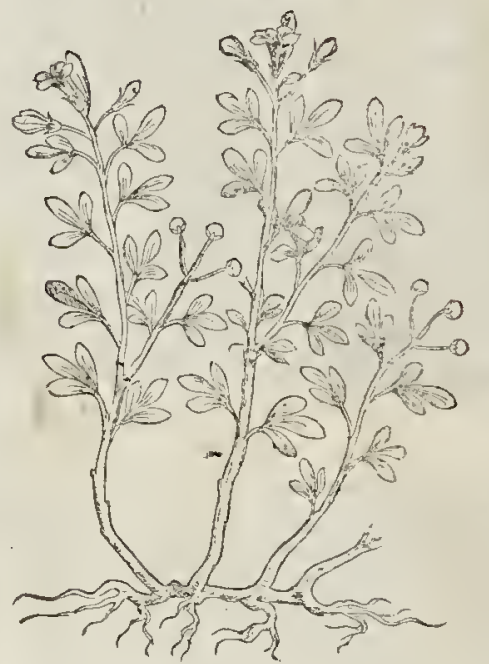
folia non adeò difparia interfemagnitudinc, vnde etiam difcas, quid Calamintha alte. Ia, feu Nepeta Diofcoridis, fit.

$M A I O R \cdot C^{-}$bortenfss Ruta, Syluefris, $\dot{0}$ ci perquám fmilis fucie? Norbonenfium Peganium, finc anguftifolia Rutula.

SEMP E R virentis hortenfis figura trifolia, fatis es fupcrioribus innotefcet, tum ctiam

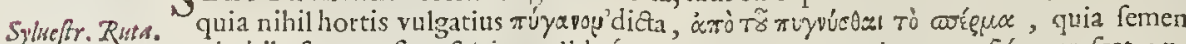
genitabile fuo prxficco fpiritu calidoq́; vapore \& tctro coagulctur, qualićue arefcat, vndeferilefcunt, prefertim viri. Agrelti autem Rutzvires vegetiores, \& odor vehemen-

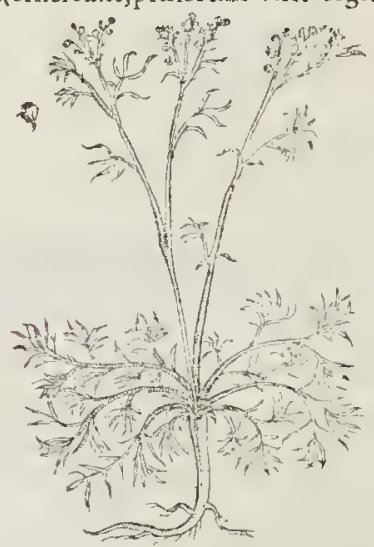
tior multò, adeóque virofus \& affatu periculofus eft: interdum cnim va porem ipfa planta intuentis vultui afflat, aut tangentis manui inurit, qua fi facicm attigeris, Erifypelas, aut Scabiem excitabis:alta cubitum eft, holtenfis, \& caule minore, fed foliis fermè iifdem exilioribus, Peganio pauctoribus, filiqua \& feminenon difpari: fed no perennar,ne in hortis quidem Gallicis \& Batauis fedulò culta, flofculis herbaceis. Minima maximè omnium virulenta, anguftifoliola, tota pallicio vi-

PEGANION Norbonen.fine Rutula. rore albicat: emperri fermè habitu, fitu, \& rigidirate, cetera non nifi magnitudinc nultò difparia. Aridi Monfpelliaci colles \& faxeidencxivtraque fcatent. Vtriufque femen, prefertim minimix, maximi ad arthritidem, \& molas, \& humiditatcs vte ri vfus Medicis illic. An Harmala Syriaca fo $S E S A M O I D E S$ magnmss
Dioforidis?

TJE $\mathrm{R}$ M illi Syriacx, quæ non modò Venetis, fed etiam Belgicis \& Anglicis viretis facilc̀ propagatur, tametf funt capicula, fet pericapia, fimilia \& trifida, aut triangula, ta- 


\section{$S \mathcal{T} \cdot I R P I V M$ admerfaria nous} men odor ille vehemens notratis illi defit, quem fi quis folı mutatione amiffum dicat;
fciat ex Syria quamrecentifstmo fenmie fatam, inodoram protentfe. Atque inter Rutaccas, quas plurcs habemus quàm Diofc. nulla minus hic Rutam prafcrat, \& fapat odore \&. guftu, quam Martinellus mifit è Syria, Harmalámque primus fecit non infcita cóicâura

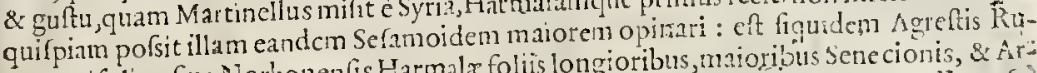
tx tenuifolix, fue Norbonen fis Harmalx folis longioribus, mioribus Senecionis, \& A r themifix tenuifolix, flore Hyperici, red albo: filiqua triquetra, Sefina minoris effigie, femine intus pullo vel cinereo, wuttu acri, anaro, masore Hyofchiami albi: teatui ratice, lutea. Ex Syria per Italix hortos, indéque Gallicis, Belgicis etiámque Anglicis viretis not: Nec fi non effet purgatrix hrce, illicò foret id eò reircicnda:quippe antiqui Helleboro foliti crant addere quadam, quz vires catharticas, vel accelerarent, quasíque ftimuli vrgerent

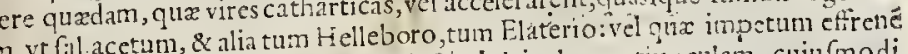
metionem, vt fallacetam, a alialiculas, aut la ois dulciculam potiunculam, cuiufmodi medicamenti moderarentur, pofterior çtas quamplun

fuem confolatoria dicta. Nec hanc inf crne detion tribus femiobolis albi Hellebori, ve fufins in Hellebouns.

$$
R V T \text { A trimigulo pricarpio. }
$$

V A N D whabuit nobífque oftendit Rutam aliam Rcgius profefor Monfpellienfium Irbertus, cui triquetra filiçux aut vafcula crant, nec ramen fajor cęteráque facies diuerfa à vulgari Ruta:quamobrem arbitrabantur.Italf (quorum in hortis adoleue. rat) lianc effe propiorem Syriacx Harmalx, quàn fuperiorcs dictis.

$$
C A N I N A R V T A \text {. }
$$

$R E$ CEN T I ORYM infuper quatuor funt plante, qua virium nut odoris cfficacia, is - témque effigie, Rutz nomen vfurparunt. Nec enim Caninx Rutx vocate Ruta vulgaris cognatz eft, nifi paucis \& vagis notis. Sed , fi nomine deficianturi, illo communi imherb $x$ opem celebratioribus fol am and , fatis, \& marginibus, cuitumodi Norbonx; Ra pertiantur. Raro, nufr locisficeis feruids, atis, cemas multis, fe fquicubiti folia Rheadis,

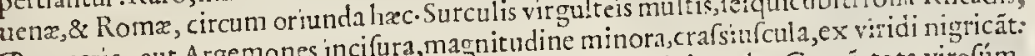
Papaneris, aut Argemones incifur, vti \& flolculi, xftate hiantes, alterins Veronica vericarpio, Rutx ferè aut Blatsarie ritu, fed ve Rutacco ingratiorem vibrat odorm. Mar reieex Alcex Venetc, quam folis \& odore

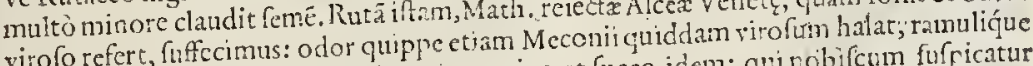
virofo refert, fuffecimus: odor quippe ecam Marat fucco, idcm: qui robifcum furpicatur exilesfunt. Succus verò, quem Meconıo xquiparat fucco, id ins a fpumci conferendas in

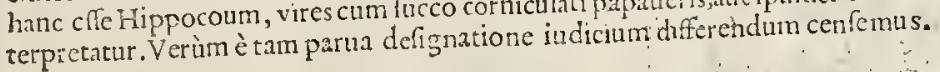

RVT A Traterfis Herbariortm, num, PHE I. I A N DR I V M Plin? quodpotius $S$ A X I F R A G I A llircina vudetur.

$M^{V}$ L T o adhuc magis Ruta pratenfis dieta abcft : Plinianum hanc $P$ hellandriun dichi tabant Lutetiani nonnulli noftra memoria, quòd propius A A pirim accederet quàm Rutam, cuius isihil nifi odorem virofum fortita eft: eodemǵue argumento ad calculum laudabant, \& Saxifragium nuncupabant alii nuperi intempeltui nomeclationum arum tores, qui tum demum fe opereprecium putant fectite, ex Pus auribus ivulgi aftueta no-

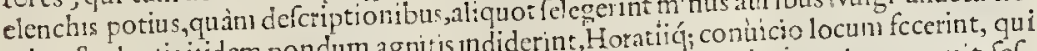
mina, \& planti itidem nondum agnitis indident, itur hxc pafsim, caulem promit fef-

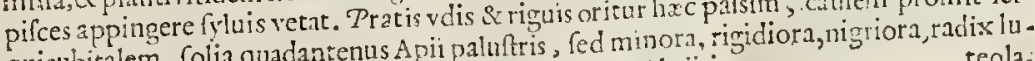
quicubitalem, folia quadantenus Apii palutris, fed $\mathrm{Kk}$ k.iij. 


\section{STIRPIVM aduerfarianous.}

Nonnulli valgo teola, fibris multis donati, latćque humi fufis, Afclepiadis modo: flores ex luteo herbacei,

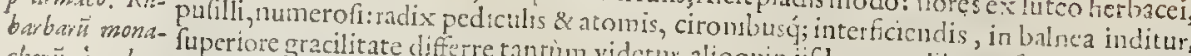
chor $\vec{k}$ i rubore remisioribus prixdita eft. vocirant.

Ruta pretengis

$G A L E G A$.

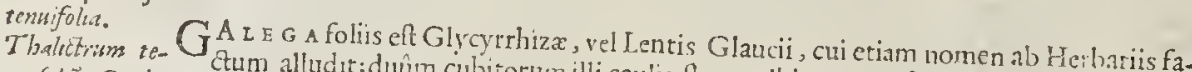
wnyfoliü Cordi. gis filiquis femen exile. In redemonti caulis, flores albi, purpurafcentes, in teretibus, oblötim luxurjat, palsinque alibi. Satis liquet planie, iuxta Eridani fuenta \& Taurinum vberne, Rute nomen inditun illi. Guia veluet, non ex delineatione, fed potius excfectioquia venenis efficacifsima, vti Ruta, odor ipfe potius Leguminis, cui videtur frmilıs: fed neti namque $P$ hatmacopci atque eriactur, cólmili vulgo nomenclatura donatur. Vegenda caufa circumferunt, atque etan Circulatorumillic fex, qui viperas ltipis collibent; eadé multó magis freti, quànillis decauri funt, nihil certius hac aut prefentius ha-

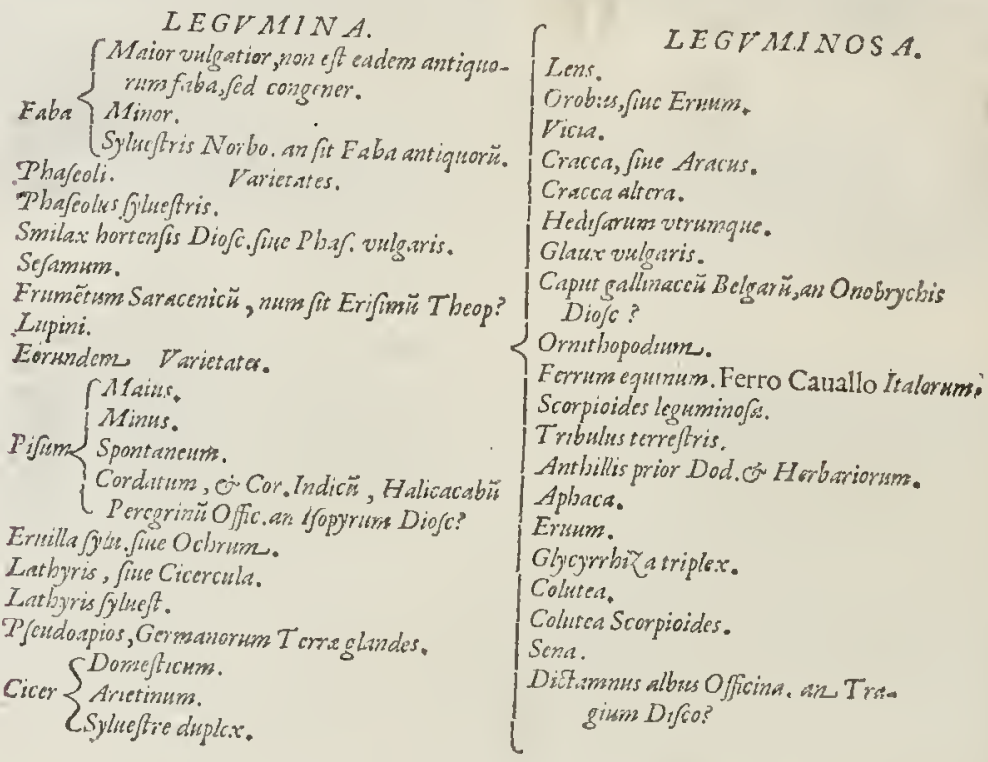

$F A B A$ antigrorum corecentionum

Germa.25onnen. Gallis. Feues. Ang.'Beanes.

A GNovmvs fuperius triticea cum Leguminofis magis quadi vfus \& partium propor tione conuenire, quàm delineatione: $n a ̄$ ve illa fpicátur glumis \& arifis, fic hæc grauidan gendo Latini vaginulis, vtraq; magno vfui tum pecori, tum homini:illa à terendo, hac à le verò orogíx, quafi fatiua aut feren falce vtiilla, fed manu vncóve auellêdo legerentur. Grecis mina nó parü føcüdıra triticeis, ni quòd fensenté multo fonore penfarët:funt enim leguà qua quidë feracitatis facilinte nunoreć; tempore \& labore, fed maiore prouétu colürur legum, na Fabas, quafi præonantes \& fers vocarüt, vt Galenus annotat, antiqui ferè cuncta

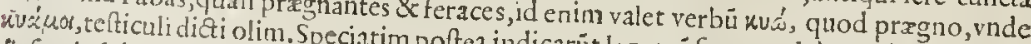
\& Eami plebeia adeo yul Speciatim poftca indicarüt lcgumé fama multò omniú notísimủ

cra- 


\section{STIRPIV $M$ aduerfaricnous.}

barü delineátionen nó tam rudem, quàm nullä rcliquerint. Cùm autë prx Faba Theop. Diofc. \& aliorum antiquorum iftam vulgarem noftram, vtpote maiorem, pinguioremq́, potiorem duxiffet pofteritas, eal penè cótempta, hęc noft râs fola nomen Fabæ fubripuit, retinétq; etiamnum hodie: Antiquorum enim Fabula fue Fabellx, pu fillæ tamctfi, veluti pares, Loto \& Terebin tho comparantur. Taxiq; bacca naior quam faba afferitur apud

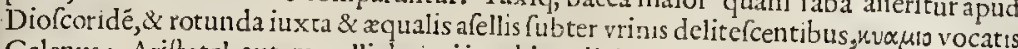
Galenus : Ariftotel.autem pulli decimi incubitus diei oculos maiores Faba facit: tamen non illicò noftrates è Fabarum cenfu amouent, vt placet dofiffímo \& modeftifimo Dodonxo:fed id nos docent,eorum Fabam fuifte minorem, qualm lodierna, nec tamen foecie diuerfam, fed congenerem, \& potius fructu, njagnitudine, figura, quàm plante natura temperamento, aut lineamentis diftare. Nam Theoph. \& $P$ li Fabam, qualıs noftras eft, defrribunt caule refto \& vnico, folamạ́; inter ligumina, vt plurimum, culmo tradunt: $\&$ multis locis Diofcorides caulem Fabx quadratü dicit, \& florem Fabx Peryclimeni afe rit. Sed id cuenire, quia variant magnitudine, colore, effigie latiore, comprcffiore, tereti rotunda. Et frequentiffma hodie Faba nottra nuaior, rarò vfpian tamen nifi fata prouenit, ferunt quippe in fcrobillas paxillo depreffas. Quare vit non eft difficilè noffe iftam va? garem Fabam, maiorem, longiorem, minúfq; rotund am effe, quàn antiquorum Faba fuerit, fic eandem $P$ hafiolum Dolicumúe affercre, neutiquan licet per coldem authores.

\section{F AB A Minss.}

Atera,qux minoreft, Italis \& Belgiofatu frequentiflima ad veterina alenda, fed nufpiam vfus frequentior quàm in Anglia, vbi panes Fabaceo: veterinx potius quànu trit1ceus dant. Hæc non multum videtur abeffe à Gręcorum, quan fuperius expendebanus, Faba:Eft enim ea illis adhuc vitatifima, frefa imbi vocata, ad pulmenta expetita: \& Italix, Venetijs pręfertin, wulgo Fana menade dicfa.

Sed fyluettris, qualem fxpius in Galloprouincia \& in Botoncti Ericetis fterilibúf 7 , non Syluefris. procul Monfpellio enatam legimus, tota minor eft, fefquicubitalis \& cubitalis: \& culmi quadrati, minus rigid, furculi, communis Fabx folijs, quafi egen sadminiculi, \& fupernè in cirros, capreolófve $P$ ifi definentibus, flore Vicix obfcurè purpureo, \& filiqua dum matu ruit aliogui nond difcrepat: cohibent autem quaternas Fabas aut quinas, guftu Fabaceo, fed non ita gtato,odore grauiufculo, magnitudine Orobi, quem Diofcorides Tithymali $P$ aralij femini comparat.Plinius quafi æqualitatem hanc $\&$ p parlitatem inn teens, Fabe pa rem tradit : qux nosadducunt, vt non inuiti credaruus hanc pre cęteris delineationem Grece explere. Quando etiam hæc non fecus atq; antiquorum Fabæfponte prodeunt, in locis Gallix paulò antè dietis, queenadum illx è Fabarijs infulis, quibus cognomine fuiffe ferunc autores: tametri malim effe illam Cherronenfem in Mari Euxino, quàm in Germa nio fiue Arctico Oceano, vbi terra alfiofa, \& minus olım nota Græcisaut Romanis fuit: nec puto in Dania infulifúe finitimis hafce reperiri, eam tamen volunt effe Cymbricam Cheronenfum fue peninfulam Plin. autoritare.Itaq; illam vulgatiffmã Fabam amifam putare, tam parú verifimile eft, quàm filigine laudatione tritico carere nos, de quo tamen fuerunt controuerfix inultx. Sed noftrates Fabæc cum caulem quadratü, ręum, furteetü, vnicum, ve plurimum folx leguminum habeant Theoph.\&P Plnadratu, antor itate, \& particulatim floreant, ipfíc; flores nigricantibus lituris (quas litur as lugubres rati Flamines Romani, non mandebant, vt tradit Varro)ir fịniätur, nč effe hux́uous fiue fabas nolim affentiri. Et in ipfius frualus latiore quafi bafi, qui cernit nigrum veftigium illud, quod hilum antiqui vocarunt, quafi germinis vmbilicellĭ \& inuolucrum, neutiquam vulgares refpuet $f_{2}-$ bas, quibus penè id figni peculiare eft. Ipfretian in duas femifes fponte ferè \& natura diuelluntur: \& planè tot iifdemq́; facultat ibus compcriuntur,quas antiqui prodiderunt, tum crbo tum medicamento: nam flatus \& tetra infomnia excitare, vulgus etiā queritur,
$\&$ ad vlcera abftergenda, att; carnem procurandā quiuis chirurgus hârum farina vtitur. Quamobremn non alı́ diffideut à Gręca notiffuna illa noftrates Fabx Germanorumúc Boonę, quàm magnitudinc \& oblongiore teretíve figura:quæ cum in plerifque eiufden! fpeciei \& naturx pomis, nucibus, \& feminibus, tum in Cicere fatiuo \& fylueftri,difcrepant, Diofc,monente: nam, inquit, à fatiuo nihil differre, nifr fernine tantum.

PHA- 
PH ASELI í Fabis \& Phafrolis difcrimen.

T)Erpauca extant apnd fcriptores antiquos de Phafeolo, quem Diofc.xgrè concoqui, in fationes aluum \& vomitum ciere tantim dici: Galenus autem à parróosa Dolichoncm difcernit,cundenzóueCicerulr aut ciuf́dem fpecici vult : Quod Plinius videtur innuffe, \& Malo vbi canit Scu pinguem viçam fercs, vilémve Fafclum : vilisenim meritò dicitur, vt cuius tantum quafi noxij aut parum vtilis meminerunt antiqui, eoque incognitum penè reliquerunt, nifi quantum ex Cicerculæ collatione percipi poteft, deq́; Ga. Ieni fententia, fortè \& Plinij verbis, qui Fabx folia rotunda, Phafiolo autem Pifo \& Eruilia longion \& venofa feribit: quẹ accip enda effe de Phafelo potius quàm de Phafiolo vidcntur, quia phafiolo Colia funt rotunda, nec venofa. Et apad Columellam etiam pufillum legunen vilećuc intelligi videtur: quando Phafioli modi quatuor obruuntur à totidem operis: nec enut thafeolus nifi rara \& peregrina in Ital a finit. Eapropter nobis videtur fai generis legumen ignobile quoddam, Phafelus, fimile tamen Eruilix aut Cice. ri,quale eit quod piftum damus, in huius operis extrcmo, Pha'cols facie, red filiquis Ciceris aut Vicrxicongruis item Sparto, aut Genift $x$, qualcs Diofcorides annotauit. Sponte hxc in Heluet 1 exit, folijs ab vno pediculo gracilibus, ordinc pofitis, fents \& feptenis in caule geniculato, ftriato, cubicali \& fefquicubitali, gracili, lcnto, fesili. Folia ipfa in inimè craffi, aut carnofa, fed vcnulis perquám exiguis fecundü longitudinem iniexta,mag: nitudine ferć,fed non pofitu $P$ hafeoli Flonibus purpurcis, Phafeoli minoribus, in prolixi oribus clauiculis : è qubus poftea filiquæ fufcx vifuntur complures, magnitudine \& offigie Genifx aut Cicerculx: tomine intus pullo, Enum anuante : radicc multum fibrofa, nigrâ, maıore quàm cxteris leguninibus, forte quia Sylueftrıs eft pläta, lian ruri repertam nobis dedit optime fpei doetrfimus amicus Penus Medicus.

\section{Cicerculanitera, an Phafeolus Diofc?}

ES r \& quxdam alia,guam nonnulli phafeolum fufpicati funt, ea etiam in agris, \& fylLuis occurrit, vnde hortus Morgani habuit. Cicerculx fimiliter hæc folia, cauléfque e. mitrit, venofa tenuiáque, aur iculis Leporis fimilia: filiq!nis Vicix latioribus \& longioribus, Hore purpureo, \& quàn Pifi minorc harum vtrumuis maluat Phafelum antiquorun receniores doctiores, quain Fabam noftram, wt qux fit lcgumen neutiquam contem-

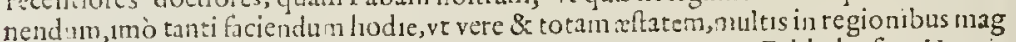
num fit anno $1 x$ fup lemérun, \& nó parum mu!tx gentes panes ex Fabis depânt Veterinaria, ctianque plebcula non incommodos: fatin autem, aut ipla tota frefa Faba pultes fap Jas, \& placentas conficiane, efficiantóue, vt de hac noltrate Fabadictum putemus n:lod antiqui fribunt, Fabx maximum honoren habitum fuife, vt qua panis attentatusfit.

$$
\begin{gathered}
\text { PHASIOLVS vilgaris Turciciva multicolor Fuba, } \\
\text { ef SMILAX horterfis Dofc. }
\end{gathered}
$$

NVurtvs verò laboris eft iftudlegumen trifolium, folijs hederaceis, Faba tereti,ob-

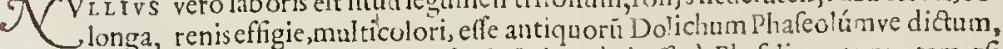
affcucrate, hanc non periude truialem fuiffe \& longè abcfie à Phafelis certunt: tametfi nonenclaturam $P$ hafelus, quafi minoris fructus à Phafeolo retinuerit,propter quan dam fimilitudinem, Cortč fruetus \& foliorum, potius quàm ob ungnituduem: Dolichü autem \& phafeolum effigiefiliquarum \& frufus, qu Lintrem Lembúnve nauiculan exprimüt, vocartant. Nufquam autem nifi fati peregrinique hortis noltris, non fecus ac lomanis olum, vifuntur phafeolicuins enat $x$ frondes hederacex prolixiffimis in viticulis deducun. tur al topiariorum ornamenta, qua de caufa vocauir Diof́corides hortenfem Smilacé, cui perquam fimilis effet folijs \& vultu,tametri diuerfa fructu. Elt autem fructus Phafeoli 


\section{STIRPIVM aduer Jarianou.}

perquam amæno afpetu, plerumque bicolor \& tricolor, maculis atris, pullis giluis, rotundis, guttatis, oblongis, obliquis, cırculatim, trniatim afperfus, nitens:plerumque ebori concolores fabx totx, non nufquam fluefunt, interdum atra prorfun, plurimum renuli effigiē referunt, vnde notifsimx funt vbiuis, \& apud Italos tenera integra filigu a in iurculis multum efitantur, multoǵue magis quam vulgares Fabx expetuntur : tameti parú lautus cibus nobis efitantibus fortè non alietis, videbantur.

Permultas accepimus à naucleris fabas Phafiolólve ex America nono orbe, èćue $\mathrm{He}$ fperia Aphrica allatas, quæ mixtæ naturæ videntur, fed propinquioris Thafiolo: nan earuin quædam exigua, minor inulto $P$ hafiolo, ex fufco purpurafcit : quxdam latifsima $\&$ candida, compreffarotunditatis, ambitu fere vncian $x$ quat, gufu, concretione $\&$ Phafeoli limilitudine, hanc non demptam ex arbore Phafiolifera, vt quidan ptitant, norunt amici quidan, qui feuerunt, legumenque non ita difsimile Phafiolo habuerunt:Sedalias perquàm raras habemus nos, munere lectifsimæ, literata virtute \& familia in Anglia illuftri, Heroine Catherinæ Killgrex, quas ferunt repertas magna copia ad Cornubix littora, \& quod non parnm mirum, eoloco nullam meminit vllus nauem illfam, nullúmve naufragium factum: \& tamen quotannis noux inueniuntur, partin fuitantes \& partim effodiuntur immerf fabulis littoreis, quafi, $v t$ putaut Cornubienfis maris Anglici $26 c 0$. $1 x$, fecundis Auftris, aut Zephyris è nowo mundo appulf fuermt.

\section{Belgarume toonchtoep, on $E R Y S I M V M$ Theopbraft?}

II I I in fegetum cenfu ponunt Theophraftus Plinius atque Galenus Eryfimum quoddam Sefamo fimile \& cognatum, cibis a ptun; tamen delincatio magis folia leguminoiatefatur. Nulla autem planta videtur affinior eruditorum fententia, quàm illud frugum genus, quod Belgis Brabantis, Heluetiif́́ue tanta copia feritur,vt ifto vnuerfa lata, quafi purpura operta eminus rutilent. Vuuer fa planta, placipue quando maturefcit, purpuracit Amaranthi colore:caulis bicubitalis, fribtus, folia Smilacis ininora aut Atripli cis : Hore candido: fenine glumis contento,triquetris fuf́cis, qux molendo exuutur, ex Farina, lafte \& butyro pinfuntur placente, \& fartagine friguntur, pueris expetitæ. BeIgium, \& prafertim Antuerpianus ager, huius eft foracifsimun. Quod fi oculis vidiffer fedulus \& perpetuıs Hermolai, Ruell, Leoniceri, cæterortimǵue doetior $\ddot{1}$ carptor MathioJus, veniam potius præcipitis iudicit, \& pauca infpe\&ionis, ne dicam lectionis, a b illis doctis exoraffet, quà colum nomen lacerafer. Vt quorum monunenta multis fudiorum anxietatibus comparata, illi quafi offam prxmanfam in os inferuerint, amplisimáque fegetem( fed immerita) litudis fuggefferint. Intuere eius duo argumenta: Triticum Sarracenicum Tridentinis Forment ono, tantuun caule rubet, non foliis: alterum argumentum, ab omnibus auidifimè depacicur. Refpondeo, Formentone totum rubrum effe demptis floribus albis:ruja Belgica \& Gallıca id affatimedere, Si tuam Dialecticã híc captionem moliri, qux dum ab omnibus auidè vorari argutatur, viriditatem, vnde tota vis rationis pendebat,reticuit: nó enindicit non edi Theoph; fed virentia folia non edi:mifera tamen vtraque argutatio. Rubor ineft palmitibus, Titymallis, Atriplicibus aliis, \& finilibus multis in locis,alıinullus. Et Bafflex agnum habuimus cicutx Helluonem; at alibi palsim animantia refpunt: bic in Anglia vire ntes afparagos veterina non tangunt; polt foenicetiú
in maritimis, illis aridis vefcuntur.

\section{aAn Officinarum S ES A MI femen fit Diofcoridis?}

SEM E N ifud perpetuo nomine \& vfu Sefamum fuit, quod fatum, vidimus adultum in horto Treuifani DoEtoris Patauini, filiquelis cylndriaceis, preffepiolis diftinctis, $f e$ mine ifto flauefcente, oblongo, Sefanino plenis. Caule fefquicubitum craffo,folis Amygdali, vel Ocymi. Flores, Ruborem, \& alia non meminimus, nec putabamus v1lum fore, qui plantan, hanc Sefaram inficiaretur, fi femen femel intueretur iftud diftum.

Quare 


\section{STIRPIVM aduerfarianowa.}

Quare fi ruborem defiderat in Sefamo Senenfis, docti in illo pudo rem, vt qui vnius piantula fortè aridę in folo peregrino adultæanimaduerfione de Sefamo aduerfus omniú iudicia ftatuerit, nec quidquam potioris docuerit. Quantum enim feminis iftius Sefaminı Venetias, Pifas, Genuam, Lucam, Antnerpiam ex Alexandria Candiaćue, vęnum vehit, huius plantæe elt, quam monitus fortè inuitus depinxit.

$$
\text { SATIVVS LVPINVS. }
$$

TEc ita procul abfunt à Fabaceis $\&$ Phafeolis fruAtus quos Áęaxs vocarunt Grxci, quia

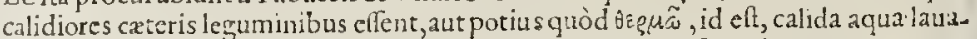
rentur \& macerarentur quò amarorem exnerent triftem \& moleftum, à quo ctian $\lambda \cup \pi \alpha-$ vépos \& Lupinus dietus, vnde Virgili. triflique Lupin fuftulevis Calamos, Quamplurimis in hortis præfertim Pharmacopoortm habetur fatiums, culmum edens, perinde ac Faba, recarn, \& firapte natura ftantem, fed rotundum, cautum, non ihil tomentofum, è radice fes. ingulari,nec multam fibrofa, à qua fere per totum cavlem \& ramos alterno fitu exeruntur iu pediculis fol a fena \& feptena dunfura, digtata Vincis, aut Sraphidis agrix finilia, adue la, virentia, fubtus incann, hirfuta:fliquę Fabaccis minores, latiores quàm Thafeoji:dur 15 fruins, rctundus, compreftus, albidus foris, fubluteus intus, perquam amasus.

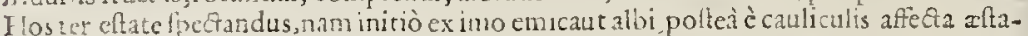
te \& per Autuinnum extunte. Pedenoniau proerunt patentes planitios fatino, quos naceratos efitat ploboctils.

$$
\text { Scgetum SY LVEST R Efore purpurco. }
$$

ZN fatis ix cult is Gramuntio luco circumicets non

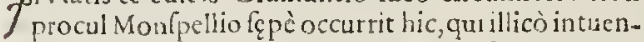
ti fat:um fuperius defcriptum refert : nili quia gracilior multò clt, caule, pedalifolio quinque partito, angufiore, \&llore purpureo \& puniceo, Pifiminore: fruchu etia in minore, guttatis, aut fortuitis afperfo maculis, pu]lis, cinereis, \& cęfris. Inibi etiamáuc in hortis herbariorum vifitur hic adem foribus luteis Geniftx, fructu nihilo fecius amaro.

PISWM FVLGATIVS MAius.

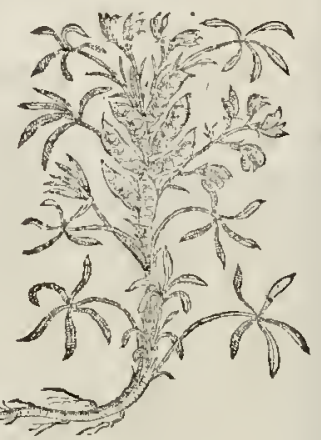

SGerma.xineyter, Ang. Peaje.

\{Belgis. Srocketwittent, Ital.Pijo.

F quadim vrbe Tifa inter Offam \& Olympum montes fita Pifum allatum \& dicum vo: lunt: de quo uhil extare apud Diofcortden non tam inirum fit, quàm certos nos facit,multa eius operi intercidiffe, quęilli norifsima fuerunt. Nam nullum legumen notius aut prxftantius fecundum Fabım Pifo eft:quod yrece etiam' $\lambda$ wutou dicitur, quafi dicas o:ıi vitellum, quem coivre \& fimilitıdine exprimunt, vbi per maturitate fauent viridefcuntve, funt in filiquis cylindriaceis ipfa femina, que vnà cum nembraneis vaginulis, vere \&. eftate iufculenta commendant: harum feges prolixè admodum luxuriat, humi femper caduca,nifi ridicas, pedamentáve fit nacta, prxlonges, gracilibus, fiftulofis caulibus, per media foliola euntibus Perfoliatę ritu fupernè entis in claticulas exeunt, folia roturda, oblonga,in duos ferè femicirculos oblongos diuifa: flore effigie papilıonis, albicantefui medio purpureo, radice exili, quibufdam Germanię locis fponte germinante.

\section{An Tifum angulofum Hortorum quadratum Plinii?}

A L J Q y M multxin femine varietates vifuntur Pifi non fecus atque Fabarum : nam A pragrande quoddam in Belgię \& Angliç hortis colitur angulofa \& quadrata corpora- 


\section{STIRTIVM aduerjarianoua.}

tura ciceris maiore, mediocrem Fabam xquante, ferruginco aut ruffo colore:ncc tamer gultu diftat: fed multum longius in denos,duodenósve pedes porrigitur:videntur hxc ar gulola Plinij Pía.

\section{Ital. Tifelli.}

P ISVM minus ex luteo virefcen.

PRopter corticem viridantem interioremó; medullan, oui lutco concolorem,certurin eft vocatum fuife "̈xpop id eft, luteo pallidum,vt eft terra Ochra: vndeetiam $\lambda$ inut nomen fuperius diftum in maiore Pifo manauit:præterea autem commendatio in iurulentis, quia illicó tenerefit, vtpote minores, pinguiores, delicatiores, facilius elixantur facilius concoquantur. Seruntur in agris, vbi minore cultu, nec fulcris agent.

$$
\text { TIS VM Sylueftre. }
$$

$\not 1$ Heluetia \& fuperiore Germania, non fecus ac Phafeilus fylneftris, obuian fe dant peregrè eunti, etiam fponte 1 ifa. Figura nó abfimili, fed radice multò adultiorc, fibrof ore,craffiore, \& perenni, qualesillic collectos, chartis inferuit nofter Penius. Quidāin fuo vnius paginulx rariorum 1tirpium libelio, memorandum mirúć; quiddäaffirmat:in faxis littoreis, nulla terra opertis, tantam tamó; portentolam fegerem Piforum fponte nulloq̣; fatu enatam in Anglia Suffolcia,inter Otfordum \& Alburnum, etiã Autunno I 555 quantum fatis, vtmillibus hominibus fuppereret.

$$
\begin{gathered}
\text { Pifum cordatum, fit ne potius I S O P Y RV } M \text {, quaim Midanthiy quadan } \\
\text { fpecies, aut Trifolium palnftre? }
\end{gathered}
$$

Voniam nomenclatura I fopyri atq; Phafeoli innuebant häc plantam effe leguminú 2. naturx affiné, aut finilem faltem, non abs re folertes veltigatores trifolium Fuba. ceum, Fafeoli folimm aquaticum, nobis commodiore loco memoratum, autumarunt venus hac aquatica Germanicè faba vocata efet, fi vocula Anifi abefiet: qux obftat quò mi rę defignationi fatiffaciat. Defideratur namAnifi foliü, quod quibufdan repetitum fruftra tiam folium interpretantur)in lıac,quàm opinantnr. Qui verò vulgarem lecticnem tuentut luxatx lectioni Diofcoridis additum, nulla prorfum Phafeoli fúc ortus, fiue linen tur, quandam Meläthij fpeciem appingüt, Comilentatoris eft, vno aut altero A nifi ramulo, ad a litudne: fed mu ta pictura, qualis fi coniecturæ indulgendum \& codici affentiedo, ad radicem Melanthij expreffo. Quare amplect fententiam, qur Cor Indicum ortum, malim cuiufdam amici exercitatifimi

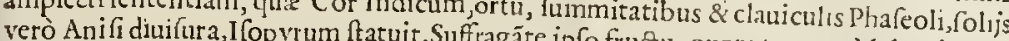
lore \& fapore Pifi, aut verz \& antiqux Fagăte ipfo fructu, quem ternum Mclanthij conitudine $\mathrm{Halicac}$ abi, folliculus col confpicuam refert, yncie Cor Indicum vulgo Cordis aut Pyramidis effigiem media fui parte ter folliculum haud admodun diuerfum grinum vocatur.

\section{Ochrusfyl. fue E RVILIA.}

$S$ Ylueftris indolis velutiq́; degeneres à Pıfis Ochríf; Eruiliæ, quafi eruenda \& eijciëdx dictx, rarius nifi in hortis $S$ cptentrionaliü herbariorum hodie feritur:iuxta tamen fe pes, vias, in Linguagotia fpontc reptat imbecillioribus viticulis, membranula triplici a duplici fecundum longitudinem veluti pinnatis, ima folia oblongiora \& lationa, in cla uiculas definentia ferentibus: fupernè vere foliola partim in plura $\&$ minora dinidin cla partim etiam clauiculis donantur cädidis, \& interdü purpureis, flote \& filiqua Cicercule;
cui admodum fimilis.

$$
\text { Li.i. IAS. }
$$




\subsection{STIRPIVM aduerfarianoua. \\ $L A T H Y R I S$ Norbonenfis latiorefolio.}

JT Alde verifimile elt a Lathyridis Cataputiæ granis qux Orobinis fimilia feminula Diof corides dicit, nomen faetum Ciccrculæ vocatæ, que hodie differentias duas habet ex agro Norbonenfi allatas, vbi fponte frequentior erumpit ea, cui latiora fupernè acuta bina, neruofa per interualla oriütur folia, citu \& imitation e auricularum lepufculi arrectarum, aut Bupleuri herbariorum,

$$
\text { Anguftioregramine flore Lat byris. }
$$

A Lteri in nudis ibidem ènatę folia admodum angufta, graminea, Venofa, \& mucronats, 1 è pediculo bina in tortiles capillaceaf́que clauiculas definente, Catanacæ ferè funt: deAuxis albidis \& luteolis florıbus fuccedit filiqua compresior, dupló breuior, latior fuperiore, wbi grana angulofa pufilla, $P$ ifi aut Heruiliefapore.

$$
\text { eA } R A C V S \text { ant Cicere. }
$$

Q Vamuis diltinxerit Galenus Aracum citra afpirationem fcribendum,ab Aracho'afpiratione fcribi folito, viciunq́; \& exitium quoddamiftud polterius Lentiü \& aliorü leguminü dixerit: tamen vtrumq; videtur ab indolc; fui cognati leguminis quafi in fpurimm abijffe, vt de illis dixinus, \& in iftis obferuamus : Eft enim prorfum cognatus \& fimilis, fortallis idem ille Aracus, quem quidam Ciccrenlam alteram volunt:necabs te,cum eius grana fordidius nigricantia inter Pifa, Orobos, \& Vicia pullulent, ì quibus videntur degcneraffe. Quod idein Columella affirmare videtur, quando nihil fapore, fed tantum colore à Cicercula dıfídere, eóque Ciccra vocarí aflerit. Ranofis è radice fibrofa prouolui cur calamis, tlexilibus per lögitudinem quafi reniolis membranulisúe pinnatim angulofa: folijs Cicerculx.

Eft vbi luteo flore inuenerunt amici quidam, qucm nifi Ochrx vicium putant effe, vt fteriles Auenæ, Lolium, Melampyrum, alijg̣; fegetum morbi.

$$
A P H A C A \text {. }
$$

$\mathrm{M}$ Ixta videtur hxc è $P$ ifo \& Lenticula, yt cuius fliquam, femenq́; fimile eft fortita: $P$ iMiatem folia, caulcs \& capreolos, longè exiliores quàn Lentis, cuius femen refert, fed minus, nigrius, durius, cfi ingratius, filıua non diffimili tamen, latiore, longiore:tenella funt folia,cx aduerfo bina, cuulis geniculum $P$ ifi modo amplexa, vnde cxeruntur capreoli.

$$
\begin{gathered}
\text { Terre GLANDES, fucPSEVDOAPIOS } \\
\text { Germanorum, an ASTRAGA- } \\
\text { LVS Diofc? }
\end{gathered}
$$

I Eguminofx huius gentilitatis of bubora, quam Germani $\$$ want arettich, id eft, Ra-

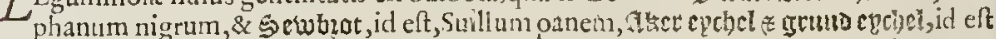
Balanum terreftrem vo cant. Spargit hums tres qnatuórve ramulos in im o rubellos, Ciceris aut $P$ ifi folio \& clauiculis donatos, quibus, fi adfint, proximas quafque plantas ample Etitur:flores item purpurei $P$ if funt: $\mathcal{X}$ in filiquis parutsexiguü femen. Radices verò ob. longæ oliuarum glandifue inftar funt, foris nigræ aut pullæ, intus albidx, mul tis quafi tra ieçx yel appenfæ fibrofis loris, feu funiculis variè inuicem implexis, \& latè fufis. Anglix, Germanix, Gallixque Nortmanıx Syluolis opacis, juxta fepes: Norbonæautem, Italix crterifóne $x$ ltuofis regionibus, non nifi in arduis \& niuofis eruitur : cuinfmodi funtillic "Feganij montes \& colles Martij Galloprouncį . Saporillis fubdulcis, glandis,ant Caftanee aftringens. Siccatx multum durefcunt,,$t i$ poonię radices, nec minus folidæ funt:nec minus contumaces tundendo (quas feruamus) quàm Thoræ glandule. In hanc vcram \& meram recenfonem vidcant fudiofi an poffit quadrarc Afiragalus, cuius lectionem apud Diofcorid . luxatam effe ex $P$ aulo perfpicuum elt, qui non Memphiticum fod Phencum Aftragalum legit, \& $P$ linius idem confirmat : Actametf defrip. 


\section{STIRPIVM aduerfarianoma.}

defcriptionem dat paulùm diuer fant, nullant tamen facir mentionem; fortè quia iam sum in Diofcoride lectio depranata erat; vel quia ex alio fcriptore verterat. Ad hæc,

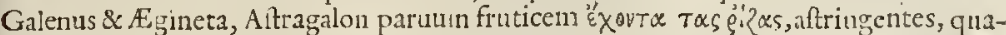
fi plures, nec tamen Raphanum memorant. Quare, tanquam non in Diofcoridem, fed abifto codice male acceptam animaduertanus hanc lectionis deprauationé, quip-

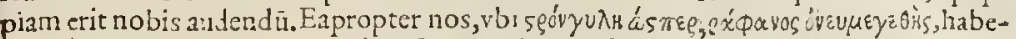

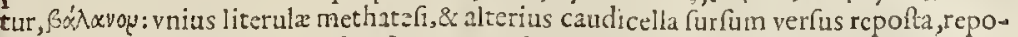
ni vellemus: qui lubricus lapfus cft ananuenfibus: quum enim Glandulam, Ficum terrę \& talum vocarint Romani, $A$ ltragalum, non Raphanum, fed potius veram, nec huius noftri fortè difparem effigiem intellexerunt: nec folùm tal um, O[siculum luforium Aftragalon vocarunt Grxci, quale refurunt hre radices, fed etiam fiagra, nodulis, aut

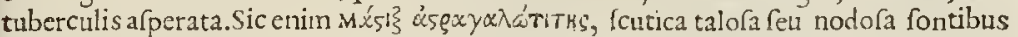
crdendis apud Lucianum vurpatur. Hifce tamen ineptiufculis fcholiis facilius quis obftrepet, quàm meliora fubdet: Cxterum candidus arbitcr, minima quxq́ue in $P_{\text {ri- }}$ fcorum defignationibus fcit non effe feucrius cxigēda: de Apio, quem qquidam putarît cum hac eundem, inanifeftum fit:Eam fiquidem,finilem dicis ASphodelo, vt idem fero cerat Thcophralt,cum tamen vnico fit bulbo.

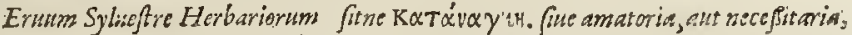 non Bulbofa unguirsilinia Diofcorid?}

VAst necefsitate inconcuffa \& fatali adigeret ad amandum, Catanancen vocarune's quafiamoris illicium necelfarium; quia onnnia vincit amorimprobus. Eam autë neutiquam notam probè no ftro æuo, minus mirun eft, cùm ctianı fi ftir ps de facic no. ta, \&apud nos nata foret; tamen incertum adhuc eifet, num vera effet cenfenda;nullis enim viribus, nifi praftigiofis \& Fafcinatricis infaniz, amatoriis illecebris conmendatur, quas Theffalica tribades \& lena prẹtexebant, fortè fuis carminibus, vt hodie factitancimpur $x$ ford $x$ Italx, verbulis abuf $x$ nefariis ad infanum amorem conciliandum, quas: vires attribuunt herbulis vulgatis. Idcirco 'Plinius, eiúff̣; coxui cordati viri , confult tò figuras harum tacuerunt. Nec fanè eas nofie, vllius eft operapretiü : nec Diofcorides vires, fed hiftoriam duntaxat alienam citat. Quodpian genus leguminis fuife hanc dcfcriptio oftendit, cui tnon malè quadrat ea herbula, qux in hortis herbariorun Iulio \& Augufto, polt flofonlos Pifi delapfos, filiquas longtores, exiles, teretes fert, femine refer tas ruffafcente: folis anguftis, gramineis, binos pollices longis, Lagopi anguftifolli, quæ marcida, recurua inftar milui conuulfic cruris vifun tur: radice exili, fimplici. Vifitur etiam in agris litorum maris $S$ eptentrionalis.

A L t e r a m Ciceris femine, oliuam radice xqunnte, mali parui magnitudine, qux vel adumbret, nullam nouinus plantă: rara namque admodum effigie oportet fit hxc: fi defcriptio vera eft. Vicictur perfuafio hre, dcliri amoris conciliandi etiam nolenti volenti. à feminis pertufi myfterio haufta:quam fi fas fuiffet, nec nos ineptix piguifiet. in Phyreumate, Leontopodio, \& proximo Antyrrhini capice patefeciffemus,

\section{CICER fatiunm, arietint:m Diofcoridis.}

FF I I N A R v Cicer rubrum vbique in Ttalia, Germania, \& Gallia feritur, \& adeò nofcitur, vt nullus nefciat ıam effe antiquorum verum Arietinum, qui nıodò videat in filiqua tereti, \& inftar marfupioli tumida, hirfuta, vnciā lóga femenna, Pifo maio ra; capnt Arietinum frontata effigte, \& angulo aliquantum mucronem æmulante: co- Vorretates; lor albus quibufdam, qux minus in medicamēta veniunt: alia obfoletè nigricant, plurima ex fufco pnrpurafcunt, qualia efficaciora ad medica commoda habent officina omnes : fementem \& mofen faciunt Itali, apud quos efitantur magna copia: fol ia L̈̈tis pofitu, medio neruulo harent, tantilium crenata: Hores purpurant punicantes.

\section{CIC E R Orobaum T beoph abb Orobonigredine tantiom diffans.}

$$
\text { Tl. ij. }
$$


D I F I C I L E tamen fit ftatuere quodnam fit

Diofcori. domefticum prinum: nam nouü quodhicdamus, tantopere fimile eft Norbonenfum Orobo, filiqua præfertim, vt certos nos reddat effe illud quod dukifsimú \& Erue fimillimū à Plinio dicitur : fed ambigunus iă,fit ne idem iftud cum Diof c. fatuo : cui eundem fecit Orobü vulgatum \& receprū officinis doctus \& perbonus friptor Dodonzus, qui nondum, hanc nouiffet. Norbone \& Galloprouinciz plerif́çue fatis per meffes flanet hæc,culmo affurgés fefquipedali,geniculato lateratim, qnafi in obli. quú flexo, leuiter ftriato, fiftulofo: foliols in imo neruuloprolixo hærentibus, Lentis aut Araci : à medio ité ramulis donatur \& foliatis pediculis : \& iuxta fummos alarí geniculos complures có-

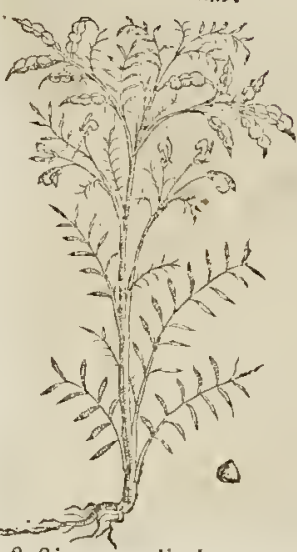
fertx filiquę, vno fere exortu nix $x$, fefe tangút \& ftipant, cylindrex, vnciam longe, rectx, terctes, inter tran fuerfa pufilla interualla foras protuberantibus fingulis quafi torulis, ternis \& quaternis, articulatim diftınet s: ipfa intus femina nulla membranula diftincta, Pifum Arietinum fermè ęquant, obtufé triangula; Orobi duplo maiora, colore albida, pallida \& fubfula, non ingratifaporis, Ciceris aut $P_{1} f$.

O $\mathbb{O} O B V S$ recoptus Herbarior.

$R O$ в v s, color rubeus antiquis fuit, qual is in ruffis bobus, \& $O$ robis cernitur. Ho-

dienihil penè ab illo dudum dicto difsidet receptus in Officinis Italicis $\&$ Norbonëfib. Orobus femine \& filiq̨ua præfertim, nifi quia huius altero tätó minor eft, cópreffior, nec vno loco, fed variis ex alarum genicul s, fecund um fummü $\&$ imum caulis exorta,pendula , alioqui terna \& quaterna claudit femina Cicere minora innltò,tangenti hebetius angulof, \& vno latere aliquantùm acutiora, guftu lentis, folio \& facie Pifi Létis aut vicix: ramofis fparfis luxuriantib us, caducis fere ramulis: ninu t tamen eft $\pi \lambda \alpha$ "óku $\Theta$ hic quam fuperiores duo, minúfque ingratus guftanti:nec enim noftro ingenio conuenit, firpum vel figuras, vel qualitates plumbea Lefbiáve norma ad nofträ fententram exigere, aut flectere, vt nimis nulti factitant:fanc par eft alterutum horum leguminum, verum effe Orobum, cum è tam multis nihil penitus finilius occurrat, oritur hic affatim in glareofis.

\section{CICER STLVESTRE VERIVS.}

Jl r r I t hac ælate in horto Morgani quoddam Cicer parùn adhuc notum è Sabau dorum \& Helıetiorum finibus huc accerfitum, facie \& filiqua A rietini Ciceris, quod eoufque pręfefert, vt primo intuitu quilıbet Cicer dicat:Siliqua quippe breuis, foliofa, comprefsior paulo: fores item purpurantes, non abfimiles, fed femina mul tò minora, compreffa \& potius Lathyridis Cicerculx : habitu tamen latior tota, latiuf́cue plures ramofos al is \& firmiores fpargit culmos, cubitales \& fefquicubitales : folia edentes Loti fylueftris fermè æqualia, Ciceris Arictini maiora, crafsiora, rotüdiora, \& tantillum etiam crenata:Radice quotannis rediuiua. Quare non ab re quis coniectet iftud Diofc. Sylues:
ftre effe.

\section{CICER Sylueftre berbariornas alind, folliculis Colutet.}

LON G I $\mathrm{S}$ adhuc videtur recedere a Diofcoridis fylueftri iftud, quod caducis ra1nulis ferpebat fuperiore anno in eodé hortulo, flevilibus gracilibus ramulis, propius Securidacam minorem aut Lentem, quàm Cicer defignantibus: \&quidem foribus Iuteis palientibus Lycoctoni, cui folliculis penè par eft, fed Coluteę figura \& Arietini Ciceris ritu vnà plures collecti, hirfuti, atri, referri perpufillo femine Sefamineo, aut Geniftellę, duro, compręffo, nitido, guftu Phafeoli.Mathiolus, huius fuam picturam men- 


\title{
STIRPIVM aduerfarianoua.
}

tionemq; ridicule inculcat in Indice, quod tamen non defcribit, quafi fuper è nihil ambigendum effe nobis imperafict, vt alibi paffin facit.

\author{
Gall, Lentille.

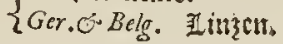

Фaró́s L ENS.

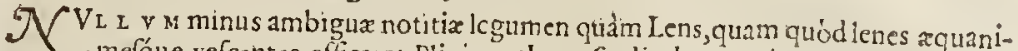
mefóue vefcentes efficeret, Plinio authore, fic dicebatur фánor autem Gracis ab $\checkmark$ tre qui fuit aoxos metathefi \& mutatione vnius eleméti. Facile de filigutula \& granulo ro tundo, xquabili circimatione compreflo, lagenulan effigiante, quilibet eam nofitet. Calidiote folo, \& fudo, ficcóq; cœlo proferi gaudet, vbilatior, lautiorçue quolibet legumine habetur. Ei Ciceris fylueftris filiquula compreffior breuior, penè quadrata:vbi duę vrplurimum lentes infunt, fxpe Fufcx \& interdum albx nigricantes. Foliola gqualia hxent fuperncin Pifo:fegetc humi fula \& reptrice.

$$
\begin{aligned}
& \text { GGor. micten. } \\
& \text { Bintoy FICIA. } \\
& \{\text { Bel. Citren. }
\end{aligned}
$$

A Vinciendo ducit Varro: nialim tamen Siklojeffe, ncmpè lagenulacffigie fomê, cuod etian áganou Atrici vocabant. Nulla autem regio algidou calidioríe Vicia fatulas: Sylucftrivacit. Seritur enim in fubfidü Auene ad iumentonm pabulun. Silique funt Genifta:femina compręfa Lentis, nigra, quina aut fena,praftè rotunda,ingrata guftu, nó difimili Lentis afpectu, fed habitior tota: foljs maioribus lifi Minoris aut Ciceris

$$
\begin{aligned}
& \text { A } \mathrm{R} A C V S \text {, fue Aracca o Craccamaior. IICrajyl. } \\
& \text { gier. Sollomicten. } \\
& \text { \{Bilg. Eisits. }
\end{aligned}
$$
A eàs cuafi peftes pernicićfc; leguminofx frugis dicunt vnde apóxor \& Cracca, vecijs in fulo infüt veluti plumatim in alę modum foliola perquàm cxigua c̀ viticulis,nuultò quàm Vicia aut Lentis exilioribus, iuxtać, alas Viciæ ritu \& fimilitudine, fores purpina dilutius rubent. Siliquala longiufculx Caranca propior eft, vbi fena aut feptena femina rotundifcernere valeat.

$$
A R \text { ACHVS fue Craccaminima. }
$$

7 Imisquàm exilis \& penè capi!lacea ha:c tum riticulis, tum foliolis ijfdem, difpo.

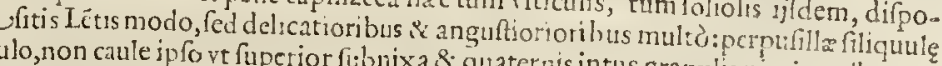
pediculo, non caule ipfo vt fuperior fubnix \& quaternis intus grandis nigricantibus, ro-
tundis 2 api aut Braficx inclufis, florum apiculis pallidulis.

\section{HEDISARVAL, fue SECVRIDACA mator Homor.}

A Ncipitis Securiculx emulo femilli fertur accepta $\pi \varepsilon \lambda \varepsilon \pi i r s o$ fue Securidaca vox quam etram ridút从९oy ob fualicolentiam vocarunt. Ea in aruis \& fegetibus quas rapidi tor. fentes ex Alpibus Taurinis pręcipiti alluuione, plerumgue vaftint, \& ad Ceuacium via, tis vel Afragali matoribus, modo ferpit \& fertilitate reftibil fefe reparat; folpolis Icn hærët, humi item fratæ, compreffe roftrellis alis \& foribus Ciceris purpureis: filiona: tudine, fed cópreffiores vtring;: \& an fibrofa, fapor amaricans \& Lupini ferme odor fon Securis cffigiante radice liguminofa tione Myropolę nomen dediffe Hedifarer fonugraci vel Meliloti, cuius commendaVtebanturfortè tunc non fecus Lliij. 
atq; reneti fuftitors, quáq; Melioti ad Chyrorechasaliál, fragrantiz grata imba êda, multunvtunitr.

\author{
Securidaca mirrar.
}

ASTR AGA- T Egumen illud multo minoribus vicıculis, follis \& Aloribus pirpureis exiens, è pecioliws Monsper. iunda, \& dublici ineus ferie digeiti fenen, fubrotundum, fubfulü, eft fimilius Gal coevel Araci quàm Securtdacę. Idcirco prxceptuies nuftri Möfpellienfes huitus fpeciem efle inficiabantur: Inbi quippe \& cæteris Norbonx Frontıgnanæá; ard is, plateofis, maritimis totu viret anum radicéfq; complures profunde merfas, prolixo implexu fpargit guftu leguminofo, necperinde vt Securidaca, amaro. Eapropter Altra galo propiorem aftruebant, quò nos etian refurendam duxiflemus, nif Raphani bene nagnı tadix lli \& aftri Etorix, cxteręq; facultates ad vlcera deeffent. Quare vniuerfas firpim gentilitat: animo voluenti, nulla qux explendx defcription tatis fit, vfpiam fele dat. Non ea, quam in collibus Lugdunenfibus prope Trenon, \& in horto $P$ atauno floribus purpures \& folijs fumblibus ciceri,fed gracilionibus, vdimus. Radix certè difuadet, nam Senenfi herbariorum Dietatori, licuit pictoris opera ad quiduis lubitum furt, alludere \& nobis illudere, ideó nunc illum illius piaturx poftremñ pudurt.

$G L A L X$ vilgaris.

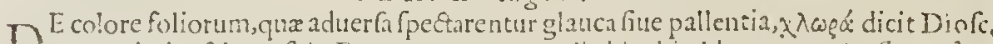
Domcn huic afcitum fuit. Fruticat autem ramulis, bicubitolibus vimneis, Aexis, fo.r fis, ftratis, totundıs, gracilibus, lıgnolis, bina crebráq, folioră fcrie, à ladıce cratlioribus \& duris, \& intortis propagimbus procurrente, yuali Arthenifix: cerumeur folia cxlio virore fupernè, auerfu verópallore glauco, Cythifi masora multò, Fabx, fitu \& craffitie propina:purpurafcunt llores extremis ramulis Galegx. Siliquis tamé nulto maioribus, crafforbus, qux per meftes matura dehilcunt in buas vaginulas fenine plenas, colore, fapore \& odore leguminofo, cuiufmodi tota planta. quz tamen proceritate fpeciolior malióq; maıor eft;quàm ve Glaux prodita videatur:multa in Belgio. Ex Angliz nos lito. reis, iten mediter raneis procul mari, Londini Serendam curauiubs.

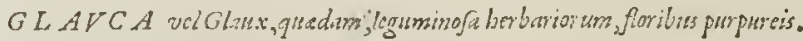

ZVxta agrorum viarúng; marginesobuian fefe dat in Francia, Anglia, \& Belgio hxc, caule rotundo pedali, radici exil, fingalur uricente, ì qua ftrtin fol 1.2 ermmput O cymoidis aut lanlimi, alb dit, Glanca, oblonga:è med o antem caule aliguammulta excune minora sainutum Lentis modo aut V/cix diufa. In fumo canle pallido, confpicui flaucat aut punicant fores, congefi iu glomerulu, ex calyculis multis confatum, oblidentibus fouano.is folliculis, acerolif́, veluti glumis, vbi femen. Tota pläta lxto afpectu.

\section{Caput Gallinaceum Belgarum, an Owobigclis Dioge?}

$\mathrm{Q}^{\mathrm{ran}}$

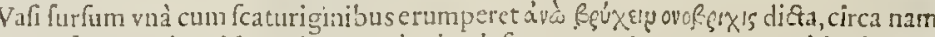
que fontes oritur. Non labor, non herbx defuer complures, qua te nobis obtrude rent, quafi legitimx forent:quas tamen omnes refpuimus, propter vman atu alteram que propius Diofc.defcriptione, tametfi valde iciunam \& parurs fignata, accedere vif $x$ funt. Ha:um notior Galega ripurum \& vliginof foli alumna, nö perperam pataretur, ni folia multo maiora effent, lentis, proceriorefć; caules, qué excelfum, (nam tota facies leguminofa, flos \& vires perbellè fuffragantur) ri qu is obijciar, (in milia collata in Cappare cú malo Cytonio, \& cxtera componat. Et interim, dum ille nolá; melins yuid veltigamus, hane ¡am defcribendam habeat, vt rárioréita minore $\mathrm{m}$ \& multo figurx propiorcm: quam in hortis Belgicis colunt herbarij, è radice parua fibrofa, cauliculos pedales, exiles habet, \& tolia lentis anguftiora, aliquanto longiona, fine capreolis:in cymıs, tcneris, Galegxfof culos, purpureos, dilutos, albcdine mixta geftant. Quibus per xifarem marcefcentibus, 


\section{STIRP IVM aduerfarianona.}

quibus frliquulam pro fenine, cafide, criftata infignitam, fpinulis muricatam, çuadantenus Tribuli terreftris, oltentat. Eruditus Coldenbergiushos femine primus do vauit, atc; in Hollandix \&:Zelandix aggeribus \& littoreis aduerfu m maris alluuiones \& procurfus erectis repagulis, nafci fponte monuit. Monfpellij in hortis enatain habuimus.

\section{ORNITOTODIVM, fime "Pes" nuis.}

SCitam rocem aptarunt ifti legumini Doati recentiores, ad huius herbulx filiquas, pedem auis effiginntes defcribendum: conftant quippe vni pediculo nis $x$, qua ternx aut quine, expanfx mucronatx, quafi ftillis aduncis, articulatis, curtuatis, in pedıs auis æmulationē: palmares \& féfquipalmares füt viticuli, fparfi humi foliolis Araci minorisiflofuli melnni Coronate Melıloti.

$$
\text { Varitas. }
$$

Quàmelegans hxc varietas quam pictam damus: $\mathrm{O}$ ritur in marginofis lierbidis Grinwicij Regię, ad Tame fim flumé, nó procul Lódinn:vix tota binos aut ternos fuperat pollices:ranulis in terram fparfis, exilioribus \& crebrioribus, venuftius ordine pofitis quàm fuperior: que non aliis ab ifta natalibus gaudet.

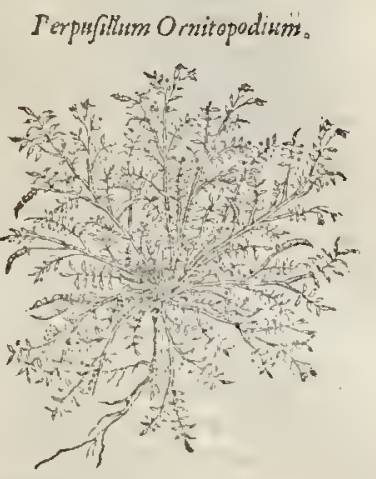

\section{SFERRO Cauallo, Ferrims Figuinum.}

$P L a n t a e t i a m$ leguminof familix eft hęc, cuius frliqua multún unitationis excitauit iftis nomendatoribus, qui Sferro Cauallo, id eft foleam equorum refringentem fabulati füt. Nam nobis experiu ndiauidis, magna copia reperta propè Mafileain, fruftra fxpins fáAum fuit periculum:etram via qux ad prædium Rondeilerij mareq́; ducit, ad dexteram, propè rufculum in fquallidis dumetis $\%$ marginibus plui ima glıfe bat, aftate minus torrida.Siliqua affab è plant an lanc à tribalo terreltri, Sco:pioide leguninofa, \& ornitopodio, quibus alioquin foliol is albidis, \& comptis finilis cit, differnit. Flores item pufil$1_{1}$, lute i. intrò nonndhil compreffe filiquax, veluti fecuriculata, vndofa \& femicirculis finuz ta acie, ternts aut quaternis equinz folex veltigijs continua $\&$ difineta fpeetantur feminulis foleamiequinam effigiantibus, aut dımidiatam Iunam, vade illi quidam nomen Lu ${ }^{3}$ narix affnxerunt: gufu leguminofa, radice Londini hortis viuaci.

\section{SCORPIOIDES leguminors.}

ESr \& alia nec minus venufta aut rara, fegetü Norbonéfium alunna:Radice nittitur fibrilhsmultis, cauliculos reAtos, graciles, binos aut ternos, pedales \& fefquipalmares erigente: quorum in fummo, admodü incuruis mucronibus adunca cornicula, Foenugraci rotundiora, graciliora infunt, introlexas Scorpionum caudicellas, tranfucrfis articulis \& argutulis liris imit2ta. Flofculi pufilli luter, alterıus Scorpioidis: Foliola Ornitopodij, aut Tribuli exiliora, ab imo ftatim cefpite, in neruulis v tring; ordine fita.

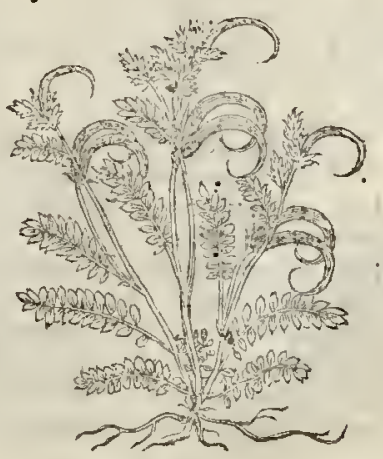

$T R I R V L S$ serreftris.

Ll.iiij。 


\section{0+ STTRPIVM adverfarianowa.}

Oliti crăt prorjecre holt imurices infeltis aculeis armatos:quos quia protercrétur $\tau$ $p$ Bo

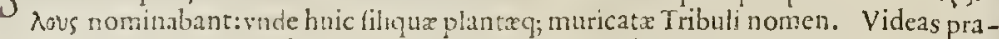
tenfes pultuerulentas \& fabulof.s. planties maritimas Adriatici, Thyreni \& Gallici Medi termal, it to terreftr \& \& minor Tribulo itineranti, exutis pręfertim calceis, infeftas \& pro pemodim inperulas. Mófuelij etiam aridis \& oliuetis ferpit,afpectu liguninofo Ciceris, ramulis complur ibus exilibus, "genino foliorum vęrfu refertis, nó Portulacę, ,ed Lentis vel Araci: coqque labeculam in Adraclne fufpicamur, \& legere Arachi ökchx aptius rei ve ritati ducimus, ić eft Vicia, vt indicio ipfanet elt plâta. Pufillos flofculos luteolos, in pediculis exalıs exeuncibus, vbi emergunt infeftis aculeis rigidufculis, fexanguli, qunquartigulíve murices, medullam \& femen oftêtantes, per maturitatem \& aftatem dehrcentes, radice parua, fibrofa nec altè depacta, nullius hodie fermè commodi, nifi Afinis, quibus pabul um illic eft. Commentatoris Senenfis folitam fedulitatem duo teftäur Tribuli:alter qui iam nobis dietus. Hunc Doet äGuino $P$ rano donoacceptü quafi in Italıa prafertim Venetijs, rarum foret, dicit:alteruin $D_{1}$ ofcoridis folijs portulaca fibi in $D$. Nicolai adis Veneto littore vifum, quam crus farè non vulgarem cognitionem \& in ftir. piü Inquifitione operan pofitam, çuidam peritus locorun illorum \& herbarü Italus fäcetus fic nobis exponebat: Commentatoren inquiens nunqnam nifi arıdum aut pictum vidiffe vul tatiffinum Tribulun,cóg; defcribere nefciuiffe: dende Crithmum feu portulacam marinam iliic frequentem, pro Tribulo Portulaca fol ị ascepife:non tané defcribere aufum: forlan quin nullus extabat author acquo defript onem fubriperet. Foftemü effe in Lio Veneta infula fabuietis, cuiuis Pharmacopocorum notiffrium terieftem, eoǵ; minimè $P$ ifis accerfenduni.

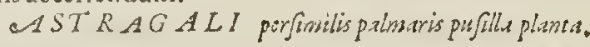
Domperegrecfemus in collibus quibufdam Gallofpectatu indiguan: rudicibus nanque prorepit lignofis, implexis, corticofis, denfo exortu, numerofos cauli . culos, fruticătes, duros, fed bremes, vix binas aut ternas vncias excedentes, \& folrola emittentes pufilla Lentis, Attrag.li, aut potius Tragacanthx, quan tota refert rigidufcula, incana hirfucie:Rofculis, luteolis, aut al bidis, Ornitopodij:guftu prẹfieco \& requè duro.

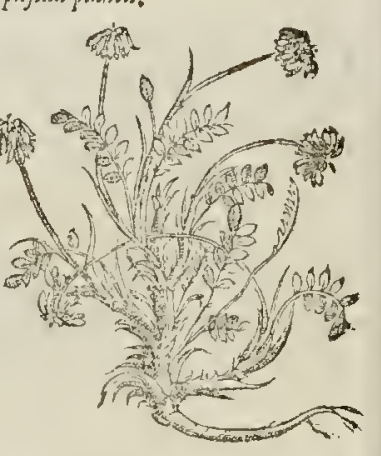

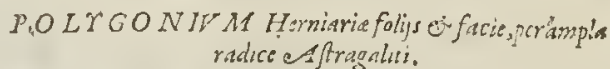

X Ec hẹcdefpectui futura erit difcendi cupidis: Ent e- Unim perquàm parum nota, perpufilla quidé herbula, \& humi accumbens cefpiti femimerla, ramulis cre. berimè geniculatis: follolis \& feminulis albidis, prorfum Herniarix:tota incana, quàmexiguo, mufcofo flore. Radice amplsore quàm pro plantę modo, dura, furculofa, im plex-2, \& in fe reciculatim conuoluta, auulfu difficilis: gufup praficco, callidiufcula. In fufiffina Crete falonenfis Galloprouincia planitıe, media via inter Aralatéces Solonam ad diuęroraun D. Martini.
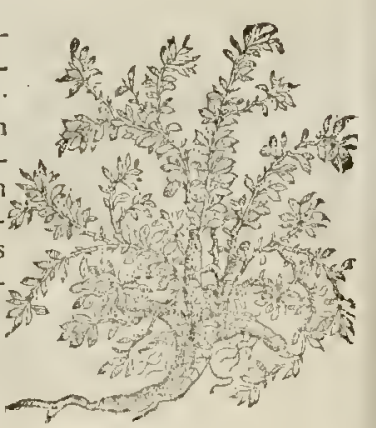

ELI. 


\section{STIRPIVM admerfarianona}

HE L I ANT H ES Species rara figura leouminofa, floribits aureis.

2 Onperinde formofam icone hanc, atquenatiua ${ }_{2}$ cie dono mifit nobis hanc nofter induftrus \& peritus Pharmacopocus lacobus Raynaudet, quam è iugis arduis montis D. Bonauenturę, non procul Aquifextiis eruerat: Radice lignofx fruticula ; ceruicem paulúm inflexam habente, flupernè \& infernè nodofam, è qua emergunt viticuli palmaresiuncei, reti, flexiles albidi, 「oliolis Lentis aut Colutee Scorpioidis ex glauco virentibus, ab imo fummo tenus ftipati:floribus aureis $\& x$ calycu lis Helianthes vulgaris:femine item non difpari, pufillo Cifti Ledi,amaro guftu.

\section{GLYCTRRHIZA Ecbineta on filiguof.}

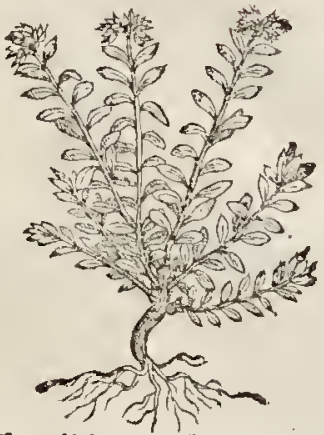

S I qua eft fterilis Glycyrrhiza, vt $M a t h$. fibi re vera certü effe auditione poftremis cómen-

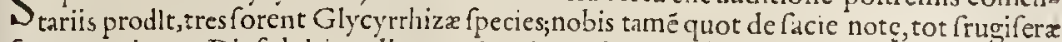
funt. Ac primum Diof.dulcis radix nota \& culta variis locis, ettå horridioribas, vti Germanix \& Belgie, fruetú fert vaginulis muricatis Caucalidis emulis, denis aut quindenis, vno imo apicc hærentib. \& in orbë fefe explicātibus, eminus intuëti quadantenus Platani Echinum ementien tib. proceritatễ in terdü affequü tur, quanta proceri eft homuis. Radix, nó ve alterius numerofa pafsim \& fufè humi fparfa, fed reeta, altè depacta, adeò vt quảtùm humo mergitur radi $x$, tantùm folo extent caules:finglis vaginulís vnü dútaxat femé ruffum lentis effigic ineft. Huius vfus officinis rarior hodie;quippe, feu arida feu recens, vti nos pcriculú fępe fecımus, löge vulgata dulcedine \& gratia vincitur, eóq; tantú voluptatis caufa colıtur.

Communis verò nullí nó nota, quę ex Hıfpaniis Londinun, Antuerpiam \&: Lugdunum defertur, \& vili vbiy; locorū diftrahitur, non paucis Gallix No bonenfis locis multum fpon tè oritur, etiam prope Latera oppidü, cuius meminit P'linius, Möfpellio lcuca. 1 difsiturr: radicibus, flexilibus, multis implexis, caule \& foliis pinguibus, \& dum eam euelleremus manū glutinc inficientibus, floribus purpureis albicantibus; menfe Iuno \& Iulio filiquas fert paruas Cicerculę magnitudine. Cuius radix nuper ex Hifpaniis adue\& \& \& hortis Pharmacopeorum depąta, facilè fuccrefcit \& reuiuifcit.

\section{CO LVT E SE Scorpioides}

SOlertis ingenii praceptor Rondelletius nó raro ratus fuit Glycyrrhizam minorem nuncupandam cffe plantam locis multis nemorofis inter buxos erumpétem, Iunio \& Iulio: floribus Colutex, vel geniftę, minoribus: folio itidem Colutex paulo minore : caulis fimilis eft, gracilior : radix buxea minus dulcis, aut potius dulciamara dicenda, \& minus grata: filiquę Math. Scorpioidi vfqueqaq; fimiles, vide vo catur nonnullis Colutea Scorpioides. Norbonx copiofain valena fylua \& propefluminis crepidines cis Lanum,

YAI E-

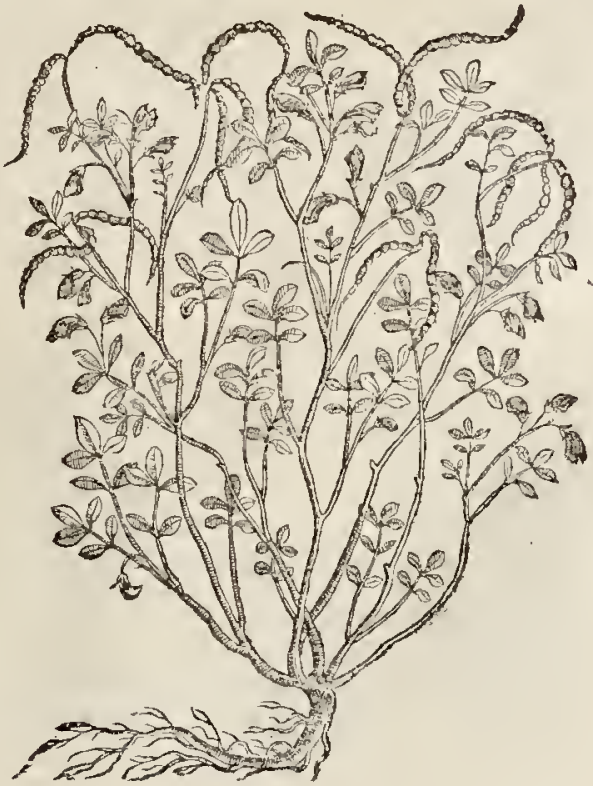




\title{
$406 \quad S T I R P I V M$ adnerfarianoud.
}

V A L E R A N D Y Dorrez Pharmacopcus I-ugdunenfis plantarum ratiorum vi quis aGiycyrbica pi lius ftudiofus \& peritu;, cui certò fidimus, filiquas paruas geniftx, atut acatia, fed minorcs, te

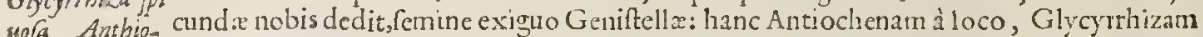
shenf. à fimilitudine $\&$ fpinis, quibus donata erat, facicbat. Sed nihil nifi filiquas vidinus, cóque

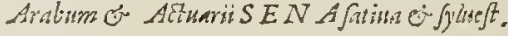

SER o \& magno xgrotantium incommodo in notuit Græcis Sena, quam vnà \&r appellationem Arabibus debemus: Albafenter vocant illi, vnde detortum Sena. Hac alteem hodic nullum purgans frequentius, tutius, aut preftantius eft. Ea herba, xftiua \& parua eft, vul zu, leguminoío Securidacx, Glycyrthiza, aut Colutex:In Ligurix, Thufciæ, Romani agri \& Appulię variis locis, legitur Autüno, nec feritur ante Maiü, quia frigoris impatiens; éó; hortis Septentrionil vix trimeftre viuit,nec promit, nec maturat flores vel filiquas. Quare Officin $x$ potius è fundo vernaculo, nempe Orientis emporiis, petunt, plurifó; faciüt, quàm iftam aut Italicam: duas enim foliorum differentias, aut varsetates habent inftitores è diuerfis plantis Senx: ptobatius foliura \& laudatius ad purgationes (finum vocant) eft oblógius, a cutus, Myrthi maioris effigie:alterum rotüdius, breuius, quod vilius habetur:quare non fecus a tque Myrthus nuaior \& minor, foliis videntur hæc duo inter fe diftare, vt præftantius folum fit Domefticx;alterum fylueftris Senx: duas itdiem Mefux agnofcit: \& ad perfuadendum alterutram earum effe fylueftrem; multum fpirilli pilulxúe ltercoris caprini aut otrini faciunt, qux frequens inter Senæ Orientalis, folia, follıculos \& quifquilias parsim apud nos allata reperiuntur, vbi emptur is proftant; feritur namque $\&$ adolefcit probatior in fimeto ouillo inibi:alıqun vtrique filiqua eft efficic Colutex, compreffa, vt Arboris Iudx, fed falculx in modum conuexa, fufca aliquot feric digefta fomina, Gygartis fimilima, comprefsiora, claudens. Flores ex pallido lutei funt, rubellis veftigiis venofi : graciles caules Meliloti, pedem \& fefquipedem alti:ingratiufcula tota guftanti, tantillùm amara,calida \& ficca:tametí veluti fænugreco affin ia, muccaginolum reddunt mandendo fputuma: folix, quibus ad purgandum confultius femper, quęflatum difcuticnt \& nonnihil lubricent, adduntur, quàm fi per fe, puluere infufo aut decofto,dentur: Sicenim turbarum multum ciere, \& inteltina, ftomachúmcue torquere, vel plebecula conqueritur. Eapropter qui aduerfum Mefuem tuetur non effe corrigenda,imo ficcitate fua atque quadan aitrictione vëtriculum iuuare, nefcit quid commentetur:nä fic Brafsicæ marinę, Thynelex \& Chamxlex ficcitas, ftomachumiuuaret, quen tamen ladunt illo virofo odore, \& purgatrice qualitate, à qua non longè abfunt folia Seuæ, vt dum virent adhuc, aut maceran tur, odoramur: Proinde ritè Mefux folliculos tutius purctre monet:népe mébranei funt, minúfq; flatulêta femina, quàm folı:fed hre plus mouent, prx́ertim infufa, quàm decotta; quia ebulliendo nonnihil virium abfumitur \& flatus difsipatur : vt vfus ipfe caftigate valeat illum Commétatorem, qui nihil addendum ad eius noxam corrigendan autumat. Sed hac explicatius in remediis.

\section{COLVIEA Gallis, Baguenaudrier.}

TV r a r v r Colutea diça, quód mutilati effractive eius ftipites aut vitogulta(nó prxfcifa)

intereant,vt Theoph. autor. Tanta aute ineft foliorum \& filiquarum parilitas Colutez cum Sena,vt pleriquenon ineruditi Senam fylueftrem hanc effe vulgo perfuaferint: at $\mathrm{Co}$ lutea cum Theophrafto arborefcat, nobis autem frute[cat, Rhumno penè par; nec herba vt Sena fit, iam quilibet poteft à Sena eam difcernere \& difcerc:quipoe folia colore, fitu, ma. gnitudine, \& fuperficie Senx, Hedifari, aut fuperiotis Colutex Scorpioidis,paulò antè diEx funt, floribus item luteis, nec difparibus : Folliculi veluti membranez veficul $x$, teretes: qux flatu turgent, \& tact $x$, ftrepitum edendo crepant: femine intus hxrente Létis(nō Gygarti)minore guftu, leguminofo. Augufto filiquam maturat, vbi fpontaneus arbultus eft, in Linguagotix iifdem faxofis fterilibus ad Frontignanam, quibus Chamxiridem or iri nonebanus: fed ea etiam vulgatior hortis Gallię, Germanię, Italiz, \& Anglix:nufpiam tamen

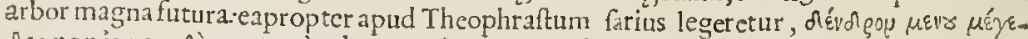

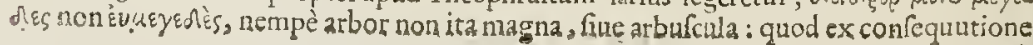




\section{STIRTIVM aduerfarianoua. $40 y$}

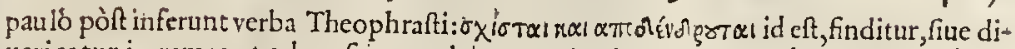
uaricatur in rames, ct arborefcit:non igitur initio al borem effe, fed arborefcere dicit. qui ortus \& adolefentia planè conuenit noftrati Colutex.

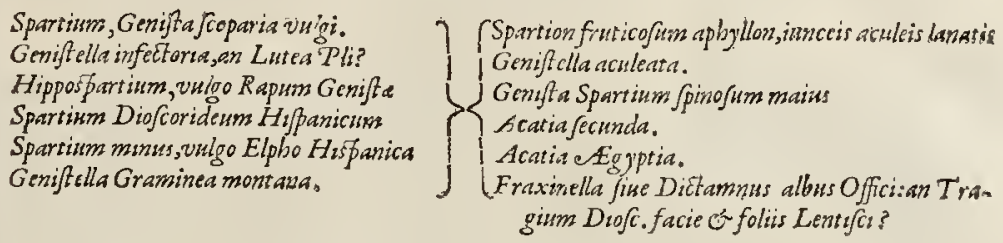

\section{$S P A R T I V M$, Geniftafeperian vulgi。}

VVI G A I I S S I M A notitix \& vitilitatis Spartium vbiuis gentium fermè antiquis Gall.Genelt.

femper fuit, vt etiam num eff. Sic vocatum, quia vinciendo, ncctendo, adeoqúue tex-Ang. Broome。 endo.fili, lorive vices expleret:fonat enim Spartium funiculum vel lorulum: Geniftam Bel. Binane

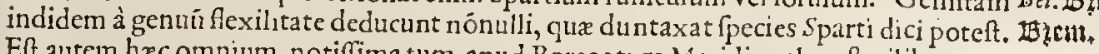

Ef autem hxc omnium notifima tum apud Borços tum Meridionales, ftcrilibus præfertim, arenofis, montofis frigidioribus. Vargis fruticat denfe pullulätibus, hominis proceritatê interdú (uperantibus; rectis, gracilibus, Itriatis, duris, fed fexilibus :per interualla foliola numerof p romés ${ }_{3}$ Hy perici, nigriora, ininora, abundeq́; luteorum Horum fuauè olentium Pifi, poft quos falcata effigie, filiquas Iunto \& Inlio maturat, feminis atri lucidi plenas, Lenticulx fimiles, quo vomitum, non fecus ac Spattio Dioficoridis, fxputss duarum vnciarum decoto propinato, citra inagnam contenticnem mouimus. Verum flores recens decerptos fxpiffinè quàmplurimos, \& per fe acetaris inditos vorat Plebecula Auernix \& Aquitanix, maxima copia, innocios non modò, fed ctiam admodum guftı fuaues:thecquicquam vomitionis nauferve vlliusaut cómotionis mouere folitos. Quin a pudBrabantios gémantes condiuntur fale \& acetofiores, men fifque inferuntur, cappa-rum olearumve pari commendatione: credütur etenim non modò cordi vires, ftomacho appetitum alere, fed etiam obftructiones referare, calculum frangere. Id circo falluntur, falluntóf; qui hofe flores vomitioni moucndæo officinis ficcandos prxcipiunt, rati iftam geniftam, effe $D$ iofcoridis Ellebori fubpar dcietorium Spartium. Quantumuisenim feminis incoxeris, viz aliufnodi vonitionem moueris, quàm qua communibus eme ticis Raphano, ficu veloleo cientur:nec enim deictione infigni, fed tantim lcuiore cona
tu excludant, qui hauferunt.

Vulgi $G E N I S T E L L A$ infectoria, an Lutca Plis?

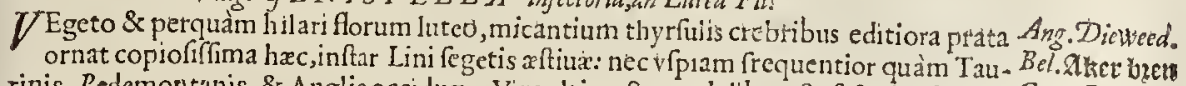

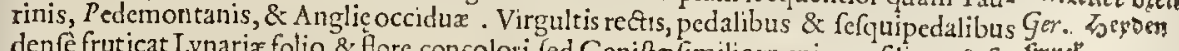
denfe fruticat Lynariz folio, \& Hore concolori, fed Genift $x$ fimiliore, minore filiqua \& fe- imuct'. mine, amaricante guftu tota:Lanarum infectorsbus expetita, fed vt proceritate, fic virium
efficacia Spartifupcratur.

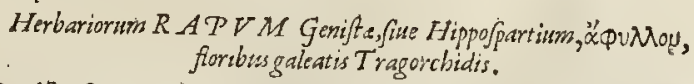

$\mathrm{R}$ Adicibus Geniftx \& Geniftellæ adnafcitur quafi foboles fouria, fed foecie vifenda \& raritate,excrementum Rapum Geniftx vocatú, non abfimile ortu, concretu, incremento,caule, \& effigie Hyppochiftidi vel Orobanchę. Quod magnis votis \& peregrinationibus Chymifte Maio menfe venantur ad vtriufg; Geniftz radices, fublectos tencriores afparagos, cnm radicibus fiue a pendicibus à Genifta auellendis alembico indüt. Indeq́; igne oleum eliciūt ad calculofos perquàm celcbre. Id auulfinus in Flädrię, Gailię, \& Anglięlocis maiore Genifta fcatentibus, alicqui frultrà quę̧itú \& diu alibi, At Sabaudix 
Tam adductis moxq́; adducendis Spartio congeneribus plantis, nulla propius explet Torbonenfibus, prefertin maritimis, vel nó procul à litoribus, vt in Grammuntia Sylua antur, maxima anni vertent

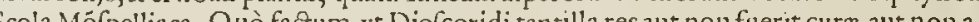
modi vult Diofcorides \& Mefux, qui à duabus ad 5.drach. forú, dandas vomituris impe difor

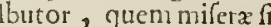

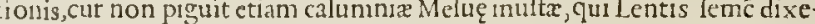
a

\section{ST ART IVM vulgo Elpho Hipanical Iuncea,nautica, vulgi Funi- Jpartion, an Lino partion Antrguorum?}

quä nota,a ingenti cupia deuehi folita $A$ ntuerpiam, Maffrleă, Genuamó, ad corbes, Atragula, ató; trircmium nauiumq; rudcıtes peraccómoda. Virgultıs iunceis, graciliori作, Gulielmi Driefch non mominimus:certum tanen lrabemus, nonntilla, fed taltt tla habu apta lportularum, quas adhuc vocaut Sportols, nempeab Spartio dictas , quò minus dubitamus

GENIST ELLA Graminea Montana.

Partea \& hecc herbula eft, \& paucis duntaxat monhię etia rinumfcfqui palmares, graciles, fiartos, enodesquibus fummis fingulis fpica mollicella,tomčtofa, Lagopi eur:indidem erum pentibus graclibus foliolis, palmum altis \& féfquipalmü articulatım veluti geniculatis, per spati 


\section{STIRT IVM aduer Jarianona.}

fpatiola \& commilfuras infecti, ea videre eft viren tia etiamnum Lordini.

\section{$S P A R T I V$ Maphyllon fruticofum, \\ Iunceis actleis, Lanatis cerpituls.}

ET inuentu minus frequẻs hic afperioribus pràruptifque decliuibus Alpium M.ıgdalenę in Gal loprouincia fruticell us, latinf culè in latera, al liquot fparteos ftriatos, ex pullo buxeos è radice Tragacanthx prolixiore,lignofos , \& fefquipedales furculos fpargit; nullis foliis, fed multis fenticofis, rigidis ftilispungêtibus, iunceis, aduncis in fummo tantùm: quibus fingulıs aduoluútur fartigiola, tomeutacexúe gemmulę Vitis, minores, fed conco. lores, partim longiufculx \& incurux, partim breuiufculx : nulluni folium, florémve vidimus; gtsftus perparum amaarican tis, exficcantis, aftringentus.

\section{GENISTELLA aculenta.}

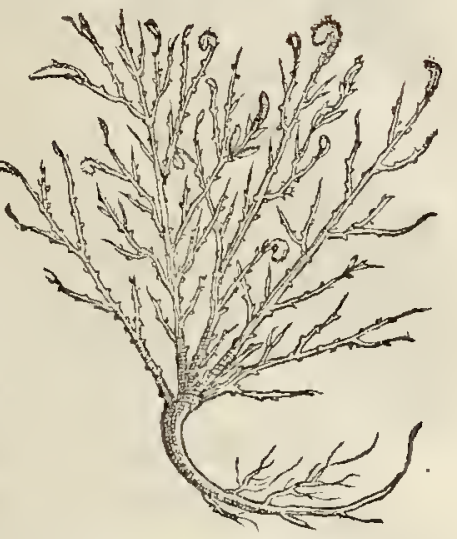

EX v c т I colles, fqualı́áqque Anglix \& Belgix ericeta hanc plantam abundè dant: E rä dice exigua, virgas graciles, rettas. complures, fininulis infeftas fubmittentem; quibus foliola Thymi vel Ericx, fores luteo pallentes, Geniftx minores:etramq́ue breuiore rotundioréque filıqua,\&femine Erui fubruffo: Hac penè carere videtur adhuc Italia \& Norbona.Et hortis negligitur.

\section{GENIST AS P ARTIVM pinofum maius.}

Belgis.t5afpcloolcit. Ang. Brike Browme. PR ORs v m cognata Genift $x$ hxc, fed admodùm afpetu horrida, fentibus preduris, in-
numeris,cancellatim armata, femper virétibus, ftriatis, lignofis virgultis, fparteis, fpinis penè folia occulentibus. Quare Doctiorum nonnullis placuit Nepam effe aut Scorpion: fed Mon/pellienfí:

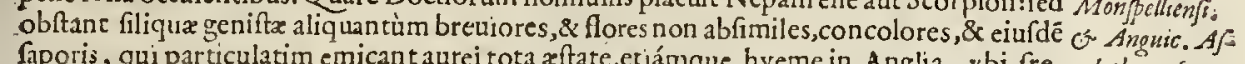
faporis, qui particulatim emicant aurei tota aftate,etiámque hyeme in Anglia, vbi fre-palatbus feckna quentifsima in fterilibus \& ericetis, in Prouincia item Norbonenfi penè par proceritate. dus. Sed Monfpellii ad Lanum, in fax ofis collibus triplò minor, rigidior, \& fqualidior eft, adeò vt parum Geniftam repręlentet, foli is ternis Rutz. Illic Spalathum vulgò opinabantur \& vocabant plerique omnes, tametfi inodora \& funis inftar pertinax frangendo fit : floribus quidam Inbentes ad ifterum viridem vtuntur, \& toto cremio calfaciunt furnos.

Spina ACAT I A Diofcorid prima, frutex arborefens, leguminofus Lestisfolius; Silegua torulis Lupini effigie djttincte, plurimum bigrana, aut trigrana, chizh G Y M I A R AB I CVM.

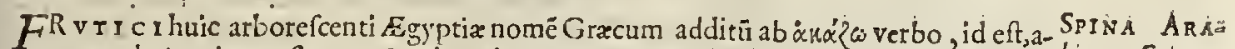
cuo,vnde Acatia, quafiacuta. Septinus iam agitur annus cùm huius Venetos, Patainos, bica Aginete. nof́c; certiores fecit Medicus \& peritus Pharmacopous Sequinus Martinellus, missis è $S y$, tia filiquarum faccis plenis Alberto Martinello frati fuo,perquàm fedulo \& erudito Phar- $S_{\text {PINA A ARA }}$ macopœo, ad Angeli fymbolum:ex quo femine in horto Patauino aliifque quadmplurimis bica Diofcor: in Venetorum locis fato,orta eft ifta $\Lambda$ caria, cuius filíqua penes nos eft, accepitó; nofter Mor- Carausis ganus plantam nuper exmaris Occidui Infulis Perunianis, ne quis purec peculiarem $\mathbb{E g y -}$ p to aut Arabie. In neruulis pralongis foliola funt Scorpioidis legumin of $x$, aut SferroCauallo, in toto virgulio gracili,aliquot rigıdis fpinis in furculis exertis. Seminis to ta filiqua non maior vno al teróve Lupino fimul iunctis, fed fuis alueolis diftincta. Quare ridiculam nobis $M$ in. $i$. dedit 


\section{STIR PIVM adwerfarianowa}

dedit Acatiam Sencnfis, cui fi fpinas demas, arborem ludę iudices, \& mcritò fufpicêre fpinas non nature, fed pictoris aut Cóme ntatoris commentum fuiffe : nec huius filiqux, fiue Lobì funt Lupini fimulcs, $f \mathrm{~cd}$ Genítx duplò latiores, vt Senz compreffx. Et Plinio cuinflibet Acatıx femen Icnticulx eft, equiden minore grano \& folliculo. Quamorbrem noftra hęc propior, illa vcrò Cerecis ar bor crit, ģuana illie, nec cogitans relatu Oratoris cxquifitius delineat.

$$
\begin{aligned}
& \text { ACATIA ALTERA Diofo. norior Enropara, folio Cytifi, facie } \\
& \text { \& filiguis Goinflapartignofs. }
\end{aligned}
$$

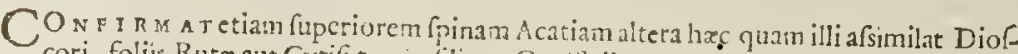
cori. foliis Rutz aut Cytifí ternis:tiliqua Geniftellæ, aut vulgaris Glycyrrhize nouaculam cffigiat dorfo obtufore, \& altero latere, quafi acie acutiore, tria aut quatuor Geniftelle etiiun femina dur a claudit:qua nondum matura flauenr,poftea nigricant, fimiluter Spartio effigic \& parilitatc magnæ fpinofx Geniftx, non arboris, vb quidä deccperunt Mathiolü. qur æquè incertus vt in fupcriore, illam cotam candidus fcriptot Anguillara dat, \& tamen fidem illi abnegat, eandem ipfe ridiculè afícrit. Quippe altcra Diofori. fpecie, vnjuerfum Tirrhenum, Ligufticum, atque moditcreancum littus Icatet, vti plet aque Italix loca.

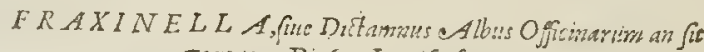

$$
\begin{aligned}
& \text { Texyloj. Diofco. Lcitifafactc. }
\end{aligned}
$$

H R C I N $\checkmark$ m odorímve putorem monet Tragii huius appcllutio: Quare docti quidam Barbari, qui hui us delincationen, natales; \& vires compares Dichano Cretenfi, piafertim ad euellenda fpicula capris infixa,legiffent, cidemóue nofträ fraxinellam contulifent, putarunt eam Dictamnum album cffe vocaudam:recentiorum autem guidam exercitatio res, Tragium iftud Lentifu facie ì Diofcoride defcriptü, huic planè quadrare alfeuerarunt. Quippe fcapos edit plurcs, fefquicubitales \& bicubitales, ramulis \& foliis Lentifci Glycyrrhizæ aut Fraxini, vnde Fraxinellä herbarii vocät: Hores Itunio \& Iulio admodùm fpeciofos \& numerofos promit, Thyrrum féquipaimi, Iógiorémve obfidétes, A fiphodeli quadätenus

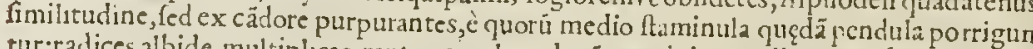
tur:radices albidę, multiphices, mutuo amplexu heeręetcs, minimum digitũ craff $x$; quas eruebamus turgidas \& fortentes, fucco lutęo, vifcido, digitis pertinacius hęrčte:quod Gümi vídentur fuggerc, aut fe Earı mufc $x$ luride, cluniám mque \& alarum virore conf picuę, cuiufmodiferè cantharides in Fraxino, vt nos fludiofé obferuabamus, in quod am pago trans Rhenum, altero à Bafilea fere miliari, prope rupes quafdam apricas, vbi maxima copin fponte fruticabat, Semina penè Lentifcinis paria, nigra, lurida, in folliculis Hellcboraftri aut $\mathrm{N}_{2}$ pelli. Quamobrem non pefsimè videntur arbitrati effe Tragium: Nam quód obiiciunt de Creta Inlula, cuius vnius hæc fit alumna, non officit affertioni noftræ: cum multæhodie in noftris tratibus: \& plurimz ex infulis, nō alisis admodùn, \& fortè núquam prifcæx gêti notis, afferătur æquè rarę, \& exden etiam metipfa, qux folius Cretx putabâatur indiacnæ. Ce-

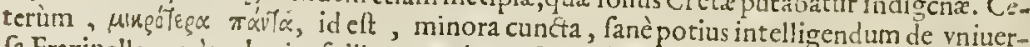
fa Fraxinella quàm de eius foliis, qux minora funt,cóque à Plinio Terebintho fcitè colla-

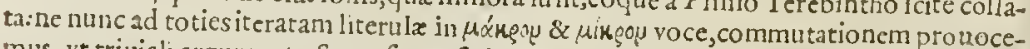
mus, ve triuiali argumento Senenfis, ne fit locus. Huius ad venenata non temerc vfi font practici radicibus, quæetiamnum in officinis nulti commodi funt: for s admotx bpis epifpafticą, intrò veró fumptę,non modó venenatos fuccos, fed etiam purridos \& foetentem illuuiern foras exigunt, decantato Agyrtarum \& quotidiano in pueris experimento, lum. bricos funditus omnes interimunt. 


\section{FRVTICVM, SVBFRVTICVM, CRE mionum es Arborimaduerjaria, concifiéque recenfiones.}

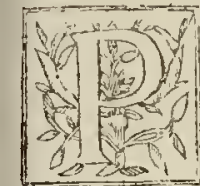

Ofteaquä coepta via prolixiffma fimul \& ope. rofifima, herbarum necefjitudines ơ gentilitates in fuas classes redegirnw, ac penè

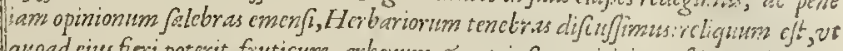
groad cines feri poterit. fruticum, arborum, co vtring ans ancipitis conftitutionis plan-

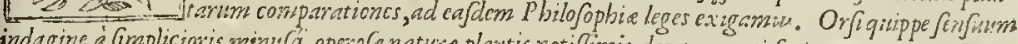

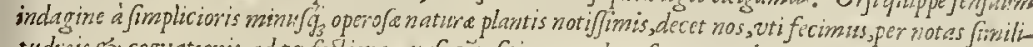

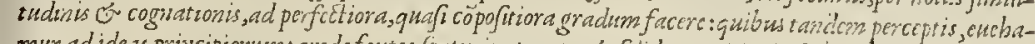
mur ad ideas principiorum: vnde fontes fcaturiunt certe of folide cognitionis facultatum co ofus. Es

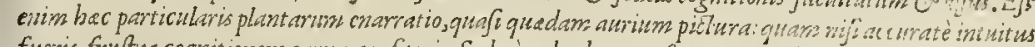

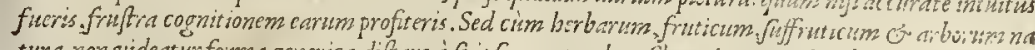

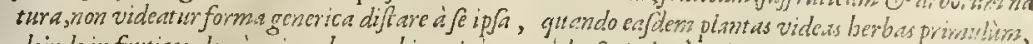

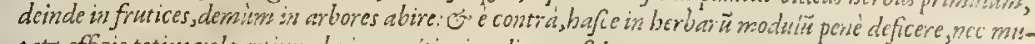

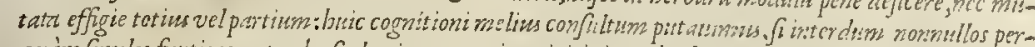
quim fimules frutices aut arbufulas incr cmonti ancipit is inter berbas adducercmus, co alibifrutica res herbas cognat as arborwm cxplicationi relinqueienus. Tam vero plucima fiuticum parti, cui maxi-

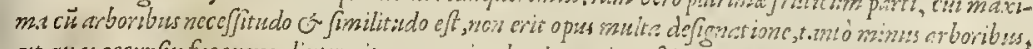

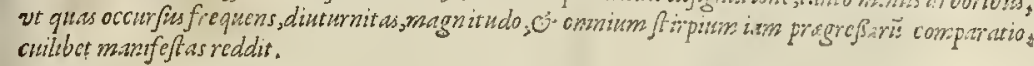

Lentifiss.

Tercbintbus maior Latifolia Norbo. minor Lentififolia.

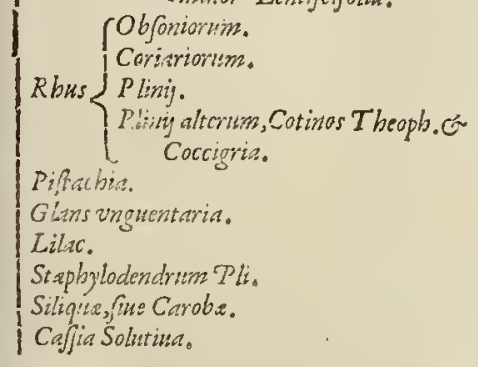

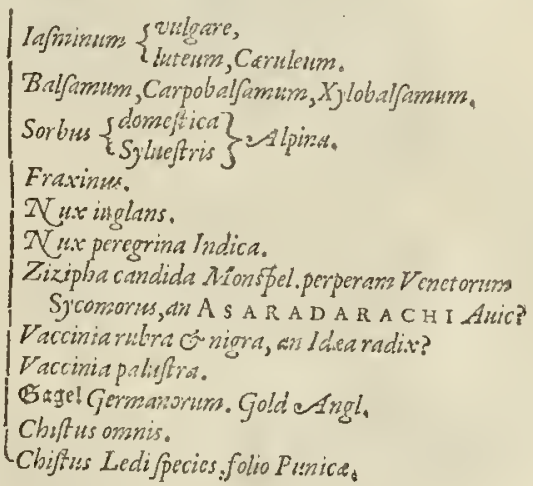

L:ENTISCVS

Entorem foliorum attręatu quilibet percipit,vndc Lentifcum dicunt,partim etiam è Gracis mutuati, qui oxîy quaf oxiso: aut fifle vocartunt, quód facilè \& frequens finderetur in dentiscalpia, ad nitillam alboremá; dentium, vectiamrum fit hodie. Fruticat \& arborefcit folonibus \& caudic concolor \& fimilis Therebintho minori, fed botris \& vtris initio ex fuluo purpurantibus, naturefcédo nigricantibus acinis, nitidis, Sumachij Phylerex, \& Sambuci:vtriculis folliculnúe oblongis, rotudis, aut incuruis, teretibus, quibus infút culiccs \& effigies ité Terebinthi, adeóq; Horcs fimiles, raccunoî, mufco fi, quos primo vere A prili méfe promit,non particulatim, vt putarút ex Arati \& Ciccronis verfu, Lentifco triplici folita grandefcref fotu, quod Theophra. meritò Scillę attribuit, autem vocis affinitate decepti, Lcncifco. Quare non cffe contcmptui habendam nomenclationum perpenfionem, alibi iure affeuerebamus. Sempernicatis auten Létifci feracir fimus vniuerfa Norbonenfis ora maritima, qux ad Taurinorum iuga, quxq́; ad montcs Min.ij. Pyaseos 


\section{\&12 Fruticum, fubfruticum, cremiorum es}

Pyreneos protéditur. Illic namq; Lentifci, Rofmarini \& Lauend ulæ virgultis ac cremijs. quàm quouis ligno magis ad calfacienda clibaua vtuntur. Nec praterquam vnam norūt Ipccicm, guarn Reffincle vocant. Ideóq; fallitur \& fallit Senenfis, quòd pumillas refécés Lể tifcos, alias à procerioribus specte facit : fit cnim tantùn refeetiscymis ad vfum, ne in arboris amulationem afurgant. Et hunc crrorem cumulauit infcitia, cùm vniuerfä plâtam grauiter olere ait:at nobis alif́f; ftudiofis faltus \&e colles aridos Norbonx peragrantibus, inferta in ọ fos folia, non modo fuauiter fptrabant: fed etiam, quod fortè nefcit Cómentator, fitim arcebant, \& fauces humidas tuebantur. Itaq́; nobis filétibus, qui norunt Maftichen, \& fciunt Icntifci furculos, vt Xylobal fami fuccedaneum in Officinis vfurpari l.étifcinifó, đentiffcalpijs poft epulas dentes emundari, illius refellont \& ridebunt cómentatiné. Porro quomodo \& quamnam ementiātur Caphuram hodie Veneti mango$\pi c s_{1}$ in fuccis Medicatis docent.

\section{TEREBINT HIVS Lentififolia minor. TEREBINT. manior $P$ iffactira folio.}

Terebinthilatio folis pecies.

Volucelle fine Culices è folliculo.

Folium Tere. binthiminoris.

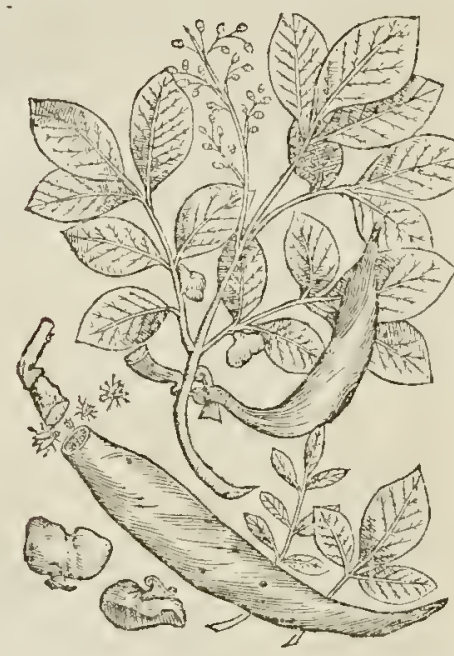

Cocinx racemorum baccula aut acini rubelli fimiles \& concolores quadantenus Ciceri, nomen Terebintho potuerunt fcciffe : nam iss?ives Grace Cicer elt. Huius autem fempervirentis \& perpetuifolia, 1ullus collis aut dcuexus paulò apricior Norbonz aut Galloptouincix non feraciffinus: vbiduas folio tentis difcernendas meminimus. Frequentior quippe efl angu fiore Ientifi pofitu (non Fraxinive Senenfis) colore \& habitu, folio duplo maiore.

Alreri autem folia multo lation, ro. túdiora, vicina Lauro \& Piftachia, adeò vteminus intucntem fallat. Vux vtriç; xedem, acinulis quàm Lentifci maioribus, coccineis, purpurantibus: demum ex viridi in cæruleum maturefcentibus, non per initia(vt putauit radiatus Apollo) Hore Létificiant Sumachi racemofi:folliculi cartilaginei,teretes, aut co

nici, angulofi, vel fphęrici:vnde culices è fuliginofo excremento ctsolant, fucco falinari ad Balfama laudato, fffluente. Vbi lxtiores, \& acultiores funt arborcum proceritatem affeEtant: \& ferro vulnufculis factis in Valena Sylua Monfpellienfum, (xpius nobis non paucam Te rebinthinam extillartunt lucidam.

\section{R IIVS Cbfomortim \& Coriariorumguid.}

Olor item coccineus fămeúfve acinulorú in racemulis nomen huic feccrunt: gous au-

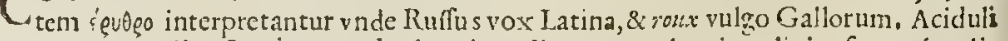
auten racemi olin, \&etiamnum lodie ad eondimenta, multus in culinis vfus:eoǵ; culigarius fiu obfonarius vocaba tur. Cortex autem \& folia alutarijs ad pelles défandas cóquifitus, vnde Coriarus dictus. Quare nou funt ve falfó produnt duarum planzarum, fed vnius arbufculx partes : hanc multó proceriotem quàn Diofcoridis fit, penè Sambuci maioris magnitudine, ferunt Monfpellio \& Caftronouo contermina Oliucta quadam glareofa \& macilentiona. Sorbo vul gari adco fimilia funt folio fuperficic \& pofitu, vt vix fit internofcere,nifi attentius perpendenti.Locis Galloprouincix aridioribus \& rede-: rofis, defitis incultis pumilla, \& quanta qualísọue apud Diofe. defcripta bicubithlisa:bufcula, vifitur. 
Arborum aduerfaria, concifenue recenfiones.

\section{RHVSTlinii Myrtifolit Mon- ppellienfium.}

EO D E M ex vfu ad coria firmandia, nö de femine, duo frutices apud Plinum R hus dicuntur: horum notifsimus \& witatifsimus cunct $x$ Norbonę,prę̧ertim Morfpellienfibus,apud quos vbeı è ad Lani amnis crepidines fruticat, virgultis ramulífque quadratıs, frequentibus, viridātibus, folio Rufci, Myrti, atit Iuiubx.Seminula intra angulofim tuniceam thecă inclufa funt cochleata, Càli modo multo ininora.

\section{COCCIGRIATheoph. Cosius Pl: ○. Theoph. Rhus alterum.}

Kótwor funtcirreíve flocci, quales in galeis, aut galligallinacei vertice vifuntur, qua de fimilitudine ffor is, dictus fuit hic futex, qui è fummis virgultis, quinûm cubitorum altis, pulcherrimum lanitiú tollit, Sericeo veliere \& contextu calamiftratum. Quod crifpatur \& explicatur in latam calariem, crinibus punıceıs, fufcis, tortilibus, femine Létis minore, ex nigro ruffefente; caudice \& virgultis fufcis, vimine is: foliis circinatis, denfis, rigidis, $\mathrm{Caf}$ paris, Piftachiam aur Terebinthum redolentibus, \& concoloribus. Auraico agro quatuor miliaribus Aunione, qua Infulas \& Aqua fextias 1tur, maguus prouenrus eft: Vidimus etiā in agro Veroēnfi, Venetiis, ex locis Hifrne alpinis. Quo magis miramıir, tantę venuftatis ftrpem frequéti vfu \& mercatu ad coria curanda expetitá, indictan fuillic Cónentatori.

Terebintbus Indica Theop.eft Piftuchia Diof.

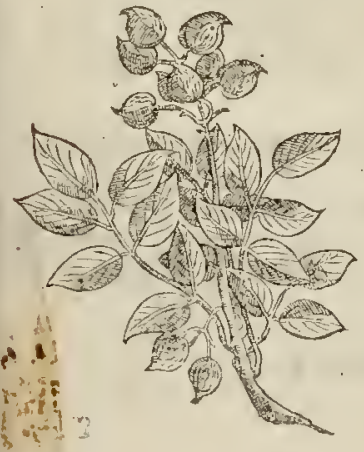

Anuculis Pi-

los imitanti-

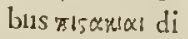
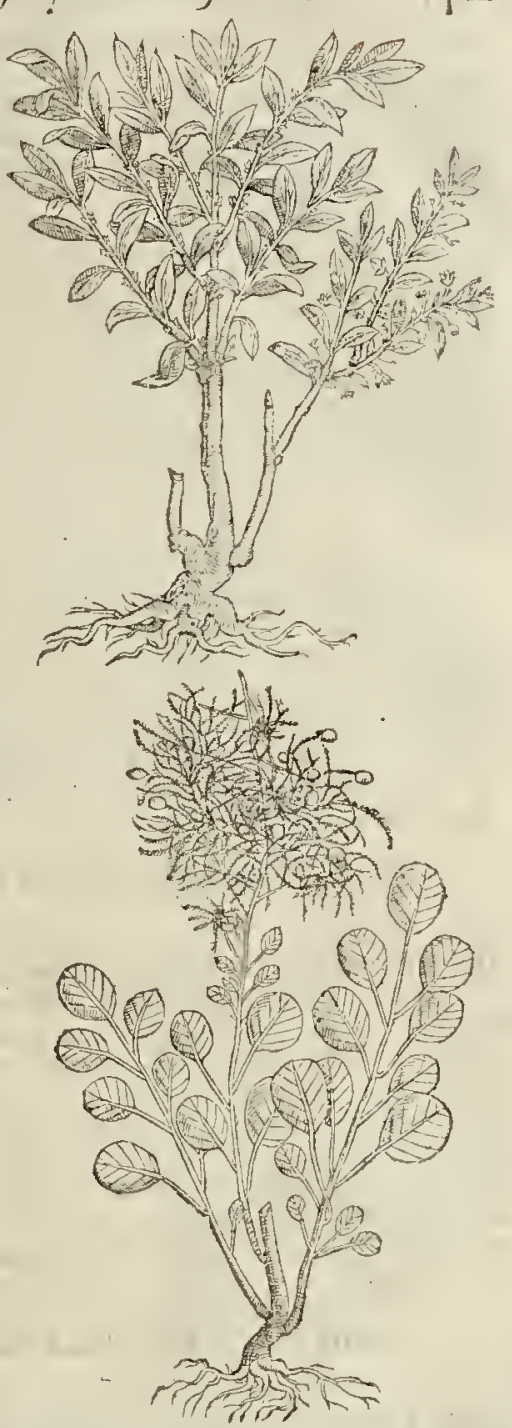

Ex , hodie funt Offinis notifsinx, \& edi folitę: non fecus ato; Pinex vefca funt:porraceo colore intus, mebranulit eati ma \& cortice amićtẹ Auellan $x$ : Arborem qualể in bortis 1talicis vidimus, etiamóne in horto Graii feduli Pharmacopeei \& Atirpiun percupidi, ad Londini menia,prorfun dicas Terebinthum, ramorum \& foliorum ortu, habitu, ma gnitudine:flores item racemofos purpurantes Tcrebinthi edunt in Italia, \& Galloprouincia, vbi feruntur,fed maturitatem non affequuntur.

$M \mathrm{~m} . \mathrm{iij}$. GLANS 


\section{Fruticum, fubfruticum, cremiorum do \\ GLANS vnguentaria, cetbartica, filiguara.}

BEN.

EFF I g I s striquetra, fed rotunda \& glandis xmula luic nomen generis aptaut:oleum verò quod prelfu remittit

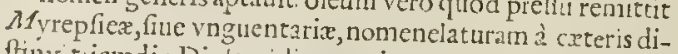
finxit iamdiu Diolcoridi non minus nota, quim noftc $x$ tati, tametfi non cius illiqua; vt qui palmulas voeatas libro primo, F henieobalano confert, vnda nomen $B$ E N Arabiftx videntur detorfife, quod ill nuculam hanc vnguentarian interpretantur. Offieinis \& fuffitoribus, tum ad valetudinem,turn ad voluptatem,oleum dat preffu, vt nullo odore ineundum, fie nullo rancore, atut fetore vetcrafcens, nulla labem aut fordem ehirothecis aut veftibus illinés, ac quamlibet edoris fragrantiam ill batam \& veretan tueri, onniü oleorum vnum aptissimum, non fecus ac Sefamium, aut Amygdalinum prcmi folitum: eff namque in filiqua, quan
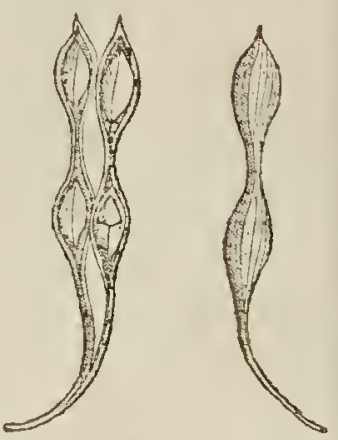
nullus veterum aut recentiorum Jireris mandauit, admodum eleganti, palmum longa, carinula bifori conflata, tereti, rotunda, graeili, binifque loculı. ventrio a;nempè ima mediáftylo, quo, roftri inftar, vel Rhododendringulam fingulo claudens; fumn nerò, acuto tendit:Intus fubruffo colore, forodendri vel $P$ eriploex repentis, acutum inucronem; proque cxarata:coriacea tota, fexilis \&ullo cinereóve, \& feeundum longitudinem ftriss rugíf-

LI I A . que cxarata:coriacea tota,fexilis \& corticofa, infipida, fubaftringés \&̊ ficca.Hæc dono data primùm praceptori Rondelletio fuit, deinde nobis, qualem icone damus."

fat: Nam Populnea longiote fronde, frucu pitor apud Mathiol. qui hie nefeio quid mur timprodit.

\section{Germenorm joimpetmilzle. ar ST APHYLODENDRON PlL?}

PR OR T E R periucundos Aotes albidos Bryonix, aut La-

brufex, odore \& fimilitudine, videtut tranfalpina quædä arbor, Staphyllodendrum apud Plinium(qui tamen A ceris follum dieit) quan volunt efle hîe depitain, \& multis locis Hcluetix non procul Bafilea arboreícentem,deprefsis, vdis, autimolis, luxta amnes \& fepes, velut Sambueus, eui ha bitu re?pondet, aut Terebinthi: fed erenulis perpufillis, elcgantissimis, \&e fupernè acutis donatur. Semen quadantenus muclei Cerafi, intus efculentum. Qirburdam in eonobiis caudiee Prunum $x$ quat, \& nuculis preeulatum globu-

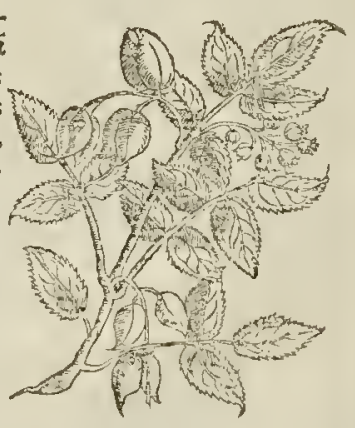

Carobia Artum arit, or vulgo Sronincivilitim.

$$
\text { KEģ́́tix SILILVA, CAROBE. }
$$

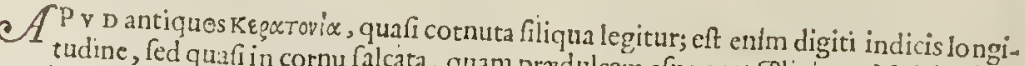
tudine, fed quafi in cornu falcata, quan prædulcem efu voeat Plinius. Multum hac cognita Nieee \& maris Liguftici accolis, vbi eã efitant pueri etiamć; porci: Quare,qui facrä to. Non parim tu,vt nuper intuebamur in horto amici

$$
\begin{gathered}
\text { SILIQYA, aut CASSIA PVRGATRIX, } \\
\text { eArabum Carrobiis fimilis. }
\end{gathered}
$$




\section{Arborum aduerfaria, concifaque recenfiones.}

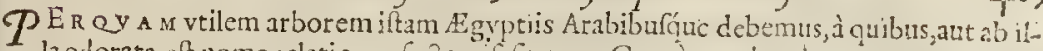
la odorata, elt nomenclatio profezanifi it ax 5 us Grecì, quo il cotiaceum vocant, qutafi fit cociacea ipfa filıua infignis, qua:in nallus non nouit, cuin (qú fi femina lata, qua intus tranfuerfis membrancis alu colis difsepiun tur, feras, prous macerata in aqual frigrda, \& terra in fodias, videbis planć ortu totoć; 1 p fo habitu Catrobiam initari. Flores Juter funt; Chelidonii minoris,odori,plufculs, vno crortu, fenis aut feptenis foliolis radinti, quales multafque perquàm raras vidit \& attulit ex Infulis Americis \& $D$. Dominci, cxercitaif fimę cognitionis pcritifsimus D. Ionnes Brion Hoppeuilleus Northmanus.

$$
\text { GELSEMINVNI vulgatius, fore albo: }
$$

CONCIN N O R M quàm certiöem afciuit fibi appellationem de fententia quorundam doetıorum, quibus Iafme di fum putatur', quafi viola odora, quina oleú apud Perfas olim folitum effet ittius floribis imbui: quod tamen grauius fpirat Diofcoridt, énue arguit non efe noltrum Gelfeminum. Et violæ vox, laxior multo eft, quàm vt ceță gatannpiam plantam defignare valeat, nedum hanc quan Mauritani $Z$ ambac \& Gcleminum dcunt : vbiuis in hottorum anģulis apricis, \& pro pretforum caurdiis furculo panzitur, adq́ue ornamenta pergulnrum, induttria \& pedamentis erigitur ad fornices. Folı funt in imo latiora, lateribus veringue rcduata, acutiora fupernè quàn Lentifci:forcsaibr vt plu. rimùn, Polemoni, in flexilibus prolixifsimis virgultis octo \& decem cubitorum, Clemu- Letoms

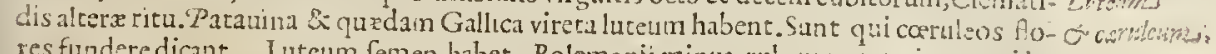
ses fuadere dicant. Lutcum femen habet, Polemoniminus, rubrun, aut nigrum, ni la-
bat memoti?.

\section{$B A L S A M V M$.}

PVro Diofcoridem vires melius quàm ftirpem notam habuiffe: de viribus namis; multa, de figura nihil. Hanc fic amici noltri oratione referunt: Humilis efl frutex, afpecte deformis, cineracei colotis, fore pufilli Iafmini lutei fimili, minote, petpereis virgis, foits horna e.suit Decembri,quibus nonnifi menfe Maio noua fufficiuntur. Cari atu; Batilione fata viget. Decembri menfe ramuliprafciduntur, quibus ceñ oblita appendunter aniphorz, excipiend o aureo liquori, qui molchum fapit, Hune notre non diffcile, fed bi m: ucris longe difficilimum habere. Opera danda accutatifsima, quò eius vires çửm expioratifsimas habeamus, vt quando no:l licet illo frui, faltem bonitate proxumis te fimil fu-

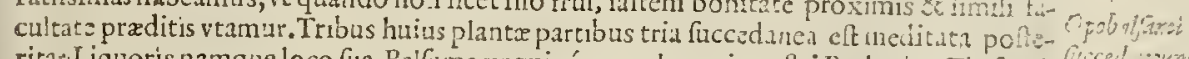

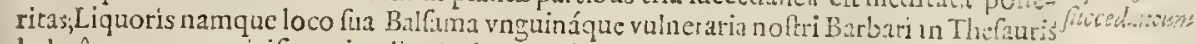
habuêre, quorum mirificas vires literis \& experimentis prodita funt. Iignum veró, atrod Xylobalfamum dicunt officina, Lcatrfi funt futculi, pierumque cariofi, tamen nerotiquan 等

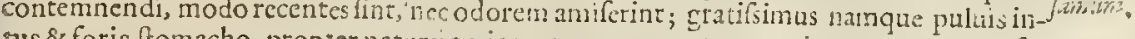
tus \& foris, fromacho, propier natura anicum teraperamcntum: cuius argunentum faciunt dentiffcalpia, qux aromatica \& modcrata aftritione a calefactione dentes, gingt-

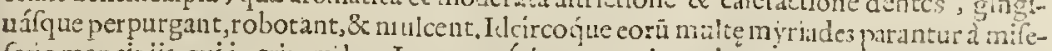
feris mancipiis, qui in triremibus Lygurum fub nerto vitam degunt. Pfeudos, lobalami huius magna copia pauco.ære parari potelt ex Itaila \& Gallia Norbonen fi. Sic femen, 1..' of , Carpobalsamuns Carpobalfamum officinarum, cum neutiqum frufus lial fami fit, imò cuiufnam planta, inscertum fit, rancidum, vietum, exoletti, inodorum, minime Carpobalfami loco vfurpari debet: quin potius huius penutia, femen Terebinthï,vel Lentifei inmatnaturi exmir vires, omnesCarpobalfani facultates, \& dote, ve fi quodaliud, explere mihi videtur. Quin Tere- Terebinth the binthii è pullulantibus botris atcue fagellis tempore verno laticem limpidifsimum, o- qerés:
doratifsimum, non parum tenacem emunvimus, qui digerendo, glutinando, doloremque
nulcendo, omnia qua Opobalfamo infunt, conferre videtur. Quod non modò domulcendo, omnia quz Opobalfamo infunt, conferre videtur. Quod non modò doctiorum antiquorum, fed etiam Barbarorum Barbitonfor um confenfus feglutus elt. Nullum enim videre eft ex illis vnguinibus, quod v riỉ praftantia nomen Balfami morucrit,cui non fit adnixta Terebinthina vulgatz: Quid putas futurum, fi genuinum Tcrcbinthïl liquorem admifcuiffent,qualem defcripfimus Capite de Tetebinthio? Ea de caufa nullum praftantius fuccedaneum arbitrainur, cuilus omnes partes onnibus refpondent Min.iii.

partibus 


\section{Fruticum, Jubfruticum, cremionum of}

partibus,ligno, liqquori,femini refpondeant, quàm Tcrebinthum gentinum. Mathiolus \& qui fumm Garyophyllorum, nucis myrifticx, aut Cinamomi oleum, buic liçuori nre:runt, fitauitati \& fapori plus quàn optatis facultatibus defer unt. Hac nanzque tamerfi eximios fundant liquores:tamen nec Diofcoridi nota, nec venenis aut Theriacis comparata fuêre. Et præterquàm quod plerumque vel fœetent vel feruent ignis cmpyreumate; etiansfi fint optimè parata, tamen fxpius acriora funt quàn par fit, \& intcmperiem fertzidam imprimere nata: Oculorum verò hebeti acici fi quis admouete aufit, ne jllc honzinem ex lufciofo cęcum facie t: corrugat enim pupillam, nec penetrat: fed viam fibi intercludit, dolore vexat: Myrifticum verò oleum, laxando \& inquinando, nec foris vulneribus giutinandis, nec ftomachi vires celligendo idoneum eft, nec quidquam Ballamo fimile habet.

$$
\text { SORBVS domefica o Sytuef. Alpina. }
$$

SOR в y s hodie notifsima in Gallia, Germania, \& Italia, arbor magna eft, foliis \& facie Sfraxini,Sumach, aut Sycomori Venetorum colore partim ex luteo pallefcente, partim plinicante, fructu rotundo, aut Pyri parui effigie, perquàm aftringente:floribus albidis, race-
mation colęrentibus.

grasizus bit $\quad$ H v I c prorfum fimilimontibits oriunda frigidioribus, foribus iifdem, fed vmbellatim bula Dod. candidis. Fiuctumultò minore, copiofo, maiore Oxyacanthx vulgaris, concolore, acerbo guftu, auibus potius quàm homini, vbi vidınus, expetito.

$$
F R A X J V S \text {. }
$$

EX fuperioribus Sorbis facilc̀ innotefeet Fraxinus; cuius femen Officinis Lingua auis rocatur,quòd auium lingulas imitetur, guftu acre, amarım.

$$
N V X I V G L A N S \text {. }
$$

NEc infrequens puerifởue notifsima Iuglans, foliis pręgrandis, neruofis, Terebintho, aut Fraxino multo maioribus, Centaureo magno paribus. Cuius nuces condiuntur die vna albę,hoc modo: Tener $x$ rulcis cortex putaménve antequàm lignef́cant, deglubuntur illicò cultro, teffa albida \& tencriufcula tenus, è veftigioque ne nigrefcát, in aquam puram proiiciuntur, \& vfque dum mollefcant coquuntur, Cinamomi \& Garyophyllis traiear, faccha ro in Sy rupum perfętè cocto bulliunt tribus qquatnórve ebullitionibus : tumq́ue quio faccharum ebibant, triduo, aut quatriduo inibi finuntur. Et quia Saccharum rccrudefcrt,propter humorem quem imbiberat, illud iden faccharum per fe denuò, coquitur, \& fic bis térve repetitur.

$$
\text { NVX perearina Indic.s, non biforis. }
$$

C $\mathrm{D}$ v f H I T v R quidam fructusex occiduis, adeò nuci Iuglandi fimilis, vt nondum introfpectum, fępins putauerimus nucem Iuglandem cfie : fed effractú , caro fuit vefca, intus albida, Caftancer fapore, fiore, quàm nucis Iuglandis. Hunc Rocella nobis dono dedit eraditıSinus Doa.Launæus Medicus.

$$
\begin{gathered}
Z I Z I T U A \text { candida Monpel. qua perperim Vesetorum Sycomorus, } \\
\text { an } A S A R A D \text { arachic Auicenna? }
\end{gathered}
$$

HA x c ̀̀ fruftus $\&$ totins arboris figura Monfpellienfes candidam Ziziplam dixerunt, quamuis facultatibus fit prorfum abfimilis, vtpote guftu admodum ingrata, virofa, amaricante, Fed Zizipham fatis referente, carne \& nucleo; colore tamen buxeo, pallido. Flore ftcliato, Flammulæ, aut potius Circex concolori,folia Fraxini, Staphyllodendri aut Sorbi,atrovirentia.Venetiis \& Norbonæ frequens. Belgis colitur in hortis.

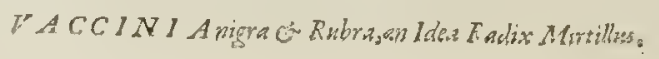




\section{Arbormanaduerfaria, concifeque recenfiones.}

Herbariorü Y AC C INIV M nigrüant Rubrü,an Idea Radsx.

N ON PERPERAM quadrat huic Iǫ̛̣ plantz vteulus horum fruticum afpectu Myr. Mirtilli Offic

um aut Rufcum illicò referentiun, vnde Pharmacopci cum plebecula guafi Myrtillos vocarunt \& vfurparunt, aftringunt etenim \& exficcaint ambo, nonnilil refrigerando, qux omnia appofitè quadrant Idex radici, cuius fuit potiffimum vfus, cuiq; nomen incitum à monte, quia non nifi mon to fis: locis \& accluibus arduis calidarum tcgionum, quibus faltus \&nemora frigidiorum plagarum refpondent vtplurimú. In Anglia,Belgio Gallia \& Germania,Scuenx inacceffis Tridcntiq; alpibus vtrumó; fructum efitaumus. Sed virent initio, deinde rubcnt tandem nigrx baccx fuauiores maturitatcm affequut $x$ vinco fucco turgent, pradulci guftu. Proxime folia lignofis furculis crebribus farmentofis multi harent:Horibus Ericx aut Vucdon is minoribus, pallentibus. Radix lignofa multa edit virgulta, pede altiora. Folia vircnt obfcurè, effigie Myrti aut Rufci, rotund o ra,molliora, fed Hyeme decidua,

\section{$\checkmark A C C I N I A$ mbra.} F Ifdem natalibus Rubre frutex-latiore \& habitiore a f ectu femperviret: hon petind albam fine maiorem \& Rhus Plinianum accedentia rotundiora. Baccula aon ninorcs nec diffimiles fed rubrx, aftringentes magis, nec perindè fueculcrita. Radix aque lignofa fibris frpit Ericx ritu, Flores oblongis caliculis paruulis fubpurpuresis apiculos è mediu cxerunt.

$$
\text { Palufria } V A C C I N I A_{6}
$$

$S$ Vnt etiam parum frequentia alibi quàm in Germania \& Batatix paludofis \& maritimis hæc Vaccinia, quæ Iohannes Cruthmanus Mechlinicrifs, vocatus de Vroedc,illinc Antuerpiam nobis primum adferebat non difimilia colore, longiore tamen \& nönihil turbinata figura, paruä lachrymam Iob effigiante, in viticulis farmentofis exllibus quamplurimis humilibus breuibus, foliolis Serpilli minoris, vel Heruiarix. Interdü baccx quę rubre funt maculofx punetis viluntur,acerbi aftringentiso; guftus. Hanc cur Com mentator Ericam bacciferam indigitet, neq; caufan dicit, neq; ratio fubeft, neq; quidquă Ericx illi ineft. Exilitatcm quippe foliorum, effe vagam notam quàmplurimar quid planta

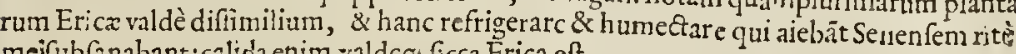
mej̧fubfanabant:calida enim,; ;aldcq̧; ficca Erica eft.

\section{Qagel Germanortum vel Gold Anglorum Myrtus
Brabantia quibufdam.}

$\mathcal{F N}$ Ericetis vinbrofis, nemorofifg; faltibus fruticat

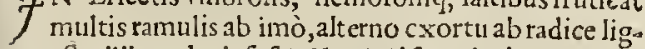
nea flexilibus, duris fufcis Vaccinij fuperioris. Folia punici Chamęlex paulò latiora. Seminum crebri racemuli conferti \& conflati quafi fpicis poft pufillorü, luteorum florum pallentium Lapfü apparét: in quibus femen pin gue odorī Stæchadis citrinæ vehementius, \& trifolij odorati quadãtenus fimile. Iunio \& Iulio Angl zmulierculę vęnú adferunt ramos forentes å concinnäda $x$ diü, conclauia \& triclinia fuaui odore quem halant flores, imbuenda. Adduntur ctiã idē flores potioribus cōfuetis Septentrionalium, penuriam Lupulorum int erdú refarcturi. Interdum ad hylaritatem bene potis conciliandamsferit namq́ue caput lxciore temulentia Bał?

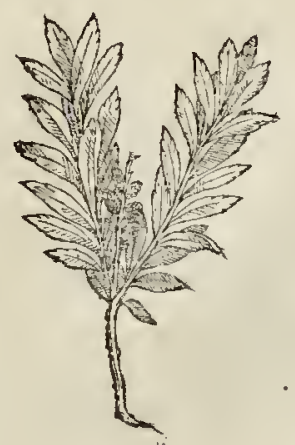




\section{4is Fruticum, fub fruticum, cremiorum \&}

ad cucrińcandam animalcula, qux eius odore fugantur fufficiuntur quxdam loca \& fuffulciuntur fummitatis veftes.

\section{CIS T YS mas, Fomina, \& Cifus Ledon.}

VI Eluti hederaceus folijs circinatis atq; rotundis nisos videtur vocatus, \& quia non erẳt Ixua, nitida, fed potius fquabrn \& pannofa $\lambda$ й̊o dieta. Vninerfa plaga g̨ux ab Eridano amæniffimo ad Rauenam, qnx́́; ab Hetruria ad Maffiliam, frcquenti ornatur Cifto Mari vocato, Fomina \& Ledo, quę importuno penè prouentu in collhbus macilêtioribus, exulais Norbonx lafciuit. Vtrif́que eadem facies, fed forminx rotundius folium \& minus nec adeo fquabrum ant lanıginofinn: flos ctiam rofeus, fed decolor \& obfoletior minore frutice tota, fef̣́uicubitalı \&r cubitali, Mari verò longius, maius, hirfutieq; cana pubens fo-

Leáon. hutu, quadantitum Saluix, rofeus Cynorhodi flos.

Sedenim Ledon cui frequentior Hippocyftis adnafcicur, folia admodìm angufta,tangenti glutinofa \& fquabra, nigriora Ronfinari culti, paulò latiora:flores candidi fominę Cift minores ominibus, femen in triquctro ix tricocco pericarpio, pufillum Hyocyami.

\section{CHISTVS LEDON Lufolium.}

PRxter hafec tres fempar virentes, rarior fpecies, cft quxdam Ladanifera, virgts furculis. folijs malto crafiusibus, lationbus, longioribus: Sumachi Plinij aut Rufci modo fruticăs, femineiten tricocco:multa lafciuit quopiam in móte celfffimo agri fte rilis.Sauena, cui nomen S. Colübx. Alioqui gufu Cifi Le di, \& fragrantia gtauiufcula.

Hanc demum monuit nos fe habere $f$, rentem Coldenbergius. Semine \& flore alterius Cifti.

Candiciad radicem Ledi adnafcitur $\mathrm{Hy}_{\mathrm{y}}$ pociftus, frequens Galloprouincix \& Norbonz, fobole fungofa,cxluteo in puniceum Granati bicoloris genmante, cętero Hypo fparti \& Orobanche æmula.

CHyrtus maior baccis nigris, oblongis, teretibus. cilyrtis maior baccis albis.

Cigyrtus minor.

Buxus.

Lycium fue Pixacantba Norbcrenfitu.

Malum punicum.

Liguftrum.

$\left.\begin{array}{l}\text { Pigylerea maior Oleaftrifacie } \\ \text { Phylereaminor anonftifolua }\end{array}\right\}$ Norbonenfium.

Pbylcreaminor angnflifolia

I Pbylerea arbor an Macalcb Arabum?

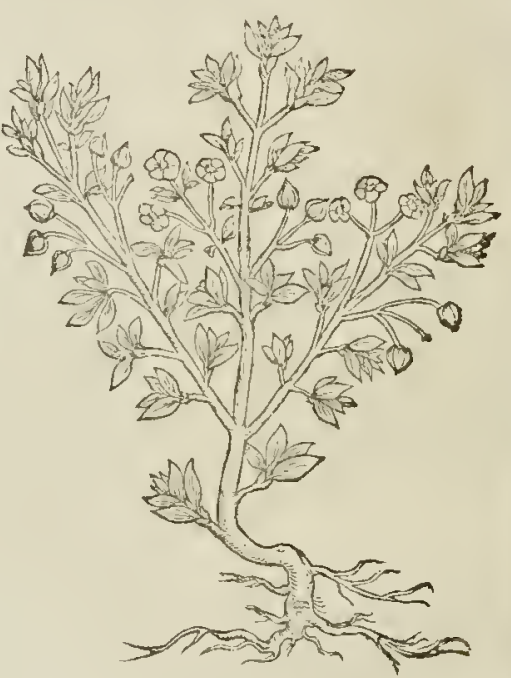

Bourgeßpine Monjpellicurfum.

Olea.

Olea fyl

Salix. $\left\{\begin{array}{l}\text { Olenfolia. } \\ \text { Latifolia. }\end{array}\right.$

Salix burailis repens.

Perficamalus.

Nhax Myrifica.

leAvertus, 


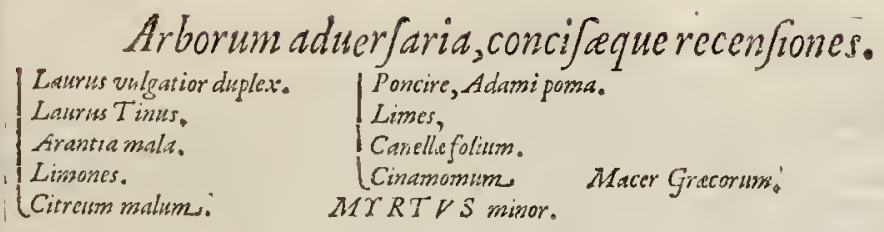

TOL v $\mathrm{x}$ fic vocatam propter $M$ yruh quandam $x$ mulam odore gratiam, qua pollent

femperuirentis Myrti baccula. Ef autem minor, Officinis notior fuis baccis,adeoć; to. ta hortis Septentrionalium delitię \& ornamentum eft. Frucicat vir gis tonlifibus, reftis, flexilib ${ }^{2}$, nigricátibus, effigie Buxi, folio nunore, fed Rufci mucronato, baccis nigris Hędera, vineum fuccum preffu remittentibus:eis poft vindemias faginantur aues, tanciue fuaues èdédo funt, vt integras, nó exentaratas efitcnt, cóq; prouerbio feratur, ftercus carū prệtare carnibus, in Galloprouincia marıtima, vbi ficcaneus collis sullus, cui arrideat paulo placidior atura, vbi non inulta vernet lięc niyrtus. $M X R T V S$ Maior.

$V$ В г $\pi$ I v illic etiam fruticat hæc,propter baccas, lagenulas effigiantes, maior dieta: fo-

lia itein maiora Phylerex aut granati nine1a:floribus iten albidis \& fuperioris fimili- Yarickates. bus. Alteritis modi ex hortis Francifcanorum Venetornm habuinus folis albidioribus, \& fructu albo, pars, \& fimili,nec alioqui ita diuerfo,illic alba Myrtus vocata.

$$
B V X V S \text {. }
$$

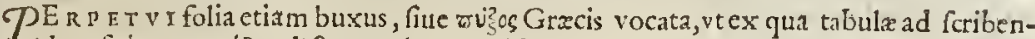
dumfiebant, zúz̧ue dictx, vnde \& pyxides. Nulla autem magis quàn hac glifcune montes \& colles in Delphinatu \& Galloprouncia. Quibufuis etiam alfiofis ad Septentriones, cliuofis; incultis frutefcit \& arborefcit,prædenfis rigidis virgultis \& ramis admodum foliofis, graueolentia \& ad myrtum finilitudine cognitu facilibus; luteus fue buxeus ligni perquam folidi color:baccula tripodes, coronula denticulata in figniuntur, Myrto alio qui aon abfimiles.

$$
L Y C I V M \text {, fue PYXACANTHA Norbonenfum, }
$$

SO I x T Y m fuerat aduehi l.yciun ex Lycia,vnde nomen illi:verum quid fit hodie norut perpauci;nec tamen pigebit (quod nos vius docuit \& coniceturę adeò vero fimiles, vt verifimiles credamus) hic addere. Eft in Trouincix Norbonx plerifque locis arbufcula $\mathrm{O}$. lex fylueftri fimilis, Arbuti magnitudine, folis Olex, fed brcuioribus, rigidioribus, rotundioribus, minoribus, caudicis foliorúmque viridi, obfcuro, faturiore colore, fubfuluo, Spinis crafsis, atque rigidis, ptrduris. Bacre funt ve Thylerex maioris, fed rotundiores quàn Olea, fucco fubrubro, Oleaginofo, vti Phylerex:qui fuccus amatus, ingratifsimus, acconfus, cum ftrepitu quodam fligrat, extinctus rubet. Hanc tamerfi pr $x$ fe vndique ferat Lycium, tamen non auderemus afferere candem efle: Id tancn audeo dicere, vix maiore poffe vfurpari commodo Lycium, quàm iftud noftrum: \& poffe longè propius, aptinfóue fubdi illi quàm Amurcã : habet nanque vires digerendi, quadam cum åtrictione. Quod fi non fit Iycium; fuerit Sanè fpecies Olea' fyluetris, cuius Amurca omnium praftantifsima vice Lycii eft; nam quò minus pinguis eft \& cleaginola, eò melior: Nocet enim oculis, pręfertim olei pinguedo, vti docet ratio Thyfica. Valde putamus Senen fen exercitatum apud declamationes, aut latrationes oratorias Quintiliani : nam vt illic Methrodorus vtitur imaginibus, pro locis; fic is non modó iconibus abutitur, fed etiam Anguillarx \& aliis Ger. tótrnate doctioribus vera monentibus conuiciatur.

$$
M A L Y M P V N I C V M \text {. }
$$

ocyffel.

Gal. Pommes

TV в E N T E R coniectamur ९́ó dictam ab acinorum colore Cytiníq; \& Banlaufti afpe- de Grenades Eu rofeo: etiamąue ad Rhus, de ono fuperius egimus, quadan fimilitudine, \& vfu, in cu \& Mygraines, linis, ad coria edenfand2, non diuerfo. Sponte arboream magnitudinem affequitur fylueft. Ftal. Melagrano in Italia Hifpania \& præfertim Mauritania, vnde pulcherrime feruntur allatæ, Punico item pomo Granate, cognomine:Septętrionis cęlú non fert, nifi xgrè \& in hortis: horto Regio Waftmeftrifloret. quotannis, Belgio \& Francia, gigartis ipfis terre mandatis,germinare in arbufculam vidimus, Myrti rotundiore fronde. Pomum vbique efitatur, angulolo acinulo, dulcis acidi, mixti vinofique faporis, deliciis \& medicamentis cxpetenda. 


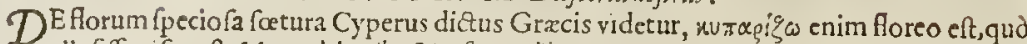
allufife vifus eft Mato vbi Alba Liguftra cadüt, canit. Nulli a utem calıdiorum aut frigidiorun regionu m hęc hodie declt, femperuirente fröde Olcx, atriore, latiore, molliore, hor torum feptis \& areis accommoda, \& tonfilis: flores mufcaceos, candidos, odoros, ceu vux oblongęrudimentum edit $A$ prili \& Maio in lętiorıbus Galloprouinciz conuallibus, aut collibus Angliz non perinde ftrigofis,Septembri: racernulis Lentifci,aut montanx Sambuci,quos Auicenna efu fangusneum lotium, aut potius colore cruentum ciete dicit:quod praftitiffet quibufdä rcfrąariis experiri, quàm iftud Liģuftrü verum elie inficiari:guftu autẹ \& facultate aftringit. Quę tamē nomine Alkanx afferuntur affulx, vel bacilli, ex tranfina. rinis Africę emporiis, luteo funt intus ligno, cóq; fi crinem (vt videturAuicenna ex Diofcoride velle) ruffant, funt fanc̀ aut melioris notę Liguftri, aut diverf $x$ plantż.

\section{PH H L RE A du Norbonenfis Galloprouincie.}

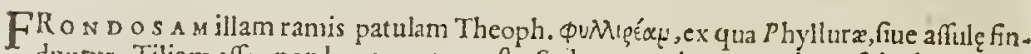
duntur, Tiliam effe, non hanc, certum eft. Sed germanias rocis impofuit doetirsinio

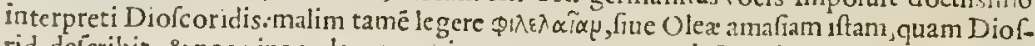
rid. deícribit, \& nos pingcndam curatimus, percongraam defcription, \& Olex non mo. dò fimilem, fed etiam fociam, vt ab oleaftris, quibufcü frequēs reperitur, nihil ferèdifcrepet.

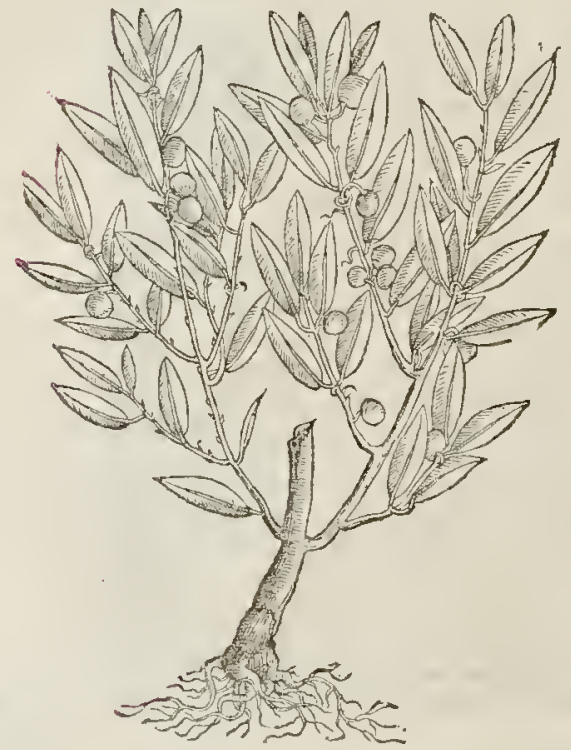

PHYLERE A mirior.

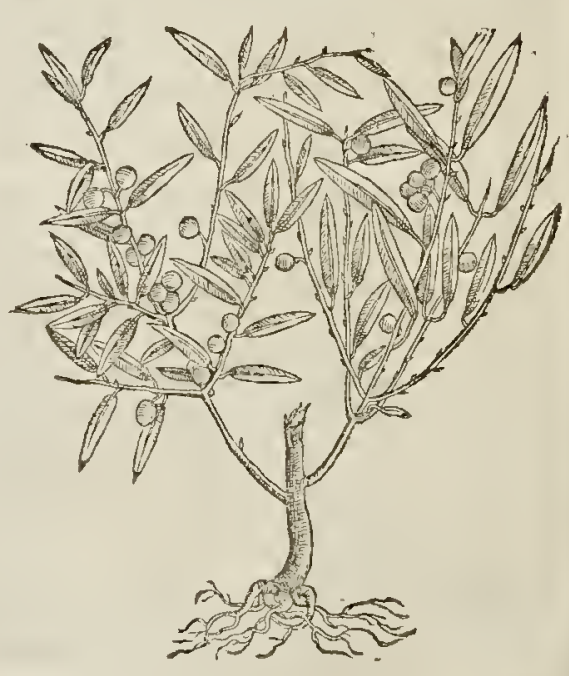

Huius autem duo modi arborefcunt in Galloprouincię viarü marginibus \& oliuetis Malfilia vicin is: \& qux maior, rarior, perfimilis pumillæ olex, caudice ramífq; nigrioribus, lon. gioribus quàm olex e $f$ grctis, $\&$ folio magis Liguftrum accedentibus: baccula multe in PHY L. MIN O R multó frequentior iffë in natalibus \& Mólpellii collibusglareofis : folio cquę Afinor. Longo, fed.anguftiore duplò:duploq̣ ue minor tota planta. fimiles acini Lentif́ninis, \& fimiliter racematim proximè hẹrentes admodùm curto pediculo, qux iten matura fubdulces funt, aliquantum acres, fed neutiquam ingrata, vt funt Oliux fatiux \& goteftes 
Arborum aduerfaria, concifanne recenficnes.

Senenfis infarcit piauftra verbofarum autoritatum, nec tamen quam dat defribie,

\section{$P H Y L E R E A$ UARBOR Gallo- pronisicia, verior $M A C A L E B$ Serapionis.}

Expreflan de viua arbore hanc iconem, prorfun refert prior maiotǵue dicta $P$ hilerea: reperitur in Galloprouincia prope Tholonam, æquat fapo \& Sparfis ftellonibus irunum aut Cerafum, folio planè Phylerex, aliquantum latiore:flos Ilicis mufcolus, albidus \& plurculis vnà aceruatis baccis Terebinthi maioribus, nigricantibus, herbidis, dulciculie nucleoli intus crafli: quales prorfusproltant hodie in Officinis nomine Machaleb. Et certe fi Liguftrú Serapionis fit Machaleb, erit hac illius $\mathrm{Li}$ guitrum, non illa quam Matholeus dat nec delcribit.

Vulyo Monipellinjium $B O V R G E S$. $P I N E$ perpetuo virens, an $A$ P HARCA Theoph?

Frontignana Linguagotix Iliceta $\mathrm{P}$ ftam arburculam frequentem pariunt: cui facies \& habizus fuperioris Phileree, red Ilicis adolefcentis fol ia:rigida, rotüdiora, latiore quàn Olea ambitu, tantillùm denticulis afpero: nuufcolis, numerofis, racemolis, Lentifci flofculis, fubter folia aggeltis: Bacculx funt Lauri Tynn didimæ, bino veluti gigarto $\mathrm{v}$ uæ cóflatz: furcul is ramiĺ, , magnitudo \& habitudo ctiam Ilicis:guftu amaricäc folia, S tantillùm aftringunt.

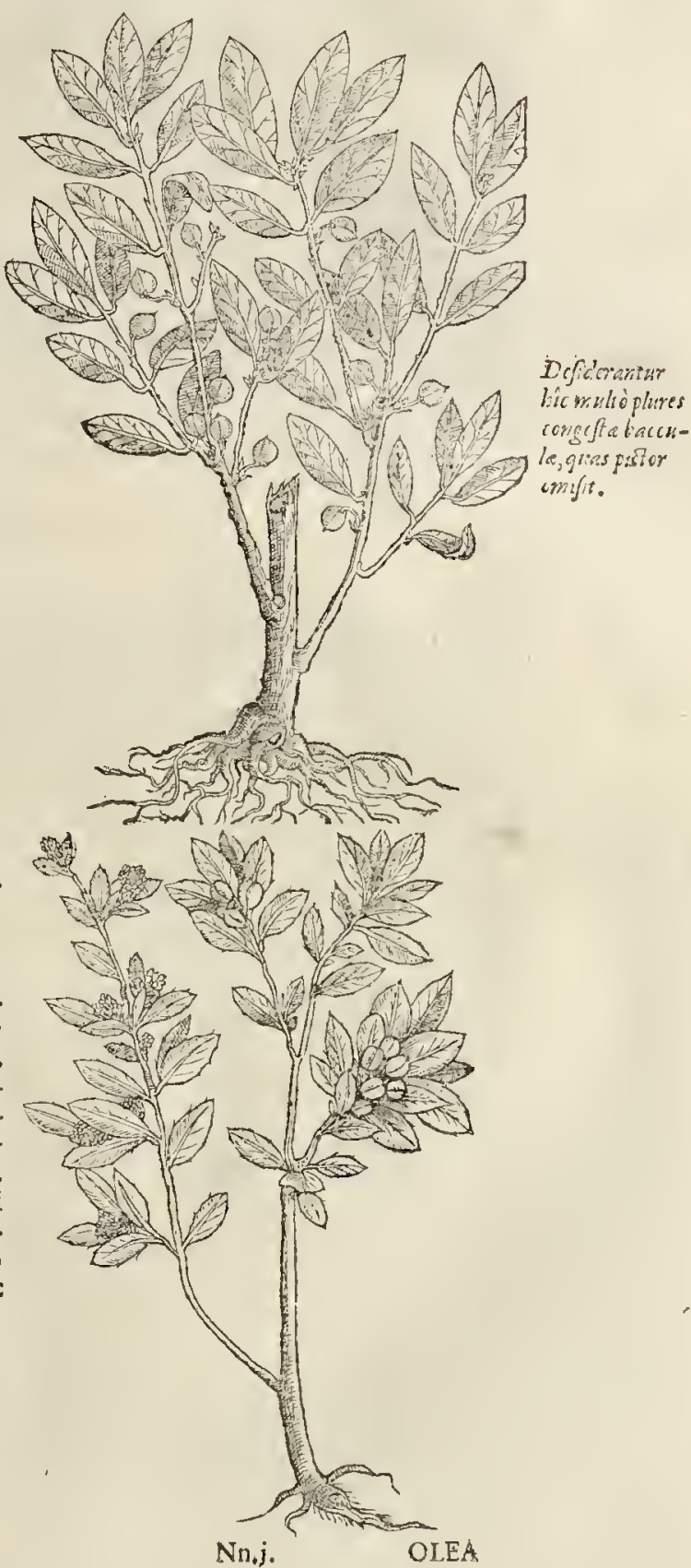




\section{Fruticum, Jubfuticum,cremionm do \\ $O L E A$.}

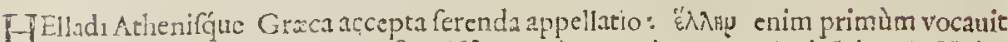
Minerua,qua arbore Olea,praftantiflimo quàm pottit munere Atticä ditauit. Huius luces perennes denfifimos \& amoniffimos alunt aprica tepidiores conualles Hifpanix, Galloprouincix, \& Norbonx, $v$ bi in Monfoellij vineris duplucem perquàm robilem fundunt liticem: aimirum olcum, bacc: callo: \& mel, fiue Elxomeli, quod nirum dictu, fed veriffimum, caudice vulnerato: de quibus cum lachryma olex tithiopice, in fuccis dicen dum. Eleonidi iam memorauimus in Manna . Baccx caro callufue immaturx virefcit: nigricat atem nitiore cuticuli maturæ:elegátiores ad Frontignanam via, cx pupurco punicant, tariores hę alibi: Fronde exit flaccidiore, latiore, \& ferc̀ Saligna, in folo \& colo Septentrionali, vbi nihilofecius perennis viroris eft, Londini in vireto operis \& ftirpium nouitate vifcndo, Cxcilij regni florentiffmi Anglię incomparabilis tum fapientix", tum eruditionis Neftoris.Amurcz fiue fxcis, qux oliux effracta atc; expreflx fraces fut, efficaciam eôdem relegamus: hac autem non lubenter carerent Medici, fi quot \& quanta ad morbos quàmdifficillimos curandos prafter remedia, fcirent: nec enim vel Lycio vel Accix cedit, quin potius quibufdam viribus excellit.

\section{OLE A Syluefris fue Oleafter.}

Q

Vos vnyuam meminimus fpontè atborefcentes olcarí frutices, duntaxat magnitudine \& habitiore corporaturavidētur diftare à fatiua, quả hẹc prorfú oltendit,nó fecus atq; Prunella Prunum fotiua, altera quippe in al teram, träfmotione aut inoculatione, aut neglectu abit, rigidiufcula enim fit Olua, inpexo atc; horridioreafpequ: interdum fenticofa, quando in faxofis defitis, eius radix paftitationc non diffatur, aut nocitura pul Julatio, \& Fcricofa ad caudicem fobolcs, non interiucatur. Quare huius non effigiem, qux alioquin eadem fuperiori $\mathrm{eft}$, fed vires, vtpotè in ficciore adultæloco, vt magis altringëttes, terreftres, vegetiorcs dicit Diofc: folia duplò ninora, Phyleree, fed fubtus glauca:fructus numerofior, fimilis \& par Myrto maiori: fofculı racemofi, candidi, odori, Lambrufcx foliati.

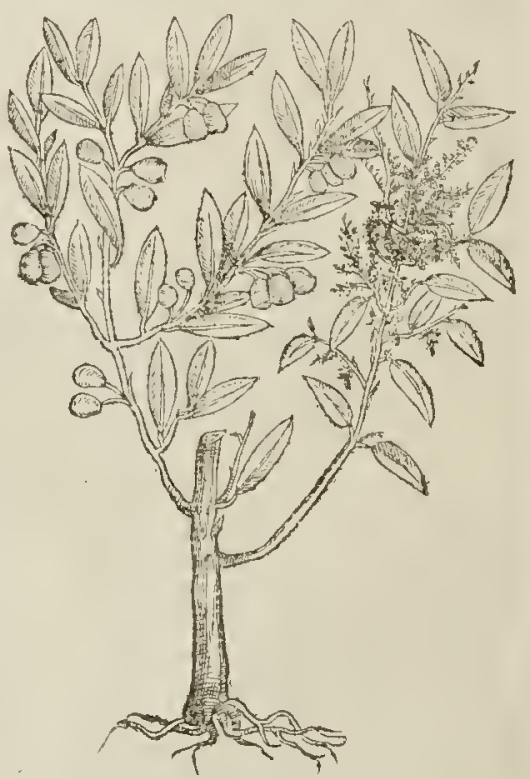

$S A L I X$.

GL ISCIT OMNIBYS VDIS A QVARVM POTRIX ET AMATRIX

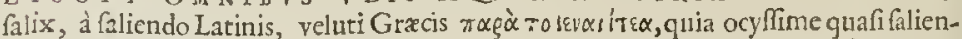
do in incrementum eat : Olcæ frondelatiore, glauca, aucrfa, anara, fupernè virente, 


\section{Arborum aduerfaria, concifequerecenfiones.}

foris vice Ianitium amenti fefquiunciam oblongum \& teres propendet nec feminiper. da femper eft, vt Homerus vule, quia alıcubi femen excipitur \& fatum oritur.

Plerifque non adeo deprefsis lubentius oritur qux vocatur $P$ latiphyllos, ca cinerea eft magis, folio latiore, iulo fiue catulo hirfutiore, breuiore, Salicis amerinx vinencis virgis, cereęflexilitatis \& coloris, aptifsimis ad quafillos texendos; fronde longiore Lyfímachix purpurex.

\section{$S A L I X$ bumilis, repens.}

$\mathcal{P}^{R}$ × T E R vulgatas Salices eft quædam humilis, fer$T_{\text {pens humi,pedem \& fefquipalınum alta: foliis par- }}$ uulis, Myrti minoribus; flores amento $M u$ ufcofo in puberat auolante, cani. Montibus Sabaudiz, Lugdunenfibus \& Veganis multa, afpectu decora.

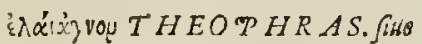 Agrus Caftus.}

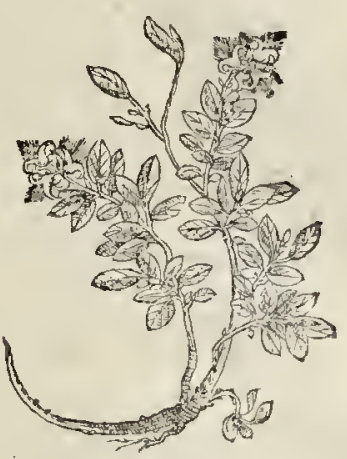

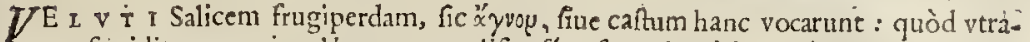

que, frigiditate quapiam Venereos prolifico fọ́ue feminjs fpiritus videtur enecare, aut eneruarc, Hortenfis eft Europxis, Italis, Gallis, \& Anglis; tametfi amantior fit agri calidioris: Expandit in pediculis frondes digitatas, plurimum foliis feptem, Salignas, Lupini, aut Ricini pofitn: in ramulis fummis Lauendulx concolores flores, \& alicubi albicantes, vt in Conobiis Italorum funecinctorum, qui virgarum cinctu ad Venereos frenandos infultus, quafi Amuleto, hac freti erant: tametfi femen Coriandro par, nonnullis efitatuni libidinis inciet inpetum, non fecus atque Ruthe femen, nonnullis adunit.

\section{Platiphyllos:}

ONAGR, $\mathcal{B}_{\text {I } x \text { y A R V }}$, cùm fera rabie corda tument, domitricem hanc it demultricem in fine Mulcibrute Apenninis uugis \& plerifq; Alpinis, ac in ipfo Vcronéfi Bado fcifcitati fumus,num inibi vipiam comperiffent: fed id rcfponfi tulimus, nullam repertam plantam,que quadret Onagix, piztcrquam Rhododendrum, Sambucum montanam \& Latrut Thynum. Se facilè depręlicnfuros fi ea occurriffet, ex radicis odore, folıorü foríl luculenta nínagnitudine. Ex certè non ea furt negligenta Guints eruditifsinus \& thenuifsinus heibarum yenator, vt fi verami inueniffet, tain raram, tamóue expetendam, non \& cultu it horris, \& literis pofteritati propagafet. Ainn amici cruditiores, lianc effe Iy fimachix fpeciem quandam circa Lugdunum oriundan: at ea herba, won arbor elt. PERS IC \&

TVIonars Perfica rolo malus.

VV r g a r is Perfica folo mutato \& venenatavi, patrio nomine notifima hodie Germ. Pferfich eft arbufcrilas qua confita funt plerac; onnia Europæ vineta: fronde Salicis eft, aut $P$ er - baum.

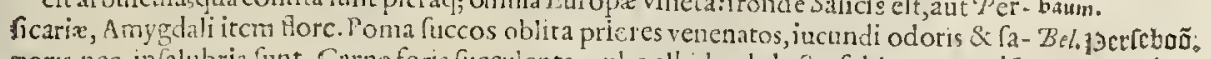
poris, nec infalubria funt. Carne foris fucculenta, pube albida obduéta, fublutea quadä, Ang. Perchetre dent.omnibus Lityyriuteis alueolis fculptis; amaro intus nucleo.

Amygdatus. Germ.zhmande?

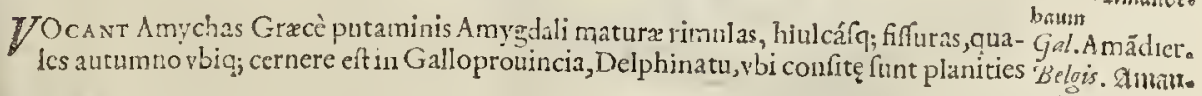

$$
\text { Nn.ij.: pat Dciboom, }
$$




\section{Fruticum, Jubfruticum,cremionum to}

patcntifsimx Amygdalo arborc, cui facic, fronde fimilis, \& par Perfico, procerior tamen \& frondofior. Earè foret Aquilonio colo; tametí in Anglia naturat initerdum nuces.

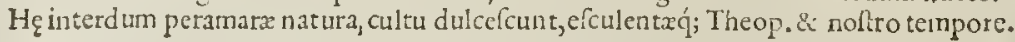

$$
\text { Mofcata } N V X \text {, fue Myrifice Macis Arabum of Officin. }
$$

A F F I e m fronde \& frucu Perfico effe arborem nucis Myriftice, quam frequentem habent infulę Orientis c̀ Molufcis, vnà reterebant, qui attulerunt cafdeın nuces decerptas fuis manibus anici, \& triplici cortice protetas, quales conditx proftant in Officınis, \& poffe noftro cęlo affuefcere negabant. Tota vefcendo eft condita : nanx callofum

De Maeere in extimum putamen elt,cui proximè fubeft Macis Officinis notifsinus; Cutaceus deinceps Cmnamomo. liberinteriacet Macerem ipfum \&nucem, qux eft lignofa, odora \& perpinguis, dum recens eft, \& matura.

$$
A R B V T V S \text {, fueVNEDO a'siboux. }
$$

FRondes Citri \& Lauri, nó tenues, vt perperam legitur apud Diof coridê huicfunt At.

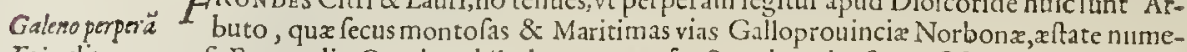
Epimelis. rofa Fraga edit, Coccinco hilaris purpuræafpequ micantia, \& quafi fuperbiét ia, acerofis compaetis partibus, conıofis intus, edendoque guttur afperantibus conflata: vnde for tè réuços dicta. Berberidi concolor flos calyculis lutcolis.

\section{Vulgatior $L A V R V S$ baccifera Laurier.}

Luturus bumilis FA I I D C e Lauro Hauefcit flos, nigrefunt baccr maturx: frondes autem fempitervirgultacea, non no nitent virore; inicế ignifragoré edüt falis ftrepitu, vnde Daphne quafi Duophne Baccata. dicta. Sponte multa calido folo, non nifi fatu in $A$ nglia \& Belgio. Alia Gigartifera furculo, 110 femine oritur, hyeme in Belgio emoritur, \& arbufculan tantum aquat.

Latorusregin 1. valorim.

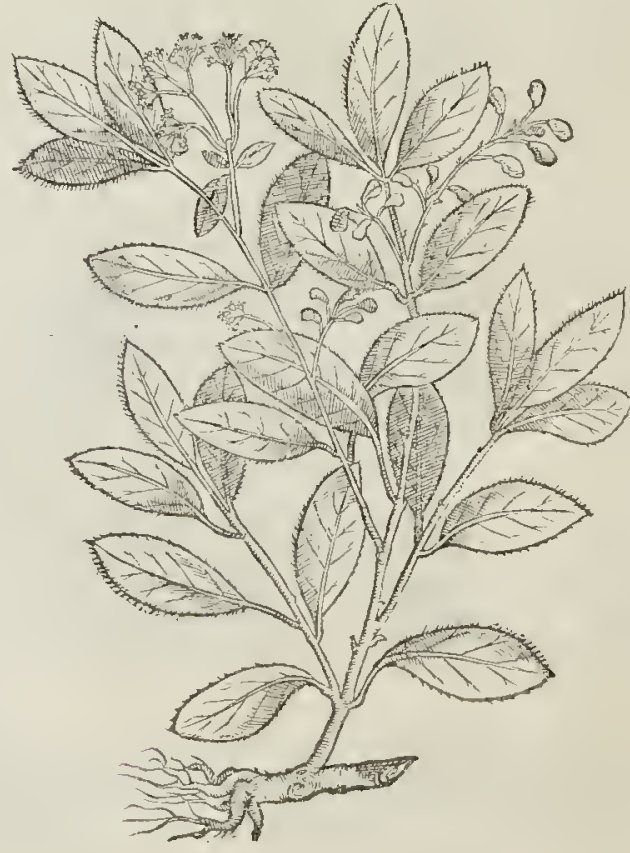

\section{Laturus T T NNUS corule bacca.}

T Trancye carú prorfum vula tu çmulatur Laurus Tynnus, valdequàm e!egās \& noua, affurgitǵue in arboris æmulationem. Fert Corymbaceam vinbellam multis conflatam Terebinthi feminibus, aut Gigartis vuarúfimilibus, fed cxargenteo in coruleum luridis. Flore ex albo purpurafcente. In Valenę nemore Norbonęplurima, \& plerifque locis Ceti montis, inter Cocciferas Ilices, frequens. Premitur oleum ex bacculis, quibus valdequàm lubenter vefcuntur fturio. nes, turmatimáue ad illas convolant. 


\section{Arborum aduerfaria, concifeque recenfiones.}

CEDRVS Theoph. cuins Diof. MEDICA MALVS, fine

Cidromela. AR A N T I A, L I M N I A, C I T KI A, L I -

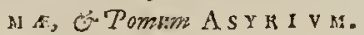

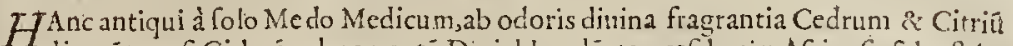
dixerütquafi Cithyó odoramentú Diuis libandū: tametri hęc in Africa fit fy̆lueftris; \& Olbix G; !loprouinciæ adeò familiars in affatu oræ maritimx, vt fempervircntiun Lucorum amœnitate \& $P$ 'omorun fotura perenni, neutiquam inquilina videatur.Si quis horum Poinorum duo fumma ftatuat quafi faftigria Arancij \& Citrij, vno intuitu cunctas varietates difcernet: Nam Arantio folium non planè Lauti,fed veluti geminum, nempe vnum in petiolo quafi pinnatim ineft, maioriç; fubeft, qquod nonnihil anguftius fupernè . videtur quàm Laurinum. Ipfa autem mala Arantia etiam cortice funt reliquisflauiore:nä ex aureo vel herbacco Charätix fiunt concoloria, minus medicati faporis, fucco gratiore \& magis culinis familiaria, interdú dulcia, intetdumacida.Cxtero Citrij generi frondes funt Arbuti aut Lauri, fed latiores, nec pinnatx, mults ité intercurfantibus fecund ñ ra- Aqua Napheo mos fencibus: fores niuei Ornthogali aut Styracis, qui condiütur \& nufcétur cardiacis: aut fullatitiam dant multò fuauifima fragrantix.

Hac autem Citri tribu poma $L$ imonia vocata frequentiota funt, eoć; minot is fǘt:ob- Limones. lóz̧a, fucco acidiore, acerbiore, frigidiore. Cortice \& carne magis cfculentis, nec pcrinde vt Atanciorum amaris, rnaio ris ad incidendum efficacitatis.

Deinde Medicum Diofc.malum, tres amplexum eft varietates. Vuigatius ef fimilius Citrum. Limonio, oblonga oni effigie:Sed maiore, cute rugofiore, magifq; caperata, odoratius eft medicatius, antidotis commendatius: $P$ ulpa \& fucco in acetarijsmiltò gratius.

Lima auten qux dicuntur, illis duplò ferc̀ maiores füt,callofo carnofo cotio, pollicem interdum craflo, oblonga Cucumeris aut Melonis effigie, fuperficie concolore Limonio Limn aut Citrio puluillis \& torulis rugofis papillatim extuberante, vt Citri fapore condito,\& crudograto.

Pomum e Afrirum Adami rocatum, è latiore bafi in obtufiorem conum rotundius tur. binatur, vertice circulatim obtufo \& quafi vmbone depreffo.

\section{CINAMOMVM \& CASSIA Gracorum $X$ XLOCASSIA Offic.}

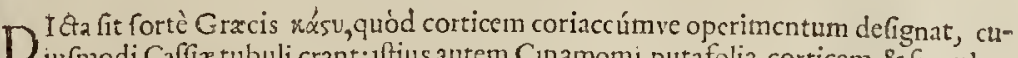
iufnodi Caffix tubuli crant:1ftius autem Cinamomi,puta folia, corticem, \& furculos, qux vidimus,qux partim audiuimus à peregrinatoribus, partim \& legimus, teftantur effe arborem afinulem Olex magnitudine:adeo limilitudine Lauri \&. Arbuti, ve quidã recentiores minus confideratc̀ hanc fecerint cum noftra Lauro eãden, fed duntaxat foJo druet fă. Iam non ambigitur, an vera extet Caflia, fed difceptatur, guid ab hac Cinamo mum diftet. Iftud autem hodiernum Cinamomun, neq; iderì Caffix, neo; tamen multò duber lú effe, certú eft Nam fiv vtriufa; ex Diofcoride notas perpendas, videbis fermè ealdem effe vires, non item difparcm vfum. Si rccentioribus affentiaris, \& exploratioribus, eiufdem arboris non ita diuerfas partes effe difecs. Quod ctiam percipitur de Galeno \& Plinio. Nam quod vterģue fur picatus eft, adeo verifimile eft, vt veriffimum videaturinépe, effe varia arboris, aut eiufdé diucrfas partes. Defcriptioni Dióc. nó magnopcrè attendendum: ıam cum dıcit varias fpecies effe, intel ligit gradus potius \& varietates, etiám v* nius fpcciei.Locus eft Arabia,nempe Emporium, que madmodum hodie $\nabla$ encta voca-

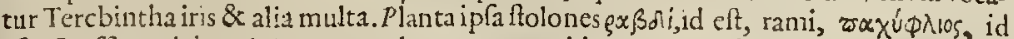
eft, Crafli corticis : igitur non arborem, nce quidem tanum, fed potius eilis corticem

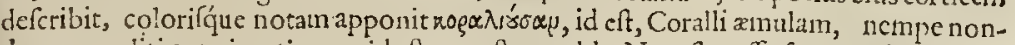
dum perpoliti aut nitentis sevp, id eft, anguftam valde: Nam fi ctaffo funt cortice, tubum non valde latum relinquunt. Ideoq́ue craflum \& latan addit. Quibus è conicequris Nn.iij.

qॄuid 


\section{$426 \quad$ Fruticum, Jubfruticum,cremionuner}

quid inter Cinamomum \& Caffiam fit differentix percipi poteft Nos veró meminimus duodecim antuis fermè elaplis, Calfiam ad Cinzmomum veru m proximè accedentë nos vidıffe in officina Gulteln! Dries Pharmacopoci Antuerpienfis, in hac partc valde exercitati. Erat vero multorum iudicio furculus ilte Cinamonin, baccillo folido, fractu facili, Cinamomro cortice obtef̂, cui etıandun cuticella pnllo colore óbducta fuit. Folium verò feu pietum, feu ficcum multis in locis vidcre eft.

zy zocassia Dv a lize meditaremur, quidā Veneti inftitores, qui Londini negotiantyr Morgano noftro, corticem, fermè pollicem craftu, fabrum, calofum, \& foris llici aut Ulex concolo rein, interius vcro connexum mollius fuperficie:odore, fapore \& colore quadantenus Canellx vulgaris, quam prorfum guftando prafifert noftra:idcirco \& quorundam confultiorum medicorum fententia fort effe Cafíx arbon is cxtimum \& crafiffimum corticé, vt iam vnius arbotis duos cortices habuerimus, quorum hic fit craffior, altcr delicatior, odoratior, multoǵ; ad vtendum comınodior. Elt hic gu fu aftringenti, ficco, adć; fiftendü fuorcin, vt putarim non parûm oportuno. Eius interior fuperficies videtur à caudice arboris Canellx auulfa, odoris prafen tia nares feriens, \& os manfu, complens gufu Cinamo meo. Quare 110 modò non dect nobis Cinamomum verum, quod conqueruntur ex Galen defcriptionc, fcd etiam adfunt plura quàn ille memoratinempe illud graciliore filtula, colorc fufco. fapore \& odore vegetiffimis, quod plurimi, hodie fit Venetis, \& Theriacıs ve verum additur Cinamomü: deinde noftra Canclla vulgatior:poftrcmo ifte cortex ian dietus, qui neutiquam eft contemnendus, olex caudici concolor cxtina fuper ficies, quod magis fulcit coniceturam.

$$
\begin{gathered}
\text { Corter XYLOCASSI AE facie,anfit Diof. } \\
\text { O P Plt. CMACER. }
\end{gathered}
$$

F Ntcr fuperioris corticis magna frag méta, ctiam repertus eft alius quui cx cuiufdam arbufculę ftipt tis imso exéptus:interiori fu1 parte valde fimilis \& concolor fuperiori eft, fed minus craffus, ferè inodorus, aut quiddam iuglandis \& Lauri redolens, guftu.perparü caloris glutinifye mixti aftrietioui habens, cum autem Diof. \& Galeni aftringens fit \& calfaciat, arboris cortcx hic vidctur.

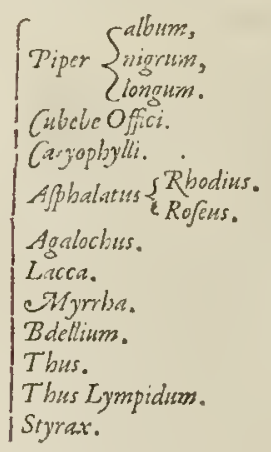

|Coronea malies.

fler bumilis coccifera.

Aquifolia.

licivarbor.

Suber Olbic Galloprouincia folio raturdiore.

Subcr anguftiorefolio.

Fbellodris.

Querquns.

Cerris Pliny ccliynata.

Glandes Guinea.

Galla.

Fagus.

Caftranea.

Laftanea equina.

PIP ERIS ROTVNDI daplicirf frutex, longè diuerfus a' Piperelongo.

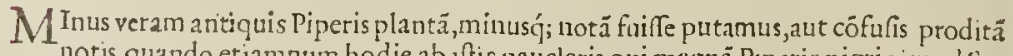
notis,quando etiamnum hodie ab iftis naucleris qui magnä Pıperis nigri vimad Sep tentriones afportarunt, nó rite referatur effigies: Eami dicebat quidam eorü non imperitus efe arborem, plurimi iam fruticem aduolui folitam Periclymeni modo, ramis ctebri 
Arbormaduerfaria, concifeque recenliones.

bus, tripedalibus. Citrij folio, magis exueto, minus nitido, ina parte peroùm vonofo. In pralongis racemofisó; gracilibus pedıculis gemma ferie racemating; acini condütur, vocátur lì nigrij: Rugofi funt lxuiores \& fæpiffime victs.

A L B 1 verò rotundi, ta metfi fanfilis planta fit, finiluma nigra:tamen calidioris effe naturx indicio eft feruor, q̨ui maio multò m albo l'ipere percipitur, \& carius habctur, pucioreq; copja mittıtur ex Orientis, fub Eguatore, Infulis Molucis,

Piper autem Longum, longe alia planta, alia loco dicenda.

\section{$C V B E B E$ Offic. non eft Carpefum,}

F Stius Bacculx, quæ Officinis notiffima eft Cubebx nomenclatura planta, iffem pene in locis oritur, \& pariter Hederaceus frutex defcribitur, folijs Myrto latioribu, angut oribus Mali Granati: acinuli in fingulis pediculis finguli propendét:fieri poteft ve fit $\mathrm{Ni}$. gro Piperi congener quando rugofum \& euanidum videmus.

\section{CARIOPHYLLI:}

X On nif recenti oribus Gracis innotuere Cariophylli, vtpote ex maxime diffitis o* ris Indiæ meridionalis Orientis adferri foliti. Eius folia qua habuimus, fucrüt, Arantij magnitudine minus virentia : alia latiora \& rotundiora oftendebant Doctiffimi Comafcus \& Anguillara, hic Ferrarię,ille Venetijs: fpirabat iftud Ciriophyllum. Flores cond ti cum petiolis \& ramulis teneris, nonnullis Emporij celebrionbus, vt Antuetpie Venetijs, \& Genux fxpe vifütur. Alioquin foridi ipfi clau denticellis fellatim decuflätbus criftati, noti funt omnibus, notamq; arborcm facile redderćt: Eius Gummi quod e:sinij odorıs eft, glebx Ammoniaci cócretione \& colore, feruamus lic mufarú thefauris.

A STALATHVS.

FAud difpar $A$ fpalathi difficultas, fed non perinde magna neceffitas fuit haetcnus. Yerum, recentiorum fedula veftigatione factü eft,vt treslignorü differentix nobis inno* tuerint, quarum quxlibet Afpalathi nomine digna eft. 'Prima nobis vila Veron $x$ \& mtneri data abexinijs Plarmacopœis Francifco Cocleario \& Andrca Bellicoco, qui fnis Theriacis myticis, de Doforum Veronenfum confilio, mifcuerunt. Fruftrun cuod habemus denfum folidü \& compadum fuit, qnafi cuiufda frnticis jme parti refcetú, radiatis fibris, ponder,fum, colore buxeo fed faturiore, fuatiflimo odore \& pertinaci. Eü offe verum Afpalat hum tum perfuafi fumus. Sapor non ita anarus nec guftu infuauis.

Altera fpecies Venetias aduecta Rhodo miffa fujt : Nicola Comafco Medico imprimis erudito, apud quem tum niaximu'n trücum vidimus, cortice exutum, rubenté, taxo eApulatbrs concolorem, odore adeò fragrantem, vt quam latè patebat cænaculum cximio imbueret odore. Eufdem nosadhuc fruftulum feruanus dono mifum à peritifsimo Pharmaco. pœo Valerando Donrez, qui ab codem accepit.

Supereft tert ia,albida foris,intus torulo fubflauo aut citrco, fandalı albi \& Cirrini fimillima albam Rofam fapit,nullam guftant! manifeftam exhibetqualitatem, nifi tantilium calidi, quod vix guftu difcerni poteft. Hanc primim nobis dono dedic optimus vir Pharmacopaus Londinenfis Morganus \& nomé id indicauit. Alioqui Oliuaftri Rhodienfis aut Sandali fpeciem arbitrantibus

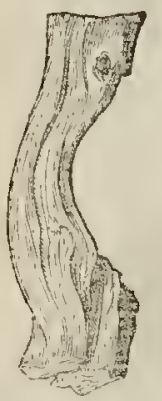

$$
\begin{aligned}
& \text { Aspalathus } \\
& \text { Rogcus. Officina Vocaxf } \\
& \text { Lignum Rhodium. }
\end{aligned}
$$

Nin.iiij AGAL 


\section{Fruticum, subfruticum, cremiorum \\ e $A$ ALLOCHVS.}

Vot funt paulo intrnfiores Offinæ, totfunt fermè Agallochi fpecies. Quxdame- nim Ebenum, A fpalathum. Ahx nonnullx Sand ilum, Citrinum alix autumant. Sed charifimun \& vfu probatifinum hodic mngna copi. Venetijs habét inftitores, guftu $2-$ frungenti,praficco, non multim amaro, fuffitu fuauifimum reddit odorem, \& fuccú aue liquorem pinguem, odorem, qualem in Ebeno vel Guaiaco videas, cui concolor,\& fortè congencr. Arabü Lacca of offianfit Diofc. CANCAMON.

$T$ Accam arborem \& nomenclaturam Arabicam effe quadantenus arbuto \& pruno finiLem multi refcrunt, cuils fint fruftula \& furculi, quos vulgari Lacca obductos in of fein!s habent: quain nullıs rationibus feueriores veri exaftores, Laccam Arabum Diofcoridis Cancamü efie inficiantur: hinc petfpicuum, quòd alius alio vcrgit, omnes diuerfi abeunt. Cenfet Anguillara à docto Montano perfuafus, Benzoin potius effe Cancamon. Quia, inquic Montanus, Cancamum odoratiffimum eft:Lacca non odorata:fed neutrum verum. Quia nec Diofcorides odoratiffman dixit, fed tantium odoratam: \& fanè eius odor fuauis \& gratus fuffitu, quomodo Diofcorides vfus fuit. Addit vir doAtus: Itaq; Benzoin putarim, cuj congrum ea qux de Cancamo antiqu dixerunt. Neq; iftud quidem compertum, nam adeo non magni fust apud antiquos Cancamü, vt Theoplı. Galeno atq; Atio, magno medicaminum recenfori, filentio pręteritun fit, qui tamé toties Balfamü, Laferpitium fuccuin, Cyrenaicü, Myrrham, A fpalathum, cxterạ́j; id genus, inculcät. Deinde aliunde denelirur Benzo in quàn Carcamú, fiquidẻ hoc Arabič plantæ Lachryma cft, illud nó Arboris lögè alius folo, effigie, \& viribus. Jam fi propterea ouiz odore fragrat vergetıfỉmo, \& adeò nyytrhả çmulatur, vt nō rarò imponat(fic inquit Mótanus) nóıdcirco illico probatum eft, nam non fimilimum, fed quuadantenus fimile Myrrhæ dixit Diofcorides. Et erıā fi dixiffet, parñ Montano id arzumentü füuifet. Quippe Styrax, Bdellium, Thus Limpidü, Album animx, multẹć, alix Lachrynix, Myrrhe fimiles funt, \& proinde huic Jacca: non tamen funt idem, non eft igitur Benzoin, CancanumDiofc.

An veró fit Chermes, cuiufuis clt feifcitari, at non niff eruditiftatucre. Excrementum

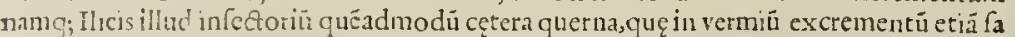
riféit, vnde vermilló, crafiarü eft partiü,aftringit nó incidirq́;: odore nullo,\& incerto ex matione euentus $e f i$. Ná quòd fua experiméta quafi arguméta certa vendität recentiol es, $\mathrm{f}_{a}$ tua neraó; eft ınfcitia:nö enim perfe dant neq; certi funt, illiusúe, an aliorü fudorificorŭ virıbus \& merito proliciătur fudores. Hic tamë cum anxijanimi qual tanta de re ftucuédiü foret alternaremur, Oraculú, id eft, Appolinis fpeciofü illud delubrú, quod illiglorio fo Vercellcnfi hiatori in honoris æde erectü fperabamus, confultú rogatüg; fentétiam ire
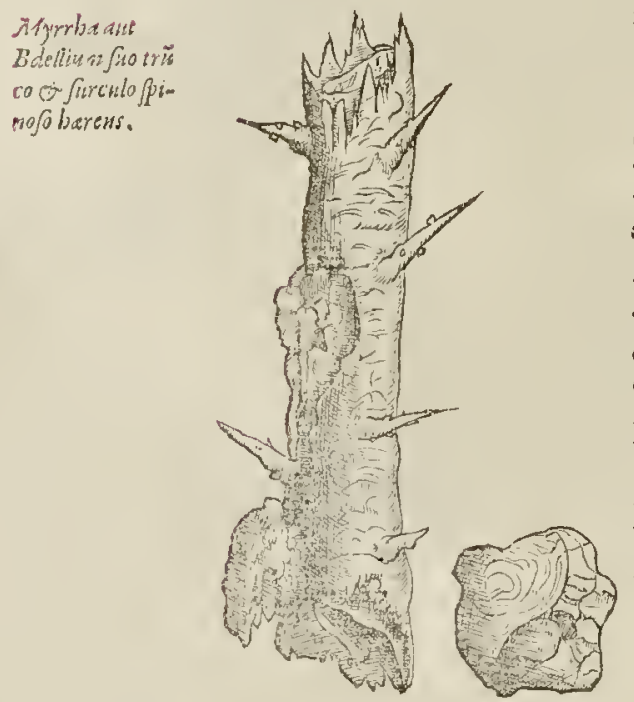
vifum fuit. at ille illufit nobis, nec dubiü exemit, fed tutbella Pharmacariorú rifum tocófq; mouit.

Ceterùm, fi cuiminus placeat ifta valde bona, \& iä inde ab vfọ; Arabú primis téporibus vfurpari copta ad omnes illas affectiones, quas Diof corides cónındat,potius, quàmilla incerta \& inerti vtatur, Myrrham vel Bdellium optimum per nos rfurpareliceat. Quid vero cui magis quadret, in antiballomenis latius. Myrrla.

M Yrha, quafi fuauiter \& odore fluentis vnguétarixć; dictx, nomen indicat Lachrymx, fed cùm tam multa fitaffinitas huic cû̉ Bdelío, Styra ce, Cãcamo Benzoino, Albo anima, racitilla atêa fimilitudo,vt neg; penitus nuliä,neq; planè optatã nancifcamur. Nirrha tanē nó carere nos certú, v' nec; Bdellio, fodquia vtriq; tanta neceffitudo, vt ró tam \{́fccie quä accidētib ${ }^{9}$ diftare videätur. Vtrï Bdelliü praferédum fit,meritò anbigimus, Etenim quod Bdellīi plitatur, quia certo f́cimss 


\section{Arborumaduerfaria, concifenue recenfones.}

¿à Rondelietio experimentis perfuafi fumus optimè viribus Myrrlix refpondere, puta. mus illud Myrrhx lpcciem effe, nec vulgare rationis momentum iftud. Iondinum fuperiore anno a liatx multx peregrınx merces fuêre, inter quas quàmpiurinos huiufce ligni furculos cxpifcati fumus, folida fubfantia, cortice duro, nugricante, fpinis nultis \& rigidis,crafsiufculis, horrentes, quibus multa copia Bdellii erat aggefa, intus forífque valde quàm amari; Cătera defcriptioni Difcoridıs perquam finilia. Càterùm fruftra vellitane feriptores ifti, $\&$ de colore refragantur herbariorum Senenfi:nam vidmus nos in Olficina Guillielmi Driefch perit' Pharmacopoi Aritucrpienfis, fuluam, albefentem, adeóque

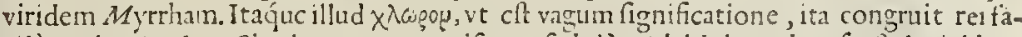
cilè varianticolorc. Siquis namque expifcetur fedulò, videbit interdum frultula viridantia, cuiufinodi nos vnum habuimus, quod multis oftendimus.

\section{B D E L L I $V M$.}

BDE L I I v M quafi olidum putridúmve dictum. Quia autem à nemine proditum eff, qua planta Myrrha manaret, eaćuc adeò fimilis proditur Bdellıo, vt ferè indifcreta fí militudin is fint,valde verifimile eft eiufdem effe fim ilitudenis fpinofas arbores. Nam \& nobis compertum eft crebro vfu, vtrăuis ciere menfes, mollire achotu, illıtu, fuffitu , ac quouis alio modo, tametri maioris, minoris virium momento quadantenus, vti cxtera o muia, differ ant, colores, varietates, fapores, fermè eafdem. Nam fí qui dc odore vellitët, fociant fuauitatem in odore, non femper ab feccie, fed gradu mixtionis manare. Etenim eiufdem gencris plantę foetent quædan, aliæ fuauiter olent. Itaque fic accipiendum, Bdcl-

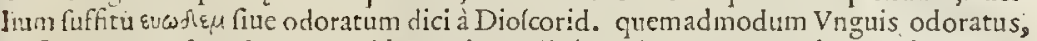

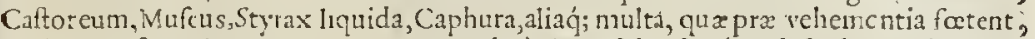
aut ingrata funt. Quarc cum vtraque proxinè altcrā fpinofa arbor defcribatur, \& Gummi adeci fimile cffigie fundat, voluerunt quidam, non uifi tanouam fylueftrem a fatiua Mytrha diftare Bdcliiun. Porrò Myrrhr defcriptio, quam dant, non êt ita diucrfa ab ea q:am Plnits Bdelii feripto reliquit, Bdellium nominatifsinam arborem, nigram, masinitudine Olex, folio Roborss; fruęu Caprifici, naturáque. Quem Caprifici quadante. nus effigie fruttum induftria peritifsimi exoticarum plantarum Caroli Clufii in verfionie bus è Garcia habernus.

\section{$S T r R A X$}

$V$ o $D$ exhac cmanaret liquor, ac veluti ftiriatim cxtillaret, Styrax dicta videtur. Elus feracifsimus jlie tractus Galloprosincię,qui à trium Marię Sororum fano antiquifsimo, ad form Iulium vfque porrigitur: eit nanque prope oppidum Solarium collis latiffimus \& opertus frequenti, Styrace,nullidú illic cognita, quam primi nos iunenióue inultitum Pharmacopceis \& ftudiofis, tum Monfpelfuli Profefforibus oftendimus. nan iandu videramus Venctils in Francifcanorum horto: truncus ipfe fimilis betulę ligno, aut mali cotonex: folia vtrauisminora, \& quàm Cotoncx minus ri-

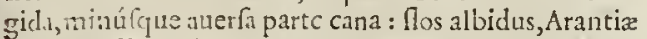
magnitudine, nỏ odore. Baccx aliquàm multę Staphylodendri magnitudine, rotundiores tamen, quas exci-

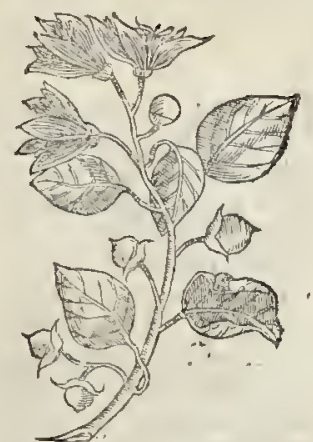
piunt vnqulx ternx atque amplectuntur, qux pediculo longo hxrent. Inibi tametfí tana ta copia eft, nihil tamen liquoris eftluit, fed Lacrima Styracis Venetias defertur purifsima perquà̀n odora, inqúc grana \& glebas hammoniaci modò coaetas, quibus ineft quidam melligem fimilis liq̨uor, qualis è facis defuit.

\section{$C D O N I A$ MALA}




\section{$43^{\circ}$ Fruticum, fub fruticum, cremiorumes} D $\mathrm{E}$ P o M I orbiculata circiniatione turbinati Cytonium vocaruntiplam arborem, bi malo fpeciofiore, aureo, melino, feeta vifitur, lanugine tomentacea obducto, ipfa fic odore grato,perutili ftomacho carue.

$$
\text { THVS. }
$$

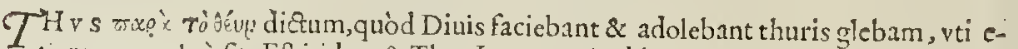
tiamnum vulgò fit. Eft itidem \& Thus Lacryma Arabicx arboris, gux inultis ian.diu fęculis cognita \& vfu recepta, vera genuinaque eft: Verum ipfa planta vixdum cogntta planè eft,nif de paucis notis, quia pufilla eft arbor, folits Lentifcinis, Arabiæ indigena. Eius funt vires mirifice, intus \& foris aduerfus morbos perquàm graues magnę \& confoicux veilitatis, quas recenfere longum foret.

TH v r I s Limpidi, peilucidi \& refinz Cedrie enuli nitorem puritatémque Succini affequnti, nobis $\&$ vifendi \& habendifuit copiamulris in locis, quod non perperanı Diofcorid.notisquadrat, fi notas, vfumáue perpendas : nam \& dum adoletur fuauifsimum halat odoren, \& vulneribus, tumoribus, difcutiendi vi,nonnulla relica aftrictone, ad robur partis opem certam fert. Rupelle occidui maris quadrienniü fermè ef cum doftus medicus Launams nos gummi iftus giebis, arlsoris fruetu \& folio, donauit. Afferebat nihil tamen, fed fibi relatum ì natis vtrüque, trunci Pinofimilis fobolé elfe. At folium, quia valdequàm rarum, nequedum ab vllo depictum, hic dedimus, magis feifcitaturi, fitne Refiniferæ plante, quim afterturi.Eft namque, quod rarò contingit aliis, ab imo pediculo ad fummum vqque cuculie verticem, duplicatum, quafi ex geminis conflatun tenuibus tunicis, vagina, fefquipalmum longa, inftar infundibuli, hiancis hiftrionis fpeciem prx fe ferentis; fupernè Galeata videtur, quod de Horibus $\mathrm{Na}$ pelli \& Lonchitide, non de folnis vllis, memorant autores.

$$
\text { COCCVS infectoria, fen llex Coccifera, an Agrifolia } P l_{i}
$$

INFECTOR I VM granum cruore miniato \& muricato pannos imbuens, nomen Ars bafculæ fuit. Si,quamı fẹpè meritò \& profufe laudat, fuam Italiam Senenfis Commentator tam diligenter luftraffet, ncutiquam dubirafier, an huius arbufcula, vt vocat, reperiatur in Italia, ac multò minus bizantio Cocciferam Ilicem hanc accerfuiftet. Siquidem frequentifsima hæc humillima Ilex, cum plerıff; Italiç locis, tum prẹfcrtim in Hetrulco, Romano \& Senenfi finitimo agro, locis montofis, glareofis, Iterilibus, inter varias Ilices, Sunilaces afperas, Terebinchos, Lentifcos vbi etiam, tameti paucx \& parum, nec quotannis, tamen nounullæ Coccum ferunt. Sed quia minus Coccinum \& paucum, citóque euancfens, partim ignomatur,partim negligitur. At in Galloprouincix Arilatenfi planitie patétilsi ma, folibus ęftiuis retorrida, fqualida, glareofa, lapillis filicibúfque conftrata, \& Frontignane Norbonęque maritimis hanc legunt menfe Maio, annis adcò æftuofis, ve totum femeltre nihil penitus pluat. Plebecula tunc turmatim \& vicatim confluit illuc Coccum leftun , quem Vermilionem voce vernacula vocitat, at que venundat in mercatu fingulam libram I 2 . \& interdum vicenis afsibus Gallicis. Pcrelegans naturæopus Ervifendum, non tamen fruetus aut femen, fed excrementum !nobile tantillẹ llicis, quę à crteris Ilicibus exilicate tantim differt, horridiote afpectu, \& rigedis fpinulis, denfis, crifpifque folis ac finuofis, angulofis, minoribus, femper virentibus, fed Agrifolium prefe fert. Coccum autem ferunt copiofuin, \& amplexantur folii imi introilexe feilix, atq; fur- 


\section{Arbormaduerfaria, concifergue recenfones.}

culi præduri copiofiorcm, nitidum, Agrifolij aut A foaragi hortéfis planè fimilem, concolorem. Fufciore ancn \& obfcuriore foris, int us veno languinco eruore lucido glifcit, qué prefu excipiūt recétem ad nedicatas cordić; amicas, Alkermes prefcrtim contectiones, Pharnzacopcei Mófpellienfes, A quifertienfes, Maffíenfes, \& Arelatenfes, crudo, candido, vel fuluo ferico, illic etiam à Serificis vermibus neto \& glomerato. Verùm infectores, qui magnan vim cocci enunt, non premüt: fed aceto at albo vino irrolant, ne itı vernichlos, aut vinifugas exiles mufcas abeat cruor, penè vacuis relicis tunicis. Sicq́; in puluerem rubellü miniatum redactü feruãt, vnde Scoletium antiquis diEum, feu verniculofü iftud effe, fatis liquet : \& cópertiffnum non cfe fr uclum, fed excrementü llicis: cui in furculis funt glandes longiores, nitidiores,nigriores Quernis, fed Echinato acetabulo, ron builato ima parte, inclufe. Flores verò Martio illic promit mufcolos, fublutcos aut herbaccos Olee Ilicis, aut Querquitus. Cuius etiann medijs folijs \& trüco non rarò animaduertimus excre méta rotunda, rubella, \&cinterdun flaua, majoraó; iftis, in varijs locis Gallia. I talıæ, Germanix, quercetis prope Bafilcam in Hcluetia plurima. Quanon alia videtur ab ea, quam mulierculix, Diolccride dicente, legebant ore, \& vocabant Coccum, fortalfis o uadam, vt verifimilius fit, fimilitudine. Sed cum nofrati Norbonenfi \& Hifpano nullus hodie notior aut porior habeatur, virélq; eidem omnes congruät, q!ras neminerint foriptores, fruftra iftum improbat, \& alinm expetit, qui neutrum probè nouit Senenfis Comuétator. Scptentrionis eA $Q V I F O L I V M$, fuc $A G R I F O L I V M$, non of Flev, reque Crateggon,yeque Aphricana Palyurus.

I Vbens hac \& pciquàn frequens arbor crefcit in frigidis regionibus, vt Anglia, Germania, \& Francia:calidorum autem duntaxat montofis alfiofis ratò \& æcrè frutefcit: quare nequit effe Palyurus A phricana, chim fre etia cius iniucundi faporis bacca. Neq; effe Ilicis fpecien cet tunn:non enin glandifera eft, \& natales llicum feraces, adeoque $a-$ Atuofos odre. Quare indicta fuit Diof.nec fortè valdè nota Græcis. Ett tamé perfimilis Coc $\mathrm{co}_{0}$, infectorix folio, quod perpetuò viret, fed laxtjus hyeme, fpinis horrido, in margiue mul tilatero, leniter finuato: bacca Oxyacanthx, Kermes, aut Afparago cócolor, fed ingrati faporis:cortice ad gluten aucupatorum conficiendun apto.

Tr auis fuperiorun adeò huie fimilis eft,vt non fit dif́ccnere illicò facilè, ̀̀ Coeco prz- IL ex mediaCó

fertim: huius tamen gland ofus Echinatus fructus oblongior eft, dactylum aquaas, muf- ciferc flci plan piam coceum ferês, 'etiam vbi inter Cocciferas llices frutercit, proceriore maioreçue trü-föppar, folio At co,ramis \& frondibus perenuibus.

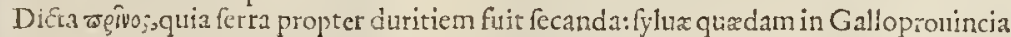
\& Norbona,quantx quanta funt, Iliceta füt, cuiumodi cll Garanotius lucus ad Mófpel- Ilex arbor ans lium, vbi proceras \& querna elegantia quàmplitimas videas, fed oblongo Arbutifolio, arboren. tantillum déticul is per ambitú afperato, penneruo atrovirente, oblongiore, graciliore fu- SVBERIFERA pernc̀: Querquus giande propendéte,nucamento mufcoro, lutcolo, non diuerfo. buc accerfis.

Eadem 1 llic variat fipite huniliore, albidiore foris, \& Ole fimiliore: itemq́ue glande, Prrictas. altcro tantòminote.

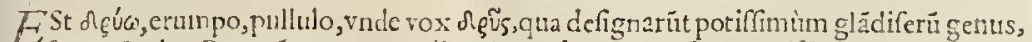

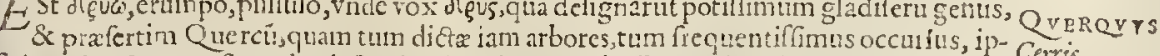

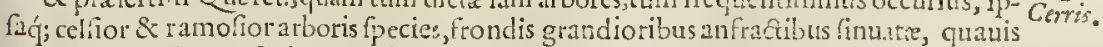
notatione notiorem faciüt, tun frigidis, tum ealidis plagis. De cuius adnata, exeremenritiáque multiplici fobolc, plantis, fungis, fructuum rudimentis, mufco \& vellere nouitate fpectando,iam cuadam diximus, $\$ x$ nulto plura in Agaricis diccinus. De Quercu marina inter Algas, de efu \& vfu Medico omniū partium \& fruetum, deć; Quenuo falecon ficsendo ad corporis humani \& metallorum medieamenta,inter renedia.

Querquas àly incotes fue procelfe diria C ER R IS T li. trifi pregranéi Echinato glandes. O Va itur Pẹaro Romam publica via, vifuntur eelfífima, alibi minus peruix, nec valde notæ hodie:cuius glandes prægrandes capulum habent Echinatuni,ambiti fquãmis praduris fibi mutuo ineumbentibus, horridum, magnitudinem fere Echinimarisi aut femiconi laricis aquans, cuius nonnullam fimilitudmen retinet:valde craffus efr, interiore fir parte lenis:-glans, quam claudit, nonnifi magnitudme differt, folia maiora maltò: eadem alioquin Quercui. 
EX vnaqualibet fuperius narratarum primo quoq; intuitu quiuis fuberiferă nofcitet I-

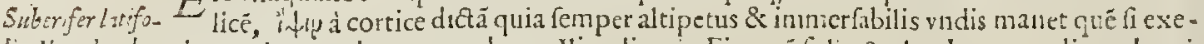
Lia llex glande ris,omnino eandem cum arborea Ilice dixeris. Ei tamé folia \& glandes rottindiora, breui echinato. oza,item détata:cortex geminus ftipitem amicit, alter interior qui perpetuo hæret : alter craffior duos pollices, rimolus rugofus, perquadm leuis, qui deglubitur, \& quolibet getium dcfertur ad crepida rum foleas fuffulciédas, aliáq; multa neceffaria. Multa Galloprouincie maritimis Tholonę, OI bie \& al ijs adieztis, \&ै in Túfcanię Luce prẹtura. Suberifera angr $S$ Enad Apénini radififolla llex. nemorofis collibs multò frequentifima, qux angufture, lögiore, minuf́, crennto folio eft, ad arboream Ilicem ac cedšte: giădofo femine, cupulo foris pungenti, afperedine fquabro.

sprollodris.

Vafi è cófufis llicis Z.8 curerquns in hác puncipijs, noin enclatu ram Theophra $\Phi: M \tilde{3}-$ dẹu, fite Suberiquer-

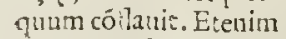
defacie \& folris Ilicem quinpian dicas: ipfú autem ligntiss mollius \&laxius Ilice, fed folij incifura ferrata Cafta-

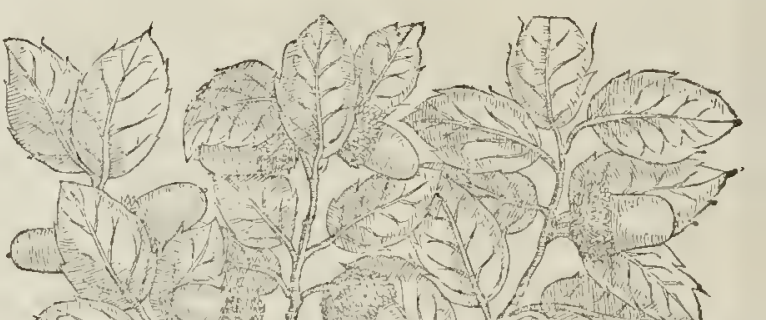
ncx, non Querquas: reliçua effigies llicis, mino: tamen Quernis:maior Ilignis, non glandes, fed ¿xudu exiliora \& oblongiora.

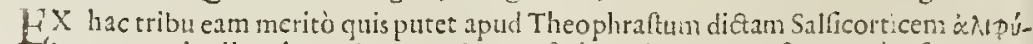

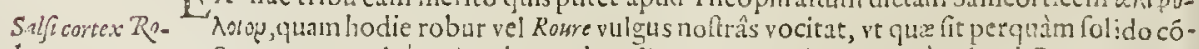
ür. pacto trunco, multúm cincrisyrendo relinquente, qualem etian c̀ vulgari Querno trunco nos pirandum curauimus. An Thboph. Q Vaxtem Gallas dat Quercus, duplex videtur: Earü vulgatifima remorum \& faltuŭ
Eagus. Antheoph. re ftipite, brachijs \& fronde. Huius quxdan varietas aut differentia videtur Fagus Theophra, dreta vocis argunecto Latinis Efculus, cuins ef́culenta glans \& poft Q Liemã dulciffima celebratur, famemq; explebat primis mortalibus: hodie Fargni \& Farguo Italice: Hargm Gallice: lignum iftus frmius proditur, quan v rbanx Quercus. 


\section{Arborum aduerfaria, concifeque recenfiones.}

A $\mathrm{r}$ Fagus vulgaris,glande diuerfà Querna eft, triquetra, pufilla, vtringue acumi- $F A \&$ s nata, vide ósix Theophra. videt ur vocata. Ligno etiam eft nunus compacto \& robufto, fronde Populnea, aut Alni: longiufculéque viderur abeffe à Qucrcu; tametfi \& hax potuit Fagus ab edendo dici; cuius glandis nucleus efca paupercule plebi \& vrfis quxfita, regionibus frigidis \& calidis.

CAsT A N E \&yluæ funt Allobrogum \& in Alucrnis, quamplurimífque nemorolis, al- CAstaves. folis, regionum tamen non frigidiorum; nam calum Aquilonium non ferunt:prxgrädes, filis muricatas, echinofis tyandes edunt:medulla omnium glandiferarum fuauifsima, \& ad panificium aptifsima: frondibus longioribus Canabinis, aut llicis grandioribus, fimiliter Fago aut Ilici,fed angulofis plicis.

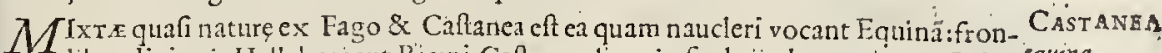
dibus digitatis Hellebori aut Ricıni, Caftınę̧alioquin fimbris donata in qua Echi- equira. nus octennium aut decennium Caftaneã, ciúfg; nucleum claudit \& tuetur faporis perboni; vt nónullas incorruptas prędulces guftabamus in Mufcolo Pręceptoris Ródelletii ; \& etiamnum habemus dono cuiufdam Pictaui, qui multa rara ex Barutho \& \&igypto no bis cómunicauit. Affabrè vifitur exprelfa, vt quamplurima, in Commentaris Mathioli.

Sambucus vulgaris corymbaces.

Ebulus, fiuc pursilla Saribucus.

Malus.

Pyras, Pyrafter.

Mepilus.

Aria Theoph.

Alpina arbufcula, bacca Oxyacantbe, recentiorum Chamsersepilum.

Enonymos T beoph.

Cormus arbor ơ fruter.

Cornus formina, fute virga fonguines.

Cerafa varietates.

Cerafer racemoja.

Chamacerajus.

$$
\text { Prunus fyl }\left\{\begin{array}{l}
\text { Vitraque. } \\
\text { Domseftice. } \\
\text { Varietates. }
\end{array}\right.
$$

Prunoperficum.

Armeniaca walus $\left\{\begin{array}{l}\text { Maior. } \\ \text { Minor }\end{array}\right.$

Sebefter.

Iuiube veraque

Paliurus

Paliurus altere T beophre:

Paliurus altera peregrina;

Pyracanba.

Berberis.

Myrobalami Arabum;

Thamarindi.

Lotus arbor Diofco.

Lotus arbor $T$ beoph.

Guaiscum Patauium.

Guaiacum Officinarum.

Palma fancta, fue Palum fanctum.

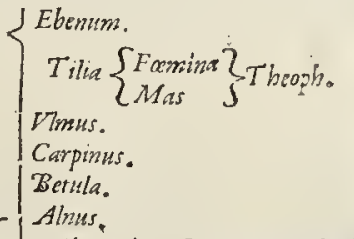

eAlnus nigra,fue Frangula berboriorum.

Nuces anellame.

Populus $\left\{\begin{array}{l}\text { Altha } \\ \text { Nigna } \\ \text { Lyitca }\end{array}\right.$

Arbor Inde.

Populus Noui Or bis arboris Indefolio.

Mornes omnis.

Sycomorus.

Ficus omnis.

Platanus.

Acer.

Sorbustorminalis.

Oxyacantba.

Mepilus Aroniz.

Sambucus $\left\{\begin{array}{l}\text { efquatics. } \\ \text { Varietas. } \\ \text { Montane. }\end{array}\right.$

Piperlongum,

Ribes vulgaris of nigra.

Vuacripa, fue Vitis precia.

Amomi o Cardami differentic.

Rofa fatius, fyluefrios, coerulea, intea, ob waris tates.

Efglentine.

Rubus omnis.

Lynojatos.

$$
\text { Qo.i. }
$$




\section{Fruticum, fubfruticum, cremionn ó \\ SAMBVCUS VVLGARIS coryminced.}

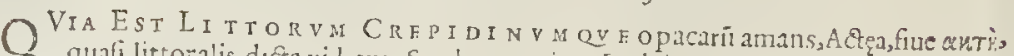
Sereno quafi litoralis dicta videcur: Sambucus ctian Latinis vocati aut potus Sibucus, dulla excnteraris, Guibus inftrumenti frmilitu dine, que illi cum cauis virges tubífve medulla excnteratis, quibus nulli non è plebe notifsma Sambucuseft; fraxinex ficie, \& fionde, fed latiore, nonmhil ambitu crenato: vmbell is candidis, Drabz, idtioribus, circinatis,magifque fpeciofis, \& corymbacea fottura acinulorun fangtineorum, nigricantranimittunturíne cribris luxte, ad Vux xmulationcm, Augufto; quando decerpuntur tranímittunturúue cribris ad pultes, \& condimenta,pręfertimapud Germanos \& HelAldermooft Hel uetios, vbi pucruli crnorem efculentum farina denfutum auidè forbent. A cetum Gallia sesiorm. c̀floribus \& racenorum fucco admodùm laudatum \& rubrum parat.

A NNoS.E arborissipud Borcales prẹfertim,ramis accrefcit cxcrementun corticofum coriaceúmve multis dotibus cognitu diginissimum, plebique Angle \& Germanæ, Iudxaures vocatum, proptereffigiem aris, quan cartilagineo concretu rugofógue complcxu multis plicis \& mandris æmulatur: led colorc pullo, prædurum, aquis merfum mollefcens, fpongixćuc ritu tumens: anginis ccrtifsimo experimento vtilifsimum, \& tumoribus intus forifque nunquam facs laudatum: guftu pené infipido, cutis elixz,
at corii.

$$
\text { E B V L V S , fire purmullat Sambecis. }
$$

SC I T E admodim hanc pumillam humiléne Sambucum Diofcorides dixit, quippe tanta vtriufg; inter fe cognatio, vt prino ineunte Vere, nif quis ndicen \& \&urculos her herba eft: Sambucus autem an nofa fit arbor:\& Ebulo fronda , fuciéque minor fit ; fcapi fimiles, fed vefcendo vir ferend, \& pargandi vis vegetior. Vm bellę corymbacex perquàm

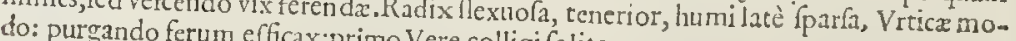

MI \& $\angle$ I.

$$
M A L I, M A L A \text {. }
$$

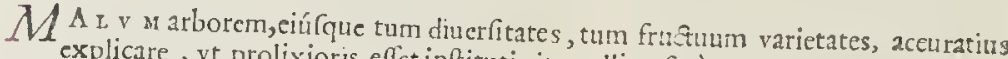
explicare, vt prolixioris effct inftituti, ita nullius ferè operxpreci; quando $\mathrm{Ma}_{\mathrm{a}}$ lus vrbana eft arbor pradiis \& paradifis perquam familiaris \& nota, cui unfluet coli admodum patiens: Sed amant or tamcr huruidioris, fapidior fructus ficcioribus, prime hodie commendationis Curtipendula ad nobilem Alkermes confeEtionem. PY A. Northmania, qua foris intúfque coccinio fucco \& afpectu micant.

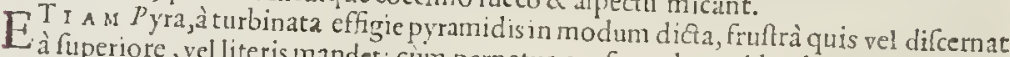
tandi in menfis, vihil fremendet: cum perpetua confuetudine videndi in viretis, \& cfiBelgio, Northman as factitant. Lubeus anglix . vbi Cidre, \& $P$ ere admodum fuaues potiones vini vicaritum fructus, tum arboris tacemus diffcrentias \& nonenclaturas fatinæ \& fyluefris,

$$
M E S P I L V S \text {. }
$$

ES T M E S P I Y sarbufcula congener \& fimilis Sylueftri Pyro, non folùn folio, quod tamen longius \& anguftus eft, fed etiam pomo, quod tiem pufilum fert, Sorfupernè extätc, Pyro fylueftri par magnitudine, guftu, \& effigie; vnibilicello tamen

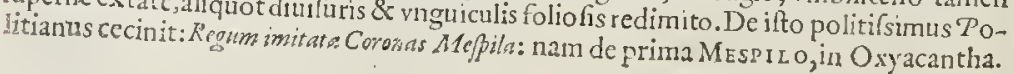


Arborum aduerfaria, concifaque recenfiones. 435

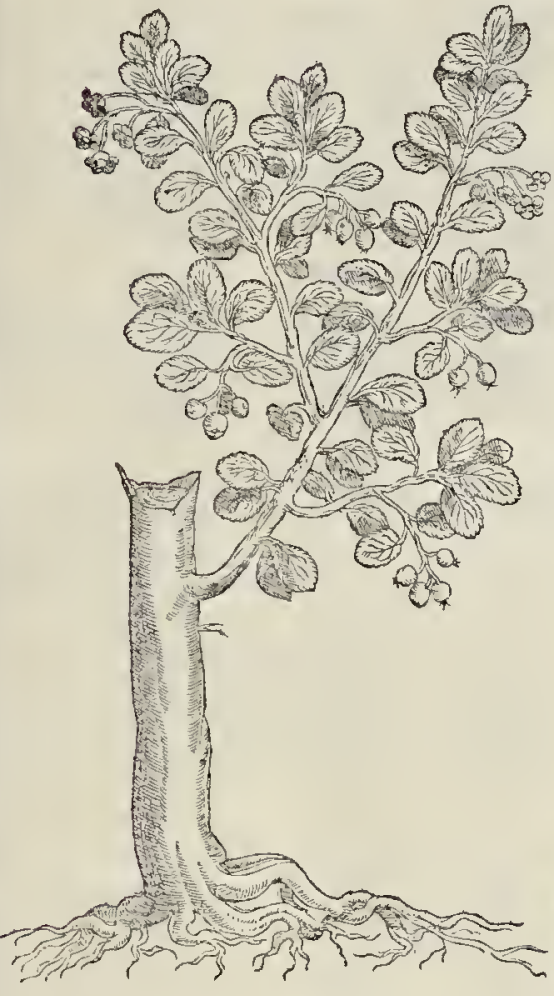

Arbufculafrutéxve Alpinus folio Mali, Bacca Oxyacanthe aut Pyracantke.

FT hrc Alpini foli indigena in afperis Mindenis Nortonx, \& faxofisad Baldum "Jcronenfi $\mathrm{m}$ : Fagells exit vimineis nigricantibus duos trefúe cubitos furreqis:folia item fuibtus glauca, fupernè virentia, propiora nano Pomo, cui nó abfinilis tota pläta praterquàm fructu, qui bacca $A$ rię finilis,æqualis Pyracäthæ ant Oxyacāthæ. Qui cam apprimè docti Chamamefpilium nobis fuacebant:alij Euonymum Alpinam faciebant. Præ. f.cco guftu nonnihil tanen calido, acri \& aftrngente.
$A R / A$ Theoph.effirie Aln:

X) Ecita difpariauteffigic aut $\mathrm{fa}_{\mathrm{a}}$ cultate, fed longe rarior, am:tiorǵue Alpinj coely, Aria vocata Theophra, quam in Angliz frigidioribus fyluofis frequentem videas: ranus calidionbus, necnifi Alpium iugis Norbonenfis Sauenz \& Sabaudia. Folio Pyri,Fagi aut Alni,auerfo, glauco, fuperncatrovirente: foribus plufculis, in vmbella candidis Pyracantha, aut $\mathrm{O}$ xyacantha: exiguo pomo, rotundo \& guftu Aroniæ Mefpili, aut Cynorhodi alabaftriculum æquante: fapote nó ingrato,nec perinde aftringence, auicus lis expetito.

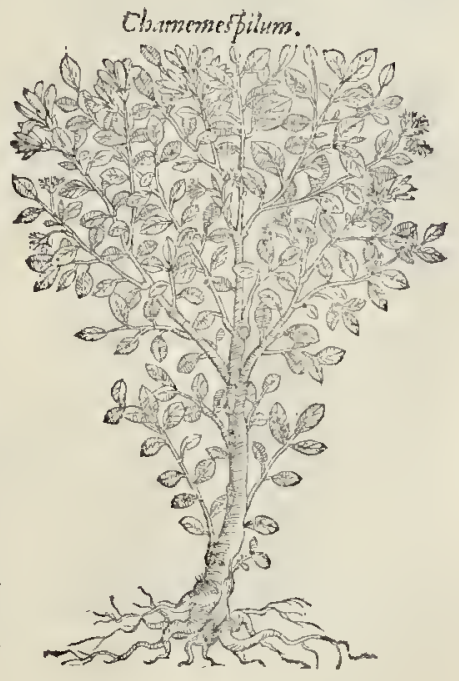

$S$ Ed vt verior,ita \& frequétior infolix Euonymos:nulli enim regioni calidęaut frigidę Ev o N $_{\text {y }}$ o $s$ iuxta fapes \& margines deeft, aut ignota eft de filiquula quadrangula, quadricocco he 7 hsoph. ceo fiust: folia, rami, reliquá́, facies llli Malde claudüt femina: ex timus colos ex pun:la materia commodior verunculis culinarijs punicx, fed pallidę ex lateo virga, quánul das, ideo Lardariam vocant: tota quiddam fpirat ingrati:fores lutcoli.

$$
\text { Oo.ij. }
$$




\begin{abstract}
436 Fruticum, /ubfruticum,cremionum os

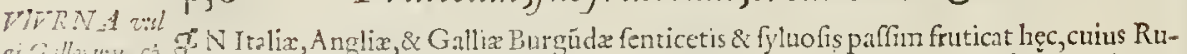

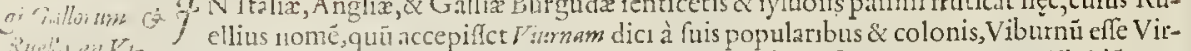

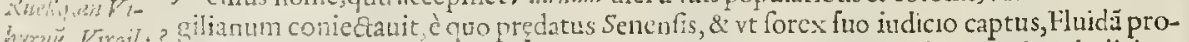

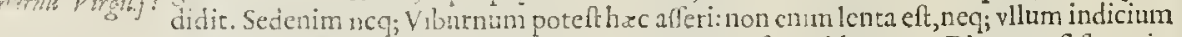

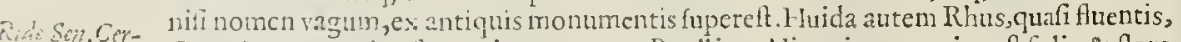
W.eus litretio, Gaza intcrpretatio elt, vt pritus monuerat Ruellius. Aliounin cognatior eft folio \& Aore ucsin Cith" Arię \& Mefpli, priter acino in vmbella condito, fed compreffo, oblonge, nondum ma"res turo rubro, maturo auté nigro, non(vt doctus Ruel.fcripfit)rubro:folia Alni pubent cani

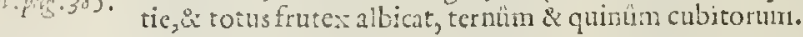

CORAVS G - fli confimilis afpetu ligni \& foliorum Comus, fed plufquàm cornea flipitis duritie, bor.

interdum iuti modiarboris, interdun tantum fruticis. Fioribus luteolis, mufcofis, ipfum ver o:tu antevertentibus:fru氏tu Ccrafi oblongi,cócoloris, oliuę effigic. Gallis \& Ger manis nota \& frequens inter dumeta minusar da, a:ıt iuxta Auenta:gufu perquàn auferu, acorenon ingrato.

FOEMIINA Atera,nutê qux roçtur fomina, foliorom \& ramulorum effigiatura adcò appropin cornus. 1 cuat huic Enonymo, vt Cornü dixerint. Licet ea nó fit foliditate ligni aut baccà venuPeredoranis ftate; fertenim purfllas baccasnigricantes Hederæaut Polcmonij, \& edendo ingratas, non Comi. acidas: flores albos Ligufri, in virgis con ticc anietis, ex viridi in fufcum purpurantibus,

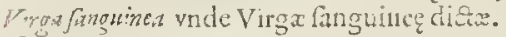

CLKASA.

Triuialis etiam conntionis Cerafus, \& multiplicis eft differécix, qux magnitudire arbo ris, fructus faporc difeenenda eft, aut exvalgatis libris holitorjjs percipicnda. Flos Perfici candidior: \& rotundiori folio fatiux quän fyl. que paffin arborefcî́ fructn acido mixto, aut dulci.Suzuiffima omnium Corafa acidula, quę A Agrettes vocancur, veniuntọ́; in culiuis \& Officinas.

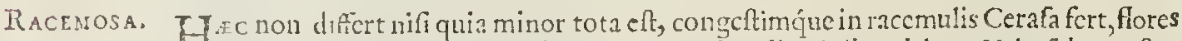
Hariter albos, quales nobis often debat ex śabaudis Al pibus delatos Valerädus nofter

CHAmecera- DErquàn ram \& Alpigena humilis Cerafus, cubitum pedéúc eguans, folijs,ramis \& svs.

fipite Cornus,albidis. fogullidis nodofrs. Floribus albidis, pallétibus, aut luteolis. Fru Etusbinos notuatut in pediculis longioribus, pendulis, Ceraf ritu, fed in imo duo foraminula albida, quoddan rudincntum pupillarun aut oculorum adumbrantia : Gigarta quini, int fena,albida, Incida, Oxyacantha paria.

BRVNTS 17 Bicue viarum agros fenit aut fepes fulcit inter arbufta vitz contumacis Sylueftris P. unus:ian betiora edens, iamó; \& vt plurimum,pufilla pruna:quarum frutices gemina in differestia fút, altera horridior, 'unor, fpinis rigidior, fructu minore, acerbjore, ex quo fr Pruncllorum Acatia.Lation auten fylueftris tranfplätatione, infertione, \& cul tu, in granú: proceram, so donefican abit:mitiore pomo, ficculentiore, fuauiore. Cú-

Varictates. Etis diferentias nec otiun, nec animus eft perfequi, cimm liceat bene longas paginas multorum feriptorum de iftis confulerc: Damafcenis omniü olim praftätifimis, Brignolienfia hodie in Galloprouincı palmam præripuerunt bonitate, falubritate, \& fapiditate.

POmaria quęam cultiora Gallica quandam Prunopetficum colüt, cuius fruetus caro, Pruni eft: cute fubviridi Pruni, fed nucleo Perfici.

$$
\text { A R MENIACA malus smaior }
$$

SEdinnumeram ferè turbä Prunorĭ, Malorum, Ceraforum, \& eiufmodi fructú, para-

Gal. Apricos.

Pritcotir.
Sedinnumeram fere turbá Prunoru, Malorum, Ceralorum, \& eiulmodi fructuu, para-
difs nimifo:àm notorum, nec lubet, nec licet per anguftä temporis \& paginæ profequi, qundo ea poffunt ex varijs \& prolix is Rei Ruftic, fcriptoribus peti,vti \& arborum cuàm luximaxum, qux communione principiorum, cultu mangonio, \& infertione quãpion ditierfan vel figuram, vel fpcciem obtinuernnt:vt funt $P$ runoperfica fortè, \& MaIa Armcniaca, Precocin difa, qux figura \& folio rcferunt Pyrum, pomo autem ipfo Malum Perficum. 


\section{Arborum adiber faria, concifeque recenfiones.}

7 ER I A a aliam efle à Perfica \& temperamento vario, vel de Diofcoride difcas,ne- PERSEA.

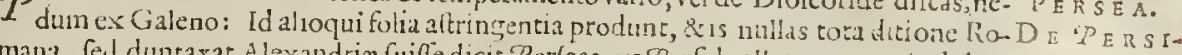
mana, fed duntaxat Alexandrix fuife dicit Perleas ex Perfideallatas, quum ind dem cas lo furerins

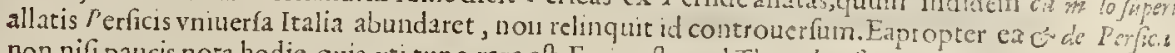
non nifi paucis nora hodie, quia, vti tunc, rara ef. Facie eftapud Theophraltum pracosis mace. Mali, aut Pyri, cuius manitudinem emulatur : altritione 3 magnitudine "F' y ro finilior, fructu alstem Perfico

$I^{S}$ т a Truna qux voce Maura ex Serapione notifsima funt Officinjs. Nec nifi Graco-

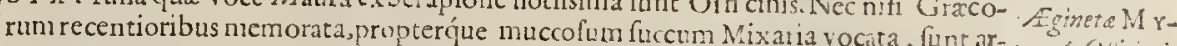

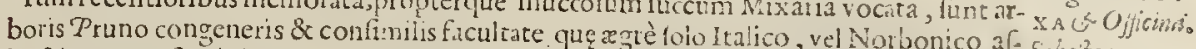

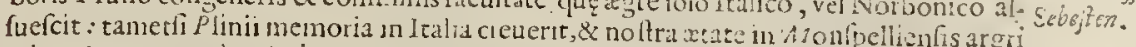
vrbecula veruaculè Magilllarges nomindta, illic fuperfuit, \& tantum arbufcuiafuit, facie Pruni \& folio, fed latore : futa, non du cognato,atro \& magis vilcido.

HA c vix vllan reperias qux ramis folis tocóque fenticoro occurfu magis ęmule tue liswbe. Paliurum (quem Rhamam tertium faciunt) in aridis $\&$ glareofis ftriforis Norbonæarbor is alicubi, alibi duntaxat fruticis magnitudinen?, vt Monfpclii \& Anconen agro in Italia, afequitur : furculis praduris, foliofs Lentifi, aut Rhamni, miltis aduncis [pinis, intercalantibus, prxacutis: flos mifcolus Olex aut Rhus 'Pliniane, liteolus fructus, dulcis, $P$ runi cure Phonicea, vel Rubella.

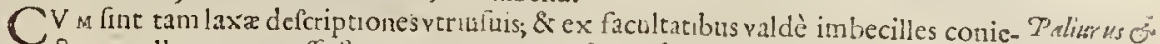

Exura, nullum puto poffe ftatuere quanan cul fit praferenda. Qux liuic Diofcori- Rhowmins. dis defcriptioni valdequam accedit, eft Rhamnus tertus, nau frutex quanius eft, prxdurus eft ftipes, aculeatus, femine pingui, lincoguenon fuliginofo, fed fotis duro, vt Jini : vireshuic congrumnt: nam lapillos exerit potentifsimé: diureticus eft ac prome haud abs re doctu' Anguillara anıbigcbat elfétne Thamnus Paliurus alio nomine ( vt fapé fit) no:a Africanis tranfmariníque regionibus, vel Diofcoridis fuerit vitiatus codex. Quod ad femen attinet, huic funt terna ofscula, vti Thcophralsus vule, fenune Lini xmulo, non fuliginofo, vti corruptè legitur, læue, non lentum tangenti , Exin filıqua lata follicular fpecie, terna, quaternáve habet, ve fanc̀ hxc ipfifsima videatur.

Q V a a verò lib.4. \& capite Theoph.meminit Palurum, fi quis expendat,comperict $P$ A I I V $R \nabla 3$ alterum effe Iuiubam Sylueftrein:nam fructus rotundus elt, ruber.quancus C edro, alters Theophr.

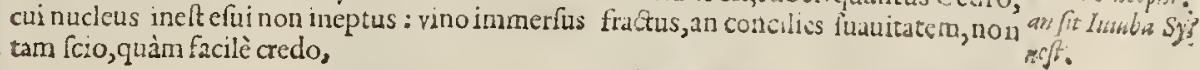

\section{PALIVRVS alter peregrinus.}

SVNr \& alia nónulla, quas fi aufi e1renus hîcaddere, potuiffemus pro' $\mathrm{Pa}$ linro fubderc:nam fatis cógruunt, præfertim quxdam quæ Mófpellienfi agro oritur, fpunis horrida, foliis Olex, mino ribus, baccis nigris, tricoccis, Smilacis, grauidis, fucco fuluo, tinfure apto, pręgrandibus, Berberidis modo, granis ternis, fed uninoribus, oblongis, gufu fubacri, cuius hic picquam damus, non procul Monfpellio, qua itur ad fcaturiginem Lani amnis, fecus ripam \& propevian multa.

Oo.iij.

$\dot{P}_{R}$

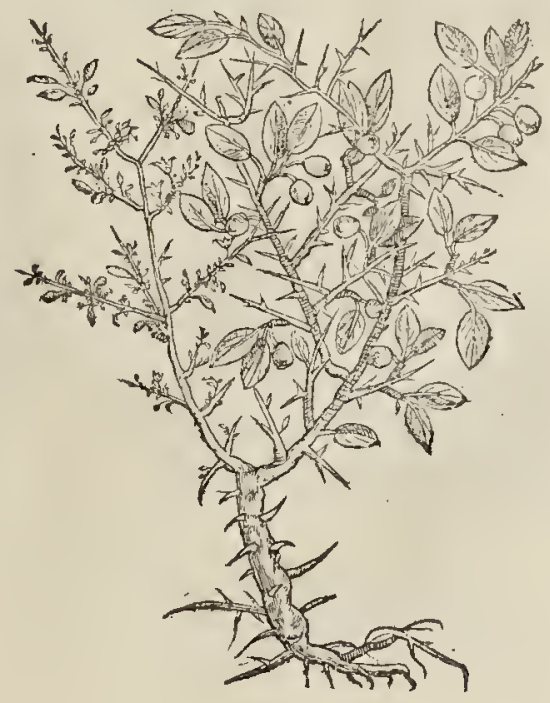


R н A м N v S PR I м v $s$ Rhannus Italiæ, Gallię, \& Hollandic maritimis pluribus in locis, ramofus ab primus Divfo. Pimo fummo tenus frutex, aculeatus, furculis albidis, folits anguftioribus, multis, lięrentibus, Cham $x$ lcx longioribus: iuxta alds fruftu denfo, racematimạon fo, Afparagi, aut Agrifolii, minorc, fucco Hauo, turgido.

\title{
RHAMNVS Secundres Monfpellienfum.
}

SEc v N A fpecies Cónentatoris minus exquifitèrefpondere Diofcoridi notisvidebitur, 1 lis qui lecundam fpeciem Rhamni Monfpeltiifepibus muniendis aptifsima vidcrunt : nam tota planta alba \& minoribus floribus, foliis Olex, fed candidioribus Iefamini pubet, at herbacei coloris:cortice ex viridi pallefcente : vtriulque rarus $v-$ fus: Monfpellienfes lunc Rhamnum fecundum rocant.

\author{
$S P I N A$ INFECTORIA, \\ Rhamnus Catharticus, Recertiorum \\ folio of flore Malifylue. Bacca \\ eAlni rigrefü Frägula.
}

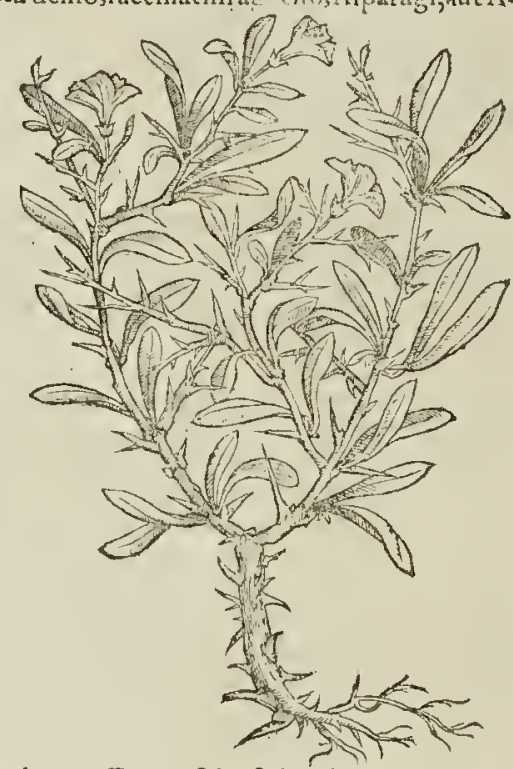

$S^{P}$ I N s infectorix plus eft fimilitudinis facie cum Pruno fyluefri, quàm cum Rham-

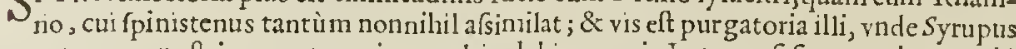
paratur, quo noftri pręceptores iam multis ab hinc annis Lutetię vfi funt; certiores viriü quàm Senenfis:vt qui non ad pituitam craflam \& vifcidam, fed potius tenuen educendam, \& impetum esus in artsculos citatum auertendum \& cohıédum prudētius vtuntur: Nam fine calfactione purgat, \& nóntulla aftrictiuncula partibus robur conciliat:neq; liquefacit humores, inde maior fluxus fublequatur.

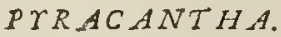

$F^{S}$ T \& in Galloprouincia \& Italia arE. bufcula fepibus non ita frequens, cui facies \& folium Pyraltri ; alpectu fqualida : eiusbaccærubrę cfitantur pueris. Semina oblonga habent, quafi Pyri aut Berberidis.In vmbella flores ra cematim candidos \& fructus Oxyacanthx pares edit,quem, propter foliorum fimilitudinem, nonnulli Pyracanthan rocant.valde eft fpinofis ramis, non fojiis: vfus hodie nullus aut neglectus.

A t.

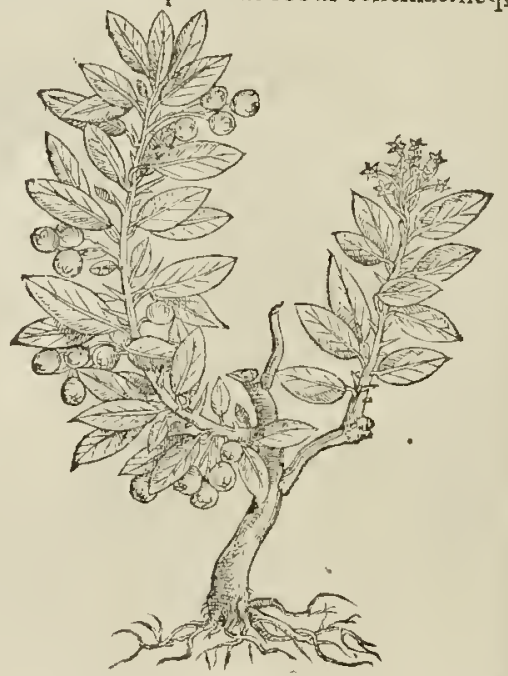




\section{Arborum aduerfaria, concifertue recenfiones. 439}

A LGIDIOR Is foliaut Montani Berberis eft indigena: fruticat \& urborefeit fenti- BER BER I

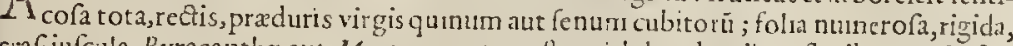
ciafsiufcula, $P$ yracanth $x$ aut $M$ yrtr, crenata, guttu acidula edentibus floribus mufcofis, emicantibus, Kibes, aut Cornus.perpufills actnis, racematm in pediculis condris, oblongis, Cori item effigie, colore \& pend lapore: corticc cinereo, libro fubtus luteo, quem Ofticinę Bugtamı vocant.

H I Syriaci fruefus vulgatius quàn verius Myrobalani vocantur: neque enim glan- Mrrobar Aw

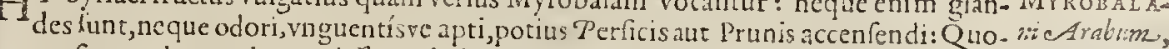
rum et fi complures oriantur differentix in Sytiacis, Crabicis, \& Calecutiis regionibus, de Graco Myro quibus dcbentur à Gracis \& à nobis:taméquat no quinquéve duncaxat hodıe proftant bahano fupcriks: in Offic̈inis differentię c̀ rotiden arborıbs. Nan Cepulifer $\&$ : Citrnifera eadem videtur arbor, proditurǵue à nuperis nauigatoribus, Perfici aut Anygdali folio. Bellericiferę autem latoores I.aurex funt frordes ; fed Indiciferz Salicis, cuiufinodi etiam Emblici videntur : alioquin inter fecongeneres arbores pronunt ipfi frudus; me- Kebuli. diam quandam naturam inter Oleam \& Prunum fortitx. Horum plurimùm dıo genera condiuntur, aut huc condita adferuntur:pluris inftitores faciunt alterum horum, qui Bellerici。 Kebulus, aut Cebulus vocatur,ommitim maximus: is oblonga pufili Limoni,aut 'T'erfici effigie, compazt a callofa nigraque carne, fapore ingland is códitę. Alter minor eft, rotun- Citrini。 dior, tenerior edendo, Bellericus vocatur. Kebulo funt Cirrini finiliores facie, cute, nucleo oblongo, \& pulpa, fed fulua, unde nomen. Indi nigri dieti \& notifsimi de colore: Airari. nuclei expertes, callo pene la pideo, quos concolorem melancholicum humore, vt cxtcros, quemlibet fuum aptiuseducere putant. Vltinó Enblicipotius fragmenta, quàm Emblci, integra Pruna, quiadantenus triangul., Deliericis minora.

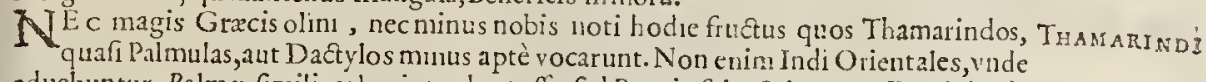
aduehuntur, $P$ almæ fimilis arboris tradunt effe, fed Prunis, folso Salgno, vt Fraxini, minutim incifo, magnitudine Querci, tametfieffigies fruetus Dactyion, fiue digitum inflexum pręferat, cute, pulpa, fibris neruofis, füfcis, \& a tris intertextum, qui cohibet femina terna aut quaterna, Cafsie, compreffa, \& angulofa : gutha quouis Pruno acidiore.

L O r multx arbores in Gallia Norbonenf mirx \& fpectāidx proceritatis occurrunt: Lot

fuperant namque magnitudiné quamlibet maximam, vel querquum, vel iuglandem, præfertim loco non proçul Monfpellı, cui Bontonnet nomë:foliis eft Populi nigræ, vel Betulæ, red aliquantò anguftioribus:baccis nigris, $P_{1}$ peris maioribus, aut $M_{y}$ rthi, rotundis, prius Eftate virentibus, Autumno nigris, naturis, nufquam rubris, vt neminit quidam: intus Inbebarum nucleolo, fruftrs fuauis efui:vulgo pueris expetitus, dulcis namque, tneque aftringens eft, \& tamen dyfenteriç prodeft, hxc Diof coridea vulgatifima.

V.s verò in horto Patauino elegantifsima viftur, \& digentifsinè colitur, iamdiu à

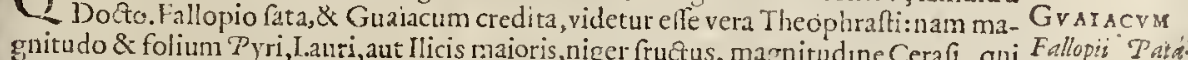
perinitia viret, fine pediculo;vel admodùn cxigno, deinde fufeefcit maturus, dulcis ninum

valde ficcatus, id teftantur : \& hæc Theophrafti Plinifíque Lotus. Quam cùm turbulentus Commentator nefcit diftinguere, nihil alind quàm ineptè congẹfta verborum mole onerat leforcm difcendiatuidum. Namque quam fibi Conltantinopoli inifiam iaetat, non alia eft certò, tametifille non de pinxerit, quàm $P_{\text {atauina. Sed quia illa ficca miffa }}$ fuit, paulò aretior ftrigofiórve erat, alioqui foliorü \& vniuerł ftr pis idem modus:quod nobis certò licet a!pectu ip o \& docufsimorum fide afferere, nempe Bauhini noftri MericiLugdunenfis, omniun ft rpium confultifsimi, atque Valerandi Donrez peritifsimi inibi $P$ harmacopcri, qui eandem in Syluis Lugdunenfibus copiofam col!1git. Itaque dux funt omnino cognitx fpecies: altera Diofcoridis, altera Plinï \& Theop. nam iftus corticéfcarificabamus adacto fcalpello nos, intus libro luteo, foris fufco colore tum fruetu. $\mathcal{F}$ S r v d lignum ex Orientis Calecutii Indiïs,eq́ue Occiduis infulis \& continenti noui norunt, nedum eruditi artifices, qui lubente Deo, huius limni 3ertis ope, diramedici non luem, qua longè lateạue per vninerfam Europan fxuiter ferpfiffet, eôdeñ vnde irrepfe. Oo:iiij, 


\section{tto Fruticum, fubfruticum, cremiones}

rat, penè iam repulerunt, tamen nondum plenèinotuic arboris 1pfius figura natioa; quam exactè delineatandabimus nos breui, modo anicos notros trufrata non fue-

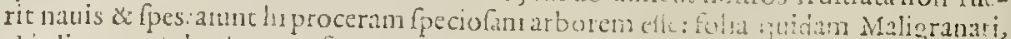

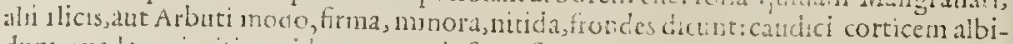
dum, quadam nigritie varidunte, maculo[um: fores lateos pl Hique onnes facunt: funEum nailerinciciunt delineare, led rotundun, nec ita nisghim dicunt. Hilpalenfes feriptores luteum ité cun nattirucrst cicune, geninis quafi Lupiuis conllatum: Lignun

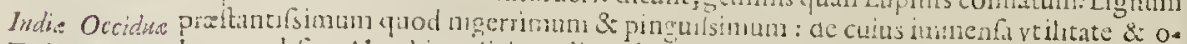
Palmefoncti leo,quod dine Alembico elicitur, dicendum poftè.

PALmix SAN- EX eiufdem classis Nincicris, qui indiden fupenore

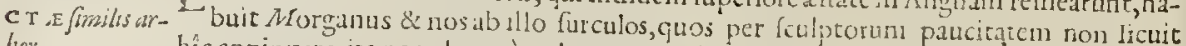
bor. hic appingerc; ita nec ala quatmplurma, qua in operis calce cenentu:. Ramı funt arboris grandiorts, recti, cortice arboris Inde, folio Citrii, carnofo, nudo, Lauri latiole, breuiore, neru ofo, horum in fumnis harent folliculi pallidi, coriacei, circinatx rotunditatis adnodum comprefsi, numo corona Gallica ferè pares, qutrorum medo infunt fenina Lentis effigic \& colore, comprésion, sultu anaticante.

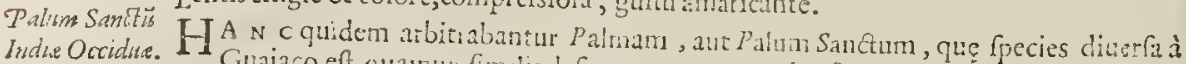

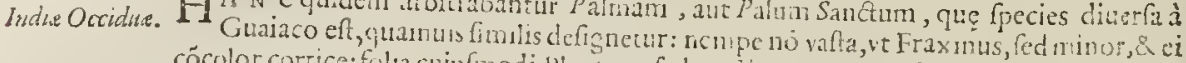

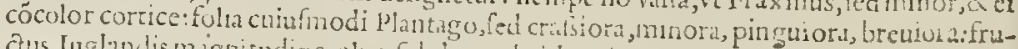
ctus Iuglandis mignitudine, alwo fub́tucendaidonci.

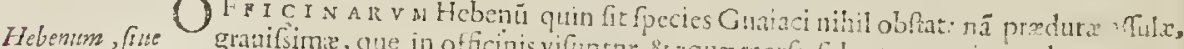

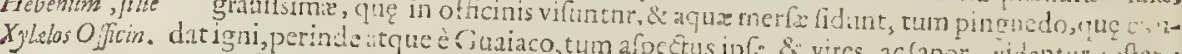

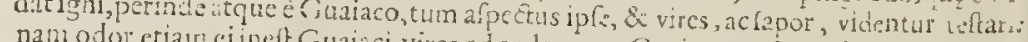

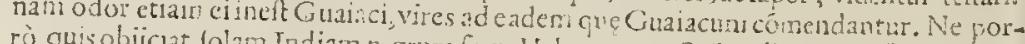
ro quis obiciat, folan Indiam n, grum ferre Hebenum ex Pöta; dicmus, Heleno idem cuenire pofte vt Guaiaco , quod non modò in Traprobanefutemis ad Oricnten Auftrum, fed etian in India occiatua longifsimed difsita, fyluefiris frondet.

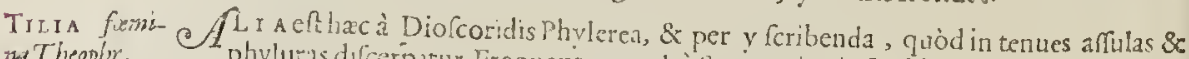

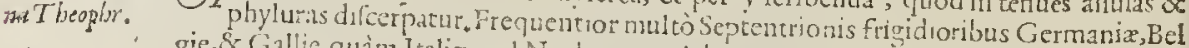
gię, S Galliģ, quàn Italix, vel Nortonx:pulcherrma Bafilex Hcluetion in Diui Petri area, patuls ramis, fparfis, inquevafta magnitudinis ambitum fornicatum propagata, folio hatore, Populnco aut Betule, ferito ambitu Lotiramis iten frondofis, \& Amentis perinitia Corylízur Iuglandis.

TIII a Mas. 1 As altem non perinde effigie tota atque folio dificrt, tamcti evigum fit difcrimen. folin Vlmi fabra rugofave funtilofeulos, non baccas, vai fomina, fert, fed fe-
men \& flures in folliculis Carpini modo.

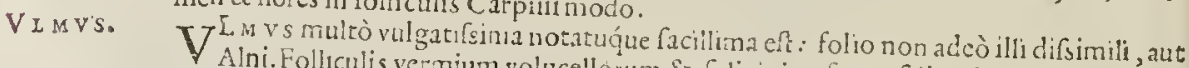
manantibus. Buxi color ligno.

Carpinvs.

O L V N T recentiores hanc effe Carpinum Theophra.tametri Vlma congener fit: fo-
liis quippe infdem, fed follicora fobole feming cur BET VL' ${ }^{\prime}$, ribus Lupuil.

ET Detula perinde pucris nota,vt de virgis infofa, folio Ani aut Fagi: virgis flexilibus, Alwusnigra. reetis, gracilibus, ad copas nectendas idoneis: nucamento Coryl.

Gurmurno. Ful- $V$ D o s falicum natales crepidinéfque riuulorim fequitur hec, ad infectoriam quęita, bumban Colycen fuco.
Thso. Ermingho.

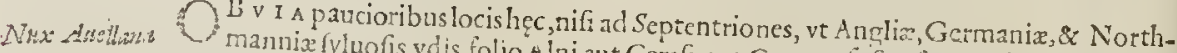

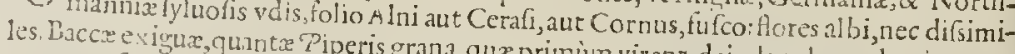
turz atræ funt, infua gui gufu.vir grana, qux primùn vircne, deinde rubent, demum ma-

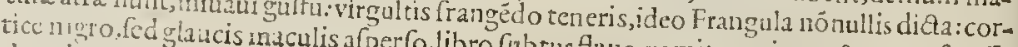
detwotintur. 


\section{Arbormm adverfaria, concu feque recenliones. $\quad 44 \mathrm{I}$}

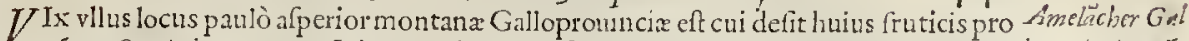

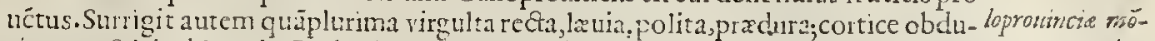
cta nigro, \$2 folijs oblongis, Berberidis, maioribus, frmis, inter qux crebra foetura bacex tana, an eaders rotundx admodum nigrx \& plenx erumpit, magnitudine Myrt 1 , fapore planè melleo, Alifur Gallor h̆s? \& pergrato plebecula, quas ideo vocat Amelächos, quafi mellea. Virgis furrigitur virenti bus \& ramofis, omnium rigideffmis \& duriffmis, quaternos aut quinos cubitos longis: quibus in fcopas vincts, vtuntur ad areas veričdas. Scatent hac loca afpcra prope Duinam Mofterias \& Siftcronem illic rrbeculas. . Corylus perfirmilis', Alino.

$\mathrm{R}$ Amis \& fronde Colurnus fuperiori Alno frmilis admodú fed catulis pendulis hyeme, NVX A tuet-

Vitimoris betulæ quàm Alni:nuces ip fæ piftachijs pares, tü fitur, tum fylucftres:vel lana. pueris efu notifima.

EST fuentorüriguonumíe vtraq; populus affecla, fed nigra frequentior, foilo rotundo, Pop rz y snigra

oblongo, fupernc acuto, initio atrovircnte, hicderacco, in cuits pediculis oblógis racematim harene acinuli, Piperisrotundi ritu. Qux veró alba vocatur, fródibus eft perpetuò tremnlis, fupernè virentibus, fubtus incanis, Tuffilaginis, intcrdin in angulos exeuntibus: Alis, catilos ante foliorum exortum, la tifolio Salici modo edit.

Lybica ex vtraus earü faciè nofcitur, fed magis nigręaffimilatur, rotüdiore, minore, \& $L_{y}$ bica, breniore folio, duriore, albiore, obeufiore, fed crebrò criftato, aut finunto, adluyc magis tic
mulo:vnde Gallis Truth dicta.

CErcis Theoph.ob friliquam

femenć; lentis effigie indi catur perycrufta arbor hac: quxitidem propter riuos aut latiotes margines int rdum \& in cullibus Veronx amœins \& Norbonę, Hetrurię etiā nó pro cul Sienas,quò min'decuit hize ignotam fuifle Senenfi, nam fi nouiffet, qui alioqui folitus eft vel triuiales quardam Conftãti nopoli accerferc, \&r occafioné dicendı parú tempcftitran deplantis arripere, exớ; alijs Có. métarijs in fuos raperc, iftâ fua populatem tacuiffe. Venuftas tranc ilicò oculis commédat \& notam facit. Flos copiofus cófertim pullulatibuss aut nondí exortis folijs, purpureus punicãs, hilaris, Cicercula aut $P$ ifi. Siliqua per Áugufũ maturät, femé Lenris effigie, cópreflum, Geniftáe:ipfá foris Xirāpeli no filiqu $x$ aut fpadicco finl $30-$ re nicât cóprefíx, digito latiores \& longiores, 'quadantenus Senx fd rectx: folio exactè ro tundo, Afari, neruofo \& venofo, Cyclaminis, craffo nitido.

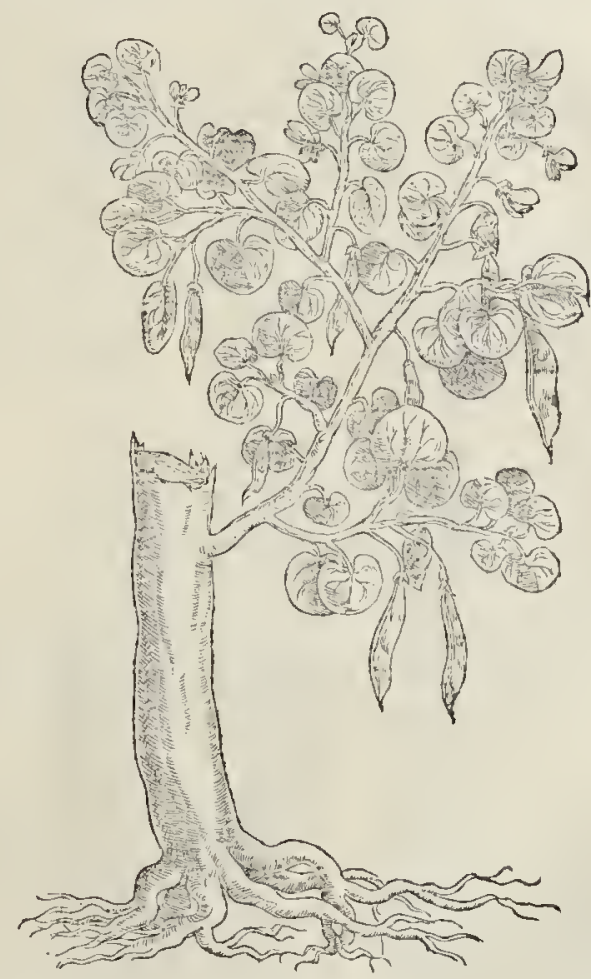

Arbor IVDes: Mowpellienfints fane CERCIS Theoph.

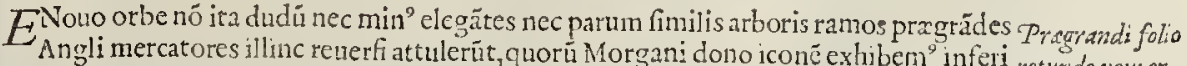

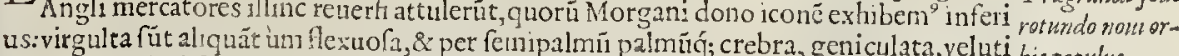
infertione cómiffuraó; partiú nodofa vnde excúr è fingulo pediculo fingula fol ia, ora cx- quifitè rotúda,nec vfíä nifí qua pediculis hęrct, intercifa crafta,rigida, lationa arboris In dę: cui Populialternatim exeñt prẹlögi loruli,ftipati acinulis multis exiguis,planè ropuli 


\subsection{Fruticum, fubfruticum, cremiorumes}

ritu,quare \& hanc Populum Perunianam vocare vifum fuit:gufu perquaun aftringente, aliguātùm calfaciente, fubialfo. A1ORVS ommis I v v a T morun temperies coli moderation, cuiufmodi eft agri Veronenfis, AuinionenSer ici paltonen: vulgatior morts ferotinos floresedit, catulos hirfutos \& folia Alni oblongiora, masora,rotundiora, nigriora, fquabra, lauiter crenata mora, maturefcétia cocci nis contlata prinum acinuls matura cruentats, \& fuaursima in delicijs. A L I A.

Pumille guam $S E$ is enimalbx minora imbecillora funt folia, tenuiora, finuata ambitu, albx popuvocint r. berace- $S_{\mathrm{li}}$, ant Sambuci montane albida fiacida gratiora, fed mora multò infipidiora,candida morum nom: fî nitent, ad naufeam potius guàm alendum nata, caduca fatuè dulcia, tota arbore minore: modo magritu- quam tamen pluris faciunt coloni ad velleris opus. SY COM O R V S.

dine fra totues CX Sxria \& \& \&y to Sycomorumn aut potius Moroficum (vt Celfus diceret)quidam fru rata purte d- Lufrà funt cỏati Italize Hifpanixq; tum Europex, tum Indicx inquilinan facere:nam ne Et:t. Nec esim germinauit quidens: tancef in fy! uis Sy riacis perfaniliaren effe, vel propheta teftatur Chanzaficts, fune Anos, qui fe Opilioné dicebat \& legere foljtu Sycomora illic aut locis vicinis: nec paubumalss Eicus. ci funt lodie qui căden inibi illuc per egrinati viderunt, Amicifg; noftris \& nobis quidä ftudiofiores ambulones Monachi, Veronę \& Bononix ita orationc rap refentabãt, fimili^ orem multo moro quàm Ficui:fronde A poci aut Mori, \& cognitu facillimä de fructu, çui caudici, aut inis ramis propè alas hæret, media inter Ficü \& morum confluttitione \& figu FICVS. ra,p ufillan Ficum xquante, granulorum tamen intus experte,

II Se magno fubfidio fruetus ficus Hifpanix, Italix, \& Gallopronincix, vbi fyluulas verna Le Autumnali foetura biferæ Ficus, perelegantes videas: fronde pragrandi, lacinijs an fractoofis quinquepartito finuata, afperà, glauca Mori albi \& fpondyli : frucu fuauore plentore, recentr, ficco folito, cuiufrodi vbiq; efitantur.

\section{PLAT ANRS PErquàm fumiliuris} lopunefo Platanus, qửinibi raró orıtur, \& vaftan magnitude nem ad vunbracula comparatam adipifcitur:Italize multis in locis colitur, \& fpeciofa vifitur, nec minus annofa Florétix prope pomęria, \& in iube urbio quodã, nó procul monijs vrbis,vbi hofce ramos \& fur. culos defregimus a.l Gufto,cum penè echinimaturuifient:penduli harenthi pediculis fingulis longio. ribus \& breuioribus, non $x q q u a l i b u s$, aut $v-$ no exortu iunctis (vt pingunt qui non viderant) parillitate $v$ uedonis fetè, Bardanx concolores, apicuJis acerofis afperati, Sphrophali in mo. dum, quę funt femina

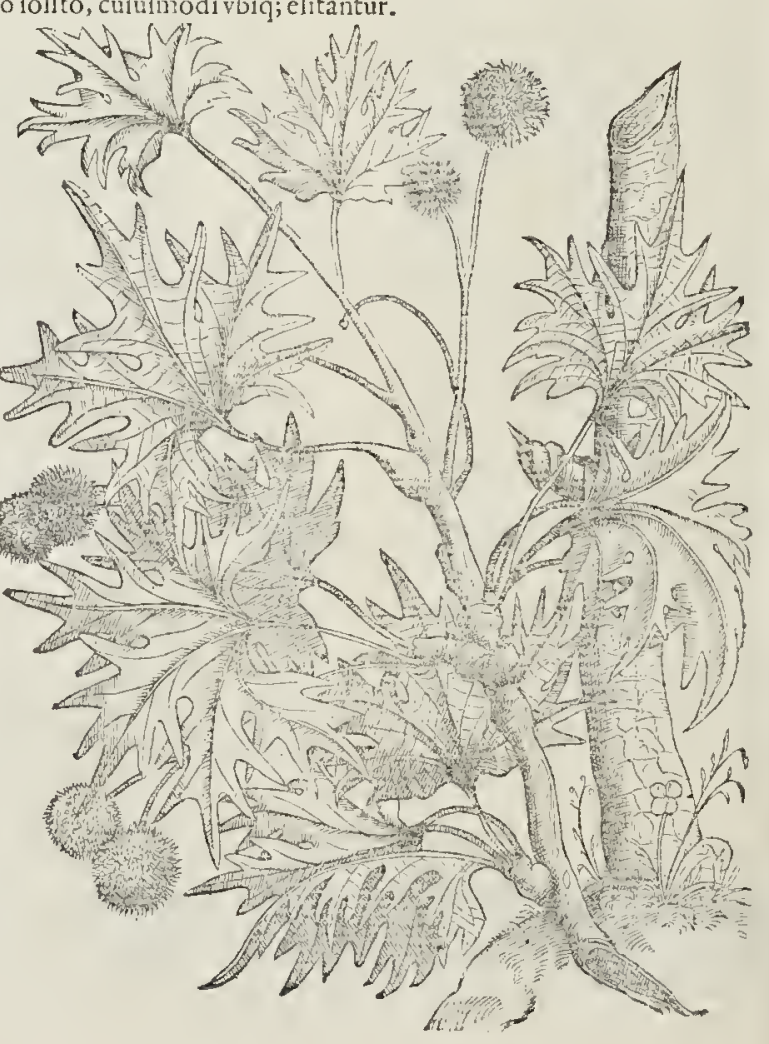




\section{Arbormm aduerfaria, concifanue recenfones. 443} ip $\int_{a}$ fabiofx montanx non difsimulia, tomento leni fubrufo intexta; fronde perquam lata (vnde Platanus dicta) Vitis aut Acerts, fed altionbus finuú durufuris, \& lacinis porrectionibus, destatis: ligno non valde conpafto.

Acognitu facilis Aceris fpecies illa, quam antiqui voca rüt u tâta quippe folı fiusilitudine funt cura Platano, vt $F$ anepifternos $C a r$ danus ille fibi vifas $T$ latanos frequentes in Sco tia literis niảuarit, \& nó nulli prope Oxoniá einde oriri fponte nobis afferuermnt, etiamq́; ofté derint hanc rati effe Platani eft quippe ambitu \&idiuifura Platani aut Sorbi Torminalis vocatęnó tamé adco profun dè aciajanguftus folium eft, nec itá cópleta circi. natione, vt ex ramuli hu- ius cum comuni Aceris intuitu piâura hîc nonet. Folliacea filiqua cópreffa, bipennem expãfam, \& inuerfam, aut Papillionis alas initata, vno :trinque femine donata:mufcofi flores, líteoli, Corni, aut Alarx Darac.

HV i v s congeneres dux funt:vinins folia

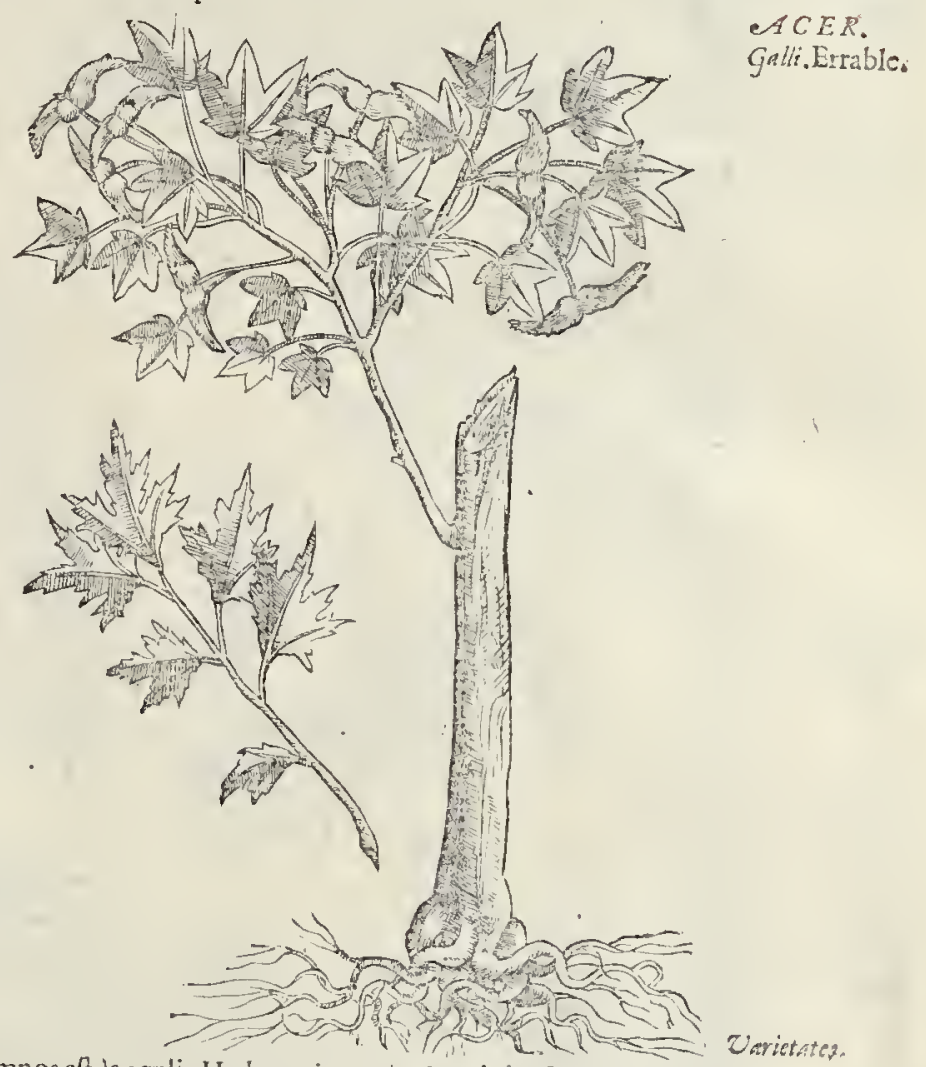

ACER. (qux Theophra. Sphendamnos eft) angulis Hederaceis, ternis \& quinis, finperiorem $x-$ mulantur, fune minora tamen, \& minore folliculo. Hxc vbinis praruptis \& fyluofis freuentior. Infreguentior altera Septentrioni, qua fortè apud Theophra. Zygia fit:tanetfi $\&$ frigidis proficiat, folio \& fuctu ninus laciniofo, minore:fauente intus ligno.

\section{SORBUS TORAINALIS.}

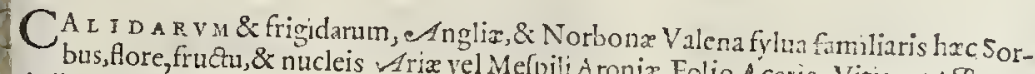
li albx.
lore, fructu, \& nucleis Arix vel Mefpili Aronix. Folio Aceris, Vitis, aut $\mathcal{T}$ opu-

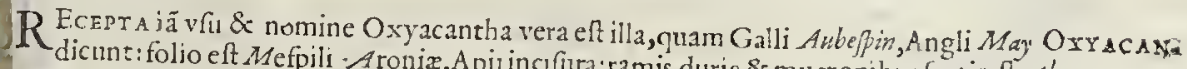

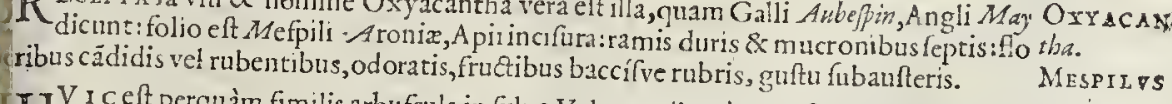

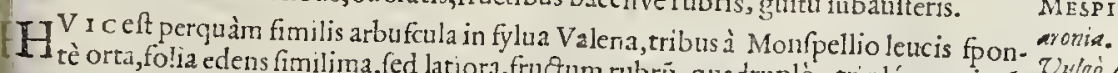

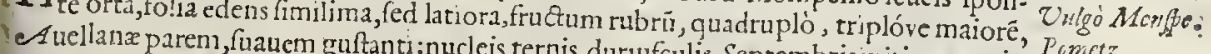
A uellanx parem, fuaucm guftanti:nucleis ternis, durufculis, Septembrisinitio maturis. Pomotz. MO Jta. eAfaides: 


\section{- 444 Fruticum, fubfruticum,cremiorumés}

Mont an a MOntym \& Nemorum amafia Sambucus, fuperioribus perquam finilis, facie, cor: Sambacis racemojos.

tice \& ligno concolor eft, fed fronde minore:flore autem non in vmbella, fed racematim Ligultri in morem ex luteo albicante, racemóque multis acinis congeftos, odoratis, Coccineis \& puniceis, vuã integrā exprimentibus relınquéte, nó infuaues per Augu ftunı efui, vti ceruis, frondes, quas depafci dicuntur auidifsinè, prxfertim dum prægnantes funt fomiux. Frigidi elt temperamenti fomnúmqu conciliare potis, adeóq; veternum, præfertim baccarun efu:qui fi nimius, admodùm noxius prodrtur.

SAM B YCTSMontmaracemara. A R A T CA, Rose.
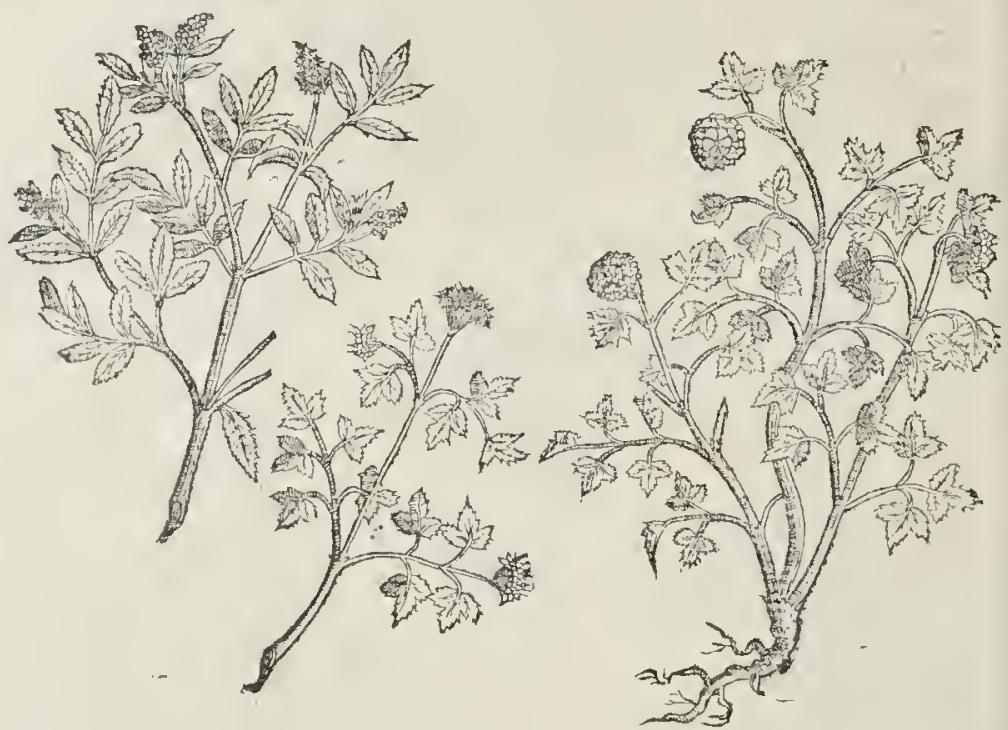

A ov a I c A TInzo fecius \& hec fibi nomé Aetz vindicat, vtpote vmbrofarmm amcenarúmq; riparum, quas rblandè igant aqux, alumna, in Germaniz, Gallie, Anglie, Ital ix, Pedemontiúmque pratenfibus, vdis,conualliúmg; marginibus:verum fronde potius propiúqque Aceri, quàm Ribes nigrræ, vel quàm Säbuco accedit; virgis gracilioribus,gुeniculatis, politis, fraetu facilibus, Sanguinex, frutici fue cornui foemine concoloribus, nec medulla pluri:forum foliolis Thlafpi Candix, latioribus quàm Sambuci, fed effigie \& odorefimilibus, vti \& fenine ruberrmo, compreffo, Viburrı, dictę Aluide Theoph.guntu naufeam faciente: Gallinis \& auibus in cibum cedit.

Ros a A. FLE G A T I O R, hilarior afpectu, \& rarior Rofea SAM B rcys hæc, herbanum fudiofis in hortis alitur:Folio, ftipite, to to habitu aquaticã Sambucum prefert, fore tantìm vifu iucundo,multiplo, glomeratim cógelto, Rofam candidam equante \&x effigiante, di¿c ernitur.

Bryonit folio T $\mathrm{O}$ parum affinitatis Amomo effe cum Cardamomo,præter ipfam nomenclaturâ

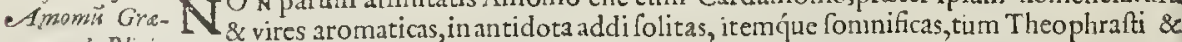
corsem o Plini. Plinii autoritas nos certiores reddunt:vt enim Diofco. pofterior visit Plinius, ita cerAlterü apud Plis tiorem collationem reliquit; vbi inquit; Simile of Amomum Cardamomo nomine, frutice, $f e-$ nirm Purica fo- mine oblongo : metitur eodé modo ơ in Arabia. Dixcrat idem paulò fuperius: A momi vua in lisa var eft, Indica vite Labrus ca, quare quam Labrufcã Indicã vocat híc, videtur cum Amomo Diofcor. folio vitis albx, eadem: qux cum doctos diu exercuiffet, \& eos peregrina planta defecif- 


\section{Crborm aduerfaria, concifeque recenfiones. $\quad$ \$4} wifeciffet, noftram Ribes nigram opinati funt: qux vt vera non fit, faltem nommento Ribes nigraco

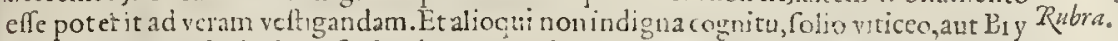
oniæ, virgultis odoris, intcrfindendum vircmibus, nigra veæ modo racetrofa, fofculis herbidis, luteolis:locis fytuofis Alpinis frequens, \& in herts culta, vt Hypris, \&alibi, ,in Oćcidua Flandria.

Eft alıa R:bes longe fimilima folio,facie \& furculis, baccis non nigris, fed rubris, pellucidis, fuauioribus multò, \& notioribus, tum officinisad Rob.de Ribes, tum hortis.

$V$ Erum, \& alterum defcr ibit Amomum Plinius, quafi excribens aliorun fententia, qui Aмом rm apud exıftimau erüt effe fruticem Myrtuofum, Palmi altitudinc: laudabatur quàmmaxinè $P$ li. Pumace folio Punici mali folijs finile, nec rugolis, colore ruffo. Preciti vuæ un hbras $x$. \& $\times 1$. Adulterabatur autem folijs $P$ unicis. Hinc item factum, ve accuratiores expenfores arbitrati fuerint, illum fruticem acini Alkekengi, \& folio Punicæ aut Perficx, qualem in Solonis defcripfimus. Et quàmuis autores confulturo, in promptu erit nofle nos hodie veroǵ; vero Amomo carere: tamen hafce plantas huc adductas efle par fuit,ad veras, quando fefe offer ent,ccrtius dignofcendas.

Vı verò ignaniorem huius vuam ducerent,aliams peregrinam plantã, vt multò Ámo- Piper caud.tur. Q mo aptiorem, adducunt:quxquidem ipfis acinis, aut granulis Pıperis mmoribus, Cubebr rotundionbus,pedicellis extantibus. iṕóq; demun guftu, illam Amomi ruam adumbrat. Sunt tanen ea quol bet Pipere feruidiora, acriora, nec aromatıca. Eóq; $p_{i e-}$ mento del rabo vocäi, Lulitani quorã cómercio ex Indis habemus: ed tam defitü adferri, in Septentrionem, 11e vulgatum Piper vilefceret. 3 etjer met fferiun vocabant Belgx, id eft, caudacum Piper: folia produnturvitis Anguilaræ.

EAdem delineationc perfuafi, non paucis placult Rofa Hiericontea vocata pro Amo- Rofá Hieriootris

mo: quod tamen minimè decuit eos afferere, incertos folorum, iqux neminimas vidiffe, \& creuife Doct. Trcuifano Patauij. Crefcit enim haud ita difficile cx femine recen t1: harent auten feminula complura, racematim vnà ftipata, glumofa, Sorgi ninora:\&r intra fruticis, cancellatim, re ticularimque implexi gloinum contenta . Folia verò non fuccurrunt.

F Am autem qui nouit A momum Diofcoridis \& Plinij, illicò nofcet corundem Carda-Cardañamunì monum, vtpote Amomo fimile nomine, frutice, femme oblongo: \& idem difcet noftrum filiquofum, Cardamomum Officinarü, aut Græcorum non effe, aut defcriptiones prorfus dieprauatas efle: nam Galeni locus adductus de exenterato fiuetu Cardamomi, poteft intelligi de gluntis mundato: nec vllus locus aduerfatur ex-Diofcoride.Neutiquă tamen contemendi fus hafe filiquas putamus: tum quia tacito confenfu, \& preroga- - Millegettra tua vfus receptx füt: \& fortè Arabum funt. Earú qux maxima, Melegetta, aut Millegettra dieta maiufculisà feie crebro. farcto, octhifo in folliculo membranco, Ficū foris effigiâs nomine Grani Paradifi notıfima eft, \& ex Occidua A phrica frequetis allata. E quatuor alijs filiquis, qux inter fe perguàm fimiles funt:ea gux, Officinis, maius Cardamomum vo catur, oblonga triquetra, lapıdi dactyli concolor \& par, Semen condit angulofú, Mille gettæ minus. Triquetra iten filiqua fed breuior eft media vocata, nec difpari fe mine, quä veriùs putant Caidanomum, propter amarorem \& acrimoniam non exiguam. Minima pariter triquetra, fed vix nucleum Pruni æquar. Perclegantem aliambabenus à Morgano quandam, recens allatam ex Indijs Occiduis, pufilla Melegettx penè parem:fed tri plici carna triquctra graciliorem, \& adnodum $X$ yrjdis filiqux accedentem: fed corticofo capillitio obduetan, albidam, intus oppletam femine pari,albido, lncido Melegettxe fed albo,manfu facili, \& guftu multò gratiore, Gingiber prorfum teftante: fubtusetiam, quà filiqua lıxfit feapo,arguit Gingiberis ftipitem: quatc iftas omnes filiquas Cardamomi, effe plantarum confimilium, nec Gingiberi abfinihum, non abs rc quidam peregrinator narrabat.

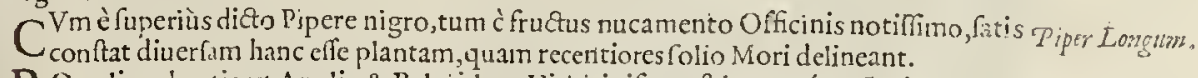

B Orealium hortis, vt Anglix \& Belgij, loco Vitišiviniferx eft hæc:coú; vuã crifpam vocant hebarij, viticea item fronde, aut Ribes, fed incana totis virgis, \& fpinis horridis, Vna crisfa ime Pp.ij. acinuli Vitisprecia, 


\section{4t6 Fruticum, Jubfruticum, cremiorum o}

acinuli c:cbri,finguli, in virgis tamé funt pellucidi, pallidiores, intrò matur i, fubfului, cul tumiliófuluiores \& maiores.

Satiua ROSE
Rubra Prouins.

Olibis delicix, florum princeps \& honos Rofa,Annlix fforętiffmi Sceptri, perinde au-

Candrda.

Pallid.s. fpicatifinu, ac meritiffima teffera, vt itl ciuo regno hunc fruticem, non modò ipfa bru!na virentë, \& nterdum penè perpetuifolıum, fed etiatn mirè feracen, biferum fape, quảdoq; trillorum videas. Triplex eft vulgatiorisè colore differētia:nanı aut purpura fangrinea, fature punicant:vel afpectu niueo micant:aut candore $8:$ rubore confufis, flammeo rutilane, virgineis genis, \& malis concolores, quas plebecula pallidas vocat. Tres $h x$ infigmores fatiux differentix funt, qux, quòd fexcentis ferè lenocinijs, colores, odores, fapores: magnitudinem, numerumq́; folior un, \& vires dernutare queant: \& foleant ficri praptoperę, ferotine, brumales, non funt huius inflituti.

Cinemomer. SYlueltris tamen natiuz funt varictates, \& notatu perquàm dignx:cius prafertim quä borcales cand toofe, fiuc Cinamomeam appellant: hre foliols, funt omnium forum Moficate. inin:ma: Francix, Belgio, Anglix, ruri fponte crebrx,ipfo odore notifimx.

Mofchatx videntur fylueftrem exuife anmum mangonio, \& hortenfes duplę factę:v1 bi fragrätix conendatione coluıtur, condunturớ; \& e efitalttur paflim in Italia, Venetijs prefertim: aluū iucundius, fed vehementius cicnt: : animi deliquia, ftomachi,cordifó; lancinationes accerfunt.

Lutex. PA Ares \& cognatiores illis Luteas, cùm aliàs fape vidimus Argiera Affricx ex Numidia, Cornlas.

2 Gallix inquilinas factas: tum in Anglia confitniles, foler ti manu in Genifta fcaví infitas, vnde colorem, odorem, virefq́ue mutuantur nouas. Elt \& iandiu videre Cartule-

Eiglentine ou as in hortis Italicis. Elglentier. Shatx:fruetum fimilem cateris fert, \& xqualem:tora planta multo odoratior, vulgò Efglentinc. Angla: \& Flandria hortis, ad odoris syratian colitur.

Spongia Bedeguaris.

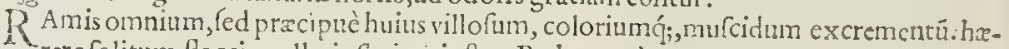
rerefolitum floccis, vellcris Sericei, inftar, Bedcguard vocntur.

Dunen Rofem. F Nter Sylueftres non pottemx venuftacis alia Anglix perquàm familiaris, \& EfglantiPomifera. $\quad \pi x \operatorname{cognatior:~frut~ticat~pumilla,~bicubito~non~altior,~fed~inodora:~fulio~minore,~\& ~pere~}$ Marifira. Baciferi. Batis Rubus moraí, Batt.

$\pi$. leganti: Mefplo Aronix non difpari: pomo donata minore multò, colore vinidiore, rubello fubpuniceo, per Auguftum maturo:flos Rofa fylueftris eft.

SVnt Rofis perinde facie, ve viribus \& nomine affines Rubi Batis ve fint, vbiuis perinde notı\& ıunin, importuna, nocuaç; feracitate: duplicé in eis differentıä fucile percipias: vnus nanç; vulgatifimus, quo mexix vinciütur fxpes:inter dumeta \& luncta nihil ifto frequëtius:virgilta crafla, quadrungula, fentibus infufa promit: fola fpinofa, fertata, ter

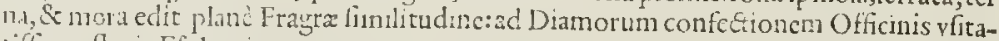
tiffime, floris Efglantina.

Repiens. A Lter libus nulium latere quit, in aruis paffim reftibili, fećue progignente tediuiua fobole granneis feminibus fparfim pulullate, in fatus plurinum triticens:prorfum f mili, fed tantùm miuor reptanfọ; eft minorem minufq; fucculent um maturat fruetum. Vcitem fpeetat Framboyficr, quadi Fragra lıguea ant fyluofa Gallis dicta, \& admodum ribus acinulis conflato, cærula purpura nitentibus: condiuntur mota \&iefitantur,ad vo. luptitcin \& fitim quxfita, afpcetu amcniore. Minus horridus fpinis frutex, foliotcrno, แor: difpari Fragranx, crenato.

Cynofuaton. NEfcio qua fui fiducia nos inuitos nihil fire docere vult doctif.Math. qui iädiu nô no uit, nequadé poftremó monitus agnouit Cynolbaton. Cuius duo frutices, vt nomenclatura, fic effigiaturx ex antiqua deforiptione ${ }^{\prime}$ crfiniles, certos nos faci[t, aut faltem ea

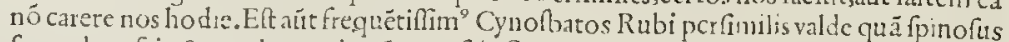
fepe arborcfit, \& amplcxu arborü accrefcir, Пore \& frutıcé Rofæ fylueftris promés : eius baccas cornui aut ceralo pares $\&$ cócolores, intuslanuģine farças, piucti cfitabanus.

$\mathscr{F}$ Vgiter virétis Cupreffi lncus eft perquä amoun \& venuftus propè Burderaiam,alibiCupreffus proxi- q́ue hortis ad Septentrione puichre adolefcit, vt un Anglia, Ranis $\&$ folijs sabina bac me Sabmasred- ciferæ, fed nucula oblongapufilla, fculpta aut rimofa, ouo columbino pari, intus femine dende. comprefio, perpufillo, 


\section{Cibomm aduerfaria, concifeque reconfiones. $\quad 447$}

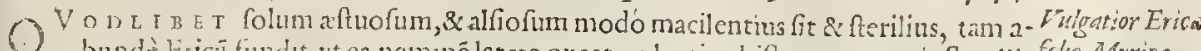

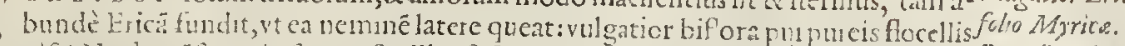

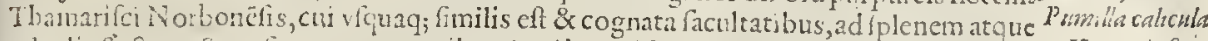
calculi aftectus. Saxolis tamen montibus Anglix occiduæ ad Briftoiam exilior, tota fef- to Varecionisfore yuipalmaris, fed denfior fruticat:flore calyculato, longiore \& Vhę̧onis ferc̀, hilarius pur jurante, nec caterò diuerfa.

Ainor Erica $\checkmark$ Ed quafi gandent aridis \& fqualidis, fpeciofior fruticofior q; cuadit in Romano, Thuf- Imwiperifolia

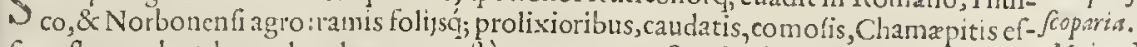
fige, flores edentibus calyculatos, venuitè purpurantes, fimilitudine Vhedonis, apiculis Maior Norbofibrarî. Et hanc, fi, vti nos floridam pedibus triuifet in Italia Mathiolus, neuticuam Fallo noryfrm Chame pio, feu plantam percgrinam acceptam tuliffet.

Non cofdể hax nacta natales, fed fabuleta maritima Veneta:eandê futd dofrores videbãt pytcosfolio.

Mófpellij fecus paribulú Caftri noui humilis reptat humi, \{équipalmais s, fol jis pufilli Coryfonthemis Germanici Thamarifi, Lini pericarpijs aut Cylti:ferninc, fiocellis luteolss, itcm Cyiti aut Ericaminima. Helianthes:quare Cyftum quintum opinatus fuit Dotor \& Praceptor Affatus,

VVlgatiorem prorfun, faciéque Enicæ prioris Norbonenfes. Germanica.

videas, pręcipuè in riguis st maritimis Galloprouincix \& Lio.Venetorum, in Co:onar magntreudinem caudicencíuc abire, c̀ quo ad folenes detornantur pocula.At quam hic Mediterra nex proximam appinximus, ad Rheni ripas in Germania fpóte frutefcit:fed exilior humilioró; multò, nec arbor fit. imó plerumg; in hortis Anglix Brtmà interit. Et fores lunic tomentofi, pappofić; diffluunt vnà cunn femine,maioref̧; funt fere pares \& fimiles vulgaris Lampfane, fed purpures. Norbonenfi autem rainofi exigui flofculi, nec pappofi, fed rotundi Olex, ex albo pu nicantes funt, \& acinulis, quos interdun totum triduum Soli obiectos obferuanimus fubfilicntes \& tripudiantes, vermicello intus orto agitante, \& tripudijantore, qui pertufis aut defilientibus tandé granis,foras prodibat. Sabunbacifera.
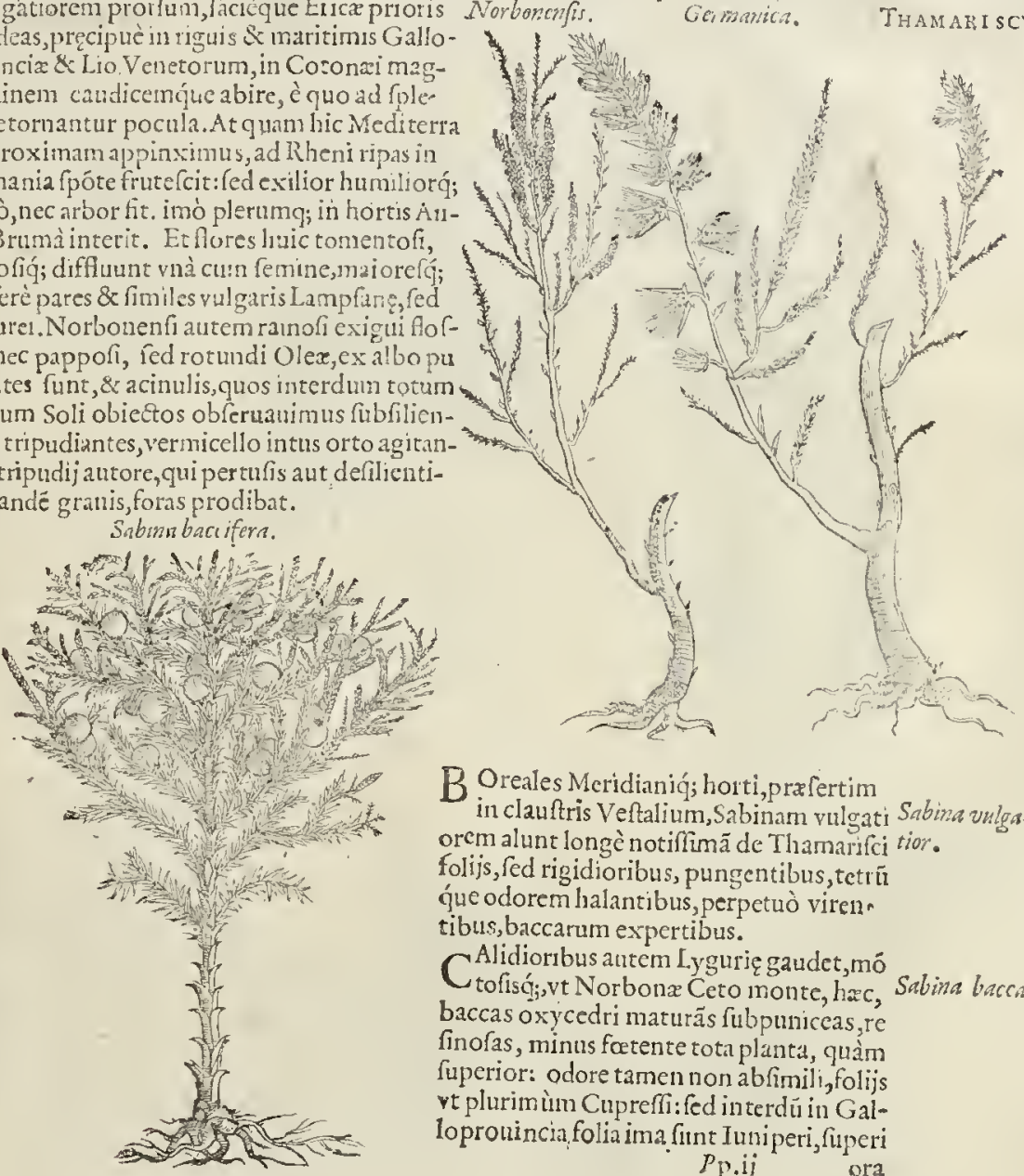

B Oreales Meridianiq́; horti,prafertim in clauftris Veftalium, Sabinam vulgati Sabina vulgaorem alunt longè notifimã de Thamarifi tior. folijs, fed rigidioribus, pungentibus, tetrú que odorem halantibus, perpetuò viren. tibus, baccarum expertibus.

Clidiorrbus antem Lygurię gaudet,mó Ctofisći,vt Norbonæ Ceto monte, håc, Sabina bacentot baccas oxycedri maturäs fubpuniceas, re finofas, minus fæetente tota planta, quàm fuperior: odore tamen non abfimili, folijs vt plurim ùm Cupreffi:fed interdūin Galloprouincia, folia ima fint Iuniperi, fuperi $P$ p.ij ora 


\section{$44^{8} \quad$ Fruticum, Jubfuticum,cremion of \\ ora Cipreffininus afpera ant pungentia.

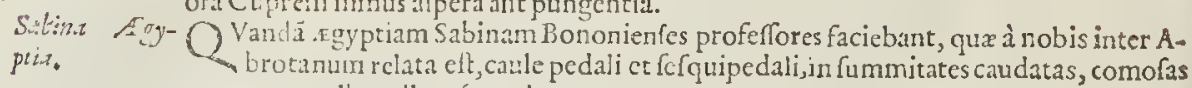 escinte, pullo pallentéve colore.}

Ivniperys GLareolis tum Meridiani, tum Botealis foli fterilis, inter Ericeta, fruticofa fobole femvutyatior, petvirente, fruticat minor:folio \& facie Ericex aut Sabine, fruetu Piperis, grano fubdulci, odoro, yti lignum totum.

OXYARCE - V VIgatifina eft etia in Galloprouncia Iuniperus maior hac, inibi $C_{A D E}$ vocata:folio

OXYARCEV- IUnipcrinomaiore, acuto, Inordaci, pungente bacca triplo maiore, Sabinzer:fmili,

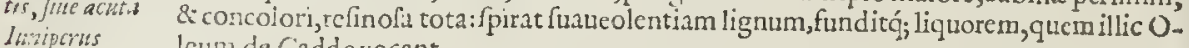
leun de Cadde vocant.

CEDKVS

EX Iftria quafdam habuimus plantas, non difparcs fronde \& figura, fed fruecuserat teres, oblongior, mediocris Oliux par.

PHachice

Eadem Norbouenfi agro vifitur bacca,buxeajtripode, qux quidem non peffimè quadrat Cedro $P$ honicex.

Cecsus Lycir L Ycian Cedrum iamdiu vidimus Lutetix in quibufdam hortis, folio Iuniperi multò ininorc,ad Sabiuam accedente:bacca Phoenicex minor eft. A Lix füt CedriGrx CEDRVS Libanis ó Paleffinaprecelfa,

nonnulla in Citrijs di Ctx: hac antem illis indseta, Palcitinorum in Libano Alpigen, ex facta pagina admo dum celebris \& nota filit : Eiusalitempufilla cuprefí femina, fed coprofiona, in Iigulinis fara, nobis arbufculas tres aut quatuor pepercunt: qua perquàm venufum arboris cómenfum, \& indolem,iam cum per initia praferebant. $\mathcal{P}_{\text {atauj fenen habuj- }}$ mus, vbi induftrius \& gencrofus vir Cortulius ctiam feucrat, \&e colcbat:vtmirum fic tantillum femen alio cceio \& folo, tam celeriter \& eleganter in artufculam fefquipal maremantcubitalem crumpere: hîc pietas c:: conis ${ }^{2}$ icone has plätas crinibomus: ix facilc̀leorchédere fit, nin verè in Wathol.

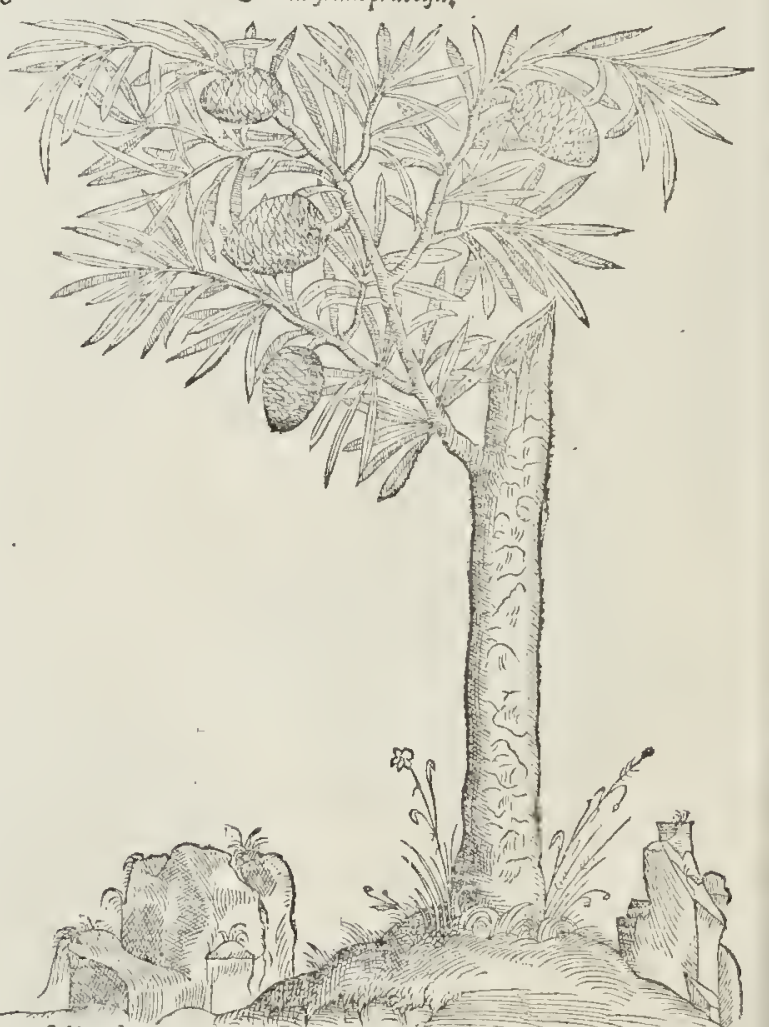
delineatas. Sempervirent folia Abietina:ant Pino breniora: Ligni autem materies \& affuls, hifari funt \& nitido afpeetu, ex Phœniceo purpurätes, non valde durx, odorem rofeum, quàm Sandali frlauiorem aut Cupreffi habentes, prafertim dum pruni adolentur: Gallix Northmanx, Lödini, \&- Belgio, iam valde nota materics: häs fortè innuit Poeta, clim de Circe canit, Vrit odoratam noeturna in Iumina Cedrum.

Eduabus 


\section{Arborum aducrfaria, concifeque reconfones. $\quad 449$}

$F$ D v A B v s quas veluti fummas coniferarum differentias ftatuit Diofcorides, vulgatif- $P$ I N v $S$. fimam Pinum multis hortis cultum in Belgio \& Angla, Italix \& Norbonæ ad aquas Resi N ift 2.5 Marianas f pontè natam in promptu noffe elt: quippe arbor euadit celfa, pragrandis, fo- co confere. liorum prolixioribus longioribufque, qua fonofa, pilis \& cono ampliore, crafsiore, breniore, prefsius Cedrinum conum exprumente : nucles compactis, efculents, item habitioribus, quos oificine vocant Pineas.

TVIvs atutem fylueitrs vidcntur cire plures varietates è conis, foliis, totiúfque magni- Pinus fylucfris

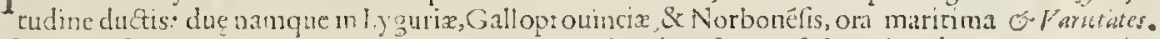
pafsim fvluefcunt:foliorum prxton o lectóg; capillitutiosli perfimiles, fed vna brachiata clt, cui folia manipulatins erumput c̀ medis glabris ranis, zquabili plurimùn exortu,cepaluminftar.

A L T E A perfinilis vndequaque fipite ramorun, foliorum, ex capilata facie, vtriufque earum conus oblongtor, ninor \& anguftior fupernè, quàm Pinex.

E A autem, quam vocant quidam Cembronem, vndique item foliorum comóadenfá́: fobole Riputur,conis obtuliotibus, breuioribus donata, per maturitaté facilè hiulcis.

$S$ V N T adhuc fyueltes dux, qua breuiore foliorum foetura, magis curca ramos reduda, M y G o. prefsius 'jiceampreferunt, aut Abıetem. Quarum qux ampliore cono \& tongiore folıo donatur, Mugo rocatur.

A LTER A exılius viliufque comatur, donaturçue nuce multò ninore, \& ferè Larigna. $Z A R I X$.

LARI cis ne nomen qudim Cręcix olim innotuife certú eft: quippe qua oblectetur frigidiore \& Boreali colo. Ac ta metí Diofco.alicubi huius refinx meminic quafi pergrine \& $\mathrm{cx}$ fubalpinis Gallix \& Germania in Graciá aduehi folitas : tamen arboré minus nouiffe indicio eft Agaricú: cuod ille radicemeffe dicit, \& ex Amenia peti. Iam verò perquàm nota, \& nobilitata triplici excteméto \& prafidio Larix, Manua nempe, Agarico, \& refina Larigna, qux Lagrimo hodie Venetis dicitur \& fillò Septentrion. \& Träfalpinis indicatura Terebiting̨ venŭ mittitur: folia plurima, fed delicatiore pu be frondet, nobis etiam Bruma fatiente \& niuibus Alpes infternente: In Gernanix Alpinis Montes Nicolai \& Allobrogum Sabaudis, per exortr quo fdam ead iu foliz manipulatim \& penicilli in morem promit.

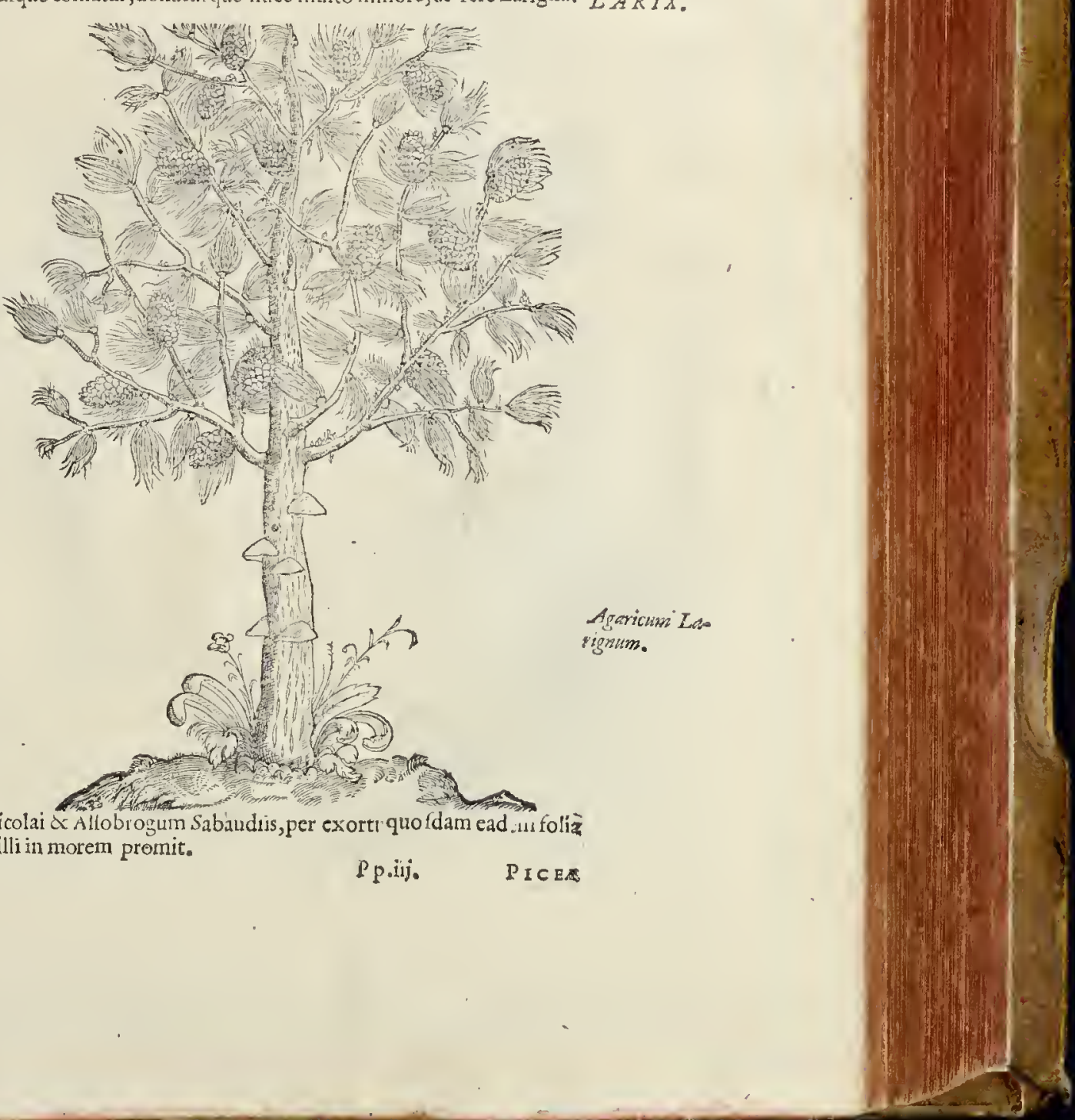


T I CE A, O P P CE a autem \& Abietis vaftifsimanemora tran fmittunf, qui ex Gernania, Triden. eAbies.

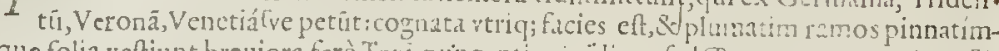
que folia veftunt breuiota ferè Taxi, pungentia, tigidiora; fed $P$ IC E, F, in extremis, rectis Sapin Gall. of flexilibus ramis Coni grandiores, ventrofiorétque, S afpeetu ilucundiore: Abietı anPhoropios tem pręcelfa proccritas, ereeti, ctafíque caudiccs, adúnc naumum malos fuccindi foliti,nó Theo. hec mul modo antiquitus, vt un Nemore Pelio, cuitis execraturabiegras trabes, 'poëta fed hotum thede dat. die ad Aquilonem in Noruegra\& Rufsia. Et huic vni fummis in ramis, E' in coelum ob: uerfi mueronibus funt coni.

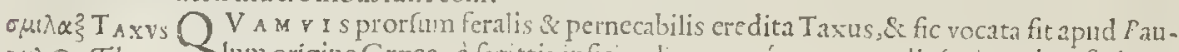
Mh @ Theop. Llum origine Græea, à fagittis inficiendis, venenóque armandis (cuius etiam ftolones curuantur in arcus, ve canit Virgilius) cius tamen baccas rubentes, Coccinas, tetetes, perfimiles \& fubpares Smilacis afperx, vel Afparagi granıs, innoxiè puerulı efitant in Anglia,nofíue guftaumus fub hyem em,non ingrato fapore, fed fatuo, vel anaicante, vbi porci pafsim eas, quafi glandes pafeuntur. Nulli fanè anglixangulo deeft hrc, vbi femperuirente vmbrofa, denfáque ramorum iuba latifsina, fimiliter A bieti, plunatim longis quafi pectinum radiis atrovirentıbus comatur, inq́i; fepuleretis $\&$ areis pro templorun foribus pangitur, ad arcendos Solis aftus à concione, plebéc; , fub tegmine Taxi vin brofx \& annofa conuentus reliziofos agere fepius folita, nullo percepto inde vel tantillo inconmodo.
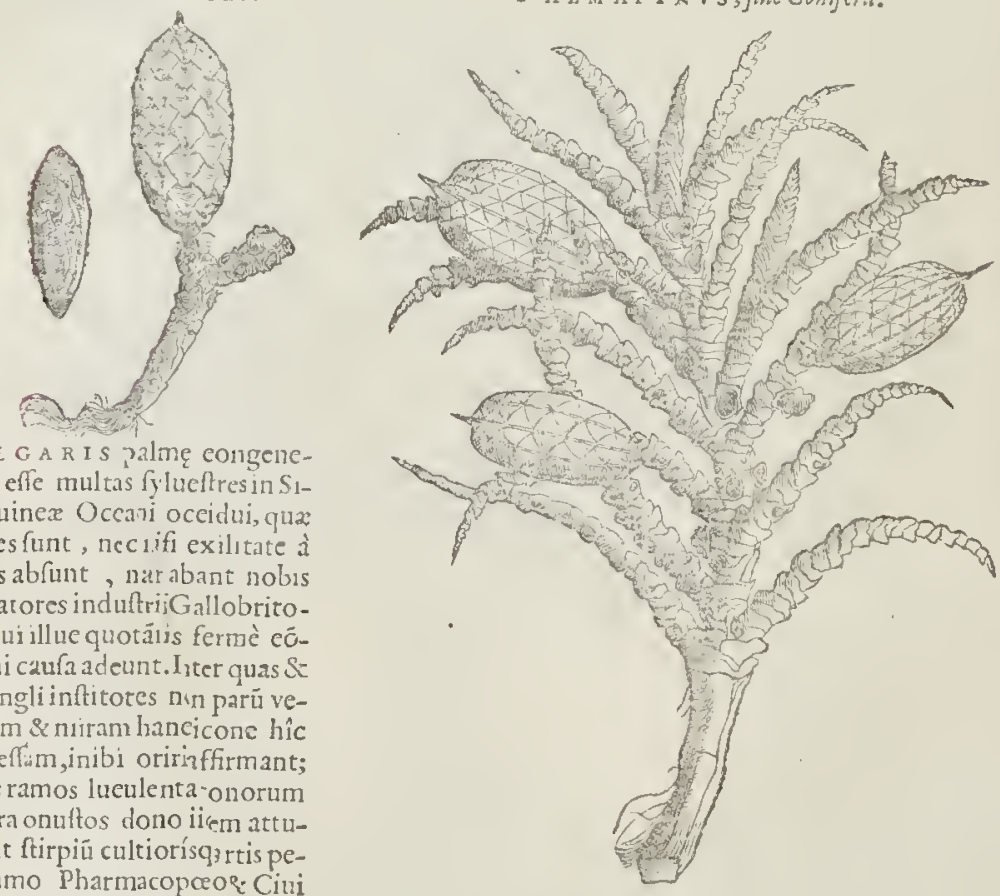

VVIGARIS palmę eongeneres effe multas fylueftresin $S_{1-}$ nu Guinex Occavi occidui, qux Ateriles funt, nec ififi exilitate fatiuis abfunt, natrabant nobis mereatores induftrijGallobritones, qui illue quotäis fermè eômercii caufa adeunt. Ister quas $S$ alii Angli inftitotes nın parū venuftam \& nuiram laneicone hîc expreflum,inibi oririzfirmant; cuius ramos lueulenta-onorum fertura onuftos dono ii rem attulerunt ftirpiü cultiorísqurtis peritifsimo Pharmacopeor Cini Iondinenfi Iohan. Rice, qui nos donauit ifto palmite aut potius Pinopalmę termite:cius arborem, quafi quandatr ex Palma \& Tino hybridam nitura ludibunda videtur confaffe : elt quippe lignum ipfum fungola Palnz prorfum textur in villos tota dehifcens, \& fquamofa cute loricatum, faftigiato ter- 


\section{Arbomm aduerfaria, coneifenue recenfiones. $4 \%$}

mitis numerofis, \& in orbem exnrtis furculofis ligulis guadinginta, aut quinquagntas compuetili vertibulorun \& fquamarum ferie pyidatim articulatis, pedewiongts, totundis, parun comprefsis. Quarun fingulis comifuris, finevili, nlimerofi conialtus inferuntur triccni, ant quadrageni, qu mediocrem conum Cedri enentiuntur, pulullis in quinquücem digetts, reticulatog; \& imbricatin exruberäte vétriofo ntcés corticc, fisfeo,nitido, polito, crafsitic \& concretione nucs Indicę: intus nucle un glandámve oblongam, fefquiunciun aut duas vnc as longam, praduro, ,nque furinann agtè fratili, guftu

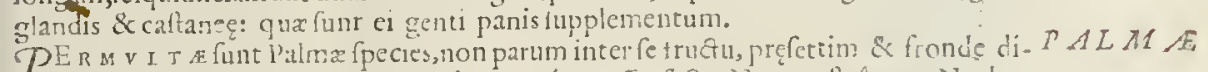

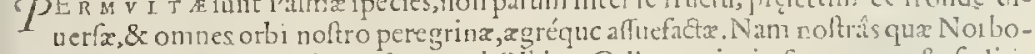
nx \& Lyguriç martinais, \& prafertım ad Olbiam Galloprouincix frequenter \& f foliciter enata vifitur, fructum non maturat; eóque potius voluptatis, guàm vtilitatis caufsalitur.Seruntur auté non in iucundo fpectaculo \&̈ Naturx oftento Dactylorí tria ofsicula,vnáque iunfa panguntur: tres inde oriuntur exiles ftipites, fed in vnum conflati: foliorum tamen pufillorum \& harundinaccorum trina pullulatione diflincti, cuiufin odi in Francia, ctímque in Anglia fucile proueniunt: adulrx, funt fouamatim imbricatínve teqo caudice, craffo, harundinacea cultrata fronde XYphis, vnde Spatlı̨ vocuntur, quas, vt \& hores, ¿ix fructus \& ramos è cacumine fece è proment.

CH A M XER I D H Es, fiue reptatrices \& humiles apud Theophratum palmule, notisi-

mafunt Hifpaniæ, Galloprouincia, \& Italia maritumis, tum al fopartum *um quxfitx, tum ob encephalum illud, fiuc cerebelium gulx blandmentun, antiçuis inptinis

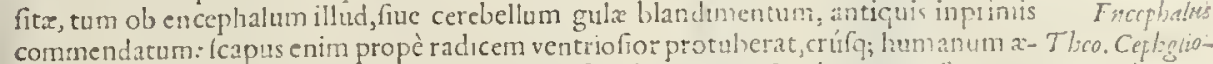
quat, fiftulofus claudit hanc medullatn, qualen efitauirus fuaui Cardionum enftu: tota ni ltalcè. minor cft, fohis anguftiorbus, baccis al terius $P$ almx crebriorbus, numoribus.

HV c etiarn Mufareddenda eft, qua ex Orientali in Occiduas Indicas infulas,ad sóque Cmophorens

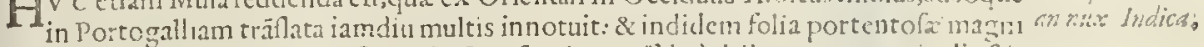

tudinis nos hahuimus: eius effigies, fruetus, forćfque afïabrè delincara extant in ditî́simis Commentaris famigeratifsimi Mathioli.

IN T F n Talmas prętantia obtınet palmä \& Camam Nucis Indicę arbor, Caiecutiis In . NHx: Indice. $\mathrm{d} x$ fabuletis maritums vaftifsina \& vtilfsima : foliis vulgaris Palna maioribus : fore Glandis aut Ilacis fruetu, quem nucem vocat \& Auicenna, qualem pafsim pro foribus Officinarum videmus luculenta Melonis magnitudinis Scrunt Func \& tranfinoucut indiger $x$, quò lixtiores excant arbores: funt hx laxiore molliorreque ligno.

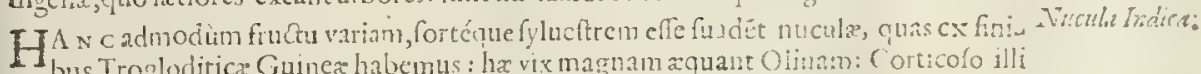
bus Trogloditica Guinex habemus : hx vix magnama aquant Olinam: Corticolo illi

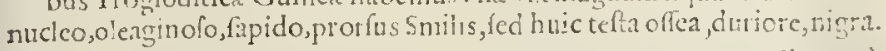

NO v I a t e \& vilitite vifenda altera ex rei argunento f'atmalimum à nobis voca-

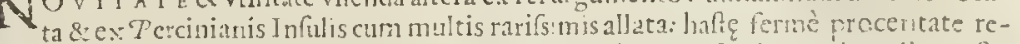
eta edit virgulta, digitum \& polficem craffa, altera fui partc fenirotunda, polita,coft $x$ pralongre cffigic:anterius gcmino fulco profundo guàtm longa cfl veluti carinata, in quas cauas ftrias fece induunt \& ftipant multa denfa fol 1 a, quadaintcrus $f$ alnca, aut arundinacea, fed anguftiora, \& in villos canabini-corticisplane fimiles, perçuàm renaces \& f f:- A C A T I . ronibus torquendis aptifsimos diuulfa, ra pcy cxottus fumniotenus in finu friatum velant grata plants.

\& occulüt penitus iuncellos complures Sparteos, Elphix pares:prateıquàn in fummo, vbi comatur fcapus, fparfa fobole in thyrfielegantis effigiem.

T $V_{\text {g }}$ i r etiam permultarum arborum \& fruticum percorinat un alionot defcriptio, Hafue fub fincm

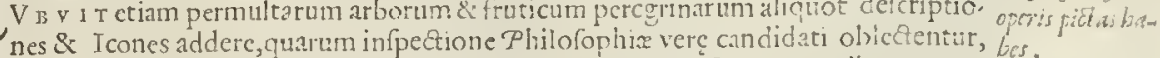
\& quafi fpecimine vel verbis, vel literis indicare plătas nauclcris \& mercatoribus queant certius confequi. Quxdã earum Acatix congener eft folis \& fpinis: furculi tortsles, Inis. bę cócoloribusitem per crcbra interualla geminis aculeıs donätur, cornua Lımacis cxerza rcferentibus, interóue cirri exiles foliola Acatiæ prime pofitu \& fimnitudine gernnt. S r \& alia, qux non foliolis difsimilıs, in viminibus fefquipedalibus, fpinulis aduncis Edonatur concoloribus vuz crifpx; fed exilioribus.

$$
\text { Pp.iii. } \quad \Lambda \& B O
$$




\section{Fruticum, Jubfruticum, cremionumes}

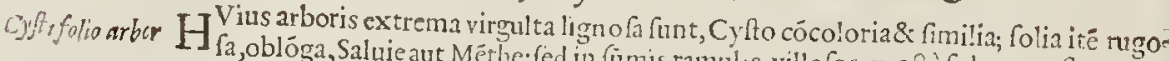
ftentant, fiue lanofa capitula $P$ latani.

P A M A E A, aut Anundinucea pinnata Spinofa.

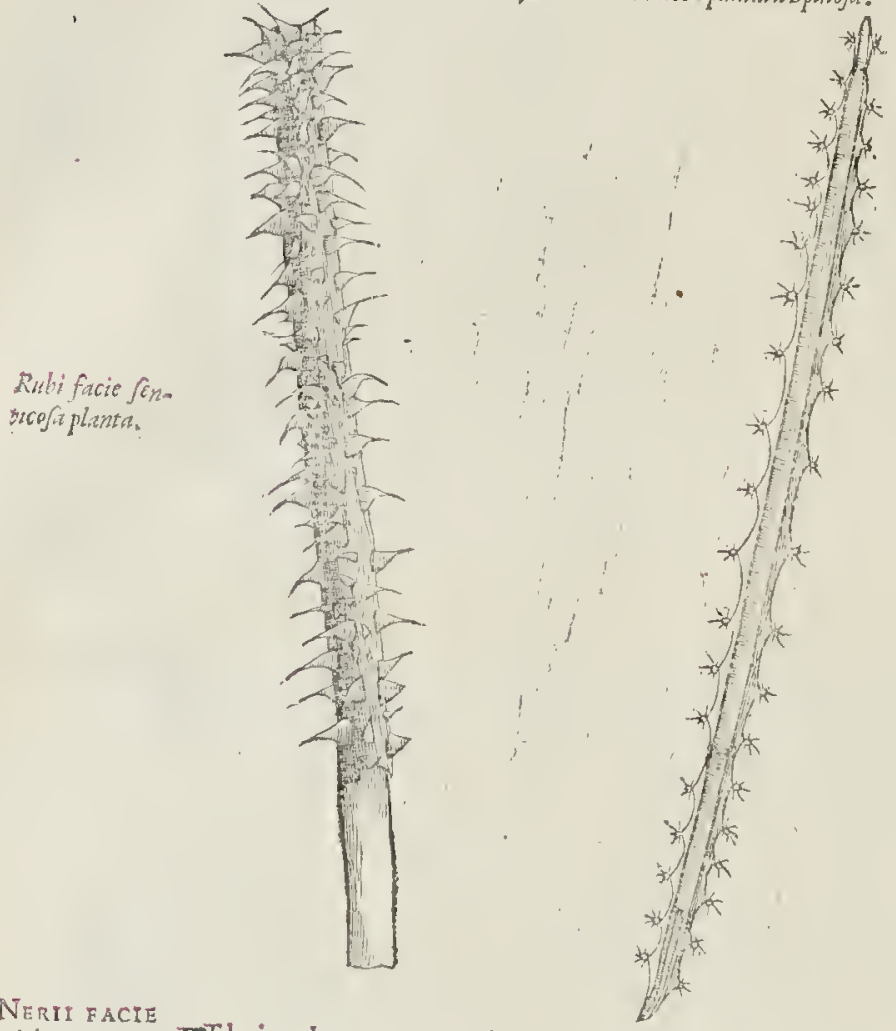

SVNT huits plante ind dematueqi ramifuliofi, ilis affines, nec minus intuenti effigie poretrina : quippe Săbricini, aut fertu. lacei funt, fiftulofi, \& medullx pleni, reeti, rotundi, octonimr aut denûm cubitorum:ed per longitudnem triplici cartilagine, dizitú lata, pinnati, aut alati, inftar teli: \& oris extremis modice fimbriis finuatc fint cart:lagines,ftellulsfó, , pino fis omate, folertis opificis lapičti ia arguêtes. $A_{\text {TE I I sillic na }}$ txaboris truncum aut bacillú híc prosimè exprimendum curauimus, gualé vnà accepimus. Quod carpi crifsitie elt, longan haft ā æquās, \& cortice nigro, défo veftitur:tuber culis cralsis, fenticofis, creberrimis, in clate modum muricato, 50 lido, \& graui, præduro ligno.

Arbor

$E$ Thuius plantę operxprecium eft intueri paucis hafenus notas filiquas, tercuàm puldofrs, fefouipalmum \& e ramis \& furculis Sübrici paluftris, medullofis,p.llidis, pullis, nofingulis oracilem I a pedem longis vaginis, cutaccis, vno cohęefu feptenis aut nouzenis, fis, adeo exunium Lerpetrẩ effigiantibis : intus farciñtur pelliculis cepaceis \& tonrétoucntibus, vt pueris hortori ementientibus, \& quiddam cadaueruli anguini fmile intol-

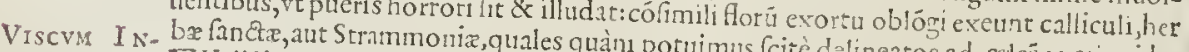
dscun $\quad$ EX iifdem plagis accepimus hanc, EX iifdem plagis accepimus hanc, nufpiam nifi in ranis \& truncis arborum enz fci folitam, ritu Vifci, quod, quia unultim adübrat, Indicū Vifcü vocautimus: fésili, fed tranfuerfim excurrëte eft radicis cefpite; gramineis geniculis \& Polypodii quadätenus; fed albicintubus: culmis item ev pallido virentibus, à medio luminotenıs crafsioribus, fungofis, ftriatis, ferquipedem longis in quibus folia femper virencia Vifci efficie, fed duplò malora, cralsion, fungofiora, \& fecund um neruum, tnedium folium intercurrentem, circulis vtrinque fenis, non parum admirationis monentibus, veluti fcalpro impreffa. Fi-
den colo \& natalibus gem coelo \& natalibus ramorum arborum, Indicarum debemus hanc, vnde auulferunt, dicata: vnde proximè furrunt fotiore, felsilis caudicibus iacumbit, fibrillis cepaceis ra- 


\section{Arbortm aduerfaria, concifeque recenfiones.}

hata, nunerofa,quadätenus f́loes aut $S c y l l x$ : \& fupernè in ligulas pratenues, mucronatas definentia: purpureum, ftriatum, concautum, alis donatum Scapum Haftulx Regia aut Aloes duorum \& trium cubitornm ambientia, qux multis glumofis filiquulis f́picátur,Auenæ fitu:magnitudinc verò, \& fericco tonento candido, Apocinum vcl Afclepiadem reprefentant, \& femine, fed Conifre exili, guftu falfo, ingrato, nitrofo: fortè, quiain aura martima adoleuit, vt Aloes illic in Sabuletis.

Coniecerunt iidem Naucleri in eafdem fportulas, furculos effraftos arboris, Alno quidem fimilis, fronde \& ligno: fed tamé diuerfos, racemofo, mufcofo flore, glomerulos cōflante:fortè duntaxat coelo \& agro variat.

Scd hxc, tanctf Petafitidem adumbtet, ortu \& ambitu exactè circinato, vegrädis folij Petafites galerum fere $x$ quätis:eft nihiloninus cefpite radicis implexo, multa fobole lateratim re-- Fndica. pulluläte, \& caules fun dēte aut potius folıotū pediculos bicubitales, culmofos, medullofos, fingulis fingulo folio hærente:nec anfraetuofum, lunatum finum, pcdiculus fulcit, vti in Bardana. Fungofo, ftrumofo cefpite, cariofo: \& fupernè denfê, circum caules vti Meum, comante, maxiuam Ofinundam æquante, lorulis viniuzeis, fubtus late fufis, guftu ficco aftringente, auul fam hanc ex annofu arbore, ni fallat memoria,diccbant.

HV I vs penè portentofa elegantia, Natura Genius omnem prousocauit an noltratibus plâtis admiratıoné: nam mirabilitatis opplet frectantis animum \& oculos, huins ra riffimx venultatis plantx fpeEtaculum. Eam plebccula effigiei arguinento, Cereuin vernaculè vocauit : hafas entm furrigit quaternas \& quinas; noucmdecin \& vicenûm clubitorum, virgatis \& ad normä directis ftrijs, canulatas: in externis catantibus ftriarum angulis obsulis exermatur ftellul $x$, corricis Ptilis raciatim è fuo centro quoçuouerfum minacibus,vno dintaxat prominulo horfum, eq̣ue durecto longiùs: tota quandam elfigiaturam, \& concolorcm fuperficiem Echinomelocast profert, fed brachium æquabili duâtı xouãte: Columcliæ, aut Ccrei Funalis prelongi inftar. Eius èmedio \& ftriàu dorfis,

CEREXYS. anfatim, anguftiore ceruice, chcumetis ventre, furriguntur brachia terna, quali folia teretia craflis, eundé cómenfun proportionis \& figuram fortita. Intus torulus ligneus, prædu rus, carpi crafitie, obduetus eft, callofa carne, \& fucco Aloes: gummeo enim turget,perquàm antaro lentore:flores in faftigio fummo promit, referête qui attulit, Digitalis purpurex: fruetns hilari purpura miniata rubet, ficus ferè effigie, guftu non infipido.

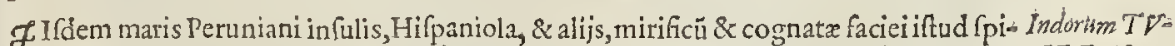
Tolum foliü, ruri, ac fponte, abundè arborefcit perbella foliorú annuorü fuccretione, $N E$ Ficifera \& connexu:fed inde permultis in locis Hifpanix Gallię \& I talię fatum, fores nec fructus 


\section{Arborum aduerfaria, concifeque recen/iones. $\quad 455$}

ola oblonga concaua pufillum cochlear vel aurifcalpium imitata hirfutie purpurea plabêt:ambitu crenata, lubter verò glabra \& polita, rorulētis guttulis afperfa viticofis cauliculis ternos quatuorúe digitos longis, rubellis \& inflexis, albidos fofculos gerétibus: \& rotunda feia in glumis pericarpio Anagalidis quadãtenus fimilia claudüt: totuıs acris guftus, fubatringens,nonnihil acidus \& acerbus, admodum exficcans. Ad falfr pituitx decubitus in pulmones (quorum vlcera 22 tabem fanat) nulli fecüda:tufa vnà cum falis nigri grumis cutê rumpir admota. Fuluus aureufq limpidus ros, qui detillatur ex folijs \&eflofculis, bibiturad eadem.

Fijcuss Indicuses fuperius pag. 452.

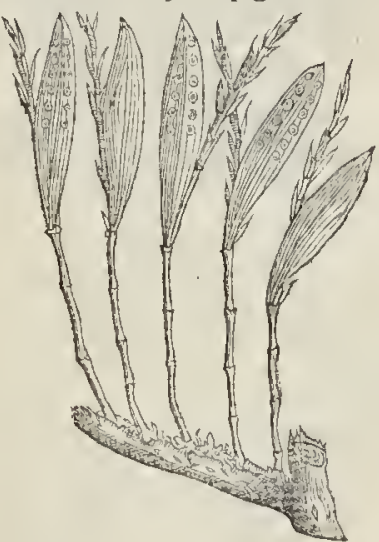

POPVLVS nowiorbis.

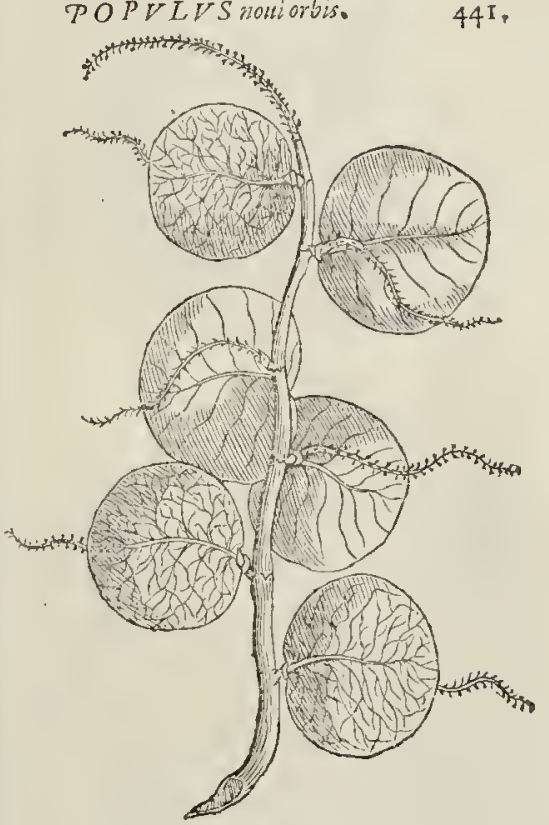

Perunima allia Aloesfacie artoribus item imajiens pag.eaderm.

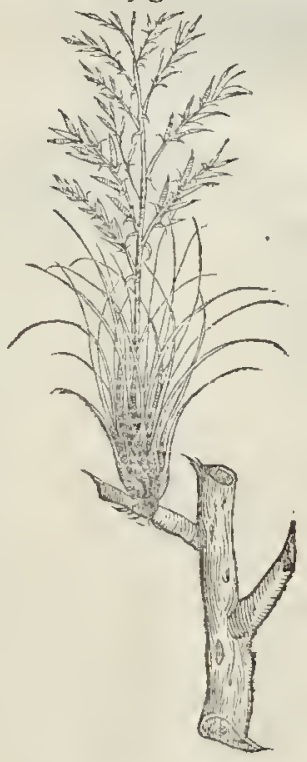

NVCVL A Indica. Peg. $45 I_{i}$

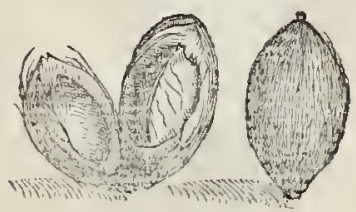



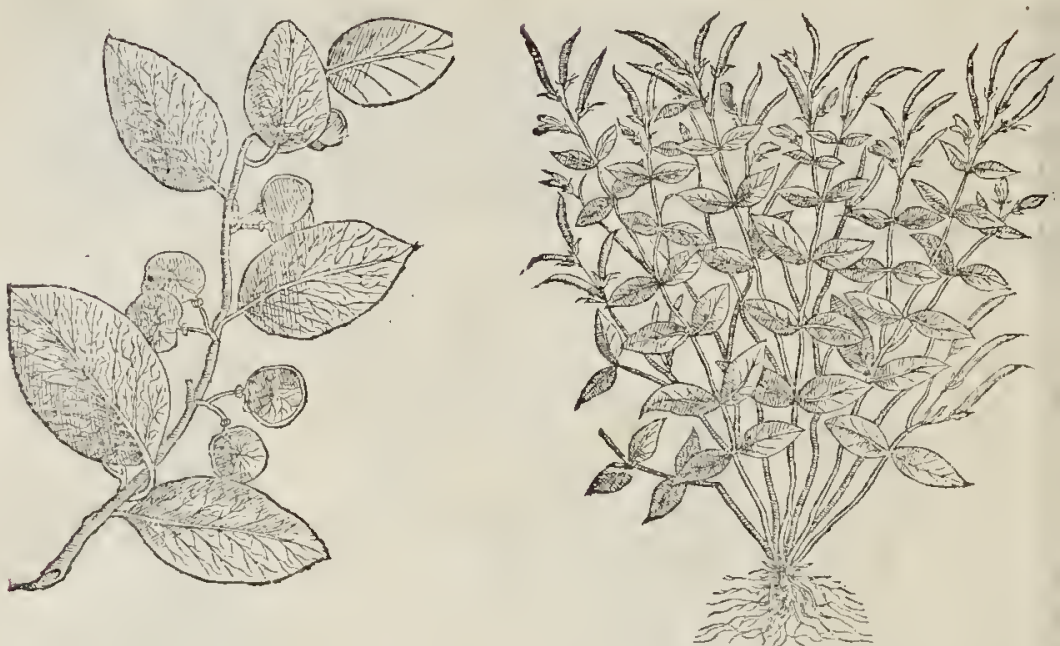

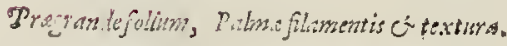
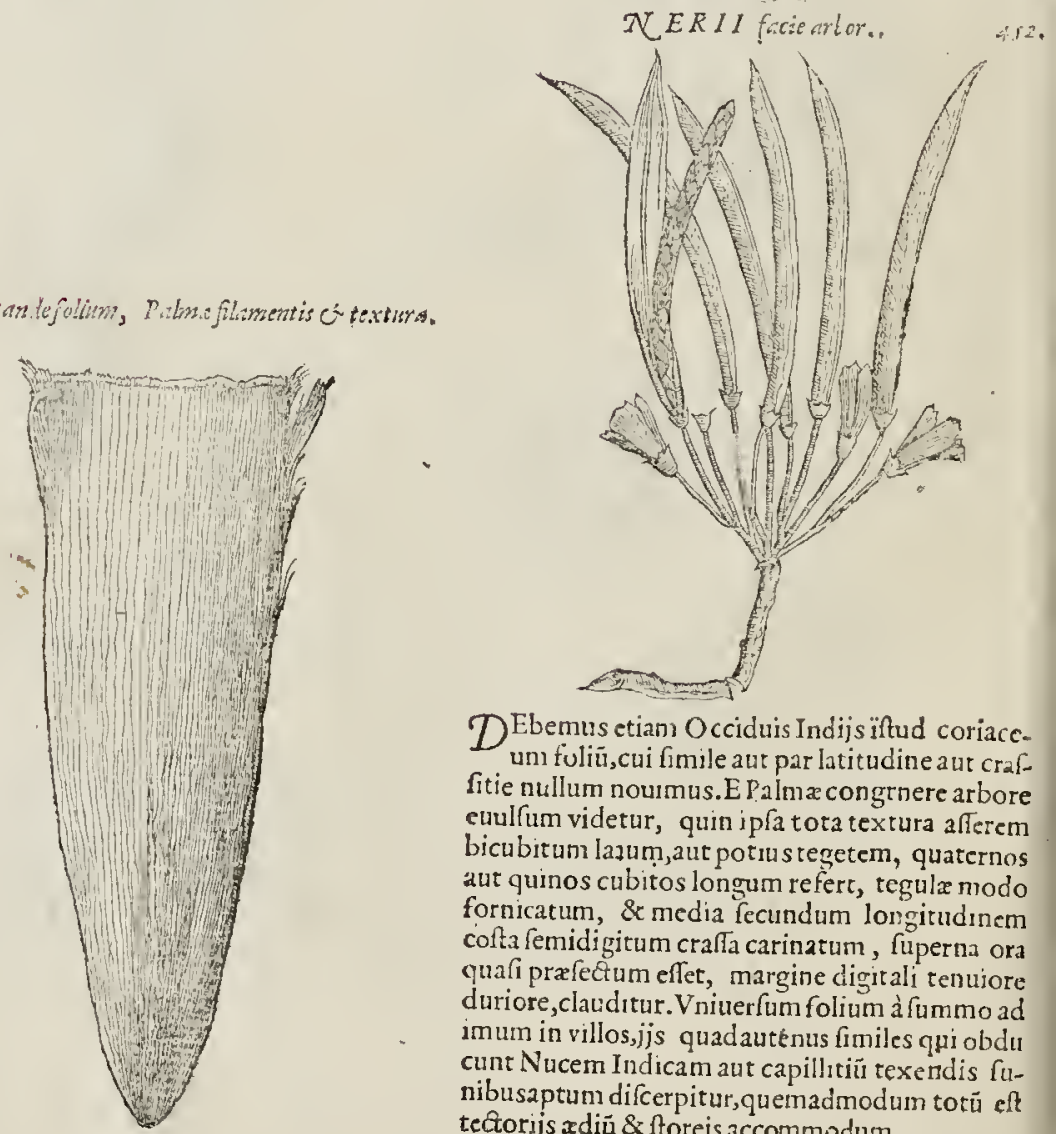

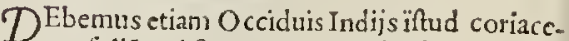
un fuliū,cui fmile aut par latitudine aut craffitie nullum noumus.EPalm a congtnere arbore euulfum videtur, quin ipfa tota textura afterem bicubitum lazum, aut potius tegetem, quaternos aut quinos cubitos longum refert, tegulx nodo fornicatum, \& media fecundum longitudnem cofta femidigitum cralta carinatum, fuperna ora quafi prafectum effer, margine digitali tenuiore duriore, clacditur. Vniuerfum folium à fummoad imum in villos,jjs quadautenus fimiles qui obdu cunt Nucem Indicam aut capillutiü texendis funibusaptum difcerpitur,quemadmodum totú eft tectorijs $x$ diū \& ftoreis accommodum. 


\section{$A \quad P \quad P \quad E \quad N \quad D \quad I X$, \\ NONNVLLARVM STIRPIVM \\ PARTIM OPERARVM, PARTIM noltra properantia in Obferuationibus noltris pratermifarum.}

Cui polthac in ftudioforum gratiam, fumptuum vitandorum caufa, quxcumque comparare porerimus, fubnectere confilium eft.

\section{A D I E C TOR E M.}

Abfolutis noftris Stirpium Obferuationibus, in fudioforum reiherbarix vtilitatem \& voluptatem, nonnullarum plantarum defcripriones aut i cones fuis locis omiffarum, ad calcem Aduerfariorum noftrorü, tanquam in commodiorem locum, quia tumultuariè fine ordine congeftx funt, annectere lubuit, vt fuo loco reponi, aut fuo generi tanquam fub vexillo aggregariqueant; quando nullis noftris peregrinationibus, fedulitate ac pertinasi diligencia vnquam prxeltari potuit, vt vno codemá; tempore tanra iconum copia c̀ viu is natura typis delinearentur \& fculperentur. Earum enim quamplurimarum femina autfores etiam per diuerfas $x$ fates nancifci operofum fuit. Quare omnes rogatos velim qui in hoc ftudium incumbunt, yt fi quid präte: has nouatú plantarum, aut quidpiá aliud nouo Narur $x$ foru exortum reperiant, in has Planriniani horti arcolas liberalicer cóferanr; cùm omnes homines adnici debeant ve rempublicam literariam pro fui ingeniifacultate \& viribus iuuent \& exornét, necinterim fuiingenij gloria cos fraudatum iri fibi perfuadeant; quippe cùm nobis femper suerit propofitum, ijs qui aliquid nobifcum communicant beneficium agnofcere, laborifq; prxmium impertiri. 
$I R$ Is foreceruleo, nb folervimereoue polyfiora. reddenda olfermiti.pag.s2.

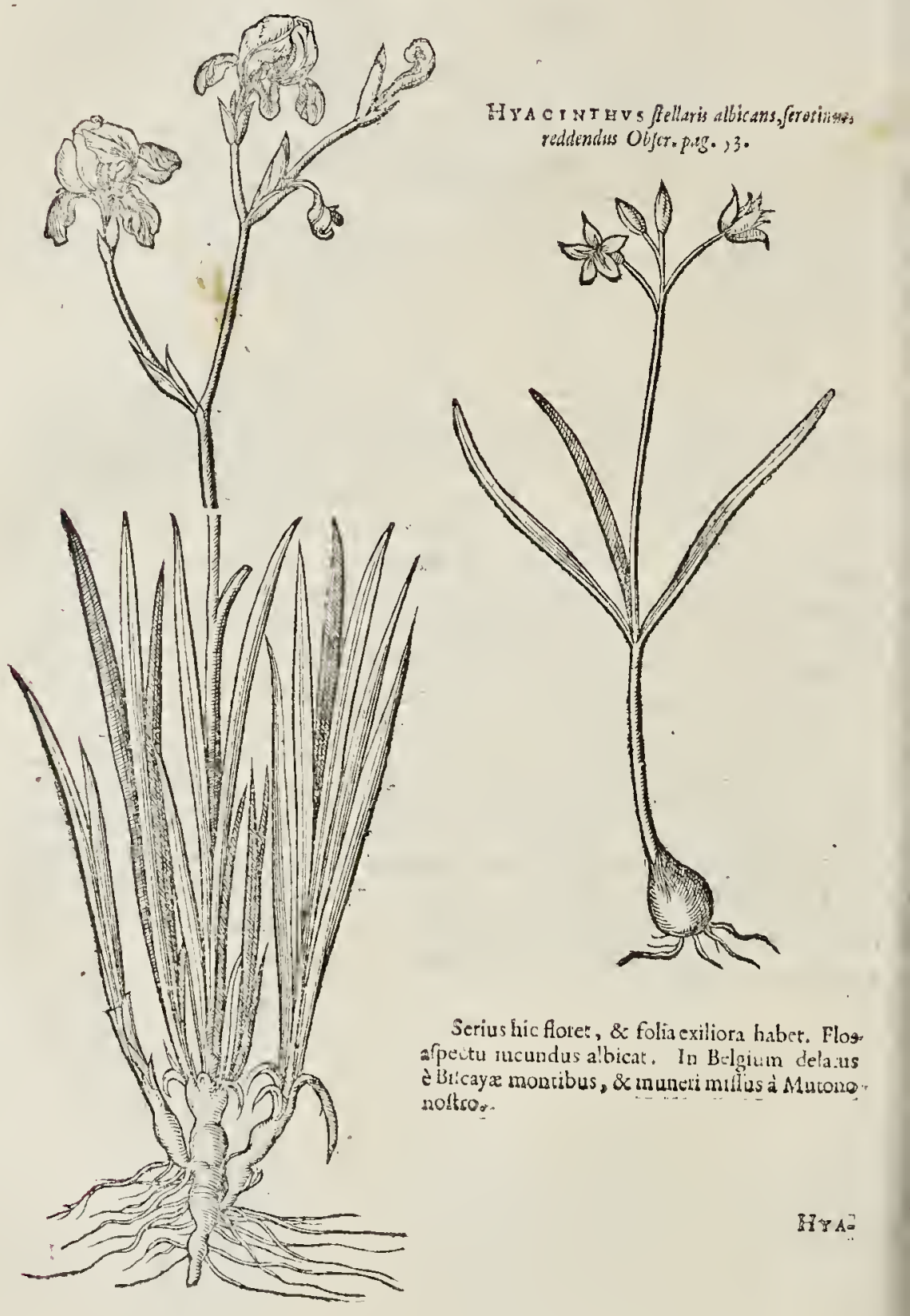


HY A C I T TH Mutoni, red.pag. Aducr 4.48 . obferu. s;.
L I I I C E V S Hycinthu: fiueftellaris Hyacinthe Liriopbyllus, cum raduce, folys of feminc.
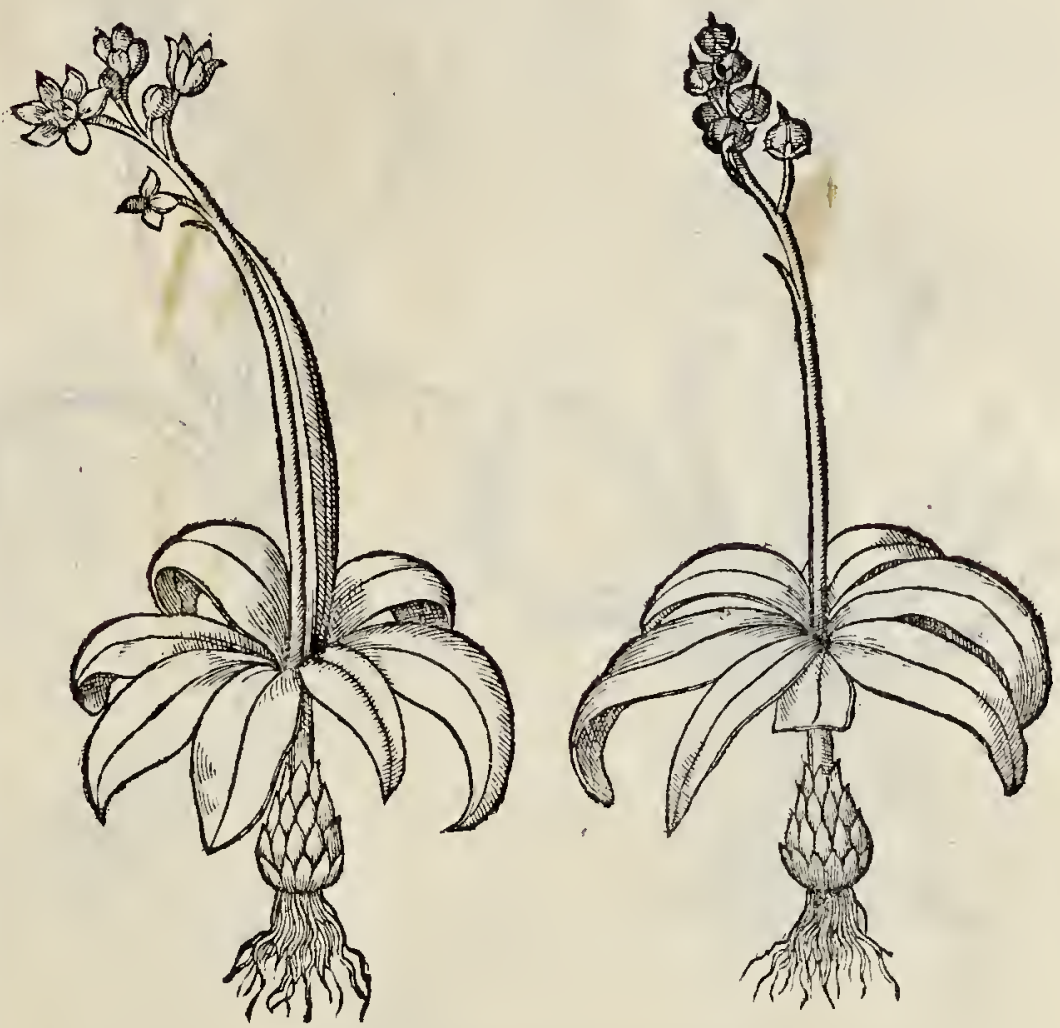

E Bifcayx montibus Mutnno itidé afportatus \& ab co mihi liberalifimè cőmunicatıs hic admodü rarus \& perelegans Hyacinthus, quem appoficè Liliaceum quis dixetit. Radices enim bulbolilij eft, frd minore \& oblongiore, flatefcente; vr Lilij cruenti, fue Martagonis. Folia Lilio candido fimillima tena aut feptena, inter qux medius exilitnudus fine folijs fpithameus caulis, in cuius fummo flures Hyacarthi Itellaris carulopurpurei.

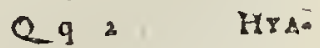


460

HY A C INT TES Grumulis, Oriantalit albus.

Obfert. 54. Feddinder.
$A>I D I x$ :

HY obferuationum. pag. 55. 56.

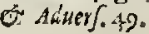
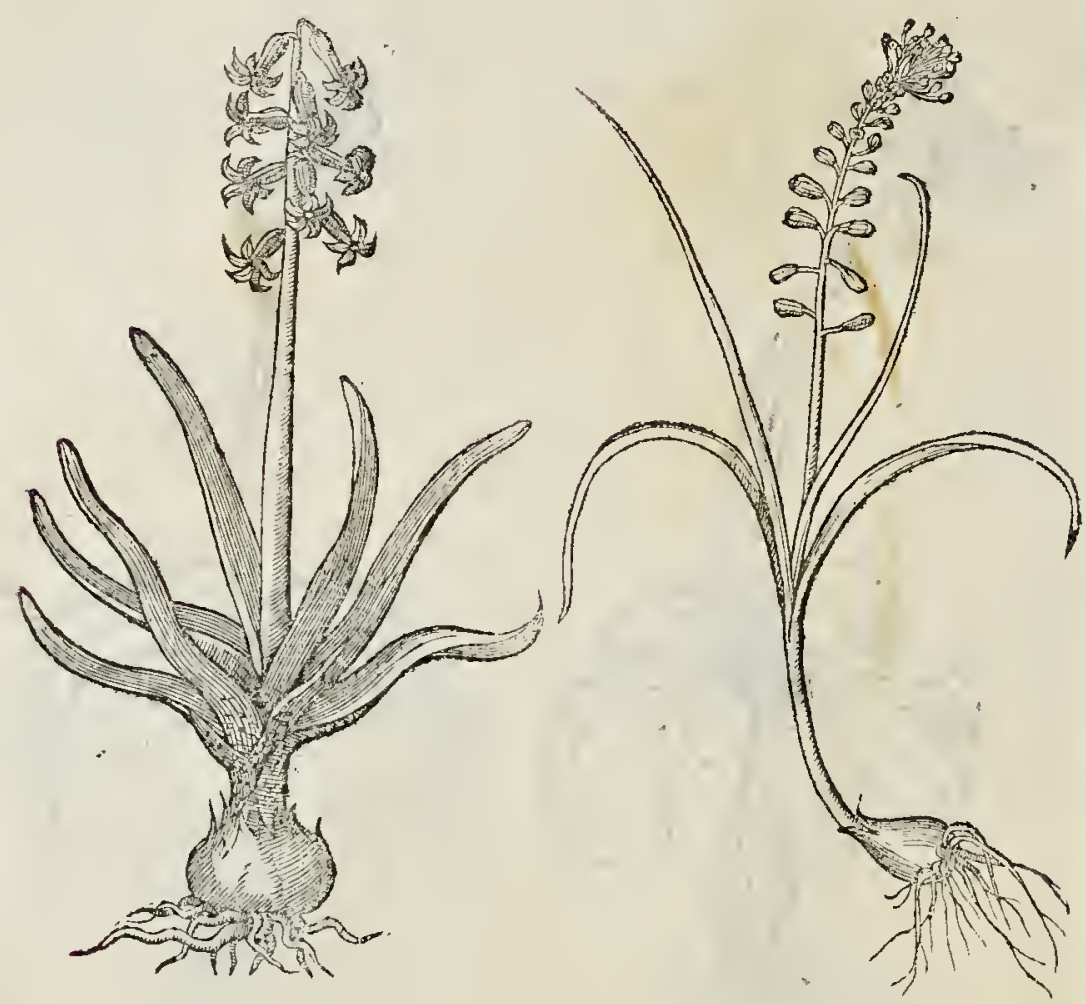

Louanio ad nos primum miffurn hoc Hyacinthi orientalis venufteffmun \& rarum genus à doctir. himo profeffore Regio D. Cornelio Gemma, icone \& oratione f́ctè expreffun \& defriptú. Eius bul. lanus.

C. Gemun Rarum hoc prorfisvidecura rü cum alijs pletrisq; cóueniart videtur atq; exoticon Hyacinthi genus, nám etfi folior ü forma \& floterris erum par, caulen queque protrudens interdum fingulare, quod ftarin fub folis hibernú tropon citca principia Innuarij: ve apud me iam têr quardum per medias niues. Florem venuftifinum laxar

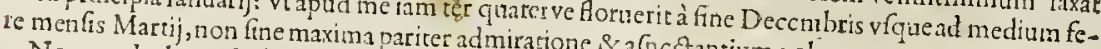
Non gaudec hunidis locis, fed ablumore riutione \& afp cetantium voluptate.

fidelins aferuatur:feméramen aut bulbi gce prius quàm frigidinte corrumpitur: idcoque \& in tefta Gorum illa nimis preciritata protrufio facit:
Suntilli folia non wern ab eadem plätaimpetrare nö porui, quod

bus Aizoi. Nerui in his nulli confoicuifed ftrix folummodo, pifia, ac fe:e femper erecta, ve in generi-

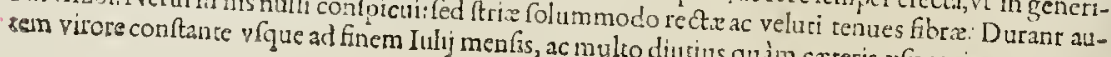


Flos lari caule, nonnihil citca faftigia ad pediculos fingulosexcanata, propendet candidus, nonnihil tanen fub initia, \& circa fupremas oras quiddan fubcęruleum leuiter præfeferens : quo quidem euanefente fenfun Febtuario menfe totus frelacteus, odore fragrantifinus, in ea fpecie deinceps une. fe plus integro pet feuerans.

Radix bulbora, intus candida, foris ruffa, circa foliorum exoutus maculas quacdam,ouales in Serpentarir maioris caule fpectan tur, effundit, interfuf purpurz nigro. Verum id maxime fub veris aufpicia, \& cum terr $x$ rurfus mandata caulem emeritum gerit.

HYACINTHY s comofus albus.

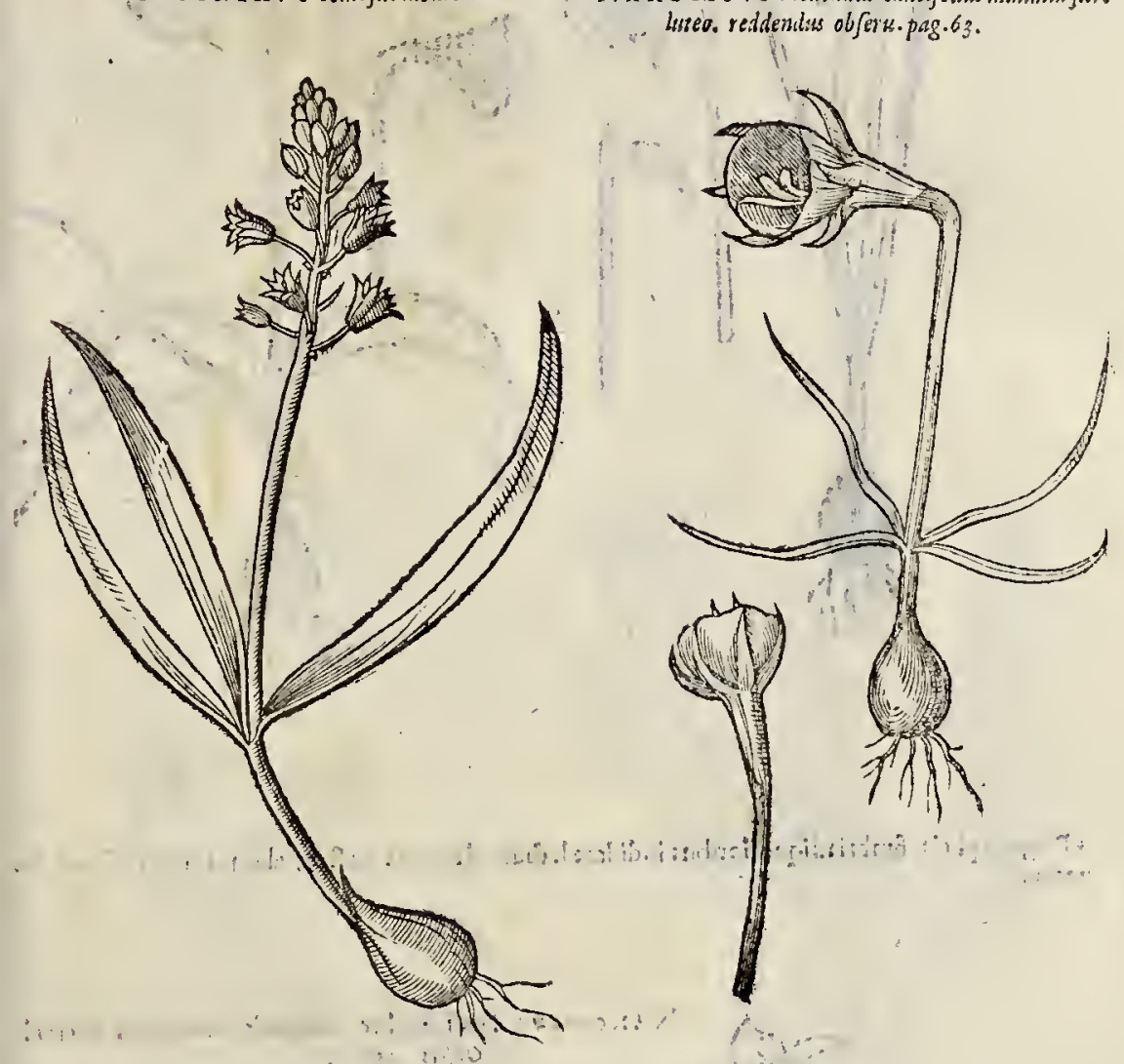

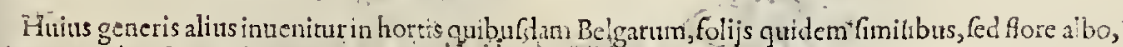
intus caruleis ftaminibus decorato. Radicis tụticen nimine rubent.

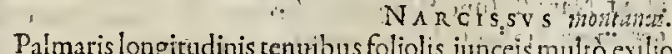

Palmaris longitudinis tenuibus foliolis, iunceis multo exilioribus, interdú erectis, in:crdum ad terram reflexis:inter qux cauliculus palmaris exeritur, in cinus fumno ex tenui, inftat caterorum Narciforum, cófimili mébrana Hos fingularis vulguto Narcifo montano finilis, \& pen è par, afpectu

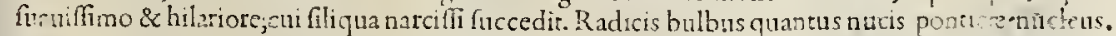
H rus peregriniforis primus me monuir C.v. Aluarus Nonius inedicus A nuerpianuser 1dirifimus. Poftea eius bulbo me donautrliluftriffima D. Matia de Brimeur, èculus vrceis forérem plantam deliniari curaumus. Paucis poft diebus ejufdemiconem Tornacoad memifit nofter Muronus, fed erectis foliys ab hac duntaxat variam.

In figlinis nlferuatur \& colitur, cum mo: fubdendo, è Bifcaix montbus in Belgium delasis hul- Trintus . bis à quiodam ambulone è Gallicia redeunte.

$$
\text { Q } 93 \text { NAR- }
$$


NA RCISs v montanas Iuncifolius minimu atier fore Luteo fimbruato; rewdendus pag. Obliru. oj.k . .
NARCISSY s wontanus omnikm minimus Hiffaricus fiors Avarcifsi lutes jod albo; Objertat.pig. 6 z.
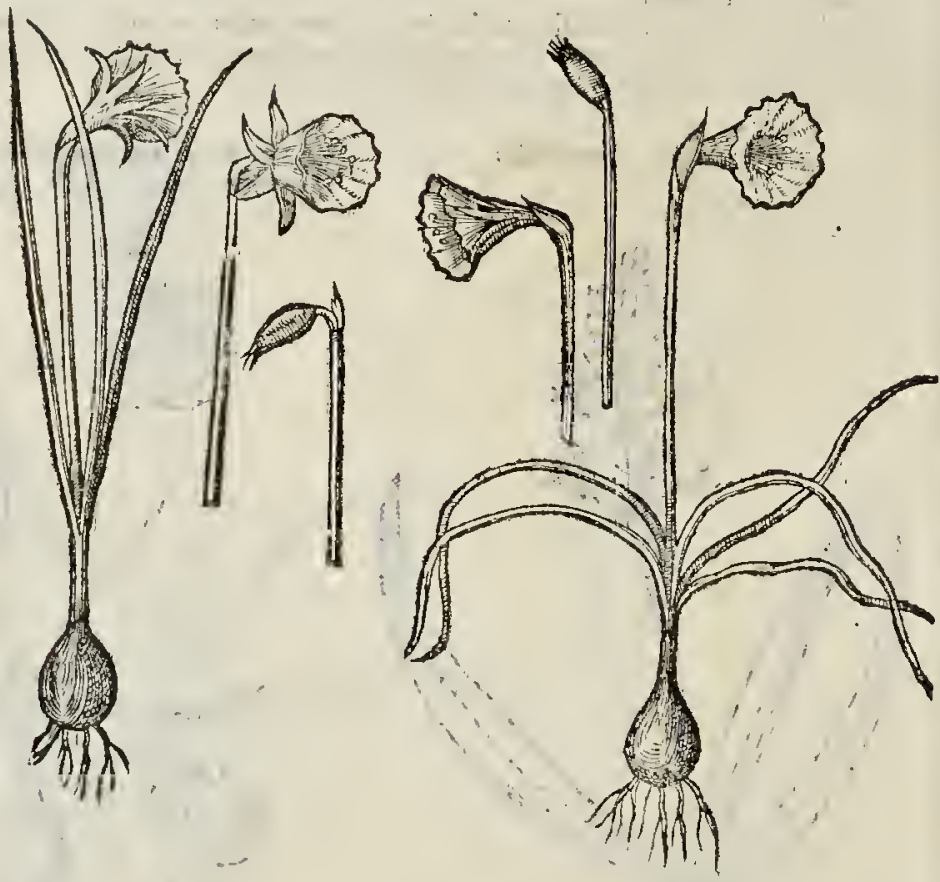
*Rugotis plicis, fimbriatúqueforibus indidem habuic Mutosus noter, alioqui non diffet 2 fu:
priote.

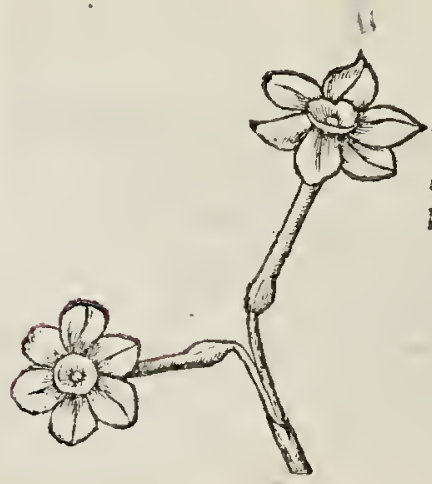

NA c c18585. Iuncifolius fore rotwndecircinitatis Rofre reddend. obferk. pag. 62.

In horto C. D. Marixe de Brimeu \& D. Aluari Nonní alitur Narcifi luncifolij genus ferotino It ncifolio Narcifo per omaia funile, fed flos soundic s ef \& laucr. 
A P N

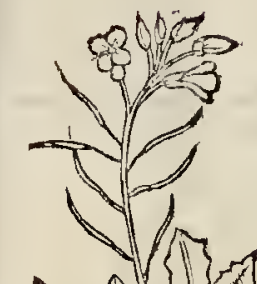

00 Q

11

1

4

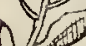

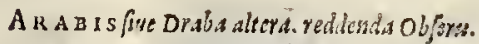

pig. 111 . of Aduerf. 78 .

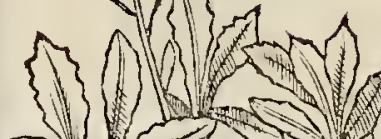

Inter Narbonenfum Draban \& Myágrú me-
diaeft hac \& congener. Dignofcitur reptatu do-
drantalıum cauliculorum denfifimorum, \& radi-
ci, exilitate. Flos albidus eft, quatuor foliolis cō-
ftans. hanc nobis primus dedıt Mutonus norter.
Iuxuriat in horris ybi femel fata

Iuxuriat in horris vbi femel fata.

CAYIORAPVM.

Aduerf.pag. 92.
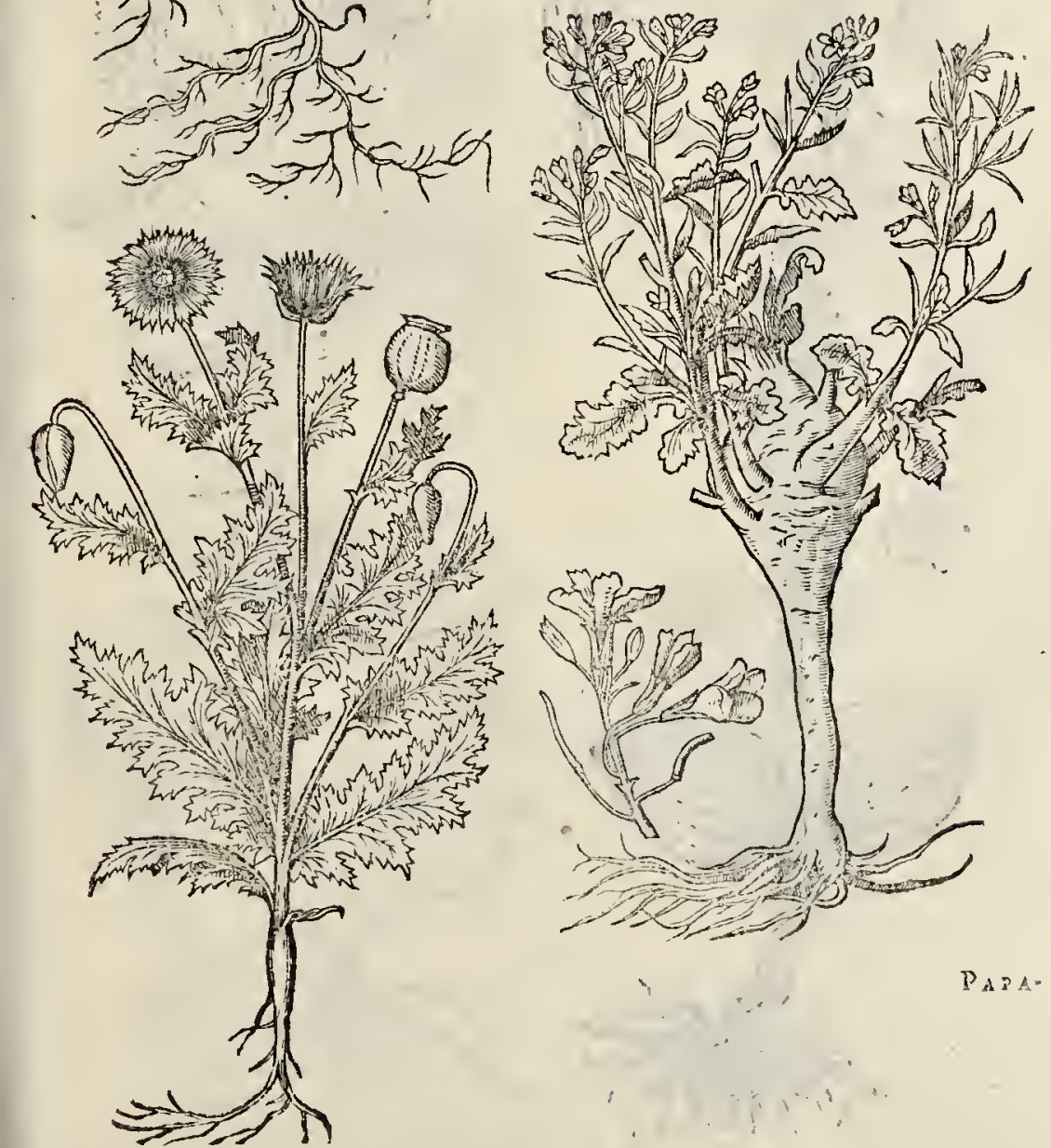

PAPA= 


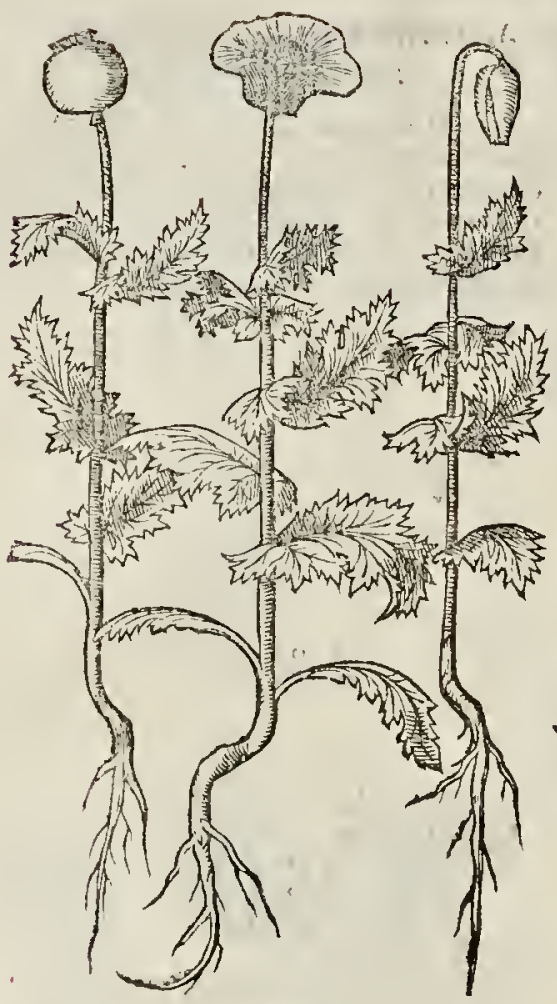

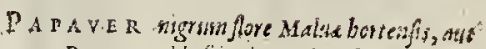
Peome.redde fiperius Aducrf.p.g.g. 210 .

PAPAVER fpontuneumfylueftre of horterife: fenine interdam nigro, alias albo. Aducr. p.g. III.

Bifolij exp.

a. Ifima effi-

mes. A ivert

Fat 127. \&

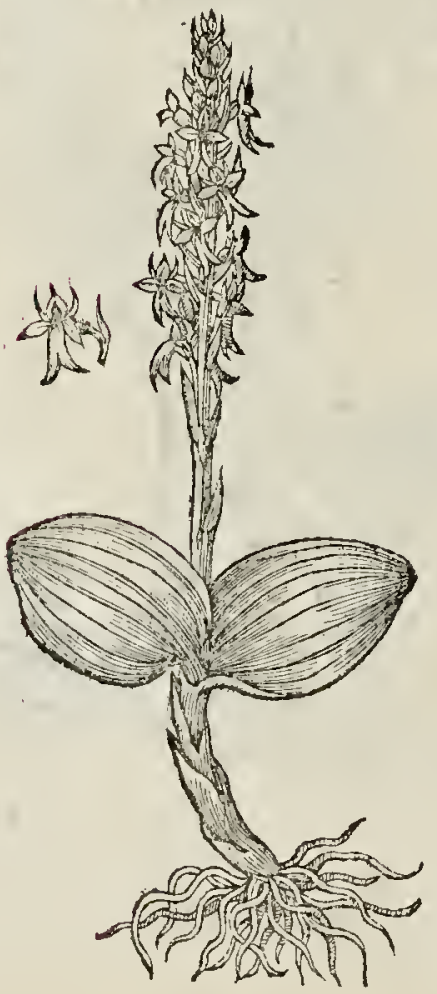

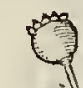

(1.)

vey

wher

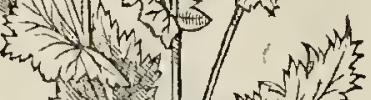

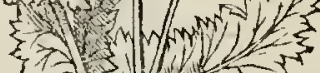

In) 17 .

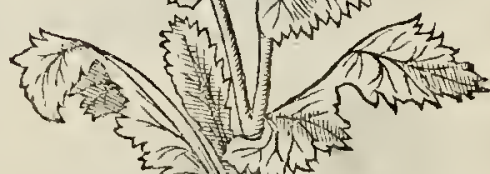

b:ets.16: 
A P B N DIX:

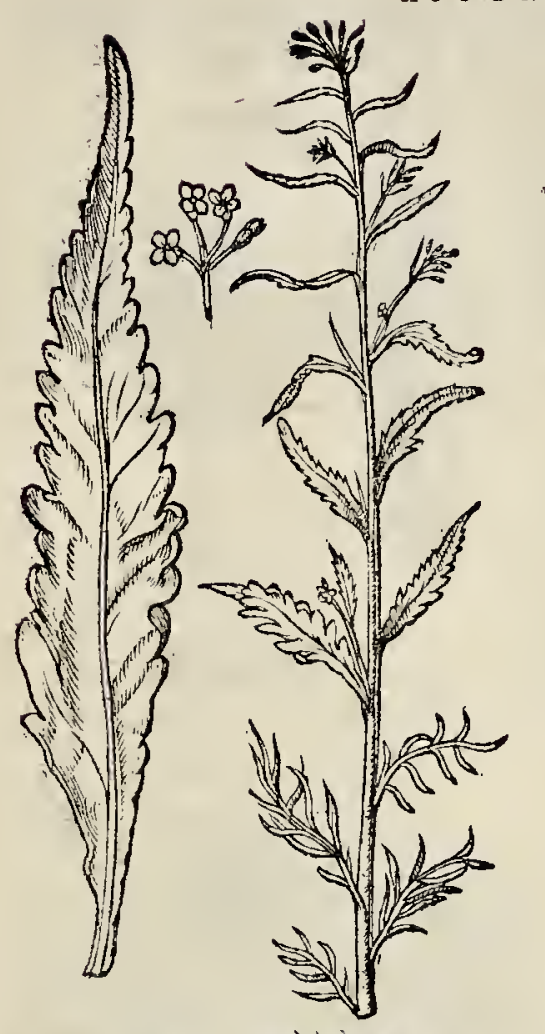

Craffaradice $R$ n A P u A v v rulficanus fiorens. Aduerf.pag. 135. \& obfer. 173.

Dum floret folia ve plurimum redduntur las. * ciniata, cuiufmodi hac cffigie cernuntur.

\author{
TELEPHIV M fortiossporpureis. \\ Adueryipag. 167.
}

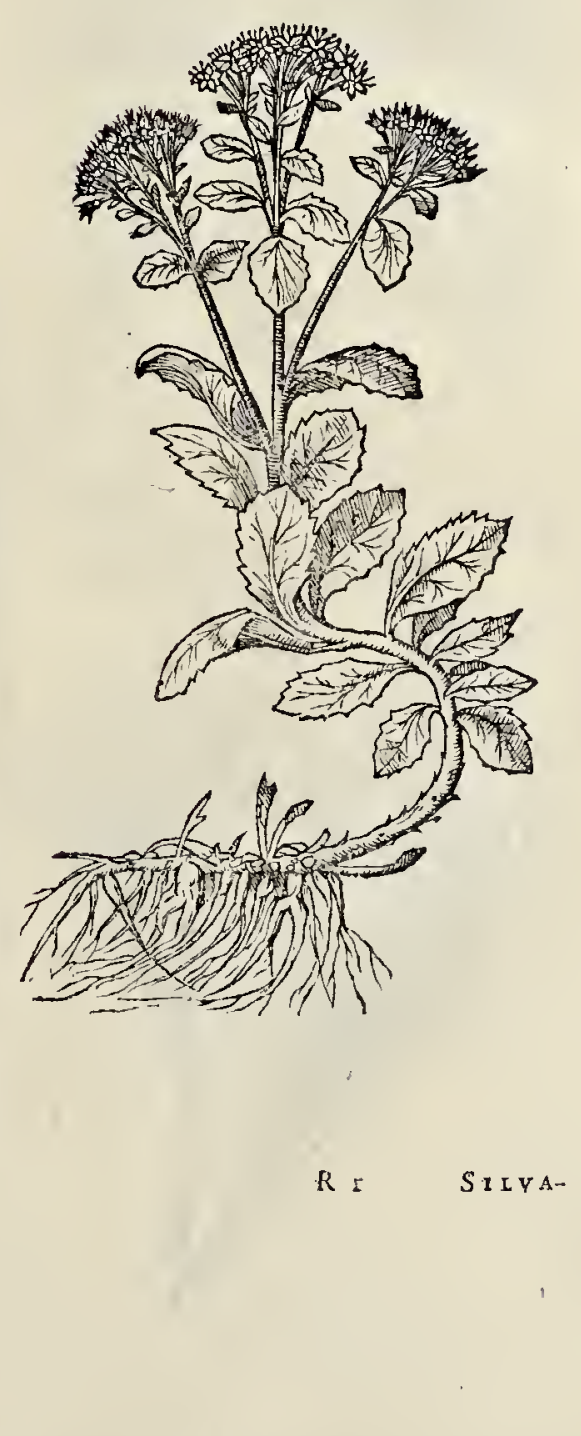


VE R B A S C V M nigram faldisolikm fiosculis

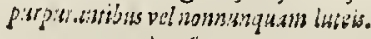
Aluerf. 241 .

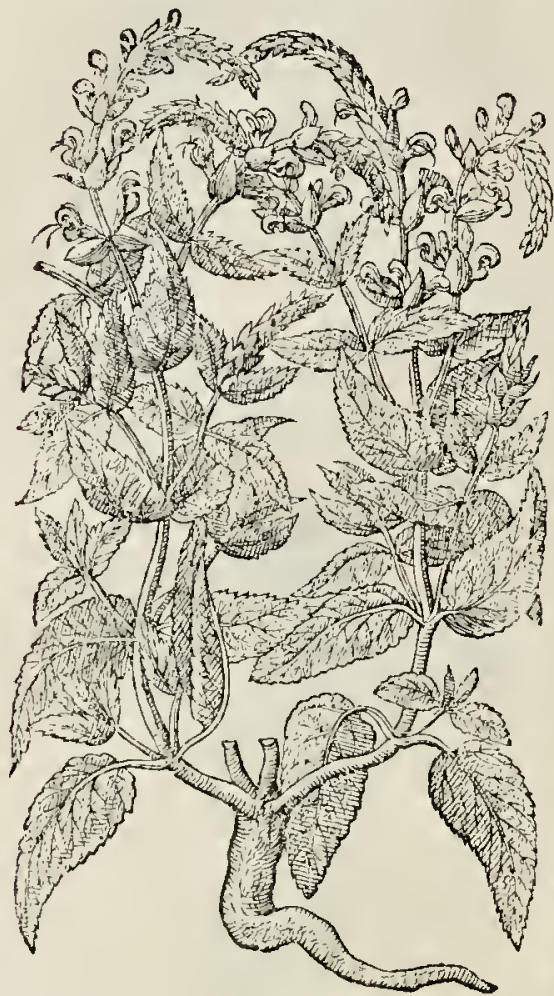

$P \Omega \perp M V L A$ veris flore gemino, altero alcerininato. sidd. Obferu. 30 s. \& Aduerf. pus. $2+4$.

Eelgis \& Anglishortenfis.

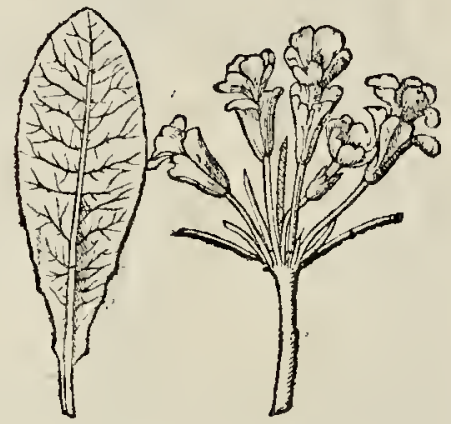

CANN A IS Istri,r.

C.mutlis fy lueftris nupcrorum.redaenda

Aituerf.porg. $22 \%$ Objern. $284.28 \%$.

SILYARVM Primhle veris fore peciofo muliplici. Aituerf. 244 .
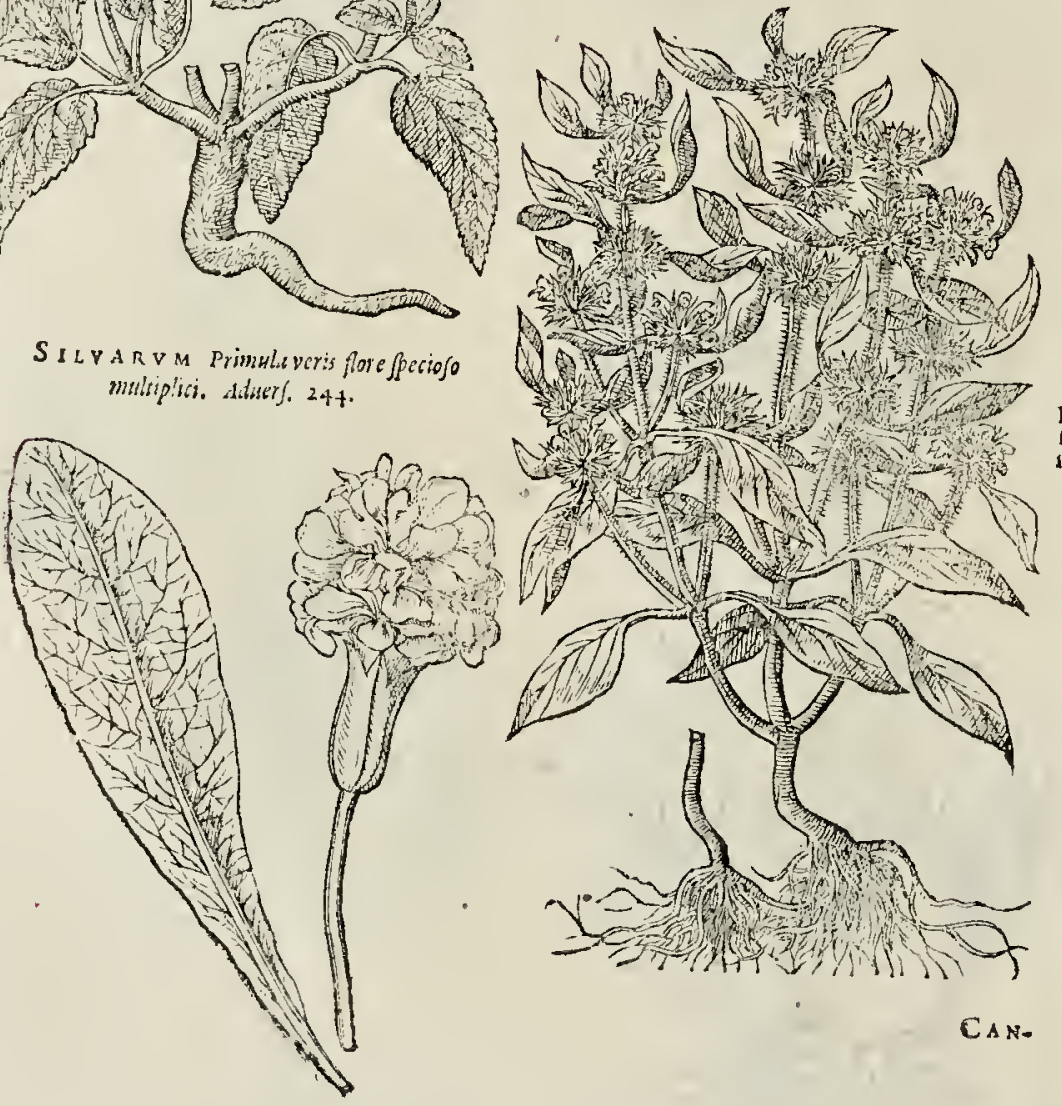
(4) fiefolicrul
ierrateras.
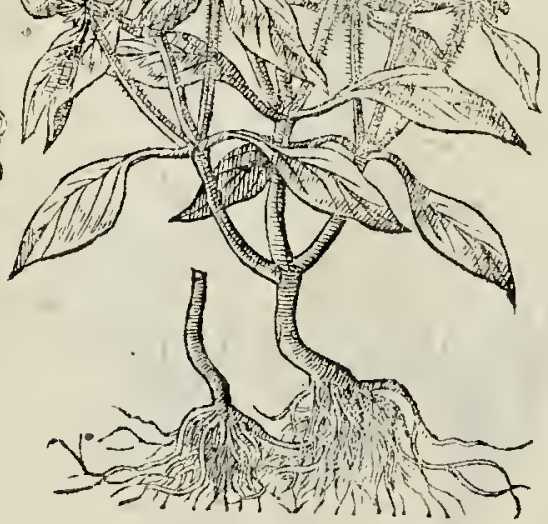

CAN- 


\section{CAN N A IS Spuria.}

Quotquot funt rei herbarix fudiofi nomenclatores in Italia \& Lugdunenfi Gallia hane Cannabinam Vrrica folijs plantam, lylueftrem Cannabin vocarunt. Pix memoria nofter Valerancius Donrez etiam huius fentetix fuit. Cubitali \& bicubirali magnitudine alfurgit, caule quadrato, villofo, Virge paftoris concolore, folin item nonábfimulia, Eerrara, ad Eupatorium Canmabinum \& Vrticam accedentia. Flores edit punicantes orbiculatim Sideritiois, in verticellis Cardiacx.Radix innumeris implexa fibris. Ad ripas deuexaslenefluentorum riunlorú \& in vdis agrorum marginibus frope Patanium Lombardia, \& Berchem Antuerpiani agri, alibique palfim mul ta occurrit. Eius hedie nullus a dhuc vfus exploratus.

C Y C I A M E v vulgate officinarum orbichs lato folvo. Aducrf.ping. 264 . obferw. 33 .

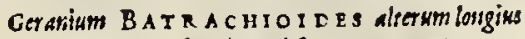
radicatum. Superius Obferust.pag.37G.
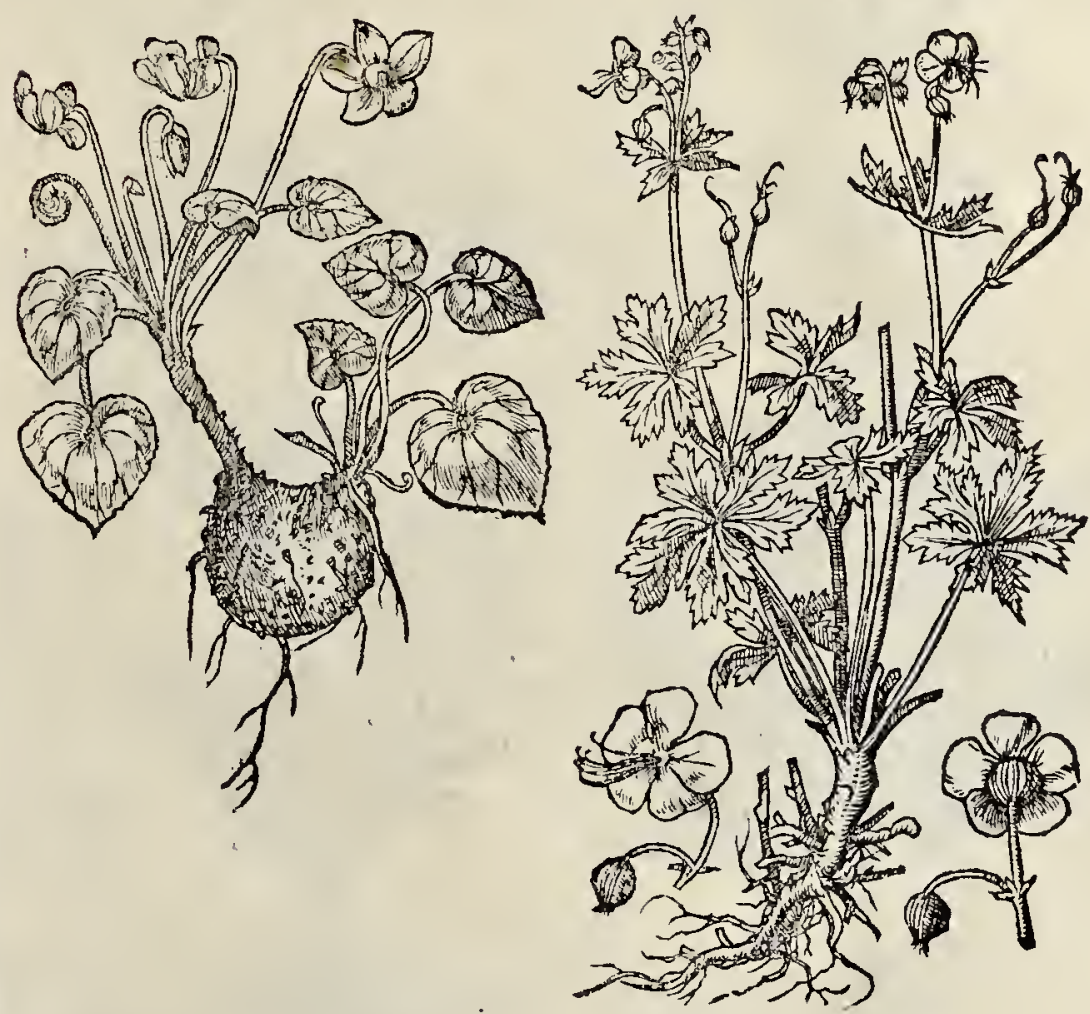

RE $i$

T: :- 


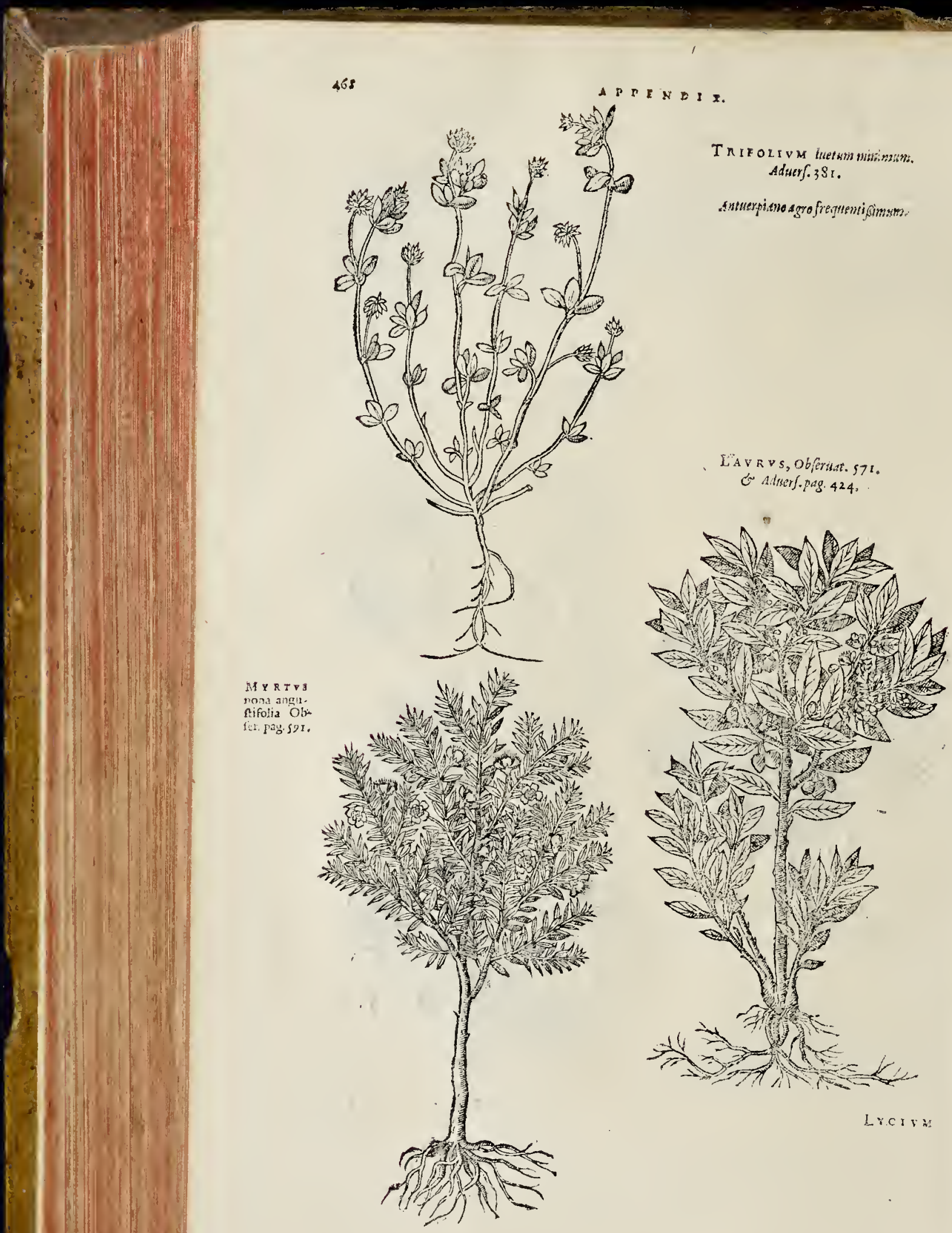


LYсIV Mißparicum. obferk. pag. 563 .

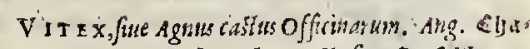
fte tre.Germ. Sryafsmuplie fue Sctrfrblamp. Ital.Agno cafto. Hilf. Gatriglio cafto. Aduerf. 423.

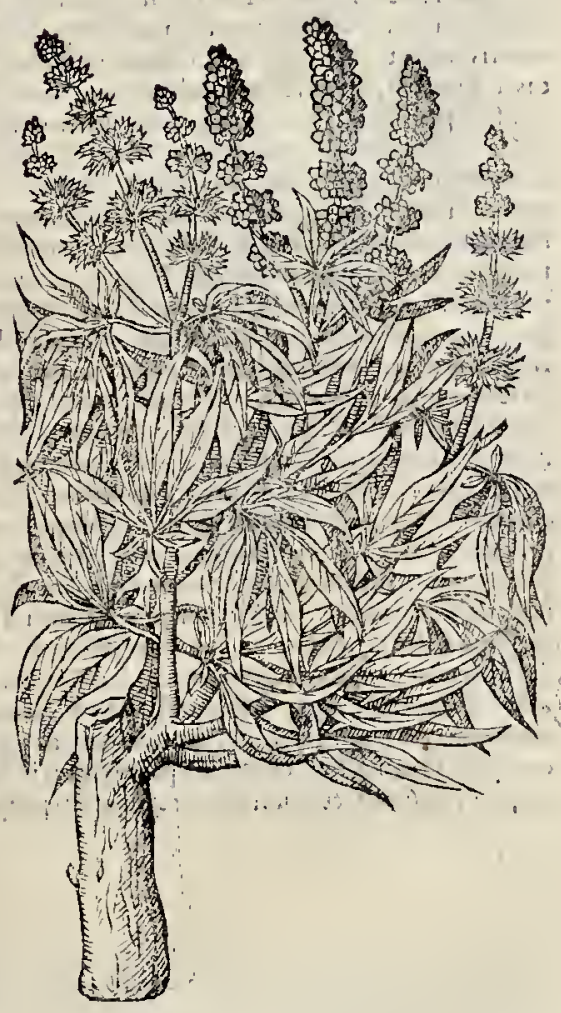

Hodie tria Viticis (Pinij xเю, dró) inuenmntur genera, vnain arborefcens, alteram exilius. bumilius multo fruticat, necarbor fir in hortis Bulgicis:

$$
\text { R:I } 3 \text { VITEX }
$$


VIT EX latiore ferrato folto, terriam Viticum genus.

Similimis cum humili vitice farmentis nalcitut, fed telia laciora, amplicra, ambitu ferrata: oc vires, cxteraque cun qua per omnia fimilia. Oritur Bruxellisin horto D. "quó me dede

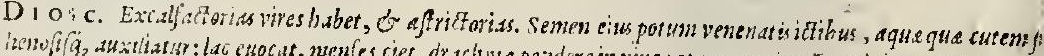

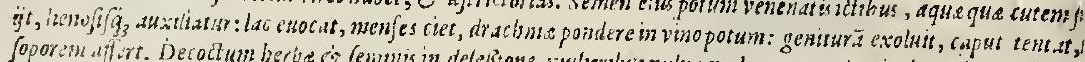

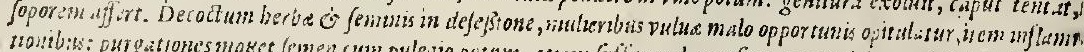

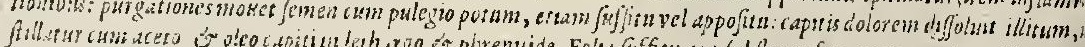

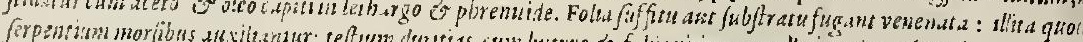

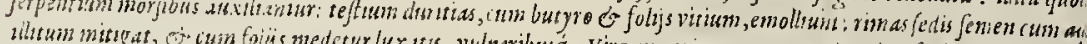
trimem fentore.

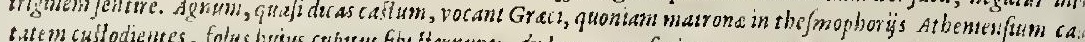
litatein.

Gal. Agnos, aut lygos, hoc eft vitex, planta illa fruticofa, calidus quidem eft \& ficcus tertio or ne, verùm multum tenuis fubltantix rum guitu acris funul \& aftringens: ipfas tamen vitices ad $\mathrm{m}$ dicinam habetinutiles: caterùm folia femenque calida ficcaque facultate funt, fubftantia verò ter Nam \& vicuntibus ita apparet, \& guft antibusacre fimul \& fubadftingens percipitur, tum foliư, tu ne dolorem pariat. At fi frigarur etiam femen eft: verùn tam per'picuò callacit, ve capiti hoc nom ventris difurite cus in venerem, \&um cum woin frictus, \& multò magis ciùn frictus fucric Cohiber porrò imp idipfom praftare poffunt I toxpers, tum etiam ipfam expertus : folia item floresque ipfus frutic

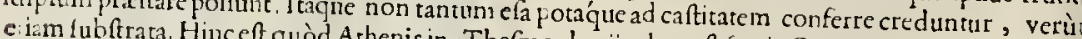
fruticem fubfternunc. Hinc illi quenis in Thefmophoriis, hoc eft facris Cereris, muleres totum fi manifefum eft, fi quidem memoriaue nomen inditum agni [ hoc eft cafti.] Ex quibus omnib facere, finulque exiccare, cum omniumeams qux fuperionbus commentaris funt dicta, agnum ca partium, facultas cius indicio oft Nam maximè flatus dilcutere. Porrò quod exactè tenuium fi prognacorü, quàm à calidicio cft. Nam quòd caput tentac, non magis à inulritudine vaporum abe procreare poffer, fanc̀ \& ventrĕ infacer, \& nó excirare, imò ctiam reprimere queat, fueneréftimularet, perinde vt eruca. Vcrùm cùm nó tantù faciédo, rum in reficcando, non queat, fuerit profectò fecundū rutæ maximè faculaté, tú in exca magıs eft excalfactoria, Nam agnifemen.ac germinagis deficcatoria. Differt etiam qualiratis fimul ac faculatis miftion 2cris: vbi verò lumid fubamadicam ferunt adfrictionem ; at ruta vbi arucrit, exactè amara eft effe, ca vtique omnino obfcura. Non tamen aufteritas aut acerbitas illi ineft, aut fi cui videatur in lienem in dum pertinet, quam vtoma agni femen potius quàm ru ta ccmpetit. Sed hac ad curandi ian metho non potef: verum celeriter nino non attingam de medicamentorum pronuntians faculatibus fier id ipfum in fequentibus medicam propofiram refleacre, virict vique ten:perati. Magíque eciar neralem facul ratem collkgero, particulares conabor, hoc eft, vbi ex quiburdam euidencibus ge uiffe fufficit, quod agnus calidus eft \& fres poltea ationes cmittam. Nam in præfensid folum no admodnm tenuium partiom. Hæe $\&$ liccus facultate, id que non mediocriter, led tertio excelfu, rum guo pacto menfes binc ciear, que qui norit, ac pefed methedem curandi didicerit, ipfemer inuenie acopum, \& excallactorium ex co vogtentum preparetur. 
PLE R Aethiopicum Matth. Amomum officinarum non Longa pirs.
ALG A MAR I N A. B.tthis \& Zolsndis ifolionm fimiludane seftelon, quafi diculigulas asiridorias.
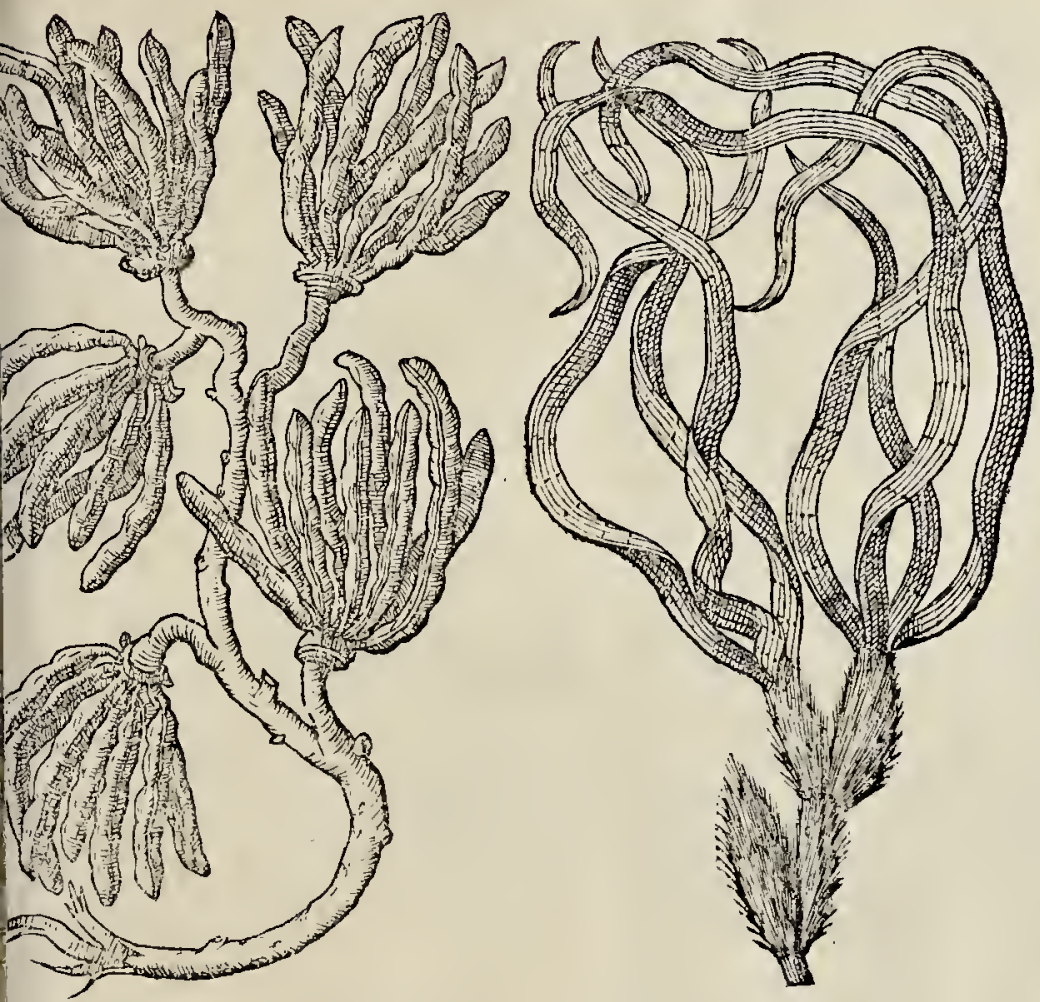

Ulis officinis Antuerpianis iam diu proftar hoc Piperis genus, manipulatim vno pediculo plures nens filiquas rereres, "rigras, corticolas, \& coriaceas, duas vncias longas, quinis aut fenis loculis ricofas, granum trres, oblongum, P'xonix minus, fingulis claudentibus, guftu piperis aut caromi, ctuius virẹs referre creditur.

\section{ALGA MARINA.}

o tractu mediterraneo ad Aquas Marianas, A driarici, \& Occidari maris vniuerfi penè littoribus vilius \& frequen ruus fluctuante Alga. E fpicatis torulis vnciam craffis folia atrouirentia, Hacmollia, cubiralin, longiora fe exerunt. Veneri iis virrea vafa inuoluere \& pramunire folent, cius ui hodie nullus vfus. Imam radicem non obferuare licuis. 


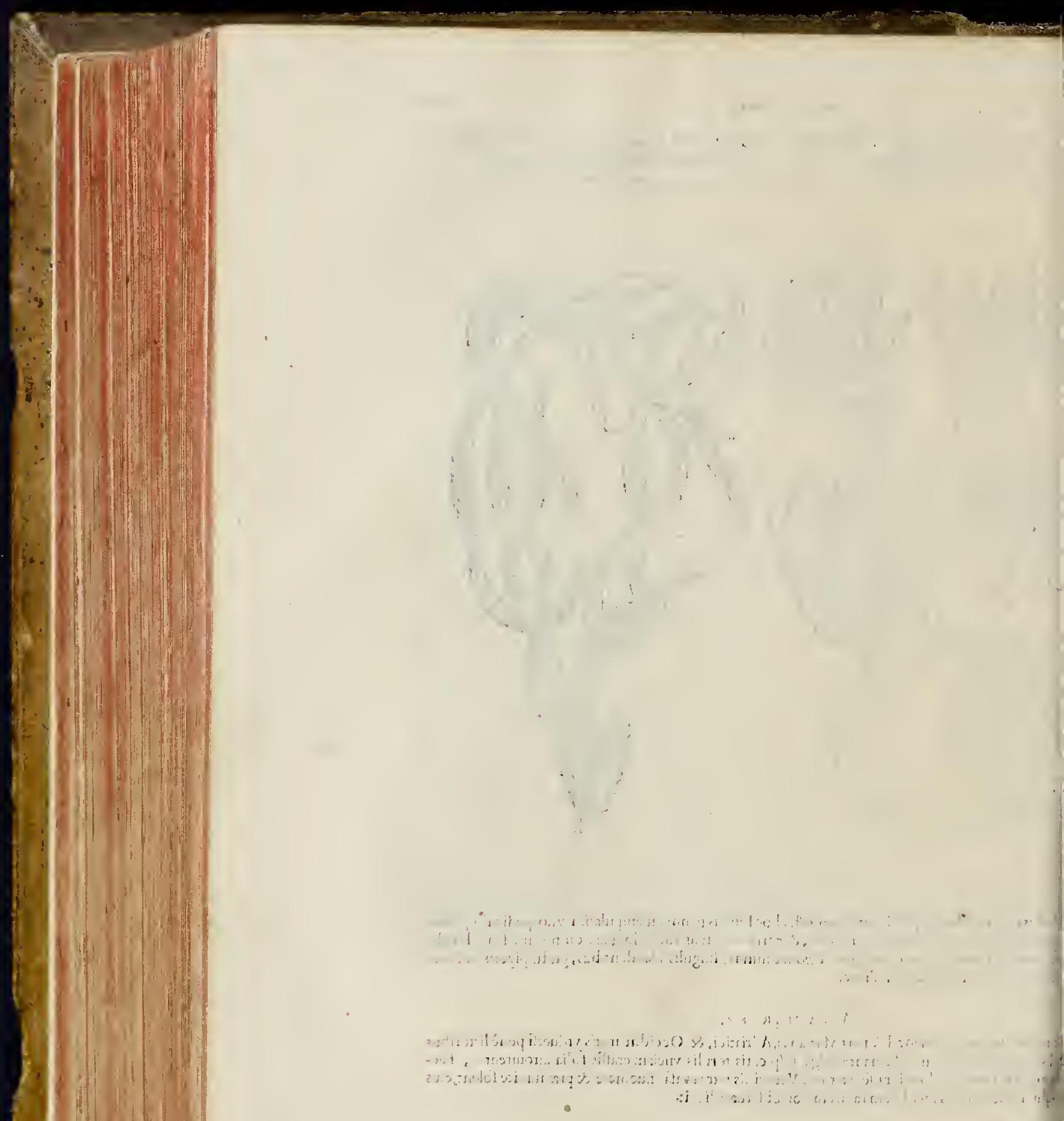




\title{
FORMVLE ALIQVOT REMEDIORVM
}

\author{
.GVILLIEIMI RONDEILETII, LIBRO DE INTERNIS
}

REMEDIIS OMISSA.

\section{DE, PVRGANTIBVS SIVE ATTRAHENTI BVS}

MEDICA MENIIS.

Purgantium medicamentorum alia funt fimplicia, alia compofita; quorum omnium aliqua fine moleltiz vacuant, vt

Manna,
Cafia,
Myrobalani oés,
Thamarindi,
Sebeften,
Sena,
Rhabatbarum,
Pelypodium,
Pruna,
Pagricum,
Paffula,

Excompofitis,

Diacatholicon, Diaprunis $\Upsilon$. \& omnes alix compofitiones qua Diagredium non recipiunt, v Trifera Perfica \& Saracenica.

- Ex pilulis, de Hiera compofica, Affaierer, de A romanb. fuue Aloephangine, de Maftiche, \& alix qux nec Diagredium, nec Colocynthida, neç.Turbith, nec lapidem Lazuli recipiunt. Cōtrà verò molelta funt in ellacuando quảcumqu1e ifta recipiunt, fiue pilula fint, fue alind. Sed ex ex hișalia magis, alia minus.

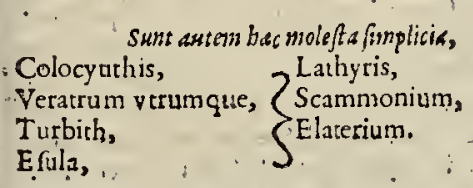

Horum dofis eft diuerfa, \& , vt fummatim dieam, his qux benedict a dicuntur, in maiori quátrate $\&$ dofi eft vtendum. Vehe mentioribus alltem non nifi exigua quatritate, \& fumna quidem animaduerfione \& iudicio, nec nifi bene \&. exactè mixtis alijs medicamétis exhiberidebent. \& hoc cocta iam inateria \& præparata, vt à medi. camento trahi fine omnimolettia poffit.

In regionibus humidis minori quantitate fumendaluntmedıcamenta purgătia, quod incolx. calium regionum Huxionibus ventris ferè fint obnoxij. In regionibus autem multum calidis in quibus corpora parun habét calidi innati, medicamentorum vehementer attrahentium nó $\mathrm{cft}$ turus vfus, quòd corpus ficceuc \& vires diffoluant. In frigidis \& humidis, \& maximè tempore frigido vii Caffia non eft turum: foler fiqui- Cafie rfug. dé ob nimiam emollitionem diarthaam $\&$ lxuitatem inteftinori(maxime fir recens fit) \& tandem dylenteriam, excitare.

In pręcribendis medicamentis interrogandus eft rget an non habeat occultam aliquam $\$$ malan proprietatem, quam indiuiduam dicunt, cuius ratio reddi non poteft. Alij namque folo Rhábar.obfactu, fcilicet qui magis funt picrocoli:alij fumpta Caffia, vel minimain porionem promptè in dy fenteriam cadunt Alijs fufficit 3 . j. folutiui cum eiufdem medicamenti $3 i$. alios verò ne minimum quidem mouere porfit: Cùm itsque tales occurrunt, videndum inprimis quibus oblectarifoleant, quóue medicamento offendi lxdique pontint.

Si quis adeò adftriça fis aluo, ve nō facilè me. dicamentisirricetur, præftabit pręcedenti dic clyfterem mollem prefcribere quàm ad ipfum medicamentum valentius ftation venire.

Videndūe tiá an non facilè vomant, facile enim vomentes à medicimento vomitum prouocante arceri debent, vt Agarico \& alijs huiufmodi. At $f 1$ Agaricus fit neceflatius, vrendum potius in decoctione, vi vomi tum nó tam cirò prouocer, vel detus Agaricus infufus in oxyrvelite : facit cnim oxymelfua fubrilitate, vt ad partes infernas penetret \& permeet, \& idcirco vomitum minus mouere poffit.

Vomitibus obnoxij vd Cardiofmo ob exaCtum oris ventticulifenfum, ftatim à medicamento, Ptifana cremorem exhibere fuerit optimum. Is cnim ventriculi folutionem cim non impediat, prohibet oris ventriculi conructum, obeftque quo minus medicamentum per yomitum retici golfit. Cùm prafcribis medica- 
nentum in forma potabili; hoc faci, cutafacilus, quim bolus aut pilula funi poieft, minulque molefume it argroantious. Syrmi qui ciumoli medicumists immifientur,ton funt vefpcri imponend! \& permifiédi; ́et ananè cùm fumendun eftmedicam nturo. Primum quidem vafi infuidinusfyrupum, poftea li juidum medicamentum, vt lytupus iple ex valis fundo iucúduin fiporem prabear Atque fi $x$ get median matum potionem lumere voluerit at pofis, fyrupum thatum relmyutminus ad purgationen neceflitum. Medicn nenus purgantibiferè necelfe et Gmplicialiqua adnifceri: vel ai facus difcutiendosex medicamento relictos: vel ad medicimenti actionemiuundam, aut vim refrenandan. Qua ratione Scammonio addimus vel carnen Cyd niorum cum Gal. yel matt chen. Prohibetenim Cydoniorum caro fun aftrictione na Scamnonium penetret ad intefti$22 z_{3} \&$ fua ficulare purgatrice ora vaforun rela xet \& feguntul fupcrpurgatio. Agarico \& Turbirh teitian Zingberis partcm fol enucosadungeread refrenantain corum vim, ne fua leuitate e. mergentes \& innatares ventriculo fint mole?i, praterea ne folum pianiam tenitem, fed \& craffan \& à partib.remotisiuncturíque purgent.

Ditur etiam Turbith cum molle Rur. palfil: decosto, vel in late infuloal caftigationem. Infunditur verò Agaricus in-oxymelie, val vino alboad incifioné $\mathrm{S}$ foluendá materiā. Colócin. thys corrigiturad dito Gummi tragacantho,ob ict uochifcos Alhädal eius loco, vt pro $S_{\text {camm onio }}$ Diagridium, folemus ponere:refrenat enim vim cius"inafiche \& galla. quia eroditinteftina $\mathrm{Co}$ locynthis, idco fatius effet in panno ligati \&ita dicoqui. Rhabarbacum quod terrea fina fubftantia \& aftringéte vinó factie diftribuacur, d.ui folet cum tertia parte Spica natdi, vel cinamoni, vel matiches, vel iunci odorati, vt eorum tenuitase permeare quouis poffr, cùn Rhabarbaro pirgare volumus. Etian cun ferolactis, vel cum decoeto Intybidariporeft, \&c folet. Sin aftringe. re, $v t$ in dyfenteria, femé Nafturtij affum adiunginus ad adtrictionem, \& tuncin fubftantia darur. Heceiam dicta Myrobalanis funt admifen. da, quia fua terrea \&aftringente faculate admodum tardèoperantur.

Polyped. Polypoditivires obeundune odorata: ve funt femen A aifi, Zingiber, Caryopliylli \& Cina Sic Epici

Sic E pithymus datur cum falis pauxillo vel paffo vel aceto in ulfo.

Eaphorbium cutn Anifo, Maltiche, Ipica fo.

Hel'eborus niger cum pullo aut aceto mul-

Hcrmodatylus non venen fús datur cum $O$. xymelite Scyllirico, \& nelle Rol, aut curn pipere longo. Tirhymalis admifcenda odorata aliqua ad corum vehementiam coercendam. Et fic de alijs, de quibus non fuit virum lîncagete.

Aedicamentum purgans ad cradicationem macrix ijfdem omnino nods cuib. misoratiuum, parari folet in formam Pilularum, potionun, \& bolorum. Ex ijldem etiam tum" fimplicibus turn compolitis, aut va!entiorib. Fed exigua quantitate componi folent Minoratiua qua ab eradicantib. virium tantum differunt vehementir, ante materie concoctionem:

Eradicatiun contrà ad materiam expulfioni para an apetifque meatibusfolent prxforibi \& c: $t$ valentifimis componuntur. Totam enim in corpore pecantem materiam, non folum portionem ve purgent prafcribuntur. In componendis auten medicamentis videndum primó quis hurr. or purgandus, vel an facilè excrahi poffir.

Facilc̀ verò trahuntur humoresex vijs ductıú, magnis valis, ventriculo \& inteftinis, \& fi qui fintvitioft qure fua acrimonia tacultatem expul: tricem itritent.

Egrc̀ verò trahuntur frigidi; cralli, \& Ienti humores; \& qui à ventriculo \& partibus remoti füt. Confideranda verò xgri natura, vel tém peratura, xtas, anni tempus, vitæ conditio, guãtitas; \& qua'litas materix vactādx: quibus om nibus adauns pre fim perpenfis medicametitum humori vel parti affectę déterminatum eligimus, \& çuod nó mul. tumab xgriteriaperaturartcedar aut fréi contrarium.

Si quantitas materia magna fie, maiorem folutiuorum quantitatem, vel iliguidex his quxi in purgädofuntvalétiona, nifcemus, vifi pauca fit materia biliofa, tempus anni calidü, calida in:ẽpe ries, imbecilioribus minusque calidis vimir $\&$ qux obtundendx bilis A.ux vim haberi,vel que Gluendo minime caleficiont, ve Thambtind, Manna, Rhabarl. Syr' Rof. fol. Succus Rof Elect. de Pfylio, Confed Hamedh, Trifer. Perfica, \& Saracenica, Catholicon. 'In boli irał̧ue formam purgansmedicamentum 'faúam bilem hoc modo pareur:

\section{Bilèn emctiantia levitcr.}

Re. Catholici z r. Elect. de Suc. RnC $\approx$ ij. vel $\div$ j. Syr. Rof. hax val Elect. de Pfyio q. f. mifcecun facch. fiat bolus: vel fo. ? 
4. Diaprunis fimplicis, Elect. de Pfylio ań. 3 ij. Elett. de fucco Kor. 5. f. mife cum farch. fiat bolus, vel

Aliud tempore a ftiuo.

7. Calfix recentis 3, vj. Diaprunis fol.\& elect. de pfylio,vel fyr.rof laxatiui añ 3 ij. vel fing. 5 j. fiatholus. Si magna eft materix quantitas, vel xger difficilè retjciat, vel in regione fit ad feptentrionem, pofumus dolim augere, .vel valentius laxaiuum dare, ve vis purgatoria augeatur. Mo- les enimmedicamentorum plurimum faftidit,vt fi ita paretur,moleftifimum rolet effe agris.

F2. Caff $z$. j. vel 5.x.Diaprunis $z \mathrm{j}$. Rhabarb.pul. $z$ j. fiat holus.

Cùm itaque moles ea xgris mölefta fit', vixque inrerdum median parten agri deuorare foleant, $z$ virium lit imbecillima, fiet Diagredij adiectione eradicatiun in forma potabili diffoluendo predicta Electuaria, aut alia in de coctionibus. humorem peccantem vacuantibus, vel in aquis cordialibus, vel in alijs purgandishumoribusproprijs, vel in aqua hordei,hoc modo.

Bilem euacuantia fortius.

Re, Catholici 5 . f. Elect. de frucco Rof, 3 j. Rhabarb, infufi in aqua Endiuix, vel vino (pro xftatis aut hycmis ratione) \& expreffi Э iiij. Cinamomi grana v j. Cyrupi Rofati lax. fi multum volumus purgare \& valens medicamentum facere, $\overline{3} \mathrm{ij}$. Difólue in decotiome communi, vel ca quxad Haur bilis concodionen parari folct. Si iucundiorem potionem volumus, accipimus Syrupum capill. Veneris hoc modo.

Aliud debilins.

fge. Diaprunis folutiui \& de Pylioañ. 4 iij. aqux Endiuix \& capil. Veneris añ. żij. Syrupi Violati 3 j. mifecefiat potio. Eft autem animaduertendum; quòd minori medicamentorum pondere vtimur, fi in Cyrupis aut purgantibus decottis difoluantur. Quod fi in aquis deltillatis,quæ nullam aut admodum paucam vin habent mouendi, ant aqua hordei difoluantur, mainreni quantitatem addemus. Si Syr. Rof. vel de florib. Perficorum, qui quidem purgant infigniter, vel decoctione qux aliqua recipit purgantia \& incidentia, qua longeे vehementius euadit medicamentum, minor foluentium eft ponendaquantitas.

Quando verò materia eft in pauca quantitate, vel xger eft delicatus, \& viribus imbecillis , 6 - tius eiufmodi medicamento leui vti.

In delicatis oblituetione, cbferuandum in primis eft, ve purgationi eiadeam febrem fanandan vtamur medicaméto, in quo fy r. aut a qux aut femina aliqua qůęvim habentincidendi, imponantur, \& fimul decoquantur, vt facilius medicamentum illud diftribuatur, intro permee, $\&$ vacuando humores trahat;cuiufmodifunt in febre bilicfa, \& materia calida Syr. Capil., Veneris.

Febris bilio. a.

Febrispituitofa.

-In pituitofa Syr. Byzantinus, qui quidem fyrupi eo fcopo folentmiferi lyr. Ror. ad corrigendam eius facultatem aftringentem. horum autem fyruporum loco v timuraquis Capil. Endiuix in biliofa materia, Graminis, Foniculi, A fpar.gi: in pituitof, feminis Apij \& Petro. quorum hac quàm 1 lla minori pręlcribuntur pondere,ne calorem febrilem augeant, hoc modo.

\section{Eradicatiutm in febre ob chftructionem} in buliofa materia, forma potabili.

3e. Decoctionis communis medicinx q. Fin qua difolue Caffix \& Catholici iñ. 3 ïj. fytupi rof. laxatiuizj.fyr. Capil. Veneris z.f.\& fivnico fyr. fufficiat lad medicamenti d:filutionem, tamen adprioris fyrupi corrigendä afcictioné fi aliqua fit, \& febris fit cū obitructione, alium appofuimus. Si fine obftruction hac-febris fuerit, fifficit fyr. Ror. laxatiuus, purgando humori biliofo aptifimus, quo citra magnum calorem purget: vel addendum eft Rlabarbarum cum Cinamomo, vel aqua aperiente vel decocto ex aperientibus feminibus, hoc modo, vi'fequitur.

\section{Eradicatiuum in febribus fine ob- ftruetione à bile.}

Ju. Catholici $\div$. Eleat de Pfylio $\overline{5}$ j. Rhabarbari infufi in aqua Endiuiz 5.j. Cinamoni $\rightarrow$. C. fyr.Rof. lax. Zj j.aqua Endiuia \& capil. quod eiufinodiaquę cú Cinamomo \& fyr. Ror. lax. ad adfrictionem $R$ hab. fatis effe videantur.

\section{Cum decotione autem paratur tale} medicamentum ad idem.

หe. Pafful. 亏.j. Prunorum, Sebeften, añ.'N. x. quaruor feminúfrig. Inaiorum añ. 3 iij. 'feminis apij, petro.añ. Э. . . Alorum ecrd.añ.p.j. fiat decoatio, \& in quartario colaturx diffol. Mănz granatz 3 j. Rhab. infufi in aqua Endiuiz 3 j. . . fyr. Rof.laxatiui $z$ ij. cinamomi 7 . j.milce. fiat potio.fit auten decotio ex folis florib cordialib. vel ex fola mercuriali pro pauperibus, quia vim habet purgauricem.

† 2 Man- 
Mannam veró pro diuitibus addimus, quamuis in materia biliofa parú vidcatur competere, guòd promptè admodum in bilem vertatur, vt mal \& omnia fumne dulcia. Alijs ramen nedicamenis foluentib. \& refrigerantib. huic fcopo citra onkem moleftram v tillfima, quia in bilem vetri nэา porc?t.

Medicaméta cradicatiua dantur in forma pilularum in fébribus, modò non fint acure. In alijs fibribus ve chronicis, vrimur pilulis deferiptis ad omnes febres: vt pilulis de. Rhabarb. \& aggre. gz:iuis. In alijs $m$ rrbis poftumus vti aliis pilulis b.lem purgansibus, quales funt qux Rhabarb. Diacridium vel Myrobalanos recipiunt, quas. damus poft primum fomnum ad eradicationem, nonate cibun, vt in minoratiuo faciebam.

Eradicatiutum in forma Pilularu'n in febrib, chronicis.

ze. Pilul. agyregat vel $f$ quibus 3 . j. vel fingul $3 \int$. cum aqua Endiuta formentur piIulx s.proz.j. japiat à media nocte.

Pitui:am euacuantia.

Pituita cuncuatur medicamento fortiori \& $\mathrm{ca}$ lidiori iffdem modisquib: \& bils, in tabuls, potionib. bolo, \& pilulis. In forma-boll fit ex.Diaphanico, Indo vtrogue, ve fequitur.

pe Indi maioris 5 iij. vel quatuor cum faccharo. fiat bolus. velfic,

pe. Diaphoenici 5 ij. Elcet. de Citro fol. vel diacarthami 3 j.f. cum face. fint bolus. Sunt qui huic medicamenti form $x$ addunz: A gavicum pro materia pituitofa, \& R hab pro biliofi, fed id mihi ingrarú videcur obamaritndiné. Satius verò fuericyti R habarb: vel Ag garico in infufione, cùm ifta fifnplicia, vel lapis Lazuli in bolo aur fubftãtia vétriculum fubucrtant, \& vominú pron scér, nifi addantur gux eorum malitiam obtundunt,quod mifceri ob rempotis breuitatem non polfit redè, ra de caufa minus vniuntur \& caffigancur. In tabulis fro medicamentum ex Elect. Diacarthani vel de Citrofol. illa namque pituitam purgant, neq; palato admodum funt ingrata, quorum dofis communis eft 3 iij. aut quatuor. In fortiorib. 3. vj. vel proxgriviribus, materix copia, \& deijciendifaculcare. Flect de Cirro ventrculum mi nímè lxdit, ideogue pituicx purg.nd่ $x$ 'aptifimü eft medicamentî́. In atriculari morbo, se morbis. diurnis cōuenit magis Di.acarthamú \& pro patiperibus; \& cùm citò paranda eft medi. ina, vtimur êtiann ipfis in minoriquantitate cùm medicamë: tum, turdx operationis excisure volumus, vel cùn ager medicamentum detiotatun reijcit fatim, \& zuncpropinanus illi $3 \mathrm{ij}$. vel 3 iij. cùm videmus medicamentú nihil egife in materian. Si autem remanferitintracorpus, nee propter imbecill- tatcm ventrom purgatit, danus 3. j. illius elect. cum iufculo fine fale, \& panlo antequam fumat cibum, \& id illis propinamus, ve longius firinter tallum inter prandiun \& iufculum füm ptum.ldem facimus in medicamento cholagogo, nifi quòd Elect.de fuc. Ror.tanquã magis dererminatum, accipimus. Elacuarur pituita multo me'iùs pifrulis, vel liquito nxedicamento. In decoctionibus omnia addi foknt que ad deterfionem, \& incifionem materix pituitole neceflaria funt. Valentius tamen cuacnatur pilulis, quòd diutius in ventriculo hxreant, \& aे partibus remotioribus trahant. Medicanenta enim qua purgant pituitam; funt

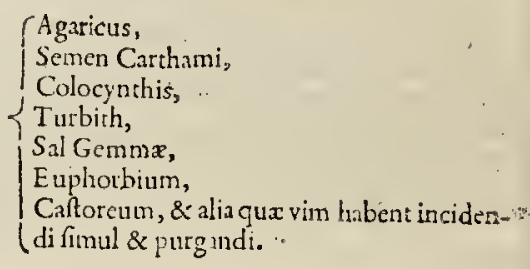

Purgare eciam piruitam poffirit qux bilem vacuant fi lyis addas qux cra?os humores attenuẫt \& incidunt. Vt in uenitur medicamentum paratum ad pituicx enacuationé ex Caffor io \& Diagredio. Diagredium primo \& per fe picuitarn purgar in forma porabili, paraturque ve fequitur. Ad pieuiam.

Be. decoctionis pectoralis, vcl capicalis quartarium $j$. in qua diffolue Indi maioris 5 iij. El. de Citrofolur. $z$ j.f.Agarici infufion by melite $5 . j$. Zing. $g^{2}:$ vj. mells ReC. parum fixt potio. Addimus medicamétis, ve gratiora \&́ cislciora fiant, mel,quia detergendo etam iuna:folurionem pituitx, vel fyr die byzan:iis qui incidit $\&$ attentnat, vẹl fyr. capil.qui medı ${ }^{9}$ cet $\&$ incindit. Vel fic fiar:

12. Diaphoenici, \& clect. diacarthami añ. ₹ ij. Aliu difolne in decoctione coquente \& purgante pituitam, quix decoctio hoc modo fieti poterir.

se. Glycyrrhizz; Polypodij, an. 3 iij. paftul. \& feminis Carthami añ. 3 iij.f Agarici 5. j. Zingiberis $7 . j$ Hor buglor.ftuechados' \& anthos añ. p. f. fratdecoctio; in colatura diffolue Indi maio. ris; el. de Citro añ. ż ij. Syr. caril. z j. mifce. fiat porio. Poffumus addere Rhabarb. maxime in infufione augčrło quazcitarem Cinamomi, vel iñfundendo in vino albo vel in décoctione dieta, vel in oxymelite Tunc fitmedicarr cntri Phleg- Rhab magogum, ob infulioné in vino fast.m, vel oxy - gum melite, vel ob cinamomum.śunt etiă qui myrobalanos addunt in decoctionc; Fri milhi ramévidécur parum conuenic ob antictione quam ha- 
bent maiorem Rhabarb. Quod fiaddas hos in decoctione, ponëdi autē kebuli, vel emblicielixi \& confricati cú oleo amygd, amararum. Turbith verò addere decoctioni optimum erit, addé do Zingiber, \& Eemina aliquą qux vin habeant attenuandi. Nunquam enimi danduin medicamétum purgans fine incidentibus \& tergentibus, alioqui fequitur difficilis purgatio. Si loco decoationis fueric vifum vti aquis, eligend $x$ funt incidentes, tenuantes, calefacientes ventriculum $f_{1}$ : ne altrictione, inter quas principatum obrinent fequentes aqux.

Aqua Cichorij, foniculi, apij, petro. gräminis, bethonicx, Melifix, Marrubij: Aqua abfinthij minus conuenit ob aftrictionem. Aquę Menthx, vel Pulegij polfunt etiam allumi. Sed aqux primò funt eligendęquę affectam partem re fiçiút. Verim multo valentius purgatur pituita ( $v \mathrm{di}_{-}$ximus) pilulis quim decoctis. Pilulx pituitam cuacuantes funt Cochi: ob Colocynthidem, $A$,fayeret, de Agarico, de Hermodactylis, de Sagapàno, de Euphorbio, \& onmes denique, qux Turbith, Colocynthidem \& Agaricú tecipiunt, vel Sal gemmx,quòd detergendo pituitam purgent. Hierx ommes purgant pituitam, fet; ob am arorem his non vitimur, nifi in his qui ob cerebri affecturin faporeni ac fenfum exictum no habént, vt in Apoplexin, aut fom no profundo, quibuspotiones ex Hiera componimus, vel pilulas dilloluimus, quòd hi eas nullo modo deuorare poffunt.

\section{Melancholiam cuacuantia,}

Melancholicus fuccus ijfdem quibus alij humores enacuantur modis, bolo, pilulis, porione cie eiurmodi. Bolus fre ex Carholico, Caflia, additis el etuarijs qua ne lácholian purgant, vt Diaphocnicum, Confeetio hamech, Sena \& âlià. fiat hoc modo bolus.

F.. Cathblici, confect. hamec añ.z iij. mifce cum facc. fiat bolus.

Multo conmodius melancholia potionibus quam pilulis, \& bolo expurgatir, cu'òd ficctis fit hic fuccus \& terreftris, \& non facile trahiturnif incidatur \& humectetur. 'Hoc autem cómỏdius potione quảm pilulis, quod his exficcetur pluriintum, fit. Itacue in form porus' fit ex atrenuanribus, incidentibus, \& trahentibus melancholia

Eadem Cutè ratione fir qua ad pituitam 'expurgandam funt potiones, nifi quod mölientia \& humectantia recipiunt. Phlegmagnga atitem quę calefaciunt, incidunt, exiccant \& attentant."

Ad Melancholiam porio: : i : : ? 'xe. Polypodij $z$ j. palfil. prunorium ań. xx. N* Ceminis melonum 3 iij. Anifi, feminis ocymi añ. -ij. Cafuthe 2 f.Alown Bugl. Borring \& vio larumañ. pufilluj. Senx z ij. cpithymi 5 i. mifce. fiat decoctio, $\&$ in 4 .j. colatura dirfolue $\mathrm{Ca}_{2}$ tholici 5 iij. Confec. liamech $; f . S_{\gamma} \mathrm{r}_{1}$, violati j. fir potio. vel

seconfect, hamech 3 iij. Diapho nici \& In; Alus. di maioris ań. $5 . j$. diacarthani i. f. cum decoctione fuperiori tiat potio, vel difoluatur cum decoctione cicerum rubeorum, vel in acuis I $x$ tificantibus, quales funt Huglofl, Brrag. Hrkenij, Meliffz. In euncuando melanchisliam infpicere oportet precipuci an fit ex aduftione faur bilis: tunc admifcenda funt elect waria qux deniédo purgant \& bilem Hauam trahunt;vt R, habarbatum in wifufione, vel Myrobalan Indi in decoctione, addantur Elect. de Pfyllio, elect de Citro, vel Diaprinis folutiui. Alia anir medicamenta melancholiam ex fancrinis fece purgant in mo bis diuturnis à melancholiz femper enim pituta admifcetur: ob id optinum fuetit adijcere Diacarthamú maximè in fibrilios quartants, \& pracipue quảdo admifcetur pituita. Vtimur de coctioniburs fupradictis, vel aguis leuiter incidentibus, \& calefacientibus.

Sibilis, aquis I ndiuix, vel Fumarix, vel lupuli: vel aliis qux ferofos humores purgant.

Pilulisquoque vacuatur melanchótia Pilulis de Fumoterre, Indes, fo tidis, \& alijs qux Senam vel myrobetinos Indos, vel Veratrum vel lapidem lazuli recipiunt. Pulnis Dinfene cum iure Capi pinguis, vel decoctione pafularum conuenir maximè.

A purgatione refaurania.

Poft medicamenta laxätia folemus praferibere in craftiun aliquid cuod ventriculum roboret, vel mnitiam medicamenti venenof aleret, vel vtabluntur ventriculus $\$$ humectetur.

- Sit auteminformath ti, vel porionis. In forma böl fit ex Conferis pepirijs \& determinatis parti, \&-'praction ventriculo, vi cor fer. Buglof. Borrag. Stechidi's, Anthes, Violmum,vitheriticha, vel Midridato, \& - iricili eft conferuandum $\&$ tiepatis.

- Poft .vfun Agaríci , Scammonij \& aliorum

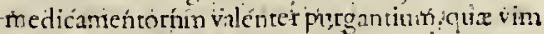
contrariam, hepar \& ventricįium ledunt. Polt pilulasin morbis diuturnis \& frigidis folemus dare Theriacă, vel Mïthridatum, vel Conferua Ror. cum alicua parte 'Tlietraces aut Mithridatij, hoc modo.

Re Theriacx veteris \& Confer. Ro $\mathscr{C}_{5}$ ij. fiat bolus. detur in craftinum inedicamenti eradicatinii in morbis frigidis.

3. Mithridatij, confer. Ror. \& Viol. an. 3 j. mifce cum facch. fiat bolus, detur mane, vr ian 
dictun $\in$ ft. fnlemus iddere confer. Rol: cuim timenus calc factionem nimian totius corporis, velp.rrisalicuius, \& cim medicimentum fupra modum purgar. Dantur eriam in morbo frigido Theriaca, Mịchridatunis per fe \& cum conferuis, maximè tempore frigido. fit criam bolus maxime in febrib. \& morbis calidis ex conferuis temperatis \& frigidis addito aliquo puluere cordiali ex Diamargarito frigido, vel Triafantalo, vel Diarhodon Abbatis, vel Rofat.l nouella, hoc modo.

Bolus ad febres calidis s mórbos calidos polt diem medicamenti eradicatiui.

k. Confer. rof. zj. conf bugl, s.f. pul. Diamarga frig. 9 j.cum facc. fiat bolus. fit aliquädo Ad fiecita ad refigerationem \& humectationem maximè rozù à e- cìm timemus ficcitarem inteftinorum à calididiemento. tate \& ficcitatc medicanenti tunc fumimus confer. violarum. Sed quia hæe remedia dantur poAd fomachitius ad corroborationem ventriculi debilitati lade tistatemexatione inedicamenti, conferuam rol.accipimus, Ad cerebrü qure leuiter confringit, \& partes laxatas corroin mosbis borat. Cùm certbrum volumus corroborare, nec trigiais. tempus nec morbus prohibent: Confer. Stochados \& Rorifmalini, vel Salnix addinus, maxime in morbis nerporum frigidis.
Ad robur cordis confer uam Bug lofi, Borrag. A vel Rolmarini. Ad heparis confortationem ex florịb. Cichorij, ficuti in morbis fplenis addimus côfer. violarum \& capill. In frigid is conf. Helcnij, vel Iridis \& ex Aorib. Hyllopi. Sed hec in pri. mis obferuandum eft, vrad corroborationé ven-? triculi \& partis affect a aliqua fomper medicamétis admifceantul: Propinari ctiam eo fropo folet porio ex hordei decocto vel Syrupo cuns aqua aliqua propria affectui \& parti affectx, \& roftro fcopo. Præferibi folet potio, in morbis acutis caIidis, corpore ficco, tempere calido, vel in quo timetur aftrictio poft medicamentum purgans, hoc modo,

Rz. Decoationis hordei perfedtè codti ziiij. Syr. $c_{\text {; }}$ violatizij. mifce.capiatpoft vfú medicamérorú at cradicatiuorum. Si nulla fit noxa, folemus dare $\mathrm{ta}^{-} \mathrm{m}$ bulamalicuins ele cuarii, vt Triafantali, in affeEtibus Heparis, vel febribus, vel diarhodö Abha. A vel in morbis frigidis ventriculi \& aliarum par-A tium tabulam Aromatici rof. vel rof. Noucllx, vt ad cot Dianofchi, vel Diambra. Iifdem eriam vrimur in affectib. vteri. Eadẹm autem die qura aflumptum eft medicamentum, quatuor horis poft dari folec iufculum aliquod pulli aut Capi leuirer decocti, aut rei alrerius fine fale, aut decom ctum cicerum rub. \& alia huiufmodi.

\section{DE MINORATIVIS.}

Medicamentum purgãs vel eft Minoratiuurn, vel Eradicatiuum. Minoratium commune eft remedium quo vtimur ad euacuationem materix morbum committentis, eftque in ventriculo aut inteftinis: \& quo facitius hanc componendi rarioné intelligamus, \& in quib. morbis eo vtioporteat, fic monftrabimus. In primis eft notandum quòd morbi qui fiùt à reple tione, inanitione $\mathrm{ctl}$ rantur. Inanitio fit fanguiois iniffione, medicamento purgante, inedia, exe rcitatione $\&$ id genus: Minoratio per medicameuta purgans. Eft purgatio vel communis humoris, qui adhuc nó putret, nee morbum excitat; poteft tamé facile putrefcere, \& morbum excitare, vel matetix turgentis in venis prope ventriculum, inteftina \& hepat non expectata eius concoctione. Talis enim euacuatio fit inch oantibus morbis acutis in quib. nateria turget; nam in aliis morbot um a cutorum temporibus vti etiam mitzotatiuis poltumus, vel vbi materia non poreft tomm concoquere, \& quo facilius quod reliaum eft concoqui pofit, aliquam partem materixauferimus minoratione. Tuncitaque addimus medicamentum qued fuz facnlate aliquid de peccante humore euacuet, ficque enacuatione vna in dnas aut tres diuidimus. Minoratiuo e cian vtimur, vbi videmus naturam non polle aliqua infignem vacuationem facere. Minoratiti verò bafin conftiruimus in medicamento communi humores purgante, cui additur aliud ad humorem fpecialen peccantem purgandum, quod in minori efle debet quantitate, vr.fi pituita videtur rcdundare ex ructibus.

Statu xëris, ztate, fexu, \& viQus ratione minuendifunt omnes humores, \& fpeciatim ip $\mathbf{a}$ pittita. Rarò enim fit vt folus \& vnicus in ventriculo redundet humor, cum etiam pituita bilis \& fuccus melancholicus, qui multi colligi 
folent; maximc̀ in ventriculo crudi hamores redindent. Prater hane alia eft euacuatio, vt pura eradicáio, qux non nifi cola materia, \& ad expulionem iam parata adhibetur, vt fic mecamento valentiori, \& determinato alicui humo ripurgando. Minoratiuum oportet effe nedicamentum leuiter purgans, \& non vehementer, quod line attractione humores qui funt in vijs duatum, ve fomacho, inreftinis, venis mereraicis, \& ipfa etiam hepatis gibba expurget. Coda enum \& nun cruda medicamento funtedacenda, nifi nater ia turgear.tenuifimus quoq; mouserifacile poteft. Medicamento quidem rraliente vehementer non eft vtendum, ne prxter id quod eft in ventriculo i venis eciam remotifimis trahar \& plutimúcorpori, faceffat negotium. Materia autem qux eft in venis ductuum, nulla eget ad fii expulionemi prxparatione, quod facilc criā nó coêa \& citra moléfian educatur, fit minor itiun potiune. Potionuni multa funt gethera vel a munendum, vel ad eradicandum, velad confortandum, quix cordiales vocantur: \&a ad multa alin de quibiss alias. Nunc verò de minoratiua potione. Potio fiue potus eft nedi camentu:n liquidum, minus t.1nen quàm fyru'. pu.s,quia compofitionen molle, vel puluere ali-

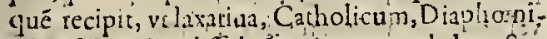

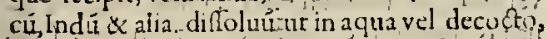
\& y potio dulcior ted tarur, Syrupo aliquo ad mifcetur. fiunt erco potiones laxates quibus vij mu: pro minotatius \& eradicatiuo polt roetione mote: Potiones minoratiua funt cum ayuis vel decoetis puluerib. vel confuctionibus, \& pauco lyr.vi ian dictumeft, naterix communis eductionem, vel ventris, emollitionem. $\mathrm{vt}_{\mathrm{z}}$

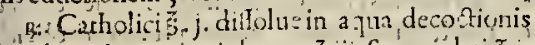
torde, vel in azua violarum. 3 iij Syr violati $z$ j.

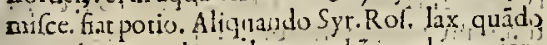
magis laxare, vel in eaden yi ad $z$ j. vel in nuaiore guantitate ad $z$ ij potio ad pisuitam laxand anj,vel Diahonicu, vel lndím mus viminus recipit, \& Syr. Capil. Vẹn Viularumparu:n, vel finon fit morofus, ninil ad Simus, ne angendo nolem im. becilius reddatur medieamen:un.

Ad pituicam.

De. Diaplaxnici 3 f. diffulue in pauca aqua tryfopi, \& fiat potio Minor quntitas vfurparur, vel decostione picuitofa paramus ad diffolutionem vel cum fyr, Rof. laxitiuo aldimusladun, maius, Diacartha'ni, de Cirro fol. diffolutunnir, \& für potiones, Petiones.laxpries melancholian. fim ex confec. hamech, Diaphcenico, Diafenx Col dirfolutis in aquis Fupirer, Bormginis vel decoctione Sen $x$, Epitlymi yil mercurialis. hoc modo.

mo. Polypodij quercinirecent ż par mund-

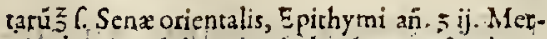
curialis M.j. Horum cordial. an. p. j. fiut decoEtio,in quartarioj.didoluc Diphonici uj. Syr. Rof. fol z j. milce capiat manc. tí decoćlio quádo vrivolumus minus pruprio medicamenio; vil quiapr sprio caremus, vei quia conuenit magis proptẹr atud. Cùm veió confictone hamech vtimur, conte in famus yu aquis, vel decofto Mer curialis,quia fatis purgit hmonem. Ad ferola recrementa viinns cötectione $\mathrm{H}$,mech, cum decoćtione purgãaimichores humorum, dé quib. flipradiximus. Potio ad furofa,rectementa.

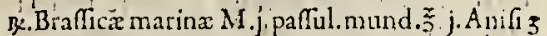
j.fiat decoctio in iure pulli vel galii ant qui, \& in quart.j: dilTolue conf. laumech 5 iij. Syr.Rot.lax. aut Fumiterra compofit 3 j. mifce. fiat potio. $C_{u}$ brífica marina noceat yentriculo \& hepati,folenus vei iuregalii autaliograro. Simp.iciaquibus ferc Gunt milorariua, func Calla ad z vj. vel zj. vel 5 x. Mamina granaca adzj. vel zij. Syr. Ror. lax ad z vel zij, Conipofitiones citibus vtimur, eoden parantur fopo communiter. Catholicón $a b_{3}$. f ad s.j. Diaprunis fimplexeaden menfi1a. Diaphunio ì $j$ jad $5 i_{j}$. Cöif.haricel à 5 . ad $\mathbf{j}$ ij. hx quidem compofitiones forticer loluctes mitiorib:alijs nuifceri Tolent, ve monftrabirit. Syr. Ror. Clutiuus bilem \& pituinn: Cacholicum omnes hitnores, idq; biands aimodun, quód fit Gine Diagredió. Diaprunis funplex \& Cafia recens lenicindo folum vacuat guod in véniculo \& in teftinis collectum eft. D iaphonicum ob Diagrediún nim quantitare dari foler quàma juędidta cum camen à longinquo non urahat:quo fiv vin minctatitis ferè emper audatur CathoJico, $\mathrm{Caflax}$, R'hab, maxime di peccare videatur bijlis \& piruita, cum tamen \& eo folo aliquando vंtamur adjiij. vei quatuor. Crnfectio hamech ichores purgat piritice falix, bilis, \& melancholip, álijs tumen fere femper mifecturin panca quantitate, quia vehémenter crahic, vi Elecá de fucco Kof́lvel de Citro, Diaprunis folutium, Indum maus, quxomna ferć prę́feribütur quantiraceadem. Pótelt etram fieri mineratio pilulis fine Diagredio paratis, leuiter \& à própinquo mheńtibus, vt pilulis de Hicraf. de Aromatib. Af fyeretad biléaddito Rhib. Agarico ad pituic: Senaad Velancholiam. Ad Melanchol ä purgădañ munoratua quidẹ funt in forma bolivel pilularú, vel Syr oro ratione mórbi smurib. agro rum. In febrous putridis vimur minoratiuis fiue furis lit continua, filve intermitiens. In continua ante fngunis mifionem tale minormung fat: "Cañr reces extract 3 vj cútace, firt bolus, vel difol ie in decolaion comnunis medicinz, velaquiBuglon, Enditile, Cichorij,capiat ante sanan velprandium pes tres horas. pirgat 
Ii quidem Caffa bilen", fituritam \& alia cxcreméta leniendo inteftina, quod eriamprętat Mána, fed imbecillùs longè. Si magis volumis purgare bilem, addimus Callie nedicanétum choIigogon vt Rhab. Si pituitam, phlegmagogum, vit Indum virumque vel eandem, Cafíamicum decoctione purganie pituitim. Datur verò in minori quantiate quando volimus fariguinem - mittere, velloco Caflix Catholici 3 iij. vel $z$ iij. - fi agier tolerste poffit.

Prominoratino eriam polfumus viti clyttere, maximè cùm ager inteftina habet recrementis plena: \& quando Cáfia vel Catholicum ob intc- Atinorum obftructionem nihilexpellere pollunt, vel cùm aeger vomiru reciec quicquid erat in vếtriculo: Clyftere etiam vtimur pro minoratiuo, \& hoc quiden quoties nuffuri fumus fanguiné, In anitx fiquidem ven r per fonguinis milsionem à venis meferaicis, hxab inteltinis, illa à ventriculo trahuntrecrementi', ob id clyftere vel minoratiuo cónuni, vel alio leniter purgante, vel vomitu enacuamus. Sic faciédum in his qui cacochymia \&r fabie laborant, vtprxcedat femper euacuatio materix qua eft in vijs ductuli cömunibas, fanguinis millionem. Vtimur minoratiuo in morbis dhurnis, \& quorum tarus lögü éft, in qubus ob diuturititum lice intermiltis aliquot diebus differre minorationem, ne languinis miffione \& purgatione flatu fequenti profternātur vires. Vtimut min ratiuo in morbis qui funt abobttuctione $e^{\prime}$ hepatis vel lienis, in quonu curatione neceftâti funt fyr incidentes ${ }^{2} \&$ a periêtes. Nă cú his fýrupisvimur nō eụacuata materia vétriculi \& intertinorupet minoration pin, materi. ill a vi fyruporum incidentiúreducitur ad venàs iatn obltuatis. Inde nín fequitur. noxa \& ohitruetio, ante vfum fyruporum iaciclentiund \& aperiénim. vtendum eft necéfario minoratiuo nifi precefferis vomitus, qui colfegtos cibicru dosfuccośblet enacuare. Quod idem eit obferuandum quories volumusmerifes proúcicare \& lapides conminthere, \& vinärétentan ciere,

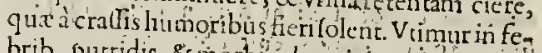
brib. purridis, \& merbis chroucis minoratiuo vel cum videmus agros morófó in allumptione

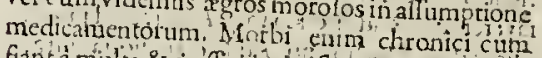

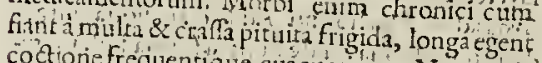
coctionefrequentique cuancuatione. Nam periculofum eft vnà \& fimilupurgare, fed bis aut ter putgationeṇ reiterare opor ter. Quándo mino-

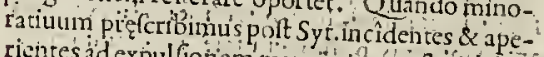
rientes ad expulGon m materix, qú fieridebet pótbacper medicamentun purgans quoderadicatiuäm vocant, cùm morbus diuturnuseft, $\&$. materia nulta, prominoratio opanum eft, $p i$ lulas line cultodia "qua Diagrediu von recipiunt,
\& pilulas ante clbüprafcribere. Et ex illis fumar ager tetrio aut quarto dic $\overline{3}$. $\int_{\text {. aut }} \overline{3}$. j. vel loco hatum vtatur apuzemate $i$. decoctione purgante, concoquente; \& aperiente, fimul ac atrahente, \& maximè témpore calido, crim timemus calefa Etionem ex pilulis; vel cùm xger non potet has deuorare. Ante tamen vium a pozematis melias fuerit vti bolo, quia apozema recipit aliqua medicaméta foluencia obtru ctiones; guod deduceret materiam adhuccrudam is craflam intra vénas: Vel fitprima A pozematis magis foluens quá requeńs dolis, vt hac dofi purgato ventriculo tutius fequentibus a perias, \& quod reliquú eft purges pro materia cônuni, vel cü humores ita funt commixti,vt antelli facile non poffint.

- Minoratiuum in forma boli fiat hoc modo.

F. Catholici z. $f$ vel इ. vj.cum facc. fiat bolus, vel loco Catholici,

pir. Cafliam vel Mannam. Vel hxe diffoluanturin decoctione communi \& in aquis cordialibus, vel in forma pilularum; minuunt enim materiam illam communem, vi pilnla de Hier. f.compofita, Affayerct, de Aromavibus, \& fine quibus; hoc maxime cum febris abelt, id quod etiam Callin fic \& Catholico, qux mitiora multo funt \& imbecilliora, \& maiore quātitate dantur. vél ctiam quia cómúnis fre \& aptior, vt ipfa Manna : Eilla Caffia ècarna extracta, recenti fem pet vrendum, eo quòd vbi diutins exeracannam inanet, aciditatem acquitit.

Pro miteria biliofa minoratiuum.

'R. Diaprunis fimplicis' \& Caflix añ zij: Rhab: pul.3. f. cum fac. fiat bolus. Si fuerit pro febricitanté, Gatius erit rhabarb. infundere in aqua Endiniæ, vi minus aftringar, \& facilius penetret, fua enimaftrictione ( qua febribus plurimim obeft) infufioneilla deperdit $R$ hab.ficque fit conueniéfiflinum medicamentum. Infunditurerian in vinoalbo vi magis penetret \& aperiat.

Hoc modo, infufum prafcribifoletpro materia biliufa.

Re. Dinprunis $r$ vel Caflix $\lesssim$ vj. R.hab. infulfin aqua Endiuit, vel capil. $5 \cdot j$. cinimoni $\mathrm{g}^{2} \cdot \mathrm{vj}$ aqua Endinia \& capil. añ. diflolue in decotiofre purgante \& digerente bilem. Ad eanden bilem minoratiuun.

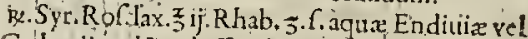
Cichorij, vel Buglofil yel graninis, vel api $z$ itj. Cinamoni $g^{2}$. quatuor mifec. fiat potio.Rhab. cŭm femper fir addédun Cinamom tú,aur Spica. Cinamono portis quàm $S$ pica corrigimus. Ervt' aftriatio facrlius teruetur \&altûs penetret, fol uatque, ćnamonum: \& quiod fit iucundioris $\mathrm{f}_{-}$? poris \& odoris ac virium lúmóris caltiget \& cor-: rigat, apponitur: aliâs folo $R$ hab. núquá vtimur nifi ad aftrictionem in fubltantia. Aqua incîden- 
tes \& aperientes addunt tenuitatem Syrupo Ror. lax. ac eius adft rictionem corrigunt fi qua fit, quę quidem pauca effe poreft; ne per fe fumptus cum aftrictione foluat, \& inde obitructiones \& morbumaugeat. Si enim adfit obftructio, vtin febribus putridis, ictero, \& alijs morbis cú obftructione, oportet minoratiuú nihil aftrictionis habere. Nam quę foluút aftringédo, vt myrobalani, fubftantia fua terreftri, Rhabarb. \& fimilia, obftructiones augent. Quare reprehenditeos Auicéna qui in initio febrium myrobalanos exhibét. Ne igitur in hunc erroré incidamus, diligé tifimè obferuandum eft, an morbus fircủ obftructione, tunc macerandum eft Rhabarbarnm aqua Endiuix \& vino albo, ac addćdum eft Cinainomum: Si addimus aquas aperientes, minus calidæ mifcendx erunt, ve Graminis, Afparagi, Endiuix, Capil. veń. Datur etiam fyr. Rof.lax.vel Rhabarbarum, vel myrobalani cum decoctione herbarum \& feminum aperientium; ve illorum corri:gatur aftrictio eo modo ve fequutur.

Minoratiuum pro materia biliofa cum ob. ftructionib. in forma potion is, cum decoctione obftructiones aperiente.

ge. Endiuix, Cichorij, Agrimonix ań. · m. j: quaruor femin .frig.maior: quę fua tenuitate mouét prínas \& obftructiones foluunt, añ. 3 iij. Anifi 3 j. feminis petro. \& apij ań. $\exists$ j. fiat decoctio: $\&$ in $z$ iiij colaturx diffolue Syr.rol.laxatini $z$ ij. fyr. capil. veñ. j. vel z) f. fýr. Endiuia vel de Byzantijs $\xi \hat{f}$. tantum quia valentius aperit. Sed Endiuia omibus hepatis affectionibus tam frigidis quàm calidis eft v ciliffima. Addi ctiam poffunt fores cordiales, paffula \& pruna in hac de codtione; in qua qux fapore gráta' funt, fuperare debérea quorum faporingratus eft, vel'Anifi 3 i: aut $A$ pij, aut Petro. quæ femina ponuntur ad $3 . j$. ctiam fi fint eiufdem facultatis. Poffunt præterea darifyrupi cum aquis Bugloffi, Borraginis \& Endiuir vel cum decoctione cice rum tubeorum.

Pilulis etiam minuimus materiă biliofam mo-. dò tempus calidum, \& temperatura xgri nöprohibeat: tunc porius vtendu bolo, decoctione,,$y$ nupis, vt füpra monftratú eft. Omnes enimi Piluilę ferè exaloë fiunt \& alijs calidis \& ficcantibus; coque bilem ipfam magis irritantibus: Qua ratione calidoanni tempore \& in calida \& ficca intemperie vtendum eft potius decoctis, \& bolis, quàm pilulis. Si attem non polfit ager in forma potionis autboli deuorare medicamenta: Pilulas ex. Rhab.\& Thamarindis hoc modo parabimus. it

₹z. Pilul. Hiera f. Rhab: \& Agarici añ. ..j. Thamarindi $\exists . j$. f.Syr. Rol. laxatiui q. . Gan pilulx. Pilulx de Hiera \& Agarico purganepituitam \& bilem Rhabarbari modo, fed cum bilis purganda graria folum fumatur hoc medica. mentum: tamen Thamarindi carerorum medicamentorum acrimouiam obsundét bilem \& pituitam purgantium; vt lunic negotio aptiores fins Pilulx ex rebus minus calorificis poffunt componi:tunc verò minus foluunt. Poteft e tianu dari minoratiuum his qui ob morolitatem medicamentum recufant, idque in initijs hoc nodo.\& bilem purgabit.

Re. Prunorum dulcium número quadraginta. decoquantur in aqua \& facch: \& cribrentur \& dentur. Si aluus aftricta. fit, ac neceffe fit fortius purgare, adde Diagredij parum; Maftiches, Cinamomi grana vj. fumat duabus ho ris ante prandium.vel fi loco Diagred: $j$ ponas fucci Ror vel Alorüin Perfici z j. non minuserit efticaxquàn fi. Diagreditiaddas; pudris \& imbectlioribus éficaciffinum médicancícum futurum.' Hic pruna leniendo purgant bülem \& catera recrementa. Saccharum quidèn minus lenit, fed vnà eriam abftergir, Maftiche caterorum corit. gitvehementiam, toborar ab eis lafum ventriculum, maximè à Scämoneo. Carhąrtica fiquidem omnia vi venenofa quadam purgant, \& vim narura inferube, nif hac leniendo \& aftringerido purgent,ve Rhab. \& Myrobalini; Thamarindi, Mậna, Caflia, Carhólicon, quorun poltrema tria omnes humorcs purg.unt. Si incidentia,tenuantia \& tergenria pituitain medicamentis bilem edil centibus mifcteris, haud dubiè trahent cum ipfis educentibuis pituitam medicamentis, quibus mifcenda femper incîdentia \& detergen tia, ne tracta crafla pituita \& nón incía prius, exiguos obftrtat meatus in morbo pituitofo.

\section{Ad pituitam}

Minoratium piruitam \& crudos himores euacuans, debet ex his componi çuę tergút, tenuãt \& purgát, ob id volumus vri cómúnibus, vt $\mathrm{Ca}$ fia,Manna, Catholico in forma boli, vel alia quialibet. Hisneceffe eft mifcere aliqua qux magis func determinata \& propri: educe dę pittuịra. fiút autem magis propria pradicta cu fimplicia, tum cöpofita fi diffoluantur in decoctionibus purgar:tibus vel digerentibus pituitam; aut aquis extcnuantib. \& aperientibus, addito melle rofato ad abfterfionem in exigua quantitate, vel fyr. de By zãtijs. Áqux conuenientes funt Foniculi,petro. A pij, Hylfopi, \&c. In forma boli ad dimus Agaricitrochifcati $\ni$.j.vel $\ni$ ij.Si æger fit obeius anna:roré difficilis, minus amaris viemur, ve Diapha:nici 3 j. quem quidem 'componimus fecundum rationem pradictam. compofita funt quidem ex tenuantibus \& ex tergentibus. Et pro iftis drachmis additis, tantī poffumus de quiantitate $\mathrm{Ca}$ - 
tholici 5 vj. vel, $v$ iij, in materia biliofa : in mate. ria p 1 tuitora dicemas,

k. Cacholici $\frac{2}{5}$ C. Draphonici, 3 if vel $5 \mathrm{ij}$. vel eleet. de Citro 3 j. \& fiar bolus. Minuenda eft dolis debiliú pharmacorum in materia pituitofa, \& forriorib. eft viendum, quia pituita difficilius trahitur \& euacuatur quàm bilis.

Pilulx in materia pituitofa magis funt proprix quìn in biliof, quia, ve dietum eft, pilulx calefaciunt \& exi cant magna ex purte ; lis igitur có$\mathrm{m}$ J.łiffimè educetur pituita. Pilulę erunt de Hiera compolita, Altayeret, de aromatibus, \& alix $A_{3}$ riçum recipintes. Probarur magis pilularum vẹs cùm ì longin quo volumus purgare. Tüc enim medicamentum non nif longa mora po. teft operari. Pilulx tales fint.

Be pul Hierxfimpl.zj, Agarici trochif. Эj. Cinanomi, Croci, Alari, nuyrrixañ 3.C. Cumfucco A pij vel fyrupo de Byzantiis fiantpilul. 6. pro 3. ex his, vt fupradictis, dofis erit $3: 1: j \cdot \mathrm{jel}$. . quatuor vel 3 j. . \& polfunt fumi ante cibum. Quia Agaricus purgat pituitam \& obftructiones vollit, maiori addirur quáti tate cuàm Rhabarbarum omni febrinm generi aptifimum. Prxte$r a$ vt onne cholagogum tenuantib. \& incidentibus mixtum pituitam purgare fuperius dictum eft, qua ratione Diagredio cu Caltoreo fe optime pituitam purgaffe dicit Gal. In febribus etian pituitolis potiones land ançuir magiș qu ia çitius \& è corpore \& facilius de potentia in a atum reduci folct: \& quòd faciliùs omnes \& magisabroluunrur per horum vfum intenfiones, vi obftructions aperio, deterfio \& euacuacio, citra magnam \& infignem calefactionem: qux omnianon exactì pilulis licet affequi.

Gallusantiquus cùm nitrofám quandam habeat fubltantiam, pituitofam materiā purgat, \& carue altringit. Ex eiusiufculo prodelicatus fieri poteft potio cum femınis Carthami 3 .duabus $\mathrm{E}_{2}$ pueris \& ijs qui medic amenta ægrè fumür, etiam
conuenit.

\section{Prun propituitoris.}

Poffunt infuper preparari pruna, vt fuperius monftratum eft in materia biliofa. loco Diagtedij addere poflumus $3 \mathrm{j}$. Turbitl, a ut $\$$ f.ve fequitur. ke. prunotí dul numeroxxx.paffil, mund. numero $x$. Turbith $5 . j$. Zingib 5 f cinamomi, maftiches añ. A C.Bconüerit decoquere Turbich cöquaffatum cú prunis, Iacc. paffulis, per cribrü medicum cernátur quib.adde Zingiber \& Cinamomum (quia odotata non debent decoqui) in fine. Paffulx lenimnt \& abfergunt. Turbich per fe \& folım fumptum tenurem folùm educit pituitam. Zingiber autem iuncturas refpicit, additum crallos humoses vaà purgat, Idem quood Turbitl, prę̧tar Efula, \& Tichymali radices,nec Ginanzoin um nec Mattux funtimponend.

Polfunt etiamintegra pruna \& piffula condiri.

AD MEIANCHOLIAM.

In Melancholia minuenda vrimur commurnibus; ve in biliofa \& pituitofa fecimus, addendo tamen ea qux fuccum melancholicum cogunt $\&$ purgant:. \&exhis aliqua fplenecica. qualia erunt illa qux vim foluendi obftruetiones habent, ve eò medicamenti vis deducatur. Conficiunturatutem ad eum fcopum minoratiua in bolo, in decostione, \& pilulis hoc modo.

Re. Caflix $\tilde{s}$ vj. Confect. hamech 5 ij. mifce: fiat bolus. addatur aliquando Diafene vel porius Senxorientalis, duplo melioris, quàim Sena Allobrogū, quaeft Sena communis. In forma porabili diffoluentur hax omnia in decoctione coquente \& euac uante fuccum melancholicum, ve in decoltione Cicerum rubeorum lienem purgäriı́,vel in aquis Capil. Fumarix, Graminis, Sco lopendrij \& Eupatorij,qure omnia tenuant \& lienem purgant. Adduntur \& $S$ yrupi in potionibus qui fuccú húc.vacuant, vi Syrupus de Eupatorio, Syr. de pomis compolitus, Incidunt, aperiuntob. Aructiones, vr fyr.de Byzantio, Capil. Veñ. \&id genus. In formia pilularum funcminorntiua, ve pilula de Fumpter. Ind $x$ de quinque generib. Myrob.ad dofim 5. l. non vltracùm morbus eft fine febre, nam in fibre bolnm porius, aut poric nem dabimus, ve un miteriabiliofa \& pitutura detumelt. Polfunt etian daripilnle in hac ma-

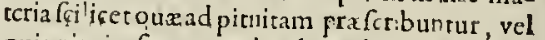
quaia pitruira femper. redundar in his qui affectus f. itintur melancholicos ob depratuatam coctionem, ynde multi crudi fucci folen cuacerusri,vel quia humor melancholicus parum à pituita difterrt \& çallishumonab. His taniē pitu!tã cducéribas optimú fuctix.addere vel Senä vel Crocü, vel aliud qued vem habear. mundandi languinem à reliouis humorib, melancholicis, hoc modo.

ge. Plul, de aromatib. 5 . Thymi, Anrum Bugloli añ': $\rightarrow$ f. furmentur pilula cum Syr. Fumarix, de Epichymo, vel de pomis compofito, qui omnes cincuant, \& faccum melancholicum purgant. Sani qui quotid ie colligunt fuperfluitates in corpore, exercitijs funt vacuandi; nou balneis, quòd fuamam tan:uin cutem purgent; multo minus mericamenro, quod non pręffribendum nifrvalde indigentibus, idque ex longis interuallis. Pronde fi quis femel vel bis in menfe euacuatur, aıetrit ne excremérorum nus limdo col ligatur, \& congcratur, prater id qued nocebir, corporaetiam trahet in malam confuetudinem. E. iufmodi autem mẹdicamenta fuprafcriptafunt \& inuifa: Scanmonium, Colocyuthis, Helleborus 
Cicxtera valentia medicamenta: non autę Rhabarbarum, Cafia, Manna, Thamarindi, Aloes, quorum omnium benigna eft operatio \& parum molefta.

Pauci funt morbi, in quibus non licet minoratiuis vti, quiafemper eft aliqua maseria peccans aat fuperflua in vijs cómunibus, qux fouet mor bum, \& naturam grauat,occupatque eam in eius coctione. Cùm autem dixit Hippoc.

Coct a medicari non cruda. de materia coniuncta \& ea qux in parte aliquaimpada eft intelligendus Aphor. non autem de antecedènte, nec de ea materia qua confittic in vijs communibus, licet ibi norbum efficiat. In in llammatione enim hepatis id que initio iubet Gal.medicamenta leviter purgantia vfurpari, $\&$ in progreffu ad fortiora progrediendum. De coniuncta verò hic loquitur. i. de ea qux ex omni inflimatione refudat. Notanduin quordan ctte qui Diafena folutiua in affeetibus melancholicis viantur. Sed quia illıus defcriptionis fü nt duę aút tres defcriptiones, quarum prima recipit Veratrum, quare fa tius eft illam pratermittere. Præterea nifi:Diagredium addatir, nihil facit, nifi quòd corpus exficcat, \& plụi lę lit quàm prodelt,atq; etiá quiá in forma pulueris paratur. Hre de concoquen tibis \& ininoratiuis dita finc: hoc tamen minime prxtereundum eft quòd prepparantia ad euacuationem funt aliquando vehementia; aliquando laxantia. Illa autem dantur die præcedenti. Hac colligo ex Gal.lib. Quos, quando purgare oportet:vbi docet danda efle levia ante Veratrum ad praparationean, ad flatum, \& vomicionem. Sic de laxántibus: fed hoc fir aliquando clýftere exhibito die praçederti: nam quando non funt vfi neque de tergentibus, neque relaxantibus, vellenientibus; Apozematis loco dantur digentui Sy rupi: Violatus ex multis infufionibus in affectib. thorasis, vel Rofatus in alijs partibus \& humoribus; obferuando quod de minoratiuis dictiom eft, filicet quòd determinatus fit humori.vaculando.

\section{Dé Digefituis, vel concoquentibus vulgo veurpatis.}

Quia ex Syrupis in off cinis paratis cirius Digeftiua medicamenta parantur, de illis hoc loco agendum. Syrupi,iuuant coctionem aut prxparant humores, vel corpus ad meliorem \& facilio. ré éductionern. Cócoquitiur bilis frigidis, humidis. Illa enim propriè caloré exrraneumi partiù m minuunt \& ad mediocritatem redicuat, quod faciendo melius coquitur: Concoctio entom fit à cálore temperato. Sýúpi quí calidiorem materiam, vel partiun calorén temperant, ex accidentibslem concoquuutr.
Bılë aút cócoquút Cichoriü, Scariola, Endiuia agreftis \& fimiles herbx: quia bilis illa magna ex parte redundat in hepate, in quo oporter aliqua aftrictionem adefe, ve vis illa hepatis conferuetur. Talia darida funt in concoetione bilis, qua vel Huxum ventris vel vomitionem facit, vt in dyfenteria \& aliis febribus curn fluxi ventris, vt fyrupus Endiaix fimplex, vel de Cichorio fine Rhabarb. Bilis etiam concoquirur fyrupis fiigidis \& aperiétibus leuiter, quales funt Syrupus Endituix compofitus, Syrupus acetolus, fimpl: \& compofitus', Syr. de Byzantijs, cum aquis Endiuix, Cichorij. Cùm humorem concoquimus, infpicere oportet fi ille eft in venis vel alia parte; quia fi fit in venis, neq; fluxus adfit ali quis, tunc frigida $\&$ humida cópetunt: fi verò in alia parte ft, illius parris rationem habère opprtet. Quare fi in thorace, Syrupus viólatus, cum aquis Bugloni vel Nymphex propinabitur. Si in hepate cum obltuctione sc febre, fyr. Endiuix com pofitus cum decoctione radicum aperitiuarum \& herbarum Capillarium. $S$ i veró $C_{-}$ ne obltructione, vel cum Aluxu; , yrupus Eadiuix fimplex. Etquo facilius intelligatur,paradigmasa ponerida funt.

\section{Digeftitum bilis $f$ in thotace inflamn:a- tionem pulinonum faciat."}

B. "Syr. violati z vj.ạux Birglofi, vel Borraginis, viol. añ. lib. f. capiat tribus matutinis. vel potelt dari cum decoctione fequenti.

Bx. Sebeften numero quinque, quatuor feminum frig.maior. añ 5 ij: Alortun Violarum, $\mathrm{Bu}-$ glol Borrag an p. jo hordér nundati p. r. fiat decoctio in tibi i. "diffoloe Syr violaci, Syrupi Endiuia fimplicts an s iij.mifce.capiat in tribus matutinis.

\section{Ad bilem qux in hepare êt, vel cum affectú hepatis vel febre.}

R. fyr. Endiuix campofti 3. vi. aquę Clchorij, Endiuià, Capil añ quartariú j. mifce.cr. piar in tribus dónibus.

$$
\text { Décoctioad idem:" }
$$

g. Endiutę, Cichorij; Buglontin an. M. j. $\mathrm{re}$ minis Apij . f.forum Cichorij, Bugl fri añ. p.j. frat decoctio, \& in lib. $j$. diflolue fyr. acetofi finplicis \& compofiti añ.z tij.ınifce. capiat in trubis Inatutinis.

Ad bilem qua cum fuxu eft, decostio. R2. Pilofellx, Caưdę équínç, Cichorij \& Scariolęañ. M j leminís Endiuię, Portủlacęan $3 \mathrm{j}$ Alerum Rof.p. i. fiat decoctio,s in lib. l. 'culaturę difolue fyr. Enditilę fimplic is $\frac{\vdots}{3}$ vj. fat digeftium prótrib. dofitus.

t† 
Adidem

R.: Syr. Endiuix finpl. Ace tofę \& Nymplicix añ žijj.mifce.capiat manc̀.

Ad Melancholiam concoquendam.

$\mathrm{Vel}$ eft in venis fine febre, vel fine obftuctione, vel eft ex fanguine, vcl eft melancholia ex aduftione alicuiưs humoris. Hac diftinetione $\mathrm{f}_{\mathrm{a}}$ eta eligantur fyrupi concoquentes materiam. Sunt autem qui puigantduabus qualitatibus, vt fyr. è Borragine, \& Bugloffo, vel altera tantùm qualitate, nempe humiditate; vel calore temperato, vt aqua Enulx campana, decodtio Glycyrrhizx. Si ergo fit concoquenda citra apertionem fplenis fiat, hoc modo.

R2. Syr. de Bugloflo,vel Borragine z vj. aqux Bugloni, Borrag.añ. quarcariumj. aquæ Enulx Camparix, \& Meliflx añ quarcariun f.mifce. capiat in tribus maturinis. Si obftuctio in fplene fit, tunc addantur fyt. acetófi velleuiter apericntes, vit

Bz. Syr. de Byzātijs, vel cápill.veí. ż viij. aqua Portulaca, Buglofi, Helenij \& Capil.añ. quartarium j. mife. capiar in tribus matutinis, vel quatuor. In morbis inelancholicis quia cor afficitur, Cordialia addantir: vt

R. Syr. de pomis redolenubus \& de Buglofro añ. 3iij. aqux Borkag. Scabiora, Enula \& Capil. añ.quartarium j. mifce. capiat in tribus matutinis. Si decoctum parare volumus, tales vfurpan$\mathrm{d} x$ funt herbx, fciliçet ex his quibus paratx fueEuntaqux.

Decotio pro melancholia in qua afficitur cór, \& adeft fplenis obitructio.

Be. Buglor. Scabiofx, Melifix, Borraginis, her-; barum capil ań. Mi:j radicis Enula, Glycyrrhizx \& Buglor.an. P. j. fiat decoctio. In lib.j. f. colaturix diffolue fyr. de pomis redolentibus finp. \& fyrupi de buglof. ań. quartariumj. mifce pro trib. dofibus, $f$ ad concoctioné melancholiz oportct prafcribere vnum fyrupuin accommodacuin humori, ex quo factaef melächolia, \& álium qui refpiciathunorem melancholicum, vel huwelancholia miditate vftionem temperet, quod facit fyr. vioexprutre latus in melancholia ex aduftione bilis : fi ex pituitæe adultione, fyr. de Buglofo; \& capiat cum aqua Melifę \& Buglofi in ea proportione in qua
dietum oft.

\section{Ad pituitx concoctionem.}

Dulcis. Pituita variaeft, vt.varia funt concoquentia, Dulcis pituita leuiter incidentibus, \& calidis $\mathrm{co}$ quitur, vt fyr. Capil.melle Ror. \& aquis Melıfix, Graminis, Buglolli, hoc modo.

ne. Syr, Capil, z ij. mellis Rof, f.ij.aquę Graminis, Hyffopi, Betonica elt buglor.añ.z ij. 2roma- tifetur cū 5. f. Diarhodonis Abbatis pro duabus dofibus;vel cúdecoetione Hyffopi vel Betonica. A Ad'pituitx acidre concoctionem, fyr. magis incidentes \& magis calidi vfurpandi funt.

Rz. Syr. Capil \& de Byzantijs añ. żij. mellis rof.z ij. aqua Hyfopi, Betonicx, A pij, petto: añ. quartarium j. aromanfetur cum 3 .j. Diarhodonis $V$ abbat. Iiflem coquitur pituita vitrea angendo $\mathrm{Ca}$ - $\mathrm{A}$ Iorem \& attenuationem. Aquea pituita tenuis cft, quare incifione multa non eget, fed calore ad concoctionem. Quare fyr. conferuationis corticis Citti, mel Rof colatum, fyr.de Stachade \& Glycyrrhiza conueniunt, loc modo.

Re. Mellis Rof. col. fyr. conf. corticis Citri añ. 5 ij. fyr.de Stoechade z j. l. aquarú Menthx, Betonicæ, Melifx, capil. Veŕ, añ. quart. j.mifce. capiat in tribus matutinis.

\section{DE BOLIS.}

I N T E R varias medicamentorü formas recenfentur boli, qui medij funt inter medicamenta ficca, \& valdcliquida. funt autem bolorum differentix tres: ad quas reliqua omnes reduci poffunt. Quidam enim matctias communes euacuát \& Retcora fubducint: Alij purgantes, qui ex alto corpore humores educunt noxios. Nonuulli funt corroborantes, \& quodammodo alterantes, qui exconditis magna ex parte fiunt.

Aluum lenientes parantur

Ex pulpa Cafliæ, Manna,quibus pro partiü \& affectuun varietate, atque adeò ipfius medicamenti natura, varia medicamenta permifcentur, vt pulpa: Caffix Glycyrrhizã admifcemus cùm pul mones inuare volumus: grana Alkekengi,cum rcnes. Anifum ad fiatus difcutiendos quos $\mathrm{Ca} f-$ fia fua natura excirat: Propterea in cholico dolore à Aatibus \& alijsintemis doloribus àb ijdem nó eft ea vtendú : aliquădogranapiperis ad eundé vfum:in natura calida \& biliofa Thamafindi.

Ad Mclancholicum humorem aduftum. ze. Pulp $x$ Cafia recens extract $\&$ per fe taceí tranfrnifixad furntim aqux $\tilde{3} \mathrm{j}$. feminis Anifi $\xi$ ij. Deber autem Caffia brcui tempore ante cibum exhiberi, ne conueraturin alimentum.

Alius Boilusad eundem humorem.

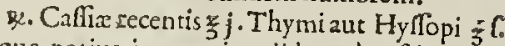
idque potils in materia calida quàm frigida $v$ furpainus.

\section{Bolus ex Manna.}

Re. Mannx recontis albifimx \& granatx zj. C. fiat bolus.detur paulo ante prandium.aliquo humore Manna eft liumectanda aut irroranda ad bolos formandos. 
Ad eundem effectum poreft pomum excaua$r i, \&$ in catitate $₹ j$. Mannx decoqui fuper prunas, deinde pomuri illud egro deuorandum exhiberi, quod haber vim detergendi, leniendi, $\&$ aluum fubducendi.

\section{Boli purgantes.}

Boli putgantis cerraquantitas pref́cribi nố poteft, cum mutetur pro xgti viribus, \& humoris purgandi \& $x$ gri natura. In illis tamen omnibus eft id obferuandū, vt nunquã excedat quantitas 5.j. fi fint vehemétes, exhibendi erunt longo tépore ante cibum. I tem fuperdormire licebit, alioqui non licebit.

R. Caffix recentis z vj. Rhab, z j.facch. q $\mathrm{f}$. fat bolus. Caflix loco poreft poni Catholicon.

\section{Bolialterantes.}

Alterantes boli poftremi funt qui varijs de caufis preferibuntur. Nonn ulli ad ventriculum corroborandum, alijad tollendam intemperien iecinoris, alij ad corrigendam malignitatem tum medicamentorum, tum humorum in nobis corruptorum: quida ad renes detergendos \& lotium prouocädum. boli autem magna ex parte parantur ex conditis, \& ad corroborationem ven tricu$\mathrm{li}$, quibus permifcentur pulueres : vr

R. Confer. Rof. 亏. . Exhibeatur manè praferrim poft aftumptum medicamentum. Talis aút bolus prafcribitur cùm medicamenti vi \& nimia vacuatione diffolutus eft ventriculus. vol fic,

Bi. Confec. aromat. Rof.loco Opiat $x_{5}$ iij.cum facc. fiatbolus. Poteftetiam ad hanc rem parari bolus ex carne Cydoniorum, \& Mýyrobalanis, \& corticib. Citri fac. conditis, quibus omnibusincft vis corroborandi ventriculum. Bolicnim iecinoris intemperiem temperantes, \& relictam à medicamentis qualitatem tollentes conficiuntur ex cóferua Buglor. Borraginis, Cichorij, Acetorx \& confimilium, qux poffunt exhiberiad 3 iij. vel ร).

Sic etiam calefacientes boli in morbis frigidis ex corticibus Citri, \& cemf. Horum anthos \& fimilium.

DE DECOCTIONIBVS.

Decoctionum multa funt differentix, alixe. nim funt alterantes vel aliquam noftri corporis partem, vel humorem aliquem. Alix purgantes bilem flauam, vel pituitam, aut ipfam exiam melancholiam aut ferofa recrementa. Alix flatus difcutienres. Decoctio fir ex radiçib. herbis, fruatibus, feminibus, foribus. Decoctio itaque alterans aliquam parcem fit ex fimplicibus proprijs
\& partillli deftinatis, vnde vel pectorales vel capitales dicifolent, quòd velcapiti, vel pectori fint proprix; \& fic de alijs partibus, ve ad renes, ventriculum laxatum. Decoctio pectoralis fit ex his qux relaxant, \& nequicquam conftringunt, $\&$ abftergunt actenuant. Pectori fiquiden fune inimica aftringentia, v qua eius actionem impedient: quod ad liberam refpirationem \& thoracis dilatationem eft imprimis neceffariú, mufculos\& neruos efle laxos \& obfequentes. Quapropter pectuslicetcalidum fit refrigerandú, id tanien femper roborare folemus medicamentis modicd calidis. vt

\section{Decoctio pectoralis media \& communis.}

pe. Glycyrrhizaz z.j. Capil. M.j. palful.múd. numeroxx. Iuiubarum, ficuun añ. numero x. feminis Anifi 5.j.hordei integri p.j. fiat decoctio, exqua poffumus accipere quart. $j$. ad commixtionem nedicamenti laxantis \& purgantis pectus.

Vel fieri poteft fyrupus medius, pro tuffi, plet:ritide \& peripneumonia,addendo faccharum aut aliquid ex fyrupis communibus, guo v ti poterimus in affectibus pectoris, donec melius profpectum fuerit materix à qua affectus dependet. Quod fi cognoueris morbum efle pituitofum, fyrupos huic decoctioni addes calefacientes \& tenuantes, tergentes \& incidentes, quales funt fyrupi de Hyffopo, de Praffio, de Glycyrthiza, Oxymel fimplex \& Squilliticú: fi fit à materia calida, fyrupus conueniens, addendo decoction i huic refrigerās aliquod fine aftrictione \& incraf. fans, vt fyr, de Violis, de Iuiubis, de papauere.

\section{Exempligratia}

R.. Decodtionis prafcripta $\frac{5}{3}$ iij. fyr, violati \& de Iuiubisań. 3 j. mifce pro vna dof vtatur manè cum tabella vna Diatragacanthi frig. Cìm exploratum habemus materiam effe calidam, minuimus in decoctione qux calfaciunt, auctis quærefrigerant \& incraflant, addimufque qua tuor femina frigida maiora. Lenientibus eodem modo poffumus vti,quod in hac \& in vtrag; mareria admodum fint neceffaria, vt Glycyrrhiza, paffulx.

ze. Glycyrthizx rafa z $f$ capil. M.j. (omnes enim capillares funt medix ofacultatis) hordei mundi p. i. prunorum, pafful. Iuiubarum, Sebeften añ. numerox. quatuor feminum frigidorum maiorum, feminis Berberis qua refrigerant \& humectantañ. 3 ij feminis Bifmalux \& Anifi añ. 5 j. f. florú Violarum \& Bugleffi añ. p.j. 
fiadecoctio, cui poteft addi faccharum \& conficifyrupus; vel fi mauis,adde aliquem ex fyrupis r.figerantibus. Poieft digeftuum ex quatuor d.sib.cunfici,accipiendo pro qualibet dof $\approx$ iiij. decottionis, \& Syiupi ij, huic decofioni eriam poteft addi folutiuum aliquod a 1 materiam collectain in thorace, ve Manna, Callia \& Cartha. m:um Inducoetione aliquando ( $v t$ in pleurrtide \& peripueumonia) Lunt qui velint adderead euacuationem maerix calidx Rhabarbarum, cum ramen ob obftu cti onem minus conueniat, nifí cùm materia purè eat buliora, \& quando damus, potius eft tundum in infufione. Infundatur ergoin decoetione, vel leuiter decoquatur. Addimus præterea Thumarindos, vt in catarrho, $\&$ alia pectorisaffectione cirra in A.tumationé. Alia vacuantiabilem; yt Elect. defucco Ror.de Pfylio, Diaprunis folur. \& alia luufunod. Rofaceo fyrupo folutiuo vi poltimus etiă, quòd huic f́cpo cóneniat, quo quidé cum decoctione aliquá. dovtimur. Illa decotio piadicta quicquid eft in eolyr. aftrictionis, aufert. Notandum camé eft quòd cum decoctionc parazir fro diffolutione. medicaméti laxantis, bonú eft dofin fati iaıgere, \& femen Papaueris auferre. Notandum etiam in omni thorasis affectu iunct a in $\mathrm{m}$ m matione, ve in pleuritide, \& peripneumonia abitinédú in ri misefle à lentiotıbus \& vehementoubus trahétibus medicamentis. Quod iiberum eft vii !n ccr tis affectibus, fimateria fit mulum fubrilis, ve $\mathrm{e}$ geat magnainctaffaione \& refrigeratione, vel in fomnijs torqueatur xger: addimus femé papatreris albi. Promateria frigid a plezumgue vfurpanus radices qux vim habentabftergendi, \& ali. quo modo têperandi \& incidendi: fru Cusetiam quiabftergunt \& leniunt, femina quix tenuant \& calefaciunt: quibuscalidis funt addcnda aliqua humectantia, ne nimium exficcando, materia quxeft in thorace, fiat per exficcationem minus aptaad expuitionem. Fiat igitur in mareria frigida. decoctio pectoralis, hoc modo.

及e. Glycyrrhizarafe 5 j. rad. Iridis 5 ij. Hele nij $z j$. Colum propter eius amarorem \& ingratitudinem. Daffularum mundararum, ficium, Iuiubarum añ. N. x. fol.. Marrubij,vel Hy fopi M. f. fi febris fit, fin minus $M$ j feminis anifi, $F_{x-}$ niculiañ. $\xi j$. Femiais Melonum \& Maluarum añ. 3. . hordei integri parun. Poffumus addere flores Rofmarioi \& Strechadis cìm fufoicio febrisabef. Ex hac decoctione porest fierihos. modoIulapium.

Re. Decoctionis pradicta z vi. ly r. de Hyfiopo, \& mellis Ror.an 疋 I. fyr. de Glycyrrhiza z ij. raife produabus dofibus, Addimus aliquando fyrupum de Srachade huic decoûioni, :cl Oxyniel Scylliticum cum materia eq admodri vifcofa \& e tret multa incifione, Et hac ratione fi volumus decoctioné folutiuam facere, vel in ea vołumus dilluluere medicamenta laxantia, ad furgationem addimus Carholici $;$ j. vel $z$ ij. A arici antundé coquimusaut infundinus, \& praferrim quando vomitum metuinus: Agaricumenim in decotione minus vomitum nouet.

\section{Diecoetio capitzlis.}

Decoctio capitalis ealem rationefaciend Vi:- $^{-}$ dendum enim promùn qua fit intemperies, \& qux fit materia caput grauans: tandem eligimus fimplicia qua in eadem materia apta funt, \& qua capiti \& pecturi conueniunt. Agaricus enim à capire \& thorace pitnitá purgat, fic \& Carchanus. Hyliopus pituitora capitis \& thoracis purgat , vs Batonica, Marrubium , \& il genus. Componi-' mus facilc̀ plures decoctiones, vit cognouimus herbas, caput,pectns; ventriculam refpicientes \& qux feruiunt ad alterationcm, \& euacuationem alicuius materix. Fiunt decoctiones tales, guales primùn dedimus promateria pituitofa \& biliofa, Nunc verò ad ea qux Meluncholiam refpice. te polfunt, deucniendum.

\section{Ad Melancholiam.}

Pro Melanchỏlia autem pritnùm accipiútu: radices gux melancholiam euacuant, vt Polypodium, ( $\&$ lienem aperiuns) ve Thamarifci cortex, \& cortex rad.Capparorum \& Fraxini.herba accipiütur, qua idem prellant, \& ipfum fanguinem mundani, ve Buglotim, Borrago, Fumaria lupulus \& eiufinodi. Cùrz volumus dizcoctio. nem folutiuä facere, addemus femina in decoEtione, \& alia qua fuccum melanch dicum eua-. cuant, vt Thymum, Epithynum, fencn Cafisthx. Decnetio purgans Melancholiam fimilrs eft decoetioni qua lieni pręfcribitur, vt decoctio pituitam purgans, fimilis erit decoctioni pector. Addimus enam \& fructus \&: paftulas \& dactylos. fiat itague hoc modo.

R2. Cnreicis radic Capparorum (ad extenuationem tumoris melunc holici \& lienis me atuum apertionem) Corticis Thamarifi añ. Żj cùm adeft obftuctio, \& lienis tumor feirrofus, infundantur per nectem in vino albo, vel aceto cùm opus eft maiore attenuatione: \& fil tamen viuum magis laudetur (nam: acetum mor 8 eft cholerx, \& humoris melancholici vita) act obftuctionem aperiendam, \& expulfionem.

$S i$ autem tacienda lis laxatina, addimus indecoctione, Polypodij \& Senæañ ż j. Ád.timus \& aliquando Thymum, Epithymum, \& remé Caf fychx. 
fythx: fed minori quantitate; quod inígniter exficcent melancholicos; nam funt natura ficci. Optimum etiam femper his addere aliquod mcdicamenum quod vim hi best purgädi pituitam. Qux enim pituitam craflam euacuant, humoremetium melancholicum purgant, maximè $f_{1}$ adiungantur temperantia \& aferientia, \& exim quę melancholicum humorem refpiciunt. In decóttionibus purgátibus \& attenuantibus humorem melancholicum, ea nunquam funt prater- mittenda qux cordialia dicuntur, quippe hxc vim habenr commodcrandi expurgandique fanguinem, ve Buglolfum, Borrago. ficutinec femen alicuius eorun qux vim-difcutiendi fatus habens, quòd melancholici fatulenti fere cmnes efle foleant. Decoctioni huic addimus faccharum, vel fyrupos, hoc modo.

14. Decoctionis predicta క ziij. fyr. Bug. Borrag. vel Fumariæañ zj. mifce.fiar Syr. Quotiefcunque ex deco fo aliquo fyrupos digeftiuos, $f_{1}$ ue concoetorios paramus pro divitibus vel deli- catis, folemus imperare ve člakificétur \& aromatifentur, cuin puluere alıquo ref́piciéte partem, vel materiam alicguam, ve fic fiat decoctio: $\&$ in decoctione dillolue faccharig. $\mathrm{f}$ aromati. $z \mathrm{ij}$. Cinamomi, clacificatione fucta. Cinamomum enim addimus pro delicatis \& morofis, quia odor \& fapor eius eft multo iucüdior: aliquando esiam aliquo alio molimur id. Quod fi minus conueniat Cinamomum ob caliditaten tum xgri tum tcmporis, addimus Santalú aut albú, aut rubrum, vel Cinamomú \& Santalum fimul,ve hui us fiigiditate illius minuatur caliditas. Menfura autem odor atorum eft ve cuiliber lib. decoctionis apponatur $3 \mathrm{j}$. aut $\xi \mathrm{ij}$.

Decoctio fatiss difipans.

Decoctio flatus difuricns fir ex feminibus Hatus diffipantibus, vt in Carminatino Clyftere aliâs monftratum eft. Hoc tamen intereft quòd in decoctione carminatiua quaad clyfteris compofitionem paratur, minus fumus folliciti de fapore \& odore: In decoetione autem deuoranda, vtimur potius Anifo \& Freniculo quàm alijs qure magis funt amara, vt femen Apij, Petro.

Decoctio communis ferè fit hoc modo. zh. Thamarindorum, prunorum, Sebelten, vio. larum, \& hordei añ. partes aquales c ú q. f. aqunx fontis tiat de coctio. In qua diffolui poteft omne medicamentorum genus, pro tatione affectus xgri, \& temporis. Et vt $f$ cit D. Fintanonus in praxi pradiatorum decoctorum: Iura vtpote etian medicamentefa inftar Serapiorum aflumunturappetenti delicato, pondere trium aus quatuor $\xi$. Interdum etiam vefperi, prafertim vbi tiequentes potiones non fintrgro molettx.

Idem meretur iste libelus testimoniun cum fuperiori.

Sebattianus qui jup. 


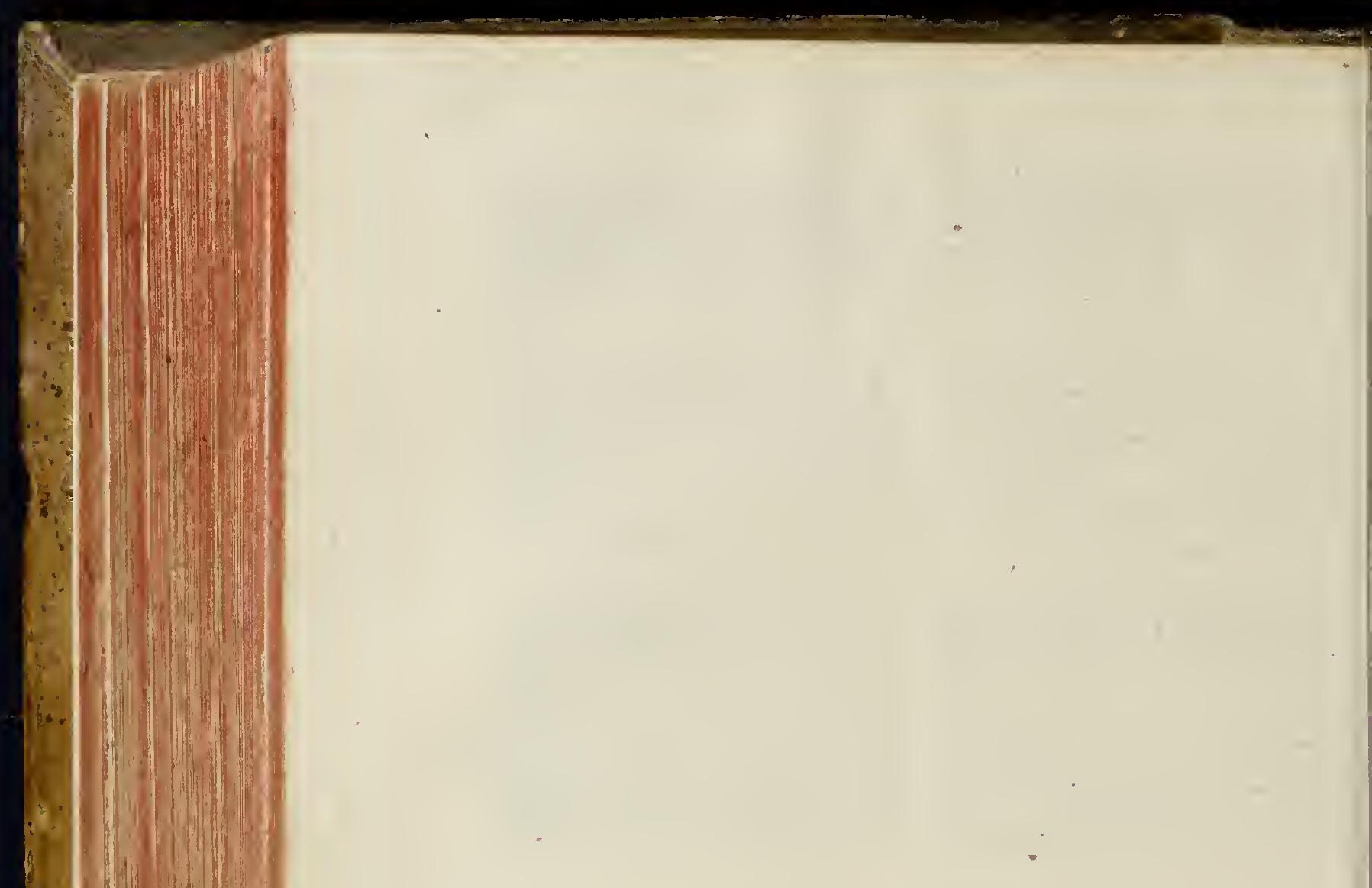




\title{
IN STIRPIVM OBSERVATIONES
}

\author{
ET ADVERSARIA MATTHIEDE LOBEI
}

INDEX CODIOSISSIMVS.

A Bies, Phthorophios Theoph. obt.s33. adu. 450 Abrotanum mas. obc. 443 adu. $34_{2}$. Fcmina, Santonjcutn minus Diofc. Cordo. joid. Abronnu odoratu himilc. ob!. 444 Abr. inoiorum. olsi. ibid. Abrotanum candidum Cordi \& mina Fuchtobl. 436 Abrotanum pereer inu Cupiedi folijs. adtu.

342 Abfrnchires.obl: 353 Ablinhium vulgaie Romant, Pöticum Rucllij ob

433 abinchum vu'sarer on eft aliud a Romano \& l'ontico. adu. ;3j Ablinthi, $m$ fupinum herbariorum. obl:

434 Abinthism Ponticum Tidentibun Ablinthij Ponicimulex fmijiudi nes \& variatates. ibid. Ablinthium arborécens, del Comafeo Anguill, ob ferv.

435 Abinthitubu rnbelliferu. obl.435 Abfinthium vinbeliferusu nitcrum Italicum. olferu: $\quad 435$ Abfintium Galatium, Sarkoniu. cbreru.

Abletia. Santonicum. ibidem. Ablinthium Ponict Dod". Fuches tonicum Ruclij. obi. $\quad 436$ Abfintium falio Romanum oficioa rum. ob?.

Abinthum perertinun:, fue Aerypilum.ob[. $4: 97$ adu.

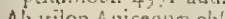
a.d่.

cnarces. adu

Acanos Plin obr. Acanthina 365 Acanthu, Germauica Fuchifolof. 401 Acanthus Th:o, h. Anguillobr: 836 Acanthisfatiuts obl. 477 . ad. 365 Acantlus fylu.ob $\$ 477.2 d u$. $\quad 365$ Acarne. obl: 485 Acarna humilis quorundam.cbr. $48+$ Acatna Theor h. Anguillobr. 486 Acer maior Cordiobi.614.ad11. 4.t3 cius varictas. ibidem. Acatir S Sina Dio?c.obf. $336.2 \mathrm{~d}$. 409 - Acaria altera Diolc. olé536.3d. 410 Acatia cogmata planta. 2lu. $45 \mathrm{~T}$ Acerofa offici. adu.

Accum. obf

Acctum mulfum. ob? Achillcalurco fore C. Clur.obr. $4 \xi I$ Achillea mourama. adt. $\quad 3330333$ Acinaria paluftris Gero. obf. इ47 Acinos. obliz6?. adu. 2.15.216 Acinus Ded. ob? $\quad 270$ Aconitum Batrachoiles, an fit Diorc. Kantunculus albo flo:e. ad. $3 c^{\circ} \circ$ Aconitun Hyedzale Beigarum, obr,
395.386.

Aconitum minimum, obf $\quad 336$ Aconitum monococcon. obr. I 37 Acon. Pardalianches Dod.obif. I 37 Aconizm luteum Ponticum, Itu ici da. obr. Aconitum luteem minus Thcoph. \& Do 1 . ob?. Aconiclam Iycoctorium fiore 29 Acorus Aquiconicus. ad. . 29 Acorustofiras paitutis. obf. ads.

Acorus Tolofas. adu

Aculeora Gaza oblidis9. 24u. 57

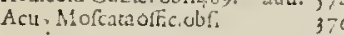
adu.

Acr nis, fuefterilis a th. Adiantum. obl. 471 . adu. Adantí albú \& nigré Plin.ałt. jbid. Adiancum album Theoph. Guillan tino \&: Cordo.obi. 472 .ad 36 I Adonis recentioni.ob 6 , 5 50.2 da. Ir A.lonium Potarum. adu. II Acgipyros Cratetia.ol:f.492.01. 378 Acigrors kromoides Belgartim. cbi 21 adu.

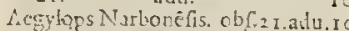
Acriyluys I linij Trago. ad i. Acrzeon.obl: 201. Ritu. ICI Acrconci. adu. Acthiop:s, obt: 304 . adu. 242 Acoypriz taia 20 fit Aron Aegypt: puractin. adis. 25 Acallechen. ob: 576 . aitu. 428 A grallechus rerior. obl. 576 Afgricuns. obf. 636 adis. 44 Agaricum Larignun. al. 44 Agerntum foribus candidis: obe. ? 5 adu. 208 Egetatum, veluon fenefeens $M$ efuri. adu. 207 Agerarum minus. obf. 2 e9.adu. 298 Ageratum Septet.ticnalium. olv.2 adu. 208 Agriacnolin RukJij, old. $\quad 4.89$ Agrum caftus. ad. adu. 358 Agrioriganum. ob C. 262 , ad. 2 I Alousy Theuetrant Clufiabr, 604 Aiuga mas. Diulc. u!r.207, adu. I 6 ส4ti, Anglortm potio.obC. Alabaltritas obr. $\quad$ 49.150 Alabaftites Cordi. adu. 305 Alabanties alteráobi:

Alaterrus I'lin. Clef. \&r Anguill. obe s66.

S.Alberti herba Dosonjcfiú. obf ro Alece valeatis. oldi. 374. adu. 293 Alcer fulifeaua. ibidem Alcer futicofiot.obr. 374. adu. 295 Alcea maior Muconi. obf. 284 Alcen peregrina Solifegua, an Theophrafti Malua? an Argemone al- tera Fuchts adu. Alchimilla obt 378 . 379 adu 295 Alchindion obr 3 I adu. Aleftorolc phos pedicularis: adu. 228 Alga marina adu. A.lie'nyn officinarum, adu. . 38I Alliaria ob 6.285 adt. $\quad \because 2 \geq 8$ Allium, obr: Allium farjui a domefiicum. ad. 59 A liun fyluefre tenuifolitin. jbid. Allium latifolia maculofun fine Serpentinum. sdu.

Alfium yafilito obs so atu 5 , Alifma obl: I 60 a a tu. 126 Alifina Traci. ols. alti. $\quad 126$ Alifma Tragi. obs. A lilima quoindam Cordo obe. I 69 Alifina pufiltum aggufifolium muricatum. obl. 160 Alnus nigra. obf. 594.adtu. $\quad 440$ Alni nigte fue Frangulx bacca adix. 438

Aloe.cbr.20:. adu. I6 Aloe folio mucronato: America Cluf. obferu.

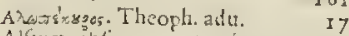
Alfux. obli: $2+5 \cdot 246$ adt. 93 Alfi.e comicular Clifip. obr. 246 Aitine media Fuche. our. $\quad 247$ Alfine minor recentio:um. itu. 193 Alfine minimu obl: 246 . 2du. $\quad 193$ Alfine in jotrtis. adu. 193 Acercuni $A$ able 136 Althez obs $\rightarrow 3$ aln. $\quad 107$ Althea arborclcens Clicij obs 2.93 Alther arborca Obiẹ in Gallo proI incia. adu. 2y Athea hortunfis Dod. obr. $\quad 374$ Althea pritustis Citini flore.ob! 374 Aduch luteis floribus an Ibifus The. oph. \& Abutio Auicennx. obr.374 allu. 294 Alus officin. otr. $\quad 394$ Alypum montis Cetiobe. 20 r Alytrom. obe 283 . adu. 258 Al. lfon Diofcumentiobriztad 255 Aly fin Guleni Ciufio \& Herbarijs. $\begin{array}{cc}\text { obf. } & 283 \\ \text { Aly Don Pin. Corto obf. } & 464\end{array}$ Alyffon Germantum Echioides obe. 466 Alyfion Ytalorum, adu. , 406 Aly Hon facie Cytrat obr. " sos Amaractifipens.adu. 22 A ma-acus tenuiorobi.265.adu. 21 Amarcis vuleatior. adto 2 I

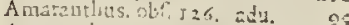
Anamothus angerficulius firplic

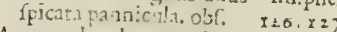
Amelanthis latens. adu, 203 Amaranthus luteus Fina is Tragi. ouf 256 Amarathits ha iariens, fanguirielas obl, I26. adu. A maras. 
A maranthus Galenionts.

A mrenthus maior Horbus pami $\mathrm{C}$ lofi. ficicatis. odil: I25. adu. gs Amaranchus purpureus. atil. of Amaráthts trico'or, obriz 7.2 tn. 95 Aaroruli latilla horen is procerso: obli, 442 , atsit.

Anbrofid fountanea frigofior $3+$ $\begin{array}{ll}+4 \ldots \text { adu. } & \\ \text { tenuifolid, altera Match obr, } 3+\mathrm{I} & 412\end{array}$ Ambibeia, out: Ametanches. obt: 608. atu.
Amclus Virg. adu.

Ammi.adu.

Ammi Creticum aromaticum. 32

Am.t. adu

Am.ni vulgarius obr. 4. 5. 3 d. 321.323

Amonum. obs. 615 atu.

Am.nommillarum offic, adu. Anomus Plin. obr: Inx fuliof altertim aput Plun. $p: a-$ nica fol. ald." $\quad 414.4 \div 5$ Amores. obl.

Ampelops.to.3. obr.

mulca vol. s 67 . ald

Amygdaits. . du.

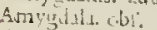

Aam logidaloides nbe.

Anzmilis 3 ?

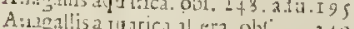

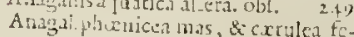

mato olf 247.248 alu. Ig 4

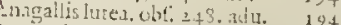

Anzgyris Diolc, obr. S-5.adu. 389

Andyyris minus fuetens, arborefcens.

oll. 504 adr. 388

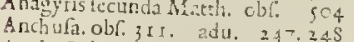

Anchufa degener A coinerix. adit. 24

lignofior anguiftitolis. adu. 248

Andula ninor alu.

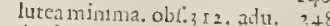

Androfaces, obr, 210.d ditu. 165.165

Androfaces Tragi obi:

Androfuces Cotyluton marum 233

b.a. obf.210. adto. 169.166

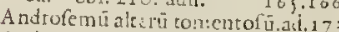

Androfemon, obf. 217, adu. I-

Androfemum Dod.\& Fuchroul. $35 ?$

Anemone tuberolia radice.

unguft tolia altera Clut:

tertia Dod. abe 195 . adu.

Anemone fore multiplicato coci

nco. tinarta Doú.

anguntedia t: rtia multiplex Clufij.

Aacmone maxima foly ärloo 145 cedonica. obc.

Anetrone taberóa Bulboraforai dice, an Ansurone lutcat G.1. obr? - St7 adtl.

Latifolin altcra Clufij.

hrifolia prina Clufy. of ilvit.

Anemone rulorer Gerifor: 147

Secunda Dod. \& remuículiatertia Clufij obt:

tertia Matrhioli, fiore albo, luculen-

ta magnitudine obr. 4 8 8 adu. I 14

Anemome trifulia Doot. \& herbario

rum. ab?: I49.150 dnemone perperam Cordi. obr. iso Anemone tenujfolia Cordi.obr. abid. Anemane Narbonêfis maios obrtidi 2.41
Anemoneminor Coriádri folso adu 1611

Aluemones quinz \& fexta fpecies Dos. ob!

Ansmone Bononienfis. obf.

A iletham. obl". 443. adu.

Angelica, obl. 3ys. adu.

A ngelica fis lu. obt: $399 \cdot 2$ du.

Angelica valieds. dulu.

Aitgina Draco 1ci1. ob/.327.adla.26

A nguina aquirica, obi", 328.341126

An puria Matr.h. \& Italorum. obf. 364 Anifum. obt" +1 s adu.

Anonis varietas. adu.

Anteuphoibium ; obt

ajotati. obl.44s. adu, 34 ?

Anchem is vulgarior. obl. 44 5. ad. 342

a.fu.

Anthora fer aryopatas ob. 385.386 $a d u$

Anthylis prior adu.

Anthyllis Chungroides ato Iys Anthylis 13 monz incans an prom. Anthyllis Diofe.? adu.

Anthyllamarimalcera. adu. 195 Anthyilis altera I tolotin obr Anthylis Chamequontes manor.ob!" 208. a.tu.

Vilencina Clufij \& Place obs 230 Authyllis lezuminoli Belgarim prior Djit. obl?

Aaripashes. obr.

Ancirthiaum. ob斤 $22 \mathrm{I}, 3$ Ju.

Antirthinum tylu obe.

Anturhunu Trastobl I go.alu. 149 A stirdinu mistinti forata Uronthi Archigen:3, obl.t22, dith 575 Antifpoldum, adu.

A paline obt. $4^{6}+$ ats

Aphaca cubl. gis.ads.

Aphaca Theoph. obs:

A phs llanchos Monfpell. adu.

Aplattruin: obli.277.34u.

Apijtes. obl

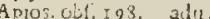

Apros veru,

Diolic.adu.

Apios Fuchr. \& Tragi. ob

Apios Tutneri Angliobr

Apiunatuation obr.

Apium hortenie. adu

Aprum fili. Duil. ohl:

Apium riius, obl: 382 adi1.

Apocynos, ob:

Apocynum.ob5.356.357. 254 .

Apolluaris lierba adu.

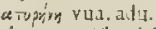

A qual mulía. ob C

A juirolium, fiue A

Agrifolium, Gue Arrifolium seotê-

goin, neque Paliurus Aphricana. adu.

Aquile gia recentio:ü nom fit Potho

Thcoph. fue Defideriu ad 339

Aqutina. oblitzo. adu.

339
339

Aquiline variens obt:

Arabis. obr. 111. adu. 78. \& 463

Aracis. obi: 517.522. ad. 398. \& 401

Arantia, abe:573. adu.

Arbor Cifti folio obl:

Arbor I uila Monfpell. fit ne Cercis Theoph.? obf.6I0. adu. $4+1$
Arbot vitre obr:

Arbufcula Alrina folio mali. afu 435 Aichangelica. obl. Archanzelica valgi. adu.

Archargencas Horealbo obe ind.t.

Archangclica quorundam. obf. $\quad 2 \geq 6$ Arction montaluin obs $318 \cdot a^{2}$ Perlolaba Plinij.? adtu. 253 Arefta bouis. adn.

Arge:none capitulo torulis canulato obic. 1 4t. aitu.

capitulo lonoiore, obr \& adu Itz

Argentina. obt. 345 . atu. 308

A ra Theoph. A ai cffigic. adu. 435

Aris Plinij. adto. 260

Arifaruin Veronsufum. adu. ibis.

A rifandn Hipanican congener cum Arilino anitolio Clu[i]

fecumbin Aciorü Ciufij. obr. 326 Arifarum latufoliu Clutij, num jicm cü Nabonen f? 0\$f.326. adu. 260 rilarum angutufolim c cun fructu racemolo ábo, \& conicuio purpu. rafcentc. ob!:326.327. .4u. 26 r Ariftolochis lonis vera, aju. $\quad 264$ tomnda. ob: $332.2 \mathrm{du}, \quad 26$ Ariftolochia C'enurticis noftras, pir perä longra Matzhio li « Fuchliubr 332. 2.tu.

265

Ciematitis altera Hifpanica.obf. 33 Ariftolochia Polyrrhizon I'lin. \& I. ftolochia. obi, 333.atu. $\quad 265$

Armenincamatus obf

ntiot \& minor, adu. $\quad 436$

Armeria, obl: $2+1$, alu. ISS

Armerius flos frumus Doł. obf. 24 r Armerif floris varictas. ibid.

Armerius flos certius Dod. obr. 242

Armoracin Diofic obf. 100

Armoracia Tragi ob:: $\quad 173$

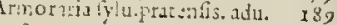

\& 465 .

Armararia alxera. obl. 24

Arnaboarbor ajto. $\quad 35.36$

Arno lolton. adu.

Aromatites obi:

226

Aron Aeovolit, glyod \&. Theoph nu

fit recelitioru Calocali, ?2du, $59^{\circ}$

Arrbeno onois. ob? 130

Arthmira obl:

Artenufia o:se. $4+$ r.adu. $\quad 33$ i

marina ob.. $4+1.4+4$ att.

marina alecra ubr. ibid.

terta Diofe. Leptophull. adu. 34

morind tenuifolia obi: 4 ;

marua neotcricoram aju.

renuifoliz Fuche. obl.

monoclonos Fuch fij, \&-Artheni-

(ine tercia fpecies Ruel ob

afu.

Afum Aesyptium Dot.8. Recenzio-

rum. obC. 325 . adu. 259

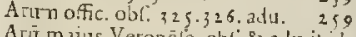

Arī muius Veronéle obl: \& adu.ioid.

A trim Narbonenie adu.

Acuisdines. obliz 8. adu.

Alundo valutoria aju.

Doaar,uac Cypria.0bi.28.2du. 2

Arundo $f_{t}$ ef.

Nones.

Artulo Indica forida. obl":=9.ad ibi.l.

Artnitopapyracen, adu.

A cundirac:a foinoti plinia. at. 45

Afiradarachi Auicening vide infra $A$. zedaractl. 
Afarnm, fue Nardus ruftica. obr,, 23 A u litis harundo, feu tibicinaria.ad. 2 \& adu.
Afrina ferilis. ob!. 329. adu. $\quad 262$ Alcalonirides antriquorum.âdu. Acclepias. obr.3 6 . alu. 278 A celopiasalreta fore nig:o. obr. 356

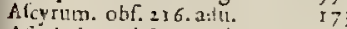
A pialarbus obr. 576. adi. 427 A palathus fecund tis Monfp. obf. 534 Afpalathus rof cus ati.

A parngus domeflicus vulgaris

Sylneteris Manth. obl: 458 8.adu. 593 Afparagr:s domefticus Diofc.idč curn horrenfi $\&$ bijleraceo. ad u. 35

A paranofetreus \& myacanthinus Gale ob:"

Afuaragi \&i Corrudę differétia ad.ibi. A rera Lappago fiue Alperugro Plin. Dod.obi:

Afpervil, liue Afpergula. ad. $\quad 357$

Afperula crrulca obe

A fphoselus maior allus.

Juteus minor. Inteus liliflorus. minimus.

Hyacinthisus forte Ga!en. obf, 46 47. 48 . adit

Acphodedus femina Fuche. obr: $\quad 46$ Afphodelus mincr Clufij 3i Dod. obr. 27.

Afplcnium:bor. 470. åd

Afplenimm lylu. Tragi.

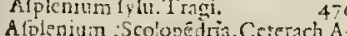
rab. E offici. adu. 360
Afa freteos, an fit fuecus Cyrcnaicus mixtus. adu. Aftonc italica Anguill adu. $\quad 374$ Aftrantix. obr. $\quad 3.88$ Aftrantia migra. ollf. $388 . ; 89.2 d u .304$ Afteraticus.cbr.r\$8.189.asin. Is7 After articus lateus Fuchlobr. $\quad$ r 87 adis.

Afteratticus fupirus C infij ois 143 Afternetscus Cordi obl: 446 Aiteratticusmatinus.obr. 2IS Afternonarrichs Tragi. obf. 137 Afer Conyzoides Géfinesıobr. 188 I 82 .

After J talorum. ohr. ibil. adu. 147 After minor Norbonenl. allu. I I After montnnus diplex. adu. ibil. Aftragalus force Mratth obr. 525 Altrigilas Inlitanicur Cluf. obf. 52 Antravalus Sy racus. ob: $\quad \$ 2$ Monfre licnfiú.obf. $\{23$. adu. 40
Afrao ali pe: fimilis pulilla planta. Aftranali perfimilis pufilla planta. $2 \mathrm{du}$

Aftragaloider Herbarjorum. obf: 525 Afragaioide al cera Herbar. obl: 52 Atranafin Liveli, obe

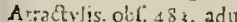

Atractylis micior Fuchr, obr.

A triplex fatiua ol fl: 127 . adu. Atriple\% fyln. vulgatior finudia, obf I27. 128 . a1u.

Atriplex fylu. latifolia.

Atriplex terian Matth.

Atriplex marina repelis.

A triplex olida.

Aureis virga Villanonant. obf. I59 adu.

I 25 Aares virga yilatalant an Letros A vereaviga altera lerrato fol. obl. Is Auscula intress adu. $\quad 200$ Auricula ir.uris maior Tragi obr. 317 Aur cula ludx. adu. $\quad 434$ Auricula leporis, adu. Auriculavrfiluteo. obr. 306.2du. 244 Auridifolutio obl: $\quad 652$ Auena. obr.

Auena vefra \& ferilis. adu.

Auenanuda.ad.

Azedaractr Auisennx. obr. astu.

\section{$B$.}

B Accharis adu.

Bacchris Monfpell ors 249 B3.2.lote obf. Ballamjina cucumerina punicea, obd: 36). aśt. 289

Balfamina ferina perfici folia. obe I72. adu. ${ }^{\mathrm{I}} 34$ Balfamine ofic.obf. 272. adt. 218 Balfamita nulior Dod. obf. 174 Balfamum Djofc.obr. 943. adut 415 Balfanu A prinli.ob1. r 99.2co.ad. Iss Tamia Eircn. ad. 295 Bartifecula Trasi \& officinarū. obr. $=95$. aduerf.

Barbicupra. olf. 409 ad́l. 236 Batbarea. obC.I 04. adt1. 7o. 7 I Barbars a minor. ibid. Barlama, atu. $\quad 253$ Bafilicum adu.
Butrata Hifpanom, fitue Datrades. cbl: 369. adtl. 357

Barmchium A puleij. Batrachioid is bulbora obr,386.ad.;00 Sx 301 .

Eatrathoider gernnivm. adtu. 467 Batis 1'in.folócrafto olf.21 3.2d.168 Baris risbus, morabaina. adu. 446 Baucia. olf 408. atu. 317 Pepleguard vide Stinzallio. Bdellum.obf. 5ro.adu.

cits fruetus, oht.

-

epra.sdu2. 195

Brizbse idu.
Behen album Salamantinum.obl.182 Behen albunu Moufp.obr. $\quad 18$ Belien rubium Belearum. obr. 134 Bchen rubrum Cordt obf. is Behen iubr. Sali mant. Cluf.obr. 242 Butis naior. obf.22 22.253.adu. 242 Betlis bortefis multiplici flote.oly.2 53 Bellis matia. adu. $\quad 2-3$ Bellis crrulea noftra.obf.25 3.ad. 2 co Bellis aphyllanthes \& trondiflora An

nuill. obr. 253

Be"u vide Glans vnguentatia.

Beuzoin recentiorum, non eft fuccins Cy resaicus. adu.

Rerlens. obf. 509. adu.

Reta. abf, I2s. adu.

folijs. obt: 129 .ndis.

Atuplex Halimoides.

Anellana nux.adu.

Eeragliba a alu.

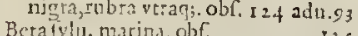

Detorica. ob:

286.237

Betonica aqquatica Seprentrional 20
Clymenü Diofc.obf.288.a\{u. 2 zo Bctonica Pauli, Dod. ad́u. I 97 Betula. obf:60\% adu. $\quad 440$ Bicre fine Cercurfix côfofitio oblig Bifoljum.obf. 161.adu. $\quad \$ 27.464$ non eी Alifmz.videcur Ophris Pltnij. ibid. Bipinella fangurforba.obr, $\quad 112$ atu. 320.321 Bipinella faxifraga hiscina minorob: 41 3. adu. $\quad ; 25$ Biftoita triflex; quarem vna quarujs aíleritur Ditannica. obC. I ss.rgó adu.

nifturia Gerneri \& Lugduncnium. adu.
adineri ü Lugdunentium. Butumen Diofe obr. 635 Blattaria. dor. 303. j04. an Chrylo gorum. adu.

243 Blizmoncting adu. 94 Blitum maius Mattl.obf 226 .adu.95 Blicum maiusalbum: minusalbum, rubrtm, minus rubrum. adu. 94 Bollerine Belg.obs:

adit. 136.237

Bana Dod.ch. $5 \mathrm{sg}$

Bonus Henricus.adu. 97

Borlagominfma herbariorü. obf 246 Borys. obf. II 3. adu. 80

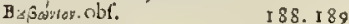

Brancavrfisa. adu. $\quad 365$

Brarca vifina arulenta. obc. 477

Brnffict diueríx. adu.

Brafica, ailua \& rubra copitatz.obr. 23

adu.

Braffcayulgeris ratiua. cbr. 212

foridatorytis. obf. 123. adu. 92

marnh Sabazuda yuluo odu

fintbinax. obl: 123.124

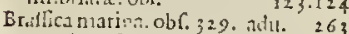

marina fylueftis monofpermos.

of I2s. adu.

Caulorapaperegtins, medio caule tubinata \& rapata. adu. 92 tchur folia lacinata obl: I13

Aaglica mmina. àtu. $\quad 92$

Betriter compeftris Clufij.olf 215

Britatinjea obirsz. Jdu. 121

..nnisa Gefneri \& I ugdunéfium.

Briza monococcos recentionâ S Dod. obf. Iy. adu. Bromos, \& Bromos Aterilisaltera. c br. 20.21. ad.

Bromoides Beloarumofe? Brunella:obt: 2si.2s? Boyas.obr. 64 Biyonlacturefolijs Plin. obC. 647 Bryonia filneftris !cu nigra. ob? 344 . adu.

Bucianfic obr. 279

Buglotim vulgare angutifolia. obr. 310. aite. $\quad 246$ ius varicess.

l.2trolizm obl.

ibid.

Burofoffun minirium fore 30 obf: 310 . idu. 247 Titulofium remper virens. adu. $\quad 247$ Builaflumpers yinum. adu. $\quad 247$ cius yaitecas. obr. ibid. adu. 247 Buglofien craticu Echioides ad 27 Englohum acrefe, adio. $\quad 2,49$ Bugula, obt:252. adu. 1 , 


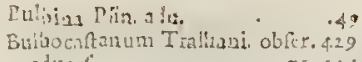
ajuert.

Bulbuphoidclus atti.

Buibus Codion Theonth" oly?

Bulbus Letcon: hemus uninar bat.

Bubisefericntus Diofer ob: 73 adiatc:

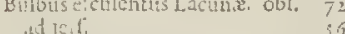
Bulbusit. Fuche. \& Trngt obre ibis. Bulbus ionituries Dolgis.a.'s is Bulbu's Semains ala. Bunias. Bunins fylueftris, ndu. Bunitun, adn. Bupleuram, olfr.z4;. adte. I 9 Buplearum Dod. \& Herbation obl: 244 adur and I 92 Bupl:

Buptithalmura odu.

2n.2.3.

But.

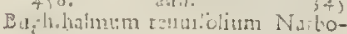
Euphehalmum alterum, folio \& fici $^{445}$

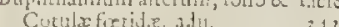
Butomó Theoph. Valusato oor, $3+3$ Butca paftoris. obli iro. alds. 75 Buxus, obf, 562, ad:

c.

CAcalia. obri, 321.24 l. 255 Uacinges verio obr +5 s.adu, 395 Cakile Serationis, oblitio, ad. Culaminth mentaftrifoli.i aquarica hirfuti, tertia Diole. obte 273 aduerf.

Calamintian montana preftancior. obferu. 274. adu. Cla

Calamiatha altera odere rraui Pule gij folis inaculutis. obf:275.ad.219 Calaminiha fecubda incana.obli 278 Calamintha a juatic. B B:Igarit.cbe. 270 aduerf 217 Calamogroftis, obr. r 2, a'u. Calamusiold Calathinna viola Plin. Dod. obf. I 66 Caleculus Mariẹ recêtioruas obli: 162 aduer:

Calcifraga obl:

Calcier

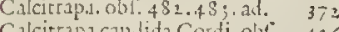
Calcitrafa candida Cordi. obfi. 426 adveri:

Ca'endula offico adu.

C.allitrche Tlimaj, ob:

Gallizrichon A puleij. obr

Calth.s A lpina Gefieti. obr

Caltha paluftris Gef. oble 323. " \& 336 Caltha Virg. Tragi, obli, 23 ad, 2 \$ 6 Caltha paluftris recentiorum non eft Chamaleuce Plin, adu. $\quad 256$ Caltha Pétrarum obli 298. 299 $\begin{array}{ll}\text { aduet. } & 237 \\ \text { Camotes. cobr } & 360\end{array}$ Campanula maiorlazelcês, pyranidalis Litetani obi. I7 Campanuia perficifolia noftras. cbl. 177. adu. $23 \%$ Campanula minor rotundi foliz, obl:
Compante lafuraherhariornm. obr.

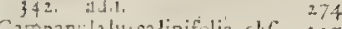
Compantalu: calinifoliz cte, 227

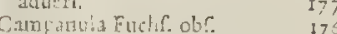
Carapandize cha loorentes an turione Thoophr. adte. I 39 Camphorata-Monfpellienfium. ob! 20. an Clamepence liatemint

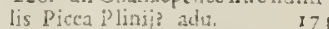
Ca'mia Plin. A nezul, o's: Canis Pla acrus adus.

Caniela regia ob Camabra aquatica, Enpaiorium

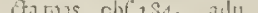
Cannabina aquaica femina Septentrion-lium: adu. $\quad 1: 7$ Camabis obl:284. afia, $2 \div 5$ Cumabis erratea paladola fylu. obl: 284 adtr. C.mmatis l. Diolc. Mutono. ob? 37 . 2ult. 466 Connacotus qror'tndam, obr. 27

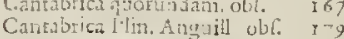
Cantabrea Turairi Aajli. obs 245 Capilus Vinerio ve us. adu. $\quad 3$ or Caprios. oblo 437 . ada. 3 is Capnosalos hicifolia obr: 433 C.rpros phrugmitis Piinij Cordo obt: Caphos renuifolia.obf.438, adu. 338 Capros renuifolia.obl. 438 , adu: 338
Capnosalera fabacea radiccobl:439 C.?tritum Actij. obr.

Cippare. alu.

$2.3 \mathrm{r}$

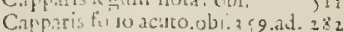
Copparis recufu bolio. obto 359 attueri:

Caprificus a:tu.

Caprifoliun. ad

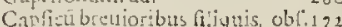
Iaz. all. Copher galliniceum Bercatum, obi. 525. 227 , in Onobry dis Dioic. ddu. 4 .

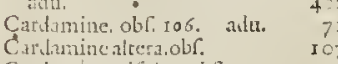
Cardaninetrifolia obl:

Cardanum Apuleij obf:

Cariaci, ob 278.279 afu 106 Cardisez Metica. ibil. Cardom onum obf 616. adu. 445 Cardomonum maius vulyi, minus, min minumedirob: 16 adu 445 C.udu. aúu.

Carduas acaulis feptentrionalium. obli. 480 Criduus butbor:s Montpell enfitum, an fir Leucacantha Diofc.adu. 371 eius varictas. obt:

Cardurs Benejictus. obc. $\quad 494$ aduerf. 372,373 Carduus echinatus Gefneri. atu, 358 Carduus eriocephalir D d.obl: 48 ? Caridus ferox obf. 485 Carduus Gahaxias l'lirs. obr. $48=$ Card. hateus obr. 479 . 2du 356 Cinduus leo obs

Carduus Marix. ad.

Carduus Morize. ad y.

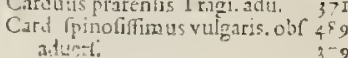
advert.

Carduus rentes. Carduus romenzofies Angicus. eb? 98\% astis 320 C.ardtus fyuet. Doas. obr. 139 CAd ancellic moncis Lupi, adu. 489 Cailina Iterbsriotu obf: 479 , ad, 367 Cirli. a iytu. Doud obr 479 . ad, $36 \%$ Carl a iy lu. Doul obr. 48 Catlina fylu minor Clufij, cbr. 485 Carlmax vifum, adu. $\quad 387$ Carobian atu. 4 I Catomatbu, nigra. adu. $\quad 32$ Carotaly lu, vulugiobr. A56.ad. 32 Carpinus. cblino7. adu. tito Carpoulanum adn, 4Is Catyoplyolata Alyina : crophyltas auder: 30 Cnyorhylata mior rotundifolia,

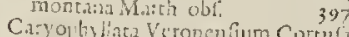

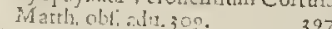
Caryophlylutuvilgaris, obro Cuncert 309. adtu. 309 Caryophylins, c br.241. ad, 133,427 $\begin{array}{lr}\text { Caryophy'llus minor i:- obr. } & 245 \\ \text { aduent. } & 188\end{array}$

Caryophy llus maxinus, cbs. 243 adverl. 139 Caryoghyllus meztanus alter obr. 242 Caryorly litli noftrates an Cantibrica Carjogltylli noftrates an Cantibrica
bin. andu. Caflia Greconm obf. 573.57 alduct.
Calta foctica Menfell an Theoph. Calia pretica Monfell au Theoph. Cadiapte gatrix obs 54 adu 48 की Catfycha plin oble 233 adu in Caltanex. obli $588.264 . \quad 4: 3$ Catanea equinz du Caftrangula, adil. $2 ; 0$ Cramancheverague a'u. C. Caltapucia nimer obli i ). adu. 113 Cattaria. obf. 276. atu. 219 Catotehites ex currcia vinū. ob:? is Caud radix lierbariorum, adt. 338 Caucafun, Moly Indicum vocatum. obler.

Cauculis vuloaris albis tlozbus, obt? 420. allu. 324. 32 Cuucalis flore rubro folio latior. obt. 420
Cnucalides dux vulgatiores, ad. 325 Cancon Pin Anorisile obl Canda muris. obf: 241. adu. 157 Cauda vulpis Monfpellienfiú.adu. 17 Caules, vide Btaflica:

Cuulorapas adur.

Kn:is. abl:

92. 463

Cectrostycis obs 630 adu 586

Cedrus Libania, \&: Palcęt1ma prixcelfa. obr. $6: 0.2 d u$.

Cedrus Phoenices, obf

Cedrus phenicca media. 423 wheca minor. plir. Pheratea aleca plin. \& Cethus Phosice. Math. obr. 4:5 Cetringm vinmm. obr: Ceterach ramefism obr. $\quad 313$ Centanrium maius obr. 409 , 45

Centauriũ maius alterum. obr. ibid. 
Cestatrij maiotis varietas obf. 4 ro. atteet. 3 . Cêtâtrum minus forbus durcis ob

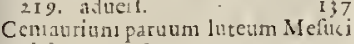
obli, 213 . adi. Ix. Centumcria,nun Ereftedani Theopli. adu. cell romirini Theoph. Anguill. 36

Gentrumgalli. adu.

Centummurbia. adu.

Centunmodia. adu.

Ccp3 ob 73 .

Cefamarina Hilanica, fine flore

oblo 75 . adu, 57

Cerca.obr.2r4. adu. 169

Cerafi, obf. $\{92$. adu. 436

Curafavio pediculo plara obr. 593 Cernfaracemofa. obi. 593 adu. 436 Cerafus atium Herbaiorum.obf. 994 Keecrias filiqur. ad'u.

Cercis Theorh. adu.

Cerealia. adu.

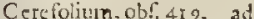

Cerevif Plin. 419, 3tu. $\quad 324$

Gerenina Plin obf.

Cerinch Illin ad

Cerinthe nasior, obf a $x$ s adu. I 72

Ceriuthes maior is tres differentix. obleru.

Cerua maior, adu.

Ecruicaria. obt 176, adu.

Cenuicuria Gefieri quorundā.ob.260

Cerui ipina Cordi. obs: 599. adu.433

- Cerris Plin. maiore glande. obr. s\$4

adu.

$43 \mathrm{x}$

Cerris Tin. תinore glonde \& calyce

Cerris clans immaiusa.

Cerris Theoph.

Chamacilfus, obr 335 ibid.

Chamxeilfos Oribatij. cbr

Clamxceraf:15 obe 593 du 436

Chamxseratus alpirens \& Cordi. ibidem.

Chameclema Corui. ebf. $\quad 336$ Chamxcy parifitus l'in. Herbariorú. who d4\%. aćtu. 34

Chanxeyparihüs agreftis Traoi. ob. 709.

Chamedaphne. obf. 200 . adtr. Is Chamadaphne Diofc, Mutono. obf. $468 . \quad$ adu.

358

Chamedapluse, fiue pufilla Laurus,an Germanicum Mezereum, an jotius roftrü Chamęthododendrum. adueis.

Chamxdrys maior. obl. $\quad 260$ aduerl: $20 \%$

Chamedrys montana darior. ibi.t.

Chamedrys minima fumina Dodonxi, adu. 209 Chamędrys lacir iatis fulijs. obf. 2 (C) Chamędrys varictates.cbf. $\quad 260$ Chamxficus. obli, 612 adu. Chamxgelieminum grandi forum peramonum, obf. Chameg

Chamelxa Diof. obf zor adu. 157 Chamelara Alrina incanitadu. I5 Chamcla incana Renonié? olif.zos Chamclar tricocsos, adu. $\quad 197$ Chemaleon albus Diofć obr. 479 Chamalcoa albus caule donatus \& albus Furhe. obf.

480 meon niger hembat. obr. ibid. Cmaleo niger vulgaris Diofc. ob. ibidem.

Chamxleo niger Maranthx. obf,48 I Chamaleor non actalcatus 'Theoph. adu. Chamixlcon Salamanticanfis Cluffi. 486
Obf.
Chamelecnis nigri fpecics. obf. 484
373 altr.

Chamaleuce Plin. Anguill. ob? 323

adu. 268

Chamelinum. obf. 227

Chamcmelim Chry fanthemü fuch: dre.

446

Chninmelume eranthemun perpeChamanefpilum. adu. $\quad 435$

Chamennilla. obf.445: adu. $\quad 342$

Chamxnerion Gefmori. obf. $\quad$ I 86

Cham:epeuce Plinij. obl: I74

Chamapeuce Cordo perperá.obf. 645

Ch.mxpytis maior Diofc. adu. *I 6

Chanapytis prime Diof. pinum rctulens obi: 208 . adu. 16 Chamapytismas, \& tertia Diofc.

ouf. 207

Chamepytis in Dod. \& Matth. ob ibidem.

Chamepytisprimaltera. oblezog

Chamepyets tertis obf. ibid.

Charixpytis molcata. adtu. $\quad 164$

Chamępytis adulterina. obl. $\quad 209$

Clumxrododendrum. adu. 155

Chamarododendros Alpigena odora.

obti. 299. adir. Ifs

Chamaroledendri oúor.x Aipigenx

vatictas. ob.

Chanęrithes, atlu. $45 x$

Chamafputiun Tragi. obs. 534

Chameljece obfirgs. adu. Is \& Math, cbi

Characias Platyphylló Matth.ad.t sz

Ciarncias Anglicus \& Fratacus, adu. I 52.

Characiasprimus Dod. obr. rs9

cius vareezs. ibid.

Chelias quarta a Belgam. obi

Chelidoniun maius. obl: $439.4 \% 0$ aduet:

339
256

Chelidoniun minus. obt. 322 .ad.2

- 323

Chelidonia phramitis. obf. 439 Chelidonij crfertia Theophratticè.

obl

440 Chodrila cartulea, cichorij Sylu. Chondrilla prior Diofe. Clufij. obl. 116

Chondritla altera Diofc, obc. if atu.

Chondrilla altera Ded.obc. ibid.

Chondrilla Galeni Avgt obs. 117

Chondrilla rara pur furante flore.obl: I16. 2inl. I89 Chondilla vesrucaria. obf. Ix adtr.

85

Chondrilla pufilla marima lutea bulbofa, an Divic, sogration, \&an Cichorium Perdionue Theophr. atu. 83.

Chryfanthemum obr

298
Chry fanthemum fegettrm.obC. 299 adtr. 237 Chryfanthcmum oculaurial reitis Diof. adu. 237 Chryfanthemi flore Buphthalni. ado. 175 Chryfauthemum Peruuianum Dod. obr. 322 Ciryorantheinum litoreum. obs. 215 adu. 171

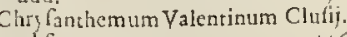
obr: adu. 203 Chavfocome Gefn. Dalerc, obr. 223 Chrylocome altera Mutoni. obf. 224 Chrýlogonum. adu. 243 Chry folachanon obf. $\quad$ I 17 Chiy fomela Athenxi. obl. $\quad 572$ Clirifophoriana obl, ;88.adu. 304 Circxa. adu. $\quad \mathrm{IO}_{4}$ Circxa Lutetians. ob\%. $\quad$ I37 Circra $a$ ófpeli.olyi. I 36.137 ad.r 04 Cicera. obt. $\{17$. adu. $\quad 399$ Cicer Orobeum. olv. s I 9. adú. 4co Cicer Oroboides yvormindam. oblig16 Cicer fatiú Diof́c. obf. 519. adlu. 399 Cicer fylu verius obr. 520 a du. 452 Cicerlylu. herbariorum. ibist. Cicercula Plin. Pennino. olve $\$ 13$ Cicercula alecta,an Phuleolus Diolís? adu. 324 Cichoritum \& Ambubeja. adu. \&: Cichorium fatian, cortulcum, picris eadem, fed culte variatum. ad. 8 ,

Cichorium luteum praréflé. a.Ju. itid.

Cichorium Coufantiropolitalusm Matth. obf. 117

Cicuta. obl. $4 \geq 2$

Cicuta minor Cordi. obr. 4

Cicutaria maxima Brácionisan Th1 pfia tertia Salamanticeufium Claiio. obr.
Cicutaria latifolia fectidifima obf. $4 \geq 2: 3$ Cicutaria fatua. obi. 423 . adu. Cicutncis poluftris ob:

Cicutx, \& Cicutarix diferentive a.ju. $\quad 326.327$

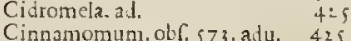
Cineraria. adu 80 Circasa. alu. rou Circexa Monfpell. \& Lutetiana. oly 137.

Cirfium Diofc. obf. 3I4. adu. \{2I Cirfium altcrum. ibsd. Cirfiun luteum sequanorí. obr. $4^{x}+$ an Acarna \& Eryfithz.is Theop h. alu.

Cirfun Anglicum. obf. 3 I 4 . 3 is Cirfium malus, obr Cirfij Carlinxue fyt. varietas.ob 6.4\% Cirfii valictates. obf. 3 is Cirfampelas Helvine. obf. $\quad 343$ adu.
Ciflampe os altera, Atriplicis effigie. obl 343 adu. 27 Kergis. aciu. 269 Ciftus mas cun Hypociftide.obr. 348 adu. 413 adu.
Ciftus mas anguftifolius. Scetndus Clufij obf.

Ciftus mastercius. Ciftus mas quartins. ibid. Ciftus mas rupinus, finnaris \& finbitatis folijs. mas guintus Cliti: ibidem.

Ciftis 


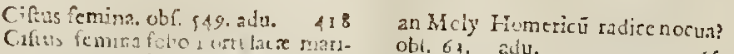
กı: p":mus folio Fcrealuca mariMaclinis. aht. 550 Ciftustecurdas Clutij folio Hinlini. Ibistr.

Cilti varie fpecirs. obf ibid. lerandi. obl:

Cifus folio Santruci Ciufij.

Ciftus folno Thymi Cluh

Ciftusbumstis anguetichus. \& s5l.

Ciftus humilis Clufij.

Cittus bomilis annuus, folio salus humilis. obr.

Cittus anumus folio Ledi.

Cinti lediditerente ibid.

Citus Ledon 418

rius. Ol.t.

Caitus ledon fronde populnea. obit. is 4.

Cirti tolio as bor. obr. 559. adu, 387 Citra. obf. 572 , adu, was 387

Citmus phelladris Arcadum apud

Theorh. adu. Arcadum apud Cirrog. ant

Crrulus uticinarum. obr 220 adil.

Clematis, fue Peruinca mitor, 28

360. adu. 282

Clemstis Brtica Clifoj obr. $\quad 347$

Clematis Daplnoistes, an Centunctilus Plinij? obi

Clemat, aitera Matt, se Cord. ob. 340 Clematisatera Diote. Dost. Ob. 34 s

Clematis pe egrina carulea or purpurea: an Puthos Theoph. . Doid. adu.

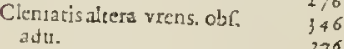

Clematis aliera minot longrifolia.

Clematis purpurorubens polyf 346

Clematis purpurorubens polyntora.

Clematitis, adu.

360
165

C'lematitis altera Hifpanica.obr. 333

Cleme Anguillare, Gemanoruni,

\& I Lchf. obf.

Clinopodium ruigare, cbl. ailu.

103
270

Rusct?ox Anguill, nIf. 61 4.adu. 44

Cigmelum yuorundam. obf. 346

Clymenu I taiorun; lite Sicilizna 346

sijguorundan. obf

noneft Andruficnon adu. 357

Clymenum Matih. obi:

Turberi. obf.

Cnicus, Carrhamus, adu.

Cincus latius Theoph. cobs.

Cnicus por. corruleo, Cnicus alter Ciufij obr

Cnirustupicus Cordi obr 488

Cincos fylu. vrergue, vide Candum 484 Bencifotum \& A.r. ?tylidesn. Cercus infectorta, coccos baphicos.

ohf.81, nn Aquifolia Dlin.ad 430 ohf 58 . nn Aquifolia Ilin.ad. 430
Coccigra Theoptr. adu. 412

Ceschlearie Entauica. obling.adu.121

Cechiesta Brizanica. obf. $\quad 1: 6$

गdu $\quad 1: 6$

Colchicum fiue ftrangulatoritiobi. 69

alit.

Colchicum candido ftere Agrlicuin, obi, 63. aitu.

Colchictim Lufitanci ferotinum, 45

eitus varukas. obf

Colchicū Syriacum Alexandrinum Obi. 70 . atu.

Cokhicum monus: montanum CluLij. obl:

Colchicum Illyricum fue Gracú no venenatum Anum aracú no

Colchicunj lateun, au Ephenero $7 \mathrm{r}$ venenato Diofc congenet? obl Culocalia. obf. 32 s. adu. an ea lit Aron Aenyptiü putatum Inaliz nuper anquabum? Colocrnthis, obf. 367. adu. ibid. Colocynthis, obf. 367. adu, 287 Colocynthis pyriformis. obe. ibit. Columbaria dodtãtalis, an fit Scabiolaminima adu.

Columbina recentiorum, adu. 339

Colus Iours, obf, 301. adu. $\quad 24 \mathrm{I}$

Colutea Scorpioides, \& eius varictas.

cbf: 529 adu. 405,406
Coluted Scorploides coronata, obfor.

C2).

Colures. Theoth. our.

aju.

Coliteaminims, obf

Colycea Tlieophron. 53 440

Concivanatiferx.obr

Condrilla Belgarum adn.

Condrilla pus:lla marina adu.

Cödrilta Coronopi tenuifolia. 8

Couderlla vinnoca vifcofa vucarum. adis.

Conferua l'linit. ob!"

Conferux m.rrinģ genus quoddam$$
\text { obf }
$$

Confiligo Matth. obf.

Confihgo Ruellij.obl:

Confolith aurea nemorum Iit 387

folio obf

Confolibinaior, adu, IIs

adu.
Confolid minor officinarum, an $\mathrm{Lel}$.

lides Plinunx atu.

I 9

253. adu. $\quad 200$

Confolida regia obf. $\quad 426$

fit ne Delphinium vel So.andrum Diofc, adu.

Confolih regia fecerum obr $\quad 3=9$

Conuoluulus mator Plin. adu. 271

Conuolualas minor purpurcus. $27 \mathrm{r}$ ?

$3 \neq 0.3 \mathrm{~d} u$.
Conor purpure

Conuolutus minimus fpicxfolius.

obr: 343. adu. 274

Connolutus afureus fioe cxruleus,

obf.34\%. adu. 274

Conuoluulus peregrinus Clufij, ${ }^{274}$ Conuolurilus Scammonij facie.

obf. 343. adv。

Conyzamaior vera, afu.

Conyza minor vera ad

Conyzamedia obs abs.

Conyza mininia

CorIndumina, 0bf.187.2du. Its

Corallin. nbl.s16.adu.

.06!

Corallitim nigrum

rallium album.

eius varietas, obr.

Corallina. obr.

ist

ilid.
Condivile fpecies Dod. obs

Cótolidx ninores \& medix. obc. 2 If
Corallina rubens Antipathis facic, as Qnercus marina tolo Alyriex Th:oph. obi.

6 so

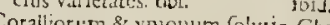
mifice. obr. $6 ; 1$

Coralina alba, ob:

Corallioides Cordi. adu.

Cordic adus 305

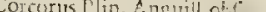

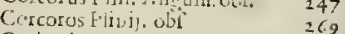

Corianúrum, obl.403. al.u. $\quad 314$

Corinirum altertim, ininus odorum.

obt.

Common, Ccrion, Coriandum,

Coriophora fue Coriofmites flore $4 \mathrm{c}$

ftarcunicum obe

Co:is Diofc. obt: 90

Coristonfpellienfum. obr. 120

I 74

Corts Matthioli.

Coronopus. ob?

ailu.

Therser. 243 an Tes miluinus Columele

Lo: ob. 239 . alu. I 87

Coronopusfyl obf. 240

Coronopi media planen Mlonfpellien.

fium, adu.

Corona \& caput monachi obr. 117

Coroma ratrum.herbariortiobio 4 ts

Coromateria. obt.

Corrada, diftert ab Aparago altili,

Corruitateria Clufij. obs 35

Corrudatertia Chufij. obs. 4 ,

Cortuda varietas obr.

Comn ceruinum. adu.

Cornu Cernialterun rulgi 21 . 187

Corras Diolc, obl. s9r. 59

adu. J91. 39

Cornus femina, obf. $\quad 59$.

adu. 436

Corylus. obr.

Corylus perfimilis Aino ob?. $60 \mathrm{c}$

$4+38$

adu

Colus dulats s. amarum atu.

Coltus Arabicus \& Syriacus Zingi-

berisefficic alt:.

Cortus indicus nigrer, adu. 34

Cofus Indicus Clufij. obr.

Cofur. Malucenfis corciculus, rugo.

fus. atur. 3

ibi Mongefis lignolus feruldior.

Jbidem.

cofus curn caulis ferulacei fruftulo radice pulla, num Diofc. Indicus coftus? obc.

Ceftus facieradicis Cerma $33^{3}$

ris. obr
Coltus hortorum. obr. 174 adu. 136

Cofus minor horteulis Gefneri 36

Dot.obr.

Coftus niver nuperonum obr 259

Contus ipurius Ily rous ab

Cofus fpurius Mandis. 3 ts

Contus buxcris, adu.

Cofus cficinarum, adu.

Cotinos Piniti. adu.

Cotonatia vulni. adu. ithid.

200 
Cotoriea \&.Crtoria mataob́. gso adu. 429 Cotula, fi te Pathonionmarinú nirimun. adu.

Cormla inojora.

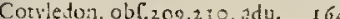
Cotylelun acrisquatica Sepecntrionatium, au Callirriche I'liny .? obf. 209. adu.

Coryledon minor Sedi foiso mon:a nus. obl. 2 ro. adu.

Cotylado Vubilicus Vencris a 16 Cotylaton marinus. adu. I 65 Craccaminima. obf. 52.2.atu. 401 Craftula maiorlilfarica. obl: 212. 2 I 3.

Crafula minor officinarum.adu. 163 Cratxous Theoph. Anquill. obf. 614 Cratiogus fore Theophr.obr. 597 Ciatrogonon.obr. 22. adu. II
ciusvarieras.

ibit.

Cratrogonum alterum qucrundam. obf

Crarxogenum Cordi. obr. $\quad x 71$

Crimnom ab!.

18

ta Plin an porius of Alliaria iectorionm? olf e 85 adu Crithmus Chry fanthomus Dod. obt 2 Is.

Crithmum, feu Crithamon, an Foruuluca inarina? adu. 168

Crichmun tcrtium Matth. obd 21 Cribmum quartum Mattí.obl. 49 adu. $\quad 168$

Crocodylias magna Actij. adur. 368

Crucodylion. obi. $48 \mathrm{~s}$ adu. 368 an lit Chameleoniger Marautha: ibidem.

Crocodylion Fucheii. adur. $\quad 368$

Crocomagma. obf.

Crocus fatiuns.obf.67. \& 68.aitu. 5

Crocus moncantus autumn nis, obl. 69

Crocus vernus ferotinus primus, Hore purpureo rubente, violaceis li neis itriate, obt". ibid. Crocus vernus albus fecúdus cretu:eis oris, Cgarfis in lutera folijs oblibid. Cracus verus minor primus Clufij. obr. lbikm.

Crocus f luctris monzanus florc aibo. adu.

Crocus fylueftis, pernus, tertius.obi 68. adu.

Crocus fylu. minor Hicpan fure 5 tulo. obf:
Crocifvi. verni se autumnalis è coCrocily. verni \& autumnalis e
lore $\&$ fore differentix feptem. obf.

Erocus vernis nurpurouiolaceus 10 tus, q'iartus Valerandi obl. 69 2 Ju.

Crocus fylu. Hifpan. vernus teritus Clutij. obt:

Cruciara receniorum.cbr. I 66 atu.

Cuciara minor. obf. 467, adn. 358 Crupina Belgarum. obl. I16 Cubebe officinarum. ob?

Cucumeres fatiui \& efculenti.obli: 463 Cucumer Citrullus Fuche. obe. 3 ro. Cucumer Flaterij fylu. Cucunis A lininus officinarum, obf. atu.

363
288

Cucamcres, $\Gamma$ eporefue oblongi fite ouales vilgarifrini. adu. corumyaticias.

Cucumer frumofus. adu.

C:teamis antiguotum adu.

Cucan's flexuolis fitic anmuinus.

obt. 353.adu. 28

Cucurbia, fiue Zuccha onniti ma xima anguna. ob:" $\quad 366$ adu.

ibid.

Cuc.lagenaria, \& eius varietas. ibic.

Cucurbiula amara, cathartica. adit.

Cumiuum Diofc. Satium s: Syl ueftre obf. 428.429. adu. 330 Cumiumen fylt. Cordi. obl: ibid. Cuminum fylu. alterum Diofc. Inalor. \& Nacthiols obi:

Cunder Auicen. Valerando obr. $t>0$

Cunila. adu. 211

Cunophorí, an nux Indica adu. 4 ร

Cupreitis obf. 628. adu. 440

Curcas. obf. 392

Curcuma officinartm. obf. 38 . adu. 33.34 .

Curni Diofc obf.

17

Cyanes vulparis: obf. 299 . adu. 236

Cyanusmator horcentis. obi. 295

adu.

Cyanus peramarus repens capitulis fquarofis Sefamoidis parui. obl: 296.

Cyanus repensalter. obf. ibid,

Cyanes minimus. adu. 236

Cyclaminos alcera, hederaceis fuliys

flanta. obt: 339

C) claminos aitcra Dod.ob!. $\quad 136$

Cyclaminos altera Lucx Chini. jbist.

Cychmen sulare ollicinaum orbiculato folio. adu. $\quad 46$

Cyclamen folio Heder $x$. ohf: 331 adtu.

cius varictates.

ibld.

C) donia roala obf. 5 So. adu. 429.430

Cymbalaria J alica hacteracco fulio.

ob:. 337 . adu. $\quad 260$

Cyminum, vade Cominum.

Kuratideis obl:

Cy natiz. adiu.

ecehalis Apuleij. obl. 221

Cynocrambe obl: 132.2dur. $\quad 100$

C ynoytollim vulgaze disc flore. obs. 313. alu.

Cy Hogloftum vulgare cí flore. ibid.

Cynorlofinm naxinum obf ibjd.

Cynoglofum fufillum Narbonen-

C)noglodtim Matthioli.adu. $\quad 249$

Cymolbaroul ath. $\quad 446$

Cynolbatos Iragi. obt.

Cinoforciss adu.

Cynoforchis morio obl.

C) roforchismorio 87

C)noforcinis matoris fecinda fpecics Cynoiorchisaltera Dod. cbr. 87

Cynotorchis noftramaior obl: 89

Cynotorchis malor altera nufira.

ibidem.

Cynoforchis inontana folio maculoto C. Gemmex obi:

Cynoforchis falult ris placyphylla, fo-

liokerilacogue Gemme ibid.

Cynutorchis faluttris altera Gemmix

ibidem.

Cynolorchis paluntis altera Gem.

$m x$ : ibidem.

notorchis montana fol. maculoto. obr.
Cynoforchismontana folio levi Gë.

m.e.

Cynolo chis Dracuntias folins $\$ 10$

ribus inpente rubris Gomn:x.

wil:

93

loforchis macrocatilos, Genmaz. obf. ib: Cynotorchis paluteris Içui folto \& an. gufto. ibid. Cynotorchis paluftris altera. obl. ol Cynoforchidum diuerla genera.obl:

95.

Crperus. obl. 39 . adu.

Cyperiefculenti. adu.

C) perus lougus odutatior obr. 40

C) perus aquaticus fiptentrionalis.

.rorus rotundis litoreus jiodorus. ibidem.

Cyperushabitior adu. 37

Cyperus gramineus fiue Miliateus

adtu.

Cyperus Indicus Diofc.obr. 38

Cyperusdulcis Theoph. Dol obe. 12

( yisāpelos Helnue obl:343.at. 27

C) flampelas Helxincaltera, Atriph.

cis cffigic. obi: $3+3$.adu. 275

Cytifus. obr. goz.adu. $\quad 387$

cins varictos. obi: ibitem

C) tifisaltera minor \& vulgatior adu. 388.

Cytilus Maranche \& Match obf. $\mathrm{c}$ $\mathrm{Cy}$ tifus Hifpanicus primus, lecundas, tertius, quarcus, Clulij.obi. 503

Cytitusfecundus Theeph. Guilland. obt.

504

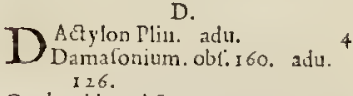

Daphnoides. obf. 200. adu.

Daphlonoides poly flora. obr.

Dutictsalter. adu.

aucus niger Theophr. obr. AI

$4 \mathrm{I} 7$. adu. 323

Daucus fecundus Fuchr. obr. 402 Daucus Selinoldis fecundus. obf. +17

Dancifecundi felino idis varictas. ob

$4 \mathrm{r} 4$. adu.

Daucus fylu. officintrum.obf $\quad 417$

Daucus v fitatior offic. adu.

Deliens Theoph. Anguillarx.cbr.

Delphinium. obf: $42 \%$

Delphinium Bucinum Diof. obf. I86

atu. its

Delphinium Dior. Dalefc.obr. I 85

Dendroides. obf. 194. altu. 152

Dens caninus I'elgartum. obl: 97

Densleonis Dot abf. IIs

Dens lecnis valgi. obi. I r 7.a1.83.84

Dens lconis Monfpelisenfum Afpho-

deli bulbults, abf. 117. adu. 8

Dens leonis Monfpellientinm an Cö-

drilla alcera Dicfcord. adu. 8

Dentaria alba Brắcionis. obfi 149.150

Dentaria alcera hertariorum obi: $39 \mathrm{I}$

Den tiria bulbifera. cbi. $\quad 392$

Dentaria pufilla obf. 392

Dentaria Rödllctii. obf.173.ad. I36

Diapenlia. obf. 378 379, adu 297

Ditamrum obf 67.29

Dirtan 


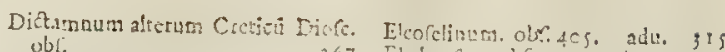

Dictamnus albus officianum, an 267

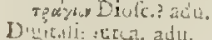

D'yit.11: :liter. adu. $\quad 4.0$

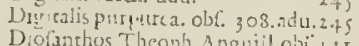

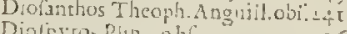

Difcati Chalcecionicum. obr. 55.56

Dipeadi cinulidis flonbus varictas ofe

milat. obi"

Diplacus iaciuus. obr.

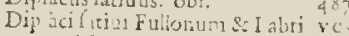
seteiffonte hafcentis difcinen.

a.tuert.
Dondx ar: d, fativa noftras, adu. 273

Dorca Nabruenfum, an Theo, ts: Panax Chiruniun \& Plinij Itiar-

nacetur? adu.

Doronisum ninus offcinarum. ob!

370. nlu. 289. \& 290

Dunapicun brochiata rdece obs. 370

ads. 29.

Loton:citerij vatetas. obl, 370.37

allu. 200

Deryentum. obf. sos.adu. . $\quad 389$

$\begin{array}{lr}\text { Dtaba, obtir ri adu. } & 78 \\ \text { Drabsaltira. alu. } & 463\end{array}$

1)taco. obt. 243 . adu.

463
190

Dracons funguis, \& Dragonal Clufi

Fraciculus. Fracuncitles arüduace

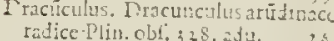

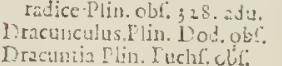

Drolicm Cerdi. dif.

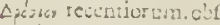

a.tu.

Apootrisd adu.

Dryopteris.obt. $4^{-}$s. aúu.

Drypis 'Theoph. obf.

Drypis Theoph. Ancuill ob!

Drypis Theoph. Griliand obc

Duldichinun Guillandini. ol:C

$$
\text { E. }
$$

Pernus. ote.

Ebalus, five Sombucus oumita 5 है? 434.

Echinopus. atu.

Echinomelocatos. aúu.

Echinos, adu.

Echium, a Ju.

Echium thoribus purporntibs

bellis, obf. 312 , xulu.

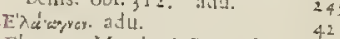

El tagnos Macth. \& Theovh, folio viticis, obf: 567 Flatcriom. obf. 368. atu. $\quad 288$ Elatine Dod. cbf Flatine recta obr. Elativie Diofc obf $24 \%$ ad 249.251

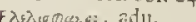
Eilcboracea plututula obr. $\quad 239$ $\begin{array}{ll} & \\ \text { adu. } & 386\end{array}$

Ellctorina $\dot{A}^{\prime}$ pina. obr.

aúu.

Elielorus Ferulaceus Theof hob 298 h.ob. 456 Iliebori albidifferenri:e. ob $345 \cdot 351$ Llebortun album foribus atrorubcit.bus precox. ouf. Klleborus niger Diofc.Dod. ob! 388

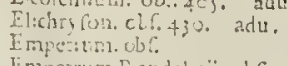

Empetrter Rardclcrij. cur.

Empersura Tragi. obl.

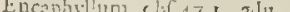

Encephalus Thooph, Cephaglioni I trilice. adu.

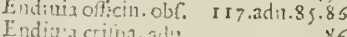

Endivia $y_{10}$

Endiuiculd adu.

In apelyllum obs

Lphorizon \$a:th. obr

If hemerim fpurium. ols?

phemetitn non yenenoum 19

$$
\text { aćlu }
$$

Epincdium ob! $1>6$, adu, $\quad x>5$

Epimediun Tragi Cordo. obf. $\$ 96$ Epinediun, an Epipetron \& Lpi-

mecron I'tur.? adu. I is

Epipactis adu.

Ipipadis recentiorum \& Belgasun. obr. I69. adu.

Ipiractic Anguil. obr.

I32

Epinymbra, Lpichymum, obr. 233

adt?. 181

obf. 232.232 . adit.

Fpiurtica. obr.

E.juictum naius cum afparagis ro

vellis. obf. 465 ad1.

Equifcidiferenti.l.

(5) Eranthemon, ob6.

I5 atu.

Eryteos folio. adu. 447

S) Erica minor I uniperi folio. ału. 447

48, lium \& Merdionalium, ob? $6 \pm 0$ adtu.

Ericx \& cins diutefe fuecies ofr 647

Lricavulgation folio M yricx pumi la. alu.
latio Myticx pumi-

Erigeron. obf I I2. a du.

Erigeron tomentofum. obt:

E'pireci. obl. 6 I3 adis.

Irophorus fiue Bulbus Bombycinus

commentitius obr:

76 Eriofioribulbigenuina effures, ob 56. dafcripio. ubf.

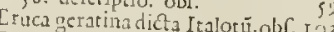

Fruca nobilis. obf.

Eruca peregrina Clufij. obr. 103

Eruca percgrima Belgis, Italica yel Cä.

tabrica. astu.

Eruca marina. adu.

Lruca faciua obl. ror. adu, 67

Erugatylu. obi. to2, adu.

Eruca fylueftris anguft Folia. obr. 102
Eruca Nifturtio cognata tenuifolia.

obi:

Irusum facium Cordi. obe $\quad 397$

Irutim fyluefte Herbarjorum, Gine

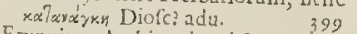

Eryngitun Archigenis obr. 435 375

Eryngium campefte medirenaneu.

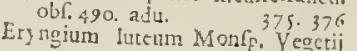

72 L"uican abr. I so

St Licm masor Norbonenfum Chame-

Irinus. obf. 269. adu. $44^{4}$
13

H

ad

Edyonginm montanuta ob?

trys $11, \mathrm{~m}$ fusilut: Planú Yuton.

obl. $49=491$. रीuेu. 375.378

Erygit'm fumilum Clufj. ibil.

Lrjimum. ob5 103. adu 68

Lryfinum Gals Theo h. Dot E

obt"

Erygmum Geineri. obs. Io

Ey fim:in March.altctum, obs. $\mathrm{I}=$

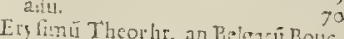

vyer? adu. 395

Erjimifpecies Aldroanuri. old, 395

Fevisoisayon cbl.

Eidthrodulim m.rinum. adu. 462

Lrytheonij dificrearie, obl.

adu.

Crul maior Germanica. obe

afil

Elivla minior Germatica an fit Pityu-

fi Diotcondu. Is

Elula minotobi, Iyz. adu. If

Lfild dakis olvi. I3s

Eulexigua tract. obl.

Eiulntara d Lo Tenctorum infult.

obli zor. alu.

Eful. rotunda. obi.

Ifula filue?tis 7 . 197

Ciila aitera fylu. Troui a du.

Ifila vulceris Travi, oof.

Euony mos 1 hcoph. obf. 99 . I9

Euonymos vera Theoph. Dat ${ }^{2} \mathrm{r}$

Herbatiorum, cbl, Dalde.

Eupatoriun. ols, 284. da. $\quad 227$

Euparoriun Cannabinum Auicena.

Eupatcrim Grodu.

Eupatcrim Grocerans. obf. 394

Fuparo:ium offic. adu. $\quad 308$

Euphrafra obr. 261 . adn. 207

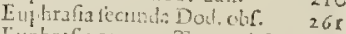

Euphrafiagramelz Tlagy, obs: $\quad=6$

Euphrofynon. alu.

F.

FAbamior recentionm obl, sos $I$ aduerf. 392. \& 393

Fabx Acryptix fpecics.ob!: 325

fiuc Craffula, an Tele

Fabainuerta Cerdi, obf. 167

Fab.x purgatrices Clufij. obs, $\mathrm{SO}_{4}$

Faba fylieftris Grecorum, ob SIr

adu. 393

Fabra

Fogopyrum oric

Fagus. obf. 587 adu.

Far candid:m, adu.

254

crumbu obf tolticro, co codern

crutum. obf

Ferula \& feruligo. obf.

at: 
Ferula oalbanifera. ob? Ferruminatrix:a adu.

Ferrum equinum. obf. $527.2 \mathrm{du} .40$ Feftuca. obl.

Feftuca altera Dod. obl.

Feftucago Gazx, obl

Ficaria, ferraria. adu.

Fici . obf. 6r2. adu.

Filago centunculus adu.

Filius ante pattem, adu

Fiftularia Dod. obr.

Fiipendula, obf, 420 , adu.

Filix. obl.

Filix famina. obf. 473 . adu.

Filis flor:da. adu.

Filix cuerna adu

Feniculam 363 adu.

Ilarimula obr

Flammula aliera furrecta. obl: 346 Flammula vulgi. obl. $346.3 \mathrm{du} . \quad 276$

llos Confancinopolitanus Dod. obC. 183.

Flos suculi. aju

Fornictum obt. 48 . adt

Fceniculum erraticum obl.

Jel. 448

adu. $\quad$ I68

Fonum Burgundiacum.obr.498.499

alu. $\quad 382$

Fænum Gracum, obc

adu.

502

387

Fonum Grxcum herbariorum, obr

so2. $\{26$.

Folium faccha, inuofucrum,adu. 39

Fentalis, obf, 16 . adtu, 128

Fontilupathm pufilum. adu. 117

Fragaria \& Fraza. obi.396.adu. 309

Fraguria fyluctilis. che. $\quad 396$

Frangula. ote. 594 adu. 440

Fraxinella Cordici oficinar. obf. $\{37$ afu.

Fraxinus. obf. 545. adu. $\quad 416$

Fraxinus bubula Dod. ob. 444 .at. 416

Fraxinus minor Tragi ob! 592

Fritillaria fine Lilonarcifis purpu-

reus variegatus, obf

Frumentuni Int cunt, ad

Fucus feruinceus obr:

Fucus marinus iclijs A brotani marts. obf.

Fuci prim epecies Diofc obt" 65 Fuigo liquidx picis D ofc. obf. 635 Fumaria. ot? adu.

Fumaria bulbofa Plin. obf.

Fumaria lutea montana. ob? 338,339 adu. 338 Fumarix fabacex radicis varictas. ob1 439.

C Alangamaior, minor. obc. ; (T) adu. Galedragon Xenoctatis Ang. ob ${ }^{3} 87$ Galega. ubl: go9. adu. Galcopfis, obf. 280.508 adu. 222. 391 Galcoplis Dod. obl. 258 . 2du. 230 289.

$G$ aleop fis lutea recentiorum. ad. $24 \mathrm{r}$ Galion album quorundam. obf. 465
F'disy. Galium luteum, obc. adu.

. 358

Galla quetcus. adu. $43:$

Galla maior \& diuerfe fpecies: ob! 586. $5^{87}$.

Galli erus Apuleij. ob[. r2. adu.

Galitricum. adu. 240

Garyophyllaca.adu.

Garyophyllata Septentrionalium. ad 309

Garyophyllata,an Geú Plin.? alu. 309 Garyophyli cum folio \& fructu. obi, 575 .

Gelleminum vulgatius. obf. $5+2$ adu. 415

Gelfeminum humilc. obi". $\quad 54$

GeniftaSpartum fpinofum. obr. 335

adu. 409

Genifta fcopariz vuigi \&z Plinij. obf. $53 \mathrm{r}$.

Geniftella aculeata c bf.

adu.
Geniftella infectoria. obC. 531.5332

adu. 407

Geniftelia infectoria vulgi, an Lurea Plinij? adu. $4: 7$ Geniftella'mötana, Genifta angulor Genil a lagittalus nuperorum, oht.

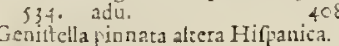

obf. 334

Genitella tinctoria Clufij. ob?. 532 Gentianamaior. obl. Ios. adus 129 Gentiana minor, obf. I 65. adu. I 30 Gentianx minoris fpecies. obl. 166 adu.

Genciana purpureis floribus. obf. 1 65 Gentiane extratum. off. I 6 Geaciancllu $\mathrm{Al}_{\mathrm{p}}$ ina, Vana Clufijobi. $16 ?$ ?

Gencianeila Campanula fore purfireo, ficlucta. adu. $\quad 130$ Gercianela minima. obr. If adu. 13 Gentinnella verna Clulij. obf. I67 Geratium Ratrachioides alterum töcolus radicatū obf:376́.ad.:96 \& 297 Geranium Crelicun annuui. obt. 377 Geraniü altert radice reptice. ob. 377 Geraniun puidexasodśs.obr. $\quad .378$ adu. 277 Geranium Robertianum. ob!. 375 adu. Geraniumbulbofum Diofe, primun. obf. 377 ade. 297 Geraniun alterum Diofe. ob? $\quad 376$

$2 \mathrm{du}$. $\quad 296.297$

Geranim fufcum obf. 377

Gerardi herba Dod. \& Mechlinien-

fium. oln: 308. adt. $31 \mathrm{r}$ Geum Apintim recentioram folio hederaceo. adu.

Gingidium Anguil, obs

267

Gingidium Syriacum folijs Baucia.

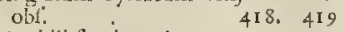
Gingidij fpecies. adu.

Gitago Tragi. obt:

Gladiolus I talicus ob 52 adu 4

Gladiolus maior obc adt.

Gladiolus Narbonenfis, obC adu.

Gludiolus paluttris Cordi , \& aquati-

cus Dot. obC. 44

Glans. obf. 583
Glans ynguentarid. obC

adu.

Glaftum primun Ane. obr

adtum priminn Ane obr. $\quad$ isa
adu. 148. videlfistis.

Glocum ratiuun. obr. 189 . adu. I 48

Glaftum fyluctire obr.

Glancium. obe. $\quad 140$

Glaux, adu. $\quad 278$

Glaux quorundam. obf. 530

Glaux exigua maritima obr. $\quad 227$

adu.

Glaux yulgaris Diofcor. Clufij. obf,

526. adtr. 402

Globularia Mondpellienfib. obr. is 3

adu. 200

Glycy"rrhiza cchinata Diof. olf 528

Glyor rrhza filiquofa cbr. 529

adu. 405

Gly cyrrhiza fylu. Gefn, cbc. 526

Gisaphalimn.obr. 254

Gnaphaliun vulgare. obr. 255

Gnaphalium marinum.adu. $\quad 200$ $V$ arietas Gnaphalij Germanici maicris, adu. $20 x$

202

m. obl. 255

Golfypium.obr. 370. adu. $\quad 202$

Graminis enne gुenus.obr.

adu. 1.2 .3 .4

Gramen bulbo'tim nodcfum. obc. $x^{3}$ adu Gramen Canatium alterum obr. 12 adu.

Gramen Cyperoides obs

Gramen exite turius obf

Granen hirfuxum nemorofum.adu. Gramen Leucanthemun Dod.obf 26 Gramen Miannæ efculentum.obl. I adu.

Granế Mannx alcerum Dod.obr. 25

Gramen marinum arundinaceum maxinzlm. adu.

Gramen medicatum officin adu. 4 Gramen fanmiculofun Phalarioides. obt. Ic. \& 1 t Gramen Parnafi quorundam.obli I 6 I alti. 127 Gramcn Parnalli Cotti \& Leoniceri. obl". I 61

Grané Parnaffum hederace um ad.4 Gramen Durnafi recentiorum heteraceism obf. 330 adu. 263 Crancen Parnalfi duplicatis floribus. ob!

Gromen pracêfe maius vulgatius. 330 Gramen fulcarum vel ftratum albū. adu.

Gramentertium Plinianum Anguil. oblozor. adu.

Gramen Typhinum obs.

Graminis varicrutes quam plurime.

obf. 9. adu. 2

Granum Gnidium. obf zor.adu.r ss I56. $157^{\circ}$

Grana Paradifi. obr.616.adu. 445 Granum regium Mcfice adu. 306 Gratia Dei. obf. 376. adu. 297 Gratiola, \& Gratia Dei. obr. $\quad 2 ; 8$ adu. 18

Gratiola recentiorum, an Spumeum

Papauer Diofcor.? adu. Is

Gromphena Flin. obe. : 298

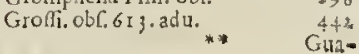

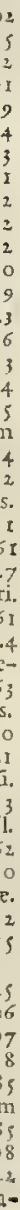


Guxiacum Fallopij Patainura obs

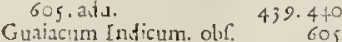
Guanamus Scaiperi Clufio eius! mad dila \&: femina ob: $\quad 603$ Gummi Arubicun. alu.

7 Alicacabum peregrinum Euche.

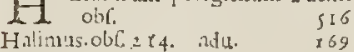
Halinuss.obe 24 . adu. 169 Harmala Syriaca an dit Sefamoides

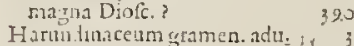
Harmituacelam gramen. adus : 3 Hitila regi.l. ads.

Hebenum. ads.

Helera abores reets. adu. $\quad 267$

Hedera comminis. adu. 269

Hedera carymbofa. ob! $\quad 336.337$

$\begin{array}{ll}\text { adr. } & \\ \text { Helera humilis.ohC. 336.adu, } & 269\end{array}$

Holer fterilis, obl, 337 . adu, 269

Hedaratertedris obl. 336

Helorula a ur oblo

Hederula fuxatilis. adu.

Hedypois Plin obfi irgads. 8:

Hedyingum. obf s2 $^{2}$. adu. $\quad 4=1$

Hedy frum alcerum Dot. \&e alterum

clyfatum. obl:

Halentum. obr. 359 . adt. $2+6$

Helonium Aegyptium quorundan.

Helianthenum Cordis Tray. obl.

238.

Helinuthes, adi.

Heinnthes. adu. 405

Helianthos Anguill. \& Fuch Cobre 38
Helianthos, liue flos Solis. obt, 2 is

Helianthos, fute fos Solis, an Panzx Chironium, \& Helenium lecund Distc.?.Att. I 5 Hetioch:y fos fyl. Tragi, obr. 256 . Helio: topium maxius. obli r 3 I.ad. 16 I Helictopium paruum Diotc.

Cl:tif obli 3 3.adit.

Heliotropiit, Verrucariafcorpioides. adu.

Heliotropium vulgnte adit. $\quad$ IOI $\begin{array}{ll}\text { Helix obt. } 337 \text {. adu } & 269 \\ \text { Hellcboran rum. obf. } 387 . \text { adu. } & 303\end{array}$ Heileborafter maximus tlore \& femi. ne preqgnans. obf. 387
Hellebornitri S Confiligines.adu. 303 Hellebornttri S Confligines.adu. 303 Helleboraftri duplex difierentia. adu.

Helieborine. obt 69 . adu.13 r. I 32 Heltehorines rarafpeciesnobf, I 69 Halleborinum Corli.obs. 456 Hellcborum album obf. I 67 .atil o j I Hellehorus niger obi. 339 . adu. 304 Helleboris niger Theophradu. 35 I

Helxise obt: Iso alu.

He:xine Plinian Anmill. oor $\quad 343$

Hexine Pliniand Anguill oof 479 funguinea polyanthos. ouf 8 rouro. Hemerocallis herbariorm. obt: \& Hemerocallis Valenuna Clufij. obi:

Icmion: is obr 463 adu

Hamionitis altara perezima Clufij obl.

Hepatica obs,

Heparics obs, $49 \% 646$
Hepatica polyanthos. elic. Hitradea lilin. Ir roi, oof Heraclet fy derius Diolic. Cordo, Cluf \&.slijs. col

He bas Batbara, adu.

Habacanca barb. obi:

Herbi Dort.. obt: i \& 8, adu.

Herba S. Ioan. vulgyiobr. adu.

Herbu Patis. obf. I 37. adus.

Herba Radioli A puleij.obc:

Herba facia Agrippr, ubl.

Herba lancta obl.

Herbiterrilsils. aúv.

Herbs Trintatis Fuche, obc.

adı.

Herbu Tunicx Gordonij. adı.

Herba Turca, Gue Herniara obf 4

ad u.

Herba renti Rondel. obf, 286.24 I 229

Het ba vulneratio obl:
Hercuiea, fue Heraclea fronde SmyINij.obi

Hermoinatylus. obs

Hermodactylus offeining ob

Hcrmod.etylialbi, rubi, \&:c. an fin Behen olbum \& rubrum? afu. is

Hefpers Theopl. guorunda. obf. I 79

Hieracium maius, obf, I s 9 . adu. 88

Heracium maius, obf, I 9 9. adu. 88 obl. Irg. adu.

Hieracium Sabaudum obC.120.44.89

Hieracium longus zadicatum. obt

I 20. adu, 38

qua, obf.

qua. obf.

Hicracium montanum, \&c, adu 88

Huppia adit.

Hippia minor. adu:

Hippoylofiurn.adu.

Hippojlolfon Bonitacia obs,

qua. 18

Ripponiolsu Valen:inu Cluf, obf 20 Hippolapathou. obi i s r. adu. is

Hi. polpathum fatidum Iatitolium.

Hippolapatiun torundifolium its

IS 2. alu.

Hippomarathtum. ob[.4+8.adu. 317 Ilippophaës, Hippophęitu. a. 375.376 Hipolelinum Matrh. ob

Hippofelinum $M$ acetonicum Belo rum, Grxcorum, nuperoru \& Mat thioli, Curdi, Marcelli, La cuna, \& Bracíalr. obf. 407. adta. 3 I

Hippofpartium, ob!: - 315

Hipputis adu

Hipparis minor. obr. 46 r.adu: 35

Hippuris foncalis. Equifctum fecuit (12m Dio!c.alterum Match.obi.46

ad a. 35

Hirculus, Nafdoceltice finjlis her bil in. obic, 170 . adu

Hirundiaria minor. adus

Holcas Plinij Anguitl obc.

Holem \& Holeracea, obl.

Holtisun Diolc. inśseo Aeginet alir.

Holonium alcerum. adu.

Holaltum Monfpellienle.adi.

Holofum Ruelij, cbl'.26.3 tu.

Holotium Salmon (j). ob[. I $6+$. .44.
7 Holontiü guorü dam Laeunx. obf. 254 Hordanm. obi: I s. adu.

Hordeun ruminun. obi, 21 adu. ío Hordelin nutum, obl:

Hordeumlpomaneum ffurium, obr Is. atu.

Horminam. obf. 300 . औงtl. 7

Honzinum lj fueltre obl, 300, adit.

301

Fluteocolon Bononienfrum, obf. 255 Hyacinthes Ang'icus, obl:
Hyacmativs bumslis, ore alis abus. comolis, conotits albus, adts. 460
coms Hyacint conotus misior. obt. 55.56 Hyaci ithus comofis Diofc.adu. 49 Hyacinthas comolus minor. obr. is

56. adu. 49 yecinthus Germanicts, An ticus \& Begricus, autumnalis, autumnalis

mylor.obl' \$4.55. altu. 4 obl, 48 . adu.

Hyacinchus ordentalis Gracus, obr. 54

a du.

Hy acinthus ozientalis maior polyanthos. obr.

Iyacinilus Poctarum latifolius, ob: so. adu.

Hyacinthus poécarum luteus, obr. 49

Hyacinthus l'oëtarun filiquis pra

gnans obi:

Hyacinthus Poétarum Trarsiobr 4 Hyaciuthus Reliaris albicwis, ftellaris hioflotus, lilaceus, cum radice. folits \& lemine.adu. 458.459 Hydrolapathit mal tes.ob[ I g I.ad. I I Ifydrolapathum minus.obr Hyifromelum, obi:

Hydropiper obf. $17 \mathrm{~J}$. add, 351

Hyofcyinus albus.ob[: I 3 g-adu. I C Hyofcyanms lureolus dulanifolins, niger \& cutartus $M$ atth. obr. Ito adu

Hyofingus niger obf Hyofe. Peruuiamus Con 39.adu. I o Hyofcyamus Perulizaus Dou.obe $\begin{array}{ll}252 . & \text { adu. } \\ \text { Hyofists Plin. Anguill. ojr. } & 292 \\ \text { aill. } & 293\end{array}$ all. 234

fypecoum Clut a Doul. obla. 429 Hypericumminiratm fupinut 172 tentrionale obf. $2 \mathrm{I} 7$ Hypericun fipinum Clufij. obf, $2: 8$ Hypericum Syriacum \& Alexantracum, onf.

Hypericú rométofum obf.218.a.1.73 Hypericonis olenm.adu,

Hypociftis D1ofc, obf

173
$5+8$

Hy flopi A abur fore rubro. obr, $2 ; \gamma$ Aopl Arabum e for is colore vatie.

tyates. obi. 1armm. obr: 237 adu. is,
Hyfiopus candida Anglorem, ad. 85

Hyllopus gentina Grxcorum folio Ormas, vmbellato fore obf aifu. 264 Hyforum Diofe. Cilicum Anguil!. Hyfopus vmbellafera Diofc. Guillandino. obs

I.

Icen fiue Flos Trinitatis Matth. obf.335. adu. 
Iacea maior littea. obf.292.adu. 2;4 Iunci, Iunces. adu

Iacea cap tulis finof 234 Innelis aquaticus minor. ob?

Iacex maioris varietis. 6 bf, 293 . adu. 234.

Incea albu Mcnfpel. adu.

$\begin{array}{lr}\text { Iacea lutea Clufij. obf. } & 483 \\ \text { Iacea nig ra vulgaris. obf.293.ad. } 234\end{array}$

Iacea altera pufilla incaza fol. Olex. obf. 294.298 Iacea monana Narbonenfis. obs. 293. 294.

Iacca pumila, flore cyaneo \& albo. accs $\mathrm{put}$

lacobar maina. adu. 235

Iarus. obr 79 $3=$

Ioris Cariama

Ibifas Theoph. obf

adu.

I07

37

293

Idxa vitis Theoph. Dalefe. obf. $\$ 46$

adu. 417

liex arbor obf. $8^{8} 8_{2}$ a atu. $43 \mathrm{I}$

Ihe coccifera, an Aquifolia Pliu.

lez coccirera, an Aquutolia Plu.

lex fenina. adu.

430
432

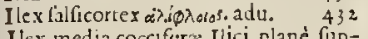

Itex media coccifers Iici plane fuppar, folio Acuifoline adtu. .431

Ilex fiberifera anguntifolia. adu. 432

Ilex fuberifera hafifolia gläde echinata. adu.

Imperatoria. obr. $397.398 .2 d$ ts. $\quad 310$ Indorum Ferruminatrix, adu: 454 Indica florida cinna. adu.

Indorum Salna Sancta.obr. atu.

Intyba.- adil.

Intyum 80 ind

Iphyon'Theoph. Anguil. obr. adu.

Irio.obf. r 03 . adu.

Iriones. adu.

Irion Cordi. obr.

Irides. obf. 32. adu

I: is bulbof, Dod, obf.

Iris bulbora Cluf.obf:

Iris buibofa luteo flore Clufij. obs 48

Iris domefica, Florentima, Illyrica.

$$
\text { adn. }
$$

Irisfore cxrulco, adu.

Iris farua Math. obl"

Iris lutea Dod. obC

30: 31

458

I) I

Ins lutea val iata, Chalcedonica obr. 34

ris maritima Norbonenfis an Mediu Diofc.? adu.

Iris perfufilla fyluetris angutifolia. obf. 34. adu.

Iris tuberola Doit. olf.

31.32

l.tis vularis Daimarica maior obf 53 minor biflota Lutitanica petpufi1. obf.

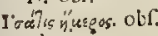

aitu.

Ifatis fvitu. obf.roo. adve

Ifrisfylu. Vaccaria dist obf 14

I 48

Ifehemon vulgare obf. r 2.I 3.adu. 3.4 If chemon Plin. Clufio. obf.

Iropyrnm. obf

luz arthritic offic obr.

Iu. mofchata Monfp.obr.208.2d. 16

Iuiube A rabum. ob?

Iucaria Salamanticérs Chufij.obf.462 626 I.

T Abrtm Veneris. obf.

Lactucer, adu. Lamiun Plin adu.$$
\text { adru. }
$$

anceola adu. uncus botnbycinus. obf. 44.adu. 47 Lappaminot Galeni. obf

Iuncus Cyperoides floridus paludo- Lappa antent is Tragi. obi. fus.oll. 44.adu. 44 Iarix. obf.633. adu.

Iuncus, laxuis vulgatus.obC. $\quad 43.44$ Laferpitium. obl.400. adu. 3 i 3.314 adu. 43 Laferpitium Germanicum \& Diofe uncusmarinus gramincus.obf. 43 obf, 4 or,adu. 3 I 3 adu. $\quad 42$ Laferpiium Fuchf. obf. 398 uncus quadratus, angulofus \& triä- Lafepitium è regione Mafilix regularis Celfi \& Plinij. obf. 39 protuni, adit. 3 t3 I uncus odotatus obr. $\quad \mathbf{4 2 . 4 3}$ Iathyris. obf, r $97 . a$ tu. Is adu. 42 Lath s anguftore gramineo flore. luncellus. adto. 44 adu. 398 uniperi. obf.628.629. sdu. 448 Lathy ris Na bonenfis. obf. 5 I 7. 2 du. Iuriperus maior folio Cuprefi. obf

398 .

Laudata nobilium. adu. 197 Iaduendula multifuto folio Clufij.obt Iuniperus marimus, Illyricus. ob 629. adu. 443 Iatuer. obf. rog. Wh. 75 Iuniperus vulgatior.adu. $\quad 448$ I auer Fuchfobr. $\quad \mathbf{2 4 8}$ Ixis.antu. 367 Laureola.obl. 200

Ixopus Cordi: obf. $\$ 27$ Laurusiaduerf. 468

Laurus Alcxandrina. obf $;\{2$,ad. 283 K. Lautus baccifera.obf, izradu. 424

K Ali geniculaum vermicularum. Lanrus bumilis viguleca,non tacca1 adi. 170 ta adu. 424 Kalimagnum. obf. 2 I 4. 2du. 169 Laurus pufilla. adu. 155 Kaliminus, adu. - I Keiri.Arabum.ob! I79 Laurus rolea, adu. Laurus Tinus Plin, adu. $\quad 424$ Lestipes. adur. 207 487 Ledol1 2. 4.5.7.8.9.10.0b5. 554

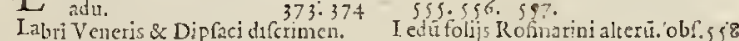
adu.

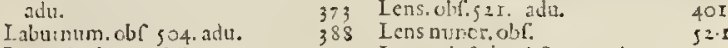
Lacca Arabum. ob!: $\quad 577$ Lens filuftis. ob 647 . adv. I 29 Lacca Arabum \& offc. an fit Diolc. Lencicula marina Serspionis, \& LcnCaucamon? adu. $\quad+28$ ticulamarina ferratis folijs.obf.6 53

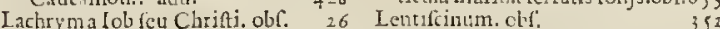
Lachryma Lobfeu Carift. obf. 26 Lenticintm. eld,
adu.

89 Leohetba. obt.

80 .7 tatra Dod. obr. 440 on copitata, Roman T.xuntopetalon. oll.395.adu. 305 Lactuca latiua folio Scariola.gbf I 1 I Leontopodium recentionm. adu.298 Lactuca latiua folio Scariola.gbf i i 1 Lcontopodium recentiorum. adu. 298
adv. 89 Lcontopodium alterü Matth.ad. 202 Lactucz capicata crifpis Braficx folijs. I contopodiun paruum. obr. 25 obl. I2r.adu. $\quad 90$ Lepidiü Aeginet.e. obf I 73. adu. I75 Láfuca fyluentis. obf. I: Iepidium Aeginetx Monf obf i 73 Iactuc $x$ fyl. yatiotas, obf, I2, adu. I 36 Lactucafyl. Fuchir \& $M$ Ratth.obf. Is Lepidiumannumm, obf. 173 Iactucina Setis atcta Diofe. adu.s6 Lepidium Diolc. adu. 77 Ladanum. obf: 558 Lepidum Diolc. quorundam.ob. I7 Lagopus.ob\{498.490. Adu. 333 Lepldium majus Cord, e. Iragiob. Lgapis \& Palet. lla Iragl. obt. 2s

Lapopus maximus alter angufi- Lepidium Piperitis.adu. 135 folsus.adu. 384 Leticacantha. obf. 482 adtr. 371

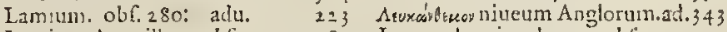
Lamium Anguillarx.obl. $\quad 280$ Leucanthemis odorata. obl. 445

223 Lencographis Plin. obr. 479 Lampfana obf 104. adu. 70 , Leuconisn bubofum hexaphylum Lampfana vera quorundam, obf. $s$ I

395 Leucoium floribus luteis. ob.

28. I.eucoium lureú marinum.adtu. 74

apathi genera. adu. IIs Leucoiun marinum mivus, fiore purLapathum acutum.obf. I50.ada. II 7 purante obf. I79.adu. I 4 r Lapathū folio retufo, nó acuto.ad. I 7 Leucoiun marinumaltetum lazı́Lapathm Oxalida.obC. Iss lium: ob? Lapathumfanguincum, obf. Is4 Lcucoium Pataunü marini.obf. 180 adu. $\quad$ IIg Levcojun purpureú $\&$ albí.obf. 178 
I eucoivm bullefun ninirtun astumnale Clutij. ob?

Leucolum bulbofum triphyllum Dod. olv. 65 .

Leuconim luteum, keiri A cab.ad i 4 t Leucoi m matitimum maius. ad. $14 \mathrm{I}$ Leucojum duplis foribus.adu. ibid. Letconarcifol rium numimum obr $64.65 ., 3 j u$

Leuconarcifolirió paucioribus foribus. obr. 64. ału.

Leuconarcificlirion pratenfe vernum, rum Visla alb. Theoph. vei Moly Rondelletio ? a du.

Leuconarcifolition pratenle. obl: 64 Iibanctis coronaria Galen. obf. $\quad 52$ Litanotis Galcn obr I.ibanntis Jletbrioum Soplentrio n.1. adu. Lib.motis Theoph obf. 02 adi, 3 is I.tmotis minot, outi

Ligneim RGodiäm. adv 427 .
Leucoium bulbo'un polyanth $50 d$

Leuconarcifolirim minimum autü-

obr. $3 ; 8$. adu.

Limones. obl. 573 . adu

Limonim. adu. 425

Limonium Angujt obr. 160 . ad. 126 Linonium Cordi is Germanorum. obf. 157 adu. . 122 obf obr.

Limonium Gefis, ob?

Limonitm paruum Norbonenfe olexfolium. adu.

Limouium fecundü Mathioliad. I? Linaria cbr, $\quad \$ 22.22$ Linarja aurea Tragi, obr. $\quad 22$ Linaria aurea.obl

Linaria purpurea odorata.obf, adu.

Linarix purpurex varietas obf 213.

Linaria Valentina Clufii, obr. Lingua Cerujiat oflicm obl:

Lingua vulueraria Cordi, liugua 459

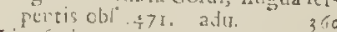
Linofyrisnuperorum. ob: $\quad 30$

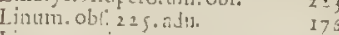
Linum marinun Iucum Nabonen fe, \& fyliten, obr: $2 \geq 5$. adts, 177 Linun perpufillun, olx. $2 \geq 7$ Linum fylta. Horibis albis, obf. 226 Liunmillu, tenuifoljum. ob. 226 Lijifylueft. varietates.obf. 226 Lijnur Tareari, obr.

Lisiotghotelusiuteus liliflor us. Lirim atim.

Liguftram Dio cor. Nontras. adu. $4 \div 0$ I.ilic Marih. ols, $5 \neq 0$

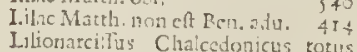

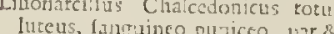
Iuceus, fanguneo puziceo par \& Lilionarcifus lutcus Eononieafis. obl:

Lilionarcifus luteus montanus $\mathrm{Nar}^{63}$ bonerfis. ohf $b_{3}$. a d

Lilionareilits luteiscris, hoze patu-

Lilional cifip precoci a at furotini fan

ruine punicsiue ef thore varietates

feptem obf.
Lilionarifi gracocis unu'tiplex 660

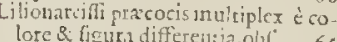
Lilionarcifiss polyanthos, obl. Lilionarcinus purpureus. obr? adu.

Liljonarcifi varietutes, $\mathrm{cb}$. , sa Lilium Alexandrinum Neotericorum

$\begin{array}{ll}\text { chr. } & 73 \\ \text { Lilium candidum.obr. } 83 . \text { adu. } & 60\end{array}$ Lilium conuallit, vel verne Theoph, obr. $8 \rightarrow$ adu.

Lilij conuall. é Poris colore d.fferen. tij. obc: Liliú, fue Corona Imperialis.obr. 86 Lili crueati yaremates. obf Lilim croceum Fuch, obr. Lilium cruentum bulbos ge-ens fum moalis diritó carale, obr. Lilium inaterfinas. adu. 8 Lilium montitums, obl: 89.2 du. Lilium nonbulbofum Dod, obl, 4
Lilium Pericum, obf.

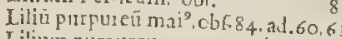
Litum purpureum minus, obs. adu.

Lilium fylu. Dot.ob

Limegurm Cordi fil.
Lithofpromam Pin obf. 26. 2ulu it Litholpermó Anchure facle. obf. 24 Litholp $\begin{array}{ll}130 & 145 \\ 192\end{array}$

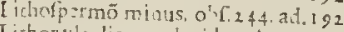
Lithnxyla, ligiana lapjudea Ang $1 \mathrm{ca}$. obr.

I.nlium obf" 2 r.ad

J.olitun rubeum obs

Lonchitis grimia adu.

Ionchitis prior Diofe obt

Lonchicis aliera \& Matanthę obr 47 476 . alu.

Lo hudes vel Nephelodes C $G^{7}$ obl: Lotus arbor obf. 60 4.adu.
Lotis Acsypria, Nilotica aur FuphraLotusafperior fruticora, fue $\mathrm{Na}$ bo nenfis incana. obr.

Lotushortorum odora fium sylueftris Alwgisly. \& Math. obr:

adu. Lotusfylu. D ofc. adu.

Lotustrifolia pratenfis, ndu.

Lotiduerfix, obi, s0o.adu.

Lunarsa Grxca. obf. $174.2 d 1 \%$

Lunarialiutea Monfpel. adu.

Luaria magorum Arabum obf. 470

Lunaria racenola. obl. 470 . ath. 360

Lunaria radinta Iralorum.obe 493

Lupinus fyl. obs

Lapus Glicta
347 . adu

(i) ILiteola, obr. 190. adu $8 ;$
Lupiuus fatiuus, obt. SI4, adu, 396

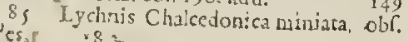

I.ychnis coronatia obf. I 31 . adtu. I/12

1.ychnids vartctas.adu. $i_{42}$

Iychnis marir: Anglica adu.

Lychnis fylu. Dod obt: $\quad$ J 84

Lychnis fylu. hirta obr. $\quad$ I8I

Ljehnis fyl. Lirta minima. obf. I 83

Lychnis fyl. prima Clurij, ob: 8 ,

I.ychnis flu. alternobí, $\quad 242$

L) chnis .jyl. altera incana cauliculis Atriaris obl. I8\%.

Ly"chnisfylu. tertis Clur, cauliculis

Lychnis ty liarta Coufij, obr 183

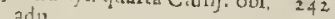

Lychtis! yl grinta Clufij obf 189

Ly"chnes tyl. fextamininia Clufij.obr. I 8 ; .

I ychnis fyl rubello fore obr. . I8:. Lychnoiles fegetum Mutoni ob 23.

I. jejum. obf. $\sigma_{2}$, aju.

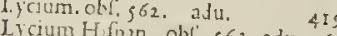

hexay? inev. obf. obl. 563 . adu, 469

Iycoctonum cẹruleum paruum 386

cie Napali.oll:

I.ycogerlicum quorundam. obc \$86

I.ycopfis adu. 248

Ij copfis Lacuna ob 3 r 3 . adu, 2 go

y) copfisaltera Anglica. obl, 312 adu. $2 \neq 0$ Lycoftaghylus mas \&: femina Cordi. ofimachia cxrulen horecofs. 61 136 adu cerulea hortedis. obl. Lyfimachia gal riculata cxrulcolut purea obir86. adu. 144 L) fimachiolieraktath obf, 18 s ahu 3 is

Lyfimachirztutez, obr.185. adu, it Lyimachir purpurea forte $P$ liniana. oblir 85 adu.

Lyfinachation tuor obr 185 a 144 Lyfimechix fillow of oblis s.ad. It 136. aju. 145

Mica'cb Gefneti \& Math obr, 65 Maci: Arabum \& Ofricialu. Mucet. adu.

Nacropiper. cbf. gr - adu.

Masioramobi. 265 adu.

Maiorama noftras adu. Majorma tenuifoliz delicatior. obf.

Mais occidentelium. atu.

Mala, obi: s9o. adu. $\quad$ I3 $^{2}$ Malabathrum. ohr. 165 adu. $1=9$ Malabathri folinm. 16 - adu. $\quad \div 9$ Malicocrisus - Caffani Bafii. adu. 256.

Malua arborea fylueftris, adu. 29 Mialta criftatis oris, Malita crifpa vul go. ob!

Malua tof a frucicor obf $\begin{array}{ll}\text { adu. } & 372 \\ & 293\end{array}$ Malua rofca mnltiplex, an Gal. Anadendromalache? obl. 373 adu. $29=$ Malua fylu. repers pumila: olf. $29 ?$

Malua vulgatis procerior. ob. $\quad 292$ 292 Malii A pring 295 Malum Hefpericum. Cireeum \& 572 Milum Hefpetictm, Cirzeum \& Malum Perticum Thsophiobl. 5? 
Malum punicum. obf. 563.564. adu.
459 Miandratroras morion. obl. Mandragoras iterỵe. obl. a.du.

Mirite. adu.

Minis. 23

Manna Arabum adu. 23

Maina liraclitarum qualis. adu. 26

Manna è ramis Laticis.adu.

Mhanng iomo.lo fiat, adu.

- Marach. adu.

Harathriphytlum paluntre.obr. 460 adu.
Maratheum vulgatius dulce. adtere 347.

Marrubium. adu.

Marruium. adu. 222 obe $\quad 278.279$ $\begin{array}{cc}\text { ad.l. } & 222 \\ \text { Marrubium agrefte Tragi. obr, } & 284\end{array}$ Marrubium ayuaticü vulgi. obr. 28

adur franicum. obt: 278 Marrubij candidi yarietates, obr. 279 Marrubium Creticum. adu. $2: 2$ Marrubitum Hifp. odore stachadis.

obf. 279

M.rrubium nigrum. obe. 279

Martagon candidum Chalcedonicu. obl.

Martagon Chymift.rum. adu. 60

Mactagon I calorum \& Marth, obf. 85

Marum. obli,265.266. adu. 2 I3

Marum Cortufij, \& Marth. obf, 263 adu.

Marum fupinum. obC.

Marum Symacum oracilioribus farnéts, minoribus cnpitulis \& foljis. obf. $26 \mathrm{~g}$. adu. 2 I 3 Maftic Gallorum \& Angiotum. adu. 213.

Marer filu adu. 280

Matricaria noltras.obli433 noórctínoder Parhenio Paul \& Plin. ad. 335 Matrifyluta Tiagi. ojt:

Maurolicbraicaput obr.

Mechin. adu.

Mechini rara varietas, alu.

Meconium. ob[1 43 .adu.

Meda Mofcouitarum adu.

Medica malus. ojr. 572 . adu. 425

A L clica folliculo finofo. obr.498.499

$38=$

Redica marina. adu. $\quad 383$

Mledica tresinfemine varietates.adu. 383.

Miediü, xu fit Mariana viola: adu. 137 Heherilechene obf

$\mathrm{Mcl}$ apum commune. adu. $\quad 22$ Mel Cedran Hippoc. \& Syriacum. a.tu.

Mcl frugum Dioclis Anguil. obr. 25 Mel frum Theorh. obs. 500 Melamprum. obf:

Melamprum alierum Neoteticori adu.

Melampyrum Dod.as Alopecuros Plin.? adu.

Melampyrum perpufillum luteun. obilio. adu. 11 Mélangena, ycl Mala infana.obr. 130 adur.

Mclanthium. obr. 427. adis. $3 \geq 9$

Melanthium fylu. obr. 428 . adi, 329 Melanthium fylu. altcriad.obf, $4=8$
Melengrisfíos Dol. obr.

Melicaitalorum, obl.

Meislors obi , 500.230.

Mcliotus alba \& lutez Autc

1utez Auicennis. obl.

Meli orus coronnta.obr. son. ad. 386

Melilows Gernanica \& Gallica.obr.

Melilons Italica \& Patauina.obr, 501

atu.
Melilotus Londinenfis altera purilla.

Nelitotus Sysinca. adı.

Melilotus (y'l. pinguis Pénei. obl. 493

Melifaccharum, adu. 2; \& 25

Meliffę cxtraEtú Chymicum.obr.277

Melifiophyllon. obl. $\quad \geq 77$

Meliilophyllon Fuchf.Cordi, \& Tra$\begin{array}{ll}\text { gi. cbi, } & 277 \\ \text { Meliftophyllon Turcicum adu. } & 220\end{array}$ Meliftophyllon Turcicum adu. 220 Melo vulgi fiue Melopepo Diofc.ob

Mciongena Auer rhois \& Auicéne, . Mandagoras Theoph.' adu. to

Melocarduus echinatus Indix occidentalis adu.

Merlanthe paluftris Theoph obr. 426

Menria aquarica, fiue Sifymbria.adu.

218.

Mentha cataria d uplex peregrina, latifolia, \& angufitolia. obi: 276 adu.

21.

Mentha cataria non eft Nepeta anti cuorum. adu. ubi.t.

Mentha corymbirera Cordi.obr. 174 colymbifira minor Cordi.obl. 259 Mentha cruciata. obf. 275

Mentha rotuind:folia altera forc $f_{i} \cdot \mathrm{i}$ caro. obs.

Mentha Romana officin. fiue pox Aantior, obl. 271.adu. 2 I8

Menthaterti. Dod. \& prima Matti.

obf. 271

Mentha Romana anginftifolia, fiuc cardiaca, obl, z71. adu. 218 Mcntha quarta Dod. fecunda Marrh. obf. 271 Mouhafpicatz varictates quinque. obr. $\quad 272$

Mentha Sifymbria agreftis. obf: 272

Mentha fativa prior Dod. obf. 27

Menthafecurda Dod, obi: 27

Menit.r vulgara ferpens rotundiore folio. obf, 270 . adu. $\quad 218$

Ivisuchufturi. obf. 273

ndu.
Méthafrifolia avuatica planta. adtu. 119

Menthoftrū minus fpicatum,ob[27 Menth.taru niuet Anglicü.obf. 27

$$
\text { eius varietas. ailu. } 2.19
$$

Mérhaftri varietates.obf, 273 ,adun:19

Metcurialis mas, \& femina. obr, I 3 I adu.

Mefpilus. obf. s9r. 592. adu. 434

Mefilus Aronia. obf. 615 a adu. 442 443.

Mefereum Germanicum. obf. I 99 Metcolin Britunnorum. adu. 21 Meun. obf. 449 atu. 347,348 Mcum fpurium altetum Italicum.

fecundium Ma:th. obr, 455

Mezereon Arabum. adu. $\quad$ I5 57

Mezcreum Germanicum. adu. Is

Militaris Aizo:des. obr: 20

Mutitaris, fiue Millcfolium, forea
bo, purpurco, \& lutco. adu.
Miliatis, fute Millefolium tertefre vulgate. obr 430. ad. ;3;

Militarıs terreftris \& aquatice dignotio. adu.

Mitiun. obl. $\quad 24.25$

adil.

Milium Indicim Plin. obf. 24. 25

Milium Solis, zdu. I9:

Millefolitum aquaticum alterum Coriandrifolium. adu. \$33

Millefolium lurcum. obr. . 431

adu. 33 I

Millefolium terrefte purpureis fioribus, obf. 4 ; iadu. $3 ; 3$ Milleguetta.jut Míclegetta.obr. 616

Millegrana Cordi. obr. 230.8251 Millemorbia. adu. $\quad 230$ Milzatella Italorum. 2du . $\quad 222$ Mochus, obf. Sis

Molle Clufij, obr.

Molochia S rapionis Valerandt. obC $2+7$.

Moluca Syriacn. adu. $\quad 221$

Moluca numusafptra obf. 279

Molucalpera.oofid $27 \%$

adu. $2 \geq 1$

Mollugo Belgarum, montana Dod. obl: 456

Molluco vulgatior herb. obf. $\quad 465$

Moly Diotooriveum putatum. ob!.8

adu.

Moly liliflorum Honeriçum forts. obf. 82 .adu.

Moly folijs Narcift. obf,

Moly Hippocratis. 2du. $\quad 60$

Moly Plin.

Moly Serpentinum rocatum. obC. $8 z$

Molybuana Plin. ob 1 . 173

a.tu. 135

Monophyllon recentiorum, dof. $16 x$ adu. $\quad 127$ Mosfax y" ouxdurys. ObS. 6I0 Morfus Drabuli.obr. 295

Morfus gallina folio hederulz. obr 247.2 atu. 194 $\begin{array}{ll}\text { Murfus rance. o's. } & 3 ? 4 \\ \text { adu. } & 2 \leqslant 3\end{array}$

Iorus omnis,albz, pumila adu 4 , Morus candida, Morus celia ofticnarum. obf. 6 ro. adu. 441

Murgo. adu. $4+2$

Mulcibrut.. adu. $\quad 4 \div 3$

Mulfa.adu. 22

Mula Serapionis, ciufque fruetus. obi. 636 . adu. 451

Mufcarelia Cordi. obr. $\quad 334$

Mulcipula.obr 242. adu. Is9

Mufcipula altera flore mufcofo. obr.

Múfcipula, num flos Conftantinopolitmus alrer minor GeCneri: obf. 242 $M$ ufcus candidus Corall vides fquammulis loricazus. obr. $\quad 648$ $M$ ufcus cnpillutue aureus minos.obf. 646.

Mufcus intybaceuscrifpus marinus. o's,
Mufcus marinus vuigatifimus. 647 ? 648.

Múcles pulmonarius. obf. 647 Muicus guterous. obi: 643

**3 Mutcus 
Mulcustereftisdenticulatus: denti- Nercilusluteus inncifolius prxcox,

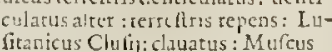
icoparius, obf. 647.645

Mynorum. obf. 1 Ir adu.

Myagrumalerum Ihlatpi cffigic. obi:

Myolutis hirfuta reptans. obr. adu.

Aivercúges. obf. I 41 . adu.

Mupixy obli. 625 . 2 du.

4.1 ricipler 447

Mathripliyllum Faluite obf 460 , adu, 354.333 .3 ;
Muriophyllum equiferifolum uintile. altetum Matth. obr. 460 adir.

Mrtobalani Arubum, Kebuli, Bellerici, Citrini, Nist, Embliciobf: 600 adu. $\begin{array}{ll}\text { adu. } & 439 \\ \text { Myrsh obf } 577 . \text { adu. } & 428\end{array}$ Aryrahiba Pliu. obt. 376. adu. $\quad 296$ Myrrhis. abf. $42 ;$ adu. Myrrhis altera farua. obt adu.

Alyfintes, ob

Mytlinites altern. obf

Myrfinites : Mystifolia, Myrtaria Gazx. obf I92. I93. adu.

Myitacantha. adu. 28 Myrtillus officinarä \& Myttus inontana. obf. $546^{\circ}$ ad a. $\quad 417$

Myrtimaioris varietaresfex.

1. Latrea onnum masima; fecunda. tertia. iis. exotica Myrtus Plinij. v. vulgaris. lexta. obj.560. adu. 419 Myrtus Bxtica Intifolia Clufij. obi,

Myrriminoris differentix quatuor. obC. $56 \mathrm{I}$ Myrtus Mlauritanicasltera, fite Myrtiss exutica Plimiminor. obf. 561
Myrtitesvinum. obl: Myxi A 2dit.

$$
\begin{aligned}
& 596 \\
& 437
\end{aligned}
$$

N. DVApellus Auicen, Guill obe. 398 386 adu.

Napellimufex atus.

Naphrha Diofc obt:

Nupus. obt'.99.100. ad́u.

Narcaphelion. adtu.

Narcifít. adu.

Narcilis autinglis arrums 49. 50

Narciftisantumnalis cuorunda Clu

Lio. ob!
Narciflis autunalis Marcelli Virgilij Muzono tore lureo paliéte obf. Nincintus totus athus, obt: $\quad 60.6 \mathrm{I}$ Narcifitus allus polyanthos.obf.60 6I Chalcedonicus clegätior. obf. 6 r

Narcifus Conftátincpolitaus Matr. non defcriptus. obl"

Narciltus iuncifolius ferotinus pau cioribus folijs, \& folijs dontay diterfus, cbf. 6\%. adu.

Narefius luteus inncifolius pracox. Nareifins luteus multiplici fore, obl: $61,62$.

Narcifi montani Theoph, yatictates. obf. na Dubus vomitorus? ob.62.ad. S I
Nacifius rot s lutets. montanus Theonh, obl. 6p.ndu adn. Narciflirs montans iuncifoliusadir, 465.462 . nicus. obf.

Narcifius poëticus mediocroceus Dod. chli6o. adu.

Narcifiuspurpureus Ilinij \& Virgilij. obl. 65 . Natcifus purpurocartuleus. adu. Si Narcilitus quartus pietus Matt obf.73 Nareifius lexcus Matth, obt:" 65 Narcifus feptimus Matth, non deNarcilus feptumus Math. non de-
ferip:us. obl. Nardoftachys A eginetx adir.

Nirdus obi

Nardus Celtica obc : 70 adu 43 Nardus Celcica altera.obf. I $70 . a d .1$;

Narjus D

Nardus Gangitis Spuria Narbonef adiv.

Nardus Gangitis Anguill. obf. Nardus Italica. obf. 23 g.adu.

Nardus montana. coff.412. adti. 32

Nardus ruftica, adu.

Naltos. adu.

Nafturtium.obr. ro7.adu.

Nafturia aquaticn planta adu. 7

Nafturtim antuaricum Trari.ob 10

Nafturtum Bahylonicum, adu.

Nafturitim hortenie.adu. $\quad 72$

Nafturtium Indicum Dod. obr. 338

Nafturtium fyl, Clufij. obf. I0z

Naqurium fylu. Cordi, \& pratenfe

'Tragiob!

Nalturium tedorum fylu. adu, 72

Nattix Phin. Guill. \& Anguili.obli,4

Natrix Plin. Herbatiorma, obl. 49

Nepa Theoph. adtu.

Nepera. adis.

Nepera Ttagi obf 176.94

Nerjon. obri 198 .ati.

Netion albis floribus. obt

Nerij facieatbor adu.

301
302
635

Nerfin Serapionis Anortill.

Neracis adu.

Jicotiana Gallormm. obf

adu.

icotiana inferitur infïdibulo $2 \int^{2}$

haturiunt fumum Indi \& maucleri.

adul.

Nigelia Romaña odora. obC

adu.

Nolime tangere.olf. I7r. adu.

Nummularia. obr.a s1. adu.

Nueula terentris-Septentrionalium an fit Burion Diofe. $\&$. Buboca ftanum-Tralliani? obf .429 adu.

Nucula Iudicá. ob?

Nux auellana، adu.

Nux Indica. ob6, 64 I.adu.

Nux iuglans. obf. 545 .adu.

cartum conditura. adu.

Nux Metel Marth. \& Iral, obf. I 36

NuxMufcata, fiue my rifticafiue nux
Narcilus metioluteus. obf 60 st

Narcifius ounium minimus Hifpa-

pernecam Moly H. Tragi. obr. 65

Naftutium Iralicum. obr: $\quad$ ic6

Nigellantum Dod. obr. odorata es aromarica oic

ac่u

$5 \%$

Nuxperenrina Indica, non biforis actu. 415

V Fophasalba, lutea. obf:;23. 324 minot. adts.

Nympea lutea minor Septenrionaliuar. adu.

257

O.

Chrus fylu obeg I6. adu. ;97 Ocimaftrú alterú Tragi obt: asa Ocimaltrum Valcrianthon, ob! 184. aरीu.

Ccimaftrum aherum eft Spument4 Papputrvalgo. adu. Ocimosdes, fue Ocinaftrum oblis \&

an Meliandrism I'linij? ibid. Ocimum aq̣utacum. Ob. 2698 alu.

Ocinum maximum Caropliyllatis ac Citrearum. obli.268. atu. 2 Is Ocmunn nedum vuigatius, obt. 26 a adu. $2 i$

Ocimum aninimum Amaraci figur

Caryophyllatum.obe 269.24tu. 2 I Ocimunifyl.obf. 270 Oculus Chrifti Monfp. obl: 18 Ocymoidesregés polygonitolia. obr 185. adu.

Ocymum Marci Varronis Angui!i.

obl. SI \}. adu.

Oeleomcli adu. 25 . proquorepone

Eixomeli.

Denamhe. obC. 420.42 r. adu. 325

Ocuanthe. I abrufca obf. 348 .2. 27

Oenanthe angnififolia obf. 420.42I

Oenanthe aquatica, quata Matth.

Dod obt

Oenanthe Cieutefacic. obf. $\quad 42 x$ adte.

Oenanthinum. obC.

Olea fylueftris \& Latiua obc

adil.

Olea lyl. Septentrionalitum. obf. 567

Olex Acthiopicx hachryma obt. 967
Oleander.adu.

Oleafter Germanicus Cordi.obc 598

Olfenichiun Cordi. obf. $42 \mathrm{I}$, adu.

$\$ 26$

Olus atrum. obr.

Olysa Diofc 127

Omphacomelites obi: adt.

Omphacium Dinfe ecber. 349

Ophioglolfum olf 475 a du 360

Ophiofcotodon, obf. St. adu.

Opitm. adtu. 1 I

Opobslianifuccedaneum.adu, 4 is

Onis inajor obf. 26

Onobrychis Dal. obf, $\$ 26$

Onobrychisatera Belgarum \& Dou. obf.

Onoclex.adis.

Ononis obf. 422. du

228

nopordon alterum hesbariorum 378

- Dod.obi".

Onofma. ob 312 adn.

Onopyras Guiland.obf. 489

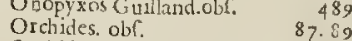

Orchidum differentix \& genera. obf 92.93.

Orchis bafilica altera. cbf. 89

Orchis Delphinia montana C: Gcm $m x$, obf. 
Orchis Earrachires, rel Eatrachiocides C. Geminze obf. Orchis Delphista palufti; C. Gem. nus obl.

Orcitis Ftrfin lizonalis. ob

87

92

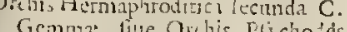
Gemnix, fiue Orehis Ifjcho'és dipluyli.t. obf: - 92 Otchis mas anguntifolia Fuchf.cbr.87 Orchis rainor odotata. aju. $\quad 63$ Orchis minor Leod enfis. obr. 92 Orihis miliztias, fiue apis cadaueru-

$\lim$ exprimens. obf.
Orchis Myodes lutea Narbonen is.

obi. 91 . adis.

Ordhis ivlyodes altera C. Gemmx. ois.

91

Orchis Omithophora, vel Ornithes folia lixui C.Gemmax obligy ad. 6 Orehis Ornirhophora folijs maculolis C. Gemm:x. obr:

Orchis Szurodes vel Scincopltora, Lacettarum xriulatiode C. Gemmx.

obf: 89

Otchis ftrateumatica. olr.
Orch s ftratcumatica minor C.Gemin 2 obl:

Ordelion Nicandri Anguil. obr. 426 Oteoflinum. obf.406. 軲u. 3 Is

Origanum Heracleoticum.obr. $\quad 262$ adu.

Origanum Onitis Gal oprouincix maius \& meniss. adu. 21 Otiganum fylu. Sy riacum, Cteterre.cble63. aju. 21 Origanuna Tragoriganum fue Hircinum. adu.

Oraithogalon mains Dod. obr. 73

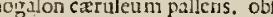

Oruithogalon candidum vulgare.obr 72. adu.

Ornithogalon luteum an fit Bulbus vomitorius! obr.72, adu.

Ornithogahum fpicatim. obr. 47.48

Ornithopodium obf. 527.2 ta. 403

Ornithopodij varietas. adu.

Otobus receptus Herbariorum. obt

- Sig. alu.

Oruala certia Dod. obr.

Oryza.obl. 23. adu.

Ofmuuda obi $47+$ adu.

Ottrutiuni obr.

Ofyris.obr $22 \div .223$. adu.

Ofyris Grecoruin Dod. A 27 obr. 223 adu. Ang

Ofytis purpuro cxrulea repés: ad. 176

Othonna, obf.286.287. adu. 229

Othonna Italorum. obf, 410 . ad. 3 is

Othoina ltalorum, aut flos Aphricanus, an Lycoperfion Galeni? adu.

Othonna maior poly anthos. obr. 310 adu.

Oxalis. obr. r s s. adu.

Oxalis fatiuz france rorundifolia $x$ pens. obt: I $6:$ adv. $\quad 120$

Oxalis veruecina tenuifolia Cinuata. obf 156 adu. 120 Oxialis tenuifoliz. adu

Oxalis tuberota.obt

(xyacantha. ohf, 614 adu.

C xy arantha Diofc. Fuchfii. adu. 499 Cxyarceur:s, five acuta I uniperus. addu.

Oxycedtus folio Cupreffi, obr $\quad 443$ Dxycoccon Cordi.obr.
Oxylapathm. ob6.

Oxyclininion ob 195 adu 158 Oxy's lutes corriculata repens, lutea Ciufip. obt:

Oxyeriphyilun Scribonij Latgi; \& alcerum Scribonit, Herb. adu. 38 I.

PAconiamas obf. 390 and: . 305 1 Pronit fremisa. ibid. Pxonia fixmiua polyanthos. obf. $39 \mathrm{r}$ Pronia promifcua feu neutt. ibil. paldurus. obf. 998. ada. 437 Paliurus Aphecasus Theoph obr. 527 Paliurus fecundus Lacunx. obl: 582 Paliutusalice Theoplar. an Ge I uiuba fylu ? adu.

palurus alec peremrious, adu. 437 Palma Chrifti. obf. 302.adu. 305 Palma Chrifti hetbariozum.obr. 92 Palma Elate. obr

638

Palma, palmarum fruetus fiue dacty -

li \& entus flores. obf, 637. adu. 4 \&

Palma minor Marth. Palmites Hirp. oble

Palma fancta fiue Palum fanctis Indir occidure \& alia atbor fimilis Palmx fante. adu.

Palmx fanctar fimilis arbor. ad.456

Palmx Chtiftiades. adu. 63

Palma pinus, fiue Conifera. adu. 450

Palmx petmultx fpecies. adu. $\quad 4$;

Palmacea, aut Arundinacea pinnata

- Evinofa planta adu. 452

Paludapiun obficos. adu. 315

Panax A iclepiun obt. 455 . 2 du, 355

Panar Chironium, obf. 585

Panaz Chitonium Anguill obf. $\quad 309$

310. adu. 245

Pamax Chironium Tragi. obr. 245

Panax Heracleum. obf. 399.adu. 312

Panax alcerum. obf. 400 adu. 312

57

Pancratium alterum Mōoell.adu. 49

Pancratium matinum. adu. 57

tas. oul. 76.77

Pancratium verum Clutij. obr. 76

Panicum cornlemm Ind. adu.

Panicum Indum Diofcor. adu.

Panicum laticum. obf.

I 4
Is
is

Pancum fyluettie Herbatiorum. obs 25. 26. adu.

Paris Circuli. adu.

Papauer album \& nigrum polyadhó. obr. 142. adu.

Papaner corniculatum violaceum, obf. 24 I. Edt?

Pap̧atrer cortuutum fore phoeniceo.

oblis itr. adu. 'sog

Papals. fimbriarualbú. ad.ro.\& 463

Papaver nivrum, frontaneun fylucftre, \& hottenfe. adu.

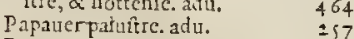

Papauerparuttre. adu. $\quad \$ 57$

Papauer Rhocas. obfil 3. adu. III

Papatier faritnim. obr, I 42 . adu. I 10

Papaner fpumeti yllorund, obf.18 an Gratiola recentiorum? adb. i \&s

Papaver fpumeum Diofc. Anguitl. obf 238 . atu.

Tap. frumeum vulgo ob. I 81 a i 14

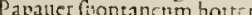

Papyrus: obli $42.2 d$, 38.39 .40
Papyrus Nilotica. aldo.

Papyacez a rundo ordu.

Paraly taca Alpira Sanicula obf $\quad 40$

adu. 24

Paralycica Alpina Sanicula angurit folin. obr. Patietaria. obs:

adu.

130

Parictatia Cordi Monfrch obr 9

Paronychia Alfine folia. obl:

Paronychia alcera tutaceo folio. ob! 249. adu. 196 Parnuychia $\mathrm{H}$ if Parthenion. obl. 447. adu. $\quad 34 t$ Parther:ium, vel Vratines oft Cotula rotida, non Matricaria. ad. Parthenium Tragi obl: 44 Parthenif varietas. adts. Paffetina Linatix foho obr. Paferina pricaulis Herbar.adu. 35 Partinaca. obf. 416. adu. $\quad 323$ Poftinaca aquatica. adu. $\quad 3 \mathrm{I}$ Paftinaca domeftica vulgi. obr. 407 adu. 3 is Paftinacamatina, an Secacul A rabu? obl: 408.ídut. 317.318 Partinaca fatiua Diofc. obr. 416 adtr- 323 Paftinaca fatitua atrorubens.obr. 417 Paftinaca fylueftris. atud," - 3 i7 IPatientia vulgi, obf. I Pediculuris.adu. $\quad 306$ Pedicularis alectorolophos. obr. $43 \mathrm{I}$ adu. 334 rin Tragi,an Sielophotos Plinij? ad u.

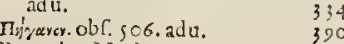
l'eganion Notbon. adu. 390 Pentaphy' lon maius, forc luteo. cot 393. adu.
Pentaphyllum incana effigie, an Leucas Diofc.? 307 Pentaphyllum minus Iuteum, album, album \& putpurcum, pettofim \& minimum. a.tu.

Pentaphyllú pet:aü Afutoni.obr. 39

1'entaphyillum fupinum Tornentille facic, obr.
Pepleos Pet. Quthe \& Parifioruni. 395

Terlis or 197 S1

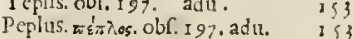

Pepo. obr.

Pepooblongus. obr. 76 g. adu. $\quad 286$

Pepo maximus Indicus conprefius.

obf. 365 . adu. 256

Pepo rotúdus comprefitis Mclonis of figie. obf. 365 . 2dut. 186 Percepier Anglorum. obr. 41 adu. $\quad 32$

Petdicium. adu. 88

Perfoliata filiquofa. cobr. 2 Is

adu. $\quad 172$

Perfoliatum vulgatius flore iureo.sbr. 2rs. adu. 171 Periclymenon. obf. 358 . adu. 280 Periclymenon Allub:ogum, obf. 358 adis. 280 Iericlymenon pet foliatun calidarum regionum. obl: 337 . adu. 280 Periclymenon non rerfoliatum $5 \mathrm{e}$ f:entrionaizum. obre 3 s 8.adu. 280 Periploca Gexca.cb6. 356.357 Periplocafetpens, angutiore folio. obf. 357. 2du. 279

Peri- 
Periploca Greca, fit ne Díof. Apo279
Periploca frior Dod. \& Belsarü quorundam obi. Perifteron adiu. Periftetona Cratesx Anguil.obr. 207 adil.

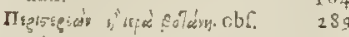

Perfeabbr.

Peifica $4 j 7$

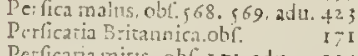
Perfearamirts obti, I 7 .ad u. I 34 Perficaria pufilla tepens. obl. 17 Perficarafiliquofanofta, obf. I>I adu.

Perficarinvens. cbf. 17 i. adis. Perficatia varjetares. obr.

Perfonata obf 38.850 .171 Pernincamaior, obr, $; 60.3 d$. 282 Peruuiana arbor A loes facic, adu. 454 Pesanferinus, obf, 127.128 . adu. 97 Pesafini Pandectarij, an Alcetorolo phos Plinii! adu.

Pes atis. adu.

$22 \mathrm{~S}$

Pescolimbinus. obr. $375.0 \mathrm{~d} 11.296$ Pesleoninus. obr. 255.645 aciu. 202 Pesleporis. obr. $\quad 498.499$ Peslocuftze Aticennas. adu. 139
Pesviruli.obr. adu. Perafies. obf

adu.
Petalites Indica, alu

Petrofelinum Guillansui s- A 453 obr.

Pecrofelinum Macedonicnm.obl.4cs

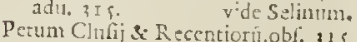

Perum Clufij \& Recentioríobi: 3 is
Peucedanumi. obr. $4 ; 3.454$

adti.

$4 j 3.454$

Peucedanum maius I talicm obt. +54 Peucedani facie pufilla pláta an PfeuJobunion Diolc.?adu. 33

Pluacos, adu. 40

Thalangium Cretx Saloneufis Tragi. adu.

Thalang

Pinlaterim an Moly Plin.? adu. I8 Phalaris hetba. obc 26. adu. If Phalaris pratenfis minor. adu.

l'hafelus a Phafiolo dinerfus. adu. as Phatcli a Fabis \& Thateolis difcrime. adar. 39 Phafelus Diofc. Dod. obr. 390 Thafcoli nouiorbis, obr?

ader.

Phafeolus Erafilianus, eiusćue filiqux obr. Phifeolus aller Prafilinaus Clufit, \& Parui ex Americn delati. obf. 513

color Fabi, ef Smilax hortenfis

Diofc. obf.err. adu. $\quad 394$ Pheliandrium Dod obf

Phellandrinm Pln, Guilland, ob

Phellodris. adu.

Drsios Theoph.adu.

कirespe. obr.

606

Pbillyrea arbor Galloprouincix, ve rior Macaleb Serapionis. adu. 421 Phillyrea Narbonenfis, obl: adu

Phillyea angußifolia. obf.

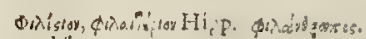
obl, 464

Phoenix, obf, 21.485. adu.

Drouid as. adtu.

Phlomits. żlu.

Dixéuos. adtr.

Phlomos Lychnitis. obf. 242

Ihlomos Lychnitis altera Syrizca.obf.

phiox, fiue Flamma Theoph. Atgu"l. obr.

क) $76^{y}$ Theorh. obf.

Ilithora Valdenfium, allu, is

Thu minimum alterume obf. 4 I $2.4 \mathrm{I}$ a.lu. 319 . vide Valerian.s Phyllitis obf. 468.469. adu. 399
Phyllitis mnltifido folio, clufque varietas, obr.

Phyllon mas.obr. I 30 adu.

Phyllon faminiparum. adu

Phyllon Theoph.adu.

l'hyteuna Dod. obr.

Phyteuma Matth. obr

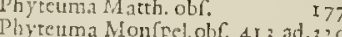
Thyteuma Norbonenfum. adu. 320 Picea.olx. 633. adu. 4:0 Picinum aleum Dinls. obf. 635 Picnonos Creta: Salonenfis, obf. 48 ind1

Pignolatum. adu.

Pilolitla obl: 254 adu.

Pilofella maxinja Syriaca. obr.

Ptuefella Tragi obi.

Pimpinclla, obs 477 adu. 32

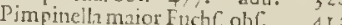

linafter, Pinus fyi mötana Theoph. obl.

Pinafter alter maritimus, obf. $\quad 632$ Pinafter fccundus, rerrius Clusijo onniummininus. obr. 63

Pintrs \& Picca. obf. 6;4. adu. 449

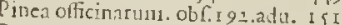
Pinus Iteca Theoph videtur Pini inaritimic siterumgenus Matth. obi: 634. \&:633. rroxim e Laricem.

Pinusmariuma Theorh. obf: 63 Pinus: refinitere \& conifere adu 440.

Pinus $f y$ lu, altera. obf.

Pinusvalgatifima. obr. 63 r.adu. 449 Piper. adil.

Piper Acthiopicum Math 134

Piper caudartumi.3du.

Piper Hippocmis, \& Piper rotulu dum Theoph. Guilland. obl: 575 Piper Indicum. obf

Pipet longum. adu.

Piper longum. Piper longum Monar di.obt.6r7.adu. 44 5. \& 446 Piper nigrum \& album. ob 5 . 575 I'iperi rorundi duplicis frutex. ad, +26 Tirola. obr. $x<7$, adu.

Pillafphatrum Diofc. obf

$1 \geq 2$
635

Piftacia obi: 539. adu. $4: 3$

iftana Magonis, fiue Plinij Sagiteariaj an Stcobe femina? ob? I6I adu.

Piftolochia, obf. 333 . adu. 265 Tifum Americum coccineum, ob:". 5 I 6.

Pifum angulofum hortorum maius Dod. obr.

Pifum angulofum hotrorum, an fie quadratum Plinij? adu. 396 420 Pifism cordatum, obr. 5?6.adu. 397 s6s Plum Gracorum Tragi, obr. 397
Pifun minus exluteo virefcens.

obl: sI6. adu.

Píma ly lucfire adu

397

Pifrom lyluctic fogerum. adu. 397

rifum vulgatius maius. adu.

Pitytra. obfigz. adu. I5

Pityl fa fiue Efuli mirior alcera flori

bus rubris. obf:

Tixatidn Diolc, obr.

Pix liyuida Diof cobr.

Pix naualis obr.

lantago aquatica obf. I60, eftne $\mathrm{Li}$

moniti aut porius Alirma ? adtu. 126 Planiago aquatica minor. obt: 160 Plantago hrifolialeuis.adu. I 27.128 Plintago matina. obt. 163 . adu. $I 28$ Plantago malicu incana, obf. 162 adu. $\quad 128$ Plantago quinqueacruia. obi. 163 adu.

Plantagororea pannicula ffarfa. obl

I62. ader. I28

Plant,no vulgaris latifolia. obr. 162

Plákaginis rolex varietas. obf. $\quad 16$

Plataniss obf 653 . adu. $\quad 442$

Platyphyllos,obr. 423

Matyphyllon Characias Matth.ad. Is Datyphyltum Hifpanicum. obf. I96 Pleuronatia nectu dorens. obf. $3+2$ Pneumonanthe Cordi, obr. Í́ adu.

Pneumonanthes fuve Geniftla 13

rietas. obt. 166

Poulagraria Germanica aut Belgica

obl, 398. adu.

Polemonium. obl. 506 adu. 89,31 .

Folemsonium Dad.obr.

Polium Lauendula foliol, femina re

centjorum. obr. 258 . adu, 207

Polium lutelin sapitulis ex luteo yi ridantibus, obr. 257 . adu. 207

Poliú montanú.obf.2 97. ad. 2c6.207 Polium montanum fipintm.c bf. 257 Polinm İepens fupinú Clưij.obli, 25 Polium Venetú, Creticum, minus \& mediterraneuni Jutelim, Lauendula tolto. adu.

Folyacatha Theoph obf 20.7 Polyinthemon paluifte Dod. \& Dilfij. obf.
Polysriemury wb.270, adu. $\quad-497$ Polycnemon, an Calanincha aquatic Belgarum? adu.

Polygala. adu. 178 . noftra. autu. $\quad 379$ Polygala Match.obr.
Polygala recentiorú, obr, 228 ad. 1259 Polygala iecétioni varietates.obr. 228 Poly gala Diof. Dod. obr. 527 Polygala repens nuperorum. obr. 227 Polyggala Valétina prima CluCob. 529 Polygrala vera Dalefc. obr. \$26 Polygalon.Cordi.obf. $\$ 26$ Polygonatum. obf. 361 adts. 283 Polygonatum minus Rubix folijs. obf. 468, adu.

Polygonatum Tragi. obr. 35 Polygonum.obf. 228.229.adu. 179 Polygoni alterú ferpilli $f_{0}$ lio.adu, 180 Polygonum mas vil. are. adv. 179 Polygonou femina fcmene vidua. ad. 354.

Polygonum Herniarix folijs, ad. 404 polygonum maius. adu. Polygonum marintim maximun a? altum. adu. 
Polygonum minimum niueum \& fericium obf. 229 adu. $\quad 179$ Polygonum minus Matth. obf. 230 P'olypodium. obf. 475 adu. $\quad 363$ Polyrrhizon Plin.obil 333 .2du. 265 Polylporon CuCani Baffi Anguill.

obr.

129.130

Polytrichum. adu. $\quad 36 \mathrm{I}$ Poma amoris, an Glaucium Diole. ?
ad.pag.

108
425

Pomum Afyrium. obr. 573 . adu. 42 s Populus allba \& nigra. ob?. $44 x$ populus Libyca. obf. 6r o. adu. $44 \mathrm{I}$ Populus noui orbis prxgrandi rotudo colıo adu.

Populus pumila, an Populago? adu. 268.

Porrum capitatum \& fectile. adu. 98 Porrum fylu. olse. $\quad 78$ Porrum rylueftre inodorum obr. 78 Portum tonfile \& capitarum, obf. 78 adu.

Torrum vulgare. obs

Forrulaca domeftica obr. aju.

Portulaca matina obr

Portulaca fylueftris. obf. adu.

Pfrudoxylobalfamum. adu. P fyllium. ob 239 . adu.

Pfyllum masinum 3 du.

Pfylliu Plininu Corre ob 2390 Ptarmica folio Tasaconis, obf. 243 adu.

Piarmica altern Gallorum adu

Ptatmicx fpceses. obr. 294

II7ris $\alpha$ obs? 606

Preridion mafculum Cordi. obs. 476

Preridion femina Cordi.obr. 475

Ptifana obs:

Pulegium regium, vulgatum.obf. 266 antu.

213
214

Pulegiū mas \& femina Plinij. ad. 214 Pulegium Cerunum, angufti folium

Monfpellienfiū odoratıus, adu.2 I 4

Julicaria adu.

Pulicaris herba. adu. I 86

Pulmonaria alba exorica.obr. 357

Pulmonaria Gallorum, tore Hieracij

obf. 3 I 7 . adu.

Pulmonarian 25

Pulmonaria maculofa. obr. 317 . adu. 252. 253 .

Pulmonaria officinarum obr. 647

Pulfarilla alba. obf. T49. I 50

PulGatilla rubra. obf.r 49. adu. Ii

Pulfatilla vulgaris. obf.i 49. adu. 154 Pülfarilla, an Sylu. Anemoneiad. Ir 4 Pulfatill $x$ varieras, obf. 5 o 0 adu. 114 Purpurea Galcopfis. obr. $\quad 280$

Pyrn.Pyrus.obf. $590 . a d u . \quad 434$

$\begin{array}{ll}\text { Pyracantha. adu. } & 434 \\ & 438\end{array}$

Pyracantha herbar. obf. 599. adu. 438 Pyracantha Narbonenfium. adu. 419 Pyrethrum officin.obr.447.adu. 347 Pyrethrum alterum. obr. 447.ad. 347 Pyrethrum fylu. quorundam.obf.243 Pyrola à Pyi folio. Limenium Germanicum.obf, r 57 , adu.

$$
\text { Q. }
$$

Vadrifolium phixum. obr. 496 adu.

Qundrifolium Phyllon.adt.

Quereus Cerris.adu.

Quercus marina obf

Onerus $\quad 652$

Quercus perperua frōde virěs.obr. 58

Quereus pumila. obr.

Quercus vulgatis, cum fuis exereniéris fungofis, cú glăde \& mutco fuo. obr.

Queicula minor. adu.

583

Queicula minor. adu. 209 Quinquefoliū fiue Pentaphyllū vul-
gare. obf.393. 394. adu. 306

Preudobunias. obr. ro4. adu. 70.7 Preudocapficum Dod.obr. $\quad 136$ Preudochamxpirys. obf. 209 Prendocinamomum Diofe. obf. 57 Preudocrania Cordi. adu. $\quad 436$ Preudodictamnum fio ribus verticillatis'obr. 267 adiu 215 Pfeudoiris Dod. obf.

Preudohepatorium mas Dod. obf. 284 PRéudohermodactylus Ital. \& Matth. obf.

Pfeudoleontopodium. Matth. obr. 296 P feudolöchitis afpera Matth. obf. 476 Pfeudomelanthium obf. 23 .adu. 12 P feudo-Nare uffus Cluf. \& Dod.ob. $6 \mathrm{r}$ preudonardus Fuchf. \& Matth. obC 235. adu. 184 Preudonardus femina Matth.obr.236 Pfeudotchis bifolium Dod, obf. 161 preudotha recentiorū.obr. Y 52.2 .118 picudof thonanthum.obf

Preudo ftachys Matr. obr. $284.3 \mathrm{~d} .223$

\section{R.}

R Adix caua herbariorum. obr. 439

$\mathbf{R}_{\text {adu. }}$ Adix 38.339 Ranx morfus. obr. 324. adu. 258 Ranúculus albus flore fimpbici.ob. 38 I $\mathrm{R}$ anunculus albus alrer. obr. $\mathrm{R}$ anunculus minimus albus obr. $38 \mathrm{I}$ adu. $\quad 300$ Ranüculus aquatilis angnftifolius ferratus. obf. $\quad 384$

Ranunculus aquaticus, obr. 497

$R$ anunculus aquaticus Fuchr.\& Tragi. obf. . $\quad . \quad 38$ Ranunculus aquaticus flammeus anRanunculus bulbofus. obf. 380 adu. 299. vaifolius aut bifolius. adu. guftifolius, obr. 382 adu. 299
Ranunculus Illyricus. obr. $\quad 383$ Ranunculus Lufitanicus autumnab's Clufij. obf. $\quad 384$ Ranunculus monophyllos. obr. 385 Ranunculus montanus Alpinus glomeratus.obr. $\quad 384.385$ Ranunculus nemotofus. quartus Fuchf. lacteus \& luteus, candiduc Cordi \& Tragi. obr. 384 Ranūculus niueus polyáthos. obf. $38 \mathrm{I}$ Ranūculus niueus polyáthos. obr. lio. obr. 38 Ranunculus polyanthemos, multifiorus Fuch.obf. 380 . adu. 299 pratenfis, \& hortenfis.obr. $\quad 379$ Ranunculuspratenfis furrectis caubculis: horenfis fecundus Dod.obf 379. adu. 298

Ran.pratefis yarietas. obC. 380. ad.298

Ravunculus pumilis folijs gramineis. obf. 383 adu. 299 Ranunculus quartus Matth.adu. , 300 Ranunevlus fanguineus multiplex Conftantinopolitanus. obf. $\quad 383$

Ranunculus Seprentrionalium minimus. obf. 384 adu. 300 Ranunculus tertius fyl. echinatus horrenfis fimplex Fuch obr. 380 Ranunculus tuberofus Dod.obr. 380 Raphanus magnus. obr. Raphan. primus Matth.obf.99.ad.67 Raphanus minor purpureus. obf. 99 adu.

67
4.67

Raphani omne genus. obr.1oo. ad.67 e colore tertia differéria.obf. 500

Raphanus rufticanus florens. ad. 495 Raphanus rufticanus, Lapathij folio. obf.

173

Raphanusfylu.obr. too

Raphanus fyl. Diofe. Dod. obf. I 75 adu.
Raphanus fylucftris officinarum. obf. I72. $173 . a d u$. 17 Rapiftum.adu.

69

Rapiftrum aruorum. ob. 99 adu. 66 Rapú maius orbiculatú.obf.98.ad.66 Rapumfy!.non bulbofum obf. $\quad 98$ adu. 66 Rapum tereti, rotunda, oblongaq́ue radice. obl.98. adu.

Rapum geniftx. obf. 531. adu. 407

Rapum rerrz. obf. 33 I. adu. 264

Rapi varieras. adu. 66

Rapuntium maius.obf. 178 . adu. 140 Rapuntium paruum. obf. 178.179 adu. 139

Rapunculi c̀ foris colore varietas. obr I 79.

Refeda maxima, eiufque varietates. obf. r ro. adu.

Refin $x$ alix. obf.

Refinarum vinum obf.

R habarbarum Cholagogon. adu. II

Rhabarbari exrraktum per firitum Tartari Theophraftice \& chymice.

Rha capitatum folio Enule, Centaurei maioris facic.obf. I S3. 2 du. 158 Rhamouachorum. obf. ige Rha Ponticum. obf. r $52,2 d u$. 1 I 8 R ha lonticum antiquorum adu, $\mathrm{r}$ 多 Rha Póticum alterum anguftiore folio. ob.

Rhamnus. adu. I53

Rhamnus Catharticus recent ad. 437 Rhamnus primus Diof. prioris fpe- 
eici alter Clufii, fecundus Liofe. obr. 998 . adu.

Rhamnus fecundus Monfpeli. ad. 438

Rhamn.tertius primx fpeciei. ol S $_{5} 6_{3}$

Rhaued Seni c Sinarum India.ad. 18

Rhereda Plin. adu. 76 , vide Refeda.

Rhodiusu licusur: adv. $4 \times 7$.

Rhodia radix. obf. 12.233 . adu.177
Rhododaphne parua ruftica. obl. 199

Rhododédrum purpureurn \& album. adis.

Rhoites. ob:

Rhodites. obs

Rhus ob: 539 adu.

Rhisalcrum.adu.

Rhus Allobrogum. adu.

Rhus Plinimyrifolium $4 \mathrm{I}$

Rhus tylu. Il n Dilfio. old: 547

Rhufcusfylu.cbl: g8z, vide Rufcus

Ribes Arabum obr 6: 6 s. adu. 448

Ribestara \& rubta. adu. 445

Ricin us. obl: 392 adu. $\quad 306$

Ricinus Americus obi

Ricinus maior. adu.

Rima Mara Anguili. obf. 285

Ritro, feu Rutro Thcophr.adu. 363

Robur fecuda, quinta Ciufij. obt: 536

Robus. adu.

Rorclla Cordi.obr.

Rorda fiue Solis os or $\quad 472$

Roridie varictas. obr. 354355.454

Ros coeleitis, adu.

Rofa, obf.

Rola Alpina.obr.

Rofa canina odorata. obf

Ror a Cinnaniomea

Roli Damafectab. $\quad 446$

Rota Damarcena. obf.6I8.adis. 446

Rofa Hierichontis.obr.616.1du. 44 s

Rofa Mofcata adu.

Rofa fatiua, Rubra Prouin. candida pallida, cinamomea, morchata, lutea, cxrulca, pomifera, morifera,

Rofalyfucftris pomifera obf 446

Rofmarinum Bohenicum Matth. ob?

ob?. 598 adu.
as

Rofindrinus ferulaccus. obf. $\begin{array}{r}183.184 \\ \text { adu. } \\ 4 \% 5\end{array}$ adu.

Rotrum Ciconix ob . 376. adu. 296 Rubifaciefenticofaplanta adu. 452 Rubiateuis Taurjuenfum obf. 462 Rubismaior, tindtorum officin. obf. 462. $46_{3}$. adu

Rubia vrraque adu.

Rubia $\quad 356$

Rubia fylueftris minor. obf 357 \begin{tabular}{ll} 
Rubia fyluetris minor. obr. $\quad 468$ \\
adis. \\
\hline
\end{tabular}

Rubię maximx varictas.obf.

Rubia minima.obr.

Rubus, Rubus.Idxus, obf 65944

Rubustcprans, Idęa. adu. 446

Rumex. adu.

Rumicisertium genus Fuch, \& Turnerifecuntum obr. 130

Rumicum genera.adu. I

Rufeus. 0. 362, a. 283 vide Rhufcus.

Ruta carina, cbf so8 adu. 391
Ruta hortenfis. cbi s06.adu. 390,391

Ruta muraria, non eft Parony. 390.39 Diof.

Rutaptutenfis herbariorum 362 landrium Plin.robf.508. adu. 391

Rutze ptatenfis varietates, obt: 391

Ruia fylu. montana, obf.
Ruta triangulo pericarpio. adu. 391 Satyrium bafilicú primú Dod.obr.g2 Rutula Sylu. obí. go7. adu. $\quad 390$ Satyriun Bafilicī alterī Dod. obt.92

Cabdar.fa. obr.

SSabina. obt:

Sabinz 625.627 obc. 625 . adu.

Salina baccota alrera obr $\quad 447$

Sabina baccifera, valuatior, Act 626

adu. 447.448

Sabina maior M anfpell.obr. $\begin{array}{r}447.448 \\ 626\end{array}$

Saccharum Candum.adu.

Sacra herba. obf.

Sacra verbena Hifp minor. obf. 259

Sigapenum. obl: 452.adu. $\quad 349$

Sagitte minor. obf. I 61. adu. $\quad 127$

Sagitraria aquatica. obf $\$ 61$. adu. 126

Sal Indum. adu.

Saricaria. adu.

Salıcaria Germanica. obr.

Salicornia. adu.

Saliuaris. obs

Saliunca officinarum. obf, 170.

Sulux obt: 567.568 . adu.

Salix humilis. obi. g68. adu.

Sallaparilu. olx: 339 adis.

Saluia coccitera, fiuc baccata Crete-

iis. adu.

Saluia major. obl. 299.2du.

Saluia minor pinnata

299. adu.

Saluja fylu. Tragi adulterioa.

302. adu.

Salutfolium fylu. Verbafcū. adu. $24 r$

Saluia vita. obr" 472 . adu. 362

Salifirola Cordi. obr.

Sambucus. obe

Sambucus folijs aciniatis obs 88.589

Sambucusaquatica, fue roléa. obf 6I s. adu.

Sambucus montana racemof, aqua.

$\begin{array}{cr}\text { tica, rofea. } & 444 \\ \text { Sambucus vulgaris corymbacea. adu. } & \end{array}$ 434 .

Simpfiucus. obr.26g. 266.adu. 2t Samplucus Diolc. repens. obt. $2 \mathrm{t}$

Samamunda prima \& altera Clunjo.

obi:

Sana Sancta, obr

Sanguinasia, adı.

624
316.317

S.unguiforba, Bipinella noftras, obf 430 adu.
Sanguifotba altera maior. obr. 3320 adu.

Sanicula. obf:;06.373. 379.adu. 244 Sanicula Alpina minor, fine media.

obf 307 minima obi:

Sanicula femina Fuch obr 308 Sanieuix lutere fiue Primula varicta-
tes. obf.

purputex varietates. obf.

Santolinx Dud. obf.

Santonicummaius Cordi obs 436

Saponaria obr 770 adu. obr. 436

Saponatia altera \& Srruthiō Alidroandi. obf.

Satiuus vibanus Lupulus.adu. $\quad 184$

Satureia. obr. 2 12. adu. 277

Saturcia hortenfis. obs: 232 , adu. 18

Satytion Apuleij.obf. $\quad 87$

Satyrion Erythronimm.obr.

adu.

Satyrium.obf.
Satyriorum vnuerfa Sylua C. Gem. mx. obf.

Saxifraga Anglorum. obr. $\quad 94.25$ adu. 183,3 52 Saxifraga magna. obf. 18,3 , Saxifraga magna Matth.\&: Ital. 0.233 Sasifragia; fiue Saxifragia antiquorum.adu.

Saxifragia albachelidonides, ciuf 182 varietas. obf. 335 . adis. 267 Saxifragla aurea Lichenis facie. obf 336.adu. 267 Saxitragia Venetorum. adu. 323 Saxifräga Dod, obf.230.2du. 80.181 Scabiola :rftiua minor. obf: 293 Scabiofa Alpina nuxima. adu. 232 Scabiofa naior far orú.obi. 29 r.ad.z Scabiofaniaior, fit ne voiga Acrij?

Scabiofa maior Hifp. obf. 292 . 232 adu. 223

Scabiofa media obr.291.adu. 223

Scabiola montana maior calidarum

regiontm.obl. 29 r. adu. 23

Scabiofa montana omnium minimat adu.

Scabiofa minor. obf 290 adu. 232 Scabiolá peregrina. obf. 292. 29 Scammoniun, obf. 340 adu. Scammonium Monfpellienfe.ad, 77

Scammonij Möfpell. vatieras.obf. 34

Scammonium Syriacum, Antoche.

num \& Narbonenfe. adu. 27 Scammonjum tenue Plin. quorundä. obl.

Scandix, adu.

Scariola offic, obf. I 17 . adu.

Scarlca, obr. 300 , alu.

342

Scilla, obr. 300 , at

Scilla Hifpanicre fiofculi

Scilla rubencibus tiolculi ftellati. 0.75

A loes carinat radicis tunicis, folia

Schocnarithum obr. 76 adu.

Schemopallon, 42.2du. 42

Schoroprafton, A fcalonica Matth.

ob. 77. .adu.

Scolymos. obr. 478 idu. 8

Scolymos Dod obr adu.

Scolymos fylueftris.

Scolymos Theoph. atu. $\quad 365$

Scolymus verus Diofc. obf, $\quad 366$

Scordiana Cordi. obc

Scordioides foribus luteis. obf.

obf. $\quad 28$

Scordion. obf. zzr. adu.

225

Scordotis lin. obf: $\quad 284.28$

Exópodón. obf: 284.28

Scorodoprafum, obf 79 adu. $\quad 85$

Scorolopraftonalicrum. obf. $\quad 38$

Scorpio.dzs. obf.z I 2.adu. $\quad 79$

Scorptoidesleguminof 168

Scorpioiles repens Bupleuifolio 403

244. adu. ?

Scorpioides, an Trlephium Ctatcurs?

adis.

Scorpio. adu.

Scorpins fecundus Clufij. obf 353

Scorfonera. obr:
Scriftoria.

Scrophularia niajor.obr.289. adur 27

Scrophularia altera Dod. obf. 28 Saxifi:gra ferulacsa I talorum. $2 d_{.3}^{26}$ ?

Scopratia, obf 22 ;. adu. $\quad 482$ 
Scrophularia Tragi. obf, 21I. ad. I67 Seberten offic. obl. 596 . adu. $\quad 437$ Secalc. obr. Is. adu.

Securidaca maior \& minot. ob. adu

Sedum amarum Col. Dod. obr. 202 Sedum aq uatilc Dod.obr.

Sedum maius adu.

Sedum arborefens maius for 164 candidis. ob. 206. at.

${ }_{162}$ Sedum arboteficens Gracum, Illyri. cū, Anglicū fiue maritimūi. ad.16; Sedum medium teretifolium, ad. 162 Sedum minus, facie \& foltjs Sedi maioris, obt:

204 cdum minimum arborefcens vermi-
culatum. obf. 206 .adu. 162

Sed um minimum tertium .obf. 204

Sed um petrçum monranum.adu. 163

Sedi terrū genus'nō féper vitēs.a. I 62

Selinoidis Cordíobr

Selinonc.obr.40s: adu.

414

SemenSanctum. obt. 437 adu. 337

Semperuiuum maius obf.202.a. I61

Semperuiuú minimú. obr. 205.2 .162

Semperuiuum mariuum. obl. 202

Semperuiuum minis xxtiuli. obr. 206

Semperuiuum minu soltic, adu. 162 Semperuiuum paruú.ob.206.ad 162 Seus fatius \& fylueft. Arabum \&: A. ctuarij. obf. 530 adu. $\quad 406$ Senecio obr

Senecio lacila, adu. $\quad 79$ Senecio lacobxa. obfir I 3.adu. 79
Senecio incanz. obf.

Scrapiades.adu.

Serapiades Fuch o Dod obr. Serapias mas lau folio.obf, 92 Serapias candido flore noontana na. culatis foliijs. ob?

Serapias Diofe. C. Gemmx obf. 39 Serapias Diofe. fecuida C.Génec.o 89 Serapias fernina pratenfis, folijs notutujis confperfis obr 92 . adu. 63 minor rubelio nirente flore.obf.93

Scrapias montana folio lxus. ob C $_{93}$ Serapias paluftris latitolin obt: 9 paluftris ali era leptophylla. obr. 93 Serapiadum genets. obi:

Serrola.adu. tiax obl. 436 adu. Seriphium vulgare. obt: $\quad 436$ Serides.adu.

436
80

Seris domeltica. obf.1 I 4.a. 82.35 .86 domeftica alrera. obf. I 18.ad. 86 fylu. obf.114 adu.

Serpentina. obı. 240. adu. $\quad 187$ Serpentina Colnbrina. obr. 327.2 .261 Serpentina Matth. obl: $\quad 240$ Serpentina omnium minima.obr. 240 Serpillum.obf, 230 .adu. $\quad 180.18$ Serpillum Narbonenfe folijs petpufilli anguftifolij Thymi. obr. 230 23 radu.

$18 \mathrm{x}$

Serpilli \& Clinopodij alteta planta, an Polvenemon ? adu Seratu'a ob 288 adu. Sertula campana obr. Sefarnoldes magna Cordi. obr. 387 Selamoides muior Sealingerj. obr. 20 Sefamoides minor Gefn. obl. $\quad 456$ miuor forte Solim 3 no obr. $\quad 288$ Sefain. parua Cluf.ob, 190.19 r.a.r 49 Sefamoides parua Diofiob.297.2.237 Sefamum. obr. $\{14$. adu. 395 Sefamú Cordi, \& Trag1: \& Sefamum quorindam Matth. obr.

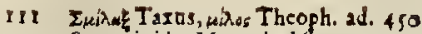
Selami femé offe an fie Diofe. 29.385 Sefeli Aethiopicum obf. $358.2 \mathrm{du} .38 \mathrm{r}$ Aethiopicú herba Dod, \& Matth. obf.

Smyrnioides Mutoni. obl. 407 Smyrnium. obr. 407. adu. Smyrnium Cordi. obf. 398. adu. 3 I r Smyrnium Lacunx. obf: $\quad$ 40r Smyrnium Tragi obf. Solani genera adu. Solanum arborefcens Belgar.adu. 10 Solanum folijs Tithymali. adu. 10 Solanum halicacsbum yeficarium. obr. I 34 . adu.

Solanum hortenfe. obf 133, adu 102 Solanum lignofum. obr. $\quad$ I 36

Solnnum manieum Diócorid. eruca Solunum manieum Dio cotid. eruc.x
folium. obf. folium. obr. Solanum romiferum herb.obf. I Solanum fomniferum Clufij folijs

Hyolcyamilutei obr I3

Solanum fomm ferum lethale. obf. I adu. 103

Solanũ tetraphyllum. ob. I 37.ad.105

Soldanella. obf. 329. adu. 263

Soldanclla montana. adu. $\quad 262$

Solidamo Sarrafenica. obf.1 $59 . a d$. I 25 Solis flos minor. obr. $\quad 322$ Solis flos Peruuianus, five Sol Indianus, obr.

Solis ros obr.

322

Sonchus afpera an Sonchus arbore.

feens Diofc.? a fu. 87

Sonchus alrera tolio profundis tacinijs finuaro hederaceo. obf. Sonchus tęuis te nerior latifolia. obr: I1 18 adu,
Sonchus lauis vulgaris folijs laciniofis Dentis Leonis. obf. 1 rg

Sonchi l.ruis varietas. adu. 87 Sonchus tenerior aculeis afpetior.

414 obr 118 . adu. 87 Diofc?obr.426.adu. $\quad 328$ Sorbus domeftica olve $\$ 44$ adu. 416 Sorbus torminalis Plin. Anguil. obr. 6 I 4. adu.

Sorbus $f y$ lu Alpina. obf s 44 ad 443 Sorgho obf r 2425 Sphxrocephalos Cordi. atu. $\quad 368$ Sphacelus Guillandino.obf.286, a.229 Sphacelus Theopb. Dot. obr. 262 Iodx $x \lambda$ cs adu. $\quad 240$ Sparganium, Butomos, adu. $\quad 40$ Sparganion alterum. obr. $\quad 41.97$ Spartium ols. $53 \mathrm{r}$.adu. 407 Spartitm Dioscorideum Narbonenfe \& Hifinicum. obs \{32, adu. 408 Spartiú Genifta fooparia vulgi. 408 Spartiū Hifp.alterú Cles, monofper. mum Hifp. Mut. feeundum foribus albis Chufij, obr

424 mastion 533

I7 Spartiats Cirpan. iuncea an Linof attiu antiguorum? a. 408 Spartí aphyllí fruticorí.0. Sis.a.409 Spartum noftras. obl: 45 Spartum Plin. Clufio. ohr. 45 $S$ partum alrerum Plin. Clur.obr. 45 Spergnalabdi, 467. adu 357 Sphegodes C. Gemmx. obf. 357 Sphergodes C. Gemm x. obr. $9 \mathrm{r}$ Spica recentiorum, obf.235. adu.18 Spina alba.nbr 481. adu. $\quad 369$ Spina alba Matthicli. obf. 48 2 Spina Arabicz. obr: 48 r adu. $\quad 370$ Spina Arabica Arginerx. adu. 409 Spina Arabjea Dicfe. adu. 409 Spina aculeofa Gazx, an Polyacantha Theoph.i adu. 
Spina Borda, ob:

Spina Ceanotos Theophadu.

Spina Ceruina quorundam. obr. spina infectoria. obr. 599. adu. Spina peregrina Dodonxi.adu. 368 Spina fancta quorundam. obf. 599 Spina Solftitialis an Pliniana? 2d. 372 Spinacia. obr. I29. adu. 98 Splith album quorundam, obr. 438 Splith I Ilyricu, an Aetij Phragmites, \& Corydalis Galeni? adu. $\quad 339$

Spodium. adu.

Spondylium. obfi. 4or. adu. $3 x\}$ Spondylium Diorc.Anguill. obr. 401 Spondylium alterum Dod. obr. 399 Spumeú Papaner vulgo.ob.1 84,a.143 Stachys Anguillarx. obr.

Stachys Diofc. obr. 284.28 5.adu. 227 Stachys Lufitanca quorundam. obf. 286.287.

Stachys f puria. adu.

Stachys fpuria Flınúro: ū.obr. adu.

ETaxoily;s.adu.

Staphylagria, fiue vitifolia. obf. 398

adu, Stapliylodendron Plin. an fie Gernanorum Bernyernurile. adu. Stella Atuca Monfpell. adu. $\quad 147$

Srellaria obf.

Sternutamentoria. obC

Stcobe obr.294. Adu

Stcobe atgentea incana Aldroandi 4

obr: 294 Brancionis, Brancionis. obl: 293.294
Storbe argentea Salamaarica minor Stabe argentea Salamaarica minor
altera Clufji. obf.

Stcobe Salamätina prior Clur.obr:,293 Staechas. obr. 234 . 2du. 284 S:cech. Arabica Mef. obf, 23 g.ad. 184 Stcchas citrina noftras.adu. 20 Citrina aitera inodora.ad. 20,204 Stochas folio ferrato \& crifpo Citlij. obr.

Sroec uudis cauliculis fummis.ob. 334 Stramonium percgrinum, Ly"coperfi.

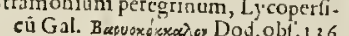
Stramonium perecurinu, an Solanum manicum, fiue Poma lpisiofa recentior um? Metel Italorum adu

Stratiotes obl: 204 . adu. 334 ma. obr.
tratiotes maior, fue Militaris C.Ge-
mat.

Stratiotes millefolium Diofe obr. 430

adu.

Stratiotes, fiue Militaris Aizoides, adit.

Stratiotes poramios. obr. $\quad 334$

Strichnodendrum, obf, i 36 adu. 204

Strobilites.obf?

Strumaria adi.

Struthiopteris Cordi, obt

Struthim. obr. r70. adu

Srysax.obf: 579. adu.

Suter diplex. aju

Suchaha Maritanis, obf

Sumach officinarum. 370

Superb? Fuchr \& recent. $339.2 d .4 \mathrm{I}$ Superba Fuche \& recent.obr. 2.41
adu.

sux ô. ob?

Syecmorus. obr. $61 \%$ adu, 112

Sycomorus Venetorum \& Italorum. obr
Syluus Plin. Valerando. obC sylueftre Lilium. ad.

Symphytum Alum. obf. 31 5.adu. 6 Symphytum petraum. obr. 251.252 adis.

Symphytum pumilum repens Bo 99

ginis facie obf.
Symphytum tuberofixm.obf, 3 I 5.316 Syringa-adu.

Syringa carulea Lufitanica. obf. 540 adu.

Syringa Italica. obf

\section{T.}

7 Abacum miaus. obr:

1 Tabactm minimum.ob. 316.31 Tamalapatra Garcix \& C. Clufij obC

Tog g.adu. obr.

Tamarifcus, obr. 6zs, adu.

Tamus Dod. obr.

Tanacetum. obf 432 , adu.

Tanacerīacutú abum. $\quad 334$

Tanacetú non odorá. obr $432.0 r^{2} 43$

Tanncetú Peruuianú Cord Tanacetum fpeciofius criftatum An glicum. obf. 432 . adu.

Taraxacon offic, obr. " Idu,

Ta chö Simeonis Sethi.o. 243.2. I 90
Taxus. obi.

\begin{tabular}{ll} 
Telephium. obf, $211,2 \leq 2$ adu. & 637 \\
\hline
\end{tabular}

Telephium Anguill. obf.2. 2 , ade. 168

Telephium flotibus purpureis.ad. 465

Telephium glaucum ver1us. ob:: 2 I
Telephium Lacina, obr: 6 I 6

Telephium minus femper virens.obr. 212.213.

Tcmbul fruetus exigux glădis figura. obs.

Terebinthinum vinum. obr. $\quad 165$

Terebinthus. ob $: 5 ; 8$ adu. $\quad 412$

Terebinthus Indica Theoph. eft Pi-"

Itachia Diofc, adu.

Terebinthiliquor adu. $\quad, 412$

Terenuabin aút?.

4 .5

Teriouarcha Pli. Guilládino. obt.r 99

Terperantia Dilfij. obt:

288

Terre Frlandes. ob 5 18. 2du. 433

Terrx glaudes, fure Pleudoapios Germallorum, an Aftragalus Diof c.?

Tetrorchis, vel Triorchis alba spiralis vel aurumnatis C. Gemmx. obr.

Teftuculi. adu.

Tefticulus hircinus vulgaris, s. Tefi culus leporis nofiras. 0.88 .20 a 62 Tefticulus mas neotericorum obr. 87 Telticulus odoracus. obf. 92 . atu, 6 Tefticuli odorati varictas, olf 93 Tefticulus vulpinus primus.obr. 33.92 Teftic. vulpinus fecrndus, obf. Tertic. vulfinus norer. obr.91.2d. 62 Tefticuli vulpini yarietas. obf, 88,91 adtu.

Tetrahit. obC. 28 2. adu.

Terralit herbar, $v$ arietace's. obf. 22

Teucrims. alu.

Teucrium pratenfe officinarum

259. adu. 208

Teucrium pratenfe alret $1 \mathrm{~m}$. ob!" 2,59 rurgorum? adu.
Thalictrum nigrum Coidi.obf so8 Thalietrum Dod, obf, 426.508 Thalietrum Ronde'l, obr.4 13 ,ad. 2 r Thamarilcus Norbonenfis, GermaniCa. adu, 447. vide Tanarifcus.

Thanecnemó Cordi obf. I 90 ad. 148 Thapfia Afclepiadis Anguill. cbi. 462

Thapfia latifolia Clufij \& 357 dam.obr.

Thapfa Turbith Gallicum, \& Tur birh cineritium officinarum.ad. 349
Ihaplia vulgaris Carota effigie. obf. $45^{2} .453$. adu.

350

Theligonon femilia. obl: $\quad 452$

Onduxzarisa Cordi. obf.

Theombrotum Perfarum apud Plin. adu.

Theophras. adu.

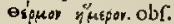

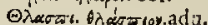

Thafpi alteruns minus clypeatum.

adu.

Thlafpi alterum Nafturcij horten 74

folio, adu. folio. obli. 108 . adu.

Thlafpi Centuculi ang uftif tio.ad. 75 Thlafpi Crateux Dioic. obf. 173

Thlatp Crateik, \&c. an fit nofter

R'haphanus agrellis? adis. 75

Thlafpi folio Drabx.obf.108. adu. 73

Thaspi fruticofum foll. Leucoij marinimaioris, obi.

Thlatpi fruticofum fpinofum IO Thas pifruticofum alterum. obr, 109

Thlarpi Gtxcum. 3du.

Thlaf i teraceum.

Tharpi incanti Mechliniefe. obr. ${ }^{338}$

Thlalpi media Prousucialis planta.

adu.

Thlafei Ofy ridis folio adu

Thlapfi paruun Hicracij fol. adu. 74

Thlalpi Perlicum, obr. 37

Thlalpi Syriacum. adu.

Thlafgi vulgacifimum Yacarie folio

obi. 508.2 du.

Thora. adu. 39.263

Thus obf. 580 adu. 430

Thuris co:tex, Manna thuris, \& fu-
ligo thurs, obl:

Thuris limpedifoliuns adu $58 \mathrm{r}$

Thymbravera S, Iulimi. adu. 18

Thymbra altera adu. a

Thymelat Diofc. obr. 201

Thymelaa grani,Gnidij.adu. 196

Thymum. obr: $23 \ldots$. adu. Is

Thyllioum Plinij, obr. 409

Tibicinaria arund semina 409

Tigridis flos an Dracuncul fpccies? of

Titiafemina Theoph. \& mas, obl:

606. Adu.

Tinearca Germ. obt.

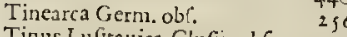

Tith Lutica Clufij. obr. $\quad 572$

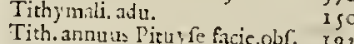

Tith.annu us Piruy fe facic.obr. Y93

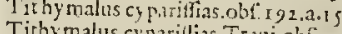

Tithy malus cyparilins Tragiobfing

Tithymalusheliofcopins. obr. Is

ithymalus ieliofcopins. obr. 192
adu.

Tirlymahus paralius obf. rat.adu.

Tithymalis lerratus $M$ unfpellienfivi,

an Ciracias? adu. 19

153
Tithy 
Tithymalus tuberofus Dod. obf. 198 Tordilion. obf. 42 5.426.adu. 328 Tormentilla.obf. g95.adu. 308 Tormentilla vel Heptaphyllon, an Chryfogonum Diofc,? adu. 308 Tota bona Spinacix facie. obf. , $\quad 129$ . 130. ad.u.

Toxica Theoph. adu

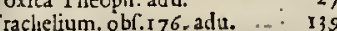

Ttachelium candidum, Anglicum Septentrionale maius. obr. $\quad 177$

Trachelium maius Belgarum. ob 177 Trachel .minus.obC.176.177.ad. I 39 Trachelij vatietares. obf.r 76. adu. 139

Tragacantha obf. $492 .$. adu.

Tramom 377

Tragium alrerum. adu. $\quad 360$

Tragium Guillandini. obC. $\quad 537$

Tragoa Matth. obr. 463 . adu. $\quad 356$

Tragoriganú flore albo Cluf.obr. 264

Tragoriganum praffoides Franc. Pen. nini. obf.

283

Tragoriganú aiterum.obr.263.ad.2 I

Tragopa purpureú Alpinum.obf: 246

Tragorchis altera. obr. 99

$T$ trgorchis minor \& verior $\mathrm{C}$. $\mathrm{Gcm}$. mix.obC

Tragopogon. obf

90
297

Ttagopogon luteum. obf. $\quad 297$

Tragopogon paruum tione Condtill. purpuro cxrulcx. obfi. $\quad 297$

Tragos. obf. 462 , adu. 354

Tragós vel Tragonou Diörcian tacemofa Equiferi facie plăta fir? ad.35S T tafi recentiorum \& Veronenfium obr 4r. adu. " ! ! 37

Tribulus aquaticus. obr. $\quad 324.325$ adu. $\quad 258$ Ttibulus coro nope us Ruéliji.2du. 372 Tribulus terreftris.adu. 403 Trecoccon Plin. obf. 193. adu. Ior Tritici genera, obf. I z.adu. $\quad 5.6$ Triticum yaccinum Tragi. obr. 23 Trichomanes Diofciobf: 47 1.adu. $36 \mathrm{t}$ Tridaches.adu.

Trifolium acetofum.adu 87

Trifolum Afphalenifiue Bituminofum. Americum obl: 494 mos atu:

$\begin{array}{r}494 \\ -\quad 380 \\ \hline\end{array}$ corniculatii alterum Dod.obr. sor Trifolium Heparicui. ob[.496.ad. 38 Trifolium lureũ minimú ad. $381: 468$ Trifolium odoncum Dod. obf. sor Tr̂́ifoliū odoratú alterū Dod.obf. 500 Trifolium paludofum, paluftre Curdi, \& Dod obf,

496

Trifolii paludofum fitne porius Ifopyron, quàm - Melanrhij ápecies? adu.

Trifolium pratente, \& eius yarietates. olli. 493 .adu. 380

Trifolium ptacenfe Salamant. Clufij, obio

494
496

Triorchis lutea, flore lutco C. Gemm $x$; fiue Bafilica minor. obr. 92

Ttiorchis lurea altera C. Gemmx. obf.

Ttiorchis lutea tertia C.Gemm ž. obi:

Tripolium littoreum. adu. $\quad 92$

Tripolium lureum, obr.

Tripolium minus. obr. 158 . adu, 12

Tripolium vulgare. obf

Tripolij vatietas. obf.

Triésgo, fiue Ttixago. adu.
Triticum ariftis circinuallatum.obl. $x$ Tricicum Typhinum Dod. obf. $\quad$ it Triticof elrum. obf. a 8.adu. Triticum temulent num. adu. Triticum vaccinum Dod.àdu.

Trixago paluftris. adu.

Trodilij fue Sefeli obr.

Tulipa. obr

Than fiue Lilionarciffus luteus la tifolius, obtufis phoniccis yubentibus oris. obf. 66 . adu.

Túlipx fpecies minor Monfpellienfis Herbariorum, obf. 63 . adu. Si

Tulipa varietstes quam plurimx. obf.

Tune Ficifera Indorum.adu. 45 Turbith, Gue Turpetū. obf. $\quad 20$ adu.

I $59.160^{\circ}$

Turbith Alexand rinum officin.ad.1 59 Turbith Alcxandrinum quorundam. obr.
196

Turbith Mefue ob $\{.453$. adu. 350

Turbith nigrum \& adul terinum. obr I94. adu.

Turbith officinarum. adu. $\quad 272$

Turbith varietas. adu. I

Turones Norbonenfium. adu. 2

Turpetum nigrum AEtuarij. obr. 192

Tuffilago obi.320. adu. ..254

Tuffilago altera Matth.obr. $\quad{ }^{2} 3$

Tuffilago maior Match. obl: $\quad 32$.

Tuffilago niontana minima. obf. 32

Tuya Thcoph. herbariorum. obf.630

Typha.obr: 42. adu.

Typha ininori. adu?

Typha, an Spelta?adu.

4 4I

V Accinam herbariorum nigtum aut rubtui, an Idęa ra jir?a.417 Vaccinia nigta \& tubra. obs. $\quad 546$ a du.

415

Vaccinia paluftria.obf. 547 . adu, $4 \mathrm{I}\}$

Valetiana Graca, Dod obs. 4I

Valeriana maior. obr. 4rt.adu. 318

Valeriana ninor fyl. obf. $4 \mathrm{r}$ r.ad. 319

Valerianx noftrates fintne Diolic.

Valcriana petegtina Beigarũ.obr. 412 adu. 3 ry tubra Dod. \& Belgarum. obr: - 184

Valeriana fylueftris: obf-4I r.adu.3.19

Verbalcula Fuchf. obf. 306

Verbafcú leptophyllú Cotdi, obC. 30 Verbaf́cú Mas, \& femina. 303 .ad.242 Verbalcuú nigrum faluifolium, tertium Matrh. obf. 302. adu. 24I.466 Verbafcú purputeum Erucx folium.

obf. 303 . adu. . 302

Verbafcum faluifolium fruticofum. quarsum Matth. obf. $\quad=42$ adu. 302

Verbafcú fyl.fáluiflorú laciniatū verbafcíaliud Matth.obf.302. ad. 242

Verb. fyl. folips Saluix. ob . . 02 .a. 242 Verbalcum fylueftre folijs Salu' $x$ te. nuifolix. obr. 301 an Phlomos Lychnitis Diofc.? adu. II.

Verbafcum Tragi. obf. 296

Verbena Diofc. obr. 289 . adn. ${ }_{2} 3 \mathrm{I}$

Verbena comnunis frue facra. ad. 231

Verbenaca fupina Clufij. obr. 290

Verbenaca fupina femina Dod. obC

259.

Yermicularis. obf. 20 g. 2du. $\quad 26$
Vermiculatx fruticis varietas. obf: 207.

Veperispecten Plin.obf.419. adu. 324

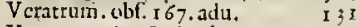
Veratrum alterú nigrú Dod obs 387 Verbena femina. obr. Veronica feniva Dod. olt. 250 femina Fucht. \& Matth. obr. 249 Veronica maior Seprentrionalium mas Fuch. \& Dod. obf. 250.25 Vetonica minor ferpillıfolta. obl. 250 Veronica recta Herbatiorum.obf, 2 รI recta mas Matth.obt: 250.2st Veronica testa minima ob:" 250,25 Veronicaredta querundam obs 186 Veronica vera \& maior. adı. $\quad 197$ Vefiearia tepens Maith. obro. 516 Vetonica altera Fuchl: Dod. obr. 24 I Vicia. obf. 522, adu. $40 \mathrm{r}$ Villiarborum, fasorü \& terre.obr. 643 Vincaperuinca. adu. $\quad 282$ Vini natura Diofc. obr. 349 Vini fpiritus Chymiftarum. obr. 3 s 5 Vinum Cydonites obr. $35 \mathrm{~s}$ Vinu ex duerfis herbis. obr. $\quad 354$ Vinú ex diuerís odoramentis.ob. 354 Vinú ex diuerfis plantis. obr. $\quad 353$ Vinamarina. obr. 351

Vinum melitites Diof. obr. 350

$V$ inum palmeum. obr. $\quad 352$

Vinum picatum. obf. $\quad 353$

Vinum Scillintim. obr. $\quad 351$

Viola aquatilis Dod obf. 460

coloria.obr. 33 ,.adu.,265

ba Tragiobr. r75. adu. 137

Violx matronales Fuch., obr. I 79

Violx matronalis vatietas, obf. I75

Víola Mariana. obr. 175. adu. I37

Viola Marcia purpurea. obr. $\quad 334$ adu. 226

Viola Marria futreetis cauliculis. obf. 334. adu. $\quad 266$

Ylola rricolor Dod obr 335.2 du, 266

Viorna vulgi. obî. 345 . aúu. 275

Viperaria. obl: 298

Virga Patoris. obr. 487 . adu. $\quad 374$

Virga Ganguinea. adı. $4 ; 6$

Virginea. obí. $4+7$.adu. $\quad 344$

Vifcaris. obf. 2+3 2. alu

Vifcum. obf" $361.2 \mathrm{~d} 1 \mathrm{l}$. $\quad 282$

Vifcum Indum. adu. $\quad 452.455$

Vifnaga.obl 4 i 9 .peregrina. adu. 324

Vitex. adu.

Vítis alba Bryonia Diofc. obs, ;43 adu. 285

Vitis vel Bryotia ninza. 0.345.24.275

Vitis, fime Bryonia fylu. obi. $\quad 344$

adu. 275

Vitis Coristhia. adn.

Vitis nigra Fuchl" obr. 345 -adu. 275

Vitis precia Plin. obf 617 adu. 415

Vitis ieptentrionaliuna. adu. $\quad 276$

Vitis vinfera fyilu. fronancaue. obr.

348 . alu. 277

Vitriola.alu. $\quad 98$

iurna vulgi Gallorum \& Ruellij. obr

Vlex Flin. olr.

Vlmaria vulgi obf.

291

Vnimula cabaltina offic. adit. 


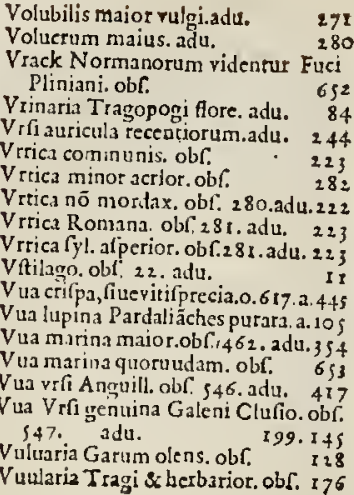

Vulpini tefticuli. adu.

$x$.

$X$ Anthium, obr, 3 rg. adv.

Xylobalfamum. adu. 4 Is

Xylocaffį facie correx, an fit Diore.

\& Plinij Macer.? adu. 426

Xylocinamomum. adu. $\quad 426$

$\mathrm{Xylon}$ obr. 370 , adu.

Xylofteu alrerum quorĩdam.obr. 593

Xylofteon Dod.obi: 358 . adu. 280

Xyris. obr. 37 adu

7 Acyntha Marth. obf.

LZea, zuci obfig. adu.

Zea Theophr. adu.

Zedoar arbor. adu.

Zedoarix Semen Belgis. adu.

$F$ I I $s$
Xyloaloes offic. obf. $576.2 \mathrm{du} .440$

Zeduaria, fiue Zadura herba \& Z $Z_{\text {erü }}$

62 bet.adu.

Eisyey. adu.

Zeopyrum. obr. i 8.ada

Zerumber Serapionis \& Zeduaria e

Iu fẩ radicis partes. o. 3 8. 39. a. Zingiber. adit.

Zingiber Calecurium recentotu

recentiotum.

Zingiber caninú Auicennze, adu. $\mathrm{r} 34$ Zungiber fuicum officinarum adu Zingiberis fliqua cum granis fuis. obl.

Ziziphncandida, obc.

Ziziphncandida. obl. 546 Zizipha candida Monipell. an Afara Darachi Auicennze? adu.

Zopita Diofs officinurum obr 635

Zuccha omnium maxima, anguina. 35 obs,

zudis Diofe. obe.

Zythum Plin.obs.

T A B L E,

\section{O V BRIEVE ENARRATION DES \\ NOMS VVLGAIRES TANT FRANCOIS, PICCARTZ que Valons, des plantes contenues en ceft Herbier.}

A.

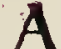

Bricos obr

Ablynre. adu.

Afrudiles. adis.

Agrimoine. adu.

Agripaume. adu.

Aigretre obr.

Ail \& $2 u x$. obr.

Ail porreau. obr

Alifier. ob:

adu.

Alliair obr

Alluy ne forte. adu.

Amelancher. adu.

Angelic de Nortryegen. obC.

Ancholies. adu.

Anet obr.449.adu.

De l"Ap e obl:

A refte beuf. obl.

Argentine adu

Armole, aj

Arrache, adu.

Atrochefourage adu.

Artichaur. adu.

Afche cbr.

Afche des rochiers. obC

Afperges. adu.

Afpergoute menue.obf

Aubel nof

A uxelanques. obr

Atilne obr.

Aueron, obs.

Alurelle, Airelie, obr
$B$

R Acilles. ob

596

45 Barbe de bouc obl:

308 Bafilicq. adu.

$22 \mathrm{r}$ Bafiner.adu.

Iss Bec de Cigogne. adu.

8o Becdegrue. obf

79 Berle. obr.

60 . \& 608 Bete blanche.adu.

441 Bere ronge. adu.

Bierre, obf.

33 B!anc vicau, adu.

44r Blauez \& Bluerz. adu.

399 Bled.obr.

339 Bled de Mars. adu.

347 Bled Sarazin obf.

405 Bletre adu.

402 Bois S. Ican. obC

340 Borage. adu.

365

405

406

353

189

609

608

608

546
28 , Biftorte. obf.

308 Bonet de preatrc obr

96 Bouilion blanç mafle. adu.

97 Bouleau, \& bouillet. obf.
365 Bourfe de Patteur ou berger.adu.
Bourgefpine, obf.

Brayesde Cocu. adu.

Bruc.adu.

Brufure. adu.

Bugloffe fauuage . adu.

obe.
213

540

Camamille des chās vulgaire, ob 44

2rs Caneile obr 574. Canne. obr. 28

.28

296 Cardon argentin, adu, 369

375 Carline. obr. 480 . adu, $\quad 37$

tos Carne.obf.

93 Ca obe obf

94 Carottes iaulnes, obr

94 Carottes ialnes. obr.

16 Carotes rotiges. ob.

iss Cedre du Liban.obr:

257 Centaute grande. adu.

236 Cerifes obr.

I4 Ceruoife obs.

6 Ceruys adu.

SI Chmaraz. adu.

94 Chardou benie. obe.

443 Chardon à carder.

aigners. obr 583

246 Chaftaignes deats adu,

67 Chelidoinge.

6 Chsine obi.

599 Cherises verds. obf

243 Chefnetre adu.

28 Cheure fueille adu

$r$ Cichoree des tardins. ad

Chou cabu, blace. adu.

\$62 Chouflory, obr.
24 Chaufferanpe.obf 258

620 Cichorec faumarins.adu.

240 Chiendent. adu.

492 Choud dechien obf 
Chou de mer. adu.

Fene efpelfe. adu.

167 Yuraye fauuagre. obr.

Churles. obr.

Cices, Cices de belier. obr. Figuier. obs

326 Fambe baftardc. obr. Cipres. ob!

Citron. obr:

Clous de gyroffles. obr

Coingz. obr.

Colequinte. obr.

Comin. adu.

Concombre adu.

Concoinbre faunage adu.

Confanons. adu.

Confoulde farrafinc. obf.

Confyre. a du.

Coq. adu.

Coguelicot. adu.

Coquelourde. adu.

Cotiandre obr

Cornier. obr.

Cornier fautuge. obr.

Corrigiole. adu.

Cormeille. adu.

Corne de Cerf, adu.

Cornier, Corniole. obr.

Cotron. adu.

Couilion de chien. adu.

Cotrillons de preftre. adu.

Coleure. adu.

Courge la uuage. obr.

Foin de Bourcoingne adu, 31.92

Frefes. obr.

375 Frefue obf

575 Froument.obr.

380 Froument. obr.

330 Fulan.obr.

285

88

Griot.adu.

Gant nofte dame. adu.

Gatance. obf 462 .adu.

Garderobbe.adu.

II Garipolt. obf.

So Garipolt. obl.

\$44 Geneure. obr

\$44 Geneft. ad

179 Gentiane. ad u.

144 Gentiane croilece obs

186 Germandrce.adu.

592 Germandree groffe. adu.

291 Glayeul. obr.

62 Glais. adu.

2 s6 Glouteton ou Gletteron.adu.

275 Grande Scrofulaire. adu.

367 Graine defcarlate, obr.

Grenouillé. adu.

72 Groifelier. obr. 6r7

Ios Sauge Groffe adu.

II Groules douges \& Groureiles

171 Goude obf. 19,298

24 Grateron. obr. $\therefore 464$

$\begin{array}{lll}\text { Guefde. obr } & \\ \text { Guimalues. adu. } & & \end{array}$

6.37 Guindolier, obr.

2 Gyroftes adu.

84 Gyruflees des dames adu

Gyroftlees d'caue,obr.

293
597

T Aictues. obr.

Laifferon \& Luiteron obf 121 adu.

Langue de cetf. obr.

Langue de chien. adu.

Laurier. obf. $\quad 57 \mathbf{I}$

Lentille. adu.

309 Ientifc.obr. 538

$\$ 86$ Lierre. adu. 209

45 Lierre terreftre. obf. 336

96 Limons obr. 573

41 Lin adu. 176

63 Linfatruage, adu. 175

628 Lis deftang. adu.

07 Lis iaunc obr

29 Lisorengé. adu. 60

66 Lisfuuage, adu.

208 Liviefche, obf 340

$\begin{array}{ll}32 & \text { Lugins. obr. } \quad= \\ 77 & 501\end{array}$

Dent de chien adu.

Dent de Lyon. adu.

Doigrier, adu.

243
78

E.

$T$ Bene roir, obr

EEnula Campana.adu.

Endine.adu.

- Eoule obr.

Errable adu.

Efcharbotz. adu.

Efclayre adu.

Efcuelles.adu.

Efglentine, Efglentier. obf.

Edu;

Efpeantre obr:

Ecpinars.adu.

Efpine aigrerte obf

Efpy dieaue. adu.

Efpurge obf.

Eftillee menne, obf.

Eufrale, adu.

$M$.

M Acreufes.obr. 6ss

Mimandragore ou Mandegloire.

adu.

Marguerites. adu. 199

Mariolaine. adu.
Mariolaine baftardé, adu.

Marons. obf. 588

Marrubin \& Marochemin. adu. 222

Marrubin noir. obr. , 279

Maffede Ionc. adu. $\quad 40$

88 Matricarte. obr: 433

137 Melze \& Meleze obf. 633

460 Meliffe adu.

$\begin{array}{ll}\text { Melons.adu. } & 220 \\ \text { Mentalus } & 285\end{array}$

Mente fausage obr. 1: 27 ,

Mercurial.adu. 273

Mercurial fauuage. $\quad$ I32

246 T A nebane. adu. . 207 Meurier, obf. 6 ro

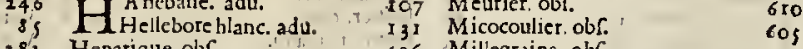

$\begin{array}{llll}282 & \text { Hepatique obr } & 605\end{array}$

443 Herbeau Char adu, 2 irg Millepertuis.adu. I

258 Herbede Elane, adu. = 246 Miller.2du. 13

339 Herbe S. Iean adu. 340 Morelle adu.

I64 Herbe aulait.adu. I igo Moron violer, ou Mouroni fleurs

6'i' Herbe despraiz, obr. 9 blewes \& rouges. 2dL. I75. 194

146 Herbe aux Pulmóns.adu. 92 Morsde Diable. adu. 2 175. 94

3 Herbe aux perles. adu.

I9 Herbe i puces. adu.

98 Hyeble obf

99 Hy rope obr. 237. adu

28 Hylope des garigues. ob

97 Horge ou Sucrion. 2 du.

189 Houblon.adu.

210 Hous, obr.

I.

$$
\text { F. }
$$

Fin.obr.

Felongne. adu.

Fenegrec. ob

Fenoil. adu.

Fenouil marin. obf.

Ferule. obf.

Feues. adu.

TAnettes obf

339 Llonc, obr.

soz Iotte blance. adu.

$\$ 47$ loubarbegrande.ada.

213 Ioubarbe desvignes. ado.

450 Ita artericiue. obf.

192 Iuiubier.obr.
88 Muguerre obf. 570. 214.

is Myoraines. adu. 357

2,38

277

582

TArciftes. obr

I Nafirorr.obr. 107. adu. Naueau rond.adu.

99. Nauer. adu.

43 Néfples, Nefplier. obs.

Nielle. adu

167 Niefpe oble

207 Noix, Noycr.obs

597 Noir Mufcade.obf.

57
49

N.
186 Muguer adu
L.

(1) (3)

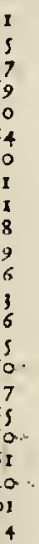

6
8
9
9
3
3
5
3
2
0
3
3
2
4
1
7
9

59
72
66
67
592
329
12
610
545
570
be 52 
TADLE ERA NCOUSE.

\section{o.}

Oeau, obí. Oeilletz. adu

Oeillers. \& Oeillets Dicu. adu. 142

Oeillerz d'Inde. obr. 4 ro

Oignon.adu.

Oignon blane champeftrc. obf. Oignon marin. adu.

Omeau. obr.

Orcanerte adu.

Oreille d'Afne. adu

Oreille d' homme. adu.

Oreille de rat ou fouris, obf.

Orenge, Orenger. obf.

Origan, adu.

Orrie Romaine obr.

Oruale. adu.

Oufeille obf. Iss, adu.

D Ain de Cocu ob.

Pain d'oy feau.adu.

Pain de pourceruralu

Palhis de licure. obr.

Palmier obf.

Paniz ou Panic.adu.

Parelle. obf

Parietoire, \& Parietaire adu.

Pas diafne, pas de cheual. adu. 25

Pafquettes. adu.

Pafferage. obr. I 73. adu

Paterage fauuage ob

Paffevelours, adu.

Paftel cultiué obf

Paftel fauage. obr.

Patinades. obr $407.4 \% 6.417 .3 d$ is

Pafture de Chameau, obr.

Pauot blane, \& Pauot prive. adu. I 10

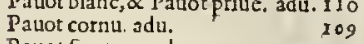

Pauot faunige. adu.

Pelitre obf.

Peluetre obf.

Penfees, menues penfecs, adu

Perce boffe, adu.

Perfoliata. adu.

Perroquet. adu.

Pefche, Pefchier. obf.

Pérfil. obs 405 . adu.

Perfil d'afre. adu.

Perueache obf.

Pefle. obf.

Pecit Cypres. adu.

Petit Gloutteron, adu.

Petite Ioubarbe. adu.

Petit Muguet. obf.

Perite oreille de fouris. adu.

Peucedane. obf.

Peuoifne. Peuoine obr.

Peiplier. obf.

Piedd Alouetre adu.

Pic ded Cornelle adu.

Picd de lieure. obf.

pied de lion. adu.

Pied d'oye. adu.

Pied de pigeon.obr.

pied de reau. obf

Pilofelle. obr.

$25 \mathrm{I}$

262

254

$2 \mathrm{II}$

281

240
119

(1)

49
16

162

264
118

637

14

150
98

98
254
199

I 39 7. III

95

89

16

42
110
109

447

254

267

144

171

$16:$

568

314
327
306

63

341

254

c 6 ?

367

193

453

389
-600

329

319
186

499
298

298
97

97
376

376
Piment obf. I I 3. adus. Pin. ob

Pin fattunge obr.

Piffaulit adu.

Plane obf.

Plantain, adi.

Plantain deaue. adu.

Poire obr

Poivre. obf.

Poiure d Inde \& de Brefil. obr.

254
Poly pode. adu.

Pomme obr.

Pommes dorees. adu.

Pommes de Grenades. adu.

Pommes de merueilles. obr.

ommés \& Pommelés Monfpell.

obl. 6Is. adu.

Ponceau. adu.

Porcellaine obr.

Porreau adu.

Pouilleufe. adu.

Pouliot adu.

Pourpier. adu.

rime verc,

Prunier \& Prune, obf.

Pucellage. obr.

Pucelaged homme. obr

$$
\text { Q }
$$

Veue de Souris. adu. Quintefueille, obr.

\section{R.}

$R$ Acinecreufe obr Raifort. adu.

s) fort fauuage. obr.

argalife, Raiglice obr.

Reprife adu.

Refponce perit. adu.

ecuelle marin fuiuär le foleil a

Refueille matin des vignes. obr. I 97

is.adu.

Roquette. adu.

Rolage. adu.

Rofier. obf.

Rofmarin. adu.

Rue. obr.

Rue fusuagc. obr.

CAfran.adu

\section{5.}

Saftran baftard. obf.

aligotz. adu.

Sang de dragon. adu.

allade de Chanoine. obr

Sanues blanches. adu.

apin. obr 633 .adu.

apinettes.obf

aunier. obs

ulx. obi.

Scabicufe. adu.

Scordion adu.

Seigle. adu. 166

re.

360

18.2

625

567

210

6 so Secrieffon. obr. I I 2. adu.

631 Sèneue blanc. ad u.

632 Seneue domeftique. adu.

Seneue fauigge. adu.

Senicle. adu.

1:7 Sérmontain, obf.

126 Serpentine deaue. obr.

590 Serpolet adu.

Serpentine grande. Serpentina Colu-

3 brina.obf. 327

363 Siguet de Salomon, adu. 28

590 Siny rnium de Candic ou Crete. obf

108407.

Soede adu.

Sorbier.obr.

444 Soucrion forte d horge. adu.

I I Soury. obr.

$\$ 73$ Soufy d'eaue adu.

IIO Stechados adu.

58 Surelle, obf. I s5. adu.

306 Sufyer, \& Sufeau. obr

214 Suyn \& fehu. obr.

595

s64$$
\text { The }
$$

TAmarisobr

\section{$T$.}

1 Targon. ob:

Terebinthe obf.

Thym adu.

Tione de lin. obr.

397

Tormentille adu.

Tornefol. adu.

439 Toureboune.adu.

67 Toute faine, adu.

173 Treftle adu.

528 Triquemadame.obf.202.ado

464 Troefne obf.

167 Truffles d'eau. adu.

Turbitgris. obf.

\section{TYAcet obr.}

V.

68 Valerianc, 2du.

I 54 Vanche obs

28 Veluette obr

618 Verangenes.adu.

I83 Verge d'or. obf.

506 Vermillon. obf

506 Veraire obf

Verucine obf.

Vefce. adu.

53 Vefce fuuuage obf.

488 Vigne. adu.

169

II 9 voles de Damas, adu. ' 1 ,

$4 \mathrm{r}$ Violes de muretz adu. , , : 1,37

70 Violettesde Mats.adu. . $\quad 266$

450 Violiers blancs. adu.

6s, W Wande. obr.

232

Yraie. adu.
Yeure. obr.$$
Y^{4.6}
$$

190

ZÍngembre z.

62,5

243

538

181

606

I 50

240

279

162

564

452

58

318

60

254
106

159

28x

167

89 


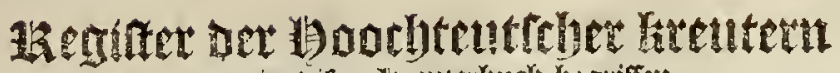 \\ namen in oifen farcuterburly begriffet.}

1 thethaum. obferuat. 609

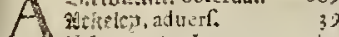
Ilfernent. ob. $\quad 2=0$ Xchiorkitetivi o. 420 Xettertinsblaterib. o. $\quad 79$ Frherpziminen, o. 190

3ielectuinjet. $3 . \quad 72$

Alantmuts. 3.

利tam menlin, a.

Jimandalbatini, a, $\quad 423$

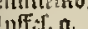

xutptutuktatit. $\alpha$.

Efpett. a. 60 9

trine.

Xugentroft, a.

Bitilien. 0

B zallam ktaut. o.

23alitg:tt. a.

23 attimfaen. a.

23 aแnosolt.a.

$25 a t r u l e t f$ a.

tseirwistt; a.

zactuljalt; tiu. c.

25 tncotctat wests, \&

25ctuntall, a

2Btrt. a.

2sertram. D.

Letuctuti. a.

botuftit? a

2otine 0.

Tsiftomer. a.

zathgrtluratt. Â.

zoint? gcu litututr. 0 .

ront:en Chmelno. 0

Girkirmbaun. 0.

Tsitter 3Clatos. A.

sotter wi:lty. a.

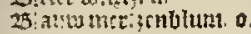

25:atm ketel. ก.

25!gmalfuntiz, 0 .

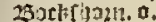

23 aolien, a.

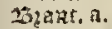

25:antlattich. a.

tóntm betanir. $a$.

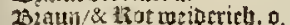

13?auntoutrt; $a$

zo:tit falmen. a.

23 ement a.

23:tumeItr \& bayerueftel. o.

jiuc wutt2. a.

23 inen lezth waffer litefi, 0 .

tisunting. 0.

25.unnen jaterlin. 0 .

sôntuteterlith. 0.

sutuhbaum. 0 .

Euchiraut. $a$.

3 ureifch. $A$

sitracl. a.

zottrt; thlicàtt. o.

23นtbatm.

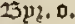

4.

Cambifchncit!. 0. CEamelíne. Caroabentost. o.

Etintuturt: $a$

cipestri:. o.

Cirrot. 0 .

Clepter bauctufuţ. 0 .

citiullon, o.
Colianoet $a$.

Coloquint opterin. a

conteltatm. 0 .

cantbintit. a.

Coffents. a.

Ereitribit; a.

Crcutiuset. a.

Sintorym.

จ习.

D Dmenbaum a. inatufert fehoon.a.

Distlopffil. a.

Jeniurst o.

dalacbertwuters. 0 .

Biahtrhuts. o.

oplien. a.

Dolcralt.a.

Durchluarbs.s. E.

T25:tbutt. 0. 480 , ค. 367 Eedelicberkitaut. o. a. $\quad 367$ Coel Dalben.a. $\quad 2<0$

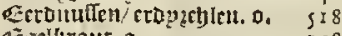
Ezelfitaut. a. $\quad$ rg8 cinvlast. o. 165 Eifrutirat//riterthart. o. $\quad 289$ Epfonlixat weiblit, o. 103 Eliomicii. a.

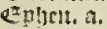

erutrl o.

erotanftet. a.

Extotuci?. o.

Erethuti. a.

Exubcifia. a.

Ericibatmi. D.

Eturafrn. a.

Etrocutrtit. a.

ETclyonbatur.a.

t.

F Pantuet. a.

fecio Aliton?t. o.

felo kunirl].

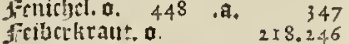

foriguen baแแ. $0 . \quad 6 I_{2}$

filingtitant. o. 233

fimgrbut/\& jingerkraut.a.245

fractit? a.

fits frh Cenotn. a. $\quad 233$

filafrlifbottern. D. III

ficrcintraut. a. 3 II

Flarhiratit. a.

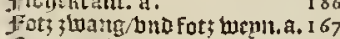

Framuentzrams. a. $\quad 136$

Jrâtioctr liofin. â. 142

Fratuentell)แs. a. $\quad 127$

fortolcamkraut, a.

fintfingbethant funblat 0.393

Gact. o. 547. a. 417

Gofmander. a. 209 ธa nanter irp [eน / 23 atbengel, a. 209

ciallseptely/ rfi Euthodfet.o. 587 Gaturti. a.

Sิatren Cpu!cis. a.

Earten inoblatib. a.
Sarten arest a.

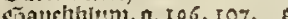

5atch brul. a.

Ged gate cit trit:1?. A. $14 \mathrm{I}$

ciec flarfatien. a.

Get liabetc. o. 285

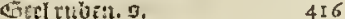

Eeri toritegrb. a. I 44

Gitl but: biutien. a. $\quad 323$

Escigam palenty, a. $\quad 416$

Demint. a. 7

Eofn!ter banenfuts. o. $\quad 380$

Gijouttr magtamet. a. ICg

Grloainters. is. $\quad$ rog

Gelp tialter intisti, a. 29

Citfich toeted, a. 3 I

Geisten toolfs milef. o, $19=$

stenrif́. à. $\quad 407$

Getifodifit.a.

Uistifftits.a.

Erctifiatip. a 97

Centrian?. A, 129

Grntiblum. a. 299. a. 200

Grfpgctobt kuaburutraut. o. 87

Gifcl felfteristr. a. $\quad 72$

Orenitulat.a. $\quad 80$

bier'ith. $0 . \quad 408$

Gilgeil. a.

Gimic:tantio. a.

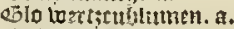

Golden biatimetter. 0.

Eoloni: re?. o.

Solthitanffin, o.

Colr Ry?

cinimiente

Gias, n, a

exafibumest. a. $\quad 188$

Givilat ocpfisio. $\quad 419$

5revivita. $3 . \quad 308$

Gycat:uttrt. a. II2

Q3ihtuttrt. a. 308

Qinotstut. A. $\quad 79.22232$

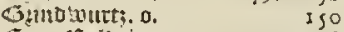

Syod 5ildiath. a. 318

Olgit bathentel. a. 208

Groficombeljatta. $\quad$ I $6 \mathrm{I}$

Gzuf Doun.a. 283

G: of; tytfitl: a. $\quad 407$

Giof figtuattsuhtaut. $0, \quad 289$

Glof; haulituttits. a. I6I

Otof; filtettcil. a.

Oiol; trpnfaru. a. $\quad 340$

Siali falben.a.

Giofy rambit.a. $\quad 298$

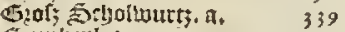

Gitutjerl, a. $\quad 197$

Gintuet rab. o. $\quad 3 ; 6$

Gutter beituricb.a. $\quad 97$

Gutbetrijeti. :

ij.

T Xarwurts. a

$\begin{array}{ll} & 138 \\ \text { jautiolabt. a. } & 283\end{array}$

298

Garbstuatil. a. 631

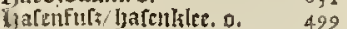

hafent:al. a. 87

lijatenybatlut. o.

yarftrang. a. 350

i)aurk. ส.

Hamberhel. 0 .

Iisa;eituettt;, $a$.

igetirofento.

***

492

$26:$

niryo 
meysto

lisodfetirls. a.

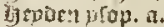

latoen [x.muct: a.

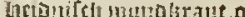

igert; freudi.

Hetrsgrfperc/bito bert; grfpan. ${ }^{46}$

嚁ert flutut. a.

2 I8

gyimat tholla. a.

bimmd fohteficl. a

biuneliaineti. o,

birfen.a.

licts;itutg.o.

nitérulitec. o.

bockitl krauto.

ijoctsmitta.

fyalict/und kjaider.o.

Holwatist;

Jyoltot

thoptten.

buiter itod,

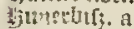

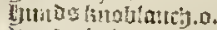

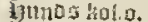

1) HMositingt.

13ptrft)ticant.a.

I)

?.

T3:teb.a.

Ifficulotion.

Finotalturct bltmmint.o.

Mnciat? the beffer.

inguer.a.

5. Wuan Jertiu. 0.

5. I1 a.t3 Lyor.o.

5. Aatoug bitum.

(5) Jats gtttel.0.

E). Mobane hraut.a.

5. Hoband pefritl.

5. folgats trenthel.o.

Fritimituo.

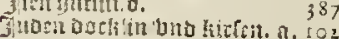

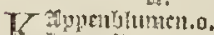

Leispliteatt.

isicten Diffel $\mathrm{D}$

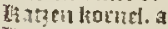

list;enmitht;.a.

hiatsen treubic.a.

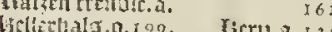

licter 23; Ientlicat Ticru.a. 135

licaten.o.

limmal.a.

Hititolis t:

hivien.o.

littent onffel.o.

blapure hielon.

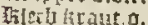

Is!cit! Butucrliet.a.

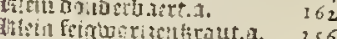

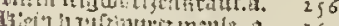

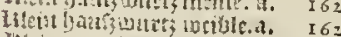

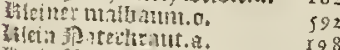

lirtit ieptutitrun.

Fitrtt Sa!m?.a.

vilin stiotoogt:a.

lat:iab butgltantit.a.

finablatertat a.

站liatu:1.o.

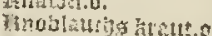

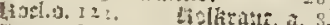

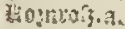

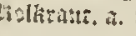

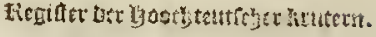

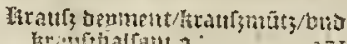

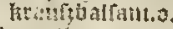

firentetbatun.o.

Irurbeclatma.

Ituninglitatte.

Hitucifirt?, a.

\section{迆.}

T Xthen knoblauty.a.

II afandel.x.

Zang pieftit. 0

Iatncts.

Zamsi). a.

Tattenot!. o.

Zeserülumefitt.o.

zitu.

Icpnoottru.o.

3cuslatatt.o. 199. a.

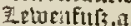

zilgeica.

Eimoliar.o.

zitionti.

Diftrftalit.

2iulen.

Literwart: o.

co.Ielfitaut.

Lajtretsi?.

lulth.o.

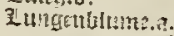

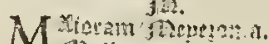

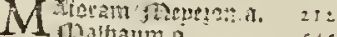
Jilatem oiffel.a.

10 aticil diodinn.

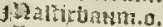

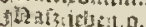

jitatinbiumente.

yhanlibertemm.

Dit attep fiver.o.

1)alicitalt.?

172ancr.a.

5):

fincutgolburr. 0

Digerficaltio.

11)

1)enentratt.a.

jiciant;in a.

Ancliktatt.o.

Jitionels.a.

flest fritiriget.o.

fllithirfin.a.

1)ier:bibel.a

fHerteticli. i.

3 Dert;itl blot:m.

giriftruatert:o.

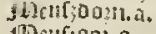

Ametif;00\%.0.

fitcrifsoitut o. 255 a

staint.a.

filotilget. 2. I $65, \mathrm{a}$.

slaen.a.

17thosett. a.

1.20filice. o.

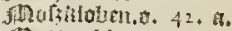

Dottert LItunetu.a.

mouchenktout.?.

1titutatboits.o.

Sthuteat nttiot.

Snut tortwit: a.

foutitritatitio

Tarbtrchaten

1 Jitgel.o.

mogulkutur.a.

Anuriten zollin.x.

Atarcentappet.o.

Marrentiolfors.0, 4ะ. a.

3) 3torumito.

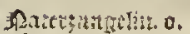

jemsilia.

Alelit.a

Duโs.c.

83.

Crylenderer.o.

Otinst113attm. 366

Dranterisaum, Is. Is

Q?

Dientuann.

Qiterlucepto.

Pipprl.a.

3).

Tappeisatmo.

poatsiekberto.

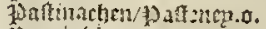

Forraic stmment.

Jurrfiejhraut. o.

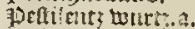

Deftintr.a.

Motartitris.

7) tetrfirct: jestetin.o.

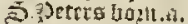

5. Jiterg knatuta.

1) frbetl.a.

Deffer 0 .

3) frifer krait.2. 173. a.

3 extristo.o.

pferces tauts.a.

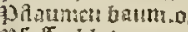

7) faffenulat.a.

3) faftet ?int:

phontel $x$.

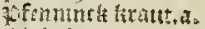

Dintyolts.o.

Folip.a.

Jomerant;ent.o.

Fapel wocion o,

Jurpitu lratit.a.

Oonusta.

a.

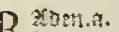

ii.

R livaminter.o.

Initereters.a.

Tzappena.

iamern.o.

tietitblunten. 0. 256. *.

Tienteant.

Lirify.A.

zittticio. a.

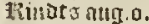

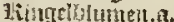

tirfenholts.o.

titterfperta.

tiodel.a.

tiom: Irye treloe.a.

tiotentyum.

fioles butets.o.

Tioflyutea.

thofmartito?

12offcyout:

10eksit. a. 15. a.

inotiats.

Ratbuedueztiti.o.

1'otiongtein.

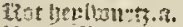

1ister fmatrotr.

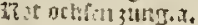

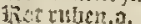

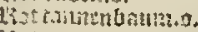

liatrio.

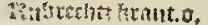

findmethillo.

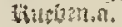




\section{Kicgiftex ber ljootbteutfoher Fetuterh.}

thin toturen.o.

îunigblım.o.

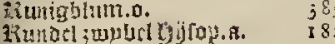

Tiuckraut.o.

ڤ.

S Xitara.a.

SSalt:iraut.o. Somarbtum.

Gantecl.a.

Saur anubir.a.

कauterkilce.o.

Ëcariol.a.

Scljafmuntlti.

Ẽ thathatân.

Sebarten litiut.a.

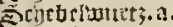

Fectirting.a.

a)eblangettkraut, a.

Êchletrazn o.

Scbmalizblu n.n.

Echtoalbentuut:

5rbivalbetn kraut. a.

Sorbwart antoa!n.o.

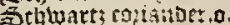

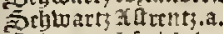

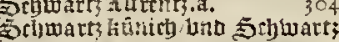
kimime! a.

5 thinartivurty 5thanitur 329

Schmetwitt3.0. 3 is

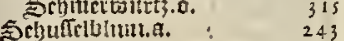

Sistbeintobt.a. .., 97

Scliburrecl a.

Ferblunten a

Dुec trolf mulct 0 .

Sechyalmett.o

Eิmiti.a.

Serti.o.

Scborit. a.

Eัculubut.a.

5ีtub fourljel.a.

Bีtumkraut.a.

Semtoht.a.

Sicócribaum.o.

Dieban mezciten brant.a.

Singutuen.a.

Sunnaw.a.

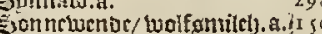

Japhicistat.

可orglamen.

E)

Eprerentict 3.0 .

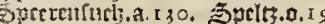

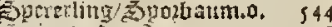

Evintotoser Spinet.a. $\quad 98$

spintustiogtion. $\quad 992$

Spilt: must:

Eptriger torgtich.

218
128

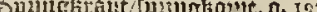

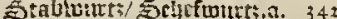
5tachelmu[z/ bno fpitznuf:. a.2s8 Etralitant.t.

Soretbenioe sintt.o.

Etrel offel.a.

stectitubert.a.

Sttinpalmen. a. $\quad 582$

Doteirblume / treinblumen.0. 446 Etein Epfitth.a. $\quad 406$ 5ేteinlinoen.o.
Êtrinpatn. o.

Etrethitut.a.

Ëticloos licanto.

Eicilumitt.a.

E) togctiru fronabel.a.

Ëtrabilon!ll.n.

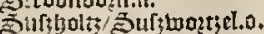

¿nturtolant.o.

is.

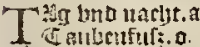

Trufentgathenticantio.

Satécutiouta.

Tuffels bitz.a.

cortifels nulrb.a.

Tierlintuanm.o.

Tournetiel.a.

Gotatern.o.

Cofchel titatt.a.

Iriaten tivatut a.

Crribhatruer.o.

Trctublitio.

Tuftalturats.a.

Curchitrebs soąn.0.

cwalct.o.

1).

VEergif: mrin uicht.a.

werifici.a.

D:men. 0

thogelkeatst.a.

Durferf rautwen flaích;. a.

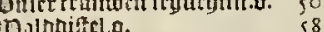

11)alofarn mële bno beible a 36

113alt Gistart.o.

ivaloknoblaurb.a. $\quad 59$

31Baimtangolt.a. $\quad 322$

16alomriftr.a. $\quad 464$

11 albricttcl.o.

maiturèsel1/uno ouerlunen. 0.34

10. Itetroo. o. 467

Wialleit biatl o. 482

malt roms.o.

10atomurtio.

1Bantzen ktablt.a.

19after buttentig.a.

赫afterouft.o.

橡 สffr rgilgen.

moafie lyatenfurs.o.

ลิ)

723affer fiblangett krattr.o.

3ibatter p Erfect.o.

70aftr werncts.a.

10entirafic.a.

mener kerter. o.

iDecliseriurs: a.

wercljelt:o.

worgbont a.

megno?tber o.

Hegetich.a.

TBeptenbaum.o.

1Briffer Mangeit a.

meinech.o. 348. a.

tusinruten a.

wentit.o.

tocutseit.

turif's alturthaum.t.

bueif anoun.a. wrift gattom biole.a.

toc15 bouttung bultum. a.

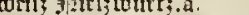

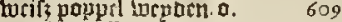

turrifrermfi.a. 68

weif twege diffel.a. $\quad 365$

turtis winter bialen.a. $\quad 175$

wrif; wutt;.A. $\quad 283$

wolfamen.o. $\quad 426$

lurliche bittel.a. $\quad 368$

Luelfetl firrent. D. $\quad\{92$

welfrb neflt.o. $\quad 28 \mathrm{r}$

welfrb ni:fobanm. a. $\quad 545$

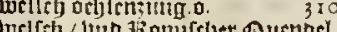

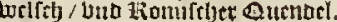

a.

belfeber fteptitlec.o.
welfrhet lurpien.a.

wermult.a. 335

bickert.a. 401

witherkirely ulop.o. $\quad 270$

will Zingrica.r. $\quad 399$

wilt bafticn.o. $\quad 269$

wilot tnugclianut. $0 . \quad \quad 132$

wilorr Eucuntmrt.A,

twilure Galgan. a. $\quad 37$

wither finoblaucly.a. $\quad 59$

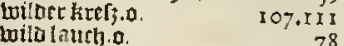

wilt Molteic.

wilte munt:

Eulth arbfaly;tug.a. $\quad 249$

toitbe lialen o. 618

bilt rattan. a.

twilder 5enfi.a. 210

wolbe beguanterin.o. I I 4, a. 82

wilt taribr.o.

bilis mickien. $\mathrm{A}$. $\quad 40 \mathrm{z}$

mildenktautt.o. $\quad 336$

wilthkrat.o. $\quad 314$

wifen tiltr. a. 380

tudiffs mildtia.

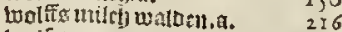

Lecleswurt 3.0 . $\quad 386$

tonllktantia. $\quad 242$

butidistsutit.o.

wutbthram 0. 244. a. $\quad 267$

Y figituito. 3 . 360

7 Xchentamu.

Z Eampzumtic.o. $\quad 633$

Kam blatwe wirgwart. 398

Zante NPagtemen.

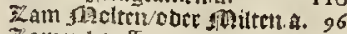

Zamer banff o.

Eamikraut.D.

Zauffintiraut...

zerckenhoula. $\quad 392$

Zribslisat/\%ciantb.o. $\quad 199.200$

Zcitlolen.0. 69.8253

Żungrublatit.a. $\quad 283$

Ewibel.a.

zun orum.a.

Zunimirt liacrlin o.

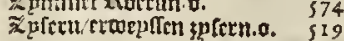




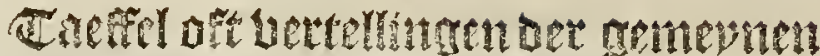

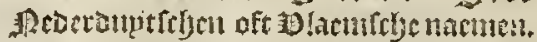

.

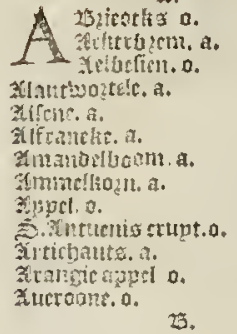

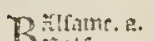

Bisatism thusts.o.

2attito:as.

25.in barchtiact. 0

2 ärchícumnctupt. o.

Scitanlilatu. a.

25.trlics beals. 0.

Estragic. a.

zifficn bcam. v.

$25 *$ tonic. a.

25mtenares. 0.

zjic: 0.

כit:. 0.

zicloork. a.

Zirersit. o.

23 ilfet, bilfentrutnt. a.

23 ingeicrumt. 0.132.

zitier Riocs. a

Hlodozict a.

25 lat botctulonmenti. o.

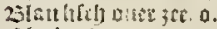

23 lati iroutar a.

23 laetwoitcle. a

20 bermlacteri. a.

750

5joeren herie. a.

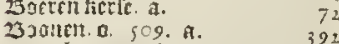

230011 tents hooilogitele. a. 339

tomiclseits a.

25aterblocmett. B.

23otteived, at

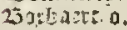

simula.

23 : mult 23:amen.

23)ant: 15 scm. a.

Litifite peper. o.

23:mattrelic:ts. त.

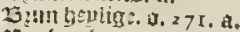

5iefien boon. o.

Espuost. a.

$$
8 .
$$

Cincundiaden.

Cactisn boloets cartsent. caliboct. $a$.

Eathiteljaut.

Cartitit. 0 .

Easteel.o.

Enerlicole. a.

Carotent. :

Caíi:3. 3.

Cantatiehnoin. o.

Cartencrutut. $a$.

Caniuetcrupt.

Ebyifus oogten. $a$.

eitre?t. D.

cipres.o.

sitrosian. D

525

430
Citefrrupt, 0 .

cleunte citren. a.

Clcmil oonorebart. a

cicun timantre!len. a.

Cltpu warec bette. $D$.

Eaccheors blocmir. o.

Cetclaces buat. o.

Coliarder. D.

Eontammetell. .

Comiin. o.

Confilic of grtput. a.

Cacectrrupt.a.

Cornt blosmeri. a.

Cozent robfen. a.

Eoznorliclaom, a.

coitoen. a.

Lraeym blocmkens. a.

Eracponboct.e.

erock. a.

Eraonketo crmpt,a.

eriţ\{atult a

crupartuie, a.

\section{政,}

D Fontuonts.

Qo!n aypri. $n$.

Soltitbtocmelt, a

Tas acticn blact a

Unaken toastele.

Diantuct o.

(1) E⿱thencrupt a.

Duertwao.a.

Cultrumt. a.

Dulicheturl. a.

Tombert lioren, c. 6I 8. a.

tomplit knoop. a.

Dimutriterturl. a.

Dumactivoct. a

Eêticutrtupto.

Crrot appel. a.

Ecrutbeficst.

Eirüntenserbedicten o. a.

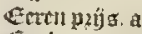

crefrimt.

Efgillioolett. a.

Efr!cutier. a

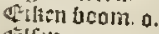

celferto

Enerloort. o.

Etape. 0.405.

Euerwortcic

\section{$\mathrm{F}$}

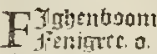

Eloulucto a. Fonteysters?

C:ncto. 5.

I jalatitus rele, a

Galingation mele. a. $\quad 245$ Daw frit diftel. a. galcgast. a. 40 sinart bot.

ciafpetonati. a.

Eet ganfe Jloeme!t. 0 .

coe! hutct. at.

Ged Iifch.

Siel pect get tworedctt, a

Gerl biaícret. a

Eetiluesertijek, o.

Gettiten:

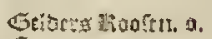

Concuetucom. o.

Qengetre a.

Cientlante. a

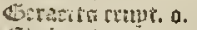

cinclaterorcicute.

Eucutts biadt. a.

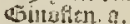

Sodots gentibt. 0.

Go:ce firyiticiti. e.

(298. a. 237

Toubue. A. 339

UTाpl] 0. 462.a

bias. o. 9.

Stitrent. $a$

ciscistonagyel.o.

Ezost difien. a.

Gloote Halcupe. a.

Giont sertroil. C.litornapyitct, a. Gumf!rlicul a.

\section{Ij.}

T-Tutopltens rrupt. o. Jifrount a

1) anccumuthetso. a

ijancmitoct. 0.379 .

l)afclate. 0 .

lyalelwortel. a

1) afest laraume. a.

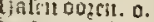

jafen pootkens. o.

1)attici. a

biscte neterout. 0

locioe. o

Lyelitifilint. 0.

urntets data

lycrtere fuall a.

Deteabact crupt. a.

Wertimute. 0 .

getto tangtic. 0 .

locroential?. 0 .

(1)

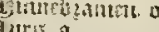

Livêne.

jofiladeret. a.

jolvouztalc. o.

t):stocibiet a.

1) o!rustibles a.

lints tpngbt.

t)omclutul. a.

i. uifr. 0 .

\section{7.}

5. Tfcolig trigem a.

T!10tracil

safeplys blomnent. o.

* lercrut entoe J farljert.

oatficoutumeiclt. 0 i.

TEEl rrunt. 0 .

L tircsichs irunt. a.

Itcriat. 0 .

lierfonturat.

thar binle. 5

Iiriaket. 0 .

litricket bau duce

intersbelats. o.

오. 


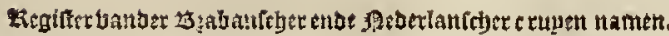

tanglye peper o.

Iaucnot. a. 236 , a.

$6 \mathrm{I} 7$

ז 84

57.5

11

85

Leedgras. 0 .

I rite o. 83 . a.

Iclic ban Calnatic, o.

Icuclerumt.0. I 56 . Ilettatue. 0. I 2 Llifchboben \& Doufm. $\mathrm{D}$. 42 zincen. 0.

Iinitit. o. 521. a. 401

I aocli founar laoci. o.

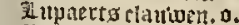

Iupitten.

m.

$\mathrm{M}^{\text {Xotlienen.a. }}$

SABacitat palm. o, $360, a, 282$ jilzifotic \& 5 Titatucuie. a, 222 fnallue. 2.22 . fithancoy.a. I 10 j72atioragora matunelien.a. 106

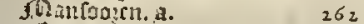
harcionen a

(n)arnolitune.a.

Sizaetbolocmeti. a.

38

Shatuti $\pi . \%$ ARet. 0.46

Jitislic wepe. a.

mivloentn. $a$.

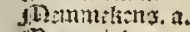

finertitial. $\pi$.

sizert retuaztele. o.

Shitisti crunt: a.

Matrcinozztelt. a.

flater. 0. 4 62

89
285

285
280
100

398

227
489

. Moeberernut.0.43

Mrarrbelie. o.

Shoerbrtîllboont. o. SIO

Malentrut. 0.

fRondthatiot. o.

Jinctacit. a

A)ott crut 203 . Muer 67

Munctieappenta. a. 302

Mule bosti. 0 .

Alupler met fiemten.o. Sis

jliup [003 Cht. o.

Mupleti fertitsits. a. . 187

$$
\text { 5.?. }
$$

N Toljecrupt:0.

D jilardus füct. $a$.

254

329

5) afcane cube nac'stifade. a.

3) atcr tontgirn.o. , $47 t$

Sancl cutut, $\mathrm{D}$. 209

Niegriblarment. a.

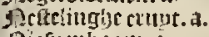

SRirpenuoant 0 .

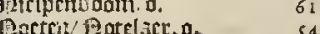

Shotemifiaten a. $\quad 570$

Oeltcrutribiom o. 545

Olinebom a. 566

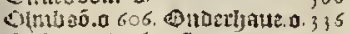
Enfr biontue vedifraga. is a Onfer bzontwent ouftl.a. $\quad 366$ Buter bountar maittel. a. 298

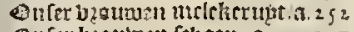
Bnler bantontll foben a. $\quad 127$ Dosbcrtrouft. a. ; 2 io

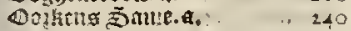
Qevuthts bech a. . $\quad 206$

P Pilepe a. $\quad: \quad 247$ apalicebonta. a. 3 ji j60 3apen remptia. $\quad \cdots \quad$ if 84 parifebe catpeta.

pantich kouct. a.

partplise 0 .

paprcutle?tentr. a.

Daftinaken. o.

407

250

ijore. 0

7) sertoblaencit a.

Jesnninte crupt. a.

p)

jocper. a.

popstertust. a.

poper met feertan, a.

peparnen o.

Declectivt. a.

perfeloain. a.

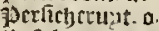

10rfillence wa:teIrn. a,

B. Jjeterg truvt a

24

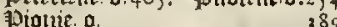

Binappsitoon. o. $\quad 635$

Plampen a. $: 3 . \quad 257$

pluputitus. a.

pzattgwo:tel. $\mathbf{o}$. $\quad 492$

piotetbruin o. $\quad 447$

polcue a. $\quad 206$

joppulier/papulacre a. $\quad 609$

pjoztclewne. a

a

$\mathrm{Q}^{\text {Bi appel Oupeerzuom. }}$

Qumt appel, a

R Fijara. a. a.68. liaptit. a. 66

1:ipen bicemetr. a. 301

liatelen \& ncelc kiatclen. o. 285

IRepnbioentert a. 203

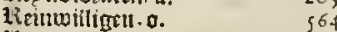

tieps a.

kitionแbeften a.

3itoverfyorell o.

liict a. $\quad 4 \div 6$

liabctts crupt. a.

liogglic. o. 15. a

liodur brete. a.

thacderatelcu a

kiocmlebs samiblocmen. a. 3 t

Ronmfrlye uteten. a. 281

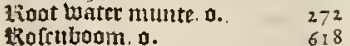

vicen wastelen a.

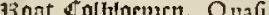

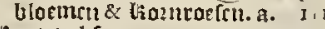

Thoot mehtoen clupt. o. 25

l'ioomiftie multe. 0.

liofntarin. $a$.

tounut

Linte/mintrite. D.

5

Sxlomeng fendel, a

a. $\quad 683$

SEamitis/:Danirle. a. 297

5)anto ye cleune Santospe.0.218

53 attioan o. $\quad 524$

हatricom. o. $\quad 599$

Eacausiofe. a. - $\quad 1,2$

อิ)

Eorrilepe a. $\quad 24.0$

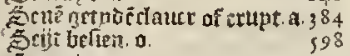

Scoepiane ctupt. o. $\quad 344$
Eิธo?

हु)

Eิethlirbrant. 0 .

Birroant a. 595

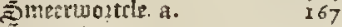

Boncr tarme. A. 6

Eombats a.454 5o!nlact.0.25

Epaentelu fenetion. a.

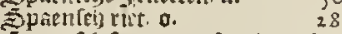

zpartllit lart/ choe faet ban Cas

narien. ‘. 16. Speen erupt.0.299

7. perterunt. a.

Euccrwastele. 0.

Epputagic a. $\quad 98$

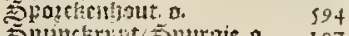

Sprinckrtat/Epurgie. o. 197

हิpurrpa.

Etalcupt o. $\quad 45 z$

Etctirapen a. $\quad 67$

Eotcelt crupt a. $\quad 230$

Dreett cppe. 0

Etrecturegle $a$.

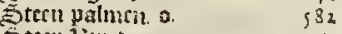

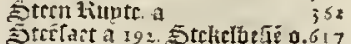

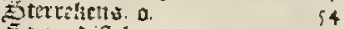

Frive biftel. o. 482

हुtorkerbutten. สิ. $\quad 396$

STtupchilaenen o. $\quad 446$

S) Surlicle. a.

F)

Eliptljout $\mathfrak{a}$. $\quad 328$

Elvalula $\mathrm{f} \mathrm{watcie.} \mathrm{a.} \quad 356$

$\begin{array}{ll}\text { Bistert niefrupt a. } & 3 \mathrm{C} 4 \\ \text { Spttantwe. a. } & 293\end{array}$

it.

Timme eicorcpe. a

camme meloe.

camme meloe a. $\quad 96$

Corture o

Eitlolen a.

Toutgen bladt a. $\quad 283$

Tlircks hazen a

Cluccblad 0 .

Tern. a

$$
\text { io. }
$$

7 cen. a. 317

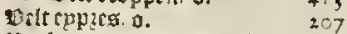

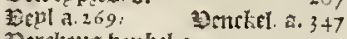

Decketus bethel.a. 350

Derămgents a 1.6 Oerber:c:0.28,

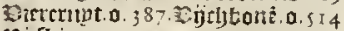

Diffimigrtrupe.a. 392

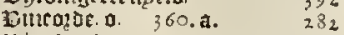

Dinglier bont tecutt. a. 254

violetten.a. 66 . Bisitim a.I to

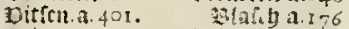

bier.j88. ploptrapta. I 6

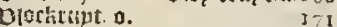

Dogibcrutut.a. $\quad 193$

Fontic? boct. $\mathrm{D}$

sookifluer. a. 299

1Eozskenes o. 92

Bzancibe o. 233 Wiack 0.692

ojorgly per [en. D. $\quad 596$

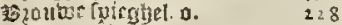

walroott! a. 319

ivater crpesi o.

10.ter Irete. o. IOS

Dater leterizat o. $\quad 497$

Barter nottet. a.

Mater purglicu. a

1Dater vecur. o.

1Daret Rabictictupt. o. 328

tonter biolleten o. 450 
matcrumetye at 1200 cer 125

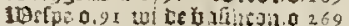
witor Caretenta. wailor cirougele a wion nalber.

wilbe Jiercutial.o. milber meftart a. wilt toit nic fertut. a. tolbe ofre tongt.a wilbe Izafirtter.

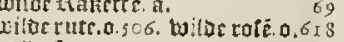
wilter fatte.a. wilit tbume. a.
25

269
+16

82

97

132

132

49

210 wiloblar:

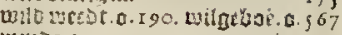
Ln? monefacticntic wijnttoch. o. 348 . tutititigestutt.o.

wuter lioofer.a.

wiffll wollen.0.

ixite 25ectent.

wite bofret torment o.

witte sitontic.a.

witef bilcult

ust moftast

wit ARicternat.a.
157

293

44

93
497

85

83

68

I 3 witte fittetliooltti.a.

witte wech silfel.a.

witte wi:1ter biolet.o

welctipt.a.

woifæ nclik.a.

wolfwattic.o.

wonberbaom.o.

unonien crtpt. as,

wolituce.

watange. 0

7 cribarto.

zituse.o.

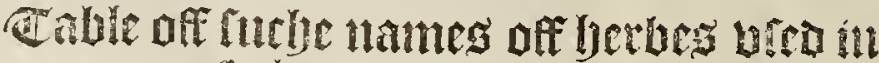

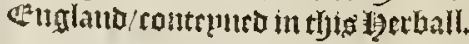

$x$

$\triangle$ Stiberro.

2 ingrimatie.

zlchont.a

Utrkattoze.o.

allmanso tree.o.

Ancts'anple.

zipyel.o.

Etetbicaques. o.

בCly.o.

สิtกนร.ส.

K3ara Laccata.o.

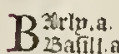

23attart faffron.o.

23awme.a.

2 geaneg.a.

zoscistre 0 .

$25 \mathrm{er}$ istig.o.

25 stfote.0.

23 ersuutt:a.

Letomb.a.

23 itr.a.

20 musmertst.o.

25 itter 2 tock.a.

23lack betrpe burche. o.

23lew Jattel. a.

3 lao frattge.a.

250 hbers 25 sotomic. a

250 iser.a.

25 zamble butche.o.

Tsictul!cbe a.

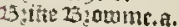

25rume.

25200172 .

$25 u r ! c e s$ bearder.

23 tetationtiz.n.

23 ircuheat.o.

3uttri burre.a.

SItte.0.

\section{c.}

Cicbungr.a.

Ceaburleliz/kcolofse

Calamint 0.

Calfits frosote.a.

comorging.

Camanols.

Cartusenes.o.

Catris Ataputr.a.

Cattijas taolc.a.

Ceozetero.

Eedifrala.a.

crlerbine.a.

cortagy.a.
Eberifa.o.

Cberucl.o

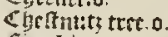

cicctbita.a.

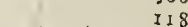

cirbe.a. 5I9. cicbelingero.si

cirboupra.

Cinck folpo.

Citron tre.o.

clarpea.

Clanter.o.

Sochompuntt.o.

To!ontiutioa.a.

Coltes fonts.a.

Colmmbine.

contertu.a.

Cantm?.o.

Commotl topimewood ato.

Cociantore/Caliandzo 0 .

Comations a.

Comeltrec. o.

Cotton.a.

Cottalt witar.o.

Cotarlípupco.

230

thtiçs.t.

○.

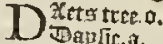

Dardurtil.a.

Berle.o.

Deturlles bit.a.

Dicurco a.

Bill.a.

Bittamner. a

Dork.s.

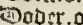

Dotgers codder.

Dargers tangr. 0 .

Doutule touge.a.

Diagonta.

खaturch incat.o.

खimalc.a.

e.

Eirfonirtiye.o.

Cinet treo.

(E) ecampatte. $a$.

alm ir?e. o.

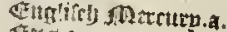

atson

$$
\text { ff. }
$$

G vemorte.

Feithe.

Ferite the
$\$ 92$

8

82

393

572

240

493

325
287

339

251

428

335
403

403
188

992

9 I

05

298
285

637

$\pm 99$

223

633

233
407
347

347

I) 5

150

233

87

313

$28 ;$

243

243
643
102

$17 x$

110
588

588
246

606

97
19

129

502

347

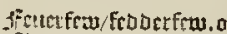

itirbe. 0.

Fitge tre. 0 .

finstoonte. a

Eitifies. 0 .

fiptte fingerte graftio

ferthell.o.

flar.a.

fircfroto.

fileruagte.a.

filower getitill.

fflout of Etter of fout be 95

fiole fuote.

folfoort a.

fore filous a

framboile.o.

Frentely $z$ altci der.a.

frecilet Jheretira. a.

jernfebe fuick llarbe.

fimotertio.

6.

Tiroen claner.

$\checkmark$ varbont cretipg

Sarlike.a.

Sriptlours/Calouers.0.

cosigntra.

Smitiane a

Germanier a.

Shobon of falle Xeonits.o.

Goolefrote. a.

Sacslyarte.

ểolo.a.

Golb apel a.

Sold foluri.a.

Goltrocio. 36

Great 5urte. a.25

Ercat Centogye a

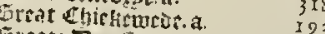

Ereate Davfit. 2.

Grtate moint a

ciceat inochert a

Grrat Barge.

Sisomelt.a.

Djeunos ypne.o.

Erountril o.

Sponturil a

Gumine ftecosn.o.

遮.

T zares balloses a

Iilaris faot.o.

()artpotar.a.

lyartres titige. o.

yaub thozintre. 0.

balter.o.

batwlic webe.o

Gearbe two vence a.

433

322

256 
mirs torfil.

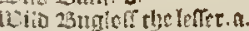
10ito Sicha:pe. D. 114.a.

uide entunturr. $a$.

10 lo finc o ranc. of

1010 c ctma:tocr. a.

1Bito happes. a.

ID! fin forrutp. o.

Dilde fimute. a.

12) iar orrate. a.

Mito rctor popper.

inilot sictual 0 .

Btio time. a.

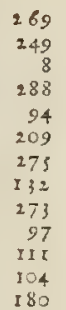

30itb has ase \& watbe. o.

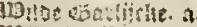
जutce hrat?. o.

1D: l ie iretse. 0

10 iloz sisurgarm: a.

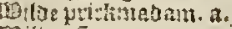

Ditto Spurge. .

itive Dpute.

1ibitide 0

10urer cicrne. a

10inte brtia o

wisite Enbiuc a

wyite tarom bopyic, a.

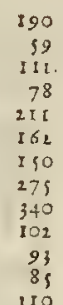

abite rogte $a$.

1D Bite BHonet. a.

Doinllitu.0.

wite butt. 0 .

quos lintor a.

meoratsca.

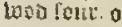

Yicrober a.

$Z$
283
140
83
361
280
210
495
133
237
489

\section{TABLA DE LOS NOMBRES CASTELLANOS Y ALGVNOS PORTVGVESES.}

A A. Broios. obr": A broyos, Abrollos, $\$ 28$ 258 Acarreadora de fueño obl. I I 34 Açufrau. obr.

Açıtran faluage. ob?

Açofeifo. ob?

Acucenas amaril!ns, obr

Adelfa. obr.

Aio porruno. obf

Ayos, obr:

Aluzor, obs

Albahaca. adu.

Albahaca de atroyos.obr.

Albahaca Gatuare obl.

Albardir obr.

Alcamo negro. obl.

Alcapparas. adu

Alcarouea ob:

Alecrin obl

Alegria obi:

Alíabeca obr

Alfena, obl:

Algartotras. ob

Algodon, obf

Althelys, ob:

Alichrin Erancez. obe

Alipiure, obf.

Alineidras. obr.

Almerones. obc

Almez, obs.

Amapolas ob

Anormyos, ob?

Amor de hortulano, olsc

Amotes, obc.

Ancula obr.

Andrimas. obr

Apio Macedonico. obt

Apio quil ereecen las piedras ob 407

Arayhan marifco, obit. $\quad 560$

Arbol patadyfo. obf. $\quad 546$

Artiueja. obf?

Ariftologulus obf.

Armoles. adus.

Armuelles, obs

Arroz, obr,

Artem: fin. obf

Aruejas. obs:

A fouzenas de las Intias. obr.

Anez, A uena, obr.

Axedrea ob

Azeto.obr.

Azederas, Azcos \& Agrello

Azeytuna. obS
Azumbar. obr

B Arbacabruna,

D obl:

Bardroegns, obf.

Batata. obf:

Behordo. ob?

Bidollo.obr.

Bien granada, obf

Birtorta ob?

Bledas, obr:

Bobas. obr

Boga, Boxa blanca. obs.

Bon varoll, obs:

Bredos, Blcdos, obC

Burhaliga. obf

\section{C.}

Cabezade ternera. obr.

Cabecuela obr

Cafelale Iurcarum, obf

Calamenta obf

Camarinhera. obr.

Cannotes obf.

Campanilla, obf.

Cañ. obs:

Cańa fiftola obr.

Cimanheia, adu.

çanahoria filuage, obs

Candilcra obf.

Cancla obr

Caritueffo, cantuello obf.

çarȩ̧a, çarçamoras. obr:

çarça llamada Idea. obc.

Cardencha Cardopenteator 619 Cardo $\mathrm{Cat}$ dos de comer obs

Cardo morro obf.

Cafca obr?

Cebolla, obr.

Cebolla albatrana obf $75-$ ady 73

Celidonia obr.

Cedri, obs.

Cerśą̧os, obf:

Centeno. obr:

Centoria. obf.

Cepa marina obf

Cerefas, obf

Cerezo fylueftre, \& Cornizolos obf 592

Cuuada obr

Chamedreos obf

Chamedreos de arro yos. obf.

Chantage obr.

Cheriula obr.

Cibollina Alborana.obr
43

n.

(a)

297

369

$4 ?$

607
113
155

124

I 89

504

I1 2

624

221

293

65
274

$6: 1$

369

61
28

541

348

416

302.

574

34

19

9

78

12

73

22

439

630

28

75

bi.

Is 260

261

63

73.
Cicoria obr.

Cidras obr.

Cinco en Rama obf

Cipres. obr.

Ciruclas obf

Clanellos, clauos de ef recin obe 595

Coaialeche, yerua ob!. 367

Cuchiclos, obf: 209

Cogombro our $\quad 363$

Cagombrillos. obr. $\quad 368$

Cogombrillos amargos.ob. 368. 508

Coyon de perro.adu.

Collacl, obi:

Colleion. obr.

Coloquintida obr.

Comino obr.

Coraçoncillo. obs

Corayas. obr,

Cornicubra obs

Coronilla del Rey. obr.

Corcoila obr.

Corcoia. obf.

Culcuta, obf.

Dicne buey. obr:

Diptamo: obe

Durmiclers. obf 267

$\begin{array}{ll}\text { Durmidera. obf. I } 4 \mathrm{r} \text {, adu. } & \text { I } 10 \\ \text { Dora idera marina, ad. } & \text { I } 09\end{array}$

Fano. obr.

C.Eloendro, ob

Endiura. obr.

Enebro. ob:

Encldo obr.

Entramocos, obr.

Enzambac A raburn, obr.

Enziaz obf 8 . 46

Efcolo ob

Efpigatio, obr

Efrigefil obs.

Elpina obr:

Espinaca obr.

Eipino de mainelas. obs

Eitepa. obr.

Eforaque obr.

Elula menor, obr.

Fababrauabr.

HFarfara ob:

Elel de tierra. obr

Figuera del inferno obs

Frailitios obe

Falno. obr.

Funcho. obs.

114

8 122 215

423

16

11
38

233

92

609

28

35

504

164

43

129

48. 553

575 
.

G Amarca. obf: , .. 508

I Gamones, Gamonites, obl: 46

Garauancillos. obl: $\$ 24$

Gatrillo cafto adu.
Gatilbos, obf.

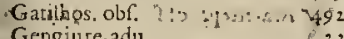

Gentiana obf. $\quad 233$

Gioante. obf:

Gilbarbera adu. $\quad \ldots \ldots 283$

Gioul catamer. obr: :

Gordolobo. obr. $\quad 303$

Granata. obr. $\quad 564$

Granza. obf. 462

Grauanços. obf. 519

$\begin{array}{ll}\text { Guiabelha. obf. } & 239 \\ \text { Guindas de las Indias.obr. } & \quad 136\end{array}$

T Auas.obr H.

1 Haja, Luf. Faya، obr.

Hallenz. ob

Helecho. obl

Higuera. obl.

Hombrezillos. obf

Hortiga obf.

Horriga muerte. obc

TVnca cheyrofa, I unca auellana1 da. obl.

Iuncia olorofa obf.

Iunco: obi:

Iunco Amicerotaco. ob

Iunquillos blancos. obi", 61.

Iulbarba adu. 283

Yaro. obr.

Yedra.obl: $\quad \therefore \quad 337$

Yedra Campana olef: $\quad 340$

Yerua benederea." obf: $\quad 4$ II

Yerua de balefte, adu. - $13 I$

Ycrua cana. obf.

Yerua Cannamera. obr. $\quad 373$

Yerua Codreira. obf: $\quad 277$

Yerva eftrella. ob!

Yerua gatera, 'obe.

Yerua delas rolondrinas obs 276

Yerua Lonbriguera. ob:"

Yerua mora oḅl. 133

Yerua mora miyor, obf

Yerua mora que acarrea locuta. ob

135

Yerua del muro. adu.

Yerua pionta. obf.

Yerua de las pulgis olorofa.obl. 187

Yerna puntera.obf. $\quad 202$

Yerua de valletteros. obr. $\quad 388$

adu.

Yeruo, Yeruos, obr

Yezgos. obs

Yniefta.obl

Yio. obr.

Y fopo. obf. $2 ; 7$ adu

Yua archetica, obf.

T Appaza. obr:

Llaurel. Laureiro. obc.

Leche Gallina. obf.

Leche trelma obr.

Lechuga, Letuga. obf

Lechuga falunge. obr.

Lemeriniza obl:

Lengua Ceruina. obr

Lenteyas. obr.

Lycluzede coronaria. ob?

Lietugas, \& Liechulas dentre los pia. $\because$ nos. obf ins

Eiga y Lyta. obs.

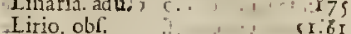

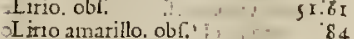

Lino amarillo. obf."

Eirio blanco \& Cebolina. obr. $\quad 60$

Iirio cardeno, Lirio del color del cic-

lo. obl". , 32

Licio Id y rico' obf. .2, $\quad \ldots, 4,4$

Llante. obl:

Lleteramarina. obf.

MAdre fylua. obr.

I Maios flores, obc.

Malua abí.

Perexildela nar. obc.

Peruinqua. obl.

Pexegos. obl.

Pie de borto, obr.

Pico de grus. obf.

Pico de Cinoña.adu.

Pinilo $\quad \$ 75.617$

449

Polio negro obs.

olio. obt.

Polypotio obr.

Piolheyra. obf.

Porrandillo, ob!.

Prefera. obf.

Puerro, obr

Puerro cabicudo, obf.

Mançana, Manfanas. obf. $\$ 90$

$$
\text { obl. }
$$

Mandragula, mandracola. obr. 138

Marmaio, Matuauifco obf. 373

Marrudo blanco. obi.

Marrutrobaitardo, nerro. obf. 279

Mattantos.Meftrantos. obf: $\quad 17$

Maftucrco. obf. ; : 107

Miftuerco faluage. obf

Mafucas. obr.

Mara. obf.

Mcimendro. obf.

Melon. obf.

Menbrillos. ob

Mercurial. obr.

Miyo, Milloo obr.

Moml Moras obl. it " 2

Morella obf. $\quad 1.35$

$\begin{array}{ll}\text { Mortinoin, obl." } & 123 \\ & 247\end{array}$

Mollaza. obr. $\quad 100$

Maltaza laluage. obf

N. Naps, obr.

NAboconumun, Naps, obf. 99
Naborctomdo, obf.

Nabolaluage. obl.

Napello. obi:

Naranzas, obf.

Narciffo. obr.

Neguilla. obr

Noefes. obf.

Nofellat obt:

Nozellas.ob:

Puerrofaluage, obr.

$Q^{\text {Veiro.obi: }}$

T) Abacas, obl

12 Raiz del alla, obr.

Rapontico vulyar. obl

Ratama.obr

Ratuato.obr 533

Regalitia, regaliza. obr: 528

Rcilla Bucy. obi: , : 49

Ribes. obf. * 6Is

Rincham, obf, "

Roble, Ronre. obf. . $\quad$. 83

Romaza. obl. $C$, I 50

Rofa.ubf. 618

Rofa de monte, Rofa albartcira.

obr.

Rofilaluage onc: $\quad 389$

Rofclla.obi: 143

Rofmarinto.obr. $\quad 234$

Ruda. obl: $\quad 506$

Ruda falunge obr. $\quad 506$

S. $\quad 462$

SSalce, faliucro obf: $\quad$, 625

Salifice, arilia. atu. $\quad 567$

Saty riou, ob:

Situa liue Saluizadu.

Sauco, Sabuco, Se Canincro obi s 88

Scabiofi. obfi.

Scoba obl $\$ 31$

Scriba Hediona ob: $\quad 430$

Scorloncro. dol: 298

Scudetes. obr. 209 adu. I64

Scmiente de papagaios. obr. 438

Serpol, Serpillo, obl. $\quad 230$

Serpollo aitu.

Scruas, old, $5+4$

Soluanella.obr. $\quad 329$

Sombrerera. obr. $\quad 32 \tau$

Sorba.obf 544

Siempre viua major. obr. 202

Siftro. obr. $\quad 449$

sparto. obs

Spelta obf.

Spino negro, obf.

Squilla menor. obr.

Suelda maior. adu.

Sultan Simbac, obf.

7 Artago. ob

Tomillo faliero. ob:

Tonnada obr.

Torongil. obr.

Peplo, obf.

Peras obf.

Perexil obf

405

os

60

3

93

64

8

8

(n)

8

0

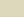

(1)

9

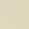

.

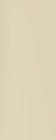


Tragontia obr,

Trebol de prados, obr.

Trebol real. obr.

Trigo obr.

Turfani \& Lale.obC

TA fillos. obr.

Velenno, obf:

Ferangerias. obl
$3+7$

49

493
494

494
500

I

86

$Y$.

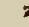

309

575

139
138
Verbens, obr.

Verça marina. obs

Verdegambre blanco. obe

Verdegambre nero. obf.

Verça perruaa. obr.

Verdolagas, obr.

Veferra yerua obr.

Veziga de perro.obf.

Vezina de Rios, obf

Vid. obr.

Violeta. obc.

Violetas amarill
183

$3=9$

167

388
132

132
210

221

134

164

348

334 tas , adu.

Vifnama adu.

Vngle caualluca, obf:

Vua crefpa.obf.

YAra-eltepa.obr.

$\$ 49.553$

7 Ampal.obr.

\section{2}

Zergatona
140

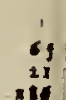

E N.

'T A V O L A

I T A I I A A.

A. Bete. ob::

Aglio de gli orfiobr.

Aghio ferpentino obr

Agliporro obf.

Arno cafto. adus.

Agretto adu

Aio, Aglio ob?

Albricochi obf.

Alegracuore. obr.

Alliaria obs:

Alno, obr.

Aloe.adu.

Amarantho giallo: ob?

Amarella obr.

Aneto, obf:

Apio. obr:

Aquifolio. obs.

Aquileja obr:

Aranciata obr.

Armeriache. obf

Artemifia. obr.

Artichoca. adu.

A fciro. obr.

Afphodelo adu

Affenzo.adu.

Affenfo ombelifero obt

Atriplice. adu.

Azasoli. obf ors. ada. $B$.

B Acoche obr:

B Bagolauro.

Balfamin.obr?

Batfamina. obr.

Balgmita. obr.

Bafilico. adu.

Bella dona. adu.

Berbena \& Berbenaca, abf.

Berula Bertula \& Bidollo obr. 289

Biaua.adu.

Bietas, obf.

Bietola faliatica obr

Biondelle obr.

Biedoni, Bliso.abr
Bombace. adu

Bonaga , obc.

Bofto, obr.

Botonaria, obf.

Alamantrina. adu

Calami a far conoscbic, obr.

Camamilla obr

Cabcia ob!.

Canne a far liepe. obr:

Cappellazi. obr.

Capriola obrig. adu.

Caranzi, ob

Carcioffo.obi

Catuo da panni obs

487

obr: - 485

Carduncello. a du.

Carduncello maggiore: obr.

Carobe obi: $54 \mathrm{r}$. Carpino obr. 607

Caftagne obr:

Catapufe fninore. ob?

Cauole lifcio. obr:

Caulo cappucio eappuzzino.c

Canlo fiore. obr?

Cauolo marino. adu.

Ceei. obf:

Ceci faluatici. obf.

Cedriobr.

Cedri. Citroni. obs

Cedro minore. obs

Cedionellis, obr.

Celidonja maggiore. obr

Celidonia faltiatica: obr.

Centauria maggioce. obr.

Centograna. obe

Centone. adu

Cephalionitobr.640. adu.

Ceferone. obf

Centaurida.obr.

Centocchi obr.

Chioma de Gione, obf

Cicerbita sdu

Ciecrbisa lifcia, adu

Cichoria verrucaria obr

Cichoria faluatica adu.

Cinogloffa. obr.
291 Cinque fontio. obs

Cypero. adu.37. Cipole adu

Ciregc. obl:

Cifto obr.

Cocometo. obr:

Cocomero faluatico. obf.

Coda dicsuallo obf

Coliandolo. obr.

Coloquintida. obf.

Comino obf:"

Conaftrelto. obf

Confolida muior adu

Cope rrincle adu.

Cornai, Cortioli. obl:

Cripini obf:

Croftofanaria obr.

Cupiefro obs:

Cuficuta. obf?

Dentedicane ob?

Ditlaco obr

Dittarno obf.

Dolzolini obl:

Dragoncello, Dragonc. obf. E.

$\mathrm{E}_{\text {Elice obl: }}^{\text {But. }}$

Eirdivia obs

Enula, I Ella, adu.

Erica. ob

Eufrafia.adu. $F$.

Fibanrafa ado

Eaknivio obs

Falari.obr.26. Fasto.obe,

Fane obs

Fatralupina. ob

Fauofelliadu.

Folche obe

Ferola ob:

Fico obl:

Fiengreco old

Firrochiells. obf

Finocehi. oir

Finocchio marioo obc

11) Finocthio ar oro obf.
(3)

548

36

368

46

367

428

564

64

592

409

622

23

13?

487

267

243

582

582

246

6:0.:613

210

57

587

27

19

505

256

410

612

449

$+48$

453 
T.

T. Amarigio obr - Tafobarbaffo obs Terebinto obs

Térracrepolo, obf:

Tefticulo de cane adut ? , I 15

Thaffia. obt:

Thymo.adis.

Thingi adis.

Tilis, 'Teio obr.

Tithymaloarborco obs

Tithymalo marino obf:

Tornatole. obr.

Tirafi dolce obr

Trifoglio, obs.

Trifogio cauallino. obr

\section{V.}

VẢde bon:

Valeriana maguiore obs $4 \mathrm{r}$ Vecione, obr.

Vermumacola obe

Verigenili obf

Vilucchio minore obe. ${ }^{2}, 253$

Vilucchio maggiore obr . , 340

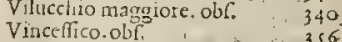

Vinci bolco, adis. $\quad 280$

Viola bianca adu. ,

Viola Ialla adu. . o 140 Viola siammola, Viola purpurea c 334 Vifchio, adu." Vite, obr.
Viticella obf

Vanbilico di venere. 2du. 35y Vngla Cauallinat def a Vua orfa, virna dellorfo ob 34

Vuálpiuz. obl 546 is

7 Afrano adiı.

$\therefore \quad$ ing

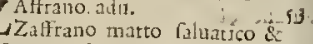
Saracenefco obl:
Zaffranofaltuatico obr, $\therefore \quad 483$ Zeingole obf. 493 Vichio. adu 


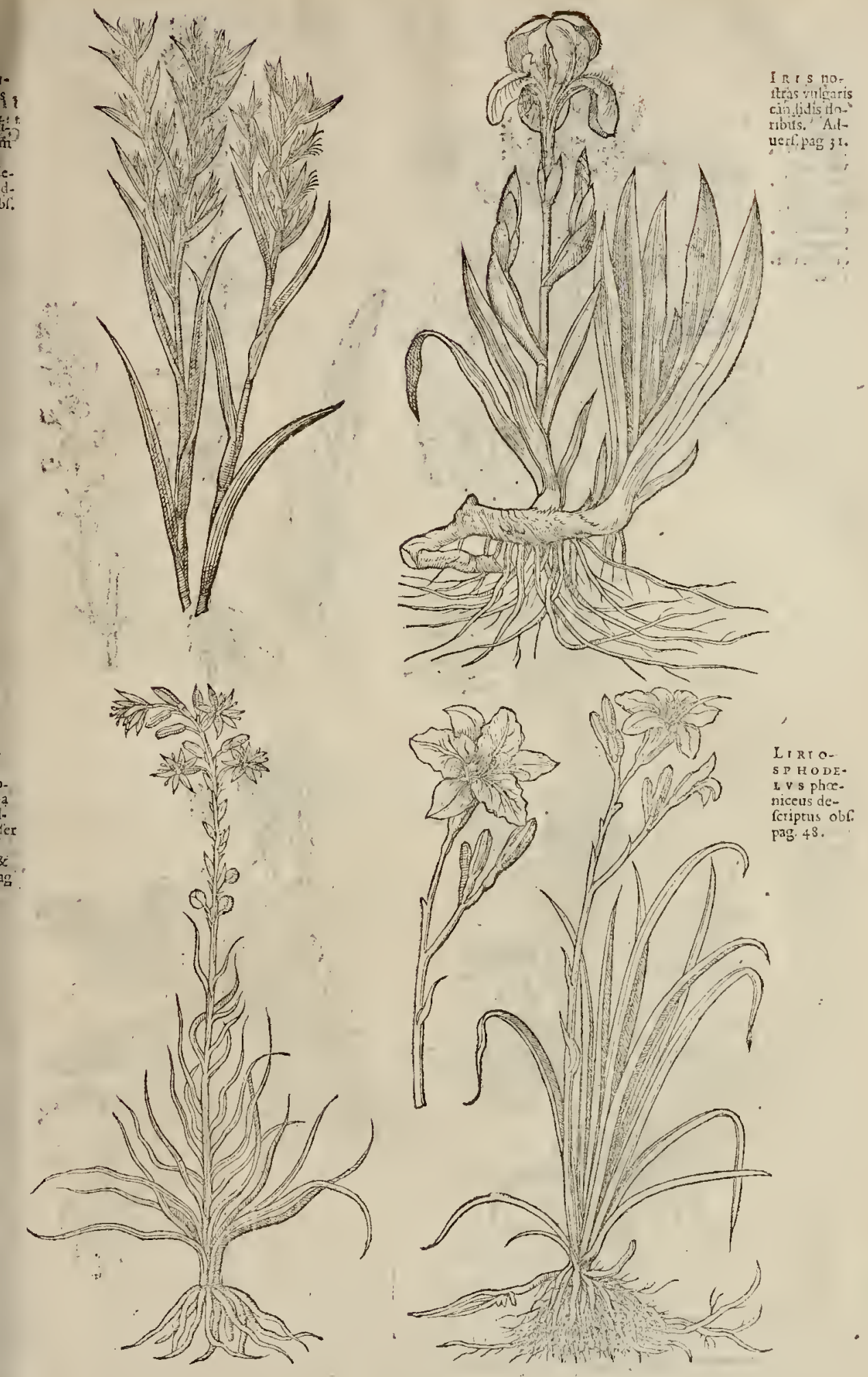




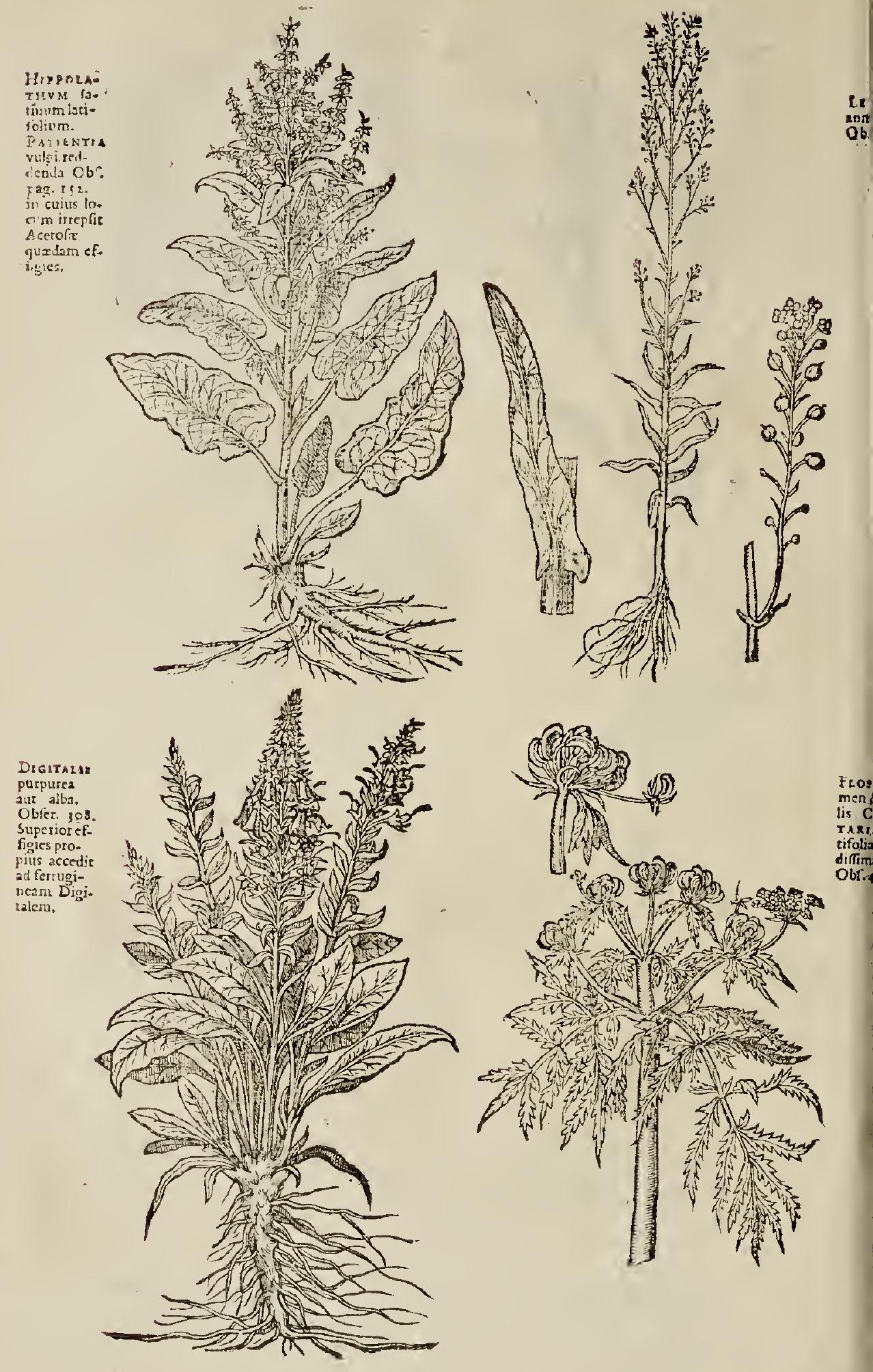




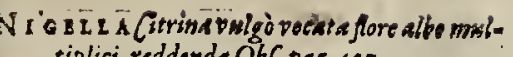
tiplici, reddenda Obf.pag. 427.

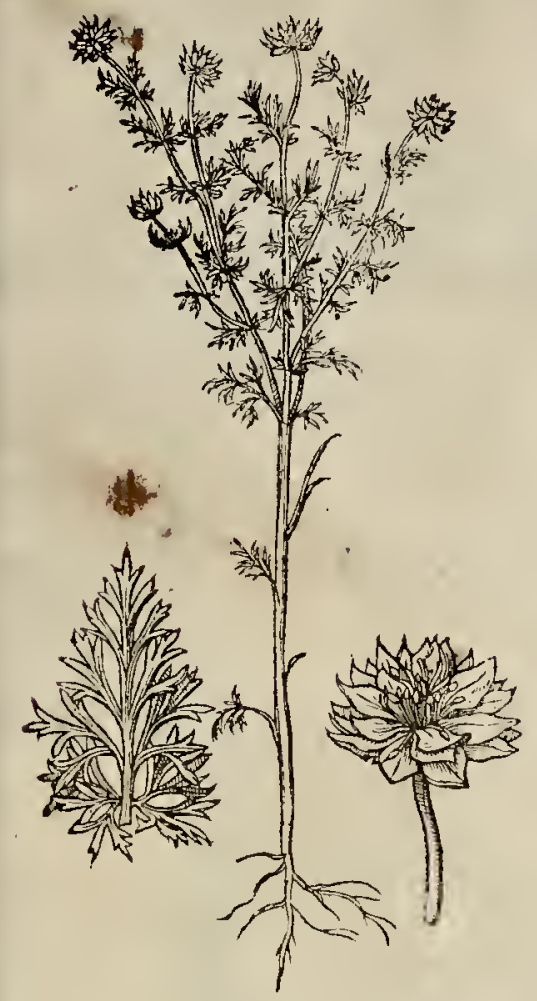

TA A C ET V M minks, cardidisfloribsu, redd-pro ximè Taracetum Obf.pag. 432.

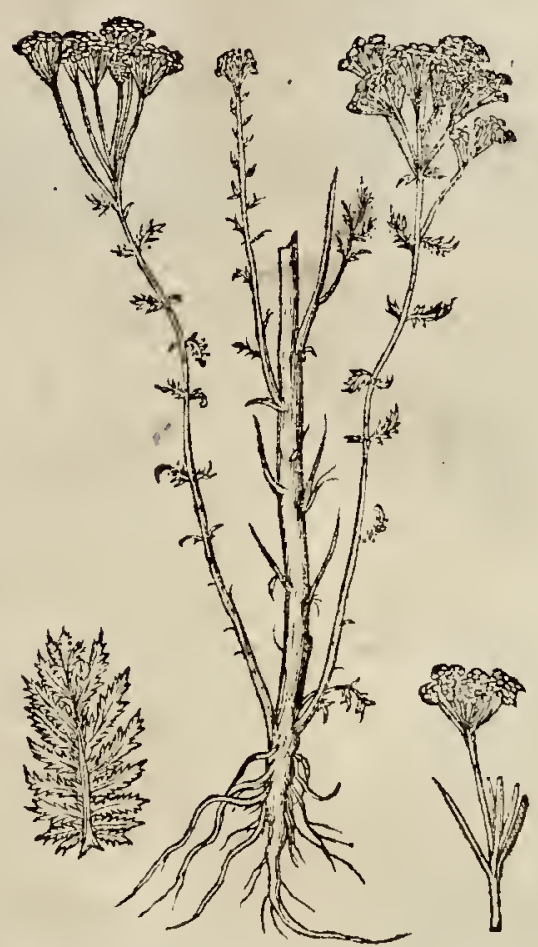

N 1 G 2 \& ^ Cítrioa rulgodicts.

Non nifi reeentioribusinnotuit hxc.mihiprimum communicata a Roberto le Fer Atrebatenfi apud Aotuerpizoos feminumomnis genetis \& medicamentorü fimpliciü mercatoris inftructifimo. A fuperioti Syriaca Nigella Cirrina aihil diftat nifi flotis amoena duplicatione.

T A N A C I T $\mathrm{M}$ paraum album.

Media planta eft inter Millefolium, Sideritidem Acbilleam \&. Tanacetum. Folia quippe Tanzecto proxima odote, a figura, fed minora. Cauliculi numerofi, \&radix fibrofa Sideritidis: Flof culi verò cñdidi in vmbellis Millefolij rulgaris. Beigis hortenfis eft.

\section{ANTVERPIAE EXCVDEBAT CHRISTO:}

PHORVS PLANTINYS, ARCHITYPOGRAIHVS REGIYS, A.NNO M. D. IXXYI. YIL, CALENDL AYGVSTI. 


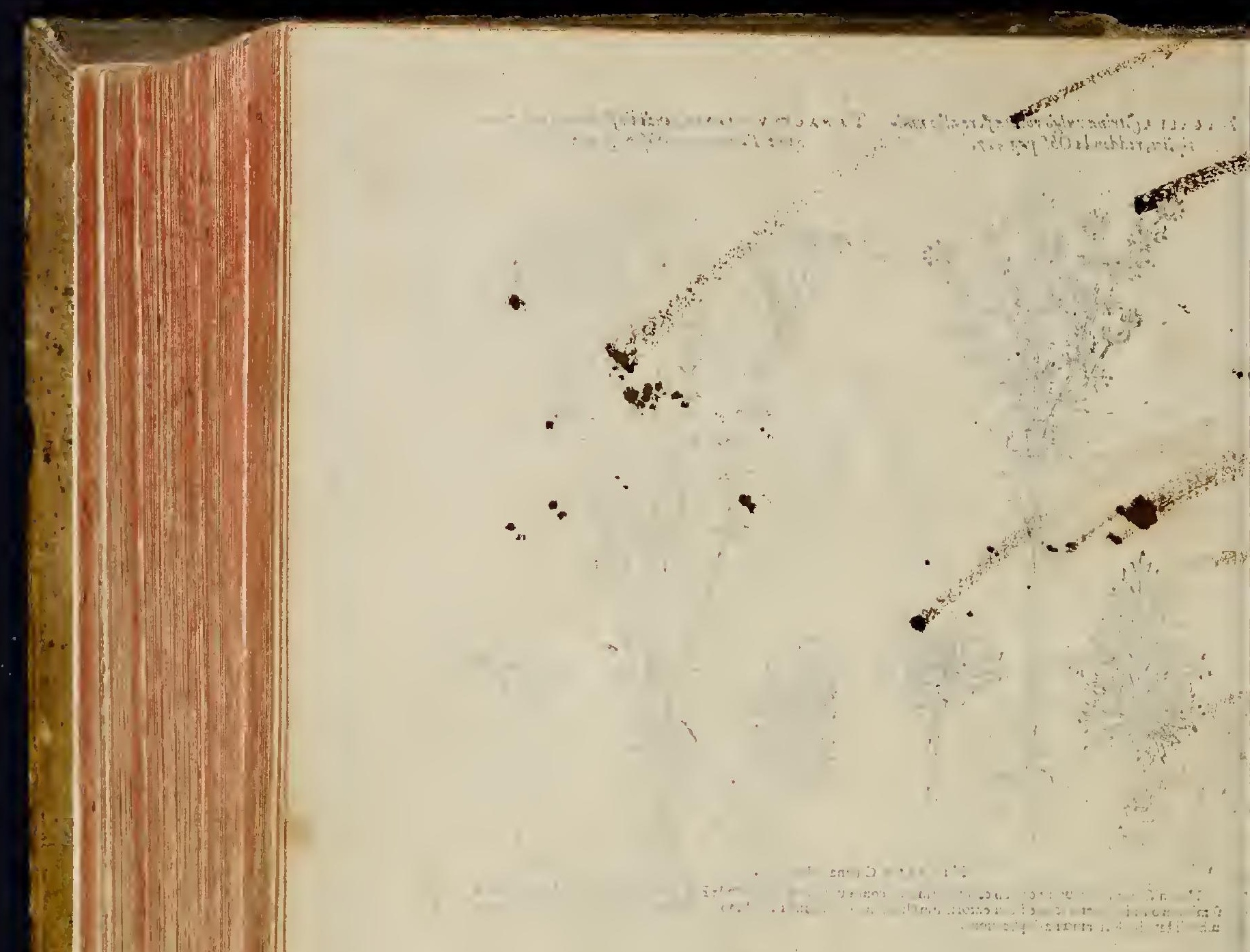





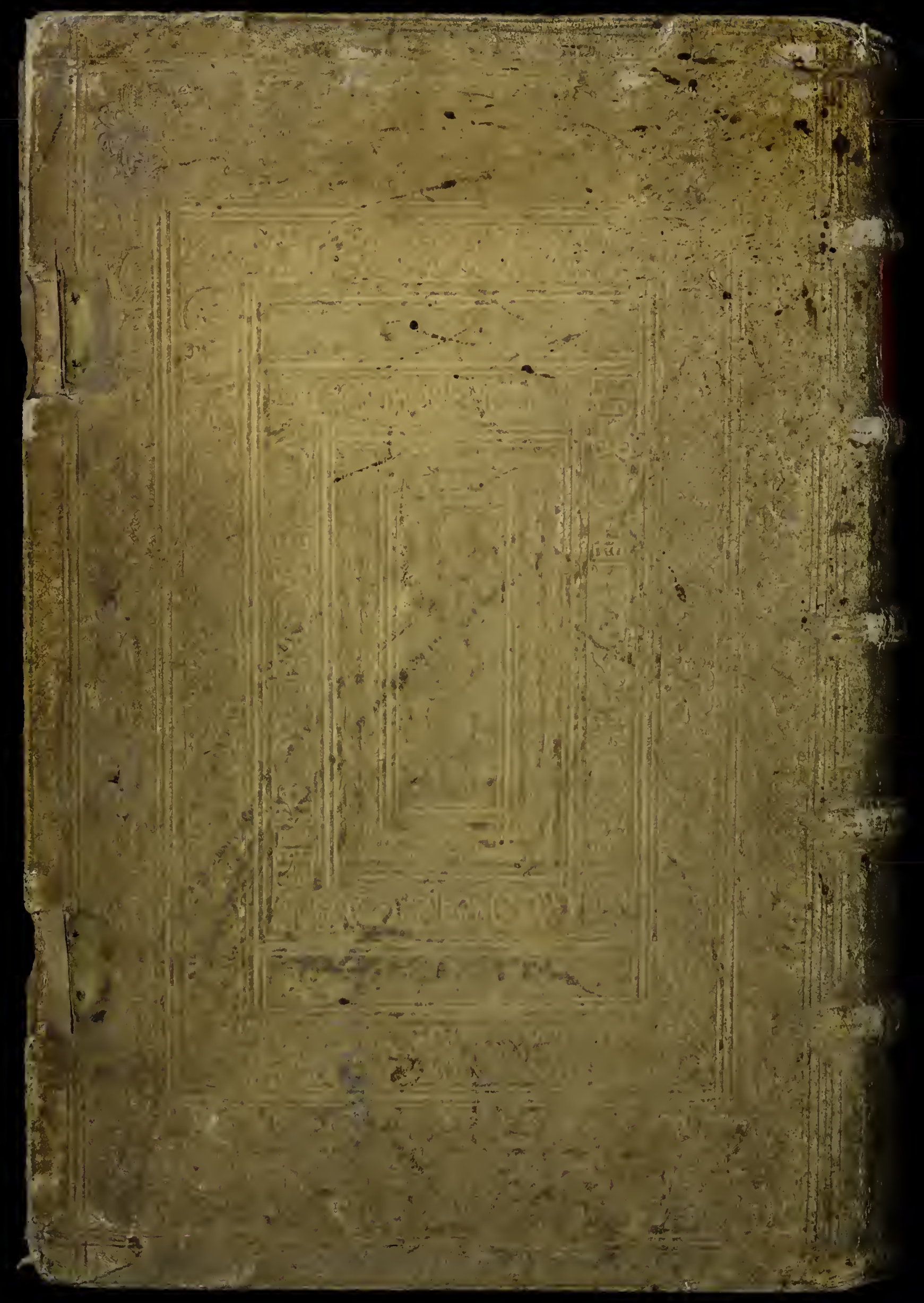

